

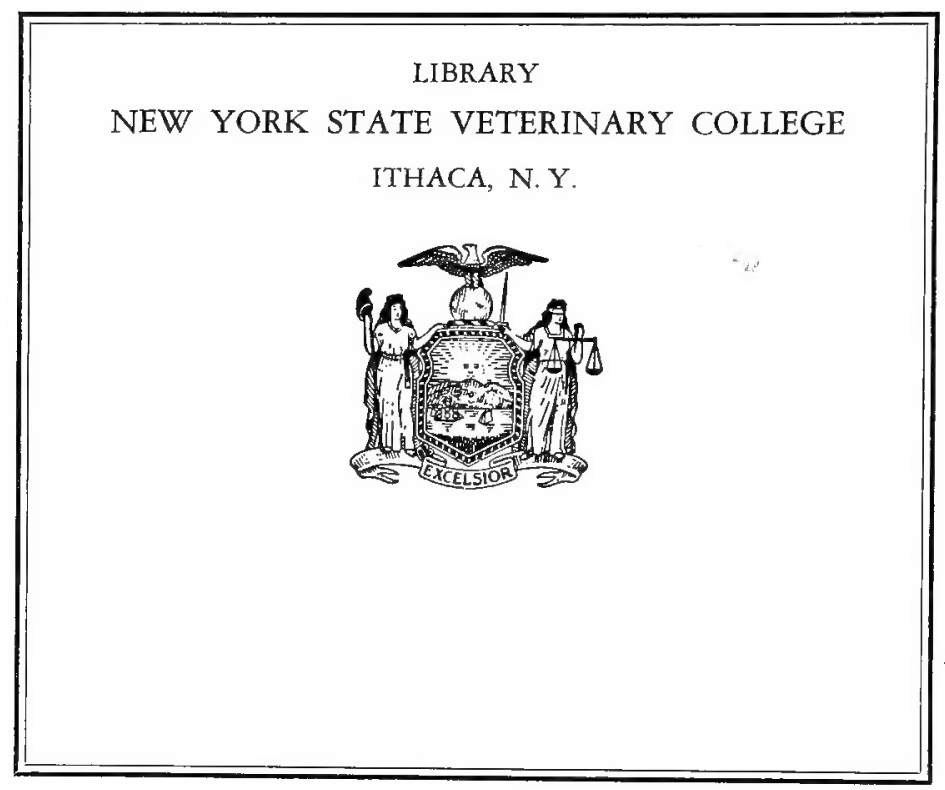




\section{SF 105.P73 1920}

Types and breeds of farm animals,

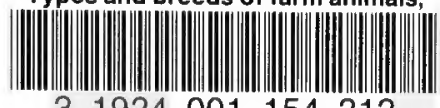

31924001154313 
This book was digitized by Microsoft Corporation in cooperation with Cornell University Libraries, 2007. You may use and print this copy in limited quantity for your personal purposes, but may not distribute or provide access to it (or modified or partial versions of it) for revenue-generating or other commercial purposes. 


\section{Cornell University Library}

The original of this book is in the Cornell University Library.

There are no known copyright restrictions in the United States on the use of the text. 
Digitized by Microsofte 
Digitized by Microsofte 


\section{COUNTRY LIFE EDUCATION SERIES}

Edited by Charles William Burkett, Editor of American Agriculturist; formerly Director of Experiment

Station, Kansas State Agricultural College

TTPES AND BREEDS OF FARM ANIMALS

(Revised Edition) By Charles S. Plumb, Ohio State University

PRINCIPLES OF BREEDING

By Eugene Davenport, University of Illinois

FUNGOUS DISEASES OF PLANTS

By Benjamin Minge Duggar, Washington University

SOIL FERTILITT AND PERMANENT AGRICULTURE

By Cyril George Hopkins

PRINCIPLES AND PRACTICE OF POULTR $Y$ CULTURE

By John Henry Robinson

GARDEN FARMING

By Lee Cleveland Corbett, United States Department of Agriculture

THE APPLE

By Albert E. Wilkinson

EQUIPMENT FOR THE FARM AND THE FARMSTE $A D$

By Harry C. Ramsower, Ohio State University Other volumes in preparation 
Digitized by Microsofte 


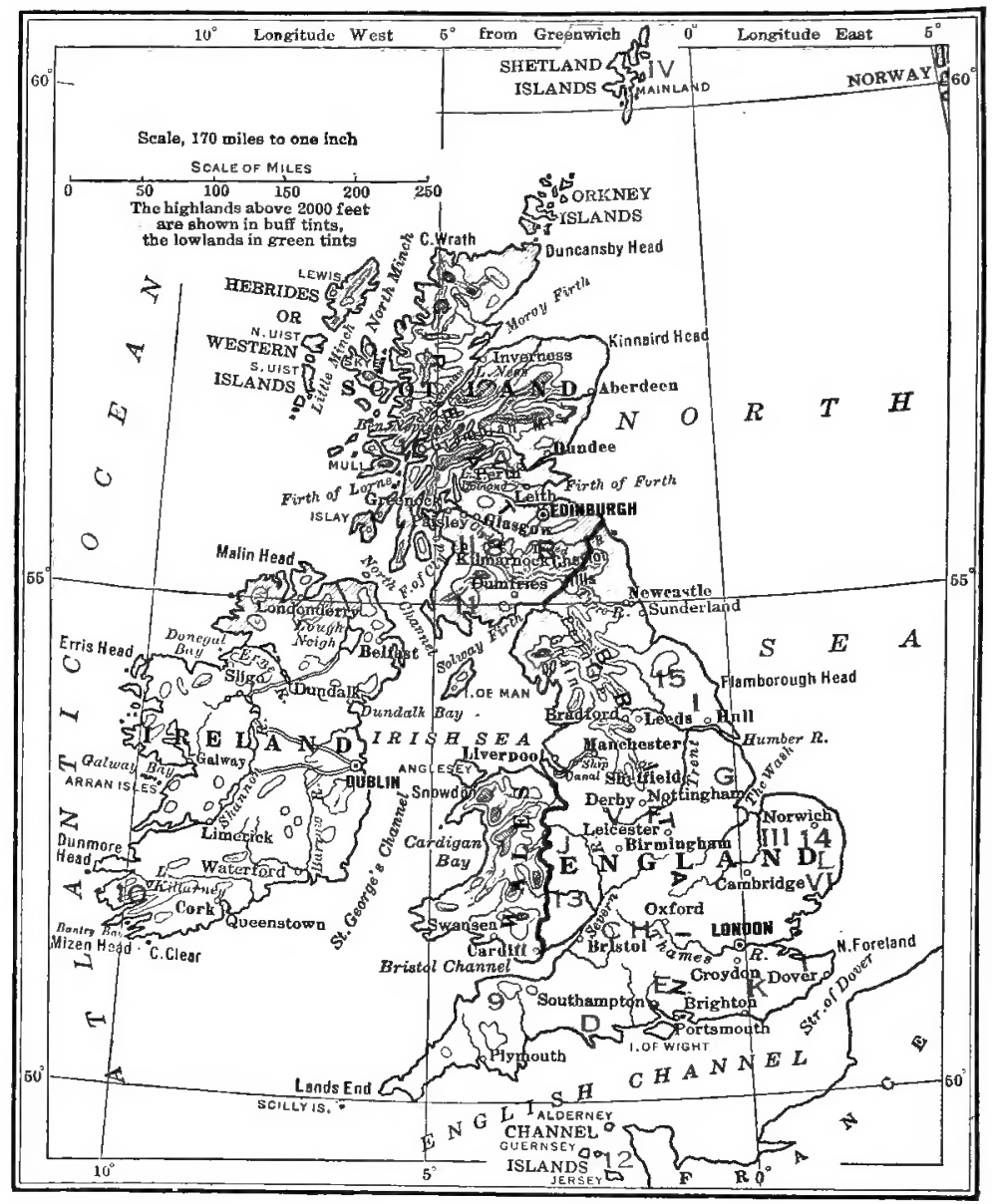

The British Isles

This map shows the native homes of prominent breeds of horses and cattle (see numerals) and sheep (see letters)

I, Cleveland; II, Clydesdale; II I, Hackney; IV, Shetland ; V, Shire ; VI, Suffolk ; 7 , Aberdeen Angus ; 8, Ayrshire ; 9 , Devon ; 10, Dexter and Kerry; II, Galloway; 12, Guernsey and Jersey; 13, Hereford; 14, Red Polled; 15, Shorthorn; 16, West Highland; $A$, BlackFaced Highland ; $B$, Cheviot ; $C$, Cotswold ; $D$, Dorset Horn ; $E$, Hampshire; $F$, Leicester ; $G$, Lincoln ; $H$, Oxford ; $I$, Romney Marsh ; $J$, Shropshire ; $K$, Southdown ; $L$, Suffolk 


\section{TYPES AND BREEDS OF FARM ANIMALS}

BY

CHARLES S. PLUMB

PROFESSOR OF ANIMAL HUSBANDRY IN THE COLLEGE OF AGRICULTURE OF THE OHIO STATE UNIVERSITY. AUTHOR OF "JUDGING FARM ANIMALS," "BEgINNINGS IN ANIMAI HUSBANIRY", ETC.

REVISED EDITION

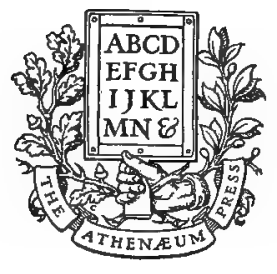

GINN AND COMPANY

BOSTON - NEW YORK - CHICAGO LONDON

atlanta - DALlas - COLUMBUS - SAN FRANCisCo

Digitized hy Microsofte 
ENTERED'AT STA'TIONERS' HALL

COPYRIGHT, 1906, 1920, BY

CHARLES S. PLUMB

ALL RIGHTS RESERVED

320.12

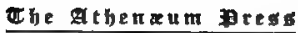
GINN AND COMPANY - PROPRIETYOSS - BOSTYN - U.S.A.

Digitized by Microsofte 


\section{FOREWORD}

"Types and Breeds of Farm Animals" was first published in 1906. The reception accorded the first edition far surpassed the most sanguine expectations of the author, and his first impulse is to express a deep appreciation for the many generous expressions regarding it that have come to him from many sources. In this revised edition is a more detailed discussion relative to the great breeds, and considerable space is devoted to families of importance and to noted individuals. A large amount of new data has been collected relating to various phases of production, although it is a hopeless task to bring such records down to date. Milk, butter-fat, speed, and sale-ring records have been shattered over and over again during the last few years, so that what is new to-day will to-morrow be out of date. The number of chapters remains the same, but several obsolete breeds have been omitted in this revision and other new and more important ones have been substituted. Maps and many illustrations have been added.

The author desires to emphasize the importance of breed study. The value of all our farm animals is dependent upon the breeds being maintained not only in their purity but in a high degree of excellence. A great number of men without plan or purpose are producing inferior horses, cattle, sheep, and swine, mixing breeds and blood-lines, totally ignoring all thought of constructive breeding. Were it not for the relatively few men breeding along definite lines and upholding high standards within the breeds, our herds and flocks would sink to much lower levels. To overcome the damages done by nondescript breeding, it is absolutely essential that men shall familiarize themselves with the ancestry, characteristics, capacities, and adaptations of the breeds, that they may intelligently undertake breeding operations. 
Inasmuch as this volume will be largely used by students and young stockmen, who are essentially beginners in the study and breeding of farm animals, the author wishes to emphasize the importance of the breeder being a person of integrity, with a character above reproach. It is most unfortunate that the hand of suspicion has pointed at some breeders as engaged in practices that reflect upon their reliability. Errors of record due to carelessness may happen, and be excused, but premeditated crookedness in breeding, testing, or selling pure-bred live stock cannot be justified and should be severely punished. Our breeds must be established and maintained with honesty of purpose a first requirement. Whoever attempts to establish a herd under any other conditions is sure to degrade rather than elevate the breeder's art, to injure the innocent, to carry a tainted name, and to have a disastrous career. Public sentiment should place a premium on a good name as worth more than great riches and attach the stain of disgrace and a just punishment on the man guilty of intentional deceit.

One of the most hopeful signs on the horizon of American live-stock husbandry is the present interest in community and coöperative breeding and the establishment of thousands of boys' and girls' live-stock clubs. For this reason the future prospects of improved live-stock husbandry are most encouraging. Both types and breeds are receiving greatly increased attention, and many more are seriously interested in constructive breeding than ever before. It is the profound desire of the author that this work shall contribute to this end.

CHARLES S. PLUMB

OHio State University,

Columbus, Ohio 


\section{CONTENTS}

I. The Prehistoric Horse . . . . . . . . . . . . . I

II. The Arab Horse . . . . . . . . . . . . . . . 7

III. The Thoroughbred . . . . . . . . . . 17

IV. The American Saddle Horse . . . . . . . 3 I

V. The Light Harness Type . . . . . . 40

VI. The American Trotter and Pacer . . . . . . . tt

VII. The Heavy Harness Horse Type . . . . . 64

VIII. The Hackney . . . . . . 70

IX. The French Coach . . . . . 78

X. The German Coach . . . . . . $\quad 82$

XI. The Cleveland Bay . . . . $\quad . \quad$. 85

XII. The Draft-Horse Type. . . . . . . . . . $\quad 89$

XIII. The Percheron . . . . . . . . 95

XIV. The French Draft . . . . . . . . II 8

$X V$. The Belgian

XVI. The Clydesdale . . . . . 134

XVII. The Shire . . . . . $\mathrm{I}_{4} 8$

XVIII. The Suffolk . . . . . . ${ }_{160}$

XIX. Ponies

XX. The Shetland Pony

XXI. The Ass

XXII. The Mule .

XXIII. Beef Type of Cattle . . . . . 201

XXIV. The Shorthorn . . . 207

XXV. The Polled Shorthorn . . . . . . . 247

XXVI. The Hereford . . . . . . . . . 252

XXVII. The Aberdeen-Angus . . . . . . . . 279

XXVIII. The Galloway . . . . . . . . . . . . 300

XXIX. The West Highland . . . . . . 3I

XXX. Dairy Type of Cattle . . . . . . . . . . . 3I7

XXXI. The Jersey . . . . . . . . . . . 323

XXXII. The Holstein-Friesian . . . . . . . . . . 354

XXXIII. The Guernsey . $\quad$. . . . . . . . 385

XXXIV. The Ayrshire . . . . . . . . . . . 4 II

XXXV. The Dutch Belted . . . . . . . . . 428

XXXVI. The French Canadian . . . . . . . . . . 434 
CHAPTER

XXXVII. The Kerry

XXXVIII. The Dexter

XXXIX. Dual-Purpose Type of Cattle . . . . . . . . 447

XL. The Red Polled

XLI. The Brown Swiss.

XLII. The Devon

XLIII. The Merino, or Fine-Wool Type of Sheep .

XLIV. The American Merino

XLV. The Delaine Merino.

XLVI. The Rambouillet

XLVII. The Mutton Type of Sheep.

XLVIII. The Southdown

XLIX. The Shropshire.

L. The Oxford Down .

LI. The Hampshire Down

LII. The Dorset Horn

LIII. The Cheviot .

LIV. The Suffolk .

LV. The Tunis

LVI. The Leicester

LVII. The Cotswold

LVIII. The Lincoln .

LIX. The Romney Marsh .

LX. The Black-Faced Highland . . . . . . . . . 65I

LXI. The Corriedale.

LXII. The Karakul

LXIII. The Angora Goat

LXIV. The Milch Goat

LXV. The American, or Lard, Type of Pig .

LXVI. The Berkshire

LXVII. The Duroc-Jersey .

LXVIII. The Poland-China .

LXIX. The Chester White

LXX. The Hampshire

LXXI. The Mule-Foot .

LXXII. The Large Black

LXXIII. The Cheshire

LXXIV. The Small Yorkshire

LXXV. The Essex

LXXVI. The Bacon Type of Pig

463

473

$48 \mathrm{I}$

488

5 I I

520

533

537

$55 \mathrm{I}$

566

575

586

597

607

6 I 3

6I 8

628

636

646

655

660

666

673

683

689

705

720

737

749

759

762

766

770

774

778

782

LXXVII. The Large Yorkshire

792

INDEX 


\title{
TYPES AND BREEDS OF FARM ANIMALS
}

\section{PAR'T I. THE HORSE, ASS, AND MULE}

\author{
CHAPTER I \\ THE PREHISTORIC HORSE
}

The world-wide distribution of the horse in prehistoric times has been well established. Fossil remains have been discovered in Europe, Asia, Africa, and North and South America. Nothing of the kind, however, has been found in Australia or the Oceanic Islands. These remains have been found in earth and sand deposits in various parts of Europe, antedating the glacial period. In I90 important discoveries were made of drawings of horses in a cave at $\mathrm{La}$ Mouthe, France, supposed to have been made prior to the Stone Age. These drawings were partly cut in rock and partly made in ocher and represented animals associated with hunting. These well-defined drawings show a horse with no forelock and a head with Roman-nose character, also one with a head similar to that of the Celtic pony. From the evidence left in these caves it is thought that a larger type of horse lived toward the south, while farther north a smaller form existed. The ass is also known to have been in existence in Europe at this period.

The discovery of the prehistoric horse in America was first made by Mitchell in 1826 near the Navesink Highlands in New Jersey, and caused great discussion. About 1850 Dr. Leidy made similar discoveries in Nebraska, and late in the nineteenth century the wide distribution of this early horse in North and South America was well understood. These remains have been found all over the Southern states, in the Northeastern and Middle 
states, in California and Oregon, and in greatest abundance in the so-called Bad Lands of Nebraska, Wyoming, and South Dakota. The fossil remains of the horse are generally fragmentary and date as remotely as the Lower Eocene period. A number of complete skeletons, however, have been discovered, notably in 1899 in Texas, when several of the size of a trotting horse were found.

The evolution of the horse from prehistoric to present times covers geological ages of time and represents a passing of perhaps

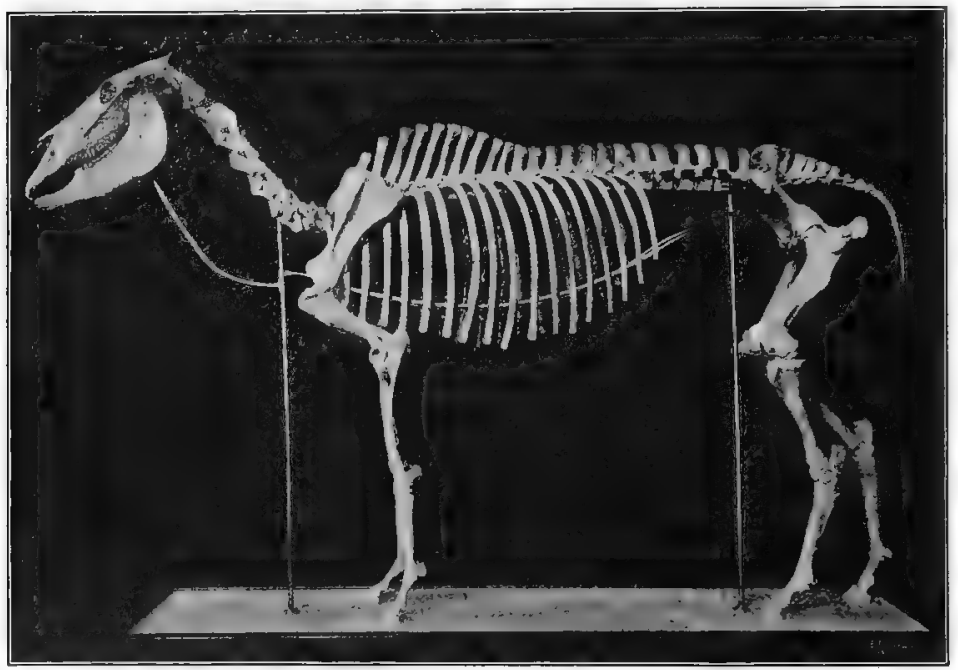

Fig. I. Skeleton of prehistoric horse from the Lower Pleistocene of Texas, in the American Museum of Natural History. Reproduced by courtesy of the American Museum

three million years. Extensive researches relative to the prehistoric horse, conducted by the scientific staff of the American Museum of Natural History, directed by Drs. Osborn and Matthews, have resulted in securing a wonderful collection of remains and a large amount of valuable new data. As a result of these discoveries, there has been set up in this museum a complete collection of skeletons showing the various stages of development from the Lower Eocene to the present day horse. Many of these skeletons, originally more or less incomplete, have been restored, so that the exhibit appears perfect. Based on the 
above-referred-to discoveries, the following descriptive information is presented relative to the evolution of the prehistoric horse through several geological periods:

Eohippus, formerly known as Hyracotherium, existed in the Lower Eocene period. The teeth, short-crowned, were covered with little knobs of enamel. The fore foot had four complete toes and a splint of a fifth, while the hind foot had three toes and a

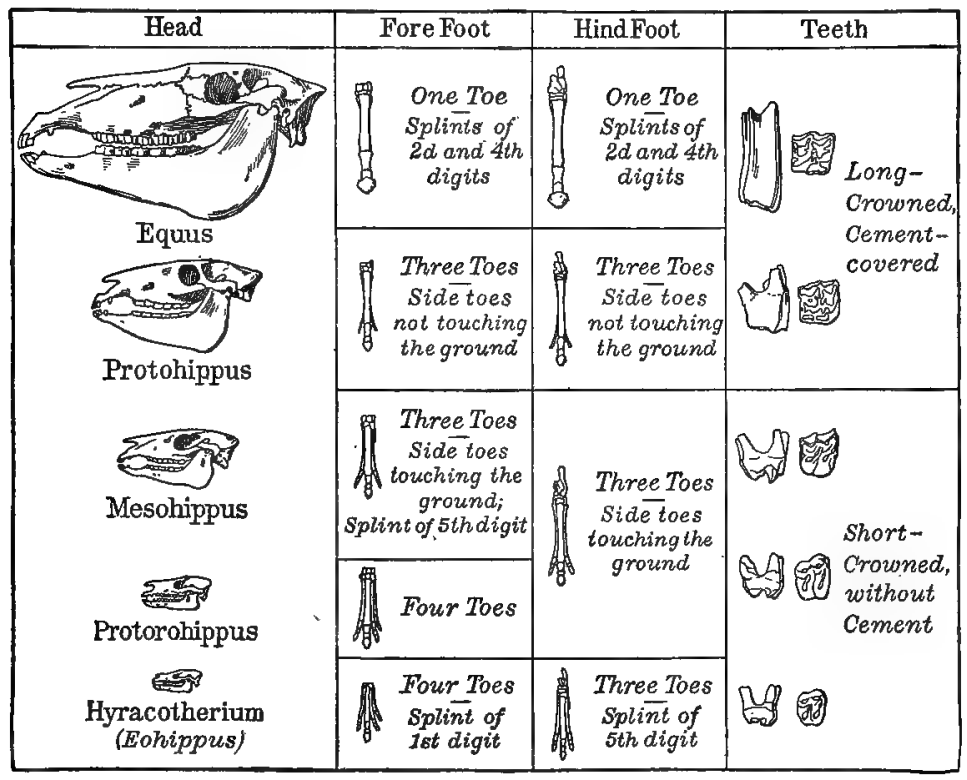

FIG. 2. Comparative drawings of skulls, feet, and teeth of prehistoric horse, showing evolutionary development. Reproduced by permission from Guide Leaflet No. 9, American Museum of Natural Histor

splint. The skull suggests a civet rather than a horse. Remains have been found in a number of parts of the world, but more especially in the Bad Lands of the Western states. These are about the size of a cat or fox terrier, and have been termed "dawn horses." Eleven stages of development have been assumed to have taken place from and including this period to the present time.

Protorohippus and Orohippus are from the Middle Eocene period. Here the splints in the hind feet have disappeared, and the crests on the molars are more apparent. These horses were 
about the size of a small dog or fox. The complete skeleton of a Protorohippus was found in 1880 in Wyoming and is now in the American Museum collection.

Epinippus is from the Upper Eocene period. Only incomplete specimens have been found. There are four toes in front and three behind, but the central toe in each case is larger, stronger, and more important than the side toes. The teeth have gone through changes, with more crescents and crests.

Mesohippus is from the Oligocene period. There are three toes on each foot and a splint representing the fourth toe of the fore foot. The middle toe is now much larger than it was in the preceding stage, the side toes bearing but little weight of the body. There is an increased development of the molars. In the Middle Oligocene is found one species about the size of a coyote, or eighteen inches high, while in the Upper Oligocene is another species as large as a sheep. Several complete skeletons have been found.

Protohippus is from the Miocene period. A number of different species existed in the Lower, Middle, and Upper Miocene periods. The side toes are slender and no longer reach the ground. In some species they have completely disappeared. The teeth are more like those of the modern horse - the crowns being much lengthened, and the crests and ridges higher and more complicated, with cement between the ridges. Horses of this period ranged in size from a mastiff dog to a Shetland pony.

Pliohippus is from the Pliocene period. Comparatively little is known of this form, excepting that it was either one-toed or very nearly so.

Equus is from the Pleistocene period and Recent. The side toes are gone, but are represented by splints on fore and hind foot. On the fore foot no trace of the first and fifth toes, found on the Protohippus, remains. The crowns of the teeth are much longer, and the teeth have changed otherwise. The skull has lengthened, and the horse is much larger.

Tracing the evolution of the horse, we find that this animal gradually increases in height, the number of toes reduces to one on each foot, while the teeth increase in length and crown development. With increase in height comes a gain in the proportionate length of the limbs, more especially in the lower part, 
thereby increasing the length of stride and securing greater speed. The surfaces of the joints, at first more or less open and of the ball-and-socket type, changed to a grooved or pulley-like form, this limiting the direction of movement forward and backward, - a development better fitted for locomotion over level than rough ground. The horse being a grazing animal, the increase in height of body and length of leg necessitated elongation of neck and head. The natural habitat of the earlier horse was the

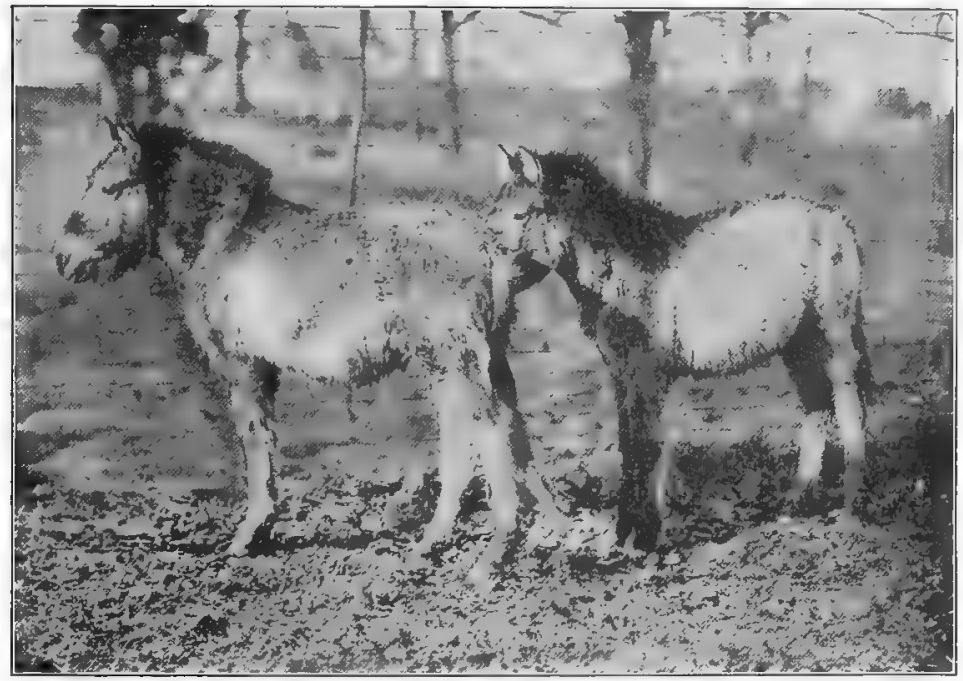

FIG. 3. Prejvalsky ponies in New York Zoölogical Park. Photograph by courtesy of Edwin R. Sanborn

forest, where it undoubtedly subsisted on the more tender parts of plants and branches. In the course of time, however, along with the increase in size came the development of teeth with cutting and grinding surfaces better suited to the product of grassy plains than the forest; hence the horse eventually found its natural home on the open plain or meadow where grazing was afforded.

The color of the prehistoric horse is not known, but it is supposed to have been more or less striped, like the zebra, though not brilliant in hue. The groundwork of this color was presumably dun, or khaki. 
Man and the prehistoric horse were associated as early as the Paleolithic, or Stone Implement Age. It is assumed that man first hunted horses for food, then drove them, and finally used them for riding and as beasts of burden. The bones of human beings have been found in connection with prehistoric-horse remains in South America, but not in North America. In Europe man and the prehistoric horse were without doubt associated.

The connecting link between the prehistoric and modern horse is assumed to be the present form of the zebra, the wild ass of Asia and Africa, and Prejvalsky's horse. The prehistoric horse became extinct in America and Europe during the Quaternary period, or Age of Man, while those of Asia and Africa survived. It has been assumed by various authorities that Prejvalsky's horse, discovered in I88 I by Poliakoff on the desert of Zungaria in western Mongolia in Asia, is the connecting link between the recent and prehistoric horse. This type of wild pony, standing forty inches high, bears a striking resemblance to the European cave drawings of the horse. The rough, small, coarse-headed ponies native to Norway, Ireland, and other parts of northern Europe show much resemblance to the wild ponies of Mongolia and China. Professor J. Cossar Ewart of Scotland, who has given much study to the origin of our domestic breeds, states ${ }^{1}$ that "though the wild horse discovered some years ago by Prejvalsky in Mongolia has neither coarse limbs nor broad hoofs, it is regarded by many as the modern representative of the fossil horse from which domestic breeds are said to have descended. This is the view adopted by Professor Dürst in his report on the 'Animal Remains from the Excavations at Anau." ' In I9O4 Ewart recognized as connecting links three distinct types of horses - Prejvalsky's, Celtic, and Norwegian, which he later respectively designated as "steppe," "plateau," and "forest" types. Dürst of Germany, who arrived at the same conclusion, though independently, represented in graphic form the origin of the modern breeds. However, he assumed that both wild and tame modern horses are all descended from a fossil species now represented by Equus Prejvalsky.

1 "The Principles of Breeding and the Origin of Domesticated Breeds of Animals," 27th Report Bureau A nimal Industry for the year I9Io, pp. I25-239. 


\section{CHAPTER II}

\section{THE ARAB HORSE}

The native home of the Arab horse is Arabia. This is an extensive country lying just east of the Red Sea, extending some fifteen hundred miles northwest to southeast, and varying in width from about one thousand miles in its southern portion to five hundred at its northern end. Wide expanses of deserts are found in this country that are dry and unattractive from an agricultural point of view. The Arab horse, more or less pure, is found in great numbers in Turkey, Persia, and parts of northern Africa, notably the Sahara region. The best Arabian horses are found in the desert region, among the migratory Bedouin tribes, of which there are several groups. The most powerful of these are the Shammar race of Mesopotamia in the north and to the east of the Euphrates, and the Anezah in the south. The latter have the best horses, a fact generally recognized by the Bedouins.

The origin of the pure Arabian has been the subject of wide discussion. Undoubtedly much has been written based on nothing more substantial than romance and tradition. Some writers - notably Professor William Ridgeway of Cambridge, England - have assumed that the Arab horse originated in Africa; others seriously question the accuracy of this claim. The Arabians themselves offer only traditional evidence. These people are descendants of Ishmael, who, according to tradition, inherited a valuable horse of the Kuhl race. The Anezah tribe descends in a direct line from Ishmael, through Sheik Salaman, who lived about I635 B. C. and who owned five famous mares. These are known as the Al Khamseh mares, and from this ancestry, it is claimed, has come the purest and best Arab horse blood. This race was in existence many centuries before the time of Mohammed. Many people have visited Arabia to study the Arabian horse and to import it to other countries, and from these people there has been some diversity of opinion. Major Upton and Lady Anne Blunt, however, 
have no doubt given more careful consideration to this subject than any other persons. They made special journeys to Arabia, where careful studies were made of the horse of the people, concerning which we learn much in their writings. ${ }^{1}$ Major Upton lived among the Arabs for months and spoke their language. The late Homer Davenport, an American artist who was for many years interested in this breed of horses, after a trip to Arabia also

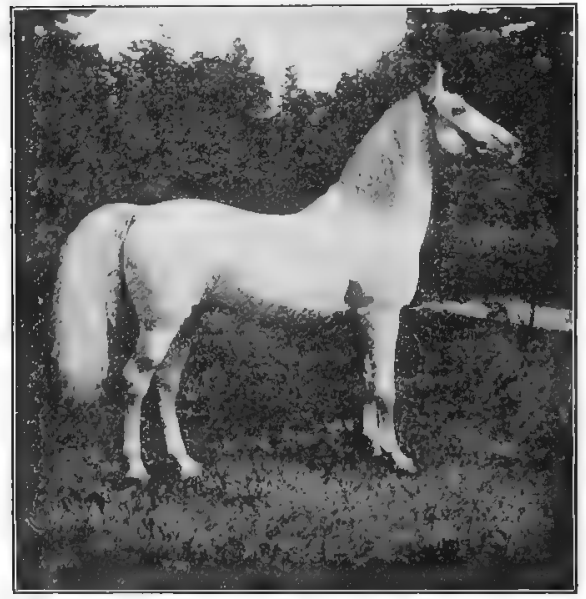

FIG. 4. Shahwan, an Arab stallion bred by Ali Pacha Sherif of Egypt. Used in stud by W. S. Blunt, Esq., England. Imported in 1895 by J. A. P. Ramsdell, Newburg, New York. Photograph by courtesy of Mr. Ramsdell published more or less regarding the origin of this horse and its various families and subfamilies. ${ }^{2}$

Five great families of Arabian horses of to-day trace their ancestry to the five mares above referred to. These families are as follows: (I) Keheilet Ajuz, (2) Seglawi, (3) Abeyan, (4) Hamdani, and (5) Hadban. There is some difference of opinion as to the families descending from these mares, but present-day authorities as a rule regard the above as descended from the Khamseh mares. Numerous subfamilies or strains are credited to these five great families. From the first-named family, the Keheilet Ajuz, comes the choicest Arab blood. As applied to horses, Keheilan means "male" and Keheilet "female," and indicates purity of blood traceable without a break to the five mares of Salaman. The word ajus means "old woman." The following story of the origin of this family is given by the Arabian people and has been widely

1 Roger D. Upton, Gleanings from the Desert of Arabia (London, I881); Lady Anne Blunt, The Bedouin Tribes of the Euphrates, 2 vols. (London, 1879); Lady Anne Blunt, A Pilgrimage to Nejd, 2 vols. (London, I881).

${ }^{2}$ Homer Davenport, My Quest of the Arab Horse. New York, Igog. 
quoted. An Arab chief was endeavoring to escape from an enemy while mounted on his favorite mare. The journey was a long and hard one, and while resting at noon the mare gave birth to a filly foal. The owner of the mare being hard pressed mounted and rode away, leaving the newborn colt, and after much difficulty reached his own people. To the utter surprise of all, the colt followed and reached the camp shortly after the arrival of her dam. She was given into the care of one of the old women of the tribe, whence her name Keheilet Ajuz (" the mare of the old woman"). This colt lived to become the most famous mare ever seen on the desert, and from her are descended the choicest of pure Arabian horses. The claim is made that nineteen families are descended from her, five through mares and fourteen through stallions. Some even believe that eight other families also should be credited to her.

The Seglawi is descended from four great mares owned by a man of that name. Davenport, who classes this as one of the great Arabian families, states that Seglawi at his death gave his favorite mare to his brother Jedran, from which the name "Seglawi Jedran" is given this, the most popular branch of the Keheilet Ajuz family. Horses of this ancestry are said to be mostly bays in color, are possessed of the greatest speed of any Arab family, and in conformation closely resemble the Thoroughbred. Davenport states ${ }^{1}$ that the Darley Arabian, "perhaps the only Anezeh horse in our studbooks, was a Keheilan of the subfamily called Ras-el-Fadawi."

The characteristics of the Arab horse. The head represents very superior character and intelligence, the forehead being broad and prominent, and the head tapering toward the nose more than with other breeds. The nostrils are prominent, the eyes fairly so, the ears delicate and pointing inward, and the general head expression lean and representing high spirit. The neck is of medium length and sustains the head most gracefully. Captain Hayes states that the shoulders of the Arab slope well, though from the saddle point of view they are often too thick, while the withers incline to be rather low and broad. The body is fairly short and is usually deeply ribbed, the back is well sustained, and the loins are broad and muscular. The croup tends to be

1 My Quest of the Arab Horse (I909), p. 259. 
high, sometimes making specimens of the breed appear higher here than at the withers. The tail sets high and is carried with style. The quarters are long and deep, but the gaskins and hocks hardly equal those of the Thoroughbred. The legs and feet are very superior. For his size the strength of the Arabian horse is remarkable, this being due in part to large development of muscle of loin and arm, whereby he becomes a superior burden carrier. The Arab has a great constitution and extraordinary staying power. $\mathrm{He}$ is not noted so much for speed as for endurance, as he is not nearly the equal of the Thoroughbred or American trotter for rapid speed. Yet the Arab will perform long journeys across country with comparative ease, such as require great staying power. In height the Arab ranges from I 4 to $I 4_{2}^{1}$ hands, so that he stands at the boundary line between pony and horse. Many of the most famous Arabs brought to England were ponies. Esa ben Curtas, a large importer of Arabs to Bombay, is credited with the statement that the best Arabs did not, as a rule, exceed 14 hands $\mathrm{I} \frac{1}{2}$ inches to $\mathrm{I} 4 \frac{1}{2}$ hands high. In color there is some variation, for there are bays, whites, grays, chestnuts, and blacks. No pure-bred Arabs are spotted or roan of color. Rowe gives the prevalence of the various colors as follows ${ }^{1}$ : bay, 50 to 60 per cent; chestnut, 25 per cent; and gray or white, 15 to 25 per cent. A black Arabian is exceedingly rare.

The introduction of the Arab horse to America dates back many years. No doubt numerous horses called Arabian were not of that breed, but were of oriental ancestry. About 1765 an Arab stallion named Ranger was imported to New London, Connecticut. A half-bred, gray son of this horse was used by General Washington during the Revolutionary War. Ranger was later taken to Virginia, where he became known as the Lindsay Arabian. In I 838 a large consignment of both stallions and mares was brought to the United States by Commodore J. D. Elliott of the United States Navy. The first volume of Bruce's "American Studbook" (Thoroughbred) contains a list of 42 Arab stallions imported into the United States between I760 and I860, besides I 2 Arab mares, 4 Barb stallions, and 2 Barb mares. About I 855 A. Keene

1 Breeders' Gazettc, May 29, 1912. 
Richards of Kentucky made a trip to Arabia with Troyon, the animal painter. They visited among the Anezah, and Richards brought back to America 3 stallions and 2 mares. The stallions were much used in service, and their blood occupies a place of prominence in the Gold Dust family of trotters. In I893 a company of men brought several stallions and mares from near Damascus and exhibited at the World's Columbian Exposition at Chicago. Most of these horses later were lost in a fire, but one

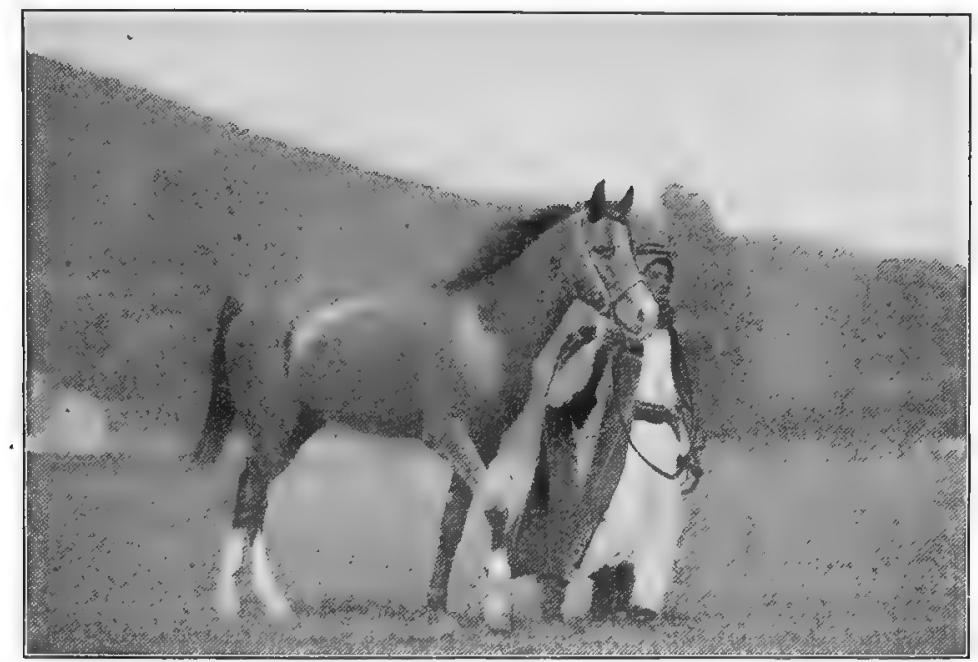

FIG. 5. Hamrah 28, a bay Arab stallion, sire a Hamdani, dam a Seglawi Jedran. Owned by Hingham Stock Farm, Hingham, Massachusetts. Photograph by Pictorial News Company

of the finest, a gray mare known as Nedjma, was saved. In I 906 Homer Davenport imported Io mares and I 7 stallions to his farm in New Jersey. J. A. P. Ramsdell of New York, Spencer Borden of Massachusetts, and Randolph Huntington of New York each owned imported Arabs of merit.

The influence of the Arab horse upon the improvement of the present-day breeds is well recognized among students. As early as the reign of King James I of England (I603-1625) Arab horses were introduced into that country and crossed with light horses. Between I 700 and I 800 many oriental horses found their 
way to England, and these had a most important influence in improving the Thoroughbred. The so-called "Royal Mares," imported by Charles II (I660-1685), became foundation stock in the best of British light-horse blood, their descendants attaining great distinction. From the Darley Arabian imported in 1706 is descended the best of Hackney blood to-day. According to Joseph Osborne, ${ }^{1}$ since the time of James I 164 oriental sires of known record have been taken to England and used in service. This list includes go Arabs, 36 Barbs, 32 Turks, 4 Persians, and 2 horses of unknown ancestry. Arab horses have also been used for centuries in improving the horses of continental Europe. Much of the quality produced in the early Percheron, it is claimed, came from the Arab, while the French have set a high value on this horse in producing half-breeds and improving coach horses. In I 522 the Turks invaded Hungary five hundred thousand strong, which number, so history informs us, included three hundred thousand horsemen. With the defeat of the Mohammedans they were driven from the country, but they left large numbers of Arabian horses behind. Until the World War Arab horse blood had been in use in the stables of Hungary, and a Bedouin of the desert, thoroughly familiar with the breed, was attached to the Hungarian army as master of horse, his duty being to select the best Arabian horses for the royal studs. These studs were established in 1785 . In addition to the royal studs, there were some I 50 private studs, in which were to be found 5000 Arab mares of purest blood. Russia and Germany have also used the Arabian in the stud. It is said that in I 895 no less than 200 Arab stallions belonging to the French government were at the free service of owners of mares in Algiers, Africa, this being a French colony.

In recent years Major Upton maintained a pure Arab stud in England, as did Henry Chaplin, once Minister of Agriculture. Sir Wilfred Blunt and his wife, Lady Anne Blunt, in 1877 became interested in the Arab and brought to England from Arabia some choice pure-bred stallions and mares. They owned a stud in Egypt as well as in England, and about I905 their Crabbet stud in England contained about 125 head. Reverend F. F. Vidal,

I The Horse Breeders' Handbook, London. (No date.) 
Sir Walter Gilbey, Miss Ethelred Dillon, and others have promoted the Arab horse in England and maintained studs.

Notable Arab horses of recent years were the stallions Kismet, Blitz, El Emir, Maidan, Kouch, Kars, Shahwan, Cunningham, Garaveen, and Himyarite. Kismet and Blitz had remarkable records in India as race horses. During I 883 and I 884 Kismet never lost a race or heat and won about $\$ 150,000$ in money. Kismet was brought to England, where he not only raced but was used in the stud. In I89I he was leased to Mr. Huntington of Oyster Bay, New York, and shipped to this country, but died two hours after landing. Maidan was foaled in I869 at Nejd and was taken to India, where he attained fame as a race horse. After a remarkable career of many years as a cavalry and racing horse in India, he was taken to France and from there to England, where he lived to be twenty-three years old. Shahwan was a small white stallion imported from Cairo by the Blunts and sold to J. A. P. Ramsdell. He was very beautiful, but died before his value in the stud could be determined. Notable Arab mares were Hagar, Haidee, Naomi, Rodania, Kesia, and Nazli. Hagar was a Keheilet Ajuz and was purchased at Aleppo when five years of age and taken to England by the Blunts. She produced thirteen foals and died in I898, at twenty-five years of age, one of the greatest Arab mares ever imported to England. Haidee was imported by the Uptons and left one foal, Naomi, after which she died. Naomi became the property of Mr. Vidal, who, in I888, sold her to Randolph Huntington. She had twelve foals, four in England and eight in America, and died at twenty-two years of age, famous as a remarkable dam. Nazli was a daughter of Naomi, sired by Maidan. She produced a number of high-class sons and daughters.

The value of the Arab in crossbreeding has been very notable. Wherever used he has transmitted constitution, quality, intelligence, and style in a marked degree. His value to horse stock in the past has undoubtedly been important, especially in the earlier stages of breed development. Not only this, but European governments, even of to-day, recognize the value of an Arabian cross to instill the qualities above referred to into depleted stock. As an example of this crossing, in 1899 it is stated that the Digitized by Microsofte 
French government mated sixty Thoroughbred mares with pure Arabian stallions at the national stud at Pompadour. The object was to obtain Anglo-Arab stallions for service in the government studs. These crossbred stallions are usually placed in low, soft districts, where the horses are coarse and of inferior bone. The progeny from such stallions have more refinement and quality than those obtained by other matings. At the present time one important use for Arab sires is breeding to Welsh, New Forest, Exmoor, or similar ponies to produce crossbreds for polo playing. In I9I 3 fifteen Arabian stallions were shipped to West Virginia to be used on farm mares in the blue-grass counties of that state. ${ }^{1}$

The present-day recognition of the Arab horse in America is very slight. The breed is not popular among horsemen, and although for many years efforts have been made to interest the people in Arabs, but very few are to be found on the American continent. The argument advanced is that our own American saddle horses are far superior to the Arab for riding in the saddle, while for speed in harness nothing compares with our trotter or pacer. In the opinion of most horsemen there is no special place or use for the Arab in America. The advocates of the Arab regard him as a premier saddle horse or pony and assign him large credit in the development of the breeds of light horses. "The Arab horse is par excellence the general utility animal," writes H. K. Bush-Brown, ${ }^{2}$ "and as such has no equal because of his intelligence, docility, fleetness, and endurance, and his strong back makes him the best weight carrier in the world." Professor H. F. Osborn states that ${ }^{3}$ "the unpopularity of the Arab in some quarters is due to mistakes which have been made in breeding and environment or nurture. It is impossible to rear the Arab and preserve it true to type without regard to the hardy conditions in feeding methods and environment of the semi-desert regions of Arabia where these animals were originally bred." In his opinion the chief value of the Arab to-day will be in giving a finish to cavalry stock and the saddle type in general, "but the mixture can only be made in the most scientific manner."

\footnotetext{
1 Breeders' Gazette, May 21, 19I3.

2 Arabian National Studbook, Vol. I (I9I3), p. 9.

8 Ibid. p. 3.
} 


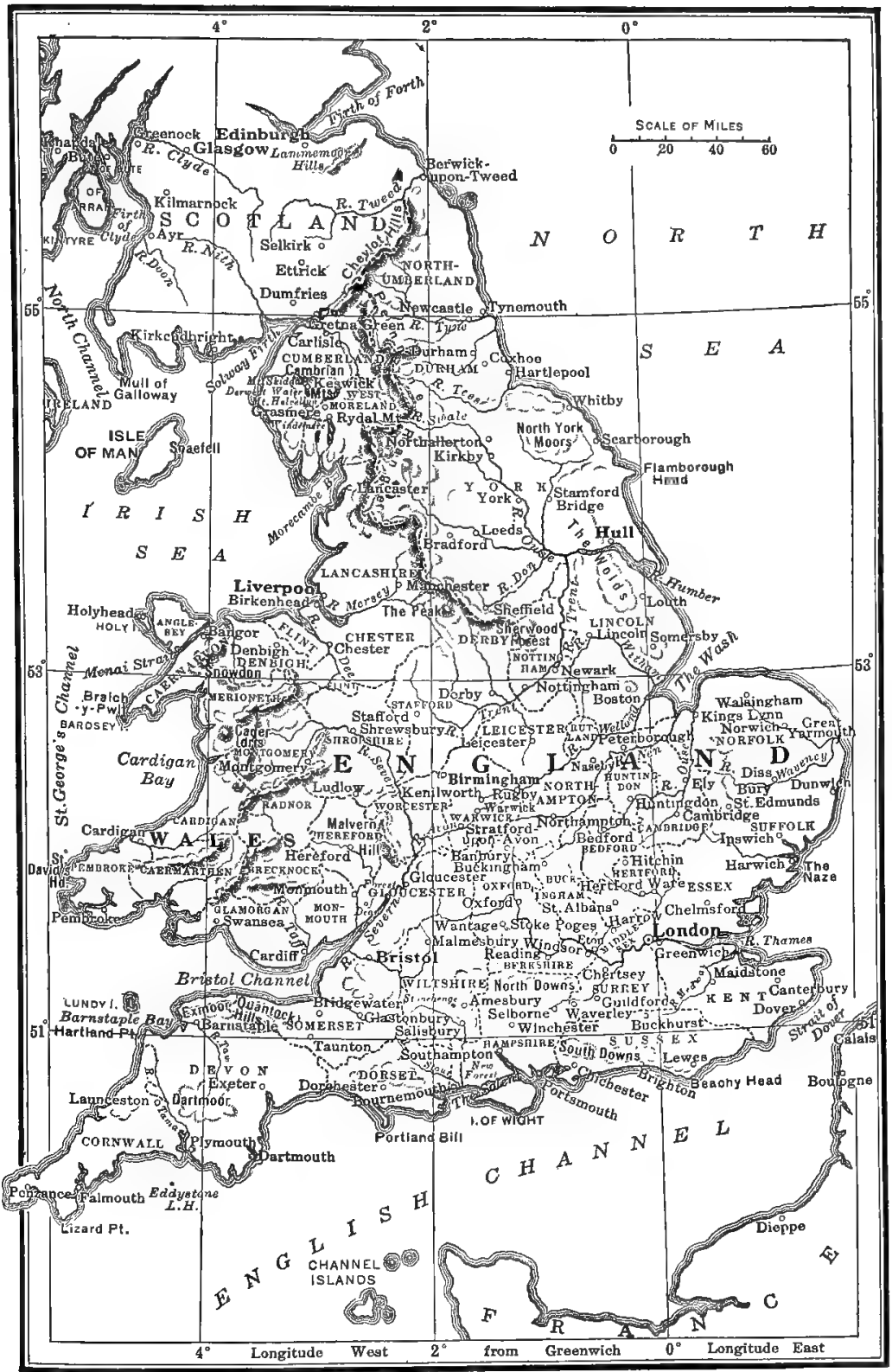

Fig. 6. A county map of England, on which will be found points of interest connected with the ancestry and development of many breeds 
Societies for promoting Arab horses are found in various countries. In the United States Arab horses are registered in "The American Thoroughbred Studbook." The "General Studbook of Great Britain" serves the same purpose in that country. In I908 the Arabian Horse Club of America was incorporated, and Volume I of the "Arabian National Studbook" was published in I9I3. This contains the registration of one hundred and twenty-seven Arabs and sixty-eight Americo-Arabs. In addition to registering pure Arabs, this association registers, under certain conditions, crosses with Thoroughbreds, trotters, "Kentucky saddle horses," Morgans, and Clays. 


\section{CHAPTER III}

\section{THE THOROUGHBRED}

The history of the Thoroughbred is so closely associated with the improvement of the modern horse that much consideration should be given it.

The horse in England prior to Queen Elizabeth's reign was mainly of the draft type, coarse and strong. We know little of his general merits. He was used in war for chariots and as a saddle horse. The early Romans brought horses to England in the fifth century, and so did the succeeding Normans and others. Early in the thirteenth century King John imported one hundred stallions from Flanders. It is related that during the fourteenth century Edward III brought to England over fifty Spanish horses at a cost of over eight hundred dollars each. Henry VIII maintained a royal stud, had laws enacted regarding horse breeding, and imported from Turkey, Spain, and Italy. Yet during all these years the prevailing horses were burden bearers with the exception of a few of greater speed, known as running horses. The use of heavy armor in the army had justified breeding a horse of this type.

Systematic horse racing in England was first introduced by James I. During the reign of Queen Elizabeth (I 558-I603) the use of armor grew to be unpopular, though the use of horses changed but little. James I, succeeding Elizabeth, was not warlike in temperament, and the use of armor passed away during his reign. Not only this, but James established the race course, gave attention to horse breeding, and imported from the Orient. $\mathrm{He}$ established a code of regulations from which the modern race course has derived its foundation. James imported from the Orient through an English merchant named Markham, an Arabian stallion for which he paid five hundred pounds $(\$ 2500)$. This horse was much ridiculed and played no special part in improving racing stock. About I6I7 Sir Thomas Edmunds brought to England six Barb stallions which were bred to English mares. 
Charles I (I625-I649), the son of James I, established racing at Newmarket and Hyde Park. Charles II is regarded by British authorities as the leading promoter of horse racing following the time of Henry VIII. He brought many horses from the Orient and was a pioneer in establishing the Thoroughbred as a breed. Two Barb mares which Charles II imported became famous among the brood mares of England, and were named the "Royal Mares."

Horse racing and the race track in Great Britain have thus been institutions from early times, and since the day of James I (1566-1625) every British ruler has patronized the race course and promoted horse breeding. The most noted race course in England is that at Newmarket, established in 1667. On this course in May, July, and October are held notable racing events, of which the Two Thousand Guineas stake is the most famous. What are known as the classic races of England, in the order of their occurrence, are the Two Thousand Guineas, One Thousand Guineas, Derby, ${ }^{1}$ Oaks, and St. Leger. The Derby, the most noted of these, was established at Epsom in I780 and has been held each year since until I9I5, when it was discontinued until after the World War. The race as run in England and generally elsewhere in western Europe is with a jockey in the saddle, the gait being at a gallop, which is the fastest speed produced by the horse. The course is a closely cropped sod; hence the name of "the turf," as applied to the European race track. The length of the course and its form vary more or less. In 1892 Curzon wrote, ${ }^{2}$ "There are thirty-one different race courses at Newmarket, ranging from a little over a furlong (40 rods, or one eighth of a mile) to the Beacon course of four miles." The Derby race is over a course I mile 4 furlongs 29 yards. Four miles is rarely run. A popular distance is one and one-fourth or one and one-half miles.

The early improvement of the Thoroughbred dates back several . hundred years. Since the time of James I about one hundred and sixty-four oriental sires have been imported into England. The keen desire for a running horse and the race track have

1 In England pronounced as though spelled Darby.

2 Henry Curzon, A Mirror of the Turf. 
resulted in the development of the Thoroughbred, which for two hundred years or more has been bred with considerable purity.

Three early oriental horses introduced into England during the formative period of the Thoroughbred exercised a most important influence. These were the following:

I. The Godolphin Barb, also known as Godolphin Arabian, was probably foaled in Barbary about I724. Later he found his way to France and for a time was used to haul a water cart. About I 728 he was taken to England and presented to Lord Godolphin, who always insisted that the horse was an Arabian. He was used in the stud with great success. His blood contributes in a most important degree to founding the Thoroughbred.

2. The Byerly Turk, the saddle horse of Captain Byerly; used later in the seventeenth century in the wars of William in Ireland, was probably brought to England in 1689 . He was very famous as a sire, and horses descended from him are known as Byerly Turk horses. Of the famous Thoroughbred sires in England a few years ago, sixty are direct descendants of this horse.

3. The Darley Arabian, supposed to be a pure Maneghi Arabian, was bought at Aleppo, Syria, by Mr. Brewster Darley, as a gift to his brother Mr. John B. Darley of Aldby Park, near York. This horse was brought to England in I706. He was a dark bay in color, with a blaze on face and white on three feet, and stood about I 5 hands high. To the Darley Arabian can be traced the choicest of Thoroughbred blood.

These three oriental horses preceded the development of the Thoroughbred, yet their blood had a most potent influence in establishing the breed which followed.

Three early English Thoroughbred sires of great prepotency, important in establishing the breed, stand out as really great ancestors of the modern speed horse. They are the following:

I. Herod (King Herod). This horse was foaled in 1758 and was bred by the Duke of Cumberland, a brother of George II. $\mathrm{He}$ was used on the race course for a time and was then retired to the stud. He is said to have sired four hundred and ninetyseven prize winners on various race courses, and it is estimated that they won for their owners $£ 201,505$, or over one million dollars. Herod was a difirect descendant of the Byerly Turk. 
2. Matchem. One of the important sons of the Godolphin Barb was named Cade. He proved to be an indifferent race horse, but a great sire owing to his superior blood and conformation. Matchem, his best-known son, became a great racer as well as a prominent sire. It is stated that he made a record on the Beacon course at the rate of a mile in $I: 44$. He also became well known for the excellence of his progeny in speed quality, for he sired three hundred and fifty-four sons and daughters that were winners of races. Matchem was foaled in 1748 and died in $178 \mathrm{I}$.

3. Eclipse. The Darley Arabian was the sire of two great horses in their day - notably Flying Childers (also known as The Devonshire) and Bartlett's Childers. The former was a chestnut horse with four white feet and was the fastest horse on the English turf up to his time. Bartlett's Childers was never trained to race, but was used in the stud instead. A grandson of his, named Marske, bred to the mare Spiletta, was the sire of Eclipse, foaled in I 764 during a great eclipse, from which he takes his name. From two points of view this horse may be regarded as perhaps the greatest in history - one as a racer, the other as a progenitor of racers. He was bred by the Duke of Cumberland, and at the sale of his stud brought 75 guineas. He was five years old before going on the turf, running first at Epsom. In his second race, at York, he distanced his competitors. In 1769 Dennis O'Kelly bought him for 1650 guineas $(\$ 8250)$. As a racer he distanced some of the best horses of his time. Finally, as no one would race against him, he closed his racing career of seventeen months by walking over the Newmarket race course for the King's Plate in October, I770. In I 779 O'Kelly was asked by one of the Bedford family for his price on Eclipse, and he replied that "all Bedford Level would not purchase him." From another person he asked $\$ 125,000$ and an annuity of $\$ 2500$ for life.

Eclipse won eleven King's Plates, and O'Kelly cleared $\mathcal{L}_{25,000}$ on him. In historical descriptions of this horse he is said to have been about I $5 \frac{1}{4}$ hands high; his shoulders were very low and oblique and thick above, while he stood high behind. He had a great loin, very long quarters, powerful and long thighs and forearms, and his stride was very wide. He was so thick winded 
that he could be heard some distance. He was of fine disposition, and in a race he took his own gait, rushing along with his head down, indifferent to his jockeys, who found it impossible to hold him in. Eclipse sired three hundred and thirty-four winners of races. He died in 1789 , aged twenty-five years. This horse was a direct descendant of the Darley Arabian, and the very best of British and American racing-horse blood traces its source from these two great sires.

Of these three English-bred stallions Eclipse as a breeder was most important, especially in the male line of descent, while Matchem was least so. The influence of both the oriental and English sires on the creation of the Thoroughbred as a breed has been very profound, but without doubt numerous females have had an important part. However, much less is known of the personality and breeding of the mares than of the sires. C. Bruce Lowe, in an elaborate study of speed lines of many great Thoroughbreds, compiles a list of forty-four important foundation mares. At the head of that list he places first Iregonzuell's Natural Barb Mare; second, Burton's Barb Mare; third, Dam of treo True Blues.

The origin of the Thoroughbred commences with the union of Arabian, Barb, and Turkish blood with the lighter type of English horse. From this amalgamation came great stamina, remarkable speed, unusual endurance, and great symmetry of form. No other European breed of horses at the present time shows so much purity of breeding as does the Thoroughbred, notwithstanding the early combination of blood. For many years animals recorded in the "General Studbook" have been regarded as free of all impure breeding.

The conformation of the Thoroughbred is distinctive. The head should be fine and lean and moderately small, bearing evidence of quality and breeding; eyes prominent and intelligent; ears of medium size, not too wide apart, and carried in a lively manner. The neck should be long, the upper part from withers to poll being about twice as long as the lower part from point of shoulder to larynx, and strongly muscular. The shoulders should slope obliquely back to a notable degree, be strongly muscled, and extend back to form high fairly close long withers; no collar 
heaviness should be noticeable. The chest tends to narrow rather than broad conformation, with good depth, yet able authorities prefer a broad rather than deep and narrow chest. The body should be somewhat circular in type, with a depth at the withers rather less than half the height, with a length equal to the height at withers and croup; the back and loins should be comparatively broad, level, and muscular; the ribs well sprung and of enough

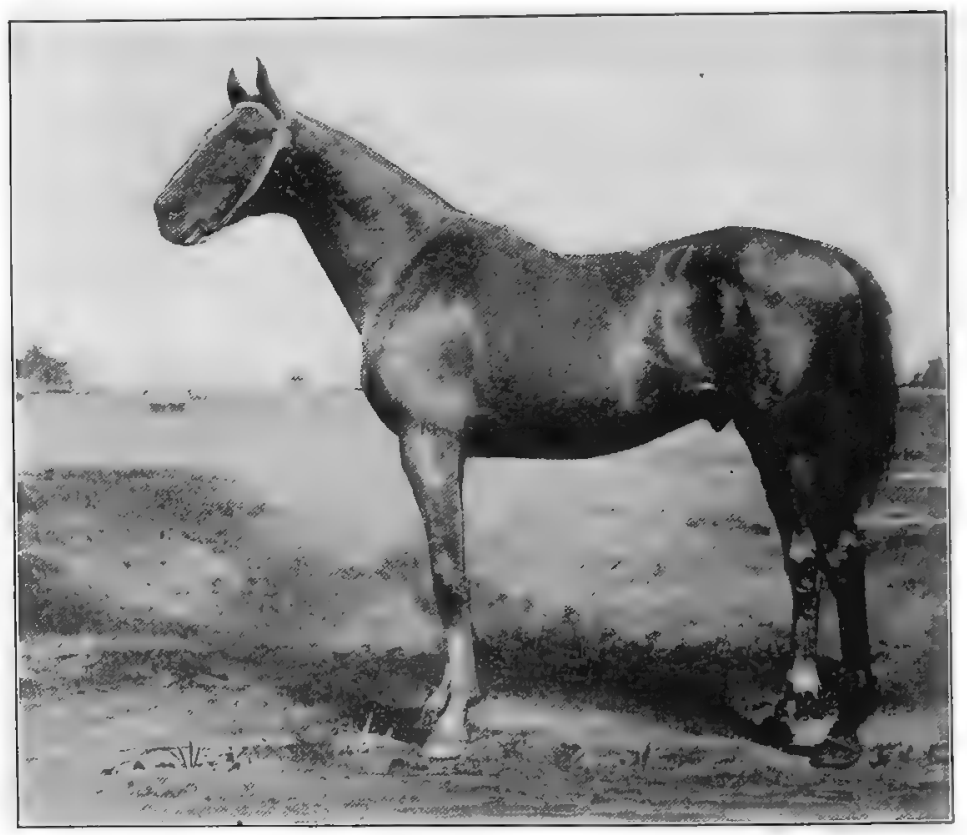

FIG. 7. Hanover, a Thoroughbred stallion foaled in 1884 . A famous runner, starting in fifty races, winning thirty-two, securing $\$ 120,9 \mathrm{I} 2$ in prize money. The leading sire of prize winners from 1895 to 1898 inclusive. From photograph by courtesy of the Thoroughbred Record

depth to show good feeding capacity. The croup is carried high and tends to be long, rather level, curving gracefully, with the tail attached medium high. The hind quarter is one of the features of the Thoroughbred, being long and strongly muscled, exhibiting great driving power; the gaskins, or lower thighs, should be broad. The fore $\operatorname{lgg}$ should be muscular and strong in arm and long and wide in forearm, with comparatively little width between 
the legs. A rather broad, strong knce, supported by a short, flat cannon bone extending well back, is desirable. The hind leg at the hocks ought to be deep, clean, free from fleshiness, and be supported by a short, flat, clean cannon bone. The pastern joint should be smooth, placed true, and in harmony with the leg as a whole. The pasterns should be rather long and slanting, yet strong, clean, and springy, being carried at an angle of about 45 degrees. The feet should be of medium size, wide and high at the heel, concave below, and be carried straight and true. In order to secure speed it is essential that the knees and hocks move smoothly and freely and that this movement be true. The gait of the Thoroughbred is essentially the gallop, which horses of this breed show to perfection.

The height of the Thoroughbred ranges from $I 4_{2}^{1}$ to $I \sigma_{2}^{1}$ hands, but I 5 to $I 5 \frac{1}{2}$ is most approved. It is probable that this breed has increased in height with its development. About the middle of the last century Rous asserted that the breed had increased a hand in height during the preceding hundred years. Sir Walter Gilbey states that "from an average height of 14 hands in 1700 the breed has been graded up to an average of 15 hands $2 \frac{1}{2}$ inches in the year 1900."

The weight of the Thoroughbred is quite variable, but in general ranges from 900 to I050 pounds.

The color of the Thoroughbred is variable. Bays and browns are quite general and most popular, though chestnuts frequently occur, while blacks, grays, and roans may be found.

The temperament of the Thoroughbred is nervous and mettlesome, this horse being endowed with great spirit and endurance in the race. Frequently riders have great difficulty in restraining their horses at the opening of a race, so impatient are they to make the start.

A list of famous British Thoroughbreds might include a large number of animals. The following horses have attained great fame on the British turf and may be regarded as among the very best representatives of the breed. This brief list, which covers nearly one hundred and fifty years, gives the date of foaling and the name of sire and dam in each case: Squirt, I732, by Bart-

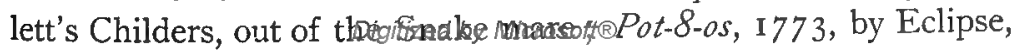


out of Sportsmistress ; Woodpecker, r773, by Herod, out of Misfortune; Highfyer, I774, by Herod, out of Rachael ; Sir Peter Teazle (also known as Sir Peter), I784, by Highflyer, out of Papillon; Waxy, I 790, by Pot-8-os, out of Maria by Herod; Whalebone, I807, by Waxy, out of Penelope; Tramp, I810, by Dick Andrews, dam by Gohanna; Whisker, I8 I 2, by Waxy, out of Penelope; Sir Hercules, I 826, by Whalebone, out of Peri; Touchstone, I83 I, by Camel, out of Banter; Irish Bird Catcher, 1833, by Sir Hercules, out of Guiccioli; Gladiator, I833, by Partisan, out of Pauline; Faugh-a-Ballagh, I841, by Sir Hercules, out of Guiccioli ; Orlando, I84 I, by Touchstone, out of Vulture; The Baron, 1842 , by Irish Bird Catcher, out of Echidna; Stockwell, I849, by The Baron, out of Pocahontas; Kingston, I 849 , by Venison, out of Queen Anne; King Tom, I851, by Harkaway, out of Pocahontas ; Blair Athol, I86I, by Stockwell, out of Blink Bonny; Hermit, 1864, by Newminster, out of Seclusion; Robert The Devil, 1877 , by Bertram, out of Cast Off; Bcnd Or, I878, by Doncaster, out of Rouge Rose; St. Simon, I 88 I, by Gallopin, out of St. Angela; Isinglass, I 890 , by Isonomy, out of Deadlock; Persimmon, I 893, by St. Simon, out of Perdita II; Flying Fox, I896, by Orme, out of Vampire; Diamond Jubilee, I897, by St. Simon; Rock Sand, I900, by Sainfoin, out of Roquebrune.

Importations of Thoroughbreds to America were made at a comparatively early date, and some of the most famous horses of the breed found their way to the United States during the eighteenth century. The first to come to America is said to have been the horse Bulle Rock, imported to Virginia in 1730. Diomed, winner of the first Derby ever run, was imported in I 799 at twentytwo years of age. Messenger, imported in 1788 as a Thoroughbred to improve the running horse, became a distinguished progenitor of trotters. Fearnought (I 775), Buzzard (I787), Shark (I771), Alderman (I787), Pantaloon (I778), Highflyer (I 784), Saltram (I 780), and Matchem (I 773) represent eminent early importations. The men of Virginia, South Carolina, Maryland, and Kentucky, from very early days, showed great interest in Thoroughbreds and promoted the race track. In 1665 the first track in America, known as the Newmarket course, was established at Hempstead 
Plains, Long Island, New York, by Governor Nicolls. In I 760 a Newmarket course was also established at Charleston, South Carolina. Among the many Thoroughbreds imported to America since the opening of the nineteenth century, the following are noteworthy: Sarpedon, 1828, by Emilius, out of Icaria; Glencoe, I $83 \mathrm{I}$, by Sultan, out of Trampoline; Leamington, I853, by Faugh-a-Ballagh, out of Daughter of b.m.; Bonnie Scotland, 1853, by Iago, out of Queen Mary; Australian, I858, by West Australian, out of Emilia; Phaeton, I 865 , by King Tom, out of Merry Sunshine; Prince Charlie, I869, by Blair Athol, out of Eastern Princess; Rayon d'Or, I876, by Flageolet, out of Auracaria; St. Blaise, I880, by Hermit, out of Fusee; Kingston, I882, by Flageolet; Ormonde, I884, by Bend Or, out of Lily Agnes; Sysonby, I90I, by Melton, out of Optime.

Thoroughbreds of American breeding that have attained great prominence date from about 1800 , but this list is not a long one. The following are of special distinction, though others of merit might be mentioned: Sir Archy, I 805, by Diomed, out of Castianira; American Eclipse, I8I4, by Duroc, out of Miller's Damsel ; Boston, I 833, by Timoleon, out of Sister to Tuckahoe; Lexington, 1850, by Boston, out of Alice Carneal; Norfolk, I86o, by Lexington, out of Novice; Longfellow, I 867, by Leamington, out of Nantura; Parole, 1874, by Leamington, out of Maiden; Himyar, 1875, by Alarm, out of Hira; Luke Blackburn, I877, by Bonnie Scotland, out of Nevada; Iroquois, I878, by Leamington, out of Maggie B.B.; The Bard, 1883, by Longfellow, out of Brademante; Firenzi, I884, by Glenelg, out of Florida ; Hanover, 1884, by Hindoo, out of Bourbon Belle; Salvator, I886, by Prince Charlie, out of Salina; Hamburg, I89I, by Hanover, out of Lady Reel.

Thoroughbred sires of winners on the course vary greatly in degrees of distinction. Many sires have but small opportunity, owing to short lives or to being owned by men who have no opportunity to use them in the stud in an important degree. The horse Lexington was one of the greatest sires in the history of the American turf, and during seven different years his progeny were the leading winners. In twenty-one seasons he sired 600 horses, of which 236 were winitized by 
his offspring won a total of $\$ \mathbf{I}, \mathbf{I} 59,32 \mathrm{I}$. Two imported horses, Leamington and Bonnie Scotland, left a strong impress on running horse blood. Leamington was used in the stud in England and in 1865 was purchased for $\$ 7500$ by Mr. Cameron and brought to America. Miss Theo, by Leamington, was a noted brood mare, and Parole, a son, was a famous racer. Hanover, by Hindoo, was one of the more recent great American-bred sires, being foaled in I884. He not only possessed great speed but

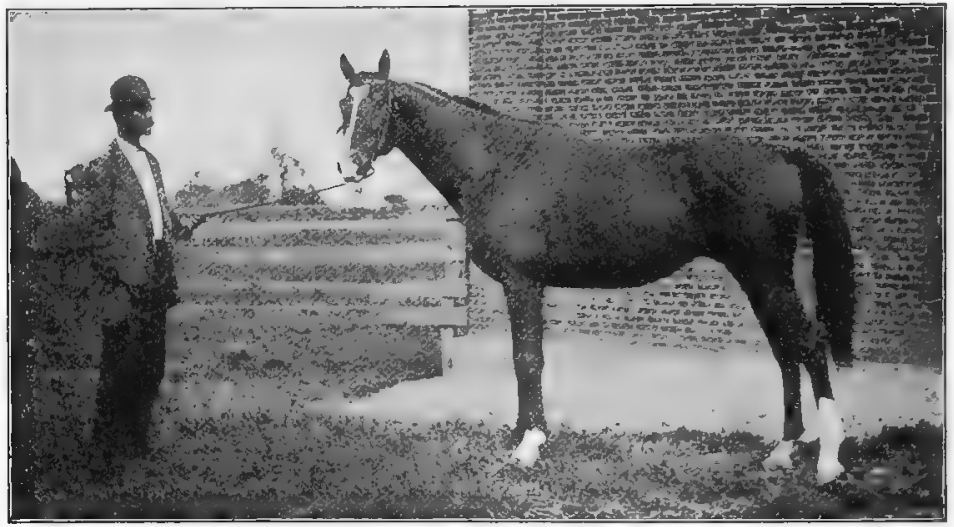

FIG. 8. Lamplighter, a Thoroughbred racer and sire in the stud of Milton Young, Lexington, Kentucky. One of the leading sires of 1904 and 1905 winners. From photograph by the author

transmitted this quality to many sons and daughters. The horse Kingston, that died in I9I 2 at twenty-nine years of age, raced for nine years and sired many winners.

The speed record of the Thoroughbred is faster than that of any other horse. Races with this breed are run under the saddle, with jockeys up. A light, skillful jockey is needed in the saddle. A very satisfactory jockey weight is I Io to I I 5 pounds, but many great races have been won with weight up to 125 pounds. The fastest record by a Thoroughbred up to I 9 I 8 was that of $I: 35 \frac{1}{2}$ by Salvator on a straightaway track of one mile, in 1890 , at Monmouth Park, New Jersey. However, on August 2I, I9 I 8, the horse Roamer at Saratoga, New York, reduced the record to $I: 34 \frac{4}{5}$. On the Harlem standard track, in I903, Dick Wells ran a mile in $1: 37_{5}^{2}$. Only a few days before Alan-a-Dale had passed around 
the Washington Park track, making the mile in $1: 37 \frac{3}{5}$. In I910 Fashion Plate made a mile in $\mathrm{r}: 37 \frac{4}{5}$ in the Metropolitan Handicap, which record was again equaled in the same race in I9I4 by Buskin. The above are the fastest mile records up to 1919 inclusive. In 1855 Lexington ran four miles in 7:1934, winning $\$ 20,000$ in a race against time. In I 876 Ten Broeck, in a race against time, lowered the four-mile record to $7: 15_{4}^{3}$. This same year he made a mile in $1: 39 \frac{3}{4}$, which was the record for about thirteen years. In I88 I Luke Blackburn, a very famous runner, then four years old, made a mile at Jerome Park in $1: 45$. In I 880 he also made a record of 2:34 for a mile and a half, which was not lowered for many years.

Thoroughbred records of the English Derby are regarded as of first importance. The winners from Igoo to the present day have furnished some of the most remarkable speed in the history of that historic course. The following are the more recent records :

\begin{tabular}{|c|c|c|c|}
\hline YEAR & NAME of Horse & Sire & Time \\
\hline I900 & Diamond Jubilee & St. Simon & $2: 42$ \\
\hline I9OI & Volodyovski & Florizel & $2: 40 \frac{4}{5}$ \\
\hline 1902 & Ard Patrick & St. Florian & $2: 42 \frac{1}{5}$ \\
\hline 1903 & Rock Sand & Sainfoin & $2: 42 \frac{4}{5}$ \\
\hline 1904 & St. Amant & Frusquin & $2: 42 \frac{4}{5}$ \\
\hline 1905 & Cicero & Cyllene & $2: 39 \frac{9}{5}$ \\
\hline I 906 & Spearmint & Carbine & $2: 36 \frac{4}{5}$ \\
\hline 1907 & Orby & Orme & $2: 44$ \\
\hline 1908 & Signorinetta & Chaleureux & $2: 39 \frac{4}{5}$ \\
\hline 1909 & Minoru & CyIlene & $2: 42 \frac{2}{5}$ \\
\hline 1910 & Lemberg $^{1}$ & Cyllene & $2: 35 \frac{1}{5}$ \\
\hline I9I I & Sunstar & Sunbridge & $2: 36 \frac{4}{5}$ \\
\hline 1912 & Tagalic & Cyllene & $2: 38 \frac{4}{5}$ \\
\hline 19.13 & Aboyeur & Desmond & $2: 37 \frac{8}{5}$ \\
\hline $1914^{2}$ & Durbar II & Rabelais & $2: 3^{8}$ \\
\hline
\end{tabular}

Thoroughbred records on the American turf of special interest are those made in the Futurity and in the Suburban Handicap, Sheepshead Bay, New York; the Brooklyn Handicap, Gravesend, New York; the Metropolitan Handicap, Belmont Park, New York; the Brighton Handicap, Brighton Beach, New York;

1 Record time.

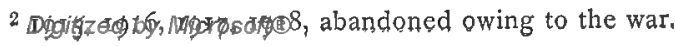


the Excelsior Handicap, Jamaica, New York; and the Saratoga Handicap, Saratoga, New York. During the winter season running races are conducted in the South, more especially at New Orleans.

The following are the more recent winning records of the Suburban Handicap, over a course of one and one-fourth miles, and of the Futurity, over a course of six furlongs.

Suburban Handicap

\begin{tabular}{c|l|l|c}
\hline \hline Year & Name of Horse & Time & VAlur of Pursi \\
\hline I904 & IIermis & $2: 05$ & $\$ 16,800$ \\
1905 & Beldame & $2: 05 \frac{3}{5}$ & I6,800 \\
1906 & Go-Between & $2: 05 \frac{1}{5}$ & 16,800 \\
1907 & Nealon & $2: 06 \frac{2}{5}$ & 16,800 \\
1908 & Ballot & $2: 03$ & 19,750 \\
1909 & Fitz Herbert & $2: 03 \frac{2}{5}$ & 3,850 \\
1910 & Olambala & $2: 04 \frac{2}{5}$ & 6,000 \\
I913 & Whisk Broom II & $2: 00$ & 3,000 \\
$1915^{1}$ & Stromboli & $2: 05 \frac{2}{3}$ & 5,000 \\
\hline
\end{tabular}

The Futurity

\begin{tabular}{|c|c|c|c|}
\hline YeAR & Name of Horse & $T_{\text {IME }}$ & Value of Purse \\
\hline I9O4 & Artful & $1: 11 \frac{4}{3}$ & $\$ 42,880$ \\
\hline 1905 & Ormondale & $1: 11 \frac{4}{5}$ & 38,680 \\
\hline I906 & Electioneer & $1: 13 \frac{8}{5}$ & 37,270 \\
\hline 1907 & Colin & $I: I 1 \frac{1}{5}$ & 24,830 \\
\hline 1908 & Maskette & I : I I $\frac{1}{5}$ & 24,985 \\
\hline I909 & Sweep & $I: I I \frac{4}{5}$ & 25,710 \\
\hline 1910 & Novelty & $I: 12 \frac{1}{5}$ & 10,000 \\
\hline 1913 & Pennant & I:I 5 & I 5,000 \\
\hline 1914 & Trojan & $1: 16 \frac{4}{5}$ & 16,010 \\
\hline I9I 5 & Thunderer & $1: 11 \frac{4}{5}$ & $23,45^{\circ}$ \\
\hline
\end{tabular}

Thoroughbred winnings in money, prior to the World War, amounted to very large sums. This is brought out by Lieutenant R. M. Danford in a striking way, in the following reference ${ }^{2}$ to the Castleton Stud of Kentucky, long owned by James R. Keene, one of the greatest promoters of the Thoroughbred:

\footnotetext{
1 Not run in rgi4.

2 Bit and Spur, February, 1912.
} 
The first five names on the list of America's greatest winning races horses are Domino $\$ 193,550$, Sysonby $\$ 184,430$, Colin $\$$ I 80,9 I 2 , Ballot $\$ 154,545$ and Kingston $\$ 141,823$. Sysonby was imported in utero and raised on the farm. On the list of great American winners are the following horses bred at the farm: Peter Pan, with $\$$ I I 6,450; Delhi, with $\$$ I I5,640; Maskette, with $\$ 77,090$; Novelty, with $\$ 72,630$; and Commando, with $\$ 58$, I96. These, together with numerous turf stars of less brilliancy, placed Mr. Keene at the head of the list of winning owners in America in 1905, I 906, I 907 , and I 908 , and in 1907 made him the world's record winning owner, having that year to his credit the remarkable sum of $\$ 406,59 \mathrm{I}$. The next largest winning owner is the Duke of Portland, who, in I889, won on the English turf an amount equal to $\$ 365,872.63$. The winnings of the farm [Castleton] have exceeded the enormous sum of $\$ 2,000,000$.

Prices paid for Thoroughbred horses have reached higher figures than for any other breed. In I9I3 J. B. Joel paid about $\$ 200,000$ for Prince Palatine (sire, Persimmon; dam, Lady Lightfoot), the winner in I9I I of the St. Leger and in I9I 2 of the Ascot gold cup, Eclipse stakes, Doncaster cup, and the Jockey Club stakes. Also in 19I3 Edmund Blanc of France paid $\$ 200$,ooo for White Knight, by Desmond, owned by W. R. Wynham of England. In I904 Flying Fox, at the sale of the Duke of Westminster, sold for $\$ 187,500$. In I9I 2 Rock Sand, that had cost August Belmont $\$$ I 25,000 , was sold by him at thirteen years of age for \$I 50,000. Diamond Jubilee, Ormonde, and Cyllene also each sold for \$I50,000. Commenting on the high prices paid for Thoroughbreds, Mr. J. I. Teasdale says : ${ }^{1}$

At a sale in Sydney, Australia, in Easter week (1 910 ), 385 yearlings were sold for an average of over \$972 each. At the Doncaster yearling sales in September, I 9 I I, 298 lots averaged $\$ 1905$. In Argentina recently I 88 yearlings sold at an average of nearly $\$ 6500 ;$ I 2 Cyllene colts made an average of $\$ 15,000$, and 8 fillies made an average of $\$ 7500$. Thirteen Polar Star colts made an average of $\$ 9500$, and Io fillies averaged $\$ 6000$. Seven colts and 7 fillies by Diamond Jubilee fetched respectively an average of $\$ 8000$ and $\$ 4000$. Fourteen Jardy colts reached an average of $\$ 10,000$, and 6 fillies an average of $\$ 5000$. The Vale d'Or colts averaged $\$ 4500$, the Io fillies $\$ 5000$.

The distribution of the Thoroughbred is world-wide in regions where the Caucasian race prevails and where horses are kept for racing purposes. England is the native home of the breed, but 
to-day it is bred in all Great Britain. France has long maintained noted studs of Thoroughbreds, while Germany, Austria-Hungary, Italy, Russia, Argentina, and the United States have had important studs.

A Thoroughbred studbook, known as the "General Studbook of Great Britain," is published in England. It is interesting to note that "An Introduction to a General Studbook" was published in I79I, while in I808 there was published the first volume of "The General Stud-Book, containing pedigrees of Race Horses, etc., etc., from the earliest accounts to the year I807, inclusive." This was the first pedigree book of any kind up to this time. This publication has been continued ever since under the same title of the "General Studbook," being published in London. In America "The American Thoroughbred Studbook" is published by the American Jockey Club, with headquarters in New York. Studbooks for this breed are also published in France and Argentina. 


\section{CHAPTER IV}

\section{THE AMERICAN SADDLE HORSE}

The native home of the American saddle horse embraces the more fertile sections of the states of Virginia, Kentucky, Tennessee, and Missouri. Within latitudes $35^{\circ}-38^{\circ} \mathrm{N}$. and including a distance westward from the Virginia coast of almost one thousand miles, we find the territory within which this comparatively new breed has been developed. Amid blue-grass fields and in the hands of the better-class farmers and horse lovers of the South, the American saddle horse has reached a high stage of perfection. Much of this improvement has been brought about in Kentucky; hence the common term "Kentucky saddle horse." Lexington, Kentucky, has long been regarded as the great center of breed activity.

The ancestry of the American saddle horse involves several rather distinct families of American-bred horses and one longestablished British breed, the Thoroughbred. Early in the history of Kentucky - when railroads were unknown and bridle paths, trails, and poor roads were common - horseback riding was not only necessary but universal. The early saddle horses were hardgaited, and this resulted in the selection of the better type of Thoroughbreds, easy of gait and light of foot, some of which found their way into Kentucky from Virginia. Mares with an ambling, or slow-pacing, gait were sought for and found many years ago, and to them Thoroughbred saddle stallions of easy movement were bred. The pacing blood came in part from Canada and New England and so involved some Morgan breeding. Thus, by selection there developed à class of very easygaited saddlers. The significance of Thoroughbred blood in this early development is brought out in striking manner, as shown in the blood lines in Volume I of the "American Saddle Horse

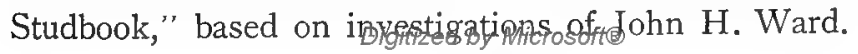


In the 108 I horses registered we find the following Thoroughbred blood:

Pure-bred Thoroughbreds . . . . . . . . . 2 horses

Containing 50 per cent Thoroughbred blood . . . 50 horses

Containing 25 per cent Thoroughbred blood . . . . 296 horses

Containing I $2 \frac{1}{2}$ per cent Thoroughbred blood . . . . 343 horses

Containing $6 \frac{1}{4}$ per cent Thoroughbred blood. . . . I 52 horses

Containing 3 per cent Thoroughbred blood . . . 36 horses

Uncertain breeding . . . . . . . . . 202 horses

Total $\overline{108 \mathrm{I}}$ horses

The foundation stock of the American saddle horse, as agreed upon by the American Saddle Horse Breeders' Association, after years of careful investigation and as revised in 1902, consists of the following ten stallions:

Denmark (Thoroughbred), by imp. Hedgeford

John Dillard, by Indian Chief (Canadian)

Tom Hal (imported from Canada)

Cabell's Lexington, by Gist's Black Hawk (Morgan)

Coleman's Eureka (Thoroughbred and Morgan)

Van Meter's Waxy (Thoroughbred)

Stump-The-Dealer(Thoroughbred)

Peter's Halcorn, Thoroughbred on sire's side

Davy Crockett

Pat Cleburne, by Benton's Gray Diomed

The value of the Thoroughbred in developing the American saddle horse is set forth in the Breeders' Gasctte in interesting manner by the late Charles L. Railey, long noted as a leader in the improvement of the saddle horse. After referring to the hard gait of the Thoroughbred, he says:

In a life experience I do not recall one high-class saddle horse that was strictly a Thoroughbred. I have bought many beautiful specimens of the Thoroughbred, and tried faithfully to develop a saddle horse, only to find disastrous failure in each instance. The Kentucky breeder long ago realized that the Thoroughbred horse was the foundation from which to build for fineness of head and neck, obliquity of shoulders, texture of coat, quality of bone and fluted leg; and while retaining these qualities, added to them a higher carriage of head, more action, a more docile temperament, and from this idea was evolved the saddle-bred horse of Kentucky. 
The characteristics of the American saddle horse are similar in many respects to those found in the roadster of superior conformation. However, he is notable for his beautiful head and expressive eye, a gracefully arched and well-proportioned neck, fairly high and refined withers, a short, strong back, well suited to the saddle, a long, rather level croup, and high-set, arched tail. The body should be round and neatly turned, and the shoulders and pasterns must be long and sloping, as necessary factors in an easy, springy gait. Not infrequently these horses appear to lack in depth of rib and so seem somewhat upstanding. This is essentially a stylish breed, as shown in the jaunty carriage of head, neck, and tail, and as evidenced in the nervous temperament commonly seen in American saddle horses of good breeding. " From an artistic point of view," writes Gay," "he is perhaps the most beautiful of all horses, being the

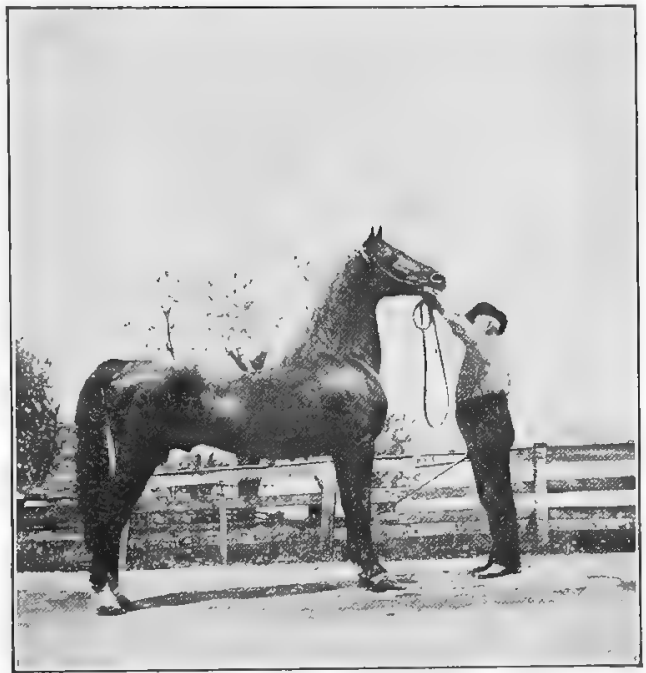

FIG. 9. Woodland Chief 2958 , an American saddle horse at twenty-one years of age. From photograph by Professor J. J. Hooper

extreme embodiment of quality and finish, an ideal which has been fostered by the so-called 'model' classes of Southern shows. Some have been bred so very fine, however, as to be markedly deficient in substance."

The size of the American saddle horse is comparable with that of the average roadster. In height I $5 \frac{1}{4}$ to $I 5 \frac{3}{4}$ hands may be regarded with favor, while the weight should vary between Iooo to I I 50 pounds. For ladies the lighter type is preferred, while for heavy weights the larger horse is more desirable. An

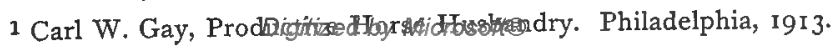


average height may be placed at $15 \frac{1}{2}$ hands, and a large percentage of these horses weigh about ro50 pounds.

The color of the American saddle horse is of several shades. Brown, bay, black, and chestnut are common, while gray is much less so. Some families tend more to one color than another, as, for example, with the Denmarks black is predominant, while with the Chiefs chestnut prevails. Color is not regarded as of prime importance.

The gaits of the saddle horse are especially distinctive. Saddlers may be divided into two classes: (I) the walk-trot-canter horse, having gaits commonly. found in all saddlers; and (2) the American saddle horse in particular, having the walk, trot, canter, rack, and the running walk or fox trot or slow pace.

A comprehensive discussion of the gaits of the saddle horse, coming from the pen of one well qualified to present the subject ${ }^{1}$ and long identified with saddle-horse interests, the writer thinks appropriate to introduce here.

There are different kinds of saddle horses, and they are classified in part at least by their gaits. The three natural gaits of a horse are the walk, trot, and gallop, or run. Artificially, that is, by education, the gallop is made into a canter, which is a gait performed by practically the same movement of the legs, but slower, more restrained, and easier to ride. We then have one kind of a saddle horse called the walk-trot-canter, or plain-gaited, horse. This horse suits a lot of people, primarily, because they do not know any other gait; secondarily, because they are imitators of the English fashion of riding; and lastly, and leastly, because they do not like other educated and easier gaits.

These easier gaits are the running walk and the rack. The latter is also called single foot, inasmuch as in this gait each foot has a separate impact on the ground, no two of them striking it at the same time, as in the trot and pace.

The running walk is called a slow gait, and there are two other gaits allied to it, - the slow pace and the fox trot. The name "running walk" defines the gait accurately, and at once identifies it to the understanding. It is faster than a flat-foot walk, and is produced by a movement of the legs more rapid than in a walk, but in about the same rhythm; that is, each foot strikes the ground independently of the others. Most horses going the running walk bob or nod their heads, and some of them even flop their ears in rhythm with their footfalls. It is an all-day gait, easy alike to the horse and the rider, and it covers ground at an astonishing fashion for its apparent speed. It is taught by urging a horse out of the walk but restraining him from a trot.

1 Editorial by the late W. R. Goodwin, Jr., Breeders' Gazette, June 10, 1903. 
The slow pace is a somewhat similar movement, but borders more on the side-wheel gait, or lateral pace, in which the two feet on one side of a horse strike the ground at the same instant. The true pace, however, is in no sense a saddle gait. It is rough and uncomfortable. A rider cannot rise to it and save himself, as in a trot, and it is positively the worst gait a saddle horse can possess. In the slow pace this side-wheel motion is slightly modified so that the impact on the ground of the two feet on a side is broken, thus avoiding the rolling motion of the true pace. The slow pace is a very comfortable gait, and is very showy, especially when a horse throws just a bit of knee action into it. It has grown common in the show ring during recent years, as saddlehorse trainers appreciate its catchy qualities and endeavor to teach their horses to go this gait. The best saddle-horse men, however, do not look on it with favor, as it is so easily corrupted into the abominable side-wheel pace, which ruins a saddle horse for comfortable and satisfactory work. Unless a rider is careful his mount may almost imperceptibly degenerate from a distinct and correct slow pace into a plainly defined pace, and then there is sure-enough trouble.

The fox trot is a slow trot or a jog trot. It is a

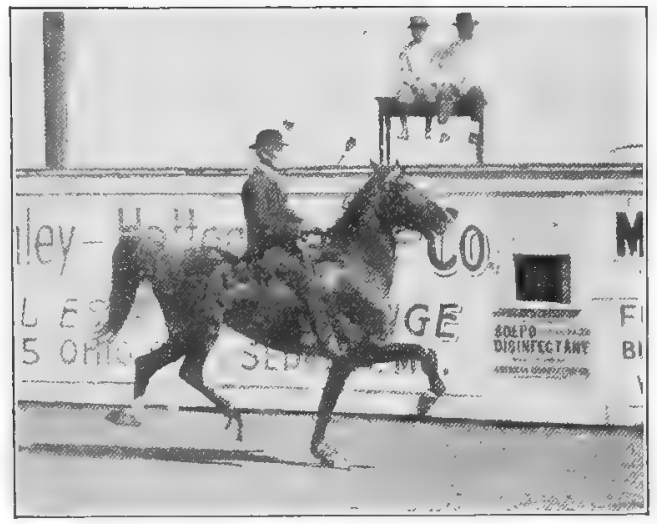

FIG. IO. An American saddle horse showing his gaits at the fair. Photograph from the American Breeder rather peculiar gait and not so desirable as the running walk or the slow pace. Some horses cannot acquire either of these two gaits, and so their trainers pull them down into a very slow trot and seek to pass that gait off as a fox trot. It is a broken-time gait, in a measure, somewhat easier than a pure trot, and when cleanly performed it will answer as a business gait.

The trot is the diagonal gait. The off fore foot and the near hind foot strike the ground at the same instant, and the horse bounds off them to hit the ground again with the near fore and the off hind. This gives a two-beat gait. The impact of the feet on the ground is one, two, one, two.

The pace is the lateral gait. The off fore and off hind foot hit the ground at the same interval, and the other pair on the near side follow. This is also a two-beat gait.

The rack is a four-beat gait. Each foot hits the ground at a separate interval in a one-two-three-four beat. The rack can be distinguished by ear as far as the footfalls of the horse may be heard; each foot rings clear its own note on

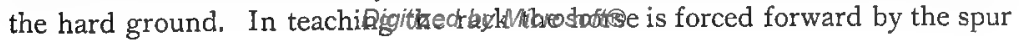


and restrained by the curb. His diagonal gait is thereby broken up and he flies into a four-beat gait. The rack is easy for the rider, hard for the horse. It is a showy gait, and is performed at great speed sometimes. The trainer who has a fast racking horse will generally keep him on that gait when in the show ring, hoping to dazzle the judge by the flashiness of the performance. . . . This gait has been officially named the rack by the American Saddle Horse Breeders' Association, and hence the name "single foot" should not be used, as it merely leads to confusion among the uninformed.

The five gaits recognized by that association are the walk, trot, canter, rack, and the running walk, or slow pace, or fox trot. Any one of these three slow gaits will answer. Some horses can go only one of them, some can show them all. When a horse can show these five gaits he is called a gaited horse.

Two notable families of American saddle horses are the Denmark and the Chief, and to these most of the more outstanding individuals of the breed largely trace their ancestry.

The Denmark family, as indicated on page 32, derives its name from a horse named Denmark, sired by imported Hedgeford. A son of Denmark, known as Gaines's Denmark 6I, was a black horse with white hind feet and of great beauty. He transmitted to his offspring not only beauty but also graceful action. According to the late David Castleman, ${ }^{1}$ of the 3000 entries in Volume IV of the studbook, I 282 , or 42.7 per cent, have a direct male trace to Denmark. Of these Gaines's Denmark has 1277 , or practically a perfect percentage. Of the II,977 entries in the first four volumes, 73II, or 61.4 per cent, trace to Denmark, while Gaines's Denmark traces 73I I lines of male descent to 730I of his sires. A son of Gaines's Denmark foaled in 1855, named Washington Denmark 64, transmitted the valued features of this line in a marked degree. Another son, Diamond Denmark 68, was the sire of Montrose I06, one of the notable sires of the breed. Black Squirrel 58 (foaled in 1876, sired by Black Eagle 74) and Rex Denmark 840 (foaled in 1884 , a great grandson of Gaines's Denmark) hold distinguished places in this remarkable family. This family represents the more refined type of the American saddle horse, individuals tending to an extreme in this respect and lacking in substance.

The Chief family has its fountainhead in Mambrino Chief II, a trotter foaled in 1844 in New York and ten years later taken

${ }^{1}$ American Saddle Horse Breeders' Register, Vol. IV (IgII), p. VI. 
to Kentucky. He was coarse in appearance, bay in color, stood about 16 hands, and never sired colts of quality, though he produced speed. He traced back three generations to imported Messenger, the Thoroughbred. Through a son, Clark Chief 89 , was sired Harrison Chief 1606 , who in turn sired eight sons of

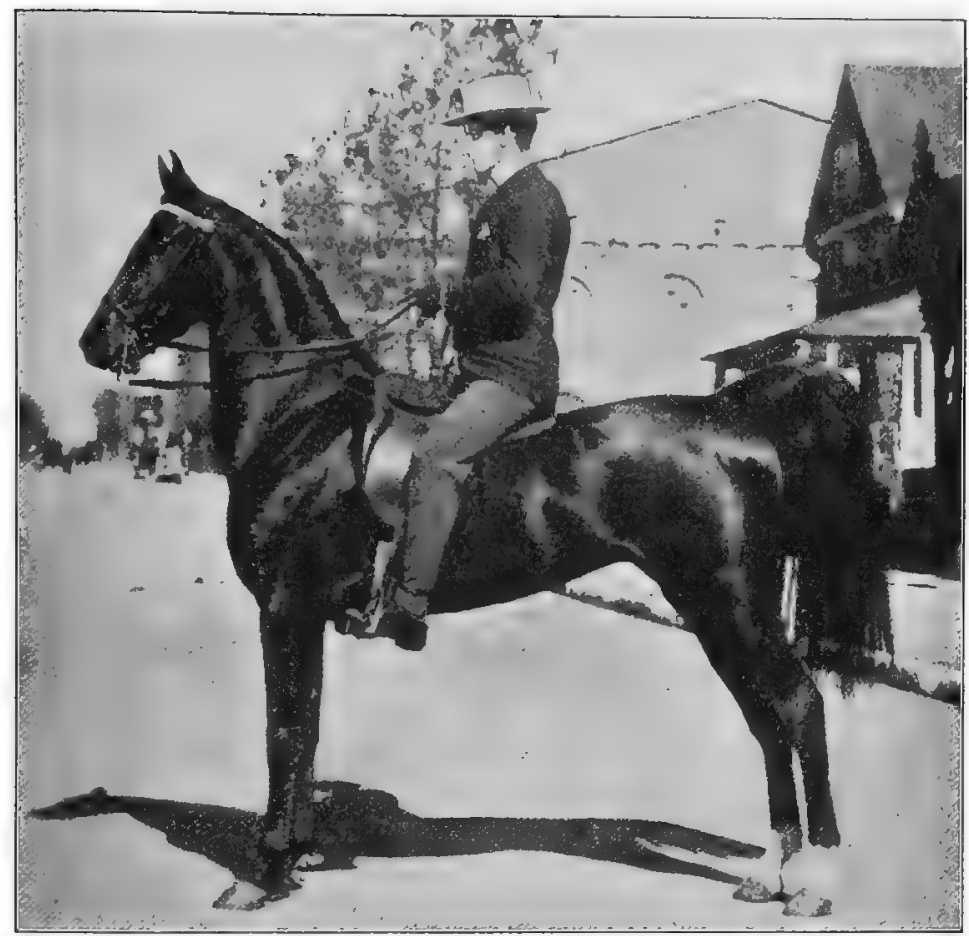

FIG. II. Gypsy Queen, an outstanding American saddle mare and prize winner. First in class at the Chicago Horse Show, 1903 and 1904 . From a photograph by courtesy of Ball Brothers, Versailles, Kentucky

distinction, Bourbon Chief 976 being especially so. This latter sired many fine sons and daughters, through whom this family came into marked favor. Bourbon King I 788, by Bourbon Chief, foaled in 1900, has proved to be one of the most illustrious sires of this family. Horses of this family show considerable substance, as a rule, and may appear a bit coarse in comparison with the Denmarks.

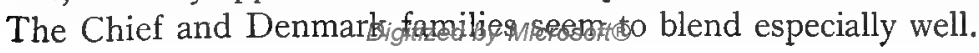


Prominent American saddle-horse sires additional to those mentioned under the preceding families are the following, the date of foaling, which is given in parenthesis, indicating the period when service began: Wilson's Chief; Harrison's Chief I606 (I872); Black Squirrel 58 (I876); Chester Dare Io (I882); Bourbon Chief 976 (I883); Forest Squirrel 80I (1890); Highland Denmark 730 (I890); Rex McDonald 883 (I 890) ; Montgomery Chief I 36I (I 897); Dandy Jim 2d I53 I (I900); My Dare 2642 (I90I); My Own Kentucky 3764 (I9OI); Kentucky Choice 3765 (I905); and Astral King 2808 (I906). The above fourteen horses cover a period of thirty-four years of foaling, from that of Harrison's Chief. In the studbook Wilson's Chief is given no registry number or date of foaling, being an early foundation sire. Rex McDonald 833, by Rex Denmark 840, who died at twenty-three years of age in 1913 , was regarded not only as almost a perfect specimen of a gaited saddle horse but as the most impressive sire of his time.

Noteworthy American saddle-horse mares are Mollie, dam of Black Squirrel 58 ; Amelia 1354 , by Red Eagle 28 ; Patsy McCord 1600, by Black Squirrel; Highland Maid I270, by Highland Denmark; Emily 855, by Bourbon Chief, by Harrison's Chief 384 I ; Rowena I 362, by Chester Dare Io, by Black Squirrel 58 ; Miss Rex 820 , by Rex Denmark; and Little Kate $585 \mathrm{I}$, by Prince of Denmark 423.

The prices paid for American saddle horses often run into high figures, \$500 to \$IO0O not being uncommon. There is but a limited supply of gaited saddlers, and these are always in demand by a class of patrons who are willing to pay a price consistent with merit. In I906 Major David Castleman sold the stallion The Moor I907, by Cecil Palmer, for $\$ 7500$ to General William Palmer of Colorado Springs. This same year General John B. Castleman of Kentucky sold the mares Eugenia (by Highland Denmark, out of Emily) and Magna (by Cromwell, Jr., out of Maria) to J. A. Davis of Massachusetts for \$5000. Rex McDonald sold for $\$ 2500$ as a six-year-old and later for $\$ 5000$. In 1907 the mare Miss Flirtation sold for $\$ 63$ I 8 . Kentucky Choice 3765 sold in 1909 for $\$ 6000$ and later changed hands at \$7500, In I9r3 My Major Dare 4424 sold for $\$ 10,000$, the 
top price for a stallion of the breed. As illustrative of the high values placed on these horses by their admirers, it is reported that $\$ 5000$ was refused for Black Squirrel at eighteen years of age, $\$ 7000$ was refused for Dandy Jim, and $\$ 12,000$ for Bourbon King.

The American Saddle Horse Breeders' Association was organized at Louisville, Kentucky, in I89I, as the National Saddle Horse Breeders' Association. In 1899 the name was changed to the American Saddle Horse Breeders' Association. Up to I9I9 seven volumes of the studbook have been published, indicating a registration of 7500 stallions and 13,500 mares. 


\section{CHAPTER V}

\section{THE LIGHT HARNESS TYPE}

.The light harness horse, or roadster, occupies a class by itself, representing a lighter type of driver than the coach horse. Such a horse is desirable for speed in conveying along roadways a light driving vehicle. The American trotter or pacer is the common type used for this work. Speed and endurance seem to be the principal points sought in the roadster, and less uniformity of type is found in this class than in any other. Light harness horses vary widely in height, weight, and conformation.

The best type of roadster stands from I $5 \frac{1}{4}$ to $15 \frac{3}{4}$ hands high, although he may vary even more than this. A desirable weight ranges from IOOO to I IOO pounds, but stallions as a rule weigh somewhat more, sometimes exceeding I 250 pounds. In conformation this horse tends to be angular, the muscles and joints showing prominence, with the ribs more or less noticeable. There is proportionately less body and more leg, a thinner neck, with muscularity at the croup and quarters.

The head of the light harness horse should be lean and shapely, the profile showing quite straight from poll to nose. There is a tendency for stallions to have a slight Roman profile, and the mares a dished face. Coarseness of head is very objectionable. The ears should be small and refined, the eyes prominent and clear, the nostrils well defined, and the lips thin and evenly mated.

The neck of the light harness horse is essentially long, lean, and muscular. Stallions tend to have a slight crest of neck, while mares frequently are lacking in depth of this part, having what is termed a ewe neck. Length of neck is naturally associated with speed, while shortness shows draft character. The neck should be flexible and easily bent and extended — important factors in establishing equilibrium.

The shoulders of the light harness horse should be long and especially oblique or sloping, because the horse with a long, oblique, 
light shoulder is able to raise the fore limb and advance it more easily than with the more upright shoulder. Thickness or fullness of shoulder, especially about the withers, is very undesirable in a horse of this type, resulting in an indifferent gait.

The arms and forearms of the light harness horse should be reasonably muscular, not like those of a draft horse, but as indicat. ing strength of action. Especially should the muscles back of the forearms be well developed, as they are brought into active use in raising the fore leg.

The cannons of the light harness horse are usually lean and show the skin, type of bone, and ligaments very clearly. A short, clean, smooth cannon with the tendons carried well back and parallel with the bone are prime features of the horse with rapid gait. Long cannon bones are undesirable, for they lack the strength of the shorter ones. Great emphasis is placed on the cannons being clean and smooth, with no roughness or evidence of bone disease.

The pasterns of the light harness horse should be comparatively long, smooth, and strongly carried at an angle of about 45 degrees. The shoulders and pasterns have much work to do in common, and the pastern that is long and springy will bear concussion much better than a short one. The long pastern allows for a greater movement of the fetlock joint, an essential if speed is desired.

The foot of the light harness horse should be of medium size, wide at the heel, not too low set at this point, and have a welldeveloped frog and strong bars. The length of the heel should be about one third the length of the front of the hoof.

The body of the light harness horse should have a greater relative depth than breadth. A front view gives a greater degree of narrowness than obtains with the draft horse. A noted English authority, Hayes, states that he is convinced that a race horse cannot be too narrow in front. The high elevation of the withers and their lean, long appearance add to the general effect of the depth of body. Light harness horses often appear to lack girth, or are termed "light waisted." Some of the most famous trotters and pacers have certainly had this appearance accentuated by high flanks. The back should be strong, well carried, with a wide, muscular loin. Digitized by Microsofte 
The hind quarters of the light harness horse often stand slightly higher than the fore quarters at the withers and have a lean and somewhat angular appearance. The hips should be muscular to a limited extent and not fleshy. A long, wide, comparatively level croup is very desirable. Steepness of croup is common among light harness horses, more especially pacers. Hayes states ${ }^{1}$ that "to have the point of the buttock placed high and projecting well to the rear is a great beauty, which may be seen in some Thoroughbreds and in high-caste Arabs." The gaskin

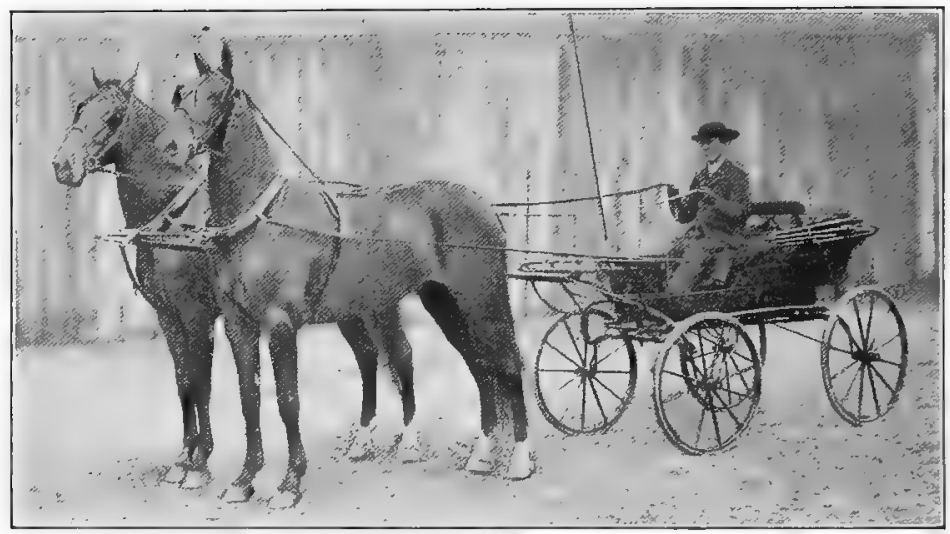

FIG. I 2. Rhea W. and Easter Belle, champion roadsters at the National Horse Show, Madison Square Garden, New York, 1904. The property of Miss K. L.

Wilks, Galt, Ontario, Canada. From photograph by courtesy of Miss Wilks

should be long, broad, and muscular. Length and strength of gaskin muscle are especially important if speed is desired. The stifle joint should be fairly high and face outward enough to permit freedom of motion. The hock should be lean and sharply defined, with no tendency to fleshiness, and should be straight and open enough to permit the cannon bone to hold a vertical line. Such a leg has a maximum of extension in producing speed. Curved or sickle hocks are often seen with race horses, in which case the natural tendency is to carry the hind feet well under the body when at rest.

1 The Points of the Horse, p. 3 II. 
The action of the light harness horse is one of his most valued features. If lacking a free, easy, fairly speedy gait, he is of inferior value. The walk should be free and easy, the feet being raised with snap and then laid upon the ground with decision, and with no stumbling tendency. As one stands behind the horse in action the bottom of the shoes should easily be seen. As watched from the side, the knees and hocks should appear strongly flexed and the stride long, representing great efficiency of motion. A high knee action is undesirable, but a long, moderately low extension is sought. The action should be true, and the legs move in harmony with each other. 


\section{CHAPTER VI}

\section{THE AMERICAN TROTTER AND PACER}

The history of the English trotting horse goes back for several centuries. About Norfolk and Yorkshire trotters were great favorites two centuries ago, and trotting races of an unofficial character were of frequent occurrence. Old records tell us that the Norfolk trotting mare Phenomena in I 800 trotted I 7 miles in 56 minutes on the Huntingdon road, carrying a weight in saddle of about 225 pounds. In 1806 the horse Pretender trotted 16 miles within an hour, carrying 2 Io pounds. All the early racing records were made under the saddle. In connection with the early evolution of the Hackney its use as a trotter and racer became popular.

The early use of the trotter in America no doubt extends back into colonial times, though to what degree is uncertain. What were probably running horses were taken from England to Massachusetts as early as 1629. Horses of this class were also bred in Virginia and the Carolinas. The recorded use of the trotter in America extends back to the first part of the nineteenth century. In I 802 a law forbidding all horse racing and trotting was enacted in New York, but this law was amended in I82I to permit training, pacing, trotting, and running of horses upon certain regulated courses in Queens County on Long Island. Early trotting records take us back to June, I806, when the horse Yankee, under saddle, trotted a mile in 2:59 on the Harlem race course, New York. On August 25, I8IO, a horse from Boston is reported to have trotted a mile at Philadelphia in harness in 2:48 $\frac{1}{2}$. Later, in $18 \mathrm{I} 8$, Boston Blue made an authentic mile in 3:00 at Jamaica, New York. This record compares favorably with English records in Norfolk and elsewhere.

A most important trotting blood foundation in America was the importation of the stallions Messenger, Diomed, and Bellfounder, whose histories are worthy of special mention. 
Messenger, commonly known as Imported Messenger, was a Thoroughbred, his pedigree tracing back through his sire to Flying Childers and the Darley Arabian. He was foaled in 1780 in England and proved a successful racer, and as a five-year-old won the King's Plate. Believing that he would do valuable service in the stud, he was imported to the United States in May, I788. Messenger, however, though a trotting sire, had no immediate descendants that proved to be noted trotters. He secured his chief fame through his son Mambrino, a Thoroughbred, that in turn was sire of Abdallah, a sire of trotters. Messenger was a gray, I $5 \frac{3}{4}$ hands high, with strong loins and powerful hind quarters. He was in stud service for twenty years in America, - in Pennsylvania, New Jersey, and New York. He died January 28 , 1808, leaving a lineage of driving horses of remarkable excellence.

Diomed (imported) was foaled in England in 1777 . He was a Thoroughbred, $15_{4}^{\frac{3}{4}}$ hands high, chestnut in color, and a horse of substance and great muscular power. His sire, Florizel, was by the famous Herod, out of a daughter of Cygnet, by Godolphin Barb. Diomed's dam Juno was by Alcock's Arabian, while through his second dam he traced to Godolphin Barb and his third dam was by Flying Childers. Thus it is seen he came from the fastest Thoroughbred ancestry. He was a successful race horse for four years, when he retired lame and was used in service in England until I 799, when he was imported to Virginia. In America Diomed proved a great sire of race horses. One of his sons, Sir Archy, has been designated the "Godolphin Arabian of America" 1 and was one of the fastest racers of his time. In ninety of the best races run in America up to I 844, about 66 per cent were direct descendants of Diomed. "The name of Diomed," says Parlin, "is found more frequently in the pedigrees of record-breaking runners, trotters, and pacers in this country than is that of any other animal."

Bellfounder, known as Jary's Bellfounder in England and as Imported Bellfounder in the United States, was foaled in I8 I 5 and was imported from Norfolk in 1822 . He was a bright bay, with black mane, tail, and legs, stood I 5 hands high, and was a

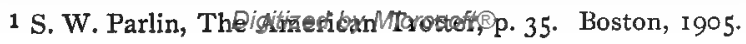


natural trotter. At the time he was brought to America he was regarded as one of the very fleetest and most powerful trotters and is said to have trotted $I 7$ miles in an hour. Velocity, his dam, trotted I6 miles in an hour on the Norwich road in 1806 , while two years later she is reported to have made I 8 miles in I hour and 47 seconds. Thus it can be seen how a strong line of trotting blood was brought to America. Bellfounder was taken

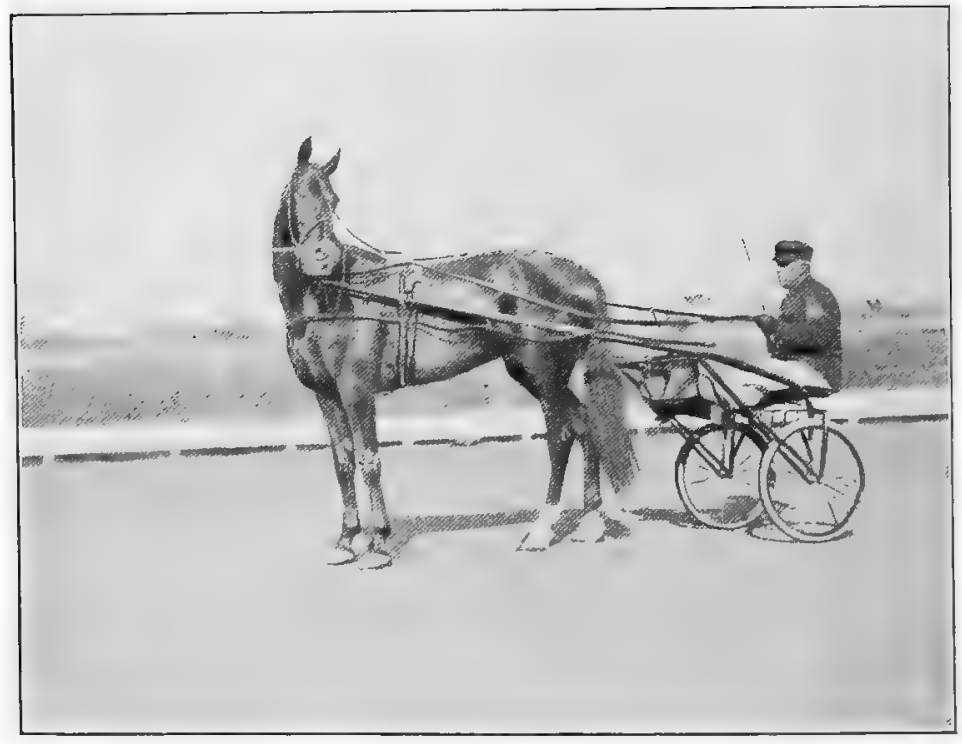

FIG. I3. The Harvester (2:01), by Walnut Hall (2:08 $)$, one of the fastest trotting stallions of record, as well as a great sire. The driver is Edward Geers, the most popular and highly respected driver on the American circuit. From photograph by the author

to Orange County, New York, where he went into stud service. Here he sired the Charles Kent Mare, a most important connecting link with his American fame. Bellfounder died on Long Island in 1843 .

The type of the American trotter or pacer is far from being fixed. No breed of horses has been produced under more variable conditions, and no recognized breed of stock contains a greater variation in size, color, and character than does this light harness 
breed. In fact, there is so little breed type that many persons refuse to recognize it as a breed. In its best development this light harness horse has symmetry of form, - a lean, intelligent head; a medium-long, refined, and graceful neck; sloping, welllaid shoulders; sharp withers; fairly level, short, strong back; graceful muscular croup, with tail well carried and set high; lean, muscular thigh; round, deep body; and legs short, clean, fineboned, and with excellent feet. This horse has a strong, long, quick stride, a clean hock action, and greater activity of motion than any other trotter known. The conformation of the pacing horse often shows a steepness of croup and curving of hocks which appear to be more or less associated with the pacing gait, though not necessarily so. Some of the most famous pacers in American racing history have had this peculiar conformation, which is, to say the least, not beautiful. A more detailed consideration of the conformation of the trotter and pacer is found in the preceding chapter on "The Light Harness Type." Weights of II 50 pounds for a stallion and 900 pounds for a mare are very acceptable, while any color will pass, although bays and browns are most numerous.

The gaits of the trotter and pacer are distinctly different, although an animal may be able to trot or pace as desired. To a certain degree, however, the distinguishing differences between trotter and pacer depend upon the gait.

The trot consists in moving forward at much the same time front and rear opposite limbs; as, for example, the left front leg and the right hind leg. On account of the special leg movement, as exhibited by the gait, the trotter is said to be " diagonal-gaited." It is not only important but interesting to note here that in the show ring, where the gait is considered, the trot furnishes the approved form of locomotion, the pace being regarded as inferior to the trot.

The pace consists in the two legs on one side being moved forward at about the same time, thus presenting a sort of parallel movement. Due to this side movement of the legs the pacer is sometimes spoken of as a "side wheeler" or "racker." The horse naturally paces when his body is hardly long enough to

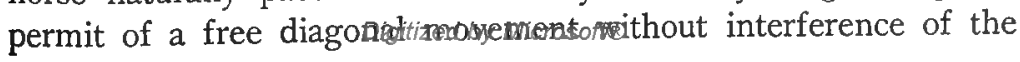


fect. The pace provides a freer movement, involves more of a swaying motion than the trot, and, while faster by about three seconds, is much less popular than the smoother-moving trot.

The trot and pace are interchangeable, and numerous race horses possess both gaits. The stallion Direct, with a pacing

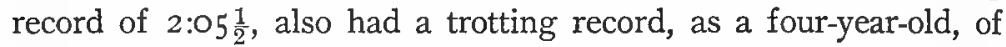
2:I $8 \frac{1}{4}$. Brown Hal, a great pacing sire, also had a trotting record. John R. Gentry, 2:00 $\frac{1}{2}$, a standard-bred trotter, was a very fast pacer and a sire of pacers. Jay-Eye-See was first a trotter at

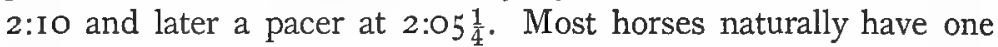
gait, but many of them are easily taught the other. Hamilton Busby states that he has seen the late Robert Bonner, the wellknown light-horse enthusiast and student of equine form and foot ballast, take a pacing colt and in a few minutes change it to a trotter by simply changing the bearing of its heels.

What is a standard-bred trotter? In I 882 the constitution of the National Association of Trotting Horse Breeders, an association organized in 1876, was amended, and among the rules adopted were the following:

In order to define what constitutes a trotting-bred horse; and to establish a breed of trotters on a more intelligent basis, the following rules are adopted to control admission to the records of pedigrees. When an animal meets with the requirements of admission and is duly registered, it shall be accepted as a standard trotting-bred animal.

First. Any stallion that has, himself, a record of two minutes and thirty seconds (2:30) or better; provided any of his get has a record of 2:40 or better, or provided his sire or his dam, his grandsire or his grandam, is already a standard animal.

Second. Any mare or gelding that has a record of 2:30 or better.

Third. Any horse that is the sire of two animals with a record of 2:30 or better.

Fourth. Any horse that is the sire of one animal with a record of 2:30 or better; provided he has either of the following additional qualifications: (I) a record himself of $2: 40$ or better; (2) is the sire of two other animals with a record of 2:40 or better; (3) has a sire or dam, grandsire or grandam, that is already a standard animal.

Fifth. Any mare that has produced an animal with a record of 2:30 or better.

Sixth. The progeny of a standard horse when out of a standard mare.

Seventh. The progeny of a standard horse out of a mare by a standard horse.

Eighth. The progeny of a standard horse when out of a mare whose dam is a standard mare. 
Ninth. Any mare that has a record of 2:40 or better, and whose sire or dam, grandsire or grandam, is a-standard animal.

Tenth. A record to wagon of 2:35 or better shall be regarded as equal to a 2:30 record.

The above rules, on the basis of breed standards, are subject to criticism, in that speed is the only requirement, no consideration being given conformation, height, etc. For this reason breed critics refuse to recognize the trotter or pacer as an established breed.

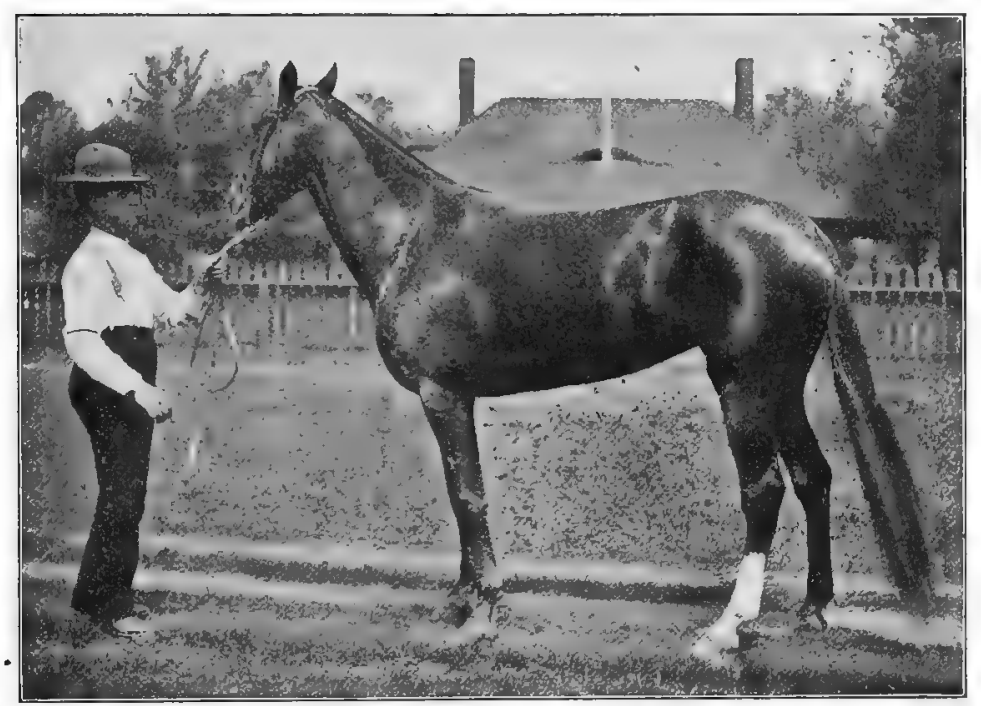

FIG. I4. Lou Dillon, I: $58 \frac{1}{2}$, by Sidney Dillon. This great little mare long held the trotting championship of the world. The most sensational trotter in American history. Owned by C. K. G. Billings. From photograph taken in 1905 , by courtesy of the National Stockman and Farmer

The standard of eligibility for trotters as given by the American Trotting Registry Association ${ }^{1}$ is as follows:

When an animal meets these requirements and is duly registered it shall be accepted as a standard-bred trotter.

I. The progeny of a registered standard trotting horse and a registered standard trotting mare. 
2. A stallion sired by a registered standard trotting horse, provided his dam and grandam were sired by registered standard trotting horses, and he himself has a trotting record of 2:30 and is the sire of three trotters with records of 2:30 from different mares.

3. A mare whose sire is a registered standard trotting horse, and whose dam and grandam were sired by registered standard trotting horses, provided she herself has a trotting record of 2:30 or is a dam of one trotter with a record of 2:30.

4. A mare sired by a registered standard trotting horse, provided she is the dam of two trotters with records of 2:30.

5. A mare sired by a registered standard trotting horse, provided her first, second, and third dams are each sired by a registered standard trotting horse.

The pacing standard is the same as the trotting standard except that the word "pacer" is substituted for the word "trotter," the word "pacing" for the word "trotting," and the speed standard $2: 25$ for 2:30. The first five paragraphs of official trotting and pacing standards are alike. The pacing standard, however, has a sixth paragraph, which is as follows:

6. The progeny of a registered standard trotting horse out of a registered standard pacing mare, or of a registered standard pacing horse out of a registered trotting mare.

This last paragraph brings out the interesting point in an offcial 'way that the result of the union of a pacer and trotter may create a standard-bred pacer.

Trotting families of note have been developed in America during the past century from which are descended the trotting horses of eminence to-day. The families introduced below are recognized as the most important. The judicious blending of these families has, in cases, resulted in very great success; as, for example, in the case of the Hambletonian and Mambrino.

The Hambletonian family. On May I 5, I 849, the Charles Kent Mare gave birth to a male foal from the service of Abdallah, the grandson of Messenger. This mare was owned by Jonas Seely of Chester, Orange County, New York, who later sold her with foal at side to William M. Rysdyk for \$I25. This colt was later named Hambletonian IO and is frequently referred to as Rysdyk's Hambletonian. He was a bay in color, with a star and white hind ankles, stood $15 \frac{1}{2}$ hands high, and was 
powerful in build. His head was large, with pleasant eyes, his neck and shoulders strong, the body round and full, legs and feet of superior character, and he stood somewhat higher behind than in front. As a three-year-old Hambletonian is said to have made a record of $2: 48$ over the Union course.

In I85 I Hambletonian began service in stud, which, with the exception of one year (I868), he continued until I875. During fifteen years of service, between 1853 and 1867 , he sired I 87

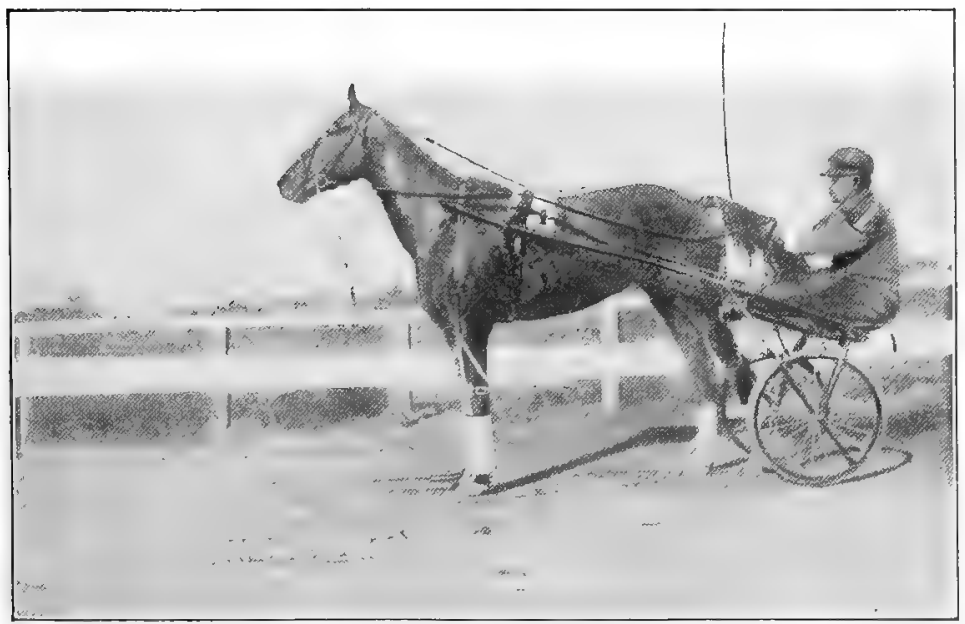

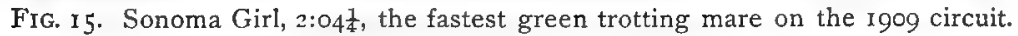
From photograph by the author

foals - an average of 79 each year. He died March 27, I876, long after his value as a sire began to be appreciated. This stallion proved the founder of the most famous American family of trotters, for to him may be traced many of the most illustrious trotters of history. In 1905 Parlin states ${ }^{1}$ that he was credited with 150 sons that have sired 1487 trotters and 220 pacers which have made records in standard time. Eighty of his daughters have produced I ro standard trotters and 7 standard pacers, a total of I 824 .

Among the famous sons and daughters of Hambletonian Io are Alexander's Abdallah, Electioneer, George Wilkes, Aberdeen,

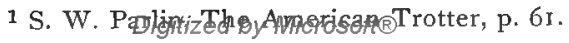


Volunteer, Happy Medium, Harold, Strathmore, Egbert, Dictator, Dexter, Nettie (2:18), Orange Girl (2:20), Gazelle (2:21), Jay Gould $\left(2: 2 \mathrm{I} \frac{1}{2}\right)$, and Bella $(2: 22)$. The first ten of these proved very prepotent sires and thus demonstrated in an impressive manner the value of their remarkable sire.

\section{Pedigree of Hambletonian io (Foaled i 849 )}

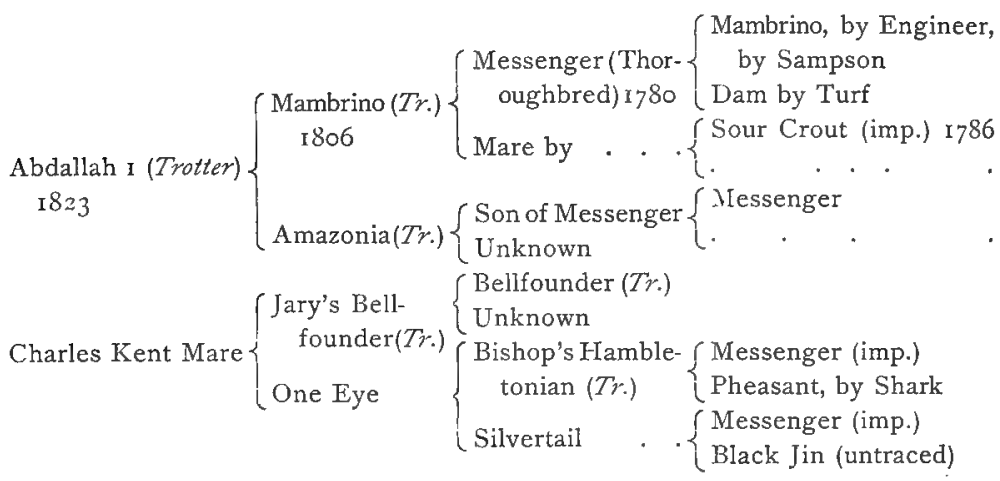

The Mambrino family. This family is named from Mambrino Chief, foaled in 1844 and bred by Richard Eldridge of Dutchess County, New York. Mambrino Chief was by Mambrino Paymaster, and he by Mambrino, the Thoroughbred son of Messenger. His dam is untraced. He was a dark-brown stallion about I6 hands high, by some referred to as coarse, though he proved a very superior breeder. Mambrino Chief in $\mathbf{1} 854$ was taken to Kentucky, where he was in stud three seasons at Ashland Farms, after which he was bought for $\$ 5020$ by Gray and Jones of Woodford County, in whose service he died in I862. His son Mambrino Patchen sired scores of trotters, while his daughter Dolly was the dam of Onward, Director, and Thorndale, a remarkable trio. Mambrino King, by Mambrino Patchen, was regarded by many as the most beautiful horse in America in his day. Woodford Mambrino, Mambrino Pilot, Fisk's Mambrino Chief, and Ericsson were also successful sires by Mambrino Chief. Lady Thorn, a daughter of Mambrino Chief, trotted I06 heats inside 2:30 and won national fame. The union of the descendants of 
Mambrino Chief and Hambletonian Io produced most efficient results. While the Mambrino family ranks perhaps second in importance, it is gradually being absorbed by Hambletonian blood and, according to Parlin, will in time become extinct.

The Clay family. In I 820 a Barb stallion known as Grand Bashaw, foaled in 18 I6, was imported from Tripoli, Africa. He was regarded as of great beauty and showed both action and speed. He was a small iron gray, standing $14 \frac{1}{4}$ hands high. Used in the stud near Philadelphia he sired Young Bashaw out of a granddaughter of Imported Messenger. Young Bashaw sired Andrew Jackson, the fastest trotter of his day. The trotting mare Lady Surrey, brought from Canada and owned by George M. Patchen, was bred to Andrew Jackson, from which in I 837 she dropped a black foal named Henry Clay, the sire from which this family derives its name. He stood about $15 \frac{1}{4}$ hands high, had plenty of substance, was a natural trotter, and "an untiring roadster." He was not himself a prolific sire, and but three of his sons - Cassius M. Clay, Andy Johnson, and Henry Clay Junior - are noteworthy. Cassius M. Clay was sire of George M. Patchen $\left(2: 23_{2}^{1}\right)$, that in I 860 established a world's record and also became a noted sire of both sons and daughters. Stamboul (2:07 $\frac{1}{2}$ ) had for second dam Patchen Maid, by George M. Patchen. The Clay family, though possessing a long line of trotting inheritance, bids fair to become extinct through absorption by the Hambletonians.

The Morgan family. This is one of our oldest trotting families and inherits its name from a stallion named Justin Morgan, foaled in 1793 at West Springfield, Massachusetts. From this place he was taken to Vermont, in which state this family of horses has gained great distinction. Justin Morgan was sired by True Briton, whose ancestry may be traced back to the Godolphin Barb; his dam is given as Diamond, she also tracing back to the Godolphin Barb. It is but fair to state here that the breeding of Justin Morgan is more or less questioned, and the above ancestry is based on investigations of Joseph Battell of Middlebury, Vermont. This stallion is described as about I4 hands high, weighing 950 pounds, dark bay with black points, and possessed of 
great vitality; he died in 1821 , at twenty-eight years of age. $\mathrm{He}$ was a fast walker, a good trotter, and was most intelligent, being used as a military charger or parade horse, a short-distance runner, and a farm-work horse. He proved to be a wonderfully prepotent stallion, and on his blood is founded the Morgan family.

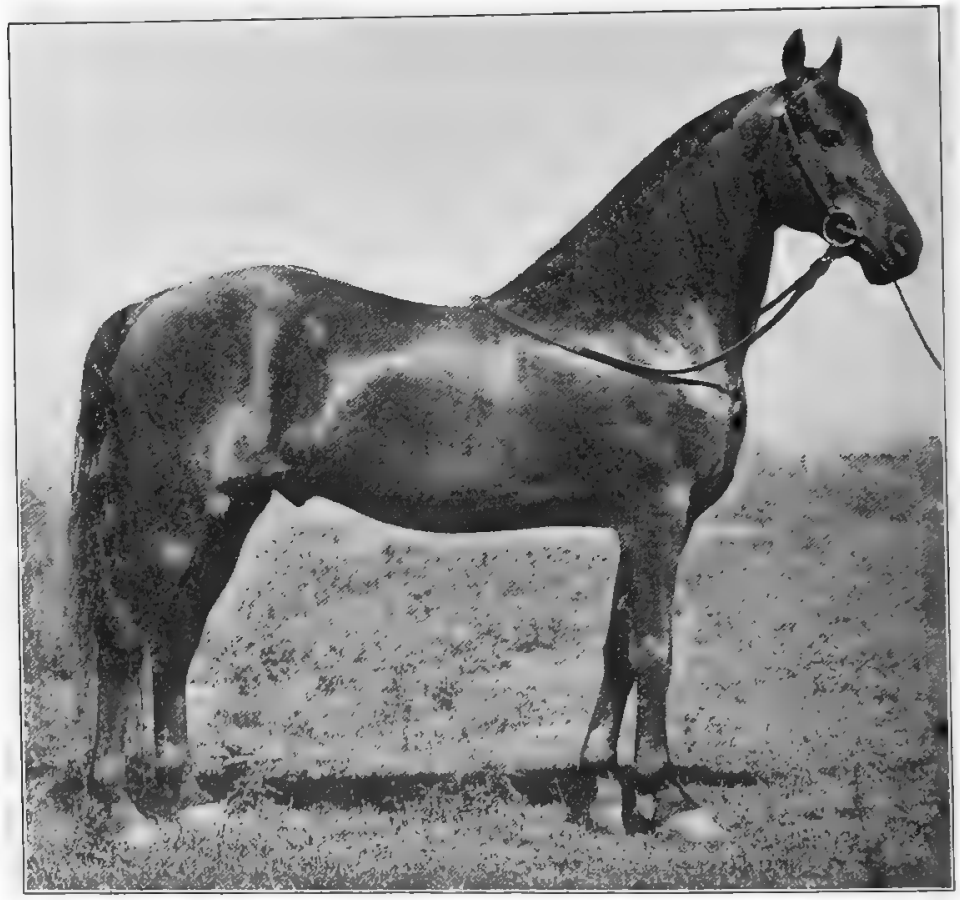

FIG. I6. Donald, a Morgan stallion, noted both as a show horse and a sire. Donald is regarded as a fine example of the true type of Morgan. Owned by C. C. Stillman, Newburgh, New York. From photograph by H. H. Strohmeyer, Jr., by courtesy of Mr. Stillman

Justin Morgan had a long stud career, but he did not produce great breeding sons in the same degree as did Hambletonian 10. Three of his sons - Bulrush, Woodbury, and Sherman Morgan were his greatest offspring. A son of Sherman Morgan, named Black Hawk, foaled in 1833 , was a trotter and vigorous sire, and fourteen of his sons became recognized trotters. Ethan Allen, his greatest son, was bred in New York State and was foaled in 
I 849 from a dam of unknown ancestry. He became very famous and popular as a successful trotter and proved also to be a great sire. The mare Pocahontas, by Iron's Cadmus, with a record of 2:1 $7 \frac{1}{2}$ in 1855 , bred to Ethan Allen became the dam of another Pocahontas, for which Robert Bonner later on paid $\$ 40,000$. Among the thirty-six producing sons and daughters of Ethan Allen no one attained such distinction as did Daniel Lambert, himself the sire of thirty-eight trotters. The sire of the dam of Daniel Lambert was Abdallah, the sire of Hambletonian I0. Later years have shown that the Hambletonian and Morgan families could be bred together to very great advantage. For some years the United States Department of Agriculture has been conducting breeding operations, with the Morgan as a foundation, to establish a distinct American breed of heavy harness horses. The Colorado Agricultural Experiment Station has coöperated with the government in this work. A government stud at Middlebury, Vermont, has also been maintained. Thus far the results of this experimental breeding have not been especially noteworthy. The Morgan family in recent years has been given considerable publicity, but as this has been directed toward heavy harness lines it has not met with an especially favorable reception. There is a register for Morgan horses, and up to 1919 three volumes of the studbook have been published. To be eligible for registration the pedigree of every horse recorded must trace in some degree to Justin Morgan.

The Pilot family. A black or dark-brown horse by the name of Pilot first attracted attention in this family. $\mathrm{He}$ was foaled in I 828 in the province of Quebec. His sire is unknown, and his dam was Jeanne d'Arc, by Voyager. When eighteen months old he was taken to Connecticut and in 1830 to New York. In I831 he was sold to go to New Orleans and in 1832 he was returned to Kentucky, where he died about 1853 on the farm of Robert Bell near Henderson. Pilot was not only a pacer but would also trot. His greatest son was Pilot Jr., a gray horse I $5 \frac{1}{2}$ hands high, foaled in I844, out of Nancy Polk by Funk's Havoc. Pilot Jr. was a very successful sire of brood mares. Bred to Sally Russell, a Thoroughbred daughter of Boston, he sired Miss Russell, one of the greatest American brood mares, 
the mother of the great Maud S., also Nutwood, Lord Russell, and fifteen others. Another daughter, Midnight, out of a Thoroughbred daughter of Lexington, was the dam of Jay-Eye-See, with a pacing record of 2:06 $\frac{1}{4}$ and a trotting record of 2:10. Waterwitch, another daughter of Pilot Jr., produced nineteen foals that lived, six of which made records of 2:30 or better. The family history of Pilot is more or less obscure. He bred both pacers and trotters and rendered valuable service to the American racing-horse interests.

The Hal family. Years ago down in Kentucky was kept a roan saddle stallion, bred in Canada, known as Kittrel's Tom Hal. It is said that he was much abused in his time and was ridden nearly to death over rocky roads by a drunken wretch in an elm-crotch saddle. For years he stood at a fee of $\$ 5$ to insure, with no pay if he did not get a good saddle horse. His ancestry is somewhat obscure, but it is claimed that he had Morgan blood in his veins. Tom Hal attained fame as the sire of Gibson's Tom Hal, the sire of Hal Pointer (2:04 $\left.\frac{1}{2}\right)$, Little Brown Jug (2:I I $\left.\frac{1}{4}\right)$, and Brown Hal (2:1 $\left.2 \frac{1}{2}\right)$. The latter became the sire of Star Pointer, the leading sire of this family, a pacer of marvelous speed, character, and endurance that reduced the pacing record to $\mathrm{I}: 59 \frac{1}{4}$. Brown $\mathrm{Hal}$ is the sire of about ninety in the list, including $\mathrm{Hal}$

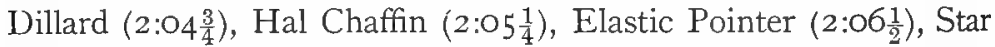
Hal $\left(2: 06 \frac{1}{4}\right)$, and Hal Braden $\left(2: 07 \frac{1}{4}\right)$. This is the most distinguished family containing a large percentage of pacing blood.

The list of famous trotting or pacing brood mares is a very long one, there being several thousand of more or less distinction at this time. Three of these mares well deserve to be placed at the head of this list.

Beautiful Bells, by The Moor, dam Minnehaha, was foaled in I 872. She was bred by L. J. Rose in California, though owned at Palo Alto by Leland Stanford, where she dropped her first foal in 1880 to the service of Electioneer. She produced eleven trotters of great merit, either by Electioneer or his sons, that made records from 2:I $2 \frac{3}{4}$ to $2: 29 \frac{1}{2}$. On her sire's side she was a Pilot, on the dam's a Mambrino.

Green Mountain Maid was foaled in I862. She was bred by Samuel Conklin of Middletown, New York. Her sire was Harry 
Clay, dam Shanghai Mary. She was a brown mare with stur and white hind ankles and stood 15 hands high. At the Stony Ford Farm of Charles Backman she spent most of the twenty-six years of her life, dying in I888. Her greatest son was Electionecr, one of America's most prepotent sires. Green Mountain Maid was the dam of sixteen foals. In memory of this mare a redgranite monument was erected in 1889 by Mr. Backman " on the spot dedicated to her worth and honored by her dust."

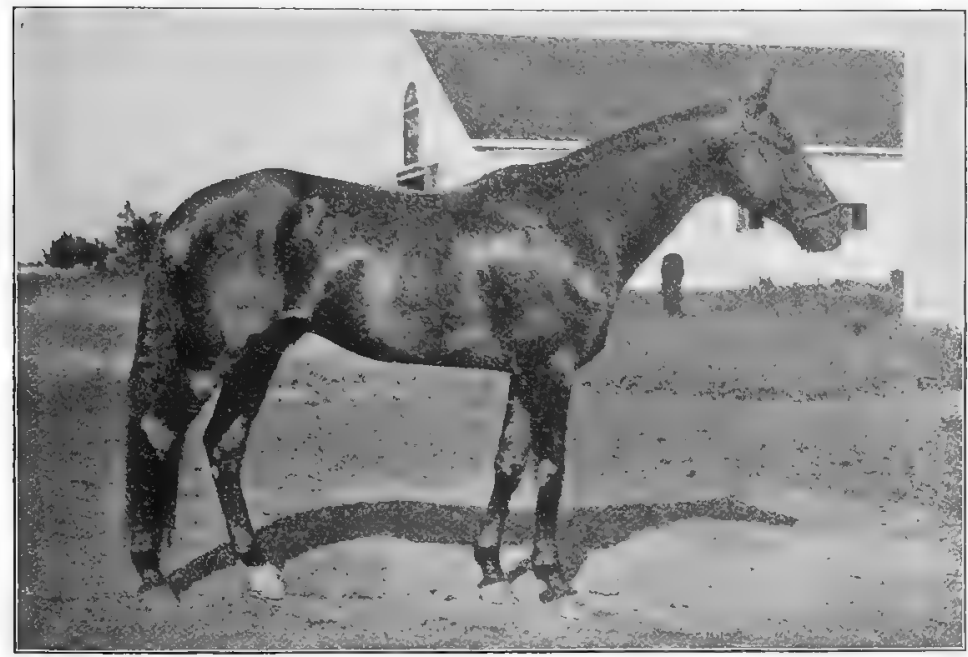

Fig. 17. Elastic Pointer, $2: 06 \frac{1}{2}$, by Brown Hal, $2: 12 \frac{1}{2}$. A pacer and full brother of Star Pointer, I: 59: one of the greatest pacers in history. From photograph, by courtesy of National Stockman and Farmer

Miss Russell, a gray mare foaled in 1865 , bred by R. A. Alexander at Woodburn, Kentucky, is the third worthy. She was sired by Pilot Jr. and out of Sally Russell, by Boston, and her fifth dam was by the great imported Thoroughbred Diomed. Miss Russell was the dam of eighteen foals. Nutwood, by Belmont, her first foal, was her greatest son, he siring one hundred and thirty-three trotters and thirty-five pacers, while Maud S., by Harold, was her most famous daughter. Lord Russell, a full brother to Maud S., was a great sire, and among his sons was

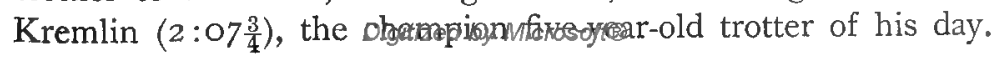


Leading sires of trotting horses up to I9I8, on the basis of offspring with records of 2:30 or better, are as follows, in their order of importance. The number of offspring with trotting records follows the name of the sire, with the number of pacers in parentheses:

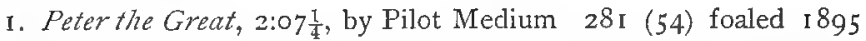

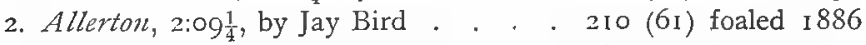

3. Bingen, 2:06 $\frac{1}{4}$, by May King, 2:20 . . I 82 (47) foaled I 893

4. ITCKinney, 2:I I $\frac{1}{4}$, by Alcyone, 2:27 . I64 (42) foaled I 887

5. Electioneer, by Hambletonian 10. . . 158 (2) foaled 1868

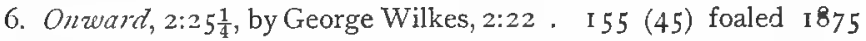

7. Axworthy, 2:281, by Axtell, 2:I 2 . . I 51 (8) foaled 1892

8. Moko, by Baron Wilkes, 2:I8 . . . I39 (I2) foaled 1893

9. Nutwood, 2:188, by Belmont . . 137 (37) foaled 1870

10. Red Wilkes, 2:40, by George Wilkes, 2:22 I33 (45) foaled 1874

The sire having the greatest number of grandsons and granddaughters to his credit as trotters and pacers is George Wilkes, by Hambletonian IO, with Electioneer in second place in that respect. At the present day (I9I9) Peter the Great, in active service at twenty-four years, with a limited fee of $\$ \mathbf{I} 000$, is regarded as the greatest living sirc.

Leading sires of pacing horses up to 1918 , that is, sires whose progeny made greater records as pacers than as trotters, are as follows, the trotters being indicated in parentheses:

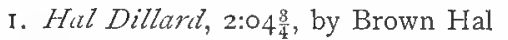
93 (5) foaled I 887
2. Brown Hal, 2: $2 \frac{1}{2}$, by Tom Hal
89 (3) foaled I 879

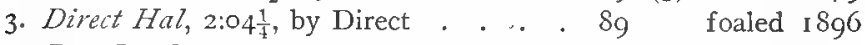

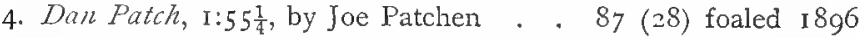

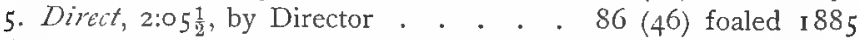

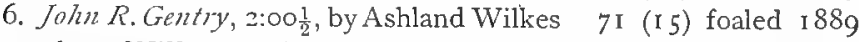
7. Argot llitkes, 2: $4+1$, by Tennessee Wilkes 67 (3) foaled I 886

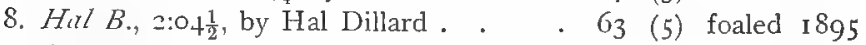
9. Strontgwood, 2: $12 \frac{9}{4}$, by Nutwood . . 6r (14) foaled 1890

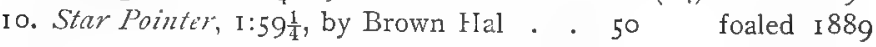

Carried to the third generation, Brown $\mathrm{Hal}$ is most prepotent in producing pacers, with Direct a creditable second. The above figures are subject to revision, as the number of offspring credited to several of these horses will materially increase. 
The speed of the trotter is the main factor influencing values, and the speed record of an animal or its relationship to such will essentially affect its selling price. As might be expected, foals occasionally change hands at large prices based on pedigree and speed records of the family. The speed of the trotter has been constantly improved, until the end of I9I9 saw records that would not have been thought possible by persons living a generation ago. All of the standard racing records have been materially changed during the last fifty years. The following statement

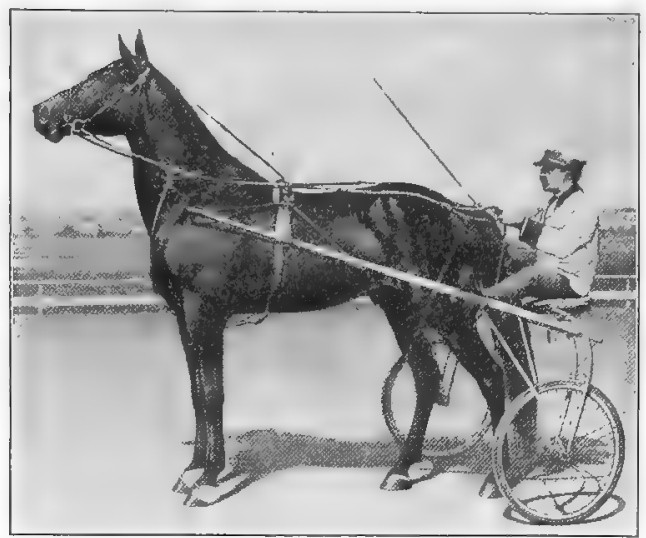

FIG. I7A. Dan Patch, 1:55t, by Joe Patchen. The fastest pacer of record up to date, and one of the leading sires of pacers. Purchased for $\$ 60,000$ by M. W. Savage, Minneapolis, Minnesota. From illustration by courtesy of Mr. Savage

shows how this record, representing horses in harness and not under saddle, has been lowered between I845 and I9I8. Not every reduction in time is given, but enough to show the gradual process by which it took place.

\begin{tabular}{|c|c|c|c|}
\hline Name of Horse and Sire & Place of Record & DATE & Tine \\
\hline Lady Suffolk, by Engineer. & Iloboken, N.J. & Oct. 13,1845 & $2: 29 \frac{1}{2}$ \\
\hline Highland Maid, by Saltram. & Jamaica, N.Y. & July I4, I 853 & $2: 27$ \\
\hline Flora Temple, by Bogus Hunter & Kalamazoo, Mich. & Oct. 15,1859 & $2: 19 \frac{8}{4}$ \\
\hline Dexter, by Hambletonian io . & Buffalo, N.Y. & Aug. 14, 1867 & $2: 17 \frac{1}{4}$ \\
\hline Goldsmith Maid, by Abdallah. & Boston, Mass. & Sept. 2, I 874 & $2: 14$ \\
\hline Jay-Eye-See, by Dictator. & Providence, R.I. & Aug. I, $\mathbf{1} 884$ & $2: 10$ \\
\hline Maud S., by Harold . . . . & Cleveland, Ohio & July 30,1885 & $2: 08 \frac{8}{4}$ \\
\hline Nancy Hanks, by Happy Medium & Terre Haute, Ind. & Sept. 28, I 892 & $2: 04$ \\
\hline Cresceus, by Robert McGregor. & Columbus, Ohio & Aug. 2, rgor & $2: 02 \frac{1}{4}$ \\
\hline Lou Dillon, by Sidney Dillon & Memphis, Tenn. & Oct. 24,1903 & I: $58 \frac{1}{2} 1$ \\
\hline Uhlan, by Bingen . & Lexington, Ky. & Oct. 8, I9I 2 & I: $5^{8}$ \\
\hline
\end{tabular}

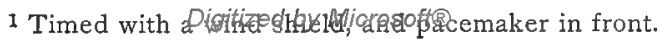


Some of the fastest trotting records to January 1, 1919, are given below. There are numerous standard trotting events, such as against time, in races, double teams, three abreast, half-mile track, mile track, etc. There are many fastest records, of which the following are selected as of perhaps the most interest:

\begin{tabular}{|c|c|c|c|}
\hline Event & Name of Horse and Sire & Date & TIME \\
\hline One mile. & Uhlan, by Bingen . . . & I9I2 & $1: 58$ \\
\hline Two miles & The Harvester, by Walnut Hail & I9io & $4: 15 \frac{1}{4}$ \\
\hline Five miles & Zombro, by McKinney . & 1902 & $12: 24$ \\
\hline Ten miles & Controller, by May Boy . & I 878 & $27: 23 \frac{1}{4}$ \\
\hline Fastest stallion & Lee Axworthy, by Guy Axworthy & I916 & $1: 58 \frac{1}{4}$ \\
\hline Fastest mare & Lou Dillon, by Sidney Dillon. & 1903 & $1: 58 \frac{1}{8}$ \\
\hline Fastest gelding & Uhlan, by Bingen . & I91 2 & $1: 58$ \\
\hline Fastest new performer & Colorado $E$., by The Bondsman & I910 & $2: 04 \frac{8}{4}$ \\
\hline Fastest yearling & Airdale, by Tregantle. & 1912 & $2: 15 \frac{8}{4}$ \\
\hline Fastest two-year-old. & The Real Lady, by Moko & 1916 & $2: 04 \frac{1}{4}$ \\
\hline Fastest four-year-old & Peter Volo, by Peter the Great. & 1915 & $2: 02$ \\
\hline Team record against time & Roy Miller and Lucy I'an. & I9I 8 & $2: 01 \frac{1}{4}$ \\
\hline Team, three abreast & Belle Hamlin, Globe, Justina & 1891 & $2: 14$ \\
\hline
\end{tabular}

Pacing records now receive much attention from the public, although in early days the trot was the greater favorite of the two, especially prior to I860. The following table shows how the pacing record has been reduced since I839:

Reduction of Pacing Record from i839 to January i, igi9

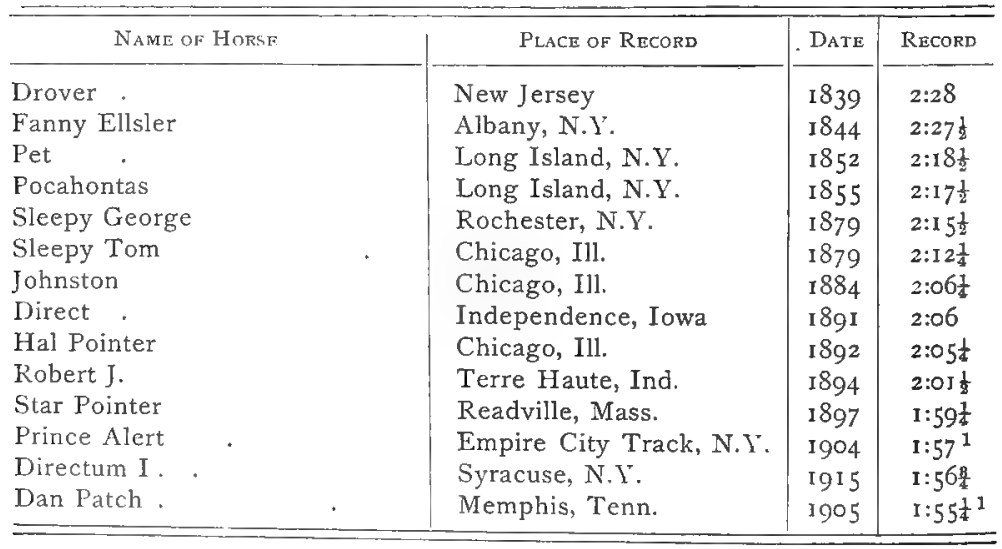

1 Timed with a wind shield, and pacemaker in front. 
The number of trotters and pacers with records has steadily increased, until at the present day the list makes up a large book. At the end of the 1917 season there were recorded a total of 33,695 trotters with records of 2:30 or better and 25,475 pacers with records of $2: 25$ or better. Even the select $2: 10$ list has grown in a remarkable way, so that at the completion of the I9I 8 season, according to the Horse Revicw (November 12, I918), there were 993 trotters in the 2:IO class and nearly 450 pacers in the 2:08 list.

The money winnings on the race track by light harness horses mount up into considerable sums. While there are thousands of horse races each year on different tracks in America, what are known as the Grand Circuit races represent the most important held. These races begin in the more northerly section of the country in July, as at North Randall, Ohio, and end the last of October in the South, at Atlanta, Georgia, and many of the same horses follow the circuit from start to finish. In the Grand Circuit of 1918 were the following places, in the order the races were held: North Randall, Kalamazoo, Toledo, Columbus, North Randall, Philadelphia, Poughkeepsie, Readville, Hartford, Syracuse, Columbus, Lexington, Atlanta. At the above thirteen meetings two hundred and sixty-one races were held, eight hundred and twenty-five heats were recorded, with an average time of 2:07.89, a remarkable showing. A total of $\$ 471,742$ was awarded to the prize winners. The four leading families in the 1918 circuit, according to the Horse Review, were the following:

\footnotetext{
Bingen (2:06 $\frac{1}{4}$ ), with I 92 winners, secured $\$ 70,09 \mathrm{I}$

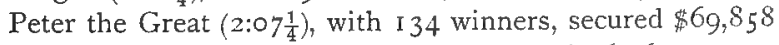

Axworthy (2: I $5 \frac{1}{2}$ ), with 96 winners, secured $\$ 67,692$

McKinney (2: I I $\left.\frac{1}{4}\right)$, with 108 winners, secured $\$ 59,595$
}

Up to I9I 8 inclusive the get of Peter the Great have won over $\$ 800,000$.

The prices paid for standard-bred horses represent in some cases remarkable valuations, while a long list might be given of animals that have changed hands at $\$ 10,000$ or more each. The highest price ever paid for a trotter was $\$ 150,000$, paid by Mr. J. Malcolm Forbes gf $\mathrm{B}$ Bosten for Axion $\left(2: 07 \frac{3}{4}\right)$, by Electioneer. 
In 1905, at a sale at Madison Square Garden, Mr. M. W. Savage of Minneapolis purchased Arion for $\$ 2500$. The trotting stallion Axtell (2:12), by William L., was purchased by a company at Terre Haute, Indiana, for $\$ 105,000$. Dan Patch $\left(1: 55 \frac{1}{4}\right)$, the great pacing horse, was purchased for $\$ 60,000$ by Mr. M. W. Savage, who later, it is reported, refused $\$ 180,000$ for him. In I916 Peter the Great, at twenty-one years of age, was sold by W. E. D. Stokes of New York to S. J. Fletcher of Indiana for $\$ 50,000$, the highest price ever paid for so old a horse. Among

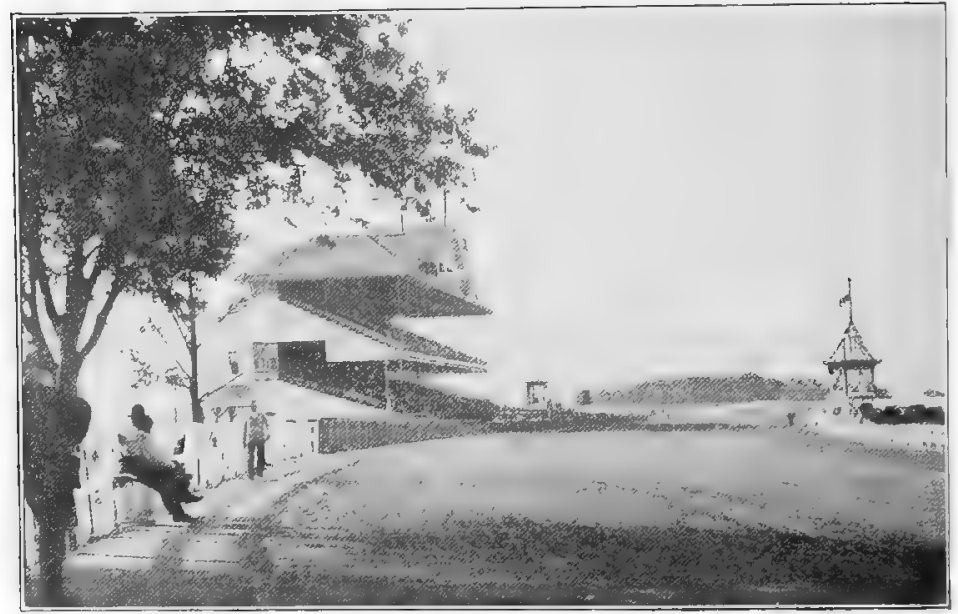

FIG. I8. The grandstand and race track at Lexington, Kentucky, one of the fastest and best American tracks. From photograph by the author

other notable prices paid for standard-bred horses are the following: Nancy Hanks, \$45,000; Sunol, \$4 I,000; Maud S., \$40,000; Mascot, \$26,000.

The drivers of race horses occupy very prominent positions in the sporting world. If successful they receive much attention and may win large sums of money during the season. Such men should have exemplary habits, which unfortunately many of them do not have, and should possess keen knowledge of the temperament and capacity of the horse. Among the early famous American drivers were Hiram Woodruff, Budd Doble, John Splan, and Charles Marvin, men who drove the greatest horses on the track 
between 1850 and 1900. Among present-day drivers of note are Edward Geers, "the silent man," the most highly respected driver on the circuit, Alta McDonald, Walter R. Cox, Thomas W. Murphy, Charles Valentine, "Mike" McDevitt, and Dick McMahon. In one year Mr. Murphy won $\$ 86$, I Io in various races.

The distribution of the standard-bred horse is very general over the United States, although more especially east of the Missouri River. It is the most adaptable of horses and seems well suited to the sunny South or to the cooler latitudes farther to the north. The automobile has reduced the interest in maintaining stables of standard-breds, excepting in a limited number of cases, where horses are specifically bred for the race course and for gentlemen's drivers. American trotters have been

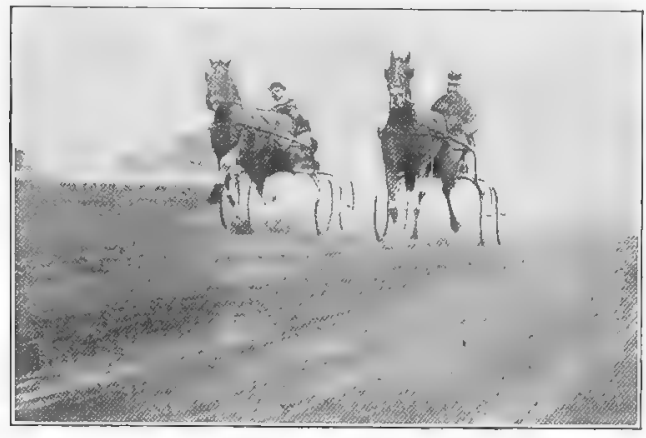

FIG. 19. A close finish between two of the most noted horse owners and drivers in America. From photograph by courtesy of the Horse Reviczo

exported to some extent in the past, more especially to Russia, Austria, and Germany. Russians were considerably interested and were good buyers prior to the World War. In I9I I Bit and Spur stated that more than one hundred of our fastest and best-bred trotting stallions had been exported, and gave a list of eighteen, including Cresceus, with records ranging from 2:02 $\frac{1}{4}$ to $2: 09_{4}^{3}$.

The official promotion of the standard-bred horse is under the supervision of the American Trotting Register Association, with headquarters for many years at Chicago. The "Trotting Register" was established and first published in I $87 \mathrm{I}$ by J. H. Wallace. The American Trotting Register Association purchased the register from Mr. Wallace and also an annual yearbook of records which he also published. Since then these two sets of volumes have been known as Wallace's "American Trotting Register" and Wallace's "Yearbook of Trotting and Pacing." Up to and including I9 I 8 the

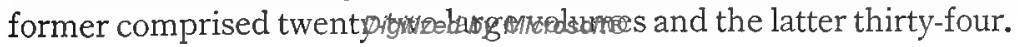




\section{CHAPTER VII}

\section{THE HEAVY HARNESS HORSE TYPE}

The heavy harness horse is often referred to as the coach, or carriage, horse. This type is intended for the special purpose of drawing heavier kinds of carriages and coaches. This horse is also of value in light, active work, where a heavier type than the American trotter is desired. The size and conformation generally found in the coach breeds are associated with this type. The American trotter of the larger size may, however, furnish the essentials needed in a high-class heavy harness horse.

The general appearance of a heavy harness horse in good condition shows smooth, graceful body lines. The height should be about I 6 hands and the weight from I IOO to I 250 pounds for geldings or mares. Stallions will usually range from 1250 to 1550 pounds, according to breed. In quality the heavy harness horse should be superior, showing the best of feet, bone, and hair. Action, high and strong at both knee and hock, is important, while graceful carriage is equally essential. In general appearance the best type of heavy harness horse shows a long arching neck, round full body, long level croup, high carriage of tail, and what is known as a "trappy" gait.

The head of the heavy harness horse should be lean, graceful, broad of forehead, rather prominent and bright of eye, deep of cheek and wide and strong in lower jaw, the muzzle fine and nostrils full and open, the ears refined, being neither large nor small, carried close and erect and turning in slightly at the tips. The head should show quality in its leanness, intelligence in the broad, full forehead, and animation in brightness of eye and carriage of ear and head. A smooth, neat attachment of head to neck is essential, a fullness at the throat and about the windpipe being objectionable.

The neck of the heavy harness horse in its ideal development appears somewhat long, is gracefully arched, and shows a smooth, 
full, muscular development, yet is entirely free from the thickness of draft-horse character. A ewe neck is out of place in this class. Much of the style and symmetry of the heavy harness horse at rest is seen in the carriage and make up of head and neck. The neck should blend smoothly in its attachment to the body.

The chest of the heavy harness horse has neither the thickness of the draft horse nor the narrowness of the Thoroughbred, but should be a happy medium, deep, with the breast carried out in some prominence. Too broad a chest prevents a free, easy gait.

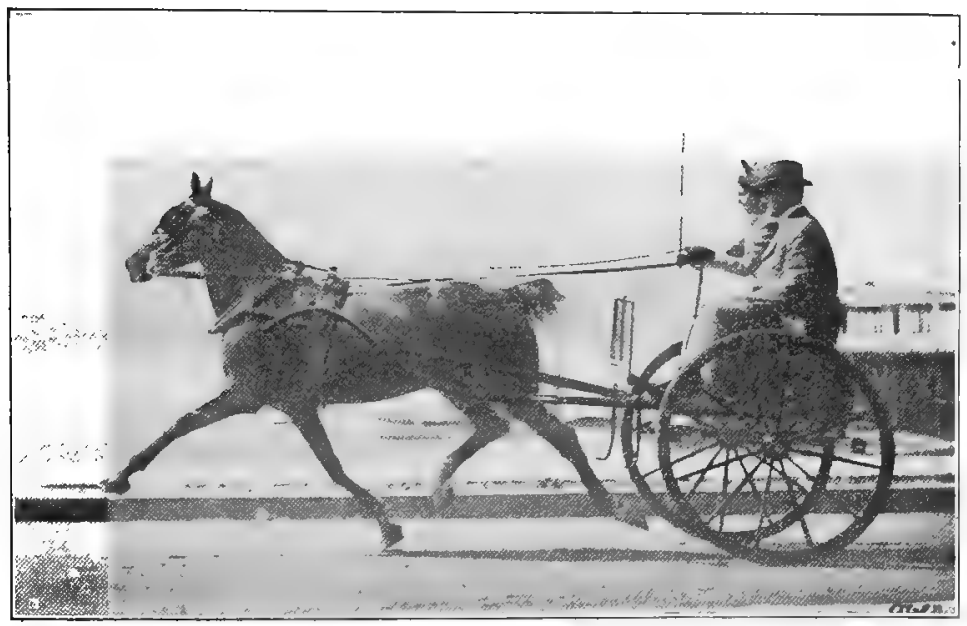

FIG. 20. Brigham Pearl, a ITackney mare and a great example of the heavy harness type. Note the maximum stride, but one foot touching the ground. From photograph by courtesy of the owner, S. L. Ilowe, Vancouver, British Columbia

The shoulders of the heavy harness horse are long and oblique, sloping well into the back, with withers somewhat prominent yet refined. A steep shoulder prevents strong, rapid movement and produces hard action, conducive to defects of feet and legs. High or free knee action is dependent on a long, well-laid, muscular shoulder.

The body of the heavy harness horse should be round, short on top, and long below, the ribs being long and well arched and the back and loin covered smoothly with strong, thick muscle. The loin, in particular, calling for strength should be level, broad, and 
thick. Depth of body at both front and hind flanks is desirable, with not too much prominence and overshadowing of hips.

The croup furnishes the power; hence it should be long and broad, carried high, and thickly muscled. A steep, short croup is inconsistent with well-balanced conformation. The tail should have a high attachment and be carried with style.

The thighs and quarters of the heavy harness horse must be muscular and plump, showing fullness of outline. The muscle of the thighs at the quarters must be thick and deep, giving fullness to the hind end. The gaskin, or lower thigh, should be strongly muscled and long.

The hocks of the heavy harness horse, viewed from one side, should be deep from front to the point behind; the front should be broad and the rear thin, the entire joint being lean and smooth, with no puffiness or coarseness. The action so essential in a coach horse can only be found in a normal, smooth, and strong hock.

The legs of the heavy harness horse, as a whole, must show cleanness, good bone, and plenty of muscle. The arm must be short, broad, and flat, with great muscle development. The elbows should stand out, showing room between the legs and chest, indicating easy-moving power. If the elbow is too close to allow the easy insertion of the hand between it and the body, the legs will not stand straight and the front toes will turn out, while if the elbow is too far from the body, the opposite result will obtain, in either case giving an awkward movement. The forearm should be very long and strongly muscled, wide at top, and tapering gracefully downward. The knee in its strength is broad in front and narrow behind, full and prominent, and strongly attached both above and below. Sometimes the knees come too close together, often they are crooked, and occasionally they project too far over the cannon bones. The cannons, both front and rear, should be flat, smooth, short, and strongly attached above and below. The tendons which pass along behind should stand out clear and strong, thus giving depth to the leg at this point. As the hand is passed down over the cannons no unnecessary roughness should be felt. Under both knee and hock the cannons should be deep, showing a strong attachment at these joints. The fetlock should be strong and placed straight and should be free from fleshiness. 
The pasterns should stand at an angle of about 45 degrees with the floor and be long, smooth, and springy. As the horse stands naturally the pasterns should be well sustained, with no tendency to drop low and appear weak. If the pastern is short or straight an easy gait cannot be assumed, and the conditions promote foot and leg diseases. A correct pastern at 45 degrees allows the proper placing of the foot, the frog striking first, with the resulting jar or concussion less than it would be otherwise. The feet are most important, and a capable judge of the horse will give them almost a first consideration. These should be of suitable size, round, wide at top, well developed at heel, and preferably of dark, hard bone. Ample size is important, for a small foot in the horse presages trouble. The hind part, or heel, should be wide and of reasonable depth, a low heel and flat foot being associated with poor feet. The bottom of the foot, or sole, should be concave and well arched. In a well-formed foot the frog should be wide at the heel, be strongly developed, and just touch the ground when the horse is at rest. Passing about the frog in a continuation of the wall of the hoof from behind is the bar of the foot. This bar helps to hold the sole of the foot together and should be strong and show character. The front feet are usually rounder than the hind and are also more subject to injury and more commonly defective than the hind feet.

Action in the heavy harness horse is an absolute requirement. People vary in the degree to which they desire this. The lover of the Hackney desires a rather high, bold knee action of a flashy sort, with a notable elevation of the foot at its highest point. The hind legs have a powerful movement, the hocks are strongly bent, or flexed, and the legs are carried well up under the body. This is what is known as a "trappy gait," and such a horse as a "highstepper." Such a gait is not consistent with the best speed, and wise lovers of the horse prefer less high action and more reach and power. Further, with high knee action comes a greater concussion to limbs and feet and consequently greater punishment and more rapid wearing out of the horse than would otherwise be the case. Especially is this true on the city pavement. Trueness of action is essential, whether a high-stepper or not, the legs being carried forward in the sampe meneral line and the feet moved 
neither in nor out. The hocks should be firm and not show weakness, as springing wide apart when in action, and the feet should be held true, neither turning in nor out at the toes. When either at walk or trot the horse should pass from or come toward the judge on the same true line, without sidewise gait, dragging feet, paddling, clicking, etc. Straight and regular movement should be sought for. Ordinarily a coach horse is expected to have a speed of about eight or ten miles an hour in continuous road work.

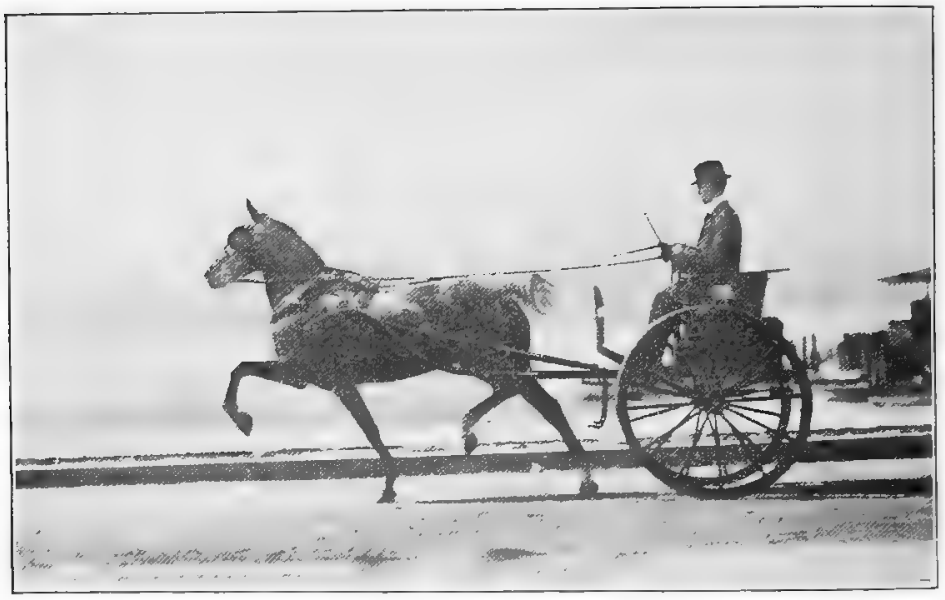

Fig. 21. Brigham Pearl, showing extreme flexing of knees and hocks, with but two feet on the ground. From photograph by courtesy of Mr. Howe

Subclasses of heavy harness horses. On account of the special requirements of city trade, in relation to the size and use of various vehicles, the coach horse is divided into groups. This classification only occurs, however, in the important horse shows and in the exclusive trade of the city dealer. Pure-bred coach horses, as a rule, do not come within these subclasses when of the smaller type, though the Hackney may furnish an exception. The following three subclasses are the principal ones of interest:

The Park horse is a coach horse of the smaller class, in which are found typical heavy harness conformation and a very flashy style of action. This represents the finest of the subtypes referred to and stands from I 5 to I $5 \frac{3}{4}$ hands and weighs I oOo to I I 50 pounds. 
Action of the Park horse should be extremely high, with the best of balance and the limbs moving in perfect rhythm. Park horses are driven single or in pairs and occasionally in fours. They are attached to light pleasure vehicles, such as phaetons, gigs, park drags, and victorias.

The $C o b$ is a small, compact type of the subclass heavy harness horse, too large for a pony. His full, compact form has come to be known as "cobby," which term expresses his general conformation. He stands from $14 \frac{1}{4}$ to $15 \frac{1}{4}$ hands high and weighs 900 to I Ioo pounds. The Cob has a smart gait, with high action and a fair amount of reach. Cobs are very common in England and Wales. They show great speed and endurance and are commonly hitched singly to comparatively heavy carts. They are also used on light broughams or phaëtons.

The Runabout combines features of conformation of a small, heavy harness horse with more of the action of the light harness horse. In fact, by some he is regarded as of the light harness class, while others place him in the heavy harness class. He stands $14 \frac{3}{4}$ to $15 \frac{1}{2}$ hands high and weighs 900 to 1050 pounds. $\mathrm{He}$ is not quite so stocky as the Cob and lacks his trappy gait. This is a handy small driver, adapted to a variety of conditions, easily handled, and valued on the market at a modest price. 


\section{CHAPTER VIII}

\section{THE HACKNEY}

The word "Hackney" has long been in use in Great Britain. The Norman invaders in the eleventh century brought from France the term "haquenée," or " hacquenée," which is of uncertain derivation. As early as I 303 this word is said to have come into active use. This same century Chaucer in his writings refers to the hakeney or haknay, spelling it both ways. ${ }^{1}$ Prior to the eleventh century it is supposed that the word "nag" (which is akin to the verb "to neigh") was the common term in reference to the saddle horse of light type. Since those early days the words "nag" and "Hackney" have been in common use.

The native home of the Hackney is located in eastern and northeastern England, in the counties of Suffolk, Norfolk, and York. The people in this region have for centuries greatly patronized the saddle horse or roadster. In the fifteenth century trotting horses were highly esteemed, and a Berney of Norfolk placed an estimate equivalent to $\$ 350$ on one of his horses.

The original Hackney stock was subjected to varjable influences. The Romans no doubt introduced horses from southern Europe, and these must have bred with the native English stock. Following them came Scandinavian intruders, and it is assumed that Norwegian ponies were used in the mixture, giving British horse stock both speed and endurance. The abundance of trotting horses in sections occupied by Danish settlers would indicate the popularity of this type. Besides the commingling of different strains of blood, some enactments on horse breeding and development took place by royal decree as far back as 1495, when Henry VII was on the throne. In I 558 Ralph Blundeville of Norfolk produced the first English book on the horse, which he designated "The Foure Chiefest Offices belonging to Horsemanship," now a rare and much-sought work.

1 The Hackney Studbook, Vol. I, I 884 ; with a Historical Introduction by Henry F. Euren. 
The early development of Hackneys really began in the eighteenth century. In Norfolk there frequently appeared in the papers advertisements regarding horses for sale or breeding purposes, various animals being named specifically. These statements showed the use of Arabian, Barb, and Turkish stallions on Norfolk mares. Undoubtedly the road horses of Norfolk and Suffolk were much appreciated for speed, and any blood that

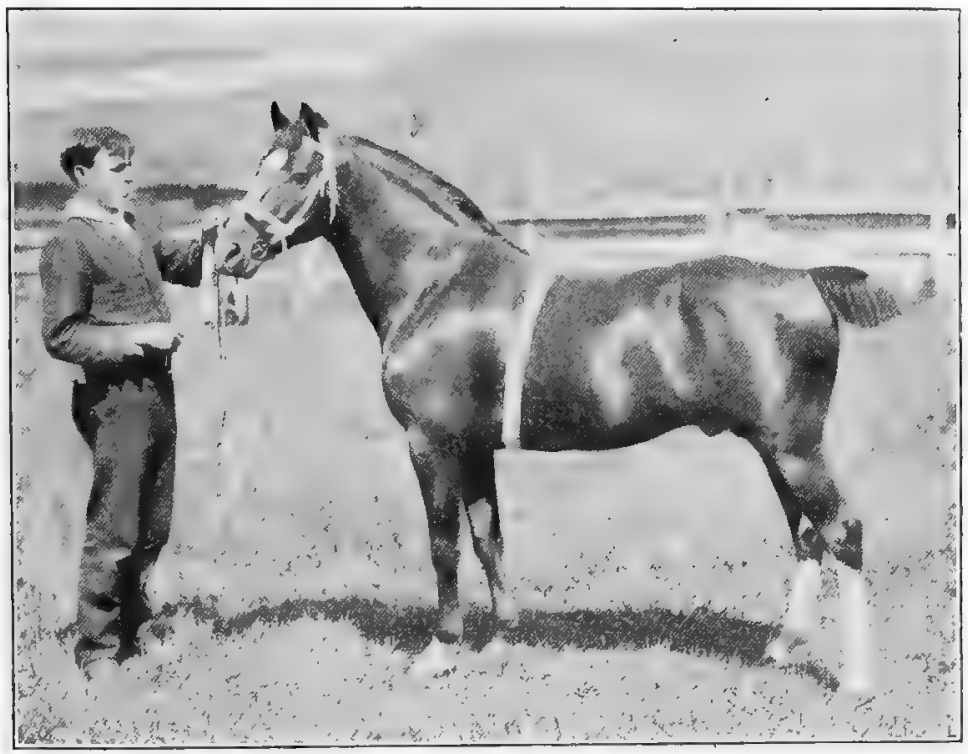

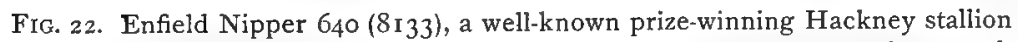
and sire. Owned by W. D. Henry, Sewickley, Pennsylvania. From photograph by Schreiber \& Sons

would contribute to this purpose and not injure stamina was used. Thus the Thoroughbred also played a part in early Hackney development.

The important evolution of the Hackney began with a horse variously known under the names of Schales, Shales, The Original Shales, and Shields. This stallion was foaled in 1755 and was thought to be sired by Blaze, a son of Flying Childers. In the breeding of this horse, registered in the first volume of the

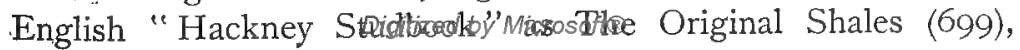


occurs Arabian, Turk, and Barb blood. He is but four generations from the Darley Arabian. The Original Shales sired among others one son, Scot Shales (692), that proved a great breeder, although not famous for speed. He was noted for getting "good stock out of common mares." In 1782 he was "justly esteemed the best stallion known to get good road horses." The Original Shales was also sire of Driver (I87), that proved a great breeder. Coming along after these, as important factors in Hackney development and history, were the following: Fireaway (2OI) (Jenkinson's), foaled in I780; Fireaway (203) (West's) ; Fireaway (2 I I) (Flanders') ; Pretender (596) (Wroot's) ; Fireaway (208) (Burgess') ; Bellfounder (52) (Stevens'); Bellfounder (55) (Jary's), imported to America in 1822 ; Wildfire (864) (Ramsdale's); The Norfolk Cab (475); The Norfolk Phenomenon (522); Phenomenon (573) (Ramsdale's), foaled in 1835; Sir Charles Beal's (768), foaled in 1843; Denmark (I 77) (Bourdas'), foaled in 1862; Danegelt (174), foaled in I879 and died in I894. During the past fifty years the blood of Denmark and Danegelt has been most potent in Hackney history. Perhaps the five sires of most importance in the last quarter of the nineteenth century were Lord Derby 2d, Bourdas' Denmark, Triffitt's Fireaway, D'Oyley's Confidence, and Danegelt.

The introduction of the Hackney to America dates back to 1822, when James Booth of Boston imported, from Liverpool, Bellfounder (55) (Jary's), commonly known as imported Bellfounder. He was sired by Bellfounder (52), with Pretender (596) for grandsire, and out of a mare named Velocity. The Bellfounders proved animals of great speed and endurance, tracing back from the original Fireaways. Bellfounder was the sire of the Charles Kent Mare, the dam of Hambletonian IO. The great speed in the Hambletonian family of trotters may justly be regarded as tracing through the Bellfounder lineage.

It is believed that the Hudson Bay Company imported to Canada in I 830 an English Hackney named Fireaway, but for years no importations of this breed other than these two came to America, and they were not brought over as Hackneys. In I 88 I M. H. Cochrane of Hillhurst, Canada, brought an importation to Canada from England, having among others a fine 
stallion named Fordham, by Denmark (I 77). The first Hackney stud founded in the United States was established by A. J. Cassatt of Philadelphia. In the spring of 1883 he imported the stallion Little Wonder and the mares Patience and Buttercup, having previously brought over the mare Stella, by Confidence (I58). Little Wonder was exhibited in I 883 and later proved to be a sire of much excellence. Other importations were as follows: Prescott Lawrence, Newport, Rhode Island, I884; J. B. Perkins, Cleveland, Ohio, I887; Henry Fairfax, Aldie, Virginia, I 888 ; John A. Logan, Youngstown, Ohio, I 888 ; Galbraith Brothers, Janesville, Wisconsin; J. H. Truman and Sons, Bushnell, Illinois; Powell Brothers, Springboro, Pennsylvania; and some others, I889. In I 890 Dr. Seward Webb, Shelburne Farms, Vermont, made an importation of twenty-seven mares and four stallions, the most important consignment up to this time. Since then many Hackneys have been brought to the United States from England.

Hackney characteristics are especially shown in conformation and gait. The head naturally tends to be wide in the forehead, full in the mouth, with an eye that is bold and active. The neck, which is often full at the throatlatch, inclines to coarseness and tends to some crest effect. The body is deep ribbed, full in front and behind, and the back wide and strong. The croup is usually long, level, and wide, and the thighs are very strongly muscled. The legs and feet are noted for their soundness. The Hackney may perhaps be regarded as blockier of form than other coach breeds of coblike character. Mr. Henry F. Euren states that the general description of the Hackney which fitted both old style and new ideal is in brief this: "A powerfully built, shortlegged, big, broad horse, with an intelligent head, neat neck, strong, level back, powerful loins, and as perfect shoulders as can be produced."

The gait of the Hackney originally had its chief value in a long, strong trot for road work. With the evolution of years the fashion of modern times called for the high-stepper, with extravagant action. The horse Confidence (I 58 ) was the sire of many horses of this type of gait, and, as some think, to the detriment of the breed, though " the get of Confidence yielded a larger total profit 
than any other horse of his day." While the fancy city trade desires matched pairs with very high action, this is inconsistent with the most graceful or forceful movement. The ideal Hackney has a perfect walk and a trot associated with a powerful stride. The feet are carried clear and full from the ground and are strongly and actively raised at the knee, while the hock is carried forward under the body with much grace, strength, and action. Hayes states ${ }^{1}$ that the Hackney has been evolved into a light,

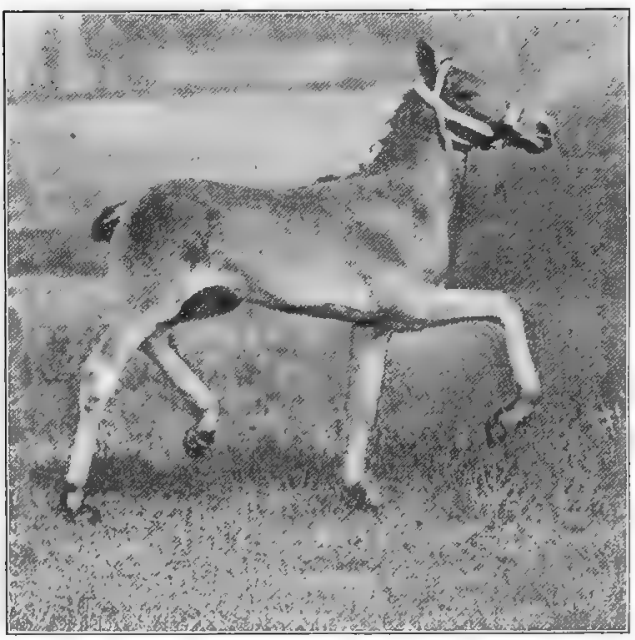

Fig. 23. A Hackney filly foal demonstrating action at six weeks of age. From photograph by courtesy of W. D. Henry, Sewickley, Pennsylvania high-stepping, showy carriage horse and that his conformation is not well suited to saddle work of the present day, which has turned toward army service and jumping.

The color of the Hackney is commonly chestnut, but bay or brown are rather frequent. Black, roan, and buckskin are found also, but are of rare occurrence. Chestnut has become almost a typical color with this breed. Referring to this color, Hayes says that "it is an interesting fact that chestnut Hackneys are generally better shaped and have more brilliant action than Hackneys of other colors, and consequently they form the large majority of winners at shows. This success of chestnut color is not always continued in the sale ring, because purchasers of harness horses usually prefer bay or brown." White markings, such as a star or blaze on the face or white on the lower part of the leg, also occur.

The height of the Hackney shows considerable variation, but in the larger type it ranges in popular favor from $15 \frac{1}{2}$ to $15 \frac{3}{4}$

1 M. H. Hayes, The Points of the Horse. London, I904. 
hands. In I 885 the Royal Agricultural Society of England, at the request of the Hackney Studbook Society, increased the standard height for the breed to I $5 \frac{1}{2}$ hands, and the class was well filled. There are Hackney ponies under I4 hands, I Iackney cobs larger than ponies, and Hackney coachers over I6 hands.

The soundness of the Hackney has been made a subject of special study by the English Hackney Society. At the first show of Hackneys in London, in I885, some twenty mature stallions

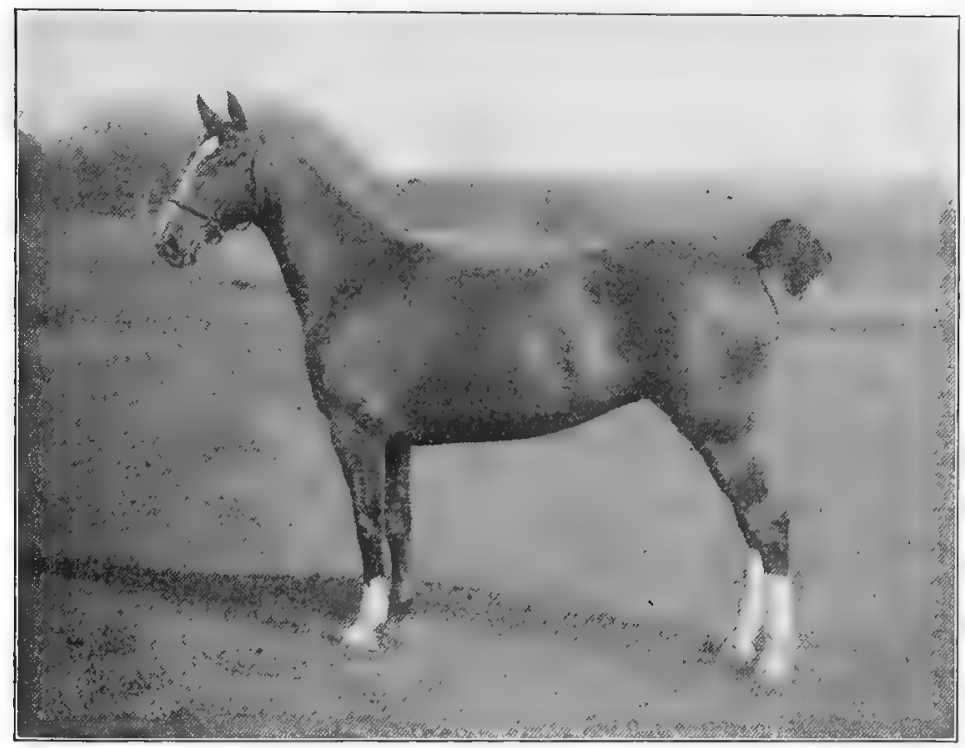

FIG. 24. Hildred, one of the most perfect Hackney mares in the history of the American show ring. Imported and owned by the late Eben D. Jordan, Boston, Massachusetts. From photograph by courtesy of Mr. Jordan

were selected by the judges as absolutely sound. For many years the Hackney Society made a rule that only sound horses, passing a veterinary examination, should compete in the annual show of the breed. Thousands of horses have been examined, with percentages of rejection ranging about five, a rather remarkable and creditable showing.

Half-bred or grade Hackneys have been looked upon with favor in Great Britain, while in France Hackney stallions have had much influence. A study of pedigrees will show an important 
relationship of Norfolk-Hackney blood in building up the French Coach, and the French have not been backward in using the Hackney for crossbreeding. In America Hackney stallions have been used in a limited way in the more eastern states. The late Henry Fairfax of Virginia used Hackney stallions on common farm mares with much success, and grades of this breeding have been successfully exhibited. Some years ago the late John A. Logan, Jr., had an extensive Hackney stud at Youngstown, Ohio, where he had about fifty racing mares of different blood lines. Crossing these with a Hackney stallion, he secured very satisfactory results. Philip Baker, in an article on the Hackney in war time, ${ }^{1}$ in which he discusses the influence of crossbreeding to secure substance, states that the Hackney on the Thoroughbred, "when the mating is undertaken with discretion," produces offspring that is generally active, handsome, and possessed of a good back, barrel, legs, and feet, and, last but not least, is sound in wind and eyesight. These good-tempered horses can either carry a heavy weight or draw a load, or both.

Imitation Hackneys in the past have had some sale, especially in America. High-acting trotters of the right conformation have been fixed by professionals to bear a close resemblance to true Hackneys. Dr. A. G. Hopkins, in a letter to Captain Hayes, ${ }^{2}$ conveys to him the methods in vogue. He writes:

During a winter's stay in Chicago, where I did post-graduate work with Dr. M. H. McKillip, who is the leading veterinarian in that city, I helped in several of these operations. Standard-bred stallions, often with marks of from 2:40 to 2:25, are procured and castrated. Later on they are docked and their tails set up by nicking, and when they get great growth of foot and plenty of iron, they can pull their knees up to their chins. The Anglomaniac gets caught, for he knows nothing about horses. The imitation Hackney seldom bends his hocks properly, and when he is pushed he often spraddles, as the trotter does in the sulky.

The distribution of the Hackney is more widespread than that of any other coach-horse breed. It is generally found in the eastern and north central United States - Pennisylvania, New York, Massachusetts, and Illinois being breeding centers. It is also

'Live Stock Journal Almanac, 1917, London.
"The Points of the I-Iorse, p. 568. 
found almost all over the world. Horses have been exported from England to Africa, Australia, Belgium, Argentina, Canada, Denmark, France, Germany, Holland, Italy, Japan, New Zealand, Spain, the United States, and elsewhere.

The effect of the motor on Hackney breeding has been very serious, as might have been expected. At the present time there are very few breeding studs in America, and these are largely for the purpose of turning out show-ring horses. The horse show is yet in public favor, and while the jumper is receiving great attention both in Europe and in America, the harness horse also awakens keen interest. In this capacity the Hackney heads the list in English-speaking countries.

The promotion of the Hackney in England has been cared for by the Hackney Horse Society, organized in 1883 and publishing its first studbook in I884. Up to I9I7 this society had published thirty-four studbooks. The American Hackney Horse Society was organized in I89I and published its first studbook in 1893 . Up to 1918 the society had published four studbooks. 


\section{CHAPTER IX}

\section{THE FRENCH COACH}

Horse racing in France dates back several centuries. It is said that racing was practiced in 1323 under Charles le Bel and even earlier. Systematic attempts to improve the racing horse began during the reign of Louis XIV, in the latter part of the seventeenth century. Colbert, one of the ministers of Louis XIV,

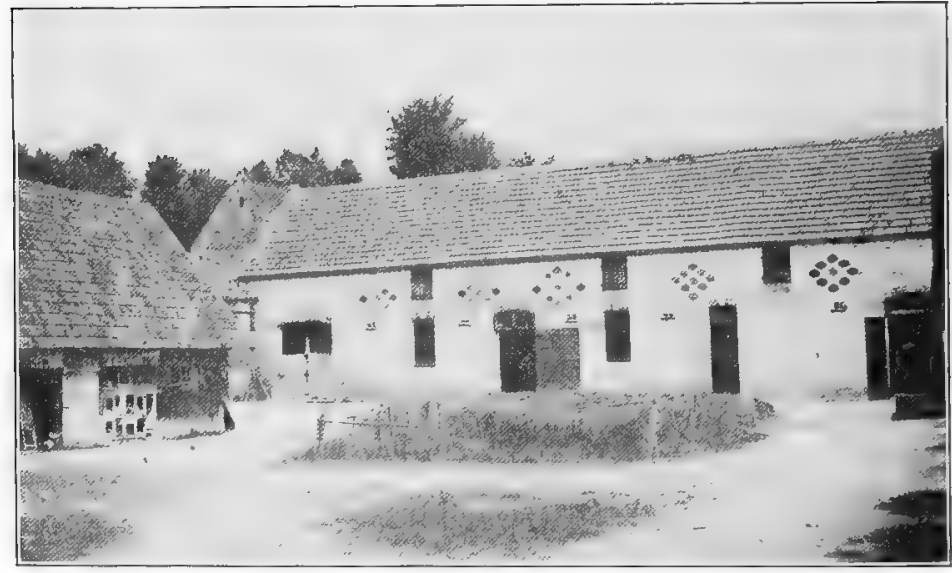

FiG. 25. A corner of the stable yard of M. Gaston Fanet, Fontaine-Henry, Calvados, France, in the French Coach country. The wall ornaments are medals indicating prizes won at shows; such medals often decorate French stables. From photograph by the author

founded the "Administration des Haras." During these early days more or less horse racing was engaged in, but in no persistent form. French horses were taken to England between 1775 and $I 790$ and raced on the turf by French owners. The French saw the merit of the English Thoroughbreds, and along in this period they began to buy and send them to France for both breeding and racing purposes. Several of the sires taken to 
France in and about 1776 became famous, as, for example, Comus, by Otho; Glowworm, by Eclipse; King P'epin, by Turf; and Pyrois, by Matchem. Some mares were also taken across the Channel. Very early in the nineteenth century Napoleon the Great undertook to promote the development of the horse, though he had in view the army service as well as use on the turf.

The French Jockey Club was organized in 1833 , and with it came the first real influential development of the light horse in France. This club was aristocratic, wealthy, and influential, and it began to promote racing and breeding. Since that time the government's haras, the Jockey Club, and horse-breeding societies have done much to improve the horses of France.

\section{Origin of the French} Coach horse. The term "French Coach" is an American one, there being no breed of that name in France. The type of horse that we know by

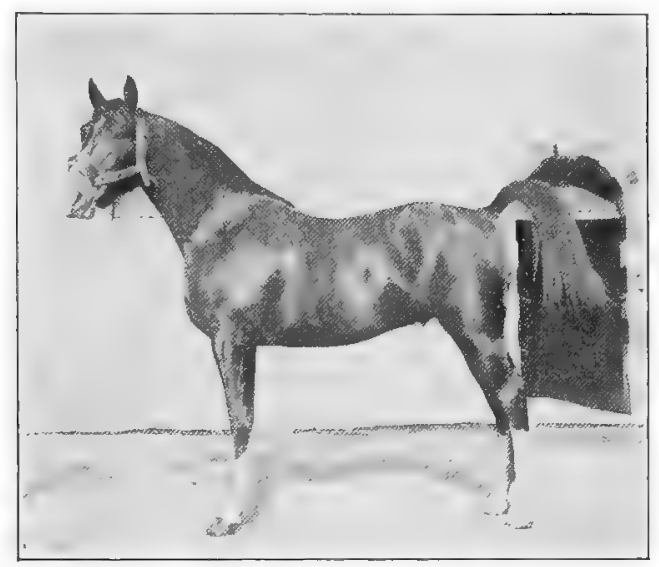

FIG. 26. Flirteur, three-year-old French Coach stallion, champion at the Paris Horse Show, rgo8. From photograph by the author

this name in America is termed Demi-Sang in France, meaning "half-blood." These horses when descended from English sires, especially Thoroughbreds and Norman mares, have been called Anglo-Normans and are often referred to as such. Hackney, Arab, and other blood has also been used in developing the Demi-Sang.

Characteristics of the French Coach. This breed really presents some variation in type. The larger, smoother sort at one time brought to America is what we know as the coacher. These generally average about 16 hands high for stallions and geldings of maturity. Mares will stand from $\mathrm{I} 5$ to 16 hands. Stallions in fair condition, weighing about I 350 pounds, may be regarded as

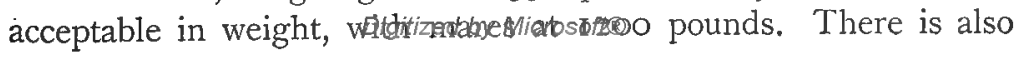


a smaller, more cobby type of coacher, or French trotter, that is highly valued by the French for its speed quality.

The French Coach is characterized by very good length of body, with a long, somewhat arching neck and a long, wide, level croup. The trot of this breed is long and powerful, rather than high and trappy like the Hackney. The French have sought strong bone and excellent feet and great speed for a heavy type of trotter.

There is not a great variation in color, bay in varying shades and brown being most common. Of 147 stallions and mares owned at one time by

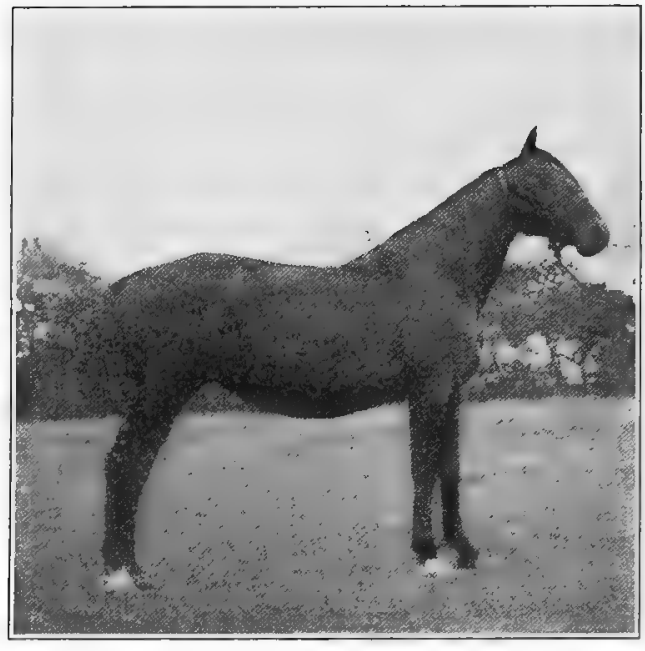

FIG. 27. A French Coach mare on pasture in Calvados. From photograph by the author two of the leading dealers in the United States there were 90 bays or brown bays, 29 browns, 7 blacks, and II chestnuts.

The French race track, which is either two and one-half or two miles long, is over a course of turf. The sod track causes a high knee action and long stride as well as a strong, well-flexed hock movement.

Speed records of French Coachers. As might naturally be supposed, the use of stallions from high-class speed ancestry on French mares produced fast trotters. The horses of France, however, have never made as fast time as those of America. In 1873 Niger trotted 2.12 miles in $6: 55$, while up to I 877 the fastest record was by Pactole, who made $2 \frac{1}{2}$ miles in $6: 38$. In 189 I there were 1399 contestants in races, 3 I 2 of which trotted races from 2 to $3 \frac{3}{4}$ miles at less than 3 minutes per mile, I 37 under $2: 50$, I I 2 under $2: 45$, and 62 under $2: 40$.

The distribution of the French Coach horse is confined almost exclusively to France, although in the past the breed was extensively 
exported to various European countries and to the United States. The late Mark W. Dunham of Illinois was a prominent importer and breeder and had a large stud, as did also Powell Brothers of Springboro, Pennsylvania. McLaughlin Brothers of Ohio were active importers for many. years. The French Coach, however, never made an acceptable record in America, though a great favorite in France, where it has in the past been the leading breed. The advent of the automobile effectively destroyed the foothold of the French Coach in America and greatly reduced its use in France.

The American French Coach studbook. There were at one time two societies in the United States for French Coach horses, namely, the French Coach Horse Society, with headquarters at Chicago, Illinois, and the French Coach Registry Company, with headquarters at Columbus, Ohio. The former was organized in 1885 and published its first and only studbook in 1906. 'The French Coach Registry Company was organized in $190_{4}$ and published Volume II, its last studbook, in I908. Both of these associations are now defunct, as the French Coach horse is practically extinct in America. 


\section{CHAPTER $\mathrm{X}$}

\section{THE GERMAN COACH}

The native home of the German Coach horse is in northwestern Germany in the rich lowlands drained by the rivers Elbe, Weser, and Ems, which flow into the North Sea. Here, especially in the states of Hanover, Oldenburg, and Schleswig-Holstein, this type of coach horse has long been bred.

Early records of horse breeding in Germany go back about five centuries. As early as I 500 important fairs in Friesland on the German border were patronized by Dutch, Belgian, and German horse buyers. From I628 to I 648 Count Ulrich II owned stables of much importance. In 1648 a government stud was established at Ilo, Germany. From these early days, up to the World War, horse-breeding operations in Oldenburg and Hanover were extensively conducted. Government supervision has prevailed over the horse breeding in this section of Germany.

The introduction of the German Coach horse to America is comparatively recent. These horses were first brought to the United States along in the eighties. Not much prior to I $890 \mathrm{did}$ the breed receive recognition at American shows. A. B. Holbert, of Greeley, Iowa, was one of the earliest introducers of the breed. The Oltmann Brothers of Illinois and Crouch and Son of Indiana were also actively and prominently identified with its promotion during its career in the United States.

Characteristics of the German Coach horse. In height the breed ranges from 16 to $16 \frac{1}{2}$ hands and in weight from 1350 to 1450 pounds. The color does not vary greatly, being almost exclusively bay, brown, or black. The head is fairly typical of the coachers, the neck being long and arched, the shoulders well placed, and the withers prominent. The body of the German Coach is somewhat larger than that of the French Coach, and the croup is high and the tail well placed. The legs show considerable length, compared with the Hackney, while the feet are excellent. On the basis 
of many specimens brought to this country, seen by the writer, the German Coach varies materially in size and quality. Coarseness is not uncommon, as seen in large heads and joints with more or less grossness of bone. In action there is a wide difference of merit and, from the coach-horse point of view, frequent deficiency. A superior folding of knee and flexing of hock, with desirable activity, is not a prevailing attribute of American specimens of the breed.

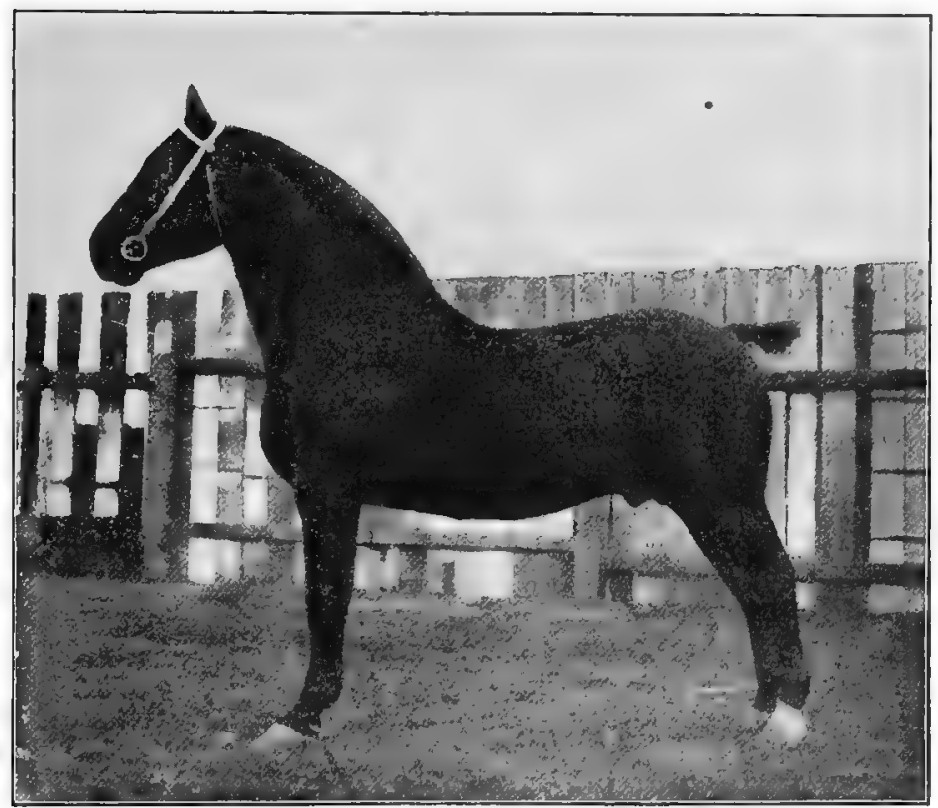

FIG. 28. Hannibal, a German Coach stallion, imported by Crouch \& Son, Lafayette, Indiana. A prize winner of the highest rank at many shows. From photograph by the author

The type of German Coach horse seen in America possesses some considerable variation. In I893, at the World's Columbian Exposition at Chicago, an exhibit of over eighty German Coach horses was made, including special exhibits from Germany made by the Oldenburg Agricultural Society, the Hanoverian Agricultural Society of central Germany, and the East Friesland Head Agricultural Society. There was some considerable variation in the types showingitizaldy flollowitivg the awards by German 
judges came pronounced objection and dissatisfaction. This resulted in an editorial statement on the German Coach type, which appeared in the Breeders' Gasettc and was authorized by the German judges. This statement is of importance to American students and so is given here:

The visiting German horsemen make the following claims concerning the light types of horses. Four types of light-legged horses are recognized, and each now has its separate studbook. The Trakehner is the lightest of all and is a carriage and saddle horse, not a heavy coacher. The Holstein and Hanor'trian horses are about the same type, but the Hanoverians are more used for saddle horses and the Holsteins for carriage horses. This difference in use implies somewhat of a difference in action. The Oldenburg is the heaviest type, and these horses are used for heavy coach work, such as state coaches, and as farm or all-purpose horses, and are not put under saddle. Then there are the East Friesland horses, which are practically Oldenburgs, as they are bred from Oldenburg sires. It is claimed that these distinctions are actual rather than artificial.

The distribution of German Coach horses has been very widespread. They have been sold to various European countries, South America, South Africa, the United States, and Canadian Northwest. For years the most prominent importers, exhibitors, and promoters of the breed had headquarters in Indiana, Illinois, and Iowa. As these horses never met with a very favorable reception in America, no stables of importance were established, and since I9I4 the breed has practically disappeared from American trade.

German Coach horse organization in America began in 1892 with the incorporation, under the laws of Illinois, of the German, Hanoverian, and Oldenburg Coach Horse Association. Very soon after the organization of this association came the Oldenburg Coach Horse Association, which was also incorporated in Illinois, but from which very little was ever heard. The former association published two volumes of studbooks, up to I906, containing the registration of 3849 animals, mostly stallions. 


\section{CHAPTER XI}

\section{THE CLEVELAND BAY}

The native home of the Cleveland Bay is in Yorkshire, England. The breeding center at present is in the counties of York, Durham, and Northumberland. In the Cleveland hills of Yorkshire it has been bred in its greatest purity and derives its name from this region.

The origin of the Cleveland Bay is very obscure. Various claims have been made as to its ancestry. Perhaps the most reasonable explanation is that it is the result of breeding Thoroughbreds on British cart-horse mares. The use of Scandinavian horses has also been suggested, thus accounting for the black points in the Cleveland. The British studbook states that with the pure Cleveland of merit the ancestry will go back to one or more of the three families that are descendants of Dart (83), The Hob Horse (3 I6), and Barley Harvest (447).

The introduction of the Cleveland Bay to America dates back about a century. In I820 R. Patterson of Maryland imported a Cleveland Bay stallion named Exile, which in I 822 was exhibited at the show of the Maryland Agricultural Society, receiving honorable mention. ${ }^{1}$ However, the breed gained no foothold. Along in the eighties quite a number were imported. At one time Stericker Brothers, then of Springfield, Illinois, had a large stud of this breed and made most attractive exhibits. The people of the United States, however, have never been favorably impressed, consequently Cleveland Bay interests have essentially died out, and these horses are now unknown in our shows. In 1900 the class for Cleveland Bays at the Illinois State Fair was discontinued, yet Illinois but a few years before had the principal stud of this breed in America. Neither is there anyone prominently advocating - in the press or otherwise - the merits of the breed. 
Cleveland Bay characteristics. The color is always bay, either light or dark, with black legs, mane, and tail. White is not permissible, except a small star in the forehead or a few white hairs on the heel. More white, the breeders say, indicates foreign blood. The color may be dappled, and dark bars may occasionally be seen on the lower arm or possibly a trifle above the hock.

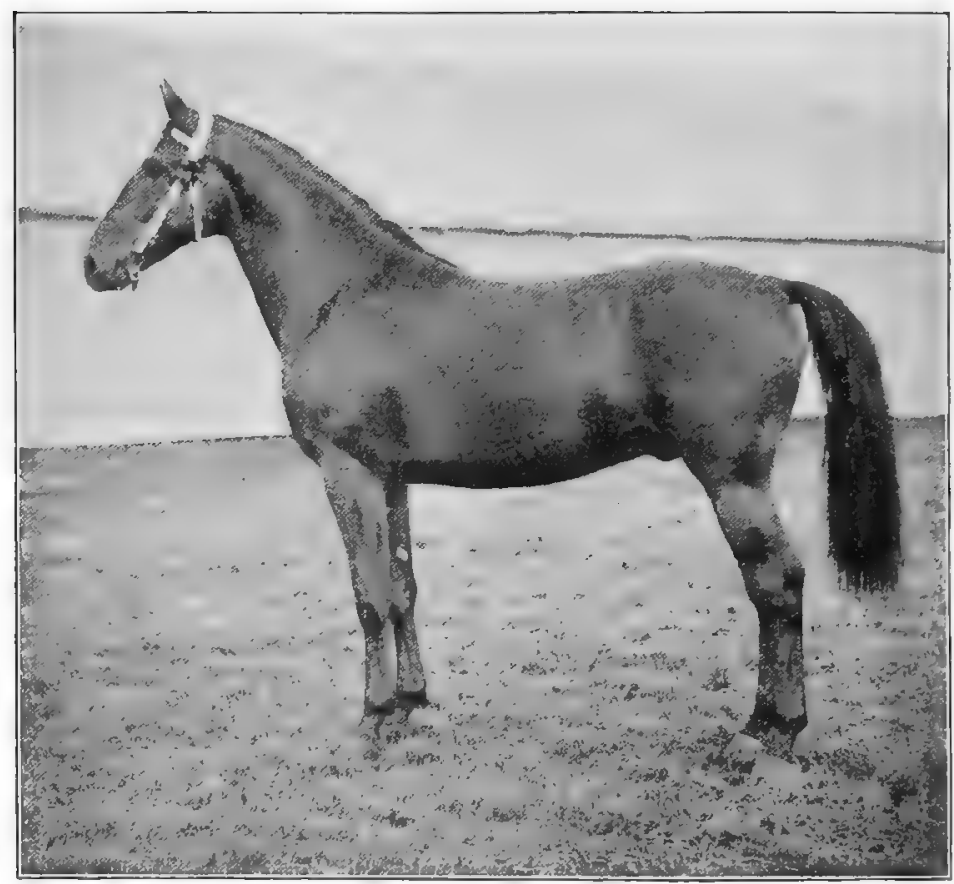

FrG. 29. Special Delight. Champion Cleveland Bay stallion at the show of the Royal Agricultural Society of England. From photograph by courtesy of William Cooper \& Nephews, England

The body of the Cleveland Bay is of the larger coach type, with long, sloping shoulder and high, broad croup. The head has been regarded as lacking in refinement, while the limbs have not as much quality as the best market demands. In action the movement is strong and powerful, but not stylish. The breed is perhaps the largest of the coach type, but lacks somewhat the quality of the prominent coach breeds. The height ranges from $16 \frac{1}{4}$ to 
I $6 \frac{3}{4}$ hands and the weight from $\mathrm{I} 200$ to $\mathrm{I} 400$ pounds. Thirteen hundred pounds is a very acceptable weight.

Cleveland Bays as roadsters have always had fame in England for this quality. Cases have been known where the Cleveland Bay has traveled from sixty to seventy miles within twenty-four hours, with heavy loads, three or four times a week, besides being employed occasionally on intermediate days. Hodgson, in a Joumal of the Royal Agricultural Society, says :

I knew a Cleveland mare that carried a man seventy miles a day for a week together. Tommy Miles, of Harlsey, near Northallerton, rode his Cleveland mare to York for a week together, to have his name called over in court as a juryman; he was in York by nine o'clock every morning (thirty-five miles), and slept in his own bed at Harlsey (thirty-five miles) every night.

The distribution of the Cleveland Bay is rather widespread, they having been exported to various parts of the world, including Sweden, Canada, the United States, South Africa, Australia, and South America. At the present time a large share of those exported go to South Africa.

Organizations to promote the Cleveland Bay exist in Great Britain and the United States. In England the Cleveland Bay Horse Society of Great Britain and Ireland, with headquarters in Yorkshire, attends to registering and promoting the breed. In the United States the Cleveland Bay Society of America was organized in I885. Up to I9I 7 this society had published three studbooks.

The Yorkshire Coach horse bears a peculiar relationship to the Cleveland Bay and calls for some consideration at this point. In England there is a Yorkshire Coach Horse Society in addition to the Cleveland Society, and horses of each kind are registered separately. In America, however, Yorkshire Coach horses and Cleveland Bays are regarded as one breed and are registered in the "Cleveland Bay Studbook of North America." The Yorkshire Coach horse is of more recent development than the Cleveland and has been designated as an improved Cleveland. It tends to be smaller in size, is more coachy in action, and has perhaps more quality. The improved quality is due to Thoroughbred blood. In the "Yorkshire Coach Horse Studbook of England," 
published in 1887 by the Yorkshire Coach Horse Society, is the following official statement of "The Origin and Characteristics of the Yorkshire Coach Horse" :

It cannot be claimed for the Yorkshire Coach horse that he is a pure-bred animal, but that, on the contrary, by the judicious crossing of large-sized, goodcolored mares with stallions altogether or nearly Thoroughbred a class of horses has been produced suited to the wants and circumstances of the times. By universal consent the color should be bay or brown, with black eyes, mane and tail abundant but not curly, the height from 16 hands to 16 hands 2 inches, with fine head, sloping shoulders, strong loins, and lengthy quarters, high-stepping. action, good sound feet, flat legs, and abundance of bone and muscle. 


\section{CHAPTER XII}

\section{THE DRAFT-HORSE TYPE}

The general conformation of the draft horse involves a massive form, a compact and blocky body, and a comparative shortness and strength of limb, the whole being in harmonious proportion. Weight is a most important consideration, for a true draft horse must weigh heavy compared with the lighter type. A draft horse in fair condition at maturity may weigh anywhere from I600 to 2000 or more pounds. Grouped into classes, the light draft horse may weigh usually from I600 to I 700 pounds, the medium from $I 700$ to 1850 , and the heavy from 1850 up. The greater the weight, as a rule, the higher the price paid for the superior specimen of the type. In order to pull heavy loads the draft horse must possess plenty of weight. It is very evident that the heavy horse in harness brings greater power into the collar than does the lighter one.

In discussing the medium of draft Hayes writes as follows:

Bodily weight is of special use in draft on slippery roads, such as those of wood pavements and asphalt, because in such case the security of the foothold of a heavy horse would not be so much endangered as that of a lighter though equally strong animal. Also, the employment of bodily weight on a smooth and level road would entail less strain and fatigue than that of muscular propulsion. Hence, improvements in roads have been accompanied by increase in weight of the cart horse. The question as to the relative proportions of the weight and strength of these animals cannot be decided with accuracy owing to the infinite variety of conditions which would have to be considered. We may, however, take for granted that the comparative weight which would be an advantage to a heavy draft horse in a city like London would be a decided drawback to the efficiency of a cart horse that had to do his work on arable land, especially if it was rough, like on ridge and furrow; because the raising of his weight at each step would entail far greater muscular exertion than if his labor was on a smooth road.

The height is not so material provided there is the necessary weight. Draft horses usually stand from 16 to $17 \frac{1}{2}$ hands, though occasional exceptions occur. The light draft represents the lesser 
height, and as the weight increases, the height may also bear a relationship to it. Quality and substance, as shown in hair, bone, and joints, should be preeminent with this horse. The hair should be fine and silky, even if long, and the bone smooth and attractive, with neatly turned joints, the lower limbs being generally free from all superfluous fleshiness. Coarse joints are usually associated with coarse and poor bone and feet and often with a coarse and undesirable head. The long hair on the leg of the Clydesdale or Shire is indicative of quality, fine silky hair being associated with superior bone and feet.

The head should be lean, not out of proportion with the body, and have plenty of breadth between the eyes, which should be reasonably prominent and bright. The nose and muzzle should be broad yet not coarse, with nostrils of ample size for easy breathing. Nicely matched lips and strong cheeks and lower jaws help to make a strong head with character. The head should be crowned with fine ears of medium size, gracefully placed and carried.

The neck of the draft horse should be strong and muscular, supporting the head cleanly and gracefully and being joined smoothly and deeply at the body. Some arch to the neck is desirable; this should appear in a very small degree with mares and geldings, yet enough to suggest power.

The shoulders should not be as long and sloping as with a light driver, but more upright, being well set into the back - a happy medium between the straight and sloping shoulder giving the best power and movement for the draft horse. Too straight a shoulder promotes excessive concussion and bone trouble of the limbs and feet. Smoothness of shoulder is essential, for roughness and prominence will be sure to involve soreness and trouble from fit of collar.

The chest should be full and deep, indicating large capacity of the vital organs. Narrowness behind the shoulders is quite common and indicates defective constitution. Too much thickness of chest - an unusual occurrence - may cause a swaying movement in action.

The am must be large and muscular and placed so as to bring the legs in proper position under the body and not standing out at the corners. 
The forcam should be comparatively long, broadly and strongly muscled in its upper part, and gradually taper to the knee. A powerful forearm on the draft horse is highly important, and its value is not likely to be overestimated.

The knce must be broad, as viewed from the front, be well carried back, and be amply supported from below by the cannon bone. This part should be neat, hard, and cleanly jointed.

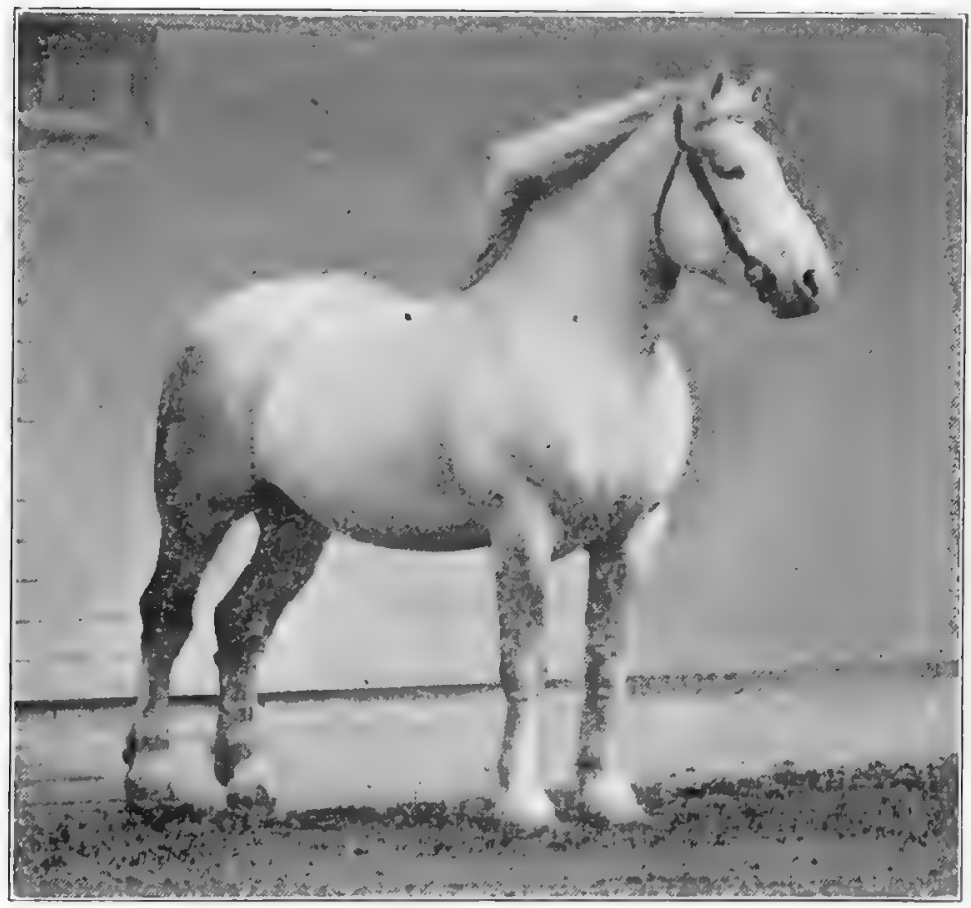

FIG. 30. A fine example of draft type. From photograph by John W. Hills

The camnon bone is round, but has tendons extending down its back edge, more or less separated from the bone. As viewed from one side, the cannon and its attachment should be deep, amply supporting the knee; viewed from rear or front it should be quite flat, thus representing the strongest conformation. Often the cannon is tied in beneath the knee, which indicates weakness. A long or rounded canng shows faulty conformation. Flatness 
and shortness below the knee are always associated with the best development. A fair girth at the smallest point is $9 \frac{3}{4}$ inches. A large girth, however, does not always indicate proper development, as the leg may be coarse and out of proportion.

The fetlock, or, as it is often called, the pastern joint, must be smooth and deep, with no roughness. It is from the tuft of hair which grows at the back of this joint that the name "fetlock" (feetlock) is derived.

The pastern is an important part of the leg. It should be fairly long, be perfectly smooth and free from extra flesh, and stand at an angle of about 45 degrees. At this slope concussion is received in perhaps the least degree and with least injury to the foot and leg. There is some difference of opinion among horsemen on the length of pastern, some preferring one reasonably long and others one of medium length. The slope is more important than the length, but no doubt better feet prevail where the pastern leans toward length rather than shortness. Sidebones, ringbones, and other foot troubles are most prevalent with short, straight-pasterned draft horses. As the horse naturally places the foot in action, the pressure first comes on the frog and is then distributed over the rest of the foot. If the pastern is straight, the toe and front of the foot strike first, and thus the concussion is aggravated.

The foot ought to be large, the hoof dense and preferably dark in color, the sole concave, and the frog large. There is an old saying, "No foot, no horse." Sound feet are absolutely essential to comfort and efficiency of work. The interior of the foot contains very sensitive nerves and membranes. If the foot is too small and contracted, if the frog is too narrow and low, inflammation of the membranes will frequently follow. The ample foot, wide on top and behind, well supported at the heel and carried true in movement, turning neither in nor out at the toe, is least likely to be troubled with disease.

The body should be short on top, long below, broad along the back, with the ribs strongly arched and of great depth. A long back indicates weakness of both constitution and draft power, while a short, deeply muscled back means strength. Ribs well sprung and deep show capacity of the internal organs, indicate a 
good feeder, and materially add to the weight necessary in the drafter. Usually satisfactory rib development provides a proper body conformation. Often immature horses appear to lack depth of body to some degree, but age and feeding establish the proper proportions. The horse that lacks depth of body will also lack such essentials as capacity and the power of endurance.

The loin should be broad and thickly muscled. Narrow, thin loins indicate weakness of a serious character. Often the loin is depressed directly in front of the space between the hips, a distinctly undesirable conformation. Animals with a sway back, as a rule, show this weakness of loin.

The croup should be broad, wide, fairly level, and heavily muscled. A steep croup is very objectionable and affects both the beauty and power of the horse. A short, steep croup is less strongly muscled than one that is long. The Belgian and French draft breeds seem most subject to steepness of croup and low setting of tail.

The thigh should be strongly muscled, and the quarters should be thick and full. A horse split up high behind, with a thin, sharply tapering thigh, lacks good draft form at this place. The gaskin, or lower thigh, when properly made, is deep from front to rear and heavily covered with muscle.

The hock is a part which requires careful study. As viewed from one side, it should show considerable depth, while from the rear it should possess a certain degree of thinness, though broad in front, the entire joint being free from extra flesh. Thick hocks are very common with draft horses, due to various reasons. The joint may be fleshy, puffiness may occur from lack of exercise, or a form of spavin may exist. The hock should be smooth and its various natural curves well defined. As the horse stands in a natural position on his feet, the hocks should be straight and true as viewed from behind, showing no evidence of weakness. Where the hock holds a correct position the hind feet also stand true, neither toeing in nor out. When toeing out the points of the hock come too close together, while if toeing in notably the points may be wide apart and the hocks appear springy and weak when in action. The hock should be supported

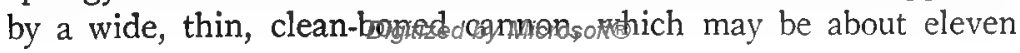


inches in girth at its smallest point. A true position of the hind leg may be ascertained by the use of the plumb line, which, dropped from the point of the buttock or croup, viewed from behind, should pass the center of point of hock, cannon, pastern, and foot. From one side it should pass parallel to the entire edge of the cannon and, when suspended from the point of the hip, should pass the gaskin at the center and drop to the center of the foot.

The action of the draft horse should be true and bold. As the horse comes toward one or goes from him the line of movement of the limbs should be true, the feet being carried straight away, with no so-called paddling or irregularity of gait. The feet should be picked up with snap, whether at walk or trot, and carried clear of the ground, showing the sole of the foot clearly in the movement. High knee action is not essential, but a strong, full, true movement of both knee and hock, without dragging or stiffness, is very important. The draft horse should have an active walk, for the value of a fast walker considerably exceeds that of the sluggish type. In the sale or show ring high-class action with a draft horse adds materially to the selling or show value, no matter what the breed. A free and easy movement of knee and hock is essential to high-class action. In connection with good action the head and neck should be carried high, with style and animation. 


\section{CHAPTER XIII}

\section{THE PERCHERON}

The native home of the Percheron horse is in France, in a region known in that country as the Perche. In northwestern France, bounded on the north and west by the sea, is the province of Normandy. It comprises nearly 7,000,000 acres and is divided into five geographical or civil departments, - La Manche, Calvados, Orne, Eure, and Seine-Inférieure. South and east of Normandy is the old province of Orleans, containing the departments of Loiret, Eure-et-Loir, and Loir-et-Cher. Within this territory, including more or less of Eure, Orne, Eure-et-Loir, Sarthe, and Loir-et-Cher, is the Perche. This locality - for it has no civil organization under this name - embraces an area of about fifty-three by sixty-six miles. The surface of the country is rather broken, having an altitude ranging from about 270 to 750 feet, and is interspersed with numerous pretty valleys and small streams of water. The upper waters of the great river Loire pass through the south edge of the Perche, while the more modest yet beautiful Huisne, with wide-spreading pastures on each side, winds its way through much of this, the home of the Percheron. Small grains and potatoes are the common crops, while here and there on the hillsides apple orchards remind one of some of the apple-growing sections of America. The town of Nogent-le-Rotrou, with a population of about 8500 , has for many years been the recognized headquarters of the horsemen of the Perche, while other towns of importance are Mortagne, Alençon, and Mamers. Seventyfive miles to the northeast from Nogent-le-Rotrou is Paris, and between these two cities is to be found one of the most productive farming sections of France.

The origin of the Percheron breed is most obscure. For centuries horses of a light draft type were bred in the vicinity of the Perche. The claim has been made by French writers that this

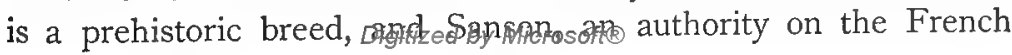


breeds, states ${ }^{1}$ that the nearly perfect skull of a prehistoric horse excavated in the Seine valley, in I 868, very closely resembled a Percheron skull. There has been a variety of opinion in France regarding the origin of the breed, but in no case have we specific and substantial information. All is based on theory. Probably the

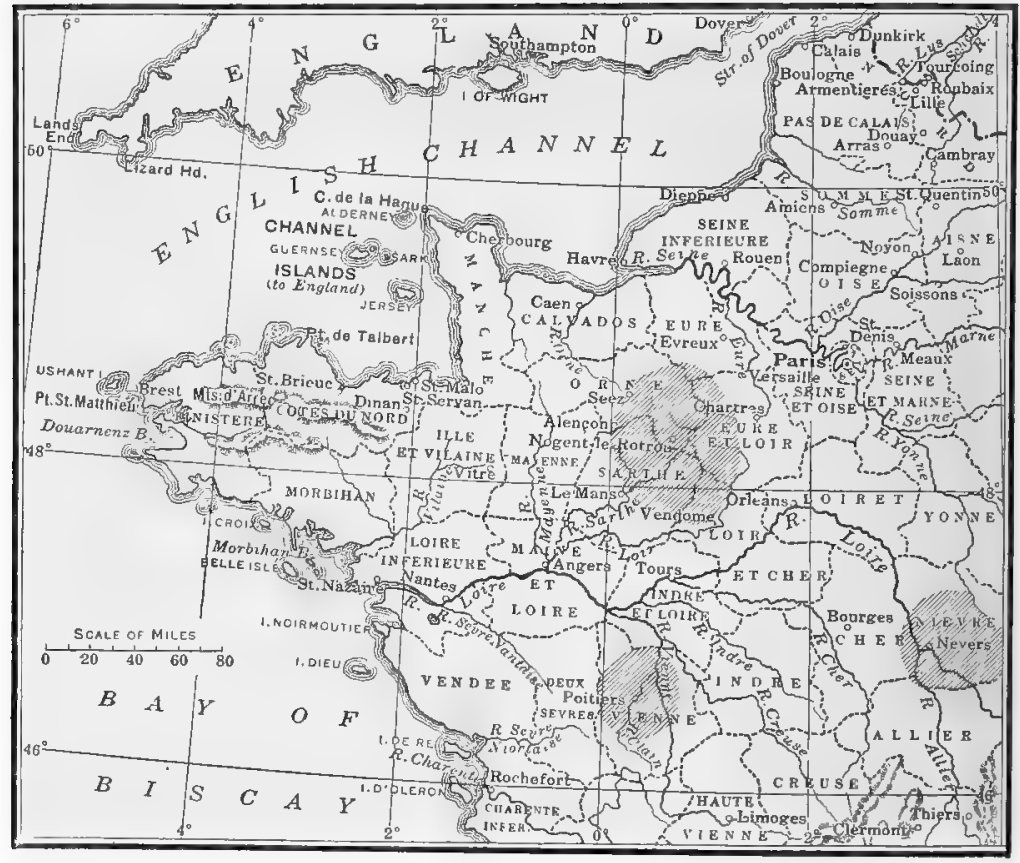

FIG. 3I. A map of northwestern France, the shaded parts indicating the Percheron country, as well as the home of the Nivernais horse and the Poitiers ass

opinion of the veterinarian M. Gautier, as quoted by Sanders and Dinsmore, ${ }^{2}$ is about right. Speaking at a congress of farmers, held in 1843 at Mortagne, this Frenchman is credited with the following:

Every man who has up to this time written on French and foreign breeds says that the Percheron is of Brittany origin. As proof, nothing. Each writer, in consulting his predecessor, has reproduced the same opinion. One writer

1 L'origine des races françaises de chevaux, Vol. III, p. 95.

${ }^{2}$ A. H. Sanders and Wayne Dinsmore, A History of the Percheron Horse. Chicago, I917. 
has said that the Percheron was of English origin. Others say that the Percheron is descended from the Arab. For me, if I may give my opinion, I believe that the Percheron is a primitive breed, singularly altered, improved by crossings at different periods with Arabian and English horses.

In early times the native stock of the Perche was without doubt typical of the draft horse generally existing in northern Europe, and it is assumed that here existed the foundation stock from which the modern Percheron is developed.

The improvement of the early Percheron, as already indicated, is generally credited by French and other writers to the use of

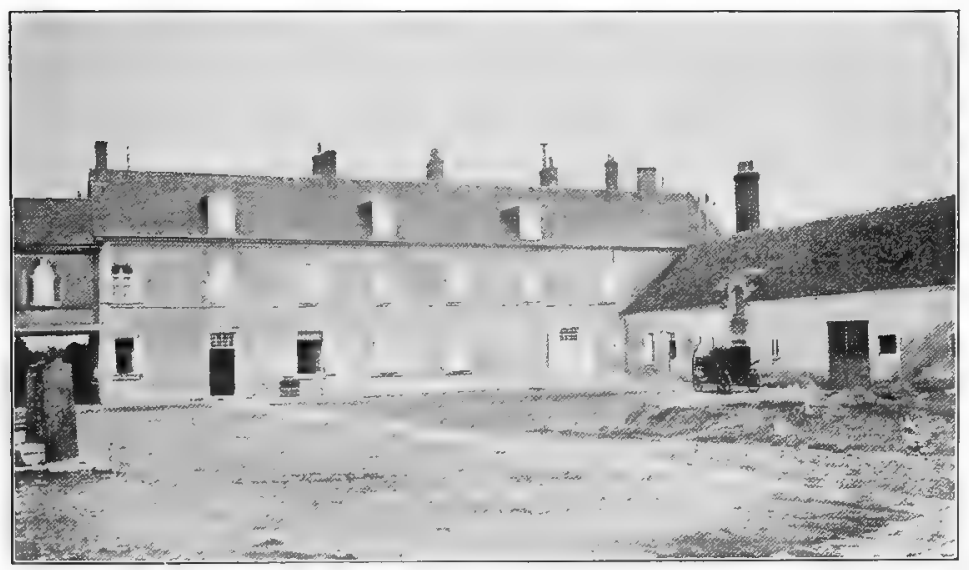

FIG. 32. The residence and stable yard of the home of the late M. Charles Aveline, La Touche, Nogent-le-Rotrou, France. From photograph by the author

oriental horses. This is accounted for by the existence of large numbers of Arab and Barb horses brought to France by the Saracens, especially in the early part of the eighth century. It must be understood, however, that the above opinion does not rest on facts. It is reasonable to assume that oriental horses may have been used to improve the horse stock of the Perche, but to what degree we do not know. Horses were used for pack purposes and as cavalry only until the improved agriculture and commerce of less than two centuries ago demanded a draft horse. There is more or less specific information regarding horse breeding in France dating back early in the eighteenth century. Two government studs were established at this time - one at Le Pin on the 
borders of the Perche, in I7 I4, and the other at Pompadour in southwestern France, in I755. These were destroyed during the Revolution, but were restored by Napoleon in I 806 and have ever since remained important breeding studs. Draft-horse breeding was not attempted in these studs until the nineteenth century, the work starting at Le Pin about I 808. The claim has been made

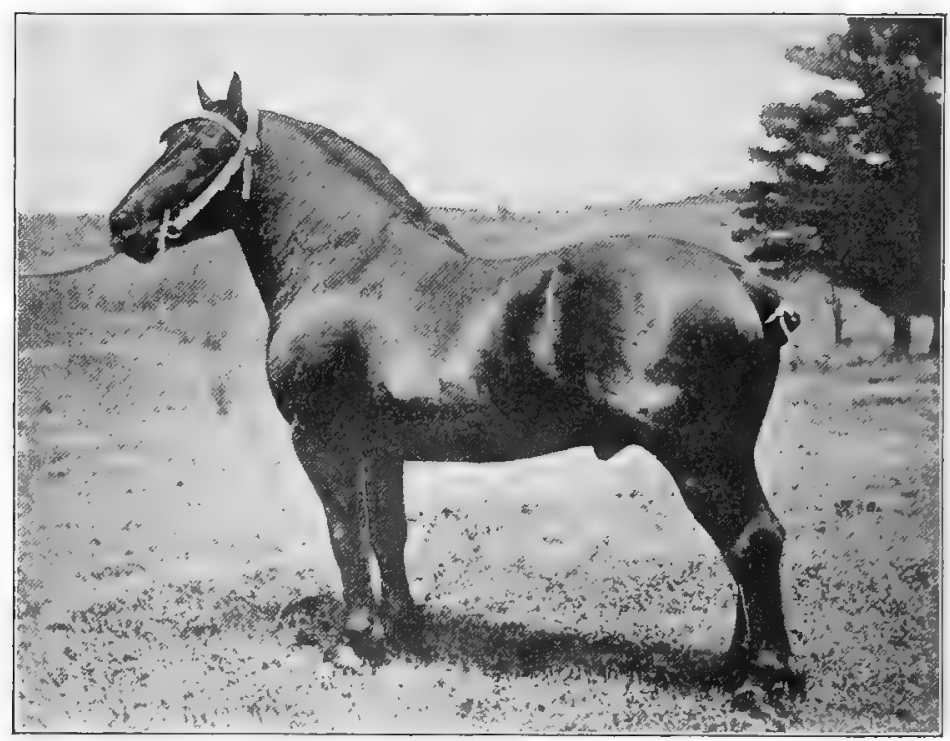

Fig. 33. Dragon 52155 (63516), champion Percheron stallion at the Igo6 and 1907 International Live-Stock Expositions, and a famous sire. Owned by E. B. White, Leesburg, Virginia. From photograph by courtesy of Mr. White

by $M$. Charles Du Hays, in a history of the Percheron, ${ }^{1}$ that two gray Arabian stallions, Godolphin and Gallipoly, were used about I 820 in the stud at Le Pin with a remarkably beneficial result. The general effect of this Arabian blood on the French horse, according to various authors, was to impart quality, as shown in superior bone, style, and finish. The first edition of this work contained this statement. However, recent investigations have given new light on this subject. Mr. John Ashton, just prior to the opening of the World War, carefully examined many official

1 Charles Du Hays, Le Cheval Percheron. 
records of the French studs, or haras, ${ }^{1}$ and ascertained from original Le Pin records that Godolphin was a chestnut English saddle horse and Gallipoly a small Turkish saddle horse. The former horse was not regarded good enough for use in the stud and was disposed of about 1818; while Gallipoly was classed as an excellent stallion, but "too small and unsuitable for Le Pin," and so, after being in the stud from I8I 2 to 1819 , was probably sent to Brittany. Jean Le Blanc (739), foaled in I823 or I824, said to have been a true Percheron and a "descendant of Gallipoly," according to the French ${ }^{2}$ was a remarkable stallion and responsible for great improvement of the breed. Ashton found records of gray draft stallions in government studs, dating back to $I 808$, while specific reference to a Percheron was first made in I822, relative to Désarmé ( 538 ), foaled in 18 I 5 , a bay of unknown Percheron ancestry. In 1826 this horse covered twenty-six mares. Besides Désarmé, along at this period there were several Percheron horses in service, including Jocko, Herbager, Remorqueur, Joly, and Superior. These horses were placed more or less in service in the Perche, under government supervision.

The early type of Percheron resulting from this amalgamation of races was not so large as the present-day type. The farmer of the Perche required a horse suited to general purposes, so the early type was smaller and more active of foot than the presentday Percheron. Either under saddle or before gig, Percherons trotted with considerable speed. Records of Percherons show that not infrequently they have trotted at a rate of about a mile in four minutes. Richardson, an English writer familiar with conditions in France, gives interesting illustrations of the ability of this horse to travel long distances with considerable speed. ${ }^{3}$

A gray mare six years old which took a heavy gig $5^{6}$ miles over a heavy road in 4 hours and 24 minutes; and another, seven years old, drew an ordinary country gig 55 miles in 4 hours I minute 35 seconds, returning the next day over the same ground in 4 hours I minute 30 seconds, the last 14 miles being covered in I hour, and neither in going or returning was she touched with the whip.

1 A History of the Percheron Horse, 1917.

2 Studbook Percheron, tome premier, p. I 4. Nogent-le-Rotrou, I883.

${ }^{3}$ G. G. Richardson, The Corn and Cattle Producing Districts of France, p. 188 . London, 1877 .

Digitized by Microsofte 
The characteristics of this early type showed less scale, a lighter weight, with a height ranging from 15 to 16 hands. It was a superior general-purpose horse of draft conformation, yet lacking large size and heavy weight. This type met with such great favor that buyers from various parts of France, Germany, and elsewhere began to draw upon the Perche for their horse stock.

Percheron deterioration came in with the improvement of the breed. Toward the close of the first third of the nineteenth century the demand for these horses in the Perche became so great

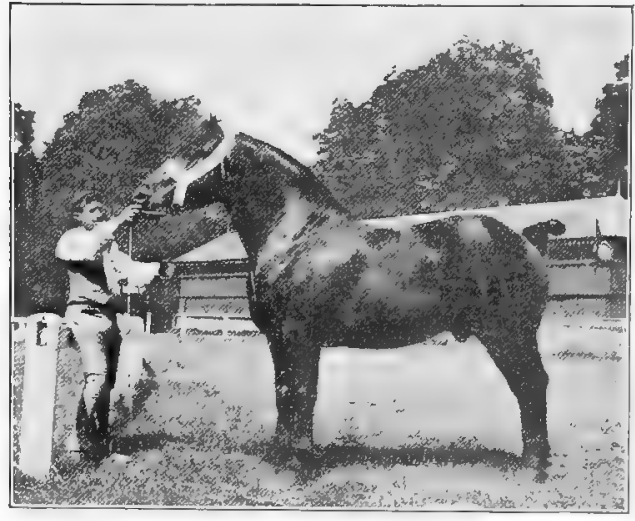

Frg. 34. Etudiant 70802 (59291), champion Percheron stallion in France, I908. Imported to America in 1909 by $\mathrm{E}$. B. White of Virginia. In stud in Ohio for some years and a successful sire. From photograph taken in France by the author that the farmers sold their best brood mares and stallions to such an extent that they had to be replaced. Not enough good Percherons were available, so that other French races were introduced. Large numbers of mares similar to Percherons in size and style were introduced from Brittany, Picardy, Boulogne, Caux, and elsewhere. A great many of these lacked bone, substance, and quality. With the improvement of highways came a demand for heavier horses, and then buyers purchased large ones to meet the increased demand. For a time quality was sacrificed for quantity, the heaviest stallion being most in demand. Many of the best brood mares of lighter type were sacrificed, thus causing serious deterioration. This condition of affairs continued for some years, until breeders recognized the absolute necessity of improving the breed so as to secure superior type and quality along with increased size.

The type of Percheron about $\mathrm{I} 877$ is described by Richardson in the following rather comprehensive manner: 
The characteristics of the best horses are that they run from $\mathrm{s}$ to 16 hands in height; the head is handsome, though perhaps sometimes heavy, but more frequently as fine as an Arab's; the nostrils wide; the eye large and expressive; the forehead broad; ears silky; neck rather short, but with a good crest; withers high; shoulders long and sloping; chest rather flat, but broad and

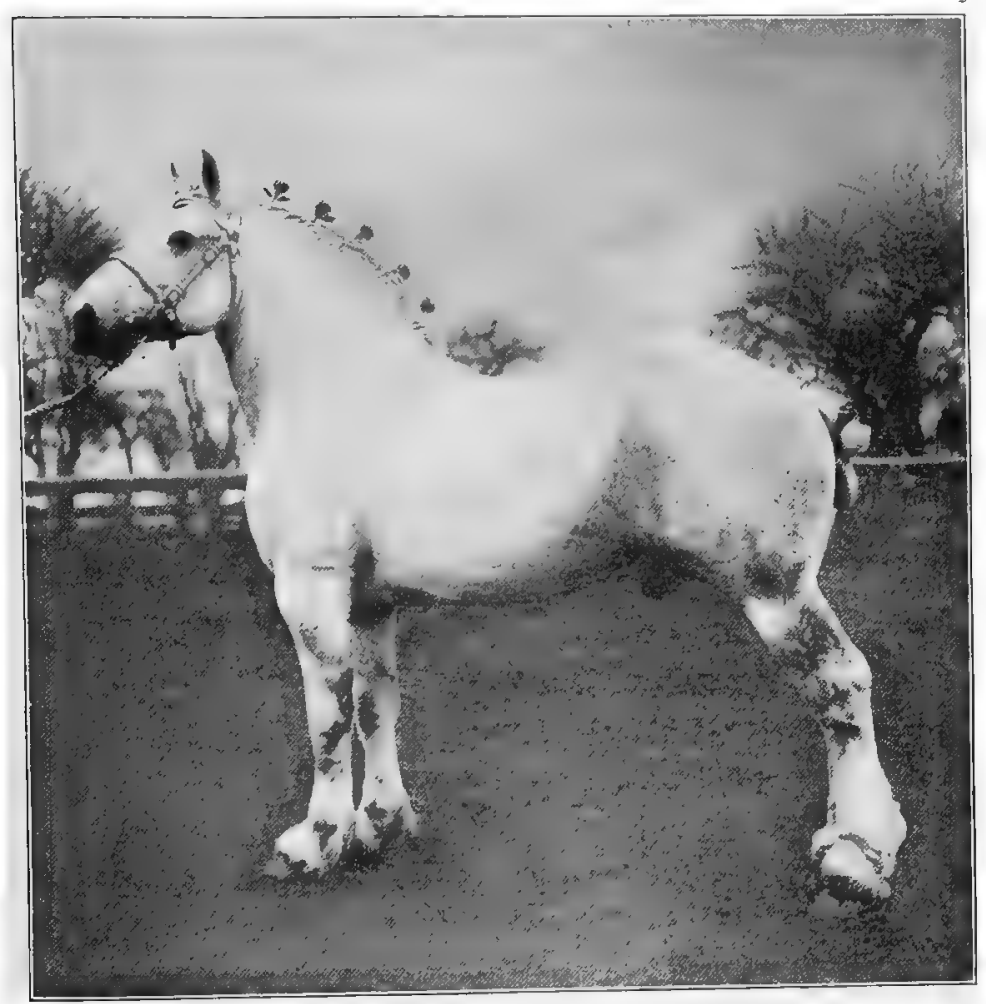

Frg. 35. Giroust 78504 (69869), a Percheron stallion owned by W. H. Butler, Sandusky, Ohio. A prominent sire of Ohio futurity winners, as well as a highclass show horse. From photograph by E. K. Emslie

deep; body well ribbed; loins rather long; crupper level and muscular; the buttocks often high, leaving a depression above the junction of the tail, which is set on high; joints short and strong; the tendons often weak; legs clean and free from coarse hair; feet always good, though rather flat when reared upon moist pastures; the skin fine, and mane silky and abundant; the color is generally gray, but there are some grand black Percherons.... Docile, patient, honest workers, vesyghardy the Percherons are unexcitable, but active 
and cheerful, rarely showing bad temper, and very free from natural blemish, trotting away cheerfully with heavy loads. The French call them the best draft horses in the world.

Yet even when Richardson penned this (1877) he stated that these qualities were rarely found combined in any of the Percheron horses on account of the deteriorating influences to which reference has already been made.

The improvement of the Percheron in France is due to both public and private methods. The best horses in France have been in the past and are at present reserved by the government for home improvement. In addition to this, subsidies are paid private individuals to keep horses of merit in the stud. Animals are critically inspected by government veterinarians, and if up to a certain standard they are designated as subsidized and a cash bonus is paid for keeping them in the country on the farm of the owner, available to the owners of mares. This bonus ranges from 300 to 500 francs ( $\$ 60$ to $\$ 100$ ) per year, according to the breeding and excellence of the stallion. Horses of not quite so good a grade are authorized after passing inspection, and the owners are given a card which is a government recommendation of the sires to farmers. A third class, known as approved, of which there are but few, are permitted to be in service, but neither bonus nor special certificate is given for them. Since I 885 a government decree has excluded from public service all stallions not coming within these classes.

The introduction of the Percheron to the United States dates back many years. French horses were brought to America as long ago as I8I6, when a stallion was taken to Quebec and later sold to go to Washington County, New York. It has been assumed that this was a Norman horse. In I 839 the first "genuine" Percheron importation to America was brought over by Edward Harris to Moorestown, New Jersey. This importation consisted of one stallion and two mares. The stallion died at sea, and the mares were unfortunate, one landing in poor health, while the other injured herself in car shipment, necessitating killing. Mr. Harris at once returned to France and imported the stallions Diligence and Bonaparte, with several mares. These were the smaller type of Percheron, standing about I 5 hands 
high and weighing I 200 to 1500 pounds. Diligence, which died in 1860 , was regarded as a fine specimen of the breed.

In I85I an important half century of Percheron history began in the United States. At this time Fullington and Martin brought to Milford Center, Ohio, the gray colt Louis Napoleon, the first importation to the West. He was I 5.1 hands high and weighed I6oo pounds. In I $856 \mathrm{~A}$. P. Cushman of Illinois purchased him. Louis Napoleon proved to be a great sire and was no doubt one of the very best draft horses ever brought to America. It has been estimated that over 400 of his sons were successful stallions. In I85 I Dr. Marcus Brown of Circleville, Ohio, commissioned Samuel Holman of Chester Springs, Pennsylvania, to purchase a stallion for him in France. Holman bought two, - one for himself and one for Brown, - both grays, and they landed at

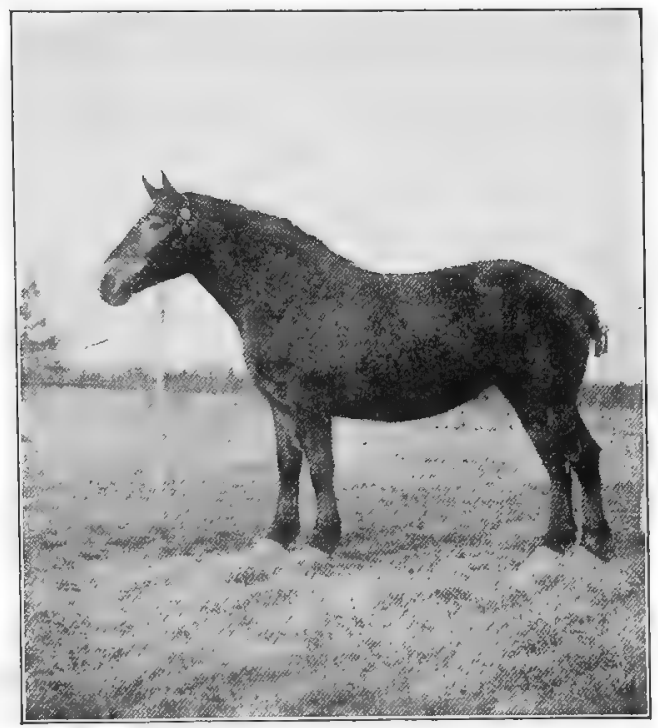

Fig. 36. Jocasse (89131), a two-year-old imported Percheron mare, the property of Illinois University. From photograph by courtesy of Professor J. L. Edmonds New York on August I 2, I 85 I. . The one for Dr. Brown was named Normandy $35 \mathrm{I}$ and is often referred to as "Pleasant Valley Bill," "Old Bill," or the "Valley Horse." He stood I $5 \frac{1}{2}$ hands high and weighed about 1400 pounds, and it is said that for eighteen years he averaged about 60 colts a year. Charles Carroll of Baltimore, Maryland, is credited in Volume I of the "Percheron Studbook of America" with importing in 1853 the stallion Chartres 88, and J. H. McHenry of the same state with importing the 1 A History of the Percheron Horse (I9I7), p. II4. 
two mares Lily 572 and Snowdrop 607 in the same year. In I 856 Jordan and Martin of Woodstock, Ohio, imported the stallion Rollin 4I8, that proved a good sire. Like Louis Napoleon, Rollin was sold into Illinois, where he was in service six years. Numerous importations followed. In I $868 \mathrm{~W}$. T. Walters of Baltimore, Maryland, brought over 7 mares and 4 stallions, he being the first person to establish an important breeding stud in America. Mr. Walters had lived in France and had studied the breed there, and so was able to buy to advantage. In 1870 M. W. Dunham of Wayne, Illinois, and in I874 William Singmaster of Keota, Iowa, began breeding and importing. They both became famous Percheron authorities, and the studs founded by them are still in existence. Besides these the Stubblefields of Bloomington, Ellis Dillon of Normal, Ezra Stetson of Neponset, Illinois, and the Fullingtons of Ohio were early breeders and importers. According to Sanders and Dinsmore 90 stallions were imported to America between I 839 and I 870 , of which 42 went to Ohio, 24 to Illinois, Io to Pennsylvania, and 5 to Maryland, with 2 each going to Massachusetts, Virginia, Missouri, and New Jersey, and I to Kansas.

The characteristics of the Percheron horse are such as are sought in a model draft horse. The head is distinguished for its bold, prominent eye, wide, full forehead, straight face, and strong jaws. The ears are usually of medium size, refined, and attractively set and carried. The neck as a rule has a slight arch and is smoothly blended at the body and neatly attached to the head. The body of the Percheron is characteristically compact and blocky of form, full in the chest, and broad of back. Horses of the breed, however, often have steep, rather short croups, with the tail set too low. In recent years, however, much attention has been given to remedying this defect, with the result that present-day exhibitions show many Percherons with excellent croups. In depth and fullness of body there is also a lack. The legs of the Percheron incline to be short, and the bone is usually superior, but the cannons not infrequently lack in depth and flatness, while a full, or puffed, hock is more common than it should be. This breed has legs free of long hair, such as is strikingly seen in Shire and Clydesdale. The feet are generally of good 
size and shapely, and the dark hoofs of excellent texture. Percheron action at a walk is reasonably true and snappy, while the trot with good representatives of the breed is free and easy. In its strong, free action this may be regarded as one of the best breeds, although not the equal of the Clydesdale in that respect. The fact that in France, even to-day, races are held between the

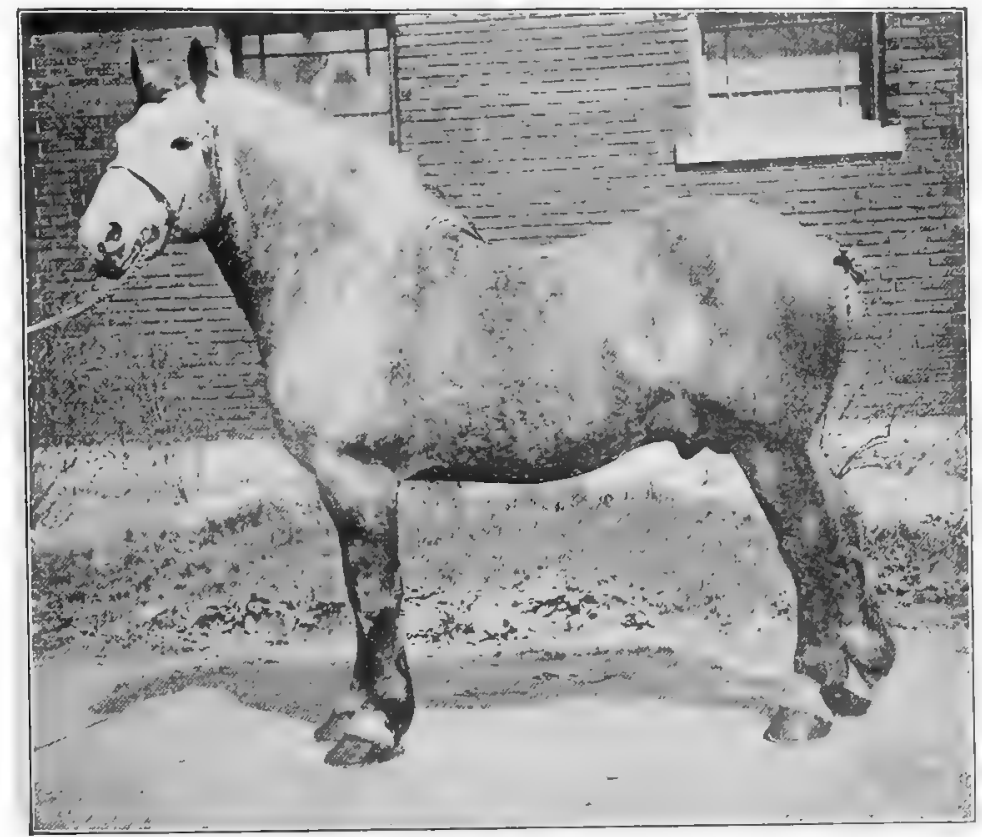

FiG. 37. Libretto 121447 (97907), aged Percheron stallion owned by the Ohio State University, Columbus. Second-prize winner at the 19 rg Ohio State Fair and an excellent sire. From photograph by E. K. Emslie

lighter type of Percherons is an evidence of their natural activity of foot. The things which especially distinguish the Percheron breed are the head and neck, suggesting the Arabian, the blocky body and steep tendency of croup, the short, smooth legs, the characteristic color, and superior action. As a draft beast the pure-bred or high-grade Percheron ranks in France and America in the very first class, as is evident from his preponderance in numbers over all othembre 
The color of the Percheron is usually a gray or black. Bays and browns occur, but are not common. Gray from the beginning has been the most popular color in the Perche, and in the days of the stagecoach the gray color, being more easily seen at night than black, contributed to its popularity. Many of the greatest stallions in the history of the breed have been grays. Fashion has had a part in influencing the color of the Percheron, and for years American importers have been seeking blacks to meet the demands of customers. It is said that at the fair at Chartres, France, in February, I877, one dealer had eighteen blacks, for which he asked about the equivalent of $\$ 10,000$ for the lot, " and they were well worth it." In recent years, however, gray has grown in popularity, ranging from a dark iron gray with light mane and tail to a pure white. A colt apparently black, but having scarcely noticeable white hairs on the body among the black, will gradually become gray with age if both mane and tail are light in color. The bay or brown is a distinctly unpopular color and is not representative of the breed. In I9I7 Secretary Wayne Dinsmore of the Percheron Society of America sent out a circular letter to Percheron breeders, in which he showed the proportions of colors with two thousand horses of the breed registered in Volume XVIII of the studbook. Commenting on the facts brought out, Mr. Dinsmore says:

The outstanding feature is the fact that 90.85 per cent are blacks and grays, either whole or colored, or with some white marks, such as star, strip, snip, white pasterns, or other distinguishing marks. Solid colored horses, even in blacks and grays, constitute but a small proportion of the total. . . . Bays or brown bays, with or without markings, make up but 3.45 per cent of the total. Browns without the bay tinge aggregate 3.25 per cent, and some of these latter prove to be blacks. Chestnut and sorrel mean the same thing in the minds of many horsemen, and all reported have some white markings, yet total only I.5 per cent. Several kinds of roans are listed, but all told they amount to only 0.95 per cent of the total, or less than one per cent.

The weight and height of the Percheron place him in the medium class of draft horses, although very large specimens of the breed are recorded. The average weight of the mature stallion is from I 700 to 2000 pounds, while the mares range from I600 to $\mathrm{I} 800$ pounds. The heavier weights are rarely reached, excepting 
with horses in high condition. The height of stallions ranges ordinarily from 16 to $I 7$ hands and mares from $I 52$ to $I 6 \frac{1}{2}$ hands. A lower-set type is desired, but where heavier weight is emphasized I7 hands is necessary to show plenty of scale and substance. The following figures of heights and weights of stallions of distinction are of interest: Brilliant $127 \mathrm{I}$ stood I6 hands and weighed 1850 pounds; Seducteur (8850), Pink 24765 (475 I3), Olbert 428 I 5 (53I09), and Villers I 3169 (I 808 ) are each said to have stood about 17 hands and weighed 2100 pounds; Calypso 25017 (44577) stood 16 $\frac{3}{4}$ hands and weighed 1900 pounds; Etudiant 70802 (5929I) stood $17 \frac{1}{4}$ hands and weighed 2100 pounds; and Introuvable I6875 (24I46), regarded as a very large Percheron, stood I $7 \frac{1}{2}$ hands and weighed 2300 pounds. Referring to weight, W. S. Corsa of Illinois, long a prominent breeder, makes the following comment: ${ }^{1}$

A mare weighing from I 700 to 1800 pounds in ordinarily good condition, is the draft mare that may be expected to give a good account of herself both at work and in the stud. Get size in the offspring through the selection of the sire and through the kind, quality and quantity of feed given the colts. Fortunately, it is among these under excessive weights that we find the greatest number of mares of acceptable breed type - sweetly feminine sorts which usually have necks long enough so that one may put his arm around and love them.

Quoting from the same source, E. B. White, a noted breeder of Virginia, states that the stallion should be of medium size and suggests that he "weigh not more than 2100 pounds in show condition."

The temperament of the Percheron is of the quiet, phlegmatic sort, such as prevails with the horse of heavy weight, although somewhat more nervous and active than the Shire or Belgian. The disposition of horses of this breed is of the best, and as one sees them at work in their native country, where many stallions of the breed are found in harness, they are all the most exacting could desire in this regard.

The maturing quality of the Percheron is of the first class, and the colts when properly nourished attain large size in a relatively short time. Many weanling colts at the fall shows weigh about 800 pounds and at twelve months of age should pass the

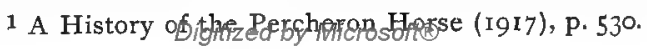


Iooo-pound mark. At twenty-four months a stallion should weigh around I 500, and a mare slightly less. In feeding experiments conducted by Professor J. L. Edmonds on ten pure-bred Percheron fillies at the Illinois Station, foaled in 19r 4 and fed two winters and one summer, the average weight at twelve months of age was I I I 2 pounds, and at twenty-four months I 548 pounds. The "growthiest" filly of the lot weighed I 260 pounds at twelve months and I775

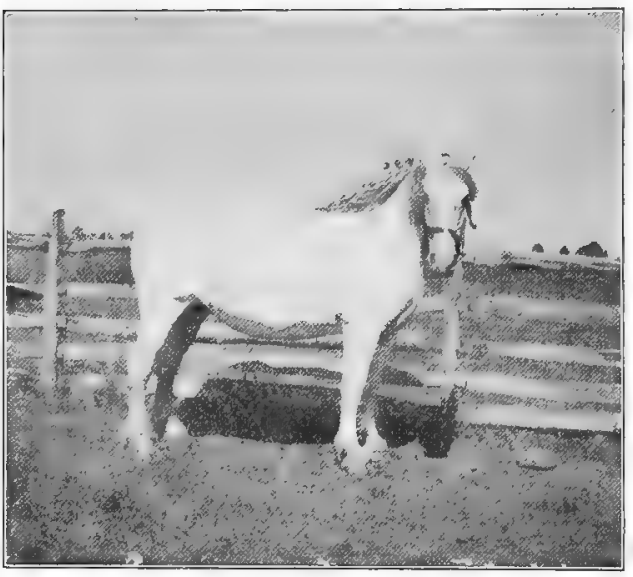

FIG. 38. La Belle 34982, an aged Percheron mare, champion American-bred mare in IgI I at the International Live-Stock Exposition. A famous dam. Owner, E. B. White, Leesburg, Virginia. From photograph by the author pounds at twenty-four months.

Crossbred or grade Percherons are very common in America. The pure-bred stallions mated to the larger type of grade mares, of drafty conformation, furnish a large per cent of our best draft teams. On the Western range, notably in Wyoming, Montana, Utah, Colorado, and the Dakotas, by the use of Percheron stallions for two or three generations the horse stock has been greatly increased in size and usefulness, many of the grades weighing from 1400 to I 5 oo pounds at maturity. Through the Middle Western states are to be seen many high-grade mares which in breed character and conformation are apparently pure-breds.

Prepotent Percheron stallions mated to mares of other draft breeds also usually give satisfactory results, and this is a favorite combination in some localities where legs with feather hairs are found on mares of Clyde or Shire ancestry. The resulting offspring are usually smooth-legged and more easily satisfy the common market demands. The most prominent buyers in the Chicago horse market have testified in the highest terms to the demand 
for Percheron grades and crosses, and grade geldings of show-ring form have repeatedly sold for $\$ 500$ per head and over.

The prolificacy of the Percheron as a breed may be regarded as about average. Under good conditions of care and keep Percheron mares should prove as fecund and give as good results in production as with other heavy breeds. There are, however, many cases on record of mares that have proved unusually prolific and profitable. The following mares are worthy of note, as

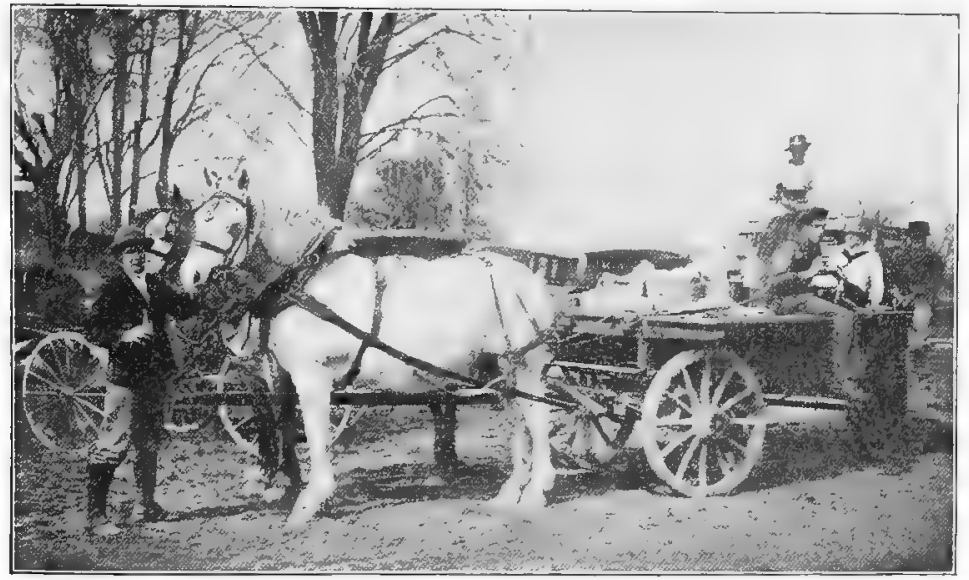

FIG. 39. Delia 65193, an uncommonly fine Percheron brood mare at nineteen years of age. Fourth-prize mare ten years old or over in large-class Eastern Percheron Breeders' Show, 1918. Owned by M. E. Lyons, Delaware, Ohio. From photograph by the author

having played important parts in building up some of the best American studs. Fany 20458, owned by L. W. Orr of Minnesota, proved in foal every year between I90I and I9I6 inclusive and raised I 2 colts, 7 of which sold for $\$ 5000$. Among the noted brood mares of Mark W. Dunham were Constance 1478 (1425), having 9 colts in twelve years; Linda 2571 (1521), producing IO colts in fourteen years; and Janecia 2768 (I 368), dropping 7 foals in ten years. Most of these foals were very superior and brought high prices. In the ownership of the Stetsons of Illinois, Flora I I 9 raised 15 colts in eighteen years, and Zoe I 42 in about the same time dropped 10 colts. The mare Delia 65193, bred by 
John Lyons in Delaware County, Ohio, has produced 9 living foals that have sold for $\$ 5220$. The De Lanceys of Minnesota owned 2 great brood mares - Mollie 19915, having Io foals in twelve years, and Charmante I093 I (2045I), having 9 in eleven years. The mare Aimie 520 is credited with I4 foals in seventeen years, and of these, 2 daughters, Olga 2185I and Prudance 21853 , dropped within nine years 7 and 8 foals respectively.

Famous Percheron sires. Naturally during the history of the breed there have been many sires of excellence in America. Among these the following stallions in service prior to 1900 may be regarded as of special importance, mainly on account of their influence as breeders, although some of them were famous show horses. Louis Napoleon 281 : foaled, 1848 ; imported, 185 I. Normandy $35 I$ (also known as Pleasant Valley Bill): foaled, I849; imported, I85I. Success 452 : foaled, I864; imported, I868. Vidocq 483 (732): foaled, I869; imported, I874; sire, Coco II (7I4); dam, by Cheri. Brilliant I27I (755): foaled, I 876 ; imported, I 881 ; sire, Brilliant I 899 (756) ; dam, Ragout, by Favori I (7II). Fenelon 2682 (38): foaled, I 880; imported, I 883 ; sire, Brilliant I 27 I ; dam, Ernestine, by Duke of Perche I $73(740)$. Gilbert $5154(461)$ : foaled, I882; imported, 1886; sire, Brilliant I27 I (755); dam, Sophie (7694). Seduicteur 8850 (7057) : foaled, I884; imported, I888; sire, Fenelon 2682 (38); dam, Rosalie (5688), by Brilliant I899 (756). Brilliant 3d IIII6 (2919) : foaled, I884; imported, I889; sire, Fenelon 2682 (38). Of the above horses Louis Napoleon and Brilliant were probably the most famous, each proving remarkable breeders, although all of the horses in question stand out as noted sires.

In a study of the show records of recent years in both France and America, as reported by Sanders and Dinsmore, ${ }^{1}$ the following interesting facts are brought out. Between I9OI and I9IO at the shows of the Percheron Society of France, Brilliant 3d (2919) appeared as grandsire of I2 3 prize winners; Besigue (I9602) of 92; Villers (8081) of 87; Fenelon (38) of 71 ; Voltaire (443) of $6 \mathrm{I}$; Jules (37987) of 50 ; Marathon (I0386) of 38 ; Briard (1630) of 30 ; Jupiter 4 th (I300I) of 19 ; and Lavater (I4574)

${ }^{1}$ A History of the Percheron Horse, I9I7. 
of $\mathrm{I} 8$, these being the ten leading grandsires among ninety, in the order given. In a study of the records of winners at the International Live-Stock Exposition between I900 and I9IO, the following stallions were shown to be of premier importance as sires or grandsires or great-grandsires: As sires of Americanbred prize winners, Calypso 25017 (44577) is credited with 38 International winners; Superior 40605 with I 5 ; Salvanos 10827 (20922) with I 2 ; Rhum Jr. 2 I627 with 9; Cadmus 2162 (929) with 8 ; Boer 24267 (446I I) with 7 ; Aride 25056 (45424) with 7 , and Villers I 3169 (808I) with 6 . As grandsires of International winners, Theudis $250 \mathrm{I} 5$ (4087I) is credited with 40 ;

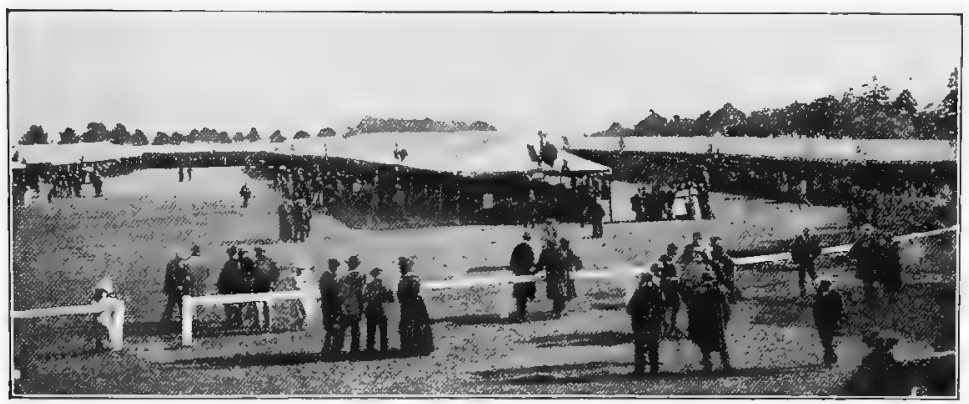

FIG. 40. A view of La Société Hippique Percheronne's 1908 show grounds at Mortagne. From photograph by the author

Highland Chief 23744 with I5; Fernando (34038) with I4; Grevin 6846 (6892) with I2; Rhum I I288 (I 3 I73) with 9; Victoria 24449 (42905) with 9; Brilliant I27 I (755) with 9, and Besigue (19602) with 8 . In rank as great-grandsires, Besigue is first with 52 winners; Marathon (10386) with I6; Sensation 22544 with I5; Brilliant 3 d (29I9) with I3; Brilliant I27 I (755) with I3; La Grange 3065 (I 334) with I 2 ; Chicago 6947 (7485) with 9; and Bienfaisant (I397) with 6. The following stallions, former International champions, have been regarded as leading sires in recent years: Pink 24765 (475 I 3), Carnot 66666 (66666), Dragon 52 I 55 (635I6), and Lagos 99093 (102389).

The leading Percheron shows are held under different conditions. Each year in France a great central show is held at Paris. For years the annual Percheron show of France has been 
held in a migratory way, coming back to the same locality every twelve years. The Percheron Society show is held in rotation once each year in the Perche district, at La Ferte, Mortagne, or Nogent-le-Rotrou. The American Percheron shows of most importance are held at the International Live-Stock Exposition, Chicago, the Kansas City Horse Show, and the state fairs of Ohio, Illinois, Iowa, Missouri, Indiana, Minnesota, and Wisconsin.

Percheron futurity shows have attracted considerable attention in recent years, especially in Ohio and Iowa. The first show of the kind in Ohio was held in I9I2, and the competition has grown steadily in numbers and merit. The following are the important rules in the Ohio show, which is under the supervision of the Ohio Percheron Breeders' Association. Eligibility: All colts recorded in the Percheron Society of America are eligible to the futurity classes in I9I9, provided the dams of said colts have been nominated in accordance with the conditions outlined below. Conditions: (I) Mare nominations must be made by April I, I9I8, if the colts from these mares are to be eligible to the futurity classes in I9I9. When the mares are nominated, the name and registry number of each mare must be given, also the name and registry number of the sire to which she is in foal. (2) A fee of one dollar (SI) must accompany the nomination of each mare. (3) In addition to the nominating fee on mares, there will be an entry fee on all colts foaled from these mares if said colts are to be kept eligible to the futurity classes. This entry fee will be seven dollars $(\$ 7)$ per colt, payable in two payments. The first payment, of two dollars, must be made by November I, I9I8. At this time the color and sex of colt must be given. The second payment, of five dollars, must be made by July I 5, I9 I9, just prior to the Ohio State Fair. At this time the name and registry number of the colt must be given.

The prices paid for Percherons from the point of view of average values are higher than for any other draft breed. High prices have also been paid for animals of merit. Mr. Dillon of Illinois was the first importer to pay as much as $\$ I 600$ for a stallion in France, paying this price in 1882 . The late M. W. Dunham, years ago, made one sale of three mares and a stallion for $\$ I 0,000$. In 1903 McLaughlin Brothers of Ohio sold the 
stallion Orangiste 29606 for $\$ 5500$, and a month later sold PourQuoi-Pas 27248 for $\$ 7000$. In December, I905, this same firm sold the stallion Rosenberg, grand-champion Percheron at the International Live-Stock Exposition, for $\$ 8000$, the highest price up to that time paid for a draft stallion in America. At the 1909 International, W. S. Corsa of Illinois purchased the champion Percheron stallion of the show, Carnot 66666, from Crouch and Son of Indiana for \$10,000, and in $1916 \mathrm{Mr}$. Corsa sold a half interest in this horse, at ten years of age, to R. G. Leeds of Indiana for

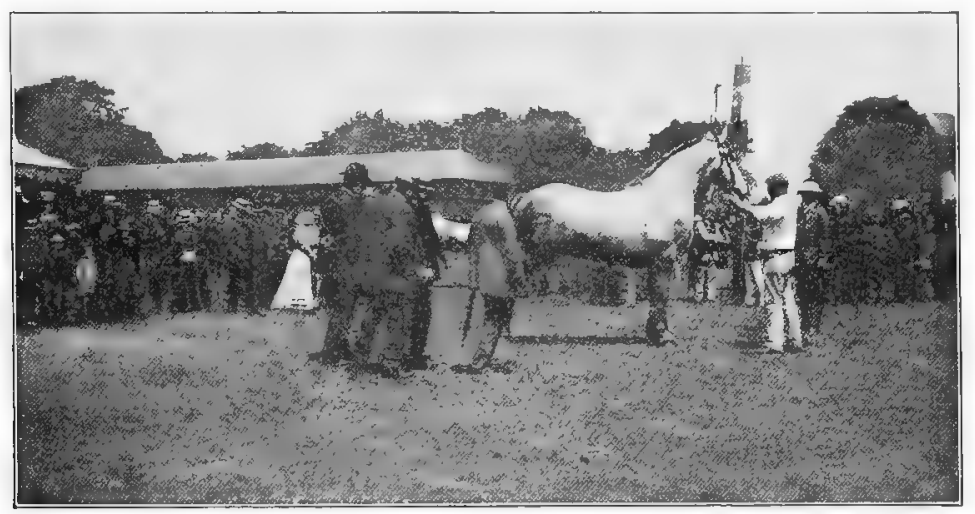

FIG. 4I. Judging the horses at the igoS show of La Société Hippique Percheronne. From photograph by the author

$\$ 20,000$. Helix 70340 (75752), champion stallion in I9I I at the International, shown by Taylor and Jones, was sold to W. C. Brown of New York for $\$ 10,000$. In I9I 2 Crouch and Son exhibited at the International the stallion Imprecation 79304 (79214), champion that year as well as in I9II, which they sold for $\$$ IO, 500 during the show.

Percheron geldings are great favorites in the horse market, and many very high-class ones are sold. At the I905 International Exposition the six-horse teams of geldings exhibited by Armour and Company and the Pabst Brewing Company caused universal admiration. George, owned by Pabst, the first-prize gelding of the I9O4 exposition, weighed when shown 2 I 40 pounds. In I9O5 the Pabst Brewing Company purchased a pair of geldings on the 
Chicago horse market, paying \$ I 300 for them, the highest price paid for such a team up to that time. In the spring of I9Io Crouch and Son of Indiana bought a pair of Percheron geldings at auction in Missouri for $\$ 2025$, the record price up to the present time for a team of the kind.

The distribution of the Percheron horse is very widespread. Large numbers have been exported from the Perche to the United States, and in recent years, prior to I9I4, a limited number of these horses were being shipped into Germany, Austria-Hungary, Russia, and Argentina. Since I9I4 quite a number of Percherons have been shipped to England, where they have stirred up warm controversy, but seem destined to grow in favor. In Canada, especially in the Northwest, this breed is getting a strong foothold; in fact, George Lane's stud on the Bar U Ranch in Alberta is said to be the largest group of Percherons in the world, numbering over four hundred head. During nineteen months, ending October 3I, I9I8, more than one thousand Percherons were exported from the United States to Canada.

The distribution of Percherons in the United States is of a national character. Weld estimated that in I 866 there were fully 5000 Percherons in this country, but no doubt many of these were French drafts of other breeds. Between I85I and I883 nearly 4000 Percherons of which a more or less correct record is kept were imported or bred in the United States. These were widely distributed, Illinois having 1834; Ohio, Indiana, and Michigan, 577 ; Wisconsin, Iowa, and Minnesota, 424 ; New York, Pennsylvania, and New Jersey, 280; and Missouri, Kansas, and Nebraska, I 86. In the early eighties many were brought over, 2600 being reported as imported or homebred in I88 I, I882, and I883. In I 884 more than 2000 of all ages were brought to America from France. In I 890 it is said that there were 593 breeders in this country, and in I900 this number had increased to 1634 , while figures in 1910 are placed at 5338. Between I9OI and I9IO some 3I,900 American-bred and 10,048 imported Percherons were registered. During the fiscal year ending October 3I, I9I7, the Percheron Society of America registered I0,508 horses and transferred 9634 during the next fiscal year. Illinois, which has occupied front rank in Percheron 
breeding since the beginning, stood first in registrations, with 2386 head, or 22.7 per cent of the total. Iowa, which from the earliest days has followed closely after Illinois, ranked second with 2 I IO registrations, or 20.07 per cent of the total. Ohio, the state to which Percherons were early imported, was third with 864 registrations, or 8.22 per cent of the total. Kansas, the leading Percheron breeding center west of the Missouri River, stood fourth, with 759 head recorded during the year, 7.22 per

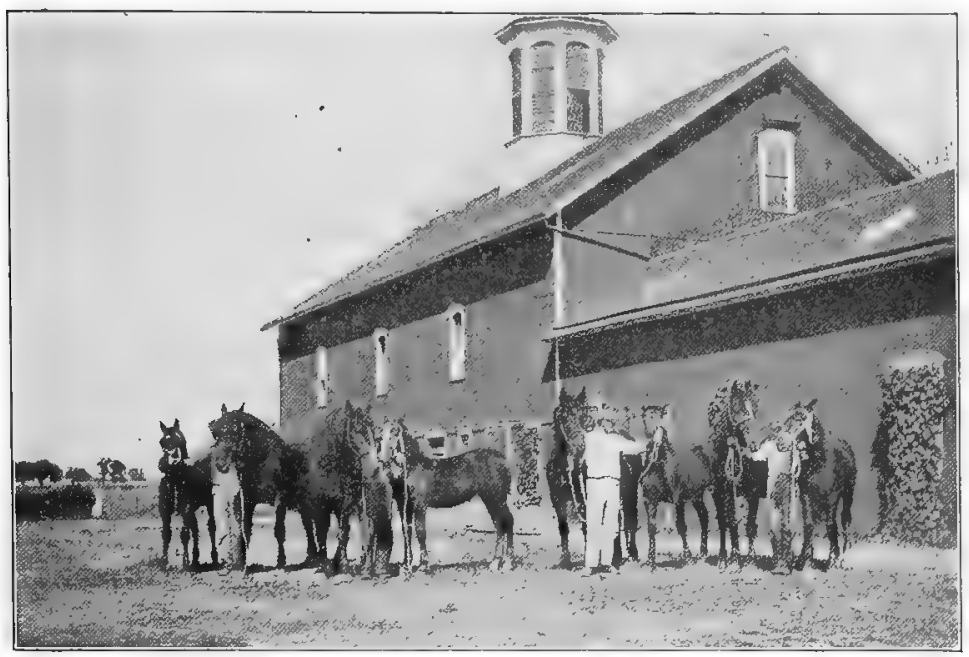

FIG. 42. Percheron mares and foals in stud of the late M. W. Dunham, Oaklawn, Wayne, Illinois. From photograph taken in $\mathrm{i} 893$ by the author

cent of the total. Nebraska came fifth, with 523 head, or 4.97 per cent; Minnesota sixth, with 447 , or 4.25 per cent; Indiana seventh, with 440 , or 4.18 per cent; and South Dakota eighth, with 392 , or 3.73 per cent. These eight states represented about 75 per cent of all the horses registered in thirty-six states. The two leading state centers in America are Tazewell County, Illinois, and Delaware County, Ohio.

Organizations for promoting Percheron horses exist in France and the United States. The French Percheron Society, known as La Société Hippique Percheronne, was organized in I883 and has always had its headquarters at Nogent-le-Rotrou. It was 
organized to promote the purity of the breed, to register horses within the Perche only, and to publish a studbook from time to time. In I 890 the society passed a rule that all colts must be entered for registry between the ages of three and six months. At the time of registration a veterinarian appointed by the society is required to brand its official mark on the colt's neck, and this should always be found on imported Percheron horses registered by the French society. Volume I of the French studbook first appeared in I883, and at intervals since that time volumes have been published in two parts, one each for stallions and mares.

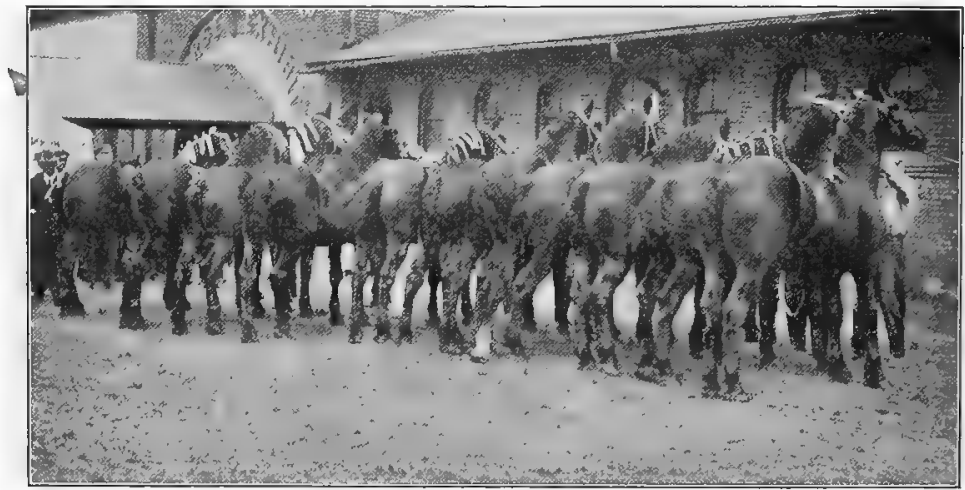

FIG. 43. Percheron futurity winners at the Ohio State Fair, I917. These are yearling horse colts. From photograph by the Columbus Photograph Service Company: By courtesy of Professor D. J. Kays

American Percheron horse associations date back to I876. At this time, owing to the common usage of the word "Norman," it was planned to organize the Norman Ilorse Association. French horses, known as Normans, had been used in the West some years, for as far back as 1854 Dillon and Company of Normal, Illinois, showed what they termed Normans. The word "Percheron" was also in use. J. H. Sanders had been made secretary of the new association, and he added the word "Percheron " to the title, so that it read Percheron-Norman Horse Association, and his action was approved. This was followed by some members withdrawing and organizing the National Register of Norman Horses, which was later changed to the National Register of French Draft Horses. With the organization in France of a Percheron society 
the word "Norman" was dropped from the American title, in order to correspond with that of the French association. The career of the American Percheron Horse Breeders' Association proved rather unsatisfactory to many of its members, due to too much one-man power vested in its secretary. This resulted in the organization, in 1902, of the American Percheron Horse Breeders' and Importers' Association, with headquarters later established at Chicago, Illinois. In 1905 the name of this was changed to the Percheron Society of America. There was also organized in 1902, at Columbus, Ohio, the Percheron Registry Company. More recently - in October, I905--another association, known as the American Breeders' and Importers' Percheron Registry, was incorporated, with headquarters in Ohio. Each of these associations was organized to promote the breed in America, to register animals, and to publish studbooks. In I 909 the Percheron Registry Company combined with the Percheron Society of America, and all animals registered in the four volumes of records of the former were made subject to re-registration in the records of the latter. Within very recent years harmony has come within Percheron circles, and the Percheron Society of America is the one recognized official organization in this country. A number of studbooks have been published. The old Percheron-Norman Horse Association published two volumes, the first appearing in 1877 . Later, with the change of name to Percheron Horse Association of America, three more volumes were issued under the name of the "Percheron Studbook of America." In 1906 this society published Volume VI, since which time the volumes have been brought down to XIX in 1918 , including 134,000 registrations to this date. 


\section{CHAPTER XIV}

\section{THE FRENCH DRAFT}

A brief consideration of the French Draft horse is essential, although no recognized breed of this name exists. In America it has been customary for many years to refer to draft horses brought from France as French Draft horses. Not only this but we now have in the United States an organization which registers draft horses from France in a French Draft studbook.

Distinct breeds of French Draft horses, however, are well known and in France are clearly recognized. Years ago there was some confusion among importers on this point, but at the present time we have more definite knowledge on the subject. All heavy horses in France are not of the same breed, even if brought to America as French Draft. It is quite customary to name certain European breeds after the localities in which they received their chief development, and this applies to the horses of France. It is extremely doubtful if any draft horses come to this country from France that cannot be properly listed as belonging to one of the following breeds, which essentially represent the characteristic draft breeds of that country.

I. Percheron. This is the best-known and most highly developed of the French Draft breeds. For an extended consideration of the breed see Chapter XIII.

2. Boulonnais. This breed is largely found in the district of Boulogne in northern France and in adjoining Belgium, deriving its name from the former. The breed is somewhat larger and coarser than the Percheron, is coarser of neck, steeper and squarer of croup, and while not deficient in action shows less than the Percheron. The color is variable, though frequently gray or white. It is claimed by the French that there is no interchange between the horses of Boulogne and the Perche, and that the Boulonnais has mainly been improved by selection and care, though it is suggested that some improvement may have come from Percheron 
blood. The Boulonnais has an excellent reputation in France, where a studbook kept in its interest is widely used, and it is regarded as second only in importance to the Percheron. I'rominent importers have stated that Boulonnais horses have not been extensively brought to America, although no doubt they are well represented in the United States under the names of "Norman" or "French Draft."

3. Breton. This breed belongs to Brittany, in extreme western France, in a section opposite southwest England, from which it is separated by the English Channel. This is quite a prominent horse section, but in its past history rather miscellaneous breeding has been resorted to. English, Arabian, and crossbred stal. lions have been used, and more recently Percheron. Richardson, in discussing these horses many years ago, says :

Though larger than the horses of the center, those in the north only run from 14 hands to $15 . \mathrm{I}$, having improved up to the latter point, which the best horses now commonly reach. They are of much the same character as the Percheron; indeed, there has been a continual interchange between the two districts, and the color is chiefly the same - gray; but the Breton horse has a heavier head, more hair about the heels, broader feet, a heavier frame, he is shorter below the knee, and the pasterns are shorter, in fact, he shows less blood.

In the past large numbers of weaned foals have been sold to go out of Brittany. "Nor," says Richardson, "are they known again as Breton horses. The grays become Percherons and the bays Normans.'

Leading Percheron importers in the past claimed that none of the Bretons were brought to America, but that they were largely used for omnibus horses in Paris.

4. Nivernais. This breed is mainly found in the department of Nièvre, in central France. It is a somewhat modern, black breed, largely the result of using black Percheron stallions on the mares of the region, which are hardly as large as Percherons. This breed has not been imported to any important degree, as it does not exist in large numbers in its native home, this region being more celebrated for its cattle.

5. Ardennais. This is a native of Ardennes on the Belgian frontier in northern France. It has been described as a small type

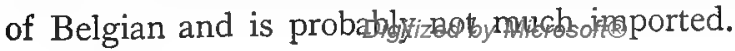


6. Picardy. French authorities rather class this as the Flemish horse, very large and generally bay in color. It is bred in northern France and Belgium and is in fact the Belgian breed, though M. La Motte Rouge, who was for many years employed in the government studs of France, claims that the Picardy is in fact a variety of Boulonnais.

Of the breeds given above the first three are the only ones of importance as possibly affecting American trade.

The National French Draft Horse Association of America publishes a studbook in which may be registered any of the abovenamed draft horses, irrespective of breed. This association was first organized in 1876 as the National Norman Horse Association, but in 1885 its title was changed to the National French Draft Horse Association. This was entirely correct, as there is no such breed of horses in France as Norman, notwithstanding the current use of this word in America for over half a century. Up to 1919 this association has published fourteen studbooks. 


\section{CHAPTER XV}

\section{'THE BELGIAN}

The native home of the Belgian horse is in western Europe, in Belgium, which lies within latitudes $499^{1}{ }^{\circ}-52^{\circ} \mathrm{N}$., with its west border bathed by the North Sea. It is a small country of but I I,373 square miles, being but slightly more than one fourth the size of Ohio. In I9I4 Belgium had about seven million population, with more persons to the square mile than any other European state. The country is level and low near the sea, undulating in the center, while the eastern part is hilly or mountainous. There are nine provinces. The soil is naturally fertile in much of Belgium, and agriculture is conducted on an intensive scale. The small grains, potatoes, market gardening, and nursery stock are important crops. Horses and cattle are the predominating farm animals, while dogs are universally used in labor both in town and country.

Horse production in Belgium extends back to remote times. Remains of the horse have been found in the cave dwellings of the Lesse and Meuse, showing the relationship of man to this valuable animal in that country in prehistoric times. Since the days of historical record the horse of Belgium has been famous. Diodorus Siculus, a Greek historical writer of the first century B.C., mentions that the Belgians were great judges of horses, and Cæsar states that they were willing to pay high prices for a superior class of foreign horses. Tacitus, the historian and well-known writer of the first century A. D., commented on the extensive buying of horses from Belgium and the inability of the people to furnish as many as were desired. It has even been assumed that perhaps the greater part of the Roman cavalry consisted of Belgian horses.

Two breeds of horses of ancient origin in Belgium are said to be the progenitors of the present-day stock. In the first volume of the "National Studbook of Belgian Breeders" the secretary states that two pure races of horses come up from early times in Belgium. One is the Ardenne, which originated in the valley of the Meuse 
in the eastern part of the kingdom, and the other the Frisonne, which developed on the western coast. A variation from the latter race was a large horse known as the Flemish. These two races crossed more or less, from which developed the Brabançon horse, or what is now commonly known as the Belgian. While what we know in America as the Belgian is bred in most of the nine provinces, the breed in its best estate is found in Brabant,

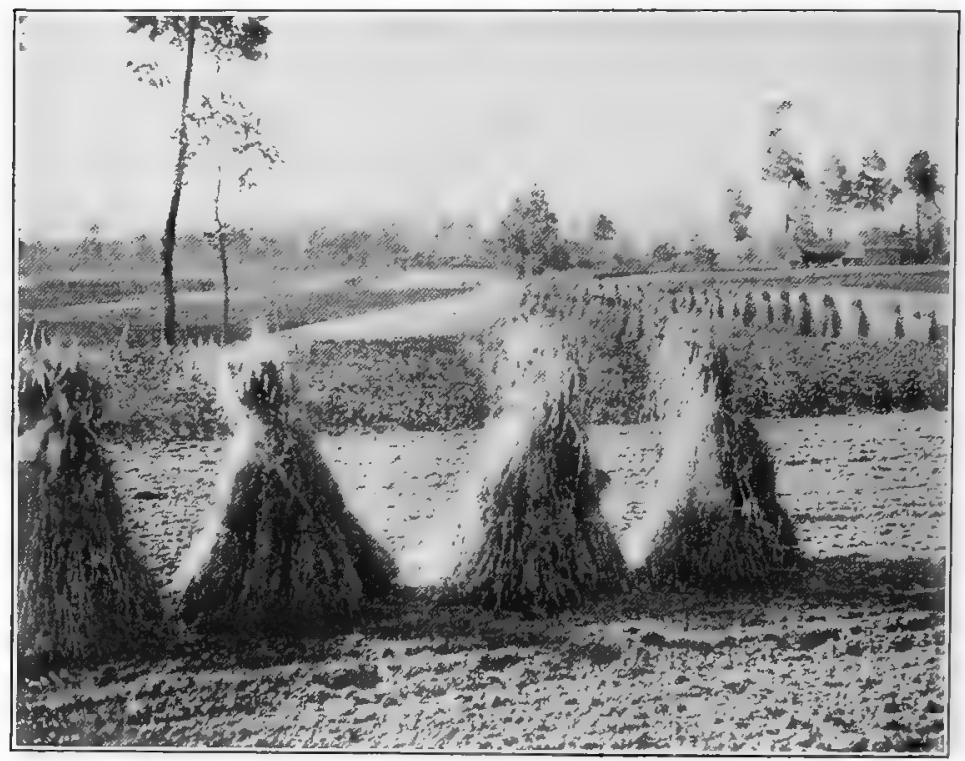

FIG. 44. A farm scene in Belgium near Borsbeke, jllustrating the intensive cultivation practiced in that country. From photograph by the author

in central Belgium near Brussels, in Hainaut south centrally located, and in Namur and Liège in the eastern section. About I9Io some fifty thousand horses were reported in Brabant alone.

The methods employed by the Belgian government to encourage horse breeding, up to the opening of the World War, are of special interest. These methods no doubt will be somewhat changed, now that the war is over, but they are presented by the author with the assumption that they are once more in operation as at the opening of hostilities. Certain state regulations concerning the breeding of draft horses are subject to constant supervision. 
The sum of about 350,000 francs $(\$ 70,000)$ is annually expended in behalf of this work. This money is used to meet the expense of shows of foals and mares, which are fixed by provincial regulations and which occur in some forty-four different places. Stallions are also submitted for examination at this time. At each of these shows two classes of prizes are awarded: (I) a first prize of 400 francs $(\$ 80)$ and a second of 300 francs for the first- and second-prize three-year-old stallions; (2) a first prize of 550 francs (\$I IO) and a second of 400 francs for the first- and second-prize four-year-old or older stallions. Other smaller, extra prizes may be awarded on stallions of rank subordinate to the first and second. To promote home horse improvement the examining committee may award a maintenance bounty of 700 francs to the owner of each stallion not under four years old that has won a first prize at a previous annual show. A similar prize of 500 francs is awarded the owner of the stallion which has won for two years the second place in the class of stallions four years old or over. If the committee regards as of

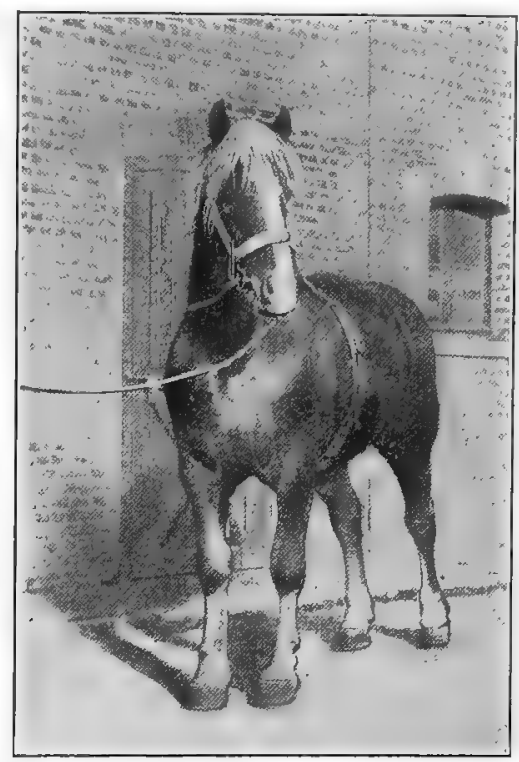

FIG. 45. A Belgian stallion of quality. From photograph by courtesy of M. A. v Van Schelle, Belgian commissioner to the Louisiana Purchase Exposition exceptional value a stallion that has won a maintenance prize, it may nominate him to compete for a bounty of 6000 francs (\$1200) payable annually by fifths, so long as the horse remains approved by the committee and retains its value. At the end of five years the owner of such a stallion, if it remains approved, may continue to enjoy an annual maintenance of from 600 to 800 francs. In case a stallion that has received the 6000 francs' bounty is sold to leave Belgium, the fifths already received by the owner must be 
returned to the treasury of the state. There is an annual competition in each province for stallions four years old or over that have won the above special prizes, at which they may compete for a first prize of 900 francs and a second of 700 francs.

The examination of stallions usually occurs the sixth year, with a show of foals and fillies of two and three years and brood mares, when considerable prize money is awarded. Maintenance bounties may also be awarded owners of the best mares in order to retain them in Belgium.

M. André Duchateau, a noted breeder of Belgium, gives an interesting account of the official supervision of breeding stock. ${ }^{1}$

In every province of Belgium at this period (November and December) there is an expert committee sent to all the farms for the purpose of examining the colts destined for public stallion service and also to inspect the older stallions, as the certificate for service must be renewed each year. This is obligatory in Belgium, even for stallions not kept at public stud, if the animals belong to two or more persons collectively. Stallion service books are delivered to all proprietors of approved sires, and each time a mare is served the groom must enter in this book the description of the mare, date of service and the name and address of the mare owner. A duplicate stating these facts is given to the latter at the same time. Subsequent services to the same mare are entered on the same sheet. These stallion books must be forwarded to the provincial commissions of agriculture each year before the first of September. Anyone winning prizes with a stallion at a show is obliged to stand him at public service. A stallion groom is forbidden to allow his horse to serve any mare with congenital deformities, or one suffering from a contagious disease. Neither must the stallion be allowed to serve fillies less than three years old.

Stud fees in Belgium vary from $\$ 5$ to $\$ 100$, according to the origin and quality of the sire. Just prior to the World War highpriced sires were in great demand. The very noted horse Indigene du Fosteau, even at eleven years of age, says M. Duchateau, was in use the entire season for the maximum fee of \$IOO. Two of his sons, Moustic de Grandglise and Brabançonne, were given all the mares they could cover at $\$ 60$. The older and better-known sires naturally command higher figures than the younger and less tried ones. The stud season lasts from January to July.

The introduction of Belgian horses to America first occurred in 1866, when Dr. A. G. van Hoorebeke of Monmouth, Illinois,

1 How the Belgian Drafters have been Bred, Brecders' Gazette, December I8, Igr2. 
imported some draft horses from Belgium. These were known at the time as Boulonnais. The incorrect use of this word, however, was recognized after a few years, when the correct title, "Belgian," was given. Massion and Son of Minonk, Illinois, were also early importers. In $1858 \mathrm{E}$. Lefebure came to America from Belgium and settled in Iowa, and from I 888 until 1905 he was an active promoter and introducer of the breed. $\mathrm{H}$. Wolff of Wabash, Indiana, was a pioncer promoter of the Belgian in that state.

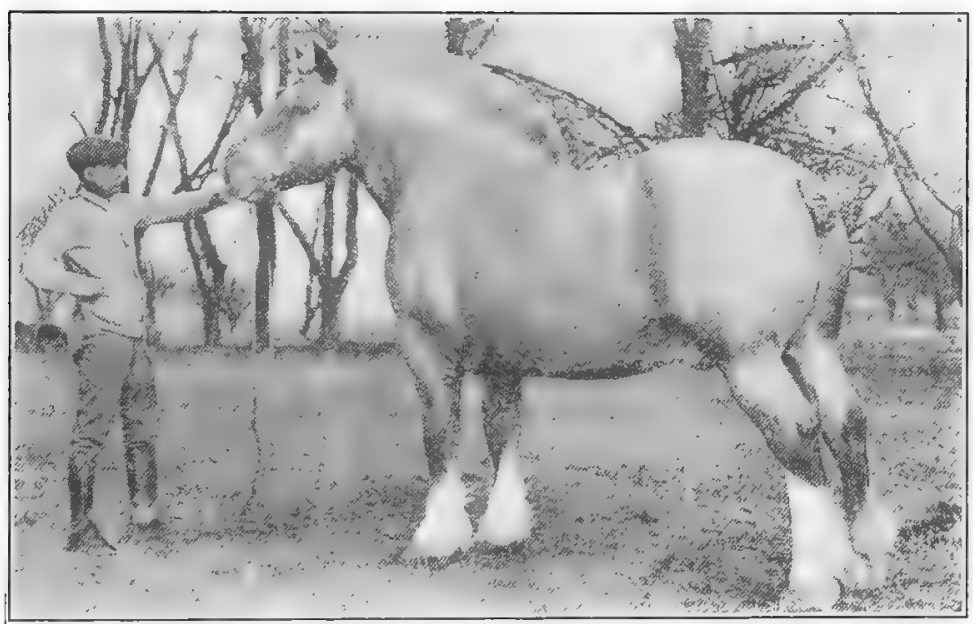

Fig. 46. Farceur 7332 (72924), champion at Brussels and at the International LiveStock Exposition. A great show horse and sire. Sold for $\$ 46,500$ to C. G. Good, Ogden, Iowa. From photograph by courtesy of Mr. Good

Characteristics of the Belgian draft horse. The general conformation is of the most compact form, this breed having a maximum of weight within a given space. The liead shows considerable refinement and is carried with animation on a short, stout neck. The head, neck, and croup rather suggest the French breeds in style and carriage. The body is very full in the breast and strong and full in the loins, with an unusual depth of middle. The legs of the Belgian are short and tend to refinement of bone and are devoid of long hair. Compared with a Clydesdale, the Belgian is much deeper of rib and shorter of leg, but not the sequal of the Clyde in feet, hocks, and bone. The foct tend to be 
somewhat small for the weight they support, and they have been criticized in the past for lack of fullness at the crown and as being rather high and narrow at the heel. In action the Belgian is somewhat slow, especially at a walk, though some remarkable actors have been exhibited at the shows. In I $909 \mathrm{~A}$. H. Thompson attended the Brussels show, after which he contributed a report on the show to the Breeders' Gazette. ${ }^{1}$ Commenting on the characteristics of the Belgian, he writes:

There is a great improvement in the breed since I first knew them from the importation into Ohio in the sixties. Their necks are longer, the ears set higher on the head, the eyes larger; they are not so thick in the throat-latch, and finer in the jaw and muzzle. They are doing away with the dip in the back, and have lengthened out and rounded their quarters, which has set up their tails where they ought to be. They still could do with a little more bone and length of pastern. They have excellent traits for a draft horse, and kind temper, easily kept, not taking a great deal of grain to fill up their short, deep bodies. They have their faults, which will in time be corrected. Many of them turn their toes in and paddle badly at the walk and trot.

He also calls attention to the fact that as a rule these horses are very sound and that at the show not a single horse was turned down by the veterinary surgeons during the entire week.

M. Duchateau states in the Brefders' Gasette, ${ }^{2}$ relative to conformation, that the two main qualities sought in the Belgian are wealth of muscular development and a correct setting of feet and legs. While strong, dense bone is required to support the thick, heavy muscles, they do not look for exaggeration in this respect, as disproportionate size of bone would militate against style and action. "We like to see a large, expressive eye, but Belgian breeders' ideals concerning the head and neck are not quite in concordance with American notions, notwithstanding the fact that we cater largely to the American trade."

The color of the Belgian horse is variable, ranging through bay, chestnut, roan, "auburn," black, gray, and dun. The degree of popularity is expressed in the order given. On this subject E. Mueleman of Belgium has given a valuable contribution. ${ }^{3} \mathrm{He}$ directs attention to the fact that the paintings of the early masters

1 July 2 I, I 909 .

2 December I8, I9I2.

'Breeders' Gazette, May I0, 19I I, p. I 68. 
of the Flemish school of the sixteenth and seventeenth centuries showed no prevailing color as indicative of breed. He quotes an early manuscript dated at the beginning of the last century relative to the color of the Brabançon horses, as follows: "Though we have horses of every color we reduce them to three principal coats, - the black, the most common; then comes the light and dark bay, and lastly the gray of several shades." Mueleman offers an interesting classification of Belgian colors of horses shown in the National show at Brussels in six different years. In I9 IO bay prevailed in 51.2 per cent of the entries, chestnut in 36.8 , roan in 5.3, auburn in 1.9 , black in 2.7 , and gray in $2 . \mathrm{I}$. There is shown a more or less steady decline in roans, grays, and blacks in recent years, while dun has not been recorded since 1886 . Nearly 90 per cent of the prize winners are included among the bays and chestnuts in the order given.

The height and weight of the Belgian vary materially. M. Albert Van Schelle, the special commissioner from Belgium in charge of the exhibit of Belgian draft horses at the Louisiana Purchase Exposition at St. Louis in I904, classes the horses of Belgium into three types according to the sections of the country to which they belong. Those from Flanders range in height from $16 \frac{3}{4}$ to I7 hands or more, and the stallions weigh about 2000 pounds. Those from Brabant stand $15_{4}^{3}$ to $16 \frac{3}{4}$ hands, and the stallions weigh about I600, while those of the Ardennais stand from I 5 to $I 5 \frac{1}{2}$ hands in height and weigh about I 200 pounds.

On the basis of the development of the breed in recent years these figures hardly measure up to American or Belgian standards. Unquestionably the breed is lower set than the other draft breeds, but the larger type should show stallions weighing in excess of 2000 pounds. Crouch and Son of Indiana, who have imported many Belgians, give the weight of the I 908 International champion, Perce 2276 , as 25 Io pounds. Some very massive examples of the breed are to be found to-day. The Belgian colt weighs heavy for its age, and there are records of males scarcely six months old weighing 850 pounds, and one Ohio breeder reports a colt at seven and one-half months weighing 990 pounds.

The temperament of the Belgian is of the very best. This is

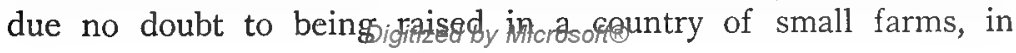


close contact with the everyday life of the people. Many of the horses are sheltered beneath the same roof as their owners or caretakers. As the author has seen these horses at work on the streets of the cities of Belgium and on the farms, he has been much impressed with their docility and their great and uniform draft power.

The maturing quality of the Belgian is distinctly superior. As has been already said, he develops quickly and attains mature size

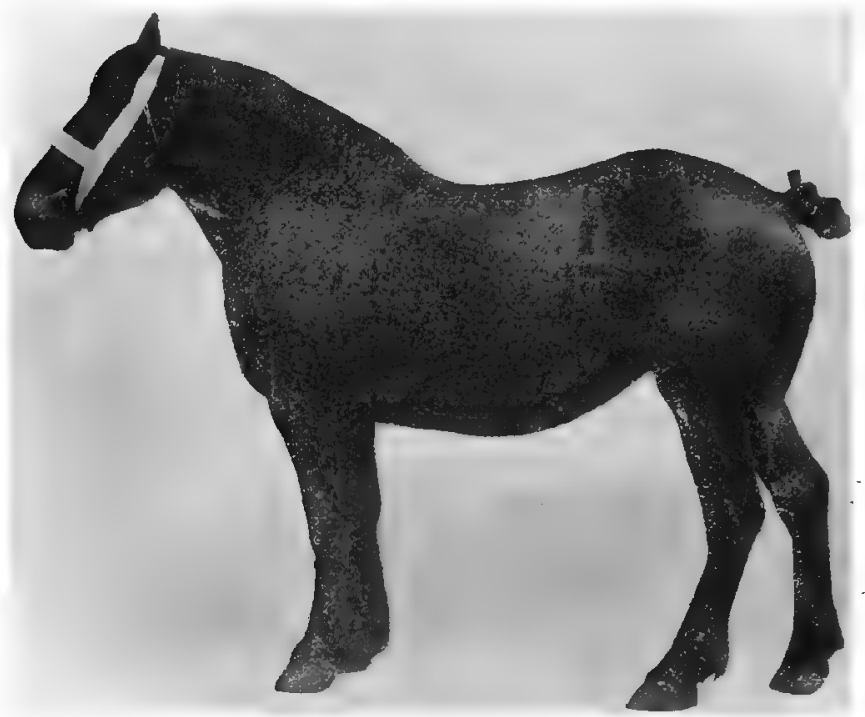

FIG. 47. Babette, a typical Belgian mare. Photograph from A. Van Schelle, . Special Commissioner of Agriculture from Belgium to the Louisiana Purchase Exposition, I904

and weight with more than ordinary rapidity. In the United Statesin the Central West - professional feeders of horses look with favor on the Belgian on account of the way he develops.

The crossbred Belgian has as yet been but little seen in the United States, but he has met with a favorable reception where produced. A few years ago a consignment of grade Belgian drafters, the product of pure-bred stallions on native mares, was sold at auction in Chicago market at excellent prices and received 
much favorable comment. The author has scen numerous grade geldings shipped to Ohio feeders from the West which have presented a most attractive individuality. Ohio shippers are looking with more and more favor on heavy Belgian geldings as quite satisfactory to the city trade. They seem to be reasonably sound of limb and possess the draft form and weight so much in demand for heavy hauling. In recent years grade Belgians have materially increased in number.

\section{Foundation Belgian} sires trace back to comparatively recent times, when we consider the age of the breed. M. Leon Van Meldert has contributed some interesting information regarding the foundation sires, ${ }^{1}$ from which the following is arranged:

Forton of Wynhuisc, known also as Le Gros de Wynhuize and in Flemish as Den dikken van Wynhuize,

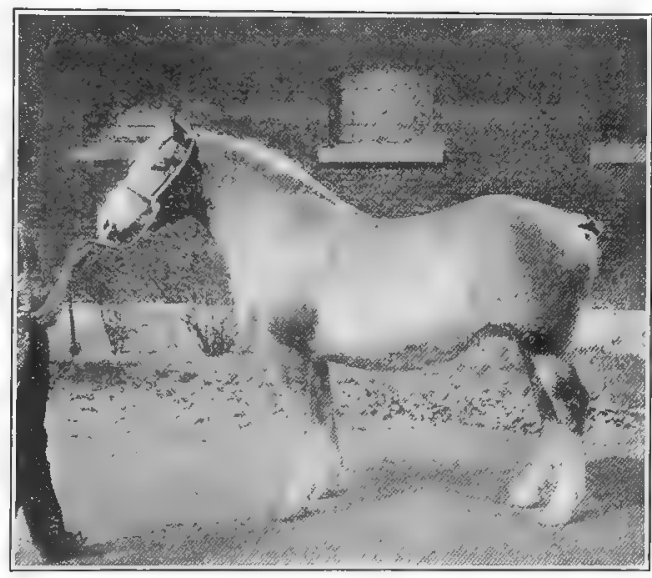

FIG. 48. Queen Ann 6I19, a Belgian mare owned by Ohio State University, Columbus. A fine type of the modern Belgian mare. Reserve champion in I9I7 at Ohio State Fair. From photograph by E. K. Emslie was foaled in 1835 in the stable of Charles L. Tuypens, Wynhuize, East Flanders. He was a bay, sired by Francis and was out of a mare, Marie, that had the same sire as Francis. Forton of Wynhuize lived from I 835 to I 858 and sired Forton of St. John, a bay foaled in I 847 . In I 856 this son sired Forton of On Rersule, a light bay, which became the sire of London, sire of Forton 2d, a dark bay foaled in $188 \mathrm{I}$.

Samson, known also as Young Forton of Wynhuize, a brown horse, was foaled late in I830. He was the sire of Alfred, also called Forton of Appelterre, a dapple gray foaled in $185 \mathrm{I}$ and living until I 877. Alfred sired Guzusse, later Orange Ist (I I44),

${ }^{1}$ Breeders' Gazette, January 29,2 I 14, p. 223. 
a light bay. Alfred proved to be one of the most valuable stallions in Belgium.

Orange Ist (I I 44), foaled in I 863 and living twenty-two years, was sired by Alfred. Orange sired four famous horses: Brilliant (708), many times champion in France, Germany, Holland, and Belgium; Jupiter ( 126 ), the champion of I889; Morius ; and Jean Ist (1200).

Brilliant (708), a chestnut, was foaled in 1868 and was sired by Orange Ist (I I44) and out of the foundation mare Blonde. Brilliant was of powerful draft type, with superior feet and legs and possessing most excellent action. For many years he was in great favor as a sire, though hardly the equal of his own sire as a producer.

Jupiter ( 126 ), the half brother of Brilliant, was foaled in 1880 and was sired by Orange Ist ( I I44); dam, Julie. He was a sire of remarkable excellence, surpassing his own sire. His sons, in particular, were in great demand and commanded high prices. Some regard Jupiter as the greatest Belgian sire in the history of the breed. From I 894 to I 904 all the male champions at Brussels but three were his sons or grandsons. These include Mont d'Or (6I20) in I 894 and I895, Olympian (8I I 4) in I 896, Reve d'Or (7406) in 1898 (champion at Paris in I900 over all breeds), Private (8878) in 1899 , Brin d'Or (7902) in I900, Bienvenue (13592) in I901, and Bourgogne (13 I 54) in I902.

Mercury (7 I4), a dapple gray, foaled in 1882 , was a product of the Chevalier stables in Hainaut. He was low set, of unusual action, and champion at the National show in I887 and I888. He sired about forty prize winners at Brussels between I 894 and I90I.

Bayard (1 I 46), a chestnut roan foaled in I864, came from a family of roan Belgians originating in Brabant. The original horse of record was a blue roan, Old Min de la Cozette, the sire of a blue roan, Mestiaux de Ronquieres. A son of his, Mouton de Gony, sired Bayard (I I 46), a horse of great individuality and draft conformation. Bayard was sire of about forty prize winners between I 886 and I904.

Notable recent-day Belgian horses are Indigene du Fosteau (297 I 8), champion at Brussels in 1907 and 1909 , a very famous sire; Marquis de Ruyen (24878), champion of I904; Gambrinus 
du Fosteau (29718), champion of 1905; Bienfait de Masnuy (447I8), champion of I9IO; Paul (46036), champion of I9II; and Farceur (20730).

Prices paid for Belgian horses have only reached high levels in recent years. In I 889 Jupiter ( I 26) was purchased for \$ $\$ 200$, the top price for a Belgian up to that time. In I 900 the stallion Citoyen was bought by a company in Limburg for $\$ 3300$. In I903 Beau Lys was bought by Liège breeders for $\$ 4500$. In I 904 another group of breeders purchased the stallion Nickel for $\$ 5400$. The above sales all took place in Belgium. In I909, at a sale of Souers and Son of Indiana, twenty-nine Belgians brought $\$ 15,885$, an average of $\$ 548$ each. The most notable sale of the breed took place on October 16, I9I7, at Hudson, Iowa, at the sale of William Crownover. The stallion Farceur 7332 (72924), by Bayard de Ruyen (32678), was sold to C. G. Good of Iowa for $\$ 47,500$. The get of Farceur averaged $\$ 1475$. Thirty-five mares brought $\$ 39,425$, an average of $\$$ I I 27 . Eighteen stallions, including Farceur, averaged $\$ 3297$. A weanling stallion by Farceur brought $\$ 1875$. The highest price for a mare by Farceur was $\$ 2900$. At Huntertown, Indiana, on February I 5, I9I9, Daron, a stallion foaled in I9I I, sold for $\$ 10,500$ to William Bleke.

The distribution of Belgian draft horses is very widespread. Germany has been a prominent buyer, while England, Holland, Sweden, France, Denmark, Austria, and the United States have buyers in the Belgian market. In 1903 more than 300 were shipped to the United States. At the 1904 Brussels show an official representative of the Hungarian government purchased Io stallions, including 6 first-prize winners. In the United States the Belgian has been longest known in Iowa, Illinois, and Indiana. Stallions and grades are, however, becoming distributed over the Mississippi Valley states north of the Ohio, wherever the heavy draft horse is needed, and the breed is steadily gaining in favor.

Organizations for promoting Belgian horses exist in Belgium and the United States. The official draft-horse society of Belgium (Le cheval de trait Belge) was founded in I886. The draft horse is the only breed in Belgium officially promoted by the government, and this society was organized (I) to encourage the breeding of native horsess by the organization of annual National 
shows and (2) to maintain a studbook of Belgian draft horses. The studbook is published by a special commission appointed by the society. To promote the work of this society the government makes an annual grant of 30,000 francs $(\$ 5000)$. Besides this, since 1890 national premiums have been offered for the best stallions. This society has some 1100 members. The American Association of Importers and Breeders of Belgian Draft Horses

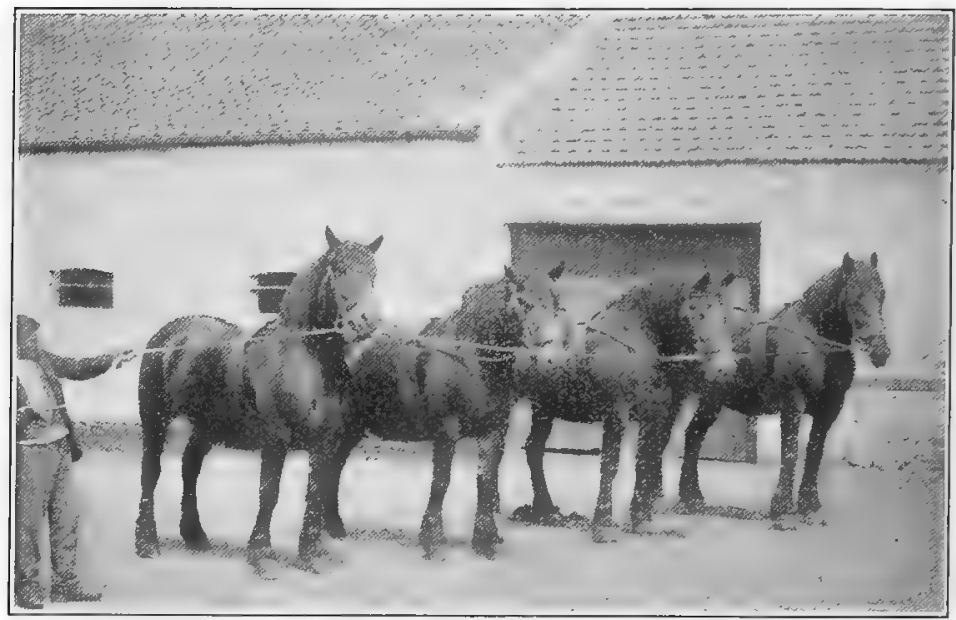

FIG. 49. A quartet of Belgian mares in their native home. From photograph by M. A. Van Schelle, Belgian commissioner to the Louisiana Purchase Exposition, 1904

was organized in 1877 and works in harmony with the Belgian society. UP to 1918 it had published six studbooks, including a large number of registrations comparatively recently.

Draft-horse shows in Belgium are held each year at Brussels in June. These are notable events, for here is the largest show of one breed that is held in Europe. In I9I2 at this show there were nearly one thousand entries. While the exhibits come from all over Belgium, the most important ones in recent years have come from Brabant and Hainaut and the provinces of Liège and Namur. This has been regarded as one of the most remarkable horse shows held in the world. Numerous agricultural associations also hold exhibitions in Belgium, at which local horses are shown. 
Exhibitions of Belgians in the United States are comparatively recent. Small exhibits have attracted attention at the Chicago horse show and at some of the Central West fairs during the past twenty years, but it is only very lately that general interest has been taken in the breed. A small show of Belgians was made at the World's Columbian Exposition in 1893 at Chicago by A. B. Holbert, Van Volsen Brothers and Vanderschuerm, Lefebure and Sons of Iowa, and J. Crouch and Son of Indiana. During recent years interest in the breed has greatly grown, and at the International Live-Stock Exposition at Chicago in I9I7 there were entered thirty-four aged stallions, while a large and creditable show of various classes was made.

The influence of the World War on the horse in Belgium was most damaging, for the German invaders essentially destroyed the horse industry of the country. However, horses were saved early in the war by taking a limited number to Holland and England, where they were given protection and care, awaiting the day of peace. With the return of peace, Belgian breeders, with the help of their friends, will be able to reëstablish their studs. In I9I8 a commission from Belgium spent some time visiting American studs with the view of looking to this country for much-needed pure-bred stock. 


\section{CHAPTER XVI}

\section{THE CLYDESDALE}

The native home of the Clydesdale horse is in western Scotland, in the southern section, in a region contiguous to Glasgow in the valley of the Clyde. Early historical evidence points to the county of Lanark as the location where the breed first received recognition. The adjoining counties of Ayr and Renfrew also were more or less the centers of early Clydesdale breeding. This region lies between latitudes $55^{\circ}-56^{\circ} \mathrm{N}$., fully one thousand miles north of New York City; the climate is raw and cold in winter and never especially warm in the milder seasons. The land about the Clyde valley is hilly, but yields great crops of the small cereals, roots, hay, and potatoes.

The early history of the Clydesdale is veiled in more or less obscurity. Scotch writers on the horse state that in the seventeenth and early part of the eighteenth century there was doubtless an interchange of draft-horse blood between Scotland and England. Scotch cattle dealers driving herds into England returned north with English mares, which were bred to stallions in the northland. This was prior to the use of the word "Clydesdale." Claims have been made that the Duke of Hamilton brought black stallions from Flanders in Belgium to Scotland about the middle of the seventeenth century and bred them to the native Scotch mares. This, however, is traditional. Undoubtedly very mixed blood was in the early breeding.

The origin of the modern Clydesdale seems to trace back to about I 7 I 5 or I720. John Paterson was a tenant farmer of Lochlyoch in Carmichael parish in the county of Lanark. This county is in southern Scotland, and through its center flows the river Clyde, from which the name "Clydesdale" is derived. Written testimony of the family shows that at about the above period Paterson brought a black Flemish stallion from England to Lochlyoch, which was bred to the mares in the region thereabouts. The 
result of this union created a superior strain of draft horses for that time, and they met with special favor during the latter part of the eighteenth and the early part of the nineteenth century. Breeders valued the influence of the Lochlyoch blood, and this is now regarded as essentially Clydesdale foundation stock. The mares descended from this Flemish stallion are described as "generally browns and blacks, with white faces añd a little white on their legs; they had gray hairs in their tails, along with occasional gray hairs over their bodies, and invariably a white spot on the belly, this latter being regarded as a mark of distinct purity of blood." The Earl of Dunmore, the first president of the Clydesdale Horse Society of Great Britain, stated in $1878^{1}$ that "the Lochlyoch stock having been long noted in the Upper Ward (Lanarkshire) and largely drawn up-

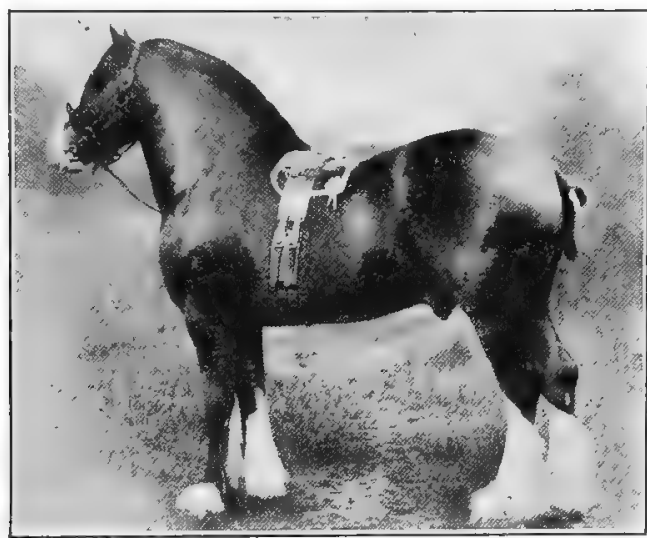

FIG. 50. Baron's Pride ( 9122 ), one of the greatest recent Clydesdale sires in Scotland. From photograph by $\mathrm{A}$. Brown \& Company, Lanark, Scotland on by breeders, there is no doubt that to them, or, more correctly, to the black horse of I 7 I 5, the Clydesdale horse owes its present distinctive character."

The use of English blood on the Clydesdale, following the days of Paterson up to comparatively recent times, is admitted by Professor Wallace, a leading Scotch authority. Tintock, a Shire stallion, along about $\mathrm{I} 860$ was used in Scotland on Clydesdale mares, producing very excellent breeding females. The grandams of the Prince of Wales were both Shires of English blood. In I 842 Professor Low commented on the distribution of the breed and stated that they "have been mixed in blood with all the other varieties." As recent as I9I9 more breeding of this kind

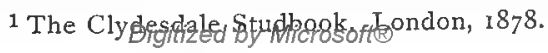


is reported from Scotland. William Dunlop, the famous Clydesdale breeder at Dunure Mains, visited England and purchased a Shire stallion and a filly, and, as reported in a British journal, "it is his intention to mate them with some of his noted Clydesdales. Mr. Dunlop is strongly of the opinion that the Clydesdale breed can be improved through Shire crossing." It must be assumed, however, that only pure-bred Clydesdales will be registered in the studbook; otherwise present standards would suffer.

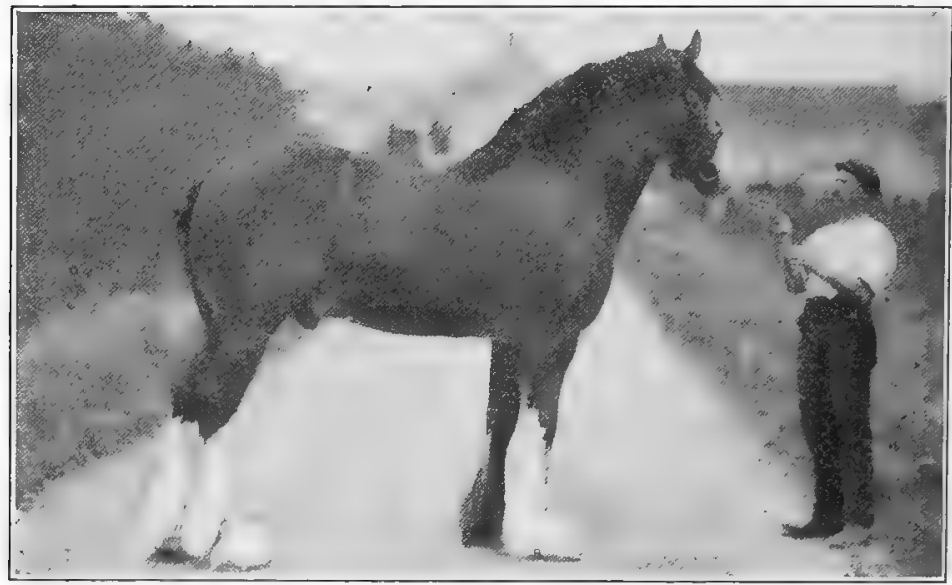

FIG. 5I. Baron of Buchlyvie (I 1263 ), the most advertised Clydesdale horse in history, a leading sire, and sold for $\$ 47,500$. From photograph by A. Brown \& Company, Lanark, Scotland

Clydesdale characteristics. This breed of draft horses possesses certain features of a distinctive kind on which loyal Scotchmen lay great emphasis. The feet and bone and action are cardinal points with Clydesdale breeders. The feet must be large, round, and open, with an elastic frog and well-spread, clearly expressed heel ; the coronet wide ; the pastems fairly long and rather sloping; the cannons short, flat, hard, and cordy; and the forearms, arms, thighs, and quarters notably muscled and strong. The tendency with the Clydesdale is to show some lightness of forearm and thigh. From the back side of the leg at the cannons should grow an abundance of long, fine hair, a striking feature in the best specimens of Clydesdales and indicative of quality. White 
feet, though common, are often objected to, on the ground that they lack the density and wearing power of dark feet, and there is a distinct objection to them in Argentina and elsewhere. Emphasis is laid on the fullness of the foot, the obliqueness of the pastern, and the flatness and cleanness of bone of lower leg. The body of the Clydesdale has been most subject to criticism in the past, lacking in depth and circumference when it should have fullness, as showing both feeding capacity and weight to draw loads. Good horse critics still insist that this deficiency of form is too prevalent with the breed. However, it is within the facts that in recent years the tendency has been to secure greater depth and spring of rib. An obliqueness of shoulder is emphasized among Clydesdale breeders, leading into strong, high withers. While the chest is narrower than with other drafters, a recent British opinion ${ }^{1}$ declares that "he must have a wide chest and his limbs be well planted under him, with no tendency to what is called being wide at the shoulder, so that the horse is compelled to walk in front somewhat after the fashion of a bulldog." The slightest inclination to this in a Clydesdale is regarded as unpardonable. The head of this breed does not differ in its essential features from what is regarded as a correct conformation. A writer discussing the Clydesdale in "Heavy Horses" (I894) notes some peculiarities of the head worth recording here:

A tendency to "dish face" may be observed in some tribes, and this is generally accompanied by a small ear and what, in the main, is characterized as a "pqny head." Wherever this style predominates there is probably a strain of Highland or old Galloway in the blood. On the other hand, the hard, narrow face and Roman nose are regarded as equally if not more objectionable. Such features are usually indicative of a strain of Shire blood and, indeed, they are not otherwise to be accounted for in the Clydesdale. An open, level countenance, vigorous eye, and large ear are greatly valued, and are not readily sacrificed.

The action of the Clydesdale is notable, not being surpassed by any breed. Says Alexander Galbraith, an acknowledged American authority on this breed:

Great attention has been paid by the Scottish breeders during the last twenty or thirty years to the matter of action. No other draft breed has received one half the attention that the Clydesdale has in this respect, and for 
that reason they far surpass all others in length of stride, in straightness and sprightliness of movement, in their ability to keep their hocks together, with mechanical accuracy of motion, whether walking or trotting.

The color of the Clydesdale is usually bay or brown, with a white star in the forehead or blaze or stripe on the face and with all or part of the legs, up to the knees and hocks, white. Black, gray, and chestnut occasionally occur. Gray is not popular from a color point of view in Scotland, though lately growing in favor, while chestnut is said to indicate Shire blood in the pedigree.

The height and weight of the Clydesdale is a subject of distinct importance in view of more or less criticism of the breed in regard to lack of weight. The height of the mature stallion should be about $16{ }_{2}^{1}$ to $I 7$ hands, with the mares two inches or so lower. Sir Everard (5352) stood $17 \frac{1}{4}$ hands high; Prince of Albion ( 6 I 78$)$, I $6 \frac{3}{4}$ hands; and Flashwood (3604); I 7 hands; and these represent models of the breed in Scotland. Weights of 2000 pounds for the stallion and I 800 for the mare, in mature form, represent good standards, though somewhat above the average. However, horses under show conditions, to meet the most exacting competition, are expected to exceed the above weights.

The first Clydesdales brought to America were probably taken to Canada, doubtless on account of the love of Scotch settlers there for their favorite breed. The following represent the earlier importations, the first occurring in 1842: Gray Clyde 78, importer, Archibald Ward, Markham, Ontario, I842; Sovereign I81, importer, R. Johnson, Scarborough, Ontario, I845; Cumberland 106, importer, David Roundtree, Jr., Weston, Ontario, I 850 ; George Buchanan I 82, importer, John Wilson, Oshawa, Ontario, I85I; Bay Hallace 5, importer, William Cochrane, Claremont, Ontario, I 854.

Along in the seventies Clydesdales were brought to the United States in a small way, both through Canada and by direct importation. In the early eighties they were brought over in larger numbers, especially in $188 \mathrm{I}$, and between then and 1892 the trade increased greatly and several thousand stallions and mares were brought across the water and distributed over the country, but in recent years comparatively few horses of the breed have been imported to the United States. 
The temperament of the Clydesdale tends to be somewhat nervous. This is manifested in his natural activity. So far as disposition is concerned, the Clydesdale is the equal of the other draft breeds.

The adaptability of the Clydesdale to environment is not first class. In some countries the breed has been objected to on account of its white feet. In hot countries it is more or less

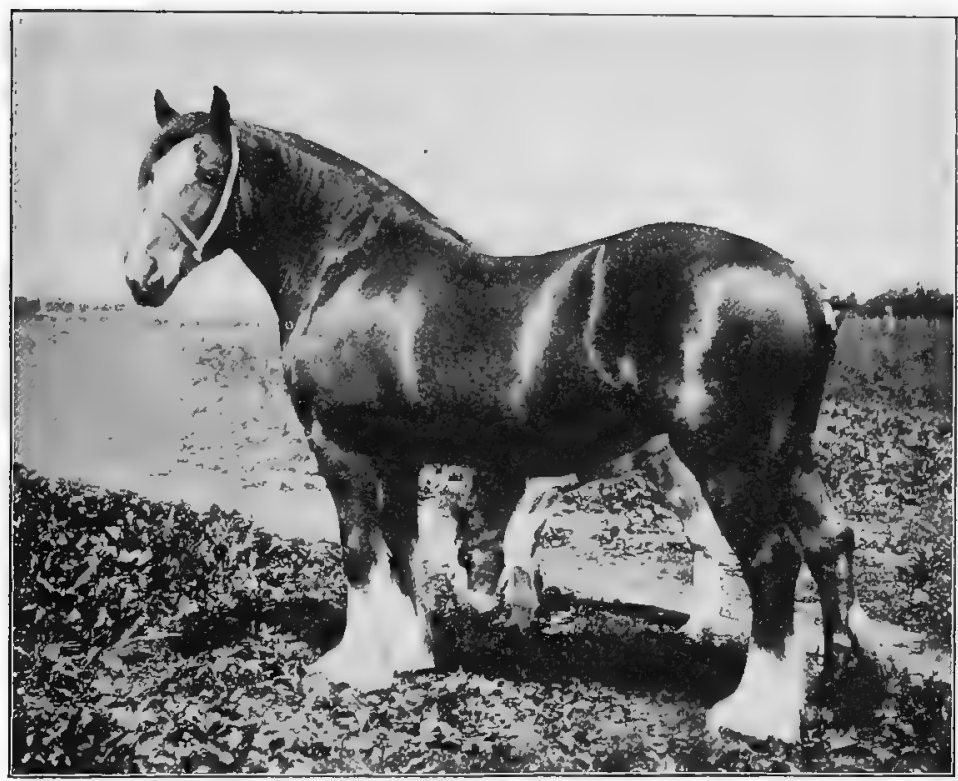

FIG. 52. Princess Handsome, one of the notable American-bred Clydesdale mares. First-prize winner at International Live Stock Exposition, Chicago, in 1901, I902, and 1903. Bred and owned by McLay Brothers, Janesville, Wisconsin. From photograph, by courtesy of owners

criticized on account of the color, especially the white on the head. On the low-lying, heavy soils, such as prevail in the Mississippi Valley, the excess of hair on the leg has influenced its popularity to a marked degree. As a whole, the breed is better adapted to uplands than are the Shire, Percheron, or Belgian, and meets with more favor in the cooler rather than the warmer sections.

The prolificacy of the Clydesdale is of the best. Naturally very active and muscular, the mares breed readily and, being hardy, tend to be long-lived. Digitized by Microsofter 
Half-bred, or grade, Clydesdales are not uncommon in some sections of the country. Pure-bred stallions on native mares of draft character produce excellent horses for farm or city work. They are usually of medium draft weight, are active on foot, and are quiet and docile of temperament. They frequently lack weight for the heaviest work, which emphasizes the necessity of using only such stallions for sires as have plenty of middle, as well as quality and bone. Clydesdales and Shires in the past have been crossed a great deal, resulting in a more drafty sort than the Clyde and a better actor than the Shire. However, very few half-breds, or grades, find their way into the horse markets of the United States.

Criticisms of the Clydesdale are not uncommon among horsemen. The hairy legs are objected to by farmers, who have to use them on dirt roads or under conditions in which mud or dampness are prevalent in the cooler months of the year. The Scotchman argues that the hair protects the skin of the leg and is an evidence of superior bone. In spite of this assertion the average buyer prefers a horse with a leg free from superfluous hair. On a city pavement or on the hard macadamized roads of Europe the hair is not so objectionable. Mr. Galbraith offers the following comments in friendly criticism ${ }^{1}$ of the Clydesdale:

Many present-day prize winners have, in my opinion, too short ribs and not enough depth of body. This kind are not always good breeders nor good shippers. They are apt to be somewhat nervous, restless and too ambitious. A good many Clydes are undersized, and quite a number are rather too fine in bone, too narrow in chest, and too light in arms and thighs. The narrow chests are the result of an urgent demand for absolutely straight action. This shortness of rib, with a tendency to ranginess of body, has counted against the breed in the past. A short coupling and broad, deep body must be a part of the best draft type, to give the necessary weight for hauling heavy loads. However, many of the more recent show horses are distinctly deeper of rib and are meeting with a more favorable reception by horsemen generally.

Important Clydesdale sires, other than the Flemish stallion of Paterson, date back to early in the nineteenth century. The first of distinction was Glancer (335), alias Thompson's Black Horse. The Scotch studbook states that he was foaled about I $8 \mathrm{IO}$, but

1 "Seventy-five Years of the Clydes," The American Breeder, January 5, I9I2. 
this date is questioned. The story is that Glancer was sired by a black stallion named Blaze, bought in Ayrshire about 1780 and taken to Lanark for service. He was a stallion $16{ }_{4}^{1}$ hands high, perhaps had some coach blood, and possessed both style and action. Blaze, in service to a mare known as the Lampits mare, on the Lampits farm in Lanark, sired Glancer. The

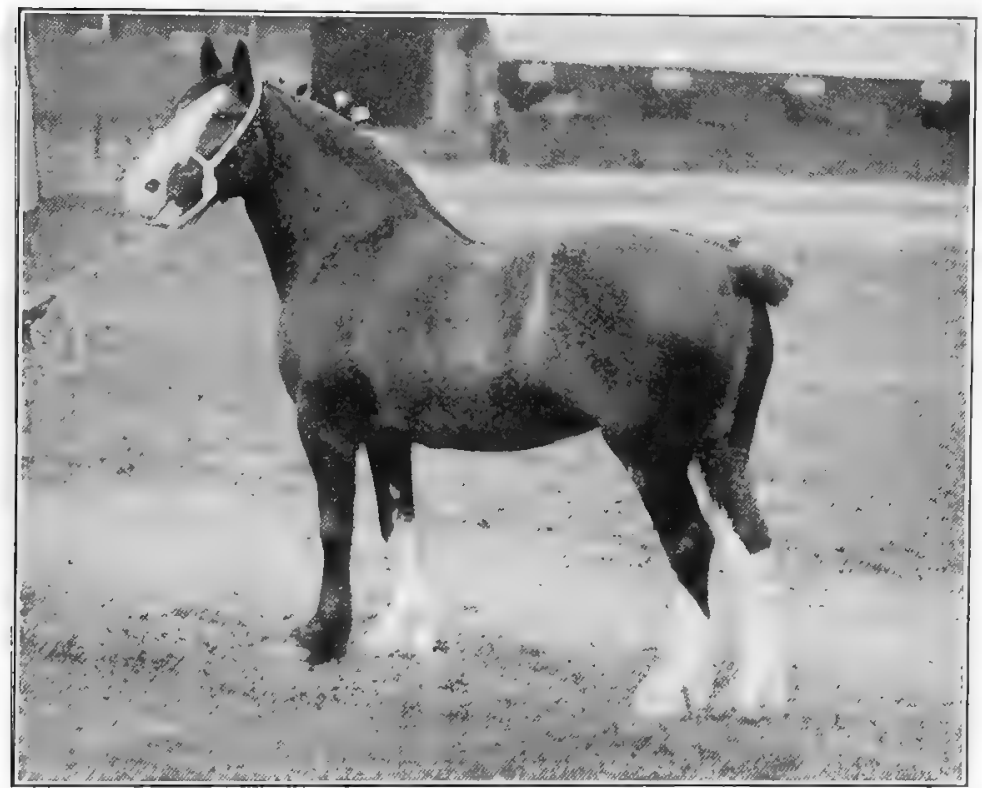

Fig. 53. Harviestoun Baroness (27086), champion and Cawdor Cup Clydesdale mare, Cupar, Scotland, I9I2, and twice breed champion at the International Live Stock Exposition, Chicago. Imported by R. A. Fairbairn, New Market, New Jersey. From photograph by Strohmeyer, by courtesy of Mr. Fairbairn

result of this union became more than locally famous, for from him " nearly all the best animals of the present day are descended," says the "American Clydesdale Studbook." Glancer's dam, which died in 1827 , was a famous brood mare, having produced other superior foals.

Broomfield Champion (95), foaled about I 820 , was a notable stallion and great-grandson of Glancer (335). He sired Clyde, alias Glancer ( 153 ), Glancer (338), Bowman's Colt (1078), and a number of great brood mares. Some of his offspring were 
successful in the show ring, but his chief distinction comes from being the sire of Glancer (I 53). According to the Scotch studbook (Vol. I) he was black in color, with four white legs, on which was set a round, capacious body with a short back. "To Broomfield Champion," says the studbook, "every Clydesdale breeder likes to trace the descent of his stock." His name is most frequent in early Clydesdale pedigrees.

Clyde, alias Glancer (I 53), foaled about 1835 , was owned by William Fulton of Renfrew County, a noted breeder, and was bred by Mr. Forest of Lanark County. Though not a, show animal himself, from I 844 to 1850 the leading honors of Scotch exhibitions went to the produce of Clyde. He was dark brown in color, and having been ruptured was known as "The Ruptured Horse." Seven sons and one daughter of his are recorded in the first volume of the "Scotch Clydesdale Studbook." Most of these sons proved later to be sires of great merit and were used in various localities in improving the breed.

Prince of Walcs (673), foaled in 1866 , bred by James $N$. Fleming of the county of Ayr and later owned by several different persons, was one of the two greatest Clydesdales in recent history. He was sired by General (322), whose sire was Sir Walter Scott (797), a great show horse and sire, while his dam was Darling, a mare of unknown breeding beyond one generation. Prince of Wales was a dark-brown horse with a white stripe on his facc and more or less white on three legs. He was somewhat straight in his hocks and a bit Roman nosed, but in general was of good form and a remarkable mover at walk or trot. $\mathrm{He}$ was not only a great show horse but was regarded as one of the greatest begetters of sires that the Clydesdale breed has produced. Prince of Wales was last owned by David Riddell of Paisley, who purchased him at auction when eighteen years old for $\$ 4725$ and in whose possession he died in 1888. Prominent among his sons are Prince of Albion, sold for $\$ 5$ 5,000, and his full brother, Prince of Kyle, sold for $\$ 8000$; Prince Alexander, sold for $\$ 6000$ as a yearling; and Prince Robert.

Damley (222), a bay, foaled in I872, was bred by Sir William Sterling-Maxwell and was purchased when three years old by David Riddell, the owner of Prince of Wales. His sire was 
Conqueror (199), and his dam, Keir P'eggy (187), had a fine show-yard record and as a dam of ten foals is regarded as one of the greatest mares of the breed. Her sons Darnley, Pollock, and Newstead all won first prizes at the Highland and Agricultural Society shows. She died in I888. Darnley himself up to twelve years of age had a most distinguished career in the show ring. If Prince of Wales was a great stallion sire, so Darnley was a famous sire of mares. The descendants of these two animals mated unusually well, and from their union has resulted much that is best in recent Clydesdale blood. Three of Darnley's best sons were MacGregor (1487), Flashwood (3604), and Topgallant (I850). These were all great horses, but especially so was MacGregor, whose sons gained fame in the show rings of Canada and the United States. As a sire this animal is regarded as second only to his own sire and Prince of Wales.

Baron's Pride (9122), bred by R. \& J. Findlay, Springhill, near Glasgow, was foaled in 1890 and died in I9I 3 at twentythree years of age. He was sired by Sir Everard (5353), a son of Topgallant (450), and had for dam Forest Queen (7233), by Springhill Darnley (2429), a son of Darnley (222). Thus he united the blood of Prince of Wales and Darnley, than which there was nothing better. Up to four years of age he was a successful horse in the show ring. In 1894 A. \& W. Montgomery purchased him, and he was from then on reserved for the stud, where he proved to be one of the greatest Clydesdale sires in the history of the breed.

Baron of Buchlyvie ( $1 \mathrm{r} 263$ ), bred by William McKeich, was foaled in $\mathbf{I} 900$ and is the best-known son of Baron's Pride. His dam was Young Maybloom (I 2003), by Knight Errant (4483). As a colt he was said to have been somewhat undersized, and in the Scotch shows he was unable to win championship honors, though securing first, second, and third places at different times. As a two-year-old he sold to Kilpatrick and Dunlop for $\$ 3500$. "The price seemed ample," writes Alexander Galbraith," "as the colt was somewhat undersized, decidedly narrow in conformation, and lacking in muscle and strength of bone. His chief points of excellence were extremely fine quality of bone and hair, the latter

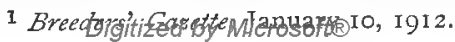


hanging like silk from his legs and hoof heads. He had also beautiful style and action. As he got older he grew and improved wonderfully, finishing a very handsome horse of nearly 2000 pounds." In I9I I at the Highland show his offspring monopolized the winnings. On December I4, I9I I, at public auction to dissolve the partnership between Kilpatrick and Dunlop, he sold for $\$ 47,500, \mathrm{Mr}$. Dunlop being the purchaser. He has been regarded as the best advertised Clydesdale horse in history.

Dunure Footprint (I 5203) was bred by William Dunlop, Dunure Mains, Ayr, and was foaled in rgo8. He was sired by Baron of Buchlyvie (1 1 263), dam Dunure Ideal (21283). Dunure Footprint is not only regarded as a model of the breed but is also the leading sire of his generation. He has won the highest honors of the Scotch shows, and his progeny are sought for at high figures. The following table will show him to lead the ten best sires in Scotland.

An honor roll of Clydesdale sires of more recent years is given by the Clydesdale Horse Society of Great Britain, embracing the ten most prominent sires in the 19 I 5 shows. The record is as follows:

\begin{tabular}{|c|c|c|c|c|c|c|}
\hline NAME & $\begin{array}{c}\text { Number } \\
\text { OF Prizes }\end{array}$ & FIRST & SECOND & THIRD & $\begin{array}{l}\text { Champion- } \\
\text { ShIP }\end{array}$ & $\begin{array}{l}\text { Total Number } \\
\text { OF OFFSPING }\end{array}$ \\
\hline Dunure Footprint (I 5203) & 72 & 18 & 16 & 8 & 5 & 34 \\
\hline Baron of Buchlyvie ( $1 \quad 1263$ ) & 37 & I I & Io & 7 & 2 & $2 I$ \\
\hline Apukwa (14567) & 37 & 7 & 6 & 7 & 6 & II \\
\hline Bonnie Buchlyvie ( $\mathrm{I}_{4} \mathrm{O}_{32}$ ) & I6 & 3 & & 6 & & 8 \\
\hline Baron's Pride (9122) & I 3 & 3 & 3 & 3 & 2 & 7 \\
\hline Everlasting ( I I 331) & 8 & r & 2 & 2 & & 6 \\
\hline Hiawatha (10067) & 7 & 4 & I & & & 5 \\
\hline Revelanta (1 1876$)$ & 7 & I & & I & & 4 \\
\hline Royal Favorite (10630) & 7 & & & $\mathbf{r}$ & & 6 \\
\hline Signet ( I 68 I6) & 6 & & , & 2 & & 4 \\
\hline
\end{tabular}

Clydesdales of merit in America date back to their early importation. Of these the following may be mentioned as of special distinction : Donald Dinnie 273, by Glancer (339) ; Johnny Cope (4I6), by Justice (420); Glencoe I 58, by Prince of Wales 487 (673); MacQueen 35 I 3, by MacGregor (I 487); Cedric 929 (I087), by Prince of Wales 487 (673); Lord Lyndoch 4 II 3 (4530), by Lord Blantyne (2243); Lyndoch Chief 5642 (8786), by Lord 
Lyndoch 4II3 (4530); Young MacQueen 8033, by MacQueen 35 I3 (5200); Laminated Steel 8700, by Cedric 929 (1087); Benedict 9300 (I0315), by Baron's Pride (9122).

Prices paid for Clydesdales have run into high money in Scotland, although in America values are often on a much lower level. In February, 1912, the Clydesdale stud of William Taylor

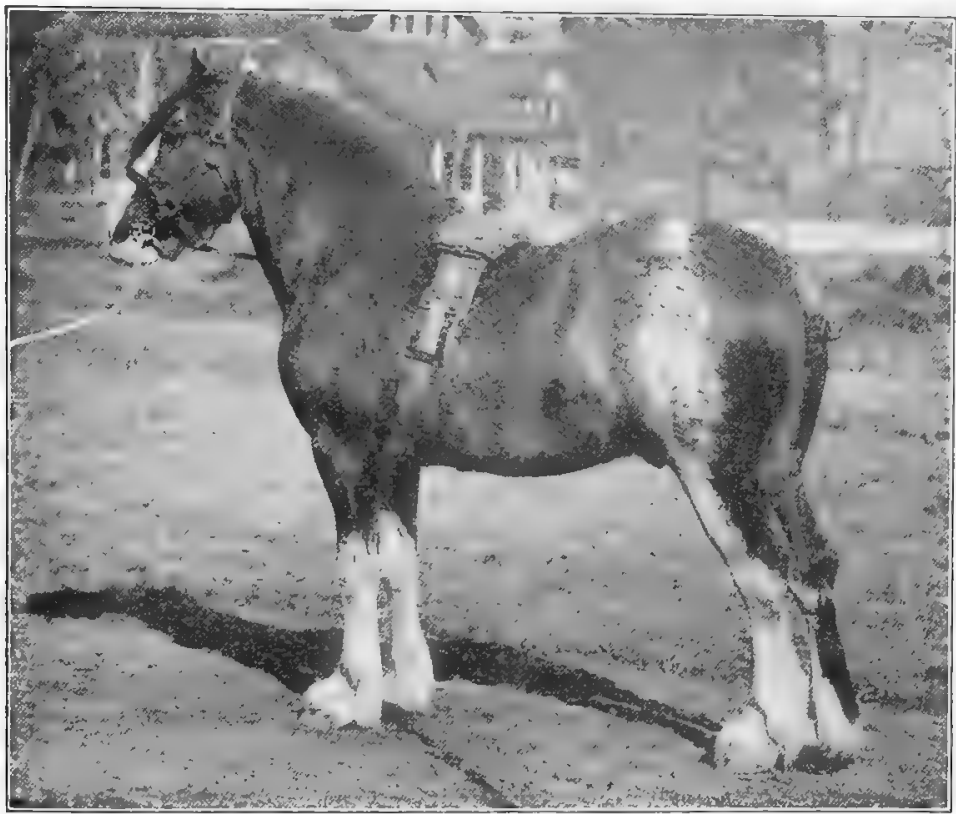

FIG. 54. Fairholm Footprint 17584 , champion Clydesdale stallion at the International Live Stock Exposition. Bred by R. A. Fairbairn and sold for $\$ 5000$ to Langwater Farms, North Easton, Massachusetts. From photograph by Hildebrand, by courtesy of Mr. Fairbairn

of Renfrew, Scotland, was sold at auction in Glasgow. Fifty-four head averaged. $\$ 657$, and nineteen aged horses averaged almost $\$$ 1223. The top price was $\$ 8400$ for Sir Rudolph. On October 7 , I9I 5, in a dispersal sale, Robert Brydon, Seaham Harbor, England, sold one hundred head for an average price of $\$ 1059.50$, a breed record. The stallion Bonnie Buchlyvie (14032) at nine years of age brought $\$ 26,250$. Phillipine, a three-year-old son of Bonnie Buchlyvie, brought $\$ 12,075$. Thirty-four mares averaged 
$\$ 784$. At the dispersal sale of William Dunlop, at Ayr, Scotland, January I4, I9 I9, thirteen stallions averaged $\$ 8382$, a record not equaled by any other breed. The horse Dunure Independence, by Baron of Buchlyvie, sold to Robert Bryan of Cumnock for $\$ 25,725$, the high price of the day. Dunure Refiner, by Dunure Footprint, brought $\$ \mathbf{I} 8,375$. Dunure Kaleidescope, by Baron of Buchlyvie, brought $\$ 21,525$. Dunure Keynote, full brother to Dunure Footprint, brought $\$ 17,325$. Prince of Albion $(6 \mathrm{I} 78)$ is said to have sold for $\$ 15,000$, and the highest price ever paid

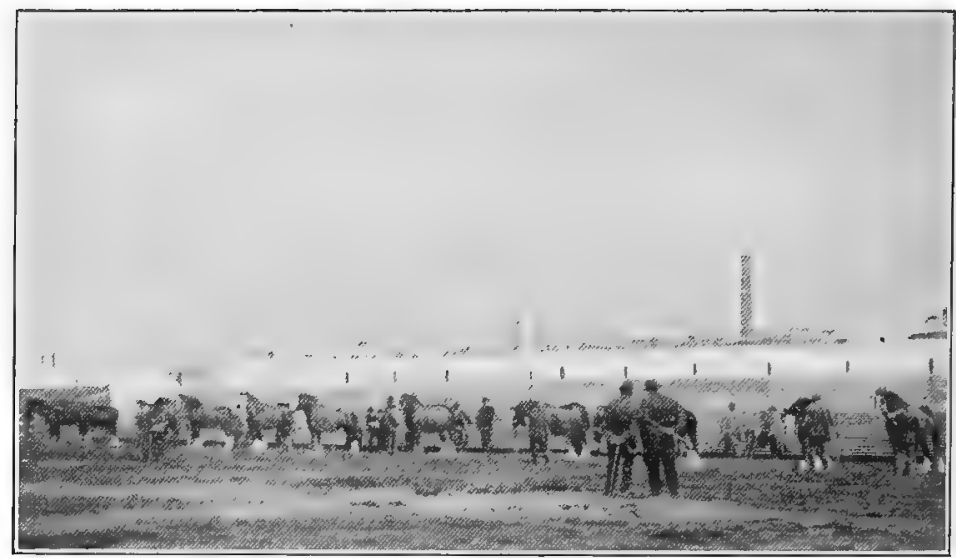

FIG. 55. Judging Clydesdales at the Highland and Agricultural Society Show, Glasgow, Scotland. From photograph by the author

for a two-year-old filly was $\$ 5000$ for Montrave Rosea, by Prince of Albion. As noted elsewhere, Baron of Buchlyvie (I I 263) sold in I9I I for $\$ 47,500$, the highest price paid for a draft horse to I9I9, being equaled, however, in I9I 7 by the Belgian Farceur.

The distribution of the Clydesdale is very widespread, but it has found most favor in English-speaking countries, notably Canada, Australia, and New Zealand. Under normal conditions there is a rather active exportation from Scotland to other countries. In 1913 Alexander Mowat ${ }^{1}$ reported from Scotland that in I9I2 there were I I 56 Clydesdales exported to Canada, as compared with I 349 in I9I I ; 57 to the United States against 97 in I9I I ;

1 Breeders' Gazette, January I, 1913. 
and 32 to South Africa against 25 in I9I I, with smaller numbers to Australia, New Zealand, South America, Russia, Sweden, and Hungary, a total of 1318 exported in I9I 2 and of 1617 in 1911. In the United States the breed has not been altogether popular, and there are comparatively few studs in this country, some of the best being in New Jersey, Pennsylvania, Massachusetts, Michigan, Wisconsin, and Illinois.

Organizations for promoting Clydesdales are mainly represented by registry associations. The Clydesdale Horse Society of Great Britain and Ireland was organized in 1877 and published the first volume of its studbook in I878, since which time, up to 1917 , it has published forty volumes and registered r9,59I stallions and 44,44 I mares. The American Clydesdale Horse Association was organized in I877 and up to January, I9I7, has published twenty volumes of studbooks, covering about 20,000 registrations. The Canadian Clydesdale Society has published twenty-six studbooks up to I9I8, and far-away New Zealand has a Clydesdale society that published two studbooks up to I9I 5 inclusive. 


\title{
CHAPTER XVII
}

\author{
THE SHIRE
}

The very early history of the Shire horse traces back into the days of Roman conquest and almost prehistoric times. Abundant evidence as set forth in British history by the earliest writers makes it clear that a heavy type of work horse existed in those days. During the period when armor was worn it was necessary that a horse be of good size and be able easily to bear heavy weight in the saddle. According to the Venerable Bede, however, the English did not commonly use saddle horses until about A.D. 63I. Neither was the horse used for war purposes in the first thousand years of the Christian Era. In the sixteenth century in England, when armor was used, according to Tower of London officials a man's armor weighed $99 \frac{1}{2}$ pounds, the horse's $8 \mathrm{I}$ pounds, and the spear 20 - a total of 200 pounds approximately. Adding to this the weight of a man, the horse had to support nearly 400 pounds, so that the necessity for a heavy horse in these days was very apparent.

Various early paintings show the draft type of horse in use. Albert Dürer, in I 505 , made a painting of "The Great Horse," as it was termed. Vandyke, about 1620 , painted a picture showing the Duke of Arenburg on such a horse. A famous painting by Paul Potter shows such a horse about 1652 .

The special region of Shire horse breeding in England has been in the east-central part, in the counties of Lincoln, Cambridge, Huntingdon, Northampton, Leicester, Nottingham, Derby, and Norwich. However, the breed has been extensively produced on the low-lying lands outside of this area. During its past history it has been known in England as the "Great Horse," the "War Horse," the "Cart Horse," the "Old English Black Horse," the "Giant Lincolnshire," and the "Shire." The name "Large Black Old English Horse" was in use from the time of Oliver Cromwell (I649-I659) to modern times. 
The real origin of the Shire is fairly speculative. It is known that horses of this large draft type existed in England from very early times. We are told that a large draft type of horse existed in Flanders, in Holland, and in Germany in the valley of the Elbe, and that one hundred stallions were brought to England from these countries as early as the twelfth century. These were used on the English horses of large type. Referring to the great paintings of cattle and sheep made by Paul Potter, who died in Amsterdam, Holland, in I654, Sir Walter Gilbey says ${ }^{1}$ : "It is only reasonable to suppose that he exercised equal care in painting horses. The strain of North German and Flandersblood was at this period so strongly represented in our English Great Horses of the best stamp that we need not inquire whether this horse was of German, Flemish, or English origin, the character of all being practically the same." Thus no doubt the early Shire

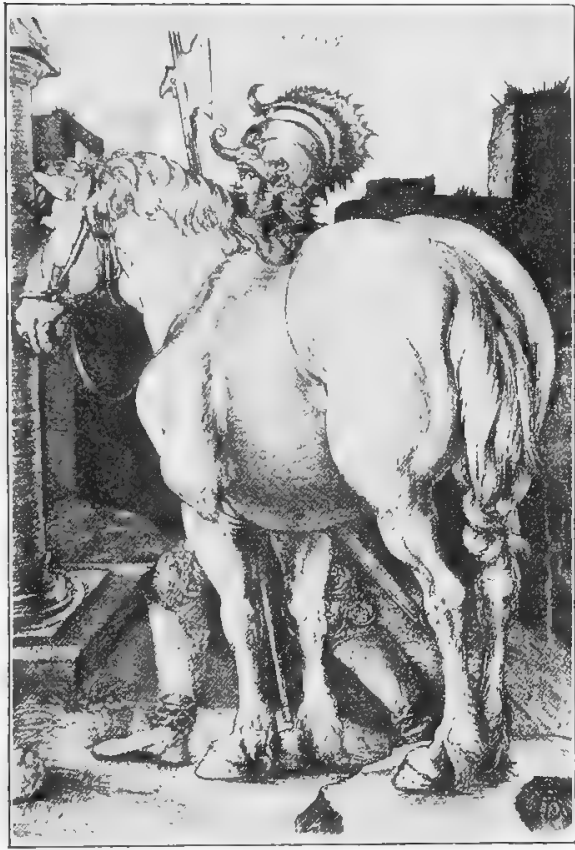

FIG. 56. "The Great Horse." Reproduced from a drawing of the painting by Albert Dürer. It is from this horse of the sixteenth century that the Shire is supposed to have derived its ancestry was of very mixed breeding.

Robert Bakewell improved the Shire during the latter part of the eighteenth century, though it was then known as the Leicestershire Cart Horse. Bakewell was the earliest important improver of the English Shire horse. He went to Holland and imported mares, using them in systematic crossing with

1 Sir Walter Gilbey, Bart., The Great Horse, or the War Horse; from the time

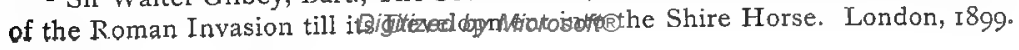


English stallions. He pursued a careful course of selection and added to the value of the breed. It was during this century that this class of horses came into use for draft and farming purposes, the coat of armor having become obsolete. With the improvement of roads and the use of coaches the draft horse came into special demand. Gilbey, in his interesting historical work on "The Great Horse," gives copies of pictures of Shire horses: one, the horse Elephant, by an unknown artist about 1792;

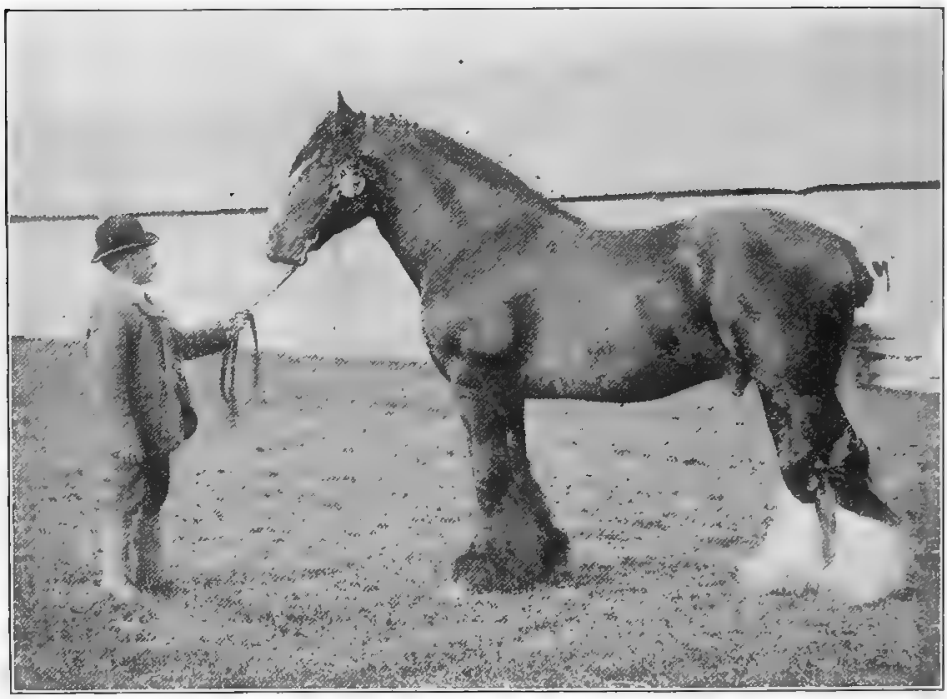

Fig. 57. Intake Albert, champion Shire stallion at the show of Royal Agricultural Society of England, 1904. From photograph by courtesy of American Agriculturist

another, a gelding in use by a brewery in I792, painted by Garrard; and a third, of two horses, Pirate and Outlaw, painted in 1810 by Zeitter. These horses are all of draft character, with hairy legs, mane, and tail.

The old-fashioned type of Shires were large, coarse, and slow. They had big heads, coarse ears, and their thick lips had long hairs on them. The shoulders were heavy, the legs hairy, and the pasterns straight. Their action was sluggish, but their temperament was mild. Excess of hair seemed a characteristic, as based on some of the pictures extant. In I842 Low wrote: 
The modern English Black Horse retains the general characteristics of the preëxisting race, but greatly modified. His color is usually a sooty black, with frequently a white lozenge-shaped mark on the forehead; and he has very generally one or more of the feet and part of the legs, and not unfrequently the muzzle, white. His body is massive, compact, and round; his limbs are stout, his chest is enormously broad, and his neck and back are short. His mane is thick and somewhat frizzled, and his legs below the knee and hock are hairy down to the heels. His whole aspect conveys the idea of great physical power without corresponding action. The main defects of this conformation and temperament are his too great bulk of body and want of action and mettle. For a pull with a heavy weight he is admirable.

Different varieties of the Shire formerly existed in England; some have said two, others three. In the first "Shire Studbook" Dr. Reynolds groups the breed into three varieties; namely:

(I) Those having the upper lip garnished with a long, thick moustache, considered at one time a distinguishing characteristic of the Lincolnshire horse.

(2) Horses having the lips, muzzle, and eyelids destitute of the hair. The skin in these places is either entirely bald or covered with exceedingly fine down, is almost invariably flesh colored, and is sometimes marked with small dark spots and blotches. These are termed bald horses or bald faced.

(3) Those having a long tuft of hair growing from the front of each knee, and rarer examples having also a similar growth from the hind part of the hock, just below its point. This is quite different from the ordinary hair on the back of the cannons.

It is also to be noted that in the past the horses in some counties of England have differed from those of other counties. However, modern effort on the part of breeders has succeeded in producing a more uniform type, in which greater refinement, better bone, more action, and perhaps less hair are found.

The modern Shire horse is an improvement over the horse of fifty years ago. The features of large size, hairy legs, and draft type have been maintained, but the modern Shire has more action and life, possesses more quality and finish, and has more uniformity of type than had his ancestors. The English breeders recognized the need of improvement of their draft horse and emphasized quality, action, flat bone, and uniformity. In recent times this improvement has been greatly aided by the. Shire Horse Society and the comparisons possible through the exhibitions of this society at Islington. Blaferzater Nivitosbkelter Gilbey, a constructive 
breeder and horse student who died in 1916, was long a leader in the work of improving the Shire.

Importation of Shires to America began many years ago, but just when the first of this sort came over cannot be absolutely stated. A horse named Tamworth, possibly of this breed, was brought from England to London, Ontario, Canada, in I836.

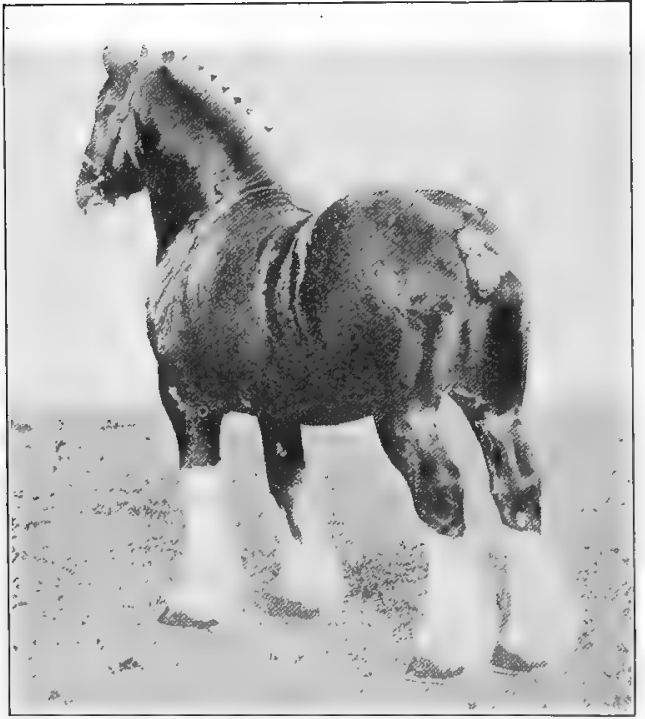

FIG. 58. Boro Blusterer I 4 I 87 (3I I 40), grand-champion Shire stallion at the Panama-Pacific and International Live-Stock Expositions, I9I 5. From photograph by IIildebrand, by courtesy of Truman's

Pioneer Stud Farm, owners, Bushnell, Illinois

In I 847 another horse, named King Alfred, was imported. In I 853 a Mr. Strickland brought a stallion known as John Bull from England to Aurora, Illinois, where he became well known. Several others were imported into northern Illinois soon after this. George E.Brown, long a prominent Shire breeder at Aurora, states that as far as he has been able to learn, the earliest advertisement of Shires by any importer in Western agricultural paperswas in 1875 . Along in the eighties many stallions were brought to America from England. In recent years there has been but little activity in importing, the leading importers being in northern Illinois.

The characteristics of the Shire that distinguish the breed and which may be considered of most interest are the following : the lead is large, with a tendency to Roman profile. The withers are high, the back strong, with wide-sprung and deep ribs, showing a large middlepiece. The croup is comparatively level and wide, and the quarters are powerfully muscled. The legs are large, and 
the bones tend to be a bit coarse. British critics in the past have objected to round cannons and meaty bone. In recent years this criticism has not been warranted. The pasterns have been subject to unfavorable comment as being too short and not sloping enough, though this does not apply so much to modern, well-bred Shires. The feet are very large and often shelly and tend to be flat at the heel. The back of the cannon bones, knees, and hocks have long, flowing, fine hair (frequently termed "feather") on the best examples of the breed. Excessive leg hair and heavy bone are objected to as evidences of sluggishness and lack of quality, as compared with less hair and finer bone. The hairy legs of the Shire have always prejudiced Americans against the breed, while in England considerable adverse criticism exists, as is evidenced by the following from C. W. Tindall in the Lire Stock Joumal of London :

What I would particularly like to call attention to, and which for some years has been a matter of great controversy and is now one of very serious importance, is the question of hair. In my opinion we have for a long time thrown away the substance for the shadow, and the excessive quantity of hair that we have in many of our Shire horses is not only a detriment to the horses, but loss in money value to the breeders. So far as I can make out, none of the users of the Shire horse want it. I am in London most weeks, and I never go through London without seeing a number of Shire horses with the hair clipped off their legs. None of the users in town want it, and so far as I know, few of the farmers, especially on strong land, want it. I believe there is no doubt whatever that the Shire is the finest draft horse in the world, and in my opinion if he could be divested of hair he would take possession of all the foreign and colonial markets. . . . From what I could gather in the Argentine, everyone liked the Shire the best, but they could not stand the hair on his legs; hence the reason the Percheron has practically taken possession of the market, and from what I can gather this applies equally to Canada, Australia and other markets, and I am of the opinion that in the future something must be done to remedy this defect.

The action of the Shire in the past has been a subject of unfavorable comment; it being regarded as heavy and sluggish. The great weight of this horse naturally influences his action, causing a slow movement. The more modern type of the Shire, however, has been improved in this regard, although he is yet decidedly inferior to the other draft breeds of prominence. 
The color of the Shire is commonly bay or brown, with white markings on the face or forehead and on the legs below the knee or hock. There is considerable variation, however, in Shire color. Gray, black, chestnut, or sorrel are not uncommon, while shades of roan also prevail to a minor degree. A Shire of chestnut

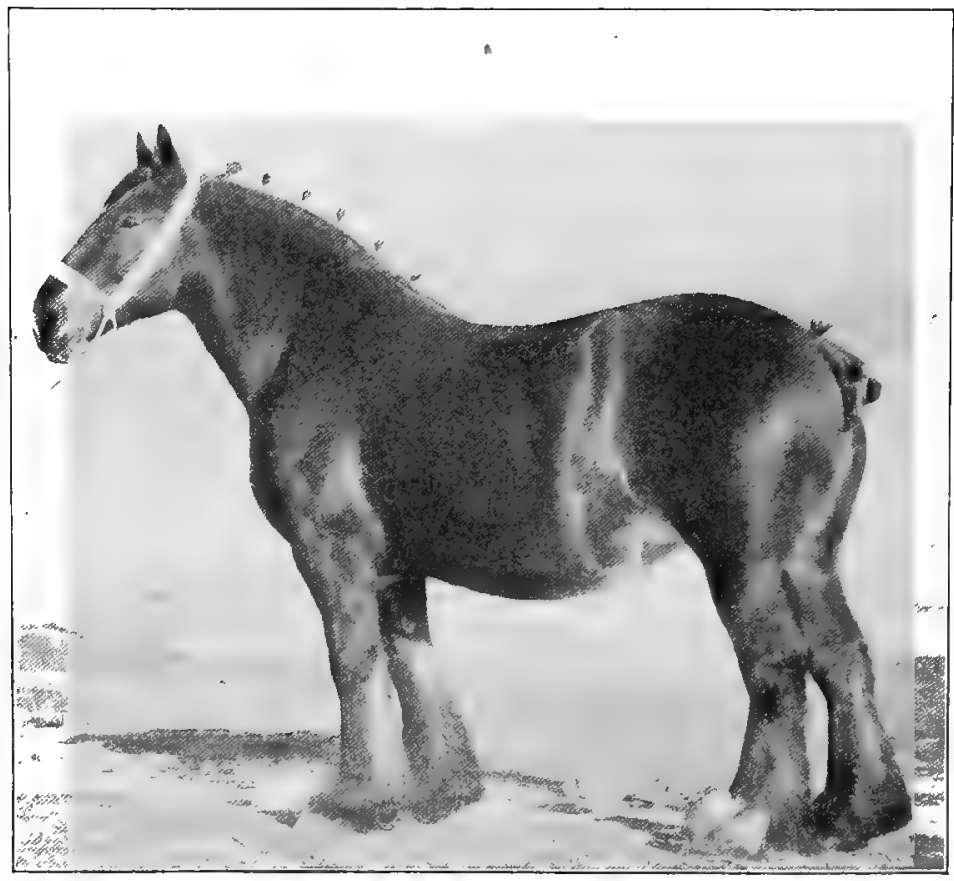

FIG. 59. Woodfield Starlight r68I4 (76532), champion Shire mare, International Live Stock Exposition, I918. Owned by Truman's Pioneer Stud Farm, Bushnell, Illinois. From photograph by Hildebrand, by courtesy of the owners

color is regarded in England as having a tendency to softness. A bay or brown Shire with white markings appears identical with the Clydesdale, so that when the two breeds are in the same stable it is quite difficult if not impossible in some cases to distinguish one from the other.

The size of the Shire exceeds that of any other draft breed known in America or Great Britain. In height the mature stallion should stand close to 17 hands, although the average may be 
about half a hand less. The zueight of the Shire of real drafty character ranges from I 800 to 2000 pounds, the latter figure not being uncommon. Discussing the subject of heavy weight of the Shire, Mr. J. G. Truman, a noted importer and authority on this breed, states ${ }^{1}$ that the heaviest horse he ever saw was the Shire stallion Great Britain (978), imported by his father in the early eighties. On the docks at Boston, after a stormy passage, he weighed 2775 pounds, and two weeks later at Bushnell, Illinois, weighed 2830 pounds and was not what would be considered fat. The heaviest mare ever seen by Mr. Truman was Fuschia, junior champion at the Shire Horse Society Show in London, weighing in her four-year form 2475 pounds.

The crossbred or grade Shire is frequently an excellent animal, showing more activity and quality than prevails in the pure bred, especially if one parent is of lighter and more active type. The great size of the Shire contributes a degree of substance highly desirable in draft work. In 1904 a grade Shire of remarkable size and quality was sold on the Chicago horse market for $\$ 865$, up to that time the highest price on record in this market for a draft gelding. A combination of Shire and Clydesdale blood is harmonious, producing a desirable crossbred that has long been in use.

The special field for the Shire is in heavy draft work on comparatively level roads, where slow, steady service is wanted and action is a minor consideration. On the level prairies of the West this horse would no doubt meet with an encouraging degree of popularity were it not for the hairy legs. At the plow or in hauling heavy loads the Shire is surpassed by none, but his hairiness, if nothing else, bars him for place as a favorite. In spite of the British claim to the contrary, the American farmer believes that these hairy legs promote scratches, and covered with frozen mud they certainly are a source of discomfort.

The temperament of the Shire, as already indicated, is phlegmatic and quiet. Without doubt the Shire is steady under the collar and easy to manage under most conditions. In England one will see many of these horses hauling great loads in the cities and working at heavy labor on the farms, giving every evidence of patient, dependable service. 
The soundness of the Shire horse has been made a subject of special investigation in connection with the annual show of the Shire Horse Society in London. Between I893 and I91 2, veterinarians examined 6457 horses presented for show, rejecting 577 , or about Io per cent, the average for twenty years being about 8 per cent a year. It is interesting to note that of the several forms of unsoundness 33.5 per cent was due to sidebones, 9.2 per cent to spavins, and 5.9 per cent to ringbones, while 26 per cent was due to defective respiration.

Important Shire stailions of breeding fame in England seem to date back to about 1755 .

Packington Blind Horse, said to have been foaled about $\mathrm{r} 760$, was recognized as a prepotent force in early days in the counties of Leicester and Derby.

Honest Tom (1062), foaled in 1806 in Lincolnshire, was a prominent sire in his day, and his descendants proved his merit. This horse at five years of age sold for 300 guineas (\$ I 500). He was also known as Old Tom, alias Little David, alias Old David.

William the Conqueror (2343) was foaled in I 862 in Nottingham County. He was a brown in color, a winner of some prizes in the show ring, and was the sire of Prince William (3956), Esquire (2774), and Staunton Hero (29I8), all noted stallions.

Lincolnshire Lad II (1365), foaled in 1872, a gray. in color, was one of the best-known modern sires of show-ring winners. He stood I 7 hands high, had an excess of hair, was somewhat lacking in depth of body, but had much ambition and courage and proved a great getter of superior stock.

Bar None (2388), a bay, foaled in 1877, was bred by Thomas Holmes of Yorkshire. He won the Shire Society championship in I 882. He attained great success in the stud, transmitting superb quality and high-class legs.

Premier (2646), a bay, foaled in I 880 , was bred by John Fisher of Lancashire. His sire, What's Wanted (2332), was a wellknown show and breeding animal. Premier proved a quite successful sire of prize-winning animals at the Shire Society Show.

Harold (3703), a brown, foaled in $188 \mathrm{I}$, bred in Derbyshire, won numerous important prizes in the show ring. He was very meritorious as a sire, transmitting to his offspring size, excellent 
bone, and plenty of energy. He was sired by Lincolnshire Lad II (I 365 ), previously referred to.

Prince William (3956), by William the Conqueror (2343), had for dam Lockington Beauty, by Champion (457). He was foaled in 1883 and died in 1905 , aged twenty-two years. For twenty years

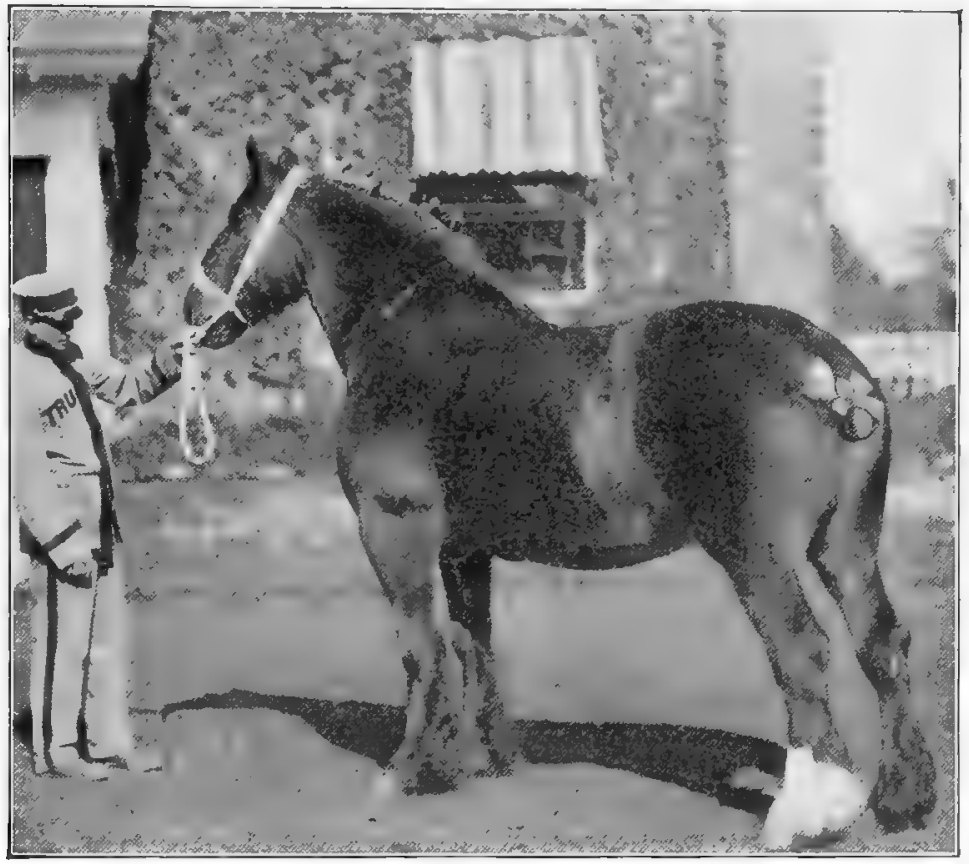

Fig. 6o. Harfine Bonsor, a fine type of Shire mare owned by Truman's Pioneer Stud Farm, Bushnell, Illinois. Photograph by Hildebrand, by courtesy of owners

he stood at the head of the stud of Lord Wantage, Lockinge Park. In I 894 fifty-two animals sired by him sold at an average of $\$ 600$.

Hitchin Conqueror (4458) was foaled in 1883 , being sired by William the Conqueror (2343). His dam was Flower, by Honest Prince (1058). Hitchin Conqueror sired many fine prize winners and superior breeding animals.

Bury Chief Victor (I I I05), a black with white markings, was foaled in i889. He was a horse of very superior conformation, a great show animalitiand prize winner, and a superior sire. 
In I 89 I he was sold to Mr. Wainwright for 2500 guineas (\$ 12,500$)$, the highest price for a Shire up to that time.

Lockinge Forest King (I8867), a bay, foaled in I899, was bred by Lord Wantage. He was sired by Lockinge Manners (I6780) and out of (4470) The Forest Queen, by Royal Albert (1885). The most noted of recent-day sires, many of his sons and grandsons have proved sires of great prepotency and value.

Birdsall Menestrcl (19337), a bay, foaled in I900, was bred by Lord Middleton, Birdsall House, York. $\mathrm{He}$ was sired by Menestrel (I4I80) and out of (22925) Birdsall Darling. This horse attained fame in the show ring and has proved a sire of distinct merit.

In a study of prepotent Shire-blood lines ${ }^{1}$ Ellis D. McFarland brings out the fact that of the 2218 Shires awarded prizes at the Shire Society Show at London during twenty years ending . in I912, 2150 trace directly to common progenitors, of which but ten are of much importance. Lincolnshire Lad II has always ranked first in the list of common progenitors. From I883 to I 899 Matchless ranked second, but since that time he has held third place, with William the Conqueror second. These are the three outstanding sires. The number of prize winners from 1893 to I9I 2 tracing directly to famous sires are as follows : 1257 trace directly to Lincolnshire Lad II ; 440 to William the Conqueror; 235 to Matchless; 81 to Bar None; 63 to Lincoln; 62 to Royal Albert ; 45 to Major; 4I to Vulcan; 19 to Heart of Oak; and 9 to What's Wanted.

The distribution of the Shire horse is world-wide. In England this is the common draft breed and is especially conspicuous in the low-lying central farming sections and in the large cities. The Shire has secured a foothold in most of the English-speaking colonies; and prior to the World War many were exported to Australia and Canada, while Germany and Argentina have also imported a considerable number. In the United States the breed is best known in Illinois, Iowa, Indiana, and Ohio, its logical field being in the corn-belt states.

The prices paid for Shires mount into very high figures. In Ig09 the stallion Tatton Dray King (23777), champion of the

1 Breeders' Gazette, June I I, I9I4. 
Shire Society Show, sold for 3700 guineas, or about $\$ 18,500$, at the dispersal sale of horses of the late Earl Egerton of Tatton, Cheshire, England. In this sale 21 head sold for an average price of about $\$ 2325$. The stallion Dan Patch 9856 (28815), foaled in 1905 and champion at the International Live Stock Exposition in I9IO, was sold during the show by Truman's Pioneer Stud Farm of Illinois, importers, for $\$ 10,000$. In I9I I the mare Bellingsborough Belle sold at auction in England for $\$ 6200$, the high price for a Shire mare up to that time. In March, 19I3, the two-year-old stallion Childwick Champion (22215) sold at Lord Rothschild's sale for $\$ 20,664$. At the dispersal sale of the Tring Park stud in England in I9I 5 the average price received for 47 animals of both sexes was $\$ 2822$, the average for 32 stallions and colts being $\$ 36$ I 4 . In 1918 the five-months-old horse foal Pendley Goalkeeper sold in England for $\$ 7000$. In various sales held in England in 1916

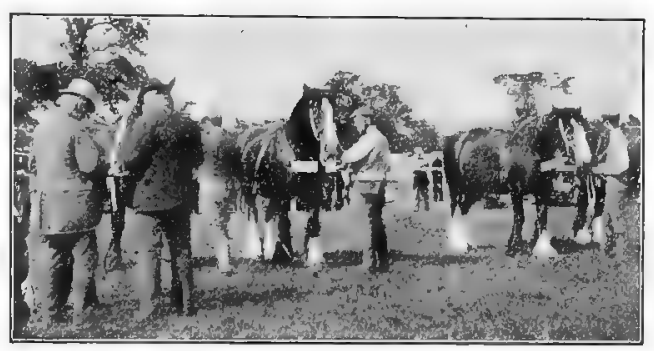

FIG. 6r. Placing awards on Shires at the Royal Show, England. From photograph by the author

Shire stallions sold up to $\$ 55,000$, Norbury Menestrel bringing this price at the sale of the late L. Solomon. Many Shire mares and fillies have sold at prices ranging from $\$ 750$ to $\$ 2000$.

Associations to promote the Shire horse are comparatively young. The English Cart Horse Society was organized in 1878 , essentially to promote the Shire, and in I884 it changed its name to that of the Shire Horse Society. Up to January, I9I9, this society had published thirty-nine volumes of studbooks and had registered I 26,437 animals. As long ago as I 898 the society had 2237 members. The annual show of the society is the greatest single-breed horse show in Great Britain, some 700 horses usually being exhibited. The Shire Horse Society of Canada published Volume I of its studbook in 190 I and Volume III in I9I 4. The American Shire Association was organized in I885, and up to January, I9I9, has published twelve volumes of studbooks. 


\section{CHAPTER XVIII}

\section{THE SUFFOLK}

The native home of the Suffolk horse, or Suffolk Punch, as it has been known, is in Suffolk County in the eastern part of England. This county is flat in character with clayey soil, is generally cultivated, borders on the seashore, and comprises about fifteen hundred square miles. This is a thickly populated community, the farms small and highly cultivated. The county of Essex, which joins Suffolk on the south, may also be considered to some extent within the native territory of this breed.

The early history of the Suffolk horse traces clearly back to about I 700. While Normandy horse stock has been assumed by some as playing an early part in the formation of the breed, no positive information exists on this point. In purity of blood it is believed that the Suffolk surpasses any other breed in Great Britain. The general evidence, as given by various authorities, indicates that for several centuries this horse has been bred in Suffolk with much purity.

The pure-bred Suffolk foundation really dates back to a horse of unknown sire, foaled in I768, known as the "Crisp Horse," being owned by a Mr. Crisp of Ufford, Sussex. To this horse are traced all pedigrees of the breed that may be registered in the studbook of either Fingland or America. This history has been clearly and fully traced and stands accepted by breeders universally. The Crisp horse was a bright chestnut in color, stood $I_{5} \frac{1}{2}$ hands high, and proved a remarkable breeder. In the development of the Suffolk since his time four attempts have been made to introduce foreign blood and thus improve the stock. In no case, however, has this blood held its own, but has been completely absorbed and the breeding lost.

The foreign blood used to improve the Suffolk was as follows:

.I. The Blake strain. This came from the use of a Lincolnshire trotting horse with no Suffolk blood, known as Blake's 
Farmer. This strain was in existence from 1780 to 1880 and at one time was very popular.

2. The Wright strain. This originated from a horse from Lincolnshire known as Wright's Farmer's Glory, or the Attleboro horse. He was a chestnut, clean-limbed, and may have been a half-bred Suffolk. This strain existed from I 800 to about I880.

3. The Shadingfield strain. This came from the produce of a trotting horse, the son of a Thoroughbred, and he also was a chestnut. This strain existed for about half a century, the last being foaled in $\mathrm{I} 846$.

4. Martin's Boxer strin. This appeared to be a Suffolk, though he was not, being out of a "black blood mare." This strain never obtained any foothold beyond two mares of remote breeding.

These strains were all started to improve the breed, but they presented deficiencies; neither could they overcome the predominant Suffolk blood and character.

The history of the modern Suffolk horse is essentially a most compact one. It deals with the development of the breed mainly in Suffolk and vicinity by the farmers generally, and is historically correct, largely due to the far-reaching investigations of Herman Biddell, the editor of the first "Suffolk Studbook." Among the horses of the last century that had much influence on the development of the breed are Edward's Old Briton (490), Catlin's Duke (296), Crisp's Fairhead's Boxer (405), Julian's Boxer (755), Crisp's Cupbearer (I4I6), Garret's Cupbearer 3d (566), and Foxhall (1423). The latter was imported to America by Galbraith Brothers.

The history of the Suffolk horse in America is rather restricted, these horses being comparatively unknown in the United States in the early eighties. In 1882 the editor of the National Lia'c Stock Joumal wrote: "If some of these Suffolk horses could be imported and bred alongside of the Shire and Clydesdale, it would give an opportunity to see what would prove the best for American purposes." In 1883 this same journal states that Suffolks are finding great favor in Canada. However, Powell Brothers of Pennsylvania imported the first stallions to the United States in I880. In 1888 Galbraith Brothers of Janesville, Wisconsin, made their first importation of stallions and Peter Hopley \& Company of 
Lewis, Iowa, the same year imported the first mares. At the World's Columbian Exposition at Chicago in 1893 a few Suffolks were exhibited, mainly by Peter Hopley \& Company, although B. Ramsey of Iowa and Mossom Boyd \& Company of Canada also exhibited. In 1903 forty-one head were imported to America.

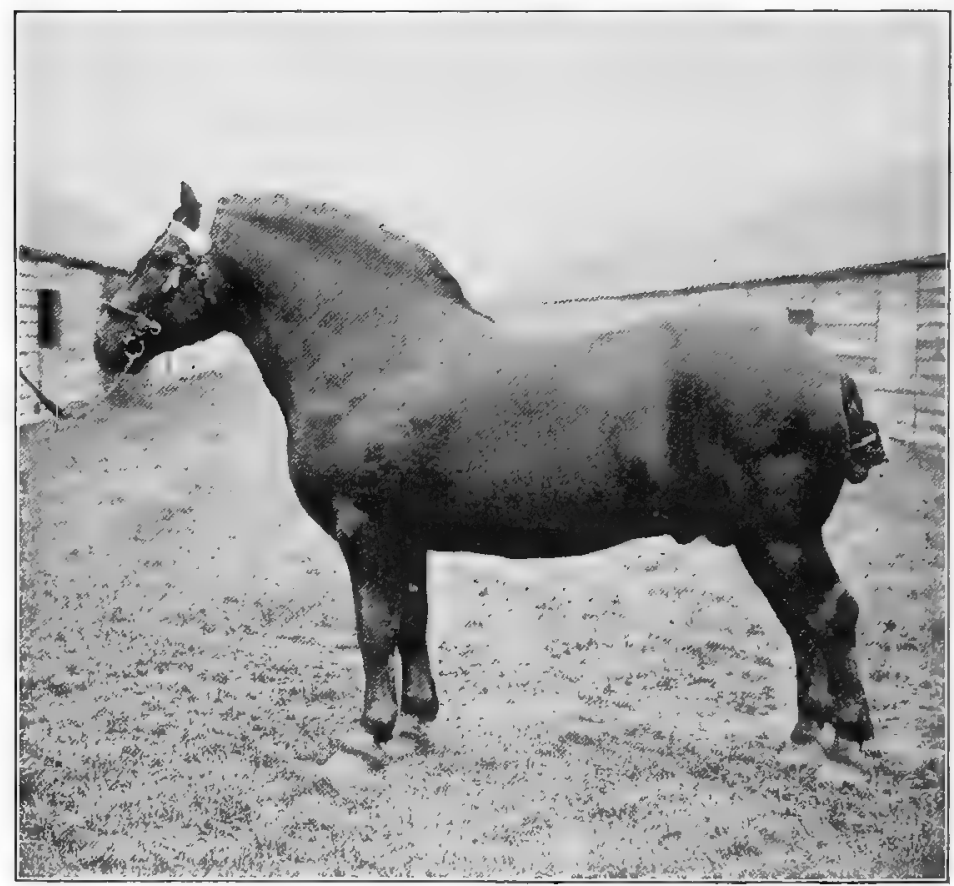

FIG. 62. Sudbourne Count (3257), a typical Suffolk stallion. From photograph, by courtesy of Fred Smith, secretary of Suffolk Horse Society, England

At the 1904 International Live-Stock Exposition an exhibit of about a dozen Suffolk stallions and mares was made by Peter Hopley \& Son. In recent years the breed has been gaining in favor in America, though slowly, and importations have continued in a small way.

Characteristics of the Suffolk horse. This breed has long possessed certain distinctive features, quite marked in contrast with other breeds. The following are worthy of special consideration: 
The Suffolk has a tendency to small ears, the forehead is broad, and the eyes are of medium size and only fairly prominent. The nose tends to Roman form, which has been rather characteristic of the breed. The jaws are strong and the cheeks deep and full. The neck has something of an arch, - in fact, with stallions this is very pronounced, - with not too much heaviness at the crest. The neck sometimes joins the head a bit heavily, but at the shoulders it is, as a rule, well placed. The shoulder should be long but not extremely oblique. A race-horse placing of shoulder is not desired among Suffolk breeders, a straighter shoulder being better, suited to draft work. The body of this breed is one of its notable features. It has long been characterized by great depth and circumference, considering the size of the horse. The ribs have an unusual spring and depth, thus giving the body a very round, full form. Formerly this was unnecessarily deep and round, giving the body a paunchiness from which the term "Punch" was evolved and given as a part of the breed name. Modern breeders object to heaviness of belly. For size the body girths unusuaily well. A girth of about eight feet back of the shoulders is commended. The croup is full and well carried out, the tendency to steepness being slight.

Strong quarters and hocks are a feature of the breed, but there has been some criticism of the hocks. One family, Catlin's Boxer 299, has had this feature of bent hind legs and weak hocks, and Crisp's Conqueror 4I 3 and Cupbearer 416, famous sires as they were, had a tendency to this trouble. The legs of the Suffolk are very free from superfluous hair, and while they have been criticized as lacking in bone, the breeders insist that this is not so. If fairly compared with the long-haired breeds, they maintain that plenty of bone will be manifest. Yet the bone is not large, but of superior texture. A girth of Io $_{2}^{1}$ inches below the knee is given by Mr. Biddell as ample, more being thought unnecessary. The feet have been criticized much in the past. The middle of the last century it was claimed that the feet were flat and the hoofs brittle and that sidebones were common. Now for years, however, by the rules of the Suffolk Society, all horses shown must be submitted to a veterinarian's examination, which has resulted in a great improyement. 
In I 893 Professor Robert Wallace, the Scotch authority, stated that "at one time they were flat-footed and liable to become lame if worked regularly on the hard road or on stone pavements, but the care bestowed upon breeding has in recent years eliminated this defect among animals of the first rank." As seen by the author, the feet tend to be somewhat small and lacking in fullness at the top of the hoof. The quality and action of the Suffolk rank well. The breed cannot be classed as coarse, while in action it stands next to the Clydesdale among draft

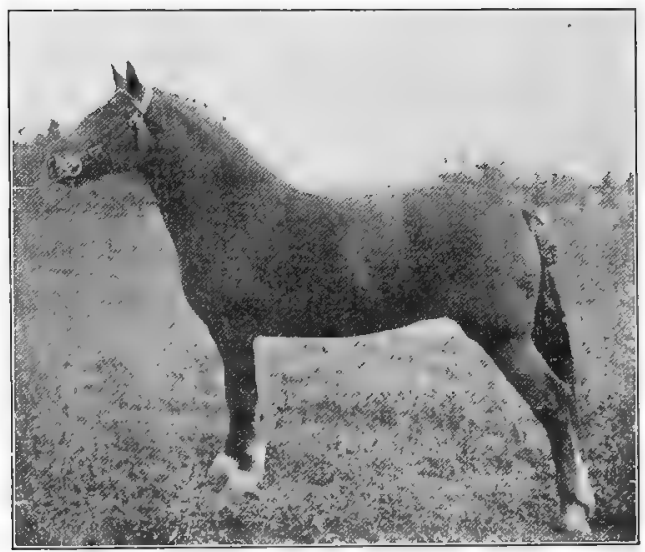

FIG. 63. An American-bred Suffolk mare. From photograph, by courtesy of F. S. Peer horses. Wallace states that they twist their legs and feet when moving, but this does not apply to-day as much as it may have formerly. The height ranges from 16 to $I 7$ hands, though 16 to I $6 \frac{1}{2}$ is more common. In fact, this breed should be short of leg and close to the ground, though the Suffolks the author has seen in this country have shown considerable height and weight. The weight should not run high, I 800 to I900 pounds being ample. Greater weights than this are attained, but they are not typical; for example, Galbraith gives I 800 to 2200 pounds, but this brings him up to a horse of large size among the draft breeds, a thing never claimed by Suffolk breeders. The Suffolk should not be as large as Clydesdale or Shire and is not bred for the heavy draft work of the city, but for farm purposes, where less weight is required. This is generally conceded by advocates of the breed.

The color of the Suffolk horse is one of its most characteristic features, always being chestnut and varying only from light to dark. The statement has been made that in an investigation of 
the color of the Suffolk, twelve thousand matings were examined and every foal found to be of a chestnut color. Biddell allows for seven shades of chestnut, ranging from a dark hue (comparable to liver color or burnt chestnut) to a "bright" one, this latter being the most common and popular of all. A light, mealy chestnut is very unpopular, as indicating weak constitution, soft legs, and slow temperament. A few white hairs in the body color may be permitted but are not desirable. White marks, such as a star in the forehead, a strip or blaze on the face, or white pasterns or ankles, are admissible. In fact "white stockings" sometimes occur, coming as high as the top of the cannon bone. There is a tendency for the manes and tails to be of a lighter shade than the body color, an inheritance from the earlier days when flaxen manes and tails were common.

The fecundity and longevity of Suffolks is highly attested. Numerous cases are given to show that the breed is very prolific and tenacious of life. The dam of Webb's Rising Star (I 266) was twenty-two years old when he was foaled, and the dam of Loft's Cupbearer $(842)$ had sixteen foals in sixteen years. A mare and foal were shown at one of the early Suffolk Agricultural Association shows, the mare being thirty-seven years of age when the foal was dropped. In I9I 7 the Mark Lane Express reported that Mr. Alfred Preston's mare Gladys, then thirty years old, was in active daily farm work and had raised fourteen foals. The great stallion Julian Boxer (755) traveled at least twenty-five seasons and left a large number of superior sons and daughters. Instances have been known where stallions have traveled from sixteen to twenty-one consecutive years, rendering breeding service each season.

The grade or crossbred Suffolk horse is not as yet common in America, while in England the breed is kept pure. Alexander Galbraith states that the grades from native American mares have good size and bone, while they are particularly smooth built and are almost invariably chestnut in color. According to official authority ${ }^{1}$ in the South, grade Suffolks have given such satisfaction as to cause a rapid increase in their use. One breeder

1 The Suffolk Horse. A pamphlet by the American Suffolk Horse Association, I917. 
in Texas says that grades bred under range conditions have proved superior to all others. In Minnesota grade Suffolks outsold the grades sired by horses of two other breeds.

The Suffolk as a draft horse ranks high among the farmers of eastern England. It is considered capable of doing a maximum amount of labor on a less amount of feed and for longer periods than other drafters. This is the opinion of the people of Suffolk, however. Its steadiness and persistence at pull have long made

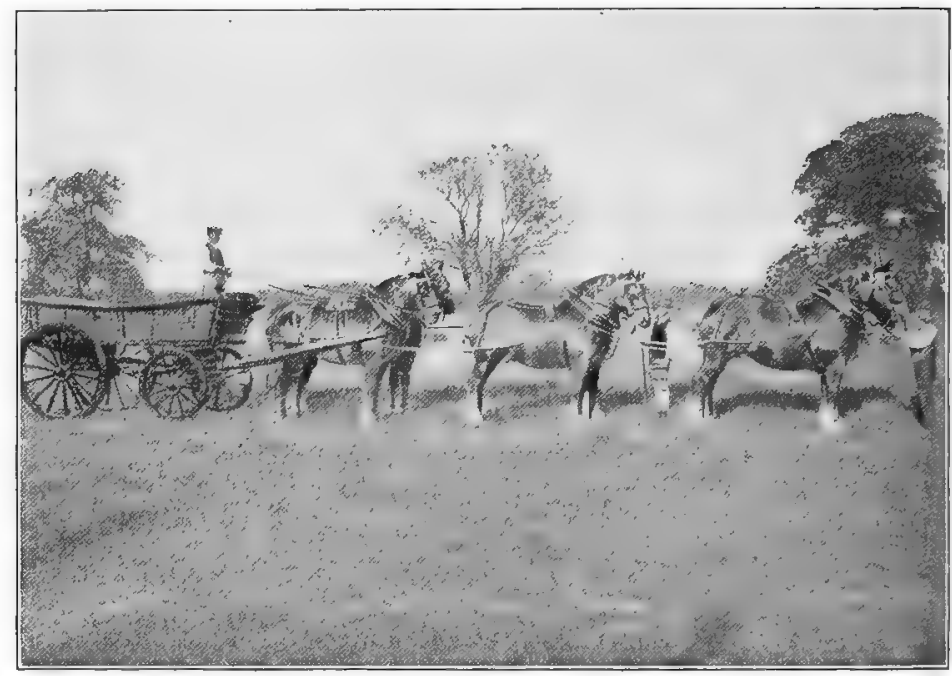

Fig. 64. A great six-horse hitch of Suffolks. From photograph, by courtesy of Fred Smith, secretary of Suffolk Horse Society, Woodbridge, England

the breed famous, but this same characteristic is probably equally well established with other breeds. During the World War the Suffolk horses used in the British army in France showed great endurance and made a most favorable impression.

The distribution of Suffolk horses is extremely widespread, in fact more so than is commonly supposed. They have been exported to Argentina, Australia, New Zealand, Spain, France, Austria, Germany, Sweden, Russia, South Africa, and the Nile region of Africa. In Canada and the United States they have no great foothold, but are scattered over these countries in a small way. 
In this country up to this time they have been best known in Iowa, but important studs have been established in recent years in Texas, Virginia, West Virginia, and Illinois. Small studs have also been formed in other states, notably Massachusetts, Washington, and Oregon.

The promotion of the Suffolk horse has long been conducted by the Suffolk Horse Society in England, and in I880 this organization published the first studbook of the breed. Up to January, I9I9, this association had published twenty-two volumes. The American Suffolk Horse Association was organized in I9I I and up to I9I9 had published but two volumes of its studbook.

The prices paid for Suffolk horses have greatly strengthened in recent years, but the demand for them has been essentially local. One thousand dollars is recorded as paid for mares in 1919, and the stallion Freston Khedive changed hands at $\$ 6250$. The Suffolk mare Beatrice was sold at Sudbourne, England, for $\$ 4500$, and her foal brought $\$ 1500$. 


\section{CHAPTER XIX}

\section{PONIES}

What is a pony? By common consent at the present day a pony is regarded as a small horse the height of which does not exceed $14 \frac{1}{2}$ hands. However, in discussing this subject Sir Walter Gilbey states ${ }^{1}$ that prior to the organization of the Hackney Horse Society in 1883 the dividing line between the horse and pony in England was vague and undefined. It was then found necessary to distinguish clearly between horses and ponies, and I4 hands was made the standard. The Polo Pony Society, however, established I $4 \frac{1}{2}$ hands as the extreme height for a polo pony, and this also is the maximum allowed by the American Shetland Pony Club. Prior to 1883 , according to Gilbey, small horses in Great Britain were indifferently known as galloways, hobbies, cobs, or ponies, irrespective of their height. It is interesting to note that the Thoroughbred two hundred years ago is said to have had an average height of 14 hands, but he has gradually increased in stature, so that to-day his standard is 15 hands $2 \frac{1}{2}$ inches. Ponies vary in height standards, according to breeds and classes.

The Welsh pony has long been bred in Wales, where for hundreds of years it has been used among the mountains of that country. It is said that these ponies were much improved early in the eightcenth century by crossing with a small race horse called Merlin. They have also been somewhat improved by the use of Arab blood. Considerable variation occurs among Welsh ponies in size and also in type. These variations have been recognized by the IVelsh Pony and Cob Society of Great Britain by classifying them for show and registration in four sections, $A, B, C$, and $D$, as follows :

A. Welsh mountain pony. Part I. Height not to exceed I 2 hands. Color of any sort. In type this resembles a small Arabian or Thoroughbred, possessing much the same character and carriage of head, rump, and tail. It is

1 Thoroughbred and Other Ponies. London, 1904. 
found in the more hilly sections and has great bone and superior muscle and endurance. No doubt it was originally improved by Arab and Thoroughbred stallions. Part II. Height not to exceed $\mathrm{I} 2 \frac{1}{2}$ hands, and to be more cobby in appearance than ponies in Part I.

$B$. Should range from $12 \frac{1}{4}$ to $13 \frac{1}{2}$ hands, is of the cobby type, and is not as well adapted to mountain lands as the preceding. In harness both classes $A$ and $B$ make a very showy appearance.

$C$. Should range from $13 \frac{1}{4}$ to $I 4 \frac{1}{2}$ hands. This comes into the cob class, a blockier sort than $A$ and $B$.

$D$. There is no height limit in this class, but these ponies are suited to mounted infantry or cavalry service. Ponies of classes $B$ and $C$ are freely used in Wales, where, attached to really heavy carts, they trot across country at remarkable speed.

\section{"A typical Welsh pony,"} says F. T. Barton," "should have a small clean-cut head, wide between the eyes, and the muzzle should taper so that it becomes free from bluntness. A narrow muzzle is the correct type in this and every other variety of pony, whilst the nostrils ought to be large and thin in their cartilage." Barton emphasizes a slender neck of the Thoroughbred sort rather than a

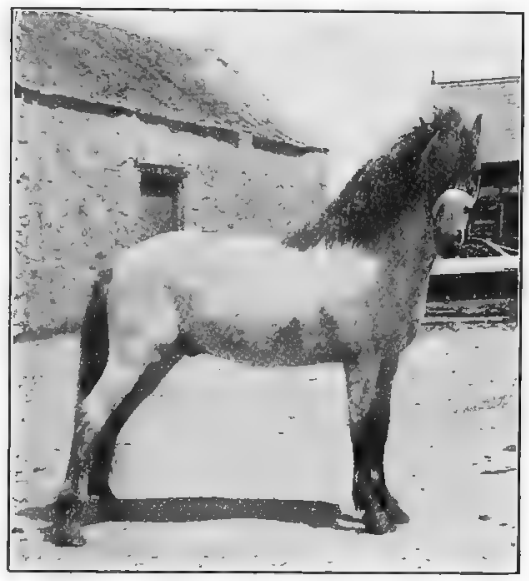

FIG. 65. Merlin Myddfai, a typical Welsh pony, bred by John Jones, Llandudno, Wales. From photograph by the author short thick one, and states that "a short-coupled strong back and loins, together with long and fine compact quarters, a deep girth, and fine shoulders, are features requisite to the Welsh pony or cob."

Welsh ponies have been used in America for many years, but are now attracting more attention than ever. They possess more style, action, and size than the Shetland and are suited to either saddle or harness. A good specimen of the breed should at least show plenty of speed and forcible knee and hock action. Owing to their general activity and endurance they find favor for polo playing. 
The Exmoor pony has long been known on the moors of southwestern England in West Somerset and North Devonshire. Here, on some twenty thousand acres, these ponies have been bred more or less wild for perhaps centuries. This breed has been classed as the highest type of pony, closely resembling the Arab in conformation. Captain W. C. Kerr describes the Exmoor in part as follows:

The true Exmoor pony is a strong, well-knit, I3-to-I4-hand animal of the dray-horse sort in miniature type . . ., sure-footed, docile, generally bay in color, and possessing an iron-clad constitution.... His salient points are strength of loin, well-sprung ribs, great breadth of chest; in fact, he is what your people would term a "chunky" little fellow.... All are natural fencers, and the way they surmount the tremendous banks is marvelous. I ought to mention that their heads are very neat and blood-like, in some cases very Arablike; they carry their tails gayly, have a little silky hair about the heels, but, like all our ponies, are often faulty about the shoulders.

These ponies commonly have a mealy color of the muzzle and flanks, and their color is dominant, it is claimed, even in the crossbreds. The standard colors are bay or brown, but those of dun color are not infrequent. A dark streak along over the spine is also characteristic. The Polo Pony Studbook gives the height as ranging from $\mathrm{II}_{2} \frac{1}{2}$ to $\mathrm{I} 3$ hands. Exmoor ponies have been considerably improved by Arab and Thoroughbred blood. The improved form meets with favor for polo playing, for use with children in saddle, and as a harness pony for cart, phaëton, or other light vehicle. There are but few Exmoor ponies in America.

The Dartmoor pony derives its name from an extensive tract of about two hundred thousand acres of land in Cornwall, in the extreme southwestern end of England. Here ponies have been bred and run wild for many generations. They closely resemble the Exmoor. Bay, brown, and black are the more common colors, though chestnut and gray occur. These ponies stand close to I 3 hands. They are very hardy and are comparatively little known. Vero Shaw states ${ }^{1}$ that it cannot be claimed for the Dartmoor that he possesses anything in the way of extravagant action to commend him to the attention of the public, nor is his appearance so striking as to extract expressions of admiration from strangers.

1 Charles Richardson, The New Book of the Horse, Vol. II. London, rgil. 
On the other hand, it can conscientiously be argued in his favor that he is capable of getting through an immense amount of hard work, that he is a fast pony for his inches, and that his constitution is as hard as iron.

The New Forest pony has its native home in the New Forest, which embraces about 145 square miles of fields and forests in south-central England, in the coastal region. Here these ponies

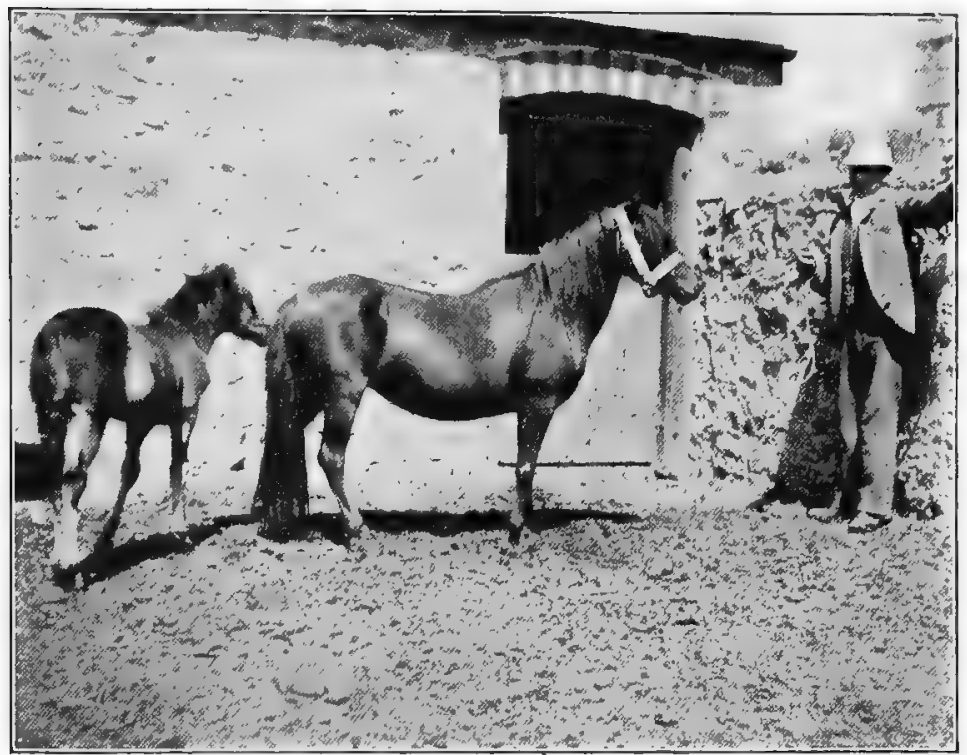

FIG. 66. A Welsh pony mare and foal, of mountain type, owned by John Jones, Llandudno, Wales. From photograph by the author

have run wild for centuries. W. Scarth Dixon states ${ }^{1}$ that this pony is a survival of Saxon times and that when he visited the New Forest in I897 it was estimated that there were over 3000 ponies in the forest, about 2000 of which were brood mares. These ponies have been crossed more or less with other breeds, notably the Thoroughbred, Arab, Welsh, Exmoor, and Norwegian. Very satisfactory results are said to have been derived from the Arab and Thoroughbred cross. These ponies stand from

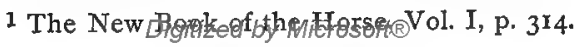


I I to I $3 \frac{1}{2}$ hands high, with I 2 to $\mathrm{I} 3$ the standard, and they are generally bay or brown, with tan muzzle and "a little white under the eyes." Other colors prevail, however. There is a New Forest Pony Association, which promotes the breed.

The Highland pony is native to certain islands off the west coast of Scotland. Mr. W. Mackenzie ${ }^{1}$ of the Isle of Mull separates the Highland into three groups, as follows: First, those of Barra and the small islands, standing $12 \frac{1}{2}$ to $13 \frac{1}{2}$ hands, somewhat plain and large of head, inclined to be straight of shoulder, and usually black, bay, or brown, with occasional duns and grays. These are very hardy ponies, suited to poor feeding and exposure. Second, a high-class riding pony of the West Highlands and Islands, standing I 4 to I $4 \frac{1}{2}$ hands high, black, brown, dun, and gray in color, and showing a "very strong cross of Arab blood." These ponies have beautiful heads and shoulders, and on poor keep are especially suited to heavy-saddle work. This line of Highland ponies has largely run out. The third class is often called the Garron pony, and is native more especially to the Central Highlands rather than the West, and may attain a height of I 5 hands. "It is thought they were bred from the original small pony crossed with the larger horses brought into the Highlands with troops during the unsettled time, and now a very typical Garron can be produced by crossing a small Clydesdale horse with the West Highland pony mare." This is more of a small horse and is better adapted to mountain farm work than to the saddle.

The Connemara pony has its native home in Connemara, an isolated locality on the extreme west side of Ireland. These ponies stand about I 4 hands high, are usually bay, chestnut, or gray in color, and have a somewhat long and deep body, oblique shoulders, and freedom of movement. The coat of hair is remarkable for its length and thickness. A strong constitution, pleasant disposition, and power of endurance are noteworthy characteristics. The Connemara has been used in Ireland and England to some extent in polo playing, to which sport it seems well adapted. It is said a cross of Hackney pony stallions on Connemara mares makes a very smart, trappy, fast-moving harness pony.

\footnotetext{
1 Ponies and All about Them (I9II), p. 2 Ig.
} 
Hackney ponies are Hackneys $14 \frac{1}{4}$ or less hands high with the general characteristics of the Hackney horse.

The Arab pony is simply an Arab under $14 \frac{1}{4}$ hands high and is discussed elsewhere as a separate breed.

Indian ponies, mustangs, or bronchos are descendants of the horses brought to America by the early Spanish conquerors.

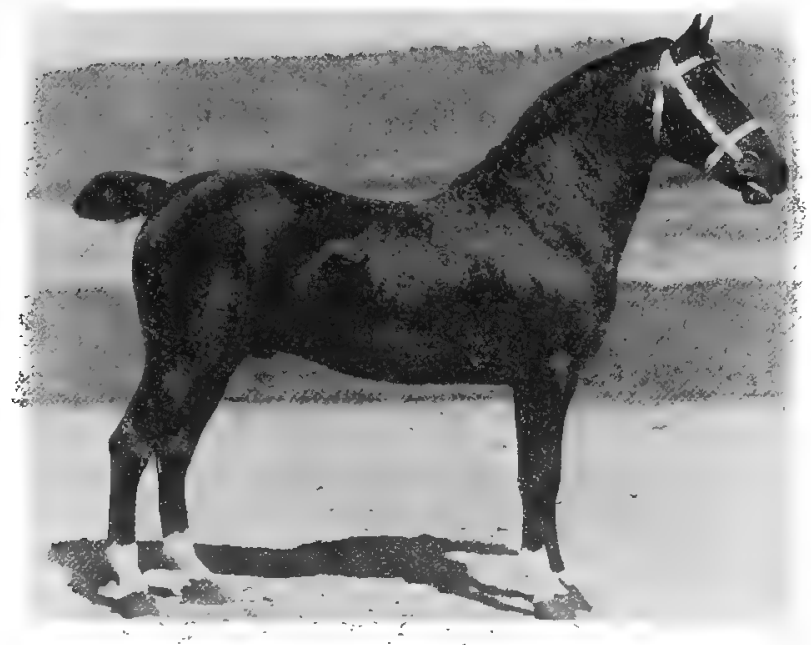

Fig. 67. Dilham Prime Minıster (5174). “'At one time the most famous Hackney pony in America, noted as a prize winner and a sire. Imported and owned by the late Eben D. Jordan, Boston, Massachusetts. From photograph, by courtesy of Mr. Jordan

They often possess much beauty of form and high-class heads and limbs. They have remarkable endurance and are capable of the severest work under the saddle. They vary somewhat in type, those owned by northern Indians not being the equal in quality and conformation of those of the south. Those of the Apache Indians are said greatly to resemble Exmoor ponies. Indian ponies are of all colors, usually solid, though piebalds occur. They tend to be ewe-necked, are often deficient in quarter, and have a remarkable spirit which is frequently far from amiable. 
Many of these ponies, with all their good qualities, are most uncertain of temper and may prove very irritating when least expected. Curtis makes the mustang and Indian pony of different breeding, though they range the same in height ( 12 to I 4 hands), weigh much the same (600 to 850 pounds), and have much the same color. The Indian pony is given as more blocky than the mustang, the cannons are wider, and the pasterns more upright.

The Polo pony is not a breed, but represents a type and size suitable to be used in playing polo. For this purpose anything possessing the necessary speed, activity, endurance, and intelligence will do. The maximum height allowed by the American Polo Association is $14 \frac{1}{2}$ hands. Small Thoroughbreds, Western ponies, and cross, or half-breds, are popular. 


\section{CHAPTER XX}

\section{THE SHETLAND PONY}

The native home of the Shetland pony is on a group of rocky islands about 200 miles north of Scotland. These lie between $59^{\circ}$ and $6 \mathrm{I}^{\circ}$ north latitude, slightly to the east of north, and comprise a total of about I 20 islands, with a total area of some 550 square miles. Only about twenty-seven of these islands are inhabited. The principal island is Mainland, on which is located Lerwick, the largest town and port, with about 3700 inhabitants. Others of importance are Fetlar, Bressay, Fair Isle, Yell, and Unst. These islands are rough and barren as a rule and are situated in a turbulent sea, under unfavorable climatic conditions, where a comparatively low temperature prevails for much of the year. No trees or brush of significance grow on the islands, and what land is cultivated lies in the valleys. On the islands the ponies are fed grass and hay, not often receiving any grain, and it is said that sometimes they are even obliged to eat seaweed on account of shortage of hay.

The ancestry of the Shetland pony is of course uncertain. The drawings of the prehistoric horse in the caves of France show considerable resemblance to the Shetland type, and it is supposed that they are descendants of this prehistoric form. How long they have been bred on the islands is not a matter of record, but they have been bred there for centuries. In their early history they are doubtless more or less related to the ponies of Iceland and Scandinavia and perhaps Wales and Ireland.

The type of the Shetland pony is really that of a small draft horse, although many are seen that are fine of bone and slender of body, more after the trotting-horse type. However, the ponies on some of the Shetland Islands are of a different type from those on others. In fact, it is claimed that a different type is found on each of the following islands: Mainland, Unst, Fetlar, Fair Isle, and Bressay. For example, on Fetlar, Lady Nicholson, a Scotch 
breeder, has used Arab pony stallions on Shetland mares, producing a pony of considerable refinement about 46 to 48 inches high. These are known in the trade as Fetlar, or Lady Nicholson ponies. On Bressay, Iceland ponies have been crossed on Shetlands. Visitors to the islands have seen work horses weighing from I 200 to I 500 pounds, some of which have been bred to

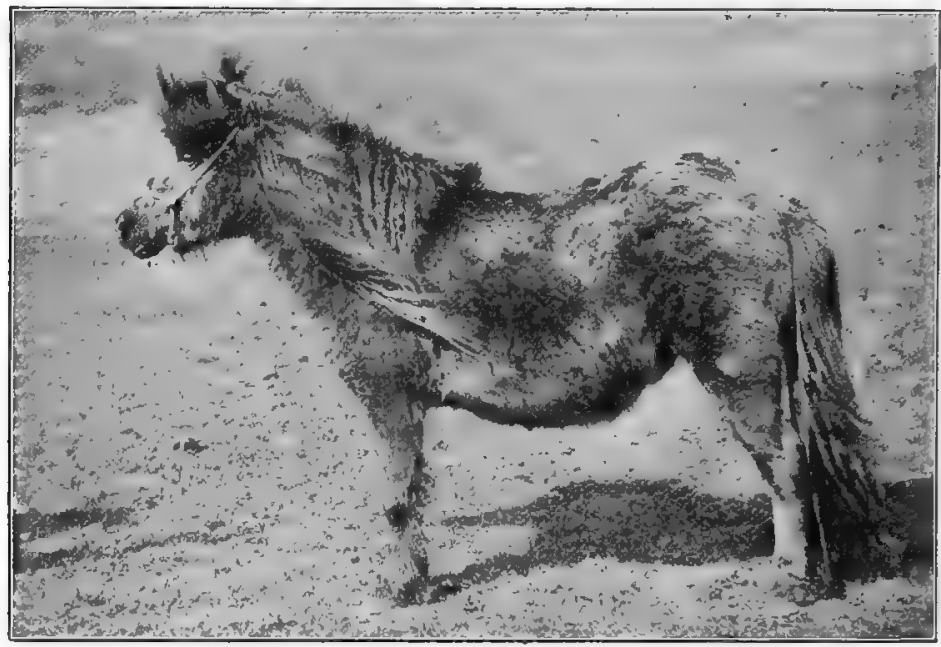

FIG. 68. A pony mare in winter coat on one of the Shetland Islands. From photograph, by courtesy of John Anderson \& Sons, Lerwick, Scotland

Shetland stallions. Bearing on the subject of Shetland type, the following, by a well-known British authority, ${ }^{1}$ is of interest:

At present, things are somewhat in a transition stage, which causes confusion in the minds of some people as to what is the correct type. When the show career of the Sheltie first commenced, the best paying demand was undoubtedly for the pits, and the aim was to get the biggest possible bulk as near the ground as possible, while symmetry and true action had to take a secondary place. Fortunately for the breed, however, the advent of the foreign demand has created a higher standard. Beauty of shape and smart, well carried head counts for more than it used to, and true, close and springy action is deemed essential. Occasionally, however, when a judge full of the old traditions officiates, the prizes will go to ponies with huge bodies on abnormally short legs, suggestive of moles, and no doubt most valuable to drag a hutch in the low galleries of a coal mine, but absolutely unsuited for a child's saddle

${ }^{1}$ Frank T. Barton, Ponies and All about Them. London, I9II. 
pony. At the very next show, perhaps, the opposite type gets the preference, which naturally creates confusion in the minds of those who are not fully conversant with the show history of the breed.

The characteristics of the Shetland pony are very marked in certain directions. The head of the Shetland should not be too fine; the eye should be prominent; the neck short and strong, with some crest in stallions; the shoulders strong, well laid in, and not too heavy; the breast prominent and full; the body short in coupling, wide on the back, with considerable spring and depth of rib; the croup broad, fairly level, and wide, with the tail set high; the quarters full and strong; the legs short and of superior bone, though perhaps appearing heavy; and the feet round, dark, and of excellent bone. The natural tendency is for the Shetland to be "cow hocked," thus giving an inferior placement of the hind legs. Narrow chests

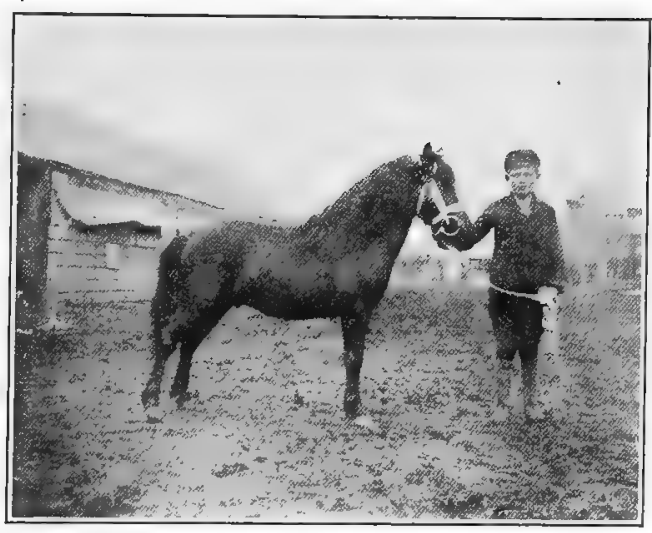

FIG. 69. A Shetland pony, first in class at show of the Highland and Agricultural Society of Scotland. From photograph by the author are also too common.

The color of the Shetland pony is variable-black, bay, and brown being the more common. Gray, chestnut, roan, and piebald (that is, spotted) are seen, the latter, in fact, being somewhat frequent.

The coat of hair of the Shetland pony is one of its striking features. In common with all animals originating in a cold, moist climate, the hair naturally tends to be thick and long. On the islands, as winter approaches, this may attain a length of three inches on the body, which causes the pony to present a very rough, hairy appearance. This furnishes important protection in winter, and in spring, as it sheds off, the pony presents a trimmer, neater appearance. In America many Shetlands have rough coats in winter, but the tendepgyyis toy show less hair than on the islands. 
The forelock, mane, and tail are also very thick and long. The policy of breeding for more refinement is reducing the amount of hair in a considerable degree.

The height of the Shetland pony usually ranges from 36 to 44 inches, but with variations outside of this. Eli Elliott of Iowa, who has bred and imported many from the islands, says : "I never saw in any country what I believed to be a 'right Shetland ' that was as much as 46 inches high. As a rule they are 40 to 43 , and some as small as 36 to 38 inches, and the smaller the better." The smallest pony ever seen by Mr. Elliott was 34 inches high and weighed under 200 pounds. Feeding and care, however, will affect the height and weight. On the prairies of the American corn belt the pony tends to increase in size from generation to generation. In the "American Shetland Pony Studbook" a number of ponies ranging from 30 to 36 inches have been registered. The American Shetland Pony Club in its standard gives twenty. five out of a hundred points to height. Ponies over four years old should be 42 inches and under, and two points are deducted for every inch over this up to 46 , above which height they are disqualified. Catherine Sinclair, in "Shetland and its Inhabitants," says that when well fed the ponies will reach the size of a donkey, and in contrast notes that a Mr. Hayes raised a perfectly formed pony only 20 inches high. As the Shetland is used to a considerable extent in coal mines in England for hauling coal cars, a small pony is preferable to a large one. The weight of a good specimen of the breed may be about 350 pounds for one 40 inches high.

The improvement of the Shetland pony was begun in 1873 by the Marquis of Londonderry of England, who then owned extensive coal mines. He purchased the island of Noss and part of Bressay and maintained studs there and at Seaham Harbor, on the northeast coast of England. The work of the Marquis of Londonderry resulted in greatly improving the uniformity of type and color, reducing size but increasing bone, without detriment to quality. On the death of the marquis some years ago the entire stock of Shetlands owned by him was sold.

The use of the Shetland pony in America is essentially for children, rather than as a beast of burden. In Ohio, where these ponies are common, they are frequently seen hitched to pony carts, 
phaëtons, or small surreys, hauling two or four persons over the pavements with comparative ease. Ponies for this heavier work approximate forty-five inches or more in height. No breed equals the Shetland for children. The inherent gentleness of these ponies makes them safe to use with the greatest freedom. Even when but two years old, Shetlands may be used in a moderate way in the saddle by little children.

The hardy nature of the Shetland is one of its conspicuous characteristics. There are many examples of these little ponies that have lived to a ripe old age. An interesting example of great longevity and breeding power is shown in the case of the Shetland mare Belle, owned on Woodburn Farm, Kentucky, that when thirty years old dropped a living foal.

The value of the Shetland pony for draft purposes is much greater than most Americans realize. On the Shetland Islands he is used for labor, especially in hauling peat for fuel. Elliott states ${ }^{1}$ that the peat is packed in "cassies," each one containing not less than sixty or seventy pounds. Two of these are slung across the pony's back on a kind of packsaddle, a good deal the shape of a sawhorse, being held in position by a breast collar, girth or two, and breeching. The whole load weighs as much as a good-sized man, and this is often carried by the pony for several miles up and down hills, across marshes, over stony and washed paths and gullies, without a halt. He is never used in his native home in harness, but only to ride and pack such things as they may wish to move. In England these ponies have been extensively used in coal mines. Relative to this work of the Shetland, Robert Brydon says ${ }^{2}$ that it is not overstating the case to say that on an average these mine, or "pit," ponies, as they are called, will travel over three thousand miles in the course of a year and shift as many tons of coal. All this work is done in the dark galleries of the mine, which are scarcely higher than the pony.

Notable Shetland pony sires are Trinket IOI, Trinket Jr. I I 87 , Prince of Wales II90, Bunn's Trinket 2598, Chestnut 3572, David Harum 4I46, Grandee 4423, and King Larigo 8778. Prince of Wales is probably the greatest sire the breed has known 
in America. He proved very prepotent, and in 19 II at the National Horse Show in Madison Square Garden, New York, in very strong competition, his get made the remarkable showing of

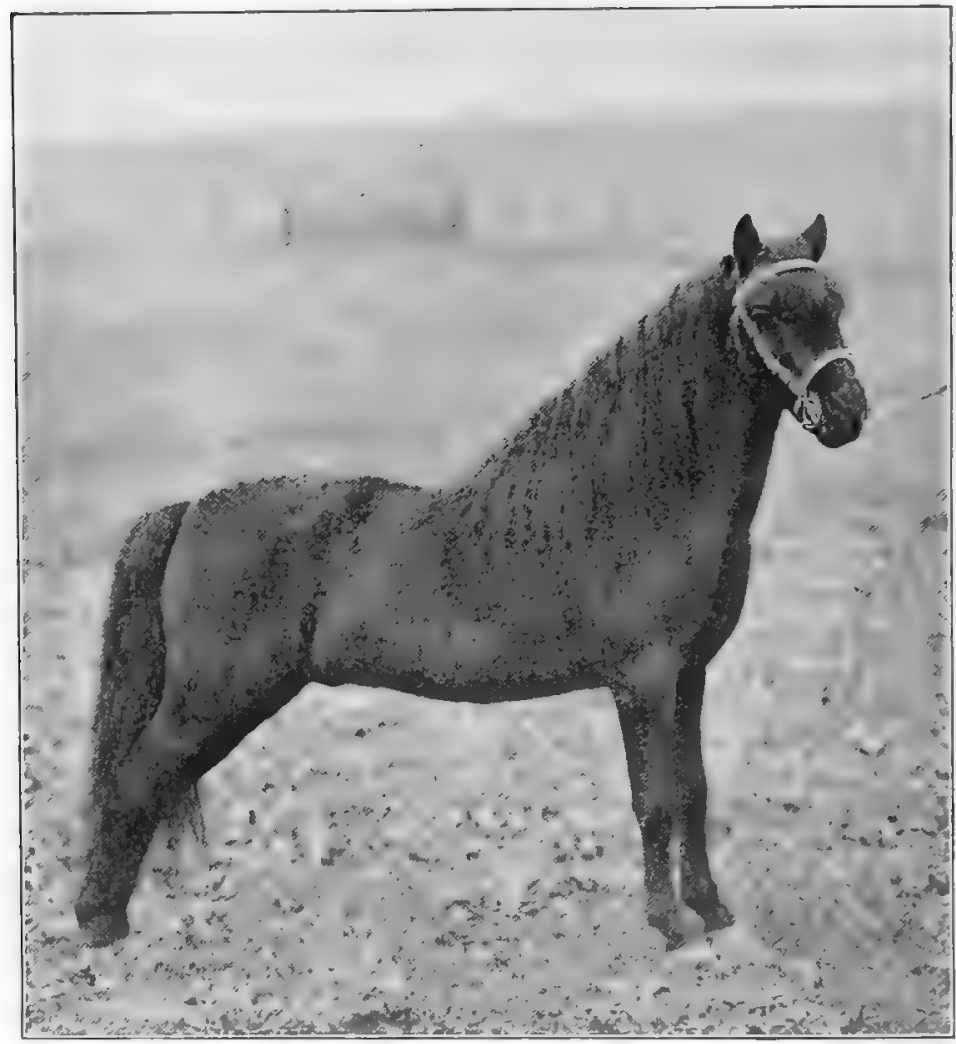

FIG. 7o. King Larigo 8778 , a champion Shetland stallion at leading shows, a noted sire, and the highest-priced animal of the breed, selling for $\$ 10,000$ to Hamilton Farms, Gladstone, New Jersey. From photograph, by courtesy of Hamilton Farms

the following winnings: first, second, and third stud pony ; first, second, and fourth mare pony; first, second, and third singleharness pony; first, second, and third in pairs. From I 893 to I90 I Prince of Wales was the greatest show stallion of the breed in this country, while in recent years Grandee and King Larigo have attracted much attention as show animals and sires. 
The prices paid for Shetland ponies as a rule are very modest, although extremely high figures have been paid. One of the notable sales in Scotland is that at Earlshall in the East Neuk of Fife. In 1912 there were sold 126 head for an average price of $\$ 79$, while in 1913 , I 40 averaged $\$ 73$. In the I9I 3 sale a prominent breeder, R. W. R. McKenzie of Earlshall, sold 25 for an average of $\$ 90.50$, his best mare, Duenna, bringing $\$ 220.50$. At the same sale C. M. Douglass sold 27 head for the average of \$74.50. At a sale of George Heyl of Illinois in I9I 2 , the top price for mares was $\$ 365$ for the show mare Harum Sparkle, while a number of choice mares sold for $\$ 200$ each. Choice stallions have sold for from $\$ 500$ to $\$ 10,000$, the latter price being paid in I9I7 to George A. Heyl for King Larigo by J. C. Brady of New Jersey. As a rule, whether for the stud or show, the smaller type of ponies command the highest prices.

The distribution of the Shetland pony outside of the islands of its nativity is largely confined to Scotland, England, the United States, and Canada. Large numbers have been imported to the United States. In 1905 one importation of 201 head was made, and many have been brought to this country since. These ponies are largely distributed in the northern United States, with Ohio, Michigan, Illinois, and Iowa prominent breeding sections. Many of these ponies have been bred in Ohio, and in 19I3 what was claimed to be the largest Shetland stud "in the world" was in operation in Highland County, where 275 pure-breds were kept.

Organizations for promoting Shetland ponies are well established. The headquarters of the Shetland Pony Studbook Society of Great Britain, founded in I 890 , are located at Aberdeen, Scotland, and their society has published a number of studbooks. The American Shetland Pony Club was organized in I 888 and up to I9I7 had published fifteen studbooks. Each of these organizations is actively engaged in promoting the breed and with substantial success. 


\section{CHAPTER XXI}

\section{THE ASS}

The ancestry of the ass may be traced to the wild ass of Asia and Africa. The males are usually termed " jacks," and the females "jennets." The following are the important species of the wild ass :

The Asiatic Wild Ass or Kiang (Equus hemionus). It occurs in Asia, on extensive plains, from Syria through Persia, Afghanistan, the Punjab, and Tibet to the Chinese frontier. The general color is reddish gray, varying to fawn or pale chestnut. A dark-brown stripe, sometimes with a white edge, extends along the spine from the back of the head to the tail. As with the domestic ass, the ears are large, the tail is covered with short hair which increases in length to form a black brush, there is an erect mane, and no foretop. The middlepiece is short, and the thighs are full, as in the case of the horse. There are callosities on the fore legs but none on the hind. The height varies from I I to I 2 hands. This ass is remarkable for speed and endurance. The voice is a shrieking bray.

The Persian Wild Ass (Equus hemippus) resembles the Asiatic ass in its general conformation, but is larger, and suggests the domestic ass. It is dun in color, with a white underline and brown dorsal stripe.

The African Wild Ass (Equus asinus) is found wild in Abyssinia, Nubia, and northeastern Africa between the Nile and the Red Sea. It is very similar to the domestic ass in color and markings, but has a distinct shoulder stripe extending from the withers to the arm of the fore leg.

From the wild ass various breeds of the domestic ass have descended, ranging in size from those no larger than a Newfoundland dog to that of a draft horse. There are several breeds of importance, from which we in America secure the jackass, or jack, for mating to mares, and these will be discussed after first briefly referring to the domestic type. 
The characteristics of the domestic ass include several features not possessed by the horse. The female is pregnant fully twelve months, the horse eleven. The fore legs have callosities (chestnuts) while the hind legs have none. The ears are very large and long, the foretop and mane are usually very scanty, and the tail has no long hair excepting at its lower part, which has a brush. The body is often covered with long hair, in some cases showing remarkable length, while in other cases it is fairly short. Hayes calls attention to patches of thickened skin, which he terms the "shell," covering the croup and pelvis in the horse. In the case of the ass, this skin extends all over the ribs; consequently this animal is not as sensitive to blows as is the horse. The body is very compact, the quarters lacking deep muscling, while the legs are very strong of bone, often heavy of joint, with small, narrow feet. The ass makes a peculiar noise called

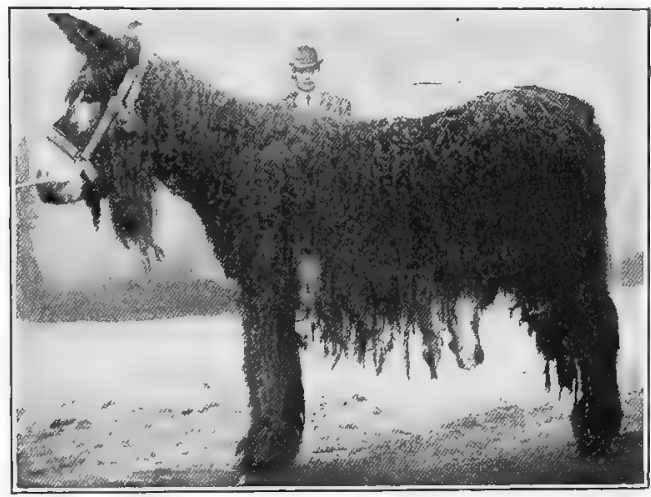

FIG. 7I. A Poitou jack with the characteristic coat of hair. This was a prize winner at the Paris Horse Show. From a French photograph a bray.

The Andalusian jack is native to Andalusia, in southern Spain, where it is an ancient breed. The color is gray, with rare cases of black. This breed has considerable size and stands $13 \frac{1}{2}$ to 15 hands high. The bone is excellent, and the breed possesses much substance. H. W. Sessions refers to one $15 \frac{1}{4}$ hands high having a girth of 67 inches with the bone below the knee measurings $8 \frac{3}{4}$ inches around. The head and neck are said to be very goadt This breed and color have never been popular in the United 5 . although well scattered over the country.

The Catalonian jack is a Spanish breed from Catalonia, in extreme northeastern Spain, a very mountainous region bordering on France. This is a black or brown breed with light points, 
black largely prevailing. The coat of hair tends to be thick and short. This breed stands from I 4 to 15 and occasionally 16 hands high. From the standpoint of critics of this class of animals the Catalonian possesses unusual style, beauty, and action. The head shows considerable character, and the ears are rarely droopy. While the bone is not so large as the Andalusian or Poitou, it is very superior in texture and free of flesh, so that it is not objectionable. The Catalonian is a wiry, tough type that matures early and has very superior style and action. This breed has been largely used as foundation stock for producing mules in Tennessee, Kentucky, and Missouri, where it is yet in great favor. H. W. Sessions states that the produce of these jacks from I 6 to 17 hands high, as seen in Missouri, Kansas, and the eastern United States, have much weight and substance and make the best mules in the world. They are quick, active, mature early, and are good sellers.

The Majorca jack is a breed of more recent introduction to America from Majorca, one of the Balearic Islands in the Mediterranean Sea off the coast of Spain. This is a large sort of drafty type with heavy bone, averaging $15_{2}^{1}$ hands high, standing somewhat higher than the Catalonian. The head and ears are said to be conspicuously large, the latter being longer than those of any other breed and poorly carried. There is a lack of style and action with the Majorca, the tendency being toward sluggishness. The breed has not attained popularity in America, and but few have been brought here. It has, however, met with considerable favor in Spain for producing artillery mules, and many. of the jacks have been exported to South America. In its native home it has long been bred with much purity.

The Maltese jack comes from the island of Malta in the Mediterranean Sea. This breed is either black or brown in color and is of the smaller type, frequently standing at 13 hands and rarely exceeding $14 \frac{1}{2}$. The head is of excellent form, with sharp, upright ears. The Maltese possesses much life and vigor, but is objected to on account of too fine a bone, undue refinement, and lack of substance. A larger type is in demand in the American trade, which restricts the importation of this breed. Maltese jacks were brought to America as early as 1788 , the pioneers of their kind. 
The Poitou jack is a native of France, where for many centuries he has been bred, especially in the province of Poitou, bordering on the Bay of Biscay. Here, in the departments of Vendée and Deux-Sèvres, the Poitou ass is bred in his greatest perfection. This is the most powerful and drafty of the several breeds of asses and averages about $15 \frac{1}{2}$ hands high, but frequently exceeds this height. In general the Poitou may be described as having an unusually big head, with large, long ears; small mouth and nostrils; thick, short neck; broad chest; good-sized, long body; quarters rather spare; forearm long but not thick, but knees and joints large; hocks as big as those of a heavy draft horse; bone large, many measuring nine inches around below the knee, but legs very short and superior; feet large. The prevailing color is black with light points. Grays occur occasionally but are not regarded with favor and are not eligible to registry in the French jack studbook. Much is said about the hairy development of the Poitou jack. He is covered with a profuse growth of long, silky hair, which adorns the ears, neck, and legs. The tail, which is rather short, is quite devoid of hair excepting at its lower part. In his native home, when in service, the Poitou jack is said to be a very unattractive beast, for he is never groomed or trimmed. In Poitou these jacks are bred to a very large, drafty, powerful type of mare, native to that region, from which are produced big mules of the most valuable kind. Thus far jacks of this breed have not been brought to America to any great extent, but they are generally regarded with favor wherever introduced.

The American jack is the result of the amalgamation of the blood of the different breeds brought to America from Europe since the days of Washington. Professors Anderson and Hooper of Kentucky have contributed much valuable information relative to the development and characteristics of this breed. ${ }^{1}$ Especial emphasis is placed on the early influences of the Maltese jack Warrior, owned by Henry Clay, and the Catalonian jack Mammoth, imported to South Carolina in 1819 and soon after taken to Kentucky, where he was used in service for eight years. ${ }^{2}$ The

1 W. S. Anderson and J. J. Hooper, "American Jack Stock and Mule Production," Bulletin 212, Kentucky Agricultural Experiment Station.

2 American Breeder, JanuaEsig? 
sons of the latter did much to establish the breed. Briefly stated, the modern American jack stands about I $_{2} \frac{1}{2}$ hands high, is deep and roomy of body, comparatively short of leg, and shows plenty of bone and substance. "A sixteen-hands jack should approximate 30 inches in depth of chest, 34 inches in length of foreleg, and should weigh rooo to I I 50 pounds." Anderson and Hooper state that it is customary to refer first to the head and ears of

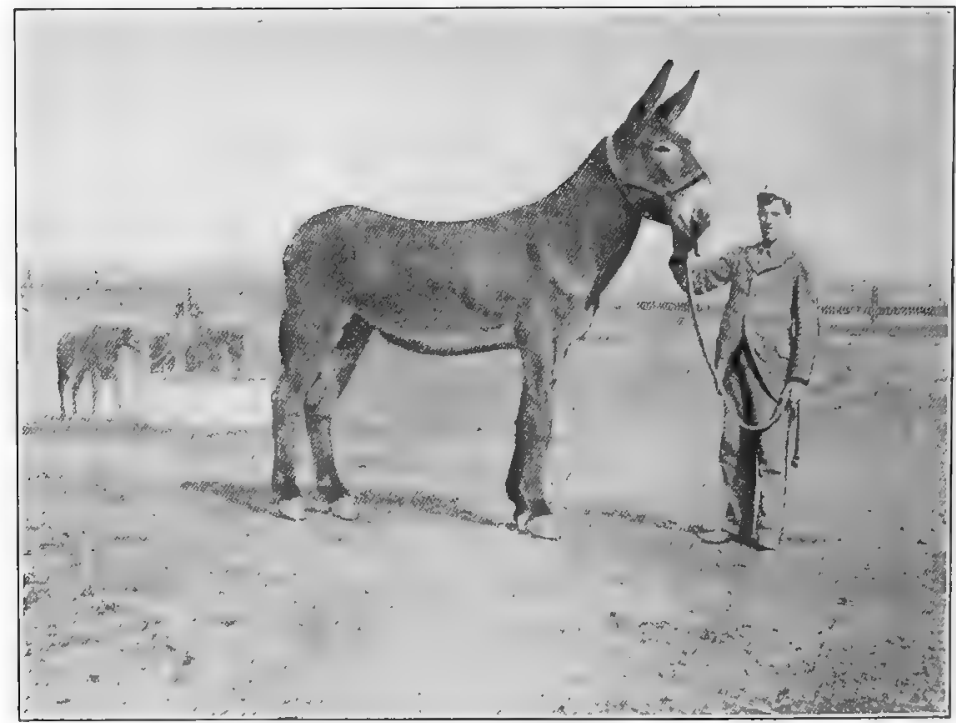

FIG, 72. Andrew Jr. 2I7, first-prize two-year-old American jack. From photograph by the author

the jack because of their importance. The face line should be straight or slightly Roman; the ears about 33 inches from tip to tip as spread level, and carried alert under natural conditions; the poll narrow; the jaw strong and heavily muscled; and the neck full and free from any tendency to a ewe-neck conformation. The hind quarters should be long, level, and wide. The natural tendency is to be droopy and short of croup, rough in the hips, light of thigh, and crooked in the hocks - defects that should be guarded against. The American jack manifests considerable style, carries the head well, and shows plenty of vigor and nervous force. 
The color of the jack has in recent years been subject to considerable discussion. Until comparatively recently black has been the standard color, with whitish or mealy shades on the underside of the body, between the forelegs and the thighs, and about the muzzle. Fancy animals, also, were often marked with mealy color around the eyes and under the throttle. The American Breeders' Association of Jacks and Jennets adopted the above for its standard on color requirements. The Standard Jack and Jennet Registry of America, however, composed of a large number of breeders, admits jacks of any color to its books, provided other requirements are satisfactory. In support of other colors than black attention is called to the following facts. Jacks are generally used to sire nonbreeding animals. The market desires mules of good conformation and bone irrespective of color. The first jacks imported to America were gray, and maltese. "Off color" jacks produce just as many black offspring as some of the black sires. It is not wise to destroy a good jack because he happens to breed back to some former color, which is sure to happen with the mixed colors. It is interesting to note in reference to color that irregular marks on the coat, such as a "blaze" or "star" on the head, or "white stockings" on the legs, while common on the horse, are rare with the ass. Hayes says," "I believe I am correct in saying that the color of the ass is never of a bright bay, chestnut, red or blue roan, or nutmeg gray. I have seen mules of an iron-gray color, but have not observed it in the ass."

The height of the jack will depend upon the breed and degree of maturity. In examining the records of a number of Catalonian jacks in the studbooks, the average height was 15 hands, while a number of Majorcas averaged $15 \frac{1}{2}$ hands. Jennets showed about a half hand less. Tegetmeier and Sutherland give the height of the Poitou jack as I $3 \frac{1}{2}$ to 15 hands, and the jennets at I 3 to I 4 hands. In I 877 Richardson describes the Poitou as standing I $3 \frac{3}{4}$ to $14 \frac{3}{4}$ hands, while Sessions says they rarely exceed I $4 \frac{1}{2}$. If the jack is of good proportions, then $15 \frac{3}{4}$ to 16 hands is looked upon with favor in the American jack, with the females standing about $14 \frac{1}{2}$ hands. Referring to this matter of height Anderson and Hooper state that "it is better for a breeder to be

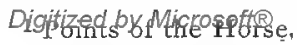


able to produce all his jacks $15 \frac{1}{4}$ hands, which will sell at $\$ 500$ when mature, rather than to produce one $155^{3}$-hand jack worth $\$ 1500$, and ten from $13 \frac{1}{2}$ to 14 hands, which will average not more than \$175." A jack 15 hands, with a heart girth of 64 inches, a cannon bone of 8 inches, and an ear of 32 inches, is worth $\$ 500$ to a breeder. The rules of the American Breeders'

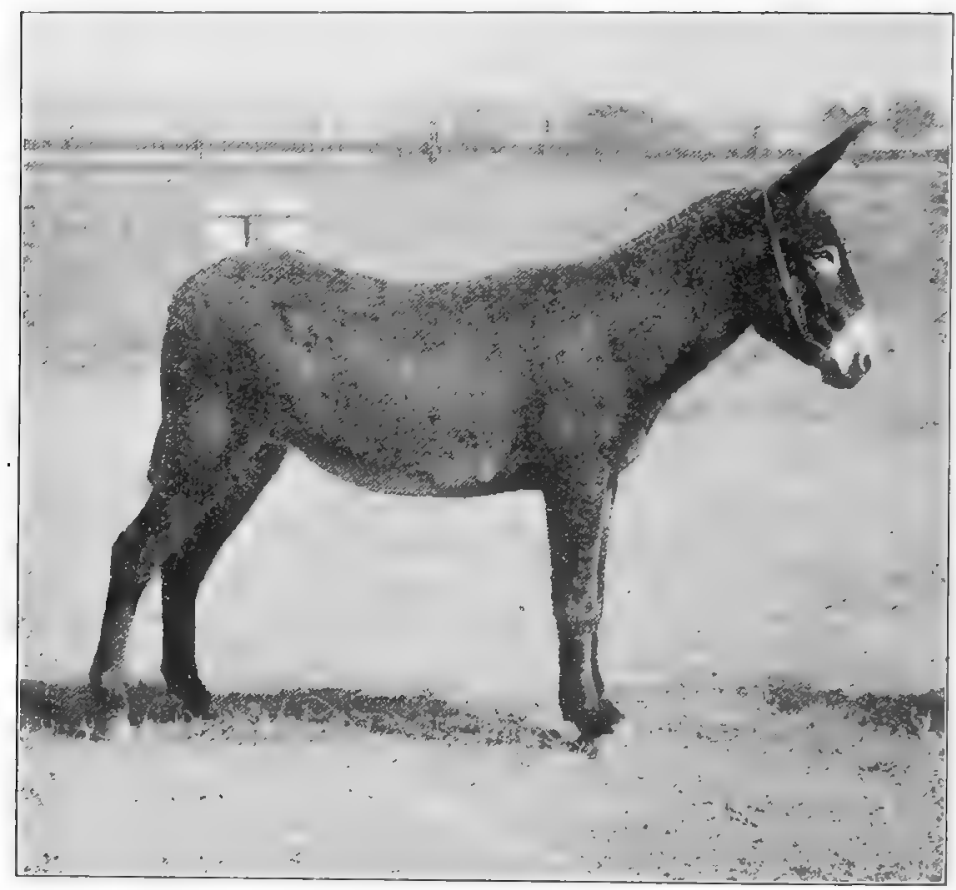

FIG. 73. An American jennet, second prize in class at Illinois State Fair. From photograph by courtesy of American Agriculturist

Association of Jacks and Jennets allow I 5 hands as the standard for imported jacks and jennets, the produce of unrecorded sire or dam. Native jacks, the produce of unrecorded sire or dam, should stand I $5 \frac{1}{2}$ hands. The Standard Jack and Jennet Registry Association of America requires jacks to be at least $14 \frac{1}{2}$ hands high and jennets I4 hands.

The introduction of the jack to America dates back to 1788 . The king of Spain sent George Washington a gray jack named 
Royal Gift and two jennets, and General de Lafayette presented him with an importation from the island of Malta consisting of a black jack known as Knight of Malta and several jennets. In I8 I9 the jack Mammoth landed at South Carolina from Spain. Henry Clay of Kentucky in 1827 received from Malta a jennet named Calypso. Two years later Clay imported a Maltese jack named Achilles and later several others, one of which, named Warrior, became noted as a sire. One of the first imported jacks taken to Tennessee was imported about 1840 and was taken to Maury County by a Mr. Thomas. About 1867 or I 868 Messrs. A. C. Franklin and Tul Craig of Sumner County, Tennessee, imported some Catalonian jacks. Atout I $882 \mathrm{Mr}$. Lyle of Kentucky imported some Andalusians from near Seville, and the same year Leonard Brothers of Missouri made a similar importation. Many importations from Spain, France, and the Balearic and Malta islands have been brought to America since I 884 .

Noted jacks in America are of record back to the days of Washington, as already indicated. The following are a number of animals especially distinguished as sires:

Warrior, imported by Henry Clay of Kentucky about 1830, proved extremely prepotent and was recognized as the best jack of his time. "So remarkable was his power of transmission," says Colonel I. S. Irvine of Kentucky, ${ }^{1}$ that I, or any other jack breeder, can, in a moment, tell if the pedigree of an animal runs back to imported Warrior."

Mammoth was imported from Catalonia, Spain, in I8I9 and landed at Charleston, South Carolina. He was given this name on account of his large size. He was bought by J. I. Brockett of Mt. Sterling, Kentucky, and was used in the stud for eight years. His progeny fused especially well with the Clay stock and proved very valuable. Many pedigrees of to-day trace to this sire.

Buena Vista, a son of Mammoth, was bred by Henry Leer of Bourbon County, Kentucky, and was sold in 1853 for $\$ 3000$ to Major Blythe of Madison County, Kentucky. Anderson and Hooper consider this as the first great jack of potential breeding value produced in America.

1 Bulletin 212, Kentucky Agricultural Experiment Station. Digitized by Microsoft(R) 
Governor Wood 33 was sired by Tip Top and was used in the stud of W. W. McElroy of Marion County, Kentucky. He was notable as a sire rather than as an individual, his sons commanding high prices.

Limestone Mammoth 298 was sired by Superior Mammoth I 24 and had for dam Lady Mackin 514. Limestone Mammoth was bred by L. M. Monsees of Missouri and has been regarded as one

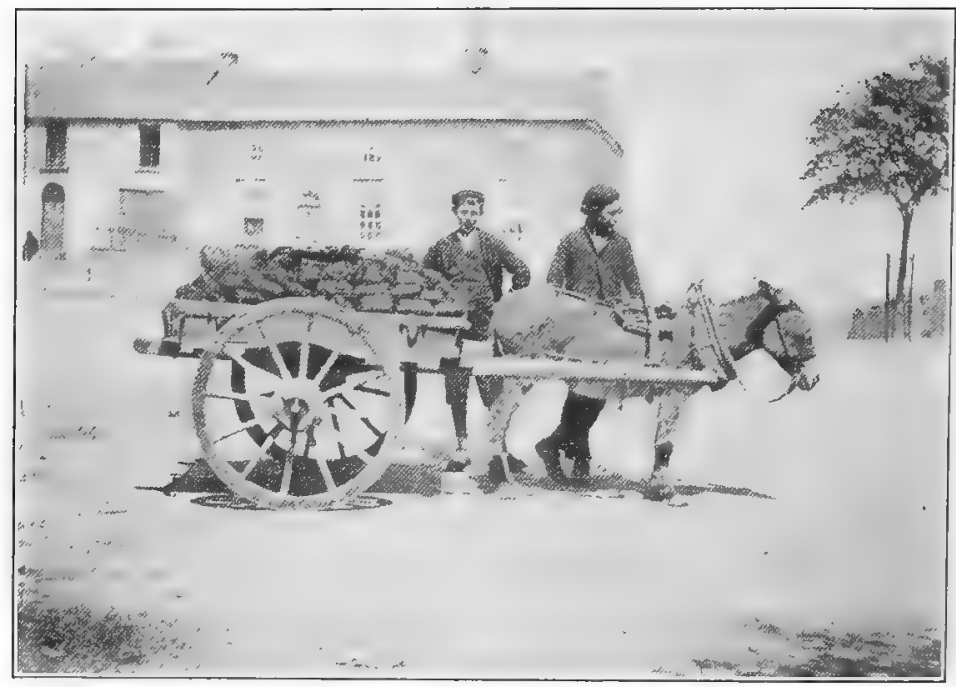

FIG. 74. A donkey and a load of peat in the public square, Kildare, Ireland. Height about 30 inches. From photograph by the author

of the greatest jacks of record. He was exhibited for ten years without defeat and has been a great sire. His breeding traces back to imported Mammoth on the sire's side and Buena Vista on the dam's. He stood I $5_{4}^{3}$ hands and weighed I I 50 pounds.

High prices for jacks prevail to an extent not generally supposed. In France the Poitou ass brings a large figure, common ones selling close up to $\$ 1000$, and the better class from $\$$ I 500 to $\$ 2000$. At a Paris exposition one is reported selling at $\$ 3200$. Buena Vista was sold in I 853 for $\$ 3000$. Paragon 63 , imported from Catalonia in 1886 , was sold for $\$ 2000$. This same year an importation of Catalonian jacks was made to Tennessee, from 
which Jumbo 45 sold for \$2000, Peacock for \$1500, Boyd's Monarch for \$I500, and the Douglas jack for \$I $\$ 50$. From another importation the jack King James sold for $\$ 2000$. In Kentucky numerous jacks have sold at prices ranging from $\$$ I 000 to $\$ 2500$. The jack Moro Castle sold for $\$ 5000$ to M. H. Mays of Maury County, Tennessee, the high price up to I9I8. At a notable sale of L. M. Monsees, Pettis County, Missouri, in I9II, the jack Bearytone Mammoth 2466 brought \$3030. The first five jacks in this sale averaged $\$ 1927$, the first ten $\$ 1666$. The highest-priced jennet brought \$I 375 , and five of these females averaged \$1006. At a sale in 1916 by Monsees and Sons the jack Belle Boy of the Grand Champions 10734 sold for $\$ 3750$, while the jennet Belie of the Grand Champions II 10730 sold for $\$ 2600$, the top price for a jennet.

The distribution of jacks and jennets in America is widespread, especially in the states south of about $40^{\circ}$ north latitude, Kentucky, Missouri, and Tennessee being noted for stock of this kind. Jacks, however, are being used in increasing numbers in the North.

Associations for the promotion of jacks and jennets in America have their headquarters in Tennessee and Kansas City. The American Breeders' Association of Jacks and Jennets was organized as a stock company at Springfield, Illinois, in 1888. Thirteen volumes of studbooks have been issued up to 1917 . The office of this association has been in Tennessee since its founding. In 1908 there was organized at Kansas City the Standard Jack and Jennet Registry of America. This is now a strong and prosperous association and has published three volumes of studbooks up to I9I9. Up to October 6, I9I9, this association had recorded I 8,2I 5 jacks and jennets. There is also an association in France for registration of the Poitou jack. 


\section{- CHAPTER XXII}

\section{THE MULE}

The mule is a hybrid, having for sire a jackass, commonly termed a jack, and a mare for dam. If a stallion be bred to a female ass, known as a jennet or jenny, the result is the hybrid known as a hinny. The latter cross has a tendency to produce an offspring inferior to the mule in size and draft character.

However, mules occupy a most important place in the economy of farm work and in many phases of business requiring limited draft power. The importance of this hybrid is shown in a measure, when we learn that according to the estimates of the United States Department of Agriculture on January I, I919, there were $4,925,000$ mules in this country.

The sterility of the mule has always been regarded as an absolute fact, and the word "mule," as applied to quadruped or bird, indicates a nonbreeder. However, a number of cases have been reported of mare mules dropping foals. Years ago the author had a photograph of a mare mule and foal sent him by the late George A. Brown of Australia, in which the evidence as submitted by him indicated this to be a fertile mule. Occasional statements are made giving information of mules that are supposed to have reproduced. In an interesting study of this subject ${ }^{1}$ Orren LloydJones shows that from a physiological point of view reproduction with the mule is impossible, owing to "a deep-seated derangement of the cell divisions which would, in normal, fertile animals, give rise to the fully developed germ cells."

The sex of the mule has a bearing on its salability. Mare mules are preferred by buyers, feeders, and dealers generally, and sell more easily than horse mules. The females assume a matured form at an earlier age and fatten best for the market. The horse or male mules have a more angular and leggy form and cannot be fattened so early as the mares. One dealer in

1 "Mules that Breed," Joumal of Iferedity, November, I916, Vol. VII, p. II. 
mules tells the author that horse mules in pasture with other stock will worry them, when mares would not.

The mule in history has been known for centuries. No doubt it has been used extensively in Europe since long before the Christian Era. In the days of ancient Rome and Greece mules served various purposes. Homer, who wrote more than eight hundred years B.C., and Varro, the best authority on ancient

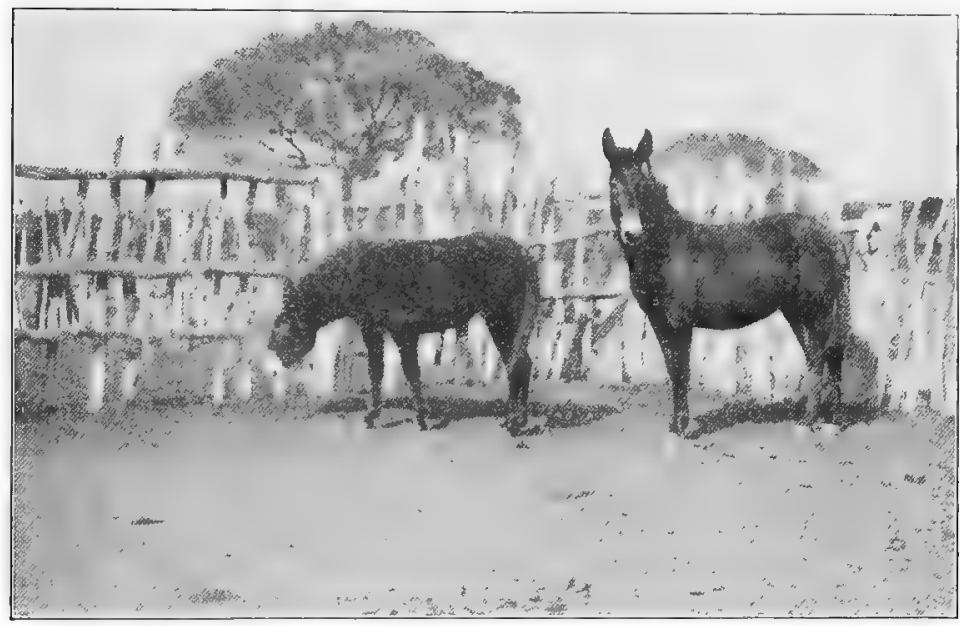

FIG. 75. A mule and foal. From a photograph sent the author by the late George A. Brown, Australia

agriculture, the author of "De Re Rustica," who wrote in the first century B.C., both refer to the mule in their writings.

The geographical distribution of the mule is world-wide. It is bred in the best degree in Spain, France, Italy, Portugal, and the United States and South America. Great Britain has never looked with favor on the mule. Sessions has written as follows in The Live Stock Joumal (London) :

The mule line extends north from the equator, and includes Africa and Europe up to 45 degrees of latitude and Asia and North America as far as 35 degrees. On the south side of the equator we can include most of Africa, the northern half of Australia, and South America as far south as 35 degrees. Within this vast area hundreds of thousands [he might better have said millions] of mules are bred each year Digitized by Mičrosoftele 
Mule-raising in the United States began in colonial times. George Washington used a jack in stud at Mount Vernon for mule-breeding, and his mules sold for upwards of $\$ 200$ each. The value of the mule as a draft animal was early recognized by intelligent Southerners. In I9I9 the leading mule-producing states, based on the United States Department of Agriculture estimates, were as follows: Texas, Missouri, Georgia, Mississippi, Arkansas, Alabama, Oklahoma, Kansas, Kentucky, and Tennessee. 'Missouri, Kentucky, and Tennessee are noted for their superior class of mules; St. Louis is the most important mule market in the world.

The characteristics of the mule partake of both sire and dam. There is the long ear, slender body, tufted or slightly haired tail, small, slender foot, and braying voice of the ass. These features seem to attach a peculiar character to this nonbreeding farm animal. Mules vary greatly in size and quality, naturally, due to their parentage. Other things being equal, a large mule brings a higher price in the market than does a small one. Mules are sorted and classed for various purposes. The larger, heavier mules are used in city drayage and heavy draft work or in lumber camps. A medium size is used on farms and in military service, while the smaller grades find places in mines and elsewhere.

The weight of the mule ranges between wide extremes, for the diminutive burro of the mountains and the heavy draft mule are of one great family. According to government estimates ${ }^{1}$ the mature mules on farms in the United States average 956 pounds, the heaviest average weight (I I Io pounds) being reported from Washington State, and the lightest (865 pounds) from Mississippi. Anderson and Hooper ${ }^{2}$ state that a draft mule of 1400 to I 500 pounds will do the work of a draft horse that weighs two or three hundred pounds more, and that excepting for exhibition or advertising purposes the mule should not exceed I 500 pounds. Emphasis, however, is placed on the production of draft mules, small ones not commanding a price which pays for production. The wise breeder, in the opinion of these Kentucky authorities, will plan to breed mules of size and quality, averaging IO00 to I 500 pounds.

1 Monthly Crop Report, February, I9I8.

${ }^{2}$ Bulletin 212, Kentucky Agricultural Experiment Station, December, I917. 
The market classes of mules vary more or less, according to the region of country where the market is held. The leading American mule markets where classifications obtain are St. Louis, Chicago, Kansas City, Louisville, and New Orleans. Mr. R. C. Obrecht has given a classification ${ }^{1}$ which comprises mining, cotton, sugar, farm, and draft mules. Mr. John Grant of the Kansas City yards states ${ }^{2}$ that the principal classes of mules known to the market are cotton, lumber, railroad, sugar, farm, levee, city, and miners. The author has arranged the following classification, reproduced here from another publication of his, ${ }^{3}$ which will have a fairly general application.

Plantation mules represent a certain class suited to farm work, especially in the South. They may be divided into two subclasses sugar and cotton mules. These are the larger, better-class mules on the market. Sugar mules stand from $\mathbf{r} 6$ to $\mathbf{I} 61$. hands high and weigh from I I 00 to I 400 pounds. These are breedy looking, show quality and finish, and have strong bone. They especially show refinement of head and neck. Cotton mules stand from I $3 \frac{1}{2}$ to I $5 \frac{1}{2}$ hands high and weigh 900 to I 100 pounds. They are not of such uniformly high quality as sugar mules, ranging from light to medium in bone, though they show smooth finish. They have small, neat heads and attractive conformation. Cotton mules are very common in the Southwest. Curtis says " this type of mule is of still lighter build than the surface mining mule. The body is inclined to be somewhat rangy, the bone small, and the body upstanding. The quality should be uniform and of about the same standard as that possessed by the mining mule, the difference being in favor of the latter."

Draft mules are large, heavy-boned mules that carry more weight than any other class. They are often divided into two subclasses, namely, lumber and railroad mules. The draft class of mule should be large, the body deep and closely coupled, the back short and strong, the croup not too drooping, the thighs and gaskins heavily muscled, the bone heavy, and the feet large.

1 Market Classes and Grades of Horses and Mules, Bulletin I22, Illinois Agricultural Experiment Station, igo8.

2 National Stockman and Fammer, October I2, I905.

8 Judging Farm Animals (19 16), Fig. 299, 590 pages.

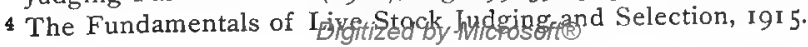


Mules for lumber camps stand as high and weigh as heavy as this class calls for, but do not show so much quality and style as do the railroad mules, which are slightly lighter than lumber mules.

Mine mules are of two kinds, known as pitters and surface mules, and range from II to $5_{2}^{1}$ hands high and weigh from 650 to 1225 pounds. They have deep compact bodies, heavy bone, short legs, and large feet. The smaller ones are used in hauling trucks in the mines, and the larger ones on the surface.

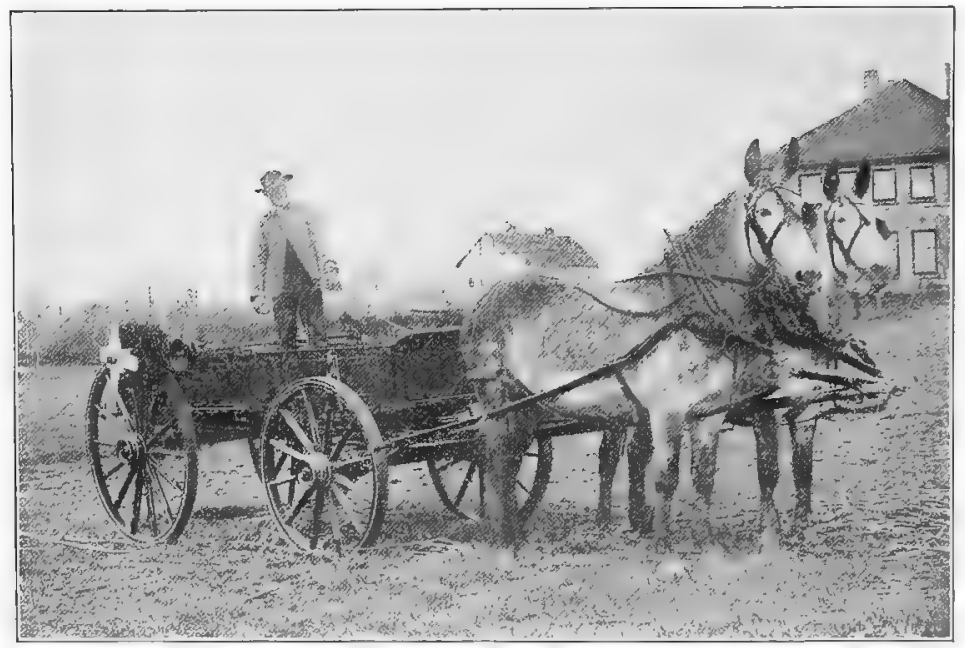

FIG. 76. A choice pair of draft mules out of Percheron mares. From photograph, by courtesy of The Farmer

Farm mules represent a class lacking somewhat in uniformity. They are used for agricultural purposes in the central states. Mules of this class resemble inferior plantation or draft mules, being plainer looking and thinner in flesh, though with good constitution, bone, and feet.

The Poitou mule is of French breeding, the result of using the Poitou ass on a large type of French mares. There are two types of these mules bred in the Poitou region, a large and a small, but the larger type is in greater demand. The finest and largest cart mares are used for this production, the French farmers making a business of producing this grade of mule. Besides size, 
Poitou mules are celebrated for the shortness and stoutness of their legs, with superior bone and unusually large and finely formed feet.

The best type of mule must show the general excellent conformation of the horse in symmetry of form. The body tends to be more cylindrical and smaller than in the horse, but a capacious body is desirable rather than otherwise, though paunchiness is objectionable. The nearer the general body conformation approaches that of the superior draft horse, the more completely will the mule suit the demands of the critical trade. In the show ring those mules which meet with marked favor possess the horse form in greatest degree. Legs of superior quality are fine and hard, the bone very smooth and dense, the tendons prominent, and the muscles well developed. The feet of the mule are smaller and longer than those of the horse, and the arch of the foot is greater. In general, the mule is distinguished for superior feet and legs.

The temperament of the mule is quiet and patient, while for steadiness under the collar and hard pulling he has no equal in the equine world. However, the mule should show an active temperament, with sprightly carriage and style. It has been common to regard the mule as given to kicking, but this is not based on fact, for mules are no worse than horses in this respect. Horses are more nervous and uncertain in temperament than mules and are more subject to fright and consequent runaway.

The color of the mule is variable, though black, brown, and bay are most common. Besides these, various shades of gray, white, sorrel or chestnut, and buckskin-yellow occur. On the Kansas City market in recent years, according to good authority, the highest-priced draft mule, everything being equal, is the steel gray, red sorrel ranking second, and black third.

The endurance of the mule is remarkable. It is worked under the severest conditions and shows great power of resistance to fatigue. Tegetmeier quotes from a Texas correspondent:

Six mules, the leaders no larger than ponies, will take 6000 to 7000 pounds anywhere, making fifteen to thirty miles a day according to the state of the roads, and I have known a team in summer driven fifty miles, with 1000

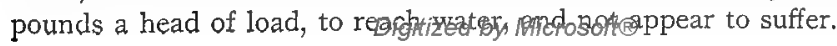


Mules usually live to a greater age than horses and perform their work with regularity and on less feed, a most important point in their favor. Cases are recorded of mules living to seventy years of age, and Mr. J. L. Jones refers to one in Tennessee that at thirty years of age was doing effective service attached to a reaper. Two Illinois men report ${ }^{1}$ mules engaged in active draft work, in one case for thirty-four years and in the other for thirty-seven years.

The resistance of the mule to disease has been a frequent subject of discussion. It is commonly claimed that the mule is not

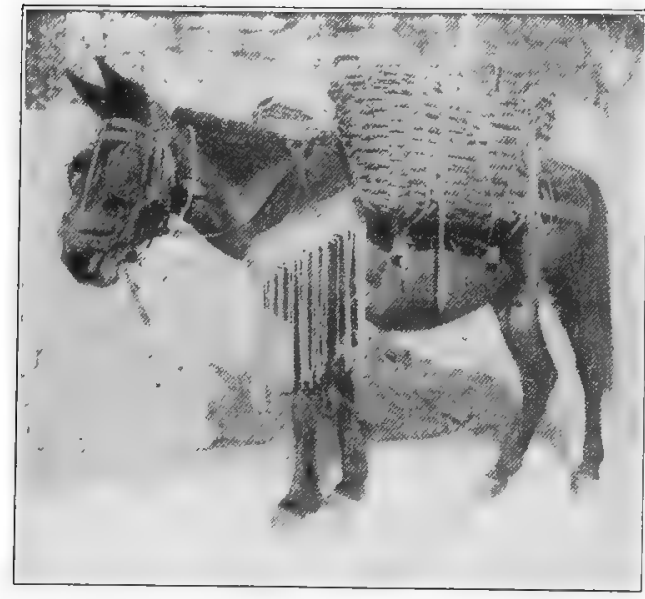

Fig. 77. An Italian mule about 13 hands high. From a photograph taken in Italy by the author so generally subject to disease as the horse. Pomeroy, in an essay on the mule, credits this animal with freedom from any kind of disorder or complaint. In an investigation of "blind staggers" among horses in Virginia and North Carolina, conducted under the direction of United States Secretary of Agriculture Coleman, mules were found quite exempt from this disease, although they are credited with other maladies. In regions in the lower Mississippi Valley infested with buffalo gnats, Professor F. M. Webster reports the mule as the animal most subject to fatality from attacks of this insect. Southern-bred mules, however, are far less susceptible to the bites of the gnats than those imported from northern localities. While the mule is not so subject to leg and foot diseases as is the horse, cases of spavin, ringbone, sidebone, and other troubles do occur. Corns are rarely found on the feet of the mule. Even when affected with foot or leg disease, without doubt this animal is, as a rule, less disabled

\section{Farmers' Review, February 3, I9r7.}


from work than is the horse. The resistance of the mule to disease and its activity, sureness of foot, docility, and easiness of keep have resulted in its finding much favor in the army service.

The mule as a carriage or saddle animal is important in certain sections. In the Southern states he is thus used very commonly by negroes and the poorer classes of whites. In the Central West, in states bordering the Ohio River, one occasionally sees gentlemen driving mules, either singly or in pairs, in harness, attached to carriages, the animals trotting with commendable speed.

The prices paid for mules vary, naturally, with the quality and character of the animals offered. However, the average farm price for mules is greater than for horses. On January I, I919, the average farm price for horses in the United States was $\$ 98.48$, while for mules it was $\$$ I 35.59 . In those markets where mules are important very high prices rule, and a pair of heavy, matched mules of superior quality and conformation sell easily for $\$ 500$ and upwards. The Poitou mule in France, rated the best in Europe, sells at $\$ 200$ to $\$ 300$ a head and sometimes fetches $\$ 400$. Large numbers of mules change hands at from $\$$ IOO to $\$$ I 50 per head. In I9IO a pair of mules in Maury County, Tennessee, weighing 3 I 50 pounds, sold for \$1000 to go to Louisiana. In I9I 3 $\mathrm{S}$. T. Harbison of Kentucky sold a closely matched pair weighing 2850 pounds for $\$ 1000$, to go to Tennessee. These were show mules of exceptional quality that had never been beaten in competition. 
Digitized by Microsofte 


\section{PART II. CATTLE}

\section{CHAPTER XXIII}

\section{BEEF TYPE OF CATTLE}

The general appearance of the beef animal of correct type is compact and broad of back from shoulder points to hips; it has a wide, deep body, short and somewhat thick neck, wide, deep, full bosom, broad, thick, fleshy hind quarters, and is generally broad and deep. Viewed from one side the top and bottom lines of body extend parallel, with the back quite level. From front or rear the outline should be rather full and broad. Cattle of this type are commonly referred to as "blocky," indicating compactness and squareness of form. If the body is inclined to be long, it may be termed "rangy," while animals long of leg and lacking in depth and fullness of body may be termed "leggy."

The head should have a broad, strong muzzle, indicating superior grazing and feeding capacity. The nostrils, when somewhat prominent and large, with a wide nose, give evidence of ample nasal capacity to supply the lungs with air. A Roman nose occasionally occurs with cattle, but it is neither attractive nor desirable. The distance from the muzzle to a point immediately between the eyes is preferably short, with some curve, or "dish," as it is termed, just below the eyes, which should be wide apart, large, and indicate a gentle temperament. A quiet eye means an easy feeder, while a nervous, restless eye shows an animal unsatisfactory to handle and care for. The forehead, as indicating mental capacity, should be broad and reasonably full. The face and cheeks in a superior head are full and deep, connected with a rather broad, strong lower jaw. If of the horned type, the homs should not be coarse at the head, but should show plenty of fine texture and quality and be graceful and of harmonious proportions. An abundance of rather long hair should crown the poll, or top of 
the head. It is most desirable that the ear should be neatly attached to the head and that it should be of superior quality, neatly pointed, and covered with silky hair, with long hair at edges and tips.

The neck of the beef animal tends to be short, thick, and muscular, of medium depth, and should be neatly attached to the head and smoothly blended with the shoulders. The bull at maturity shows a neck of more length, with heavier muscles, some arch, and a heavy coat of hair. The female will have a shorter, lighter neck, with less thickness and less depth. The steer should have a shorter, thicker, fuller, smoother-fleshed neck than the cow. When in perfect pose, with head up, the top line of the neck should be but slightly raised above the height of the withers.

The shoulders should extend well into the back, lying smoothly covered with flesh and blending neatly with the body. A high type of shoulder is uniformly covered with flesh from shoulder point to top of withers. Rough, angular shoulders unevenly covered are among the most common defects of cattle. A prominent shoulder also emphasizes the development behind it.

The breast and chest are most important. The former should be carried well forward and be broad and full in the bosom. As one stands and views a beef bull in show form a great breadth of breast and strength of brisket meets the eye. Sometimes the breast and chest have great depth, and the brisket comes within fifteen inches of the level of the foot. Viewed from one side it may curve forward like the prow of a ship. With the cow considerable bosom may show, but not in so great a degree and with less breadth and more feminine outline. The chest, which lies between the shoulders and just back of them, should be full at the crops, showing much spring of rib, and also well filled out in the front flanks. The most beautiful front on the beef animal - no matter whether bull, cow, or steer — is a smoothly laid, wellfleshed shoulder, with a strong arch of rib behind, leaving little or no depression. Much depression behind the shoulders or a narrow, contracted lower chest indicates lack of constitution.

The front legs should have a wide muscular attachment of arm at the shoulder, with plenty of room from armpit to armpit below the chest. Short, well-placed legs, coming straight down, viewed 
from front or side, are essential. The toes will point nearly straight forward when the legs are correctly placed. Closeness of knees indicates a narrow chest. Fine bone and smooth joints point to superior quality. The front shank bone of a mature animal of the beef class should show refinement at its narrowest point.

The $b a c k$ of beef cattle carries an immense weight, supported at fore and hind quarters. It should thus be very strong and

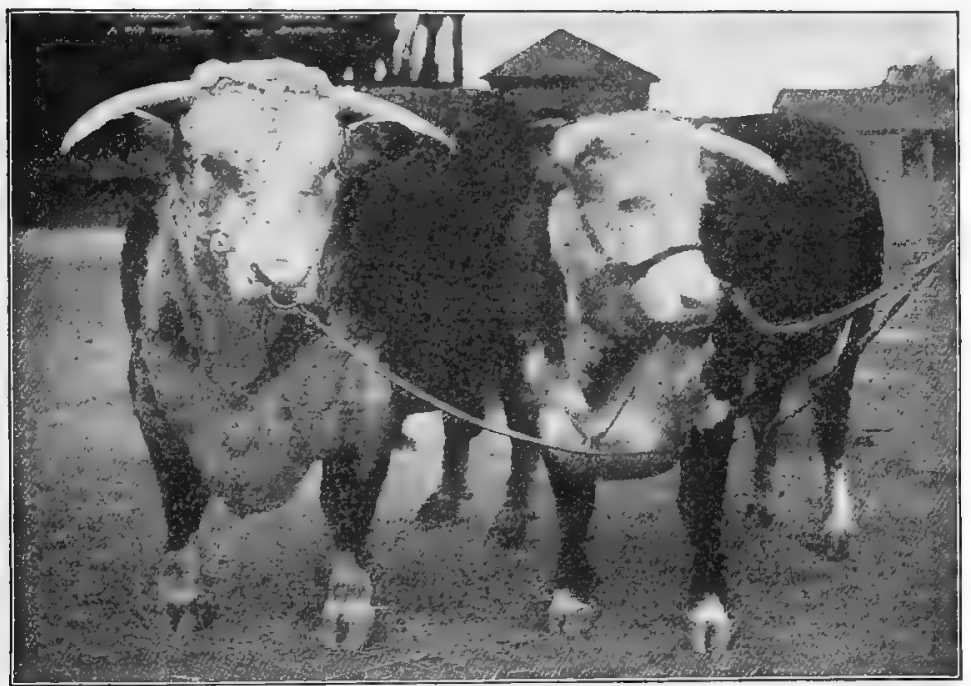

FIG. 78. The Hereford bull March On VI and the heifer Bouquet. These show beef form in a pronounced degree, especially as viewed in front. From photograph, by courtesy of the National Stockman and Farmer

level to sustain this burden. As the highest-priced meats on the carcass are found in the back, it is important that the ribs be well arched, so that a broad back is provided to carry as much meat as possible, thus adding to the value of the animal. Great width is desirable from the point of the shoulders to the hips, and as viewed from front or rear along the back there should be much breadth covered uniformly with mellow flesh. Dimples or tucks in the back, rough spots, and uneven patches of fat detract from the value of this part.

The ribs should not only be well sprung but be long and

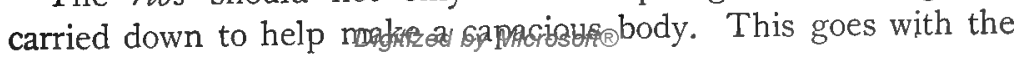


strong feeder and is also most essential with the breeding female. With bulls and steers a very close coupling between the hips and last ribs or all the ribs, in fact, is desired, but with cows for breeding purposes a greater length meets with favor. The depth at front and hind flank, with a thick, full feel at the latter, are associated with superior form and condition.

The hips should be well placed, snugly laid, and, with finished steers, be well covered with flesh. A wide hip in the bull is undesirable, for such a feature may be transmitted and be a source of danger to the cow on birth of wide-hipped offspring. A greater width and more prominence of hip is allowable among the cows, although occasionally one sees the hip too wide and rough.

The rump of a beef animal, no matter what the kind, should be long from hip to point of body, of great width, and comparatively level. This not only promotes a maximum of flesh production but gives a more beautiful form and offers a conformation better suited to the breeding female than does any other. A droopy, peaked rump is a defective conformation, obstructs easy calving, may reduce flesh capacity, and certainly detracts from beauty of form. With beef cattle in condition the rumps are sometimes rough about the tail head or at each side of the tail. Smoothness and fullness here indicate better fleshing qualities.

The hind quarter, viewed from behind, should be quite thick, coming down perpendicularly on the outside to where the thigh naturally narrows. On the inside a thick, broad edge, with much depth from tail head to a full, well-turned twist, should be apparent. From one side the hind quarter will appear long and broad, with considerable depth of flesh to the rear. The whole will appear thick and smoothly covered with flesh.

The hocks and legs indicate the capacity for fleshing at the hind end. If the hocks are strong, muscular, clean, and well placed, with no special tendency to come together, they will be generally associated with thicker-fleshed quarters than otherwise. The legs should stand squarely under the animal, so that a plumb line dropped from the point of the thurls will bisect the hock and the shank bone of the leg below. Crooked hocks are bad, showing weak conformation and ugly form. When the hocks tend to come together at the points - a very common thing - the toes 
point out. Only very rarely do the toes point in. The necessity for a graceful and straight position of the hind leg, smoothness of joint, shortness of leg, and fineness of bone is apparent.

The udder of the beef cow is too frequently ignored. It should be of good size and shape, extending well up behind and in front along under the body, with four well-placed teats. Every beef cow should be able to furnish ample milk for her calf for the

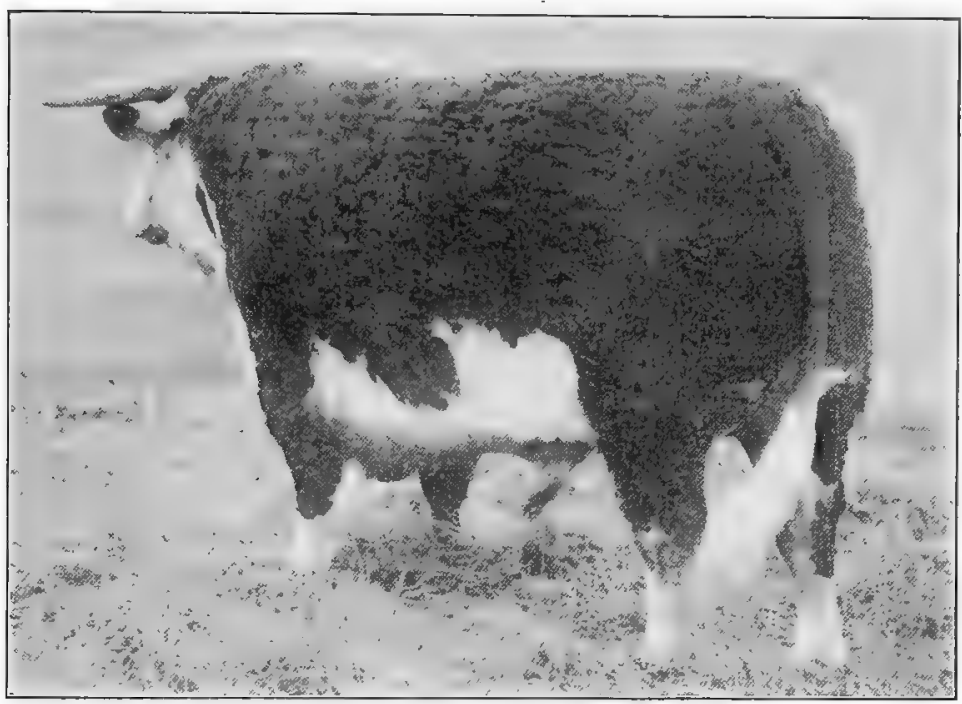

FIG. 79. Rear side view of the Hereford bull Richard Fairfax 4493I7, showing extreme thickness, depth, and superior beef type. From photograph, by courtesy of Ferguson Brothers (the owners), Canby, Minnesota

first eight months of lactation. It is not creditable to a beef cow to have an ill-shaped udder or to produce but little milk.

The quality of the beef animal is shown in bone, skin, hair, ears, and horn. A coarse bone, with large rough joints, long legs, and heavy horns, indicates lack of quality. If the ears are large and coarse, with heavy attachment, there is also lack of quality. The most signal evidence of quality is in the hide, which should always be mellow and pliable, and in the hair, which should be silky and fine. In winter there are thick, fine hairs lying in great profusion next to the skin, with longer ones projecting beyond, 
providing great protection from rough weather. As one views an animal with very distinct evidence of quality in the skin, there will be a glisten and finish to the coat and a roll to the hide which only goes with good quality. Taken in the hands, along over the ribs, the skin seems mellow and pliable to the touch, being easily grasped and stretched. A very thin hide is undesirable, the better sort having a moderate thickness, exceeding that of a dairy animal.

The fleshing of beef cattle is very important. There should be uniformity of flesh all over the body, even though it be not a fattened animal. On highly fed ones, when in good condition, especially steers, the flesh should increase in thickness, but not lose its uniform distribution over the frame. The palm of the hand pressed along the back, shoulder, or side should find no evidence of irregular covering, with bare spots in one place and heavy fleshing near by. Such condition indicates an undesirable type for feeding and killing. 


\section{CHAPTER XXIV}

\section{THE SHORTHORN}

The native home of the Shorthorn breed of cattle is in northeastern England, in the counties of York, Durham, and Northumberland. The North Sea borders this section on the east, with the Cheviot Hills of Scotland the boundary on the north. Winding its way through a beautiful grazing country, the river Tees forms the dividing line between Durham on the north and York, the largest county in England, on the south. Here in the valley of the Tees the Shorthorn received its early development and improvement, from which it spread out over the rest of Great Britain and the civilized world. This valley country has beautiful long stretches of rolling grasslands and fields of grain and roots, but farther north in Northumberland and south in York the land becomes rougher and more hilly.

The origin of the Shorthorn is veiled in obscurity. No doubt the early invaders of England - the Romans, Normans, and others - brought over cattle which crossed with the native English stock. It has been assumed that even prior to 1600 cattle of Shorthorn type were bred on the estates of the earls and dukes of Northumberland in Yorkshire. ${ }^{1}$ Black, horned cattle prevailed more or less in Yorkshire, while farther south, in Lincoln and vicinity, white, red, and other colors prevailed. Early in the eighteenth century the Teeswater cattle represented one popular type, while in southeastern Yorkshire another sort, known as the Holderness, was developed. About the middle of this same century Michael Dobinson and Sir William St. Quintin brought over bulls from Holland and used these in their herds, owned in Durham and Yorkshire respectively. In 1789 George Culley wrote ${ }^{2}$ :

1 The word "shire" in Great Britain signifies county and is often used as a part of the county name; as, for example, "Yorkshire."

2 Observations on Live Stofgetiz Dublimidribsefte 
I remember a gentleman of the county of Durham (a Mr. Michael Dobinson), who went in the early part of his life into Holland, in order to buy bulls; and those he brought over, I have been told, did much service in improving the breed; and this Mr. Dobinson, and neighbors even in my day, were noted for having the best breeds of Shorthorned cattle.

Following these importations of Dobinson and St. Quintin, came others of more inferior stock, such as really injured the

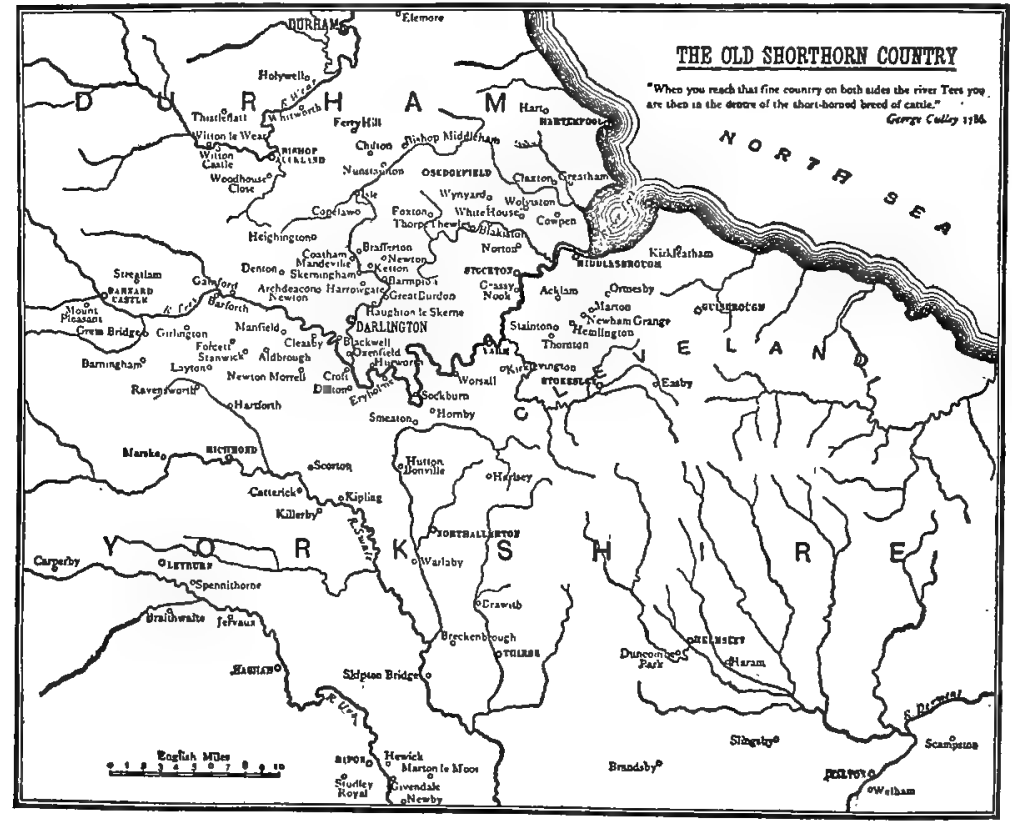

FIG. 80. A map of the native home of the Shorthorn, showing the location of famous early herds. Reproduced from "Thomas Bates and the Kirklevington Shorthorns," by Cadwallader John Bates

beef cattle of the country. By Culley's time, however, much of this evil effect, he writes, was overcome. Other improvers of the early Shorthorn were Sir James Pennyman, the Aislabies of Studley Royal, the Blacketts of Newby, Millbank of Barningham, James Brown, Stephenson, Wetherell, Maynard, Snowdon, Waistell, and Richard and William Barlier.

The distinguished early improvers of the Shorthorn really date from about I 780 and include Charles and Robert Colling; 
Thomas Bates, Thomas Booth and his sons John and Richard, and Amos Cruickshank. There were many other prominent and successful breeders, but these men distinguished themselves as epoch makers, about whose careers clusters much of the best in Shorthorn history.

The Colling brothers. These were Charles and Robert. Charles was born in $\mathbf{1} 750$ and lived at Ketton, just north of Darlington in Durham ; Robert, born in 1749 , lived at Barmpton, about a mile from Ketton. Robert, a bachelor, died in $\mathrm{I} 820$, and Charles died

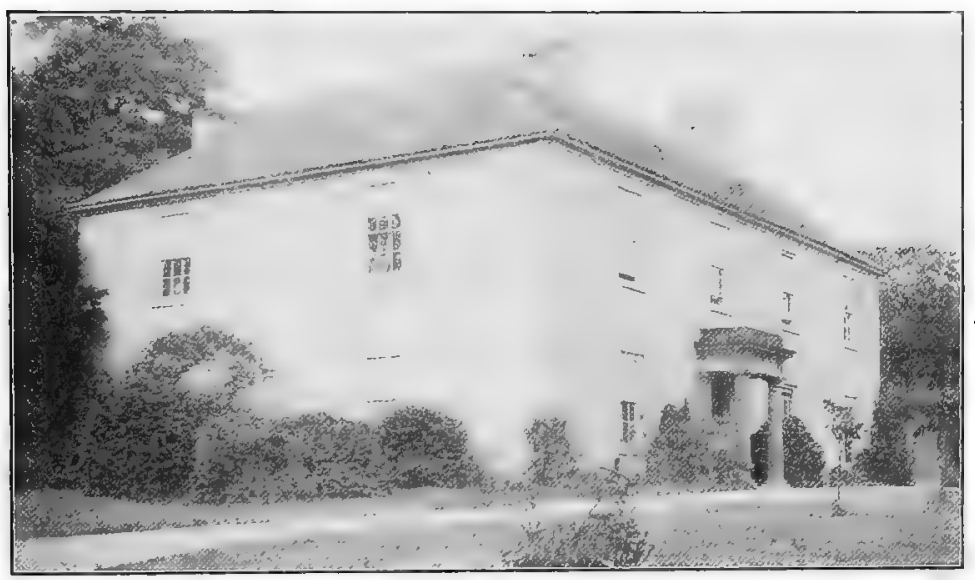

FrG. 8I. Ketton Hall, the home of Charles Colling, near Darlington, England. From photograph by the author

in 1836 , leaving a widow but no children. Charles is somewhat the more famous of the two brothers, although Robert was in fact quite his equal as a breeder. The Colling brothers have often been referred to as the founders of the Shorthorn breed, but this is not exactly the fact, although they were the first real constructive breeders of these cattle. The Collings sought to produce better feeders, to have their cattle mature early, with more constitution than the usual sort, and to dress out with less offal. The great superiority of the cattle at Ketton has been attributed to their remarkable fattening tendency and to their superior handling quality. These brothers developed two very famous herds which had a great infle Ale 
the dispersal sale at Ketton in 18 Io the 47 animals sold brought an average of $\$ 750$ a head. The herd of Robert was sold in two consignments - the first, in I8I8, of 6I head averaging about $\$ 650$; and the second, in 1820 , of 47 head averaging about $\$ 250$. Colling tribes of Shorthorns of distinction were the following:

The Lady Maynard tribe. In I 875 Charles Colling visited John Maynard at Eryholme and purchased a cow and heifer calf. The cow was Old Favorite, but named by him Lady Maynard. The calf Young Strawberry became the dam of a bull calf named Bolingbroke (86), which was in time bred to Phœnix, a daughter of Lady Maynard and sired by Foljambe (263), which resulted in I 793 in the bull Favorite (252), one of the most noted Shorthorn bulls in history. Young Phœnix, a daughter of Phœnix, bred to her sire, Favorite (252), produced Comet (I 55), which brought $\$ 5000$, the top price at the Charles Colling sale and the record price for a bull up to that time. The Lady Maynard tribe is also known as the Phonix tribe. Sixteen of this tribe in Colling's sale, including Comet ( I 55 ), averaged about $\$$ I IOO.

The Princess tribe is one of the oldest and best and is descended from a cow named Old Haughton, by Hubback (319), and a direct descendant from a cow bred at Ketton in I739 by Mr. Stephenson, who was tenant there before Charles Colling. The bull Hubback is regarded by some as the foundation sire of the breed. He was calved in 1777 and was a yellowish red with some white. He was sired by Snowdon's Bull (6I2) and was a direct descendant of the Studley Bull (626), calved in 1737, and one of the first-known Shorthorn sires. The dam of Hubback was a cow of Stephenson breeding. Hubback was owned by various persons, but his fame is chiefly due to his services when owned by Robert Colling and later by Charles, who paid his brother and Mr. Waistell about $\$ 40$ for him. He was used for two years by Colling, who then sold him in 1785 to a Mr. Hubback in Northumberland, from whom he got his name. Hubback sired some very fine heifers at Ketton, one of which, Old Haughton (already referred to), bred to Richard Barker's Bull (52), produced the calf Foljambe (263), which became a noted sire. The bull Belvedere, bred by Charles Colling, used by Thomas Bates was of this Princess tribe. 
The Cherry tribe began with a cow named Old Cherry, by the Lame Bull (358) at Ketton. A daughter of Old Cherry, by Favorite (252), proved a valuable dam. There has been some difference of opinion among early breeders as to the real merit of this tribe.

The Duchess tribe descends from old Shorthorn breeding on the estate of the Duke of Northumberland. In I784 Charles Colling bought what was known as the Stanwick cow, sired by James Brown's Red Bull (97). She was bred to Hubback (319), from which came a daughter, and this latter, bred to Favorite (252), dropped a daughter, which in turn was bred to Daisy Bull (I86), resulting in another heifer, named Duchess, calved in I 800. She was the foundress of the tribe later to become world-wide famous in the hands of Thomas Bates.

The Daisy tribe is descended from Old Daisy, a granddaughter of Old Haughton and sired by Favorite (252). This is closely related to Duchess breeding and is a Ketton tribe.

The Red Rose tribe was of Robert Colling breeding and is descended from a cow sired by Favorite (252), that was taken to America soon after I80I by a man named Hustler. He later returned to England with this cow; hence she became known as the "American Cow." Bred to the bull Yarbrough she became the dam of a calf named Red Rose Ist, which later, in the possession of Thomas Bates, was the foundress of the Red Rose tribe. The bull Pilot (496), a noted Booth sire, was of this tribe. The Cambridge Rose tribe is an offshoot from this.

The Lady tribe was bred by Charles Colling from alloy blood. A polled red Galloway cow, bred to Bolingbroke (86), dropped a bull calf in 1792 which became known as Son of Bolingbroke. He was bred to an old Shorthorn cow, Johanna, from which came a bull calf in I794 known as Grandson of Bolingbroke (280). This last bull, bred to Phœenix, dam of Favorite (252), produced a heifer calf named Lady, the foundress of the tribe. Lady produced several sons and daughters of merit, notably the cows Countess and Laura. This "alloy cross" in early days caused much controversy among Shorthorn breeders. However, at the dispersal sale of Colling in I 8 ro some of the highest prices paid were for animals of this tritiber microsofte 
Thomas Bates was born in Northumberland in I775 and died at his Kirklevington estate near Yarm, in Yorkshire, in $\mathbf{I} 849$. He early became acquainted with the prominent breeders of his time, notably the Colling brothers, and began the systematic development of a class of cattle having superior dairy as well as beef qualities. He was a careful investigator, keeping detailed records of the relationship of food consumed to beef and milk production. His cattle had much quality, were rather large for the breed, and possessed great dairy capacity, but were somewhat criticized for lack of constitution and breeding capacity. Bates

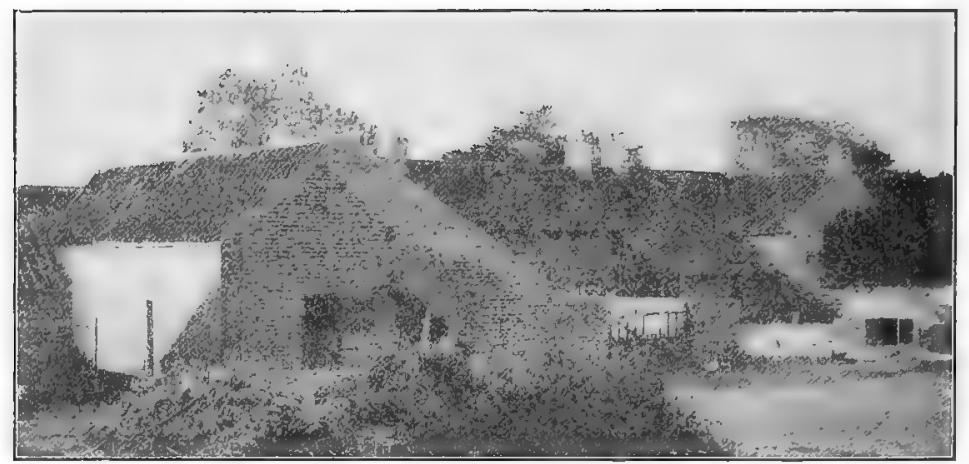

FIG. 82. A rear view of the house and part of the stable at Kirklevington, the residence of Thomas Bates, near Varm, England. From photograph by the author

was a man of very strong convictions, extremely egotistical, and did not make friends among the breeders. He was an educated man, having attended Edinburgh University, and was an unusual student for his time. He may rightly be termed one of the world's greatest breeders. Bates died a bachelor, and with his death, in I 849 , came the dispersal of his herd of sixty-eight animals at an average price of about $\$ 335$ per head. The following are the more important tribes developed by Bates:

The Duchess tribe of Bates was descended from the Duchess cow, by Daisy Bull (I86), that was calved in I 800 and bred by Colling. A daughter of Duchess owned by Charles Colling, bred to Comet (155), in 1808 dropped a heifer calf which became known as Duchess I or Young Duchess, which Bates purchased 
at the Colling sale in 18 Io for 183 guineas. Duchess $I$, the foundress of this Bates tribe, was a notable cow and the dam of Duchesses II, III, IV, V, and the bull Cleveland (I46). This was the most celebrated tribe of Bates and the one in which he centered his deepest interests. Duchess 34th, by Belvedere (1706), perhaps his most noted cow, was bred to her sire, from which came the famous Duke of Northumberland (I940), regarded by Bates as his greatest achievement as a breeder. At the Bates dispersal sale fourteen cattle of this tribe averaged about $\$ 575$ a head.

The Oxford tribe. Bates purchased of James Brown a cow known as the Matchem Cow, sired by Matchem (2281). At the first Royal Agricultural Society Show of England at Oxford her daughter was the first prize in class and was given the name "Oxford Premium Cow." The Oxfords, however, all trace to her half sister, Oxford 2d, by Short Tail (262I), a son of Belvedere (1706). This was a favorite family of Bates's. At his dispersal sale thirteen Oxfords averaged about $\$ 340$ each.

The Waterloo tribe, descended from a cow known as the Water. loo Cow, was bought by Bates in 1831. She was sired by a bull named Waterloo (28I $\mathrm{I}$ ) and was out of a cow by this same sire. Otherwise little is known of the ancestry of this tribe. Two daughters of the Waterloo Cow - IVaterloo 2d, by Belvedere, and Waterloo 3d, by Norfolk (2377) - proved excellent breeders at Kirklevington. Six Waterloos in Bates's sale averaged nearly $\$ 300$ each. The only cows secured by Scotch buyers at the Bates dispersal sale were Waterloo I 2 th and I 3 th, bought by Amos Cruickshank and W. Hay.

The Cambridge Rose tribe was a direct descendant from the Red Rose tribe of Robert Colling. In 1823 Bates had a Red Rose cow drop a bull calf which he named Second Hubback (1423). This bull he used freely on his Duchess cows, producing excellent results. In I840, with a heifer of this family, he won high honors at the Royal Agricultural Society Show at Cambridge, which resulted in his naming her Cambridge Rose, the foundress of a new tribe. The noted cow Rose of Sharon, imported in I834 from England by the Ohio Importing Company, was of this tribe. 
The Wild Eyes tribe descends from a cow known as Wildair, by Emperor (1975), purchased as a calf by Bates at J. W. Parrington's sale in 1832. Bates claimed that this tribe brought into his herd the only good blood that he obtained outside of the Colling herds.

The Foggathorpe tribe descends from a cow of that name calved in 1830 and bought by Bates from her breeder, Mr. Edwards, when she was ten years old. She proved an unusually good

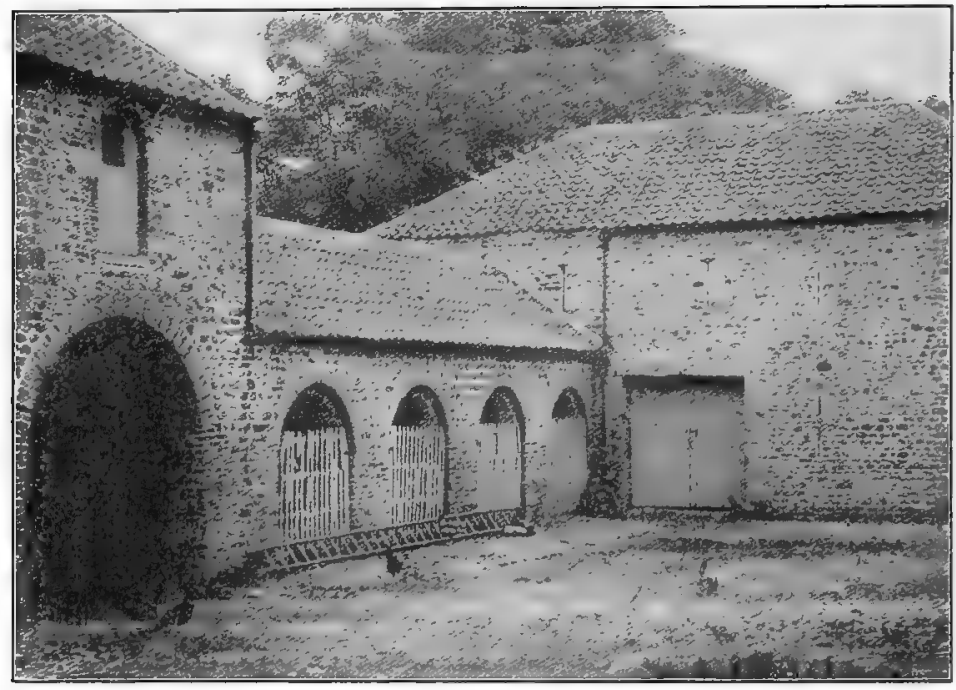

FIG. 83. One corner of the stable at Killerby, the home of Thomas Booth in Yorkshire. From photograph by the author

breeding cow and dropped calves that later became famous. This was an excellent tribe. Bates, it is said, was suspicious that Foggathorpe was of the Princess tribe.

The Booth family became prominent in Shorthorn history with the establishment of a herd by Thomas Booth at Killerby some time prior to I790. He was then farming Warlaby and Killerby, but his Shorthorn breeding began at the latter place. He is said to have bought good Teeswater cows and used Colling bulls on them. Booth had two sons, John and Richard, who took up the work where he left off. John lived at Killerby, where he died in 
I 857, aged seventy years. Richard at first lived at Studley, near Killerby, but later moved to Warlaby, where he died in 1864 , aged seventy-six. These two men had a very great influence on Shorthorn history and really developed the breed along lines adopted by the Colling brothers. The herd of John Booth was sold at auction in I 852 , while that of Richard was inherited by his nephew, Thomas C. Booth, who died in 1878. A brother of the latter, J. B. Booth, engaged in breeding at Killerby, where he died in I886. In 1898 the herd at Warlaby came into the possession of Richard Booth, son of Thomas C. Booth, who has not played a prominent part in British Shorthorn activities. Shorthorns, however, have been bred in the Booth family for three generations, covering a period of considerably over one hundred years. The Booth cattle were rougher and apparently more robust than those of Bates type and met with much favor. The Booths sought to produce thick-fleshed, easy-feeding animals with plenty of quality and strong constitution. They did not have the distinction for milk production notable with Bates's animals. Booth cattle have long been popular in Ireland, where since early days Shorthorns have been prime favorites. Among the important Booth tribes are the following:

The Anna tribe, descended from a cow named Anna, by Pilot (496), calved in I 820 , is one of the oldest Booth families. The cow Bright Eyes, calved in I808, produced two daughters, Ariadne, by Albion (14), and Agnes. Anna was a daughter of Ariadne, one of the great early-day dams. Anna was bred at Studley and was not only a famous dam but a great show cow. In its time this was one of the more popular Booth tribes.

The Isabella tribe had for foundress a cow by that name, calved in I 820, and a half sister of Anna, being sired by Pilot (496). Isabella was a very beautiful cow, being known as the "matchless Isabella," and she proved a remarkable breeder, dropping nine calves, six being heifers. A son, Isaac, proved a valuable sire, and her daughter Isabella Buckingham was a Royal winner. Carr, in his history of the Booth cattle, states that "Isabella and her descendants brought the massive yet exquisitely molded fore quarters into the herd, and also the straight underline of the belly, for which the Warlaby animals are so remarkable." 
The Halnaby, or Strawberry, tribe began with a cow named Halnaby, by Lame Bull (359), bought by Mr. Booth about 1797 on Darlington market. Bred to Albion (I 4), a son of Comet (I 55), she produced Young Albion (I5), a most valuable Booth sire and the first of the Booth bulls let out for hire. Rockingham (255I) and Priam (2452), well-known sires, are of this tribe. Priam was sire of Necklace and Bracelet, the most famous Shorthorn twins of history, of which more is said below.

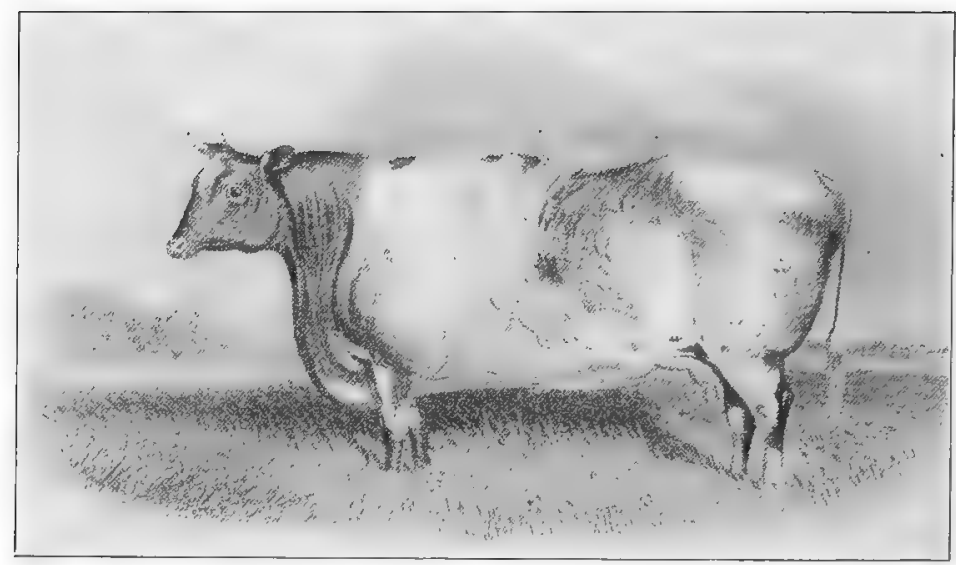

FIG. 84. Lady Fragrant, calved in 1863 . In the herd of Thomas C. Booth, she was for years the leading prize-winning Shorthorn female in England. From an engraving by E. Hacker, published in London in I 868

The Bracelet tribe is descended from the cow Countess, by Albion (I4). In fact this is also known as the Countess tribe. Four generations from Countess came the cow Vestal, owned by John Booth, by the epoch-maling Booth sire, Pilot (496). A daughter of Vestal named Toy, sired by Argus (759), bred to Priam (2452), became the dam of the twin heifers Bracelet and Necklace to which reference is above made. These twins proved to be not only the greatest show Shorthorns between I 842 and I 846 , but each became a great dam. Bracelet was the dam of several animals of unusual merit. Her son Buckingham (3239), by Musselman (4525), proved to be one of the famous bulls of his time, siring many noteworthy females. 
The Moss Rose tribe of Booth was descended from a cow named Dairymaid, by Pilot (496), said to have come "from a good stock in the village of Scorton, not far from Killerby." Though this tribe was developed at Warlaby, it should not be confused with one of the same name founded at Killerby and of less importance. From Dairymaid was descended Moss Rose, by Priam (2452), and from this line comes Vivandiere, by Buckingham (3239), one of the very best breeding Shorthorn cows of Booth ancestry. Vivandiere had ten calves, seven of which were prize winners - one, Campfollower, being regarded as one of the greatest of Warlaby-bred matrons.

The Fairholm, or Blossom, tribe had its origin in a purchase by Thomas Booth of five heifers from a Mr. Broader of Fairholm. From these heifers came three branches, of which the Blossom is most conspicuous. From it are descended the well-known Warlaby-bred animals Plum Blossom, Nectarine Blossom, Venus Victrix, Baron Warlaby (78I3), and Windsor (I 4013).

Less prominent early English Shorthorn breeders besides the above were Christopher Mason of Chilton; Jonas Whittaker of Otley, near Leeds; William Wetherell of Aldborough, near Darlington; Sir Charles Knighley of Fawsley Park, Daventry; Colonel Towneley of Towneley; and IVilliam Torr of Riby and Aylesby.

The development of the Shorthorn in Scotland first took root in the border country, among the north foothills of the Cheviots. Here Robertson of Ladykirk, near the town of Coldstream on the banks of the Tweed, was the first Scotchman to engage in breeding Shorthorns. This was early in the nineteenth century. Robertson bred some excellent cattle, but was very independent and would not register them in the Coates herdbook. John Rennie of Phantassie about I8I8 or I8I9 bought of Robertson and of English breeders and established a herd still farther north, easterly from Edinburgh, near the town of Haddington. Rennie became a noted Shorthorn breeder and produced a type of profitable cattle which, like Robertson, he refused to register in the English book. The first person to introduce the Shorthorn into north Scotland was Captain Barclay, who lived on the estate of Ury near the seapgrt of Stonehaven, a few miles south 
of Aberdeen. His first Shorthorn purchase was made in I829 at the sale of Mason at Chilton, when he bought two females, one of which, Lady Sarah, proved a great producer. Barclay bred many noted animals, among which was The Pacha (76r2), the sire of some of the most distinguished cattle of the breed. In I838 Barclay had a dispersal sale, but in 1840 he established another herd. At Ury a class of cattle of great scale and substance was developed. Following these early, constructive Scotch breeders were Grant Duff of Eden, Hay of Shethin, the Cruickshanks of Sittyton, Marr of Uppermill, and others who did much

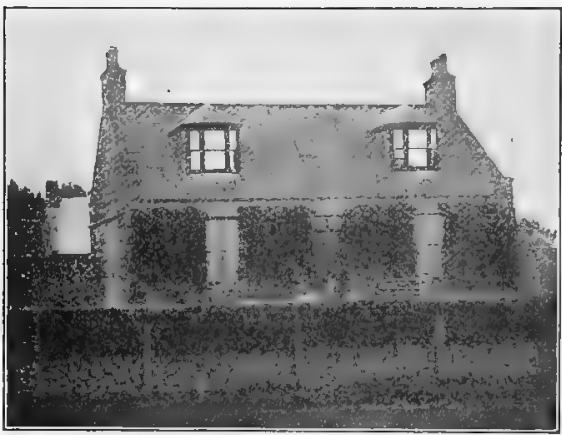

FIG. 85. The farmhouse of William Duthie at Collynie, Tarves, Scotland. From photograph by the author to give fame to the Shorthorn breed.

Amos Cruickshank was born in Aberdeen in northeastern Scotland, in I 808 , and died in 1895 at Sittyton, Aberdeenshire. In partnership with his brother Anthony, who was a merchant in the city of Aberdeen, Amos took possession in 1837 of a somewhat rolling farm where roots, the small grains, and grass were produced. Here Cruickshank began his long career as one of the world's great constructive breeders, and, as so well expressed by Sanders, ${ }^{1}$ in "a rough, broken country, possessing but limited areas of good soil, wanting in natural shelter, swept for a good portion of the year by the chill east winds of the North Sea, and enduring the long, dark winters of latitude $58^{\circ} \mathrm{N}$." Here Cruickshank began to select and buy Shorthorns from various sources, choosing animals that possessed plenty of vigor and rapid flesh-producing qualities, and that were distinctively of the beefproducing type. He was not influenced by pedigree fads, and purchased on a very independent basis. Again quoting Sanders ${ }^{2}$ :

1 A. H. Sanders, Shorthorn Cattle, p. 550. Chicago, I900.

2 Ibid. p. 578 . 
Vitality and feeding quality were with Amos Cruickshank considered paramount. A broad, full chest, wide back, and deep ribs were his all-in-all. The head had attention only as it gave some token as to the vigor or probable capacity of the animal for feed lot or reproductive purposes. The rump carried cheap meat and was, in his view, of wholly secondary importance. Level quarters and fine fronts he fully appreciated, but if the "middle" was weak the fault with him was fatal.

Cruickshank met with prime success, and to-day Scotch cattle, tracing back in an important degree to his breeding, are in great favor. Among the notable tribes established by him the following justify brief mention :

The Brawith Bud tribe originated with a cow of that name in the herd of Grant Duff, which he bought in 184 I from Benjamin Wilson of Brawith, England. In I 854 Cruickshank bought from Duff a cow named Pure Gold, descended from Brawith Bud, so the name "Pure Gold" is also given this tribe. Pure Gold lived to be the oldest cow at Sittyton, and her daughter Golden Days proved to be a remarkably fine breeder, being dam of three great bulls; namely, Golden Rule, Pride of the Isles, and Lord of the Isles. This was one of the most successfully developed tribes at Sittyton, up to the final dispersion.

The Broadhooks tribe descends from a cow named Eliza, by White Bull (5643), tracing back to the breeding of Robertson of Ladykirk. Several cows named Broadhooks are descended from Eliza, but the family was gone from the Cruickshank herd after I869. However, this tribe was promoted by Lord Lovat, and in his hands produced the noted buil New I'ear's Gift (57796), prominent in the Royal herd at Windsor and a most excellent sire.

The Clipper tribe descends from the cow Clipper, by Billy (3I5I), and traces back into the herd of Mason of Chilton. Her daughter Cressida, by John Bull (1 I6I8), bred to Czar (20947), dropped an excellent calf called Carmine, which later to the service of Champion of England (17526) - became the dam of two fine females, Carmine Rose and Princess Royal. These were two of the best females bred by Cruickshank. The latter cow bred until she was fifteen and was dam of Roan Gauntlet (35284), next to Champion of England the greatest bull ever bred by the Master of Sittyton. 
The Lavender tribe was one of the later families established at Sittyton. In $1870 \mathrm{Mr}$. Cruickshank bought some Lavender cows from Mr. Butler of Badminton, England, and these traced back to the old Lenton blood of John Wilkinson. Lavender

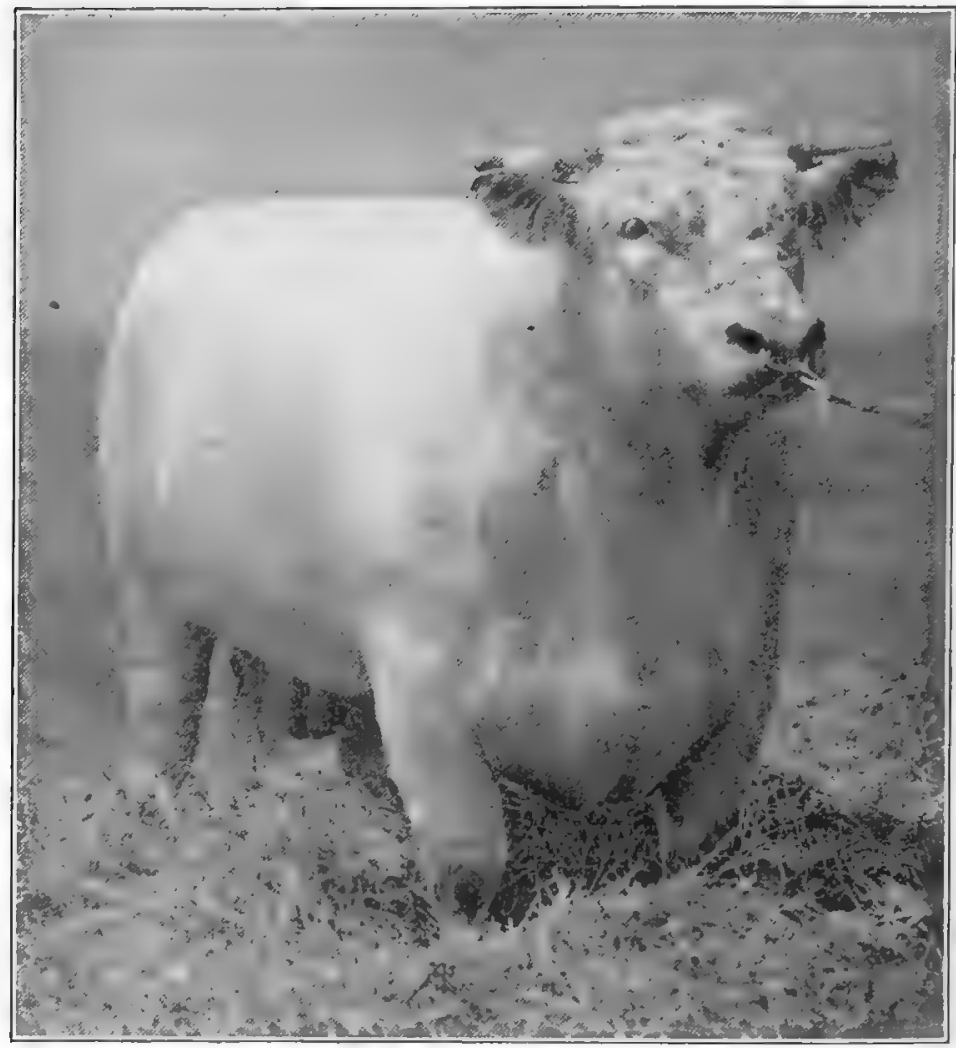

Fig. 86. Pride of Oakdale 496710 , calved in 1916 , and many times champion. A fine example of Shorthorn character. Bred and owned by F. R. Edwards, Tiffin, Ohio. From photograph by Hildebrand, by courtesy of Mr. Edwards

I6th, by Lord Lansdowne (29128), and Lavender I 7 th, by Royal Duke of Gloster (2090I), were the two outstanding females of this tribe in Cruickshank's hands. Count Lavender (60545), celebrated as a sire in the herd of J. Deane Willis, was of this tribe, which has long been popular in America. 
The Lovely tribe descends from the two cows Lovely 6 th and Lovely 8th, each sired by Bosquet (I4I83). These two descend from the cow Marion, by Anthony (I640), of English breeding, brought to Scotland by Hay of Shethin. Scotland's Pride (25100), one of the great sires at Sittyton, was a son of Lovely 8th.

The Mimulus tribe takes its name from a red cow, Mimulus, by Champion of England (17526). She traced back through several generations, it is supposed to stock of Robertson of Ladykirk. Mimulus was sold to John Dryden of Canada, but she left a son, Royal Duke of Gloster (29864) at Sittyton, that proved one of the great sires of the breed. Mimulus was also the dam of Barmpton Hero (588 I3), calved in the Dryden herd and one of the noted American-bred sires. This family did not have a large representation in the herd at Sittyton and finally disappeared entirely.

The Nonpareil tribe descends from a cow named Nonpareil in the herd of Mr. Cartwright of Lincolnshire, England. In 1844 Mr. Cruickshank purchased a cow called Nonpareil 3d, by Young Frederick (3836), and she became the Sittyton foundress of this tribe, producing some excellent progeny. This tribe seemed to run to bulls, and finally about 1864 it became nearly extinct. Later an effort was made to reëstablish it in the herd, but without much success.

The Orange Blossom, or Fancy, tribe had its start in a cow named Fancy, by Billy (3 I I), bought in I 874 from John Hutcheson of Monyruy. A daughter of Fancy named Edith Fairfax, by Sir Thomas Fairfax (5 196), was an unusual producer, and from one of her daughters, Queen of Scotland, by Matadore (I I 800), came the original Orange Blossom. She was the dam of William of Orange (50694), perhaps the best-known sire in the herd of William Marr at Uppermill. The bull Gay Monarch (924II), owned by Robbins \& Sons of Indiana, a successful show bull and sire, was by William of Orange.

The Secret tribe at Sittyton secured its foothold there through the purchase in I855 of the cow Sympathy, by Duke of Athol (roI50). She dropped a heifer named Sunrise. From these two cows the Cruickshank Secrets descend. This was an excellent and prolific family. One of the best of the Secret cows is said to have 
been Surname, the dam of Scottish Archer (59833), prominent as a sire in the herd of William Duthie at Collynie.

The Spicy tribe derives its name from the cow Spicy 4 th, purchased in I 868 from a Mr. Milne of Aberdeenshire. She had for dam a most excellent cow named Spicy, by Marmaduke (14897). Spicy 4th, bred to Champion of England, produced a very superior cow named Silvery. From this not large family came a number of high-class individuals, including the bulls Strongbow (52230) and

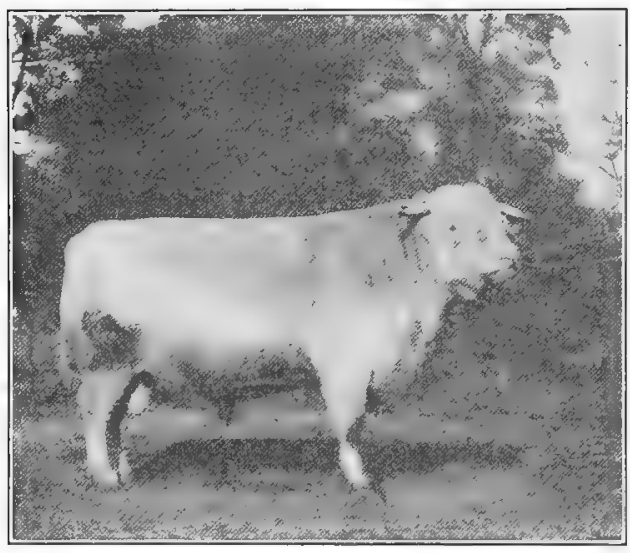

Fig. 87. Maxwalton Renown 367543 , one of the leading Shorthorn sires in the herd of Carpenter and Ross, Mansfield, Ohio. This bull died in I918. From photograph by the author

Sea King (6I 769), the former having been used in service at Sittyton. The bull Spicy Robin (69638), in the herd of J. Deane Willis at Bapton Manor, England, was of this family.

The Venus tribe descends fromared heifer of this name bought in $184 \mathrm{I}$ at the sale of Mr. Rennie in Forfarshire. Venus was by Saturn (5089), bred by Mr. Simpson, and her dam, Dairymaid, traced back to the Ladykirk herd. From the cow Flora, by Fairfax Royal (6987), and her granddaughter, Morning Star, by Champion of England (I 7526), came some of the best representatives of the Venus tribe, which was in favor with Mr. Cruickshank to the last.

The Victoria tribe secured its start at Sittyton in the purchase in Ireland, in 1853, by Anthony Cruickshank of the cow Victoria I9th, by Lord John (1173I). She was sent to Mr. Hay's at Shethin and bred to the Booth bull Red Kinight (I 1976), from which she dropped twin heifers, Victoria 29th and 3oth. This original stock was somewhat delicate, and neither mother nor daughters bred well until mated to Champion of England. Victoria 39th, out of Victoria Igth, by this bull, proved a valuable 
addition and was long used in the herd. Victoria 4 Ist, by Lord Privy Seal (I6444), and Victoria 57th, by Lord Lancaster (26666), gave distinction to the tribe, which was probably never in high favor with Amos Cruickshank, though much admired by his brother Anthony. This family has been popular in America, the bull Baron Victor (45944), out of Victoria 58 th, in his day being famous as a sire in the herd of the late Colonel IV. A. Harris of Kansas.

The Violet tribe at Sittyton is based on a roan cow named Moss Rose, calved in 1837 but of uncertain pedigree. She was a valuable dam and in $18+3$ dropped a calf called Red Rose, by Inkhorn (609I). Red Rose was an extra good breeder, and from her came several calves, among which was Violet, by Lord Bathurst (I3I73). Three of the daughters of Violet - Village Rose, by Champion of England, Sweet Violet, by Lord Stanley (I6454), and Red Violet, by Allan (2I772) - were of unusual excellence. This was a prolific family and was regarded with favor by Cruickshank.

The Augusta tribe was established by the Bruces at Inverquhomery, Aberdeenshire. It is said that about I $850 \mathrm{Mr}$. J. Bruce bought two cows at Pyrgo Park, Essex - a Rosewood and an Augusta, the former costing $\$ 100$ and the latter $\$ 160$. A heifer calf of the Augusta cow was bought for $\$ 75$. Sittyton bulls were used in the herd, Bruce and Cruickshank being special friends. The Inverquhomery herd was essentially built up from these two families up to the time of its dispersal in 1899.

The Duchess of Gloster tribe descends from a cow named Chance bought by Cruickshank in 1855 from Mr. Robinson, Burton upon Trent. She was sired by a Bates bull, Duke of Gloster (I 382 ), and out of a cow named Chaplet. Sinclair states that Chance was of a delicate constitution, and her first heifers did not live long, producing but two or three calves each. Seventh Duchess of Gloster, by Lord Raglan (1 3244), proved to be an excellent breeder and had five calves to the service of Champion of England (17526) that made a good showing. A son of Ninth Duchess of Gloster, by Champion of England, was named Grand Duke of Gloster (26288). He died at two years of age from an

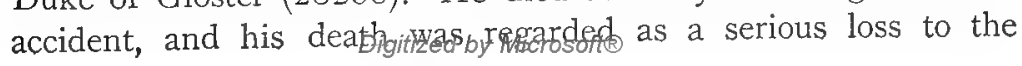


herd. Royal Duke of Gloster (29864) was considered one of the most valued bulls in service at Sittyton. This family has for many years been popular in both Canada and the United States.

The fisst Shorthorns imported to America were brought to Virginia in 1783 by Gough and Miller, and though not called Shorthoms the evidence shows them to have been of this breed. These men also imported again about I792. It is said that in I $79 \mathrm{I}$ and also in I 796 a Mr. Heaton brought Shorthorns to New York State. A Mr. Cox also brought a bull and two cows to Rensselaer County, New York, after the close of the War of 1812. In I8I7 the first pedigreed bulls, Marquis (408) and Moscow (94 I 3), were brought to America, S. M. Hopkins importing them into the Genesee valley in New York. What are known as "The Seventeens" were imported in I8I7 by Colonel Lewis Sanders of Kentucky, and included four bulls and four heifers. One of the heifers died before reaching Kentucky, but the others - Mrs. Motte (the Durham Cow) and the Teeswater Cow were the first to be imported west of the Alleghenies, and their descendants are known as "The Seventeens." In I8I7 and I8I8 importations were made to Massachusetts; in I82I, I822, and I 823 importations were brought to New York State and from then on into various sections of the Eastern states.

The Ohio Importing Company, organized at Chillicothe, Ohio, in 1833, with about fifty stockholders, became the most important factor in introducing Shorthorns to America up to this time. In I 834 Felix and Josiah Renick and E. J. Harness went to England, where they visited Bates, the Booths, Maynard, Clark, and other famous breeders and purchased nineteen head and brought them to Ohio. In this shipment were the heifers Rose of Sharon, by Belvedere (I 706), bred by Thomas Bates, and Young Mary, by Jupiter (2I 70), bred by J. Clark. The history of these cows is inseparably associated with Shorthorn fame in America. Importations were also made in 1835 and 1836 , and on October 29, I 836 , occurred the most important Shorthorn auction sale held in America, when this importation was sold off and the herd closed up. Forty-three animals sold for $\$ 34,540$, an average of $\$ 803.25$. The formation of the Ohio Company was one of the notable steps in American Shorthorn history, 
although later numerous other companies were organized in the Middle West for the importation and promotion of the breed.

The characteristics of the Shorthorn. Having traced briefly the influences that have surrounded the development of the Shorthorn breed, a consideration of its characteristics will now be appropriate. The general conformation of the Shorthorn adheres closely to the beef type, though certain tribes, the Bates bred in particular, have so strong a tendency to the production of milk as to be spoken of as generalpurpose cattle. The follow-

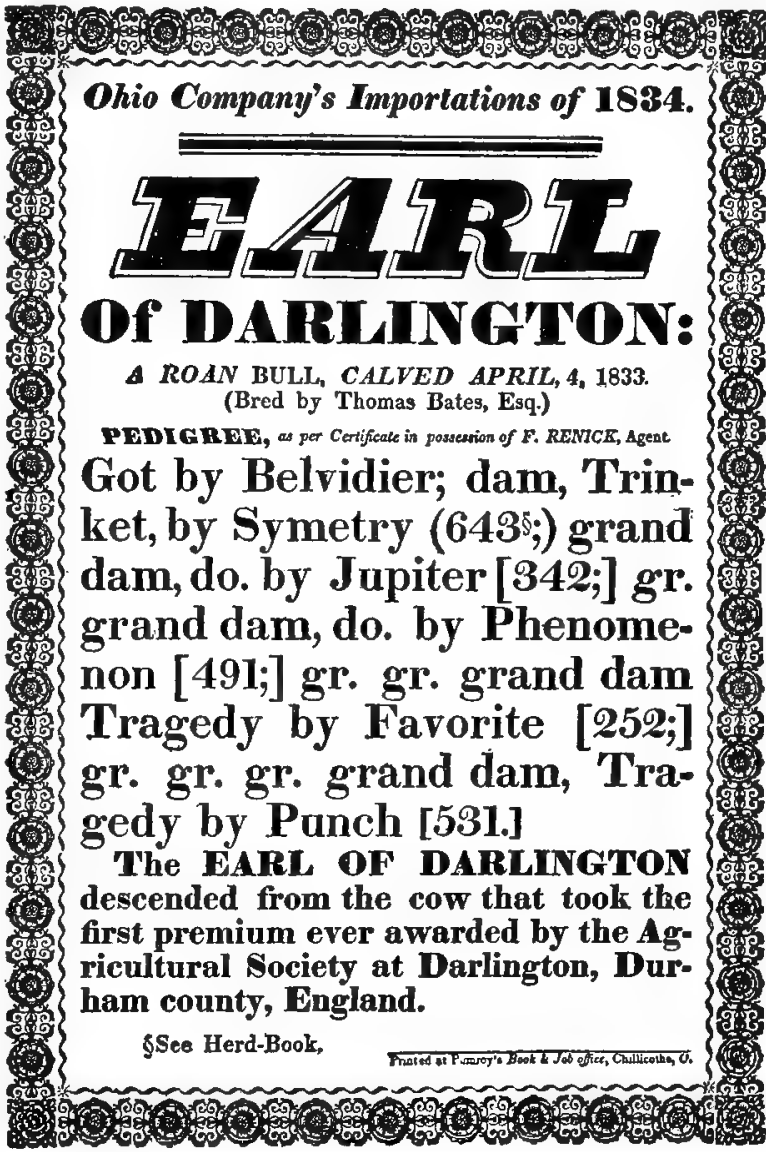

FIG. 88. Copy of the pedigree of the Earl of Darlington, in the possession of the author, published by the Ohio Importing Company about 1835 . This is no doubt a copy of one of the first pedigrees printed in America. By courtesy of Mr. O. V. Hegler, Fayette County, Ohio, whose grandfather was one of the original stockholders of the Ohio Importing Company ing points especially apply to the cow: The hom is variable, but is always comparatively small and shortand preferably curves forward, with the 
tips bending inward or upward. In color a waxy yellowish tint is preferred, though blackish tips are not debarred. The head should be lean and shapely and short from between the eyes to the muzzle, which should be flesh color and broad, with large nostrils. A dark or blackish muzzle is distinctly objected to by most breeders. The neck should be short, neatly attached to the head, and blend smoothly into the shoulders. Shorthorn shoulders tend to be a bit prominent and bare. They should be well laid in and smoothly covered with flesh. Back of the shoulders the crops and fore flanks are often deficient, and lack of heart girth is a frequent criticism of the breed. Superior animals show a body that is very broad of back, strong of loin, and so prominent of rib as to give a large girth and digestive capacity of the first order. The flanks before and behind are also low and full. A thick, deep body is usually associated with a low, full chest and prominent breast, - essentials with a proper constitutional development. The brisket should be broad and deep and carried forward as a part of a smooth, full, and attractive breast. The hind quarter of the Shorthorn is usually typical of the breed, - superior in its general development to that of any other beef breed. Regarding the hips William Housman writes of the Shorthorn: "In fat or lean animals the hip bone must be liberally covered, not bare, hard, or sharp; each hip 'cleft,' and the hollow filled with elastic flesh. This is an important test of the quality of the animal, especially in the lean state." The mmp is usually long, level, and broad and well covered with meat, while the thighs and quarters are long, thick, and deep from front to rear, showing a maximum amount of meat for this quarter. Animals of naturally heavy-fleshing qualities frequently get "patchy" about the root of the tail at the rump, and also roll some on the sides, thus detracting from the smoothness of finish. The modern demand is for smoothness, and the old-fashioned, rough, patchy class of cattle are in great disfavor among progressive Shorthorn breeders. Quality and smoothness are two essentials insisted upon, and the observant student will note that in the show ring of to-day, in important competition, those animals given preference are smooth and show a condition that signifies the distinctly superior butcher's beast. The udder of the Shorthorn usually shows greater capacity than 
does that of the other beef breeds. Shorthorn cows as a rule furnish an abundant supply of milk for the calf. It is this milk-producing capacity of the Shorthorn that has made it a favorite for a century with a class of American farmers who desire general-purpose cattle. In limb animals of this breed should show shortness of leg, small, clean bone, and strong yet

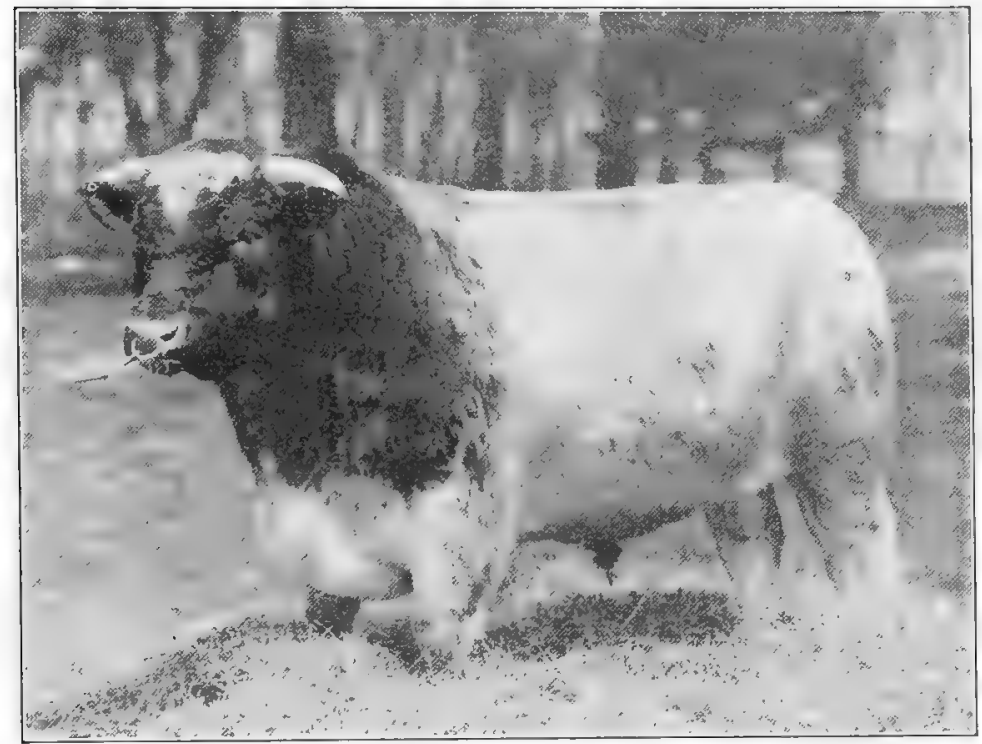

FIG. 89. Village Supreme 423865, grand-champion Shorthorn bull in 1917 at the International Live-Stock Exposition and a great sire. Sold by Bellows Brothers, Maryville, Missouri, for $\$ 16,500$. This is a fine example of the smooth-fleshed, modern type of Shorthorn, and one that meets with much favor. From photograph by Risk, by courtesy of Bellows Brothers

not coarse joints. A criticism often made of Shorthorns and not without some justice is that they have a tendency to be too long of leg. This has been especially said in the past of cattle of Bates-bred ancestry, and this criticism has been materially weakened by the influence of Scotch blood, which has produced a compact type, with depth of rib and shortness of leg essential in cattle that will kill out to best advantage. The coat of hair should be thick and fine, especially in the cooler season of the year. An abundant coat is an evidence of a rugged constitution, 
gives protection in cold weather, and is rather characteristic of animals of Scotch ancestry. What is known as a "thick, mossy undercoat" is more or less covered with a longer, coarser hair which, under favorable conditions, has a tendency to curl slightly.

The Shorthorn bull should possess in the main the desirable features of the female, without her feminine qualities. His head,

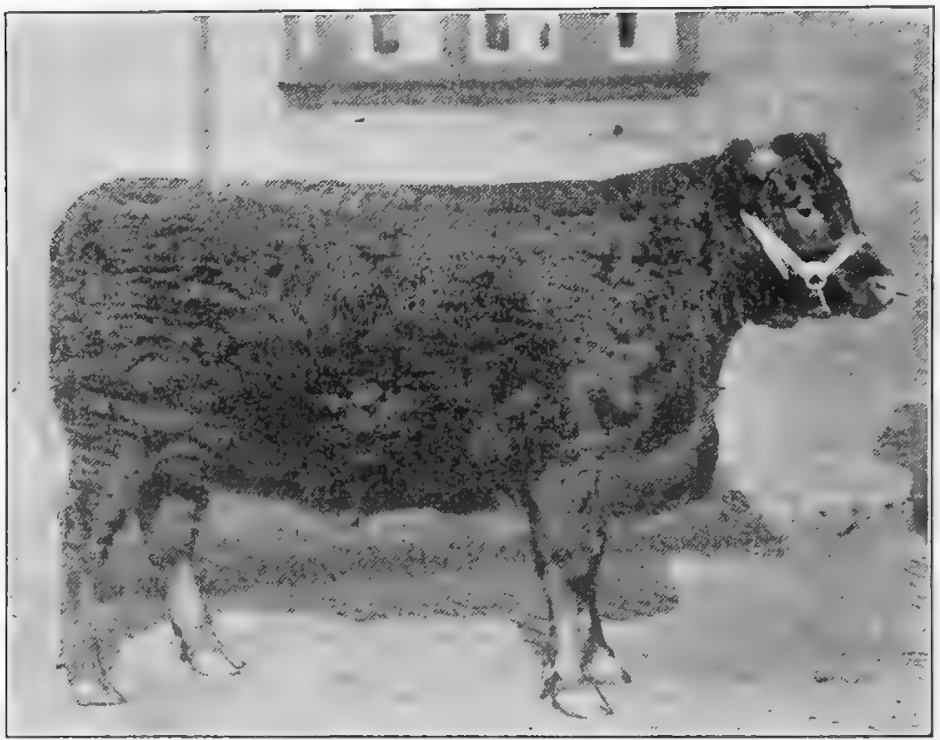

FIG. 9o. Clover Leaf Gloster, junior champion Shorthorn female in 1918 at the International Live-Stock Exposition, and champion at other shows. A model Shorthorn heifer and a fine example of red color. Bred and owned by W. C. Rosenberger \& Sons, Tiffin, Ohio. From photograph by Hildebrand, by courtesy of the owners

horns, and neck naturally should be stronger and larger, the latter being thick and arched, the whole front showing character and breeding power. The horns of the bull are less curved than those of the cow and should be prominent yet not coarse. Over the forehead and neck should be a covering of thick, fine, and moderately long hair. In general form the bull should also be broad in front, with full deep bosom, broad powerful arms, a comparatively shorter and more blocky body than that possessed by the cow and with greater relative size. 
The color of the Shorthorn is in part distinctive of the breed. This may be pure red, red and white, pure white, or roan, the latter being a commingling of red and white hairs without forming a solid color. The shades vary - the red ranging from light to dark, and the roan from light or white roan to dark or red roan. No other breed claims the roan color. Black is not a Shorthorn color and should not occur in pure-bred animals. The skin color may properly be mentioned in this connection. This should be of a very light yellow or creamy tint, as shown in the ears and about the armpits and udder, or scrotum. The bare skin on the nose should be "flesh color" and not a dark slate, such as sometimes occurs. A smutty nose is an off Shorthorn color and is distinctly objected to by breeders in general.

The relative percentage of Shorthorn colors has attracted more or less attention. Years ago the author instituted a study of the herdbooks, with the view of ascertaining the prevalence of the different Shorthorn colors. For this purpose I0,000 head registered in the herdbooks from I859 to I9O3 were classified, and color comparison made. In I9I 7 my associate, Professor S. M. Salisbury, computed the colors of 24,000 animals registered from I9ro to I9I4 inclusive. The figures thus obtained, covering 34,000 head, may be expressed as follows:

\section{Prevalence of Colors in Shorthorn Herdbooks}

\begin{tabular}{|c|c|c|c|c|c|c|c|}
\hline \multirow{2}{*}{\multicolumn{4}{|c|}{ CoLOR }} & \multicolumn{2}{|c|}{$1859-1903$} & \multicolumn{2}{|c|}{$1910-1914$} \\
\hline & & & & \multirow{2}{*}{$\frac{\text { Number }}{4,943}$} & \multirow{2}{*}{$\frac{\text { Per Cent }}{49.43}$} & \multirow{2}{*}{$\begin{array}{l}\text { NuMber } \\
15,085\end{array}$} & \multirow{2}{*}{$\frac{\text { PER CENT }}{62.85}$} \\
\hline Red & & . & . & & & & \\
\hline Red and & white & & . & 2,748 & $27 \cdot 4^{8}$ & 3,340 & 13.93 \\
\hline Roan . &. & . & & 2,034 & 20.34 & 5,072 & 21.13 \\
\hline White. & . & . & . & 275 & 2.75 & 503 & 2.09 \\
\hline Total & . . & . & . & 10,000 & 100.00 & 24,000 & 100.00 \\
\hline
\end{tabular}

These figures show red much the more prevalent and increasing with the years, a marked dropping off in red and white, no special change in roan, and a slight loss in white. The importance of color varies in the estimation of different persons, but color is no index to quality. Some have thought dark color indicates hardiness and that white is associated with possible lack of vigor or 
constitution. There are no facts, however, to support the one theory or the other, and wise breeders pay no attention to such views. There have been Shorthorn color fads, and for years Kentucky, Ohio, and Indiana breeders demanded red, and red only, but this era has passed. At the present day, however, markedly red-andwhite bulls are rarely seen in prominent herds, male calves of this color being sold for service in grade herds or converted into steers.

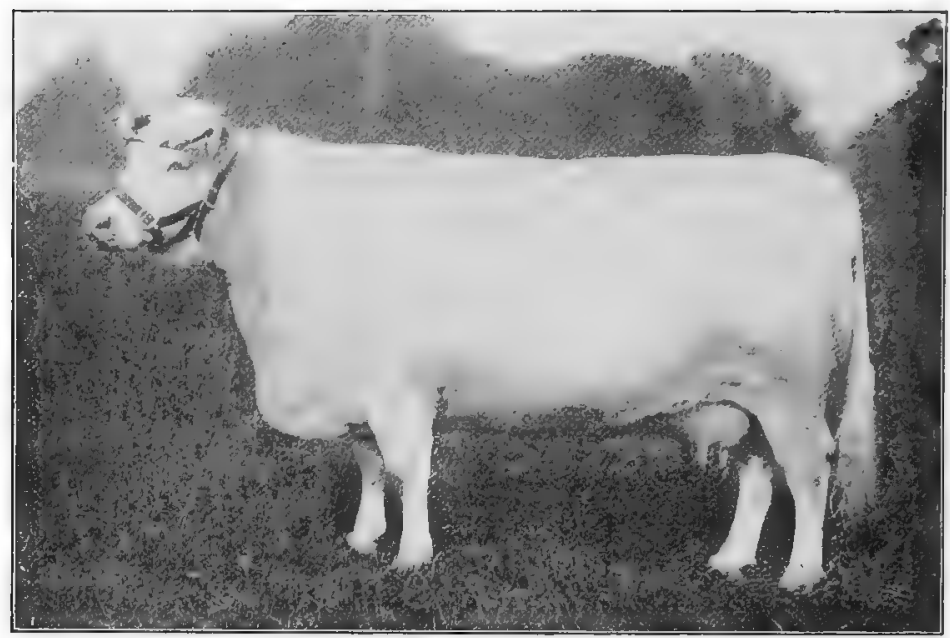

FIG. 9I. White Heather, first-prize and champion Shorthorn cow at the Ig04 show of the Royal Agricultural Society of Fngland. A beautiful example of the breed. Bred by J. Deane Willis. From photograph, by courtesy of William Cooper \& Nephews, Berkhamsted, England

The size of the Shorthorn places it in the largest class of beef cattle, and by many it is regarded as our largest breed. Records for two years at the International Live-Stock Exposition and the American Royal at Kansas City gave the following weights ${ }^{1}$ : 4 I aged bulls averaged 2224 pounds, 40 two-year-old bulls I9I7 pounds, 4I aged cows I 730 pounds, and 46 two-year-olds 1530 pounds. These, being show animals, of course were in high condition. Under fair conditions mature cows will usually weigh about I 400 pounds, though they frequently exceed that and, in rare

\footnotetext{
${ }^{1}$ B. O. Cowan, Breeders' Gazette, October 9, I9I2.
} 
cases, reach 2000 pounds. The mature bull will easily attain $\mathrm{I} 800$ to 2000 pounds; many weigh from 2000 to 2200 , and weights upward to 2500 occur, though the latter figure is infrequent. The Hereford is a close second to the Shorthorn in size, with no great difference between the two breeds.

The Shorthorn as a beef producer stands in the first class. The men who have attained the most fame as Shorthorn breeders have always emphasized the value of this breed in producing the best of beef on a profitable basis. There have been cases where great breeders - like Bates, for example - laid stress on the importance of the breed in milk production, but this was not to be at the expense of the meat-producing qualities. Cruickshank and the Scotch school of Shorthorn breeders, however, laid more emphasis on the value of the breed on the block, the final test of all meat animals. In the leading fat-stock shows of Great Britain, the United States, Argentina, and Australia, the Shorthorn far outnumbers any other breed, while in the stockyards Shorthorn grades greatly predominate. The Shorthorn produces a class of beef that is wide in the loin, thick, wide, and long in the hind quarters, and of fine fiber or quality. If compared with the Aberdeen-Angus the Shorthorn will not dress out quite as high, perhaps, in percentage of meat to offal, though the difference is not large; also the dressed carcass of the Shorthorn will show somewhat more tallow and external patches of fat than will the Aberdeen-Angus. In a study of the gains made by different breeds of steers shown at the Smithfield Show in England for twenty years (I895-I9I4), Henry and Morrison show ${ }^{1}$ that the Shorthorn ranked at the very top among eleven breeds. Eighty-five yearling steers, averaging six hundred and seventy-four days old and I 446 pounds weight, made an average daily gain of 2.14 pounds. Ninety-one two-year-olds, averaging one thousand and twelve days old and IgOI pounds in weight, made an average daily gain of $\mathrm{r} .88$ pounds. Four three-year-olds showed an average weight of 2363 pounds and a daily gain for thirteen hundred and fifty-three days of 1.74 pounds. No other breed showed as high a gain at two or three years as the Shorthorn. In the carcass

1 Feeds and Feeding (I9I5), p. 445. Compiled from The Live Stock Joumat, London. 
contests at the International Live-Stock Exposition the Shorthorn has held a very secondary position, largely, however, because of lack of breed competition. In the open market the breed or its grades are prime favorites and bring among the top values. One of the most notable market records was on September 24, I918, when ninety-one Shorthorn steer calves averaging IOOI pounds sold on the Chicago market at $\$$ I9.25 per hundredweight, bringing an

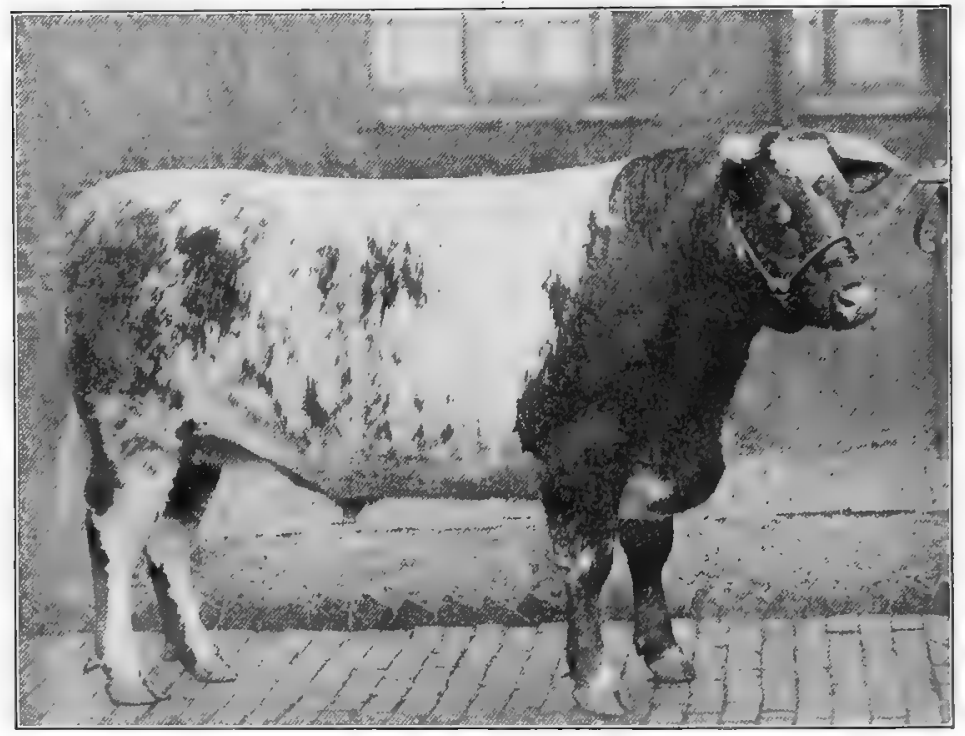

FIG. 92. Merry Monarch, champion Shorthorn and grand-champion steer over all breeds, grades and crossbreds, at the I9I7 International Live-Stock Exposition. Bred and shown by Purdue University, Lafayette, Indiana. The most beautiful Shorthorn steer in the history of the International up to 1917. From photograph by Hildebrand, by courtesy of Purdue University

average of $\$ 192.69$ per head. On October 4 , I9I 8, Hay Brown of Illinois sold a load of steers averaging I I 7 pounds at \$19.60, the top price for baby beef on the Chicago market up to this time. In I 909 the grand-champion carload of steers were Shorthorn yearlings shown by Keays and Oglesby of Illinois.

The Shorthorn steer in the show ring has made an impressive exhibit, but has played a minor part in grand-championship honors since the International Iive-Stock Exposition was established. 
At the old American Fat Stock Show held at Chicago from I878 to 1892 the Shorthorn made the strongest show of any breed, the white steer Clarence Kirklevington, in $\mathbf{1 8 8 4}$, creating a great sensation. At the International, the successor of the American, each year since I 900 there has been a notable show. Only twice in seventeen annual shows has the Shorthorn won grand-championship honors in the single-steer classes, this being

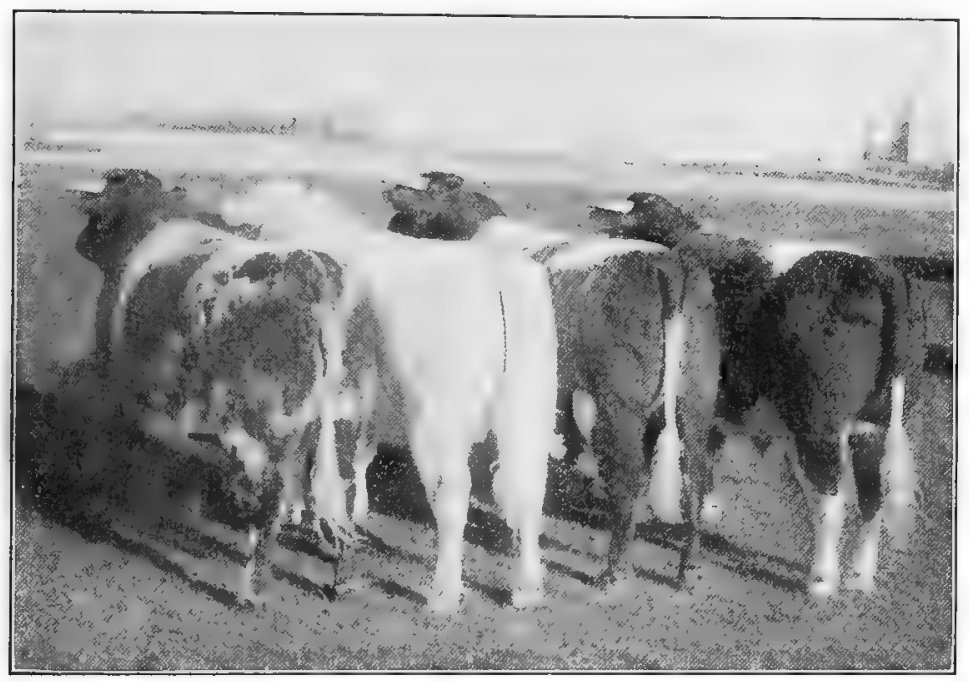

FIG. 93. Shorthorn steer herd of Purdue University, Lafayette, Indiana. Champion herd at the 1918 International Live-Stock Exposition. Bred and shown by Purdue University and sired by Lavender Sultan 354171. From photograph by J. C. Allen

in 1907 with Roan King (shown by James Leask of Canada) and in I9I7 with Merry Monarch (shown by Purdue University of Indiana). This latter steer was regarded as one of the very finest specimens of the breed ever seen in America; showing superior breed character, quality, condition, and finish. In I9I6, at the Palermo show in Argentina, the Shorthorn steer Luis, weighing I685 pounds at thirty-five months and made grand champion, sold for approximately \$II, I 30 in gold. While the Shorthorn grade or crossbred meets with distinct favor in the market, in the show ring it has, as a rule, stood second to the Aberdeen-Angus. 
The importance of the Shorthorn in grading or crossing, in spite of what is brought out in the show-ring steer test, is most important. No other breed thus far has done so much to improve beef stock. Shorthorn bulls mated to grade cows have revolutionized the character of the meat stock of the world. All over America to-day herds of excellence may be found, - animals graded up by Shorthorn bulls. In the principal stockyards of America the

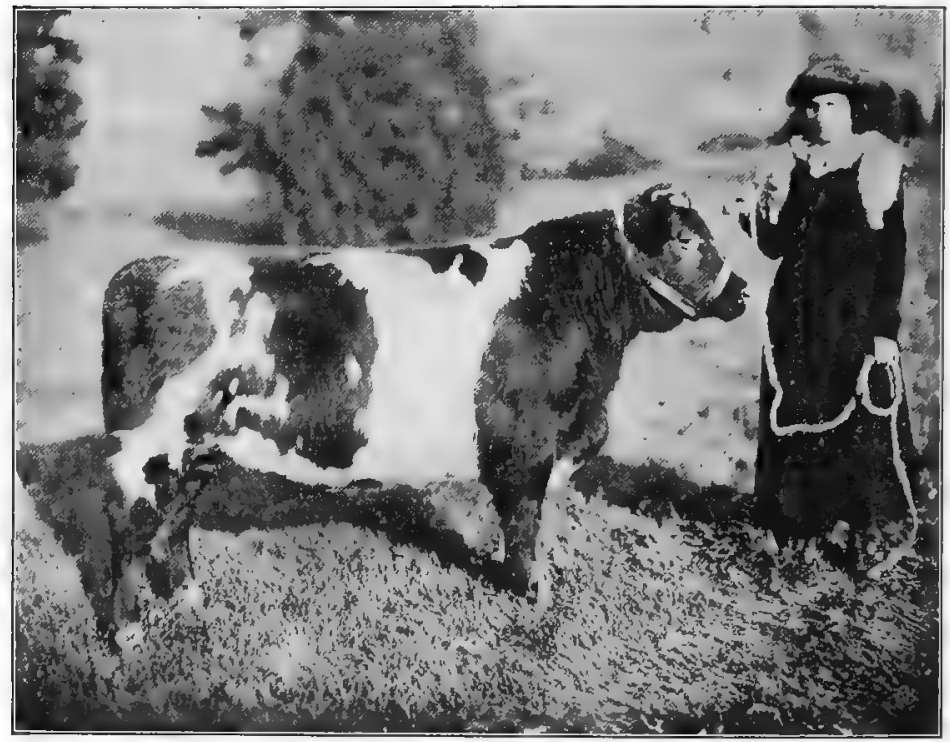

FIG. 94. Shorthorn steer calf, second prize in 1918 at the Wisconsin Baby Beef Show. Fitted and shown by Josephine Herr, Lodi, Wisconsin. From photograph, by courtesy of American Shorthorn Breeders' Association, Chicago, Illinois

blood of this breed predominates, and well-finished, high-grade Shorthorn steers are always at a premium with the butcher. In Scotland and England white Shorthorn bulls bred on Galloway or Angus cows produce what are termed " blue grays," which, as steers, meet with the highest market favor, being steel gray in color and showing much quality and superior killing value. On the Western range the Shorthorn has been a potent factor in improving the common native stock. Within what is known as the corn belt, in the Mississippi Valley, no other class of steers is so universal. 
The Shorthorn from the dairy point of view ranks high. In England a great percentage of the dairy herds are of Shorthorn blood. As one crosses the midland and southern counties he may see large numbers of Shorthorns with udders indicating great milking capacity. Much of the milk shipped into London comes from Shorthorn herds. The author visited one farm in Berkshire where some five hundred cows of this breed were milked daily and the product shipped to London. In the United States many farmers, notably in the Central West, rely upon Shorthorn cows for their milk supply. As has been already indicated, as a result of hereditary transmission and the early breeding of Bates and others, the Shorthorn produces an abundance of milk. No beef breed equals it. Shorthorns generally may be in a measure grouped into two classes - the beefy type and the general-purpose sort. As a rule, it is true, the latter class will not fatten as easily and does not present the beef conformation in as high a degree as does the former. Even then the beefy class of Shorthorn surpasses the Hereford, Aberdeen-Angus, and Galloway in furnishing milk for its offspring.

Official public-dairy tests of Shorthorn cows have been undertaken on three occasions in the United States - in I893 at the World's Columbian Exposition at Chicago, in I90 I at the PanAmerican Exposition at Buffalo, and in $\mathrm{I} 904$ at the Louisiana Purchase Exposition at St. Louis. These were each under official supervision of dairy scientists of note and superintendents representing the different breeds. At the World's Columbian Exposition, Shorthorns competed against herds of Jerseys and Guernseys. In the cheese-making test of fourteen days the Shorthorn ranked third, producing $12, \mathrm{I} 86.9$ pounds milk, from which was made I077.6 pounds cheese. The Shorthorn cow Nora stood second to a Jersey, producing 60.56 pounds cheese at a net profit of $\$ 6.27$. In the butter-making test for ninety days, in which gain in live weight was credited, the following results were secured:

\begin{tabular}{|c|c|c|c|c|c|c|}
\hline BREED & & $\begin{array}{l}\text { Number } \\
\text { OF Cows }\end{array}$ & $\begin{array}{c}\text { MILK } \\
\text { (pounds) }\end{array}$ & $\begin{array}{r}\text { ButTER } \\
\text { (pounds) }\end{array}$ & $\begin{array}{c}\text { GAIN LIVE } \\
\text { WEIGHT }\end{array}$ & Net Profit \\
\hline Jersey & & 25 & $73,478.8$ & 4573.95 & 776 & $\$ 1323.8 \mathrm{I}$ \\
\hline Shorthorn & . & 23 & $66,263.2$ & 2890.86 & 2826 & 9II.I 3 \\
\hline Guernsey & . & 25 & $6 \mathrm{r}, 78 \mathrm{r} \cdot 7$ & 3360.43 & 466 & 997.63 \\
\hline
\end{tabular}


This was a very creditable showing, especially in view of the fact that the Shorthorns were not selected with the great pains and expense that the Jerseys were and did not represent as many high-class dairy specimens as did the other breeds. Professor James Long of England, who inspected the cows, reported on his return home that in England they would not rank high as dairy Shorthorns. In this test the cow Nora made 3679.8 pounds milk,

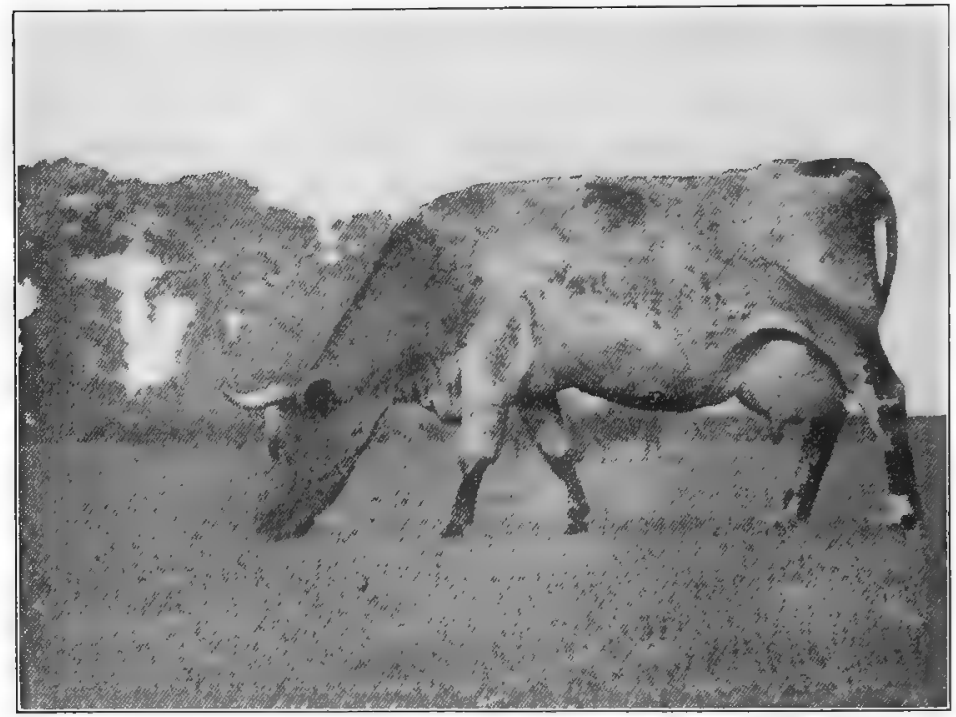

FIG. 95. A fine example of a milking Shorthorn on an English pasture. From photograph by the author

yielding I 60.57 pounds butter, and gained I I 5 pounds; while the Jersey cow Brown Bessie, which led this breed, made 3634 pounds milk, yielding $2 \mathrm{I} 6.66$ pounds butter, and gained $8 \mathrm{I}$ pounds live weight. In a thirty-day butter test at the Columbian 24 Short horns made I 5,6 I 8.3 pounds milk, yielding 662.66 pounds butter, at a net profit of $\$$ I I9.I3. Both Jersey and Guernsey made less milk, but more butter and a greater net profit. In this test the best Shorthorn cow was Kitty Clay 4th. She produced I 592.8 pounds milk, yielding 62.24 pounds butter, showing a net profit of $\$ 19.57$. In a fourth test, of one week, six Shorthorn heifers under three 
years old competed with six Jersey heifers, the Shorthorns producing $258 \mathrm{I}$ pounds milk, yielding $\mathrm{I} 22.36$ pounds butter, at a net profit of $\$ 47.42$; the Jerseys gave 3356.6 pounds milk, yielding I94.22 pounds butter and a net profit of $\$ 56.27$.

In I9OI, at the Pan-American Exposition, between May I and October 31, five Shorthorn cows produced a total of 1307.55 pounds churned butter, yielding a net profit of $\$ 164.77$. This gave the Shorthorn eighth place among ten breeds, although in value of total solids these cows stood sixth, and in value of solids and gain in live weight the Shorthorns ranked third. In I904, at the Louisiana Purchase Exposition, more satisfactory returns were secured than from either of the other two tests. In a trial of one hundred and twenty days, in which twenty Shorthorns were carried entirely through, the cows made an average of 442 I.6 pounds milk, I65.3 pounds butter fat, 382.7 pounds solids not fat, and an average gain in weight during one hundred and fourteen days of I05.3 pounds.

Important milk records of Shorthorn cows demonstrate great producing capacity. Rose of Glenside, long the milking champion of the breed, produced 18,075 pounds of milk in a year. Doris Clay, on January 22 , I9I 7 , finished a year's record of $\mathrm{I} 7,24 \mathrm{I} \frac{1}{2}$ pounds of milk. Belle Clare, from January 26, I9 Io, to January 25, I9I I, produced I 5,2 I 5 pounds of milk and in May averaged nearly 60 pounds daily. There have been some remarkable records extending through a period of years. Darlington Cranford 5 th gave over IOO,Ooo pounds of milk in ten years. Dorothy, a daughter of Darlington Cranford 4th, averaged 10,536 pounds of milk for eleven years. Blossom 5 th averaged $8,652.3$ pounds for ten years. Doris Clay dropped Io calves in ten years and produced during this period 70,856 pounds of milk. Mamie Clay $2 \mathrm{~d}$, beginning as a two-year-old, made an average of Io,640 pounds of milk per year for five years. Volumes I and II of the "Milking Shorthorn Yearbook" contain the records of 427 cows of all ages, and these produced an average yield of 8823 pounds 9 ounces of milk. Volume IV for I 919 contains IO7 records, the greatest of which is of I 4,001 . 6 pounds of milk and 545.44 pounds of fat by the cow Odette (v. 66, p. 772 ). In recent years milking Shorthorns have greatly increased in popularity and through careful selective breeding 
have come these very high-class records. Mr. George Taylor, long noted as a breeder of milking Shorthorns in England, stated ${ }^{\mathrm{I}}$ that when he first started keeping the milk records his herd average was not 600 gallons ${ }^{2}$ annually. "Now it exceeds 800 gallons, and I rarely keep a cow that does not yield 700 gallons per year." Late in 1918 the statement was published in England that the cow

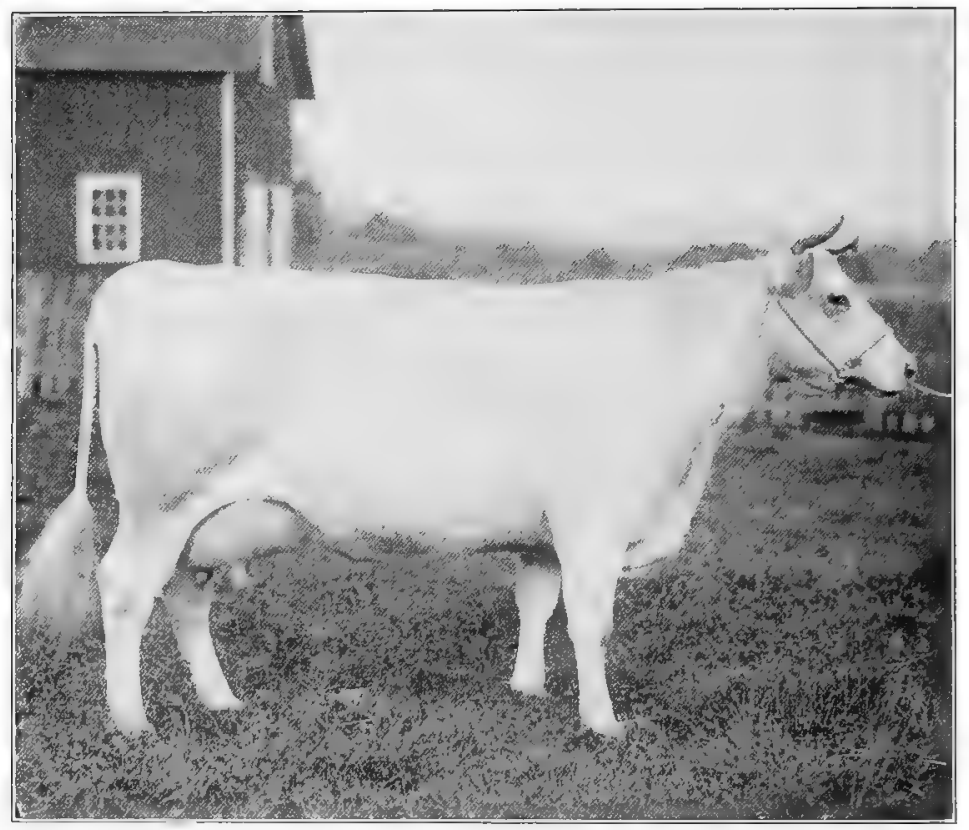

FIG. 96. White Queen, an imported dairy Shorthorn cow, bought by C. A. Otis, Willoughby, Ohio, for $\$ 3000$. She has a milk record of 10,430 pounds for one year. From photograph by Hildebrand, by courtesy of Mr. Otis

Waterloo Baroness 2 d, calved in 1908 and bred by Mr. Taylor, had produced 62,60I pounds of milk and 6 calves in six years.

Important butter-fat records of Shorthorn cows are naturally associated with large milk production, but many of the milk records have not involved fat tests. The world's record in butterfat production for a Shorthorn cow is reported late in $1917 .^{3}$

${ }^{1}$ Live Stock Joumal (London), December 3I, I909.

${ }^{2}$ The English gallon is equal to ten pounds.

${ }^{8}$ Agricultural Gazette of Nerw South Wales, December 3, I917. 
The cow Melba VII, for a period of three hundred and sixty-five days, is credited with a yield of 17,364 pounds of milk containing 868 pounds of fat, equal to IO2I.59 pounds estimated butter. Her milk showed an average test of 5 per cent fat. This cow was bred by and is owned by the Scottish-Australian Investment Company, Gundgai, New South Wales. The most notable test in the United States was by Rose of Glenside, which, on March 2, I910, completed an official yearly record, producing 735 pounds of butter fat, or 2.0 I pounds per day. The cow Ruby produced 7 I 5 pounds, Buttercup 2d 657.7 pounds, and Doris Clay 653.35 pounds of butter fat in a year. Four hundred and twenty-seven cows recorded in Volumes I and II of the "Milking Shorthorn Yearbook" show an average yearly fat record of 330.2 pounds.

The Shorthorn for early maturity ranks among the best of the beef breeds, though up to twelve months of age it is probably slightly surpassed by the Aberdeen-Angus and Hereford. Records of pure-bred steer weights secured at the International Live-Stock Exposition, covering I9Io and I9I I, showed an average weight for 29 Angus calves at 1008 pounds and 3 I Shorthorns at 9I I pounds. ${ }^{1}$ After passing the calf age the Shorthorn attains a weight equaling or surpassing the other breeds. Maturity is also more or less influenced by the family blood lines, and no doubt the popular Scotch tribes come on faster as baby beef than do the plainer, more upstanding sort.

The adaptability of the Shorthorn to a wide range of conditions is probably unsurpassed. Prominent herds are found on the lowlands, the uplands, in the colder north, the warmer south, on rich pastures and those not so desirable. While a popular breed with the small farmer, so is it also a favorite on the range of the great West and on the vast grazing fields of Argentina.

The temperament of the Shorthorn is notably phlegmatic and quiet, such as might be expected in the beef type. In disposition it may be fairly claimed that of all the beef breeds this is the quietest and most easily handled. In the writer's personal contact with the different breeds the Shorthorn has manifested in a pronounced degree a quiet disposition and ease of control under a variety of conditions.

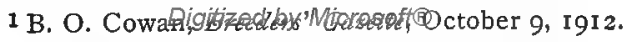


The prolificacy of the Shorthorn is fairly comparable with the other beef breeds. There are many examples to be found of Shorthorn cows that have during long lives dropped many calves, and twins are not so uncommon with the breed as to be remarkable. In early days the Duchess family, as promoted by Bates, was subject to considerable criticism for lack of fecundity, but this criticism did not have a wide application to the breed. A remarkably prolific grade Shorthorn cow that had dropped twenty-two calves is reported by George Winsak of Montana. Evan Baillie of

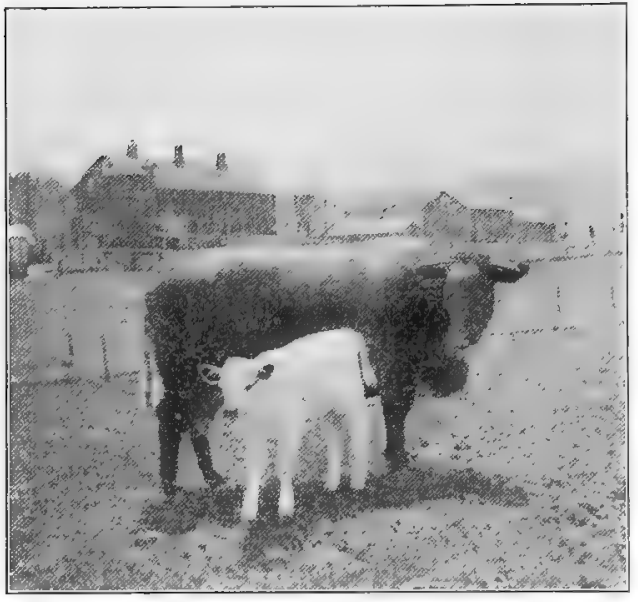

FIG. 97. A fine Shorthorn matron and calf on an

Ohio pasture. From photograph by the author

England reports in the Live Stock Joumal (London) on the cow Lady Oxford Kirklevington, that at twelve years had dropped eleven calves, all singles. Her dam, Kirklevington 8 th, had five daughters in succession and has handed down such a tendency to female produce that her youngest granddaughter is the fortyseventh female.

The prepotency of the Shorthorn is very marked, a characteristic feature of the long-established breed. Shorthorn bulls used on grade herds reproduce the dominant features of the breed in no uncertain measure. Shorthorn prepotency is shown in two striking ways - in the large pure-bred herd, where females of various tribes are brought together, and in the important stockyards, where large numbers of Shorthorn grades are to be seen. In either case the outstanding features of the breed are clearly to be seen.

Notable recent American Shorthorn sires. The history of the Shorthorn is necessarily associated with many sires of distinct importance. Among those that may be regarded as leaders since 
I900, are the following fifteen. ${ }^{1}$ Those marked with a star ( ${ }^{*}$ ) were bred in Great Britain. Each sire received 32 points for each first prize winner, 16 for each second or third sired by him, and 8 for each first prize or 4 for each second or third of which he was grandsire, and 2 points for each first or I point for each second or third of which he was great grandsire. (I) Whitehall Sultan 163573, calved 1900, points 979; (2) Avondalc 245144, calved 1905, points 709; (3) Choice Goods I8602*, calved I 899 , points 525 ; (4) Cumberland's Last I I 8578 , calved 1904, points 365 ; (5) March Knight I 88105 , calved I902, points 353 ; (6) Villager 295884, calved 1906, points 310 ; (7) Glenbrook Sultan 243185, calved 1904, points 292; (8) Bapton Sultan 163570*, calved I898, points 267 ; (9) The-Lad-for-Me I406I8, calved 1897, points 213; (10) Whitehall Marshall 209775, calved 1902, points 205 ; (I I) Conqueror I49048*, calved I899, points I89; (I2) Hampton's Best I708I8, calved 1900, points I80; (13) Nonpareil I ictor I 32573*, calved I 896, points I 75 ; (14) Lord Lovat I 30157, calved 1896, points I7I ; (15) Gallant Kinight I 24468, calved I896, points I60. Whitehall Sultan and his son Avondale may be regarded as two of the greatest sires of the past quarter of a century.

Famous Shorthorn cows of recent, years. Among the great show and producing cows of the present century may be mentioned the following, each of which has produced a grand champion: Avalanche 2d (v. 60, p. 655), Bapton Pearl (v. 48, p. 368), Dorothea (v. 45, p. 645), Emma $32 d$ (v. 46, p. 714), Geraldine 5th (v. 4I, p. 354 E), Lady-in-Waiting (v. 44, p. 632), Lady Marjory (v. 48, p. 406), Maxwalton ITina 2d 8660I, Roservood Pride (v. 60, p. 655), Ruberta (v. 45, p. 1084).

The prices paid for Shorthorns have attained figures far beyond the expectations of the most ardent admirers. of this great breed. For over a century high prices have been obtained at both private and public sales, with records of new high points during the days of the World War. Many bulls have changed hands at $\$ 5000$

1 These relative positions are based on prizes won at the American Royal and the International Live-Stock Exposition by descendants included within three generations and from 1903 to $19 \mathrm{I} 5$ inclusive. Information furnished by the courtesy of Professor Gilberleitizusler of 
each since the time of 'Charles Colling's sale in I8 I I, when Comet was the first to bring this figure. The sale of Walcott and Campbell, held September I0, I873, at New York Mills, New York, was for forty-five years the record-breaking Shorthorn sale of history, when $\mathrm{I} O 9$ animals sold for $\$ 38 \mathrm{I}, 990$, an average of $\$ 3504$. The cow Eighth Duchess of Geneva brought $\$ 40,600$, the highest price paid for cow or bull, until I9I8, while I 8 other animals ranged from $\$ 5000$ up to $\$ 35,000$ each, the latter being the price paid for Tenth Duchess of Geneva. The bull Second Duke of Oneida brought $\$ 12,000$. In I 869 Daniel McMillan sold at

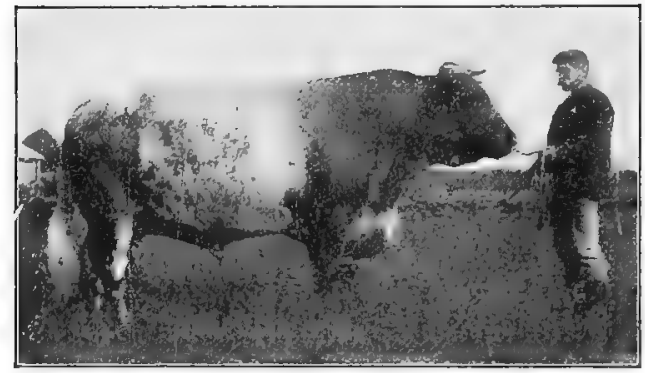

FIG. 98. Pride of Morning (12055 I), by Star of Morning (I21 243). At one time leading stock bull in the herd of William Duthie, Scotland. From photograph by the author
Xenia, Ohio, atauction 7 I head which averaged $\$ 864.6 \mathrm{r}$, while in 1874 Colonel W. S. King of Minnesota sold in Chicago 79 head at an average of $\$ 1628$, the bull Second Duke of Hillhurst selling at $\$ \mathrm{I} 4,000$. Between 1870 and I 880 there were sold at auction in this country 26, I 5 I Shorthorns at

an average price of $\$ 294$ per head. Between I89I and I900, during a period of great depression in beef-cattle prices, the Kansas Board of Agriculture reports I 5,74 I head sold at auction at an average price of \$I $38.4 \mathrm{I}$. In recent years Shorthorn values have greatly increased, and thousands of animals have changed hands at figures exceeding \$IOOO or more. In I9IO. Thomas Stanton sold the bull Prince Imperial 3257 I I for $\$ 10,000$ to George J. Sayers. In I9I5 the bull Americus, champion at the Palermo show in Argentina in I9I3, sold to Señor Ginnochio for about $\$ 33,000$ in gold. On December I, I917, at the sale of Frank Harding of IVisconsin, the bull Anoka Champion 555857 sold to B. F. Hales for $\$ 17,000$. At this sale fourteen bulls averaged $\$ 2607$, thirty-one females $\$ 1073$, and forty-five head \$55 I. A year later Mr. Harding sold 48 head for an 
average of $\$$ I 865 , and I 3 bulls averaged $\$ 3457$, one of which, Anoka Omega 698327, brought \$ I 2,000. In a sale of Carpenter \& Ross of Ohio at Chicago on June 20, I9 8 , sixteen bulls averaged $\$ 2800$, one hundred and six females $\$ 386$, and one hundred and twenty-two in all brought a total of $\$ 192,982$, or an average of $\$ 1370$. In this sale H. S. Black of Mansfield, Ohio, paid $\$ 20$, ooo for the yearling bull Rodney. In a sale held by this same firm June 24 and 25 , I9I9, in Chicago, 38 bulls averaged $\$ 3484$, while I 72 head of both sexes brought a total of $\$ 378,505$, or an average of $\$ 2200$. The imported yearling bull Cudham Dreadnought was sold to Hay Brown of Illinois for $\$ 19,500$. In June, I9I8, Bellows Brothers of Missouri sold 65 head for an average of $\$ 1709$, the bull Village Supreme 423865 bringing $\$ \mathbf{1 6 , 5 0 0 .}$. On May I5, I919, H. C. Lookabaugh, Watonga, Oklahoma, sold 38 head for \$II I, 850 , an average of $\$ 2943$. Three bulls averaged $\$ 10,316$, and one of them, Fair Acres Sultan. Jr. 596263, brought $\$ 17,250$. According to "The Shorthorn in America," I I, OI I Shorthorns were sold in America at I99 public sales, during I9I 8 , for $\$ 5,664,936$, or at an average of \$5I4. According to Mr. F. P. Mathews, ${ }^{1}$ in I9I6 there were sold in England 5838 Shorthorns for the average price of about $\$ 300$ per head. Among the greatest Shorthorn sales in recent years have been those held in North Scotland, more especially the bull sales of Mr. William Duthie. In I9 I 5 eighteen Shorthorn bull calves of Mr. Duthie averaged $\$ 1744$, in I9I6 twentythree averaged $\$ 3083$, in I9I 7 twenty-four averaged $\$ 3279.50$, and in I9I 8 twenty averaged about $\$ 5450$. At the I9I 7 sale the calf Collynie Lavender King brought \$14,175. At the Perth, Scotland, sales in February, I9I8, there were sold 434 bulls at an average price of $\$ 772$. Two bulls made high records in the Scotch sales at this time - Pride of Millhills at Perth bringing $\$ 16,275$ and Proud Conqueror at Aberdeen, $\$ 16,800$. At the I9I9 February sales abroad Cluny Proud Augustus at Perth sold for $\$ 20,000$, Pierrepont Golden Prince and Windsor Knight at Birmingham each brought $\$ 2 \mathrm{I}, 000$, and Gartley Lancer at Penrith topped all British records at $\$ 23,750$. In recent years milking Shorthorns have also brought very high prices. In October, I9I6, 
at the sale of Samuel Sandy in England, I I 5 head brought an average of \$605. In May, I9I 7, at the sale of L. D. May of Pennsylvania, 39 milking Shorthorns averaged $\$ 1008$, one of which, White Queen, sold for $\$ 3000$. On June 2I, I9I8, Arnold Wills of Northampton, England, sold 56 head for an average of \$I I 40 , with the high price of $\$ 10,000$ for the yearling bull Thornby

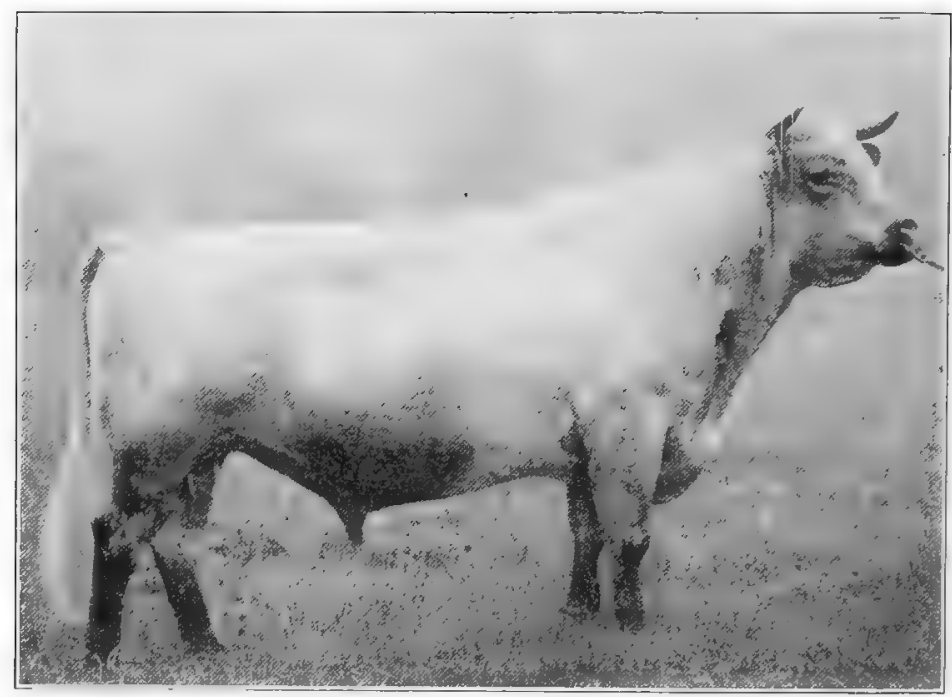

FIG. 99. Milking Shorthorn bull Waterloo Clay, weight 2300 pounds. The property of Flintstone Farm, Dalton, Massachusetts. Grand champion at Eastern States Exposition, I9I7

Premier, paid by Sir Gilbert Greenall. In October, I9I8, there were sold 68 dairy Shorthorns by R. W. Hobbs \& Sons of Kelmscott, Lechlade, England, for the high average price of \$I 55 .

The geographical distribution of the Shorthorn is most widespread, no other breed equaling it in this respect. It is so well suited to a wide range of conditions and has been so extensively distributed that it has been termed "the universal intruder." It is generally found in North America; in South America, more particularly in Argentina; in Europe, being the most prominent breed on the British Isles, although bred to some extent on the Continent; in Australasia, where it has long met with favor; 
and to some extent in South Africa and Asia. In the United States the Shorthorn is the most popular breed of cattle, as attendance at the great shows, especially in the states of the Mississippi Valley north of the Ohio, will demonstrate. In a statement from the office of the American Shorthorn Breeders Association, giving the distribution of breeders in the United States registering pure-bred Shorthorns, it is shown that $20,87 \mathrm{I}$ breeders are distributed in forty-five states, the ten leading states being as follows: Iowa, 4070; Illinois, I885; Nebraska, I740; Missouri, I625; Minnesota, 1520 ; Kansas, I 285 ; South Dakota, I 55 ; Indiana, I I oo; Ohio, 945; Wisconsin, 760. This evidence of wide distribution speaks well for the adaptability of the breed. However, on the Western range, under severe weather conditions and where "roughing it" is required, the Shorthorn will not thrive as well as the Hereford or Galloway.

Organizations for the promotion of Shorthorn cattle precede all other breeding associations for meat-producing animals. The first live-stock registry for cattle was the "Shorthorn Herdbook," published by George Coates of Yorkshire, England, in I 822. "This forms the foundation of the English "Shorthorn Herdbook," known as "Coates's Herdbook," which in 1918 attained its sixtythird volume. Mr. Coates edited the first five volumes, when, owing to his death in 1846 , he was succeeded by Mr. H. Strafford, who served as editor of the next fifteen volumes. In 1876 the Shorthorn Society of the United Kingdom of Great Britain and Ireland assumed control of the publication of the herdbook, and through its editing committee has ever since maintained supervision of the records of the society. The first volume of the "American Shorthorn Herdbook" appeared in 1846 , being published by Lewis F. Allen of New York. In 1869 the "American Shorthorn Record" first appeared, being published by A. J. Alexander of Kentucky, and ten volumes were issued. In 1878 the Ohio Shorthorn Breeders' Association published a record and followed it with two others. In I882 the American Shorthorn Breeders' Association absorbed these and continued the publication of the old herdbook established by Allen. The "Canadian Shorthorn Herdbook" first appeared in 1867, the "British American Shprithorn Micrdbook" appeared in I88I, 
and the "Dominion Shorthorn Herdbook" in 1887 , the latter absorbing the other two. The "American Shorthorn Herdbook" up to I9I9 numbers ninety-three volumes, and new volumes are appearing yearly. Already over 700,000 Shorthorns have been registered in the United States, and 250,000 in Canada. Milking Shorthorns in England are generally registered in "Coates's Herdbook," of which there is a dairy association branch that supervises the official testing of the cows. In the United States the American Shorthorn Breeders' Association provides for testing for advanced registry milking cows of the breed and publishes yearly reports of official records. In I9I 5 there was also

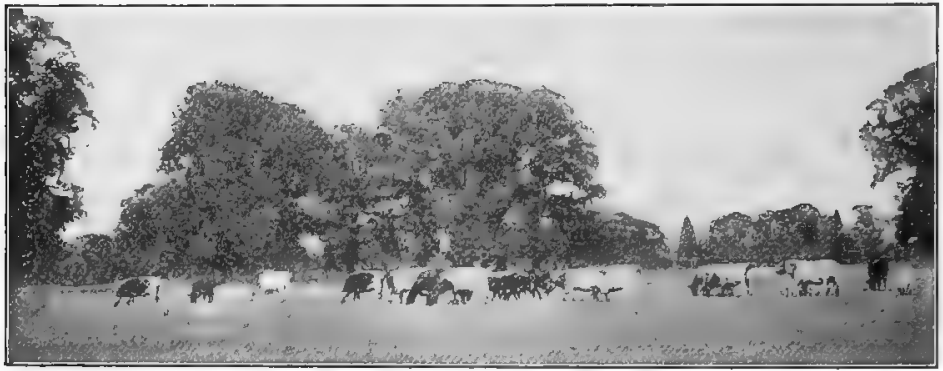

FIG. 100. Shorthorns of the royal house on the pasture at Windsor, England. From photograph by the author

organized in the United States, at the Minnesota State Fair, an American Milking Shorthorn Breeders' Association. Shorthorn associations exist in Argentina, in Australia, and in France, and herdbooks are published in these countries. A number of local Shorthorn breeders' associations have been organized in different states, these being as a rule in the nature of community breeders' associations. These are for promoting the breed in various ways, but more especially for fostering combination sales. Important service in behalf of the Shorthorn, in the way of publicity, is being rendered through a quarterly periodical published by the American association, under the title of The Shorthom in America, the first number appearing in April, I9I6. The Shorthom World, published in Chicago, the first number appearing in March, 1916, is a commendable journal devoted to this breed. 


\section{CHAPTER XXV}

\section{THE POLLED SHORTHORN}

The origin of the Polled Shorthorn. In consideration of the fact that Polled Shorthorn cattle are either pure-bred Shorthorns or nearly so, the author does not regard it as necessary to devote much space to them other than historical.

The "single standard" Polled Durham was the first type of hornless Shorthorn to attract attention in America. This is the result of uniting native mulley cows with pure-bred Shorthorn bulls. Cattle of such blood lines are quite commonly designated as "single standard" because of being eligible to registration only in the "Polled Durham Herdbook." When the movement for dehorning got well started nearly twenty years ago, men here and there began to seek combinations by which the horns might be bred off. Some men who were breeders of Shorthorns or who believed in the Shorthorn type sought to breed hornless cattle. Among the pioneers in this work were W. S. Miller, Dr. W. W. Crane, R. Clawson, and Peter Shafer of Ohio, J. F. Burleigh of Illinois, J. H. Miller of Indiana, and T. Dunham of Iowa. These men used pure Shorthorn bulls on mulley cows of Shorthorn type and so finally developed what they termed the Polled Durham breed. Cattle of this breeding were quite like Shorthorns, tending toward the dual-purpose type, were inclined to be leggy, and hardly met the demands of the Shorthorn critics for thickness of flesh. Those that had true polled heads were used for breeding, and thus gradually were developed, mainly in western Ohio, herds of Polled Durham cattle.

The "double standard" Polled Shorthorn represents the demand of Shorthorn breeders and others for a pure hornless class of Shorthorn cattle. These are often termed "double standard" because of being eligible to registration in both the "American Shorthorn Herdbook" and the "Polled Shorthorn Herdbook." Very naturally, with the development of the "single standard" 
class, breeders began to watch for pure-bred Shorthorns free of horns. This branch has its origin in several Shorthorn families, notably the White Rose, Young Phyllis, and Gwynne.

The cow Oakwood Gwynne 4th, registered in Volume XV of the "American Shorthorn Herdbook," was bred by W. S. King of Minneapolis, Minnesota, and was calved May 12, 1873. She had but very slight horns, or scurs, being almost polled. Bred to

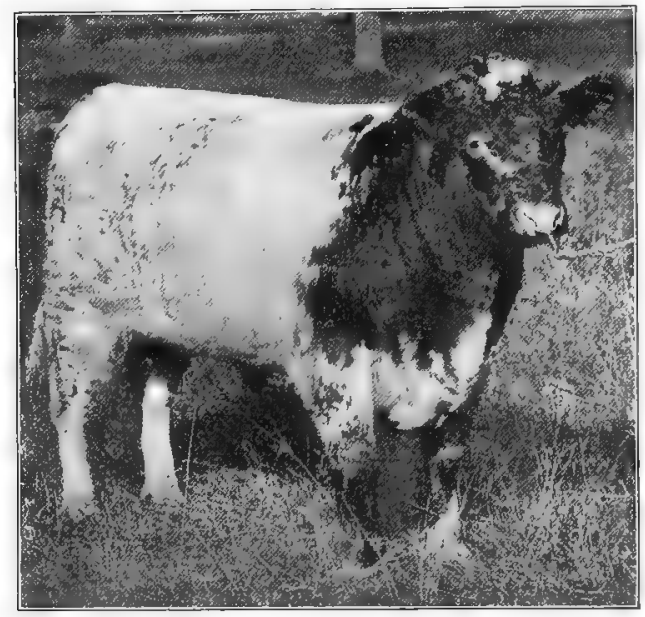

FIG. Ior. Sultan's Creed 353694, one of the best Polled Shorthorn bulls of recent years and a very noted sire. Bred and owned by J. H. Miller \& Sons, Peru, Indiana. From photograph, by courtesy of owners -

Seventh Duke of Hillhurst 3422 I, she produced twin female calves, Mollie Gwynne and Nellie Gwynne (Vol. XXIII, p. 728), that developed true polled heads. When later bred to Bright Eyes Duke 3 I 894, she produced as a result a red bull calf that was a true polled animal and which was recorded as King of Kine 874I 2. In 1888 W. S. Miller of Elmore, Ohio, purchased these three offspring of Oakwood Gwynne 4th, and with them developed a herd of pure polled Shorthorns. King of Kine was used in the herd three years and proved a very prepotent sire, some 90 per cent of his calves from horned cows being polled. He was used on cows of the Rose of Sharon, Young Mary, and Phyllis tribes with much success. Then a son of his, Ottawa Duke rog292, out of Nellie Gwynne, was used in the herd, and all his offspring proved to be hornless. Later Ottawa Duke came into the possession of Dr. W. W. Crane, in whose herd he rendered valuable service. Ottawa Duke sired Miami Boy II65I7 and Tippecanoe 4th I21365, well-known sires in the Crane herd. 
Mr. J. H. Miller of Indiana early became a celebrated breeder of Polled Durhams and in 1893, with some others, made at the World's Columbian Exposition the first notable exhibit of this breed. Mr. Miller's bull Young Hamilton I I 4 I69, a pure Shorthorn and the Columbian Exposition Polled Durham sweepstakes male, rendered valuable pioneer service in his herd.

The important requirements for registering Polled Shorthorn cattle, as originally adopted by the American Polled Durham Association, were as follows: (I) they must have true polled heads ; (2) they must have the color and characteristic markings of the Shorthorn; (3) they must have not less than $87 \frac{1}{2}$ per cent of Shorthorn blood in I 893, at least $93_{4}^{3}$ per cent after I 896, and fully 967 per cent after 1899 . Volume III of the "American Polled Durham Herdbook," published in 1905, contains the bylaws of the American Polled Durham Association as adopted April 29, rgo2. Section X, which qualifies registration and covers the old rule, is as follows:

Animals to be eligible to entry in the "American Polled Durham Herdbook" must be at least six months old; must be naturally hornless; must have both parents recorded therein or have one parent recorded in the book and the other parent recorded in the "American Shorthorn Herdbook" or other generally accepted Shorthorn herdbook; and further, must have an ancestry, that are eligible, recorded in the "American Polled Durham Herdbook."

The prepotency of the Polled Shorthorn is well maintained in herds that are carefully selected and bred with the view of reducing the horn to a minimum. By the use of polled bulls of prepotent character mated to Shorthorn cows, polled females are produced that become eligible to entry in the Polled herdbook, but the progeny thus secured offers an element of uncertainty in the reproduction of polled heads.

The popularity of Polled Shorthorns, if one looks at the situation frankly, is not great. In Ohio, where one might expect to find Polled Shorthorns in considerable numbers, there are comparatively few herds. They have seemed more in favor farther west, notably in Indiana, Illinois, Iowa, and Nebraska. One reason why the Polled Shorthorn is not in greater favor is due to the fact that there have not been enough outstanding herds of beef type and character to arouse enthusiasm among breeders of Shorthorns. 
However, some very superior Polled Shorthorns have been bred, such as reflected great credit on this strain of cattle. The growing popularity of polled cattle should benefit the Polled Shorthorn in particular.

The prices paid for Polled Shorthorns in general are very modest in comparison with Shorthorns; still a number of remarkably good sales have been held in recent years. On April 9, I9I4, Mr. J. H. Miller of Indiana, famous as a breeder and improver,

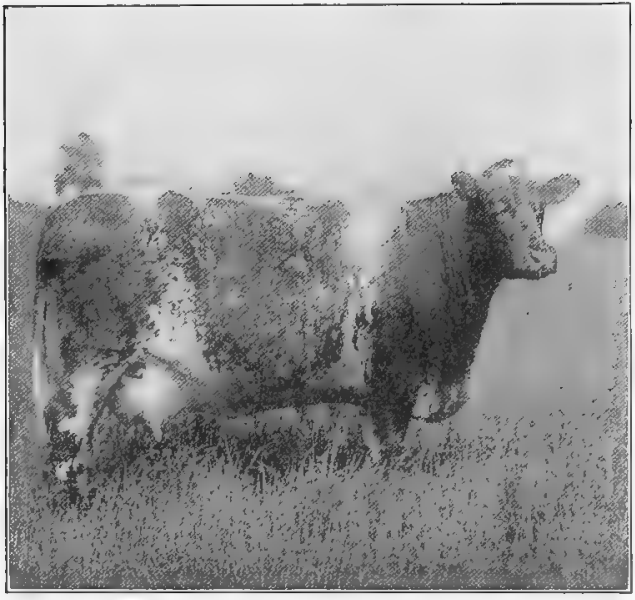

FIg. 102. Bulhla, ä Polled Shorthorn cow of great scale and very superior character. Owned by W. M. Miller \& Son, Mulberry, Indiana. From photograph by J.C. Allen disposed of thirtyseven head at a public sale for $\$ 20,960$, an average of $\$ 566$. One of the best bulls of the day, Sultan's Creed 353964 X87 I6, brought $\$ 2200$, and a son of his - Intense Sultan $385882 \mathrm{X}-$ brought $\$ 5$ 500. The cow Capacious Sultan I $328.03 \mathrm{X}$ sold for $\$ 1050$. At a breeders' sale at Oxford, Iowa, in March, 1918, forty-four head averaged $\$ 340$, and the very successful show bull Snowball $\mathrm{X}_{478714}$ brought $\$ 3600$. At the Polled Durham Breeders' Association sale at the International Live-Stock Exposition in Chicago, in 1918, forty-three head sold for $\$ 21,760$, an average of $\$ 506$, thirty-one females averaging $\$ 468$. The top bull was the grand champion of the show, Royal Stamp XI784I, which sold for \$1 525 .

The distribution of Polled Shorthorns is most common in the corn belt in the Mississippi Valley, but more especially in Ohio, Indiana, Illinois, Iowa, Missouri, Kansas, Nebraska, Michigan, Wisconsin, and Minnesota. Mr. J. H. Miller has on several occasions exported Polled Shorthorns to Argentina. 
The promotion of Polled Shorthorn interests is officially supervised by the American Polled Shorthorn Breeders' Association, organized at Chicago in I 889 as the American Polled Durham Breeders' Association. However, on July I I, I9I9, the association in session in Chicago substituted "Shorthorn" for Durham. Seven volumes of the herdbook have since been published up to 1919. It is to be noted in this connection that breeders are seeking to produce mainly animals that are eligible to registration in the "American Shorthorn Herdbook." The greater the percentage of "double standard" Polled Shorthorns produced, the less the necessity of maintaining an independent herdbook for the polled cattle of the breed. 


\section{CHAPTER XXVI}

\section{THE HEREFORD}

The native home of the Hereford breed of cattle is the county of Hereford, located in the upper part of the lower third of England, with Wales for its western boundary. The county is gently rolling in places, while in other sections it is quite hilly, and superior grazing generally prevails. Mixed farming is practiced in Herefordshire. Wheat, barley, oats, root crops, and hay are the staples. This also is a leading apple-growing section of England. Here Herefords are extensively bred, almost to the exclusion of all other kinds of cattle. They are also found more or less in the adjoining counties of Shropshire and Worcester in England, and in Radnor, Brecknock, and Monmouth counties in Wales.

The origin of the Hereford, like that of other English breeds; is clouded in obscurity. Some have regarded the Hereford as descended from the aboriginal cattle. This opinion has been expressed by Youatt and by T. Duckham, the latter once prominent as editor of the "Hereford Herdbook." In I 788 William Marshall, a well-known English judge of cattle, gave it as his belief that the Hereford might be regarded as the first breed on the island. This was written when the Longhorn and Devon were popular and the Shorthorn was coming into favor rapidly. Some have accounted for Hereford color and type as due to the importation into Herefordshire by Lord Scudamore, prior to 1671 , of some white-faced cattle from Holland or Flanders. It is worth noting here that in the Dutch galleries of fine arts one will see many old paintings of cattle in which red bodies and white faces are not unusual. One of the great paintings of the world, "The Bull," in the gallery at The Hague in Holland, by Paul Potter, who lived from 1625 to 1654 , has in the group a white-faced, red-bodied cow, much like many plain-looking Herefords of to-day. In his study of breed evolution Professor James Wilson states ${ }^{1}$

1 The Evolution of British Cattle, p. Ioz. London, Igog. 
that the cattle of Hereford and some neighboring districts acquired their red color from their Anglo-Saxon ancestors and their size and their white faces and underlines from Holland. Some emphasis has been laid on the fact that in the herd of one of the Tullys of Huntington about the middle of the eighteenth century a bull calf with white face was dropped, which later as a sire produced many white-faced calves. Hereford color, however, has varied during the history of the breed. In I 788 Marshall wrote that the

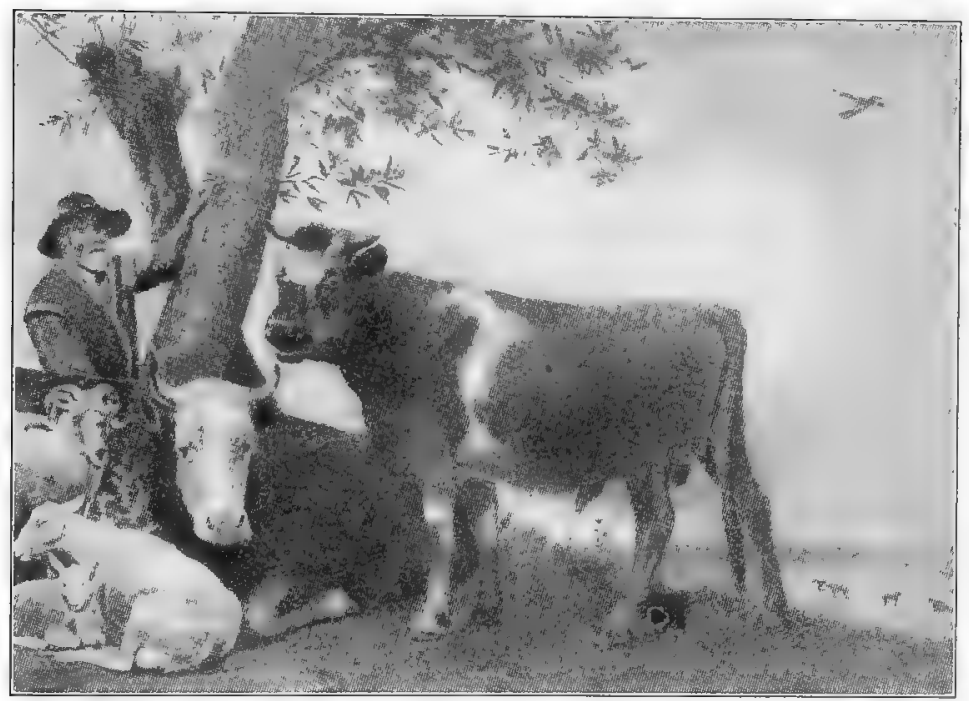

Fig. 103. "The Bull," by Paul Potter (1625-1654). From a painting in the gallery at The Hague, Holland. Note the white face and leg of the cow, suggestive of the early-day Hereford

prevailing color was red with a bald face. In time a wider range of color crept in, so that in I845, when Eyton published the first herdbook, he grouped Herefords into four classes: namely, mottle-faced, light gray, dark gray, and red with white face. Twenty-five years later, however, all of the colors but the last were practically extinct.

Early constructive Hereford breeders date back well into the eighteenth century. A number of men have attained special distinction in this work, some of whom deserve more than passing

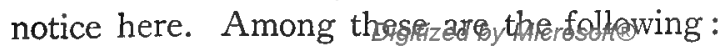


The Tomkins family has the greatest fame among early Hereford improvers. Richard Tomkins, of whose history little is known, who died in 1723, left to his son Benjamin of Court House, Canon Pyon, some cattle above the average, including the cow Silver and her calf. This son, Benjamin the Elder, was born in I7I4 and died in I789 at Wellington Court, where he had lived since I758. He was a most successful breeder and possessed a noted herd of cattle. A son of his, also named Benjamin, and designated "the Younger," was born in 1745 and died in 1815 . He farmed at Blackhall, King's Pyon, and later at Wellington Court and Brook House, King's Pyon. This latter member of the family was the great improver. He bred closely in-and-in, using only bulls of his own breeding, one of which, Silver Bull (4I), was a famous sire and perhaps his best, being a noted improver of stock. The bull Wellington (4) was also an almost equally famous sire. Through Tomkins's efforts Herefords gradually matured earlier, produced less offal, became shorter of leg and more refined, and better covered over the back. $\mathrm{He}$ also gave the breed more character. His cattle presented some range of Hereford color. In 1819 his herd of 52 animals was sold at auction, 28 head of breeding stock bringing over $\$ 20,000$, averaging nearly $\$ 750$ (£I 49 ) each, the bull Phœnix (55) bringing $\$ 2800$.

William Galliers of Wigmore Grange was born in I7I3 and died in $\mathbf{1} 779$. He was intimate with Benjamin Tomkins the Elder, and they used much of the same blood in developing their herds. His cattle passed into the hands of his son, John Galliers of Frogdon, who was born in 1755 and died in 1828 . Another son, William, Jr., a celebrated breeder, was born in 1744 and died in 1832 .

John Price of Ryall was born in 1776 and died in 1843 . He spent his more active years as a breeder near the town of Upton in Worcestershire. He was a close friend and disciple of Tomkins the Younger and adhered to Tomkins's blood lines. He practiced in-and-in breeding and developed a famous herd. $\mathrm{He}$ is said to have been rather independent on color markings and dairy qualities, giving them slight attention, but emphasizing a widespread forerib, strong constitution, great scale, and smoothness at the hind quarters. He purchased from Tomkins the famous 
mottle-faced bull Wellington (4). One of his cows, Toby Pigeon, by Toby (5), was a remarkable individual, dropping him nineteen calves. Nearly his entire herd, sold in $184 \mathrm{r}$, descended from her, and this cow, then twenty-two years old, brought $\$ 70$. Cattle of Price breeding were an important source in the improvement of many herds in Herefordshire. He had auction sales in I8I3, I 8 I6, and I84 I which realized a total of over $\$ 83,000$.

John Hewer (I7S7-I873) was a son of William Hewer, a Hereford breeder of eminence in his day. He was born in

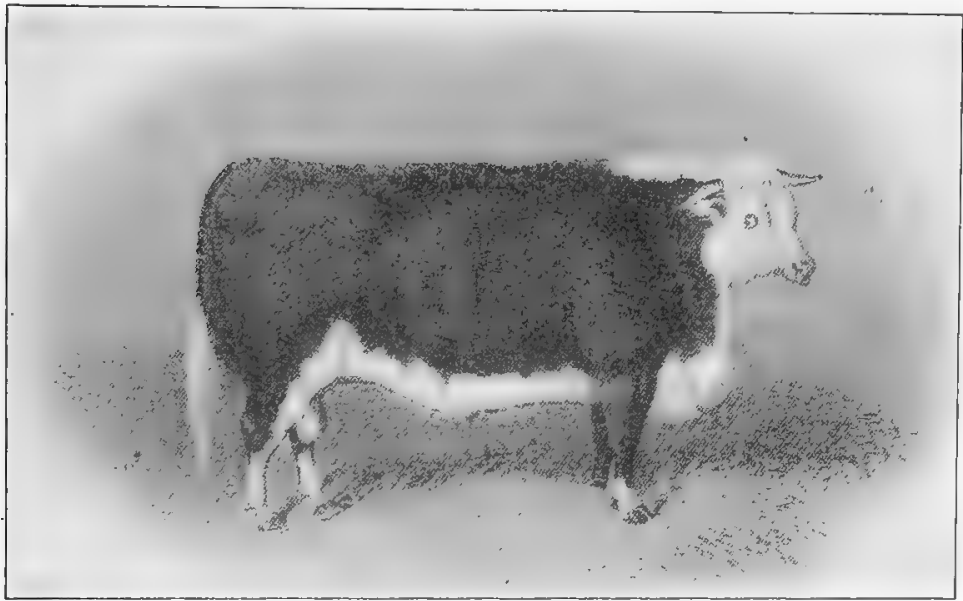

Fig. 104. Winter De Cote $(4253)$, calved in 1870 , bred by Thomas Edwards, Wintercote, Leominster, England. First-prize aged Hereford bull at the show of the Royal Agricultural Society of England. From an engraving by E. Hacker, published in $187+$

Monmouthshire, Wales, and in I8I7 moved to Shropshire, on Purslow farm near Craven Arms. Later he occupied several other estates. He did much to improve the breed, and laid great emphasis on scale, quality, and uniformity of color. He had four favorite strains, Countess, Lofty, Red Rose, and Fanny, from which his cattle mainly descend. He let out bulls to service for large sums and bred and owned many of the most eminent Herefords of the century. The following bulls bred by him are among the notable ones in the history of this breed: Sovereign (404), Lottery (410), Byron (440), Hope (44I), Chance (335), 
Defiance (4I6), Prince Dangerous (362), Lot (364), Lottery 2d (408), Young Favorite (4I3), Wonder (420), Fitzfavorite (44I), Hamlet (5 I 2), Original Ist (455), Young Waxy (45 I), Purslow (446), and Conqueror (4I 2 ). There is scarcely a line of Hereford breeding to-day that is not traceable to the Hewer stock.

Thomas Jeffries of The Grove, Pembridge, and other estates, was born in 1796 and died in 1843 . He was a son of Thomas Jeffries and came from a family of well-known Hereford breeders. He first began with the Hereford stock developed by the family, but later infused the blood of cattle bred by John Hewer, hiring from him Sovereign, Lottery, Byron, and Fitzfavorite. This blending of blood brought about remarkable success, and Jeffries produced numerous famous animals. Cotmore (376), by Sovereign, which he bred, has been classed as one of the finest Hereford bulls of history.

Foundation Herefords of importance are the following: Silver Cow of Richard Tomkins; Pigeon and Mottle of Benjamin Tomkins the Elder; Wellington (4), Silver Bull (4I), Slit Teat Cow, Storrell, Old Rose, and Old Lovely of Benjamin Tomkins the Younger; Toby Pigeon, by Toby (5), of John Price; Red Rose, by Chance (348), of John Hewer. These were really foundation stock in the early establishment of the breed. Among other very important Hereford males that had a great influence on the breed in England in the last century may be mentioned Sovereign (404), Old Wellington (507), Old Silver (540), Waxy (403), Cotmore (376), Lottery (4 I0), Chance (348), Sir David (349), Walford (871), Sir Benjamin (I 387 ), Sir Thomas (2228), Horace (3877), Winter De Cote (4253), and Lord Wilton (4740). It is said of Sovereign (404) that in his day he was acknowledged to be "the best bull ever bred in the county of Hereford, and the sire and grandsire of more prize cattle at Smithfield and elsewhere than any other bull in the kingdom." These bulls are inseparably associated with the development of the breed in England.

The introduction of the Hereford to America first occurred, so far as records show, in $18 \mathrm{I} 7$, when Henry Clay imported a young bull, a cow, and a heifer to his home at Lexington, Kentucky. About I825 Admiral Coffin of the British Navy sent the bull Sir Isaac and a cow as a gift to the Massachusetts Society for 
Promoting Agriculture. Later other importations followed in a small way. In $1840 \mathrm{~W} . \mathrm{H}$. Sotham, a native of Herefordshire, England, who had previously emigrated to America, imported to Albany, New York, in partnership with Erastus Corning, Jr., 2 I cows and heifers and a two-year-old bull. This importation was followed by others in $1843,1852-1853$, and I $861-1862$. Sotham worked hard to promote the breed, but neither the Kentucky, Massachusetts, nor New York importations awoke enthusiasm. Captain Pendleton of Maine also imported 2 calves in 1846 , and

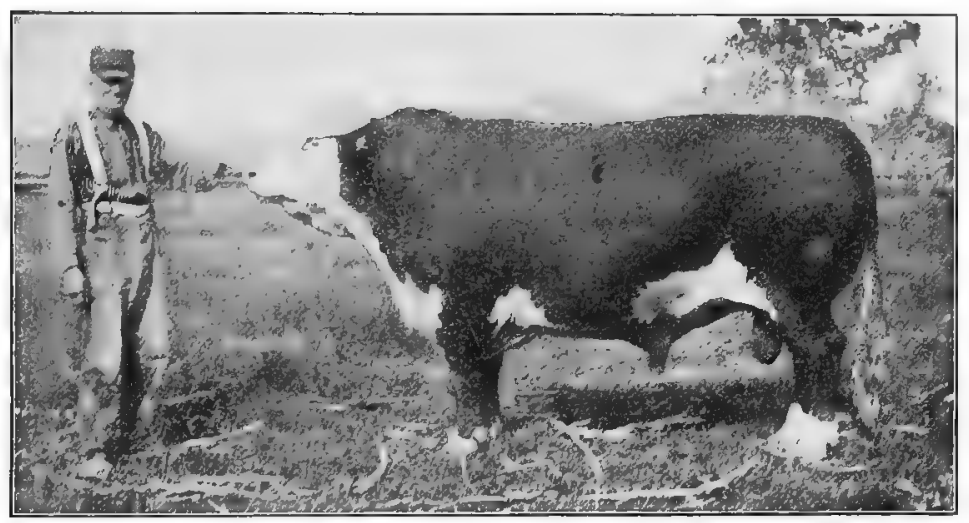

FIG. 105. Earl of Shadeland 22d 27147, by Garfield 7015, the champion Hereford bull of 1888 , known as "The Record Breaker." One of the famous bulls of his day. Held by "Uncle" John Lewis, long the successful manager of the great Shadeland herd at Lafayette, Indiana, now dispersed. From photograph by the author

in I 852 John Humphries and Thomas Aston, coming as new settlers to Ohio from England, brought with them 7 Herefords. In I 860 F. W. Stone of Guelph, Ontario, Canada, began importing and became a most important factor in promoting the breed in that country. Later, about I875, T. L. Miller of Beecher, Illinois, became interested. He was a man of wealth and ability and did much to introduce Herefords into the West and insist on the public recognizing the merits of the breed for the range country. Miller exhibited at fairs, and in 1877 his cattle attracted the attention of C. M. Culbertson of Illinois and Adams Earl, Moses Fowler, and W. S. Van Natta of Indiana, all of whom became noted breeders 
and importers. In 1879 Culbertson imported 13 head and in 1880 over I 00 of the choicest quality and breeding.

Hereford characteristics. This breed has undergone more of an evolution and made more improvement than any other beef breed in America. In I 788 Marshall gave the following description of the breed, which sixty years later Youatt stated was tolerably correct.

The countenance pleasant, cheerful, open; the forehead broad; eye full and lively; horns bright, taper, and spreading; head small; chap lean; neck long and tapering; chest deep; bosom broad and projecting forward; shoulder bone thin, flat, no way protuberant in bone (?), but full and mellow in flesh; chest full; loin broad; hips standing wide and level with the chine; quarters long and wide at the neck; rump even with the level of the back and not drooping nor standing high and sharp above the quarters; tail slender and neatly haired; barrel round and roomy; the carcass throughout deep and well spread; ribs broad, standing flat and close on the outer surface, forming a small, even barrel, the hindmost large and full of length; round bone small, snug, and not prominent; thigh clean and regularly tapering; legs upright and short; bone below the knee and hock small; feet of middle size; flank, large; flesh everywhere mellow, soft, and yielding pleasantly to the touch, especially on the chine, the shoulder, and the ribs; hide mellow, supple, of a middle thickness, and loose on the neck and huckle; coat neatly haired, bright, and silky; color a middle red with a bald face, characteristic of the true Herefordshire breed.

While this description has an important application to the Hereford of to-day, in certain respects the breed has been materially improved over what it was twenty-five years ago.

The head of the bull is different in type from that of other breeds, being rather short and broad, both in forehead and muzzle, and often dished of face, crowned with white or waxy yellow horns, which spring forward and down in a semicircular curve. The head of the cow is more refined, and the horns commonly curve around and upward, the tips pointing forward. The neck is often too full at the throat and shows excessive dewlap, especially with the bulls, but commonly blends smoothly into the shoulders.

The shoulder is most beautifully laid and covered with flesh, this being a Hereford characteristic scarcely equaled by any other breed. The spring and depth of rib and consequent expansion of body is striking, and a wide, long loin and thickness and depth 
of chest clearly account for the vigor and constitution so univer sally acknowledged for this breed. The rump often lacks in levelness and fullness, while the thig/ts are frequently thin and pared off, being deficient in thickness and depth. These deficiencies, however, have been materially bred out in many herds, so that the criticisms do not have the weight they formerly did, although even to-day the fore part of the Hereford usually delights the critics; while the hind part often meets with unfavorable comment. The successful Hereford winners in the important shows of to-day exhibit fullness behind as well as in front and bear evidence of the improvement secured by modern constructive breeding.

The skin and hair of. the Hereford are distinguishing features of the breed. The skin should be thick, mellow, and elastic, and the hair fine. Commenting on this subject, one of the greatest British breeders ${ }^{1}$ says : "One thing each Here-

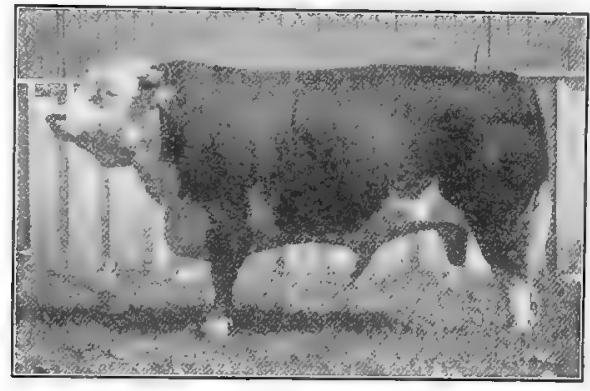

FIG. I06. Dale 6648I, by Columbus 51875, one of the greatest Hereford bulls in the history of the breed, both as sire and show bull. Bred by Clem Graves, Bunker Hill, Indiana. From photograph by the author ford breeder should particularly study in choosing the sire and dam, and therefore the offspring, is to try to keep that thick mellow hide and the soft curly coat that are principal characteristics of the well-bred Hereford. It is a sort of special feature of the breed, showing its aptitude to fatten." The coat of hair in cold weather is usually thicker and more curly than with any other breed, excepting Galloway and West Highland, furnishing abundant protection from cold and storm.

As milk producers the cows average below medium and are specially open to criticism. No class of breeders carry so many nurse cows on the show circuit as do the Hereford men. 
In temperament Herefords are less docile than Shorthorns under similar conditions and do not so readily accustom themselves to the confinement of limited quarters where grazing is not abundant.

The color of the Hereford is one of its most distinguishing features. As has already been shown, a century ago there was considerable range of color, and the first English herdbook classified the cattle into four groups - mottle-faced, light gray, dark gray, and red with white face. In the development of the breed the trend has been to secure uniformity of color. This, as seen to-day, shows in varying degree pure white hair over the face and head, breast, top of neck and withers, and legs below knee and hock, along the belly and udder and switch, the remainder of the body being red. The amount of white seen on different animals in a large herd will vary, some being marked in a much more pronounced degree than others. The color varies from a light yellow-red to a dark cherry, a medium, soft tone of red being preferred.

The size of the Hereford places this breed in the large class of cattle. From very early times great scale has been sought, and it is said that the bull Wellington in I 8 I 5 weighed 29 I 2 pounds and the cow Silk in I 820 weighed 2000 pounds. Cotmore (376), first-prize bull in 1839 at the English Royal, it is claimed, ${ }^{1}$ based on official record, weighed 35 hundredweight, or 3920 pounds, the maximum weight for a British bull. The bull The General (I25I) is also reported to have weighed 3640 pounds when six years old. A circular issued by the American Hereford Cattle Breeders' Association states that the breed is not excelled in size, either at early age or maturity, by any breed and that it is not uncommon for bulls to weigh from 2800 to 3000 pounds and for mature cows to weigh a ton. The following are given as the average weights for a period of five years of Herefords of different ages shown at the American Royal Live-Stock Show at Kansas City: aged bulls, 2238 pounds; two-year-old bulls, I9I I ; senior yearling bulls, I 439 ; junior yearling bulls, I 3 I 8 ; senior bull calves, 979 ; junior bull calves, 748 ; aged cows, I689; two-year-old heifers, I 5 I 7 ; senior yearling heifers, 1269; junior yearling heifers, I I 28 ;

1 Alvin H. Sanders, The Story of the Herefords. Chicago, I914. 
senior heifer calves, 828 ; junior heifer calves, 634 pounds. These weights are of show-ring animals and naturally are materially heavier than those in ordinary flesh.

The Herefords as meat producers have always ranked high. For many years their meat held the highest place at the Smithfield market in London. At the first fifty-two annual meetings

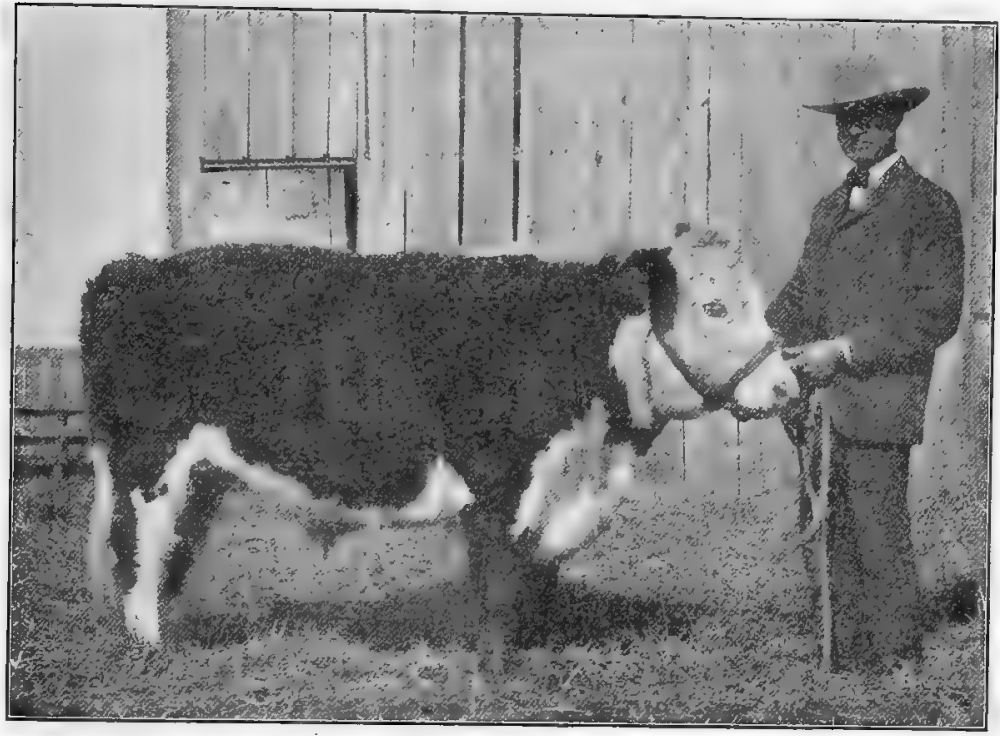

Fig. 107. Black's Ohio Champion, a grade yearling Hereford range steer, held by the noted feeder, D. W. Black, Lyndon, Ohio. Bred by Swenson Brothers of Texas. One of the grand-champion car lot of feeder calves at the IgO4 show of the International Live-Stock Exposition. Also one of the first-prize car lot of yearlings fed by Mr. Black for the 1905 show. Purchased by the Ohio State University. From photograph by the author

of the Smithfield Club, with various breeds in competition, I85 prizes went to Hereford steers or oxen and only 190 to all other breeds or crosses combined. In recent years, however, the Hereford has not been so uniformly successful, owing to the influence of Aberdeen-Angus and Shorthorn, but even to-day it may be classed in the first rank. In the carcass contests on fat cattle at the International during the period between 1907 and I9I 7 the Herefords did not attain first honors, securing second on two-year-olds 
in I9I I, third on yearlings in 1907, I908, and I9I0; and fifth on two-year-olds in 1917 , the latter being on the steer Hazford Lad 6th, shown by Colonel E. H. Taylor, Jr., weighing I650 pounds alive, dressing out 68.9 I per cent. In I9 IO the third-prize yearling Mirko, shown by the University of Nebraska, weighing I 332 pounds, dressed out the high percentage of 68.09. At the Chicago Fat Stock Show the following Hereford grand championships were awarded between I878 and I892: I883, Roan Boy, a grade sired by a Hereford bull out of a Shorthorn cow; I885, the grade Regulus; I 886, Rudolph J., a pure-bred; I89 I, Hickory Nut, a pure-bred. At the International Live-Stock Exposition but few grand championships have been won by Hereford steers. In I90I The Woods Principal, a pure-bred, was grand champion over all. In Igo3 Challenger, a grade, sired by a Hereford and shown by Nebraska University, was grand champion. In Igo6 a pure-bred calf, Peerless Wilton 39ths Defender, won the high honors, and again, in 1916, a Hereford-Shorthorn grade, California Favorite, shown by the University of California, was grand champion. In the carload lots of fat steers Herefords have been shown in large numbers, though these are mostly range-bred. Grand-championship honors on carloads have been won as follows at the International: in Igor by D. W. Black of Ohio with a carload of range-bred Herefords; in 1903 by W. F. Herrin of Illinois; in I 918 by J. W. Frazier of Illinois with calves bred on the Texas range. At the American Royal at Kansas City the grandchampion load in I9IO was Herefords. Especially strong exhibits of fat cattle and feeders of this breed are shown at the American Royal Live-Stock Show at Kansas City, at the Western Stock Show at Denver, and at the National Show at Fort Worth, Texas. In recent years the Hereford has made a poor showing at the British fat-stock shows.

The early maturity of the Hereford is one of its pronounced characteristics. No breed of beef cattle develops more rapidly into "baby beef" than this, the calves showing a thickness of fleshing and finish that is most attractive. Beyond eighteen months of age the tendency is for Herefords to take on some rolls of fat over the ribs and show more or less unevenness of fleshing. Compared with the Aberdeen-Angus in this regard, they are at some disadvantage. 
The prepotency of the Hereford is one of its most marked features. Not only is there little variation in type and color markings among pure-breds but so dominant are these characteristics that when pure-bred bulls are used on grade cows, the offspring appear in many instances like pure-breds. So prepotent is the Hereford that his smooth shoulder and thin thigh are commonly transmitted into the grade herd.

Hereford cattle for grazers are of the first rank. No other breed will sustain itself on the range, depending entirely on grass and forage, and will thrive so well as this. Inheriting a very hardy constitution and being capable of withstanding unusual severity of winter weather, and with a capacity to gain in weight and do well on a relatively sparse feed, the Hereford has proved itself to be the leading breed for the range. It is not so well suited to restricted pastures and stable confinement as

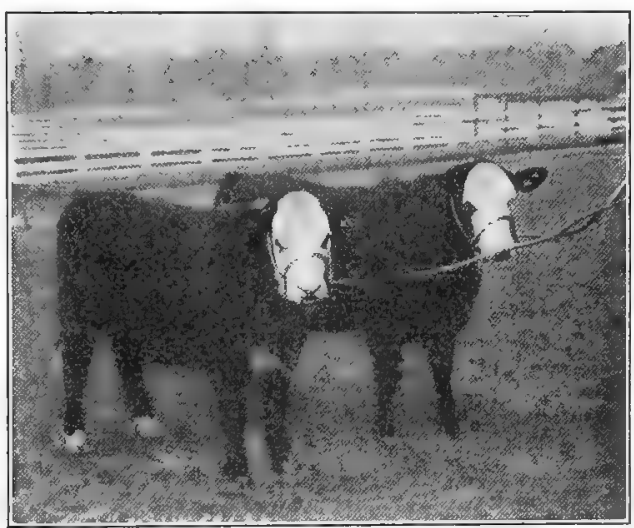

FIG. I08. Crossbred heifers out of grade Hereford cows, sired by an Aberdeen-Angus bull. Bred by Ohio State University, Columbus, Ohio. From photograph by the author either Shorthorn or Aberdeen-Angus, but on the great ranges of the western United States and Canada, in Brazil and Argentina, it has no equal.

The crossbred or grade Hereford is a prime favorite among feeders of beef cattle. Beyond the Missouri River and in the Southwest Hereford bulls have accomplished remarkable results in grading up and improving the common cattle of the range. The old-fashioned longhorn Spanish type of cattle of the Southwest have disappeared under the improving influence of Hereford blood. During the course of years grade Herefords on the range have taken on all the characteristics of the pure-breds, and millions

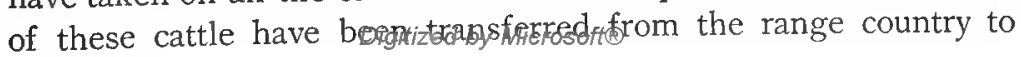


the feed lots of the corn belt, where they have met with great favor on account of their hardiness and ease of fattening. The influence of the grade Hereford in the feed lot is strikingly shown in the large numbers of cattle of this breeding to be seen in the stockyards of Chicago, Kansas City, or Fort Worth. While crossing of pure-breds is not advised, a one-generation cross of Hereford on Shorthorn or Aberdeen-Angus may produce a most excellent butcher's beast.

The prolificacy of the Hereford is a noteworthy feature. There are many cases on record of Hereford cows living to extreme old age and continuing as active breeders in the meantime. Mr. William Tudge writes of a cow in his herd that between I 873 and 1887 dropped sixteen calves. Mr. Murdo Mackenzie, noted as a manager of large cattle-breeding and feeding interests in the far western United States and in Brazil, is credited ${ }^{1}$ with preferring the Hereford on account of its prolificacy. His calf crop, he said, usually ran from 70 to 80 per cent when he used Hereford bulls. At one time he put in bulls of another breed and the calf crop dropped to 40 per cent. A return to the use of Hereford bulls was quickly reflected in the increase in the percentage of calves dropped.

Hereford families of note. While Shorthorn and AberdeenAngus breeders give the family name based on some foundation female, the custom among Hereford breeders is to use the name of the sire as indicative of the line of breeding. In reference to this subject Mr. A. H. Sanders, long an able and interested student of the breed, has written as follows: ${ }^{2}$ "In so far as they use family nomenclature at all, Hereford breeders commonly group their breeding animals under heads that convey a definite meaning. They have their Wittons, Anxieties, Grove 3d's, Garfields, Beau Donalds, Perfection Fairfaxes, Disturbers, Repeaters, etc., thus laying stress where it of right belongs, on the great producing bulls." The following families are given as based on lines of breeding that have attracted special attention since the opening of the present century.

1 The Hereford, 1917. A pamphlet published by the American Hereford Journal.

2 The Story of the Hereford (19I4), p. ro72. 
The Anxiety family descends from the imported bull Anxiety 2238, bred by T. J. Carwardine and imported by C. B. Culberson of Illinois in I879. Anxiety was sired by Longhorns 2239, a very successful sire, and out of Helena 2240, one of the best show cows of her time. Anxiety was a very superior, thick, smooth bull of much quality, and during a short life in America he sired a number of most excellent animals, including Anxiety 3d 4466

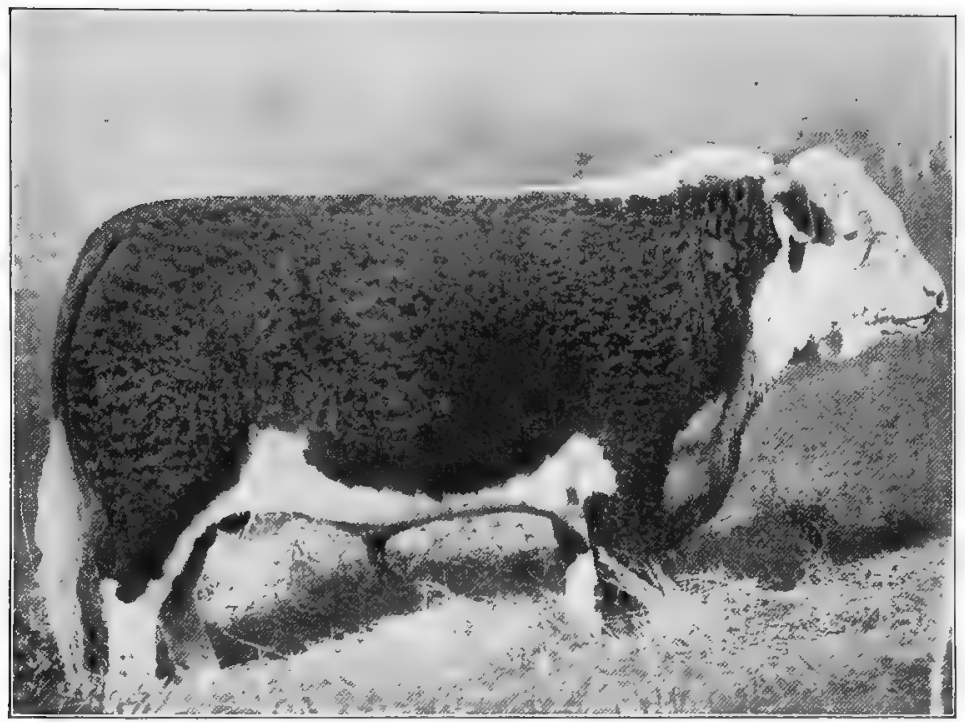

FIG. I09. Repeater 289598 , one of the greatest of twentieth-century Hereford sires, the descendants of which have been in great favor. A grand champion in his day and a sire of grand champions. Owned by Overton Harris, Harris, Missouri. From photograph by courtesy of Mr. Harris

and Anxiety 4th 9904. These two proved remarkable sires. Anxiety 3d was a great heifer getter, and Anxiety 4th sired notable bulls and cows, including Don Carlos 33734, Beau Real I I055, and Anxiety Monarch 41216. Beau Donald 58996, one of the more recent sires of note, was a grandson of Anxiety 4th through Beau Brummel 5I8I7. Prime Lad I089I I and Disturber I 39989, famous as sires, were both direct descendants from Anxiety 4th. It is doubtful if any family has had so potent an influence on the breed in recent years as has this. 
The Beau Donald family descends from Beau Donald 58996, referred to above. He was sired by Beau Brummel 5I8I7, a son of Don Carlos 33734, by Anxiety 4th. Donna 33035, the damof Beau Donald, was out of Dowager 6th 6932, the mother of Don Carlos. It can thus be seen that on both sire's and dam's side the Beau Donald family is of Anxiety breeding and so might be regarded as a subfamily. Beau Donald was bred by Gudgell and Simpson of Missouri in I893. He was bought as a calf by H. B. Watts of Missouri, who sold him in 1897 to W. H. Curtice of Kentucky, in whose herd he established the reputation of this family. In the hands of Mr. Curtice, Beau Donald sired a large number of remarkably good cattle, including some notable sires, especially Beau Donald 3d 86I40 (the sire of Disturber I 39989 and grandsire of Repeater 289598) and Prince Rupert 79539 (the sire of Prince Rupert 8th I4270I, noted as a show bull and sire). This is one of the most popular Hereford families.

The Corrector family derives its title from the bull Corrector 48976, calved in $189 \mathrm{I}$ and bred by T. F. B. Sotham of Missouri. Corrector was sired by imported Harold $2114 \mathrm{I}$, his breeding extending back to the famous Horace, while Regulus was sire of Harold's dam. Coral I 3526 , the dam of Corrector, was a great breeding as well as show cow. During the twelve years of his life Corrector sired many sons and daughters, among which were the famous prize winners Benefice 78825, Benita 58542, Sir Bredwell 63685 (that sold for $\$ 5000$ ), and Thickset 68785 (that sold for $\$ 5100)$. From I894 to 1903 inclusive 104 Corrector bulls sold for $\$ 45,520$ and 85 females for $\$ 32,920$. Many of the cattle of Corrector breeding found their way to the range herds of the Far West, where they were absorbed, the family line largely disappearing.

The Disturber family is named from the bull Disturber I39989, a son of Beau Donald 3d 86140, he by Beau Donald and out of Columbia 76779, a daughter of Columbus 51875. This family combines the blood of Beau Donald on the sire's side and runs back to Garfield 70I 5, four generations on the dam's side. Disturber was bred by Jesse Adams in I90 I and bought by John Letham for S. L. Brock of Wisconsin, in whose herd he remained until I9II, when he was bought by 
C. A. Tow of Iowa. According to Mr. Letham, who was in charge of this bull for years, ${ }^{1}$ Disturber was most successful as a sire on Kansas Lad Jr. and Prime Lad cows. Through his son Distributor I 76433 he is grandsire of Repeater 289598, whose sons and daughters have attracted much attention. Point Comfort I 4th 337488, very noted as a sire in the South, was also a grandson of Disturber through his dam Lady Christine 204806. This family represents one of the most popular lines of breeding to-day, since it stands for the more modern type, with well-filledout hind quarters and smoothness of finish.

\section{The Hesiod family} derives its name from the imported bull Hesiod I 1675 , bred by P. Turner and sired by The Grove 3d 2490. A son of Hesiod named Hesiod 2d 40679, out of Anita 33955-a daughter of Harold 2 I I 4 I and half sister of Corrector - established the fame of this family

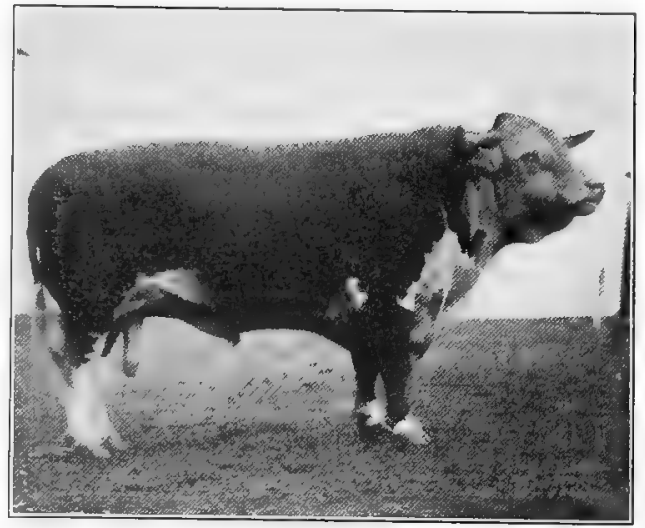

FIG. I Io. Perfection Fairfax 779676 , the greatest grandson of Dale, in field condition. Perhaps the greatest Hereford sire in the history of the breed in America. Owned by W. T. McCray, Kentland, Indiana. From photograph by the author

while in the ownership of J. A. Funkhouser of Missouri. Notable sons and daughters of his were Hesiod 29th 66304, Hesiod 5oth 76440, Hesiod 58th 86466, Dewdrop 6 I 35 I, and Keepsake 81634. Mina I 84985 , the dam of Repeater 289598 , is a great-granddaughter of Hesiod 2d. Few families show a better ancestry than does this, although it has not been especially prominent in recent years.

The March On family descends from March On 76035, imported in $\mathbf{I} 897$ by C. S. Cross of Kansas and sired by Lead On 76967, dam Royal Daisy 2d 79943. The breeding of March On goes back five generations on the sire's side to Good Boy (7668), a noted sire and show bull, and also to Lord Wilton and Grove 3d. 
The dam of March On also traces back four generations to Grove 3 d. March On in yearling age was bought at auction by W. S. Van Natta and Son of Indiana, and in their herd this family won its reputation. March On 6th 96537 , by March On, dam Jewel Fowler 49207, by Fowler I 2899, was purchased from the Van Nattas by J. A. Funkhouser. Jewel Fowler, his dam, was also dam of Java 64045 , sire of Dolly 5 th 7 I988. In the Funkhouser herd the March On family was especially promoted. March On 6th was not only a great success in the show yard but he was also a distinct success as a sire. Onward 4th I23694, by March On 6th, was champion Hereford bull at the 1903 and I904 American Royal shows at Kansas City and third aged bull in 1904 at the Louisiana Purchase Exposition. Onward 3 Ist I87476, another son, was champion at Kansas City in 1908. At the Louisiana Purchase Exposition many prizes were won by sons and daughters of March On 6th, including second on get of sire and produce of dam. During the first ten years of this century this family attained much popularity.

The Perfection family comes from most illustrious ancestry and is named from Perfection 9289r, calved in I898 and bred by F. A. Nave of Indiana. Perfection was sired by Dale $6648 \mathrm{I}$, champion in many shows, and out of Melley May 4I752, a daughter of Hoosier Tom 7732, by Anxiety 2d. Going back five generations on the line of sires we have Dale 6648I, Columbus 51875, Earl of Shadeland 4Ist 33378, and Garfield 7015, a remarkable ancestry. Perfection was repeatedly a first-prize winner and champion as calf, yearling, and two-year-old. Mr. Thomas Clark of Illinois paid $\$ 1350$ for him as a yearling and later sold him at auction to G. H. Hoxie of Illinois for $\$ 9000$. In 1907 he was bought at auction by Colonel Curtice of Kentucky. Perfection sired many animals of superior merit, but two of his sons Perfection Fairfax 179767, out of imported Berna 138482, by Fairfax 34 I 59, owned by W. T. McCray of Indiana, and Woodford 500000, out of Belle Donald I I 4th 267 I9I, a double granddaughter of Beau Donald, owned by Colonel E. H. Taylor, Jr., of Kentucky, and for which he paid \$12,000 - are his most famous sons. In the opinion of many breeders Perfection Fairfax is the greatest Hereford sire in the history of the breed and is by 
many regarded as the founder of a family itself. Calved in 1903 and used for many years in a herd of unusual excellence, Perfection Fairfax has sired a large number of sons and daughters which have been bought at high prices. At the sale of Mr. McCray on May 22, I9I8, fourteen of his sons averaged $\$ 5216$ and ten of his daughters $\$ 2870$ each. In the I9I9 sale of Mr. McCray 20 bulls (all sons of Perfection Fairfax) averaged $\$ 7955$, and 22 of

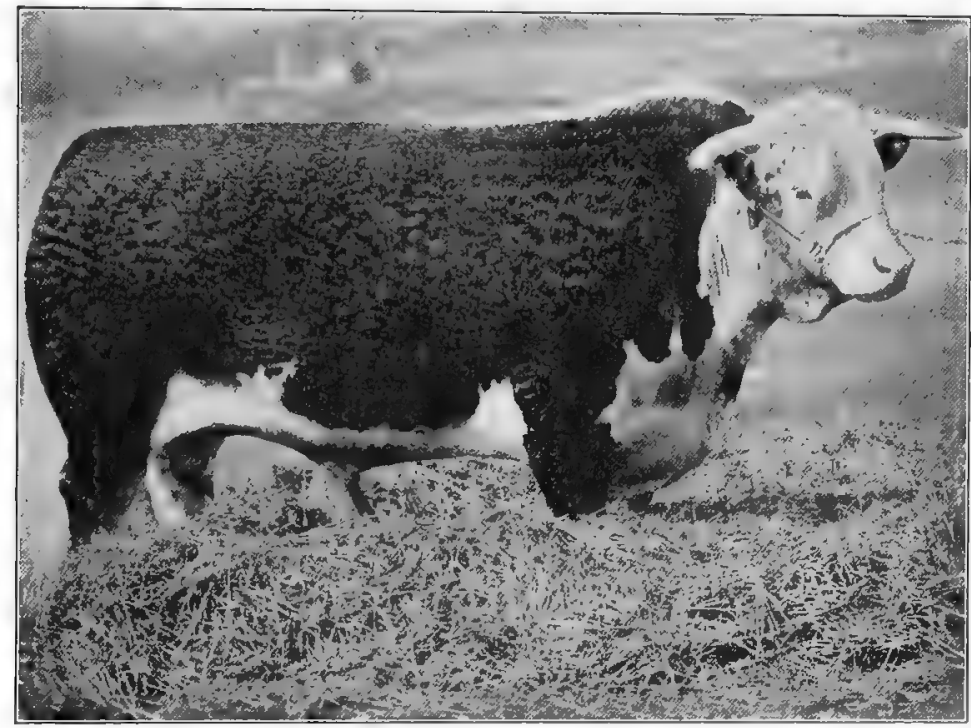

FIG. IrI. Richard Fairfax 449317, by Perfection Fairfax 179676. Sold by L. A. Pinnard to Ferguson Brothers, Canby, Minnesota, for $\$ 50,000$. One of the prominent present-day sires. From a photograph by courtesy of Ferguson Brothers

his daughters averaged $\$ 3436$. Luther Fairfax 68897 I brought $\$ 19,000$; Admiral Fairfax 633408 brought $\$ 20,500$; Hugo Fairfax 608229 brought $\$ 23,000$; and Baron Fairfax 54777 I sold for $\$ 24,000$. Another son, Richard Fairfax 449317, sold in March, I919, at private sale for $\$ 50,000$, as set forth on page 273 . While Perfection blood has been widely used in Hereford families, Beau Donald breeding has seemed to blend with it especially well.

The Prime Lad family finds its so-called beginning in the bull Prime Lad I08911, bred by W. S. Van Natta and Son, calved in I900, sired by Kansas Lad, Jr. 75 IO4, and out of Primrose Digitized by Microsofte 
80150 , by Marplot 82782. Prime Lad, through his sire and grandsire, Kansas Lad 36932, goes back to Beau Real I I055, by Anxiety 4th, a truly great line of sires. Prime Lad won many prizes in the show ring, the more important being the breed championship at the Louisiana Purchase Exposition and at the International Live-Stock Exposition in I904. As a sire, in the hands of Van Natta and Son, he was a great success, siring many notable prize winners, including Prime Lad I6th 2r 3969, out of Lorna Doone 94479 (champion at the Louisiana Purchase Exposition), and Prime Lad gth 2 I 396.3, out of Leonora 137722 (another daughter of Lorna Doone), by March On 76035 . Gay Lad 6th 316936, by Prime Lad 16th, out of Sister Perfection 139658 sired by Dale 6648I and out. of Melley May (also the dam of Perfection Fairfax), in the hands of O. Harris of Missouri, attained great fame as the progenitor of a line of Gay Lads of much merit. Gay Lad 6th was champion bull of the breed at the American Royal and the International in IgIo and $191 \mathrm{I}$, and his son Gay I ad 4oth 503718, junior champion in I9I6 at the American Royal, at the O. Harris and Sons sale in 1917 , sold for $\$ 11,900$. Since 1904 Prime Lads have been in special favor. The Prime Lad and Beau Donald families have been blended to great advantage.

Noted Hereford sires prior to Igoo may be traced in the history of the breed during the previous century. Two great epochmaking sires of long ago were Sovereign (404), calved in I 820 , and Sir David (349), calved in I845. Sir Benjamin (1387), a son of Sir David, was also a sire of great renown. Coming to a more recent date, Lord Wilton (4740) 4057, calved in 1873 (a descendant of Sir David), and Horace (3877) 249.2, calved in I 867 , have been rated as two of the greatest bulls in the history of the breed in England. Hereford sires of particular note in America date back only to the time of T. L. Miller. From about I 880 many animals of much merit were imported. Among these history accords high place to Success 2, by Banquo 4; Sir Richard 2d 970a, by Sir Oliver 2d (r733); The Grove 3d 2490; Sir Bartle Frere 64I9, by Lor A Wilton (4740) 4057; Garfield 7015 , by Quickset 6853; Anxiety 2238, by Longhorns 2236; and Tregehan 6203, by Assurance 4589. Among American-bred 
Herefords the following in particular are of distinction: Fowler I 2899, by Tregehan; Anxiety 4th 9904, by Anxiety; Corrector 48975, by Harold 2I I4I ; Peerless Wilton I2774, by Garfield; Dale 6648 r, by Columbus 51875; Earl of Shadeland 22d 27 I47 and Earl of Shadeland 4Ist 33478, both by Garfield. After making a study of the winners at the various American Royal and International Exposition shows up to and including 1917,

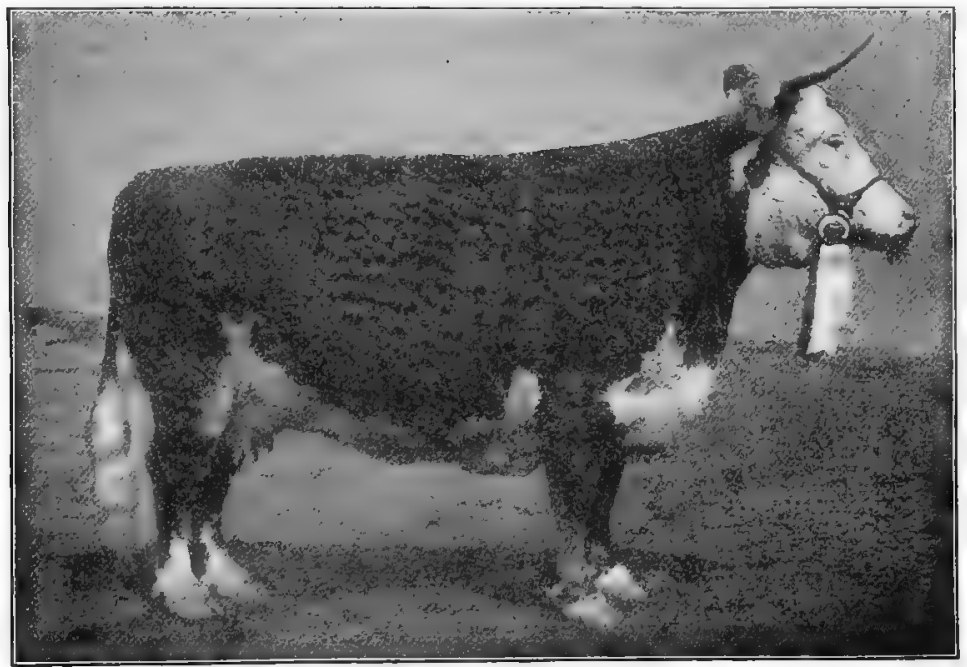

FIG. II2, Lorna l)oone 947 9), by (hristopher 69072. Grand-champion llereford cow at the Louisiana Purchase Exposition, I904, and at various other leading exhibitions, and noted as a great specimen of the breed. Bred and owned by W. S. Van Natta \& Son. From photograph by the author

L. H. Riggs gives the following, ${ }^{1}$ as all things considered, the greatest Hereford sires in order of merit: (I) Perfection Fairfax, (2) Beau Donald, (3) Prime Lad, (4) Disturber, (5) Lamplighter, (6) March On 6th, (7) Corrector, (8) Repeater, (9) Benjamin Wilton. Prices paid for Herefords have passed through wide extremes. In their native home the breed has long been valued for export, and prices have generally ruled strong. In I 884 Lord Wilton (4740) sold at auction for $\$ 19,000$, but the buyer could not cash his bid, so the bull was later sold to William Tudge and Thomas Fenn for $\$ 5000$. In the United States public-auction sales show 
the low average in I89 I of $\$ 68.23$, with a gradual increase up to I898, when I 345 head averaged $\$ 300.18$. From this time values declined, until I905, when II 79 head averaged $\$$ I I 5.25. Since 1905, however, Hereford values have steadily increased, more recently going up in unusual degree. "In I9I7," says Hayes Walker," "a total of 3266 bulls sold at public auction for an average of $\$ 508$, while so far this year $25 \mathrm{I} 8$ bulls have sold in public sales for a general average of $\$ 400$. Last year 5888 females sold at public auction for a general average of $\$ 485$, while so far this year 4073 females have brought a general average of $\$ 550$." Among the notable American sales the following are of interest. In $\mathbf{I} 902$ at the sale of Clem Graves of Indiana, the bull Crusader 86596 sold for $\$ 10,000$ and the cow Dolly $2 \mathrm{~d}$ 6 I 799 for $\$ 7000$, the highest prices for this breed in America up to that time. In January, I902, Perfection 9289I sold in the Thomas Clark sale at Chicago to G. H. Hoxie for $\$ 9000$. In I9I 3 Colonel E. H. Taylor, Jr., bought the bull Woodford 500000, by Perfection, for $\$ \mathbf{1} 2,400$. Woodford was burned to death in his stall in I918. On March I, r9i6, O. Harris and Sons of Missouri held a sale, when 6 I head averaged $\$ 1246$, six sons of Repeater 289598 averaging $\$ 3642$. On February 28 and March I, I9I7, the same firm held another sale, in which 144 head brought $\$$ I 84,450 , a new record in Hereford values, an average of \$1 28 I per head, Gay Lad 40th 5037 I 8 selling for $\$$ I I,900 and Bonnie Brae 6oth 413606 for \$10,050. In December, I916, at a combination sale at the International at Chicago, Woodford 6th 505407 , by Woodford 500000, sold for $\$$ I 5, 100 to N. J. Camden of Kentucky. In 1917 the bull Ardmore 566000 was sold by Walter L. Yost of Missouri to W. R. and W. A. Pickering of the same state for $\$ 31,000$, the top price for a Hereford bull up to 1918. For some years W. T. McCray of Indiana has held remarkable sales, and on May 22, I918, he sold 75 head for \$204, I75, an average of $\$ 2722$, only two animals selling for as little as $\$ 1000$. On June 7 , I9r 8 , all previous records were broken at the sale of E. H. Taylor, Jr., when 62 head brought $\$ 186,850$, an average of $\$ 3013$. At this sale imported Clive Iris 3d 545495 brought the record price of $\$$ I 3,850 for a Hereford cow. Two other high

1 American Hereford Joumal, June 15, I918. 
records were made on cows, Maple Lass 57th 5 I24 I I bringing $\$ 7700$ and Princess H. 609673 reaching $\$ 7800$. The price of $\$ 6300$ paid for Columbia March On 543883 at Mr. McCray's sale in May was the high price for a Hereford cow up to that date. On January 7, I9I9, Mousel Brothers of Nebraska broke all previous Hereford sale records, selling 50 head for a total of $\$ 192,250$, an average of $\$ 3845$. The three-year-old bull Superior Domino 557924 sold to Mrs. William Braddock of Nebraska for $\$ 2$ I,OOO, and the aged cow Mariana 8th 4I6438 to Fritz Bichel of Nebraska for $\$ 7200$. Early in March, I919, the bull Richard Fairfax 4493 I7, by Perfection Fairfax and out of Real Lady 2385 I 8, by Beau Real I 8 I680, was sold by L. A. Pinard of South Dakota to Ferguson Brothers of Canby, Minnesota, for $\$ 50,000$, which created a new high record of Hereford values. Finally, on May 2 I and 22, I9I9, Mr. McCray held a world-record sale for beef cattle, I 20 head bringing $\$ 436,250$, an average of $\$ 3635$. The first 50 head in the sale averaged $\$ 5360$, and 42 sons and daughters of Perfection Fairfax averaged \$559I. One cow, Miss Dale Farmer 5I2485, was bought by Z. M. Crane of Dalton, Massachusetts, for $\$ 10,500$. Two bulls brought very high prices in England in 1918 - Ringer (31920), by Starlight, selling for $\$ 45,000$ at the sale of S. C. Hayter; and Resolute, by Ringer, selling for $\$ 40,000$ to T. R. Thompson of Wales.

The distribution of the Hereford is very wide. In Great Britain it is chiefly bred in Herefordshire and vicinity, though herds are kept with success in Scotland, Ireland, and Wales. The Hereford, however, is best adapted to a grazing region of a fair degree of level surface, and its introduction to the plains of Australia, New Zealand, Argentine Republic, Canada, and the United States has met with very great success. No breed equals the Hereford for withstanding the vicissitudes of the great ranges, where winter's cold and scarcity of feed frequently obtain. The thick coat of hair, robust constitution, and easy-keeping quality of the breed make it unusually suited to such conditions. For the restricted surroundings of the Eastern farm, where grazing is not so abundant, the Hereford is not so well suited. Yet in New England, and especialiy in Maine, Herefords have long been popular. The oxen of this breed have for many years met with favor on the hills 
of New England. While the Hereford is widely bred in the United States, it is most popular in Texas, Missouri, Iowa, Kansas, Illinois, Nebraska, South Dakota, Wyoming, Colorado, Oklahoma, Minnesota, New Mexico, Utah, Indiana, Kentucky, Tennessee, and Mississippi.

The promotion of Hereford cattle interests is well established in England and the United States. The "Hereford Herdbook"

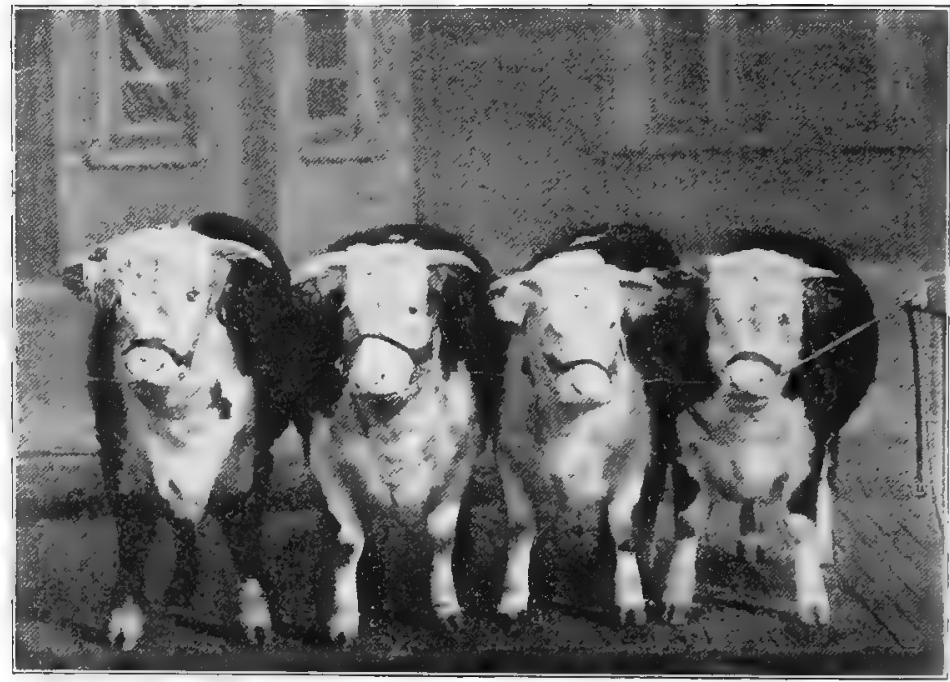

FIG. II3. Four calves sired by the Hereford bull Wyoming 505146. A fine example of breed character. From photograph by Hildebrand, through courtesy of W. N. W. Blayney, Denver, Colorado, owner of Wyoming

was first published in 1846 by T. C. Eyton, and in 1884 the Hereford Cattle Breeders' Association of England was organized and took over the publication of the herdbook, of which fifty volumes have been published up to I9 19. T. L. Miller of Illinois published in I 88 I the first "American Hereford Herdbook," and the same year the American Hereford Breeders' Association was organized. Up to January I, I9 I9, there had been published forty-eight volumes, showing a registration of 686,000 animals.

In Canada there is a Hereford Association, which up to 19r8 has published nine volumes, with registrations up to 28,800 head. 
In 1883 there were but 2500 Herefords of record in the United States, but on June II, I9I8, this number had increased to 711,485 . During the year 1918 there were recorded on the books of the American Hereford Breeders' Association 92,526 registrations and 76,0I 8 transfers, thus giving evidence of a very large amount of activity with the breed in America. At the end of six months, in I9I9, the American Association showed a total membership on its books of 10,000, as compared with 4305 stockholders at the end of I9IO. In addition to the American Hereford Cattle Breeders' Association, there are many local state and community associations for promoting the breed, nearly fifty being on record up to 1918 . An important medium for promoting the breed is the Amcrican Hereford Joumal, established in 1909, published semimonthly at Kansas City, Missouri.

\section{Polled Herefords}

The origin of Polled Herefords dates back only twenty-five years. Messrs. Mossom Boyd of Bobcaygeon, Ontario, Canada, J. L. Torrey of Embar, Wyoming, and W. W. Guthrie of Atchison, Kansas, independent of each other sought to develop strains of polled Hereford cattle. In 1898 the author saw an exhibit of eight head by Mr. Guthrie at the Trans-Mississippi Exposition at Omaha, of what he termed "Polled Kansans." These had been sired by a polled bull resulting from crossing a Hereford bull on a range-bred grade Shorthorn cow. These were rather plain cattle. Mr. Boyd attempted to produce polled Herefords by using Aberdeen-Angus bulls on pure-bred Hereford cows, and secured some polled animals wi h Hereford markings. C. T. Mercer of Iowa also bred some grade Polled Herefords, using a Red Polled bull on Hereford cows. The efforts of Mr. Guthrie, in particular, interested Warren Gammon of Iowa, who sent a circular letter to twenty-five hundred Hereford breeders, making inquiry for such polled cattle. As a result he located six polled bulls and ten cows. Of these he purchased the following: the bulls Giant IOI740, Tony II2173, Wilson I 26523, Variation I 52699, Wallace L. I27078, and Too Late, a nonbreeder; of cows, Lora I I5570, Blue Bell I06983, Duchess of Bedford 22d 
64437, Myrtie Taylor 5667 I, Olivia 98 I I 2, Charity 66888, and Beauty 95357 . This furnished the foundation stock of pure-bred polled Hereford blood from which this type was developed. Giant proved a valuable sire in the Gammon herd. Wilson was bought by $\mathrm{Mr}$. Cadwell of Illinois, and later this bull and Variation were used in the Boyd herd. Tony was first leased to Mr. Guthrie and later bought by him. The first calves in the Gammon herd from this polled foundation came in I 902 . Polled matings resulted in nearly

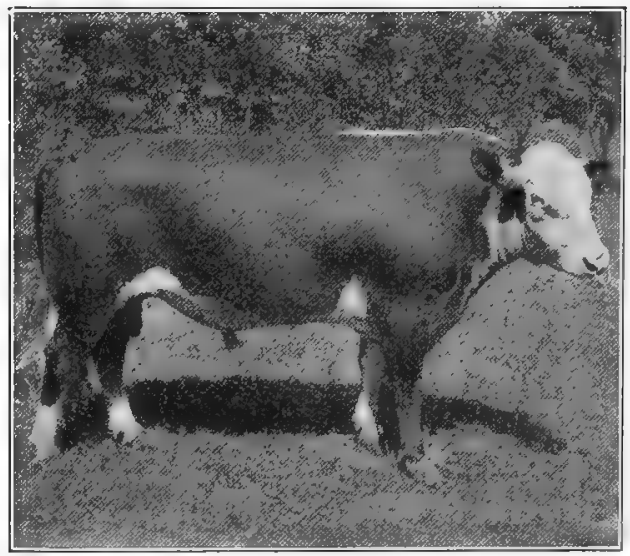

FIG. I 4. A Polled Hereford bull used in the herd of W. W. Guthrie, Atchison, Kansas. From photograph, by courtesy of Judge Guthrie, given the author in $\mathrm{I} 90 \mathrm{I}$
IOO per cent polled calves, while 50 to 75 per cent of calves sired by polled bulls and out of horned cows were polled. Among the leading early improvers and promoters, besides those mentioned above, are Benjamin Johnson of Indiana, George E. Ricker of Nebraska, Wyoming Experiment Station, Elijah Field and Son, T. W. Herron of Ohio, and $\mathrm{S}$. W. Anderson of West Virginia.

The type of Polled Hereford is essentially that of the horned Hereford but with a true polled head pointed at the top rather than broad and rounding over, such as obtains with cattle artificially dehorned. The early type of polled Hereford lacked in uniformity and did not possess the thick, low-set, blocky form so much admired in the best beef cattle of to-day. However, steady improvement has been made, so that to-day there are polled Herefords that compare favorably with the best of those with horns.

Two strains of Polled Herefords naturally resulted from the breeding above described - those from the use of impure blood, such as a pure-bred polled bull on a grade cow, and known as single standard; and those from pure-bred Hereford ancestry, as 
in the Gammon foundation stock, and known as double standard. As in the case of other breeds of similar ancestry, the doublestandard breeding steadily grew in favor, finally completely overshadowing the single-standard.

The promotion of Polled Hereford cattle through a breeding association first took place in I900, when the American Polled Hereford Cattle Club was organized at Des Moines, Iowa. Provision was made to register and transfer both single- and doublestandard cattle. In 1907 this club was reorganized, under the name of the American Polled Hereford Breeders' Association, and separate herdbooks were provided for single- and doublestandard bred cattle. At the time of reorganization the association had but five members, but this number had increased in 1918 to 988. In 1902 a National Polled Hereford Breeders' Association was organized in Kansas, but in rgi I a consolidation was effected

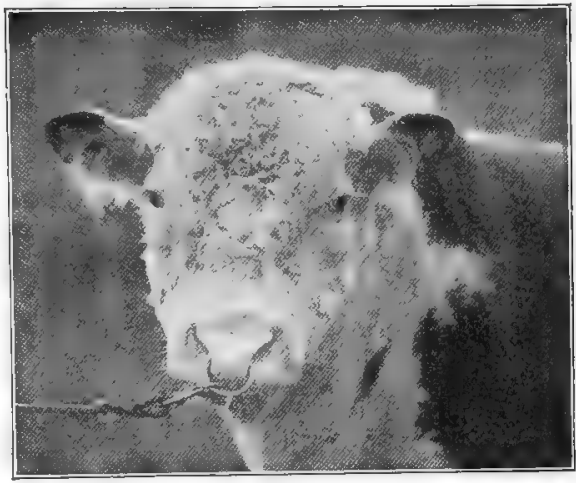

FIG. II 5. Head of Emperor 8874 (7637I5), a Polled Hereford bull in the herd of J. E. Green of Indiana. A fine type. between this and the American, continuing under the name of the latter. A herdbook is maintained by the association, and up to I9I 7 three volumes had been published containing I I, 200 registrations.

The distribution of Polled Herefords is widespread. During the period from I9OI to I9I 8 the number of these cattle has increased up to about 20,000 , distributed in forty-four states of the Union, with Iowa as the central point of importance. Early in I9I 8 there were 4300 Polled Hereford herds on record, and more than 1000 were established in 1918. In 1917 there were registered 2725 double-standard animals.

Prices paid for Polled Herefords have reached high levels. Prices from $\$ 500$ to $\$ 700$ ten years ago were regarded as satisfactory, but with the opening Mf I9I 8 the influence of higher 
values on all live stock was felt. In two sales held in Iowa early in February, 230 head averaged $\$ 630$. At the third annual sale of the American Polled Hereford Breeders' Association at Des Moines, in 1918, sixteen bulls averaged \$I4I9, and twenty-six cows $\$$ I I I 4.50, the general average being $\$$ I 230 . The top bull

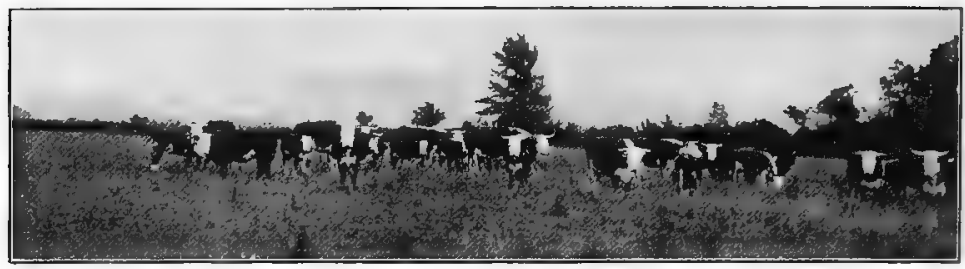

FIG. II6. A pasture view in Herefordshire. From photograph by the author

was Polled Repeater 2d I 0646, a grandson of Repeater 289598 on sire’s and dam's side bringing $\$ 4000$. Eight head passed the $\$ 2000$ mark. At the fourth sale of the association, in February, I9I9, fifty head averaged $\$$ I 63 . On March 28, I9I9, W. A. Wilkey \& Company, Sullivan, Indiana, bought at auction of the Renner Stock Farm of Indiana the seven-year-old bull Bullion 4 th (3062) 428446 for $\$ 9500$, the highest price to this date for a Polled Hereford. 


\section{CHAPTER XXVII}

\section{'THE ABERDEEN-ANGUS}

The native home of the Aberdeen-Angus breed of cattle is in northeastern Scotland, especially in the counties of Aberdeen, Kincardine, and Forfar. In southern Aberdeen, in the Buchan district, the breed was long known as "Buchan humlies," while in the section of Forfar known as Angus these cattle were called "Angus Doddies." The words "homyl," "humble," "humle," "doddie," and "dodded" are the Scotch terms for polled, or hornless. This section of Scotland is north of $56^{\circ}$ and lies about a thousand miles north of the latitude of Chicago. The climate is rather damp and cold much of the time. The land is hilly or mountainous in the main, part of it being better suited to grazing than anything else, though roots, barley, oats, and hay are quite extensively produced.

The origin of the Aberdeen-Angus is purely speculative. Among the wild white cattle of Britain were polled animals, and the Aberdeen-Angus may have descended from these. Some of the Scotch writers incline to the belief that this breed is a sport from a black breed with horns, which formerly existed in Scotland. Hornless cattle have been known in Scotland for long over a century. In an account book kept by a Mr. Graham record is made June 9, I 752 , of purchasing a two-year-old heifer "doded." The first printed reference to hornless cattle in Angus is dated I797 in the Old Statistical Account of the parish of Bendochy, where it is said of 1229 cattle in the parish "many of them are dodded, wanting horns."

Professor Wilson states ${ }^{1}$ that "early in the eighteenth century there sprang up in England a demand for hornless cattle which was responded to first in Galloway and considerably later in the northeastern counties. The result was that breeders elected to breed from hornless cattle; and hornlessness, which had hitherto

1 James Wilson, The Evolution of British Cattle, p. 53. London, Igog. 
been practically confined to the country near the coast, moved farther and farther inland. By Youatt's time (1834) the horned and the hornless cattle were almost numerically equal in the interior of the northeastern counties, while the hornless ones were still in the majority on the coast. A quarter of a century later the horns had been almost entirely removed from the inland black cattle."

About 1835 Youatt wrote "that there have always been polled cattle in Angus" and states that about I775 attention was first directed to them by enterprising farmers. Mr. William Forbes of Aberdeenshire, writing Macdonald and Sinclair over thirty years ago, mentions two sorts of polled cattle common in Buchan about the beginning of the last century. One of these was a rather small, puny type, thin-fleshed, such as the crofters (small-farm renters) kept; the other a larger kind, some black, some brindled, which more readily submitted to Shorthorn blood than did the former but lacked its power of reproduction of polled character.

The earliest improvers of Aberdeen-Angus cattle are of a comparatively recent period and are limited in number. Among those of greatest note were the following : in Forfarshire: William Watson, William Fullerton of Ardovie, Lord Southesk, and Alexander Bowie of Mains of Kelly; in Kincardine: Robert Walker of Portlethen Mains, Mr. Hector of Fernyflatt, Sir Thomas Burnett of The Leys, and Mr. McInroy of The Burn and Portlethen; in Aberdeenshire: William McCombie, Colonel Fraser of Castle Fraser, Mr. Walker of Ardhundcart, and Mr. Cooper of Hillbrae; in Banff: Sir John Macpherson Grant of Ballindalloch, Mr. Brown of Westertown, Mr. Walker of Montbletton, and Mr. Patterson of Mulben. Of the above improvers several were great constructive breeders and deserve special consideration.

Hugh Watson of Keillor, Meigle, Forfar, was the first really great Aberdeen-Angus improver - the Colling of this breed. He was born in 1789 , became a tenant at Keillor in I808, and remained there fifty-six years, dying in 1865 . His father and grandfather were lovers of good cattle, and when Hugh went to Keillor he took six cows and a bull, all black, with him. He also bought the same year, at Brechin, ten of the best heifers of various colors that he could find and a black bull named Tarnty Jock. Most writers assume that IVatson began his work of improvement 
on settling at Keillor, but his daughter states that this did not begin until about I 8 I 5 or I 816 , his ambition being aroused by at visit to the English Shorthorn country. Watson in-and-in bred and produced a more early-maturing, heavier-fleshed, blockier type that dressed out better than ever before. He also emphasized family lines and bred each family rather within itself. His bull Old Jock (I), calved in 1842 , a great-grandson of Tarnty

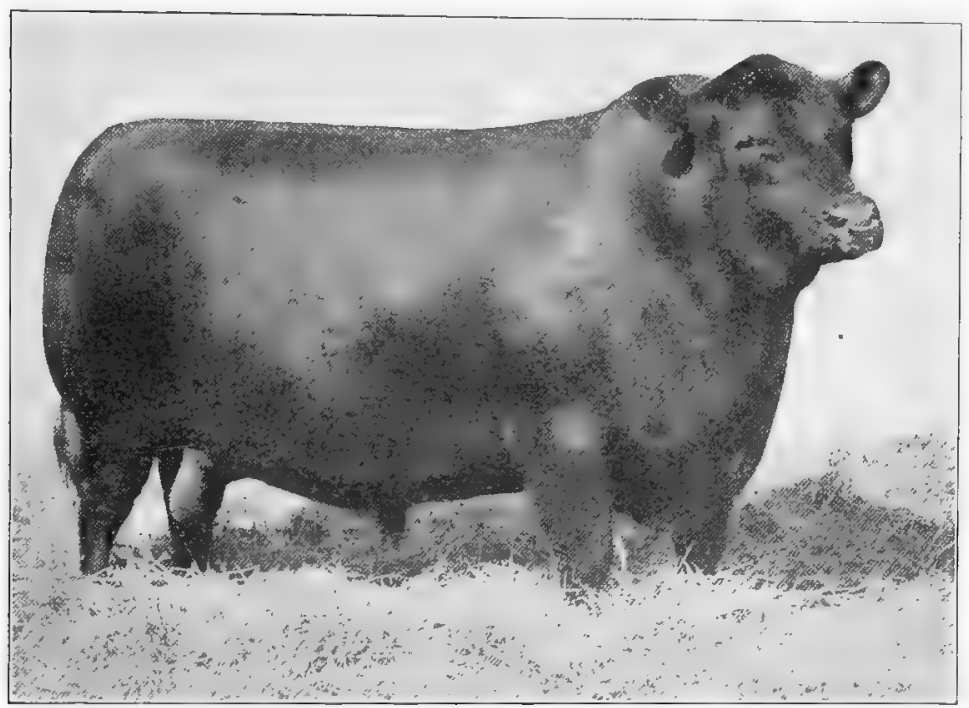

FIG. I 17. Blackcap Bertram I 83787 , a noted Aberdeen-Angus show bull and sire. Sold by C. D. and E. F. Caldwell, Burlington Junction, Missouri, for $\$ 45,000$ to L. B. McCanum, Aledo, Illinois. From photograph by IIildebrand, by courtesy of Caldwell and Caldwell

Jock, was his most valuable sire, possessing remarkable quality and constitution, and was a noted show animal. IVatson's most famous cow, Old Grannie (I), was one of the wonders of the bovine race. It is thought that this cow was among the original six bought by Watson, and that he secured her from a breeder in Kincardineshire. She lived to be thirty-six years old and had twenty-five calves, the last a bull of merit, named Hugh (I 30), being dropped in her twenty-ninth year. Referring to Watson as a breeder Mr. McCombie ${ }^{1}$ pays him the following high compliment:

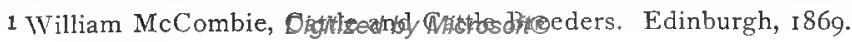


"We all look up to him as the first great improver, and no one will question his title to this distinction. There is no herd in the country which is not indebted to the Keillor blood." The first great show of black polled cattle was made in I829 at Perth, and all the animals but one were shown by Watson, who continued a most successful exhibitor at various Scotch shows until I 852 , when he discontinued exhibiting.

William McCombie was born at Tillyfour, Aberdeen, in I805 and died in $\mathbf{I} 880$, a few months before the dispersal of his herd. In 1830 he began a polled herd purchased from the best breeders of the time, consisting of "Aberdeens" from St. John's Wells and Wester Fintray, and "Angus" from Keillor, Balwyllo, Dalgairns, and elsewhere. He was a great believer in the importance of individual merit coupled with superior pedigree, and emphasized the value of the sire. At William Fullerton's sale he bought Queen Mother (348), from which he developed the famous Queen tribe. McCombie bred Pride of Aberdeen (58I), the founder of the Pride family and one of the most famous show cows of the breed. McCombie improved on the work of Watson and became his worthy successor. His success in the show ring was marvelous. He not only exhibited at the leading Scotch shows but also in France on four different occasions, always with eminent success. In I 878 his herd at the Paris International Exposition won the grand championship against all breeds and attracted international attention. Many regard McCombie as the most distinguished improver and promoter of the breed.

William Fullerton was born in I8IO, founded a herd at Ardovie in 1833, and died in I880. McDonald and Sinclair state $^{1}$ that when he secured possession of the home farm in I 833 there were three black cows on the place, and intending to establish a herd of "doddies" he went to Brechin market and made his first purchase, this being the cow Black Meg (766), later to become one of the famous animals of the breed. In I84I Mr. Fullerton bought the bull Panmure (5I) at Lord Panmure's sale, which he bred to a daughter of Black Meg known as Queen of Ardovie (29), from which union resulted Queen Mother (348), that was sold as a yearling to McCombie. The Ardovie herd was

${ }^{1}$ History of Aberdeen-Angus Cattle. London, Igro. 
destroyed by pleuro-pneumonia in I $849-1850$, but during his day Mr. Fullerton was regarded as a foremost constructive breeder.

Sir George Macpherson Grant of Ballindalloch, Banffshire, who died in 1907, was long a noted breeder. In I $869 \mathrm{Mr}$. McCombie wrote that "perhaps the Ballindalloch herd of polled cattle are the oldest in the North; they have been the talk of the country since my earliest recollection, and were then superior to all other stock." Since the time of McCombie this has been regarded as the premier herd of Scotland. Here some of the best bulls of the breed produced in the past forty years have been bred, including Juryman (42I), Ermine Bearer I749, Prince Inca. (7844), Bushranger (732), Justice 854, Judge 473 , Prince Ito (50006), Eltham (91 20), Bion 36986, Emulus 204 I 7, Eblito 50098, Eblamere $(2 \mathrm{I} 78 \mathrm{I})$, and Equestrian 34216 . The cows Erica I84, Jilt 422 , and Coquette 2538 are among the famous founders of families at

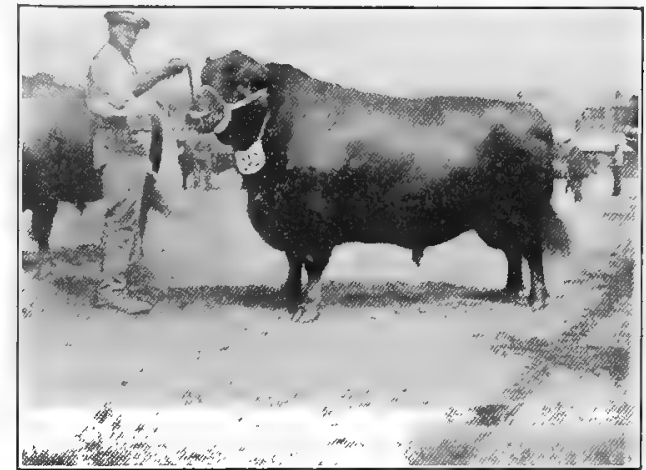

FIG. II8. Everard 2d of Haismore (31888), the most noted recent-day Aberdeen-Angus show bull in England. From photograph by the author in $19{ }^{4} 4$

Ballindalloch. On the death of Sir George Macpherson Grant his son Sir John succeeded him and is maintaining the herd.

The introduction of Aberdeen-Angus cattle to America was comparatively recent. In I873 George Grant of Victoria, Kansas, brought the first to America, the importation being three bulls, two of which were shown at the Kansas State Fair. These bulls were imported to use on Western-range cows. In 1876 the Ontario Agricultural College at Guelph brought to Canada two bulls and a cow. In I 878 Anderson \& Findlay of Lake Forest, lllinois, imported five cows and a bull, this being the first firm to exhibit prominently in the Central West. In $1879 \mathrm{~F}$. B. Redfield of Batavia, New York, and in I880 George Whitfield of Rougemont, Quebec, made importations. In I88I and I882 a 
number of importations were made, including a very superior lot by Gudgell \& Simpson of Missouri. In I $882 \mathrm{Mr}$. T. W. Harvey established at Turlington, Nebraska, in charge of William Watson (a son of the famous Hugh), a herd of Aberdeen-Angus that for ten years, until its dispersion, was a wonderful factor in advertising the breed, containing as it did some of the most noted cattle of the time. Between I 880 and I 883 inclusive it is estimated that about two thousand Aberdeen-Angus cattle were imported to the United States and Canada.

Characteristics of the Aberdeen-Angus cattle. In general conformation this breed differs somewhat from the Shorthorn and Hereford. On this especial subject a leading Scotch authority makes an interesting comparison of this breed and the Shorthorn, ${ }^{1}$ which is well worth presenting here:

In general form a model polled animal differs considerably from a model Shorthorn. Both should be lengthy, deep, wide, even, proportionate, and cylindrical. The polled animal, however, should be more truly cylindrical in the body than the Shorthorn. Its points should be more quickly rounded off; or, in other words, the frame of the polled animal is not so fully drawn out to the square as that of the Shorthorn. Critics pointed out in some of the best polled animals of about half a century ago a tendency to approach too nearly to the square type of the Shorthorn. In a beef producing animal a broad, square frame can hardly be said to be a blemish; for if it is thoroughly well covered all over, it will carry more beef than a rounder frame. A compact, well rounded frame has always been a leading characteristic of the polled breed, and the main reason why a square Shorthorn-looking frame is objected to in a polled animal is that such a form is foreign to the breed.

The head tapers at the poll and is somewhat prominent in the forehead, while the distance between the prominent eyes is considerable and the length of nose only medium. The head as a whole impresses one as belonging to a good feeder type, showing a strong, full muzzle and nostril. The neck is usually smoothly attached to head and shoulder, showing excellent finish, but the shoulder sometimes tends to be a bit prominent instead of nicely laid. The back tends to sag some behind the withers, although with the best specimens this weakness is not manifest. The ribs, as already indicated, show a rounded rather than square turn, and

1 James Macdonald and James Sinclair, History of Aberdeen-Angus Cattle, p. 4 I8. London, igio. 
the body has a great relative depth with corresponding shortness of leg. The hips of the Aberdeen-Angus are usually neatly covered and well laid in. The mimp frequently slopes considerably to each side of the tail head, which may set level or be a bit high, but is usually long and heavily fleshed. The thigh and treist carry as great a relative proportion of meat to bone as any breed of beef cattle, though it often lacks the squareness of the Shorthorn at the back thigh, being rounder in outline and very deep

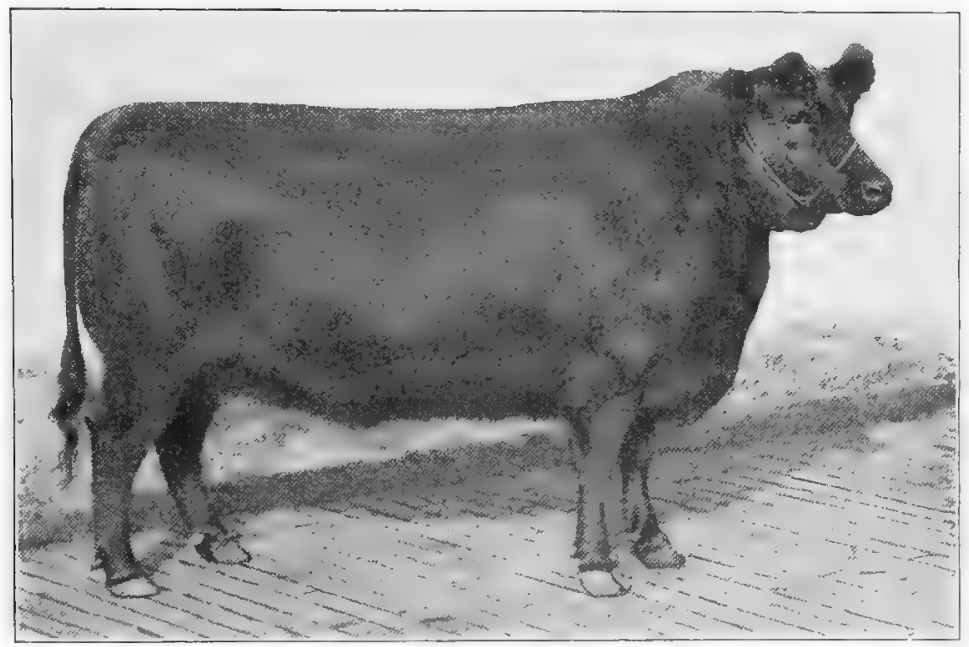

FIG. II9. Eritus $5^{\text {th }} 245516$, by Blackcap Bertram 183787 , first-prize junior yearling and reserve-champion Aberdeen-Angus female at the 1918 International LiveStock Exposition. Photograph by Hildebrand, by courtesy of the owners of the cow, C. I). and E. F. Caldwell, Burlington Junction, Missouri

in the twist. The leg is usually short and fine in quality of bone and joint. In quality this breed is of the first rank, as shown by the mellow, elastic, medium thick skin, the fine coat of hair, and moderate joints and small bone. Compared with the Galloway the Aberdeen-Angus has a smoother, shorter coat of hair and generally a shorter, blockier type of body, with more spring and depth of rib. The temperament, in general, is more nervous than that of the Shorthorn.

The color of Aberdeen-Angus cattle is almost universally black, though red occurs at rare intervals. In the early days of the 
breed the colors were variable - brindle, brown, striped, and red being common. A century or more ago, according to Professor Wilson, ${ }^{1}$ there were colors and markings among them not now seen at all, such as dun, yellow, "silver-colored yellow" as given by Youatt, and white stripes along the back and belly. Thirty years ago a red calf, a calf with white face markings or with white flecks on the body, was not uncommon. At the present time, however, pure reds are occasionally seen, and white about the rear of the underline is rather common, but the process of selection and improvement has fixed more and more firmly the uniform solid black color now so characteristic of the breed. The subject of color is given official recognition by the American Aberdeen-Angus Breeders' Association, for under the rules "males red in color, or with a noticeable amount of pure white above the underline, or on leg or legs, or with scurs, shall not be eligible to entry for breeding purposes." A black cod is preferred in the bull, but white udders with cows, with some white between navel and udder on females, are not objectionable. Red cows may be registered, however, and also black ones with small white spots on head, body, or legs.

The weight of Aberdeen-Angus cattle compares favorably with the Shorthorn and Hereford, although as a rule they are not quite so heavy. In I9I $2 \mathrm{~B}$. O. Cowan gave some interesting comparisons of Aberdeen-Angus and Shorthorn weights as taken at the American Royal at Kansas City and at the International at Chicago. ${ }^{2}$ At the former show, in but one of twenty-four classes did the average weight of the Aberdeen-Angus entries equal that of the Shorthorns. In senior yearling bulls the Aberdeen-Angus average was 1473 pounds and the Shorthorn 1467 , while 29 threeyear-old Aberdeen-Angus bulls averaged 1970 pounds and 4I Shorthorns 2224; 27 two-year-old Aberdeen-Angus bulls averaged I787 pounds, 40 Shorthorns, 19I7; 54 Aberdeen-Angus cows averaged I 505 pounds, 4I Shorthorns I730; 63 two-yearold Aberdeen-Angus cows averaged I 4 I I pounds, 46 Shorthorns 1530, with a corresponding advantage in favor of Shorthorns in every class but one. At the International in I9Io a similar

1 The Evolution of British Cattle, Igog.

2 Breeders' Gazette, October 9, 1912, p. 722. 
situation prevailed, the Aberdeen-Angus outweighing the Shorthorn in but one class, that of senior yearling bull, the respective weights being $I 575$ and 1574 pounds. Ten aged Aberdeen-Angus bulls averaged 2064 pounds, and II aged Shorthorns 228I; 9 twoyear-old Aberdeen-Angus bulls averaged 1867 pounds, and I2 Shorthorns I980; I 3 aged Aberdeen-Angus cows averaged I64I pounds, and Io Shorthorns I 876 ; 14 two-year-old Aberdeen-Angus heifers averaged I 425 pounds and I4 Shorthorns I 59 I. However,

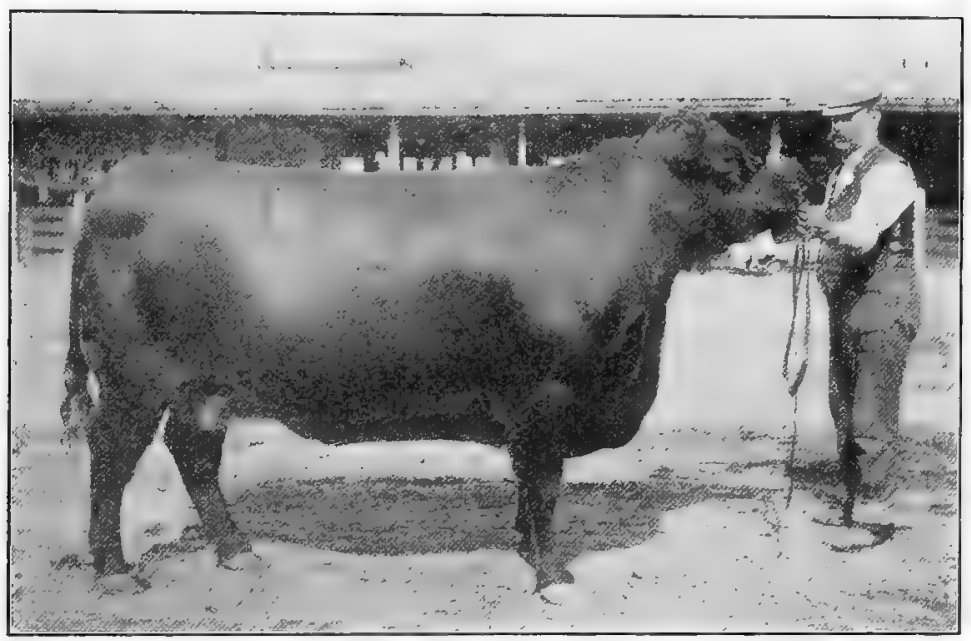

FIG. I20. Lady of Meadowbrook 21466 , by Zaire 5th 13067 . A noted AberdeenAngus show cow, winning the highest awards in 1898 , I899, and I 900 at the leading fairs. Owned by D. Bradfute \& Son, Xenia, Ohio. From photograph, by courtesy of the National Stockman and Farmer

some very large specimens of the breed are recorded. The bull Judge is said to have weighed 2800 pounds, and his brother Justice in full flesh exceeded 3000. Probably no breed weighs heavier for its size than this.

The maturing qualities of Aberdeen-Angus cattle rank high, and in this respect they are fairly comparable with the Shorthorn and Hereford. Years ago the maturing qualities were not of the best, but any deficiency in that respect has been overcome. Macdonald and Sinclair state that when well fed from their birth good specimens of the breed become ripe at the age of from 
twenty-four to twenty-eight months. In the American markets feeders showing marked Aberdeen-Angus blood rank well.

The prolificacy of the Aberdeen-Angus has been testified to by the adherents of the breed since the earliest days of its improvement. Old Grannie has often been cited in this regard on account of producing 25 calves during thirty-six years of life. Black Meg $(766)$, already referred to, was a breeder up to her twentieth year. Zarilda $2 \mathrm{~d}$ in the Heatherton herd of J. S. Goodwin had 19 calves, none being twins, and died as she approached her twenty-fifth year. Lintie of Balvenie (6933) was calved in I 883 and dropped I7 calves during twenty years. Pride of Aberdeen 7th (I777), Erica (843), Elba (7045), Bride (I 3343), Waterside Alexandra (7948), and Gay Lass $2 \mathrm{~d}$ (4723) are on record as being consistent breeders up to eighteen or twenty years of age. Seventy-six Aberdeen-Angus cows are recorded as having had I 2 or more calves each, and 26 bulls are said to have sired over Ioo calves each, His Highness 6th having sired 189 . Prolificacy may fairly be regarded as one of the valuable and notable characteristics of this breed.

The Aberdeen-Angus as a milk producer without doubt inherits distinct merit from the old Buchan polled cattle. In I805 it is said that the total dairy products of Aberdeenshire amounted to $\$$ I, I 50,000, most of which came from the Buchan district. G. J. Walker of Portlethen, Scotland, is credited with an average yield of 7866 pounds of milk from a herd of twelve. The Earl of Airlie, Cortachy Castle, has emphasized milk production in his herd, and according to Macdonald and Sinclair he owned seventeen Aberdeen-Angus cows, the greater number of which gave from I 2 to 14 and sometimes I 6 Scotch pints ( I pint weighing $2 \frac{1}{2}$ pounds) for a considerable time after calving. There are many published examples of the milking capacity of this breed, which places the Aberdeen-Angus in much the same class as the Shorthorn in this respect. The quality of the milk is above the average. This is shown in a herd of pure-breds and grades kept at one time by J. H. Moore of Illinois, who sold the milk to a condensed-milk factory, where the fat content of the herd averaged from 4 to 4.50 per cent for the entire season, with November tests averaging as high as 5.32 per cent. 
The Aberdeen-Angus as a producer of beef occupies a position of the highest rank, for almost since the day of Hugh Watson the breed has been distinguished for this quality. In I 829 Watson showed a pair of oxen that attracted much notice, one of which was slaughtered, and its carcass said to be of rare quality. McCombie showed a steer, Black Prince, in 1867 which at four years of age won the highest honors at Birmingham and Smithfield. This steer was sent to Windsor for inspection by Queen

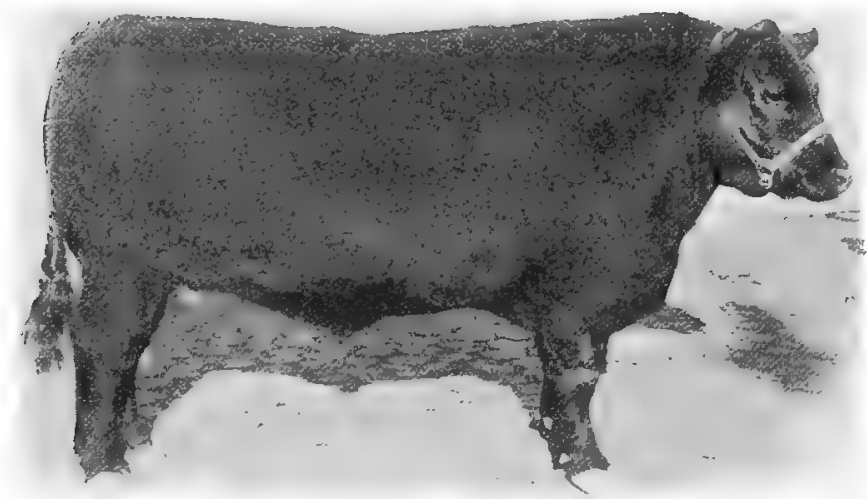

FIG. I2 I. Clear Lake Jute 2d, a pure-bred Aberdeen-Angus steer, grand champion at the International Live-Stock Exposition, Chicago, 1904. Fed and shown by the University of Minnesota School of Agriculture. From photograph by courtesy of the lational Stockman and Farmer

Victoria, at her request, so great was his fame, and later he sold for $\$ 600$ for slaughter. For years either pure-bred or grade Aberdeen-Angus steers have held the highest places of honor at the leading English fat-stock shows, at the Chicago and Kansas City fat-stock shows, and at the International Live-Stock Exposition. The following are some of the more important prizes won by Aberdeen-Angus pure-bred or grade steers in American show rings. The first pure steer of the breed shown was Black Prince, weighing 2300 pounds as a three-year-old, imported by Geary Brothers of Canada in I 883 and exhibited that year at the Kansas 
City and American fat-stock shows. He was not made grand champion, but at Chicago was awarded sweepstakes as the best threeyear-old beast passed on by butchers. In 1885 the steer Sandy, shown by Gudgell \& Simpson, won the yearling championship of the Kansas City and Chicago shows and also the medal offered by the Polled Cattle Society of Scotland. In I 886 Sandy was champion steer of the Kansas City show, winning numerous prizes for being the best steer shown. At nine hundred and thirty-nine days he weighed I 885 pounds. In I 887 , at the same show, Black Prince of Turlington, a famous bullock exhibited by T. W. Harvey, won the sweepstakes over the steer Dot shown by Messrs. Estill of Missouri, though the next year, at the American Fat-Stock Show at Chicago, Dot was grand champion over all breeds. For some years thereafter the exhibit of Angus steers did not attract much attention, the cattle market being very quiet. The International Live-Stock Exposition at Chicago, with its first show in I900, established a new arena for beef competition. From that year up to I9I9 inclusive, excepting I9 I 4 and I9I5, the leading fat-stock show on the American continent has been held under its supervision. It is interesting to note that at the eighteen International shows held up to the year I9I9 inclusive, the grandchampion steer in eleven contests was an Aberdeen-Angus.

\begin{tabular}{|c|c|c|c|c|}
\hline Name of SteER & & OWNER & $\begin{array}{c}\text { YEAR } \\
\text { CHA UPION } \\
\end{array}$ & $\begin{array}{l}\text { PRICE SOLI } \\
\text { PER POUND }\end{array}$ \\
\hline Advance & & B. R. Pierce, Illinois & 1900 & $\$ 1.50$ \\
\hline Shamrock (grade) & & Iowa State College & I902 & $0.5^{6}$ \\
\hline Clear Lake Jute 2 d. & & University of Minnesota & I9O4 & 0.36 \\
\hline Black Rock (grade) & & Iowa State College & 1905 & 0.25 \\
\hline Fyvie Knight . & & Purdue University & 1908 & $0.26 \frac{1}{2}$ \\
\hline King Ellsworth & & Kansas State Agricul. College & 1909 & 0.18 \\
\hline Shamrock 2d (grade) & & Iowa State College & igro & 0.60 \\
\hline Victor . . & & Iowa State College & I9I I & 0.90 \\
\hline Glencarnock Victor & & J. D. McGregor, Canada & 1912 & 0.50 \\
\hline Glencarnock Victor 2d & & J. D. McGregor, Canada & 1913 & (Not sold) \\
\hline Fyvie Knight 2d . & & Purdue University & 1918 & 2.50 \\
\hline
\end{tabular}

In the grand-champion contest in carload lots held at the International during the past eighteen years, fourteen times this award has gone to the Aberdeen-Angus. E. P. Hall of Illinois won the carload championship in 1910, 1912, I916, and 1917, the 
load for the last year bringing $\$ 42.50$ per hundred at auction, the highest price up to that time ever paid for a fat carload. Claus Krambeck of Iowa won the championship in 1904, 1905, and 1907; Funk Brothers of Illinois in 1906 and $1908 ; \mathrm{L} . \mathrm{H}$. Kerrick of Illinois in 1900; Charles Escher of Iowa in 1902; and Escher and Ryan of Iowa in I9II and 19I3. The carcass contest on single steers at the International, excepting in 1900,

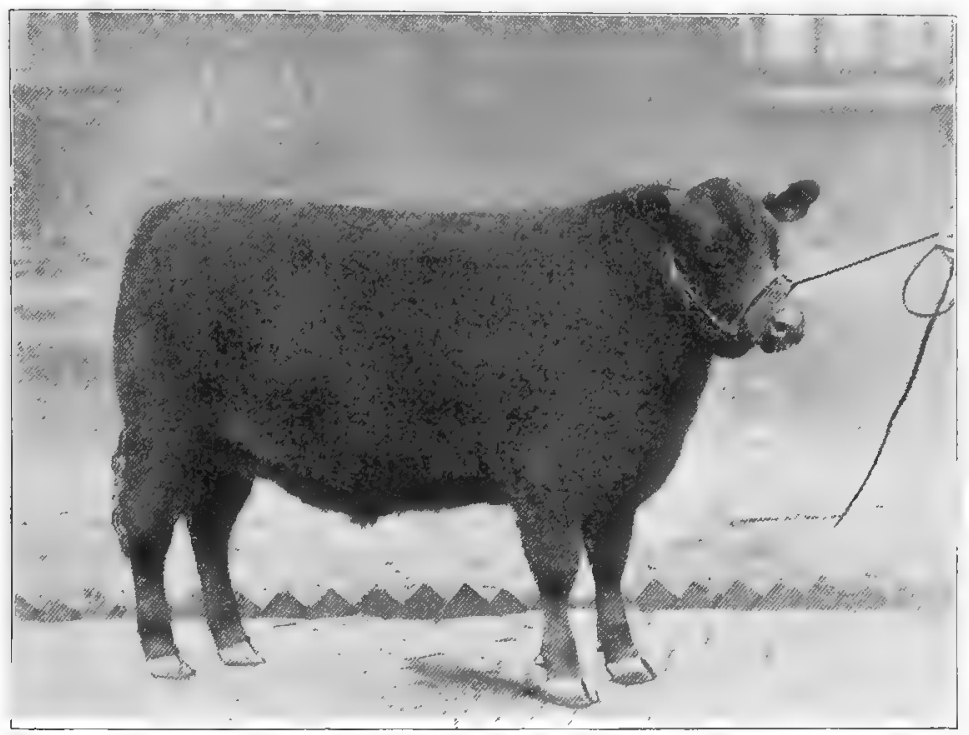

FIG. I22. Fyvie Knight 2d, pure-bred Aberdeen-Angus steer, grand champion over all breeds, grades, and crosses at the 1918 International Live-Stock Exposition. Bred and exhibited by Purdue University, La Fayette, Indiana. From photograph by Hildebrand, by courtesy of Professor J. H. Skinner

has been won each year by a pure-bred or grade Aberdeen-Angus. Five state agricultural colleges - Iowa, Michigan, Minnesota, Nebraska, and Ohio - have fed Aberdeen-Angus steers whose carcasses were awarded the grand championship. At Smithfield, in London, where the great British show of beef stock is held, the Aberdeen-Angus has done hardly as well as at Chicago, but between 1900 and 1917 grand championship on fat steer or heifer has ten times gone to this breed. Certain factors have affected the awarding of premier place to the Aberdeen-Angus. The animal 
dresses out a high per cent of carcass to offal, the meat is fine of grain or texture, the fat is distributed throughout the lean so as to show most desirable marbling, the color is usually a bright red, while the quality is unsurpassed. Without question the American butcher in a discriminating market pays the top price for AberdeenAngus cattle. Well fattened, a two-year-old steer of the breed may be expected to dress out 65 per cent carcass to offal, or better.

The crossbred or grade Aberdeen-Angus bullock has long been regarded with especial favor by feeders and butchers. Robert Bruce, a well-known British authority, in commenting ${ }^{1}$ on crossing the Aberdeen-Angus and Shorthorn, states that this cross is highly valued by northern breeders, and the large number of farmers in England and Ireland who have resorted to this cross proves pretty clearly the general appreciation of the many good qualities belonging to the blend. Where ordinary judgment is exercised in the selection of sires and dams, the excellence of the produce is at once assured, as the blending of the Shorthorn and Aberdeen-Angus blood results not only in a superior butchers' animal but also in a quick-feeding and rent-paying one. A glance at the records of the great fat-stock shows at once indicates the important position taken by these Shorthorn-AberdeenAngus crosses in the annual prize-award lists. There has been a widespread demand for Aberdeen-Angus bulls for crossing purposes all over the north of Scotland, and this system of crossing has also made its way into other portions of the kingdom. In my opinion it is immaterial how the cross is brought in whether through the Shorthorn sire on the Polled cow or the Polled bull and the Shorthorn cow. Circumstances and situation may alone be left to guide the breeder in the selection of the sire to use. A mating of Aberdeen-Angus to white Shorthorn produces a blue-gray animal that for many years has been a prime favorite on the British market. In America such crossbreds are not so common. At the Smithfield Fat-Stock Show in England, from I900 to 1916 inclusive, in the competition among crossbreds, the several combinations of Aberdeen-Angus and Shorthorn blood virtually won all championships and reserve championships. On the Western range the Aberdeen-Angus has

1 Macdonald and Sinclair, History of Aberdeen-Angus Cattle. 
not secured so strong a foothold as the Hereford, but his grade progeny is thick-fleshed, short of leg, fast-maturing, a good feeder, and kills the equal of anything in the market. It will be fortunate for our beef-cattle interests when more Aberdeen-Angus males are used to grade up common herds.

Aberdeen-Angus families make up a considerable list. Each family is descended from a cow that is regarded as its founder. Branches occur in these families, due to lines of breeding often undertaken in other herds than that from which the family came. An effort has been made by prominent breeders to discourage emphasizing certain families at the expense of others, but with none too much success. The following families have been regarded with special favor, especially in America.

The Erica family descends from Erica (843) I8 I, a cow that was bought in I86I by Sir George Macpherson Grant at the Earl of Southesk's sale. She was by Cupbearer (59), a grandson of Old Jock (I), and her dam Emily (332) was also by Old Jock (I). Emily was out of Beauty, bred by Hugh Watson. Erica (843) is described as "not a very large cow, but standing on very short legs and having a lovely feminine head and splendid quality." She was the dam of three sons: Cupbearer of Ballindalloch (658), Exciseman (473), and Elcho (595); and of four daughters: Erica $2 \mathrm{~d}$ (1284) by Chieftain (318), Eisa (977) by Trojan (402), Enchantress (98I) by Trojan (402), and Elba (1 205 ) by Kildonan (405). From these four cows this family and its branches trace the most notable line developed at Ballindalloch, possibly the most popular among Aberdeen-Angus breeders. Three branches of Ericas descended from these four daughters are known respectively as Chieftain-Ericas, Trojan-Ericas, and Kildonan-Ericas. In I910 Macdonald and Sinclair wrote: "No family of polled cattle has in recent years taken a more distinguished position in the show yard than the Ballindalloch Ericas. Since I 870 they have not been absent from the prize lists of the Highland Society's shows excepting on two occasions." Young Viscount $\mathrm{r} 8 \mathrm{I}$, perhaps the greatest bull of the breed, was a grandson of Erica $2 d$ through her daughter Erica 3d (I 249).

The Queen Mother family derives its name from Queen Mother (348) 4I, the founder of this line. She was calved in I843, 
and as a yearling came into possession of Mr. McCombie, who bought her from Mr. Fullerton of Ardovie. She was sired by Panmure (5I), the great early sire of the breed, and through her dam, Queen of Ardovie (29), was a granddaughter of Black Meg (766). Albert Pullen ${ }^{1}$ regards the Queen Mother as a tribe and credits it with nine families or branches, namely: Pride of Aberdeen, Empress of France (or Dandy of Drumin), Daisy (or Vine of Tillyfour), Rosie of Tillyfour, Duchess of Westertown, Matilda of Yonderton, Charmer, Beauty of Morlich, and Victoria of Kelly. Americans, however, do not make this distinction, and Queen Mother and Pride of Aberdeen may each be regarded as families. In McCombie's hands at Tillyfour the Queen Mother or Queen family became famous. Queen Mother had four daughters: Bloomer (2OI), Windsor (202), Lola Montes (208), and Victoria of Kelly (345). A daughter of Lola Montes named Charlotte (203) was an exceptional cow, for her daughter Pride of Aberdeen (58I) and her son Trojan (402) proved to be two of the epochmaking animals of the breed. This was the favorite family of Mr. McCombie, and it has always been very popular in America.

The Pride or Pride of Aberdeen family derives its name from Pride of Aberdeen (581), above referred to, calved in 1857 . She was sired by Hanton (228), a leading stock and show bull of Mr. McCombie. At the Paris Exposition in I $856 \mathrm{Hanton}$ and Charlotte won premier honors for the breed, so that Pride of Aberdeen rightly inherited great excellence. She had a remarkable record in the show ring, "without parallel in the chronicles of the breed." She was the mother of seven females and four bulls, and from her offspring, especially the cows, descends a great line of producers. Her five daughters, Pride of Aberdeen 2d (I 299), Pride of Aberdeen 3d (I I68), Pride of Aberdeen 4th (I I7I), Pride of Aberdeen 5th (I I 74), and Pride of Aberdeen 7th (I777), are the dams of many celebrated breeding and prizewinning animals. Prince Ito (I 2869) 50006, bred at Ballindalloch and one of the greatest sires ever imported to America, was a great-grandson of Pride of Aberdeen 5th (I I 74).

The Blackbird family is descended from imported Blackbird of Corskie 684, a daughter of Lady Ida (IO2 I). In fact, in Scotland

${ }^{1}$ Aberdeen-Angus Cattle. London, 1908. 
this is known as the Lady Ida family. This latter cow is said to have lived nineteen years and dropped fifteen calves, nearly all of whom were prize winners. Her daughter Blackbird of Corskie was the dam of Blackbird of Corskie 2d (3024), Blackbird of Corskie 3d (3766), and Blackbird of Corskie 4th (3769). This last cow was imported to America, where she made a remarkable breeding record. Bred to Abbotsford 2702, one of the more noted

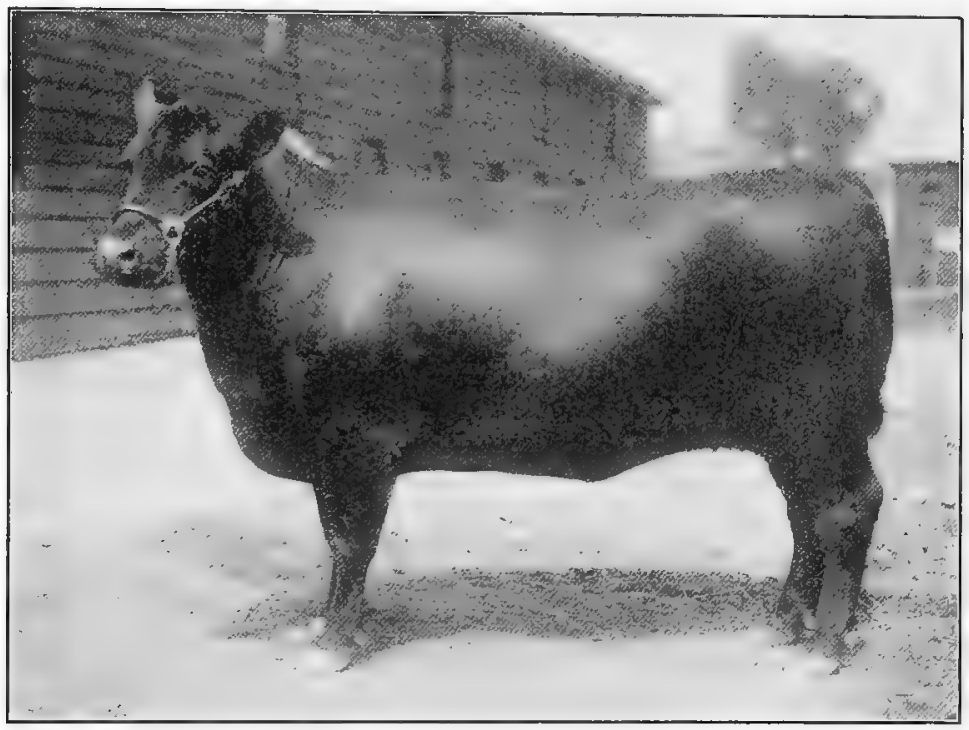

Jig. I23. Blackbird 26th 54457, by Black Monarch of Emerson 30331. Grandchampion Aberdeen-Angus female at the Louisiana Purchase Exposition, I904.

Owned by W. J. Martin, Churdan, Iowa. From photograph by the author

sires in service in America, she produced Black Abbot 10423, Black Monk I 32 I4, and Blackbird Knight I I547, all sires of special merit. The Blackbird family in recent years has had a great popularity in America, and many herds are strongly impregnated with this blood. Black Woodlawn 42088, one of the most noted American-bred Aberdeen-Angus sires, out of Blackbird I 3 th 24464, is a straight-line-bred Blackbird. Gay Blackbird 14443 , champion in 1893 at the World's Columbian Exposition and a great sire, traced back in each branch to Blackbird of Corskie. In spite of its popularity som 
The Blackcap family is an offshoot from the Blackbird, tracing from Blackcap I 552, a daughter of Blackcap of Corskie 3d 733, and sired by the bull St. Clair 693. Black Knight $475 \mathrm{I}$, perhaps the greatest sire in the history of the breed in America, was a son of Blackcap I 552. The Blackcaps are great favorites, and their blood lines have mingled more or less with the Blackbirds. Blackcap Poe $2 \mathrm{~d} 236212$, sold in 1918 .for $\$ 9200$, was sired by Bruce Ito I 87621 , a Blackbird, and had for dam the Blackcap cow Birdie Blackcap 82r29, that was the dam of Black Poe 150727 and that sold for $\$ 5000$.

The Heather Bloom or Heather Blossom family descends from the cow Heather Bloom (I I 89). She had two daughters, Heather Blossom (I7O3) and Blooming Heather (1484), both of which were prize winners as well as most successful breeders. Two granddaughters of the latter, Benton Heather (7775) and Bonnie Heather $(7776)$, were imported by $T$. IV. Harvey for his Turington herd in Nebraska, where this family first attracted attention in America. This is not listed by Macdonald and Sinclair as one of the leading families in Scotland, but in the United States it has contributed a very meritorious class of cattle.

The Nosegay family originated at Ballindalloch, having for its founder the cow Nettle 5167, her daughter Nosegay 225I, by King Charles 424, giving the family name. This is regarded as an especially good milking family.

The Coquette family is of Ballindalloch breeding, descending from Coquette (I 4I 7 ) and credited with an excellent class of progeny. The bull Ermine Bearer I 749, bred to Coquette Ioth 2703, sired Abbotsford 2702, a sire that did much for the breed in America.

The Jilt family has its origin in Jilt (973), calved in I 863 at Tillyfour. She came to Ballindalloch in 1867 , where she was a very successful producer. Three sons, Juryman (404) 421 , Judge (I I 5O) 473, and Justice (I462) 854, were Highland Society Show prize winners. The two latter were imported to America by Judge J. S. Goodwin for his Heatherton herd, but each had a short career in this country. Jilt had five daughters, from which this family derives its special reputation. These were Jewel (I4 I 3), Jewess (I9I6), Judy (2996), Joanna (I 3709), and Juno of Ballindalloch (3374). This is an excellent family, and though not largely 
represented on either side of the water, as stated by Mr. Pullen, "it has gained distinction chiefly by the production of good stock and prize winning bulls, and as this is not too common an attribute, it would appear to be a family worthy of preservation."

The prices brought by Aberdeen-Angus cattle have not ranged as high as those brought by Shorthorn or Hereford, but have made a very good showing. Figures compiled by the Kansas Board of Agriculture of sales from 1892 to I9OI inclusive, including 3269 head, give an average price realized per head of $\$ 2$ I 3.24, the bulls averaging \$190.09 and the cows $\$ 232.07$. A report based on figures published by the American AberdeenAngus Breeders' Association, covering I 3 I public auction sales between 1910 and 1916 , shows that 7160 cattle of the breed averaged $\$ 182.83$. It is interesting to note that beginning in I9I 2 with an average price of

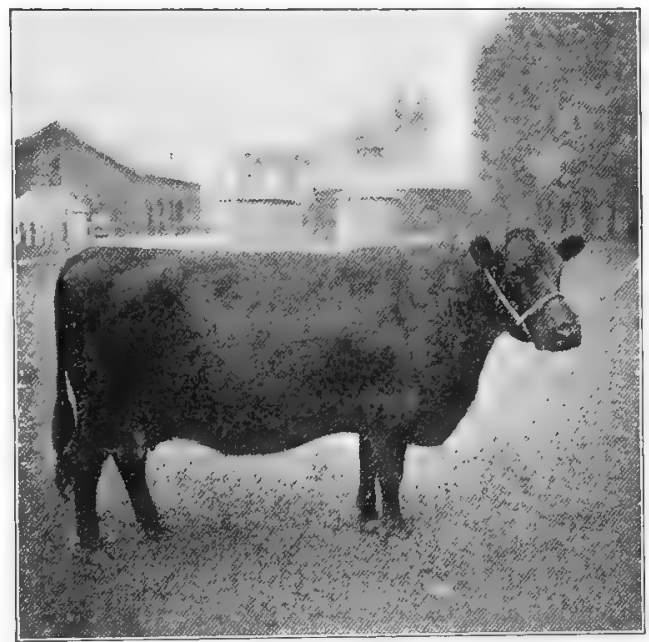

FIG. I24. Rose of Highland County, d fine type of Aberdeen-Angus cow in field condition. Owned by the Ohio State L'niversity. From photograph by E. K. Emslie $\$$ I 38.95, the average has steadily grown, until in I9I6 it was $\$ 248.75$. The records for 1917 and I9I 8 are still better. The highest prices of interest are as follows: Prince Ito 50006, by Eltham (9120), sold by M. A. Judy, February 4, I902, at Chicago, to B. R. Pierce \& Son for \$9I00. In June, I9I8, at Escher and Ryan's sale in Iowa the bull Blackcap Poe sold for $\$ 9200$ to A. D. Wilcox of Kansas. In this sale I 26 head brought $\$ 150,205$, the record for the breed to this time, I 3 bulls averaging \$I IO4 and I I 3 females $\$$ I 202. Six cows brought $\$ 3000$ or more each, Erica McHenry 43d bring 
Prince Ito brought $\$ 9100$, the cow Blackcap Judy 40226 , by Black Monarch of Emerson 30331, was purchased by C. H. Gardner of Illinois for $\$ 6300$, for years the top price for a cow of the breed. At the sale of P. J. Donahue of Iowa in May, I9I8, the cow Blackcap McHenry I 28 th 1838 I 5 sold for $\$ 5025$, and the bull Emlyn 235644 brought \$5100. Again, on May 23, I919, Mr. Donahue sold 47 head for \$121,425, an average of $\$ 2583$. On this occasion Blackcap Lassie 16th brought $\$ 7200$ and Eiba of Glynn Mawr 4th, $\$ 6800$. On June 3 and 4, I9I9, Escher and Ryan sold I7I head for an average price of $\$ 2200$. The highest price for a bull was $\$ 36,000$ for Enlate 209747 , sold to W. H. Cooper. The cow Blackcap McHenry I 5 rst 229186 sold to C. A. Rosenfeld for $\$ 10,000$. In the summer of I9I9 C. D. and E. F. Caldwell, Burlington Junction, Missouri, sold the bull Blackcap Bertram I83987 to L. B. McCanum, Aledo, Illinois, for $\$ 45,000$, this representing the highest price paid to date for an animal of this breed. In May, I9I8, at a sale of Tudor and Son of Iowa, 54 head brought an average price of $\$ 1207$ and 28 females ranged in price from $\$ 1000$ up. At the annual sales in Scotland, February 4 and 5, 1919, all records for the breed were broken, and 280 bulls averaged $\$ 560$ each, 3 passing the $\$ 10,000$ mark. The bull calf Euripus of Ballindalloch and the yearling Emblem of Harviestoun each brought $\$ 14,700$, and the calf Erodemas $\$ I I, 025$. At sales held in fifteen states and Canada, in I 1918 , the average price for 4102 head was $\$ 385.58$. The average of 82 sales ranged from $\$$ I I 10.08 to $\$$ I 519.23 .

The prices paid for Aberdeen-Angus steers represent the very top of the market so far as carload lots are concerned. The prices paid for single steers - excepting the champions at the 1916, 1917, and I9I8 International Expositions - are led over all breeds, grades, and crosses by the sale of the grand champion Advance at the I 900 International, which brought $\$$ I. 50 per pound live weight. He weighed I430 pounds, bringing \$2I45. At the I9I6 International the grand-champion carload of AberdeenAngus shown by E. P. Hall of Illinois brought $\$ 28$ per hundred at auction, while in 1918 the grand-champion load of the same breed by the same exhibitor brought $\$ 42.50$ per hundred. The average price paid per hundred on 378 carloads of fat Aberdeen-Angus 
cattle in the fifteen years between 1900 and I916 was $\$ 9.34$ as compared with $\$ 8.38$ paid on 357 loads of Herefords and $\$ 8.73$ on I98 loads of Shorthorns.

The distribution of Aberdeen-Angus cattle is very widespread. They are generaily found in northern Scotland, in various parts of England, Ireland, France, Denmark, Germany, South Africa, South America, New Zealand, Sandwich Islands, Canada, and the United States. In I9I7 the Polled Cattle Society of Scotland issued 395 certificates of export to foreign countries as follows: South Africa I95, Falkland Islands I40, Brazil 22, other parts of South America 36, United States 2. In the United States the breed is most popular in Iowa, Missouri, Illinois, and Indiana, but herds are widely distributed throughout the country. Recently the breed has been receiving substantial recognition in the South, especially in Tennessee, Georgia, and Alabama. On the range the Aberdeen-Angus has never secured such footing as have the Hereford and Shorthorn, although it has many stout champions in the Far West.

Organizations for promoting Aberdeen-Angus cattle are represented by the Polled Cattle Society of Scotland, organized in $\mathbf{1 8 7 9}$, and the American Aberdeen-Angus Breeders' Association, organized in 1883. The first "Polled Cattle Herdbook" was issued in Scotland in I862, and Galloways were registered in the first four volumes of the Scotch society. The first volume of the American association was published in I886. Up to January $\mathbf{I}$, I9I9, the Scotch society had published forty-three volumes and the American twenty-seven. About 238,500 Aberdeen-Angus cattle had been registered in the American herdbooks up to this time, and the association has about three thousand members. There are also associations for promoting the brẹed in England, Canada, New Zealand, South Africa, and Argentina. In the United States nineteen state associations for promoting the breed have been established up to November, I9I9, and thirteen county associations have also been organized, mostly in Indiana, Illinois, and Iowa. A semimonthly periodical, the Aberdeen-Angus Journal, was established in August, 1919, with headquarters at Webster City, Iowa. 


\section{CHAPTER XXVIII}

\section{THE GALLOWAY}

The native home of Galloway cattle is in the province of Galloway in southwestern Scotland. This province includes two counties - Wigtown and Kirkcudbright — as well as parts of the counties of Ayr and Dumfries. Galloway borders the sea on the west and south and is generally rough and mountainous excepting in places near the sea. Much of the land is especially suited to grazing, but wheat, oats, barley, potatoes, and turnips do well on cultivated lands of the better class. The climate is damp and cloudy much of the time, cold and inclement in winter, and often cool in summer.

The origin of the Galloway, like that of the Aberdeen-Angus, is quite obscure. According to Wilson, ${ }^{1}$ early in the eighteenth century there arose in England a demand for polled cattle to which the people of Galloway were the first to respond. Youatt states that about I 750 the greater part of the cattle of Galloway were horned, but some of them were polled, a feature of this breed. In I 789 George Culley wrote of "polled or humbled" cattle and stated that "for the original of these we must look in Galloway." Culley also notes that graziers and drovers took them "in prodigious numbers" to the fairs in Norfolk and Suffolk, England. As far back as I 723 Alexander Murray of Brochton is credited with having an enormous number of black cattle on his estate, feeding one thousand each year and driving to the English markets. Possibly the breed is descended from polled wild cattle. Various British authorities indicate that the Galloway is essentially a Kyloe or West Highland breed devoid of horns and may be a sport from this. Some authorities insist that Galloways have always been a true polled breed.

The improvement of the Galloway dates back into the eighteenth century. Culley states that the breeders of Galloway complain that the old breed has become much worn out. He then says that

1 Evolution of British Cattle, I 909. 
there is little doubt of its not only "being recovered, but still more improved, when such a leading nobleman as Lord Selkirk is among the breeders. Mr. Murray of Brochton and Mr. Herring of Corroughtree have long been very eminent in the breeding of Galloway cattle. Mr. Craik, Mr. Dalyell, and several others have tried a cross from Mr. Bakewell's bulls." This, then, was a Longhorn cross on the Galloway, but Culley says that with what success

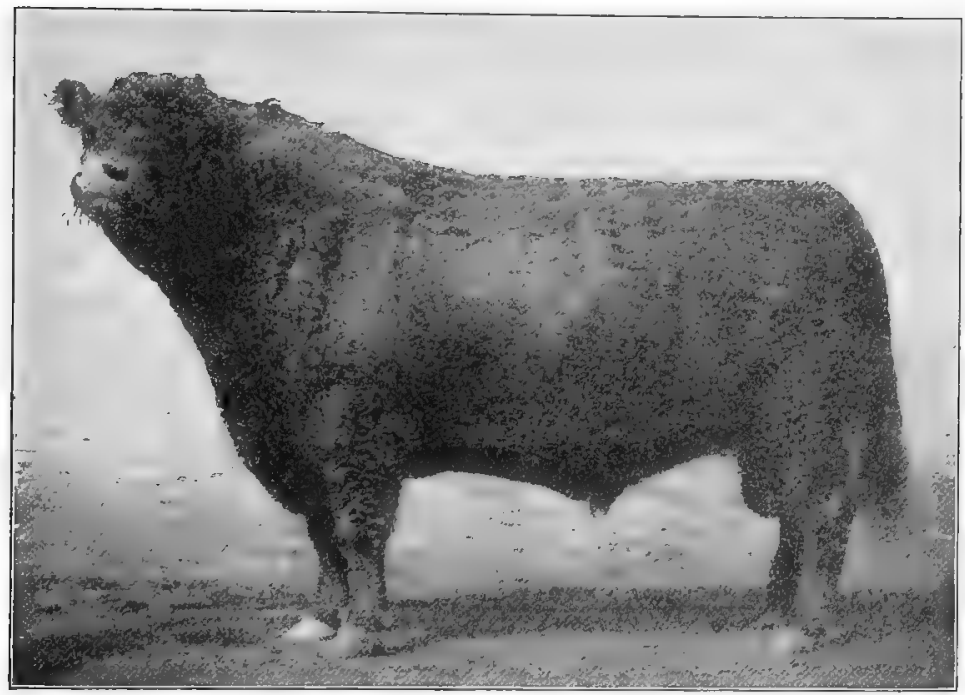

FIG. I25. Worthy 3d (imp.) 21228. A great prize-winning Galloway bull in Scotch shows, grand-champion male of the breed at the Louisiana Purchase Exposition in 1904, and champion at numerous other leading American shows. Imported by

C. E. Clark, St. Cloud, Minnesota. From photograph by the author

he has not been able to learn, although breeders were generally against crossing this on Longhorns or any other breed. The Galloway was also crossed on the cattle of Westmoreland and Cumberland in the most mountainous section of England and contiguous to the province of Galloway. Among other important early improvers were the Gordons of Greenlaw, Maxwells of Munches and Mouneith, McDowals of Logan, Stewarts of Phygell, and the Earl of Galloway. The method of improvement by these early breeders has been one of selection, it is claimed, and not of inbreeding. About 1840 dairying became popular in Galloway, 
notably in Ayr and Dumfries, and as the polled cattle were not essentially good dairy producers the people neglected them and turned to dairy stock, especially Ayrshires. In general Galloways suffered severely from neglect, and the number sensibly diminished all over the district. A few men, however, clung to the breed in its purity and worked for its improvement, notably the Duke of Buccleuch, James Graham, and the Messrs. Shennan. In I85I a step forward was taken by establishing an annual Galloway bull sale at Lockerbie, and soon after another was established at Castle Douglas. In I 862 the Herdbook Society was organized, but it is said that active interest in the Galloway was not renewed until about I 877 .

The introduction of the Galloway to America occurred long ago, though just when is uncertain. Polled cattle came to this country in some of the early importations. L. F. Allen states that in I 837 he saw a very fine black polled Galloway cow at the General Hospital in Philadelphia, but he did not ascertain how she came there. In 1853 Graham Brothers of Vaughan, Ontario, made the first importation to Canada, though L. F. Allen thinks they were brought to the vicinity of Toronto about I850. In 1857 Allen saw upwards of forty of the breed at a show at Brantford, and later saw them elsewhere in Canada. In I86I Thomas McCrae of Guelph, Ontario, made his first importation and did much to promote the breed. The first Galloways to reach the United States are said to have been brought to Michigan in 1870. In I 880 the editor of the National Live Stock Joumal, in reply to an inquiry, stated that he could give no addresses of polled-cattle breeders in the United States having cattle for sale, saying that they were very rare. Along in the eighties Galloways were owned by S. P. Clarke of Dover and I. H. Norris of Lamoille, Illinois. In I 885 M. H. Platt of Kansas City, Missouri, exhibited Galloways at the Cotton States Exposition at New Orleans.

The characteristics of the Galloway. This breed in general appearance is short of leg and close to the ground, is polled, black of color, has very thick long hair (especially in winter), and is somewhat longer of body and flatter of rib than the AberdeenAngus. Without going into general details certain features of the breed demand special consideration. The head in a good 
type should be polled and absolutely free from scurs, or abortive horns, the poll being less peaked than in the Aberdeen-Angus. There should be strong breadth between the eyes, with shortness from eyes to end of muzzle, which should be large with ample nostrils. Wallace, the Scotch author, states that the ear is set rather farther back than in most breeds and should point upward

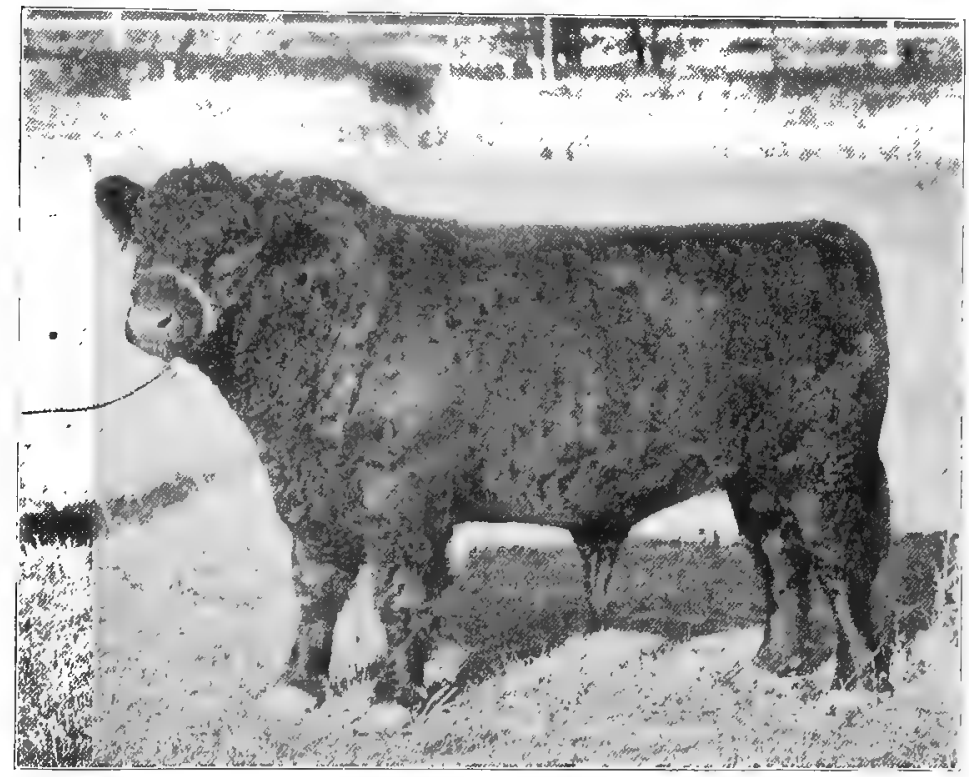

FIG. 126. Picador 2 d 42178, junior-champion Galloway bull at the Igi 7 International Live-Stock Exposition. Bred and exhibited by R. W. Brown, Carrollton, Missouri. From photograph, by courtesy of Mr. Brown

and forward. A fine, broad, pointed ear covered with long hair is characteristic. The body of the Galloway is somewhat cylindrical and has considerable length. The nump is long, and the hind quarter is usually well developed, especially in the lower thigh. In quality the breed is superior, for the bone is reasonably fine, the skin mellow, and the hair very fine, silky, curly, and long. The color is generally black, though a brownish or reddish tint frequently occurs in the black and is regarded by some as an indication of purity. White or other color is a disqualification. Digitized by Microsofte 
Formerly the breed varied in color, when there were brindles, dun-colored, or drab, and some with white spots. About $\mathbf{1} 835$ Youatt wrote that dark colors were uniformly preferred from the belief that they indicate hardiness of constitution.

The size of the Galloway hardly equals that of the Shorthorn, Hereford, or Aberdeen-Angus, and it may be rated as a bit smaller than these at the same age. Mr. A. M. Thompson states that as yearlings past they can be made to weigh from IOOO to I 200 pounds; at two, from I 200 to 1400 ; at three, from I 400 to 1600. Typical bulls will weigh about 1800 to I900 pounds and cows I 300 to I 400 pounds when not in high flesh. In show condition much better weights may be secured. Lady May I I 562, a famous show cow, weighed I 740 pounds at the 190 I International LiveStock Exposition.

The Galloway as a meat producer, as has been indicated, has always ranked high. For many years large droves of Galloways, said to exceed twenty thousand a year, were driven from Scotland into England and fattened and sold for beef. Galloway cattle have never been raised in large numbers excepting in the Galloway district and so have not usually been important factors in the show ring, at least outside of Scotland. At the 1916 International Live-Stock Exposition there were fifty-four head entered in the breeding classes and but nine steers. There never has been a large and high-class show of steers of this breed at the International. Yet Galloways feed uniformly and smooth, patches and rolls being uncommon. The Galloway carcass ranks very high in quality and is valued by discriminating buyers, but it has not played an important part in the carcass contests at the International LiveStock Expositions. In 1909, in the two-year carcass class, Galloways won second and fourth places, Domsie dressing 65 per cent and Scottish Lad, shown by Ohio State University, dressing 65.8 per cent. In I9IO the second-prize two-year-old steer Highland Laddie (which weighed I 672 pounds alive) dressed 69.55 per cent, while the fourth-prize yearling was a Galloway-Shorthorn cross, dressing 66.66 per cent. In I9I I the second-prize yearling carcass was the Galloway Bobby Burns, dressing 67.2 per cent, while in I9I 3 the third-prize two-year-old was a Galloway, dressing 66.57 per cent. All of the prize-winning Galloway carcasses were shown 
by Nebraska University excepting the one credited to Ohio. "The excellent value of the beef of the Galloway," writes David McCrae, 1 "arises from two causes: first, its marbled quality, the fat being laid amongst the lean, giving it a well mixed, fine grain, highly flavored; second, the tendency to lay their flesh and fat equally on the best parts."

The crossbred Galloway has a distinct place in the meat market of England, for the mating of white Shorthorn bulls on Galloway

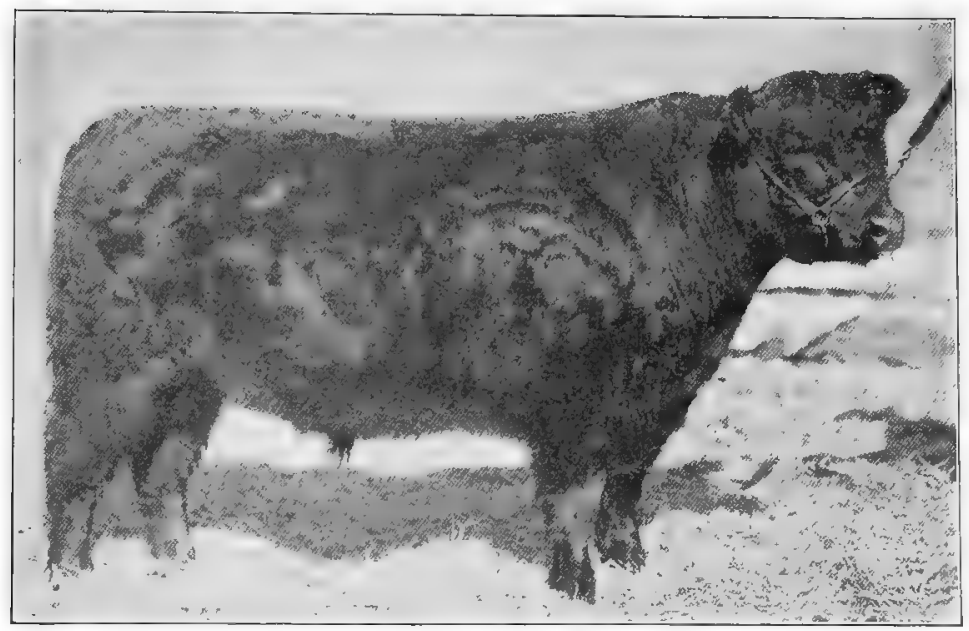

FIG. I 27. Masterful 43643, champion Galloway steer at the I 9 I 8 International LiveStock Exposition. Exhibited by Kansas Agricultural College. From photograph, by courtesy of American Galloway Cattle Breeders' Association

cows has produced a famous class of blue-gray feeders which kill out surpassingly well, often reaching 65 per cent. The Iowa Agricultural College has experimented some with this breeding and has shown a few choice blue grays at the International Live Stock Exposition at Chicago. From time to time "prime Scots" are quoted in the English markets, and these are often blue grays. In r892 the champion steer at the Smithfield show, England, was a cross between a Galloway cow and Shorthorn bull, which at I 250 days weighed 2276 pounds, an average daily gain of 1.82 pounds from birth. Mr. O. H. Swigart, in writing on the Galloway, reports 
on two loads of range calves exhibited by a Colorado man, the offspring of common-grade cows, many of them Holsteins and Jerseys, but all sired by registered Galloway bulls. These calves won first and third prizes in their class, and one load won championship in class over other breeds by ages and grand championship over all breeds and all ages as feeders. They were purchased by an Indiana feeder and returned to market July 9, I902. They had an average weight of II 77 pounds and brought $\$ 8.45$ per

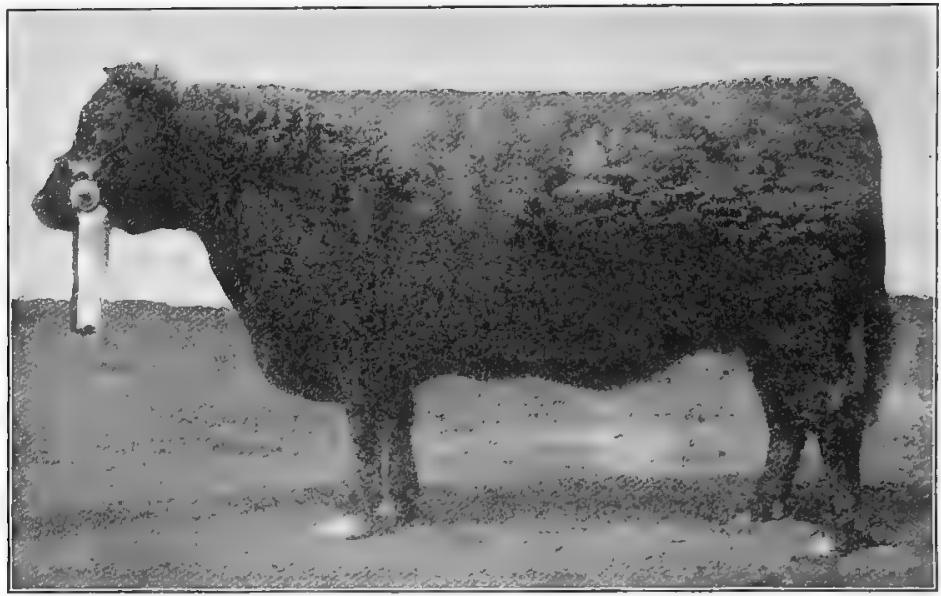

FIG. 128. Evaline 2d of Avondale 20124, grand-champion Galloway female at the Louisiana Purchase Exposition, I904, and at numerous other prominent shows. Bred by O. H. Swigart, Champaign, Illinois. From photograph by the author

hundred - within five cents of the highest price ever paid up to this time on this market for range-bred cattle of any breed, showyard animals alone excepted.

The Galloway cow in milk production is little known so far as records are concerned. The claim is generally made that the cows give a good yield of rich milk, yet one finds very little information regarding the Galloway as a milker when consulting the literature of the breed or comparative tests of cows of different breeds. The fact is, Galloway advocates emphasize the value of the breed in beef production and scarcely comment on the milkproducing factor. The cow Rosy 4 th is reported to have produced $42 \frac{1}{2}$ pounds of milk in a day, testing 7.25 per cent fat. 
A former secretary of the American Galloway Cattle Breeders' Association, Charles Gray, states" that "the Galloways as a breed cannot lay claim to any superiority as milkers. Although many herds have been kept for centuries in the south of Scotland for dairy purposes, yet as a whole the breed has been improved chiefly along the lines of beef production."

The hardiness of the Galloway is one of its inherited characteristics, and it seems eminently suited to a place on the Western range, where food may be scarce and where the rigors of winter are great. The thick, long coat of hair gives it better protection from cold than is provided any other recognized beef breed in America. It is for this reason and for its rustling ability that the Galloway is attaining more and more popularity on the Western and Northwestern range.

The hide of the Galloway, with its thick and long fall or winter coat, has a distinct value in itself. Properly tanned, it furnishes a lap robe, overcoat, or floor rug, surpassing in beauty the pelt of the buffalo, now so highly prized. Good Galloway floor rugs or lap robes easily sell for twenty-five dollars, and overcoats of this fur have changed hands at high prices. In the northwestern United States and Canada coats of this fur are very common in winter. Reverend Dr. John Gillespie, during a long life an authority on the Galloway and one of the founders of the Galloway Cattle Society of Great Britain, makes this comment on the Galloway skin and hair ${ }^{2}$ :

The skin and hair were outstanding qualities of the Galloway breed. The skin should be moderately thick, but always mellow and soft. The hair should of course be black, but not of a jet or inky black. The breeders liked to see a nice brown tinge, and all the best bred specimens would be found to have that characteristic. The objection to an inky black was that the quality of the hair was not usually so good as when the brown tinge was present. Galloways had always the two coats of hair fully developed. The upper coat should be long and soft, but not too curly. Animals with a very curly coat were generally indifferent thrivers. The under coat should always be soft, close, and silky. This was a very important point in the breed, because on it depended the power of the animal to resist cold and stand exposure. 
The prepotency of the Galloway is of the first rank. Within the breed there exists much uniformity of transmission of character. In crossing or grading, where Galloway sires are used, the offspring almost always inherits the color and features of the sire. James Biggar, one of the most noted recent Scotch breeders, states in regard to the power of transmission that "when a

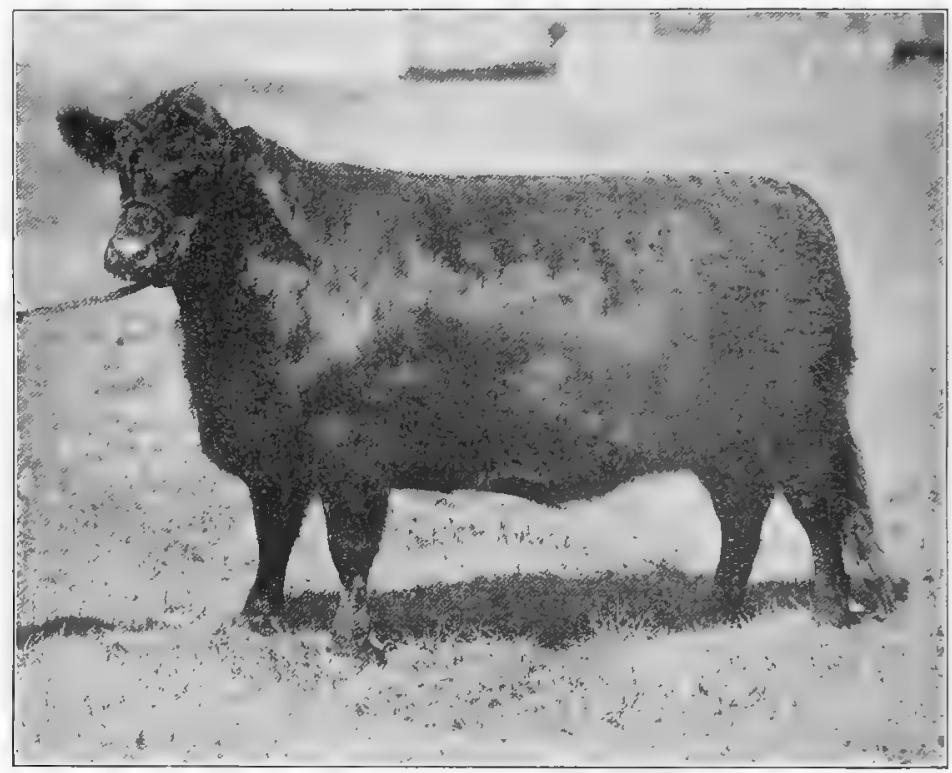

FIG. I 29. Fatima 38103 , third-prize Galloway cow at the I9I7 International LiveStock Exposition. Owned by Isaac Lincoln, Aberdeen, South Dakota. From photograph, by courtesy of American Galloway Cattle Breeders' Association

Galloway bull is crossed with any horned breed nearly 90 per cent of the produce will be black and 95 to roo per cent without horns." Mr. A. M. Thompson of Missouri reports using a Galloway bull on a herd of Shorthorn cows with very great success, 98 per cent of the calves being black and all natural polls. Galloways also cross very successfully with Herefords, producing beef of the finest quality. However, Robert Wallace says "the progeny of Galloway bulls on other breeds are on the average distinctly inferior." 
Galloway bulls of distinction that have materially helped to give fame to the breed in more recent times are Camp Follower (5042), Pathfinder 3d (599I), Scottish Standard (6488) I 522 I, Kekionga (2894) 2894, Druid of Castlemilk (6 I 59) I 7054, King Hensol 9967, Camp Follower of Stepford (7476), Worthy 3d (7762) 2 I 228, Camp Follower 3d of Stepford (8407), Keystone (9689), and Macbeth (IO32 I).

The prices derived for Galloways do not average high, yet in view of the lack of knowledge of the breed they make a fair showing. A summary of 740 animals sold at auction from 1892

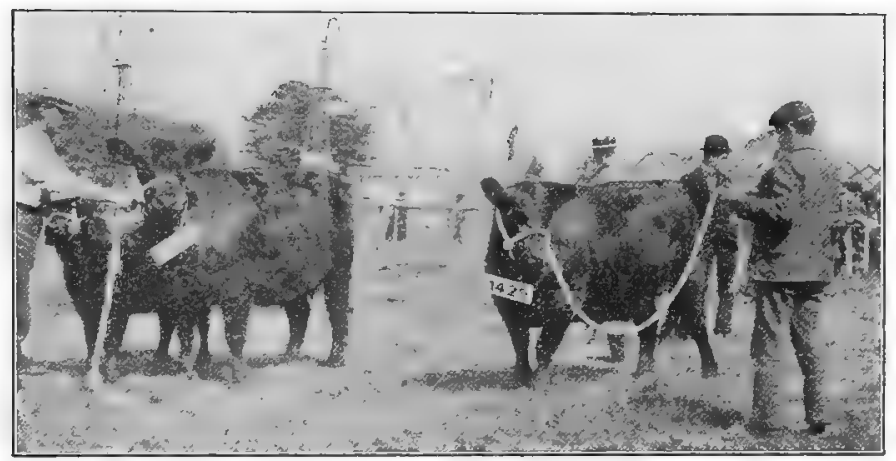

FIg. I30. A pair of Galloway cows in the ring at the Royal Show, Manchester, England, I897. No. 1429 is Dora of Durhamhill (I355) and I 430 is Maggie Lauder of Durhamhill (13994). The judges disagreed on these two for first place. From photograph by the author

to I90I inclusive, published by the Kansas Board of Agriculture, shows an average of $\$$ I 26.75 per head for both sexes, or $\$$ I 4 I.43 for 233 bulls and $\$ 110.5$ I for 3 I 8 cows.

The distribution of the Galloway is mainly in Scotland and America. The breed is found in small herds, as a rule, east of the Mississippi, though some of the best-known herds are in Indiana and Illinois. Galloways are found on the ranges and farms all over the Far West and especially in the Canadian Northwest. Important herds are also found in Missouri, Iowa, and Minnesota.

Organizations for the promotion of Galloways were first started in I862 in Scotland, although Aberdeen-Angus were registered with the Galloway in the first four volumes of the herdbook. 
Then came a breed separation, and later, in 1877 , followed the organization of the Galloway Cattle Society, with the first Galloway herdbook appearing in I878. Up to 19 I9 the Galloway Cattle Society of Scotland has published thirty-nine herdbooks. The American Galloway Cattle Breeders' Association was formed at Chicago on November 23, I882, although ten years previous to this the Ontario Galloway Stock Register of Pure-Bred Galloways had been established by the Agricultural and Arts Association of Ontario. The first American herdbook, known as the "North American Galloway Herdbook," was published in I883, since which date, up to I9r8, there have been published eighteen volumes, showing 35,000 registrations.

Criticisms of the Galloway have long been made by American stockmen, more especially for lack of spring and fullness of rib, slackness of back, prominence of tail head, and slow response to generous feeding. Some of these criticisms are justified, but the breed is nevertheless improved over its form of twenty-five years ago and is less subject to unfavorable comment.

The approved modern type of Galloway represents an animal that is free from some of the deficiencies referred to. Through the efforts of the more prominent breeders of Scotland and America the recent years have seen some improvement in the breed. A wider-backed, blockier, better-fleshed, easier-feeding sort has resulted from a more careful selection and a more discriminating use of bulls on superior cows. Even yet, however, the Galloway does not as à rule mature as early or fatten as rapidly as the Shorthorn, Hereford, or Aberdeen-Angus, although Galloway cattle produce a very high-class meat, fine in grain and flavor, with the fat internal rather than external, and command a superior price on the market. 


\section{CHAPTER XXIX}

\section{'THE WEST' HIGHLAND}

The native home of West Highland cattle is in the elevated uplands of western Scotland. This particularly applies to that section known as the Highlands in Argyll, Inverness, and Perth counties, and the Hebrides Islands off the west coast.

The origin of the West Highland breed, which has also been called the "Kyloe" by some, is generally conceded to be derived from the aboriginal cattle of Britain, of which the present wild white cattle are descendants. This breed has been known for centuries, but has been kept on a comparatively small scale. Joe Cameron gives an interesting contribution ${ }^{1}$ relative to the reputation of this as a very old breed. He states:

Colin Campbell of Jura has a record of a sale of Highland cattle held by an ancestor, Archibald Campbell, in 1764 . When the sale was held no one knew how long the breed had been in the possession of the family; the tradition was that the foundation animal had been taken from the mainland. The late Alexander MacDonald of Babranald, in a letter to the writer many years ago, said that his ten predecessors on the Babranald estate kept the native cattle, and the tradition was handed down that his forefathers, who had occupied Babranald or its neighborhood since the fourteenth century, had always bred Highland cattle.

During the first half of the last century two of the herds that improved the breed were those of $\mathrm{Mr}$. Malcolm of Poltalloch in Argyll and the Marquis of Breadalbane of Perth.

The introduction of the West Highland cattle to America is of only passing moment. In 1879 Lewis F. Allen, one of the bestinformed cattle authorities in America in the nineteenth century, stated that he knew of none in the United States, but was of the impression that a few were imported into Upper Canada some years before. About r883 some West Highlanders were imported, among which was the cow Maid of Castle Grant, that 
was shown at a number of fairs in 1888 and 1889 by Judge J. S. Goodwin of Kansas. In I89 I several West Highland cattle were exhibited at the American Fat Stock Show at Chicago. In I9O2 Mr. W. M. Van Norden of Westchester County, New York, imported a small herd and made an exhibit at the Louisiana

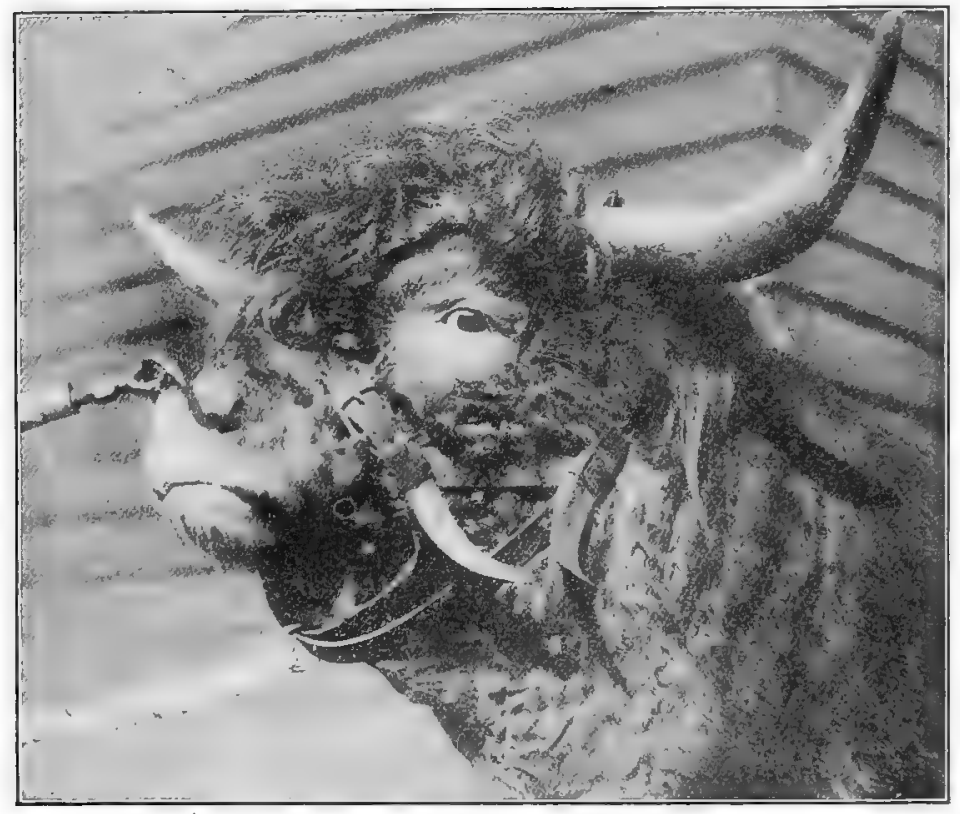

FIG. I3I. Head of the Highland bull Sir Andrew (1742), champicn of the breed at the Louisiana Purchase Exposition, I904. Owned by W. M. Van Norden, Rye, New York

Purchase Exposition in I904. In 1907 Frank R. Sanders, then of Laconia, New Hampshire, made a small importation.

Characteristics of West Highland cattle. This breed is very picturesque and distinct in character. The color is variable, being yellow, red, black, brindle, and a mixture of red and black, the red predominating. Cameron states that a fold of twenty cows might easily be composed of yellows and reds (two or three shades of each), but that there ought to be at least a couple of red brindles, a black, a silver dun, and a white, if a good one 
can be found. Unfashionable colors are brown (especially when rusty) and dark red, with black hair about the muzzlc and in the tail. Broken colors are also in disfavor. The hair on the surface appears long and rough, while beneath, next to the skin, is a soft, mossy coat, the two combining to give admirable protection in winter against very severe weather. The hcad is very bold, dignified in carriage, and in the bulls is surmounted with long, graceful horns which have a forward and slightly upward curve in mature form, with the points wide apart. The horns are white with animals of light colors, or white with dark tips with dark colors. The color of the musile varies from buff or flesh shade to dark, in harmony with depth of color of hair. The neck is short and thick, with a mane on top and heavy dewlap below. "In form," says John Robertson of Blair Athol, "it possesses all the characteristics so much and so justly prized in the Shorthorn - the straight back, the short legs, the broad chest, the breadth of loin and depth of rib, and, in short, the 'squareness' and solidity of form which always imply weight, whether in man or beast; while the noble branching horns, the fine, full, and fearless eye, the short, broad, well-bred muzzle, the shaggy coat of richest black or red or dun or brindle color, impart a picturesqueness which is still further enhanced by that grace and deliberation of movement so distinctive of all animals reared in perfect freedom." The temperament is wild and bold, due to a condition of natural lack of restraint unknown among other breeds.

The size of the West Highland cattle is comparatively small, cows perhaps averaging 900 pounds and males 1200 , although one sees some larger on the hills and at the shows in Scotland. At the I9I I Edinburgh Fat-Stock Show the steer Errol Candidate Ioth was a handsome beast weighing I 702 pounds at two years and ten months of age.

The West Highland breed as a beef producer is superlative so far as quality is concerned. The meat is fine of grain, the fat is well distributed among the lean, the flavor is unsurpassed, and the carcasses dress out well. In the British market, beef of this breed ranks at the top. Yet these cattle feed very slowly and mature late and seem best adapted to feeding under Scotch mountain environment. 
The milking qualities of the West Highland are not important, for the cows are milked usually by the calves only. The milk, however, is rich in quality.

Crossbred or grade Highland cattle are best suited to conditions where food is scarce and winters rough. Highland bulls on native Western-range cows would furnish hardy stock, but it is not likely that it would meet with a favorable reception from buyers, compared with the present very acceptable Hereford, Angus, or

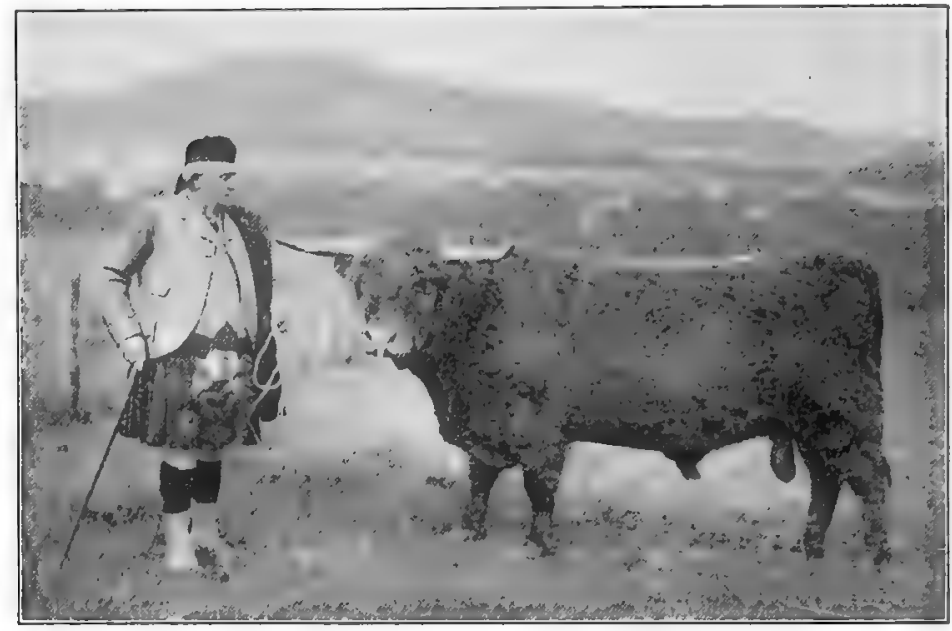

Fig. 132. Ceathernach Buidhe ( 719$)$, first-prize West Highland bull at show of the Highland and Agricultural Society of Scotland, 1891 and I 892 . From photograph by Charles Reid, by courtesy of Breeders' Gazette

Galloway grades. The claim is made by excellent Scotch authorities that West Highland cows cross well with bulls of most of the British beef breeds. Where food is abundant and the climate not too severe such a cross may be advisable. On the more elevated Scotch hills, however, where winter exposure is great, the crossbred progeny will not do so well as the pure-bred. Such crossbreds could not be expected to have the hardiness of the pure stock. Referring to crossbreeding Mr. Cameron states ${ }^{\mathbf{l}}$ :

A good many years ago the Earl of Camperdown experimented considerably with various crosses on his property near Dundee, Scotland. Putting a Shorthorn bull to well-bred Highland cows, he had splendid calves, which throve

'Breders' Gazelle, October 23, I913. 
extraordinarily and came to maturity quite as rapidly as the run of other Shorthorn crosses, but a proportion of them tended to become rather fat at the finish, the land being somewhat low-lying, sheltered, and rich. He then tried the Aberdeen-Angus bull, and with perfect success. Finer beasts for the butcher than the two Aberdeen-Angus and Highland crosses could not be wished. At twenty-four to thirty months old his lordship's Angus and Highland cross steers have generally ranged from 1200 to 1400 pounds live weight. He has also bred many superb animals by putting a white Shorthorn bull to cows and heifers of the Shorthorn-Highland cross. The result in this case from the color standpoint has been a large proportion of roans and reds with a slight frosting of white hairs all over their bodies. Putting the Aberdeen-Angus sires to those first cross cows, he has pretty dark blues and blacks with white hairs.

The hardiness of West Highland cattle is remarkable. Used to a free life on the Scotch hills, where summer and winter they graze on grass and heather, they seem capable of enduring the roughest climate. In a letter on this breed the Earl of Dunmore wrote in 1887 , bearing on their suitability to the more exposed Northwestern American range :

My average yearly loss has not been three per cent, which in a large fold of some four or five hundred head of cattle is very small. January, February, and March are pretty hard months for them, as they get no food beyond what they pick up on the hills where they are wintered. I have often seen them scraping away the snow to get at the grass; but notwithstanding their being out all winter, they produce in April and May as strong and lusty-looking calves as a man could wish to see, with lots of bone and tremendous thick coats. That, to my mind, is the coming breed for the great Northwestern ranges.

The breeding qualities of West Highland cattle rank high, though the heifers are not bred the first time until three years of age. Earl Dunmore states that he could quote from his private herdbook several cases of cows, after having their first calves at four years, continuing to produce yearly thereafter up to fourteen years of age one living calf and sometimes twins, all of them being born on the mountain side.

The distribution of the West Highland breed is mainly in Scotland, in the regions previously indicated, although herds are kept in England, where steers are also fed to a small extent. Although many owners of large estates maintain this breed for its picturesque character and easy keep, yet it is not common excepting in western Scotland. In vigitized of the fact that this is strictly a 
mountain breed, one might assume that it would do well on the better pastures of the Allegheny Mountains. Grazing of an excellent character is found on the mountains of Virginia, North Carolina,

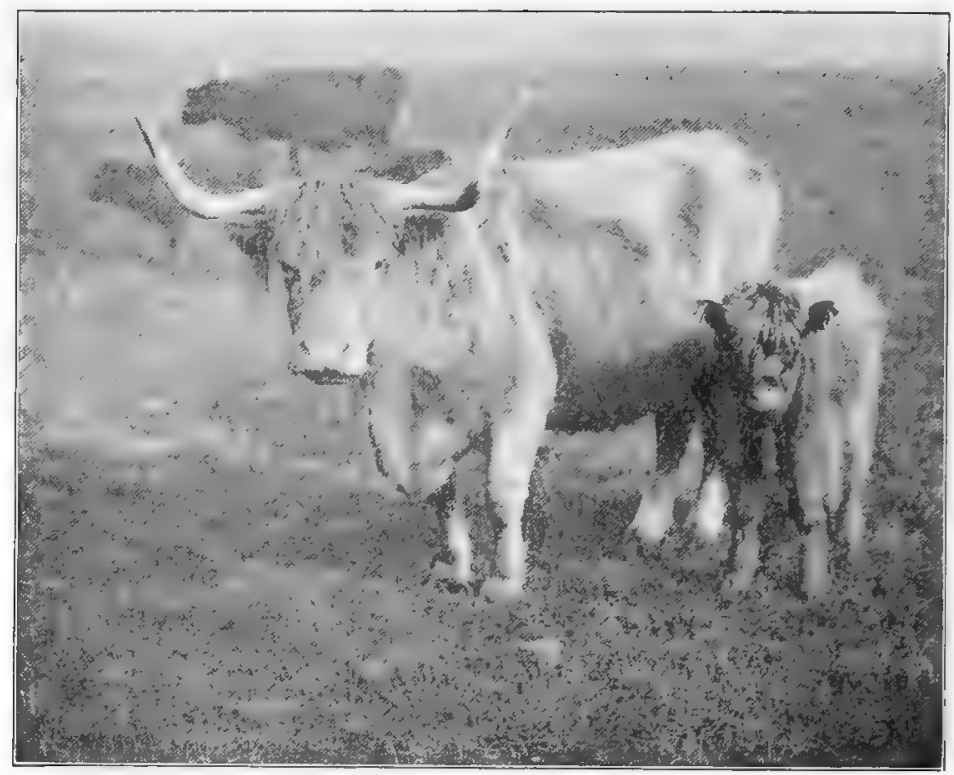

FIG. 133. A West Highland cow and calf. From photograph by W. Reid, by courtesy of the Breeders' Gazette

and Tennessee. The winters in that region lack the severity of the North, thus permitting living on the range the entire year.

An organization of West Highland cattle breeders was formed by Earl Dunmore in I884, and a herdbook was published that year, nineteen volumes having appeared up to I9I9. Some years ago an attempt was made to organize a West Highland cattle association in the United States, but without much success. 


\section{CHAPTER XXX}

\section{DAIRY TYPE OF CATTLE}

The general appearance of dairy cattle is notably different from that of beef stock. They have less thickness of body, less breadth of back, narrower thighs, a slenderer neck, and a more muscular character generally. The males are notably narrower at the withers and more divided between the hind quarters, while the females are rather sharp over the withers and full and heavy behind, with udder of ample proportions. A rather long, deepribbed, muscular, not fleshy body and shortness of leg is notable in the high-class male. A triple wedge form is associated with the dairy cow. Viewed from one side, she shows less depth of body in front than behind; secondly, she gradually widens from the breast to the points of the hips and hind quarters; thirdly, as one looks down on the back at the withers the form widens out like a wedge towards the middle of the body. Many superior dairy cows show this wedge form in a striking degree, but exceptions occur where the heavy milk production is not associated with an ideal dairy shape. Fleshiness with either sex is distinctly objectionable, unless with young animals not yet in lactation.

The head of the dairy animal should be lean, broad of muzzle, large of nostril, moderately short and broad of nose, with some dish to the face. Prominent, clear, calm eyes, wide apart, beneath a broad full forehead, are essential. The cheeks should be deep and the lower jaw strong. The fine, medium-sized, thin, pointed ears must be neatly placed and be covered with fine hair on the outside, with longer hair at tip and edges. If there be horns they should exhibit quality, not being coarse or shelly. The top of the head, or poll, should be covered with a thick layer of fine long hair, especially in cold weather. A yellow color of the inner skin of ear and a yellowish waxy color to horn, especially at the base, are regarded as indicating that a cow will yield milk rich in fat. 
The neck tends to be long and muscular. With the bulls it is especially strong and heavily muscled, usually possessing a prominent arch, while the neck of the cow is thin and long. The lower part of the neck usually has more or less dewlap, this being a thin edge of skin extending from the brisket upwards. A very deep neck with much dewlap, fullness at the throat, or a short, thick neck on dairy cattle are objectionable, showing lack of quality and type. While the neck should have a neat attachment at head and shoulders, it does not blend in so smoothly as with beef cattle, owing to lack of flesh.

The shoulders should incline at a good angle well into the back, lying fairly close together and forming with the back line rather refined, narrow, or sharp withers. With the males greater breadth of withers is sought. The shoulders are usually somewhat prominent, but heaviness or meatiness is distinctly objectionable.

The breast of dairy cattle does not show so great.width as the beef type, and the brisket is narrower and sharper and not carried quite so far forward.

The chest, like the breast, which is a part of it, does not show great thickness, but ample depth and reasonable spring of rib is desired. The crops - at the top of the chest behind the shoulders - are usually somewhat deficient in dairy cattle. At this place the ribs should have a fair arch from the back, showing ample chest room below. The front flanks also should be well filled out, showing a good constitution in the ample chest capacity.

The front legs should be straight from side or front, coming down without marked crookedness at knee or wide turning in or out of toes. A common feature of dairy cattle of both sexes is to have the knees come quite close together when in a natural position, thus indicating a narrow chest and poor constitution.

The back of the dairy type frequently shows some droop from withers to hip line. Some persons regard a sway back as necessarily associated with dairy type. A strong back, well sustained, with but little depression, if at all, is much to be preferred. Arguments have been advanced by some that a large backbone, with the vertebræ somewhat separated, offers important evidence of such a nervous temperament as should be associated with the dairy type. Through the backbone the spinal cord passes, 
connecting the brain with the entire nervous system. A large backbone may indicate a large spinal cord and strong nervous temperament, a characteristic of the dairy type. Further, there should be a strong, level, broad loin and also fair width of back throughout, although not equal to that of the beef type.

The ribs should be sufficiently long and arched to provide a capacious body, a feature most important with animals of this class. Flat and short ribs go with poor feeders and defective constitutions. The body of the dairy type being moderately long or rangy, the ribs do not appear quite so close together, perhaps, as with the beef type, neither is the coupling between the last rib and point of hip as close as with other cattle.

The hips tend to be somewhat prominent with both males and females. The hip points of the male should be neat and moderately clcse, not wide, while those of the female may be more widespread and prominent. This allows plenty of room for the breeding organs of the female.

The nump of the dairy type calls for ample length, breadth, and levelness. This offers more room for the reproductive operation, the peaked, droopy rump frequently causing trouble in calving, due to lack of room for the easy exit of the calf. The backbone should be prominent along the middle of the rump, in keeping with the rest of the back. On account of its prominence the backbone from the hips to the tail head over the pelvis shows a rise which is often termed the "pelvic arch." A fat rump is objectionable, a feature found usually in inferior milkers and animals of the beefy type.

The thighs of dairy cattle should be muscular rather than fat. A heavy, thick type of hind quarter is not desirable. The thigh should be long, should have a rather thin back edge, and should curve on the inside so as to permit ample room between the hind legs. A thick thigh and deep twist is unfavorable to large udder development.

The hocks, to secure the necessary room for the udder, must be muscular, clean, and thin, and should point directly back, with ample space between.

The legs from hock down should stand square, as viewed from side or rear, the toes pointing directly forward or nearly so. Digitized by Microsofte 
If the toes turn out, the animal hocks in and has a faulty conformation. Rarely the toes turn in and the hocks bend outward, giving a weak and poor position to the legs. The shank bones should be smooth and short, showing refinement of bone and quality.

The tail is important mainly as a medium for protection from flies. Consequently length and a heavy brush of hair are essential. The fleshy part should extend to the point of the hock, and the brush should clear the level of the feet by two or three inches.

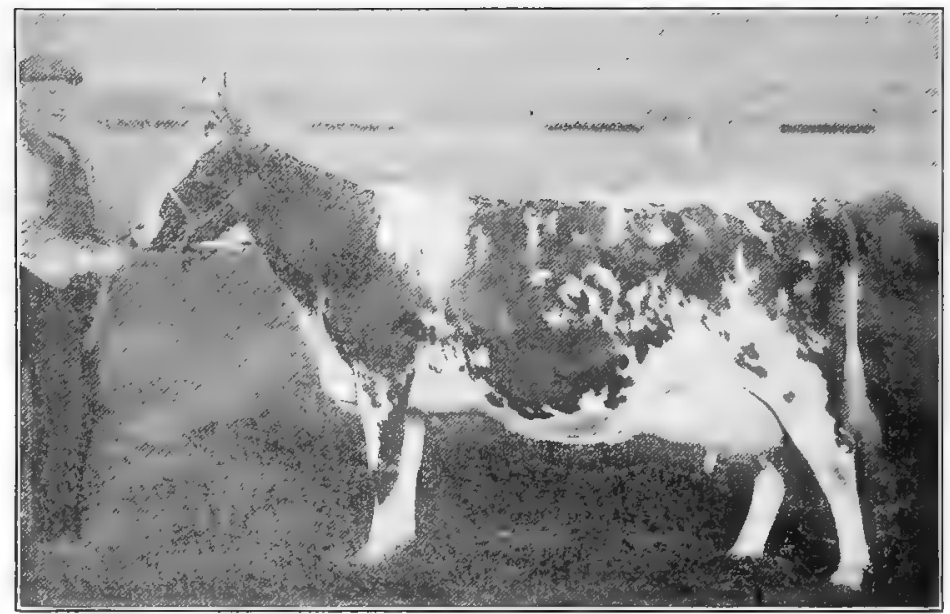

FIG. I34. Midland Nellie IV, an Ayrshire cow and a fine example of dairy type. From a Scotch photograph

The root of the tail, or tail head, should carry on a line with the back, showing no coarseness or special prominence, and fit neatly to the end of the body. The tail as a whole is an indicator of quality and should be refined rather than large and coarse.

The udder of the dairy cow is a most important part. In form it should be moderately thick, filling up well between the thighs, should extend by graceful curve high up behind, and should be extended well along the belly. The bottom of the udder in its best form has four teats some three or four inches long, hanging on the same level and placed far enough apart to be comfortably grasped in the hands. When the milk is removed from the udder that organ should be soft and pliable, showing much shrinkage. 
The hind part, located between widespreading thighs, should show much elasticity, with folds of skin apparent in the empty udder, especially with mature cows. Over the entire udder a mellow, soft skin and fine coat of hair should be found. Common defects of the udder are small, poor fronts, with the teats on this part elevated much above or close to the hind ones; small teats, especially with some breeds; meaty udders, which reduce but little with milling and yield a comparatively small flow; and last, but not least, small udders entirely lacking in profitproducing capacity. Large cows should have larger udders than small cows, but an animal of from 900 to I000 pounds weight, at six years old, in full flow of milk, should have an udder of comparatively large size, such as will yield at least 40 pounds a day. However, this standard does not apply to the larger, heavier milking breeds, which should do better than this.

The milk veins, which convey blood through the udder, are usually regarded as indications of a cow's general capacity to produce milk, although we have no actual facts bearing on this point. In spite of this the prevailing opinion among dairy-cattle critics is that the veins are in a measure indicators of producing capacity. Young heifers have small veins, which with maturity increase in prominence. On old cows they may be very tortuous, extending from the udder forward with numerous turns along the belly until they enter the wall of the belly through holes known as "milk wells." These latter should show comparatively large size on the application of the end of the finger at the orifice. Many cows have three milk veins, two long ones on the outer part of the belly and a short one between. In rare cases the veins branch into numerous small ones along the belly just in front of the udder. Small veins also occur on the udders of some cows. The length of vein varies, usually extending about halfway to the forelegs, although cases occur of their extending to the leg itself, disappearing behind the arm. The size of the vein varies much, the larger ones having a diameter of about three fourths of an inch. Small veins are found on the belly of the males, while miniature teats, known as "rudimentaries," are found along in front of and on each side of the scrotum, or purse, two usually occurring a short distance apart on a side, The length and size of the rudimentaries Digitized by Microsofte 
vary greatly, ranging from small buttons to teats an inch long. We have no definite knowledge regarding the significance of these, some persons thinking that the larger they are the better the evidence that the male will sire large milkers. Others have speculated that the position of the rudimentaries indicates the placing of the teats and form of fore udder on the offspring of the sire.

The escutcheon, also known as the "milk mirror," is found along the back of the thighs or between them and has attracted special attention on dairy cattle only. This is shown by a line of hair turning to one side or upward, in contrast to the usual downward position of the hair. This line of reversed hair was investigated by a Frenchman named Guenon, who argued that the escutcheon indicated the capacity of a cow to produce milk. In view of the fact that the extent and position of the reversed hair varies alongside or above the udder, Guenon classified its occurrence, giving different names according to the prominence and character shown. Modern dairy-cattle authorities attach no special significance to the escutcheon, Guenon's theories not having been borne out in fact.

The quality of the dairy type is shown in the character of skin and hair, size of horn, ear, and bone, and general proportions. Under the ordinary conditions of keep for cattle of this class the skin should be very mellow and pliable, thinner than with beef cattle, with a shorter length of hair. No class of cattle show quality so clearly as do some of the dairy type, as indicated by handling, there being a rich, mellow, oily feel commonly associated with the skin of high-class animals. The skin also will often show a yellow, oily secretion, conspicuous at the ears, between the thighs, about the udder and the scrotum, and at the end of the tail. 


\section{CHAPTER XXXI}

THE JERSEY

The Channel Islands are a group of islands in the English Channel, from Io to 30 miles from the coast of France and from 50 to 120 miles south of England. At one time they belonged to France, but since I 204 they have been under British sovereignty. There are four principal islands - in order of importance Jersey, Guernsey, Alderney, and Sark - and a number of very small islets of no special significance. These islands have rocky and very dangerous coasts and the tides vary greatly in height and activity, so that sailors have a great dread of this piece of sea, on which many vessels have come to a disastrous end. The English language is commonly used in the towns on the islands, while on the farms and among the fishermen a French patois prevails more or less. The islands are self-governed, having their own legislative bodies. The total population in I9I I was 96,900 .

The island of Jersey, the largest of the group, is about I2 miles long and 7 miles wide and contains 39,580 acres, of which about 25,000 are under cultivation. The island is rather rectangular in form, the north shore bold and high, the cliffs at Bouley Bay reaching an elevation of nearly 500 feet. The surface of the island gradually slopes to the south shore, where is located St. Aubin's Bay and the city of St. Helier and the principal harbor. The island is divided into twelve parishes and has a population of about 60,000. A lieutenant governor representing the British government has control of all military matters, while a bailiff is the highest civil authority, being president of the States, or Parliament. The climate is most balmy and the island is a favorite health resort, outdoor life being pleasant during the entire year. So healthful are the conditions that tuberculosis among the cattle on the island is almost unknown. Jersey has two great industries - breeding cattle and growing potatoes. The soil is very fertile, igitined theliffrepts are small, ranging from 
5 to 20 acres each. Enormous crops of potatoes are grown, a yield of 500 bushels per acre being very common, and a total yield for the island of as much as 500,000 bushels in a season. Notwithstanding its small size, there are about 12,000 cattle kept on the island, and the herds are well cared for. When on pasture each animal is tethered by a combination chain and rope, and the grass is systematically grazed from day to day. Cattle are never turned loose to graze as in America.

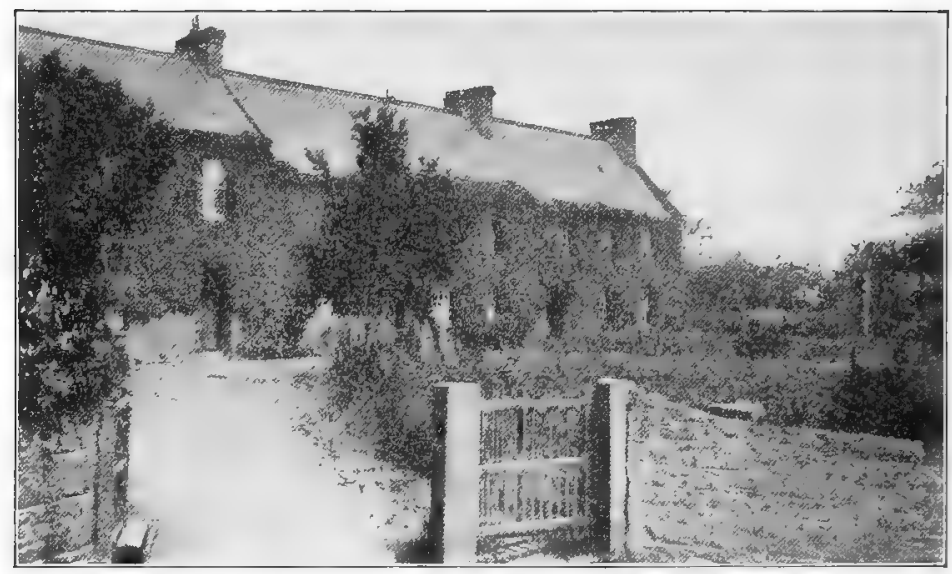

FrG. 135. A typical home on Jersey. From photograph by the author

The origin of the Jersey is unknown. The most probable theory is that it is descended from stock at one time native to those near-by departments of France known as Normandy and Brittany. While the cattle of those regions to-day do not closely resemble the Jersey, they have some things in common. The fawn or white color has been attributed to certain cattle of Normandy, while the blacker color has been ascribed to the Brittany cattle, it being assumed that the Jersey has resulted from the fusing of these French types. Historically the first description regarding the Jersey that the author has secured, showing its resemblance to the breed of to-day, was in 1789 , by Culley, ${ }^{1}$ who comments on the introduction into England of French

1 George Culley, Observations on Live Stock. Dublin, 1789. 
or Alderney cattle to ornament the grounds of the nobility and gentry and to provide rich milk. The term "Alderney" thus used applied to any of the Channel Island cattle, and the use of this word in America for many years was no doubt due to the English custom.

\section{Legislation for the protection of the purity of cattle on Jersey} dates back to early colonial times. The value of preserving the character of the breed was recognized as early as $176_{3}$, when laws were passed by the legislature of Jersey prohibiting the importing of cattle from France to the island. While this law was recognized, it probably was not enforced with much severity. In I789 an act was passed making it a severe crime, heavily punishable, to bring any cattle to Jersey from France excepting for immediate slaughter. In I 826 a new law was enacted, absolutely prohibiting importing breeding cattle from France, but this law was revised in 1864 , when provision was made for bringing cattle to Jersey from France for consumption or reëxportation. The present law prohibits bringing live cattle to the island excepting for food, and they must be slaughtered within twenty-four hours after landing at the abattoir at St. Helier. According to John Thornton efforts have been made to introduce other breeds on the island. About I 845 a Mr. Revans tried to introduce "Durhams," but these were finally sold to the butcher. Some Ayrshires imported by Colonel Godfray also met a similar fate.

The improvement of the old Jersey type really began in a general movement on the part of the islanders. In 1833 the Royal Jersey Agricultural Society was organized, with the view, among other things, of improving the cattle. In I 834 the society originated a score card for Jerseys, amounting to twenty-five points for the bull and twenty-seven for the cow. This card was used at the first show of cattle on the island, which also was held in I 834. Comments by the judges were that the cattle were poor of shape and had bad udders and that some females had short, bull necks, were heavy in shoulder, etc. The application of the score card, which was revised in $1838,1849,185 \mathrm{I}$, and 1858 , was enforced, and the cattle of Jersey gradually and rapidly improved. This work was due to the joint efforts of the members of the agricultural society, though Colonel Le Couteur was a leader in this 
movement on the island. The practice of selection was followed with much care, and the breeders constantly sacrificed animals of inferior quality and value to the butcher.

The improvement of the Jersey in England had some bearing on the general development of the breed. Many herds had been formed in England, that of Lord Braybrooke in Essex County (dating back to I $8 \mathrm{I}$ I) being still in existence in I880, when the first volume of the English herdbook appeared. About I82 I Philip Dauncey of Horwood, Buckingham County, purchased his first

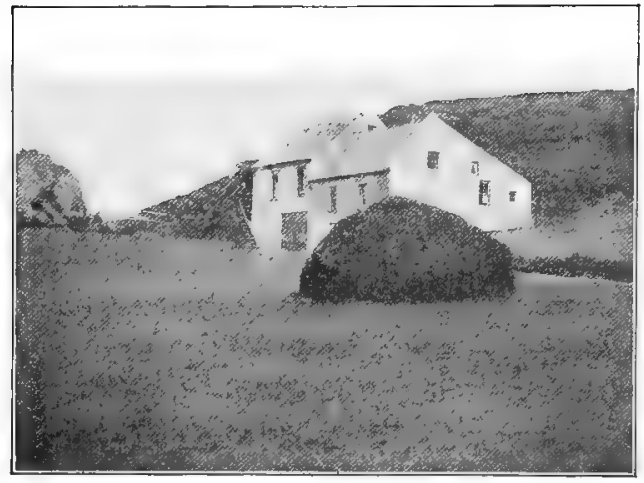

FIG. I36. A seaside farm on the island of Jersey. The stack in the foreground consists of seaweed, which is used for manure. From photograph by the author Jersey, and later became England's most celebrated breeder. He developed a remarkable herd, and it is stated that he eventually maintained a dairy of fifty Jersey cows which netted him an annual profit of $\$$ IOO each from sales of butter. His cows produced large yields of butter and greatly advertised the merits of the breed. The herd was dispersed in I867, when ninety head averaged something over \$200 each. Cattle from this herd were sold to go to different parts of England, Germany, Australia, and Tasmania. Dauncey, it is said, bred with three prime objects in view: first, a large average butter record; second, constitution; third, uniform color of hair, free from white. Among the most celebrated cows owned by him were Brunette, calved in 1833 , the dam of fourteen calves; Violet, procured from Colonel Le Couteur in I 845 ; and Negress, a favorite black cow. Pope 652, purchased in I 826 from Michael Fowler, was his first bull and proved a most valuable addition to his herd. Dauncey bred the bull Rioter $746 \mathrm{E}$, whose grandson Stoke Pogis 1269 became progenitor in America of the 
St. Lambert family. While Dauncey practiced inbreeding, he, however, greatly emphasized constitutional vigor.

The introduction of Jerseys to America dates well back into the nineteenth century. As early as I 8 1 8 Reuben Haines of Germantown, Pennsylvania, imported a pair of cattle from the island of Alderney, but no definite importation from the island of Jersey seems recorded prior to 1850 , when Messrs. Taintor, Buck, Norton, and other gentlemen near Hartford, Connecticut, brought over in the ship Splendid the first from the island to be registered in the American herdbook. The bull Splendens 16 is probably the first registered Island-bred bull brought to this country. In I $85 \mathrm{I}$ and 1855 other importations were taken to Connecticut, including some animals that later became famous - notably the bulls Splendid 2, Rob Roy I7, St. Helier 45, and Pierrot 636, and the cows Dot 7, Pansy 8 , Jessie 28 , and the Ives cow. In I85 I Thomas Motley imported for the Massachusetts Society for Promoting Agriculture, bringing over among other cows Flora I I 3 and Countess I I4. From I 850 importations became frequent. The dates of the introduction of the Jersey into some other localities are as follows: Maryland, I85 I N New York and Pennsylvania, I 855 ; Ohio, I 865 ; Canada, I 868. Many importations have been made in recent years.

Characteristics of the Jersey. In general conformation the Jersey is lean and muscular, conforming to the dairy type. The head should be lean and fairly short, broad between the eyes and muzzle, and dish-faced, both with male and female, to a greater degree than with other common breeds. The eyes are naturally of good size and prominent, in some instances being so bulging, or "pop-eyed," as it is termed, as to appear abnormal. The homs vary in form, but those of the bull should be short and strong, curving around forward and upward and slightly inward, while those of the cow should be smaller and perhaps longer, with more curve. A white or amber-colored horn with blackish tip is the approved sort, and when yellow tinted is assumed by many to indicate richness in butter fat. The shoulders tend to be a bit prominent, the withers narrow and refined, and the chest deep and of moderate thickness. Too many Jerseys are narrow chested

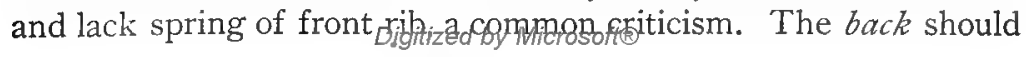


be strong and well supported, with little if any droop, the ribs well sprung and long, the entire body showing comparatively large size and strong reproductive and digestive capacity. The hips should be fairly broad in the cow, but not in the male; the rump long, wide, and level; the thighs thin and muscular and set wide apart; the hocks and fict carried straight with ample room to allow a large udder between. Jerseys tend to be narrow at the rump, as viewed from behind, and cow-hocked. The udder is usually mellow and milks well, but it has been subjected to considerable

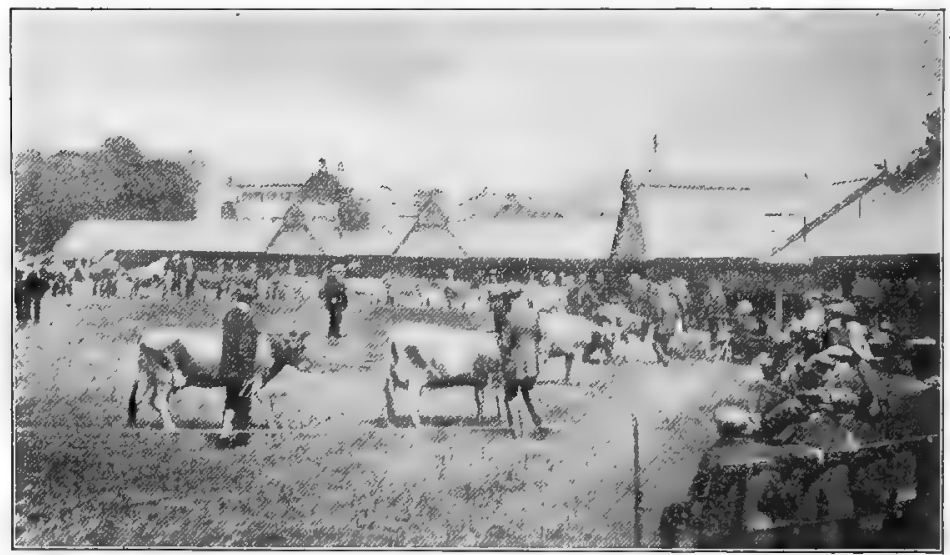

FIG. 137. A corner of the show yard at Springfield, on Jersey, at the annual Cow and Heifer Show, May, I9I4. From photograph by the author

criticism for its small size as well as small teats. The form of the udder has been much improved in recent years, especially in the extension of the fore quarters, although these are still frequently elevated and abbreviated. The milk veins no doubt attain as great relative size and prominence with the Jersey as any breed, often being very tortuous, long, and comparatively large.

The color of the Jersey is usually referred to as a fawn, but it is variable in shade, being yellowish, reddish, grayish, brownish, or silvery fawn. Some are described as orange or lemon fawn, and others as squirrel gray or mulberry black. White as a whole does not occur, but white marks are quite common, although a body of solid fawn is preferred. Brindlę, a rare color, is objected 
to and should cause disqualification. The hair about the muzzle and eyes is usually of a creamy or grayish shade, and a light tone frequently occurs along over the spine. In a study of the inheritance of color in the Jersey by Professor J. J. Hooper of Kentucky State University, the color markings of I 45 calves and 2290 sires and dams were tabulated. It was found that the solid color of coat is dominant to broken color and that black tongue and switch are dominant to white tongue and switch. Matings of 436 solid-colored cows with broken-colored bulls produced 257 solid-colored calves and $\mathbf{I} 79$ of broken color, while 500 matings of cows and bulls of solid color produced 425 calves of solid color and 75 calves of broken color.

In registering Jerseys it is necessary to specify whether the tongue is white or black, or the switch white or black, these being marks of identification. Where color is made a point of im-

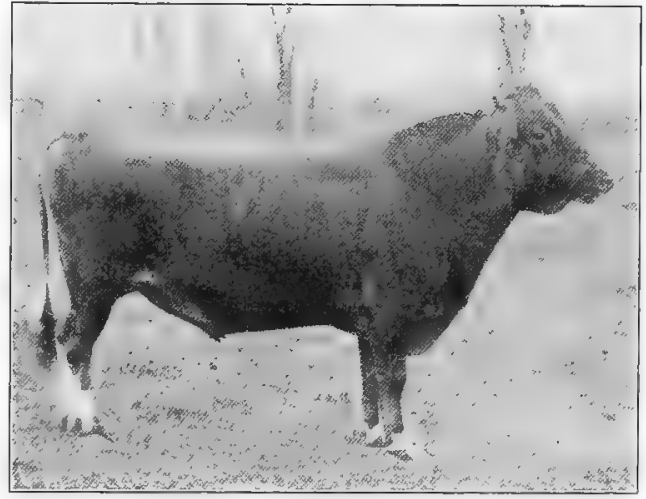

FIG. I38. Fancy Toltec 2 I 167 , about I 895 , in the herd of the late A. T. Dempsey. A popular Americantype show bull. From photograph given the author by Colonel Dempsey

portance in the breeding of a herd, a dark fawn, shading to light along the backbone and the lower limbs, meets with much favor, though solid colors of light fawn are also very popular. The most experienced and able breeders do not place primary emphasis on color, always making it secondary to the more important features, color being a fancy point and of no intrinsic value. The skin secretions are usually quite yellow, and, as seen in the ear, at tip of tail, and about the udder, indicate something of the richness of the milk. The skin itself should be thin, very elastic and mellow, and with a fine thick coat of hair.

The size of the Jersey may be classed as small to medium, with a tendency in breedersigitizededufterasontinedium sort. Taking the 
records of weights in the register of merit, many of which are estimated, 25 yearling heifers averaged 698 pounds, the range being from 600 to 850 ; 50 two-year-olds averaged 779 pounds, the range being from 600 to 1000 ; 50 three-year-olds averaged 827 pounds, the range being from 650 to Iooo; while the aged cows averaged 908 pounds, the range being from 750 to 1080 . Eleven of the aged cows weighed Iooo pounds or more and 22 weighed from 900 to Iooo pounds. The average weight of 24 cows at the World's Columbian Exposition in 1893 was $922 \frac{1}{3}$ pounds. One may regard 700 pounds as a fair weight for a heifer approaching two years of age, while fully matured cows should weigh from 850 to 900 pounds. One finds considerable range in weight of Jersey bulls. Eighteen bulls, heads of herds from which the author secured records, weighed from IO4O to I 790 pounds, the average being I 4 I 5 pounds. In general a weight of from I 300 to 1400 pounds is preferable in the mature Jersey male.

Early maturity of the Jersey is more marked than with any other common breed of cattle. Repeated cases are on record of Jersey females, through accident, having the first calf before three hundred and sixty-five days old. Both males and females develop rapidly and are often in service too early for the good of the herd or breed. Occasionally one will find a herd of Jerseys, where the owner has bred the heifers to come fresh at eighteen to twenty months old. In these herds one is impressed by the small size and runty appearance of the cows. The wiser and more thoughtful breeders of to-day plan to have their heifers come fresh about thirty months old, depending somewhat upon the vigor and size of the animals to be bred. A greater vitality and producing capacity is thus secured.

The adaptability of the Jersey. to a wide range of conditions is well established. While the breed has its native home on an island with a very mild climate, one finds important herds of Jerseys under a great variety of conditions. In America there are herds at wide extremes of latitude and altitude, for in the cold Northland and the sunny South and on the low prairies of Texas and the high altitudes of the western Rocky Mountains do we find Jerseys successfully established. Without question this breed readily adjusts itself to its environment, not only in America but also in various other cobntriziefiby Microsofte 
The prolificacy and vitality of the Jersey may be regarded as very fair, and in those herds long continued under uniform management the cows of this breed reproduce with reasonable regularity. Under average conditions the Jersey may be expected to produce one calf a year, and while twins occasionally are dropped they are the rare exception. The cows breed for many years, and it is no uncommon thing to find animals twelve years or more of age that have been steady producers. Figgis, the champion cow at the Louisiana Purchase Exposition, was thirteen years old and Marjoram 2d sixteen years old at the World's Columbian Exposition. Lass's Jewel

II 32 I I up to eighteen years of age had dropped twelve calves and so also had St. Lambert's Riotress 106220. Pogis Irene $2 \mathrm{~d}$ I 46435 at the age of fifteen years completed a year's official record of 9177 pounds of milk and was the mother of ten calves. There are many examples of aged Jersey bulls, notable among them Pedro, in service until nearly twenty years old.

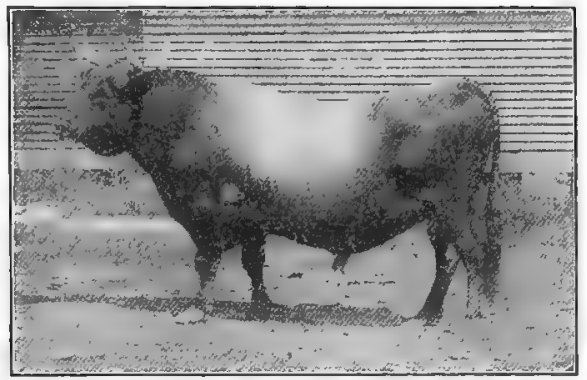

FIG. I39. Pedro 3187 at eighteen years of age. Grand-champion Jersey male at the World's Columbian Exposition, I893, and one of the most noted of American-bred Jersey bulls; long at the head of the herd of Mr. T. S. Cooper, Coopersburg, Pennsylvania. From photograph, by courtesy of Mr. Cooper

The temperament and disposition of the Jersey may be viewed from the sex standpoint in two ways: the cows are very mild and gentle of disposition and are easily handled when given kindly care. The bulls, however, tend to be nervous and irritable and need to be handled with much care and discretion. Even on the island, where the cows have the most friendly relationship with the caretakers, the bulls are nervous and are given very restricted liberties. There are examples of males of the breed that are quiet and tractable, but in general the bulls of none of our other breeds of cattle are so nervous and require such careful watching and restriction as does the Jersey. Age does not seem to modify the disposition of the average bull of the breed, and the wise Jersey cattleman will take no chances with his bull. 
The prepotency of the Jersey is one of its striking characteristics. Both form and color are transmitted from generation to generation in a marked degree. In well-established herds, where systematic breeding is attempted, one may find striking evidences of this prepotency, notably in head, udder; and color. Used on grade herds the Jersey bull impresses himself on his offspring to such an extent that the herd takes on all the external evidence of the pure-bred.

The Jersey in crossing or grading may be used to great advantage, at least in the latter way. There are many high-grade Jersey herds in the country that are very profitable producers of butter and milk. If bulls of proper breeding and individual merit are used on native cows very superior dairy herds should result. If crossed with other breeds the Jersey should be used under conditions that are not too violent as extremes. The author has seen some very attractive examples of using a Dexter bull on Jersey cows, in which small dairy cows of very milky character were produced.

The Jersey as a beef producer is not worthy of serious consideration. The meat is rich in quality and fine of grain but is too yellow in fat coloring to suit butchers. Jersey steers will lay cn flesh fairly well, but do not dress out well in slaughtering, having more offal and internal fat than the distinctive beef breeds. In a breed-feeding experiment for beef at the Michigan Agricultural College the Jersey steer Roscoe at II6I days weighed 1490 pounds (showing a daily gain of $\mathrm{I} .28$ pounds) and dressed out 59.4 per cent, compared with a Shorthorn which dressed out 66.8 per cent. Of six breeds tested the Jersey made the poorest showing. Three Jersey steers fed by two experiment stations, as reported by Henry in "Feeds and Feeding," showed an average daily gain for 1058 days of I.36 pounds per day, ranking ninth among eleven breeds in daily gain, but standing last in per cent of dressed weight. In a steer-feeding experiment conducted by the Iowa Station with nine breeds, the valuation placed on the Jersey carcass by Chicago experts was $\$ 4.50$ a hundred, the lowest of the nine, the Hereford being $\$ 6.62 \frac{1}{2}$.

The Jersey as a producer of milk, under average conditions, does not rank high. However, since official tests have become common, we find many Jersey cows that have produced relatively 
large yields of milk. Many years ago, when only private tests were made of Jersey production, some records were regarded as large that since have been displaced by official ones. For example, Gertie of Glynllyn 74474 was credited in I898-1899 with I6,780 pounds of milk, La Petite Mere 2d I 28 Io with 16,699 pounds 8 ounces in I885-I886, and Matilda 4th 12816 with I6, I 53 pounds 12 ounces the same year, these being regarded as

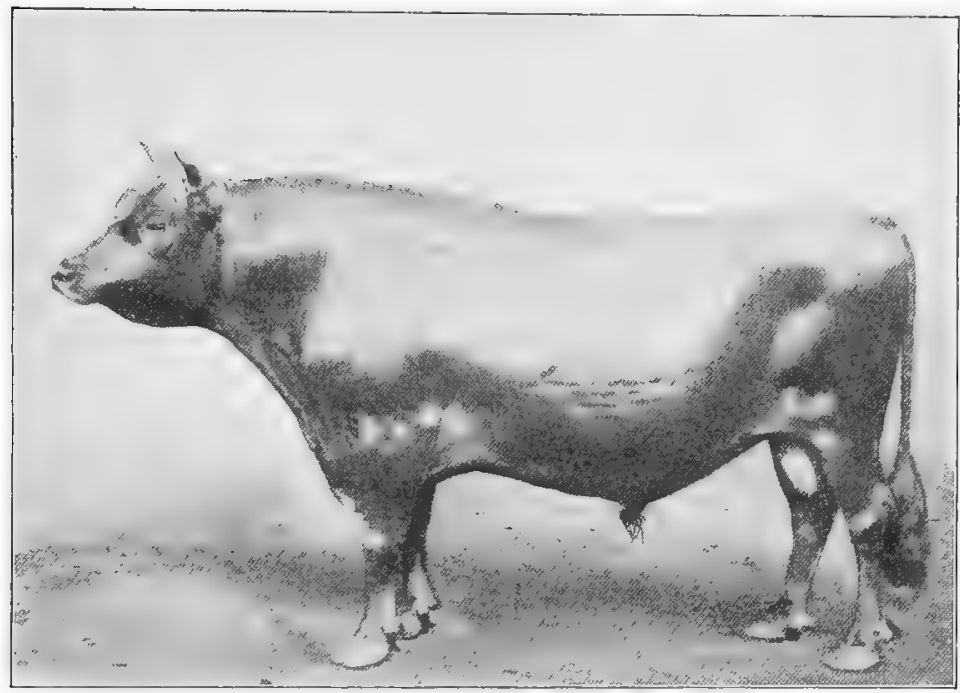

Frg. I 40. Raleigh's Fairy Boy 83767 , imported by T. S. Cooper and sold at his rgog sale for $\$ 8200$ to C. I. Hudson of New York. Notable as a champion and sire. A fine example of the modern Island-type bull. From photograph, by courtesy of Mr. Hudson

remarkable records. In one day Adelaide of St. Lambert 73652 gave a yield of 75 pounds $I 2$ ounces. But it is no longer necessary to quote private records, for official testing is now established on a large scale and the records of many cows are available. The table on page 334 contains some of the more important register-ofmerit records for one year of milk production.

In addition to these records there have been many large milk records of Jerseys for either longer or shorter periods. Some of the notable examples are as follows: Sophie rgth of Hood Farm I89748 produced in eigg, 
High Official Annual Milk Records of Jersey Cows

\begin{tabular}{|c|c|c|c|}
\hline Name and Number of Cow & $\mathrm{AGE}$ & YEAR OF TEST & MILK YIELD \\
\hline Passport 219742 & 8 & $1914-1915$ & $19,694 \mathrm{lb} . \quad 2.0 \mathrm{oz}$ \\
\hline Eminent's Bess 209719 & 7 & $1911-1912$ & I 8,782 lb. 15.6 oz. \\
\hline Lass 4 oth of Hood Farm 223642 . & 5 & $1912-1913$ & I8,66r lb. $7.0 \mathrm{oz}$ \\
\hline Lass 66th of IIood Farm 271896 & 3 & $1914-1915$ & I 7,793 lb. I I.2 oz. \\
\hline Sophie 19th of Hood Farm 189748 & 7 & $1912-1913$ & I 7,557 lb. $12.0 \mathrm{oz}$ \\
\hline Jacoba Irene 146443 & 9 & $1908-1909$ & I 7,253 lb. $3.2 \mathrm{oz}$. \\
\hline Blue Fox's Eminent's Chromo 317736 & 8 & $1917-1918$ & I 7,2 I 7 lb. $8.0 \mathrm{oz}$ \\
\hline Temisia's Owl's Rose 2 I 5973 & 8 & I9I4-I9I 5 & $17,056 \mathrm{lb} . \quad 6.4 \mathrm{oz}$ \\
\hline Dosoris Park Lily 223783 & 5 & $1916-1917$ & I $6,728 \mathrm{lb} . \quad$ I. $6 \mathrm{oz}$. \\
\hline Spermfield Owl's Eva I93934 & 8 & I9I2-1913 & I $6,457 \mathrm{lb} .6 .4 \mathrm{oz}$. \\
\hline
\end{tabular}

milk; Spermfield Owl's Eva I93934, from November, I906, to December, I9I6, produced 90,642 pounds of milk - an average of 9065 pounds a year for ten consecutive years; Pogis Irene $2 \mathrm{~d}$ I 46435 at eighteen years of age produced 9930 pounds of milk; Lucky Farce 298177 produced in one year (commencing a yearling) I 4,260 pounds of milk; Jacoba Irene I46443 in one day produced 69.8 pounds of milk; Passport 2 I9742 averaged 53.9 pounds daily for three hundred and sixty-five days.

In the ninety-day test at the Columbian Exposition the 25 Jersey cows in the trial, including sick ones, averaged 33 pounds of milk daily, while in the Louisiana Purchase Exposition test 25 cows during ninety days averaged $4 \mathrm{I} .5$ pounds of milk per day. Up to May I, I9I9, there were in register of merit tests I 493 cows and heifers of various ages. Yearly records of nearly 7000 cows have averaged 7808 pounds of milk each.

The Jersey as a milk-fat producer is justly famous. An important feature in connection with Jersey milk is that the fat globules are comparatively large and the cream rises or separates easily. The value of Jersey milk for producing superior butter was recognized over a century ago in England and first attracted Dauncey to the breed. Many fine records have been made in England and on the island of Jersey, but America has led in the testing of this breed. In I 853 the first Jersey butter test was made in this country, Thomas Motley of Massachusetts testing the cow Flora I I 3, when, as a three-year-old, I 4 pounds 
8 ounces of butter was made in seven days from her milk. The same year the cow Rose 240 yielded 17 pounds in seven days. From this time thousands of seven-day tests have been made of Jersey cows, showing records ranging from I4 pounds of churned, salted, and worked butter, up to that of Princess $2 \mathrm{~d} 8046$, reported in 1885 to have made an official test of 46 pounds $12 \frac{1}{2}$. ounces in one week. The testing of Jerseys for butter production became so extensive that Major Campbell Brown of Tennessee and others collated and published two volumes of such tests, and later, in I 890, the American Jersey Cattle Club took up this work officially. Several thousand records have been published in book form by the club. Many of these records were so high as to cause suspicion of the integrity of the testing, which finally resulted in the club's providing for butter-fat tests as well as churn tests, to be supervised by experiment-station or agricultural-college officials. However, between I879 and I892 a number of remarkable records were claimed of yearly butter production in private tests. The following six cows attained great fame in this connection:

\begin{tabular}{|c|c|c|c|c|}
\hline Name and Number of Cow & & RECORD & DURATION & YEAR OF TE \\
\hline $\begin{array}{l}\text { Eurotas } 2454 . \\
\text { Mary Ann of St. Lambert } 9770 \\
\text { Landseers' Fancy } 2876 \\
\text { Eurotissima } 29668 \\
\text { Bisson's Belle } 3 \text { I I } 44 . \\
\text { Signal's Lily Flagg } 3 \text { I035 }\end{array}$ & & $\begin{array}{l}778 \mathrm{lb} . \text { I oz. } \\
867 \mathrm{lb} .14 \frac{3}{1} \text { oz. } \\
936 \mathrm{lb} .14 \frac{8 z}{4} \text { oz. } \\
945 \text { lb. } 9 \text { oz. } \\
\text { 1025 lb. I } 5 \text { oz. } \\
\text { I047 lb. } \frac{8}{1} \text { oz. }\end{array}$ & $\begin{array}{l}365 \text { days } \\
365 \text { days } \\
365 \text { days } \\
365 \text { days } \\
365 \text { days } \\
365 \text { days }\end{array}$ & $\begin{array}{l}\text { I } 879-1880 \\
\text { I } 883-1884 \\
\text { I } 885-1886 \\
\text { I } 886-1887 \\
\text { I } 888-I 880 \\
\text { I } 89 I-I 892\end{array}$ \\
\hline
\end{tabular}

Since 1893, when the Jersey breed took official part in the dairy breed competition at the World's Columbian Exposition and disinterested persons supervised the tests, such large private tests have not been reported. Unquestionably many Jersey cows will yield from 14 to I7 pounds of butter in a week, while a few may pass 20 pounds. The best record made in a week at the Columbian was by the cow Brown Bessie 74997 of 20. I6 3 pounds; in thirty consecutive days her yield was 77.319 pounds. In the Columbian Exposition tests the Jersey excelled both Guernsey and Shorthorn in butter-fat production. At the Pan-American Exposition in I90 I the Jersey stood second among ten breeds in 
profitable fat production, the Guernsey leading. In the Louisiana Purchase Exposition the Jersey surpassed the Holstein-Friesian and Brown Swiss in butter and cost of production, the average cost per pound being $10 \frac{1}{2}$ cents for the Jersey, $132_{2}^{1}$ cents for the Holstein, and $14 \frac{2}{3}$ cents for the Brown Swiss. In ninety days in this test the Jersey cow Loretta D. I4I 708 produced 280.16 pounds butter fat, which returned a net profit of $\$ 50.52$.

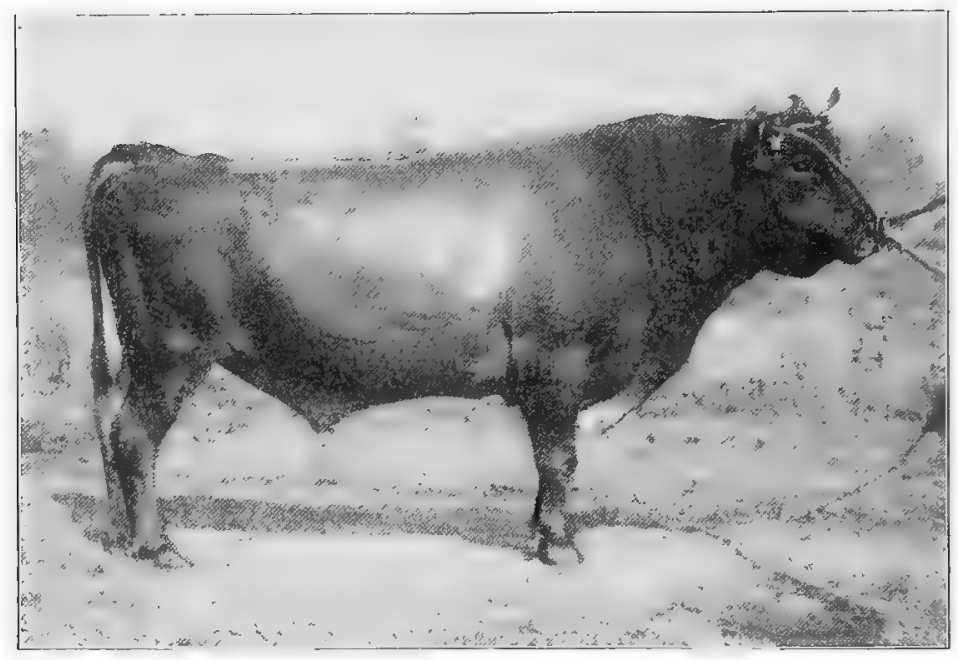

FIG. I4I. Oxford Majesty I3409o (imp.) at twelve years of age. A remarkably prepotent sire of great show cows. Owned by A. K. Heath, Creamery, Pennsylvania. From photograph, by courtesy of Mr. Heath

Authenticated butter-fat tests of Jersey cows were given indorsement on May 6, 1903, by the American Jersey Cattle Club, when what was designated a "Register of Merit" of Jersey cattle was established. The purpose of this was to raise to a higher standard the average excellence of the Jersey cow and to secure additional authoritative and permanent record to which reference could be made in the selection of breeding animals. Cows are divided into threc classes: A, AA, and B. A cow is entitled to entry in Class $A$ after producing in one year the amount of butter fat or butter specified by the rules. A cow is entitled to entry in Class AA provided she produces the required 
butter fat or butter, and also produces a living calf, which has been carried at least one hundred and fifty-five days during the test. Class B is for seven-day official tests of butter-fat or butter production. A bull is entitled to entry in the register of merit after three of his daughters from as many different dams have been entered on the year's authenticated test. "These tests are supervised by a representative of a State, Provincial or National experiment station or agricultural college, who certifies as to the weight of the milk, and the percentage of fat it contains on the days on which the cow is under official test." 1

The required yield in authenticated tests of Jerseys is as follows:

If the test is commenced the day the cow is two years old, or previous to that day, she must produce within one year from the date the test begins, $250.5 \mathrm{lb}$. butter fat. For each day the cow is over two years old at the beginning of her year's test, the amount of butter fat she must produce in the year is fixed by adding 0.1 (one-tenth) of a pound for each such day to the $250.5 \mathrm{lb}$. required when two years old. This ratio of increase applies until the cow is five years old at the beginning of her test, when the required amount will have reached $360 \mathrm{lb}$., which will be the amount of butter fat required of all cows five years old or over. These standards are based upon one complete year's record, from the time of beginning, regardless of any time which may be lost by being dry or calving during that period.

Since the establishment of the authenticated butter-fat tests a large number of cows have secured a place in the register of merit. During March, 1919, there were entered 2812 cows in official tests, while the previous March, 2703 animals were tested.

\section{The ten leading Jersey cows in butter-fat tests for one year,} as recorded in the register of merit, are as follows:

Vive La France 319616

Sophie's Agnes 296759

Sophie I gth of Hood Farm I 89748 .

Spermfield Owl's Eva I 93934

Old Man's Darling 2d 319617

Eminent's Bess 209719

Dosoris Park Lily 233783 .

Jacoba Irene r 46443

St. Mawes Poppy 21.9992

Olympia's Fern 252060 produced 1031.64 lb. fat produced $1000.07 \mathrm{lb}$. fat produced $999.10 \mathrm{lb}$. fat produced $993.30 \mathrm{lb}$. fat produced $983.68 \mathrm{lb}$. fat produced $962.80 \mathrm{lb}$. fat produced $957.43 \mathrm{lb}$. fat produced $952.90 \mathrm{lb}$. fat produced $952.28 \mathrm{lb}$. fat produced $937.8 \mathrm{o} \mathrm{lb}$. fat

${ }^{1}$ Register of Merit of Jersey Cattle, December, I917. 
Perhaps the most remarkable test up to 1918 was that of the three-year-old-cow Vive La France 319616, owned in Oregon, that produced $12,744.8$ pounds of milk in three hundred and sixty-five days, testing 892.63 pounds fat. Sophie I9th of Hood Farm occupies the greatest place of distinction among Jersey cows as a long-distance performer, for in eight periods of lactation up to I 919 she has produced a total of 5787 pounds of

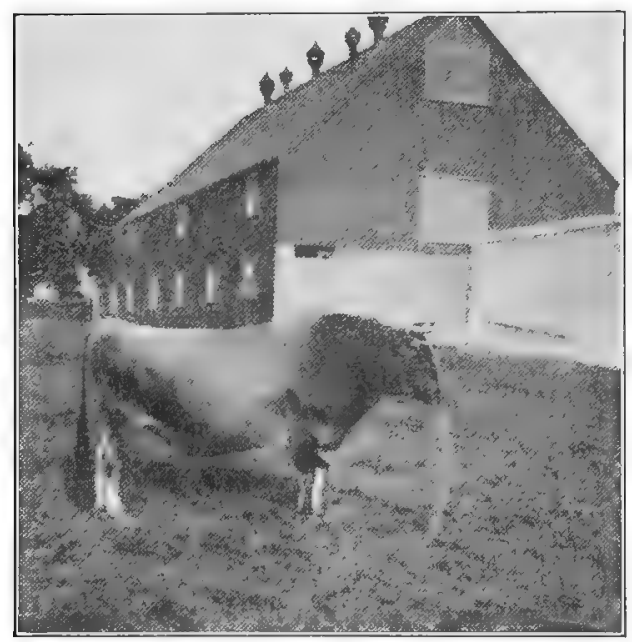

FIG. I42. Agatha's Oxford Noble, P. 4850 H. C. First-prize bull over Jersey bulls from tested dams, 191 2. Owner, J. II. Perree, Oaklands, island of Jersey. From photograph by the author fat, or more than three tons of estimated butter. About January I, I9I6, Secretary Gow of the American Jersey Cattle Club stated ${ }^{1}$ that the average per cent of fat in the milk of 4295 official annual tests was 5.34 per cent, which is probably slightly higher than would prevail under average conditions, when tests were not conducted. In reporting on the results of tests in age classes Mr. Gow stated that 1528 twoyear-old cows averaged 352.75 pounds fat, 769 three-year-olds averaged 396.10 pounds fat, 539 four-year-olds averaged 448.80 pounds fat, and I46 I cows five years old averaged 479.40 pounds fat. These records are extremely creditable to the breed and give ample evidence of the capacity of the Jersey as a producer.

Jersey milk in cheese production is used to but a limited degree. At one time it was thought that milk of average butterfat content made a better cheese than that of richer quality. However, the investigations in the working dairy at the World's Columbian Exposition at Chicago demonstrated that milk rich

1 Hoard's Dairyman, December 24, 1915. 
in butter fat made more valuable and better cheese than milk inferior in butter fat. In the Exposition cheese test the following records were secured in a fifteen-day test:

\begin{tabular}{|c|c|c|c|c|c|}
\hline Preeil & $\begin{array}{l}\text { Amount } \\
\text { CheEse }\end{array}$ & value & $\operatorname{Cos} T$ & $\begin{array}{l}\text { VMite } \\
\text { Pound }\end{array}$ & $\begin{array}{c}\text { Amunnt Muk Per } \\
\text { Pound Cheese }\end{array}$ \\
\hline Jersey & I $45 \mathrm{I} .76 \mathrm{lb}$. & का $193.9^{8}$ & $\$ 98 . x_{4}$ & $\$ 0.131$ & $9.16 \mathrm{lb}$. \\
\hline Guernsey & I $130.62 \mathrm{lb}$. & 135.22 & 76.25 & 0.12 & $9.67 \mathrm{lb}$ \\
\hline Shorthorn. & $1077.60 \mathrm{lb}$ & I fO.It & $99 \cdot 36$ & 0.13 & II.3 I lb. \\
\hline
\end{tabular}

This record clearly shows that Jersey milk holds a high place in cheese production. It finds its most important use, however, in butter-making or in the retail milk trade, comparatively little being made into cheese.

Jersey families of distinction are to-day clivided into two groups: those more especially of island breeding and those of American breeding quite removed from recent island importation. There are examples, however, in which there is essentially a combination of blood lines from the two groups. There has also been a tendency on the part of some to regard certain lines of breeding as distinct families, although in fact these are more strictly speaking subfamilies. These branch families are perhaps justifiable, but special recognition is sometimes given which is hardly worth while. Some person successfully promotes a line of breeding and then gives a family title to the same, which becomes adopted by common usage. However, the following described families may be regarded as the more distinguished of the many to which reference might be made.

\section{ISLAND-BRED FAMiLies}

The Golden Lad family descends from Sultane, P. 7 H. C., but derives its name from the bull Golden Lad, P. I $242 \mathrm{H}$. C., first-prize bull over the Island in I89o. Golden Lad was sired by Sultane's Favourite, P. 873 H. C. and had for dam Golden Lass 4th, P. 2447 H. C., second prize on Jersey in 1888 , a granddaughter of Sultane, P. 7 H. C. and regarded as founder of this family. Many of the most famous of the Island-bred animals trace directly biaitkedby Lad. 
The 0xford family descends from Oxford Daisy, F. 68 I6 H. C., but receives its special distinction through Oxford Lass, P. 3582, C., one of the most noted cows produced on the island. Oxford Lass was dam of Oxford Lad, P. 3.123 H. C., one of the great bulls of the island, sire of Majesty, Lucy's Champion, and Sultana's Oxford Lad, and also sire of forty-two tested cows. Oxford Lass was also granddam of Oxford You'll Do II I860 (imp.), winner of first prize over Jersey in I9I I and a noted sire of tested cows. The Oxford family is one of the most popular of present-day island breeding.

The Cowslip family descends from Cowslip, P. 24 C., a firstprize cow on the island in 1876. Her granddaughter Cowslip I6th, P. 6084 H. C., by Golden Lad, is regarded as the essential head of this family. Cowslip r6th was winner of the Parish Prize on the island in 1902, but she is most noted as the $\$ 5000$ cow, dam and granddam of a number of animals of exceptional merit, especially in production.

The Fontaine family began with Fontaine, F. 2058 C., first over Jersey in 1886 , and a heavy milk producer. Her daughter Fontaine 4th, P. 2537 C., was dam of Fontaine 7th, 9th, and roth, first-prize winners on the island. Fontaine's Chief, P. $4 \mathrm{I} 53 \mathrm{H}$. C., was noted as a show bull, both on the island and in America, and has a large number of officially tested daughters to his credit.

The Financial Interest family descends from Interest, F. 3582 C., a remarkable producer of milk and progeny. She has an island record of 56 pounds of milk in twenty-four hours and 25 pounds 6 ounces of butter in seven days. She produced a number of notable daughters, including Finance, P. S. 46 I I C., the dam of Financial Pride and Financial Queen, P. S. 7766 H. C., I 55098 , the latter being dam of Financial Countess 155100 with register of merit record of 935 pounds Io ounces of butter in a year. Financial King, P. 2624 H. C., a son of Finance, was sire of uncommonly high-class cows, including Financial Countess I 55100 , Financial Interest 167527, and Financial Princess I67528. From Compound Interest I 52193 (imp.), a daughter of Interest, came Interested Prince 58224 (imp.), one of the most notable recent-day sires. 
The Rosette family traces from Rosette through her daughter Rosette 2d, F. 943 H. C. and her granddaughter Rosette $\cdot 4$ th, P. 2 I 28 C. Bred to Sarabond, P. 797 H. C., Rosette 4th produced Rosette 5th, P. 288 I H. C., imported by Mr. Cooper under the name of Sultana's Rosette I49740. She proved a remarkable breeder and dropped the bulls Flying Fox, P. 2729 H. C. (Champion Flying Fox 6I44I, imp.), Ravachol, P. 2032 C., and Forfarshire, P. 29I4 H. C., three of the great island-bred bulls, and the cow Alicante, P. 3880 H. C., dam of the Owl, P. 2195 H. C., a leading island-bred sire, first over Jersey in I897. Spermfield Owl 57088 , a son of the Owl, has been one of the leading sires in America, his daughters Spermfield Owl's Eva, Spermfield Owl's Temisia, Owl's Sayda Queen, Owl's Interested Tones, Spermfield Owl's Victoria

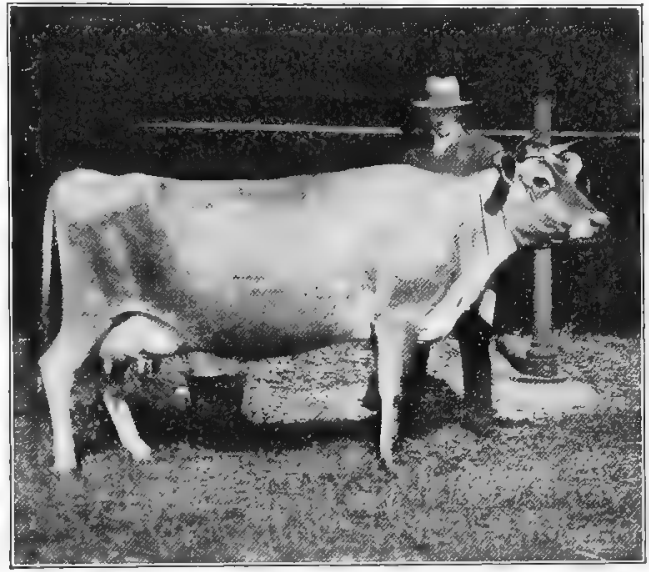

FIG. I43. Sultan's Finance (I4I00), first-prize cow over Jersey. A very beautiful Island type. From photograph by the author Lass, and Violet's Owl being a remarkable group of sisters with milk records ranging from 13,158 pounds to 16,457 pounds and butter-fat records ranging from 680 pounds to 993 pounds.

\section{American Jersey Families}

The Signal family descends from old Pansy 8, calved in r 853 and imported when two years old by Mr. John T. Norton of Connecticut. She had four daughters - Pansy 2d 259, Pansy 5th 4I4, Pansy 6th 38, and Pansy 7th I3O - and two sonsYork 8 and Living Storm I73. Pansy 6th 38 dropped ten sons and daughters, one of which, Pansy Morris 2060, calved in 1870 , 
was the dam of Signal I I o, one of the most notable and prepotent sires of the breed in the last quarter of the nineteenth century. Cows of Signal breeding were greatly in favor and especially notable for being producers of butter fat.

The Coomassie family descends from Coomassie I I 874, imported in $188 \mathrm{I}$ by S. M. Burnham. Coomassie was the dam of Khedive, P. IO3, the sire of Princess 2d, with a so-called official test of 46 pounds 121 ounces of butter in seven days. Tormentor 3533 (imp.), one of the greatest bulls of the breed, was a grandson of

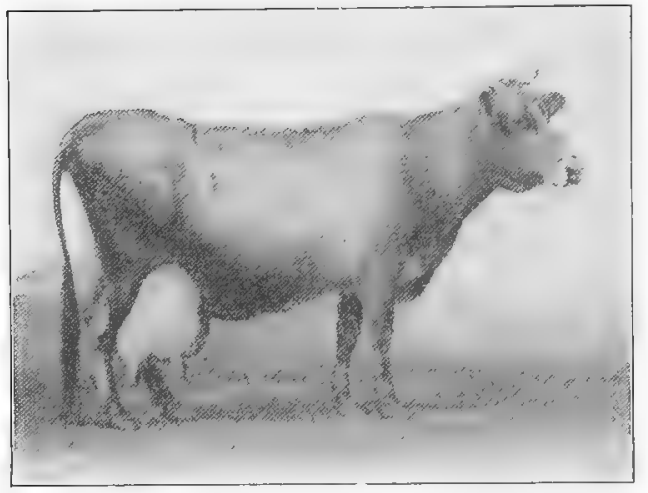

FIG. I44. Eurotas 2454 (imp.), a Jersey cow remarkable as a great dam and also as a producer of milk. The mother of Pedro. She had a private record of 778 pounds of churned butter in eleven months five days. Owned by A. B. Darling. From photograph by Schreiber

Coomassie, being sired by Khedive. Many persons have considered Coomassie the greatest cow ever imported from the island. In 1885 L. S. Hardin wrote 1 : "Her blood has developed the greatest individual butter maker, Princess $2 \mathrm{~d}$, and thirtyone animals with tests of fourteen pounds and over in direct descent from her, without the aid of any special outcross."

The Eurotas family descends from Eurotas 2454, calved in I874. This is also referred to as the Alphea family, for the reason that Eurotas was a granddaughter of Alphea I 7I. Eurotas, herself a remarkable dam, with a private record of 778 pounds I ounce of butter in a year, was also dam of eight sons and two daughters of exceptional merit. Her son Pedro 3187 will always be regarded as one of the greatest sires of the breed, and through him is a long list of unusual sons and daughters. In I9I8 Mr. T. S. Cooper, long the owner of Pedro, wrote" : "With

1 The Jersey Cow. A pamphlet by the American Jersey Cattle Club.

${ }^{2}$ Jersey Bulletin, March 27, 1918. 
I 28 tested daughters and granddaughters, the Jersey breed appears to have been benefited by the influence of Pedro $3187 . "$ Coomassie and Eurotas blood blended especially well.

The St. Lambert family originated at St. Lambert, Quebec, Canada, through importation made in I 868 by the Stephens family. This original herd consisted of two bulls and fifteen cows, with the later addition of two cows and a bull. "To be,

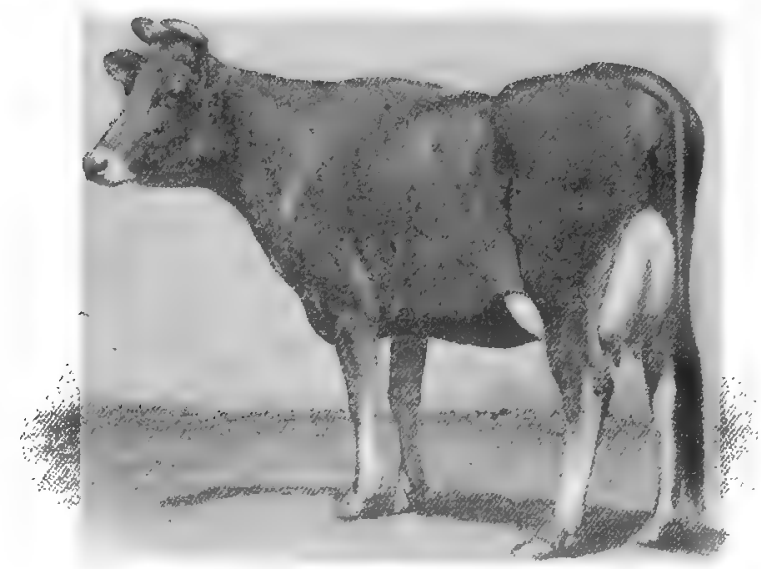

FrG. I45. Mary Anne of St. Lambert 9770, classed as one of the most beautiful Jersey cows of her time. The property of Valancey E. Fuller (then of Canada), she had a private record of 867 pounds $14 \frac{3}{4}$ ounces butter in three hundred and sixty-five days. From photograph by Schreiber

technically speaking," writes Mr. Valancey E. Fuller, the best authority on this family," "a pure St. Lambert, an animal must have as a foundation, without an outcross, one of the following bulls: Defiance 196, Victor Hugo 197, or Stoke Pogis 3d 2238; and one of the following cows: Victoria 4II, Pride of Windsor 283 , Amelia 484, Juliet 485, Alice 488, Hebe 489, Berthe 490, Bonnie 49r, Lizette 492, Ophelie 493, Pauline 494, Lydie 495, Portie 496, Fancy I3 8 , Beauty I319, Taffy 5523, or Topsey

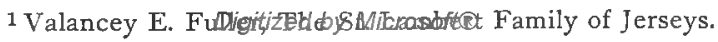


St. Lambert 5524." It is also claimed with reason that Stoke Pogis I 259 (imp.) and Marjoram 3239 (imp.) should be regarded as in this foundation stock. The fame of this family was first promoted by Mr. Fuller, who, in I88I, purchased a number of St. Lambert Jerseys from William Rolph of Markham, Ontario. Finally he purchased Mary Ann of St. Lambert 9770, sired by Stoke Pogis 3d 2238 (imp.), one of the famous cows of the breed, with a private record for a year of 867 pounds $\mathrm{I}_{4}^{3}$ ounces of butter. Stoke Pogis $3 \mathrm{~d}$ proved a most successful sire, and a daughter of his, Ida of St. Lambert 24990, bred to Bachelor of St. Lambert 4558, produced Ida's Rioter of St. Lambert I 3656 and also Exile of St. Lambert 13657 , the latter being credited with more tested daughters than any other son of this family. The St. Lamberts have had a great run of popularity, but in recent years the newer Island-bred families have superseded this. However, many of the recent-day American-bred Jerseys of special merit trace directly back into this St. Lambert breeding. Naturally this large family has broken up into various branches, or subfamilies.

The Combination family descends from Lady Mel 429, calved in $\mathrm{I} 868$ and bred by $\mathrm{S}$. W. Robbins of Connecticut. Her daughter Lady Mel 2d I795, by Albert 44, proved a remarkable cow, having in 1875 a butter test of 183 pounds in sixty-one days and being the dam of seven registered bull calves and four heifers. The bull Combination 4389, a son of Lady Mel 429, gives the name to this family. He sired many producing sons and daughters, among which Diploma I6219 was most distinguished, he siring many tested cows, including Merry Maiden 64949, champion cow in the World's Columbian Exposition at Chicago among 74 cows from three different breeds. Brown Bessie 74997 , the champion cow in the dairy test at the same exposition, was a granddaughter of Combination on the dam's side. Merry Maiden's 3d Son 605 I6, champion of the breed at the Louisiana Purchase Exposition in 1904, is the sire of numerous sons and daughters in the register of merit. This is one of the popular American Jersey families.

The Tormentor family receives its name from the bull Tormentor 3533 (imp.), he being sired by Khedive, P. IO3 and out of Angela, F. S. I607, a daughter of the noted Coomassie I I 874 
(imp.), which of course makes Tormentor a member of the Coomassie family. Tormentor proved to be one of the greatest Jersey sires, both of males and females. In the days of private tests his daughters reached high records, and his sons were credited with many daughters with tests of note. Tormentor breeding has received special distinction through his son Sophie's Tormentor 20883, the sire of Sophie 19th of Hood Farm I 89743 , without question thus far the greatest producing cow of the breed. Figgis 76106 , champion Jersey cow at the Louisiana Purchase

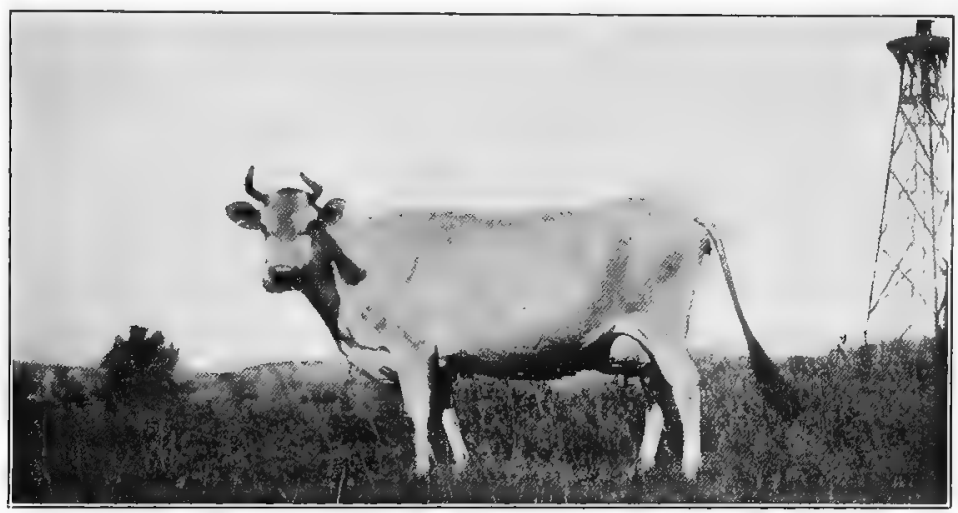

FIG. 146. Sophie Igth of Hood Farm I89748, the greatest producing Jersey cow in history. In seven periods of lactation she produced 5280 pounds of butter fat. Owner Hood Farm, Lowell, Massachusetts. From photograph by the author

Exposition and one of the great Jersey matrons, was a daughter of Sophie's Tormentor and mother of Hood Farm Pogis 9th 55552 , that up to January, I9I 8 , had more sons and daughters in the register of merit than any other bull of the breed, including three cows with records of over 700 pounds of fat each in a year. Jacoba Irene I46443, celebrated as one of the greatest producing Jersey females, is five generations removed from Tormentor on the dam's side. Among American Jersey families this at the present day is a prime favorite.

The Sayda family has for founder Sayda 4440, by Ned Booth I5OI. Her daughter Sayda 3d I73I7 was tenth in the Jersey herd at the World's Columbian Exposition in I 893. This family

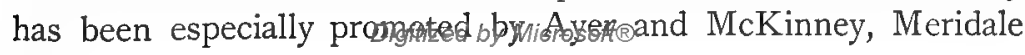


Farms, Meredith, New York, where Sayda's Queen of Ventnor I68033, by Sayda's Heir 45360, made the great record of I3,280 pounds milk and 890 pounds butter at twelve years of age. She has 4 daughters in the register of merit that average I I,604 pounds milk and 764 pounds butter. Sayda's Heir $3 d$ 748 I 7 (full brother of Sayda's Queen of Ventnor) up to January, I9I9, sired 50 cows and 2 bulls recorded in the register of merit. The Sayda and Owl-Interest families are said to blend especially well.

The 0w1-Interest

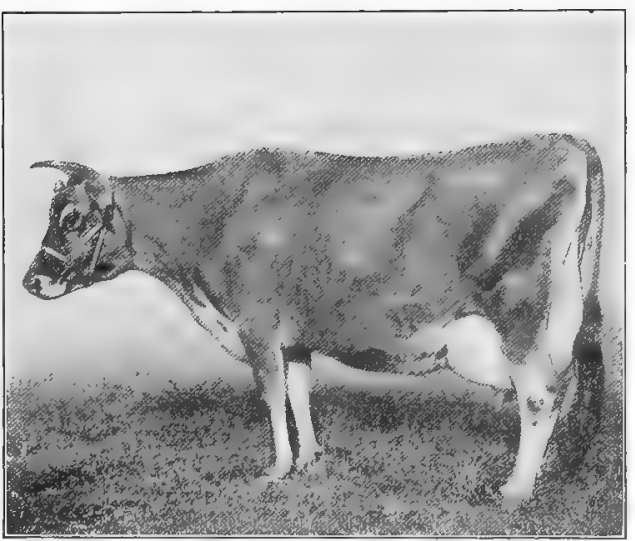

FIG. I 47. Sayda's Queen of Ventnor I68033. She has the great record as a twelve-year-old of producing 13,28 o pounds of milk and 890 pounds of butter. Owner, Meridale Farms, New York. From photograph, by courtesy of American Agriculturist family was established by R. A. Sibley, Moose Hill Farms, Spencer, Massachusetts, by crossing the bull Spermfield Owl 57088 on daughters of Interested Prince 58224 (imp.), and vice versa. These two sires were purchased in 1900 and used in service for many years at Moose Hill Farms. Remarkable records have been produced by members of this family. In 1918 Mr. Sibley published a list of 3 I Owl-Interest cows in his herd, with official milk records ranging from 9853 to 17,056 pounds and butter fat records from 595 to 993 pounds. This family is meeting with much favor.

Jersey bulls of distinction as sires may be divided into three groups: (I) notable early foundation animals, (2) sires of privatetest offspring, and (3) sires of register-of-merit progeny, this latter group being of real significance at this time.

Important foundation sires include Albert 44, Brown Prince F. 85, Clement F. 6r, Colonel 76, Jupiter 93, Khedive, P. I03, Landseer 33J, Marius 760, Mercury 432, Noble 592 E, Pilot 3, Pope 652 E, Rioter 746 E, Rioter $2 d 469$ E, Splendens I6, 
Splendid 2, St. Helier 45, Stoke Pogis 1259, Sultan F. 58, Victor Hugo 197, Welcome F. 166.

Jersey sires of private-test offspring of note include the following: Diploma I62 I9, Exile of St. Lambert I 3657, Fancy's Harry 9777 , Ida's Rioter of St. Lambert 13656, King of St. Lambert's King 30752, Pedro 3187, St. Lambert Boy I7408, Stoke Pogis 3d 2238, Stoke Pogis 55th 987, Tormentor 3533 (imp.).

Jersey sires of register-of-merit sons and daughters very naturally occupy first consideration to-day. In fact, in a careful study of Jersey pedigrees, register-of-merit tests on a yearly basis should be prime factors in consideration. It is no longer necessary or desirable to give serious thought to the private tests, although these offer important evidence. In these days of extensive official testing the records of sires are constantly changing, but the following list of sires, ${ }^{1}$ compiled by Mr. H. F. Probert, based on daughters that have produced over I0,000 pounds of milk under register-of-merit testing, is of special interest.

\section{Leading Jersey Stres with Daughters productng over ro,ooo Pounds of Milk a Year}

\begin{tabular}{|c|c|c|c|c|c|c|}
\hline Name of Cow & $\begin{array}{c}\text { Number } \\
\text { of } \\
\text { Daughters }\end{array}$ & $\begin{array}{c}\text { AveraGe } \\
\text { POUNDS } \\
\text { MILK }\end{array}$ & $\begin{array}{c}\text { Average } \\
\text { PoundS } \\
\text { FAT }\end{array}$ & \multicolumn{2}{|c|}{$\begin{array}{l}\text { AVERAGE } \\
\text { AGE } \\
\text { YR., Mo. }\end{array}$} & $\begin{array}{l}\text { Total Num- } \\
\text { BER of Regis- } \\
\text { TER of Merit } \\
\text { Daughters }\end{array}$ \\
\hline Hood Farm Torono 60326 . & 27 & $12,949 \cdot 4$ & 674.45 & 4 & 9 & 73 \\
\hline Interested Prince 58224 & IO & I $2,384 \cdot 4$ & $6 \mathrm{r}_{4} .82$ & 8 & 0 & 43 \\
\hline Spermfield Owl 57088 & 25 & I $2,142.4$ & 632.62 & 7 & I & 49 \\
\hline Raleigh's Fairy Boy 83767 . & 12 & I I ,894.2 & $573 \cdot 32$ & 5 & 8 & 43 \\
\hline Foxhall's Jubilee 76944 & 12 & I I, 8 I 2.8 & 578.93 & 5 & I & 22 \\
\hline Hood Farm Pogis 9th $5555^{2}$ & 12 & I I, 7 I 9.0 & 603.50 & 7 & 3 & 78 \\
\hline Royal Majesty 793 I3 . & 17 & I I, 706.4 & 608.34 & 6 & 6 & 37 \\
\hline Loretta's King 65050 . & 8 & I I, 594.I & 612.60 & 5 & 3 & 43 \\
\hline Eminent's Raleigh 690 I I & 9 & I I , 4 5 I.3 & 553.40 & 7 & 3 & 27 \\
\hline Golden Glow's Chief 61460 & 8 & I I, $443 \cdot 4$ & 631.69 & 6 & 2 & 27 \\
\hline $\begin{array}{l}\text { Average } \\
\text { Total }\end{array}$ & $\begin{array}{r}14 \\
\text { I } 40\end{array}$ & $12,021.07$ & 608.67 & 6 & 3 & 442 \\
\hline
\end{tabular}

Mr. Probert compiled two groups of leading sires, the above being the first one. Commenting on this study he writes as follows: 
Here is the point I want to get at, that these bulls that have the large amount of milk are the bulls that have the large amount of butter fat. They travel hand in hand. Look for one and you will get the other. I have taken the next bunch of bulls that have over four daughters that have I 0,000 pounds of milk to their credit, and there are ten of them that have five, two that have six, and two that have seven, and they immediately drop off in large production.

A comparison of native with Island-bred Jersey sires is of interest for the reason that American breeders are repeatedly questioning the productive capacity of Island-bred stock. Mr. John R. Sibley, a most successful Jersey breeder, has contributed much interesting information on this subject. ${ }^{1}$ Based on registerof-merit work, he gives the following two groups of each of the ten leading sires of native and imported breeding.

Leading Native Jersey Bulls to January 1, i 9 r 8

\begin{tabular}{|c|c|c|c|c|c|}
\hline \multirow{2}{*}{ NAMES } & \multicolumn{3}{|c|}{$\begin{array}{c}\text { Number and Per cent } \\
\text { of Daughters }\end{array}$} & \multicolumn{2}{|c|}{$\begin{array}{c}\text { Average Production } \\
\text { in Pounds }\end{array}$} \\
\hline & $\begin{array}{l}\text { Number } \\
\text { in R. M. }\end{array}$ & $\begin{array}{l}\text { Number } \\
\text { registered }\end{array}$ & $\begin{array}{l}\text { Per cent } \\
\text { in } \mathrm{R} . \mathrm{M} \text {. }\end{array}$ & Milk & Fat \\
\hline Ilood Farm Pogis $9^{\text {th }} 5555^{2}$ & 78 & I 30 & 60 & 7,553 & 416 \\
\hline Hood Farm Torono 60326 . & 73 & 109 & 67 & 9,953 & 533 \\
\hline Spermfield Owl 57088 . . & 49 & 66 & 74 & 10,259 & 542 \\
\hline Loretta's King 65050 & 43 & $13^{2}$ & 32 & 7,787 & 410 \\
\hline Sayda's Heir 3d 74817. & 42 & $8 z$ & 50 & 8,078 & 460 \\
\hline Hector Marigold 5912I . & 34 & I I 8 & 28 & $6,53^{\circ}$ & 390 \\
\hline Irene's King Pogis 73182 & $3 \mathrm{I}$ & 105 & $3^{\circ}$ & 7,922 & 469 \\
\hline Lady Letty's Victor 65020 . & 29 & I I 4 & 25 & 7,825 & 433 \\
\hline Royal Majesty of St. Cloud & 29 & 86 & 34 & 6,747 & 395 \\
\hline King Sappho King 65262 . & 28 & $7 \mathrm{I}$ & 40 & 7,973 & $3^{68}$ \\
\hline
\end{tabular}

In the list of eight gold-medal Jersey bulls up to November I, 1919, Hood Farm Torono leads with his ten highest-testing daughters, averaging $8 \mathrm{II}$ pounds fat in a year. Pogis 99th of Hood Farm comes second, his ten best daughters averaging 805 pounds fat, and Spermfield $\mathrm{Owl}$, third, his ten best daughters averaging 743 pounds fat. The remaining bulls in the list are St. Mawes, The Imported Jap, Golden Glow's Chief, Royal Majesty, and Oxford You'll Do.

\footnotetext{
1 fercy Bulletin, various issues, especially March and April, I918.
} 
Leading Imported Jersey Bulls to January i, igi 8

\begin{tabular}{|c|c|c|c|c|c|}
\hline \multirow{2}{*}{\multicolumn{2}{|c|}{ NAMES }} & \multirow{2}{*}{$\begin{array}{c}\text { Sons } \\
\text { in R. M. }\end{array}$} & \multirow{2}{*}{$\begin{array}{l}\text { Daughters } \\
\text { in R. M. }\end{array}$} & \multicolumn{2}{|c|}{ dierage Yiarley Production } \\
\hline & & & & Milk & Fat \\
\hline Interested Prince 58224 & . & 10 & 43 & $8,4 s_{3}$ & $46 I$ \\
\hline Raleigh's Fairy Boy 83767 & . & t & +3 & 9.170 & 439 \\
\hline Gamboge's Irnight 95698 & - & 3 & 40 & 8,174 & 444 \\
\hline Royal Majesty 793I3 & & $t$ & 37 & 9,805 & 520 \\
\hline Noble of Oaklands 95700 & $\cdot$ & 16 & 37 & 6,356 & $3^{8 x}$ \\
\hline Eminent $6963 \mathrm{I}$. & . & IS & $3^{I}$ & 8,3 I 8 & $44^{I}$ \\
\hline Eminent's Raleigh 690 I I & . & 3 & 27 & 9,272 & 454 \\
\hline Golden Maid's Prince 935 & S. & , & 27 & 8,757 & 463 \\
\hline The Imported Jap 75265 & & $\rightarrow$ & 25 & 6,543 & 391 \\
\hline Gedney Farm Oxford Lad & $123^{8}$. & $\mathrm{I} 2^{\circ}$ & 24 & 8,486 & 445 \\
\hline
\end{tabular}

Prices for Jersey cattle have soared very high, but as there are large numbers of animals of the breed one may find values of all degrees from high to low. Many notable sales have been held during the past both in England and America but more especially in the United States. When the Dauncey herd was dispersed in England in I 867 ninety animals averaged in excess of $\$ 2$ co each. For many years T. S. Cooper of I'ennsylvania has been the most noted figure in selling high-class Jerseys at long prices. In 1882 he astonished the Jersey world by buying Pedro 3187 at private sale for $\$ 10,000$. On May 17 and 18 , I883, in the American Institute building in New York City, Mr. Cooper disposed of II9 animals for $\$ 113,370$, an average of $\$ 952.68$ each. The average for 82 cows and heifers over a year old was $\$ I I 72.68$, and the 57 top-selling females averaged $\$ 1553.15$. This was one of the most notable sales of the breed. On May 30, I900, Mr. Cooper adopted the custom of holding an annual Decoration Day sale for Island-bred cattle, which is the most notable event of its kind in Jersey annals. In his 1918 catalogue Mr. Cooper states that in seventeen successive years (excepting I915, when no sale was held) he sold 2082 animals, imported and home bred, for a total of $\$ \mathrm{I}, 093,760$, or an average of $\$ 525$ per head. No other man has brought so many noted animals from the Island as has $\mathrm{Mr}$. Cooper, and among these the following are given as topping the sales for the year indicated: 
Champion Flying Fox 6144I, \$7500 in I902; Eminent 69631, $\$ 10,000$ in I905; Stockwell 75264, \$II,500 in I907; Viola's Golden Jolly 793I4, \$I I,000 in I909; Sultana's Oxford Lad 76506, \$II, IOO in I910; Noble of Oaklands 95700, \$1 5,000 in I9I I, and his dam, Lady Viola 238439 , brought $\$ 7000$. On May 2, I9 18, Mr. Edmond Butler of Mt. Kisco, New York, held a sale, where 60 Jerseys brought a total of $\$ 60,105$, an average of $\$$ IOOI.9I. On this occasion the cow Briar Flower, I. I8952 H. C. sold for $\$ 10,000$ to IVilliam Ross Proctor of New York,

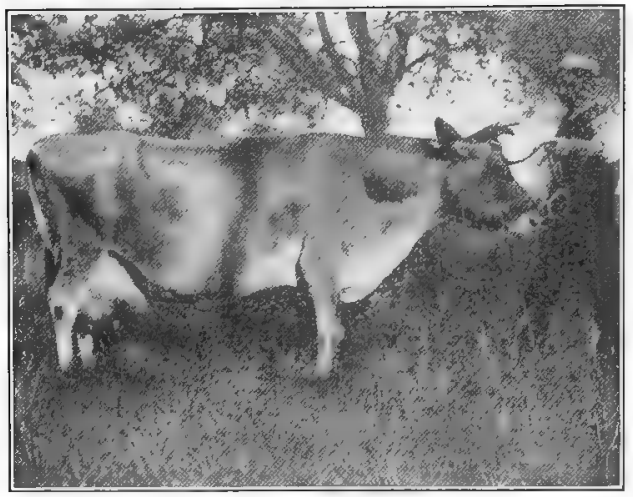

FIG. I48. Lady Aldan, P. $8470 \mathrm{H}$. C., one of the most noted cows on Jersey. Winner of the highest honors and dam of Golden Fern's Noble, the $\$ 25,000$ bull. Owned by J. A. Perree, Oaklands, Jersey. Photographed at eighteen years of age by the author who in 1916 purchased the imported bull Golden Fern's Noble I 45762 for $\$ 25,000$. Four very notable Jersey sales were held in I919. On June 16 Edward Cary, Carlton, Oregon, sold 34 head for $\$ 36$, I 45 , an average of \$1063.09. In June T.S. Cooper sold 9I head for $\$ 82,050$, an average of $\$ 901.70$. Edmond Butler, on August 4, sold 47 head for $\$ \mathbf{I} 58,250$, an average of $\$ 3367.02$.

All records were broken in this sale, for the bull Sybil's Gamboge (P. $5260 \mathrm{H}$. C.) sold to L. V. Walkley for $\$ 65,000$. At this sale I 5 daughters of this bull sold for $\$ 44,600$ (an average of \$2973.33), one of which, Bagot's Gamboge Crocus 383430 , brought \$10, I oo. On August 5, C. F. Sturhahns, Hartford, Connecticut, sold 32 head for $\$ 56$, I 25, an average of \$1753.9I. On June I, I9I8, at the Hood Farm sale, Lowell, Massachusetts, the aged cow Sophie's Agnes 296759, with the breed record for butter-fat production, sold for \$10,099 to Ayredale Stock Farm, Maine. Thus far in the twentieth century the Jersey has steadily grown in popularity, and each year the total number of animals sold at auction 
runs into considerable figures. In 1917 , according to the American Jersey Cattle Club, 8I auction sales of pure-bred Jerseys held in the United States, including 3997 head, brought a total of $\$ 630,4 \mathrm{I} 7$, or an average of \$ 58 each. In I9I6 in $8 \mathrm{r}$ sales 4337 head averaged $\$$ I 54.42 . With a large number of enthusiastic men breeding Jerseys, there is no difficulty in securing satisfactory prices for superior animals.

The distribution of the Jersey is world-wide. Many herds are found especially in England, Canada, Australia, New Zealand, and the United States. In the exportation which has taken place from the island of Jersey in the past one hundred years the cattle have been taken to many parts of the world, where they have adapted themselves very well to local conditions, all things considered. Denmark, for example, has made considerable use of the Jersey, though it is quite a secondary breed in that country. The United States is the great field of development of the breed, and according to the secretary of the American Jersey Cattle Club, during the year ending March 31, 19I8, there were registered 44,887 Jerseys on the books of the club, while 35,884 transfers of ownership of individual animals were made during this period. The Jersey has a widespread distribution in the United States, but is bred in largest numbers in the following states, much in the order given: Ohio, Texas, Indiana, Missouri, Kentucky, Tennessee, Illinois, and New York. These states are given this rating, as based on record of business in the American Jersey Cattle Club. In the Southern States the Jersey has long been a special favorite and greatly outnumbers other dairy-type breeds. In New England the Jersey also has a strong hold on popular favor.

Organizations for promoting Jersey cattle have long existed in America and on Jersey Island. The Royal Jersey Agricultural Society, founded in I833, assumed supervision of the breed on the Island and in 1866 published the first Island herdbook, since which date twenty-three volumes have been issued to I9I7. "The American Jersey Herdbook," published under the direction of the Association of Breeders of Thoroughbred Neat Stock, with headquarters in Massachusetts, was the first organization to promote Jersey interests in America, and published six herdbooks, the last 
appearing in I878. The English Jersey Cattle Society was organized in the seventies and up to I9I 7 had published twenty-nine volumes. The Maine State Pure Blood Jersey Cattle Association, chartered in 1875 , published its first herdbook in 1876 and Volume VIII in I898. The American Jersey Cattle Club was organized in 1868 and in I87 I published its first volume; since

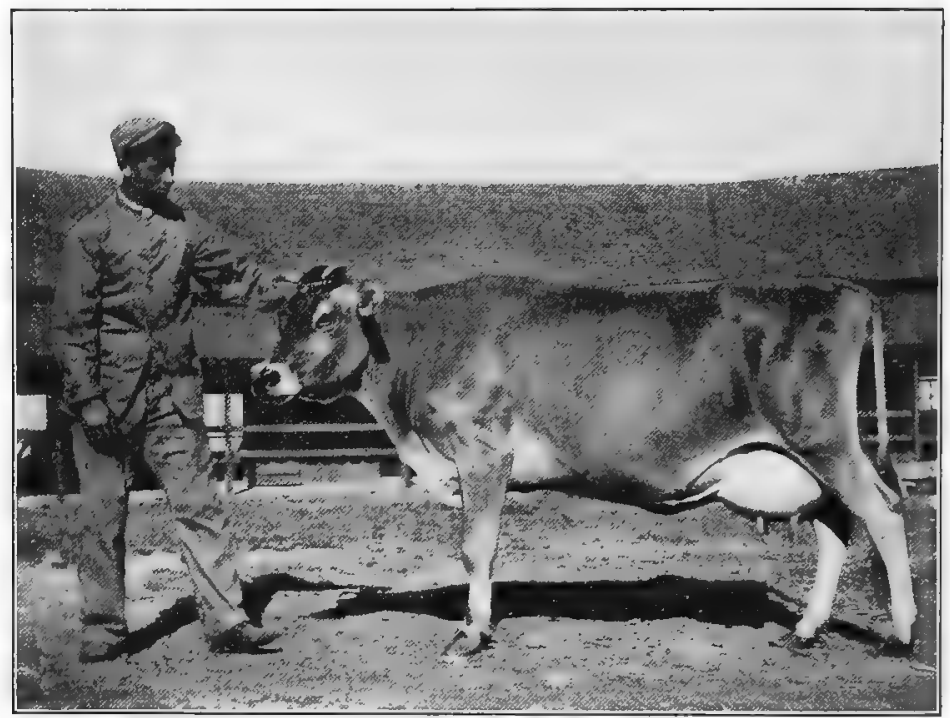

FIG. I 49. Lady Viola 238437 (imp.). First prize over Jersey and winner of the Theatre Cup in 1905. Dam of Noble of Oaklands (sold for $\$ 5,000$ ) and Viola's Golden Jolly (sold for $\$ 13,000$ ). She was imported by T. S. Cooper and bought in his sale for $\$ 7500$ by Elmendorf Farm, Lexington, Kentucky. From photograph by the author

that time, up to January, I9r9, ninety-five volumes had been issued, showing the registration by the club of 409,000 females and I62,000 males. There have been also published a number of volumes of the register of merit. On the fiftieth anniversary of the founding of the American Jersey Cattle Club there was a membership of 726. In rgo3 the New Zealand Jersey Cattle Breeders' Association published its first herdbook, and fifteen volumes have appeared since that date. Local Jersey cattle clubs for the promotion of the breed have been organized in many 
states. In Ohio there is the Ohio Jersey Cattle Club, with about 2 I 8 members in I9I7, and in addition ten local clubs scattered over the state. Wisconsin has twenty local Jersey clubs.

Polled Jersey cattle have been bred in America for many years, and in 1895 the American Polled Jersey Cattle Company was incorporated at Springfield, Ohio. In I919, at the annual meeting of the company, the name was changed to the American Polled Jersey Cattle Club. Originally polled Jerseys are supposed to trace back to a polled cow of unknown breeding named Funston, calved about I 880 and the foundation of the polled type. Later pure-bred polled Jerseys were found, so that to-day most if not all of the cattle found in the polled register are hornless and meet all the requirements of the breed except the horns. About twelve hundred polled Jerseys have been registered, but no polled herdbook has been thus far published. Some very excellent cattle of this class have been bred, but polled Jerseys have not met with much public favor. 


\section{CHAPTER XXXII}

\section{THE HOLSTEIN-FRIESIAN}

The native home of Holstein-Friesian cattle is in Holland, or, more correctly, the Netherlands. This is one of the smallest independent states of Europe, containing I2,74I square miles, with a population of about six millions, or about 470 persons to the square mile. There are eleven provinces, but those of Friesland, Drenthe, North Holland, and South Holland are more especially engaged in the keeping of dairy cattle. Holland lies between latitudes $50^{\circ}$ and $53^{\circ}$ and is bounded on the west and north by the North Sea. Much of Holland has been reclaimed from the sea, and as this land lies below sea level the water is held back by dikes. This is the flattest part of the continent of Europe. Along the sea front, especially in North and South Holland, the land surface in places is twenty feet below sea level, while the average height of the entire country is only about thirty feet above sea level. The following interesting comment is given regarding the topography of Holland ${ }^{1}$ :

Three features, the dunes, dikes and polders, characterize the north and south belt nearest to the sea. The dunes stretching along the coast were formed by the winds and sea, which heaped up the ocean sands into rows of hills from 20 to 60 feet apart and from 35 to 200 feet high. Wherever they front the coast they are adequate protection against the sea. These sand ridges and hills are sparsely wooded, but are saved from disintegration by natural or cultivated growth of plants. Few parts of them are tilled, but the sandy regions behind them are carefully cultivated. The dikes are gigantic artificial embankments of earth faced with stone or protected by stakes. They guard the country against the sea at the places where there are no dunes. The largest is the Helder Dike. There are also smaller dikes, as a precaution against floods, on the banks of the Rhine and other streams. Inside the line of dunes and dikes are great numbers of polders, which are areas of land inclosed by dikes that not only protect them from floods, but also render it possible to pump out the water from within the inclosure.

Holland is a country of canals, and in some regions these are found at four different elevations, the water being pumped from the

1 "The Netherlands," New International Encyclopæedia, Vol. XIV (I9I2), p. 396. 
lowest to the next higher level, and so on, until carried over the highest dike to the sea. The canals range from small ones useful for drainage and divisions between farms to those of considerable size and depth, on which extensive traffic takes place. The damp climate is neither hot in summer nor severely cold in winter, the

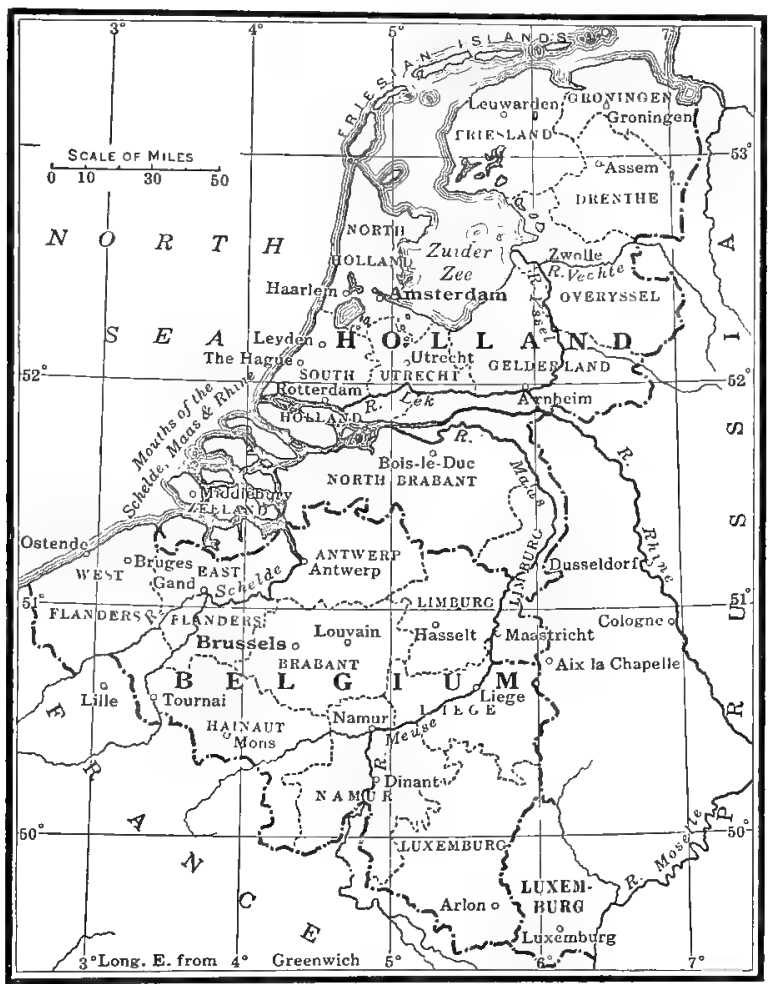

FIG. I 50. A map of Holland and Belgium showing the provinces, the important cities, water courses, etc.

average temperature being about 50 degrees. About one third of Holland is devoted to pasturage, and extensive market gardens are found near the principal cities of Amsterdam and Rotterdam. On thousands of acres about Haarlem tulips, hyacinths, etc. are grown.

The origin of Dutch cattle is very obscure. It has been claimed that for over a thousand years the people of Holland have kept

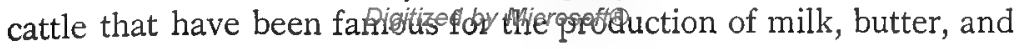


cheese. It has been assumed that these cattle are descended from the prehistoric Giant Ox (Bos taurus primigenius). Early writings refer to Dutch cattle as being large, more or less white in color, and great milk producers. Tacitus, the Roman writer, states that in the year A. D. 28, Drusus, the father of Germanicus, imposed a tax of hides of oxen upon the Friesians, which hides should come up to a certain standard. Tacitus, says Storer, ${ }^{1}$ implies that this was a difficult matter and very burdensome to the Friesians, but the passage clearly shows that the cattle of Friesland were then

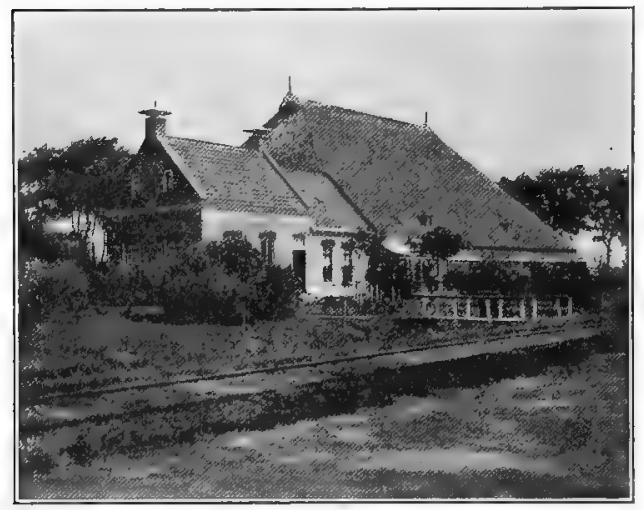

Firs. I 51. Dutch farmhouse with stable on the right. Photographed near Leeuwarden by the author of great size. During the course of time there have undoubtedly been considerable changes in the cattle of Holland. Different authorities bring this out. These changes were due to crossing varieties or breeds and to great epidemics. Storer comments on the fact that in the numerous paintings of cattle in the Dutch and Belgian art galleries, made by such noted artists as Paul Potter, Rubens, Cuyp, Teniers, Vandevelde, and others, "the Dutch cow of from 200 to 300 years since was totally different, both in color and form, from what she is now." The author has been much interested in examining many of these paintings in European galleries and can indorse the statement by Storer that black cattle are rare, black and white are still more rare, mouse-colored ones are not uncommon, neither are white ones with red ears; reds of different shades, with some white, are quite common, while the familiar red body and white face of the Hereford is not uncommon. The picture of Paul Potter's bull (see page 253) at The Hague brings out strikingly these color features. In the early part of the nineteenth century

${ }^{1}$ Reverend John Storer, Wild White Cattle of Great Britain (n. d.), p. 33. 
the cattle of the provinces of North and South Holland, according to Hobson, ${ }^{1}$ were mostly red and white and very well known in England as the Dutch breed. In the other provinces of the Netherlands "the cattle were the short horned Dutch breed, the color being generally black or black and white."

The present-day breeds of cattle in Holland are very few. The all-predominating one is that of Friesland and North and South

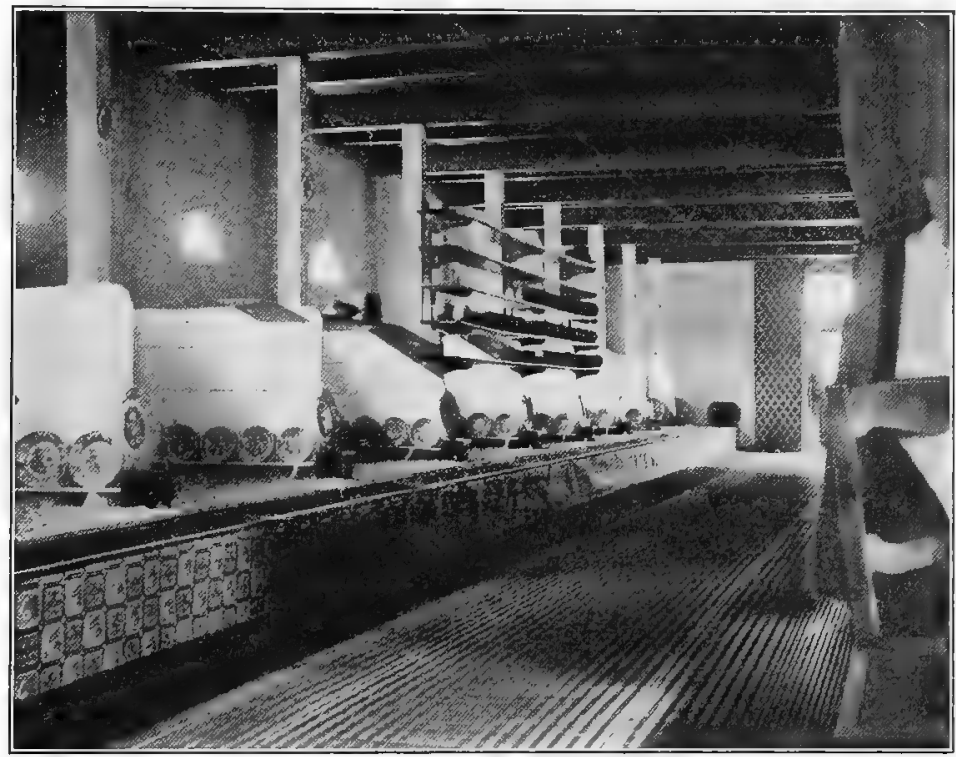

FIG. I 52. The interior of a Dutch cow stable in summer. Around the stalls on the left are placed blue dishes. The walls are painted in bright colors. During the season when the cattle are on pasture this is used as a family dining room.

From photograph by the author

Holland, black and white in color, such as we are so familiar with in America. In the province of Groningen is a breed beefy in type, black of body, but with more or less white head, legs, and tail, suggesting an Aberdeen-Angus-Hereford cross. One sees red-and-white cattle in Holland that, excepting for color, are identical with the common black-and-white sort. However, in eastern Holland there are red-and-white cattle, rather beefy in character and forming a group by themselves. 
The origin of the name "Holstein-Friesian" becomes pertinent at this point. A quarter of a century ago cattle were brought to this country under the names of "Holstein " and "Dutch Friesian," being sold as different breeds and championed by different breeding associations. The name "Holstein" has no application in Holland, but refers to a small province in Germany between the Baltic and North Seas, about a hundred miles east of the Holland boundary, where black-and-white Dutch cattle are found. The word "Friesian" is derived from the province of Friesland, and the breed in America might with propriety be called by that name alone, fớr no such breed name as "HolsteinFriesian" exists in Holland. Inasmuch as all the cattle imported to America from Holland were essentially the same, the breeders and importers, representing two distinct Dutch cattle associations in this country, met in joint sesșion in 1885 and united their interests and agreed to call the breed Holstein-Friesian. It is interesting to note that while the use of the word "Holstein" is illogical, in 1909 the British Holstein Cattle Society organized but later adopted the name "Friesian " in place of "Holstein," to conform to Dutch usage. The word "Holstein," now so universally used in America, is as much a misfit as "Holstein-Friesian." "The Netherland Rundvee Stambock of Holland," says the London Live Stock Journal (February 28, 1919), "has requested the HolsteinFriesian Association of America to drop the word 'Holstein' from its hyphenated compromise name. The Yankee body has refused the request. We are more up to date on this side apparently.'

The introduction of Holstein-Friesian cattle to America is associated with the early Dutch settlement of New York. Mr. W. W. Chenery of Belmont, Massachusetts, states ${ }^{1}$ that the Holstein or Dutch cattle were introduced into this country about $\mathbf{I} 625$ by the West India Company, and subsequently other importations were made by the early Dutch settlers in New York State. Late in the seventeenth century, when the Mohawk valley of that state was settled by the Dutch, they probably brought cattle with them from Holland. In 1795 the Holland Land Company sent two bulls and six cows to John Linklaen of Cazenovia, New York, who was an agent in charge of lands of the company there. As

${ }^{1}$ A Private Holstein or Dutch Herd Book, 3d ed. (1869), p. 5. 
described by one of the early settlers of that village, "the cows were of the size of oxen, their colors clear black and white in large patches; very handsome bodies and straight limbed; horns middling in size but gracefully set; their necks were seemingly too slender to carry their heads." In I 810 a bull and two cows were imported by Consul William Jarvis and taken to his farm at Weathersfield, Vermont. Between the years 1820 and I 825 Herman Le Roy, a New York City merchant, imported some

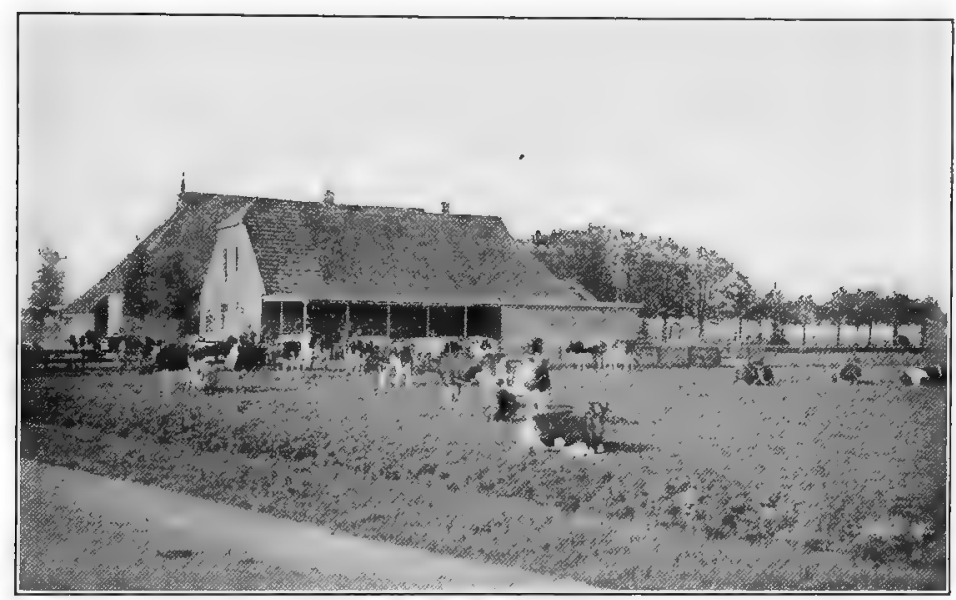

FIG. I53. The Kuperus herd near Leeuwarden, Holland. One of the famous Dutch herds. From photograph by the author

cattle from Holland, which he placed on a farm near New York City, and later, between I 827 and I829, some of them were sent to the farm of his son, Edward A. Le Roy, in the Genesee valley in New York. Lewis F. Allen states ${ }^{1}$ that he saw these cattle in I 833 , and that "they were large, well-spread cattle, black and white in color, and remarkable for their uncommon yield of milk." These Le Roy cattle were later crossed with Shorthorns, and the pure breed thus lost. The first importation of importance, having the maintenance of pure blood lines in mind, was that of Mr. Chenery, who reports as follows on his introduction of these cattle ${ }^{2}$ : 
The first of these importations was made in 1852 , and consisted of a single cow. The extraordinary good qualities possessed by that cow led in 1857 to a further importation of a bull and two cows, and in 1859 to four more cows. In consequence of a disease which occurred in I859-1860, these cattle and all their full blood descendants, with the single exception of a young bull, were destroyed under a law of the Commonwealth of Massachusetts, and in the autumn of $186 \mathrm{I}$ another importation of a bull and four cows was made from North Holland. These animals, with their progeny, comprise the stock of cattle known in this country as the "Chenery importation of Holstein or Dutch Cattle."

Mr. Chenery states that the original animals were procured from among the best breeders of the Beemster and Purmerend, in the

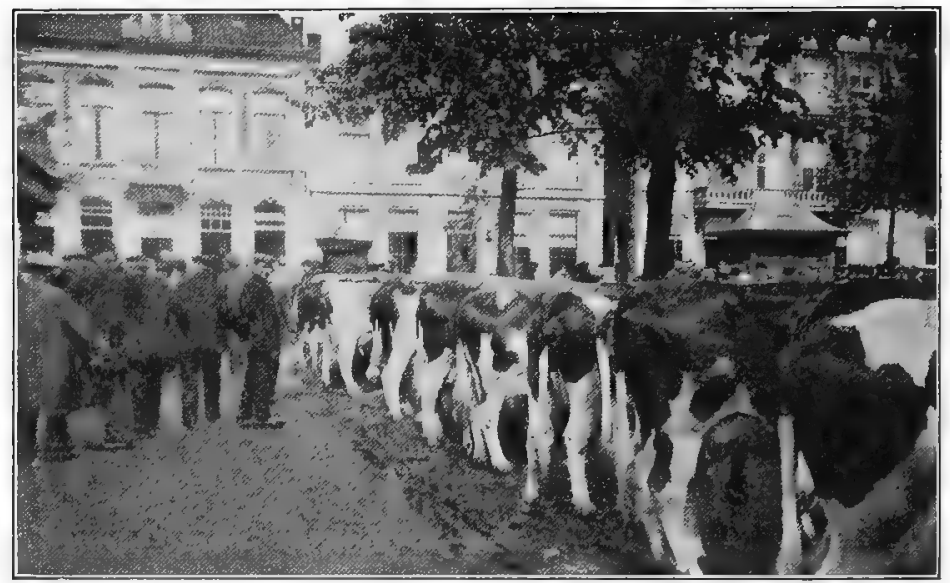

Fig. I 54. A scene in the cattle market at Leeuwarden, Holland. From photograph by the author

province of North Holland. The next importation of cattle from Holland was that of Gerrit S. Miller of Peterboro, New York, in I 869 , of a bull and three cows, purchased by his brother Dudley, at Weener, East Friesland. This importation was most important, for the three cows, Crown Princess 6, Dowager 7, and Fraulein 9, proved to be unusually fine individuals and producers and had a marked influence in establishing the breed in America. Following the Miller importation, in the early seventies importation from Holland became active, and large numbers of cattle were brought to America. Prominent among the importers late in the nineteenth century were Smith and Powell, T. G. Y'eomans, 
Henry Stevens, and Solomon Hoxie, all of central New York, and Edgar Huidekoper of Pennsylvania. Among the great cows imported in these early days were Netherland Queen 4I4 H. H. B. and Johanna 344 H. H. I3., imported in I 878 ; and Mercedcs 723 H. H. B., Empress 539 H. H. B., Ondine 828 H. H. B., and Aaggie $90 \mathrm{I}$ H. H. B., imported in I879. For many years there has been no importation from Holland, due to the existence of continuous foot-and-mouth disease over much of the continent of Europe, the United States having placed an embargo against European cattle outside of Great Britain.

The characteristics of the Holstein-Friesian are distinct and peculiar to this breed. In general conformation there is considerable variation, ranging from animals of a marked beef type to the extreme dairy type. This variation is recognized by the best authorities on the breed and has been officially described as follows ${ }^{1}$ :

There are three definite types, described as the milk and beef form, the milk form, and the beef and milk form. The average form of the breed, and that which conscientious breeders are directing their efforts to maintain and improve, is the milk and beef form. Mr. S. Hoxie thus admirably refers to the milk and beef type of the breed: "It is especially strong in all vital particulars. The bones are fine compared with size, and the chine broad and strong compared with the high and sharp chine of the extreme milk form. The loin and hips are broad and smooth, and the rump high and level compared with the angularity usually shown in the milk form. The twist is roomy and the thighs and hocks well apart. Passing forward the shoulders are smoother and more compact than in the milk form, but of lighter weight than in the beef form. The brisket is not so wide and low as in the beef form, and the chest is not so deep, but the width of the beef form through at the heart is closely retained. In the milk form the abdomen is usually swung low, and the ribs are steep, but in the milk and beef form the ribs are wider sprung and the abdomen more trimly held up though no less capacious. The general appearance of the bull is strongly masculine, but that of the cow is no less feminine than in the milk form.

In the American show ring the best-qualified judges discriminate against the beef-and-milk type and seek for more smoothness and finish than is found in the extreme milk type. HolsteinFriesian breeders have been so influenced by pedigrees that many bulls have been used in service that from the standpoint

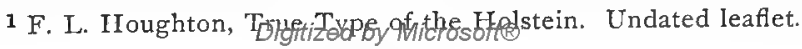


of type were anything but attractive; in fact, a ring of a dozen aged bulls of the breed will no doubt show more variation in form than will an equal number of males of any other breed. In gcncral appearance animals of the breed are large, often have great udders and milk veins, are black and white in color, and show remarkable milk-producing capacity. The head is usually lean, tends to be somewhat long, with straight nose and dark mottled or flesh-colored muzzle, is wide between the eyes, and carries a white horn usually black tipped. The horns should be short, gradually taper, and curve out forward and inward and slightly upward. A coarse horn is not common. The neck of the male is usually rather large, with a distinct arch, while that of the female is moderately slender. The shoulder is frequently heavy and prominent, with zuithers of moderate thickness, being neither fine nor thick. The body is large with long, well-sprung ribs, showing great feeding capacity. The hips are often prominent, the mmp long and often more or less steep. The thighs incline to be somewhat thick, with more quarter than obtains with other dairy breeds. The udder is frequently very large, and with maturity shows a pendant form after the shape of a letter $U$, with the teats placed at the corners. With this form the fore udder lacks extension. The discriminating breeder is seeking more and more to produce an udder with ideal front development that holds up close to the belly and is not unduly pendant. The milk vcins average large, but are not longer or more tortuous than in other breeds. In quality the HolsteinFriesian is too frequently deficient, as shown in coarse hair, large joints, and thick skin lacking in mellowness.

The color of the Holstein-Friesian is almost universally black and white in patches, varying in degree, however, some animals being mostly white and others largely black. At the present time a preponderance of white is most popular, and occasionally one will see animals entirely white excepting for very slight black spots. White by many is considered an evidence of quality. DeKol 2d, imported in I885, noted as one of the early great butter-fat producing dams of the breed, was largely white, and through her sons, and especially Hengerveld DeKol, white has undoubtedly become more of a feature than formerly. Red and 
white, as previously referred to, occurs in Dutch herds, and from time to time calves of this color marking are dropped in herds of black-and-white cattle in America, this being probably a form of reversion. The subject of color markings has also received formal action by the Holstein-Friesian Association of America, the executive committee in May, I9IO, adopting the following report, which thereby became a rule of the association relative to colors barring animals from registration. "(I) Solid black. Solid white. (3) Black switch. (4) Solid black with white on belly only. (5) Black on legs, beginning at feet and extending to knees and hocks. (6) Black on legs, beginning at feet and extending to knees, with white interspersed. (7) Gray, or mixed black and white prevailing. (8) Patches of other colors than black and white red, brown, dun, etc. (9) Red and white."

\section{The size of the}

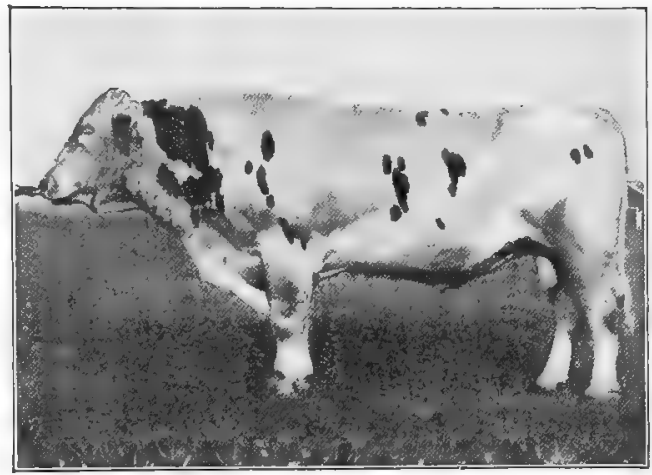

FIG. I55. Hengerveld DeKol 23102, a HolsteinFriesian bull that sired many sons and daughters of great merit. Owned by A. A. Cortelyou of New Jersey. From photograph, by courtesy of the American Agriculturist

\section{Holstein-Friesian puts}

it among the largest breeds of cattle. At birth calves usually weigh from 90 to 100 pounds, sometimes reaching the extreme weight of I 25 pounds. The Advanced Registry standard of the breed specifies weights of at least I 800 pounds for the bulls and I000 pounds for the cows, at maturity. B. W. Potter, following an investigation of weights of 60 large record cows tested between I 894 and I906, reports on only I 3 weighing more than I 500 pounds each and only 27 surpassing the I 400-pound mark. Only 9 weighed less than 1200 pounds, and the average weight of the 60 was I 383 pounds. Of the 25 bulls not one weighed less than I 800 pounds and only 5 less than 2000 pounds, while only 3 weighed over 2400 pounds. The average weight of the bulls was 2 I64 
pounds. Mature bulls are often very heavy. Kate Spray's Paul DeKol, when owned by the Ohio State University, attained a weight of 2600 pounds and never was fat. The bull Constantyn 2040 H. H. B., when six years old, weighed 2715 pounds. Netherland Prince 716 H. H. B., the most famous bull imported twentyfive years ago, at eight years weighed 2050 pounds. Parthenia 2 d's Sir Henry 12366, one of the great show bulls of his day, weighed 2500. A reasonable and moderate weight for the aged bull ranges

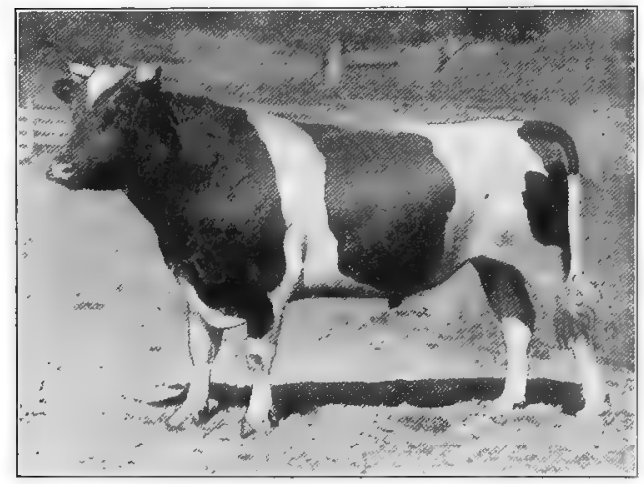

Fig. I 56. Mercedes Julip's Pietertje's Paul 29830, a Holstein-Friesian bull in two-year form and of excellent type. Owned by H. L. Bronson, Cortland, New York. From photograph, by courtesy of American Agriculturist from 1900 to 2000 pounds. Like the males, the females of the breed sometimes attain great size. The cow Rosa Bonheur 5th I 227 weighed as high as I 850 pounds while owned by the Michigan Agricultural College, while Belle Sarcastic 23039, owned by the same college, weighed I 900 pounds when fat. These cows, however, are extreme cases. Among noted cows of the breed at maturity, Pietertje $2 \mathrm{~d} 3273 \mathrm{H}$. H. B. weighed I 365 pounds; DeKol 2d 734 H. H. B., I240; Pauline Paul 2199 H. H. B., I450; Aaggie 90 I H. H. B., I 375 ; Echo I 2 I H. H. B., 1920; Princess of Wayne 954 H. H. B., I 370 ; Segis Fayne Johanna I I 4648, 1450 pounds normally, I90o fat; Finderne Hollingen Fayne I4455I, I450; College Belle Wayne, I980; and Ormsby Jane Segis Aaggie I 50943, I 500 pounds. For mature cows a weight of I 250 to I 400 is acceptable, some families tending to weigh heavier than others.

Measurements of Holstein-Friesian cows have been taken to some extent, especially in connection with Advanced Registry records. While no pertinent conclusions have thus far been drawn from measurements of this kind, the figures secured indicate 
something of the body proportions. The average measurements of cows in Volume IV of the Advanced Registry are as follows:

Height, perpendicular, at shoulders . . . . . $51.8 \mathrm{in.}$

Height, perpendicular, at hips . . . . . . $53.0 \mathrm{in}$.

Length of body, extreme point shoulder to point rump 64.9 in.

Length of rump, front hips to extreme point rump . $2 \mathrm{r} .4 \mathrm{in}$.

Width of hips . . . . . . $21.9 \mathrm{in}$.

Girth of heart at smallest chest circumference $\quad 75.6 \mathrm{in}$.

The maturing qualities of the Holstein-Friesian are not so pronounced as with some other breeds. Young males very commonly are slow in developing sex character, the crest and burly head not appearing much prior to six months or more of age. The heifers also are slow in showing the maternal characteristics. However, with maturity sex character becomes amply manifest.

The adaptability of the Holstein-Friesian to environment is admirable. It seems at home in both north and south, temperature not being an important factor. However, being a gross feeder, the mature individual of this breed should be provided with ample pasture or other food in summer. Also, being in the large, heavy class, the Holstein-Friesian is best suited to fertile lowlands, rather than to a rough and hilly country where food is more or less scarce and laborious effort is required in grazing.

The prolificacy of the Holstein-Friesian is probably comparable with most breeds of cattle, but is not especially marked. Many cows of the breed have lived to a ripe old age and have been persistent producers, leaving large families. But little publicity, however, has been given to this feature, and one finds practically no reference to the subject in the literature relative to the breed.

The disposition of the Holstein-Friesian is naturally quiet and peaceable. In their native home in Holland the cattle are brought in close touch with the people, in most cases occupying stables under the same roof with the family dwelling, and are constantly handled in an individual way. All of the conditions promote domesticity and quiet disposition. The bulls, in common with those of other dairy breeds, are often nervous and belligerent and require careful handling. The cows, however, are naturally very quiet and easily handled. 
The prepotency of the Holstein-Friesian is quite marked. The distinctive color markings, head characteristics, and type of udder are strongly reproduced in the pure-bred herd. Males of pure ancestry, used in grade herds, in due season give it the essential features of the pure-bred herd. There are many thousands of superior grade Holstein-Friesian cows in America, largely the

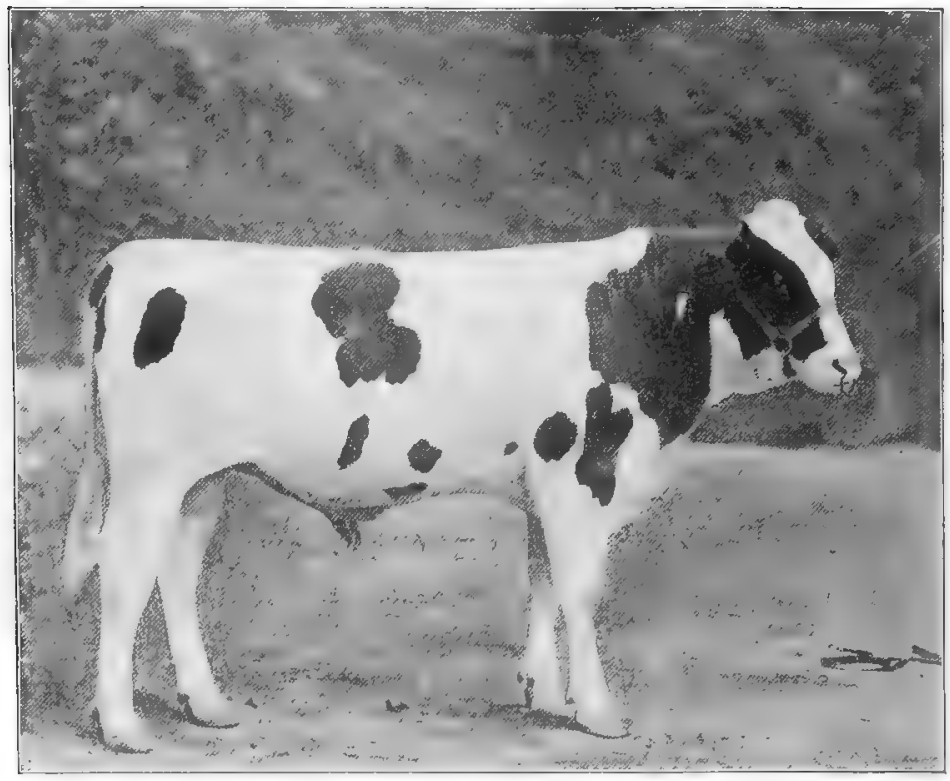

FIG. I 57. Carnation King Sylvia 231405, a Holstein-Friesian bull calf, by King Echo Sylvia Johanna 203504, out of May Echo Sylvia 223725. Bred by A. C. Hardy of Canada. Sold at auction in 1918 for $\$ 106,000$ to Carnation Stock Farms of Wisconsin and Washington. From photograph, by courtesy of the owners

result of the use of pure-bred sires. In I9I 8 the author saw grade Holstein-Friesian cows in public sale that were of such marked excellence as to change hands for over $\$ 250$ per head.

The grade or crossbred Holstein-Friesian may be an improvement over the dam if a pure-bred bull be used. The wisdom of this breeding, however, depends on the purpose. If for milk production, by means of pure-bred bulls a high-grade, very profitable herd may be produced. In the vicinity of large cities are to be found herds of high grades that produce large yields of 
milk for the retail trade. By selecting sires coming from families yielding milk superior in quality as well as quantity, more favorable results may be expected than if no care in selection is practiced. Owing to their size, the bulls should not be mated to animals of smaller breed type.

Holstein-Friesian oxen are in favor in some localities where cattle are employed in draft work. Mr. James D. Avery of Massachusetts, who has long used them, testifies highly to the worth of the breed for this purpose. A pure-bred ox of his, named Jerry, at nine years old weighed 4365 pounds, stood I $7 \frac{1}{2}$ hands high, was Io feet 3 inches in girth and I 5 feet I inches long.

Advanced Registry Official testing of Holstein-Friesians was established in 1898 for the purpose of placing the tests of milk and butter-fat production on an impartial basis. The system provides for supervision of the testing by representatives of either the state agricultural college or the state experiment station, owners of the cows paying for the testing. Two classes of tests are made, - official, where a special tester supervises all milkings and tests for butter fat; and semiofficial yearly records, where the milk for at least two consecutive clays each month is weighed and tested for fat by the inspector, the daily milk records being kept by the owner of the cow. The Holstein-Friesian Association has especially emphasized short-period testing, notably seven and thirty days. These short-time tests are not fair, for the reason that many men specializing in such testing dry off their cows prior to the test, make them as fat as possible, and thus get an abnormal fat test through milking off the fat from the body. Cows in high flesh yield a milk much richer in fat than is the case under ordinary conditions. Yearly semiofficial tests meet with favor and more nearly show the capacity of the cow. In Advanced Registry Official (A. R. O.) testing cows of this breed, being heavy yielders, are usually milked three or four times a day. In Holland milking three times daily is a common custom. During the year I917 there were 9388 cows and heifers tested for seven days or more. Up to I9I9 nearly 68,000 animals had been admitted to the Advanced Registry.

The requirements for entry in the Holstein-Friesian Advanced Registry are as follows: If the cow calves at two years of age or 
under, to qualify she must produce 7.2 pounds of fat in seven consecutive days. Calving at three years, the cow must produce 8.8 pounds of fat in seven days. Calving at four years, the cow must produce I0.4 pounds of fat in seven days. Calving at five years or over, the cow must produce I2.O pounds of fat in seven days. If the cow calves at a period between either of these ages, every day of increased age adds to the requirements of the year .00439 of a pound of fat. Only bulls having four or more A. R. O.

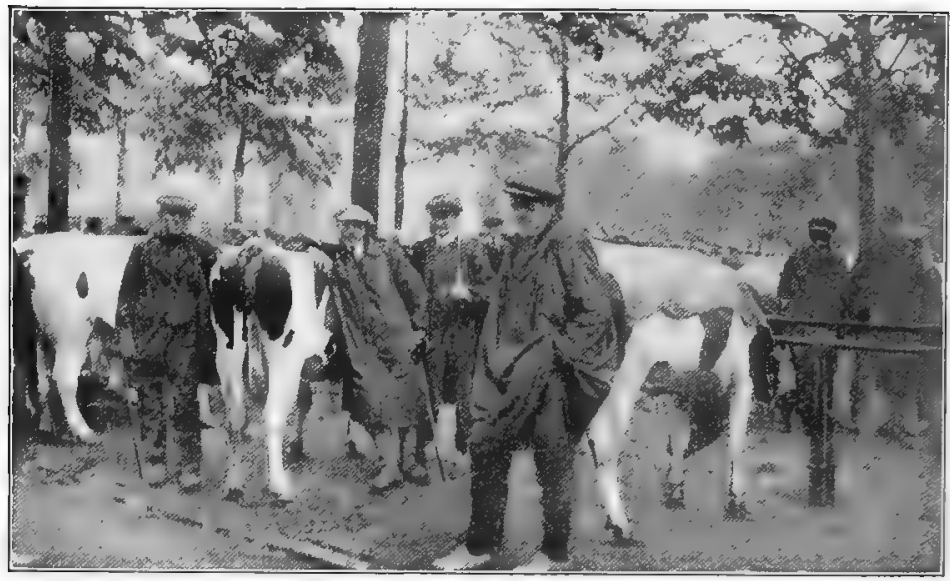

FIG. I 58. Cattle dealers in the market at Purmerend, Holland. Dutch cattle are blanketed in the spring when first put on pasture, after the style shown in the picture. From photograph by the author

daughters are eligible for entry in the Advanced Registry. An A. R. O. daughter is one that has been entered in the Advanced Registry on an official record.

The Holstein-Friesian cow as a producer of milk, so far as quantity is 'concerned, leads all breeds and occupies a class by herself. Wonderful reports have been published since I 885 , when private tests received much attention. At that time Clothilde I 308 H. H. B. was credited with a year's milk record of 26,02 I pounds 2 ounces. Following that record, Pietertje 2 d 3273 H. H. B. made a private test of $30,3 \mathbf{I} 8$ pounds 8 ounces of milk, a record that stood unbeaten for many years. Semiofficial testing has produced many remarkable yearly records, of which the following are most conspicuous up to June, I9I9. 


\section{Semiofficial Yearly Holstein-Friesian Milk Records}

\begin{tabular}{|c|c|c|c|}
\hline Name and Number & Ages: & Y'EAR tented & MiLK ReCORI \\
\hline Tilly Alcartra I23459. . . & 9 & I918-I9I9 & $33,424.8 \mathrm{lb}$ \\
\hline Lutscke Vale Cornucopia 110505 . . . . & 8 & $1915-1916$ & $3 \mathrm{I}, 243.4 \mathrm{lb}$ \\
\hline Winnie Korndyke Cornucopia DeKol ror 4.9 & 9 & $1916-1917$ & $3 \mathrm{I}, 034.2 \mathrm{lb}$ \\
\hline Raphaella Johanna Aaggie 3d i 85 I 25 . & 6 & I918-1919 & $30,637 \cdot 0 \mathrm{lb}$ \\
\hline Zarilda Clothilde 3 d DeKol I 33840 & 6 & $1918-1919$ & $30,427.0 \mathrm{lb}$ \\
\hline Jemima Johanna of Riverside & & I918-1919 & $30,373 \cdot 0 \mathrm{lb}$ \\
\hline Queen Piebe Mercedes I 54610 & $t$ & $1915-1916$ & $30,230.2 \mathrm{lb}$. \\
\hline Lindale Bonnie Pauline I7752 I & 5 & I9I7-I9I8 & $30,024 \cdot \mathrm{I} \cdot \mathrm{lb}$ \\
\hline Royalton DeKol Violet 86460 & 10 & I916-1917 & $29,949 \cdot 6 \mathrm{lb}$. \\
\hline Creamelle Vale $73357 . \quad . \quad$. & 7 & I9II-I9I2 & $29,591+4$ lb. \\
\hline
\end{tabular}

In 19 I 7 the Advanced Registry records of the Holstein-Friesian Association showed that 3550 cows and heifers had produced an average yield of $14,622.7$ pounds of milk each in semiofficial tests. Some remarkable yields are recorded, additional to the above. Years ago the cow Shadeland Boon 2d 8892 H.H.B. was credited with a private record of 122.2 pounds of milk in one day. As late as I9I 4 fifty-three cows of the breed were credited with producing each above 700 pounds of milk in seven days. The following are some of the more notable large daily records since official testing began: Riverside Sadie DeKol Burke 70708, a California cow, in seven days produced an average of 128.87 pounds per day; during thirty days she averaged I23.5 pounds. Lutscke Vale Cornucopia I 10505 , another California cow, in six months produced I 8,275 pounds of milk, or a daily average of over roo pounds. College Belle Wayne 98497 , owned by the South Dakota State College, produced I 26.7 pounds in one day. Dekol Queen La Polka 2d 72325, a New York cow, produced I 24 pounds in a day, while May Echo Sylvia 223725 produced I52.I pounds in one day and 12,898 pounds in one hundred days. Tilly Alcartra I 23459 is the world's champion cow for total production of six years, during which time she produced. I 56,776 pounds milk. Many cows of the breed have produced from 75 to 90 pounds in a day, and a fair Holstein-Friesian cow should easily produce from 7000 to 9000 pounds in a year. According to official reports up to I9I9, I 48 cows of the breed have records of over 24,000 pounds milk a year eallisitized by Microsofte 
The Holstein-Friesian as a butter-fat producer takes high rank on account of the large yield of milk, which usually tests from 3 to 4 per cent butter fat. Some families tend to produce milk poor in fat, while others show a greater amount. Breeders are persistently putting a premium on cows testing high in fat, and

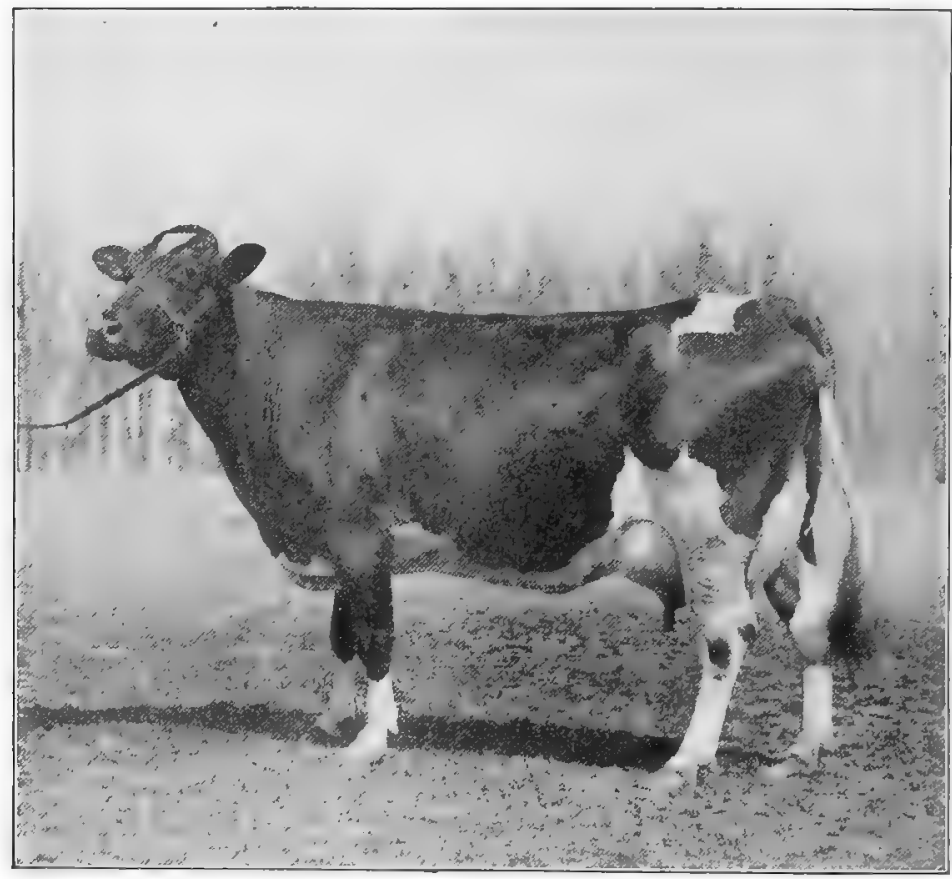

FIG. 159. Pietertje Maid Ormsby 78051, by Sir Ormsby Hengerveld DeKol 31212, a Holstein-Friesian cow owned by J. B. Irwin, Minneapolis, Minnesota. In IgII world's official 30-day record of 145.66 pounds 80 per cent butter. Dam of Sir Pietertje Ormsby Mercedes. See Fig. I63

the breed is gradually reaching higher levels as a result. The fat globules in this milk are of the smaller class and do not cream by gravity as rapidly as do Jersey or Guernsey milk. In total butter-fat or butter production, however, very large records have been made. Reference has already been made to the seven-day tests. In I9I7 M. H. Gardner, superintendent of Advanced 
Registry, gave some very interesting information ${ }^{1}$ relative to production, and more especially concerning butter-fat records.

To May I, I917, the Holstein-Friesian Association has entered 3750 bulls and 52,500 cows in its Advanced Registry... . Last winter the cow Segis Fayne Johanna produced in seven days 730.8 pounds milk and 40.546 pounds fat, and the breed can show 22 cows with seven day production above 32 pounds fat. Half of the cows tested are heifers with first or second calves, yet the seven day average for all ages shows 408 pounds milk containing I 4.4 pounds fat. The average per cent of fat shown is 3.53 . The long time test was added to the system about seven years ago, and Duchess Skylark Ormsby has shown 1205 pounds of fat from 27,76 r.7 pounds of milk in one year.... The breed can show sixteen cows with production of more than I000 pounds of fat in 365 days. There are 72 cows so far entered producing more than 850 pounds of fat.

In March, I9I9, the Canadian cow Rola Mercena DeKol 303 I 3 beat Segis Fayne Johanna's record by producing 4r.54 pounds of fat in seven days and 160.27 pounds in thirty days. Up to May 16, 1918, there were thirty-five 40-pound cows reported. Following are the leading butter-fat record cows of the breed for three hundred and sixty-five days in semiofficial tests.

\section{Leading Semtofficial Yearly Holstein-Friesian Butter-Fat RECORDS}

\begin{tabular}{|c|c|c|c|}
\hline Name and Number Cow & $A G E$ & YEAR TESTED & RECORD \\
\hline Duchess Skylark Ormsby I 24514 & 5 & $1914-1915$ & $1205.09 \mathrm{lb}$. \\
\hline Finderne Pride Johanna Rue $I_{2} 1083$. & 5 & $1914-1915$ & I $176.47 \mathrm{lb}$. \\
\hline Finderne Hollingen Fayne I44551 & 3 & $1916-1917$ & I I I $6.05 \mathrm{lb}$. \\
\hline Queen Piebe Mercedes I 54610. & 4 & $1915-1916$ & I I I I. $56 \mathrm{lb}$. \\
\hline Emeretta Korndyke DeKol 189227 & 5 & $1918-1919$ & $1077.55 \mathrm{lb}$. \\
\hline Ona Button DeKol i I 5939 . . & 6 & $1915-1916$ & $1076.44 \mathrm{lb}$. \\
\hline Maple Crest Pontiac Application I 4 I I $5^{8}$ & 6 & 19I5-1916 & $1075.44 \mathrm{lb}$. \\
\hline Champion Dora Korndyke 134002 & 8 & $1918-1919$ & $1052.75 \mathrm{lb}$ \\
\hline
\end{tabular}

It is interesting to note that in I 890 Pauline Paul 2 I99 H.H.B. was credited with a yearly record in private test of II 53 pounds I $5 \frac{3}{4}$ ounces of salted butter, and for eighteen years no official record equaled it by a dairy cow of any breed. Yet in I9I I-I9I2

'Breeders' Gazette, July 19, 1917. 
Banostine Belle DeKol 9044I produced I058.34 pounds fat, or an estimated record of I322.9 pounds of butter. In May, I9I9, Mr. Gardner, superintendent of Advanced Registry tests of the Holstein-Friesian Association of America, stated in Hoard's Dairyman that twenty-six cows of the breed up to March had records of producing over Iooo pounds of fat each within a year.

Holstein-Friesian milk for cheese is very extensively used in Holland, where large quantities of Edam, Gouda, and other cheeses are made and shipped all over the world. This milk

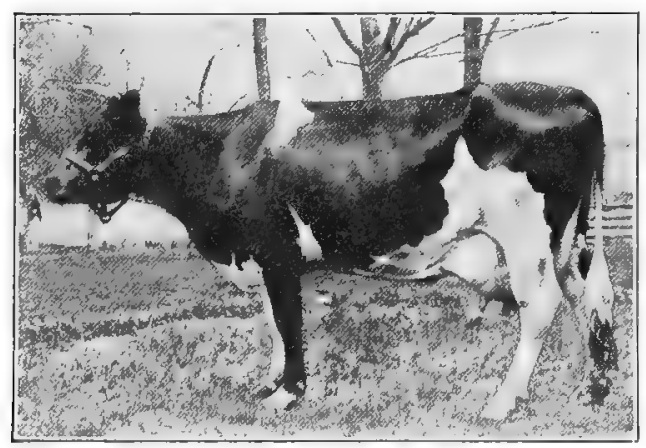

Fig. I60. Banostine Belle DeKol 9044I, a HolsteinFriesian cow owned by Dimmick Brothers of Ohio that made a world's record in I9II-IgI 2 of 1058.34 pounds butter fat in three hundred and sixty-five days. From photograph, by courtesy of Dimmick Brothers contains a large percentage of solids not fat and so makes a very nutritious cheese, though its food value would be increased by a greater percentage of fat in the milk.

\section{Holstein-Friesians} as beef producers do not rank well in America, any more than do the other dairy breeds. There is too much waste in killing, with too much bone and intestinal fat. Young Holsteins, however, make excellent veal, and the author has rarely eaten veal in America equal to that commonly served in hotels in Holland. In valuations placed on Holstein beef fed at the Iowa State College, experts rated it eighth among nine breeds, the Jersey coming last. Holstein-Friesians will gain in weight but will not produce the desired quality of beef to suit the buyers.

Holstein-Friesian families of prominence. The leading families of the breed, as known to-day, trace back to cows of notable merit, both as producers of milk and of offspring. There has been much mixing or crossing of family lines, and one finds comparatively little breeding that has been kept within a family. Branch or subfamilies also occur within the main family, some breeders especially 
exploiting these as families of their own production, which is more or less true. The following families are of special note:

The Aaggie family is descended from Aaggie 90 I H. H. B., imported in I 879 by Smith and Powell of Syracuse, New York, and sired by Rooker, one of the noted bulls in Holland. Aaggie was credited with producing $89_{4}^{3}$ pounds of ${ }^{\prime}$ milk in a day and 18,005 pounds in a year. Her daughter Aaggie 2d, by Jacob 2d, made a yearly record of 20,763 pounds of milk. In I888 Smith and Powell stated in their catalogue that "the records made by Aaggie cows have done more to give the Holstein-Friesian breed its present reputation than those of any other family." Eighteen cows of the family were then credited with an average for one year of I6,059 pounds of milk, and 19 Aaggie cows in the Smith and Powell herd averaged 18 pounds $2 \frac{1}{4}$ ounces butter in seven days. The noted Ormsby Jane Segis Aaggie I 50943, the first 44-pound A. R. O. heifer (whose son King Ormsby Jane Rag Apple sold for $\$ 53,200$ ), traces through her line of female descent to old Aaggie. So also does Sir Veeman Hengerveld 36158, a grandson of Paul DeKol 14634 (with 84 A. R. O. daughters), trace to Aaggie on the sire's side. Aaggie Cornucopia Pauline 48426, the first 34-pound cow, was seven generations descended from Aaggie. This family is not so popular as it was some years ago, yet many noted animals of to-day trace back to old Aaggie.

The Clothilde family traces to Clothilde I $308 \mathrm{H}$. H. B., imported as a yearling in 1880 by Smith and Powell. In I887 Clothilde won the sweepstakes prize as the best butter cow of any breed at the New York Dairy and Cattle Show. At six years of age she had a record of $88 \frac{1}{4}$ pounds of milk in a day and $26,02 \mathrm{I}$ pounds 2 ounces in a year. Clothilde had eight daughters and no sons. Her daughter Clothilde $2 \mathrm{~d}$ I45 I is credited with $30-1$ pounds butter in seven days and 23,600 pounds milk in a year. Pontiac Clothilde DeKol 2d 6999I, with an A. R. O. record of 1271.60 pounds 80 per cent butter in a year, combines the blood of the DeKol and Clothilde families. In recent years no very great attention has been centered on this family, although it is regarded with favor.

The DeKol family is descended from DeKol $2 \mathrm{~d} 734 \mathrm{H}$. H. B., calved in 1884 and imported from Holland in 1885 by Lord 
and Son of New York. DeKol 2d was sired by William 3d r9o N. H. B. and had for dam DeKol 6245 H. H. B. DeKol 2d became famous first in the herd of J. B. Dutcher and then in that of Henry Stevens and Son, who bought her a ten-year-old cow from the former. Between 1886 and 1900 she produced I 2 calves -8 bulls and 4 heifers. Without doubt no other cow of the breed ever produced so distinguished a family, and her sons and grandsons have contributed in a remarkable way to the

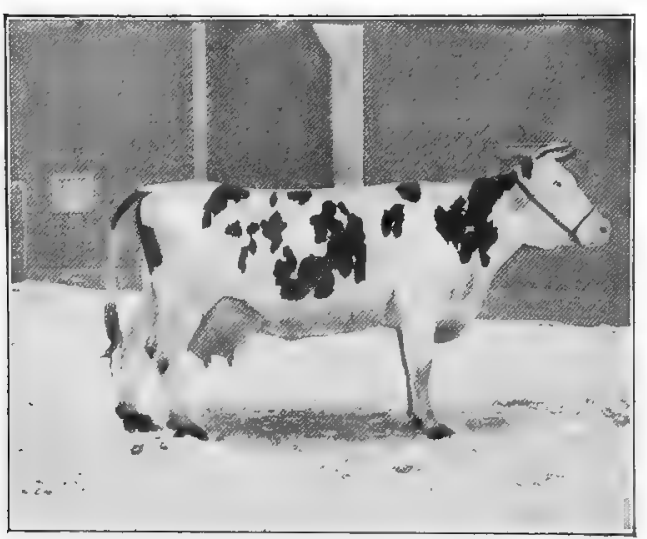

FIG. I6r. Pontiac Clothilde DeKol 2d 6999r, a Holstein-Friesian cow that in the ownership of Stevens Brothers and Company of New York made a world's record of IoI 7 pounds fat in a year. From photograph by the author production of hightesting progeny. In fact DeKol 2d was the principal medium through which important improvement in the butter-fat content of Holstein-Friesian milk was secured. DeKol 2d's Paul DeKol 20735, DeKol 2d's Butter Boy 2 I366, DeKol 2d's Butter Boy 2d 22989, and DeKol 2d's Butter Boy 3d 23260 stand out as four of the great bulls of the breed.

These sons are not far removed from present-day animals of note. Hengerveld DeKol 23102, sire of I 66 A. R. O. daughters and 53 A. R. O. sons, is a son of DeKol 2d's Butter Boy. Sir Veeman Hengerveld $36 \mathrm{I} 58$, with 84 A. R. O. daughters, is a great grandson of DeKol 2d's Prince 2767 , a son of DeKol 2 d. Paul Beet's DeKol 22235, sire of 105 A. R. O. daughters, was a grandson of DeKol 2d. DeKol Burke 2299I, sire of $66 \mathrm{~A} . \mathrm{R}$. O. daughters, was a son of DeKol 2d's Butter Boy. In I9I 8 'DeKol 2 d's Butter Boy $3 \mathrm{~d}$ was sire of I I 8 A. R. O. daughters and 95 A. R. O. sons, among which were many of the great cows of the breed. The DeKols are a large, rugged type of cattle, and their blood has been widely used with other families. 
The Johanna family has its foundation in the cow Johanna $344 \mathrm{H}$. H. B. She was brought to America from Holland by Gerrit S. Miller of New York. At ten years of age she produced 88 pounds of milk in a day and $2407 \%$ pounds in a month. She was purchased by Gillett and Son of Wisconsin in her ten-year form. Through her daughters Johanna 4th 2 I 29 and Johanna 5th 9343 this family made a strong producing record. The blood of the Johanna family in Mr. Gillett's herd mingled to great advantage with the Colantha family; and Colantha 4th's Johanna 48577 , long the world's-record cow in yearly butter-fat production (998.26 pounds), was of the Johanna family on the sire's side and a granddaughter of Colantha $6714 \mathrm{H}$. H. B. on the dam's side. Colantha Johanna Lad $3248 \mathrm{I}$, with Io6 A. R. O. daughters, is a son of Colantha 4th's Johanna. Sir Johanna DeKol 25467 , with 35 A. R. O. daughters (including Johanna DeKol Van Beers 7513I, with a 40.I pounds A. R. O. record), is by Sir Johanna 23446, sire of Colantha 4th's Johanna.

The Korndyke family descends from Belle Korndyke I 3913, calved in I 888 and bred by S. H. Blanchard of New York. When eleven years old she made an A. R. O. record of 25.77 pounds of butter in seven days. She and her daughter Korndyke Queen 40580 were purchased by Henry Stevens and Son of New York, in whose hands this family became famous. Between I890 and I906 Belle Korndyke dropped eleven calves, six of which were sons. From these sons and daughters came a large number of A. R. O. sons and daughters. Her daughter Belle DeKol I 39 I 3 is the dam of Pontiac Korndyke 25982, sire of I 39 A. R. O. daughters, and also of King of the Pontiacs 39037, with 204 A. R. O. daughters to his credit and I I 3 A. R. O. sons, the premier sire of the breed. In 1908 Stevens Brothers-Hastings Company wrote ${ }^{1}$ of Pontiac Korndyke: "The cross formed by mating this bull with the daughters of Hengerveld DeKol seems to be an especially fortunate one, and is producing some of the best record heifers ever officially tested." Pontiac Korndyke is sire of Pontiac Clothilde DeKol 2d 6999I, with a year's record of I 27 I. 6 pounds butter, and of Pontiac Rag Apple 56980, with a record of 31.62 pounds butter in seven days, noted also as selling 
for $\$ 8000$. Rag Apple Korndyke 8th 73416, that sold for $\$ 25,000$ at public sale, is a grandson of Pontiac Korndyke on both sides. At the present day the Korndyke family is at the top wave of popularity, largely due to the remarkable prepotency of Pontiac Korndyke and his son King of the Pontiacs. The name "Pontiac" is derived from the town of Pontiac, Michigan, where for many years a large herd of superior Holstein-Friesian cattle has been kept at the Eastern Michigan Insane Asylum, Pontiac Korndyke being a product of that herd.

The Netherland family was introduced to America by Smith and Powell, who regard the foundation as tracing back to Holland, to the bull Schreuder, the cow Netherland Dowager 2632 H. H. B. (which they imported), and Gert Met. Netherland Dowager had a milk record of $17,160 \frac{3}{4}$ pounds of milk in a year. She was dam of Schemmel, sire of Netherland. Prince 716 H. H. B., calved in 1880 and imported that year. His dam Lady Netherland I 263 H. H. B., a great show and producing cow, is really the foundation of this family. Netherland Prince was an animal of uncommon beauty and one of the great sires of the breed in his time. The Lakeside Model family is an offshoot of the Netherland established by E. A. Powell of New York, long a distinguished breeder and former part owner of Netherland Prince. This branch possesses great uniformity and much excellence. In discussing the establishment of this family Mr. Powell pays the following tribute to Netherland Prince ${ }^{1}$ :

Not only did he establish a finer, more uniform, breedy class, with better shaped udders and top lines, but a class of larger uniform production, as figures of the Blue Book will show, viz., that of the first 99 cows of the breed to make 30 pounds or more butter in a week, 96 - all but three - trace their pedigrees to Netherland Prince, and of the 29 cows given in the last Blue Book, which have made 35 pounds or more, all but one trace to him, including all above jo pounds.

The Netherland and DeKol families have combined to produce many noted animals.

The Pietertje family descends from Pietertje 2 d $3273 \mathrm{H}$. H. B., calved in 1877 and imported in 1882 by Alonzo Bradley of Massachusetts. Pietertje $2 \mathrm{~d}$ was a remarkable cow and had a

1 From a pamphlet descriptive of this family, published about I9I6. 
record of $I$ I 2 pounds 7 ounces of milk in a day, with an unofficial record of $30,318 \frac{1}{2}$ pounds of milk in a year. Pietertje 2d was the dam of Pietertje 3d I I 244 and Pietertje 4th I I 245, and, like their dam, great milkers. The Pietertje family, notwithstanding its heavy milking inheritance, did not attain the most widespread popularity, due perhaps to some extent to the

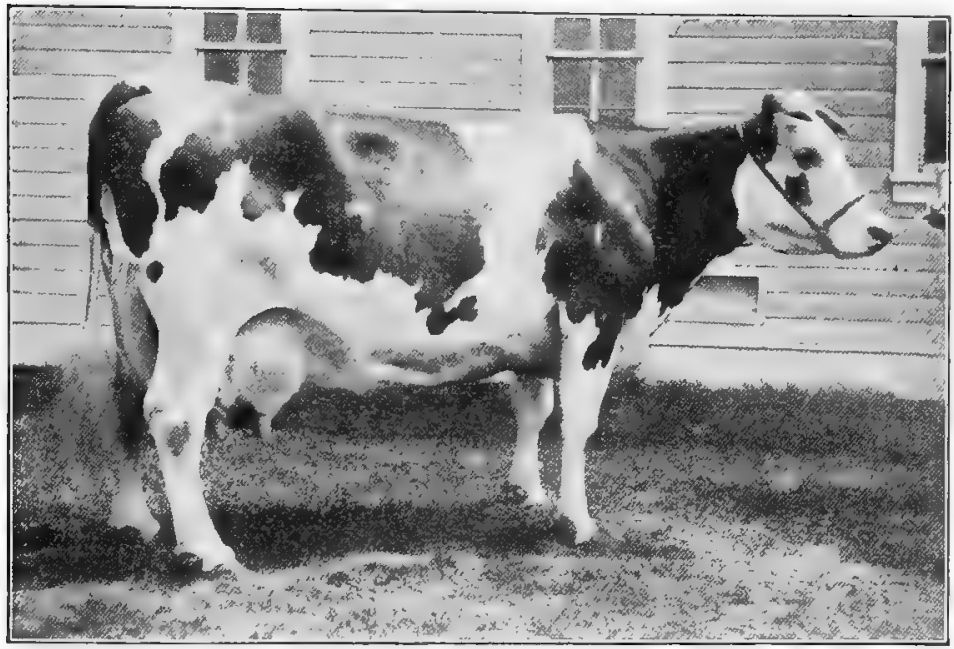

FIG. I62. Spring Brook Bess Burke 98734, one of the great Holstein-Friesian dams. She has a record of 25,227 pounds milk and ro94.I 6 pounds of 80 per cent butter and has three daughters with records of above 33 pounds of 80 per cent estimated butter in seven days and Iooo pounds in one year. From photograph, by courtesy of the owners, the E. C. Schroeder Farms, Moorhead, Minnesota

low per cent of fat in the milk, although Pietertje blood blended well with the DeKols and others rich in fat production.

The Pauline Paul family descends from Pauline Paul 2 I99 H. H. B., calved in 1882 and owned by J. B. Dutcher \& Son of New York. This cow was sired by Climax 204 H. H. B., and her dam was Johanna Paul 677 H. H. B., credited with 70 pounds of milk in one day. For years Pauline Paul was the wonder cow of the world because in three hundred and sixty-five days she made the unofficial record of 18,699 pounds of milk, from which was churned II 53 pounds I $5 \frac{3}{4}$ ounces of butter. Pauline Paul secured her greatest fame through a son, Paul DeKol I4634, 
sired by DeKol 2d's Prince 2767, a son of DeKol 2d. Paul DeKol sired 24 A. R. O. sons and 38 daughters, and these in turn proved very productive. Sir Veeman Hengerveld 36158 (with 84 A. R. O. daughters) and Paul Beets DeKol 22235 (with I04 A. R. O. daughters) are grandsons of Paul DeKol on the sire's side. One of the greatest cows of the breed, Aaggie Cornucopia Pauline 48426, had for sire a son of Paul DéKol and DeKol 2d. This family has long been one of the more popular ones of the breed and has been widely used on other blood lines.

The Segis family, one of the most popular to-day, has for its foundation cow Segis Inka 36617, with an A. R. O. record of 28.04 pounds butter and dam of five daughters and two sons with official records. Through her daughter A. \& G. Inka McKinley 55 I63 we have her grandson King Segis 36 I68, with 87 A. R. O. daughters and $82 \mathrm{~A}$. R. O. sons, one of the most popular sires of recent years. One of his sons, King Segis Pontiac 44444, with many A. R. O. daughters and sons, is sire of King Segis Pontiac Alcartra 79602 , known as the $\$ 50,000$ bull, and with many highclass A. R. O. progeny. Segis Fayne Johanna II 4648, the first so-called 5o-pound cow, is by King Fayne Segis 46767 , a son of King Segis. Finderne Holingen Fayne I4455I, with a record of I, I I6.05 pounds fat in a year, was sired by a son of King Fayne Segis. This family is noted for the large number of individuals producing milk of superior fat test.

The Glista family descends from Glista 7857 , the foundress of the entire Cornell University herd of Holstein-Friesians. This cow was very ordinary and as a three-year-old produced but I 88 pounds of butter fat in a year. Three of her daughters, Glista 2d, Glista 3d, and Glista 4th, varied in merit, but Glista 4th had a record of 274 pounds of butter fat in a year. With the use of superior bulls the herd steadily improved. Glista Ernestine is of the sixth generation and is one of the only five cows that have exceeded 30 pounds 80 per cent butter in five different seven-day official tests. Her total milk yield for eight years is I I I, I 82.9 pounds, an average of 13,897 pounds. Her butter-fat average for eight years is 510.62 pounds. She is the dam of eight calves; four of her oldest daughters have creditable A. R. O. records, and 
two sons head first-class herds. This is rather a local but very interesting family that has been little affected by outside influences.

The ten leading Holstein-Friesian sires, based on Volume XXIX of the Advanced Registry records, are the following:

NotE. T, D. = tested daughters; P.S. = producing sons; P. D. = proved daughters.

I. King of the Pontiacs 39037

2. Pontiac Korndyke 25982

3. Lord Netherland DeKol 22187

4. DeKol 2d's Butter Boy 3 d 23260

5. Hengerveld DeKol 23102

6. Colantha Johanna Lad $3248 \mathrm{I}$.

7. Homestead Girl DeKol Sarcastic Lad

\section{8}

8. Aaggie Cornucopia Johanna Lad 32554

9. Paul Beets DeKol 22235

I0. Sir Veeman Hengerveld 36158
T. D. 236

T. D. 147

T. D. 127

T. D. I 18

T. D. 116

T. D. 109

T. D. 107

T. D. 106

T. D. 105

T. D. 101
P.S. 145

P.D. 68

P.S. I IO

P.D. 90

P.S. 37

P.S. 95

P.D. 157

P.D. 85

P.S. 66

P.D. 85

P.S. 86

P.D. 52

P.S. $4+$

P.D. $6 \mathrm{I}$

P.S. 73

P.S. 49

P.S. 10
P.D. 79

P.D. 96

P.D. $5 \mathrm{I}$

In addition to the above bulls, there are many sires famous for the great records of their descendants. Sir Pietertje Ormsby Mercedes 4493 I has a wonderful record for his daughters, 22 having yearly records averaging over I ooo pounds of 80 -per-cent butter, and 8 having records ranging from IO23 pounds to I 389 pounds in a year. King Pontiac Champion 534I 8 is not only the sire of IOI A. R. O. daughters but I I have made yearly records averaging $23,082.6$ pounds milk and 923.57 pounds butter. King Segis Pontiac Count 93909 sired I I daughters with average yearly records of 22,66I pounds milk and 977.73 pounds butter. Pontiac Aaggie Korndyke 3829 I has 6 daughters that average i 214.9 pounds 80-per-cent butter.

Prices for Holstein-Friesian cattle have reached figures that surpass those of all other breeds of dairy or beef stock. As a rule, good examples of producing cows will command a satisfactory price. For many years $\$ 500$ has not been regarded as a phenomenal price for a good, plain-bred cow of the breed. Prior to the World War some remarkable figures had been reached. In I907 D. W. Field of Massachusetts paid \$8000 for the four-yearold cow Pontiac Rag Apple 56980, and in I9I I Mr. Field sold the bull calf Aaggie Cornucopia Sir Colantha IO299I, a son of 
Aaggie Cornucopia Pauline 48426, to W. H. Miner of New York for $\$$ I0,000. The same year, at an auction sale at Syracuse, New York, John Arfman of New York bought the calf King Segis Pontiac Alcartra 79602 for $\$ 10,000$. Two years later Lawson Farm of New York paid Mr. Arfman $\$ 25,000$ for a half interest in this bull. In I9I4, at auction in Chicago, the bull King Segis Pontiac 44444 was sold to a company for $\$ 20,000$. Since this latter date prices for Holstein-Friesian cattle have risen in a remarkable degree.

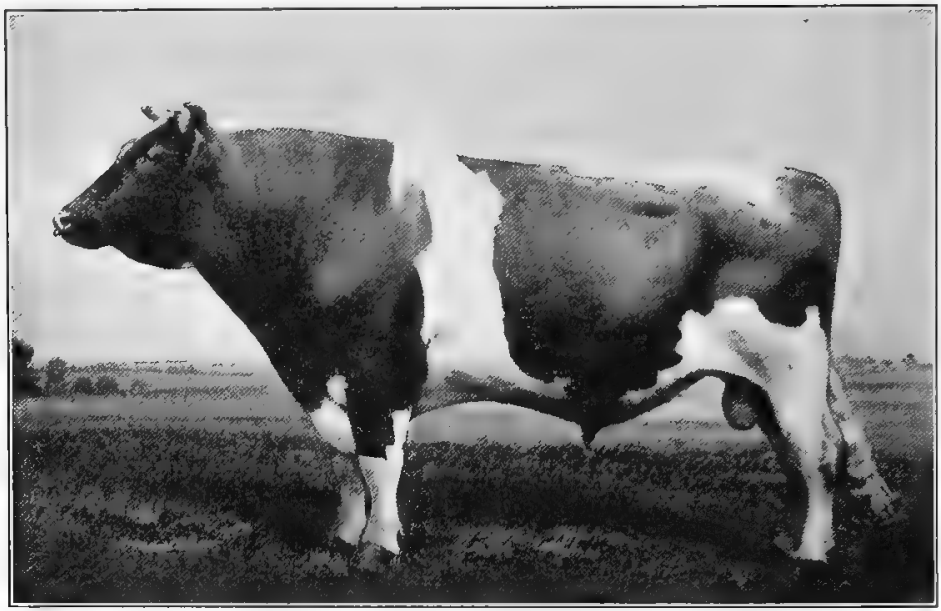

FIG. I63. Sir Pietertje Ormsby Mercedes 4493I, one of the greatest HolsteinFriesian sires. Up to 1919 twenty-two of his daughters had made yearly records which averaged over 1000 pounds 80 -per-cent estimated butter, and eight had records ranging from 1023 to 1389 pounds. From photograph, by courtesy of the owners, E. C. Schroeder Farms, Moorhead, Minnesota

At the sale of E. H. Dollar on January 5 and 6, 1915, at Syracuse, New York, I 72 head sold for $\$ 149,990$, an average of $\$ 872$, on which occasion the bull Rag Apple Korndyke 8th 734I6, a grandson of Pontiac Rag Apple, sold for $\$ 25,000$ to Oliver Cabana, Jr., of New York. Later, in June, I9I 7, in auction at Worcester, Massachusetts, a son of Rag Apple Korndyke 8th, named King Ormsby Jane Rag Apple, consigned by Pine Grove Farms of New York, sold to D. W. Field Farm Company of Massachusetts for \$53,200. At this time the dam of this calf - Ormsby Jane Segis Aaggie 150943 - had "the world's butter records over all ages and breeds 
from 30 to I00 days," being the only cow to have made two sevenday records averaging over 45 pounds each. The high price for a cow was also made at this sale, Wandermeere Belle Hengerveld 193784, consigned by E. Le Roy Pelletier of Michigan, selling for $\$ 18,300$ to Shanahan \& Dold Brothers of New York. At this same sale 143 cattle, consigned by thirty or more breeders, brought $\$ 296,470$, and 59 animals sold for $\$ 1000$ or more per head. In June, 1918, in a combination sale at Milwaukee, Wisconsin, new records were made, I 75 head bringing a total of $\$ 425,810$, an average of $\$ 2433$ each. On this occasion the bull calf Carnation King Sylvia 23I405, consigned by A. C. Hardy of Ontario, Canada, was purchased by the Carnation Stock Farm of California for $\$$ I06,000. At this same sale the cow Het-Loo Pietertje 38502 was sold for $\$ 12,750$ to Lisle Farm Company of Illinois, and the cow Idleaze Pontiac Lass 238652 was sold to A. W. Green of Ohio for $\$ 13,000$. Eight head brought figures ranging from $\$ 10,000$ to $\$ 106,000$ each, a most sensational record. The climax to all dairy-cattle sales up to date occurred May 2730, 1919, in the dispersal sale of the Pine Grove Herd of Oliver Cabana, Jr., Elma, New York, who sold 226 head for $\$ 754,270$, an average of \$3337. The bull Rag Apple the Great 230798 sold to Robert R. Pointer, Detroit, Michigan, for \$125,000. A. W. Green, Middlefield, Ohio, bought Rag Apple Korndyke 8th $734 \mathrm{I} 6$ for $\$ 60,000$, and before the sale was over sold a half interest in him for $\$ 50,000$. Sixty-seven of his sons and daughters averaged $\$ 44$ IO. In this sale many animals passed the $\$ 10,000$ mark. The cow Segis Hengerveld Fayne Johanna I 73739 sold for $\$ 40,000$ to Dold Brothers, Alden, New York, and Fairview Korndyke Mata I69926 sold for $\$ 35,000$ to J. T. Shanahan, East Aurora, New York. An important purchase of the 1919 season was that of the bull King Pontiac Hengerveld Fayne by R. E. Haeger of Illinois for \$IOO,O0O. High prices for Holstein cattle were also experienced in England, and these reached high levels on June I7, I9I9, when at a sale held by Lord Rayleigh, 82 head brought an average of $\$ 1830$. Four bulls averaged $\$ 8500$, and the imported cow Terling Jeltje 3 Ist sold for 5300 guineas, or $\$ 27,000$. A heifer calf three months old, Terling Jeltje 2 d, brought 2200 guineas, or $\$$ I I ,000. 
The distribution of Holstein-Friesian cattle outside of Holland is mainly in Belgium, northern Germany, parts of Russia, England, Australasia, Canada, and the United States. A few cattle of the breed have also been exported to Japan and to South America. In general only British breeds are kept in England, but HolsteinFriesian cattle are getting quite well established in that country. The breed is widely distributed over North America. For many years New York State has been regarded as the great center for Holstein-Friesians, but extensive herds are found to-day in Ohio, Wisconsin, Minnesota, Illinois, Missouri, Michigan, New Jersey,

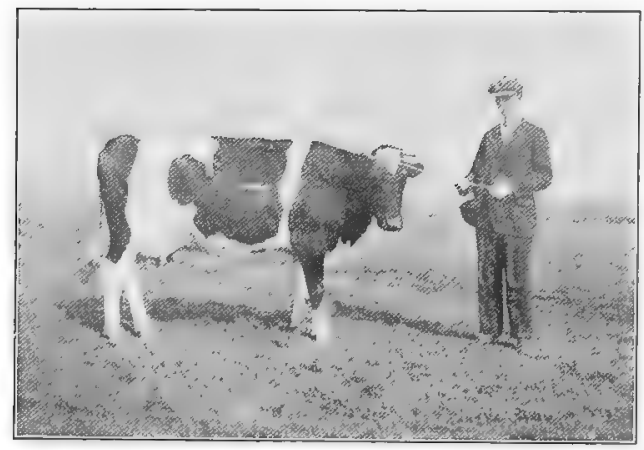

FIG. I64. A prize-winning two-year old HolsteinFriesian heifer in the Kuperus herd, Lecuwarden, Holland. From photograph by the author and Massachusetts. On the Pacific slope thereare superior herds in California, Oregon, and Washington. In the South the breed is steadily growing in favor, but thus far it is not prominent. In extensive dairy districts and near large cities herds are most common. Many public charity, correctional, and penal institutions having farms maintain herds of Holstein-Friesian cattle. The states of Ohio and Michigan own a number of noted herds of the breed that furnish milk and butter to public charges. During the year I9I7 the Holstein-Friesian Association of America registered 88,276, which shows how extensively the breed is handled to-day in this country. While not so well suited to hot, dry climates and to rough, poor lands as some breeds, HolsteinFriesians seem to thrive over a wide range.

Organizations for the promotion of Holstein-Friesian cattle first developed in America. About 1872 a number of men in the eastern United States, led by W. W. Chenery of Massachusetts, organized the Association of Breeders of Thoroughbred Holstein Cattle. In 1872 the first volume of the "Holstein Herdbook" was 
published. Nine volumes in all were issued, the last appearing in I 885 . In I 879 a number of men who had been importing and breeding Dutch cattle and who disapproved of the word "Holstein" as being illogical and out of place organized the Dutch Friesian Cattle Breeders' Association and in I880 published Volume I of the "Dutch Friesian Herdbook," of which four volumes were issued, the last in I885. After more or less friction, in view of the fact that each organization was bringing over the same class of cattle, a conference was held in $\mathbf{I} 885$, and the two associations amalgamated under the name of the Holstein-Friesian Association of North America. Since I 885, up to January, I9I9, thirty-nine herdbooks have been issued by the association and a total of over 690,000 animals recorded. Up to April 7, I9I 8, the association had a membership of 10,739 . In I 892, as a result of dissatisfaction, the Western Holstein-Friesian Association was organized, and in I 894 published a herdbook, the only one issued up to I 899, when the association consolidated with the Holstein-Friesian Association of North America. In 1875 an association was organized in Holland under the name of the North Holland Herdbook Association. In 1885 an American branch of this was organized, and Volume I of the "American Branch of the North Holland Herdbook" was published in I888. The present-day leading organization in Holland promoting the Dutch cattle, comparable with our Holstein-Friesian, is the "Netherland Rundvee Stambock," with headquarters in Friesland at Leeuwarden. Up to I9I9 this society has published fifty-five volumes of herdbooks. In I909 the British Holstein Cattle Society was organized. By I900 it had 833 members, and up to I9I9 had published nine herdbooks. This organization later changed its name to the British Friesian Cattle Society. There is also an organization in Canada, - the Holstein-Friesian Association of Canada, - founded in I89I, which has published twenty-two herdbooks to I9I8. In I9I0 the New Zealand Holstein-Friesian Association was organized. Besides the above, the Holstein-Friesian Association of North America publishes the Advanced Registry records, established in I885, of cows that have had official A. R. O. tests. This registry also contains lists of sires of tested cows. The first volume was published in 1887 , followed by three other separate volumes, after which the 
Advanced Registry was for a time incorporated in the regular issue of the herdbook. In Volume I 3 I bulls and 300 cows were registered. Recently the Holstein-Friesian records have been published in an annual yearbook. Among the organizations to promote the breed are state associations, of which there are many to-day in the United States. There are also many community breeders, associations for the promotion of this breed, notably in Ohio, Wisconsin, Michigan, and New York. In I9I4 Mr. W. H. Jenkins wrote ${ }^{1}$ : "In Chenango and Madison counties, New York, are 500 breeders of pure-bred Holstein cattle. An aid to breeding the finest cattle has been the Chenango-Madison Holstein Cattle Club organized a few years ago, which now has more than 200 members." An extension bureau of the Holstein-Friesian Association of America, organized in 1918, has been instrumental in establishing breed clubs in many communities.

Holstein-Friesian interests in America are given wide publicity through the efficient service of the Holstein-Friesian World, an illustrated weekly published at Syracuse, New York. The British Friesian Journal, published in London, advances the interests of the breed in Great Britain.

${ }^{1}$ Hoard's Dairyman, November 20, I914. 


\section{CHAPTER XXXIII}

\section{THE GUERNSEY}

The native home of Guernsey cattle is on the islands of Guernsey and Alderney, in the Channel Islands group. Guernsey is seventy-eight miles southeast of Weymouth on the coast of England, twenty-eight miles from France, and twenty-two miles northwest from the island of Jersey. Four islands, - Guernsey, Alderney, Sark, and Herm, - while under the British sovereignty, are under the local government of Guernsey. The island of Guernsey is roughly triangular in form, about nine miles in its greatest length, and five in its extreme width. While most of the coast is rocky and precipitous, that of the south shore is especially so, the cliffs rising to a height of 270 feet, the land roughly sloping northward to a low beach. The island has an area of 15,560 acres, of which about 10,000 are under cultivation. There are ten parishes on the island, and, like Jersey, a lieutenant-governor represents the British crown, while a bailiff acts as president of the local government. There is a population of about 45,000 on Guernsey, and St. Peter Port is the only town of consequence. The people, besides producing cattle, make a specialty of crops under glass, such as grapes, tomatoes, muskmelons, cut flowers, etc., largely for the London market. It is said $^{1}$ that if the greenhouses now on the island were placed end to end, they would reach eight hundred miles, - probably an extravagant statement, but indicative of the extent of culture under glass on the island. The cattle on Guernsey are kept in small herds and generally tethered when on pasture, grazing systematically and making good use of all food.

The origin of the Guernsey, like that of the Jersey, is quite obscure, but is supposed by many to have been derived from the cattle of Brittany and Normandy of near-by France. Mr. Hill refers ${ }^{2}$

1 Charles L. Hill, The Guernsey Breed, p. 22. Waterloo, Iowa, 1917.

2 Ibid. p. 3 I. 
to an undated letter written by Professor Ananias, in charge of agriculture in Les Vauxbelets Agricultural School, Guernsey, in which it is said that the monks of that institution have especially investigated the origin of the cattle of the island. The most prominent ancestor is the Brittany breed called Froment du Leon, which is much smaller than the present Guernsey, but possesses the same distinct markings - namely, red and white, fawn and white, etc. - and is naturally very active. The other source was the brindle cattle of Normandy, which were much heavier than

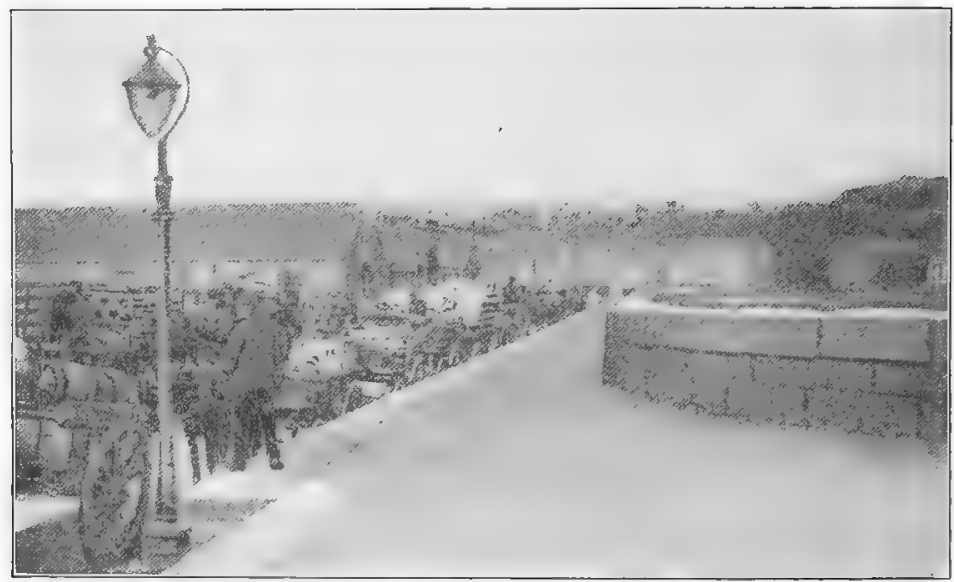

FIG. I65. A view on the dock at St, Peter Port, Guernsey. This shows a line of vehicles awaiting turn unloading fruits and vegetables on the steamer for England.

From photograph by the author

the modern Guernsey or the old Froment du Leon but which produced a heavy yield of rich milk, often sixty to seventy pounds daily. The brindle marks and black noses occasionally seen with Guernseys are supposed to be reversions to the old Normandy cattle. These two breeds of cattle, it is assumed, were taken to Guernsey centuries ago, and from the commingling of their blood, followed by careful selection, has been derived the modern breed of Guernsey. The cattle of Brittany or Normandy to-day, based on the author's observation, present little suggestion of the Guernsey. The cattle on Alderney must have come from the same source, and in fact for many years the cattle imported to 
England from any of the Channel Islands were commonly called Alderneys. No doubt the cattle of the islands were to some extent commingled. Mr. Hill, who is a noted Guernsey breeder and authority, says on this subject ${ }^{1}$ :

I have found plenty of references to the taking of cattle from both Guernsey and Jersey to Alderney, and from both Guernsey and Alderney to Jersey, and, while I do not find any direct reference to the taking of cattle from Jersey to Guernsey, it is very certain, from the color of many of the cattle on the Island of Guernsey, that there must have been an admixture of Jersey blood not many generations ago. As recent as I9I3 I saw in Guernsey two registered cows, both daughters of the well known Fanny's Sequel, that were Jersey in type, and were solid, dingy black with black noses and tails.

\section{Mr. Hill further says :}

No one could reasonably doubt for a moment that there had been in comparatively recent years an exchange of cattle from one island to another, and that within a century, and probably within sixty or seventy years, the islanders themselves considered the cattle of the different islands one and the same breed.

\section{The protection and improvement of cattle on Guernsey may} perhaps be said to date from 1824 , when an ordinance was passed forbidding the importation, under severe penalty, of "all sorts of French cows." The primary purpose of this law was to prevent the reexportation of French cattle from Guernsey to England, as of the island breed. A further effort leading to the improvement of the cattle on Guernsey must have begun about 1828 , for according to Mr. Hill, who quotes Jeremie, there were certain points of excellence observed in awarding prizes on cattle of merit, the following scale of points being used by the judges.

\section{Early Scale of Ponnts for Cattle on Guernsey}

I. Pedigree as well of the bull as the cow, yellow ears, tail, and good udder

2. General appearance, handsome color, cream, light red, or both mixed with white

3. Handsome head, well horned, and bright and prominent eye

4. Deep, barrel-shaped body

5. Good hind quarter and straight back

6. Handsome legs and small bone

Total good, or points of excellence

7 points

3 points

4 points

3 points

2 points

I point

20 points

1 C. L. Hill, The Guernsey Breed, I9I7. 
The Royal Agricultural Society of Guernsey took an active interest in promoting the improvement of the cattle and in 1842 published a scale of points for bulls (giving 28 points for perfection) and also a scale for cows and heifers (with 30 points for perfection). In I882, in Volume I of the herdbook, a revised scale for cows, embracing I oo points, was published, and in Volume II, published in 1883 , was given a revised scale for bulls, with a total of IOO points. No bull scoring less than 70 points was to be allowed a prize. Later these standards were revised. Each year the Royal Guernsey Agricultural Society holds an annual show on the first Tuesday in June, and in I9 I a fall show, held

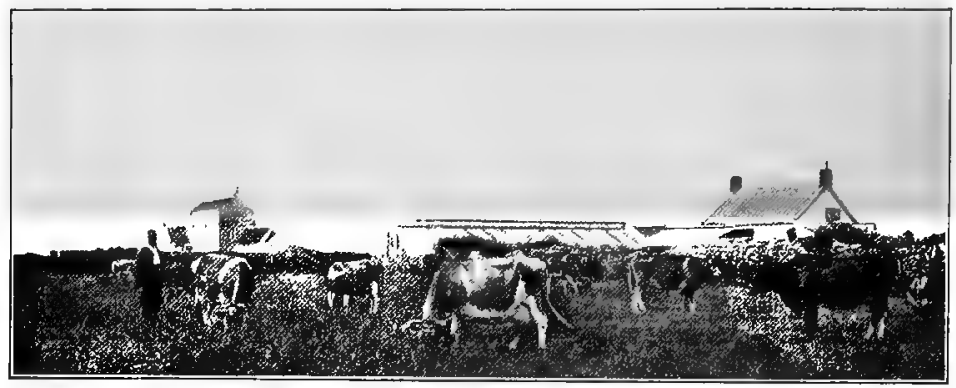

FIG. I66. A familiar scene on Guernsey. From a photograph by the author

on September 29, was inaugurated. Parish shows are also held. At the Royal Guernsey Show the king of England has for years offered cups for the best two bulls and the best cow, and an animal can win this cup but once. Animals competing for these cups must have been bred or calved on the island, and if won by a bull under two years of age he must be reserved for island service until three years of age, and if winning the prize at over two years the bull must also be kept for service at least twelve months following. The first local show was held in July, I88I, when forty cows were admitted to the herdbook as foundation stock and ranked as Commended, Highly Commended, and Very Highly Commended. This custom obtained until I9I2, when all cows were admitted and marked as "qualified at local shows," no distinction in rank being observed. Only cows in milk have ever been admitted as foundation stock, and it is a rule of the society, 
now rigidly enforced, that the birth of a calf must be attested by a member of the society within twenty-four hours, otherwise a heifer would be eligible for registration as a foundation cow only after coming in milk. Descendants of foundation ( $\left.F_{\text {. }}\right)$ or pedigree stock (P. S.) are registered as pedigree stock.

The introduction of the Guernsey to America dates back early in the last century. In I824 Reuben Haines of Germantown,

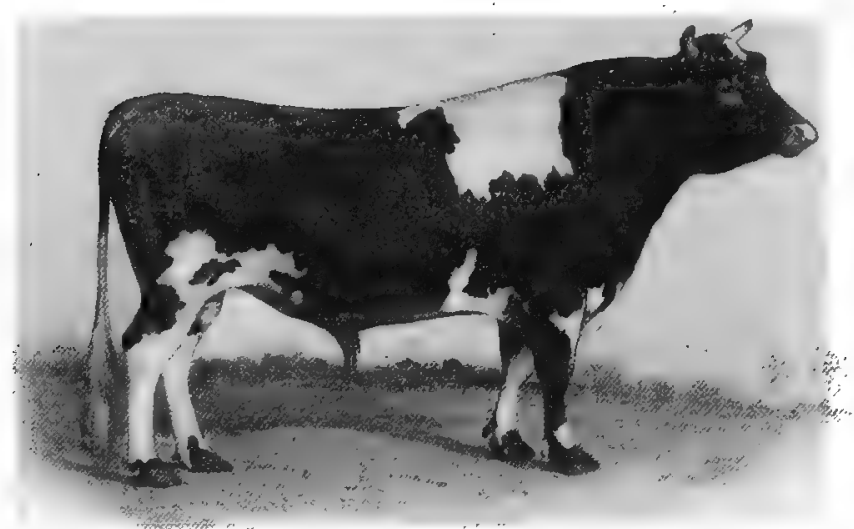

FIG. 167. Sheet Anchor 2934 (imp.), calved in 1891, a famous Guernsey sire and show bull. Owned by H. McKay Twombly, Madison, New Jersey. From photograph by Schreiber

Pennsylvania, wrote in the "Memoirs of the Pennsylvania Agricultural Society" that he "procured a pair of cattle of the Island of Alderney" and soon satisfied himself that no breed in the country would bear a comparison with them. These were imported in 1818 and may be regarded as Guernseys in fact, inasmuch as cattle on Alderney island are to-day registered in the island of Guernsey herdbook. According to publications of the American Guernsey Cattle Club, cattle were brought to America from Guernsey about I 830 by a Mr. Prince of Boston and placed on a farm of his in Massachusetts. Soon after importation a cow and bull were shipped to Cow Island, Lake Winnipesaukee, 
New Hampshire. These two animals were in I 899 registered by the American Guernsey Cattle Club as the Pillsbury bull 5816 and the Pillsbury cow II 3 IO. From them as foundation stock have descended some excellent cattle. The next oldest importation of pure-bred Guernseys occurred September 26, I840, Nicholas Biddle of Andalusia, Pennsylvania, bringing over three cows on the schooner Pilot. These were registered by the club as Jennie Deans I, Fenella 2, and Flora McIvor 3, and from them came the heifers Fanny Ellsler 4, Fairy 5, and the bull St. Patrick I. These were the first entries in the American herdbook. About I $85 \mathrm{I} \mathrm{J}$. P. Swain imported a few animals from the Channel Islands, two being from Guernsey. One of these, Guernsey I 84, was a superior milker, and her first calf, Cottie 188 , lived to a ripe old age and was a valuable producer and breeder. Importations were also made in $\mathrm{I} 855$ by W. H. Stewart and E. M. Hopkins of Torresdale, Pennsylvania, and by C. H. Fisher of Philadelphia. About 1865 E. P. P. Fowler and P. H. Fowler of England and the United States, prominent dealers in Channel Island cattle, began to bring Guernseys to America. In I 872 Mr. J. M. Codman of Brookline, Massachusetts, visited the island and imported a few animals which were looked upon with favor in New England. In I 874 the Massachusetts Society for the Promotion of Agriculture made an importation, and these cattle were distributed over the state to different farms, including those of E. F. Bowditch of Framingham, W. C. Cabot of Brookline, and James Lawrence of Groton. These three latter herds were still in existence in I9I8. Beginning with the seventies considerable activity occurred in importing Guernseys, and up to I9I8 over 6000 were imported. On February 7, 1877, eleven energetic breeders came together at the Astor House, New York City, and organized the American Guernsey Breeders' Association. At the first annual meeting, in December, I877, it was reported by Edward Norton, the secretary, that I93 Guernseys, I I 4 of which were imported, were registered by forty different breeders. Then for years the breed received but little attention, until about 1893, when public interest was excited by the record made by Guernseys in the tests at the World's Columbian Exposition at Chicago. Since then Guernseys have steadily gained in favor ; the supply has hardly equaled the demand. 
Characteristics of Guernseys. In general appearance the cattle of this breed are larger than Jerseys, are of coarser make-up, and show a more rugged character. The head tends to be somewhat plain, the face frequently being rather straight and lacking the graceful curves characteristic of the Jersey. The homs should be white or amber colored, and are often tinted a deep yellow, curving

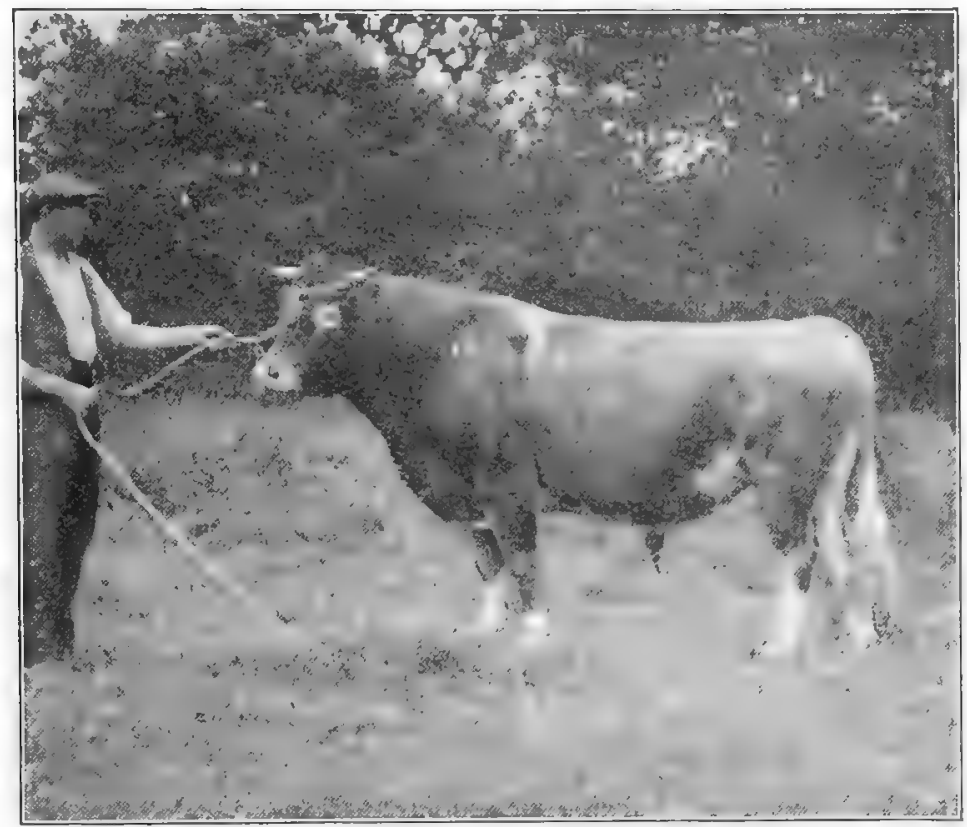

FIG. I68. Honoria's Sequel 2d, winner of the King's Cup on Guernsey. Owned by Alfred Le Patourel, La Ramee, Guernsey. From photograph by the author

gracefully around inward and slightly upward, with the cow; those of the bull being shorter, stronger, and less curved. The neck of the Guernsey shows considerable relative length, the reithers tend to be coarse rather than refined, and heaviness of shouldir is quite frequent. Many cattle of the breed lack in level top line, especially back of the withers. Excellent digestive capacity is indicated in the capacious middlepiece, which is rather characteristic of the breed. The hind quarters tend to be a bit prominent at the tail head and full at the thighs. The ndder varies 
considerably in the type, with the fore part inclined to be short and carried high. In spite of the above criticisms, those familiar with the Guernsey during the past twenty-five years have noted a marked improvement in type and dairy conformation. There is much less roughness of outline and more finish and quality than heretofore. The class of Guernsey cattle seen in the shows of importance to-day is markedly superior to those of even a few years ago.

The color of the Guernsey is either yellowish, brownish, or reddish fawn, the latter prevailing, frequently with white markings or with white on the limbs or under part of the body. The most recent scale of points in use on Guernsey applies the following color qualifications to both bulls and cows: "Hair fine and silky, fawn or red, black or brindle, with or without white markings." In the last scale of points adopted by the American Guernsey Cattle Club (I9I8) the color markings are given as "a shade of fawn with white markings." The modern tendency favors the predominance of fawn, and many Guernseys of to-day show comparatively little white. The color of the skin at the nose is commonly of a cream or buff tint, in other words, white, but a dark slatish black is not uncommon. There has been more or less controversy over the color of the Guernsey nose, a light color being much preferred, but the dark nose has never been condemned, though not by any means popular. Mr. C. L. Hill states that "the buff nose is fashionable in the show ring, but it is safe to say that this fashion has not been helpful to the Guernsey breed, as in the past it is well known that many of the brindles and dark cows have been among the very best animals." The hair about the muzzle and eyes should be of a whitish or very light fawn, sometimes termed "mealy color." The horns and hoofs are preferably of a dark-amber hue.

The skin secretions of the Guernsey have long been regarded by breeders as important guides to the quality of the milk. The I 828 points of excellence specified yellow ears and tail. In I 842 the scale of points emphasized that the ears should be orange colored inside. In the latest island scale of points fifteen credits are given to features associated with color of milk, as when the skin is deep yellow in the ear, on the end of the bone of the tail, and on the udder, teats, and body generally. The 
new I9I 8 Guernsey scale of points gives twenty points credit for essentially the same features. Some nonpartisan friends of the breed have regarded these figures as too great a proportion of the Ioo points making up the standard. However, it must be conceded that the deep yellow secretions and the thin, mellow, elastic skin of the Guernsey are very important indicators of the superior quality of the animal and its milk.

The size of the Guernsey may be classed as medium. The tendency during the past quarter of a century has been towards increase in size. Weight is not usually much discussed by European breeders, but for many years four points have been credited in the standard either to growth or to size, the latter word now being used. No standards of weight, however, are given. The present American scale adopts "about" 1600 pounds for the mature bull and I IOO pounds for the cow as standard weights. In a discussion on the subject of weight at the annual meeting of the American Guernsey Cattle Club, May I 5, I9 18, Mr. Tarbell said :

- It is not material, I believe, whether the Guernsey cow weighs 1050 pounds, I I 25 pounds, or I I 50 pounds; in fact, a I000-pound cow is quite an ideal Guernsey cow. That gives a little latitude, depending entirely upon other things in connection with the matter. Personally, I should like to see it left "about II 100 pounds," and the bull the same way, "about I 600 pounds," if it could be done. Mr. Hill stated that he thought "I I 00 pounds in milking condition a pretty big cow. I think it would be about ideal to strive for."

The temperament of the Guernsey is superior, the males perhaps being hardly as nervous and irritable as are Jersey bulls, although the dairy temperament is characteristic of each sex. In I899 the American Guernsey Cattle Club adopted standards for each sex, where thirty points were credited to "dairy temperament and constitution," but in the more recent I9I 8 standards no reference is made to temperament. From the standpoint of disposition the Guernsey is very good, being naturally quiet and easily handled.

The maturing character of the Guernsey is not remarkable. The young bulls show masculine traits more slowly than the Jersey and reach maturity somewhat later.

The crossbred or grade Guernsey has its distinctive place on the dairy farm. Crossing of breeds is not advisable, but using 
Guernsey sires on grade cows will give excellent results if intelligently followed, yielding very rich milk eminently suited to butter-making or city cream or milk trade. If a sire with strong constitution is selected for use on grade Jerseys, the constitution, size, and productivity of the herd may be improved; if used on grade Holstein-Friesian cows, a herd producing richer milk, though not so much, may be expected. In a publication of the American

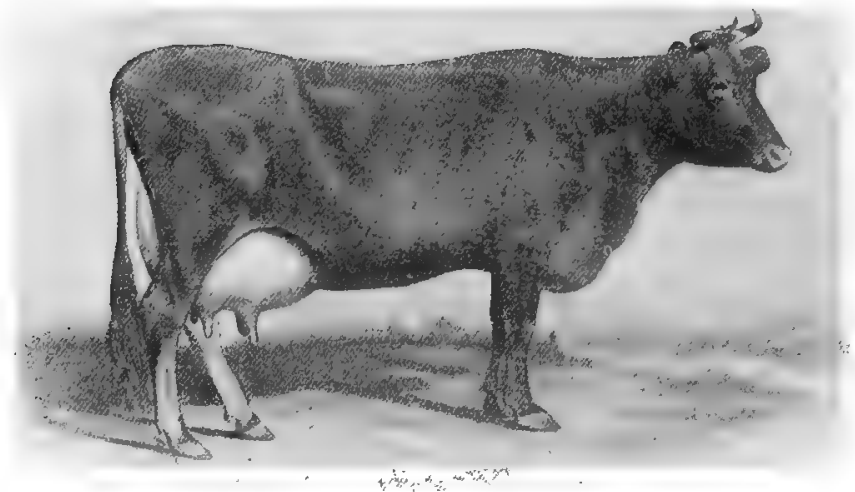

FIG. I69. Rutila's Daughter 6670, calved in I891, a very beautiful Guernsey cow with a record of 8988 pounds milk in one year, testing 489.8 pounds butter fat. Owned by H. McKay Twombly, Madison, New Jersey. From photograph by Schreiber"

Guernsey Cattle Club on "the Grade Guernsey Cow" much interesting evidence is brought forward. L. E. Bronson, referring to five years' work in grading up, states that since following this practice of grading to the Guernsey, the yearly yield of the herd has increased over Ioo pounds butter fat per cow. N. I. Bowditch of Massachusetts, a long-time Guernsey breeder, writes :

I am glad to be able to write you that this cross has been very satisfactory, especially so the first cross with Holsteins. I have bred several Holstein cows that tested from 2.8 to 3.4 butter fat, and their progeny have given me milk testing all the way from 4.5 to 5.6. I have crossed the Guernsey bull with 
grade Durhams, Ayrshires and Jerseys, and as a rule the result has been very satisfactory. I am raising about 25 grade heifers each year, and have a very promising lot of heifers and young cows.

In a recent address ${ }^{1}$ on " Grade Guernseys in the Central West," before the Western Guernsey Breeders' Association, Noel Negley reports that of 37,772 cows on test by seventy-seven Wisconsin cow-test associations, 5938, or 23 per cent, of the grades were grade Guernseys. The average milk production of I 498 of these cows was 5655 pounds, testing 4.7 per cent fat and producing 265.9 pounds butter fat. Twenty grade cows from ten herds averaged IO, I 53.4 pounds of milk and 508.4 pounds of fat.

\section{The Guernsey in beef} production can have but a subordinate place. A larger and perhaps fatter carcass may be made than with the Jersey, but this presents the same objection as other dairy breeds, - too much offal, a low percentage of high-priced

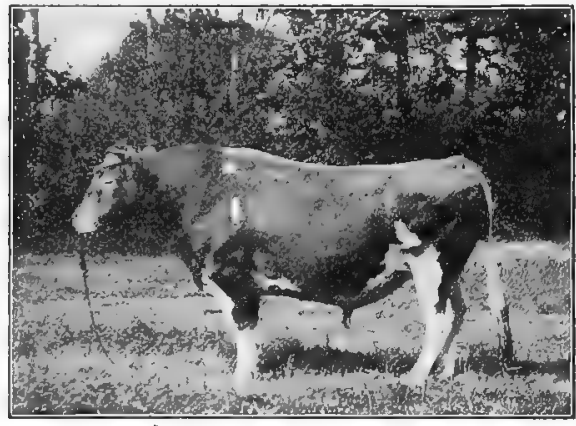

FIG. I70. Island Champion 62623 (imp). Before importation this bull, a winner of the highest honors on the island, was known as Masher II. From photograph by the author cuts, and, in this case, too yellow fat. In flavor and quality Guernsey beef or veal will rank high among dairy type breeds.

The prolificacy of the Guernsey probably does not differ much from that of the other dairy-type breeds. In I9r6 the American Guernsey Cattle Club published some comparative figures on the rate of gain of several breeds, including its own, as based on office records in registration. In 1906 the yearly increase of registrations for the Ayrshire, Guernsey, Holstein, and Jersey breeds averaged 7.66 per cent, that of the Guernsey being 9.3 per cent. In 1915 the average percentage increase of the four breeds was I 2.46 per cent, that of the Guernsey being I4 per cent. On the basis of these comparative records the conclusion is reached that "there is more assurance that the average Guernsey herd will 
double in a given number of years than there is for some of the other breeds, and just as much assurance as any breed can give."

The Advanced Registry of the American Guernsey Cattle Club was based on action of the club in May, I90I, when a set of rules for officially testing bulls and cows under the supervision of agricultural college or experiment station officials was adopted. In I 894 some preliminary work in this direction was attempted, and in July, I897, the Club published some rules for making

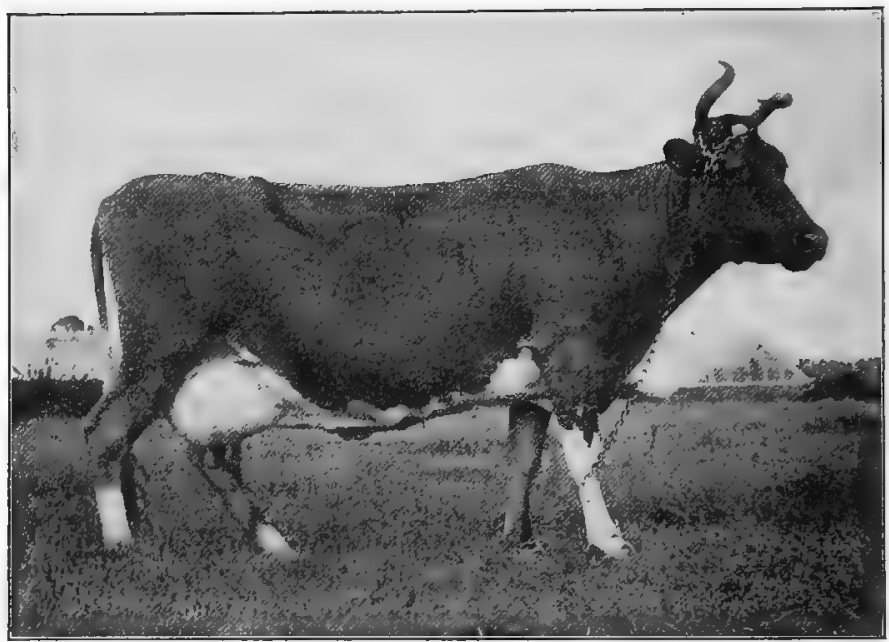

FIG. I7 I. Princess May ${ }_{479}$ F. S., a choice specimen of a Guernsey cow, and dam of the imported bull Deputy 2917, at head of the Pan-American Exposition Guernsey herd. From photograph by the author

butter tests for cows under supervision of the executive committee of the Club, samples of the milk being tested by experiment station officials, and late in 1898 four different breeders registered for testing their herds. The work then done, mainly in I 899, attracted much favorable comment, and the rules adopted in I9OI were the outgrowth of this experience. These rules (which have undergone more or less revision) in I9I 8 involve the following essential factors: If the record is commenced the day the animal is two years old, or previous to that day, she must produce within one year from that date 250.5 pounds of butter fat. For 
each day the animal is over two years old at the beginning of her year's record, the amount of butter fat she will be required to produce in the year will be established by adding O.I (one tenth) of a pound for each day to the 250.5 pounds required when two years old. This ratio is applicable until the animal is five years old, when the required amount will have reached 360 pounds, which will be the amount of butter fat required of all cows five years old or over. Any period of three hundred and sixty-five

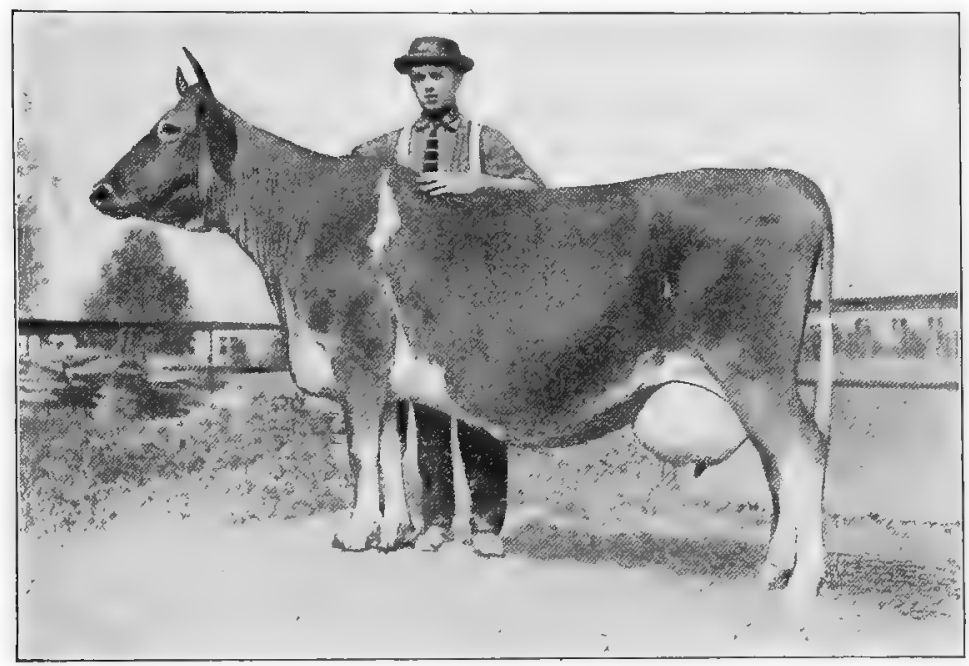

FIG. I72. Spotswood Daisy Pearl I7696, one of the great Guernsey cows, with a world's record in I910-19I I of 957 pounds butter fat. Owned by O. C. Barber, Barberton, Ohio

consecutive days or less in which a cow has made her requirements may be used for determining her record, regardless of any time lost on account of being dry during that period. The ordinary Guernsey Advanced Registry classes are $A$, for cows five years old and older; $\mathrm{B}$, four and one-half to five years; $\mathrm{C}$, four to four and one-half years; $\mathrm{D}$, three and one-half to four years; $\mathrm{E}$, three to three and one-half years; $F$, two and one-half to three years; $\mathrm{G}$, two to two and one-half years. If, in addition to making the requirements in her respective class, a cow shall carry a calf or calves two hundred and sixty-five days in her test, the letters used Digitized by Microsofte 
to indicate her class shall be doubled and would be respectively $\mathrm{AA}, \mathrm{BB}, \mathrm{CC}, \mathrm{DD}, \mathrm{EE}, \mathrm{FF}$, or GG, according to the conditions.

The Guernsey as a producer of milk has steadily grown in favor, although breeders have emphasized the quality and fat content. In the year I888-I889 the cow Lily Alexandre I059 produced I 2,856 pounds of milk. Between I883 and I903 daily milk records were kept of the N. K. Fairbanks herd of 60 head, in which 6000 to 7000 pounds were not infrequent, the best record being 9447 pounds in three hundred and twenty-eight days. The average annual yield of 62 cows and heifers of the Ellerslie herd of New York for about 1892 was 6120 pounds, with 10,316 the maximum. Various other herd records of this period gave similar results. Beginning with the Advanced Registry rules about 1900 came a greatly increased activity in record-making. The following yearly official records up to 1919 are for the more important ten animals.

\section{Leading Gufrnsey Milk Records for One Year}

\begin{tabular}{|c|c|c|c|}
\hline Name and Number of Con & $\begin{array}{c}\text { AGE WHEN } \\
\text { TESTED }\end{array}$ & Year tested & YIEL,D \\
\hline Murne Cowan 19597 & 8 years & $1914-1915$ & $24,008 \mathrm{lb}$. \\
\hline Nella Jay 4 th $3^{82} 33$ & 5 years & $1916-1917$ & 20,7 Io lb. \\
\hline Langwater Hope 27946 & 6 years & $1915-1916$ & I $9,882 \mathrm{lb}$. \\
\hline Yeksa's Tops of Gold's Fannie 22362 & ro years & $19^{1} 5^{-19} 16$ & I9,794 lb. \\
\hline May Rilma 22761 . . & 6 years & $1913-1914$ & I $9,673 \mathrm{lb}$. \\
\hline Belladia 31909 . , . & 6 years & $1915-1916$ & I $9,63^{2} \mathrm{lb}$. \\
\hline Langwater Nancy 27943 . & 7 years & $1917-1918$ & $\mathbf{I} 8,783 \mathrm{lb}$. \\
\hline Spotswood Daisy Pearl I 696 & 7 years & I9IO-I9II & $18,603 \mathrm{lb}$. \\
\hline Dolly Dimple rgi44 . . . . & 3 years & $1908-1909$ & I $8,459 \mathrm{lb}$. \\
\hline Imp. Donnington Goldie 5th 59866 & 4 years & I916-1917 & I $7,862 \mathrm{lb}$. \\
\hline
\end{tabular}

Many very large mills yields are recorded. Of 7943 Advanced Registry milk records up to March, I919, over 2300 aged cows averaged I0,288 pounds, while the average for the 7943, representing all ages from two years up, was 9000 pounds. The average yield of 70 class leaders for this group was I 5,160 pounds, a remarkable record when. one considers the size of the animal producing the yield.

The Guernsey as a producer of butter fat occupies a position of the very first rank. A study of the history of the breed brings 
into clear light the importance the islanders have long placed on the butter-producing value of the milk. The first island scale of points of importance, that of 1842 , makes as the first qualification that the pedigree shall be of ancestry known to produce "rich, yellow butter." Guernsey milk is usually of a higher natural yellow color than that of any other breed. The fat globules are comparatively large and have a deeper yellow than even the

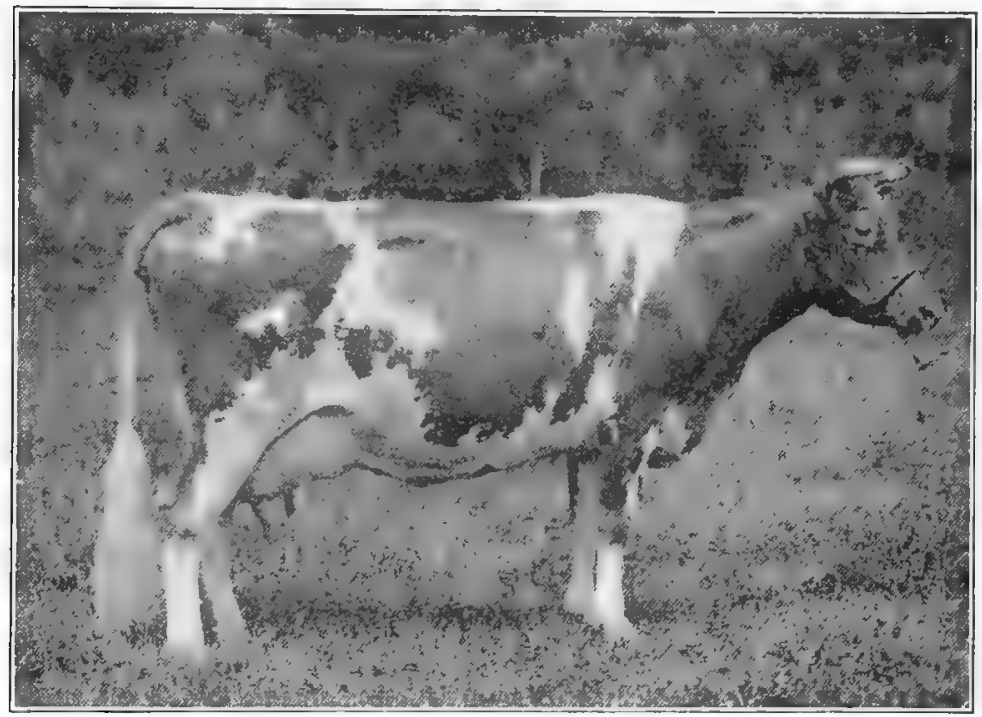

FIG. I73. Langwater Dairymaid 26377, bred by Langwater Farms, North Easton, Massachusetts, and sold at public sale for $\$ 6 r 50$. As a five-year-old, this cow produced $I 6,949$ pounds milk and 812.66 pounds fat. From photograph, by courtesy of Langwater Farms, F. L. Ames, owner

Jersey. In fact, Guernsey breeders seek the rich yellow as characteristic, arguing that with this breed it is not necessary to color the butter artificially, as its natural yellow meets the market demands. The per cent of fat in all Advanced Registry testing up to the middle of 1918 shows. 5 per cent as an average, with 5.2 per cent for the 70 class leaders. In the Pan-American dairy breed competition, in which the Guernseys secured first honors, the average per cent of fat in the milk was 4.68 compared with 4.82 for the Jersey. However, the Guernsey butter scored an 
average of 96.34 total points compared with 95.80 for the Jersey, while in color that of the Guernsey had an average grade of 14.97 out of a possible I 5 points, the best record of any of the ten breeds. The 5 Guernsey cows in the Pan-American test for the six months produced 1429.43 pounds of churned butter, valued at $\$ 357.36$, yielding a net profit of $\$ 220.37$, the best record of any breed in profit and almost the first record in amount of butter. produced, the Holstein-Friesian leading in this regard by only three fourths of a pound. In this test of 50 cows of ten breeds, the Guernsey cow Mary Marshall 5604, aged ten years, led the list, producing in six months 56 I I pounds of milk, testing 5.36 per cent and yielding 301.13 pounds butter fat and 354.26 pounds churned butter, giving a total profit of $\$ 59.43$. Guernsey breeders, however, have attached special importance to long-time tests, being from the first advocates of this method to measure the producing value of the cow. Following are the leading records in butter-fat production of Advanced Registry cows up to I9I9.

\section{Leading Guernsey Butter-Fat Records for One Year}

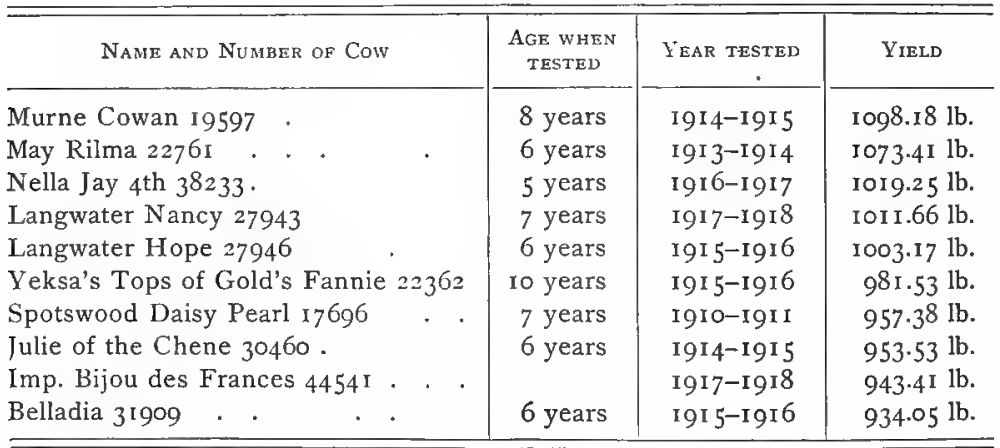

The average of the above ten records is $997 \frac{1}{2}$ pounds of butter fat, a remarkable showing. Up to January I, I9I9, there were recorded annual butter-fat records of 7943 different cows, which showed an average yield of 450 pounds, while the best 70 cows in seven classes had the high average of 790 pounds. It is interesting to note that there are Io junior and ro senior two-year-old heifers in this list of 70 class leaders, and I I of these 20 have produced 
yields of fat from 703 to 773 pounds each. With the present improved condition of the breed it is not unreasonable to expect the average herd to produce 350 pounds of butter per head, if not more.

The cheese value of Guernsey milk ranks very well, although not largely used for this purpose, being mainly turned to butter production or retail milk trade. The milk stands well in total solids, that of whole herds often averaging I4 to 15 per cent, thus furnishing a satisfactory grade of cheese. The only official test on a large scale showing the value of Guernsey milk in cheese-making was in I893 at the World's Columbian Exposition. In this trial, covering fifteen days, participated in by Guernseys, Jerseys, and Shorthorns, the Jerseys stood first, scoring 90.7 ; the Shorthorns, second, scoring 90.5 ; and the Guernseys third with 87.2. However, in net profit the Guernseys stood second to the Jerseys.

Families of Guernsey cattle have attracted attention only in comparatively recent years and more especially since official testing has become established. The number of families is not large, but of these the following may be regarded as of special distinction. Charles L. Hill has made a valuable contribution regarding Guernsey families, ${ }^{1}$ and from his writings the author quotes freely and with appreciation.

The Bonnie Lassie family descends from Bonnie Lassie of Fernwood I845 A. G. C. C., calved on Guernsey in I883 and imported to Boston in September the same year by L. W. Ledyard. Her first calf, Bonny Boy 1097, did much for the fame of this family. He sired several excellent daughters, but his real importance is through his sons, of which Lily's Bonny Boy 2676 is especially noteworthy. He was sire of Lily Ella 7240, with a semiofficial record of 782 pounds of fat in a year, and of Lillyita $724 \mathrm{I}$, with a record of 7 I I pounds. Three of his other daughters have official records of over 500 pounds of fat each, and twentyeight of his daughters have private or public records exceeding Advanced Registry requirements. The great record cow Murne Cowan 19597 is a granddaughter of a son of Lily Ella - Lily Ella's Jeweler 54I7. The blood of this and the Materna families have been much intermingled.

1 The Guernsey Breed (Lgyjt) and Hogrd's Dairyman, December 22, I9 I . 
The Dolly Bloom family is descended from Dolly Bloom I 2770, which traces back on the sire's side five generations to Bonny Boy I097. Dolly Bloom was calved April I4, I900, and was bred by Ezra Michener of Pennsylvania. Dolly Bloom was a great producer of both milk and progeny. As a five-year-old she made I 7,298 pounds of milk containing 836.21 pounds of fat. However, she receives her chief fame from her daughter Dolly Dimple I9I44,

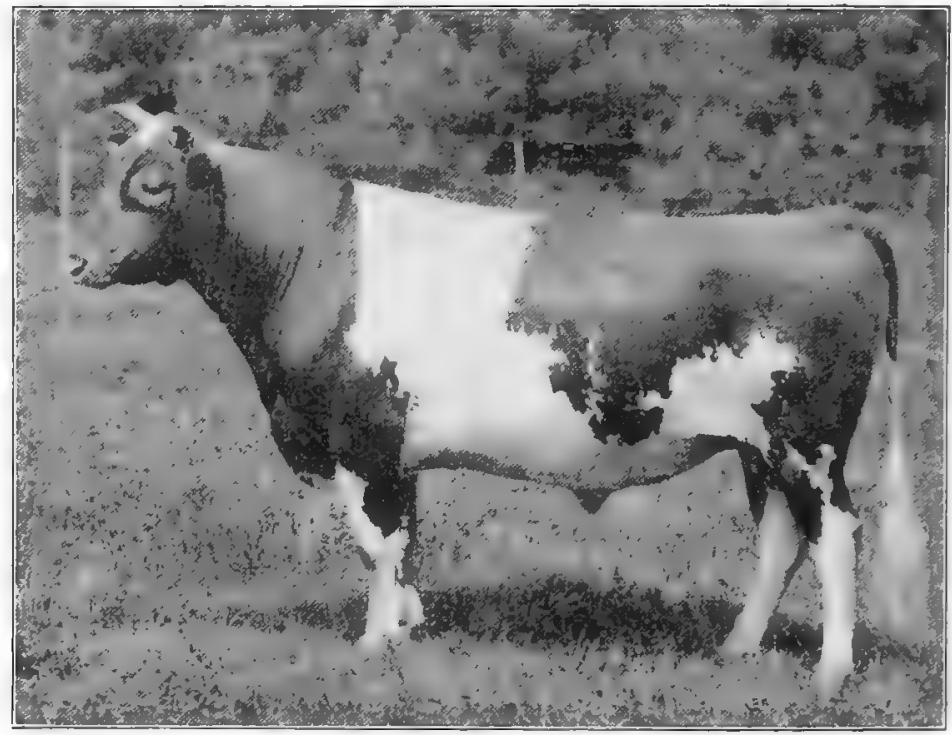

FIG. 174. Langwater Warrior 26509, a prominent Guernsey sire of fine style and type. Owned by Langwater Farms, North Easton, Massachusetts. From photograph, by courtesy of Mr. Ames

with the great record of I 8,459 pounds of milk and 906.89 pounds fat in a year as a three-year-old. Another daughter, Dolly Bloom of Langwater I 5452, had a record of 632.34 pounds of fat, and her daughter Langwater Dolly Bloom 22 I 36. had the large record of 867.89 pounds fat in a year. Jethro Bass I I 366 , a son of Dolly Bloom, has sired a number of high-producing daughters, including Rose of Langwater 24204, with a year's record of 751.62 pounds fat, and Langwater Dairymaid 26377, with a record of 812.66 pounds fat. This latter cow also sold for \$G $\$ 50$ at public auction. 
This and the May King families, in the hands of F. L. Ames of Massachusetts, have been bred together to great advantage.

The France family, one of the most popular of the breed, has its origin in the cow France 404 F. S. 2207 A. G. H. B. She was bought by P. D. Ozanne from Mr. T. Vidmour, Les Frances Farm, St. Saviours, Guernsey, and from this farm she got her name. She was imported in September, I 884, by A. F. Fuller of Pennsylvania and sold to Francis Shaw of Wayland, Massachusetts. She left on the island one daughter, France $2 \mathrm{~d}$, and as she was in calf when imported she dropped a heifer in America, France 3d 2573 (imp.). On the island her daughter, who was later imported, also dropped a heifer, named France $3 \mathrm{~d} 3018 \mathrm{P}$. S. From this latter, France $3 \mathrm{~d}$, this family descends. The mating of Masher $2 \mathrm{~d} 858$ P. S., later known as Island Champion 6263 (imp.), to France 3d, later known as La Belle France I 4454 (imp.), produced France's Masher $2 \mathrm{~d} 7248$ (imp.), the sire of Masher's Sequel I 462 (imp.), one of the greatest sires of the breed. Raymond of the Preel I 353 (imp.), sire of a large number of Advanced Registry daughters, is a son of Masher's Sequel. This family includes a large number of animals in the Advanced Registry, but the records produced are hardly as high in butter fat as some of the others. This especially applies to daughters of Masher's Sequel.

The Glenwood Girl family descends from Glenwood Girl I693, imported in dam in 1883 by $\mathrm{L}$. W. Ledyard of New York. Calved in I884, she soon after became the property of E. T. Gill of Haddonfield, New Jersey, in whose possession she dropped twelve living calves, seven being heifers. These daughters, mostly sired by different bulls, were an unusual group, but one of them, Glenwood Girl 2d 9108, produced 9945 pounds of milk and 508.7 pounds of fat in a year and lived to be sixteen years old. Her son Glenwood Boy of Haddon 4605 sired many Advanced Registry daughters, including Jedetta of Pinehurst 17434, with a record of 778.8 pounds of fat in a year, and Dairymaid of Pinehurst 24656 , with a record of 17,285 pounds of milk and 910.67 pounds of fat in a year. Mr. Hill wrote ${ }^{1}$ in I9I I that it was his opinion, if Glenwood Boy of Haddon had had the opportunity that some bulls had of serving a large number of females, he 
would easily have led all sires in the number of his Advanced Registry daughters. Through the sons and grandsons of Glenwood Boy of Haddon has come a large number of Advanced Registry cows, including Elberons' Glenwood of Haddon 28934, with test of 825.9 pounds of fat in a year, and Miranda of Mapleton I9606,

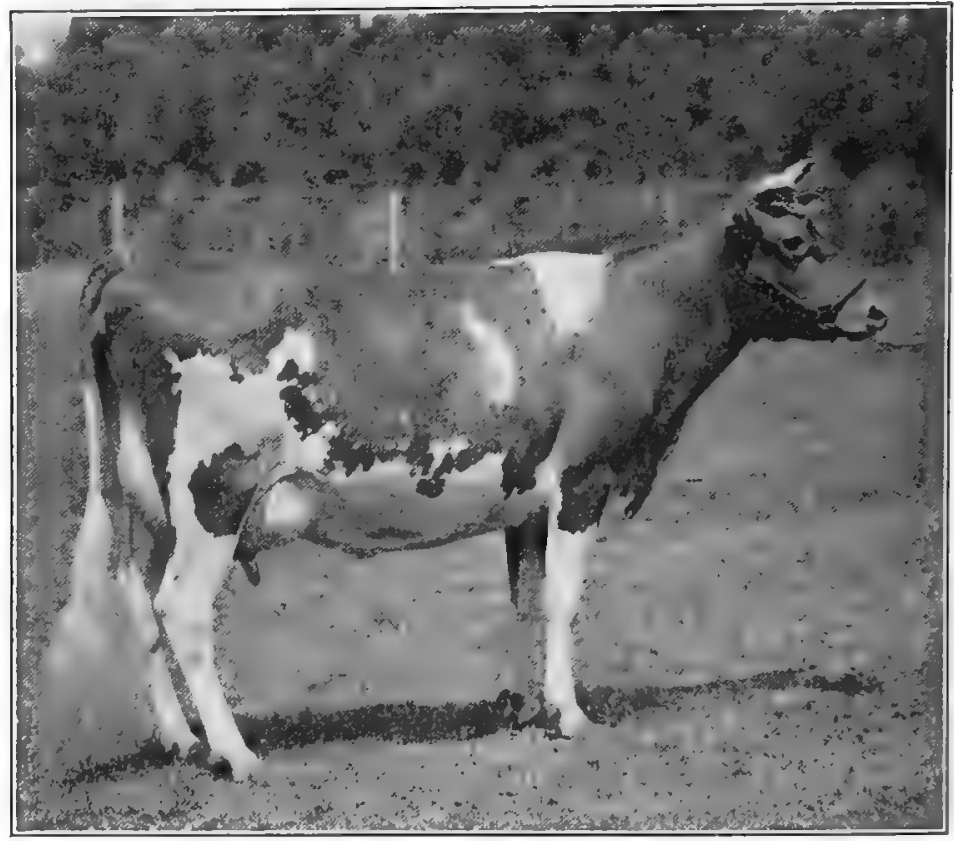

FIG. 175. Langwater Pauline 33566, by King of the May. First prize in class at National Dairy Show. Record for three hundred and forty-four days, as a threeyear-old, ro,918.8 pounds milk and 595.37 pounds fat. Bred by Langwater Farms, North Easton, Massachusetts. From photograph, by courtesy of F. L. Ames

with a record of 927.I6 pounds. Glenwood Girl 6th 9I I3, a daughter of old Glenwood Girl and long regarded as a model of the breed in conformation, was dam of Glenwood's Mainstay 6067 , with many Advanced Registry daughters. This family is looked upon with special favor.

The Masher family descends from Masher 705 P. S., calved on Guernsey May 2, I 890 , bred by F. N. Mahy, and owned by Alfred Le Patourel of La Ramee farm. Through his son Island 
Champion $626_{3}$ (Masher $2 \mathrm{~d} 858$ P. S.), a famous prize winner on the Island, comes a line of noted animals. Langwater Dorothy 27944, with Advanced Registry record of 78 I.65 pounds of fat in a year, was four generations removed from old Masher. Spotswood Sequel 9686 (imp.), son of Spotswood Busy Bee I 7606 (imp.), by Island Champion, is sire of many Advanced Registry daughters, including Lady Lesbia 25 I42, with test of 787 pounds of fat in a year. Masher's Sequel I I 462, previously referred to in the France family, is a grandson of Island Champion. Masher's Sequel bred to Galaxy 4422 P. S. sired Galaxy's Sequel I6904 (imp.), winner of the King's Cup in 1907 and sire of many daughters in the Advanced Registry. This family is very closely interwoven with the France family.

The Materna family receives its name from the cow Materna I334, calved September 3, I882, on the farm of N. K. Fairbanks, Lake Geneva, Wisconsin. She was sired by Amber I45, the grandsire of Glenwood Girl 2d. Materna came from a very good milking strain, her dam being Nerissa of Geneva 848. In I893 Materna was first-prize Guernsey cow at the Columbian Exposition at Chicago and highest ranking in the Guernsey herd test at the Exposition, in ninety days producing 3512 pounds of milk containing I 53.39 pounds of fat. Materna dropped twelve calves between 1884 and I898, two of which died early. Her daughter Morn 5947 was dam of Standard's Morning Glory I280I, with Advanced Registry record of 7I4.0I pounds of fat in a year and granddam of Starlight's Excelsior 7992, sire of many tested daughters.

The May Rose family descends from May Rose I 392 F. S., calved May I 2, 188I, bred and owned by Pierre Martel, La Masse Farm, Castel, Guernsey. Her ancestry is unknown. Through her daughter May Rose $2 \mathrm{~d} 325 \mathrm{I}$ P. S. this family came into special fame. She won first prizes at the Royal Guernsey shows in I894, I 896, and I897, and, exported to England, was third at the Royal Show the latter year. May Rose $2 \mathrm{~d}$ had four sons and five daughters. The sons were Paradox 352 E. G. H. B., a noted show bull in England; Our Paradox 873 P. S.; Jubilee de la Massee 1083 P. S., later named May. Day I 32 E. G. H. B.; and May King I 395 E. G. H. B., later known as May Rose King 8336 (imp.). 
The daughters were May Rose 3d 3252 P. S., May Rose 4th 7682. (imp.), Rose of Gold 3668 P. S., May Rose 8th 3998 P. S., and Itchen May Rose 4839 E. G. H. B. This family has been distinguished not only for a large number of show animals but also for many high-testing cows. Through the sons of May Rose $2 \mathrm{~d}$ remarkable results have been secured. May Day was the sire of May Day Pearl I 5195 (imp.), dam of Spotswood Daisy Pearl I 7696 , with a record of 957.38 pounds of fat in a year. May Rose King (imported by H. McKay Twombly in I9O2 at a cost of $\$ 3500$ ) proved a most successful sire, for all of his daughters entered the Advanced Registry, and his sons even surpassed him. The most noted of his sons is King of the May 900 I (imp.), sire of Langwater Rosie 2 I 333, with a record of 724.23 pounds of fat; Langwater Dorothy 27944, with a record of 781.65 pounds of fat; and Langwater Hope 27946 , with a record of 19882 pounds of milk and I003.I7 pounds of fat, each within a year. Beda's May King I I 893, another son of May Rose King, has been a successful sire, having many daughters in the Advanced Registry. This, without question, is the most popular family at the present day. In I9I4 L. E. P. Smith wrote ${ }^{1}$ that "an investigation of the English herdbooks to and including Volume XXIX, shows that there have been recorded almost precisely 500 female descendants of May Rose $2 \mathrm{~d}$. There were approximately 250 remaining in the English herds, I 40 have died, I oo have been imported to America, and Io have been exported to South America, Australia, and New South Wales, and even to China. The same records show approximately 200 male descendants of May Rose $2 \mathrm{~d}$. Of this number only 35 now remain in England, I 30 have died or been slaughtered, 25 imported to America, and Io exported to Australia and South America."

The Tricksey family descends from Tricksey i 760 (imp.), bred on Guernsey by John Gibson of St. Martins and imported to America by S. C. Kent. She changed hands several times, finally reaching the Minnesota Experiment Station. A daughter, Tricksey 3d 3I9I, and a son, Benjamin I93I, were her most potent offspring. Benjamin, in the herd of C. L. Hill of Wisconsin, was very successful as a show bull and a sire. Ben

1 Guemsey Breeders' Joumat. 
Bishop 3506, a son of Benjamin, was sire of a number of animals in the Advanced Registry, and his son Glenwood Bishop 9I 86 was the sire of Glenwood's Buttercup 48I 37, with a record of 769.82 pounds of fat in a year. Suke of Rosendale 6520 , by Benjamin, was the dam of Prince Rosendale 429I, well known as a show bull and as a sire of cows with creditable tests.

The Yeksa family descends from I'elisa 2426 , bred by I. J. Clapp of Wisconsin and calved April I 2, I 885. She was a heavy milker and is said to have a private record of over 600 pounds of butter as a three-yearold. She had one son, Yeksa's Prince 1943, and two daughters, Queen Vashti 605 I and Bonny Jean 3646 . This son was the sire of Yeksa Sunbeam I 5439, the record of which in $1904-1905$ of I 4,92 I pounds of milk and 857.I pounds of fat was the first notable feat of production by a cow of the breed and resulted in attracting

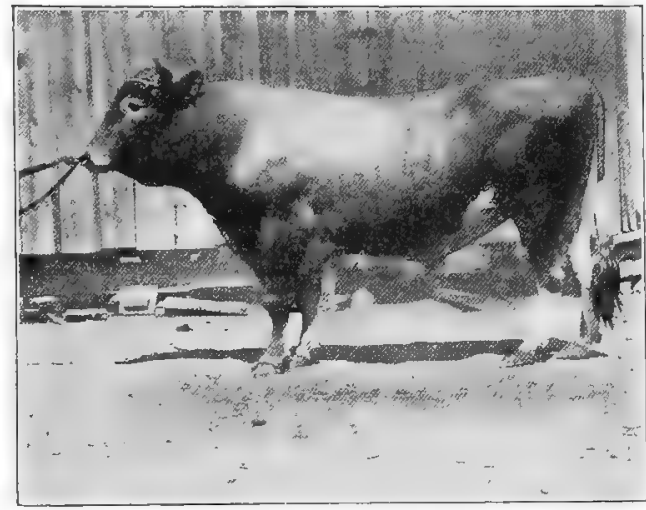

FIG. 176. Lord Yeksa 645I, owned by J. H. Beirne, Oakfield, Wisconsin. A very successful sire. From photograph, in 1904, by the author much attention to this line of breeding. Queen Vashti was the dam of Queen Deette 9794, with a record of 669.82 pounds of fat in a year, and of Yeksa's Queen $66_{3} \mathrm{I}$, whose son Guydette 3966 was sire of Yeksarose I66Io, with a record of 678.16 pounds of fat. A grandson of Yeksa's Queen in this line, Endymion 89i6, sired a number of Advanced-Registry daughters, including Endymion's Primrose 23795, with test of 848.88 pounds of fat in a year. Lord Yeksa $645 \mathrm{I}$, another grandson, sired Yeksa's Tops of Gold's Fannie 22362, with a record of 19,795 pounds of milk and 981.53 pounds of fat in a year. This family has combined show-yard and producing merit in a high degree. For some years following the test of Yeksa Sunbeam cattle of this family were in great demand. 
The ten leading Guernsey sires up to August I, I9 I8, as based on the records of their daughters and sons in the Advanced Registry of the American Guernsey Cattle Club, are as follows :

\begin{tabular}{|c|c|c|c|}
\hline Name and Number & $\begin{array}{c}\text { YEAR } \\
\text { CALVED }\end{array}$ & $\begin{array}{l}\text { A. R. } \\
\text { DAUGH- } \\
\text { TERS }\end{array}$ & $\begin{array}{l}\text { A. } R \text {. } \\
\text { Sons }\end{array}$ \\
\hline I. Governor of the Chene (R. G. A. S. I297 P. S.) & 1904 & 76 & 18 \\
\hline 2. Masher's Sequel I I462 A. R. (imp.) . . . & 1900 & 68 & 22 \\
\hline 3. Galaxy's Sequel I6904 A. R. (imp.) . . . & 1904 & 40 & I9 \\
\hline $\begin{array}{l}\text { 4. Cora's Governor of Chilmark } 897 \text { I A. R. (imp.) } \\
\text { 5. Justinees' Sequel of the Preel (R.G.A. S. } 2 \text { rig }\end{array}$ & 1903 & 40 & 3 \\
\hline 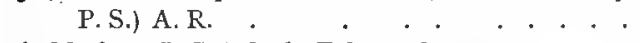 & 1907 & 35 & 3 \\
\hline 6. Masher (R.G.A.S. 63 F.S.) A.R. . . . & 1904 & $3 I$ & 8 \\
\hline 7. Princess's Jewel 24877 A. R. (imp.) . . & I904 & 28 & $\mathbf{I}$ \\
\hline 8. Lord Mar I4359 A. R. (imp.) . . . & I905 & 27 & 3 \\
\hline 9. Glenwood's Mainstay 6067 A. R. & 1899 & 26 & 15 \\
\hline Io. Glenwood Boy of Haddon 4605 A. R. & 1895 & 26 & 14 \\
\hline
\end{tabular}

Prices paid for Guernsey cattle in recent years have attracted much attention. In the United States good cows of the breed have been in strong demand since the Columbian Exposition test in I 893, but for many years following this date no abnormal prices were paid for Guernseys. In I9I0 F. L. Ames of Massachusetts paid $\$ 2000$ for the cow Imp. France 8th 21262 , and Chestnut Hill Farm of Ohio, the same year, paid $\$ 2000$ for the bull Galaxy's Sequel 16904 (imp.), these being at that time the top prices on this breed. In August, I9I I, the bull George Washington of Fairfield Farm I 0866 was sold by Corydon Peck to C. D. Ettinger of Illinois for $\$ 3500$, and late this same year F. L. Ames sold to M. H. Tichenor of Wisconsin a bull calf out of Dollie Dimple for $\$ 6000$. In I9I 4 the noted cow May Rilma 2276I was sold by E. B. Cassatt of Pennsylvania to John P. Crozier of the same state for $\$ 5010$. Since the opening of the World War prices have increased by leaps and bounds. On October IO, I9I6, at a sale at Langwater Farms, North Easton, Massachusetts, 74 head brought $\$ 80,625$, an average of $\$ 1075$. C. L. A. Whitney of New York paid \$6I 50 for Langwater Dairymaid 26377, and John A. Ames bought Langwater Generous 41958 for $\$ 5000$. H. G. Lapham of Massachusetts bought Langwater Easter Lily 
39269 and Langwater Pear 26605 at $\$ 4200$ each. On May I6, I9I8, a combination sale was held at Lake Forest, Illinois, under the auspices of the American Guernsey Cattle Club, when 67 animals brought $\$ 102,925$, an average of $\$ 5536$ each. The top price was $\$$ IO,000 for the bull Don Diavolo of Linda Vista 23565 , bought from Dr. C. G. Parnell of Michigan by John C. Haartz of New Hampshire. The highest-priced cow was Langwater Luxury

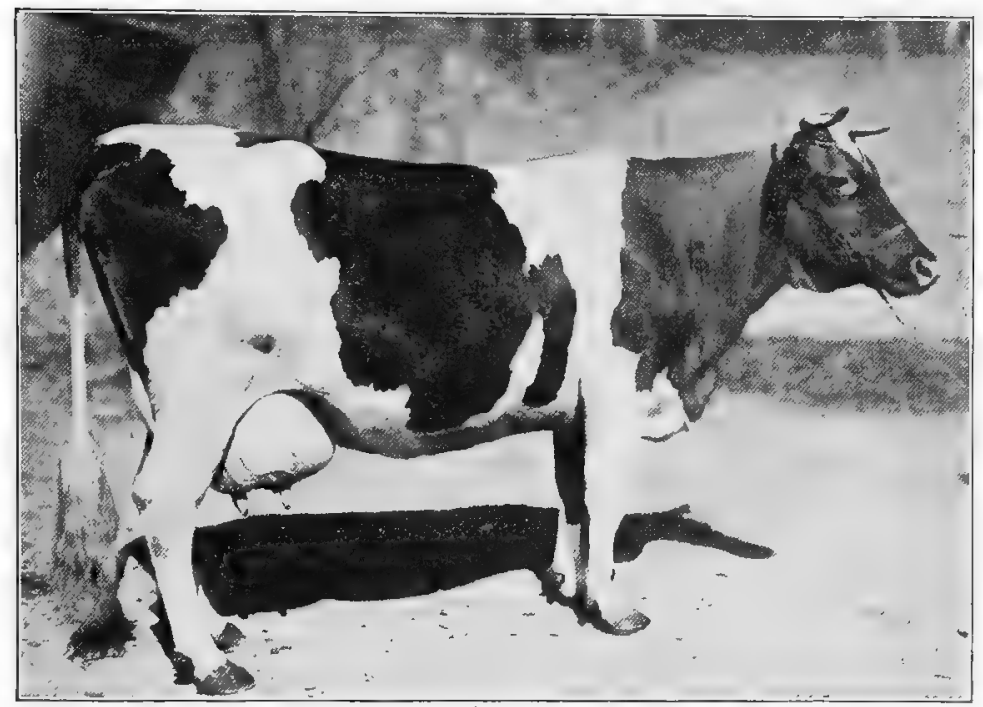

FIG. I77. Violet IV of Corbinez 32405 (imp.), a Guernsey cow with official record of 16,336 pounds milk and 756.72 pounds fat. Owned by Waddington Farm, Elm

Grove, West Virginia. From photograph, by courtesy of the owner

49484 , by Imp. King of the May 900 , sold by F. L. Ames for $\$ 5300$ to Frank D. Stout of Wisconsin. Langwater Amiable 4948o, by Langwater Stars and Stripes 21872 , consigned by Mr. Ames, was sold to Burnside Farm of Maryland for $\$ 5000$. In 1918 W. G. Jamison and Sons of Wisconsin sold to W. H. Dupee of California the bull Pencoyd's Golden May Secret 39626 for $\$ 10$, IOO, while late in I9I8 C. D. Cleveland of New Jersey sold the bull Florham Autocrat 25749, to A. T. Herd of Pennsylvania for $\$ 14,500$. This same year I 3 I 8 Guernseys sold at public sales for an average price of $\$ 330$. The 220 cows brought an average 
of $\$ 574$, and 517 heifers averaged $\$ 305$. On May I 5, 1919, Florham Farms of New Jersey established a new Guernsey sale record. Eighty-three head sold for $\$ 180,275$, an average of $\$ 2$ I 72 per head. Eight bulls brought $\$ 44,800$, averaging $\$ 5600$. Fifty-six animals exceeded the $\$$ Iooo mark. A two-months-old bull calf, Florham Leader, by Ne Plus Ultra 15265 and out of Langwater Nancy 27943, sold for $\$ 25,000$ to Oakes Farms and Hugh Bancroft of Massachusetts. The cow Follyland Nancy 52457 sold for $\$ 2.500$ to J. L. Hope, Madison, New. Jersey.

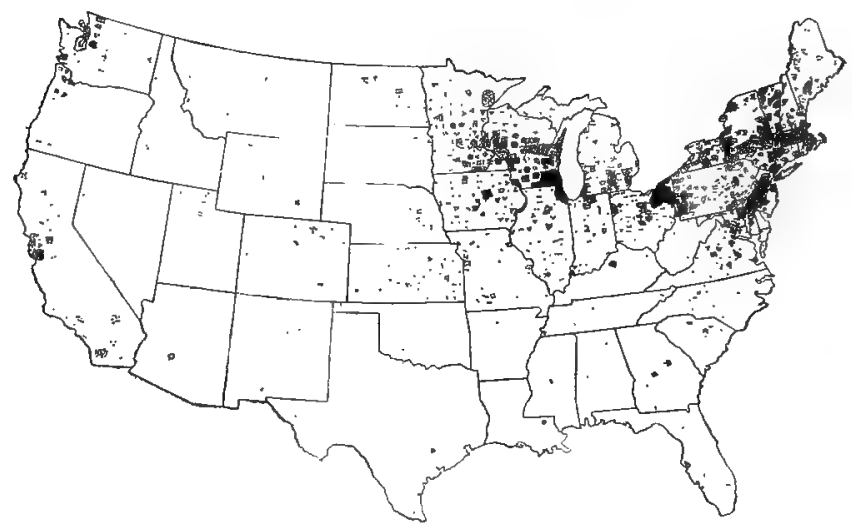

FIG. 178. A map showing the comparative distribution of the Guernsey over the United States in 1917. By courtesy of American Guernsey Cattle Club

The distribution of the Guernsey breed is mainly limited to Guernsey island, England, the United States, Australia, and Canada. The breed is popular in England, and many fine herds have long been maintained in that country, especially in midland and southern counties. In the United States the breed has its principal foothold in the states north of the Ohio and east of the Mississippi. According to the annual report of the secretary of the American Guernsey Cattle Club, up to I9I8 there were 678 members in the club, the Middle Atlantic scction having 37.58 per cent; New England, I8.58; Wisconsin, I6.48; Central states, 12.78 ; South Atlantic stạtes, 6.24; Central Western states, 4.31; Pacific coast, 3.57 ; and Canada, 46 per cent. According to the Guemsey Breeders' Joumal, in I9I Wisconsin led all 
other states with II,454 Guernsey cattle registered, New York ranking second with 63II. Guernseys have a considerable foothold in Australia and New South Wales, and a few animals have been exported to France, Japan, Brazil, Cuba, Central America, etc.

Organizations for the promotion of Guernsey interests exist on Guernsey and in England and the United States. The Royal Guernsey Agricultural and Horticultural Society has for many years supervised the registration and promotion of Guernseys on the island. Two herdbooks are maintained - one for general registration, the other for Advanced Registry. Up to I9I 8 twentynine volumes of the island herdbook had been published. The English Guernsey Cattle Society was organized in 1885 and has, up to I9I 8, published thirty-five herdbooks. The American Guernsey Cattle Club was organized in 1877 in New York City and has, up to 19 I 8 , published about thirty-two herd registers. These were for years published in book form, but in I9I 3 they became a part of the Gucmscy Breeders' Joumal, a semimonthly of merit devoted to the advancement of the breed. Independent volumes of the herdbook must now be made up from the herdbook pages of this journal. 


\section{CHAPTER XXXIV}

THE AYRSHIRE,

The native home of the Ayrshire is in southwestern Scotland in the county of Ayr, from which the breed derives its name. Ayr is triangularly crescent in shape, its southern tip just touching latitude $55^{\circ} \mathrm{N}$., its western boundary somewhat indented and bordering the Irish Sea and river Clyde, its other sides skirted by the counties of Renfrew, Lanark, Dumfries, Kirkcudbright, and Wigtown. There is an extreme length of about 80 miles, with an area of about I I 50 square miles. Rather poor and sandy land occurs in the southern part toward the sea, while much beautiful rolling pasture land of fair soil is found more inland, with rougher land on the eastern borders rising to a height of 2000 feet. On the better lands, which are clayey, roots, grass, oats, and wheat are largely grown and there is abundance of summer grazing. The climate is very moist, and the bitterness of a northern winter is somewhat tempered by the sea.

The origin of the Ayrshire has been in the main a complex one. Aiton, the first and almost only early authority on the breed, wrote "A Survey of Ayrshire" about i 8I I. He regarded it as the native breed of Ayr improved by certain other stock. Some time about I770 Teeswater cattle, Shorthorn, or similar stock were introduced into Ayrshire. John Dunlop of Dunlop is credited with importing cows of large size, of either Teeswater, Dutch, or Lincoln breeds, and in 1805 Dunlop stock is referred to by Forsythe as having been established in the parish of that name for over a century. Other writers claim that the cattle of the Channel Islands crossed with Shorthorns were early used in Ayrshire. About 1818 West Highland cattle were used by Mr. Parton near Dalry, Ayr, on a superior herd of Ayrshires. Devon and Hereford blood are also said to have been used by other breeders. The earliest accounts of the cattle of Ayrshire show them to have been black and white. About 1780 red and 
white became fashionable, while from 1785 to 1805 brown-andwhite mottled cattle were much preferred; later, in 1810 , red and white was a common color. These latter colors of brown, red, and white have been carried down to the present time. Thus it is apparent that the Ayrshire as a breed is evolved from a variety of blood, mainly from types associated with larger milking capacity.

\section{The early improv-} ers of the Ayrshire were not notably distinguished over the general run of breeders who seek to improve local cattle. It was early evident that the people laid importance on milk production. Forsythe, a Scotchman, writes in 1805 of cows yielding from 24 to 30 quarts of milk daily; and in I829 William Harley states that he had cows that occasionally gave 25 to 30 quarts in one day and even produced 40 quarts in this time. In

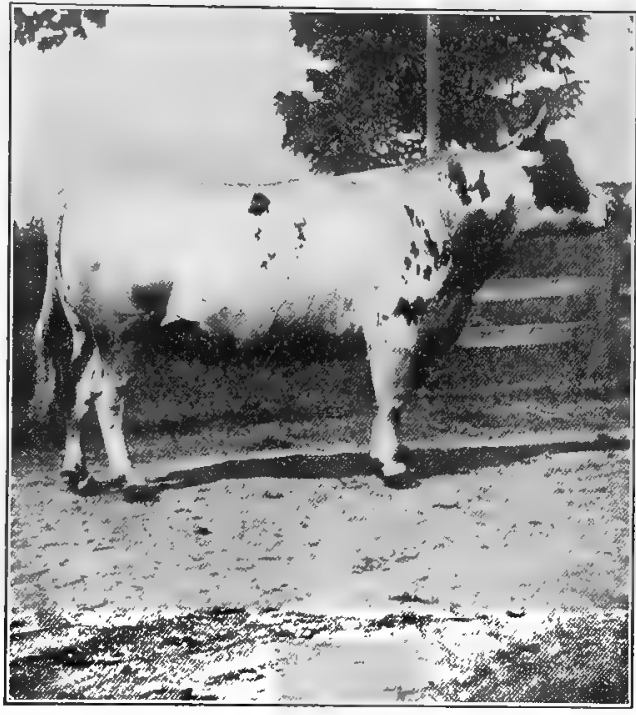

FIG. 179. Baron's Best of Bargenock I 2858 (imp.), an Ayrshire bull in Highland Farm herd, Bryn Mawr, Pennsylvania. From photograph by the author

I 836 the Highland and Agricultural Society of Scotland offered a large premium to be competed for by the breed. In 1848 , in a prize essay, ${ }^{1}$ Keary states that Ayrshires are of two distinct sorts : the native breed, a small, light-boned animal, and the Dunlop Ayrshire (a cross between the native breed and the Holderness), which is much larger. The small breed is considered of the best quality. There are herds of Dunlop Ayrshires, as well as of the native breed, in many parts of the kingdom, esteemed for their excellent milking qualities. By 1850 Ayrshires were the prevailing stock in Ayr and also in Renfrew and Lanark counties. In

1 Joumal Royal Agricultural Society of England, Vol IX, p. 442. 
I 853 the first systematic effort at improvement came in a scale of points adopted by the Ayrshire Agricultural Association. In I 866, in a prize essay on county Ayr, Archibald Sturrock writes that "a capacious and well-set udder is certainly the chief point of excellence in the Ayrshire cow."

The introduction of the Ayrshire to America probably first occurred early in the last century, when Scotch settlers moved to Canada. In the Memoirs of the Pennsylvania Agricultural Society for 1824 considerable discussion is devoted to breeds of cattle, yet the Ayrshire is not named. John Hare Powell, the secretary, who had studied the breeds in Europe, says, "I have traced every importation of which I have heard," and makes special reference to eight different states and various breeds, but does not mention the Ayrshire. Sturtevant states that the first importation -into the United States is thought to have been made in 1822 by H. W. Hills to Windsor, Connecticut. In I 837 the Massachusetts Society for Promoting Agriculture imported one cow, which is reported to have yielded sixteen pounds of butter a week for several weeks. Lewis F. Allen of New York writes that in 1837 he visited the Ayrshire herd of John P. Cushing near Boston, Massachusetts, who had imported from Ayrshire regardless of price. In $1848 \mathrm{E}$. A. Brown introduced Ayrshires to Ohio, these being the first of this dairy breed to enter the state.

The characteristics of the Ayrshire breed of cattle are very distinctive. The head, from a profile standpoint, has a somewhat straight line from poll to nose, the eyes are of fair prominence, and the homs are somewhat large, though not coarse, and are erect of carriage. Modern Ayrshire horns, besides being erect and widespread, frequently curve slightly backward at the darkcolored tips. The horns of some aged bulls are remarkably large and conspicuous and, as a rule, are brought to the desired form by mechanical device. The Ayrshire ncck is hardly as lean as that of a Jersey, the withcrs are attractive in refinement, the shoulder tends to be smooth, and the body deep of rib and of large digestive capacity. The nump is usually broad, long, and well carried, while the thighs and hind quarters partale somewhat of fleshiness, enough so in the Ayrshire steer to produce in many cases a creditable hind quarter for the butcher. A good 
type of the breed exhibits considerable depth of body and short rather than long legs. The udder of the Ayrshire has been the cause of much discussion in recent years. The most approved form is carried up high behind, extends well forward under the belly, with the underside or sole (as it is sometimes termed) level and free from a deep groove between right and left gland, and with teats of good size well placed at each quarter. This type of fleshy udder has been the source of much serious criticism in the

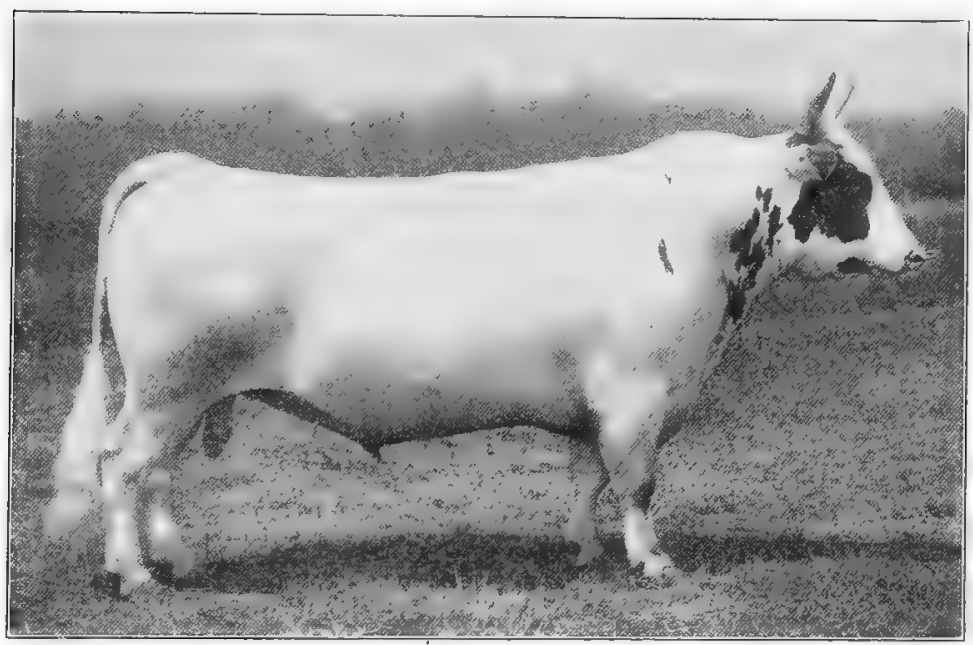

Fig. I8o. Netherhall Good Time II 447 (imp.), an Ayrshire bull owned by Branford Farms, Groton, Connecticut. This is a good representative of the modern type of mature Ayrshire bull. From photograph by Hildebrand, by courtesy of the American Agriculturist

Scotch press, and it has been repeatedly pointed out that the cow with this sort of udder was the result of catering to an American fad. From a show point of view more uniformity obtains in a ring of aged Ayrshire cows than with any other breed. In quality Ayrshires are not superior to other breeds.

The color of the Ayrshire includes red, brown, and white. In I875 Sturtevant quoted as follows from a letter from Robert Wilson, a breeder in Scotland:

Colors of Ayrshires are much the same since I can remember; different breeders have their particular color. Light yellow, though common with some 
breeders, is not the most common color. Red and white flecked, though it should incline a little to yellowish or brown, is more a prevailing color of the breed. . . . White, if there be not roan mixed with it, I do not consider a proof of the presence of Shorthorn blood. Our favorite colors are white flecked or red bodies and white legs. Dark reds and black muzzles are favorites also.

In 1875 Sturtevant published statistics of a color classification of 2852 Ayrshires in the United States, of which 2014, or 70.61 per cent, were red and white; 222 , or 7.78 per cent, red or mostly red; $24 \mathrm{I}$, or 8.45 per cent, brown and white; and 194, or 6.80 per cent, white and red, the balance being split into various colors. The Ayrshire Breeders' Association scale of points has specified red of any shade; brown; or these with white; mahogany and white; or white, - each color distinctly defined. Brindle is allowed, but is regarded as undesirable. Professor A. C. McCandlish has recently written I regarding black-andwhite Ayrshires, of which he says there are several herds in Scotland, the origin of which may be considered obscure and derived from many sources rather than one. The most popular Ayrshire color shows a greater percentage of white than of red or brown, these colors being in solid blotches. The old-fashioned flecked marking is not looked on with favor by color faddists. Many Ayrshires of to-day are very largely wlite, as, for example, the $\$ 6000$ bull Penshurst Mischief Maker, all white excepting a small bit of dark color by the tail head and upper thigh and on neck and face. Addington Queen 3d 29558, one of the great cows of the breed, has even less dark color than Penshurst Mischief Maker. This matter of color is purely a fad and should not be allowed to interfere with breed improvement.

The size of the Ayrshire is fairly uniform. The American standard calls for the mature bull to weigh not less than 1500 and the cow Iooo pounds. The Scotch standard favors a cow weighing about 1050 pounds. Sturtevant gives the weights of nine pure-bred aged cows in his herd which varied from 985 to I 200 pounds. The cows in Mr. Winslow's herd from I88I to I887 showed an average yearly weight of from IO2O to IIO2 pounds per head. Referring to the subject of size an official circular from the Ayrshire Breeders' Association states that at

1 The Ayrshire Quarterly (January, 19r8), Vol. III, No. 4, p. 24. 
maturity a cow of the breed weighs "from about rooo pounds to I 200 , sometimes going as high as I 400 or I $500 . "$

The temperament and disposition of the Ayrshire suggests something of the freedom associated with the Scotch hills. There is hardly the docility found in some breeds reared in close restraint, as, for example, the Jersey or Brown Swiss, nevertheless the Ayrshire is quiet enough for all practical purposes.

The Ayrshire for early maturity is more comparable with the Holstein-Friesian than the Jersey. The males frequently do not show strong sex character, as expressed in head and neck, until reaching well into yearling age. The heifers also are somewhat slow in developing the maternal character often seen in some breeds. These qualities, however, are fully developed when at full maturity.

The crossbred or grade Ayrshire is better

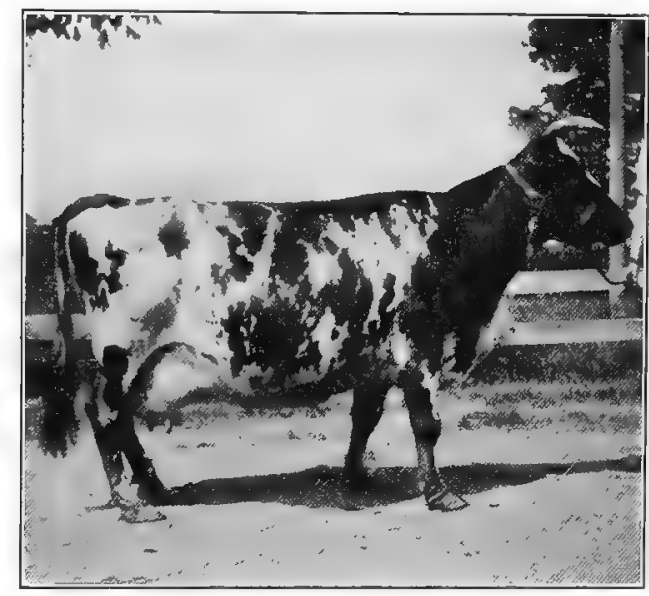

FIG. I81. Rena Ross 14539, an aged Ayrshire cow owned by Highland Farm, Bryn Mawr, Pennsylvania. Rena Ross is one of the greatest reproducing cows of record. The mother and five daughters have thirteen records averaging I 3 , I 44 pounds milk and 532.84 pounds fat. From photograph by the author

suited to milk production than anything else. Consequently Ayrshire bulls on grade cows will improve the herd to greater milkproducing power and may add to their selling value to the butcher if used on Jersey grades.

The prepotency of the Ayrshire is one of its distinguishing features. In Scotland one may see ample evidence of the impress of pure-bred bulls on the grade herds of the country. The wellbred Ayrshire bull transmits in marked degree his color and the head and udder characteristics.

The Advanced Registry system of the Ayrshire Breeders' Association was inaugurated in $1902-\mathrm{I} 903$ for the purpose of 
making official tests of cows owned by members of the association. Up to I 908 but I 20 cows and heifers had been admitted to Advanced Registry. Since this period, however, a great increase in testing has taken place, so that by 1918 a total of 2799 cows and heifers had made acceptable records. The essential features of Advanced Registry testing of Ayrshires are as follows: the tests are conducted under the supervision of a state agricultural experiment station or agricultural college official. All tests are for one year from time of freshening or until the cow comes dry from

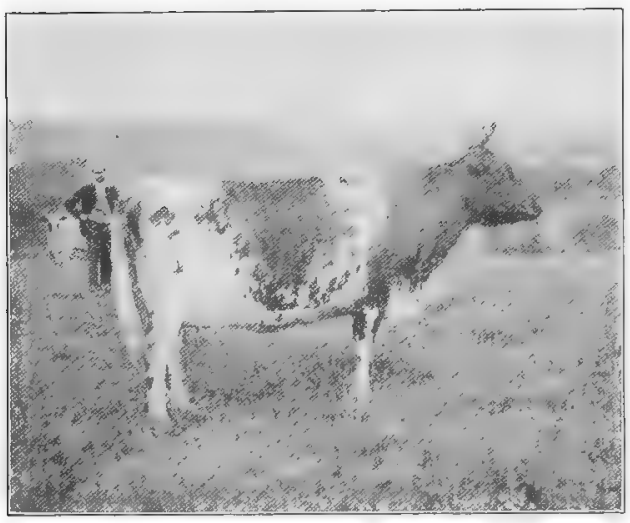

FIG. I82. Judy of Knockdon, a first-prize Ayrshire cow at the Highland and Agricultural Society Show. Owned by Alexander Cross, Knockdon, Maybole,

Scotland. From photograph by the author

that freshening. There are four cow classes: two-year, three-year, four-year, and fiveyear or older. In the two-year form: "If her record begins the day she is two years old, or before that time, she shall, to entitle her to record, give not less than 6000 pounds of milk in three hundred and sixty-five consecutive days from the beginning of the test, and 2 I 4.3 pounds of butter fat, and for each day she is over two years old at time of beginning the test there shall be added 1.37 pounds of milk to the 6000 pounds and .06 pound of butter fat to the 214.3 pounds." In the three-year form 6500 pounds of milk and 236 pounds of fat are required, with 2.74 pounds milk and . I 2 pound fat added for each day she is over three years old at time of beginning the test. In the four-year form 7500 pounds of milk and 279 pounds of fat are required, and in the mature form 8500 pounds of milk and 322 pounds of fat. A bull, to be admitted to Advanced Reg. istry, must be typical of the breed, score at least 80 points, and have two daughters from different dams in the Advanced Registry; or he may be admitted without physical qualifications and scoring 
if he has four daughters in the records, each from different dams. Official testing is also conducted in Canada and by the Ayr Society for Milk Record, in Scotland.

The Ayrshire as a milk producer has been regarded with favor for over a century, and it is this quality that has been sought from the first. In I8 I I Aiton wrote that probably I 200 Scotch pints (2148 quarts) of milk from each cow in the course of a

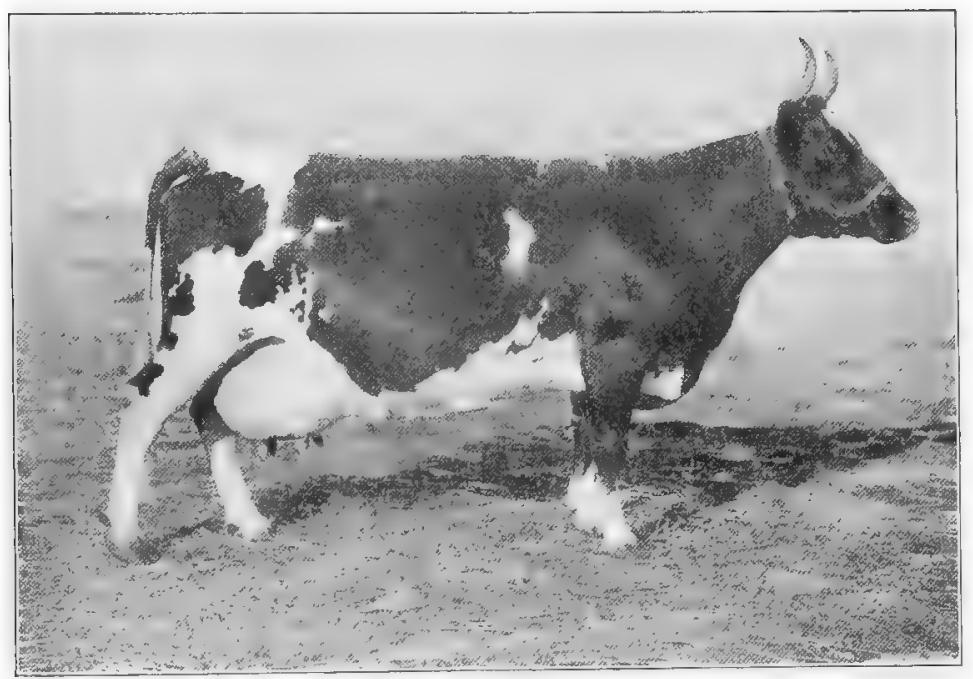

FIG. I83. Jean Armour 25487, foundress of the Jean Armour family of Ayrshires. Not only was she a great show cow but she has an official record of 20,174 pounds milk and 774.73 pounds fat in a year. Owned by Mrs. F. D. Erhardt, West Berlin,

Vermont. From photograph, by courtesy of the American Agriculturist

year would be a fair average. In I 829 Harley, a famous dairyman, placed the average of his herd at 12 quarts a day. One of his cows for a considerable time gave 40 quarts per day. In the earlier records kept in the United States the annual yields ranged from about 5000 to 7000 pounds. A number of New England herd records were kept continuously for years, beginning in 1873 or I874, notably by Sturtevant Brothers and J. W. D. French of Massachusetts and L. S. Drew and C. M. Winslow of Vermont, the latter for many years secretary of the Ayrshire Breeders' Association. Up to Igoo but few cows of the breed produced 
over I0,000 pounds of milk in a year, the best-known record previous to that time being that of Polly Puss 16296 in Pennsylvania, of 12,632 pounds, official test. In 1885 the cow Duchess of Smithfield 4256 created much favorable comment by producing in a seven-day test $463 \frac{3}{4}$ pounds of milk, from which was made I9 pounds 6 ounces of butter. Since the year Igoo very great improvement in production has taken place with this breed, and up to I9I9 eight mature cows and one three-year-old had made official records of over 20,000 pounds of milk each. Following are the ten leading official milk records previous to January I, I9I9.

Ten Leading Official Milk Records of Ayrshire Cows to igig

\begin{tabular}{|c|c|c|c|c|}
\hline Name and Number & & AGE & $\begin{array}{l}\text { YEAR OF } \\
\text { RECORD }\end{array}$ & $\begin{array}{l}\text { Pounds of } \\
\text { MILK }\end{array}$ \\
\hline Garclaugh May Mischief 27944 & . & IO & $1914-1915$ & 25,329 \\
\hline Auchenbrain Brown Kate 4th 27943 & 3 & - & I9I $2-1913$ & 23,022 \\
\hline Lily of Willowmoor 22269 & & 一 & $1912-1913$ & 22,596 \\
\hline Garclaugh Spottie 27950 & & 一 & I9I4 & 22,589 \\
\hline Jean Armour 3d 32219 & . & 3 & $1915^{-1916}$ & 21,938 \\
\hline Auchenbrain Yellow Kate $3 \mathrm{~d} 36010$ & & 一 & I9I4-I9I 5 & 21,123 \\
\hline Gerranton Dora $2 \mathrm{~d} 23^{8} 53$. . . & & - & I9II-I9I 2 & 21,023 \\
\hline Jean Armour 25487 & ${ }^{\circ}$ & I 2 & IgII-Igr2 & 20,174 \\
\hline Canary Bell 25748 . & & 9 & $1917-1918$ & I 9,863 \\
\hline August Lassie 2958 I & & $7^{\circ}$ & $1916-1917$ & 19,582 \\
\hline
\end{tabular}

The Canadian cow Grandview Rose 40395, the first cow in Canada to pass the 20,000-pound mark, has a record of $2 \mathrm{I}, 423$ pounds of milk, placing her high in the above class. The ten leading milk records in each class of the Advanced Registry to March, I9I9, range from an average of $2 \mathrm{I}, 74 \mathrm{I}$ pounds for mature cows to 14,036 pounds for the junior two-year-olds an average for the best seventy cows of 15,779 pounds. One senior two-year-old - Henderson's Dairy Gem 35176- has to her credit 17,974 pounds of milk. The greatest continuous producer of the breed is Lily of Willowmoor 22269, she having in five years produced a total of 84,99 I pounds of milk - an average of I6,99 I pounds per year - and 3362 pounds of butter fat. This is one of the most remarkable examples of Ayrshire milk production on record up to I9I9. 
The Ayrshire in butter-fat production is subordinate to the Holstein-Friesian, Guernsey, and Jersey. Fair samples of the milk average 3.5 to 4 per cent fat and about 12.5 per cent total solids. The average fat content of the seventy leading cows and heifers in the Advanced Registry records to January, 1918, was 3.89 per cent. Tested cows, as a rule, show to the best advantage in this respect. In official yearly tests as far back as I 900 a record of 500 pounds of fat was regarded as very good indeed. In I 908 the secretary of the Ayrshire Breeders' Association reported that fifty-one mature cows in the Advanced Registry produced an average of 436 "pounds of butter." Great progress has been made since then, so that up to January, I9I9, some surprisingly large official records in butter fat have been produced, as shown below.

Ten Leading Official Butter-Fat Records of Ayrshire Cows TO 19 I 9

\begin{tabular}{|c|c|c|c|c|}
\hline \multirow{2}{*}{ Name and Number } & \multirow{2}{*}{$A G E$} & \multirow{2}{*}{$\begin{array}{c}\text { YEAR OF } \\
\text { RECORD }\end{array}$} & \multicolumn{2}{|c|}{ ButTer Fat } \\
\hline & & & Pounds & Per CEnt \\
\hline Lily of Willowmoor 22269 & 一 & $1912-1913$ & 955.56 & 4.23 \\
\hline Auchenbrain Brown Kate 4 th 27943 & - & I912-1913 & 917.60 & 3.99 \\
\hline Garclaugh May Mischief 27944 . & 10 & I9I4-I9I 5 & $894 \cdot 91$ & 3.53 \\
\hline Auchenbrain Yellow Kate 3d 36910 & 一 & $1914-1915$ & 888.33 & $4.2 \mathrm{I}$ \\
\hline Jean Armour 3d 322r9 . . . & 3 & $1915-1916$ & 859.65 & 3.92 \\
\hline August Lassie 2958I . . . . & 7 & I9I6-19I7 & 831.50 & 4.25 \\
\hline Agnes Wallace of Maple Grove 25I7I & 4 & I9I4-I9I 5 & $82 \mathrm{I} .45$ & 4.65 \\
\hline Garclaugh Spottie 27950 . . . . & - & rgr4- & 816.25 & $3.6 \mathrm{r}$ \\
\hline Gerranton Dora $2 \mathrm{~d} 23853$ & - & $1911-1912$ & 804.79 & 3.83 \\
\hline Jean Armour 25487 . . . . . & IO & I9I I-I9I 2 & $774 \cdot 73$ & 3.84 \\
\hline
\end{tabular}

The ten leading records in the mature class of Advanced Registry cows average $85 \mathrm{I} .69$ pounds fat, while the junior twoyear-olds average 532.84 pounds. The average of the seventy leading cows and heifers to March, I9I9, is 617.37 pounds. The best record of a two-year-old is that of 738.32 pounds, made by Henderson's Dairy Gem 35176. The average record of 3243 cows and heifers in the Advanced Registry up to March 6, I919, is given as 380.47 pounds butter fat, the milk testing 3.96 per cent. 
Ayrshires in public tests have stood well. In the Pan-American dairy-breed test in I9OI the five Ayrshires for one hundred and twenty days ranked sccond in milk production, yielding 32,998.2 pounds milk, compared with $39,260.2$ for the Holstein-Friesian; fourth in estimated butter, 1434.7 pounds; and second in net profit, $\$ 242.24$. It is but fair to state in this connection that the Pan-American specimens of Ayrshires in the test were fine examples of the breed, which did not obtain with some of the

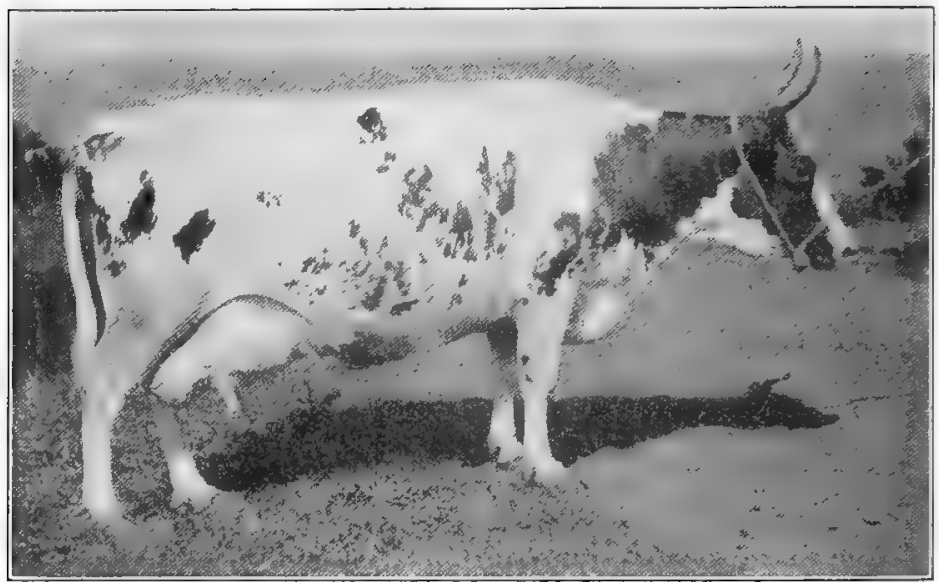

FIG. I84. August Lassie 2958I, an Ayrshire cow with an official record in a year of 19,582 pounds milk and $83 \mathrm{I} \cdot 5$ pounds fat. This cow shows very large digestive capacity and unusual development of veins on abdomen and udder. Owned by

Hilltop Farm, Wheeling, West Virginia. From photograph by the owners

other breeds. The best Ayrshire in the test, Betsey Ist, produced 7041.5 pounds milk, which tested 3.59 per cent fat and yielded in estimated butter 298.57 pounds. She was eighth in rank among the fifty cows, giving a net profit of $\$ 46.07$, compared with the Guernsey Mary Marshall Ist, with a net profit of $\$ 59.40$. In comparisons made at various experiment stations and at fairs the Ayrshire has usually stood second to the HolsteinFriesian in milk production, but above in butter fat.

Ayrshire milk for cheese-making has long been a standard for making Cheddar cheese in Scotland, where it is made on a large scale in the Ayrshire district. Containing as it does about the 
standard amount of fat and solids for cheese-making, this milk is regarded with favor for this purpose. In cheese tests at the Ontario Experimental Farm IOO pounds of Ayrshire milk produced I 2.9 pounds of curd, compared with an average of 12.8 for all breeds and grades.

The Ayrshire as a producer of beef ranks among the first of the dairy breeds. It is natural for animals of this breed to carry somewhat more flesh than the more refined dairy type. Ayrshire

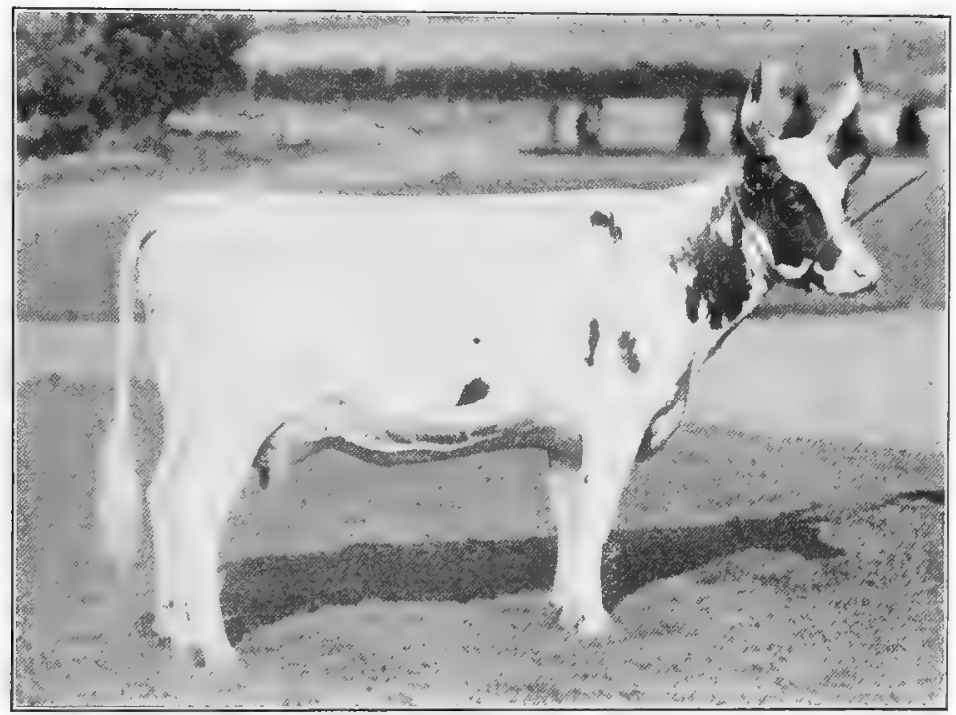

FIG. I85. Pansy's Daughter of South Farm 37642, a very beautiful Ayrshire heifer bred by John Sherwin, Willoughby, Ohio, that sold at the New England Ayrshire Club sale in 1918 for $\$ 4200$. From photograph, by courtesy of the Ayrshire Breeders' Association

steers feed to make a very salable carcass, with a killing quality more acceptable to the butcher than the other dairy breeds, lacking the high fat color of the Jersey and Guernsey and the offal of the Holstein-Friesian. One Ayrshire steer ten hundred and ninety-five days old is reported by Henry to have weighed 1320 pounds, gained I.2 pounds daily, and dressed out 63.3 per cent, the poorest daily gain made by any of eleven breeds, but dressing out better than Sussex, Holstein-Friesian, Jersey, or native. Other evidence also indicates that Ayrshires mature and feed slowly. 
Leading Ayrshire sires, based on official tests up to March, I9I9, as published in The Ayrshive Quarterly, are as follows:

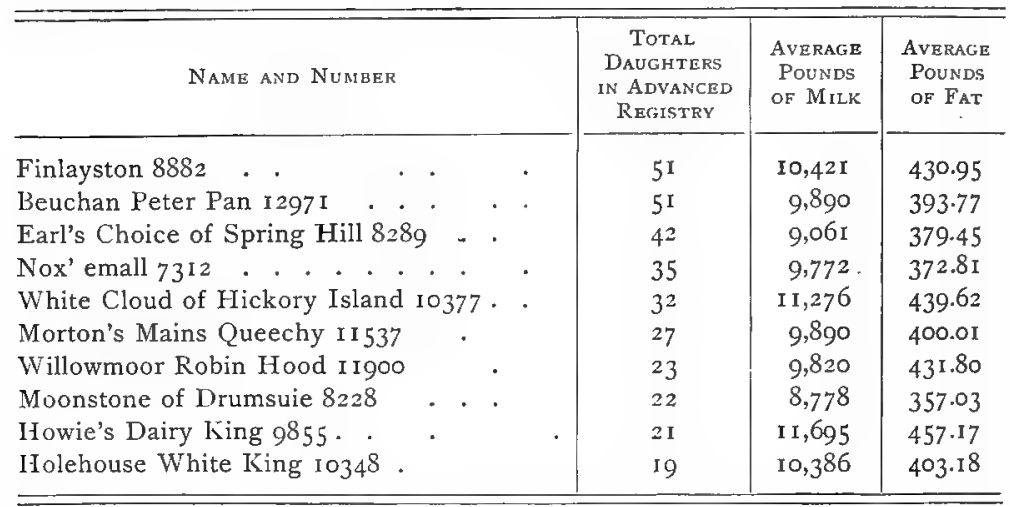

The above records are based on the number of daughters in the Advanced Registry rather than total entries, for under the latter an animal may be entered several times, based on retesting; for example, Finlayston has $5 \mathrm{I}$ daughters, and these are given 99 entries in the Advanced Registry, he leading the list in this respect. However, Howie's Dairy King, next to last on the list, with 2 I daughters and a total of 29 entries, is the sire of Jean Armour 3 d, with a record of 21,938 pounds of milk and 859.65 pounds of fat, which fact gives this sire great distinction.

Prices on Ayrshire cattle until recently have not been remarkable and for many years were within very modest bounds. In I910, at the Lotus Fields sale at West Berlin, Vermont, 37 Ayrshires sold for $\$ 8760$, an average of $\$ 236$, on which occasion the top price for a bull of the breed — \$ 600 — was paid for Bargenoch Bonnie Scotland I I974 by John Sherwin of Ohio. The ten-weeks-old calf Jean Armour $2 \mathrm{~d}$ also sold for \$I $\$$ ooo to William Hunter of Canada, and \$rooo was paid for Howie's Cream Pot 27965, the champion cow of the I9Io Scottish shows. In I9I I Hunter and Sons of Ontario, Canada, sold I I 7 head for $\$ 40,490$, and 43 cows averaged $\$ 407.55$. In I9I4 Hugh J. Chisholm of New York paid \$5000 for Hobsland Perfect Piece (imp.) I0665. In August, I 9 I 5, the champion Ayrshire cow Jean Armour 25487 , the property of W. P. Schanck, Avon, New York, sold at 
auction for $\$ 4000$ to Mrs. F. D. Erhardt of Vermont. In I9I7 Penshurst Farm of Pennsylvania sold Penshurst Mischief Maker I87 I9, a son of Garclaugh May Mischicf, for $\$ 6000$. On February 2, I9I8, at the Hillhouse Farm bull sale at Kilmarnock, Scotland, I9 bulls sold for an average of $\$ 778$, eight of which averaged $\$ 1455$. In June, I9I8, at the New England Ayrshire sale at Hartford, Connecticut, 38 cows brought an average of $\$ 702$, the top price up to this date. Six cows brought prices ranging from $\$$ I 200 to $\$ 4200$, the top figure for an Ayrshire female. This was paid for the American-bred cow Pansy's Daughter of South Farm 37642 , sold by John Sherwin to G. S. Mawhinney of New York. The imported cow Lochfergus Cherry 33297 sold for $\$ 3750$ to P. Bradley of Massachusetts. On January 15,1919 , at the sale of J. Logan of Bargenoch, the twelvemonths-old bull Bargenoch Royal Champion

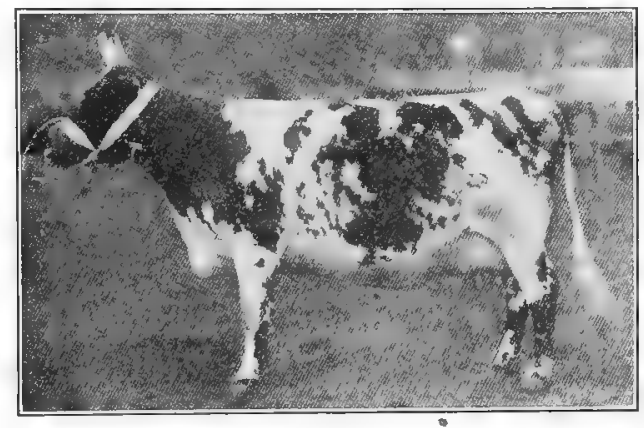

FIG. 186. Netherland Bunty, a fine type of Ayrshire and a prominent prize-winner in Scotland. From a Scotch photograph sold to A. W. Montgomery for $\$ 7455$. At this sale 20 bulls averaged $\$ 700$. On February I, I919, at the sale of James Howie, Hillhouse, Kilmarnock, Scotland, the bull calf Howie's Hotstuff 17895 , calved March I 5, I9r8, sold to Mrs. E. L. Howison-Crauford for $\$ 8670$. Twenty-two of the bull calves averaged \$904. Finally, all Ayrshire records were shattered when, at the sale of $\mathrm{C}$. H. Peverill at Waterloo, Iowa, the yearling bull Rosebud Pride 22359 was bought by L. A. Heisler of Iowa for $\$ 18,000$, while I I bulls made an average of $\$ 1767$.

The distribution of the Ayrshire is almost world-wide. Considerable numbers have been exported from Scotland to Sweden, Norway, Finland, Russia, South Africa, Australia, New Zealand, China, Japan, Canada, and the United States. Quite a trade

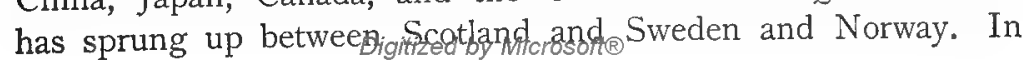


America the breed is best represented in Canada, notably in Ontario and Quebec, while in the United States it is chiefly found in the New England and Eastern states, although a few select herds are found in Ohio, Iowa, Kansas, and on the Pacific coast. In the Mississippi Valley west of New York the Ayrshire has never succeeded in securing but a frail foothold in spite of its evident merit. The breed seems to have adapted itself unusually well to the cooler and more hilly sections, being a good grazer and thriving under not the best of conditions. In fact the Ayrshire in Britain has been termed the poor man's cow, being better able

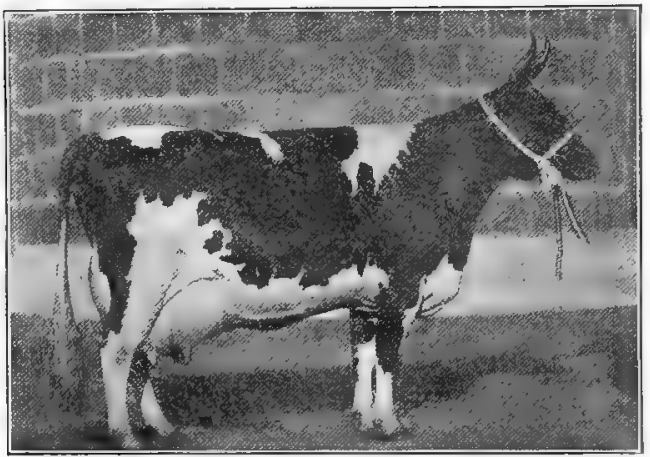

FIG. I87. Fairfield Mains Jean 6th 33274 (imp.), a very superior type of Ayrshire cow owned by IIugh J. Chisholm, Port Chester, New York. She has an official record of $\mathrm{I} 4,877$ pounds milk and 467 pounds fat in a year. From photograph, by courtesy of Mr. Chisholm to thrive on inferior land and feed than any other breed excepting the Kerry.

Organizations to promote Ayrshire interests exist in Scotland, Canada, and the United States. In I863 a few men organized in Massachusetts and that year. published Volume I of the "Herd Record of the Association of Breeders of Thoroughbred Stock, Ayrshire." In I 868 a second volume was published, and in 187 I Volume III appeared with the title "The American and Canadian Ayrshire Herd Record." In January, 1875, the American Ayrshire Breeders' Association was formed, which continued this record, publishing Volume IV that year. In 1876 Volume V (old series), or Volume I (new series), of the "Ayrshire Record" came out, since which date a total of thirty-three volumes (new series) has been published up to I9I9. In I874 E. L. and Joseph Sturtevant started a herdbook, publishing Volume I in 1875 as the "North American Ayrshire Register," this being for cattle tracing to importation. They published four volumes, the last in $\mathbf{I} 880$. The Ayrshire Importers' and Breeders' 
Association of Canada was organized in 1870 , and the Dominion Ayrshire Breeders' Association in 1889; in 1898 the former merged with the latter. In I 884 the province of Ontario published Volume I of the "Dominion Ayrshire Herdbook." In I 886 Volume I of the "Montreal Ayrshire Herdbook" was published, and four volumes in all issued as the "Canadian Ayrshire Record," after which it was merged with the Dominion book into the "Canadian Ayrshire Record," Volume XXVIII being published in 1919. The Ayrshire Breeders' Association (American) also provides for an Advanced Registry for both bulls and cows. The Scotch Ayrshire Cattle and Herdbook Society was founded in I 877 , the first volume of the herdbook appearing in 1878 , since when forty-one volumes have been published up to I9I 8 inclusive.

In 1915 the Ayrshire Association from its headquarters at Brandon, Vermont, began the publication of The Ayrshire Quarterly, a very excellent illustrated journal that is devoted to the promotion of the breed. There are a number of state Ayrshire associations, as well as district and local clubs in both Canada and the United States. 


\section{CHAPTER XXXV}

\section{THE DUTCH BELTED}

The native home of Dutch Belted cattle is Holland, where they are known as Lakenfelds, Lakenvelders, or Veldlarkers. The word laken means a sheet or blanket of white about the body.

The origin of Dutch Belted cattle is quite obscure. F. R. Sanders, long a prominent breeder of these cattle in America, made a trip to Holland in 1907 especially to investigate the early history and present conditions of these cattle in that country. He states ${ }^{1}$ that from conversation with several of the oldest breeders in Holland it is their opinion that these cattle began to flourish about $175^{\circ}$ in the vicinity of Haarlem, North Holland. Dutch noblemen owning large estates conceived the idea of breeding different kinds of farm animals so that they would have white sheets or belts about the body, with black ends. From this effort came these Dutch Belted cattle, Lakenvelder fowls, and the Lanche swine of Holland and Germany. There are but few herds of Dutch Belted cattle in Holland, and these are mostly in the provinces of Utrecht and North Holland.

The introduction of Dutch Belted cattle to America dates back to 1838 , when D. H. Haight of Goshen, New York, made the first importation, followed by a second in I848. P. T. Barnum, the famous showman, and R. W. Coleman also made importations. General Grant is said to have owned a herd at one time on a farm near St. Louis. ${ }^{2}$ About I900 several head were imported to America, since which time none have been brought to this country. The early development of the breed in the United States was largely in southern New York, in Orange County.

Characteristics of Dutch Belted cattle. In general appearance these cattle are rather distinctively of the dairy type. The best of the breed, according to Mr. Sanders, has a highly developed

1 Dutch Belted Herdbook, Vol. VIIT, I907.

2 Springfield (Massachusetts) Republican, September 3, I908. 
dairy form, thin neck, small head, straight back, deep chest, high and broad hips and rump, well-developed udder and milk veins, mellow skin, soft hair, and a highly nervous temperament. In size they are somewhat smaller than the Holstein-Friesian, being more comparable with the Ayrshire. G. G. Gibbs, late secretary of the Dutch Belted Cattle Association, states that the cows weigh from 900 to 1250 pounds, while a number of bulls have exceeded a ton in weight. The bull Duke of Ralph 255 when three years

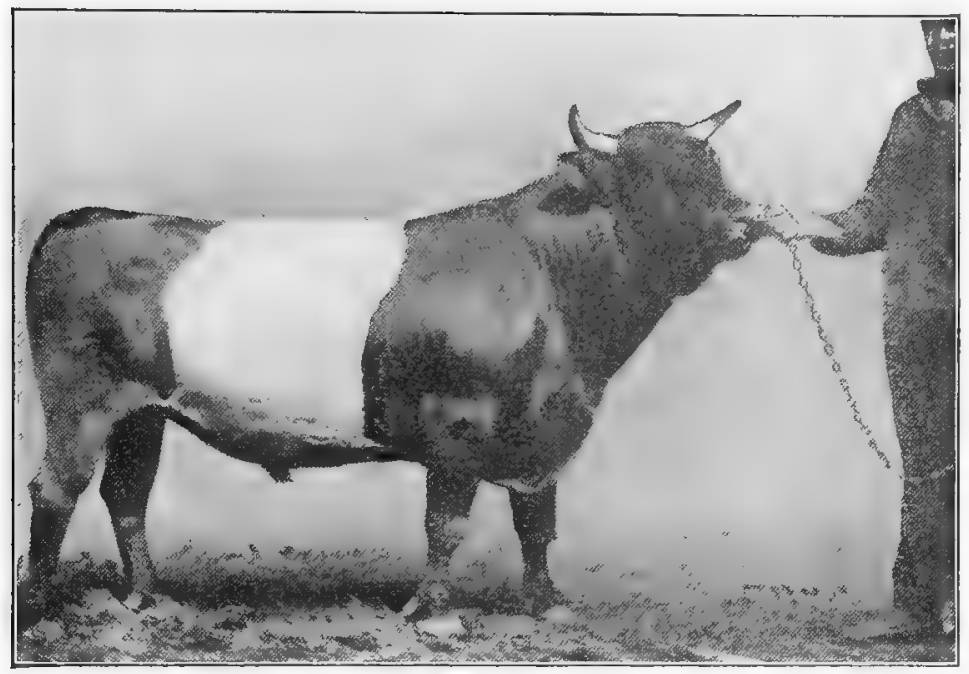

FIG. I88. Auten 435, one of the most prominent prize-winning Dutch Belted bulls in the history of the breed. Owned by F. R. Sanders. From a photograph by the author

old weighed I 200 pounds, Edward the Great I 2000 pounds, and Duke of Goshen 27 also 2000 pounds. A weight of 1500 pounds or more should prevail with the bulls. The cow Lady Aldine I24, a well-known prize winner, weighed $\mathbf{I} 200$ pounds. In color the cattle are invariably black, with a white band of varying width about the body, in front of the hips, rarely reaching the shoulders. Sometimes this band narrows to even a foot in width or less, and, again, other specimens have it as a wide blanket. The fore part of the udder of the cow is also often white. In udder conformation and development these cows are rather inferior, 
the size being comparatively small, the fore udder abbreviated, and the teats placed too closely together.

Dutch Belted cattle as milk producers are of secondary importance, but very little having been done in breeding them for heavy production. The cow Lady Baird 82 was credited with 32 quarts of milk in a day in a private record in 1893 at the World's Columbian Exposition. Lady Aldine 124 is said to have made

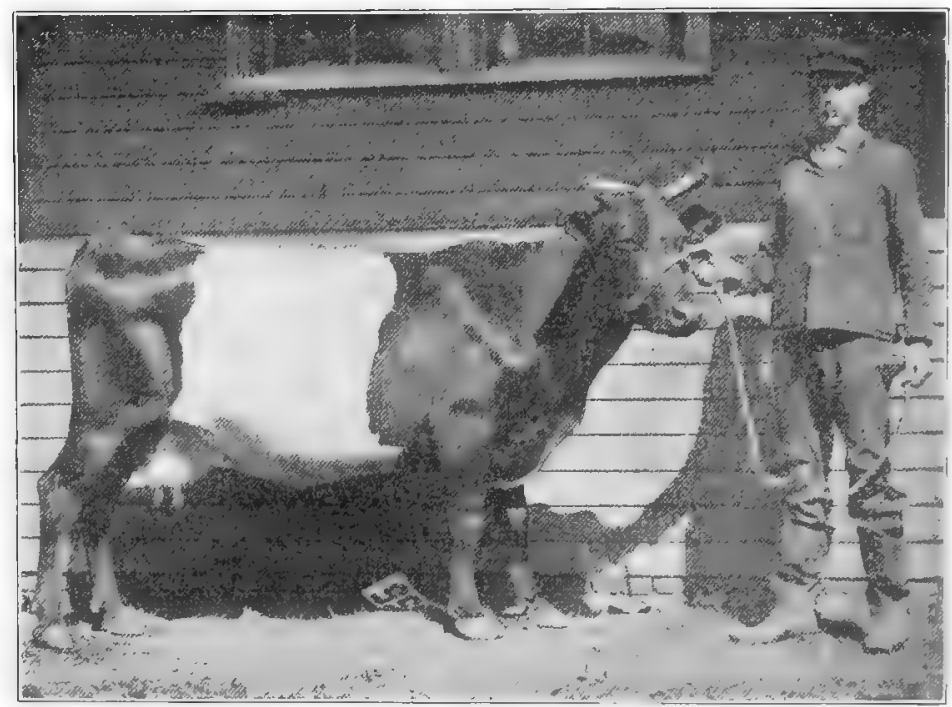

Fig. 189. Ida May 829, an excellent type of Dutch Belted cow; owned by

D. B. Wilson, Waterbury, Connecticut. From photograph by the author

32 quarts of milk in a day on grass alone. But few official tests of the cows have been made. The Lancecote herd at Peapack, New Jersey, has shown the best records up to I9I8. Of these the following are of most importance:

\begin{tabular}{|c|c|c|c|c|}
\hline \multirow{2}{*}{\multicolumn{2}{|c|}{ Name of Cow }} & \multirow{2}{*}{$A G E$} & \multicolumn{2}{|c|}{ YiELd WITHIN $36 S$ DaYs } \\
\hline & & & Milk & Fat \\
\hline $\begin{array}{l}\text { Peapack Princess } \\
\text { Peapack Pam . . } \\
\text { Peapack Dutchess } \\
\text { Peapack Anna . }\end{array}$ & . & $\begin{array}{l}2 \\
3 \\
4 \\
4\end{array}$ & $\begin{array}{r}8,745 \mathrm{lb} . \\
10,68 \mathrm{llb} . \\
13,065 \mathrm{lb} . \\
13,159 \mathrm{lb} .\end{array}$ & $\begin{array}{l}312.17 \mathrm{lb} . \\
353.17 \mathrm{lb} . \\
447.64 \mathrm{lb} . \\
484.3 \mathrm{I} \mathrm{lb} .\end{array}$ \\
\hline
\end{tabular}


F. R. Sanders states ${ }^{1}$ that in his own herd in New Hampshire eleven cows made an average of 8579 pounds of milk for eight years, and "one cow produced 12,672 pounds of milk in one year and in six years 60,297 pounds," with an average butter production of 596 pounds. The only test of this breed which has been reported to the public was in the Pan-American Model Dairy test in I9OI, in which ten breeds participated. In this trial the five Dutch Belted cows made the following record in one hundred and twenty days:

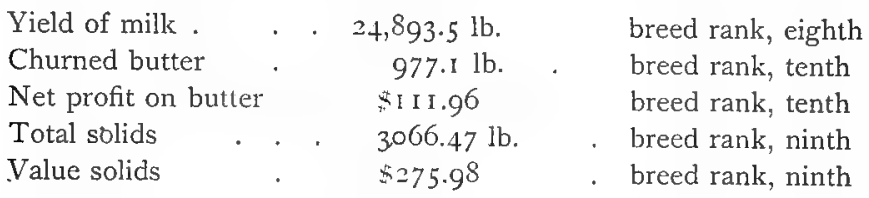

Dutch Belted milk will test from 4.5 to 5 per cent fat.

The Dutch Belted as beef producers can hardly be regarded as superior to the dairy breeds and no doubt will not compare favorably with the Holstein-Friesian. They lack the size of the latter and do not show the tendency to produce flesh so characteristic of some Holstein-Friesians. Owing to the comparative scarcity of the Dutch Belted, one finds almost. no steers of the breed on the market. A circular of a Connecticut breeder contains a picture of ten steers trained to work as five pairs of oxen one pair of which at four years of age weighed 3200 pounds.

Dutch Belted crossbreds or grades inherit the striking characteristics of the pure-bred sire. Says one breeder:

Crossed on cattle of any solid color they almost invariably produce the belt, though if the dam be a Devon the calf may be red at the ends; or if the dam is a Shorthorn, the calf may be red or roan. But the belt of the pure white is there, nevertheless.

An interesting example of this intensity of Dutch Belted prepotency took place in the herd of the Ohio State University. A cow of this breed, to the service of a pure-bred Jersey bull, dropped a crossbred calf with a white blanket about the bor ${ }^{1 / r}$, quite similar to that of the dam excepting for one small black spot on the white covering. 
The distribution and adaptability of Dutch Belted cattle is comparable with the other Dutch type, bred to thrive on abundant food under rather favorable conditions. However, some of the more prominent herds of America have been located in Canada and New England, where the winters are severe and long. No doubt the more fertile lowlands of the Mississippi Valley, and especially the Southern states with their milder climatic conditions, would prove most favorable for the development of the breed.

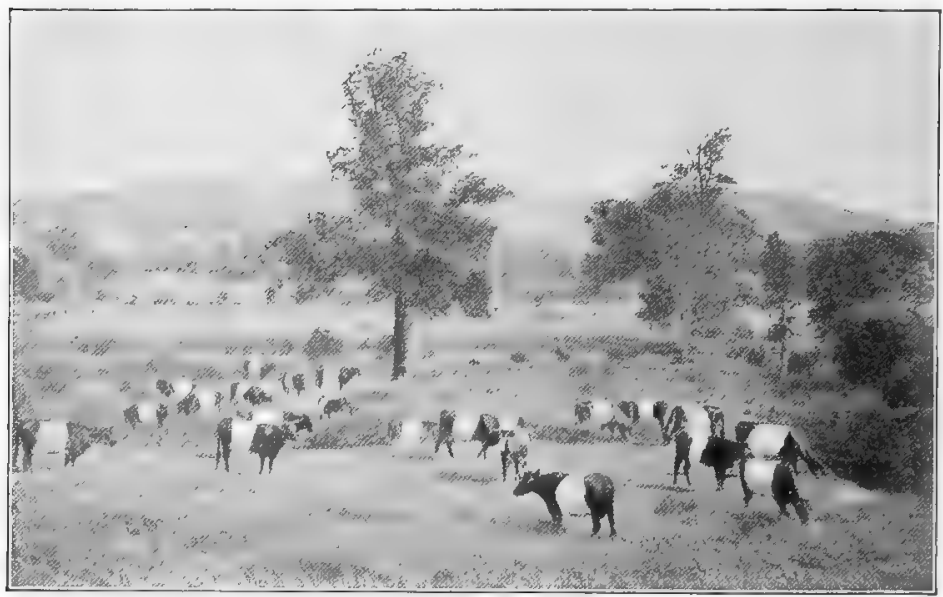

FIG. I9o. Dutch Belted cattle on pasture, Valley Farm, Warwick, New York. From photograph, by courtesy of the American Agriculturist

The distribution of Dutch Belted cattle has grown materially in recent years, although the breed has a very small representation in Holland and is but little known in America. However, they have representatives in nearly every one of our American states, while in some instances as many as twenty herds may be found. The largest herds are in the New England States and in New York, Michigan, and Indiana. These cattle have also been exported to Canada, Cuba, Brazil, Mexico, France, Austria, Germany, Spain, Portugal, South Africa.

The promotion of the Dutch Belted breed is supervised by the Dutch Belted Cattle Association of America, organized February 4, I886, in New York City. Volume I of the herdbook was 
published the same year, containing the registration of 46 males and 177 females, mainly owned in New York, with others scattered throughout New Jersey, Pennsylvania, New Hampshire, Illinois, and South Carolina. The last volume of the herdbook, numbered XI, was published in I9I7. This volume brought the registration of males up to 1250 and females up to 2500 .

The popularity of Dutch Belted cattle has been based upon the peculiar color combination and the picturesque effect of the same, as seen in a group of animals on pasture. From a producing point of view, as a dairy type the Dutch Belted has little to offer in its behalf. Taking size and feeding capacity into consideration, this breed without doubt makes a much poorer showing than any other. However, there seems no reason why, through judicious breeding and selection, a line of producers of real merit should not be established that would largely dispel adverse criticism. 


\section{CHAPTER XXXVI}

\section{THE FRENCH CANADIAN}

The native home of French Canadian cattle is in the province of Quebec, Canada. The country is somewhat undulating and rough, though not mountainous, and excellent crops of grass, oats, barley, potatoes, and roots are grown. The winters are rather long and cold, with much snow, the summers short and cool.

The origin of the French Canadian breed of cattle is claimed to be from stock brought to Quebec, Canada, by the early French settlers, at some time prior to 1665 . Professor Thomas Shaw states ${ }^{1}$ that these cattle were introduced to Quebec as early as 1620 , and that no other cattle were brought into the colony prior to 1776 . While no specific information is at hand as from just what part of France these cattle came, it is presumed that it was Brittany, and perhaps Normandy, as the original settlers of Quebec came from those French provinces. The French Canadian breed, however, resembles the cattle of Brittany much more than those of Normandy. In an address before a committee of the Canadian Parliament, Professor J. H. Grisdale said ${ }^{2}$ that up to 1850 they were about the only cattle in Quebec except for a few herds of Ayrshires and Shorthorns. In 1853 the Council of Agriculture began to discourage farmers from breeding these cattle. This succeeded so well that by $\mathbf{1} 880$ " there was hardly a French Canadian in the Province that thought enough of his cow to give her more attention than he would a dog." Then it was that two or three public-spirited men began to endeavor to save the breed from extinction by starting a breed association.

Characteristics of French Canadian cattle. In type there is considerable resemblance to the Channel Island breeds, especially the Jersey. The color is solid black or black with a yellow fawn stripe along the back and around the muzzle, brown-brindle, or

1 The Study of Breeds in America (I900), p. I33.

2 Rural Nezw Yorker, January 8, Igio. 
brown with black points. This fawn ring is very distinctive of the breed. The black type of males is preferred. The homs, which tend to be long, are generally curved outward and then in, with the tips turned toward each other. The color of horn is white with black tip. In size the mature female weighs from 700 to 800 pounds and the bull about rooo. They often, however, weigh less than this. In gencral conformation one is impressed

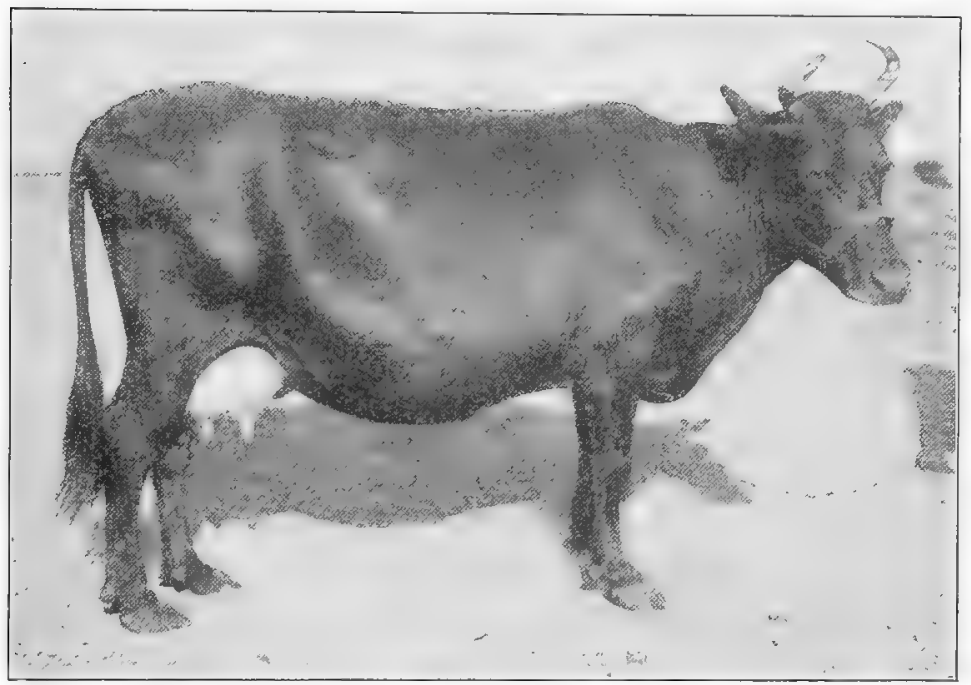

FIG. I9I. A French Canadian cow. An excellent example of the breed. From photograph, by courtesy of the Anzerican Agriculturist

with a certain roughness and angularity of form, after the more angular Jersey type. In quality they show a mellow hide and a rich yellow skin notable for its high orange-yellow color within the ear and about the udder. A fine silky coat of hair is an important indication of quality. "The chief points of these cattle," says C. N. Lepter of Quebec, "from a dairyman's point of view, are that they have large udders and teats placed far apart and pointing in front."

The French Canadian cows as milk producers make a very fair showing. J. A. Couture of Quebec, writing regarding the dairy capacity of the breed, ${ }^{1}$ states that the cow Pruniere I7 I 2 during 
three hundred and eighteen days produced I I, 3 Io pounds of milk, a daily average of over 35 pounds. This cow weighed about 675 pounds. The cow Azilza de Levis 956 is credited with 8000 pounds in a year. An average yield of 5000 pounds is regarded as a standard. The only notable public test in which the breed has taken a part was that of the Pan-American Model Dairy at Buffalo in I90I. In this competition the French Canadians secured a medium rank among the ten breeds involved. In six months the five cows produced 25,656 pounds of milk which yielded II 80 pounds of butter, on which a net profit of $\$ 18 \mathrm{r} .8 \mathrm{I}$ was secured. In cost of butter per pound the French Canadian ranked third, at 9.76 cents, Guernseys ranking first and Jerseys second. The cow Denise Championne I, in net profit of $\$ 40.63$, ranked twenty-first among the fifty cows in the test. Rouen, another French Canadian cow, ranked twenty-second, there being little difference between the two. In fat content the milk from these cows tests somewhat in excess of 4 per cent, in the Pan-American trials averaging 4.04.

The hardy character of French Canadian cattle is one of their strong features. They have vigorous constitutions, well adapted to the rigors of a Canadian winter, thriving, it is said, where other cattle would starve. The claim has been made by Canadian breeders that these cattle do not suffer from tuberculosis, but this may be doubted. French Canadians are especially suited to the rougher lands of upper New England and eastern Canada.

The grazing qualities of French Canadian cattle rank very high, and the cows are said to yield large returns of milk on pasture alone. On poor pastures or hill farms they thrive better than the larger breeds.

The maturing qualities of French Canadian cattle are inferior. This is largely due to the limited food and rigorous conditions of keeping. More abundant food and better care would improve the breed in this respect.

The distribution of French Canadian cattle is mainly restricted to Quebec, where it is the principal breed in some twenty-five counties. Registered cattle are most bred in the counties of Berthier, Joliette, Drummond, Kamouraska, and L'Islet. They are also found in a small way in the United States, in northern New York State, with a few isolated herds farther south. 
The promotion of pure French Canadian cattle has been assisted by the legislature of Quebec and a breeding association. In I886 the legislature adopted rules for the registration of foundation stock, and until I 895 a herdbook was maintained. Animals of correct form and acceptably pure descent were eligible to registration. In 1895 the French Canadian Cattle Breeders' Association was organized and in September of that year assumed the control of all herdbook records. Since I 896 no animals have been or can be registered excepting the descendants of the foundation stock already recorded. Up to I9I7 two volumes of herdbooks have been published, showing the registration of 4215 animals. 


\section{CHAPTER XXXVII}

\section{THE KERRY}

The native home of Kerry cattle is in southwestern Ireland in the county of Kerry. This is one of the wildest and most picturesque sections of Ireland, with mountains rising above three thousand feet and with the famous Killarney lakes in the setting. The climate is moist and fairly temperate. Agricultural conditions are inferior.

The origin of the Kerry is as uncertain as that of other British breeds. From time immemorial it has been bred in Ireland, where it is known as the "poor man's cow." The opinion of British students is that this is a descendant from the smaller type of aboriginal cattle of that country, of the same character as the dark-colored cattle of Britain. Nothing more is known. The development of the breed has mainly rested with the Irish farmers or tenants, who keep but small herds.

The introduction of the Kerry to America was probably first made in 1859 by Sanford Howard of Boston, Massachusetts, who imported for Arthur W. Austin a bull and five two-year-old heifers. In 1860 he imported a second bull, the first having died, and two heifers. Since that period Kerry cattle have been imported to the United States in a small way up to the present time.

Characteristics of Kerry cattle. This is a distinct dairy type breed, with the following special characteristics: The color should always be a solid black, with no white on the body in case of the bull ; with the cow a slight amount of white on the udder or underline, while undesirable, does not disqualify. The lean head of the cow carries upstanding, slender white horns with black tips, which often turn back; the bull's horns are shorter than those of the cow, but are commonly erect, with the tips turned back. The neck is slender and long, the withers fine, the back strong and well carried, the depth of body only moderate, the mup tending to be somewhat sloping, the thighs muscular, and the legs slender 
and comparatively long. The udder is frequently large for the size of the cow, but tends to have a poor front development. In size the Kerry is one of the small breeds, and when in breeding condition the bull should not weigh over one thousand pounds nor the cow over nine hundred pounds. The tompiramcnt of the Kerry is distinctly nervous, yet, when well cared for, these cattle are quiet and easily handled.

The maturing characteristics of Kerry cattle are secondary. As bred in Ireland, due to inferior care, they are slow to develop, producing the first calf later than other breeds. This slowness of maturity is overcome to a considerable degree under proper conditions of care and feeding, and in America earlier maturity may generally be expected than in Ireland.

The hardy character of Kerry cattle is one of its distinctive features. During the entire year it is necessary for the Irish cotter's cow to adapt

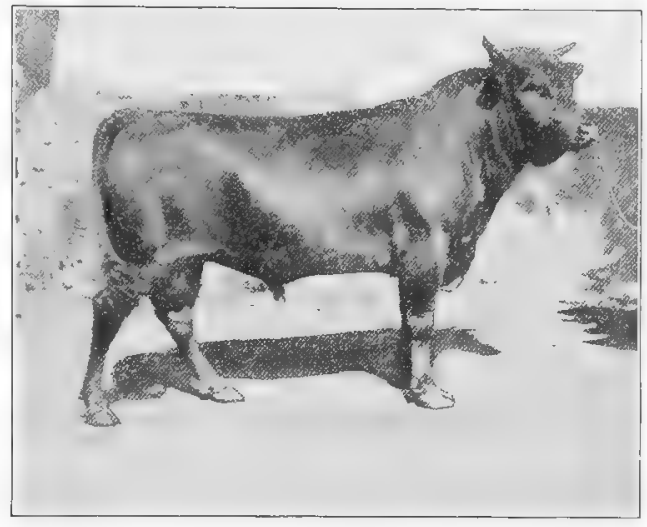

FIG. 192. La Mancha My Mistake (344), a prizewinning Kerry bull at the show of the Royal Agricultural Society of England. Owned by R. Tait Robertson, Malahide, Ireland. From photograph by the author

herself to conditions of privation, including the inclemency of winter. No breed has a more robust constitution or is less subject to common diseases than is the Kerry in Ireland.

The prepotency of Kerry cattle is very marked. Being of an ancient breed, long bred pure, it transmits its color and physical characteristics in a marked degree.

The Kerry in crossbreeding is essentially of value in improving common dairy stock. Kerry bulls from high-yielding cows, bred to ordinary cows, should sire a class of heifers possessing vigorous constitutions, showing a uniformly black color and capable of producing a good yield of superior mill at minimum cost. 
The grazing value of the Kerry is very high. This breed has been developed under adverse food conditions and thrives on comparatively poor rations. It well serves the purpose of furnishing the poor Irish laborer a maximum of return for a minimum of expenditure.

The Kerry as a milk producer ranks well, considering her size and cost of production. Messrs. William and James McDonald, reporting on the Kerry cattle shown at the Paris Exposition in I 878 , state that twelve quarts of milk daily during the season and from six to seven pounds of butter a week are the estimated yield of a Kerry cow, and that cows have been known to give sixteen quarts every day for some time after calving. Only in recent years have any systematic efforts been made to keep milk or butter-fat records of these cows. In I905 Professor James Long wrote as follows, relative to official trials ${ }^{1}$ :

If we take the milking trials at the National Dairy Show at Islington, and travel over a number of years, we find that in one year eight Kerries averaged 36 pounds, or more than $3 \frac{1}{2}$ gallons of milk per day, this milk containing 3.33 per cent fat. In another year twelve Kerries averaged $25 \frac{1}{2}$ pounds of milk per day, this milk containing the large proportion of 4.33 per cent of fat, while the solids not fat reached 9.2 per cent. Again, in a third year, seven Kerries averaged $33 \frac{1}{2}$ pounds of milk, containing 3.69 per cent fat. In two other years the averages of ten cows in each year were $27 \frac{1}{4}$ pounds of milk and 33 pounds of milk, the fat percentage in one case 4.36, and in the other 4.26.

In official tests in I9I6 and I9I7 in Ireland, under the supervision of the Department of Agriculture and Technical Instruction for Ireland, records ranged from $48 \mathrm{I} 2$ pounds of milk as a minimum to $8 \mathrm{I} 24$ pounds as a maximum yield, forty-five weeks being the extreme period of lactation. The butter-fat percentage ranged from 3.4 to 4.9 , the average being 4 per cent. From what the author has seen of these cattle in Ireland he believes the Kerry to be a milk-producing breed of much promise under a judicious system of breeding and selection.

The distribution of the Kerry is not general; even in Ireland, where it is best known, the Shorthorn is the leading breed. There are a number of excellent Kerry herds in England, but very few of these cattle have been imported to America. There are small

1 Agricultural Gazette (London), August 21, 1905. 
herds in Australia and South Africa. In the United States the principal herds are in New York, Missouri, and Minnesota.

Organizations for the promotion of Kerry cattle have been in existence for some years. In 1887 a register was started in Ireland by the owners of the Farmers' Gazette of Dublin, which was taken over by the Royal Dublin Society after the publication of three volumes of herdbooks. In I 890 this society issued the first volume of the "Kerry and Dexter Herdbook," and has

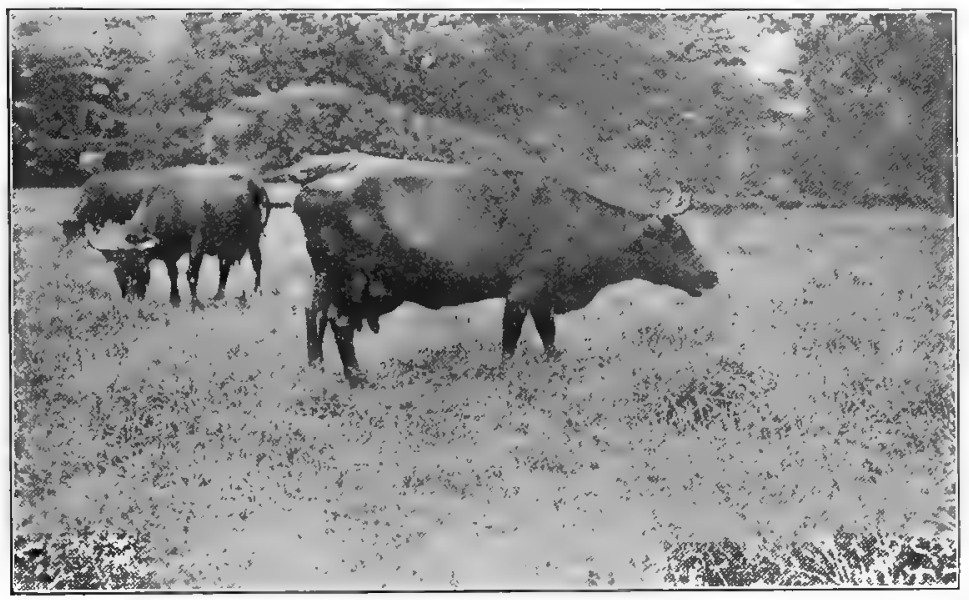

FIG. 193. Kerry cows on pasture on the estate of the Duke of Leinster, Maynooth, Ireland. From photograph by the author

continued doing so up to date. Seventeen volumes of the Irish herdbook have been published, containing the total entry up to I9I 8 of 87 I Kerry bulls and 2658 cows. An English Kerry and Dexter Cattle Society, with headquarters in London, was established in 1892 and has published eighteen herdbooks, containing a total entry to I9I 7 inclusive of 392 Kerry bulls and 2098 cows. In 1917 an Irish Kerry and Dexter Cattle Society was organized in Ireland to promote the welfare of the breed. In I9I I an American Kerry and Dexter Cattle Club was organized, but thus far has published no herdbook. Up to 1920 but 16 bulls and 6 I cows have been recorded, and to this date no important herd of Kerry cattle has been established in the United States. 


\title{
CHAPTER XXXVIII
}

\author{
THE DEXTER
}

The native home of the Dexter is in the southern part of Ireland and in the same region as that of the Kerry.

The origin of the Dexter is quite obscure. The common assumption has been that this breed is a cross between the Kerry

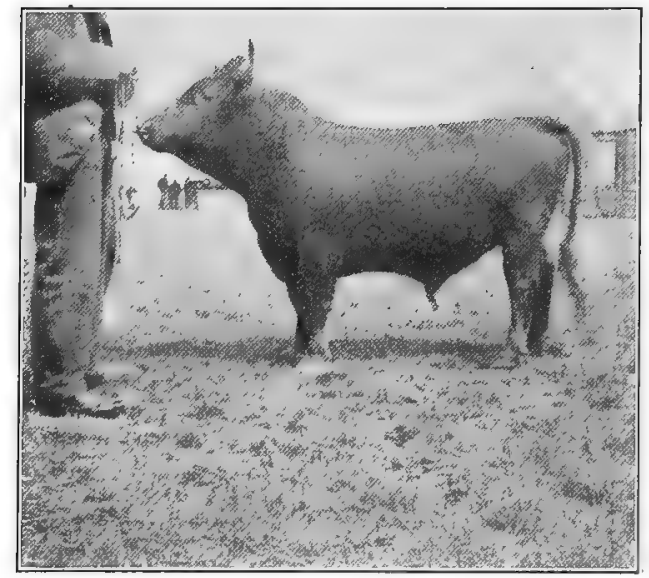

FIG. I94. La Mancha Union Jack (37), a noted prize-winning red Dexter bull. From photograph by the author and some other breed, perhaps the Devon. The opinion expressed by Professor James Wilson ${ }^{1}$ is that this is a short-legged offshoot from the Kerry, due to crossing with the Devon. It has ailso been repeatedly claimed that "a Mr. Dexter," who at one time was agent of Lord Hawarden, is responsible for this Irish breed, which for some time was known as the DexterKerry, but which now is classed by organizations promoting these cattle in Great Britain and America as d distinct and separate breed from the Kerry.

The introduction of the Dexter to America probably occurred long ago, when no discrimination was made between Kerry and Dexter in importations. Perhaps two hundred Dexters were imported to the United States between I9IO and I9I5, a large percentage of which were brought over by Elmendorf Farm of

1 The Evolution of British Cattle and the Fashioning of Breeds. London, Igog. 
Kentucky, Howard Gould of New York, and James J. Hill of Minnesota, none of whom are now maintaining herds of these cattle.

The characteristics of the Dexter. In Great Britain the Dexter is regarded as a diminutive dual-purpose breed, although in the United States the beef side is given scant consideration. The essential characteristics are found in the head, short legs, small size, and color. The head is old-fashioned in a degree, tending

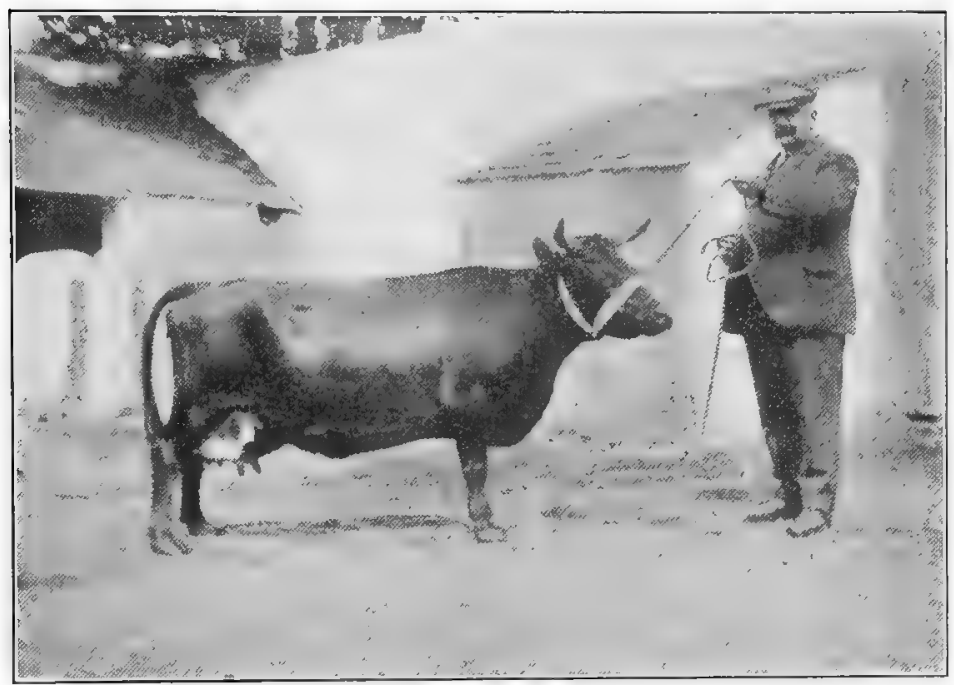

F1G. 195. Harley Coy (1655), a remarkably fine example of a Dexter cow at full maturity. Champion cow at the Royal Agricultural Society Show. Owned by R. Tait Robertson, Malahide, Ireland. From photograph by the author

toward plainness and crowned with more or less black-tipped, upright horns. The head of the bull is burly and short and the horns often extend directly out to each side and then make a wide curve forward and upward, with considerable space between the tips. The neck is moderately short and muscular, the withers show a dual-purpose thickness, the back is usually strongly supported, the depth of body and digestive capacity is comparatively great, the tail head is often prominent, the hind quarters suggest the dual-purpose type (more especially with the bull), the legs are very short, and the udder on mature cows frequently indicates great capacity for animals of such small size. 
The color of the Dexter is very generally a solid black, although pure reds are also recognized and are not uncommon. The Irish regard either color as of equal merit. White marks are permissible on the udder and on the belly up to the navel, though not outside of the flanks. The brush of the tail may also contain more or less white. No white markings are favored on the bull, although a slight amount on the scrotum or sheath will not disqualify. The horns are usually white with black tips, while the nose and hoofs may be either white or dark as the animal is black or red.

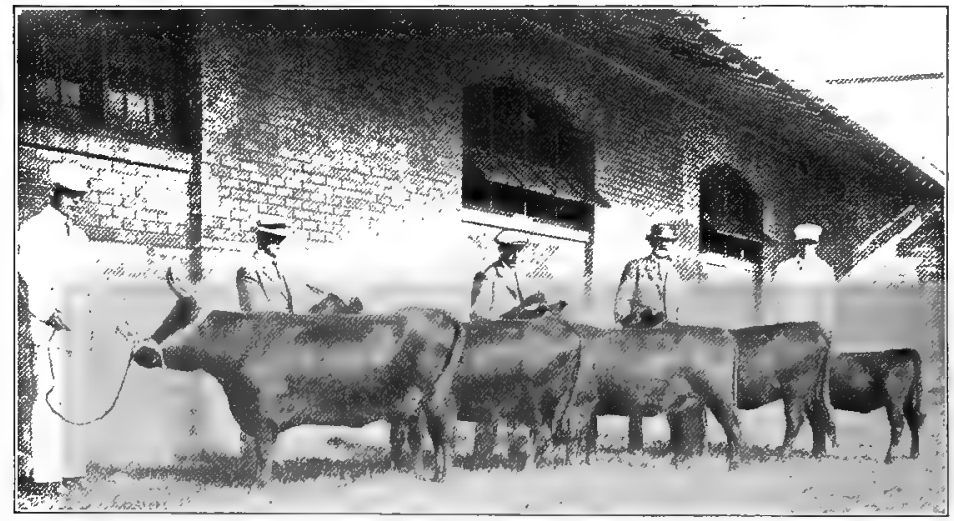

FIG. 196. A herd of Dexter females, first in class, exhibited by Howard Gould, New York, at the New York State Fair. From photograph by Smith \& Holmes

The size of the Dexter places it among the smallest of British breeds. In mature form the standard weights are 900 pounds as a maximum for the bull and 800 for the cow when in breeding condition. Some very beautiful specimens of cows that scarcely weigh over 500 pounds are seen at British shows. One of the noted bulls of the breed - La Mancha Union Jack — stood only about 38 inches high and probably weighed less than 500 pounds. In view of the fact that the Dexter has largely been sought on account of its diminutive size the tendency among breeders has been to emphasize that feature. Where breeding is conducted under conditions of plenty there is a tendency towards increase in size.

The hardy character of the Dexter is one of its outstanding features. In its native home, like the Kerry, it lives largely in the 
open, under rather rigorous conditions, and tubercular and other diseases due to close housing are quite uncommon.

The crossbred Dexter, especially with beef stock, meets with much favor in the British market. The use of Aberdeen-Angus or Shorthorn bulls on Dexter cows has produced some very beautiful small carcasses of beef. The author has seen some of these crosses in Ireland that, although small, represented high-class beef animals, indicating very superior killing quality. So highly is this kind of crossbreeding regarded in England that special classes for these small carcasses are provided at the Smithfield Club Fat-Stock Show.

\section{The Dexter as a milk pro-} ducer has considerable merit. There are many records for these little cows, of 4000 to 6000 pounds of milk produced within a year and this on just ordinary care. In Ireland, however, official testing of Dexter cows has only just begun. During the years I9I6 and I9I7 twenty-four cows were under test as supervised by the Department of Agricul-

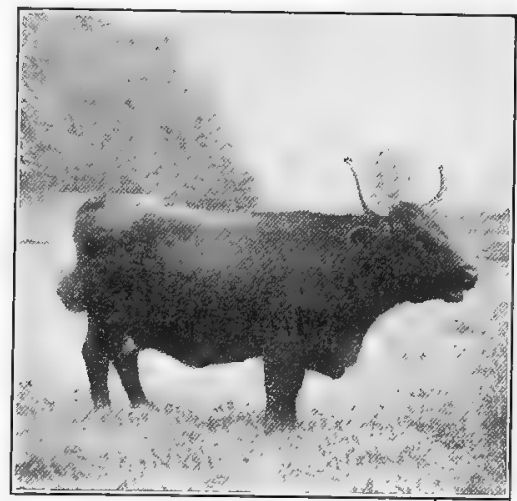

FIG. 197. A Dexter cow of dual-purpose type on the pasture of the Royal Agricultural College, Cirencester, England. From photograph by the author ture and Technical Instruction for Ireland, covering periods of lactation ranging from thirty-three to forty-five weeks. The smallest annual yield was 4555 pounds during a period of thirty-six weeks, testing an average of 4.I per cent fat, while the largest yield was 8 I 24 pounds during forty-five weeks, testing 3.7 per cent fat. The Castlegould herd of Howard Gould in New York State produced a number of excellent records, one cow - Slane Clara — having a record of 9046 pounds, testing 4.26 per cent fat. Dexter milk averages about 4 per cent fat.

The prices paid for Dexter cattle are comparatively small. As the breed is quite limited in number the demand is also limited. These cattle may be bought in Ireland for approximately $\$ 50$ a head, with a fair selection at this price, although show animals 
naturally command a higher figure. While Americans have imported several hundred Dexters, as a rule the prices paid have been modest. In a pamphlet on these cattle published by the Kerry and Dexter Cattle Society of Ireland in 1918 it is stated that the prices vary from $\$ 125$ to $\$ 350$, according to age and quality.

The distribution of the Dexter extends over Ireland, with a few select herds in England. The 1918 volume of the English Kerry and Dexter herdbook records thirty-one herds in England. Dexter cattle have been exported to South Africa, Australia, and other British colonies. In I9I9 there were Dexter herds in Vermont, New York, Kentucky, Missouri, Texas, Illinois, Wisconsin, and Minnesota. A number of herds are kept in Canada.

The official promotion of Dexter cattle is supervised by several associations. The Farmers' Gasette of Dublin, Ireland, instituted a herdbook, the first volume of which appeared in 1887. Later the Royal Dublin Society took over this work and since 1890 has published the records. The English Kerry and Dexter Cattle Society was founded in 1892 and up to I9I9 has issued nineteen herdbooks, which show a total of 639 bulls and 2544 cows registered. In I9I 7 there was organized at Killarney, Ireland, the Kerry and Dexter Cattle Society of Ireland, "to maintain the purity and promote the breeding of Kerry and Dexter cattle in Ireland." The American Kerry and Dexter Cattle Club, organized in July, I9I I, serves the purpose of registration and transfer and aims to promote the welfare of the breed. Up to I920 the club has registered fifty-five bulls and two hundred and fortysix females. 


\section{CHAPTER XXXIX}

\section{DUAL-PURPOSE TYPE OF CATTLE}

Dual-purpose and general-purpose type of cattle mean the same thing. This comes in between the beef and dairy type, combining in one animal the valuable qualities of meat and dairy types. This class has been under special discussion for some years, and strong arguments have been advanced in its behalf. It is not proposed to go into a detailed discussion of this type, - it is not necessary, - but rather to emphasize the essential features.

The dual-purpose and beef type compared show marked differences. The dual-purpose animal is narrower of body and scarcely as well rounded as the beef type, does not naturally carry so much "condition," is more lean of neck, sharper at withers, narrower at the thighs, and longer of leg than is common with true beef cattle. One receives the impression that relatively the dual-purpose type is of greater length. In the case of the cows the udder is most essential in good specimens of the dual-purpose type, milk production being of special importance.

Dual-purpose and dairy type compared show the former to be fuller in the breast, thicker at withers, broader backed, thicker and heavier at the hind quarter and twist, and generally more massive than the latter. The form is somewhat smoother and less muscular, the tendency being towards higher condition. When in high milk flow dual-purpose cows often lose flesh and incline to the dairy conformation, but when dry they usually flesh up to a marked degree. The writer has seen dual-purpose cows that have been regarded as dairy-type animals by men rated as good critics. It is difficult, in fact, to draw the line between these types in cases of certain individuals that vary according to their condition, when each tends to approach the other in conformation. For example, the American Brown Swiss Cattle Association has classed this as a dairy breed, yet if one is to judge the Brown Swiss as seen either in its native home or America, it will be 
difficult to classify a large percentage of the animals other than of dual-purpose type.

Two classes of dual-purpose cattle are common - one rather beefy in character, with inferior udders, the other lean and muscular, with strong dairy-type indications. Every large show of dual-purpose breeds contains good representations of these two classes. For example, the Devon, a dual-purpose breed, contains the two classes in a marked degree. The dairy sort is more popular in the Eastern states, the beef in the West. The same applies to a certain extent also to the Red Polled breed, though perhaps not to so great a degree as with the Devon. In the Shorthorn breed we have the most approved beef type of cattle, while a dual-purpose type of Shorthorn, with strong dairy tendencies, is very common in England and not rare in America. In IgI 4 the writer watched the judging of the dairy Shorthorns at the Royal Agricultural Society of England Show at Shrewsbury, said to have been up to that time the largest exhibit of this class ever seen. Here the animals placed first and second were beautiful large beefy-looking cows with udders of great size and apparent capacity. On one occasion the secretary of the dairy branch of "Coates's Herdbook," in reply to an inquiry as to just what was most desirable in a milking Shorthorn, replied that he wished as much natural beef conformation as possible, coupled with great milk-producing capacity. That should logically be the aim, and the policy of some breeders to emphasize a type of dual-purpose cattle that are in fact true dairy cattle is neither consistent nor desirable. Such breeders might better center their interest on dairy cattle altogether if they are unwilling to give due recognition to beef values. By combining beef and milk in a really noteworthy degree the dual purpose is secured. Minus the one or the other the animal must be classed with the beef or dairy type. Many farmers greatly prefer a type of cow productive of a liberal supply of milk, that will fatten easily to meet the demands of the butcher, and will also produce calves which will feed into superior veals or steers. In regions where dairying is not a specialty the dual-purpose type is quite commonly seen in the Shorthorn of milking strain. Notwithstanding the frequency with which cattle of this type are seen, there are comparatively 
few animals of the dual-purpose breeds to be found in America. During the last few years, however, there has been a greatly increased activity in the demand for cattle of this type in both America and Great Britain, and many animals have changed hands at good values. Certainly the excellent records made by cattle of this type will greatly promote their future popularity and usefulness. 


\title{
CHAPTER XL
}

\author{
THE RED POLLED
}

The native home of Red Polled cattle is in England, in the counties of Norfolk and Suffolk, which border the North Sea and comprise the most easterly part of England. The country is rolling, with some marsh lands, and furnishes good grazing and live-stock conditions, although parts of Norfolk have poor, thin land. The climate is fairly temperate and moist - characteristic of England.

The origin of Red Polled cattle is differently interpreted by live-stock writers. Culley thought them descended from the Galloway type and was the first to suggest this source, although the two breeds materially differ. Others have attributed the ancestry to the wild white-polled sort. Mr. Euren, the organizer of Red Polled interests abroad, has suggested that the breed was derived from the polled cattle of southern Europe - for example, Hungary or central Russia, where cattle possessed the soft satiny skin of the Red Polled - rather than from the Galloway, with its heavy, long coat and thicker hide. The fact is the breed has developed, like other British breeds, from material which passes beyond historical record. We do know, however, that the present-day Red Polled breed consists of an amalgamation of the following two types or varieties:

I. Suffolk Red Polled. The county of Suffolk lies just south of Norfolk. The northeast part, sometimes designated as East Anglia, was settled in the fifth century by Scandinavians, and it is stated that they brought cattle with them. In this section of Suffolk, only twelve by twenty miles, and later in the entire county, as well as in Norfolk, developed a polled breed that became famous for milk production. In I734 John Kirby, in the Suffolk Traveler, wrote of the butter produced in this district as "the best and pleasantest in England." These cattle were small, naturally thin of flesh, either red, brindled, or dun-colored, and always 
polled. In I 794 Arthur Young, in a general survey of the agriculture of Suffolk, describes the breed at some length. He stated that for two or three months a whole herd would average five gallons of milk a day per head, and single animals have produced eight gallons in a day. From I 778 on, numerous advertisements

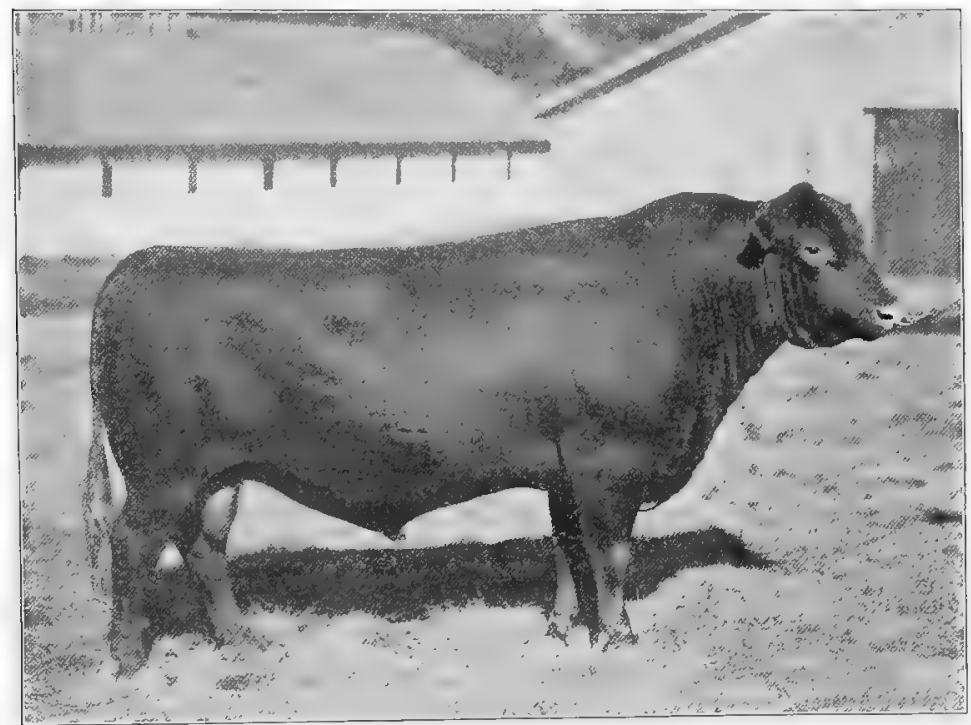

FIG. I98. Teddy's Best I7603, a noted Red Polled bull, thirty-two times a champion up to 19I9. Noted also as a sire. Owned by Jean Du Luth Farms, Nickerson, Minnesota. From photograph by Hildebrand, by courtesy of Jean Du Luth Farms

of auction sales of this dairy stock were published in the Norwich (Norfolk) Mercury. In 1802 a herd of "twenty-one beautiful polled cows and a bull" was advertised.

2. Norfolk Red Polled. In Norfolk County early writers referred to a type of cattle blood red in color, with a white or mottled face, having horns, and small of bone, "fattening as freely and finishing as highly at three years old as cattle do generally at four or five," says Marshall, who regarded the Norfolk Red Polled as a miniature Hereford in appearance. These possessed poor dairy qualities, so Jonas Reeve of Wigtown and Richard England of Binham began to improve and secure a type combining the good qualitiestize the Suffolk as well as the Norfolk. 
A Mr. George also took part in this improvement. They bred to produce a solid red color (perhaps using the Devon, which existed in the county), bred off the horns (no doubt with the help of Suffolk bulls), and so developed a dual-purpose type which attained considerable fame. In 18 I 8 the name "Norfolk Polled" began to come into use.

The amalgamation of Suffolk and Norfolk Red Polled cattle was the result of gradually developing the two breeds into a common type. Each was improved with the view of securing

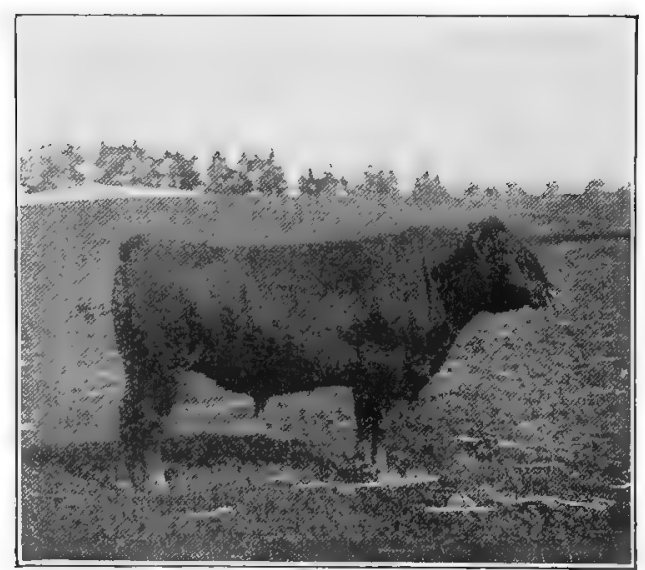

FIG. 199. Jean Du Luth Bryson 265I2, a Red Polled bull owned by Professor H. C. Price, Newark, Ohio. From photograph by the author an easy-keeping, hornless, red-colored, dualpurpose animal. The types of each county were shown for a time at the local fairs, but they gradually came to be of the same general character. The year I 846 , according to Mr. Euren, late secretary of the Red Polled Cattle Association in England, may be taken as the date from which the Norfolk and Suffolk varieties merged into each other so as to be spoken of as one and the same breed. Finally, in I 862, an international exposition was held at Battersea, when a large exhibit was made in one class from both Norfolk and Suffolk. It was then that the improved form in each county was recognized as of the same kind and given the name "Norfolk and Suffolk Red Polled." About I 882 this was shortened to "Red Polled," by which name the breed is now recognized.

The introduction of Red Polled cattle to America no doubt first occurred in colonial times in English settlements, as, for example, in Virginia. Mulley, or polled cattle, of a red or redand-white color, similar to Red Polled, have been known in the 
eastern United States for over a century. In I 847 the captain of the vessel Jamestoren, that took provisions to Ireland to relieve famine, received the gift of a Suffolk polled heifer from a Mr. Jeffries, living near Cork, as an expression of appreciation, and she was brought to Massachusetts. From her descended a line of .stock, termed Jamestown cattle in Massachusetts, that produced polled animals of superior character. In I873 G. F. Taber of Patterson, New York, made the first importation of breeding Red Polled cattle to this country, consisting of a bull and three heifers and later, in 1875 , four more cows and, again, in I882 three bulls and twenty-three heifers. In I882 Mead \& Kimball of Vermont brought over a bull and eleven females, and in I 883 G. P. Squires of New York and Geldard \& Busk, an English firm, made importations. In I $886 \mathrm{~J}$. McLain Smith of Ohio made his first importation, and until his death, in 1905, he was a prominent advocate of the breed. Captain V. T. Hills, also of Ohio, a leading American authority on the breed, imported in 1887 . During the last of the nineteenth century and up to I9I 8 very few Red Polled cattle were imported to the United States.

Red Polled characteristics. Animals of this breed present the dual-purpose type in its truest form, for good specimens yield milk liberally and fatten satisfactorily on drying off, producing a good grade of beef. The head is lean in type and presents the characteristic poll. The top of the head should show the true poll, and any scurs, or evidence of horny growth, will disqualify. The poll of the bull is not so sharply pointed as with the cow. The neck of both bull and cow lacks the fullness of the beef breeds, the cows being notably thinner in this respect. The withers are only moderately broad, and the shoulders resemble those of the Shorthorn rather than the Hereford. The body is usually very well ribbed and the back strong, but is not fleshed over in a prominent degree. The hips lack prominence and cover easily in fattening. The hind quarter presents the thinner beef form, as shown in the leaner rump, thinner thigh, and shallower twist. The udder frequently is more or less pendant, the fore part commonly being deficient, while large teats are frequently seen, although in this latter particular the breed has improved in recent years. The udders are not commonly meaty with this breed, but 
rather are mellow and elastic. Fair milk veins and wells occur; in fact, Arthur Young, over a century ago, commented on the large size of the milk veins on the Suffolk cow. The quality of the Red Polled may be classed as fair.

The color of the Red Polled varies from light to dark red, a medium shade being most common. The British standard of color is blood red, with a deep red for preference. The American standard of color, as adopted by the Red Polled Cattle Club of America in 1907, is as follows: Any shade of red. The switch of the tail and the udder may be white, with some white running

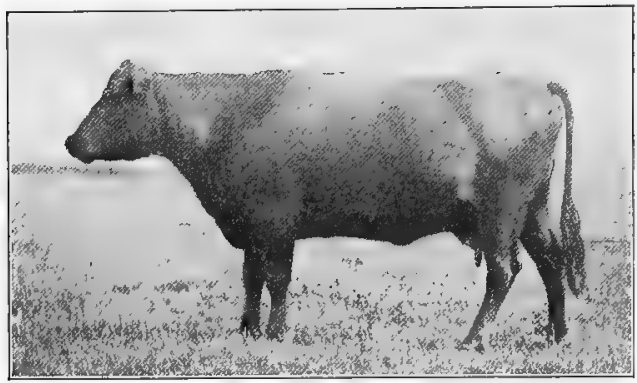

FIG. 200. I0097 Chloe (TI), second-prize Red Polled cow at the International Live-Stock Exposition, 1903. Owned by the late J. McLain Smith, secretary of the Red Polled Cattle Association.

From photograph by the author forward to the navel. Nose of a clear flesh color. Interior of ears should be of a yellowish, waxy color. Objectionable features of color, as based on the American scale of points, are an extreme dark or an extreme light red, and a cloudy nose or one with dark spots. The British association objects to any extension of white in front of the udder, any white on a bull except on tip of the tail, and a cloudy or dark nose. A blue or black nose, any white, excepting on the tip of tail, the udder, or "for a short way under the body," and any other color than red disqualifies a Red Polled in England.

The size of the Red Polled is about medium. A number of weights of well-known animals of the breed are as follows: bulls-Pando I 254 (mature), 2270 pounds; Parole 19363 (at three years), I975 pounds; Proctor Knot I 2083 (mature), 2050 pounds; Patriarch 6482 (at three years), 2460 pounds; Demon 5421 , a noted show bull (mature), 2 IOO pounds; Wild Roy I IO5 (mature), 2480 pounds ; Dasher I348 I (mature), 2 I 30 pounds; Curles' 22d 20245 (at fourteen months), 920 pounds. Cows -24888 Pear, 1440 pounds; 28400 Pattie, I 500 pounds; 2899 I J. D. Pear, I 400 pounds; 
I 1084 Claribel 3d (mature form), I 200 pounds; I $400 \mathrm{r}$ The Nun (mature), I650 pounds; 31725 Beauty (mature), I750 pounds; 6643 Pochahontas (mature), I600 pounds; 2694 Chic (mature), I670 pounds. An average weight for mature bulls is about I 800 to 2000 pounds and" for cows approximately I 250 to I 500 pounds.

Red Polled cattle as beef producers hold very good rank. While as a rule they do not win the highest honors in open competition in the great beef-show rings, they feed to a point of profitable production for the stockman and make a very good class of beef for the consumer. This beef is not usually so fat as that produced by some breeds, the outside of the frame not being so heavily covered. Red Polled steers also tend to be somewhat long of leg. Numerous cases may be cited to show that the steers gain rapidly and show well. At the I889 Smithfield Club Show two Red Polled two-year-old steers showed the largest daily gain of anything on exhibition of that class, namely, 2.18 and 2.29 pounds each. One of these afterwards was made champion as the best steer on exhibition at the Norfolk FatStock Show. At the Smithfield show in I890 a Red Polled steer dressed 73.72 per cent, the highest per cent dressed out at the show. This, however, is an extreme figure. Each year at the International Live-Stock Exposition at Chicago there has been a small exhibit of Red Polled steers, too many of which brought discredit to the breed, being inferior in conformation and in low condition. From year to year there have been one or two Red Polled steers in the International carcass contests. Eleven twoyear-old steers, covering the years 1904 to 1916 , showed live weights ranging from I 88 to I680 pounds, dressed weights of 774 to 1087 pounds, and per cent of carcass to offal of from 6I.4I to 68.7I. Red Polled steers in good flesh on the open market bring a fair price.

Red Polled cattle as milk producers have long held high rank, and a large number of records might be cited to show the value "of the breed in the dairy. In public tests the breed has stood well: At the-Pan-American dairy test in Igor five Red Polled cows took fifth rank among ten breeds, showing a net profit of $\$ 20 \mathrm{I} .6 \mathrm{I}$ ' for 'six months. Among the 50 cows tested, the cow 8025 Mayflower 2d A A stood second, producing 6I6I pounds 
milk and 323 pounds estimated butter, showing a net profit in the fat test of $\$ 52.10$. In recent years the breed has been making some very high-class milking records. One of the most noted Red Polled herds in England until recently was that of Lord Rothschild at Tring Park, where records of yearly production were kept. The average records between I898 and I910, with a

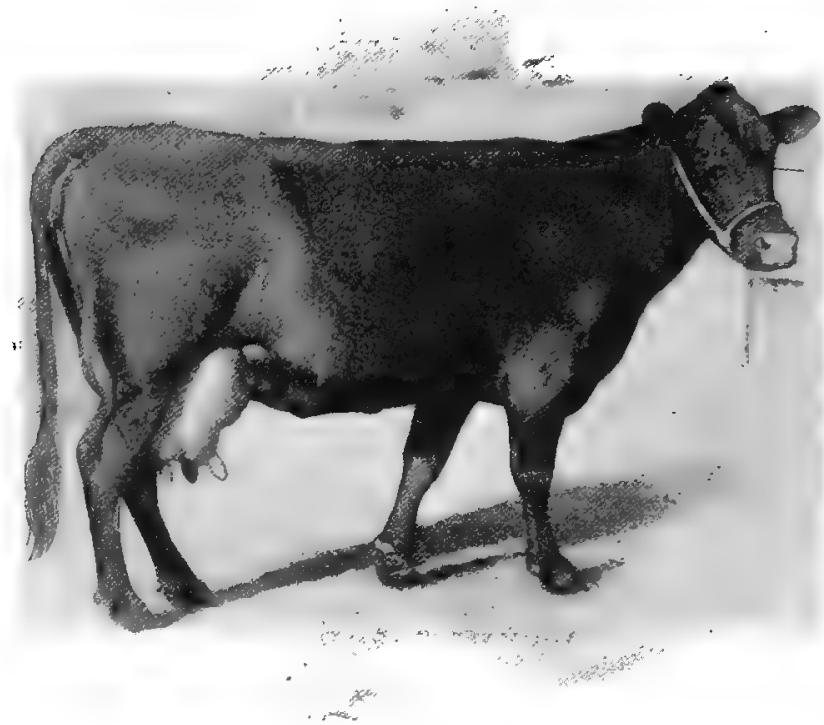

FIG. 20I. 2965 Mayflower (AI2), a Red Polled cow of dairy type, noted as the founder of the Mayflower family. This cow gave II,008 pounds of milk from July 18 , I892, to July 10 , 1893 , and $43,118 \frac{1}{4}$ pounds of milk in four years from August I, 1890 , to July 31, 1894. Owned by the late V. T. Hills, Delaware, Ohio. From photograph, by courtesy of Captain Hills

herd numbering approximately 40 head, ranged from 6174 to 7 I 6 pounds per cow. In I 903 fifteen herds contributed records of their daily milk yield to the "English Red Polled Society Herdbook." Of 267 cows which had produced in the year, having had their second calf or more, I94 gave a total yield for the year of 5000 pounds and over. Thirteen of these gave gooo pounds and over, the best record being Io,392 pounds. The cow 2965 Mayflower Ar2, in the herd of V. T. Hills of Ohio, produced 
from July I 8, I892, to July IO, I 893 , a total of I I,008 pounds of milk; while for four years, from August I, I890, to July 31 , I894, she produced 43,1181 pounds of milk, or a daily average of about 25 pounds. The London Live Stock Joumal in 1898 published the milk record of a Red Polled cow of I 3, I 26 pounds in three hundred and forty-seven days, an average of 37.82 pounds daily. This same journal also reports on the Red Polled cow Hester, that from October, 1890, to October, I904, produced the remarkable yield of 84,177 pounds of milk, an average yield for fourteen years of 6012 pounds per year. Hester was also a very successful show cow in England. Among the more prominent herds in America is that of Jean Du Luth Farms, in Minnesota, where official testing has been in progress for some years. In I9I 3 twenty-four cows in the herd averaged for the year 7645.7 pounds of milk, and in I9I4 a herd of the same size averaged 98I8.I pounds. The largest annual milk record of a Red Polled cow to January, I9I 8 , is that of Jean Du Luth Beauty, producing 20,280.6 pounds, a wonderful showing. Jean $\mathrm{Du}$ Luth Pear in two years produced 30, 136.8 pounds of milk. The cow Pear has the most remarkable record, having in seven consecutive years produced 67,548.6 pounds of milk, a yearly average of 9649.8 pounds. In I9I 8 the same cow had seven living daughters and one son in the herd where she is owned.

Red Polled cattle as butter producers stand very well. Their milk tests about 3.8 per cent fat, although many cases show even better. The average of Mayflower for four years by Babcock test is 4.35 per cent butter fat. At the Pan-American Exposition the five Red Polled cows produced in six months I 319.45 pounds churned butter valued at $\$ 329.86$, with Mayflower $2 \mathrm{~d}$ second in the butter-fat test. In this test the average butter-fat content was 3.98 per cent. In the Jean Du Luth herd the average annual yield of butter fat per cow in 1908 was 259 pounds; in 1909, 257.8 pounds; in I910, 264.9 pounds; in I91 2,268 pounds; in I9I $3,316.27$ pounds; and in I9I4, 403.5 pounds. The leading record in butter fat for a Red Polled aged cow is that of 31725 Jean Du Luth Beauty, of 891.55 pounds of fat. The cow 31787 Jean Du Luth Dorothy, in four-year form, produced 57 I.4 pounds fat, while the two-year-old heifer 34870 Jean Du Luth Lady 
Watts gave a yield of 4 I 2.4 pounds of fat. 2899 I Jean Du Luth Pear in two consecutive years produced 1253.58 pounds butter fat, while her dam 24888 Pear in seven consecutive years made 3094.5 pounds of fat, or an annual average of 442 pounds. Fifty cows in the Jean Du Luth herd have official butter-fat records which average 468 pounds. Not many Red Polled cows, however, have official records of 400 or more pounds of butter fat in a

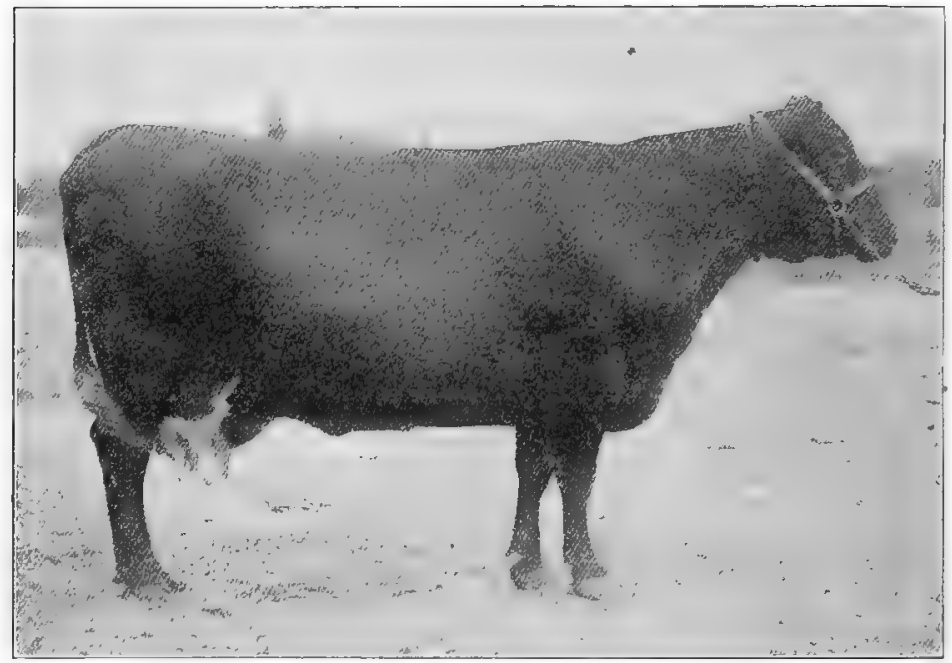

FIG. 202. 3I725 Jean Du Luth Beauty, one of the greatest producing Red Polled cows, with an official record of $20,280.6$ pounds of milk and 891.55 pounds of fat in a year. Owned by Jean Du Luth Farms, Nickerson, Minnesota. From photograph, by courtesy of Jean Du Luth Farms

year, and on the basis of published reports 300 pounds would make a very creditable showing for many herds of the breed.

The use of the Red Polled cattle in crossing or grading may be beneficial from either the beef or dairy point of view. Red Polled bulls used on the beef type should increase the milk-producing character of the descendants, but may lower the meat standard somewhat. Used on the dairy breeds, the beef character should be improved in the offspring, but whether the dairy qualities will be benefited will depend on the kind of dam used, better results coming where a small milker rather than a large producer is 
mated. Red Polled cattle are very prepotent and will transmit their red color and polled heads with much uniformity when used on other breeds or grades.

The temperament of Red Polled cattle tends to be of the nervous sort, as might be expected of a type midway between beef and dairy conformation. The disposition inclines to.be less mild than with the Shorthorn, Jersey, or Holstein-Friesian, although the Red Polled responds readily to kindly treatment. However, the animals in average herds are less friendly and individuals are more easily excited than obtains with our prominent breeds.

The prepotency of the Red Polled is very marked. One rarely sees much variation in color or character of poll in a herd of pure-bred Red Polled, or if changes do occur in these two particulars, as a rule they may be attributed to the introduction of outside blood that has broken the normal line of breeding. Pure-bred bulls used in grade herds reproduce the notable breed characteristics in a marked degree. The following interesting evidence of Red Polled prepotency is quoted from "Bruni" in The Australasian, relative to the use of bulls of this breed on Shorthorn, Hereford, and Aberdeen-Angus cows :

What was my surprise on seeing the young cattle of the Hereford-Red Polled cross at Warribee Park, to find the Hereford type almost obliterated. The horns are gone, the frame is that of a Red Polled, and, instead of the white face, there are only a few oddly shaped white blotches. But that no spot of white is seen on the dark red hide, save on the face, no one looking at them would suspect they had Hereford blood in their veins.

The prolificacy of Red Polled cattle is probably above the average. Being naturally very hardy and active they reproduce readily. One will find in the records ample evidence of cows producing good-sized families. $567 \mathrm{I}$ Lucretia $2 \mathrm{~d}$, on the Borden Stock Farm in Illinois, between 1895 and I905, produced ten calves. It is reported that the cow AI Primrose dropped her last calf at twenty-six years of age. Mr. J. W. Martin, the most experienced of American Red Polled breeders, reports 3993 Dorothy as having dropped thirteen calves up to fifteen years of age, and refers to 4589 Hemithea as heavy in calf at eighteen years of age. While these are extreme cases, they show something of the producing capacity within the breed. 
Groups and tribes of Red Polled cattle gradually developed from the various lines of breeding. The first volume of the herdbook classes the united breed into twenty-five groups of foundation stock, each indicated by a letter of the alphabet, as A, B, C, etc., these including numerous tribes or families. The first volume gave 233 tribes, and later these increased to 385 , but at present only about 200 tribes are represented in the registration. While the group will remain the same in letter the tribes naturally vary in number. The method has an advantage in studying pedigrees, for with it the group and tribe relationship is shown. The groups made up certain foundation herds. For example, the A group comprises the cows in the Elmham herd or owned by tenants of the estate of that name; the B group, the cows in the Biddell herds and others in the vicinity; etc. Thus AI refers to a foundation cow in the Elmham herd named Primrose; $\mathrm{BIO}$, to a cow in the Manfred Biddell herd named Bury; etc. Differing from other cattle associations, the registration number of the cow precedes the name (as, 42 I Primrose Ar), while the number of the bull follows his name in the customary manner. None of the above groups trace far back of the first volume of the herdbook, some being comparatively recent.

Important tribes of Red Polled cattle. The factor that has played the largest part in giving distinction to a tribe of this breed has been milk production. This especially applies to the United States. The following may be regarded as the more notable tribes: Mayflower, descended from 2965 Mayflower, by Mason 698; Dorothy, descended from 3993 Dorothy, by Falstaff 303; Pear, descended from I 2789 Plum, by Didlington Dandy 2683; Popsey, descended from 9689 Popsey 3d, by Red Shirt 2014; Princess, descended from 2146 Davy Princess, by Davyson 7 th 476.

Red Polled sires of note are not found in considerable number in the American history of the breed, and some through shrewd advertising have been given more credit than the records justify. An important reason why this list is short is that until comparatively recently but little effort has been made to conduct official milk or butter-fat tests. Further, there are but few well-known herds that have been in continuous operation for many years. 
The following sires are among those best known: Falstaff 303 ; Troston 423; Wild Roy I I05; Pando 1254 ; Iowa Davyson 2oth 2773; The Ensign 3096; Corporal 4313, sire of Proctor Knott I 2092 and 24888 Pear, the most remarkable animals of the breed; Popular 856I; and Proctor Lnott 12092, sire of ten daughters in the Advanced Registry with average records of 391.7 pounds butter fat in a year.

The distribution of Red Polled cattle is widespread, yet the breed cannot be regarded as common. In Britain it is mainly bred in Norfolk and Suffolk counties, although large herds exist elsewhere, and considerable milk is shipped to London from Red

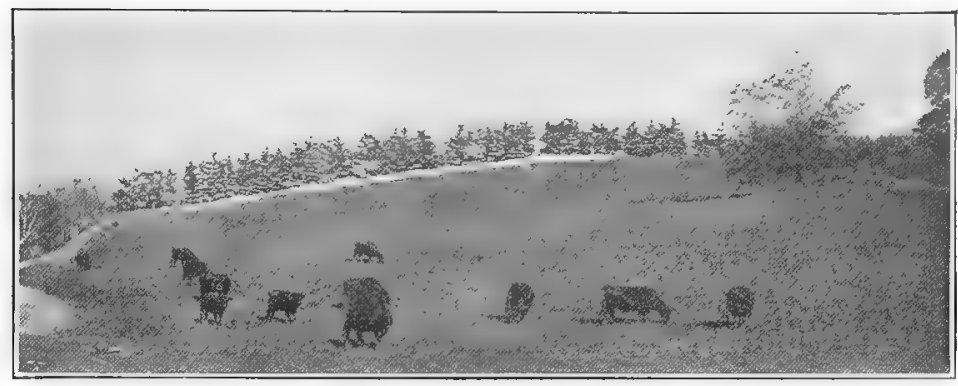

Fig. 203. Red Polled cows on pasture, Evergreen Farm, Newark, Ohio. From photograph by the author

Polled herds. Specimens of the breed have been exported from England to Russia, South Africa, Australia, New Zealand, Canada, and the United States. In the United States it is pretty well distributed, mainly in the Mississippi Valley and as far south as Texas. The more prominent herds are found in Ohio, Wisconsin, Illinois, Minnesota, and Iowa. The breed is fairly well adapted to a wide range of climate, being, perhaps, best suited to temperate latitudes.

Organizations to promote Red Polled cattle interests exist in England and the United States. Through the efforts of the late Henry F. Euren a herdbook was published in England in 1874 , and this work he continued until I888, when the Red Polled Society of England was organized. The American Red Polled Cattle Club was organized in 1883 at Chicago. In 1887 the first American herdbook appeared. This contained also the 
registrations in the first six volumes of the English society. From that period, up to I9OI inclusive, the American herdbook also contained the registrations of the English book, thus including all Red Polled registrations in England and America. At present only American-owned animals are recorded in the American herdbook, which, up to I9I9, included thirty-one volumes and the registration of 85,250 animals. The promotion of the Red Polled in America has lacked the influence of progressive breeders willing to spend money to place these cattle prominently before the public. Comparatively little has been done thus far in the United States through official testing to show Red Polled capacity in milk and butter-fat production. But one herd stands out prominently in this work in America - that of Jean Du Luth Farms. Most of the herds of the country are inactive in demonstrating the possibilities of the breed. One sees very little in American journals setting forth the merits of Red Polled cattle. In Great Britain, however, breeders are active in producing records, and British journals are at present giving much information concerning the same. Present-day publicity in both England and Ireland indicates a greatly increased interest in Red Polled cattle abroad. 


\section{CHAPTER XLI}

\section{THE BROWN SWISS}

The native home of Brown Swiss cattle is in northern and eastern Switzerland, more especially in the section adjacent to Lake Lucerne, in the cantons of Lucerne, Schwyz, Ufi, and Zug. This is a region combining beautiful valleys and high mountains. During the winter the cattle are kept in the barns in the lowlands,

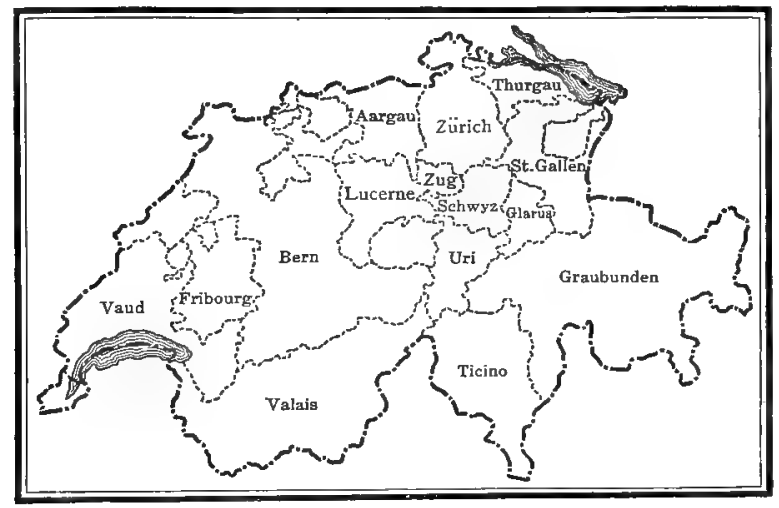

FIG. 204. A map of Switzerland showing the different cantons or provinces

while in the summer they are pastured on meadows high up on the mountains. Many stables are located in small Swiss villages, and during the summer the cattle are each day driven out to pasture and are returned at night. This is a hardy mountain breed and in general subsists on pasture or hay, but very little grain being fed.

The origin of Brown Swiss cattle is probably prehistoric. Horns, skulls, and other bones have been found in the Swiss lake dwellings, dating back to the Bronze Age, that closely resemble those of the Brown Swiss of to-day. It is generally conceded that the breed is very ancient and that it has long been bred with much purity and care by Swiss farmers. 
The introduction of Brown Swiss cattle to America first occurred in I 869, when H. M. Clark of Belmont, Massachusetts, purchased of Colonel G. Bürgi of Arth, canton of Schwyz, seven heifers and one bull, which soon after their arrival were resold to D. G. Aldrich of Worcester, Massachusetts, and David Hall of Providence, Rhode Island. In I 882 Scott \& Harris of Massachusetts and Connecticut imported nine two-year-old heifers and a bull and in I 883 ten heifers. In I 884 William Koch of New York

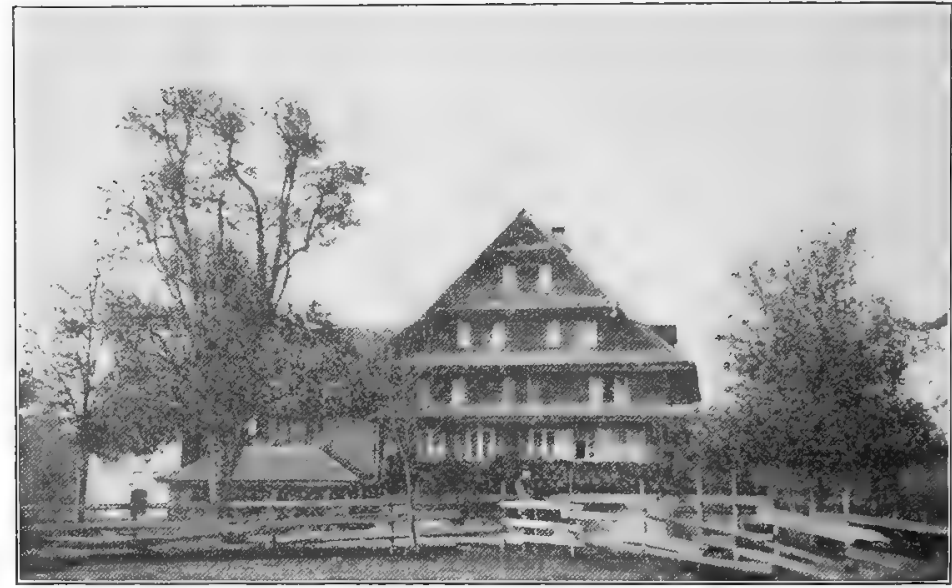

FIG. 205. A Swiss farm home near Lucerne. Photographed by the author

imported five two-year-old heifers and a bull, and the same year Eldredge and Ryder of New York imported one three-year-old, ten heifers, and a bull. In I $890 \mathrm{E}$. M. Barton of Illinois imported fourteen head. In I904 McLaury Brothers of New York made an importation, from which they showed at the Louisiana Purchase Exposition at St. Louis. In 1906 E. M. 'Barton imported five bulls and thirty-four heifers, the largest importation in many years. Owing to the continual presence of foot-and-mouth disease in much of western Europe the United States government has not permitted importation in recent years.

The characteristics of Brown Swiss cattle. This is essentially a dual-purpose breed of uniform and distinct breed character, although the Brown Swiss Cattle Breeders' Association of the 
United States has classed it as a dairy breed. The author has spent some time in Switzerland among these cattle, and all the evidence there, as expressed by breeders and shown in the cattle, is that it is a dual-purpose breed. The gencral type of Brown Swiss cattle is distinctly blocky, the points being full from breast to hind quarters, showing thickness and depth. Breeders in Switzerland regard the cattle on the higher mountains as of a somewhat lighter type than those of the lowlands. The head is rather

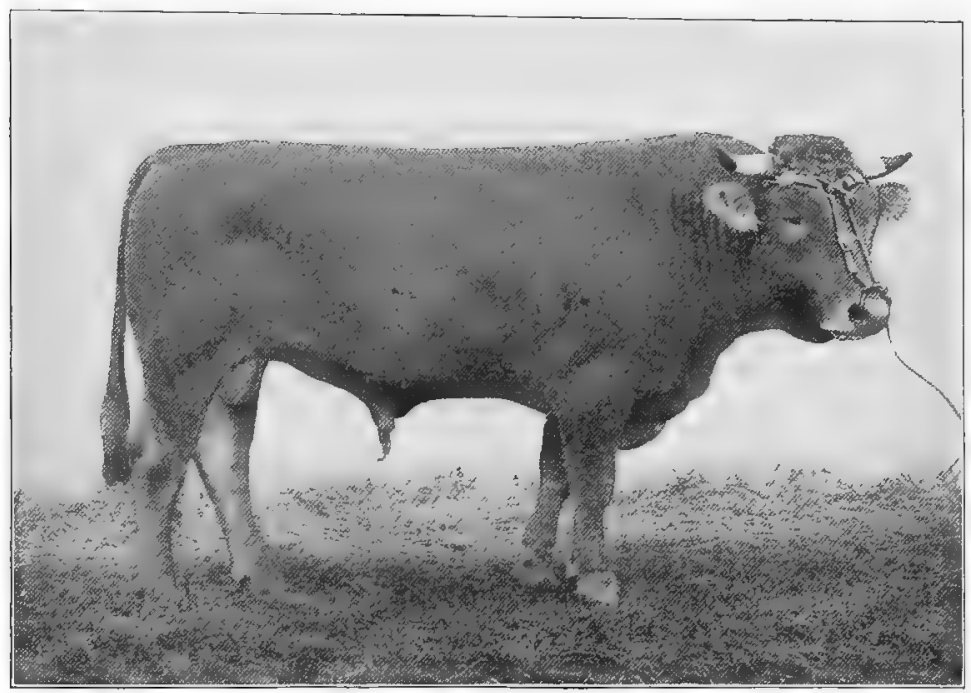

Fig. 206. Tell, fifth-prize Brown Swiss bull at Zug, Switzerland, I913. This bull scored 83.5 points. From photograph, by courtesy of Joseph Frey, secretary of Brown Swiss Cattle Association, Lucerne

heavy and, combining as it does a sizable horn and a fullness of the neck quite unknown with British breeds, impresses one as somewhat coarse. The neck is large and heavy in both sexes at all ages, the skin about the throatlatch and along the dewlap being strikingly abundant. The breast is broad and deep, and the shoulders rather heavy and prominent, not being well laid in. The body shows a great deal of feeding capacity, with plenty of depth; but the back is frequently slack back of the withers, and the fore ribs have scarcely enough spring for best conformation. The hind quarter is long, level, and broad at the rump, the thighs and twist 
incline to be distinctly beefy, and the legs are short and strong. The cows have large udders, frequently long, wide, and deep, with well-placed teats of convenient size. The milk veins and wells average medium in size, comparing fairly with dairy breeds. The quality, from the standpoint of an American, averages rather below medium, as is very commonly seen in the thick, none too elastic, deep-yellow skin, rather coarse hair, large joints, and heavy head, neck, and fore quarters. In temperament cattle of this breed are superior, being especially quiet and docile.

The color of the Brown Swiss, as indicated by the name, is brown, varying in shade. The color as approved by the Swiss breeders is given as follows ${ }^{1}$ :

The color of the animals of this race goes from dark brown and gray (the color of coffee and of chestnuts) to light brown and light gray. The opposite colors are mostly found among the animals of minor weight. At the present time the gray color prevails in all the different tints from light to dark. ... According to the different parts of the body the color is more or less pronounced. All the animals have a muzzle of the color of lead, with a lighter rim all around. The underlip, the interior of the ears, the interior part of the limbs, especially the fore limbs, the udder, and the escutcheon are also lighter than the rest of the body. Gencrally these cattle have a stripe more or less light or broad on their backs, going from the withers to the tail, but this line is sometimes broken.

At one time white spots occurred on Brown Swiss cattle, but since the middle of the nineteenth century animals with spots have been barred from exhibition unless the spots are on the lower part of the belly. The horns, which are comparatively short and curve forward and upward, have black tips. The hoofs are black and the tongue and muzzle are very dark.

The size of Brown Swiss cattle varies according to type, whether light or heavy. The Swiss Union of Cattle Breeders gives the following as average weights at maturity: bulls, I870 to 2090 pounds; cows, I 320 to I 430 pounds. E. M. Barton, in a pamphlet relative to his own herd, states that the average cow in a herd in milk weighs I 300 to I 400 pounds and I 500 fat. He also states that bulls in good condition weigh from I 700 to 2500 pounds. The latter weight, however, is rather exceptional, and mature bulls

1 The Bovine Breed of Switzerland. A pamphlet published about 1906 by the Swiss Union of Cattle Breeders. 
more commonly weigh from I 500 to 1800 pounds. The Brown Swiss Cattle Breeders' Association in the scale of points give no weight standards. It is thought by some that the two sexes more nearly approach each other in weight than with most breeds.

The Brown Swiss in crossing or grading will do very well where mated with stock lacking in vigor, for this breed is of superior vigor and hardiness. No doubt many grade dairy herds of Jersey or Guernsey character would have vigor restored by a Brown Swiss

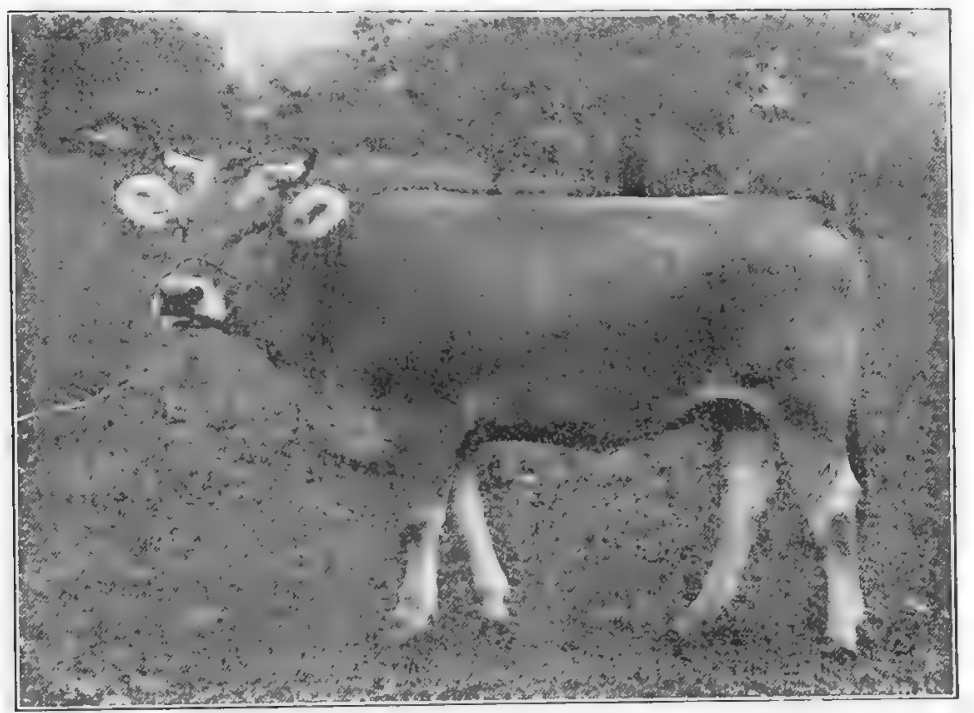

Fig. 207. Rosi, gold-medal Brown Swiss cow at Lucerne, Switzerland, I9I I. From photograph by Richard Oehler, Lucerne

cross, as well as a higher value from the butcher's point of view. At the Michigan Agricultural College Brown Swiss have been crossed on Red Polled, Jersey, and Holstein-Friesian grades, and in every case, says Professor R. S. Shaw, Swiss characteristics stand out prominently. Especial emphasis is given to the superiority of a carcass - the product of a Brown Swiss bull from a Red Polled cow - which weighed 1280 pounds as a yearling and dressed out $6 \mathrm{I}$ per cent.

The prepotency of Brown Swiss cattle is very marked, which naturally would be theigiase by considering the length of time in 
which they have been bred under uniform conditions. In the essential characteristics of color and general conformation, prepotency is very manifest.

The adaptability of the Brown Swiss to a wide range of conditions seems apparent. The native home of these cattle is in the mountains, where they thrive on rations that would not be regarded as satisfactory in America, and where they are distinctly hardy. The herds kept in the more sterile sections of the eastern United States seem to thrive equally well with those in the corn belt of the West. No doubt they have a special place in dairy sections, notably in the more elevated regions, where a rugged breed is

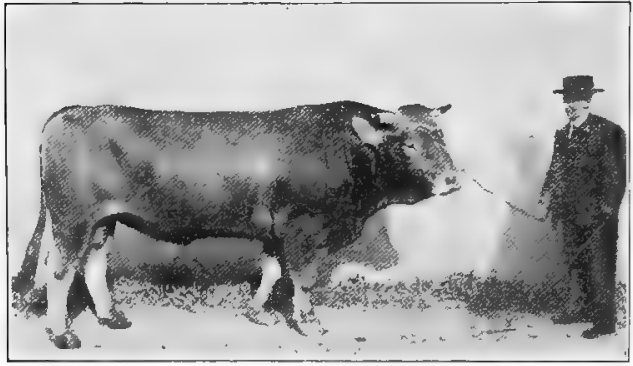

FIG. 208. Waldi, second-prize Brown Swiss bull at Lucerne, 1913. From photograph by the author desirable. From the profit point of view it is doubtful if they can compete satisfactorily with some of our other breeds in the fertile West.

The Brown Swiss cattle in milk production make a remarkably creditable showing. Numerous records of Swiss dairies show comparatively large production for these cows. F. H. Mason, as United States consul in Switzerland, reports that at Chem the 6000 cows supplying the Anglo-Swiss Condensed Milk Company yielded 53 I 5 pounds each. These cows were milked for an average of about nine months and were fed only grass and hay. The average annual production of 72 herds in Switzerland, as published from records gathered by the Swiss Union of Cattle Breeders, ${ }^{1}$ shows an average yield of 4985.8 kilos, or 10,969 pounds, with an average fat content of 3.88 per cent. The first recorded test of a Brown Swiss cow in America proved very sensational, for on this occasion the cow Brienz I68, in November, I89 $\mathrm{I}$, at the American Fat-Stock Show, produced $8 \mathrm{I} .7$ pounds of milk per day for three days, which contained a total of 9.32 pounds fat. For many years this was one

1 The Bovine Breeds of Switzerland, p. 20. 
of the notable milk and butter-fat records. In the Pan-American dairy test in I gor the 5 Brown Swiss cows stood third in total milk solids produced, eighth in net profit in fat, and fourth in pounds of milk produced, being surpassed in milk yield by the HolsteinFriesian, Ayrshire, and Shorthorn respectively. In net profit in the six-months test the highest rank attained by a Brown Swiss

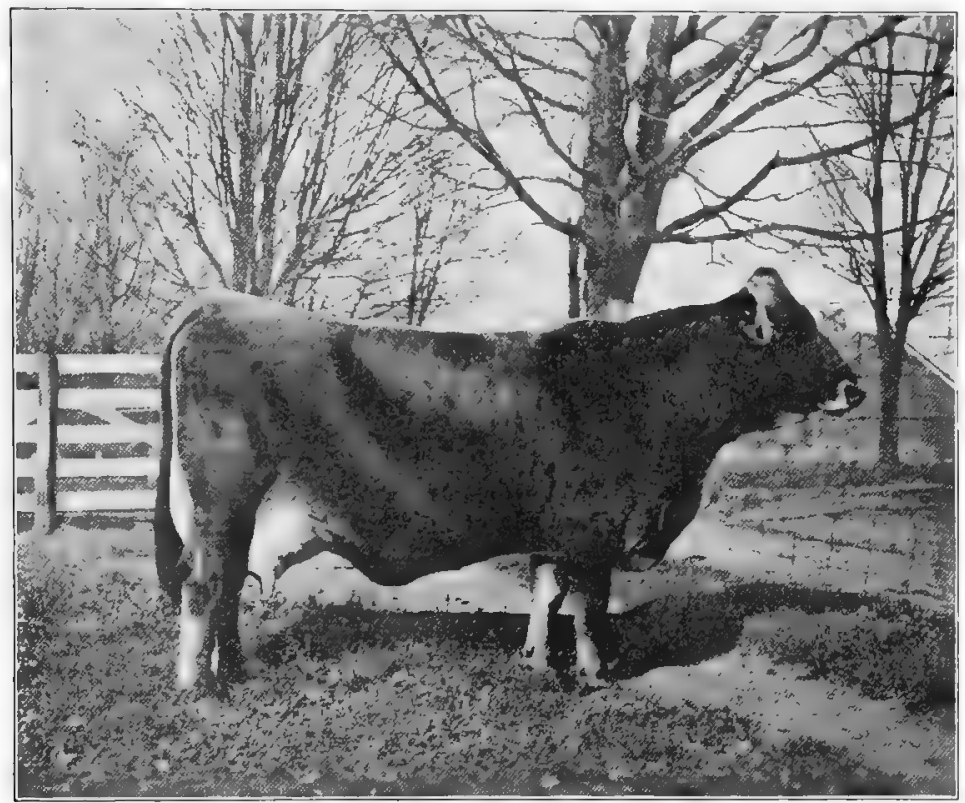

Fig. 209. College Bravura 2d, 2577, a Brown Swiss cow owned by the Michigan Agricultural College. She has an official record of $19,460.6$ pounds of milk and 798.16 pounds of fat, surpassing any other cow of the breed. From photograph, by courtesy of Michigan Agricultural College

among 50 head of ten breeds was nineteenth, the cow Bell $\mathrm{T}$. showing a net profit of $\$ 4 \mathrm{I} .23$ compared with $\$ 59.2 \mathrm{I}$ for the cow in first place, a Guernsey, Mary Marshall. At the Louisiana Purchase Exposition in 1904, in the dairy-cattle test the Brown Swiss averaged 42.2 pounds of milk daily, containing I. 6 pound fat, compared with 33.77 pounds milk and 1.20 pound fat at the PanAmerican dairy test. The Louisiana Purchase cattle were, however, quite superior individuals to those in the Pan-American test. 
The Register of Production of Brown Swiss cattle was established in the year Igr $r$. "If the test commences with a cow the day she is two years and six months old, or previous to that time, she shall produce not less than 6000 pounds. For each day the animal is over two years and six months old at the beginning of the test, 2.35 pounds of milk shall be added to the required amount. This ratio shall apply until the animal is six years old, vihen it will have

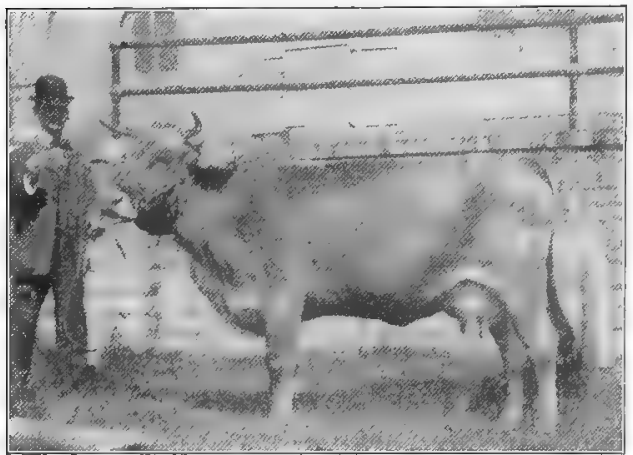

FIG. 2 10. McAlpine, a prize-winning Brown Swiss cow owned by the late E. M. Barton, Hinsdale, Illinois. From photograph by the author reached 9000, which shall be the required amount for all mature cows." In butter fat 222 pounds is the standard for the cow two and one-half years old, with an addition of .09 pound of fat daily until she is six, when 337 pounds becomes the standard for all mature cows. There are five age classes for tested cows: two, three, four, five, and mature. Bulls are in two classes: A, with two accepted daughters from different dams, each bull scaling at least 80 points; and B, without being scaled but with four accepted daughters from different dams. The following are the ten most notable records in the Register of Production, to January I, I9I8:

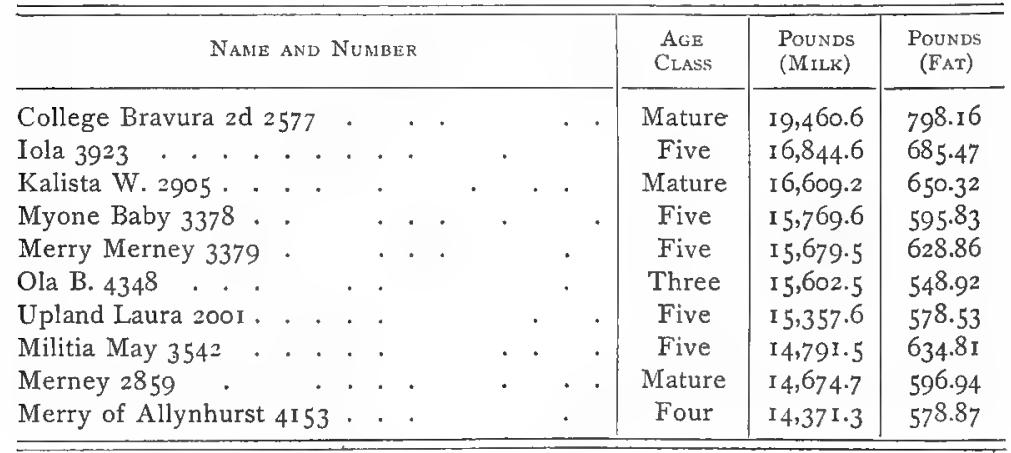


The largest two-year record in milk was $10,464.3$ pounds by Betty of Allynhurst 4539, and the largest yield of butter fat 454.24 by Scallotta K. 3993. Ninety-four cows and heifers averaged IO,805.4 pounds of milk and 43I.9I pounds of fat.

Brown Swiss cattle as beef producers rank well in Switzerland and produce an excellent class of meat. Brown Swiss veal is of superior quality when well fattened. As seen in the Swiss markets, the carcasses show more waste than occurs with the better-fed carcasses in England or the United States. Weights of 400 to 600 pounds at four to six months old are given as common, and the steers dress out 55 to 60 per cent. But very few fat Brown Swiss cattle have been seen in America. Profẹssor R. S. Shaw reports on a two-year steer at the Michigan Agricultural College which had a live weight of 1589 pounds and

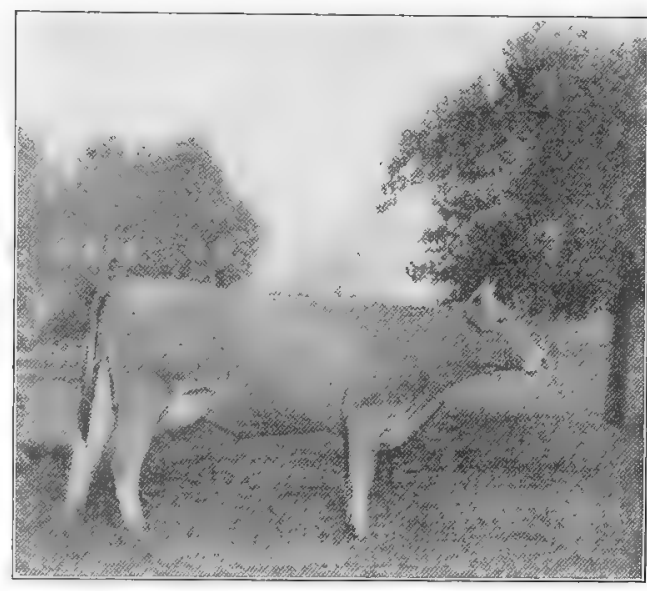

FIG. 2Ir. A prize-winning Brown Swiss heifer owned by I. Burgi \& Son, Arth, Switzerland. From photograph by the author dressed 60.6 per cent.

Two yearlings weighing 940 and 980 pounds each dressed respectively 57.07 and 58.67 per cent. Regarding the yearlings Professor Shaw says": "The hides were unusually thick and heavy, and the bones large and joints prominent. One of the most striking features noticed was the great depth of natural flesh covering the entire region of the back, and the massive development of the hind quarters. The steers were three and four inches wider at the thurl than at the hook points." It is not likely that cattle of this type will ever become popular in the American beef-cattle market.

The distribution of Brown Swiss cattle is rather widespread, especially in eastern Europe. Prior to the World War extensive

1 Breedgrgitizagatfentanusarie 25, 1905. 
exportations had been made from Switzerland into Hungary and Italy, where these cattle were regarded with favor. They are also found in western Austria, Germany, France, Spain, the United States, Canada, Mexico, Brazil, and Japan. About fifteen thousand Brown Swiss cattle have been registered in the United States, these being mostly east of the Mississippi River, the better-known herds being in New York, Ohio, Illinois, and Wisconsin.

The promotion of Brown Swiss cattle in Switzerland is under the supervision of the Brown Swiss Cattle Breeders' Association, with headquarters at Lucerne. This association has published several herdbooks. There is also the Union of the Associations of Cattle Raisers of the Swiss Race. In this country the Brown Swiss Cattle Breeders' Association of America, organized in I880, cares for the promotion of the breed and attends to registrations and transfers. Up to I 9 I 9 there have been published five herdbooks, showing a registration of 6 I 99 bulls and 8899 cows. 


\section{CHAPTER XLII}

\section{THE DEVON}

The native home of the Devon breed of cattle is in southwestern England, in the counties of Devon and Somerset. Devon is washed by the sea on its north and south borders, while Somerset also borders the Bristol Channel on the north. The section contains much rough and hilly land, reaching a height of even 2000 feet, and is better suited to grazing than tillage, though the soil is fertile. In the southern part the climate is mild and balmy, being well suited to outdoor life for cattle the year round.

The origin of the Devon is prehistoric. It has been assumed that the breed is descended from Bos longifrons, the smaller type of aboriginal cattle in Britain. The earliest English records show the prevalence of cattle in Devon of a color and type indicative of the modern breed. The early British writers on live stock testify to its ancient character.

The early improvers of the Devon were Francis Quartly and his brothers William and Henry, and John Tanner Davy and his brother William. Besides these John Tanner Davy gives much credit to Merson and Michael Thorn of North Molton, Tapp and Buckingham of Twitchen, Mogridge and Halses of Molland, and others, who maintained the high character of their herds when breeders generally, on account of high prices, were selling their best stock for slaughter and keeping poor cattle in reserve.

Francis Quartly is generally conceded to have accomplished for the Devon what the Collings did for the Shorthorn. He lived at Champson-in-Molland near South Molton, where his father in I776 began to breed Devons. The father died in I793, and Francis at once began active work as a breeder on his own responsibility. The cattle of Devon were deteriorating for the reason already given. He recognized this, and not only refused to sell but sought out and purchased the choicest individuals possible, thus developing the best herd of his time. From his 
herd, which was sold on his retirement in 1836 , has descended the most distinguished Devon blood. William Quartly also had a herd until 18I6, when he sold it to his eldest brother Henry, who continued breeding until his death in 1840 . Neither Francis nor William were ever married, but Henry was, and left two sons, James and John, who succeeded him. They also became great breeders, as did John's son Henry, later on. 'The Quartly family lived in North Devon, not far from Somerset County.

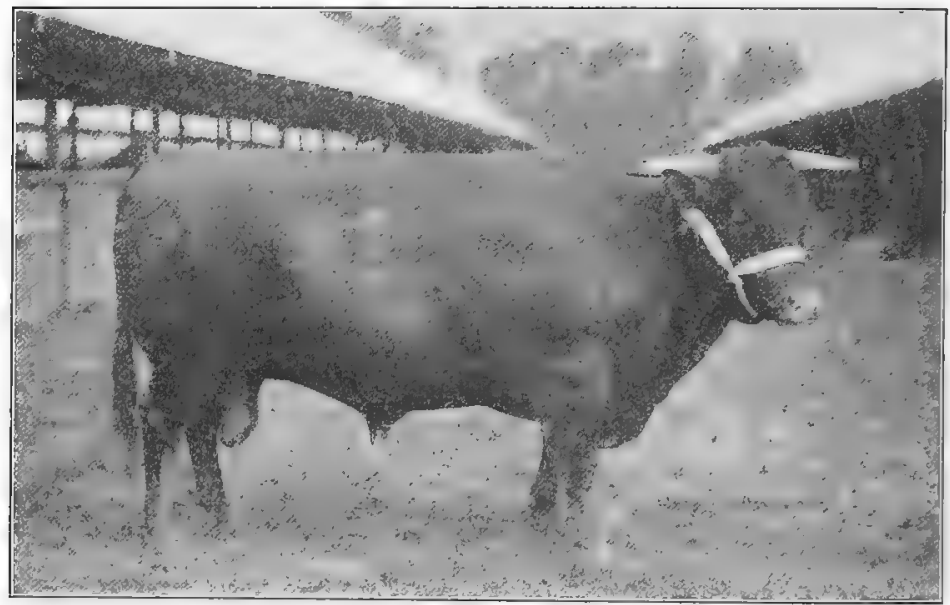

FrG. 212. Joker (4792), a Devon bull of the beef type and a noted prize-winner in England. Owned by Abraham Trible, Halsdon, Holsworthy, North Devon. From photograph, by courtesy of the late L. P. Sisson

John Tanner Davy was a son of John Davy, a Devon breeder, who was born about I 706 and died at Rose Ash, South Molton, North Devon, in I790, leaving a choice herd to two sons, John T. and Villiam. John produced a celebrated herd and won many prizes. Numerous famous Devons descend from his herd. He died in 1852 and was succeeded by his son, Colonel Davy, the founder of the Devon herdbook. This son, who died in 1887, aged fifty-nine, was during his prime the most distinguished student and promoter of Devons in. England. He not only founded the herdbook but contributed much to Devon literature and publicity respecting the merits of the breed. 
The introduction of the Devon to America doubtless dates back to colonial times, and perhaps these were the first real purebred cattle to reach our shores. The port of Plymouth, from which the early colonists and the Harflow'r sailed, is on the south shore of Devon, and the vessel Churity', which sailed in I623, is thought to have had Devon cattle on board. Devons were imported in 1800 to Massachusetts, and in I805 General Eaton took some to Otsego County, New York. In I 8 I 7 the first purebred registered Devons brought to the United States came over in the brig Margaretta and were landed at Baltimore. These were a present from Mr. Coke (later Earl of Leicester) of Holkham, England, to Robert Patterson of Baltimore, and consisted of six two-year-old heifers and a bull named Taurus. These became foundation animals in the "American Devon Record." Other importations were later made by the Patterson family, and most of the early American Devons are descended from the stock of this family. From I825 to I850 and later many Devons were imported into the Atlantic coast states and Canada.

Characteristics of the Devon. The Devon is not easily confounded with other breeds, owing to its individuality. The head is lean and shapely and, with the female, is crowned by a pair of slender horns that are "long, spreading, and gracefully turned up, of a waxy color, tipped with a darker shade." The bull's horns grow at right angles from the head or are slightly elevated, are stout and waxy at the base, and have dark tips. The neck is neat in its attachment to head and body and shows considerable refinement. The body of the Devon is compact of form and usually carries a well-sprung and deep rib, with strong heart girth. The lcgs are small and show more refinement than is the case with some other breeds. In fact, typical Devons have often been referred to as deerlike in character, owing to the natural grace and refinement of the breed. The color of the Devon is usually a bright red, from which they have been in times past nicknamed "Rubies." The shade varies from light to dark. White is not admissible excepting about the udder of the cow or in front of the scrotum of the male, and not beyond the navel with either or outside of the flanks or elsewhere on the body. The hair about the eyes and muzzle should be of a creamy tint and the muzzle flesh-colored. 
The size of the Devon shows considerable variation. Naturally Devons are of the smaller class as seen in beef-cattle classes in America, and this is one objection that has been raised here against the breed, together with the fact that the steers will not

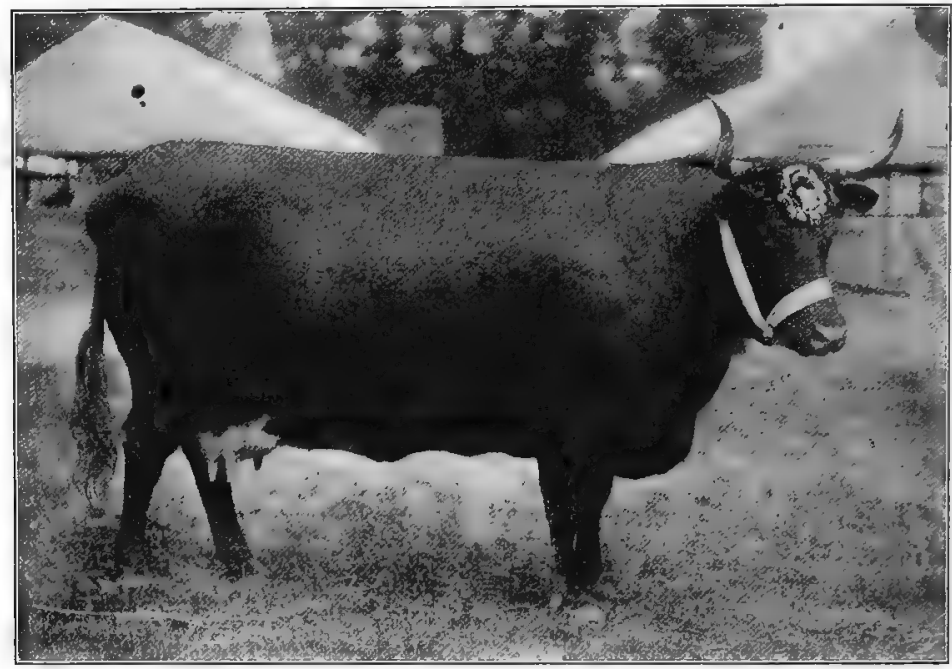

FIG. 213. Fern of Halsden, champion Devon cow at the show of the Royal Agricultural Society of England in 1904. This shows the beefy type of Devon. From photograph, by courtesy of William Cooper \& Nephews, England

fatten as rapidly as some of the other kinds. Mature cows, according to Sinclair, weigh from I 300 to I 500 pounds and bulls from I 500 to 2100 .

Two types of Devons essentially exist. Those in north Devon have always been of the smaller form, and beef production has been emphasized with them. In south Devon, where the breed is known also as the South Devon or South Hams, the cattle average larger, are lighter colored, tend to be coarser, and are more productive of milk, due, it is said, to the blood of Guernsey cattle. These two types have been more or less intermingled, but the best breeders of to-day advocate adherence to type. Professor Robert Wallace, in his work on the "Farm Live Stock of Great Britain," gives a third (a special Somerset type), found in north Devon. These cattle are larger, have a more droopy horn, 
and are coarser than the north Devon type, due to the better soil and climate of Somerset. As exhibited in America, the breed shows at a distinct disadvantage, for in the same show ring the beefy type may and does compete with the dual-purpose type. Western breeders appear to favor the north Devon style, while Eastern breeders lay emphasis on the dairy value of the breed, as does, in fact, the Devon cattle association.

The Devon as a butcher's beast does not attain the high weights of the common beef breeds nor does it fatten-as rapidly as some, but kills out extremely well, with small bone and moderate offal, producing the best of beef, fine of grain and of superior quality. Devons in the past have made a good record at the British fat-stock shows, often winning high honors. This applies in particular to the beef type of north Devon. The modern breeders of that section agree that to increase the size will injure the quality and therefore refuse to do so. Sinclair notes one English Devon breeder, whose specialty is steer breeding, who reckons that the weight of a fat Devon steer a little under three years old should be about 800 pounds. In I 89 I the first-prize Devon steer at the Smithfield Club Show, London, "not exceeding two years old," was five hundred and fifty-eight days old and had a live weight of 964 pounds.

Devons as milk producers rank very well. New England farmers formerly kept Devon grades, or pure-breds, from which they often secured fair yields. The milk is rich in fat, comparing favorably with that of the Jersey. The breed is essentially unknown in competitive dairy tests in this country. In the "American Devon Record" are numerous examples showing that many cows of the breed are ample dairy producers. E. C. Bliss states that his fullgrown cows yield an average of 300 pounds of butter a year. J. W. Collins writes: "I have one cow, Lucky 3784, that has produced $2 \frac{1}{2}$ pounds of butter per day for weeks, and I have frequently had others that have made $2 \frac{1}{4}$ to $2 \frac{1}{2}$ pounds per day." Wallace states that as a breed for milk production "it has been and still is inferior. The cows give but a smail quantity of milk and tend to go dry early." Alvord, who knew the breed well, states that some families bred and selected for dairy purposes have made fair milk records, single animals producing 40 and even 50 pounds a day ${ }_{\text {Digitized by Microsofte }}$ 
The Devon in crossing or grading has seen much service in the eastern United States. Owing to its long, pure inheritance the breed characteristics are usually strongly transmitted. Devon bulls on grade cows will produce a superior class of beef and rich milk.

The Devon as a grazing beast has always ranked high. In its native home many steers are grass fed and receive but little grain.

Devon oxen have long ranked very high. In New England and the eastern United States, when oxen were more extensively used than to-day, the Devon was a favorite sort. Years ago in New England one might

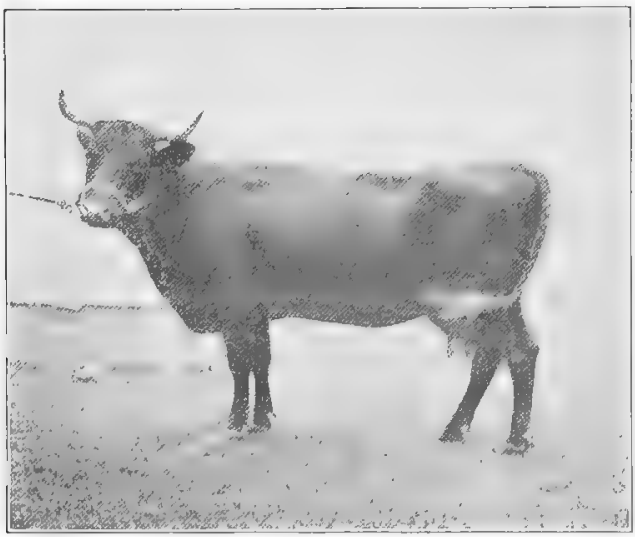

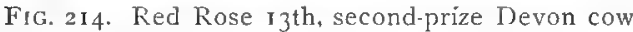
at the New York State Fair in 1916. This Devon is of the dairy type. Owned by W. H. Neal, Meredith, New Hampshire. From photograph by the author have seen many fine yokes of grade Devon oxen that were highly valued for intelligent and active draft service on the hill farms. No cattle are more light and active of foot for this purpose.

The distribution of Devons is almost worldwide, although the breed is not nearly so popular to-day as it has been. There are some herds in England outside of the Devon district, mainly in the south section, in Ireland, the United States, Canada, New South Wales, Tasmania, New Zealand, Queensland, Mexico, the West Indies, and South Africa. Devons in a general way have been distributed all over the United States, but are not in large numbers in any state. Ohio, Pennsylvania, New York, and New England are the foremost sections in Devon breeding in America. The breed seems quite adaptable either to the rougher grazing regions or to the more fertile, low-lying countries.

Organizations to promote Devon interests exist in England and America. The first Devon herdbook was published by Colonel Davy in I $85 \mathrm{I}$, who subsequently published seven more volumes, 
the last in I88I. About I880 the Devon Cattle 13reeders' Society was organized in England, and the herdbook publication was transferred to it about I 884 by Messrs. Hawkes and Risdon, who had purchased the rights from Colonel Davy in 1883. Forty-one volumes of the Devon herdbook have been published between I 85 I and I9I8. About I890 the South Devon Herdbook Society was organized, publishing its first volume soon after in I89I, since which time numerous volumes have been published up to I9I8. In the United States an "American Devon Herdbook" was first published in I863, four other volumes following, the last in I 879 . The "American Devon Record" was first published in I 881 by James Buckingham of Zanesville, Ohio. Later this record became the official register of the American Devon Cattle Breeders' Association. This organization has long been asleep, and the last volume of the herdbook that the author can locate was number seven, published in $\mathbf{1} 903$.

The popularity of the Devon in America at the present time is very low. For a breed with such an old and creditable history it is a remarkable thing that it should have come to such a subordinate place among well-known breeds in America. But few Devons are seen at the fairs outside of New England, while at the large live-stock shows and state fairs of the Middle West, classes are not provided for them, so little interest is shown by the few persons engaged in breeding them. At the Louisiana Purchase Exposition at St. Louis in I904 - the greatest American cattle show in history up to that time - the Devon exhibit was represented by two small herds and hardly produced a comment by the live-stock press. 
Digitized by Microsofte 


\section{PART III. SHEEP}

\section{CHAPTER XLIII}

\section{THE MERINO, OR FINE-WOOL TYPE OF SHEEP}

The Merino involves several families, and all sheep of this group are known as fine wools, producing the finest of fiber used in the woolen trade.

The general conformation of the Merino as commonly seen may be compared to the dairy cow. The body lacks fullness of chest, breadth of back, and general thickness all through, the leg of mutton is not thick and full, and the neck and legs tend to be long. A muscular development of the entire body prevails rather than smoothness and heavy fleshing. The wool is somewhat short of staple, is thick over the entire body, and is remarkably fine in quality. An oily secretion, commonly known as yolk, ${ }^{1}$ found on all sheep, exudes from glands at the base of the wool fiber and gradually passes up the wool to the tip. Some sheep possess much more yolk than others, notably Merinos of the A type with heavy folds. This yolk accumulates dust and dirt on the exterior of the fleece, forming a dark, dirty covering. There are exceptions, however, with the smooth-bodied Merinos, some showing but little external yolk.

Three classes or types of Merino sheep are recognized to-day by men who are familiar with this breed. The first attempt at classification occurred early in the nineties, when at the World's Columbian Exposition at Chicago the Merinos were placed in three classes, - namely, A, B, and C, _ based on the amount of folds or wrinkles shown, especially on the neck, body, and hind quarters. Since this time the Merinos at the Ohio State Fair, which is

1 The word "yolk" is used by the best authorities in referring to the natural oil of the fleece, but the words "grease" or "oil" are also made frequent use of among American breeders. 
the great American Merino show, have been given these three classes, and at the more important shows of the breed a classification of this sort is provided. These classes may be briefly described as follows:

The A type Merino represents the distinctly Spanish or American sort, with heavy folds at the neck and over the body and hind quarters. One is impressed with the surplus of skin over

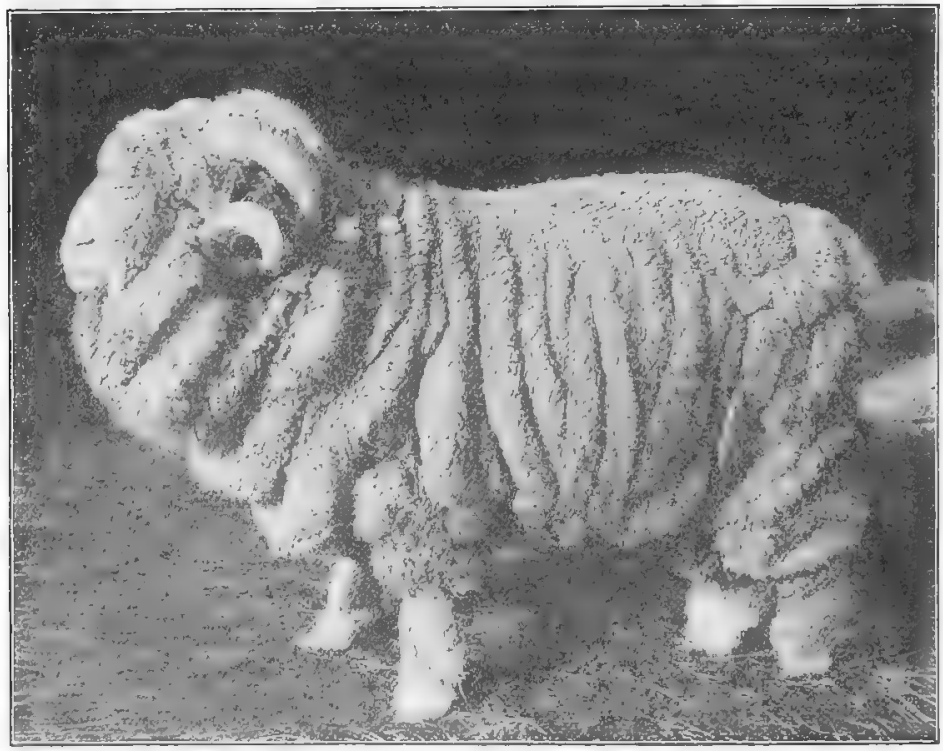

Fig. 215. A fine example of an A type Merino. Note the extreme number of folds which cover the entire body. From photograph, by courtesy of the Aational Stockman and Farmer

the entire body, but more especially at the neck, breast, flanks, rump, and thighs. The wool is short, approximately an inch and a half long, is very fine, and weighs heary in its unwashed condition, due to a large per cent of yolk. This is the lightestweighing Merino, one hundred pounds being a fairly good weight for the females. This type is discussed in detail in Chapter XLIV, on the American Merino.

The $B$ type Merino is characterized by a smoother body, with fewer folds, especially over the back and ribs, although those on 
the neck, breast, and hind quarters should be pronounced, though lighter than in the A type. The fleece also is somewhat longer, easily surpassing an inch and a half, and contains less yolk than A. The B type usually has somewhat more scale and carries more natural flesh and some less weight of fleece than $\mathrm{A}$.

The $C$ type Merino has a smooth body, with no folds unless to a slight extent at the neck or breast. A model example should be free of all folds. The Delaines and plain-bodied Rambouillets represent this type. These have a fleece with less yolk and weight than $B$, though with increased length of staple. The C type also should be somewhat larger than $\mathrm{B}$ and approach nearer to true mutton type, while the fleece retains its typical fine-wool character. Individuals of this type have been exhibited at our fairs that in mutton form compared well with the best of Southdowns or Shropshires. This type is discussed in detail in Chapter XLV, on the Delaine Merino.

The breeding of the three types of Merinos is conducted in some of the best American flocks. 'One man may keep sheep of each type and use them to improve or maintain his flock or to satisfy demands of different customers. Type A rams offer a medium for imparting to flocks in which $\mathrm{B}$ type ewes predominate a denser, heavier-weighing fleece, though naturally lowering the mutton value. The $B$ type meets with a special demand as a medium for producing more scale and substance in the A type and increasing density and weight of fleece in the $\mathrm{C}$ type. The demand for the $\mathrm{A}$ type is very restricted and is steadily growing more so, but the $\mathrm{B}$ type, judiciously bred, meets a real need in the Merino world.

The line of demarkation in Merino type is not entirely agreed to among breeders. In the great shows of the different types at the Ohio State Fair it is not uncommon to see sheep of two types in one class; as, for example, $\mathrm{A}$ and $\mathrm{B}$, or B and $\mathrm{C}$. In such cases the judge, as a rule, ignores the sheep that is off type. Merino lambs often show a strong marking of folds, so that they might naturally be placed in one class, but with a year or so of growth these folds are outgrown to some extent, thereby justifying reclassification as another type. In recent years some Merino breeders who have been careful students have discussed different 
types of fleece, assuming there was a distinct A, B, and C staple on each type. Further, it has been assumed that A type Merinos sometimes carry B type fleeces, or that one will find on a B type ram a $\mathrm{C}$ type fleece. Consequently, in an effort to draw sharp lines between the types, some breeders emphasize the necessity of uniformity of type of body, folds, and fleece in each class.

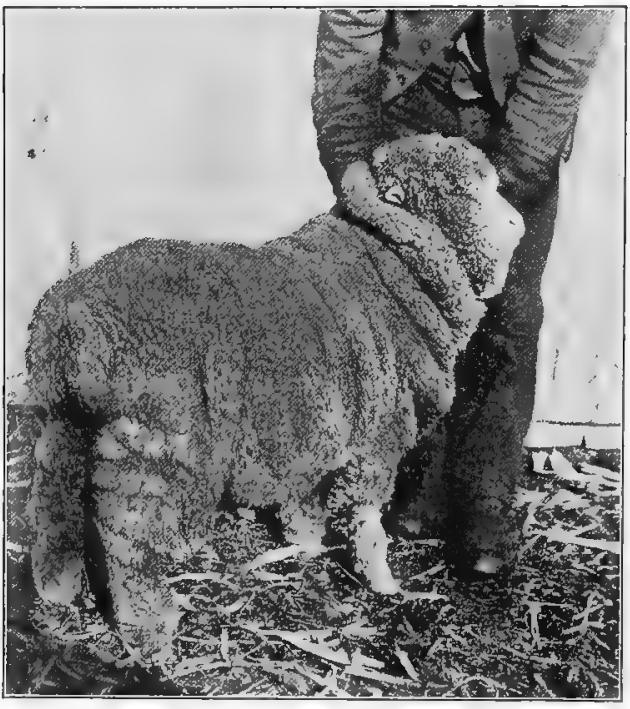

FIG. 2I6. The B type Merino. Note the prevalence of folds at each end, but with comparative freedom from those on the body. This ewe, owned by G. E. Helser, West La Fayette, Ohio, weighed I 40 pounds and sheared a fleece weighing 25 pounds.

From photograph, by courtesy of Mr. Helser

The more general characteristics of the Merino may be set forth in the following discussion of the various parts of the animal. The head of the Merino should be short, broad at the muzzle, with large nostrils. A nose short and inclined to be wrinkled and somewhat thick, and of Roman type with rams, is preferred. There should also be ample width between large, clear, mild eyes, with a prominent forehead. The ears should be fine and short, be actively carried, and have a covering of silky hair. The horns, which occur on the males, as a rule interfere with the natural action and movement of ear. The horns on mature rams are large, are rather angular at the base, and have a spiral turn backward, then downward, around forward, and up, forming a more or less corkscrew curve. The horn when fully developed usually shows one and one-half turn; with some the tip of horn turns upward, with others it turns down. The head of the male, as a whole, should show sex character in a strong degree. The neck of the Merino should be of moderate length, neither thin nor thick, and 
heavy, but should be moderately muscled and blended smoothly to head and shoulders. The neck of the male should be more heavily muscled, showing distinct masculinity, with some indication of throatiness, or folds, according to type. The shoulders should be smooth and incline well into the back and not be too prominent. A prominence of shoulder is a very common feature with this type. The withers are frequently sharp and high, although a neat, close, nicely rounded, smooth top at this point is desirable, especially with the ewes. More prominence of withers is desired with rams, and some of the greatest sires have been very strong in this respect. The breast and chest should exhibit considerable depth, with a reasonable thickness in proportion. A common feature of the Merino is to have too peaked a breast, lacking thickness at the chest. The crops and fore flank, which show material deficiency in many cases, should be reasonably well filled out. The front legs of the Merino are characteristically crooked at the knees. As one looks at them from in front the knees fairly touch together, while the toes spread out. Sometimes the wool on the legs causes deception in this respect, but as a rule the legs are crooked at the knees, due primarily to a narrow chest. The pastemis should be springy, of medium length, and should be strong and support the sheep in proper form. Merino feet naturally incline to grow long at the toes and thus throw the weight on the heel, giving a poor and weak support. No breed of sheep shows poorer feet than the Merino. The back of the Merino varies according to the type. Those of type A usually are narrower and flatter of rib. In any case a strongly supported, fairly wide back with level, wide loin is essential. The back is very commonly depressed or shows a marked dip or break, a feature to which breeders do not give enough attention. The body should have a rather strongly rounded-out form, the ribs showing a fair arch and considerable length, thus furnishing ample feeding and breeding capacity. A blocky, short body is not so typical as one with more roundness and of moderate length. The hind flanks should show ample depth. The hips of the Merino should be smooth, and not too prominent.

The rump of the Merino, in correct form, is long, level, and wide, but a common defect of specimens of this breed, no matter what the type, is a peaked, droopy rump. 
The leg of mutton varies with the type. The nearer one approaches type $\mathrm{C}$ the more filled out in all its parts the hind quarter becomes. Nevertheless, even in type A the thigh should be strong and reasonably full, though not so thick or full in twist as with types $\mathrm{B}$ and $\mathrm{C}$. Considering that type $\mathrm{C}$ emphasizes mutton value, the leg of mutton here should be strong of development.

The hind logs should be muscular and straight, whether viewed from either rear or one side, the shank bones fine and short, the pasterns strong and well carried, and the toes neatly placed. Instead of that the hind legs in all classes of Merinos strongly

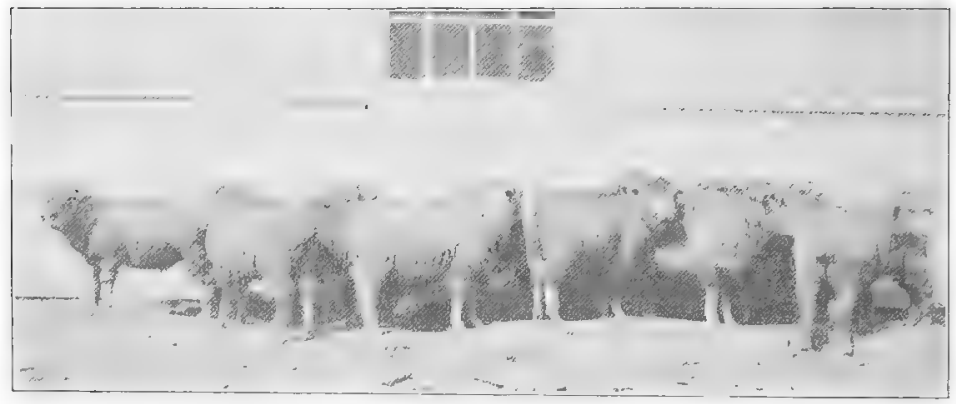

FIG.217. A group of C type Merinos at the Ohio Agricultural Experiment Station.

Note the absence of folds. From photograph, by courtesy of the Ohio Station

tend to crooked or sickle hocks, the points nearly if not quite touching, and the toes turning out. Often the legs below the hocks are carried too much under the body, the shanks being too slanting. Owing to lack of attention the toes may grow too long, and thus the foot becomes thrown out of proper placing and the entire leg is affected. Careful trimming of the toes will easily remedy this. Sheep of the A type tend to have bad feet and should be carefully selected and mated, with the view of avoiding this trouble as much as possible.

The skin of the Merino should be firm and of a bright pink color and free of all scurfiness. No class of sheep, as a rule, shows such excellent, high-class color of skin as generally prevails with this breed. The smoothness of skin varies, that of $\mathrm{A}$ having notable folds (as has been explained on page 482), 
$\mathrm{B}$ having fewer, and $\mathrm{C}$ hardly any at all. The skin of type $\mathrm{A}$, according to some Merino authorities, is also thicker, mellower, and more porous than that of $\mathrm{C}$, which is thin and more delicate than the other.

The fleshing of the Merino of A type is limited in degree, being really a very muscular body with almost no fat. A smoother, better-fleshed body occurs with type B, while $C$ in ideal form is well rounded out, smooth in all the parts, neatly covered with flesh without superfluous fat.

The wool of the Merino, as has been stated, represents the finest grade produced. This varies in diameter and length, according to the breed or breeding, and is discussed to some extent under Merino families proper. In all cases, however, the fleece should cover the body densely, and the fibers be very fine, uniform in diameter, and carry considerable crimp. The yolk shoukd be sufficiently abundant to keep the fleece in superior condition at all times, indicating a healthy condition of skin and body. This yolk exposed to the sun turns darker in color than when shaded in the fleece and so adds to the dirty external appearance. A white yolk is said to turn darker than the more yellow sort. A fleece of a light creamy yellow, being neither white nor egg-yellow, is preferred. A very heavy exudation of yolk is objected to as not only causing unnecessary shrinkage of fleece in washing but also as being something of a drain on the animal's vitality. Present-day wool buyers discriminate against the heavy-shrinking, old-fashioned, fine-wool fleeces. To some extent it is probable that the amount of yolk may be affected by the food. Professor J. A. Craig states that lambs fed grain from birth invariably sheared heavier fleeces than those that had grain only during the latter three months of feeding: The wool should be naturally bright and lustrous, with a clean white color. 


\section{CHAPTER XLIV}

\section{THE AMERICAN MERINO ${ }^{1}$}

The Spanish Merino as the parent of the American Merino should receive a brief consideration introductory to this breed.

The native home of the Merino is in Spain, in southern Europe. The country is quite variable in character, the interior consisting of plains as well as long ranges of mountains, some of which are many thousand feet high. There are numerous rivers and deep valleys. The climate is generally dry and mild in the lowlands, and oranges, citrons, olives, and grapes are commonly produced; while on the plains and mountain sides are extensive pastures, where in times past large flocks have grazed. On the lower, richer lands the sheep are larger than on the drier, poorer soils or more elevated mountains.

The origin of Merino sheep is merely.speculative. In I 809 Livingston stated ${ }^{2}$ that many supposed Merinos were originally introduced from the coast of Barbary in Africa by Don Pedro IV of Spain. It has been assumed by others that the parent stock existed in Spain prior to the Christian Era, and that this was improved by the introduction of Tarentine sheep from Tarento, southern Italy. Lucius Columella, a famous Latin writer on agriculture, who wrote during the first century, is said to have introduced these A.D. 4I, and he also imported African rams. The people of Carthage and Phøenicia in northern Africa brought fine-wooled sheep to Spain, as did probably other invaders also. The sheep of Spain in those days were of various colors, - white, black, red or tawny, the red fiber being of the finest quality.

Sheep husbandry in Spain was for centuries an important industry. Historians at the beginning of the Christian Era, especially

1 The word "Merino" is Spanish, signifying governor of a small province and likewise one who has care of the pastures or cattle in general. He receives his appointment from the king, is a person of rank, and is termed "Merino Mayor."

${ }^{2}$ Robert R. Livingston, Essay on Sheep. Albany (N. Y.), 1809. 
Columella, directed attention to the superior fleece of the sheep of Spain. As early as the eighth century, when the Saracens took possession of Spain, they established many mechanical arts, among which was the woolen industry, and the Spanish sheep furnished the fiber. The statement has been made that in Seville no less than sixteen thousand looms existed in the thirteenth century. Some of the Spanish cloths were highly esteemed for their quality. By the fifteenth century, however, the Moors had been largely driven from Spain, and the woolen industry fell into decay and finally became unimportant. Later an attempt was made to revive the manufacture of fine fabrics from wool, but without success. Undoubtedly these early sheep were much inferior to those we know to-day in America, but without question they produced finer wool than did other European sheep. The modern improvement of the Merino is distinctly an American accomplishment. The Spanish government opposed most of the first exportations, and many sheep were smuggled from the country.

Two great groups of Spanish sheep existed in times past. One, known as Estantes, or stationary, consisted of flocks of the coarser-wooled types, and these remained permanently on many of the hill farms. The other group, termed Transhumantes, or migratory, consisted of flocks that were driven during the spring season, under the care of competent shepherds, across country and into the mountains over a grazing region, to be returned in the fall to their original home. The Transhumantes were divided into two classes - the Leonese and Sorian. The former was the more numerous and was the more highly esteemed. Most of the sheep brought to America from Spain belonged to the Transhumantes group.

The annual Merino drives in Spain were most important affairs. Youatt ${ }^{1}$ writes as follows :

The Leonese after having been cantoned during the winter on the north bank of the Guadiana, in Estremadura, begin their march about the fifteenth of April in divisions of two or three thousand. They pass the Tagus at Almares, and direct their course towards Trecasas, Alfaro, and L'Epinar, where they are shorn. This operation having been performed, they recommence their

1 William Youatt, Sheep : Breeds, Management, and Diseases, p. I 50 . London, 1837. See also M. Tessier, Instruction sur les Bêtes à Laine. Paris, 18 1o. 
travels towards the kingdom of Leon. Some halt on the Sierra (ridge of the mountains) which separates Old from New Castile, but others pursue their route to the pastures of Cervera, near Aquilar del Campo. Here they graze until the end of September, when they commence their return to Estremadura. The Sorian sheep, having passed the winter on the confines of Estremadura, Andalusia, and New Castile, begin their route about the same time. They pass the Tagus at Talavera and approach Madrid; thence they proceed to Soria, where a portion of them are distributed over the neighboring mountains, while the others cross the Ebro in order to proceed to Navarre and the Pyrenees.

It is said that these periodical journeys can be traced back to the middle of the fourteenth century, when a tribunal was established for their regulation. 'The number of these migratory sheep seventy-five years ago was placed at ten millions, and they were divided into flocks, each in care of a Mayoral, or chief shepherd.

The important provincial flocks of Spain, from which the best Merino blood was exported, were represented on about a half-dozen estates, there being mainly, according to Livingston, about thirty thousand on each estate. These flocks have been described by various early writers, notably Consul William Jarvis, who, at the opening of the eighteenth century, was familiar with the flocks in Spain, he being United States consul at Lisbon, Portugal, from which port thousands of Merinos were shipped. Jarvis not only exported Merinos to America but later became one of our great constructive breeders. The information concerning the early Spanish flocks is more or less obscure, often indefinite, and sometimes conflicting. The following is such evidence as can be presented of the groups or classes from which American importations were mainly drawn. In Spain these classes were more or less interbred, and the same applies to American flocks.

Paular Merinos. This family, which produced the largest and best fleeces, was originally owned by the Carthusian friars of Paular, on the borders of Andalusia, an agricultural class of monks who paid great attention to horses and sheep. This was probably one of the handsomest flocks of Spain, having close, compact, soft, and silky wool, with less surface yolk than most types. The Paulars were credited with enlargement behind the ears, with considerable throatiness, and their lambs had a coarse, hairy appearance at birth. William Jarvis imported many Paular sheep in I 810 and made a specialty of breeding this family. 
Aguirre Merinos had more wool about the face and legs than did the other families. The wool was more crimped than that of the Paulars and less so than that of the Negrettis, and was thick and soft. The Aguirres had short legs, round and broad bodies, and much loose skin, or folds. In a letter written to Consul Jarvis in December, I $8 \mathrm{I} 0$, the writer states that Cochran Johnson had "sent about three thousand Merinos, principally Aguirres, to New York."

\section{Negretti Merinos}

were the largest and strongest of the Transhumantes sheep of Spain. The wool was somewhat shorter and more open than that of the Paular and "inclined to double." Many Negrettis were wooled on the face and on the legs to the hoofs. All the loose-skinned sheep had heavy dewlaps. The rams possessed large horns.

Guadaloupe Merinos were heavier of bone

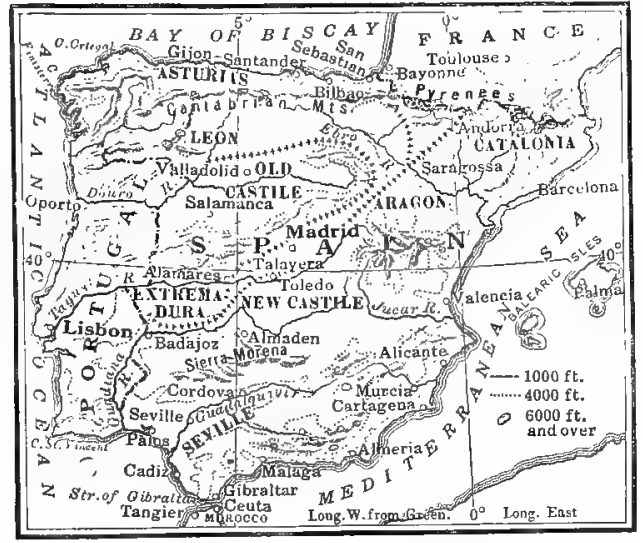

FIG. 218. A map of Spain, showing the provinces in which Merino breeding was important at the beginning of the nineteenth century. The chain marks indicate the routes that were followed by the Transhumantes flocks than the Negrettis and

were of much the same size, but were not so handsome, according to Jarvis, although Lasteyrie credits them with the most perfect form and says they are celebrated also for the quantity and quality of their wool. These sheep had numerous folds, and the wool was thick and crimped and more oily than the Negrettis.

Escurial Merinos were about as tall as the Paulars, but were slighter of frame. Their wool was crimped and not so thick as that of the Paular, and they had less wool on the legs and face. The skins of the Escurial sheep were not so loose as were those of the Negretti and Aguirre families. Another family, known as the Montarcos, very closely resembled the Escurials, but were not prime favorites for importation to America. 
Infantado Merinos were mainly bred by the Duke of Infantado. They were very superior sheep, and many of them were brought to America, notably by Charles Henry Hall. The horns on the rams came nearer to the sides of the head than did those on the Paulars and Negrettis. The Infantados of Atwood mated with Paulars resulted in a great improvement, and from this commingling of blood was derived the Atwood family of Merinos, long celebrated for superiority of fleece.

The reduction of Merino flocks in Spain became serious in I 809 with the invasion of that country by the French. The sheep on

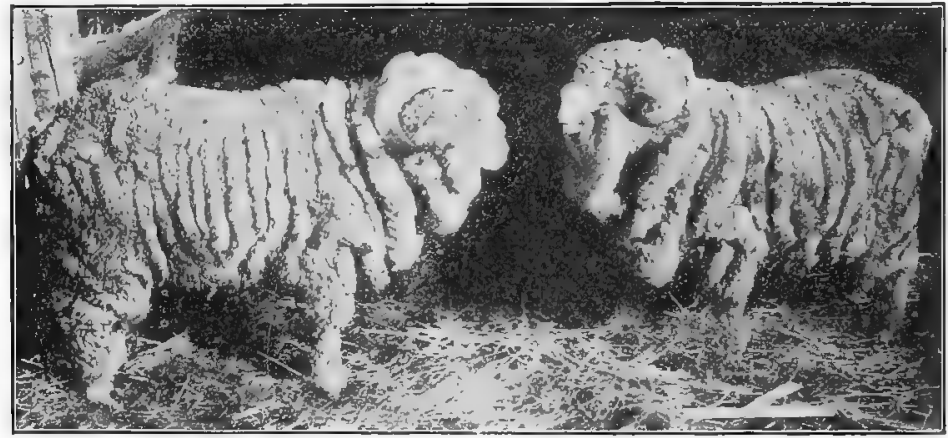

FIG. 2I9. Wooly Nose and White Nose, two American Merino rams owned by the late J. J. Deeds of Ohio. From photograph, by courtesy of the American Sheep Breeder

four estates were confiscated by the Spanish Council of State because the proprietors had joined the French, with the result that the flocks became sadly depleted. The Paulars, which had numbered 30,000 or 40,000, were reduced to 7500 head; the Negretti, that originally nearly equaled the Paulars in numbers, fell to 6000 ; the Montarcos, that at one time numbered 30,000, dropped to 4000; while the Aguirres decreased from 30,000 to 3000 head. Consul Jarvis estimated that IOO,OOO of the finest sheep in Spain were destroyed by the ravages of war, leaving only slightly over 20,000 .

The exportation of Merinos from Spain to other countries was of great importance, for with this the improvement of the Merino began. The Spaniards themselves not only did not attempt systematic improvement but eventually allowed the breed to deteriorate 
and essentially disappear. Sheep were exported from Spain and improved in their new homes, as indicated in the following examples :

Swedish Merinos. It is believed that the first of these sheep exported from Spain were taken by Mr. Alstroemer to Sweden in I 723, yet but little information seems available on this point.

Saxon Merinos. In 1765 the Elector of Saxony imported from Spain 92 rams and 128 ewes, these coming from the flocks of Count Negrette. Part of these were placed on a farm near Dresden and were later distributed to various farms, where they were carefully bred and did remarkably well. Youatt states that the wool of the Saxon Merino became finer and more serrated than its Spanish progenitor and so had an increased value. It has been claimed that the Saxon is the least hardy of the modern Merinos. The modern type of Saxon is essentially free of folds.

German, or Silesian, Merinos. The first attempt towards the establishment of this family was in 1768 by Herr Von Vinke, near Halle, who introduced some Saxon Merinos. Ten years later he secured pure Merinos from Spain and crossed them on the sheep in that section of Germany. In 1776 Frederick the Great became interested and imported 300 pure Merinos from Spain, but through disease and mismanagement these came to an unfortunate end. Later Von Vinke purchased Iooo pure Merinos under government commission, agricultural schools were established for the instruction of shepherds, and sheep husbandry was especially promoted. This resulted in establishing the German, or Silesian, family. Mr. J. G. Elsner is said to have written ${ }^{1}$ a history of some 300 flocks in Silesia which were based on the Negretti and Electoral families. Referring to these sheep in the flock of the Duke of Lichnowsky, about the year r800, located near Troppau, Silesia, he says that his type was Negretti-Infantado.

The wool was very strong, containing a large quantity of grease; the body, barrel shaped; the head well covered with wool, and folds around the neck; wool covering the limbs well down toward the extremities; the skin of a deep rose color - these are the main characteristics of the type. At that period sheep were esteemed valuable in proportion to the many folds they had on the neck and body, and that became the prevailing type in Moravia, Austrian and Prussian Silesia, and adjoining provinces.

1 Sheep Industry of the United States (I892), p. $3^{8} 3$. 
French Merinos, or Rambouillets, were imported from Spain to France in 1786 by government commission. This type is discussed by itself in Chapter XLVI.

English Merinos. About I 787, during the reign of George III, the "farmer king," a small flock of mixed Merinos was smuggled from Spain through Portugal and taken to England. These were inferior, so in I79I, at the request of the king, a select lot of Negretti shcep, consisting of four rams and thirty-six ewes, were

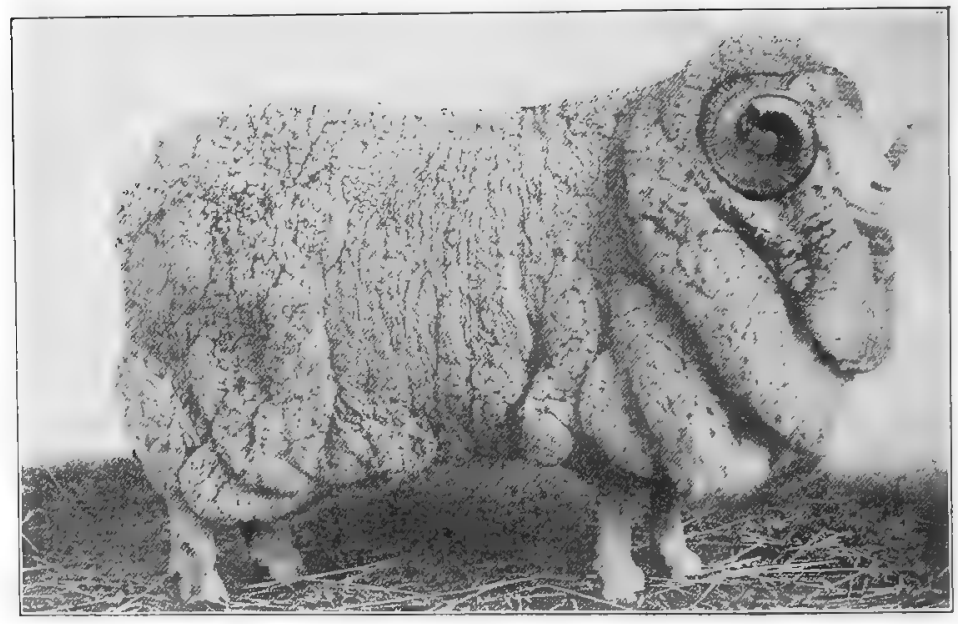

Frg. 220. A Wanganella ram sold in the annual ram sale at Sydney, New South Wales, in July, IgIS, for $\$ 13, \mathbf{1 2 5}$. This represents a very fashionable line of breeding in Australia. From photograph, by courtesy of the Americans Sheep Breeder

collected by one of the Spanish nobility and presented to the king. These arrived in England in good shape, but did poorly at first. Not being suited to the moist climate and rich pastures, they suffered much from disease and especially foot rot. They gradually became acclimated and thrived fairly well. A society was organized in I8I I to promote them, but the small size of this sheep and its inferior mutton quality caused British farmers gradually to give them up. At the present day there are no Merino flocks in En'gland.

The Australian Merino. Late in the eighteenth century a few Merinos had been taken to Cape of Good Hope, South Africa, 
from England. Later, in I797, these wcre taken to Sydney, New South Wales. Since that period Australia has become the greatest Merino-sheep country in the world. There these sheep thrive and produce a very superior grade of wool.

The introduction of the Merino to the United States probably occurred in I793. Mr. William Foster of Boston, Massachusetts, smuggled from Spain I ram and 2 ewes. These he presented to a friend, who, not realizing their value, used them for meat, though he later purchased a ram for $\$$ rooo at auction. In October, I80 I, Seth Adams, then of Dorchester, Massachusetts, imported a pair of Spanish Merinos which were conveyed through France to the seaboard. Later, in I807, Adams moved to Ohio, taking the first Merino sheep west of the Allegheny Mountains. In I8or M. Dupont de Nemours had 4 ram lambs shipped to America, 3 of which died at sea. The other, Don Carlos, was taken to Dupont's farm along the Hudson River in New York, where for nearly four years he was used on the flocks of that region. Later he was taken to Wilmington, Delaware, and the influence of his blood was extensively felt in New York, Delaware, Maryland, Pennsylvania, and Virginia. In I 802 Colonel David Humphreys imported from Spain 2I rams and 7o ewes to his home in Derby, Connecticut. In an interesting communication ${ }^{1}$ regarding this importation, made to the Massachusetts Society for Promoting Agriculture, Colonel Humphreys on August 25, I802, wrote as follows :

Convinced that this race of sheep, of which I believe not one has been brought to the United States until the importation by myself, might be introduced with great benefit to our country, I contracted with a person of the most respectable character, to deliver to me at Lisbon, one hundred, composed of twenty-five rams and seventy-five ewes, from one to two years old. They were conducted, with proper passports, across the country of Portugal by three Spanish shepherds, and escorted by a small guard of Portuguese soldiers. On the Ioth of April last they were embarked in the Tagus, on board the ship Persever ance, of 250 tons, Caleb Coggeshall, Master. In about fifty days twenty-one rams and seventy ewes were landed at Derby, in Connecticut; they having been shifted at New York on board of a sloop destined to that river. The nine which died were principally killed in consequence of bruises received by the violent rolling of the vessel on the banks of Newfoundland.

1 Bulletin of the National Association of Wool Manufacturers (September, 1905), p. $24 \mathrm{I}$. 
For this importation Colonel Humphreys was granted a gold medal. These Humphreys Merinos became important American foundation stock, to which a number of families directly trace. In the spring of 1802 Robert Livingston, minister to France, sent 4 head of Merinos of French breeding to New York. In I 805 Livingston returned to America and began breeding pure and grade Merinos. He was very successful in his breeding, and his

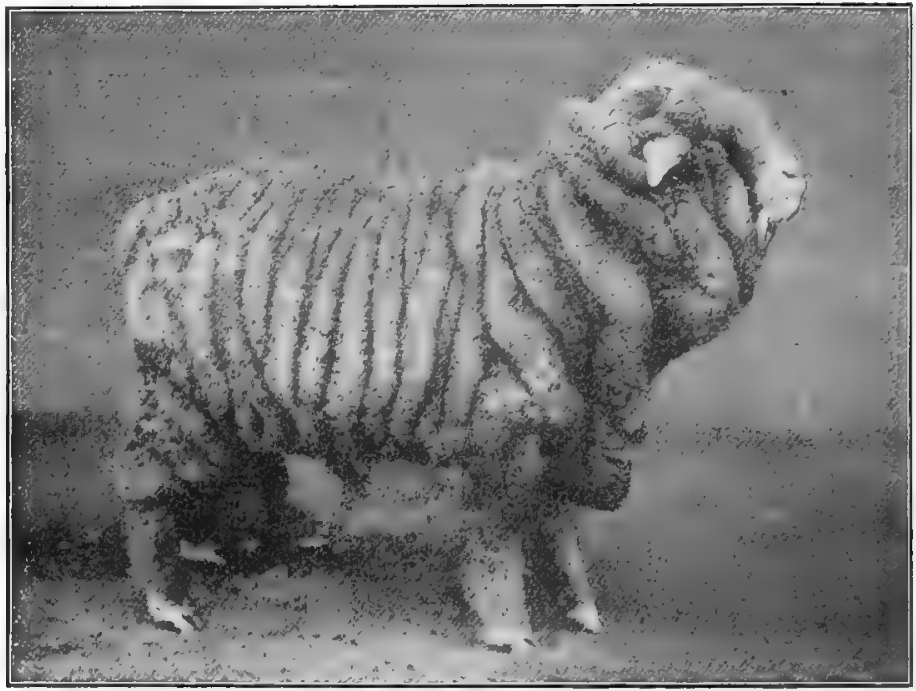

FIG. 22r. An American Merino ram shown at the Pan-American Exposition in 1901 by H. D. Jackson of Bridport, Vermont. This ram was first-prize yearling and the champion ram of the Class A type. From photograph, by courtesy of the National Stockman and Farmer

sheep attracted wide attention and brought high prices. He had great social influence and was a famous politician, so that he induced many to take up sheep husbandry. In I 809 he wrote an "Essay on Sheep," which was ordered printed by the New York legislature. Through his influence the legislature also passed an act in I 808 to encourage raising and breeding Merinos. In I809-I8IO William Jarvis of Vermont, United States consul at Lisbon, Portugal, shipped at different times a total of about 4000 Spanish Merinos, of which I 500 came to New York, Iooo to Boston and 
Newburyport, and the remainder mostly to Philadelphia, Baltimore, Alexandria, Richmond, and Norfolk. "Indeed," says Mr. Jarvis in his correspondence, "I was disposed to distribute these valuable animals to every state which would be likely to profit by their acquisition." All of these were sheep of superior breeding. They included Paulars, Aguirres, Escurials, Negrettis, and Montarcos. Jarvis placed 400 head on his farm in Vermont, in the care of Paular shepherds, and he writes: "I bred the respective flocks, separately till I8I6 and I8I7, when I mixed them together, and have so bred my Merinos ever since." The importations of Humphreys and Jarvis distributed Spanish Merinos widely over the Northeastern states, and from these our American Merinos received their important early start. Each of these men bred most successfully, greatly improving their flocks.

A mania for Merino sheep began to develop, and in I 8 ro both Livingston and Humphreys sold rams at $\$$ IOOO each, while the latter sold 2 ewes and 2 rams at $\$ 1500$ each. Then came a great craze for fine-wool sheep, and it is stated that in 1810 over 10,000 were shipped to America, - Cochran Johnston, Goold Brothers, and Charles O'Neil importing from Lisbon, and R. W. Meade and others from Cadiz. It is estimated that from April I, I8IO, to August 3I, I8II, there were brought to the United States 19,65 I Merino sheep.

The early foundation improvers of the Merino in America began with Adams and Humphreys, but during the middle of the century a few men rendered great service in the improvement of this sheep. Notable among these were four Vermont breeders; namely, William Jarvis (18II-I859), Weathersfield; Charles Rich of Shoreham (who began to breed in 1823 , and whose sons, John $T$. and Charles, continued the flock, while still later two grandsons - J. T. and Virtulan, sons of John T. - maintained the family prestige); Tyler Stickney (I 834-1882) of Stickney; and Edwin Hammond (1844-1870) of Middlebury, than whom none was more eminent among Merino flockmasters. Stephen Atwood, who established a flock in 1813 at Woodbury, Connecticut, and continued the work until 1867 , produced a famous line of breeding; while William R. Dickinson of Steuben-

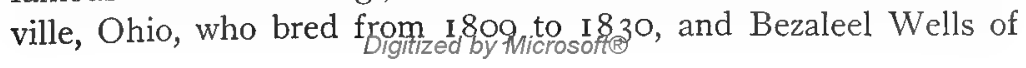


the same place and time did much for Merino improvement in the then new West. These men were among the really great pioneer breeders of America; they did much to improve the Merino, notably in character and quantity of fleece, and from their flocks descends the best blood of to-day.

Characteristics of the American Merino. This Merino is simply an improved form of the Spanish, characterized by heavy folds on the body, excepting over the back. The head is small, being

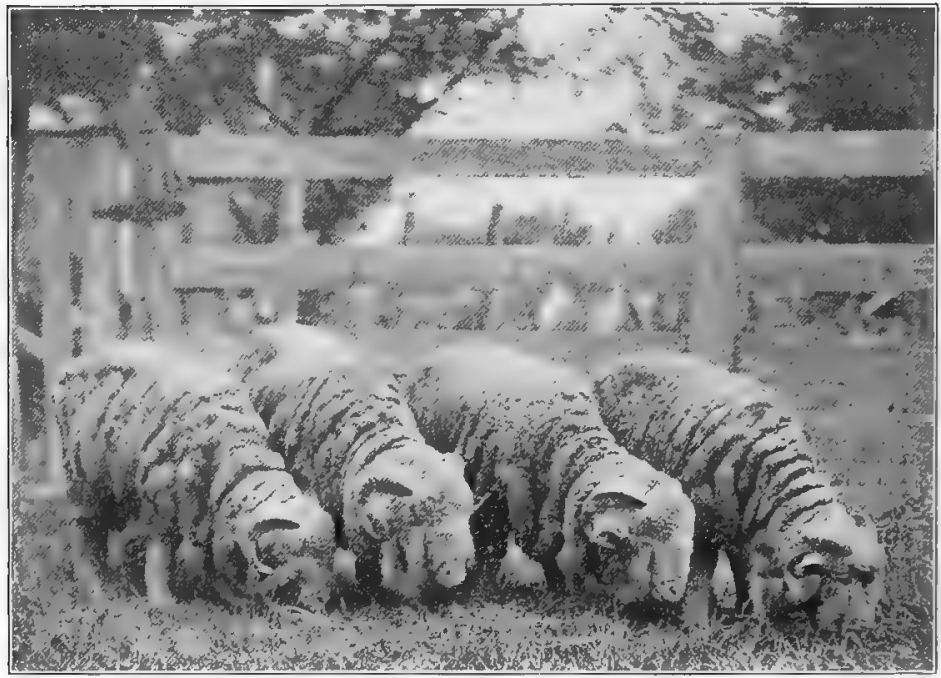

Fig. 222. A quartet of yearling American Merino rams bred by J. D. Irwin of Ohio. From photograph, by courtesy of Mr. Irwin

comparatively broad and short, the rams carrying heavy, spirally twisted horns, and the ewes being hornless. The lips and nostrils are white, and fine, silky white hairs surround the muzzle and extend part way up the nose. The ears are small and are covered with fine white hairs. Reddish or tan-colored hair is occasionally seen on the ears and nose of the Merino, which suggests a reversion to the same color of earlier days. Some Merino breeders have valued this color variation, while others have endeavored to breed it out. The neck is thin and tends to be long below and short above, the shoulders are very sloping, the chest narrow but 
deep, the withers thin, the back moderately narrow and often not well sustained, the rump frequently steep, the thighs thin, the legs small and fine. The skin is of the most attractive brightpink color, and in good specimens is in folds along the bridge of the nose and neck, about the breast, shoulders, lower part of the sides, and about the rump and thigh. There are usually no folds over the back and perhaps upper third of the sides, unless in a small degree. In 1892 an eminent breeder is thus quoted by Ezra Carman ${ }^{1}$ :

The prevailing fashion is to have from three to five heavy folds on the neck, not large on the upper side, but large on the under side; two or three short folds on and immediately back of each elbow or arm: fine, thick wrinkles running down the sides, but not extending over the back. Wrinkles across the hips, sometimes from the tail in the direction of the stifle, and sometimes at right angles with them, folds also around the tail to give it a wide appearance, and also folds across the thigh, with a deep flank.

The fleece covers the entire body and legs excepting in the armpits. The ears are covered with fine, silky hairs, and the head should be well wooled over excepting the lower end of the nose. The eyes are often hidden by the fleece covering the head. The outside of the fleece is of a dirty black color, caused by the accumulation of dust in the yolk which exudes to the end of the fiber, adding greatly to the unwashed weight. A considerable amount of oil is desirable in the fleece and especially is it important in the rams. A dry white fleece is an inferior wool, and rams with such fleeces are not usually the best stock getters. This yolk may be scoured off to show a shrinkage in weight of 65 to 75 per cent. American Merino wool is the finest produced, and the more folds on the body and the more crimped the fiber, the finer the staple. The one-year-old fleece of a mature sheep will show a length of about one and one-half to two inches. The temperament of the Merino is very lively, yet not necessarily inconsistent with docility, and no breed is more easily handled in flocks.

The modern type of Merino in Australia, where the A type has had great popularity, is of the B sort. The following is

1 Ezra Carman, H. A. Heath, and John Minto, Special Report on the History and Present Condition of the Sheep Industry of the United States. Washington, 1892 . 
abstracted from an interesting article by J. S. Dunnet, ${ }^{1}$ on "Australia's Popular Type of Merino," which is very suggestive to American students:

Leading flockmasters are agreed that the ram with a deep neck, connected right from the jaw to the brisket, with one fairly deep cross-fold about halfway along and a well-defined wrinkle at his breast, running up well in front of each forearm, thus forming a collar, is the best. This style of neck is easily shorn. It allows a growth of first-class wool, worth more per pound than that produced on any other part of the body. Such a neck should be long and deep on the underline, from brisket to jowl, and carried on a broad, strong, but short neck on top, closing up the wool as much as possible from the horns to the withers. Sheep of this class are mostly vigorous, and thrive well under hard conditions, especially if free from body-folds and wrinkles.

What is the argument in favor of neck-folds? It is that the greater the surface area of the skin covered with wool the heavier the clip. It should be closely watched, however, that the folds are not so close and deep as to cramp the wool and obscure the light and air, as the weakness would produce in the recesses a sweaty, fuzzy wool of a low type, which aims a blow at uniformity. A defect in many rams is that unless the necessary care has been exercised in breeding there is a tendency to hairiness on the neck, the thigh, and the breech. The wool on the neck-folds is generally of a higher grade than on the thigh or ham-folds, and therefore it is a better place to carry the extra wool. It is also claimed that ewes from such heavily thighed rams are apt to prove bad mothers, for their milk is short.

The reason why the corrugated, wrinkly sheep was discarded was that, by cultivating folds anywhere else on the body, excepting on the neck and behind the elbow, the breeders found they were sacrificing too much evenness of fleece for quality and losing far too much vigor. The best authorities are now agreed that one good neck-fold and a collar, or at the most two neck-folds with perhaps a wrinkle behind the elbow, are all that can be safely allowed. As the tendency of the standard Merino wool is to become stronger from the neck back to the breech this coarseness becomes greatly accentuated as the size and closeness of these folds increase.

For these reasons, as well as the tendency to weak constitution, excessive folds and wrinkles now find very few champions in Australia. A good forearm and a good thigh are generally associated with deep, heavy necks, but in no case should the sheep be so big in the thigh as not to provide space for the udder. It is remarkable that some sheep outgrow many of their wrinkles, although some of them remain with them to the end of the chapter.

The size of the American Merino naturally varies. Weights of I 30 pounds or upward for the rams and about roo pounds for the ewes are acceptable to breeders. The finer specimens of rams

${ }^{1}$ Breeders' Gazette, January I8, I9I I. 
often weigh I 50 pounds or more, and many excellent ewes weigh less than Ioo pounds. Among the great rams of a half century ago were many that weighed I IO to I 20 pounds. The weights of some of the early noted rams are as follows: Wooster*, Ioo pounds; Old Greasy*, I IO; Old Wrinkley*, I 30 ; Gold Drop*, I 40 ; California*, I 40 ; Eureka, I 50 ; Sweepstakcs*, I 50 ; Centennial, I65; Bismark, I 70. Those given a star (*) were used in

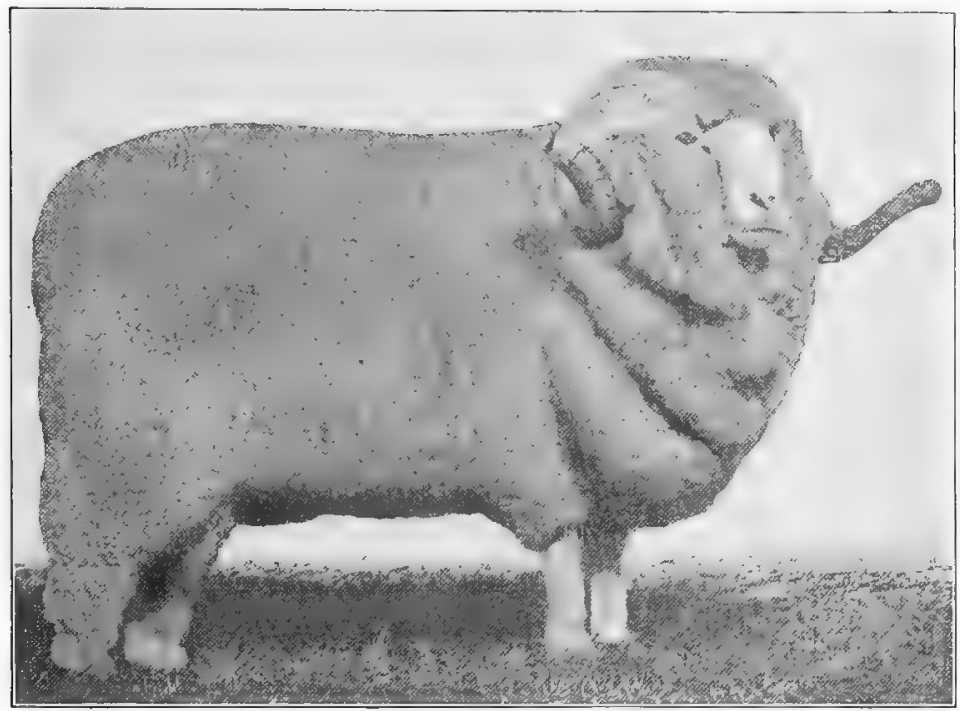

FIG. 223. Prince Charlie, a Merino ram bred by the estate of the late F. E. Body, Bundemar, Trangie, New South Wales, and sold in June, 1918 for $\$ 15,120$, the highest price on record paid for a sheep. This is the present-day popular type in Australia, though perhaps close to the $C$ type. From photograph, by courtesy of W. T. Ritch, Australian wool expert

the flock of Edwin Hammond. Of the present-day A type sheep but few rams exceed I 60 pounds and few ewes I 30 pounds, and then with a full-year weight of fleece.

The American Merino as a wool producer is famous. No class of sheep shears so strong, fine, and heavy a fleece. Many mature females shear from 12 to 15 pounds, and rams easily attain 20 pounds. The Vermont Merino Register gives thirty-six rams, three years old or over, whose fleeces averaged 3 I pounds I ounce each, one weighing 37 pigitind sy onigrasptes. A two-year-old ram, at 
the annual shearing of the Vermont Sheep Shearing Association, sheared 44 pounds 3 ounces. Records are given by the Vermont Register of fifty-four ewes, two years old and over, which sheared Io64 pounds 9 ounces (an average of I9 pounds I I ounces), the heaviest fleece weighing 25 pounds. In 1887 forty-six ewes averaged 2 I pounds 5 ounces. Gold Coin, perhaps the greatest Merino sire in recent history, bred and owned by S. M. Cleaver of Ohio, has produced three fleeces averaging about 36 pounds each for one year's growth, and one ewe in the Cleaver flock produced a fleece weighing 27 pounds 4 ounces. J. D. Irwin of Ohio is credited with producing a fleece which weighed 50 pounds, which is the heaviest of which the author has record.

The relationship of weight of Merino fleece to body is regarded as showing the true wool-producing capacity of the sheep. The thirty-six rams above referred to sheared 25.2 per cent wool to weight of carcass. Quoting from Vermont reports, in 1812 the best rams produced but about 6 per cent wool to weight of body. In 1844 the wool had increased to 15 per cent, from 1844 to I 865 to $2 \mathrm{I}$ per cent, and from then to I 880 up to 36 per cent, showing a remarkable improvement in wool production. In 1878 Vermont exhibited seventy-eight fleeces at the Paris Exposition, which showed 22 per cent wool to live weight, thirty of the best ones showing 25.2 per cent, the best six 30.I, and one up to 36.6 per cent. At a public shearing at Middlebury, Vermont, in I 882, fifty-four rams and ewes averaged 23.3 per cent unwashed wool to live weight.

The fineness of Merino fiber has doubtless improved since the introduction of this sheep to America. A set of measurements of twenty-four sheep given by Dr. Cutting showed an average diameter of fiber for rams and ewes of $\frac{1}{119} \overline{9}$ inch, the rams averaging $\frac{1}{1045}$ and the ewes $\frac{1}{13} 0 \overline{8}$, the finest ewe fiber being $\frac{1}{18} 81$ inch. Professor Hawkesworth gives interesting diameter measurements of Australian Merino wools, ${ }^{1}$ of which the following are from noted breeding animals: Bismark, $\frac{1}{154}$ inch ; Royal Simon, $\frac{1}{14 \overline{9} 2}$ inch; Young Golden Horn, $\frac{1}{12} \overline{1}$ inch; Jubilee II, $\frac{1}{10 \overline{6}}$ inch; Magic ("a pure Vermont") $\frac{1}{105}$ inch; Daisy (a champion Vermont ewe, bred in Australia, "showing a beautiful crimpy

1 Alfred Hawkesworth, Australian Sheep and Wool. Sydney, Igo6. 
formation throughout") $\frac{1}{11 \overline{9} \overline{0}}$ inch. Dr. William McMurtrie, who conducted extensive investigations on wool for the United States Department of Agriculture, gives the average diameter of Merino wool at $\frac{1}{1} \frac{1}{194}$ inch; the Southdown, $\frac{1}{8} \frac{1}{5}$; the Lincoln, $\frac{1}{6} \frac{1}{85}$; and the Cotswold, $\frac{1}{60} \overline{5}$ inch.

The crimp and elasticity of Merino wool is of the first class, and the crimp is especially characteristic of this fiber. This is shown in minute waves or serrations in the fiber. Hawkesworth states that in a superior Merino wool there are 24 to 30 crimps to the inch and sometimes more. In the English breeds the Southdown, which is the finest, contains I4 to I 8 crimps to the inch and the Lincoln 2 to 3. The crimp is an index to the elasticity of the fiber, its tensile strength, and quality. Hawkesworth says :

The Merino wool fiber possesses an elasticity of quite a peculiar kind altogether, that of crimpling. If you break a fiber of the true Merino in two pieces, they not only take their own natural form which they possessed before, but go far beyond that, inasmuch as the curves formed by this broken fiber shrink much closer than they were before. The closer the crimps of a marrowless fiber, and the greater the elasticity and extensibility, the more powerful will be its crimpling in the above-described wool fiber; science has not accounted for it yet, and all explanations concerning the same are only hypotheses. The quality of the Merino wool is greatly valued by the clothing manufacturers.

The mutton qualities of the American Merino are inferior. These sheep are muscular in type, carry but little fat, and when pure-bred are of but secondary importance as mutton.

The crossbred or grade Merino is not improved for wool production, but by mating with middle-wool blood a better mutton sheep is produced, though shearing less wool and being less hardy. Sheep of the Delaine type are more or less bred to the American type, thus reducing the folds but not seriously affecting the wool-producing value. In Australia for many years the American type was preferred to the smooth-bodied Merino, but in recent years the reverse is the case. In order, however, to maintain high-shearing qualities, studs of American Merinos must be maintained to thicken up the fleece of the smoother sort and keep up the weight. In New Zealand the Romney Marsh and Merino are crossed extensively, the crossbred withstanding, 
says Mr. George A. Brown, the bleak climate of southern New Zealand better than any other combination. Mr. Brown says that in Australia the most successful flocks of crossbred sheep he has seen were from crossing long-wool rams on Merino ewes. The half-bred ewes are culled as though pure-bred, and those selected for breeding are drafted into two lots, - one of long wool and the other of Merino type. Merino rams are then used on long-wool type ewes, and long-wool rams on Merino-type ewes. Every year this selection is followed out, and a very even type

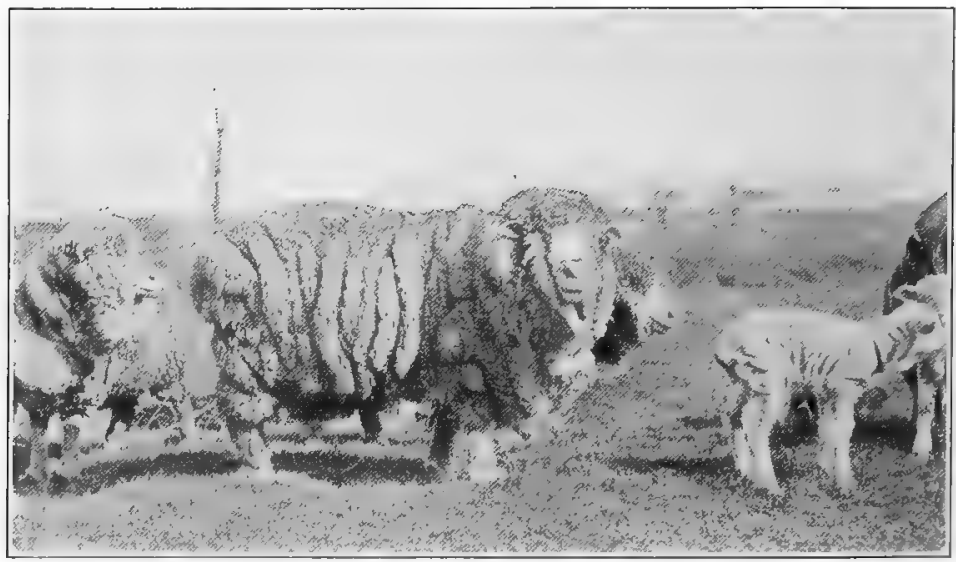

FIg. 224. A very choice American Merino ewe, Albert Peck 4I2, showing folds to the extreme. Her lamb stands in front of her. Owned by S. M. Cleaver, Delaware, Ohio. From photograph by the author

of sheep obtained. On large estates famous for crossbreds, studs of Merino and long-wool rams are kept for this kind of mating, which produces a class of sheep in favor with the butcher and the wool of which sells well. The Corriedale (see Chapter LXI), an Australian product, which since 1914 has been attracting some interest in the western United States, is the ultimate product of a crossing process based on Merino ewes and Lincoln or Leicester rams. The French have developed an important sort in France, known as the Dishley Merino, the result of using Leicester rams on Merino ewes. This line of breeding in France was established early in the nineteenth century. 
The adaptability of the American Merino is great. On the rough mountain pastures of New England and on the ranges of the Far West it seems equally at home, though a better fleece is produced in the northeast than in the southwest, the drier climate being more unfavorable. On the richer soils of the Middle West the Merino attains more size than in the Far West. The American Merino is extremely hardy and thrives on scanty pasture and in cold weather. Grazing in large flocks on the plains, it is specially adapted to the care of the shepherd. Larger flocks of Merinos may be kept together more successfully than is possible with the other breeds. Merinos are very active and rustle for themselves under unfavorable conditions. They also suffer less from animal parasites than the mutton breeds.

The breeding qualities of the American Merino are rather inferior. The lambs of the heavy-fleeced sort are often weak when dropped; the ewes are not very prolific and are not superior milkers. In 1903 the late C. S. Chapman, for years one of Ohio's best-known breeders, wrote:

For many years previous to 1880 my father and I were breeders of the heavy-folded Merinos, having ewes shearing $\mathrm{I} 8$ to 20 pounds each, and using rams shearing $3^{\circ}$ to 36 pounds each, from the flocks of the best breeders in Vermont. We had our sheep bred so strongly to the production of wool that we could not raise over 50 to 60 per cent of the lamb crop. They (the lambs) would be so feeble when dropped that in a majority of cases you could not tell for twenty-four hours whether they had vitality enough to live.

The Merinos, however, breed far longer than the average sheep and raise a fair percentage of lambs.

The early-maturing qualities of the American Merino are of secondary character, the lambs developing more slowly than the mutton breeds. To do well they should come early in spring, be given comfortable shelter and care, and be fed liberally to secure size and stamina. Many breeders have their ewes lamb in April and May, so that the lambs go into the hot weather of July and August, and between dry pastures, stomach worms, flies, and heat do not come on well and consequently mature very slowly.

Important subtypes or families of the Merino exist to-day. Among these are the Delaine and the Rambouillet, which are discussed separately and in some detail in special chapters. 
There are also several other families, which are now of less importance than formerly, notably the Atwood and Paular. The former was established by Stephen Atwood and later was especially promoted by Edwin Hammond. It was a type having many folds and was very popular from I 845 to I 895 . The Paular comes from Spanish stock imported by Andrew Cocks and later improved in the hands of Jehiel Beedle, Tyler Stickney, Erastus

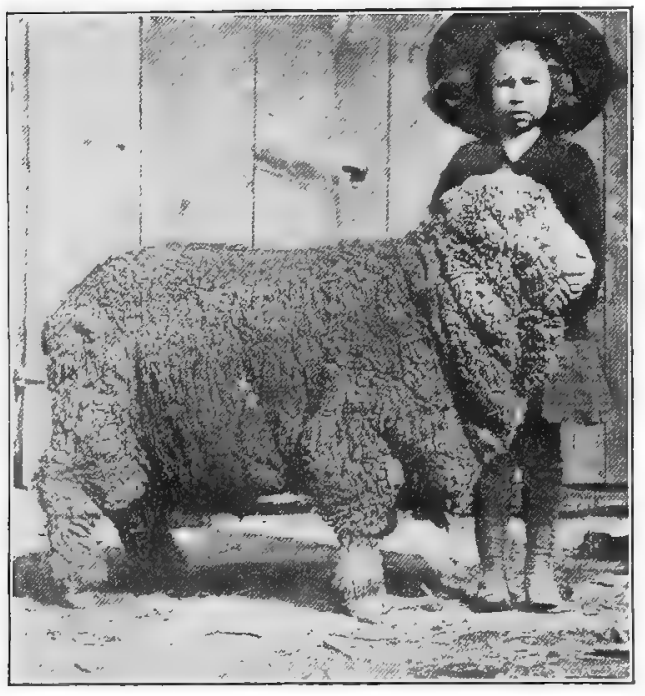

FIG. 225. A polled Merino ram of light B type. Polled rams are not common and are not in great demand. Bred by S. M. Cleaver, Delaware, Ohio. From photograph by the author Robinson, and the Rich family of Vermont. This also possessed many folds and a large amount of yolk in the fleece. Both the Atwood and Paular families are considered important strains of the American Merino stock. The Saxon Merino at one time had some popularity in America, especially so in New York, Pennsylvania, and Ohio, but this family has now comparatively few purebred representatives and these mainly in Pennsylvania. It deteriorated so in weight of fleece and constitution as to be generally discarded for a more robust sort.

Some famous Merino rams are worthy of note on account of their influence in improving the breed. Among these are the following: Bolivar, born in 1820 , died in 1834 , owned by W. R. Dickinson and others in Ohio; Consul, bred about 1838 by William Jarvis; Stickney's Consul, bred by Jarvis in I835; California, bred in I 858 by Victor Wright; Comet, bred in I86I by W. R. Sanford of Vermont and later taken to Ohio; Eureka, by Comet, and Kilpatrick, by Comet, both bred by Sanford; 
Wooster, bred in 1849 by Edwin Hammond, sired Young Matchless and Old Greasy; Gold Drop, bred in I86I by Edwin Hammond, who was several times offered \$IO,000 for him and who valued him at $\$ 25,000$; Stowell's Sweepstakes, bred in 1860 by Edwin Hammond; Golden Fleece, by Stowell's Sweepstakes, bred in 1862 , said to have earned his owner $\$ 20,000$; General Fremont, bred in $\mathbf{1} 865$ by Tyler Stickney; Bismark, owned by H. C. Burwell of Vermont, that was sweepstakes Merino in 1876 at the Centennial Exposition; Banker, bred in 1875 by V. Rich of Vermont; Rarus, bred in 1874 by George Hammond, winner in I880 of first prize as a sire at the International Sheep Show at Philadelphia ; Don Dudley, bred in I89I by J. P. Ray of New York; More Quality, bred in I 898 by R. D. Williamson of Ohio,

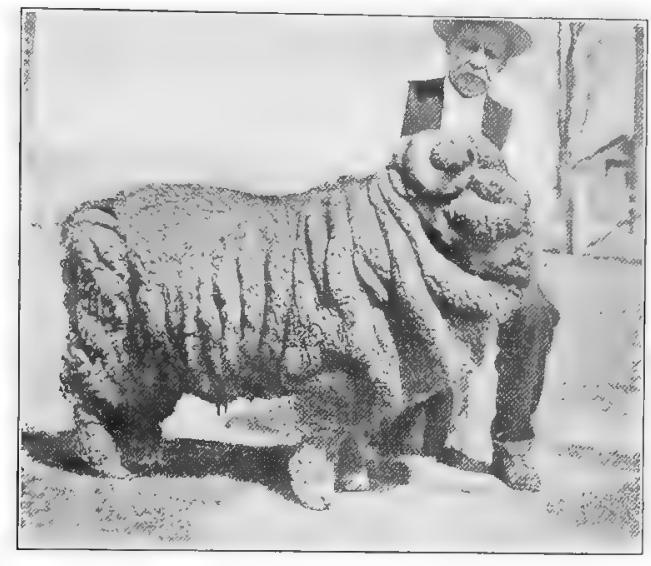

FIG. 226. Diamond Dust, sired by Gold Coin 30I3. This Merino ram is an unusually fine example of the A type. He is held by his breeder and owner, S. M. Cleaver of Delaware, Ohio. From photograph by the author premier Merino sire at the Louisiana Purchase Exposition in 1904; and Gold Coin 3013, bred by S. M. Cleaver of Ohio, distinguished as a great show individual and one of the most outstanding sires of recent years, his sons Gold Coin Jr. and Diamond Dust being remarkable examples of the A type. Gold Coin Jr. in 19I7, in a public shearing at the Ohio State University, yielded a fourteen-and-onehalf-months-old fleece weighing $47 \frac{3}{4}$ pounds.

A notable American Merino show-ring victory worthy of record here occurred in 1863, when George Campbell of Vermont exhibited 12 Vermont-bred Merinos at the International Exhibition at Hamburg, Germany. There were I 77 I sheep entered in competition, $9 \mathbf{I} 3$ being Merinos from every part of Europe, - 
France, Italy, Austria, Russia, and Germany being represented. The I 2 sheep shown by Mr. Campbell were the only ones from the United States, and these took three premiums, two firsts and one second, one first being for length of staple and one for weight of fleece. These prize sheep were later sold to Count Shen Thors of Silesia for $\$ 5000$. This was a great testimonial to the superiority of American Merinos.

Remarkable prices for Merino sheep have been paid on many occasions, dating back over a century. In 1808 James Wadsworth paid Colonel Humphreys \$1000 for a ram, and in March, I8IO, the latter sold 2 rams and 2 ewes to a Kentucky buyer for $\$ 6000$. This year (1810) there was a Merino mania on, and many sheep changed hands at phenomenal prices. On September 22, I810, an auction of 2I 5 Paular Merinos at F. B. Winthrop's, Horne's Neck, New York, brought $\$ 57,000$, an average of $\$ 265$ each. Many thousand Merinos were imported in I8IO and I8II and were largely sold at auction, bringing abnormally high prices. Then came a collapse, and Merinos were sold for a song. Again, in the early sixties, high prices prevailed, and many sheep sold at thousands of dollars each. In recent years the American Merino has not brought prices of special note in comparison with those of early days. In Australasia the highest prices paid for sheep of any kind have been paid for rams of this breed. The following prices are conversions from British guineas into American dollars. The ram President, one of the most noted animals in Australian flock history, sold for $\$ 8000$, and several of his sons sold for $\$ 5000$ each. The following rams also sold in Australia for the given prices : Sir Thomas, $\$ 3400$; Sir Thomas, 2d, \$2020; Golden Horn, \$2800; Golden Horn 2d, \$3150; Golden Tom, $\$ 2500$. At the annual stud-sheep sales at Sydney in July, I910, the ram Dandie Dinmont brought \$7812. In I9I 5 the Bundemar estate, Trangie, New South Wales, sold the two-year-old ram Lord Charles for $\$ 10,000$ to go to South Australia. This ram was bred in the famous Wanganella flock, from which many great stud sheep have come. It is said that the progeny of the sire of Lord Charles have already brought $\$ 50,000$. Five of his ewes brought $\$ 500$ each. As a culmination of high prices, at the Sydney ram sales in July, I9 I 8, a ram bred 
by Thomas Millear was sold to Lord Brothers, Queensland, for $\$$ I 2,600, a Wanganella ram brought $\$$ I 3, I 25 , while the Bundemar ram Prince Charlie, consigned by the F. E. Body estate of New South Wales, was sold for \$15, I 20 to Maurice Collins of South Australia, the highest price ever paid for a sheep up to this time. Such figures dwarf into insignificance the prices paid for even the better-class show sires of America.

The distribution of the Merino has been general all over the civilized world where sheep husbandry is followed at all. Australia, New Zealand, Germany, and the United States are the leading

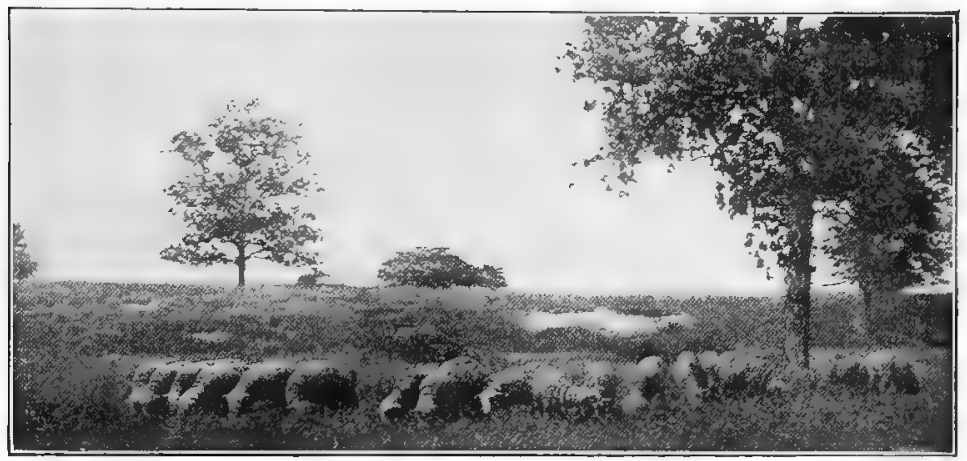

Fig. 227. A merican Merino ewes on blue-grass pasture. Owned by A. T. Gamber, Wakeman, Ohio. From photograph by the author

countries breeding sheep of the American Merino type. These sheep have been bred in all parts of the United States, but are not so popular as they were half a century ago, now that mutton is more in demand and wool has depreciated in value. Further, sheep of the American type, with numerous folds, are objected to on account of the difficulty in shearing, so that smooth-bodied Merinos are more popular than the American. In other words, it is not a utility sheep in the estimation of the present-day shepherd and so is steadily falling off in its clientage and importance of distribution. At the present time Ohio, Vermont, New York, Michigan, Wisconsin, and Missouri are the states containing the principal flocks of this class. Many Merinos have been exported from Vermont and Ohio to South Africa, Australia, New Zealand, Tasmania, and South America. 
The promotion of Merino sheep in times past has been vested in various organizations. The Vermont Merino Sheep Breeders' Association, organized in 1879 , published four volumes of flock books and registered over 300,000 sheep, mainly as flocks. The United States Merino Sheep Register was organized in Ohio in I 876 and published a volume of its flock book the same year. In I 882 the Ohio Spanish Merino Sheep Breeders' Association was organized at Columbus and published its first volume in I 885 . The National Record of the American Merino Sheep Register was organized in $188 \mathrm{I}$ in Wisconsin, the first volume of the flock book being published in I882. The New York Merino Sheep Breeders' Association was organized in I879 and the Michigan Merino Association in 1880 . In other states associations for recording Merino sheep also organized, but these have never become very active factors in the Merino industry. In I9O4 about nineteen Merino associations of different kinds, organized to register sheep, were said to be in existence. Most of them were feeble affairs, doing little or no business. In January, I906, a conference of Merino breeders, representing different registry associations, was held at Columbus, Ohio, for the purpose of consolidating into one strong organization. This resulted in the incorporation of the American and Delaine-Merino Record Association. By official action the Standard Delaine, the International Delaine, and the Improved Spanish Delaine associations merged into the new organization. In I908, at a conference held at the New York State Fair between representatives of the Vermont Merino Sheep Breeders' Association, the New York Merino Sheep Breeders' Association, and the Ohio Spanish Merino Sheep Breeders' Association, it was agreed to merge these, and in January, I909, at Columbus, Ohio, these three consolidated to form the Vermont, New York, and Ohio Merino Sheep Breeders' Association. This association was short-lived and in I9I6 consolidated with the American and Delaine-Merino Record Association, which at present is the strongest Merino organization in America. Eleven volumes of the flock book of this association have been published up to I9I9 and I 23,503 sheep recorded. 


\section{CHAPTER XLV}

\section{THE DELAINE MERINO}

The word "delaine" is derived from two French words, de, signifying "of" or "from," and laine, meaning "wool " or "woolen." The word in the woolen trade indicates a class of wool used to make fine, untwilled worsted dress goods. A combing process takes place, in which the fibers of wool are drawn parallel with each other and spun at full length in the yarn, thus securing the full strength of the fiber and making the strongest and most durable of woolen dress goods. This was due to an invention of $\mathrm{E}$. R. Mudge of Boston. Previous to this time only coarse wools were combed, fine wools being carded, a process inferior to combing.

The origin of the Delaine Merino traces back to the Humphreys importation of $\mathrm{I} 802$ and that of R. W. Meade, about $\mathrm{I} 820$. From these flocks certain selections were made and types gradually evolved, breeders generally keeping in mind both mutton and wool production. These types, or families, existed under several names. They have been established in the main by selection, and in each case a type of sheep has been sought that showed some distinctive mutton character and was free of folds. C type Merrinos are in fact true Delaines, and what is known as a light $\mathrm{B}$ type (that is, one with very slight development of folds) in the opinion of many would no doubt be regarded as a Delaine. There are, however, no remarkable differences between these families ; in fact, they are much alike.

The Dickinson Delaine was named after William R. Dickinson of Steubenville, Ohio, who was an extensive breeder and improver of Merinos. About 1807 or 1808 Thomas Rotch, a Quaker, moved from Connecticut to Stark County, Ohio, bringing with him a small flock of sheep, some of which were from the Humphreys importation. In $1809 \mathrm{Mr}$. Dickinson became the owner of some of these imported sheep of Mr. Rotch, which he kept by themselves and carefully bred. In I820 Adam Hildebrand became 
superintendent of Mr. Dickirson's farm, getting acquainted with the sheep thereon and the breeding operations. In his flock was a smooth-bodied ram named Bolivar that had very distinct individual merit and was a great prize winner at the shows. In I 830 the Dickinson flock was sold, and Hildebrand secured some of the best sheep. In I 823 James McDowell became an employee of Mr. Dickinson and later went into the service of Mr. Hildebrand. A part of his remuneration was to be "a selection of the best two ewe lambs bred by Mr. Dickinson, descended from the select Humphreys flock and sired by Bolivar." These lambs, according

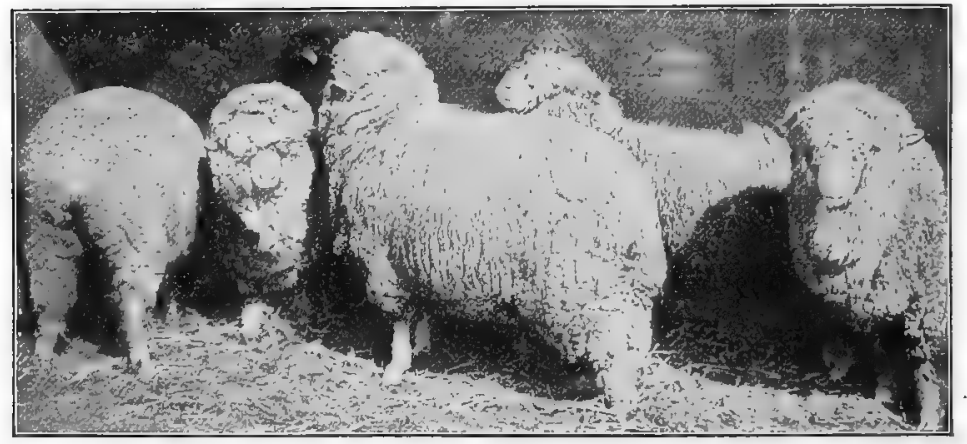

FIG. 228. A group of Dickinson Delaine Merino ewes bred by the late $H$. G. McDowell and very typical of this family. From photograph, by courtesy of $\mathrm{Mr}$. McDowell

to $\mathrm{Mr}$. McDowell, were the foundation stock of the Dickinson Merinos, and the McDowell family of Stark County, Ohio, notably the late H. G. McDowell, has been the leading improver of this family. Dickinson Merinos are still being bred in a small way in eastern Ohio, but the family has never been popular.

Characteristics of Dickinson Delaines. The standard of excellence specifies that the Dickinson Delaine shall have a deep, round, wide, and long body, showing mutton capacity, carrying heavy, thick flesh, the top and under lines being straight, and the skin being smooth, pink, and free of folds. The head may have small horns, but a polled head is preferred; the nose and small ears should be covered with silky hair. The fleece should be from three to five inches long, of XX or XXX fine Delaine combing 
grade, and should cover the body well. The ram's fleece of one year's growth should weigh 15 to 25 pounds and the ewes 10 to I 5 pounds, unwashed. The fleece carries but a moderate amount of yolk, but enough for good quality. The size of the Dickinson Delaine is of the large Merino type, the rams reaching 200 pounds and the ewes I5O. Wonderful, one of the best-known Dickinson rams, bred by H. G. McDowell, weighed 200 pounds when two years old, and his fleece weighed 26 pounds. The breeders claim superior mutton quality for this family.

The Black-Top Spanish Merino. The foundation of this family extends back to the 1802 importation of Colonel Humphreys. In I82 I William Berry of Washington County, Pennsylvania, purchased from W. R. Dickinson of Ohio a few ewes and a choice ram of Spanish breeding that traced through the Rotch sheep to Humphreys' importation. These sheep Mr. Berry bred with care and developed a large flock. He bred in family lines at first, and then crossed the families, endeavoring to breed a large, heavy-shearing, fine-wool sheep with smooth body of mutton value. In his breeding he decided that those sheep with the darkest outer covering of wool or most oil had the hardiest constitutions and most vigor and were less affected by change of climate than those with fleeces of lighter color. Hence he selected the darker sort and called them Black Tops. In 1847 his flock numbered about 500 head. These sheep he divided equally between his sons Matthew and William. The former maintained his flock in pure Black-Top lines, and William did the same until I 856, when he introduced Vermont Merino blood with such detrimental results that he eventually disposed of his flock. The Black-Top Spanish Merino Sheep Breeders' Association held an annual meeting at Washington, Pennsylvania, January I6, I919, and planned for the publication of Volume VII of the flock book.

The Improved Black-Top Spanish Merino is a family that has its foundation in ten ewes purchased in 1844 of George Craighead by Robert Johnston of Washington County, Pennsylvania. These ewes were bred to Craighead rams until I 847, after which, until I 853 , rams bred by Alexander McConnell were used, the latter obtaining his foundation stock from W. R. Dickinson. From I 853 to $1867 \mathrm{Mr}$. Johnston used only pure Black-Top rams 
in his flock, and from 1867 to $\mathrm{I} 884$ he used rams bought of Matthew Berry. In 1850 George Black of Washington County purchased twenty-five Black-Top ewes running back to Dickinson stock, and by use of Berry and Johnston and other rams established a Black-Top flock that is foundation stock in this family. This Improved Black-Top family has been regarded by its promoters as more carefully selected and bred and of higher standard than the Black-Top of original foundation.

Characteristics of the Black-Top Spanish Delaine. It is difficult to distinguish this from the other Delaines, of which it is in fact a family. The size is perhaps a trifle larger and the fleece weighs somewhat heavier. The Improved Black-Top standard requires a weight for mature rams of at least i 80 pounds and I 30 for ewes. Sheep of this family also have a somewhat darker exterior to the fleece and are not quite so heavily wooled over the head as other Delaines. The fleece should be from three to four inches long, and the rams should shear from $I 3$ to $\mathrm{I}_{4}$ pounds and the ewes from 7 to I 2 pounds of "brook washed" wool. Emphasis is placed on the mutton character of this family, which has long been bred with that feature preëminent. Improved Black-Top breeders have regarded their sheep as very similar to the Southdown in size and form, while still maintaining the fleece of the Merino.

The National Delaine Merino. About I 820 R. IV. Meade, at one time minister to Spain, imported some Merinos to the United States, which were placed on the farm of Alexander Wilson near Philadelphia, Pennsylvania. In 1821 or thereabouts Alexander Reed of Washington County, Pennsylvania, bought these Meade sheep and some other Merinos and placed them on his farm. From this Meade importation the Delaine type was first developed, tracing back to Reed stock; but the family was mainly established through the careful breeding operation of John McNary, W. H. McNary, J. S. McNary, Ebenezer McClelland, George Craighead, George Murray, and William Brownlee. In connection with the development of this family, R. H. Russell of Pennsylvania and C. H. Beall of West Virginia played an important part. In I 862 a ram of Spanish and Black-Top blood, purchased from Beall, was used in the flock formerly owned by 
McClelland, then in the hands of his sons. In I 877 R. H. Russell, who began his flock in 1852 with fifty Black-Top Merinos from William Davis, with C. J. McNary purchased a Spanish ram named Victor, bred by J. M. Miller, which was used in their flocks. Both of these rams were very prepotent and unusually fine individuals. The descendants of these two rams nicked to great advantage, resulting in superior Delaines that were long known as Victor-Beall Delaine Merinos. It can thus be seen that this Delaine family was developed by a combination of BlackTopand Spanish blood or a combination of smooth-bodied with wrinkled Merinos.

\section{Characteristics of National, Standard, or Victor-Beall Delaines.} These are essentially like the Dickinson Delaine. The body is smooth, excepting for slight folds at the neck and perhaps at the

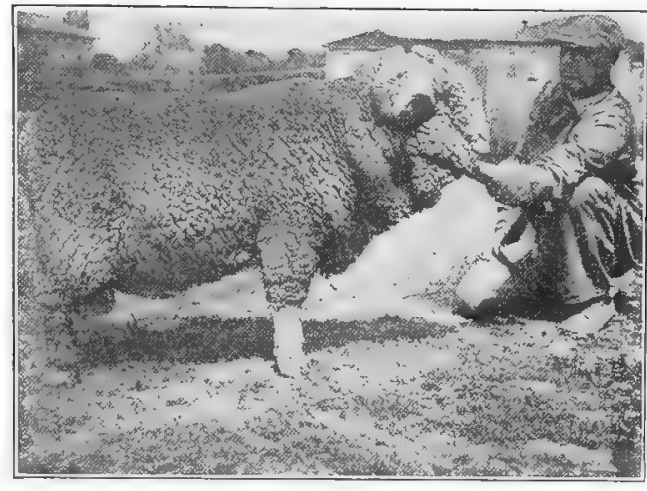

FIG. 229. Chapmans 1394, a fine type of Delaine Merino ram, owned by the Ohio Agricultural Experiment Station, Wooster. From photograph by the author

breast in the form of an apron. The rams may or may not have horns. According to S. M. Cleaver, at one time secretary of the Standard Delaine Association, writing in I890:

The demand of the times calls for a plain body growing a Delaine staple. Long experience teaches us that it is almost impossible to maintain density and weight of fleece when wrinkles are entirely done away with; for this reason it is important to insist on the blood of wrinkly sheep in selecting the sires while striving to keep the body clear of wrinkles, and the neck nearly so. It is well to pay more attention to a good broad back and deep, round quarters, ensuring a type easily kept in order. While the fleece will not be as heavy as in the wrinkly type, it should weigh from seven to nine pounds, and sell without any reduction. This will equal an oily fleece of twelve to fourteen pounds, with a third taken off by the wool buyer. Plain sheep, as a rule, are better milkers, more careful mothers, have better feet, and are more easily prepared for the butcher's block. 
Delaines of this family should have a staple three inches long for twelve months' growth. Rams at maturity should weigh at least 150 pounds and ewes not less than 100 pounds.

The maintenance of Delaine or $\mathrm{C}$ type in these families is through selection or by introducing new blood, in which as a rule the ram is of the B type. For example, one may visit the flocks of prominent Merino breeders in which both American and Delaine sheep are found. The former are mated with the latter, according to circumstances, in order to regulate type and wool production. If a Delaine ewe of excellent mutton type has too open and light a fleece she will be bred to an American ram of $\mathrm{B}$ type possessing high wool-producing qualities, with the expectation of obtaining a Delaine with a better fleece. More folds may exist at the neck and breast, but not enough to furnish serious objection on the part of the Delaine breeder. The important thing is to keep up the size and mutton form without reducing the amount and character of the wool below a satisfactory grade. This calls for a fleece to grade XX or better and have a staple of superior 'length, diameter, strength, and crimp. There should also be plenty of free-flowing oil, essential for a high-grade fleece. From a recent interesting pamphlet on the Merino, ${ }^{1}$ by $\mathrm{S}$. M. Cleaver, one of the greatest constructive breeders of the Merino, the following abstracts are made. Breeders of the C type Merino find great difficulty in uniting a satisfactory mutton form and weight of fleece in the absence of any corrugations in the skin. Folds are associated with density and weight of fleece. No family of sheep ever attained a higher quality of oil among the plain-breeding than did the Berry breeders of Pennsylvania. Very early in the history of Merino breeding in this country their flocks attained a great reputation for having a dark surface. There were other $\mathrm{C}$ type flocks in the country that produced a longer staple, but not a higher-class wool. The Wells and Dickinson flocks of Merinos never showed the high-class dark surface that the Berry breeding did, although as a rule they had a little longer staple - and possibly a little more density of fleece - with somewhat better covering. Originally they were as one flock from the same importation. After the flock was divided each part was bred purely

1 Merino History and Merino Breeding. Delaware, Ohio, I918. 
within its own blood lines for many years. During the nineties many of the wrinkly flocks were crossed with the plain-bred sheep to bring about a more practical wool-mutton Merino; also, many of the plainer flocks were crossed up with the wrinkly rams to give a greater weight of fleece. Satisfactory results were attained in each case.

The mutton value of the Delaine or $\mathrm{C}$ type has long been emphasized and is an important argument advanced by breeders in its behalf. The wethers mature fairly early and sell at a comparatively satisfactory price, being in demand on account of not carrying too much fat. They will not dress out quite so well as the true mutton type, but show a fair per cent of carcass to offal. In I $882 \mathrm{McClelland}$ Brothers of Pennsylvania sheared Ioo threeyear-old wethers that averaged I I pounds washed Delaine wool, after which the sheep weighed on the market I $10 \frac{1}{2}$ pounds each. The feeding of Delaine wethers has been made a specialty by many breeders in eastern Ohio, western Pennsylvania, and West Virginia, where the mutton has been regarded as of very excellent quality. The Ohio Experiment Station has produced a very superior class of Delaine mutton sheep on its branch station at Carpenter, using large, strong, C type rams.

The breeding quality of the Delaine is much superior to that of the A type Merino. The mothers are more prolific, yield more milk, and make better nurses. The lambs from $C$ type ewes are larger and stronger at birth and require less attention than do those of the A type.

The crossbred or grade Delaine is valued on the range. Purebred rams used on range ewes give a better mutton sheep and are more suited to the range trade than where American Merino rams are used. In fact, in recent years the Western-range shepherd has objected to sheep with folds and has put a premium on a Merino of the light $\mathrm{B}$ or the $\mathrm{C}$ type. Many Delaine rams have been used in the West, and the fact is, a large percentage of the mutton sheep produced west of the Missouri are essentially Delaine in character. At the Ohio State University very superior mutton has been produced in using pure-bred Southdown rams on ewes of Delaine type, the cross resulting in an improvement in the mutton form and a fleece of superior 
quality and weight. Delaine ewes mate to special advantage with mutton rams as has been well demonstrated in common practice.

The Delaine as a feeder ranks at the head of the Merino group, though it is not equal to the mutton breeds. The lambs at twelve months, when not forced, weigh about eighty pounds.

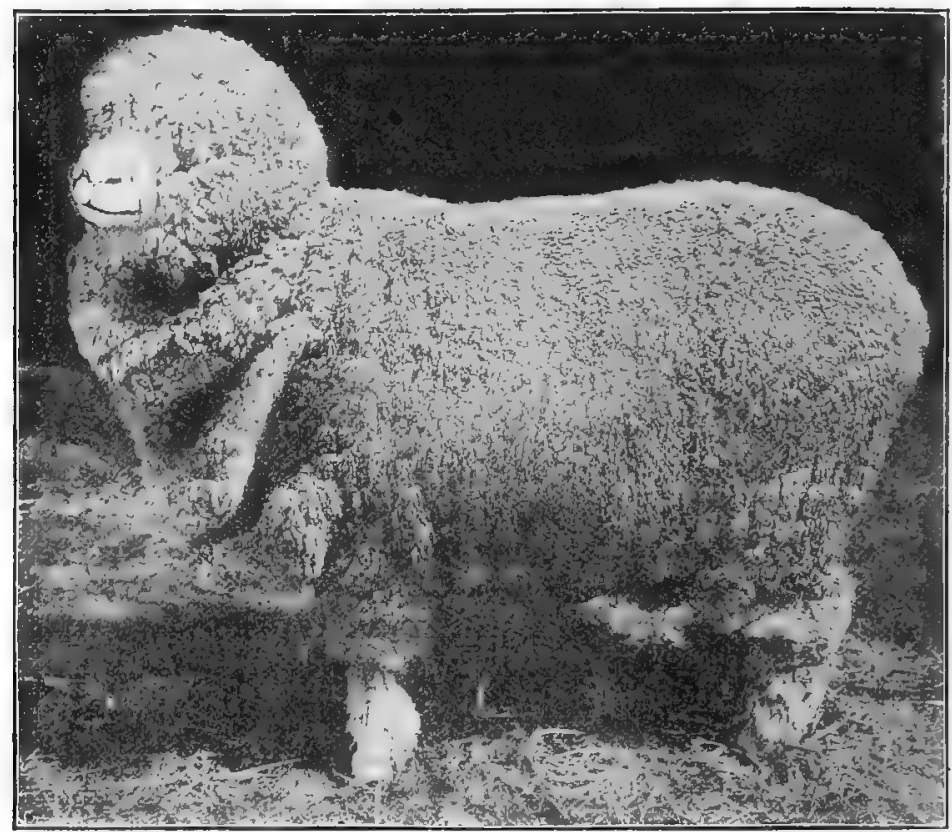

FIG. 230. A Delaine Merino ewe of superior character, exhibited by C. H. Bell of

Ohio. From photograph, by courtesy of the Yational Stockman and Farmer

The adaptability of the Delaine is not equal to that of the A type, for it lacks the rustling quality to some extent, yet the difference is not important. Delaines will do well among the hills and rougher lands and will thrive where mutton breeds would not do so well. They came into their own among the uplands of Ohio, Pennsylvania, and West Virginia, and are still produced in large numbers on these same grassy hillsides. On the range lands of the West they are valued for their adaptability to feed and climate as well as for their flocking habit, which makes the care of them comparatively easy. 
The distribution of the Delaine is widespread in the United States. Many flocks are found in Ohio, Pennsylvania, West Virginia, New York, Michigan, and Visconsin. The fine-wool type of sheep east of the Mississippi, however, is not holding its own, the mutton breeds taking its place. The Delaine, however, being essentially a mutton as well as wool sheep, is bound to have many adherents. Sheep of this type are also bred more or less in Texas and the Southwest, and in the northwestern states of Oregon, Washington, Montana, and Idaho.

The promotion of Delaine Merino sheep began in an official way with the organization of the Victor-Beall Delaine Merino Sheep Breeders' Association in Pennsylvania in 1882 . In 1887 this name was changed to the National Delaine Merino Sheep Breeders' Association, which was still in existence in 1918, with headquarters in Washington County, Pennsylvanin. In I 890 the Standard Delaine Spanish Merino Sheep Breeders' Association was organized in Pennsylvania, and the same year the Improved Delaine Merino Sheep Breeders' Association was incorporated at Columbus, Ohio. In 1882 the Ohio Spanish Delaine Merino Sheep Breeders' Association was organized. In I 883 the BlackTop Spanish Merino Sheep Breeders' Association organized in Washington County, Pennsylvania, and in 1885 the Improved Black-Top Merino Association organized in the same state. In I 884 the Dickinson Delaine Merino Sheep Breeders' Association was organized in Ohio. Each of these associations published a few flock books and registered thousands of sheep. The result of so many associations for registration and keeping records of Delaine Merinos caused considerable discussion and criticism for the lack of harmony among the breeders. In January, I906, a conference of Delaine Merino breeders met at Columbus, Ohio, consisting of members of a number of different registry associations, on which occasion it was agreed that consolidation was desirable. As a result the Improved Delaine, Standard Delaine, and International Delaine associations consolidated to form the American Delaine-Merino Record Association. The object of the new association is to promote the purity of breeding, registering, and preserving the American Merino shcep without special emphasis being placed upon the trpe recorded. 


\section{CHAPTER XLVI}

\section{THE RAMBOUILLET}

The native home of the Rambouillet is in France, in the northern part, not far from Paris. The country is gently rolling, the soil is generally of a calcareous nature, and the climate is quite temperate, being warm in summer and not severe in winter. Grasses, wheat and oats, and a variety of crops grow in this region.

The ancestry of the Rambouillet is Spanish, this being a member of the great Merino family. The people of Spain in early days produced more wool than their factories could consume, so the surplus was exported, France buying heavily. The French government anticipated an increase of factories in Spain and consequent restriction on exports of wool from that country. This led the French to try to improve their flocks and produce enough fine wool at home to meet domestic demands. In 1783 Louis XVI bought a large estate at the village of Rambouillet, some forty miles west of Paris, and here he established a farm. In 1786 M. Gilbert was sent to Spain and selected a flock of Spanish Merinos representing several different families; he landed 366 at Rambouillet, 3 I 8 being ewes. In I 799 Gilbert again went to Spain, where, after much difficulty, another importation was secured, of which 237 reached Rambouillet in May, I80I. According to Gilbert, who collected these sheep and died in Spain while doing the work, the second lot was not the equal of the first.

The improvement of the Rambouillet in the hands of the French government dates back over a century and resulted in a smoothbodied sheep of large size. Much of this development of over a hundred years has undoubtedly been accomplished by selection. During the time France has bred these sheep many careful records have been made of weights of the sheep and fleece, of length and diameter of wool, of fecundity, mutton development, etc. Probably no other such long-continued records regarding a breed are extant. The results of the work were a gradual increase 
in size, in weight and quality of fleece, in a better mutton form, and in more hardiness than had their Spanish ancestors. While the claim has been made that the stock at Rambouillet has been kept pure, in 1900 the author saw rams in the government flock which were heavy with folds, of marked A character, and different from the type the French advocated. The Rambouillet was also developed by private parties in France and Germany. In I800 M. Victor Gilbert of Wideville, France, started a flock from one ram and eight ewes bought of the government, and this

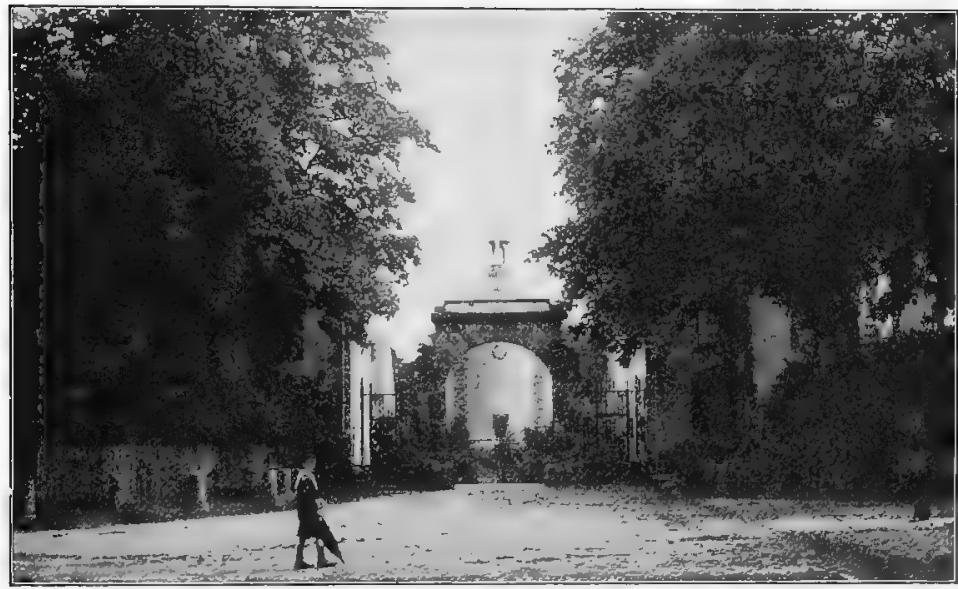

FIG. 23I. A dignified gateway on the government farm at Rambouillet, France. From photograph by the author

flock was maintained for a century in the same family by a son and a grandson named Victor. In northern Germany the breed was later introduced and was much developed, notably in the region south of the Baltic Sea and north and northeast of Berlin. Baron F. von Homeyer of Ranzin, Pomerania, in 1850 purchased some sheep of the flock at Rambouillet, and with these as foundation stock became the greatest German breeder and materially increased the size and improved the weight and quality of fleece.

The introduction of the Ramboutillet to the United States first occurred in 1840 , under the name of French Merino, by which title it was generally known until about I889. The first importation appears to have been made in 1840 by D. C. Collins of 
Hartford, Connecticut, consisting of 2 rams and 20 ewes from the government flock of France. The head ram, named Grandee, sheared I 4 pounds and was regarded as a very fine specimen. In 1846 this flock with its increase was sold to parties in Vermont. In May, I 846, John A. Taintor of Connecticut imported 2 rams and 7 ewes which he purchased of Victor Gilbert. Following this, Taintor made several other importations. In I 848 John D. Patterson of Westfield, New York, on the western border of that state, made an importation including many superior sheep,

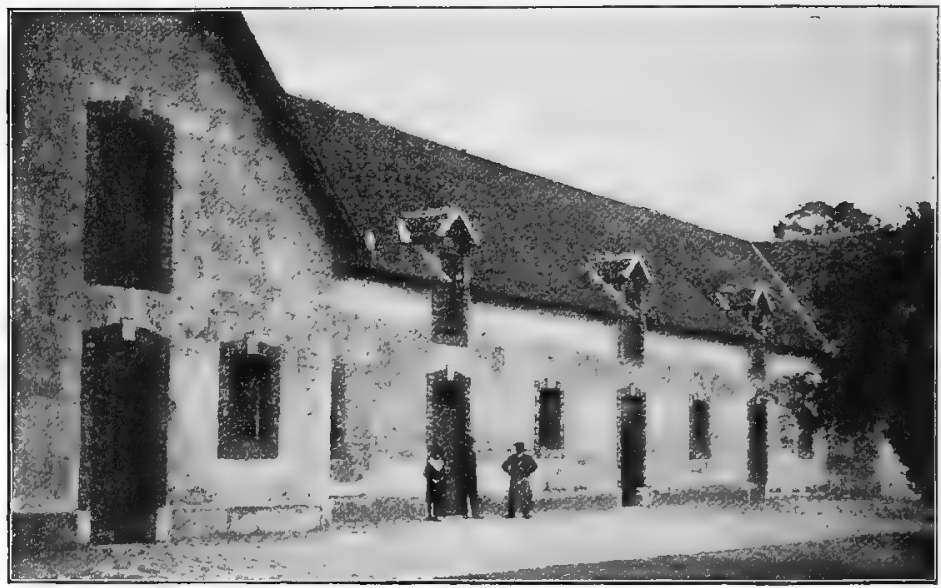

FIG. 232. One of the sheep barns on the government farm at Rambouillet, France. From photograph by the author

his ewes weighing from I 20 to I 50 pounds and some of his rams up to 300 pounds. In I $85 \mathrm{I}$ several different importations of prominence were made. F. M. Rotch of New York is said to have made an importation with Taintor of Connecticut. That same year S. W. Jewett of Middlebury, Vermont, imported I 8 rams and 82 ewes from Victor Gilbert, and George Campbell of Westminster, Vermont, also made an importation. In I85 I a company of Ohio breeders imported about 50 head selected from private flocks in France by A. P. Howard. Some of the present Ohio flocks trace back to this importation as well as to a later one of I88I. In I $85 \mathrm{I}$ the late R. C. Moulton of Woodstock, Ohio, established a flock of French Merinos, which he 
bred continuously for over half a century and which, perhaps, had a longer record than any other American flock of the breed. In 1855 A. R. Seymour of Fayette County, Ohio, bought 2 rams and 25 ewes of Jewett. Along about I855 a Mr. Downs of Calhoun County, Michigan, bought a few of the Patterson sheep. The claim has been made that a Mr. Stanton of Michigan purchased from Mr. Patterson, from which stock has descended

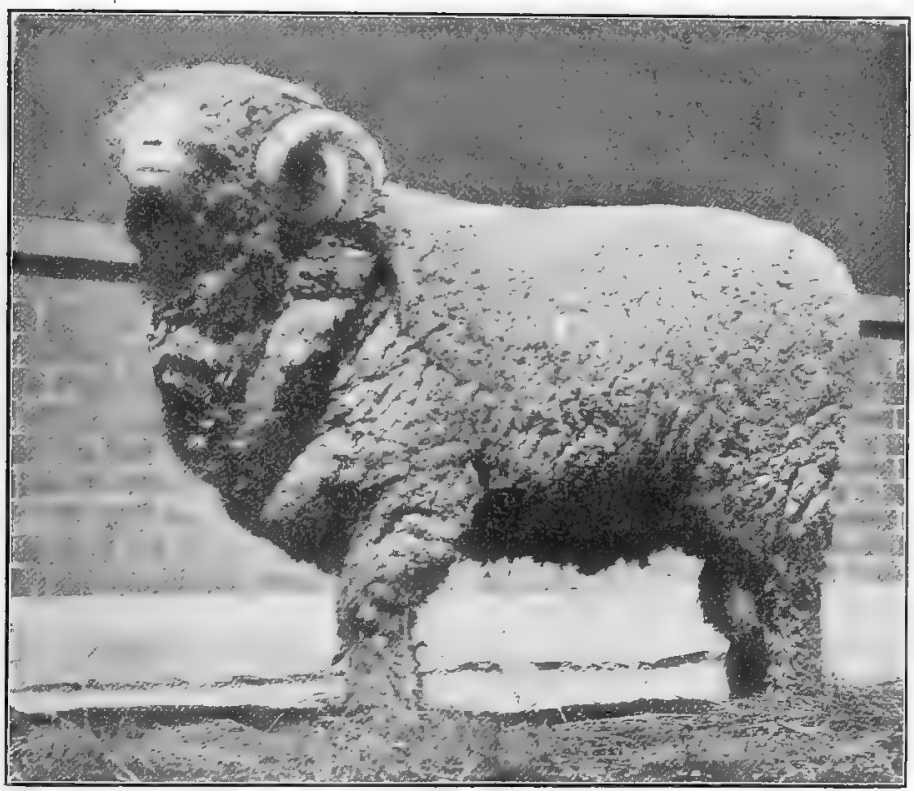

FIG. 233. A Rambouillet ram, second in class at the Ohio State Fair, I905. Bred and exhibited by Max Chapman, Marysville, Ohio. This is a C type sheep. From photograph by the author

the flocks of some of the prominent Michigan breeders, but a letter before the author, written by Mr. Patterson in 1893, does not corroborate this claim. Between I 856 and I 860 most of the sheep owned by the latter gentleman were sold to parties in California, from which stock the French Merino sheep of the Pacific slope states descend. The Blaco-Glide flock of California is said to trace back to this Patterson blood. What are now known as Franco-Merinos trace back into early Michigan flocks of years ago.

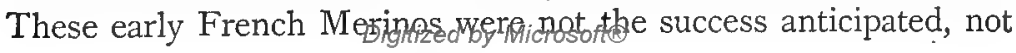


being hardy nor suited to American conditions, and the interest declined along in the sixties, to be revived about thirty years later. Reference has been made to the Von Homeyer family of Rambouillets produced in Pomerania, Germany. In I880 W. G. Markham of New York State, when on a visit to wool-producing countries, inspected the Von Homeyer flock and looked on it with much favor. In $\mathrm{I} 882$ he received a gift of a ram and 2 ewes from Von Homeyer, and these were the first of this German breeding to be brought to America. In I 885 Markham received 7 rams from the same source, 2 of which were shipped to Michigan, where they produced material improvement in the flocks where used. In I 890 Thomas Wyckoff of Orchard Lake, Michigan, purchased a pair of Rambouillets from Baron von Homeyer, these being the first brought to Michigan. Again, in I89I, Wyckoff imported 7 rams and I6 ewes from the Von Homeyer flock, and these were distributed among the Rambouillet men of Michigan. In I893 Mr. Markham supervised an exhibit of Von Homeyer sheep at the World's Columbian Exposition at Chicago which attracted widespread attention by their great size and superior merit. Many large importations of Rambouillets were made for a period of ten years or more following the Chicago show, of which a considerable portion came from Germany.

Characteristics of the Rambouillet. This variety or family of Merino does not differ essentially in appearance from the Delaine except in size and breeding. The head is large, the nose is covered with white silky hair, and the ears are inclined to be large and are covered with fine white hair or short fine wool. The rams usually have large spirally turned homs, but there are also polled males, and the females are hornless. The general form of the Rambouillet shows more grossness and bone than the Delaine. Individuals of the breed range from a distinctly $\mathrm{C}$ type, essentially free from folds, to those of $\mathrm{B}$ type, with well-marked folds about the neck, breast, flanks, and hind quarters. For this reason the Ohio State Fair for some years has provided separate B and C classes for Rambouillet sheep through all the age classes and pens. These classes have not been entirely satisfactory, for the reason that some exhibitors persist in showing sheep in one type class that belong in the other. Rambouillet breeders do not seem 
agreed on the subject of type, and those of Ohio and Michigan run more to folds than do those of the Western states. The type approved by the West is a large, smooth-bodied mutton Merino. The Eastern tendency to breed a sheep with heavy folds at neck, flanks, dock, and thighs, and with small body wrinkles, is a pronounced recognition of the importance of fleece. In breeding flocks, as a rule, the females run fairly free of folds, the service rams showing these characters in a greater degree. The fleece of the Rambouillet should be fairly close over the body, have a length for twelve months of two and one-half to three inches, and carry a moderate amount of yolk. The typical Rambouillet fleece is not so fine as that of the Delaine, is slightly longer, usually has a light-buff yolk, and has a nice, unctuous feel in handling. The wool should cover the body well, and breeders generally seek for

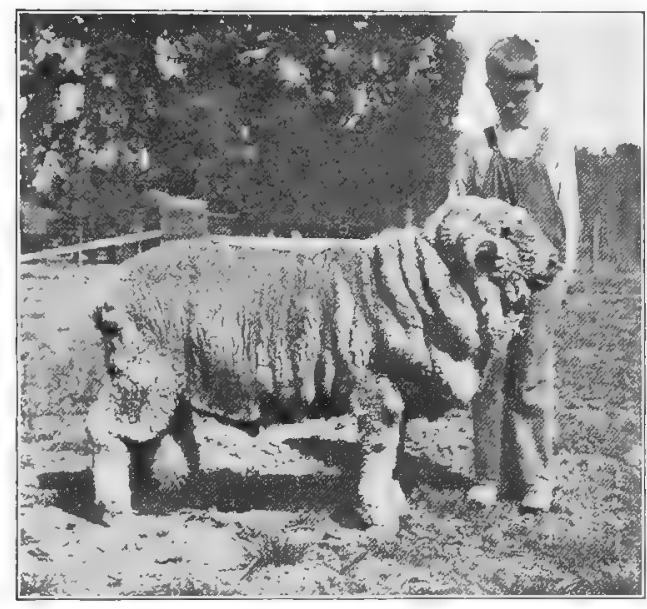

FIG. 234. Illinois 402, a Rambouillet ram bred by Illinois University, owned by California University, Davis. This is a B type sheep. From photograph by the author a cap of wool well down over the face and with legs wooled to the ankles. Commenting on the wool covering of head and legs, Professor W. C. Coffey, an authority on this breed, has the following criticism? :

Most Rambouillet breeders emphasize great extension of wool over the face and legs, a matter which has been carried too far for practical purposes. Many specimens being completely covered with wool over the head and face are blind, and a blind sheep in a flock or band is a nuisance, because it is crazy. Extreme covering over the legs collects mud and snow, and hence is an inconvenience. It is time for Rambouillet breeders to revise their notions a little on head and leg covering.

1 Productive Sheep Husbandry. Philadelphia, 1918. 
The color of the hair on the face, ears, and legs is white, and the hoofs also are white. Tan-colored spots sometimes occur amid the white hairs of the ears or nose and lips. Dark streaks may occur in the hoofs. Any variation from white is looked upon with disfavor, but does not disqualify. Tan spots are without doubt an inheritance of long standing among all Merino families.

The size of the Rambouillet averages larger than any of the other Merinos; in fact, years ago they were nicknamed "Elephant Merinos." The rams will average about I 85 pounds at maturity

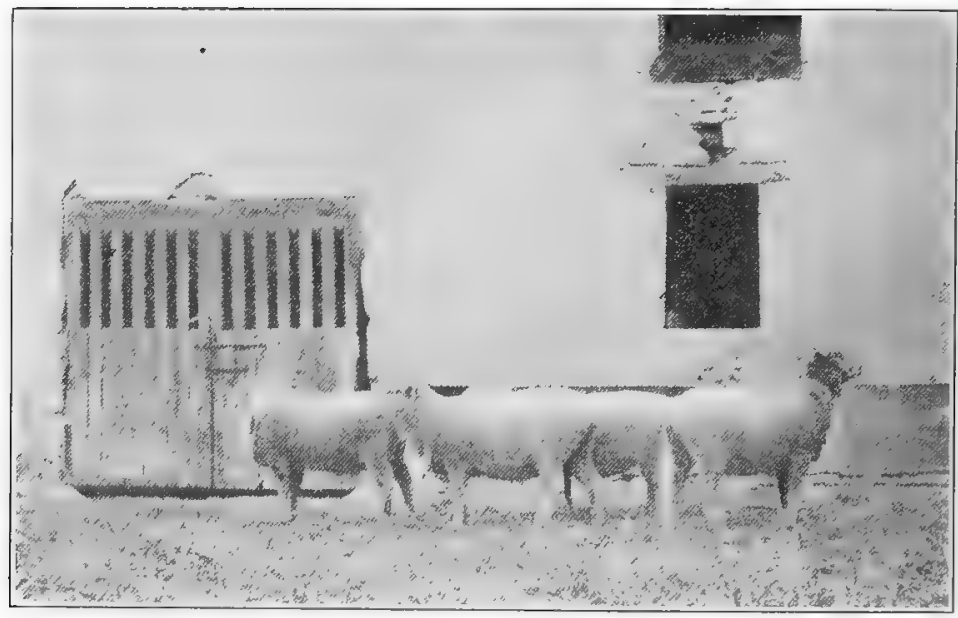

FIG. 235. Four select Rambouillet ewes in the flock of Victor Gilbert, Wideville, France, in I900. From photograph by the author

and the ewes I 50 to I60 pounds. Some rams are said to have weighed over 300 pounds, and cases are known of ewes weighing about 250 pounds. The ram Matchless, imported by George Campbell in I85 I from the Gilbert flock, weighed $26 \mathrm{I}$ pounds. Mr. Max Chapman of Ohio bred the ram Sampson, which weighed 280 pounds at twenty months old, and the ewe Bernice, which at three years weighed 244 pounds. Western breeders produce a larger, heavier-weighing type than Easterners, and weights of 250 for the mature ram and 200 for the ewe are not regarded as remarkable. The ram Big Chief, bred by F. S. King Brothers Company of Wyoming, is said to have weighed 375 pounds. 
The Rambouillet as a mutton producer ranks very well, though inferior to the mutton breeds. It will mature fairly rapidly and will produce a class of mutton which will sell well, though it is not of the highest quality. This is the only ciass of Merinos offered a place for exhibition at the International Live-Stock Exposition, a testimonial to the mutton value of the wethers. In the Iowa experiments on fattening wether lambs, in the one trial reported, the Rambouillet made an average daily gain of .37 pound, requiring I029 pounds dry matter for I oo pounds gain.

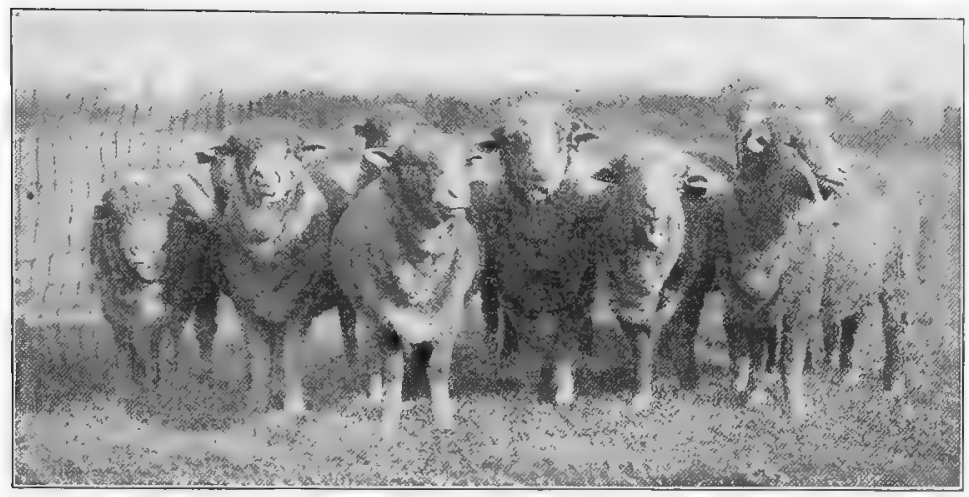

FIG. 236. Nine Rambouillet ewes in the flock of Illinois University. Notice the uniformity of type. From photograph, by courtesy of Professor W. C. Coffey

In the carcass test the Rambouillet dressed out 49.57 per cent, the poorest of ten breeds, compared with 55.26 for the Southdown, and was priced at $\$ 5$ per hundred live weight compared with $\$ 5.75$ for the Southdown.

The Rambouillet as a wool producer is regarded with favor. In 1838 , on the farm at Rambouillet, 40 rams yielded an average fleece of Io pounds 4 ounces, and $20 \mathrm{I}$ ewes and 85 lambs an average of 7 pounds. The years 1847,1869 , and 1877 saw a gradual improvement in weight and quality of fleece, the latter year I 5 adult rams averaging I 6 pounds 9.3 ounces weight of fleece, and $52 \mathrm{r}$ ewes of various ages 10 pounds 3.I ounces. At the present time it is doubtful if the average ram will shear over I 5 pounds and the average ewe over io pounds, but this, of course, does not apply to flocks as carefully bred as that at 
Rambouillet. O. M. Smithson of Illinois states that he has field ewes shearing up to 23 pounds and rams up to 28 to 30 pounds. The two-year-old ram Majestic 7i 350 , bred by F. S. King of Wyoming, is credited with producing a 40-pound fleece in one year. In 1916 the Oklahoma Agricultural College reported shearing from the two-year-old ram Laramie a fleece weighing

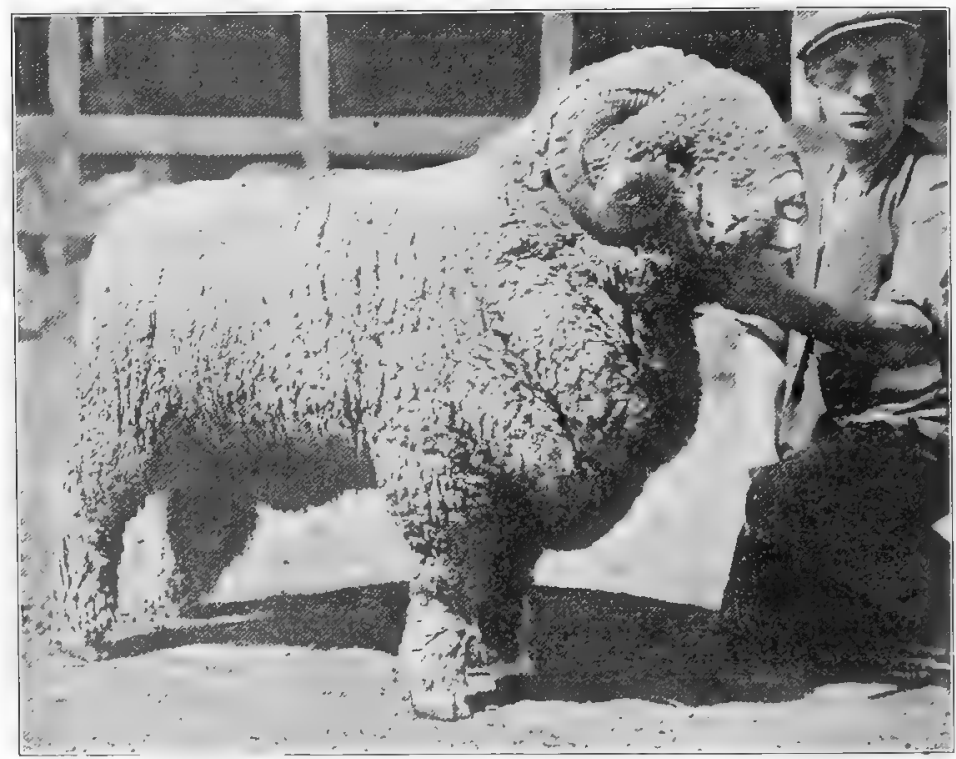

FIG. 237. Butterfield's Model, a Rambouillet ram that sold in the I9I8 Salt Lake City ram sale for $\$ 3000$. He was sold by the Butterfield Live-Stock Company of Idaho to Bullard Brothers of California. This is a C type Rambouillet. From photograph, by courtesy of the American Sheep Breeder

$46 \frac{1}{4}$ pounds with an average length of staple of $3 \frac{1}{4}$ inches. Professor Coffey states ${ }^{1}$ that a twelve months' fleece of mature rams should weigh from 15 to 25 pounds and ewes from Io to I8 pounds, but these latter figures very naturally apply to carefully bred and selected flocks.

Crossbred or grade Rambouillet sheep are best known on the Western range, where for some years large numbers of pure-bred rams have been shipped from the Middle West for use on native

1 Productive Sheep Husbandry, 1918. 
stock. This gives a larger, better mutton type, with a strong constitution, and at the same time increases the fleece value. Not only this, but the smooth-bodied grade is more in favor with the shearer on the range than the smaller, more wrinkled sort. At the South Dakota Station rams of six breeds were crossed on grade Western ewes. Fifty-three lambs sired by a Rambouillet ram made an average daily gain of .3I pound, while the carcass dressed out 54.2 per cent, the best of the six lots.

The breeding qualities of the Rambouillet rank well. For twelve years preceding I 88 I Bernardin, then in charge of the government flock in France, reports that 4005 ewes were reserved for breeders, of which 83 .I per cent were productive, the 83.I ewes dropping 92 lambs, including twins. Professor Coffey rates the ewes as fairly prolific and credits them in the flock with 125 to I 50 per cent lambs. In the author's experience with the Rambouillet, covering ten years, the ewes are prolific breeders, frequently dropping twins, and are unusually good mothers, having large udders and producing much milk. One objection to some of the ewes is too large a teat. The udders average larger than with any other breed of sheep. Owing to their natural vigor the ewes breed to a ripe old age.

The hardy quality of the Rambouillet is worthy of note. Formerly, when the French Merino was introduced, many found it unsuited to American conditions. The last quarter of a century, however, has shown that the Rambouillet has excellent wearing qualities, certainly surpassing the mutton breeds. In winter the writer has found them comparatively free from catarrh, while in summer on the same pasture with sheep badly suffering with stomach worms the Rambouillet showed a relatively greater resistance to these parasites.

The early maturity of the Rambouillet from the standpoint of Merino development is very exceptional. The lambs commonly weigh 8 to Io pounds at birth, come on rapidly with good care, and compare favorably with the best mutton breeds. In an editorial note in the American Sheep Breeder relative to Rambouillet lambs sold by W. S. Hansen at the Salt Lake sale in August, I9I8, it is stated that March lambs in August weighed I I 5 to I 20 pounds, remarkable weights for such young lambs. 
Prices of interest for Rambouillet sheep date back for over half a century. In I853 John D. Patterson of New York purchased a ram in France for $\$ 600$ from the flock of M. Cugnot. $\mathrm{He}$ also paid Victor Gilbert $\$ 400$ each for 2 rams. In the late fifties, when Mr. Patterson sold his sheep to California buyers, it is reported that he received \$1500 each for 3 rams, \$1000

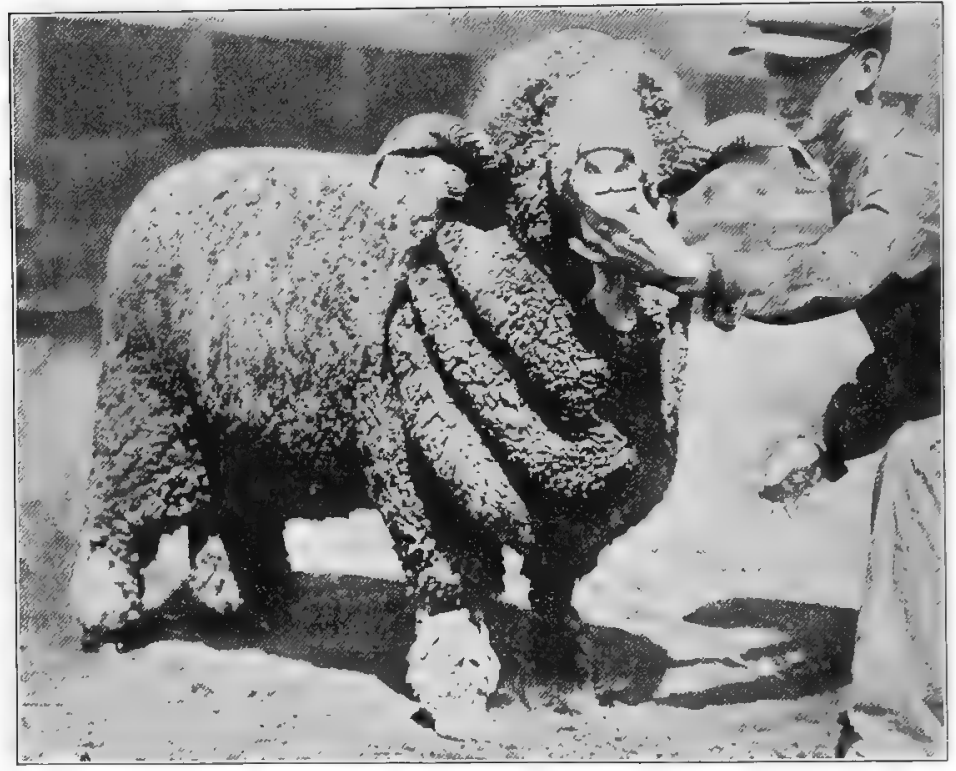

FIG. 238. This Rambouillet ram was sold by J. H. Seely to C. N. Stillman of Utah in the Igr 8 Salt Lake City ram sale for $\$ 6200$, the high price for a sheep of the breed. From photograph, by courtesy of the American Sheep Breeder

for I, $\$ 800$ apiece for 2 , and for I8 others prices ranging from $\$ 300$ to $\$ 700$. Fourteen ewes also brought $\$ 4500$, or an average of $\$ 32$ I per head. These probably represent the highest prices brought by individuals of this breed, either in America or Europe. A. L. Bingham of Vermont, between 1847 and I853, paid John A. Taintor $\$ 37,500$, or about $\$ 232$ a head, for I6 I French Merinos. Some very sensational prices have prevailed in recent years, more especially in I9I7 and I9I8 at the annual sheep sales in August at Salt Lake City. In I9I7 the ram 
Big Chief, by Wyoming Boy, consigned by F. S. King Brothers Company of Wyoming, sold for \$I 300 to Hobbs and Gillett of Idaho. John H. Seely sold to Dell Pratt a ram for \$ \$325. A ram consigned by Illinois University brought $\$ 675$. In all, I68 Rambouillet stud rams brought $\$ 39,985$, an average of $\$ 238$, and 362 ewes brought an average of $\$ 46.29$. At the 1918 sale

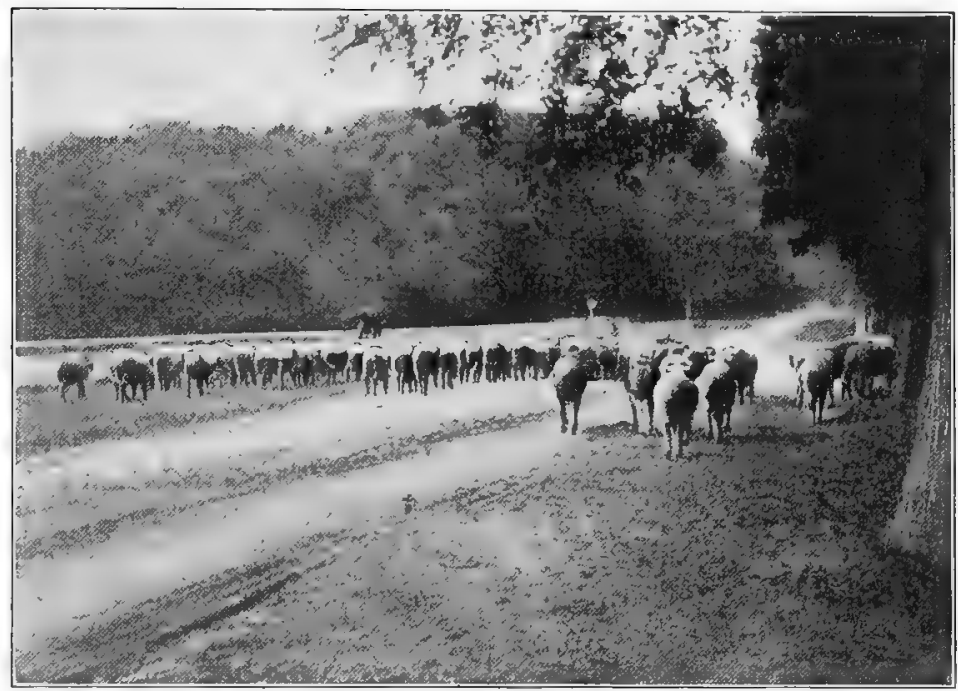

FIG. 239. The shepherd and his flock at Rambouillet, France. From photograph by the author

a two-year-old ram was sold by John H. Seely to C. N. Stillman of Utah for $\$ 6200$, the top price for the breed. The Butterfield Sheep Company sold the ram Butterfield's Model to Bullard Brothers of California for $\$ 3000$, and other rams sold for $\$$ I 500 , $\$$ I $200, \$$ I IOO, and \$IOOO respectively. Bullard Brothers sold a pen of 24 yearling rams for $\$ 300$ a head. Seely sold to Hobbs and Gillett 3 ewes for $\$ 375$, and King Brothers sold Io yearling ewes for \$I 50 each. Illinois University consigned 5 rams that averaged $\$ 425$ a head. At the I9I9 ram sale at Salt Lake City, Illinois University sold to the Butterfield Live-Stock Company of Idaho a ram for $\$ 1600$, the top price of the sale. One other ram was sold by F. S. King Brothers Company for \$ I 500, Digitized by Microsoft(B) 
another by Bullard Brothers for $\$ 1450$, and many others brought prices ranging from $\$ 200$ to $\$ 400$. These high prices were paid by Western ranchmen, who had full faith in the future of the breed.

The distribution of the Rambouillet is very widely spread. It has been extensively bred in France, Germany, Russia, and other countries of continental Europe and exported heavily to Australia, Argentina, and the United States. In South America there are large flocks of choice breeding. In the United States the Rambouillet is extensively distributed from the Atlantic to the Pacific, but it is found in pure-bred flocks to a notable degree in Ohio, Michigan, Oregon, Washington, California, Wyoming, and Utah, while excellent flocks occur in other states.

The promotion of Rambouillet sheep in an official way is through the American Rambouillet Sheep Breeders' Association, which was organized in I899 at Pontiac, Michigan, but which for many years has had its headquarters in Ohio. Volume I of the flock book was published in $189 \mathrm{I}$, since which time, up to 1919 , twenty volumes have been published, registering 27,747. sheep. In I90 I the Von Homeyer Association of Rambouillet Sheep was organized in Michigan, registering only sheep of breeding that traced to the Von Homeyer flock. This association, now defunct, issued one small flock book. There was also a FrancoAmerican Merino Association, organized in 1900, in which blood lines combine the Rambouillet and American Merino. There is an Ohio Rambouillet Sheep Breeders' Association, organized to promote the breed, having in 1919 a membership of about a hundred. 


\section{CHAPTER XLVII}

\section{THE MUTTON TYPE OF SHEEP}

The mutton breeds of sheep comprise two groups, known as the middle or medium wool and the long wool. While the breeds within these groups materially differ in character, what is known as the mutton type or form is essentially the same with each of these groups, irrespective of size of body or kind of fleece.

The general mutton conformation embodies the feature of the best beef type, involving the compact, blocky form, the short head and neck, broad, level back, deep body, indicating large digestive capacity, full, heavy leg of mutton, and short legs.

The head is short, the mouth of ample size, the nostrils large, the nose short and strong and often Roman with males, the eyes bright and prominent, the forehead broad, the poll neat, and the ears refined, short, and actively carried, indicating quality. Horns do not as a rule prevail in this type and are not a necessary consideration.

The neck should be full and smoothly muscled, of fair depth, level and short on top, and should blend in neatly at head and merge nicely at the shoulder and neck vein.

The shoulder is valuable for mutton and should be neatly placed, with the blades not prominent at the top, this entire part being smoothly covered with flesh.

The breast on a superior mutton sheep is wide in front, and the brisket prominent and well rounded out, showing a vigorous constitution and strong fleshing qualities. The whole front of the bosom should show a pronounced breadth as well as fullness in all the lines, blending neatly with the shoulders.

The chest is most important, containing as it does the vital organs, so that both thickness and depth are essential and in keeping with the properly developed breast. The withers on top should be wide and smoothly covered, and then, further down, wellrounded crops and full front flanks are to be looked for. Sunken 
crops and high front flanks indicate lack of constitution and poor feeding character. Fullness of flank is of vital importance.

The front legs should be wide apart and heavily muscled of arm, the shank bones fine and short, the joints and pasterns strong. The entire leg viewed from front or side must show good form

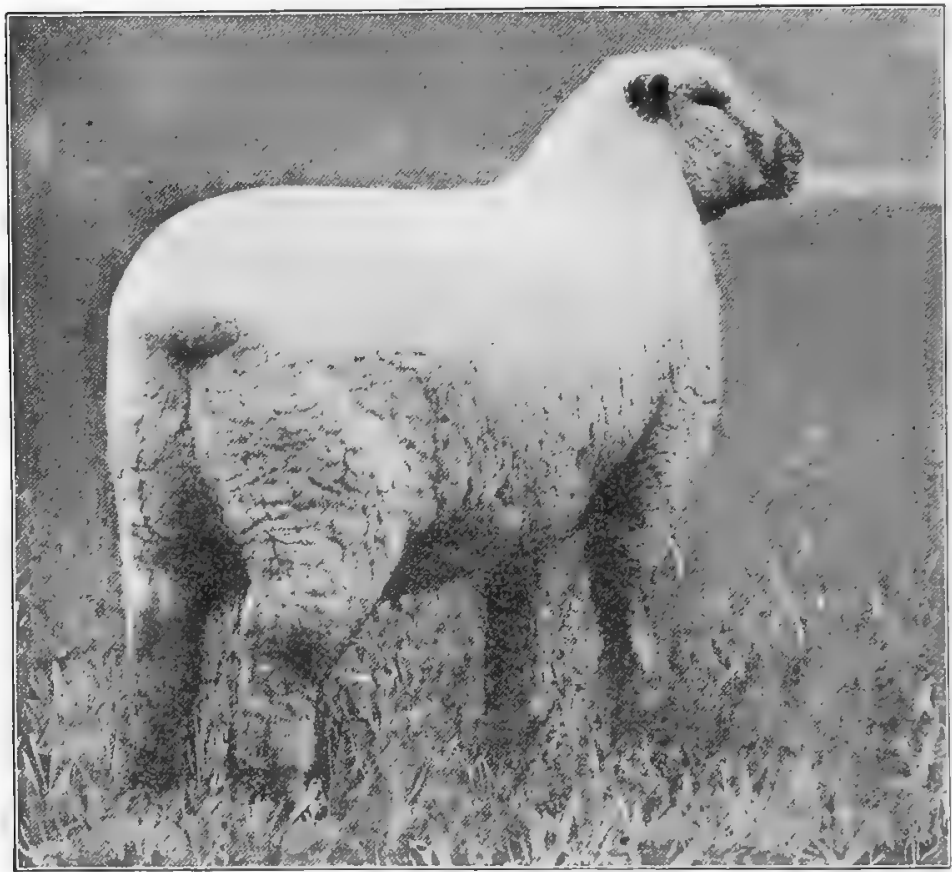

FIG. 240. A fine type of mutton sheep, the grand-champion wether, a Shropshire, at the International Live-Stock Exposition, 1917. Exhibited by Jess Andrew, West Point, Indiana. From photograph by Hildebrand, by courtesy of Mr. Andrew

and strength, the knees being well apart and the feet properly pointing straight ahead. Weak pasterns frequently occur with mutton sheep, a feature to be avoided in selecting breeding rams.

The back and loin contain the valuable cuts, so that width and thickness are highly essential at all times. Breadth and levelness of back are emphasized, with some closeness of coupling.

The body, to have ample capacity, requires a strong arch and depth of rib, thus giving depth and thickness, invariably associated 
with the best type. A short body - at least, with the male or feeder - is much preferred to a long one.

The hips should be inconspicuous, not too close together, and smoothly covered.

The rump requires length, breadth, and levelness, with a full covering of flesh. Instead of this we too frequently find the peaked, narrow, droopy rump with low-set tail, an ill form either for meat production or in relation to the proper conformation in connection with the reproductive function.

The thighs should be thick from behind, very full and low in between at the twist, and, as viewed from one side, very wide and carried strongly back. The entire upper thigh should be heavily covered with flesh. The lower thigh, above the hock, must show strength and neatness.

The hocks should be straight and strong with ample space between. If the hocks take a correct position, then the legs will probably do likewise. Crooked hocks, however, are a common and weak formation and are to be guarded against in breeding stock. The legs below the hocks should be straight, short, and strong.

The skin is a quite variable feature on mutton sheep. A bright pink is the ideal color, with the skin mellow and yet firm, indicating a healthy condition. Instead of this the skin is frequently of a bluish-white cast or appears too white. A somewhat mottled or bluish-white color also occurs with some individuals or breeds. There are differences of views as to the significance of skin color. No doubt the bluish tint of the Shropshire or Oxford skin is one of inheritance and does not necessarily signify poor condition. The clear pink skin, however, is preferable and meets with most favor among critics.

The fleshing of the mutton type calls for a smooth, uniformly covered, deep layer of high-class mutton without wads of fat or patchiness on sides or rump. Such a sheep with the fleece removed would be beautiful in the general symmetry of outline, whether in moderate flesin or fed for slaughter.

The rool of the mutton type ranges in length from about two inches, as is frequently the case with the Southdown, to some ten inches or possibly more for a year's growth, as with the Lincoln. The fleece does not cover the body so compactly as with the fine 
wool, but in this respect that of the medium class for density of covering excels the long wool, which is the most open of all. The fibers range in character from those which are fine and have considerable crimp to those which are long and wavy, with little or no real crimp. A bright fiber with more or less luster is sought. Uniformity is important in length, fineness, and diameter of staple. The entire body, including the belly and much of the armpits, should be covered with a compact fleece. The covering on head or legs varies with the breed. Hair (kemp) or abnormal color of wool fiber are distinctly objectionable. The yolk should be of moderate abundance and uniformly distributed, indicating the wool to be in a healthy condition. 


\section{CHAPTER XLVIII}

\section{THE SOUTHDOWN}

The native home of the Southdown breed is in southeastern England in the county of Sussex, which is bordered on the south by the English Channel. Extending east and west through this region is a range of low chalky hills about sixty miles long and from one to six or eight miles wide, known as the South Downs. These hills, which also occur in Kent, Hampshire, and Dorset, grow a short, fine herbage, while wheat is a leading cereal crop, though roots do well under suitable conditions on the lower-lying lands. The climate is mild and balmy, being tempered by the sea.

The original stock from which the Southdown sprung - the native Sussex sheep - was somewhat small. It had a dark face and legs, occasionally small horns, was long and thin in the neck, light in the fore quarter, with narrow, sagging back, the body lacking rib, though the hind quarter had a thick leg of mutton. Coarseness of bone was also characteristic. The wool was short and the fleece thin.

The important early improvers of the Southdown were John Ellman and Jonas Webb. Other men assisted in the improvement of the breed, but these two stand out in bold relief among the great improvers of sheep.

John Ellman lived at Glynde near Lewes, Sussex County, England. He was the first improver of Southdown sheep. He began his work about 1780 and resided on the same farm and bred Southdowns continuously for over fifty years. Ellman saw the necessity of improving the native Sussex sheep to secure a stronger constitution, a better mutton form, and ease of fattening, with a smaller per cent of offal in killing. He sought the best sheep wherever obtainable and made rapid improvement of the breed. A son of Mr. Ellman, also a prominent breeder in his day, especially credited his father with improvements made in the Southdown neck and fore quarters. Ellman very generally improved the 
sheep, creating a superior mutton beast and also greatly adding to the thickness and quality of the fleece. He demonstrated that the breed could be heavily stocked on the land. In 1788 Arthur Young wrote ${ }^{1}$ : "Mr. Ellman, on 500 acres, has 700 ewes, lambs, and wethers in winter, and 1450 of all sorts in summer, besides I 40 head of cattle." Sheep of Ellman breeding did not receive marked recognition at first, but eventually he commanded high prices. In

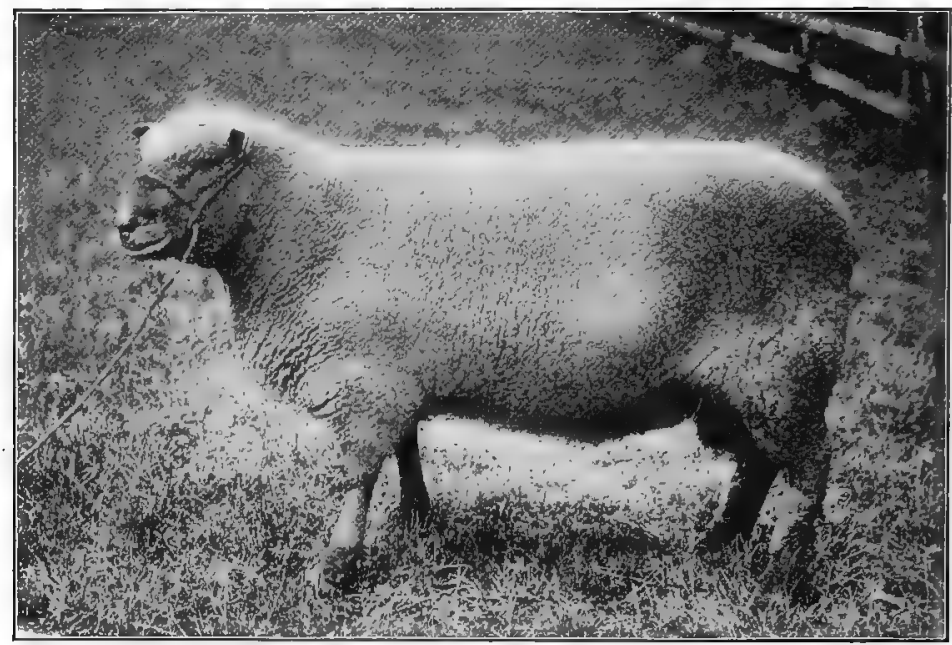

FIG. 24I. Babraham Champion, first-prize and reserve-champion Southdown ram at the Royal Agricultural Society of England Show in 1901. Also won the Blythwood Challenge Bowl for the best Southdown of either sex at the Oxfordshire Show. Bred and owned by C. Adeane, Babraham, Cambridge, England, and used in the famous Babraham flock in I90I and 1902. From photograph, by courtesy of F. N. Webb

I 798 the Emperor of Russia is said to have bought 2 rams for \$I 500. Ellman is universally regarded as the greatest of early sheep improvers, unless we except Bakewell. In I 829 he retired and dispersed his flock of about I 400 head, of which 241 were wether lambs. Mr. Ellman died in 1832 in his eightieth year.

Jonas Webb of Babraham, Cambridge, England, a tenant farmer, built on the Southdown model of Ellman. He began breeding about I 82 I and purchased the best sheep he could buy, regardless

1 Annals of Agriculture, Vol. XI, p. 200. 
of price. These he mated with much wisdom, improving the Southdown into the very best known type of mutton sheep, - symmetrical, an easy feeder, and unsurpassed in quality of flesh and dressing out at killing. Southdowns of his breeding possessed more size than did those of Ellman. He began letting out rams in 1823 , and about I 846 was placing out two hundred annually. For years his ram sales and letting-out sales were important events. He was a most successful exhibitor, and in I 855 won a special gold medal for his Southdown exhibit at the International Exposition at Paris,

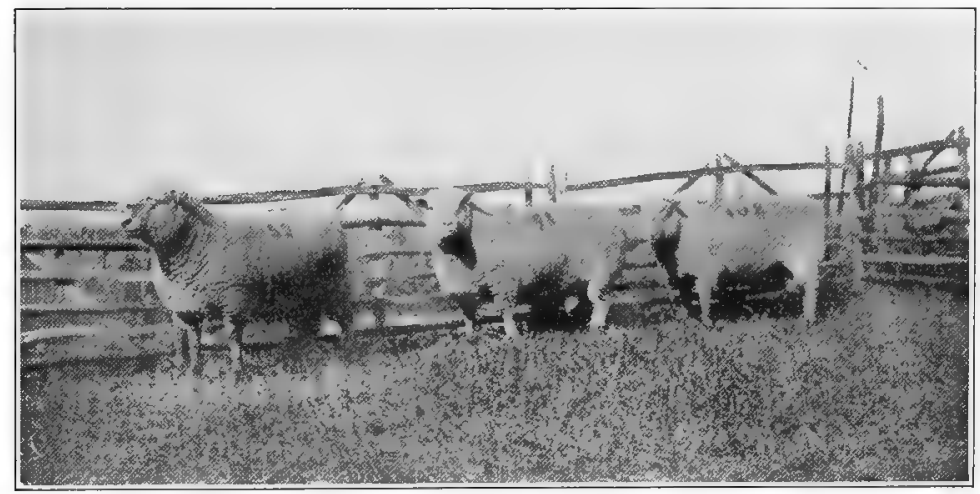

FIG. 242. Three of the Southdown stock rams on the Babraham estate, near Cambridge, England. From a photograph taken in IgI4 by the author

France. The Webb flock was dispersed in 1862 , but Mr. C. Adeane, the owner of Babraham, is one of England's best-known breeders and exhibitors of Southdowns. For years Mr. F. N. Webb, a grandson of Jonas, was manager of Babraham for Mr. Adeane.

The breeding of the Southdown by the English nobility has long been noteworthy. In the time of Ellman, George the Third became interested in this breed, which ever since has been maintained on the royal estates. The late Edward VII, as well as his son King George, maintained for years a fine flock. Lord Walsingham was long a prominent breeder; while the estate of the Duke of Richmond for over a century bred Southdowns, as have the Duke of Hamilton, Duke of Marlborough, Viscount Hampden, and numerous others. 
The introduction of the Southdown to America without doubt dates back to colonial days, and it has been assumed that the best sheep of Rhode Island and eastern Connecticut were of this breed. In I803 a Dr. Rose of Fayette, Seneca County, New York, is said to have commenced with a small flock of Southdowns which did remarkably well. In I8I3 these were crossed with Spanish Merinos. In I 823 Sidney Hawes of New York imported some Southdowns and sold 36 ewes, 2 rams, and Io wethers to C. N. Bement of Albany, who kept up his flock many years. In I 834 Francis Rotch of Otsego County, New York, imported 6 eves

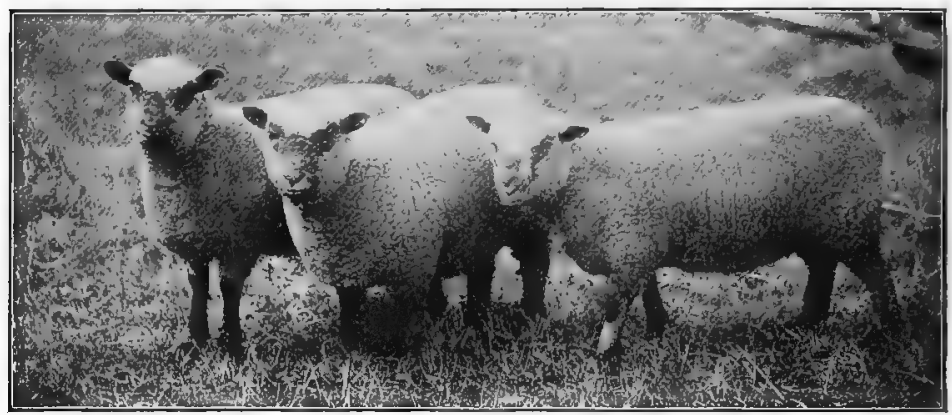

FIG. 243. A pen of three Southdown ewe lambs, first prize in class at the Royal Agricultural Society of England Show, rgor. Bred and exhibited by C. Adeane, Babraham, Cambridge, England. From photograph, by courtesy of F. N. Webb

and a ram from the flock of T. Ellman, the son of John. Following this he made several other importations from the most noted English flocks. In I 834 Isaac Maynard of Coshocton County, Ohio, brought some Southdowns to that state, while in I844 J. F. King of Warren began breeding from Jonas Webb stock, imported by J. M. Hesless of Trumbull County, Ohio. Good examples of Southdowns were shown in I85I at the Green County Fair, according to the Ohio Cultivator (October I5, I85I). With the depreciation in Merino interests Southdowns grew in favor east of the Mississippi, and many flocks were established.

The characteristics of the early Southdown, as bred in Ellman's time are interestingly set forth by Arthur Young, ${ }^{1}$ the noted English authority on agriculture of a century and more ago.

\footnotetext{
${ }^{1}$ Annals of Agriculture, Vol. XI (1789), p. I98.
} 
This true Southdown, when very well bred, has the following points : no horns; a long speckled face; clean and thin jaw ; a long but not a thin neck; no tuft of wool on the forehead, which they call owl headed; nor any frize of wool on the cheeks; thick in the shoulder ; open breasted and deep; both fore and hind legs stand wide; round and strait in the barrel ; wide upon the loin and hips; shut well in the twist, which is a projection of flesh on the inner part of the thigh, that gives a fullness when viewed behind, and makes a Southdown leg of mutton remarkably round and short, more so than in most other breeds; thin speckled leg, and free from wool ; the belly full of wool ; the wool close and hard to the feel, curdled to the eye, and free from spiry projecting or staring fibers.

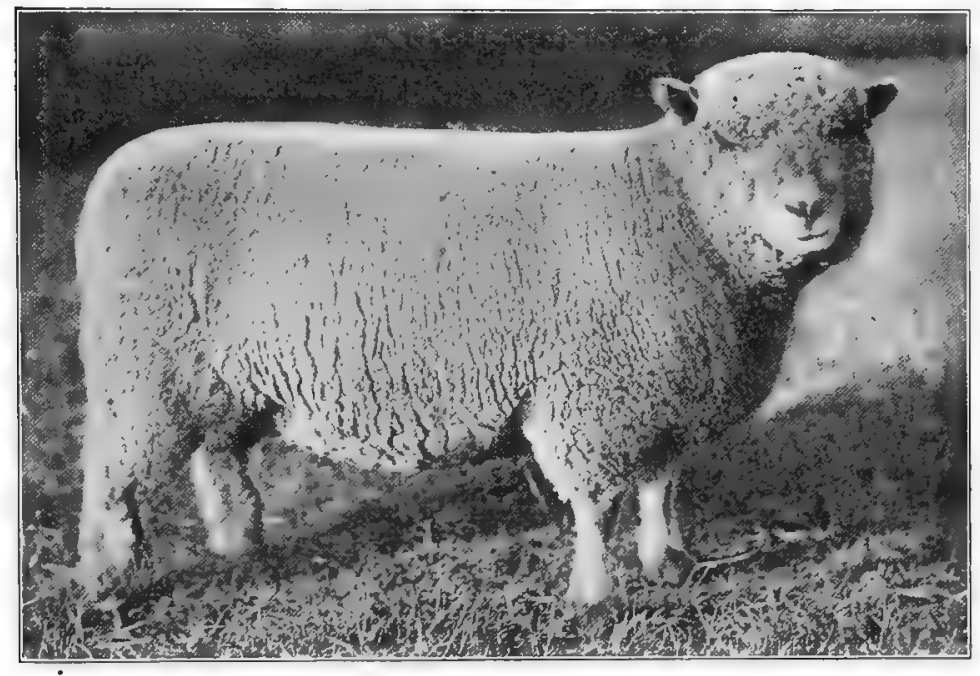

FIG. 244. A Southdown yearling ewe bred and owned by Illinois University. Champion Southdown ewe at the 1917 International Live-Stock Exposition. From photograph, by courtesy of Professor W. C. Coffey

The characteristics of the Southdown in more recent years show a distinct improvement. In I 856 Professor Wilson, discussing the British breeds of sheep, ${ }^{1}$ pays high tribute to the improvement made by Ellman and the breeders following him. At this time the Southdowns had dark brown faces and legs, had been increased in size, improved in the width and depth of fore quarter, the back and loin were broader and more level of carriage, the depth of rib increased, the hind quarters were more square and full, and the

1 Joumal of the Royal Agricultural Society of England, Vol. XVI (1856), p. 233. Digitized by Microsofte 
legs finer and shorter of bone. The present-day Southdown is by many regarded as a model mutton beast for the butcher. In conformation we have the compact form, with a desirable shortness in head, neck, and legs, a fullness of bosom, a neatly laid shoulder, a strong but not over-wide back, a deep middlepiece, and an exceptionally thick and well-laid hind quarter. No breed of sheep fattens more smoothly and uniformly than this, and, judging by carcass tests, it may be questioned if it has an equal in this respect. The

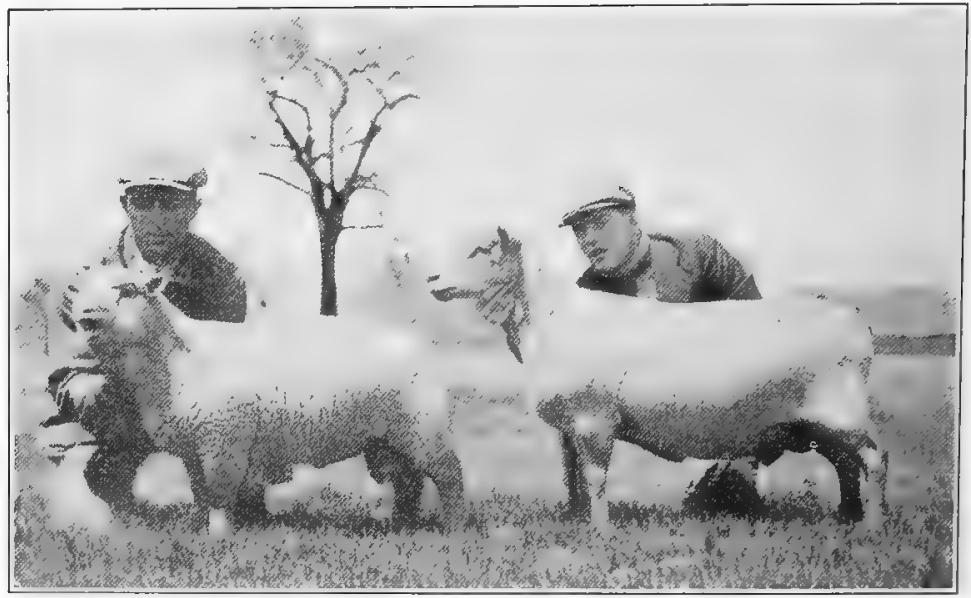

FIG. 245. A Southdown ewe and her lamb bred and owned by the Ohio State University. The early-maturing character of the Southdown is strikingly shown in this nine-months-old lamb. From photograph by the author

Southdown shows a curve in its lines, as seen in the spring of rib and turn of shoulder and thigh, that is distinctively its own. The color of face and legs ranges from a light gray to a brown or mouse color. The standard of the Southdown association specifies "a uniform tint of brown, or gray, or mouse color." The modern tendency is toward a light brown. The fleece is fine in quality, but is commonly short of staple and lacks in density. The wool extends over the head to form a cap reaching the eyes or somewhat below. The legs are well wooled to the knees and hocks, with a light covering extending to the ankles on many well-bred Southdowns. The fleece carries only a moderate amount of yolk; 
in fact, in many instances there should be more. A clear pink skin is desired and is very commonly in evidence, though dark spots may occur. The breed is hornless, and abortive horns, or scurs, which rarely occur, are disqualifications. The Southdown is noted for its quiet, docile temperament.

The size of the Southdown is inferior, ranking among the smallest of the middle-wool class. Yet the compactness of the

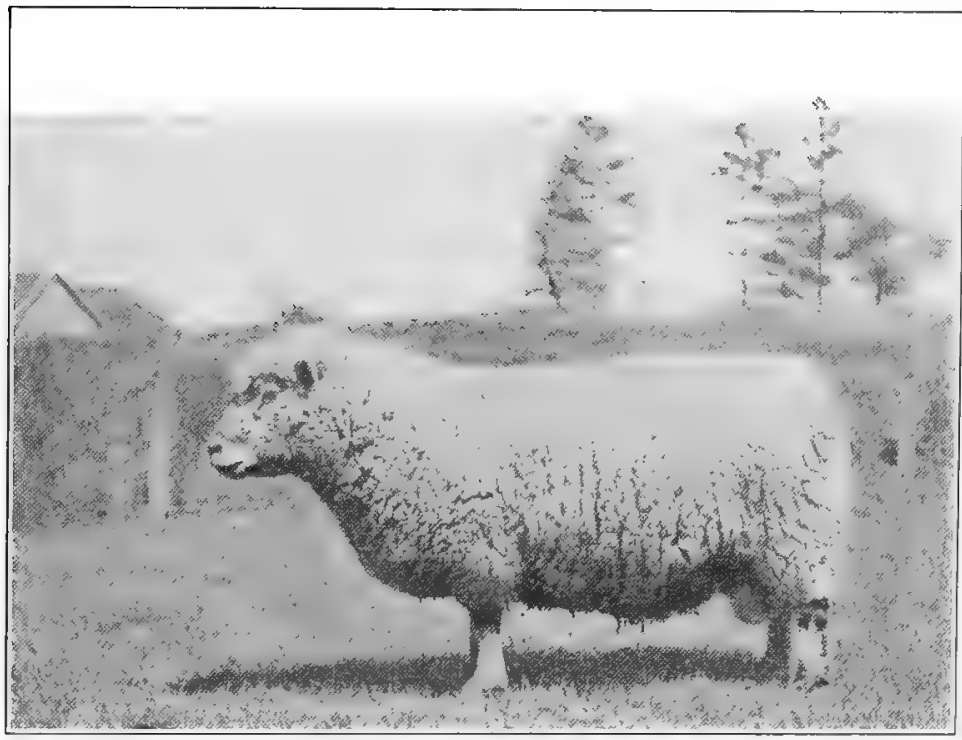

FIG. 246. Babraham Magician 3I433, an imported Southdown ram owned by the Ohio State University. This is the sire of the lambs in Figs. 248, 249, and 250 . From photograph by the author

Southdown is such that individuals weigh very heavy for their size. In 1856 Wilson wrote that at two years of age they weighed from Ioo to I 20 pounds each. Shaw and Heller commenting on the size 1 state that their deceptive weights cause them to be called "big little sheep," and assign I 70 to I9O pounds for the rams and I25. to I 30 pounds for the ewes. Coffey ${ }^{2}$ credits more weight,

1 E. L. Shaw and L. L. Heller, "Domestic Breeds of Sheep in America," Bulletin 94, United States Department of Agriculture, I9I4.

${ }^{2}$ Productive Sheep Husbandry, I9r8. 
placing that of mature rams in breeding condition at I85 to 220 pounds and ewes at 135 to I 55 pounds. George McKerrow of Wisconsin, for many years a leading Southdown breeder and importer, reports the following average weights of specimens of the breed about September 1, I889: two two-year-old rams, 206 pounds each; three yearling rams, I $53 \frac{1}{2}$ pounds each; two aged ewes, I 50 pounds each ; four yearling ewes, I $34 \frac{1}{2}$ pounds each; March lambs, I I I $\frac{1}{8}$ pounds each. The heaviest yearling weighed

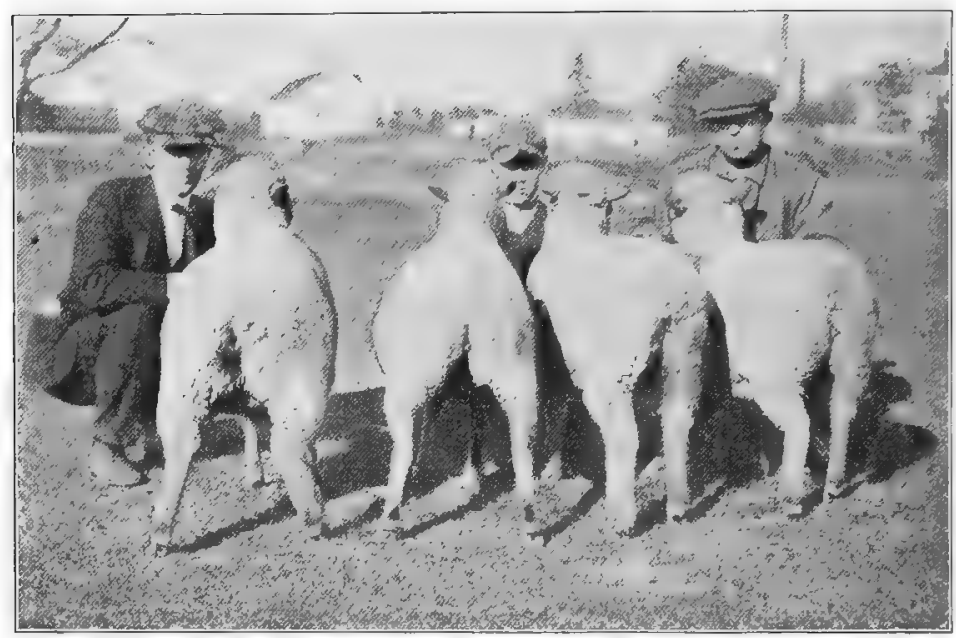

FIG. 247. Four grade C type Merino ewes, dams of the five lambs in Figs. 248, 249, and 250. Compare the hind quarter of these ewes with those of the lambs in Fig. 250. From photograph by the author

I6I pounds and the heaviest lamb I IO pounds. The imported ram Cheveley Sheik, owned by the Ohio State University, weighed 2 I 8 pounds as a three-year-old in breeding form and with a trimmed fleece. In view of the criticism the Southdown has been subjected to on account of small size, it would seem desirable for breeders to seek somewhat more scale, still maintaining quality. A weight of at least 200 pounds for rams and 150 pounds for ewes, in breeding condition, would redound to the credit of the breed.

The Southdown as a feeder is certainly in the front rank. In I 856 Wilson wrote that their disposition to fatten enables them to be brought into the market at twelve and fifteen months old, 
when they average 80 pounds each. In feeding experiments at the Iowa Experiment Station, Southdown wether lambs in one trial gained a daily average of .45 pound and in a second .35 pound, it requiring 738 pounds dry matter for Ioo pounds gain in the first trial and 989 pounds in the second. In percentage of dressed carcass the lambs in the first trial dressed 55.4 per cent and in the second 55.26 per cent, averaging higher than any other of ten breeds, while the carcass also brought in each trial the highest price per Ioo pounds. At the Ontario Agricultural College the average weight of the best fat shorn Southdown grade wethers at four hundred and forty-five days was I 85 pounds, the mean weight of all the Southdown wethers 167 pounds, while the daily gain per head was .33 pound. Wallace reports that fat wethers rising two years old, belonging to the Earl of Bathurst and sold in Cirencester market in the first.week in December, I 884, dressed I 38 pounds per carcass, or 34.5 pounds per quarter dead weight, and yielded 65.83 per cent dressed weight. At the Smithfield Club Show, between 1895 and I9I 4, according to Henry and Morrison, Southdown lambs averaged 123 pounds alive, the carcass weighing 76 pounds, dressing out 62 per cent. Yearling wethers weighed I42 pounds alive, dressing out 65 per cent.

The Southdown for quality of mutton, since its early improvement, has held premier place in the best markets. There is no excessive fat on the average fed carcass, the flesh is of the finest flavor and grain, the offal is comparatively small, and the bone is fine. It is for these reasons that the Southdown has succeeded so often in attaining the highest awards on the mutton carcasses in our fat-stock shows. At the International Live-Stock Exposition no other breed during the history of the show has in a comparative way won so many important prizes in the carcass contests. At the I9I I International the first-prize yearling wether, a South. down, weighed alive $\mathrm{I} 34$ pounds and dressed 60.45 per cent carcass. The champion carcass that year was a lamb shown by Wisconsin University, weighing I05 pounds alive and dressing 58 per cent carcass. At the I9I6 show the first-prize lamb (a Southdown shown by W. H. Miner), weighing 90 pounds alive and dressing 55.55 per cent carcass, was given the championship and sold at 60 cents a pound. At the I9I 8 International, of the six prizes in Digitized by Microsoft(e) 
the carcass contest awarded on yearlings and lambs, five were for pure-bred Southdowns and one for grade Southdowns. The grand championship went to a lamb shown by W. H. Miner that weighed 82 pounds alive, dressed 57.32 per cent carcass, and sold for 62 cents a pound. "This carcass," said Robert Lorimer, the judge, "was the most perfect I ever saw in my life; from the butcher's point of view, it might be called a model."

The Southdown crossbred or grade has long met with great favor in the mutton market. In fact the Southdown has played

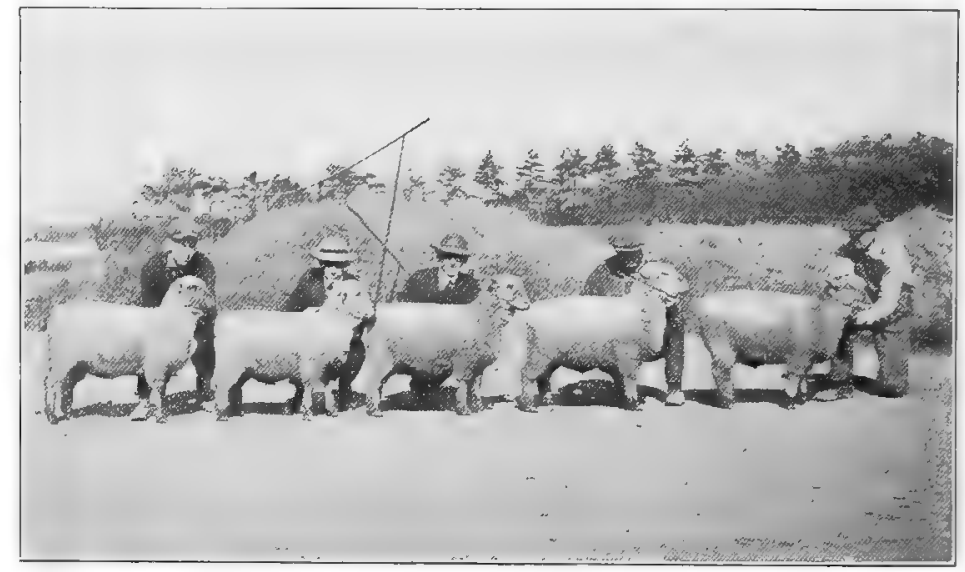

FIG. 248. Five grade Southdown wether lambs sired by Babraham Magician, out of grade Merino ewes. Bred and owned by the Ohio State University. From photograph by the author

a leading part in forming several breeds, notably the Shropshire, Hampshire, and Oxford, though it has been used more or less on other breeds to improve the fleshing and maturing qualities. Grade lambs, the result of Southdown rams on common ewes of the Merino type or of middle-wool form, will always be in comparatively high demand by butchers. In breeding Southdown rams to native grade Merino ewes at the Ohio State University, very superior progeny have resulted from a mutton point of view, showing strong Southdown character. It is an interesting tribute to the value of Southdown blood in mutton improvement that rams of this breed have been used more than any other for securing 
high-class wethers for showing in nonbreeding classes for the butcher. The Southdown blood has proved very prepotent. At the 1918 International Live-Stock Exposition a very beautiful carload of grade Southdown wether lambs, averaging 88 pounds, were awarded grand championship honors and sold for the high price of $\$ 40.50$ per hundred. In the South Dakota feeding experiment 53 lambs out of Western native ewes sired by a Southdown ram made an average daily gain of a quarter of a pound and dressed out 53.I per cent carcass to offal.

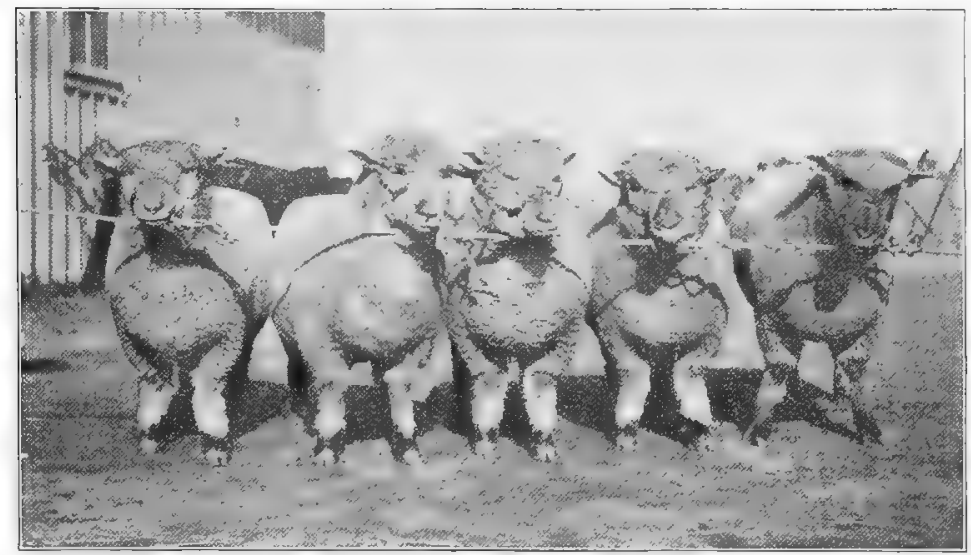

Fig. 249. Front view of the five grade Southdown wether lambs shown in Fig. 248

The breeding qualities of the Southdown are about average. In I856 Professor Wilson of Scotland wrote: "The ewes are very prolific and are excellent mothers, commonly rearing 120 or I 30 lambs to the Ioo ewes." In recent years, as compared with the Shropshire, the breed cannot be regarded as superior in fecundity. At the government flock in Vermont, according to Shaw and Heller, a lamb crop of 125 per cent has been secured. This figure is no doubt a conservative estimate. The ewes make good mothers and have a fair flow of milk.

The adaptability of the Southdown to a variety of conditions is very fair. On rolling land, and even on hilly land producing plenty of pasture, they do well. On the slightly rolling, well-drained lands of the Central West they seem to thrive, while in the South 
this has been one of the best-known breeds. They graze well and are equally hardy with most middle-wool sheep.

The Southdown as a wool sheep occupies a subordinate place. The fleece is short (averaging perhaps two inches long) and, although the finest of the native British breeds, weighs light, an average yield for a flock being less than for any other common breed. Wallace gives the weight of fleece of a ewe from 3 to 4 pounds, and Shaw from 5 to 7. In I89I General C. M. Clay, who bred Southdowns on a large scale in Kentucky for over fifty

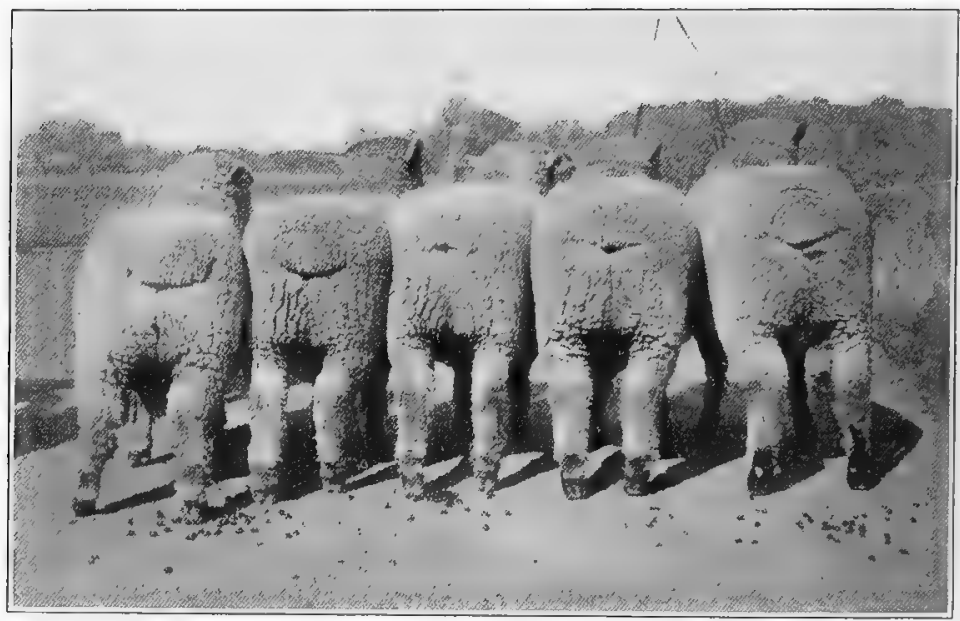

Fig. 250. Rear view of the five grade Southdown wether lambs shown in Fig. 248

consecutive years, wrote that he had "raised wool from three and one-half pounds to seven on an average." Coffey estimates a yield for twelve months of 5 to 8 pounds of wool, and the government flock at the Morgan Horse Farm at Middlebury, Vermont, has averaged approximately 7 pounds to the fleece in recent years, one ram producing over I 2 pounds. While the fleece is usually very fine, often grading half-blood combing, its short length, freedom from yolk, and small size of sheep combine to produce a fleece not weighing much over 6 pounds.

Notable prices for Southdown sheep have been paid since the days of Ellman, though the figures are not so large as those derived from Lincoln or Merino sales. In 1787 the first Southdown ram 
to bring Io guineas (\$50) was sold by Ellman to Lord Waldergrave. In I 794 the Earl of Egremont gave Ellman about \$IO each for 50 ewes. In 1796 this same breeder sold a ram for 50 guineas, or $\$ 250$. Later the Emperor of Russia and the Duke of Bedford each took two of Mr. Ellman's rams at I 50 guineas (\$750) per head. In I 829, when the Ellman flock was dispersed, 36 rams averaged about $\$$ I 25 each. At the dispersal sales of Jonas Webb in 1861 and 1862 there were sold 1404 sheep at an average of $£$ I I I $7 s .3 d$., almost $\$ 58$ each, the highest price, 260 guineas, or $\$$ I 300 , being for a ram. In I 889 and I900, at the

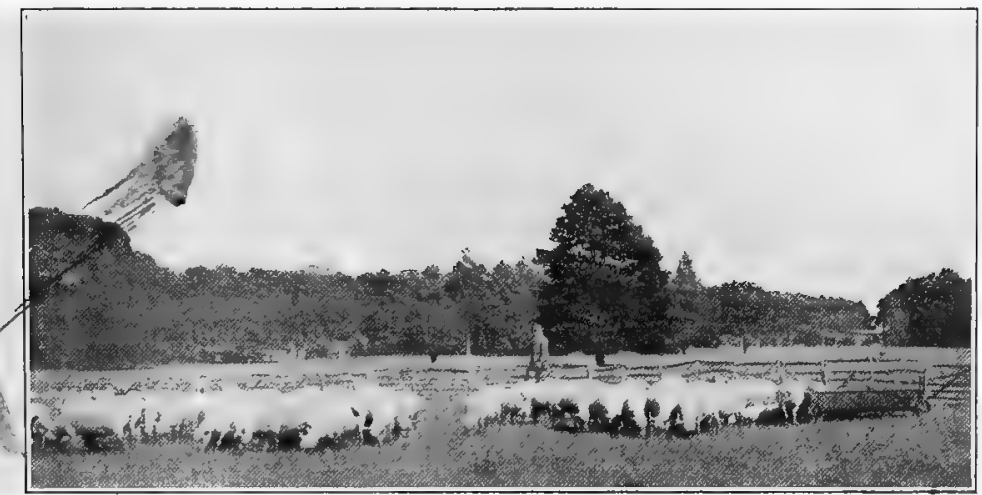

FIG. 25I. The reserve Southdown ewes on pasture at Babraham. From photograph taken in 1914 by the author

sales of Henry Webb in Cambridgeshire, 745 rams and ewes averaged about $\$ 60$ each, the top price being 210 guineas. In earlier days higher prices ruled for Snm downs in America than now. In I 856, at the sale of $\mathrm{L}$, orris, at Fordham, New York, the ewes averaged $\$ 50$, and ne imported ram brought $\$ 400$. The ram Archbishop, bred by jonas Webb, was imported by G. H. Brown andest \$1 250. No remarkable prices have been paid for Southdowns in years. The American trade is conservative on prices, and the British is very much the same. In the dispersal of the famous flock of W. M. Cazalet, Fairlawn, Kent, England, in 1916 , the leading sale for the year, 306 head brought about $\$$ IO, 500 , averaging approximately $\$ 33.50$ per head. Twenty-eight rams averaged about $\$$ IOO each, one fetching $\$ 500$. 
The promotion of Southdown sheep in an official way was first undertaken by the organization in 1882 of the American Southdown Breeders' Association, which has had headquarters at Springfield, Illinois, for many years. This association has published seventeen flock books up to I9I9. In England the Southdown Sheep Society, organized about I 892, promotes the welfare of the breed. Since 1893 , when the first volume of the British flock book was published, the society has published thirty-two volumes, including the registration of a large number of sheep.

The distribution of the Southdown is world-wide. It has been exported from England into almost every country of Europe, Africa, Australia, and America, where civilization and sheep husbandry at all prevail. Even as late as 1903 exports were made to the United States, France, Russia, Australia, the Argentine Republic, Chile, and Japan. Perhaps no breed of sheep during its career has had an equally wide distribution. In the United States Southdowns are recorded as bred in nearly fifty states, important flocks being kept in Ohio, New York, Pennsylvania, Illinois, Wisconsin, Vermont, West Virginia, and Kentucky. Southdowns, all things considered, are more popular in the South than any other breed. They are also well represented in Canada, notably in Ontario. 


\section{CHAPTER XLIX}

\section{THE SHROPSHIRE}

The native home of Shropshire sheep is in the counties of Shrop. shire and Stafford, England. Shropshire is in central-western England, being bounded on the west by Wales, while Stafford lies just to the east. Shropshire is an irregular parallelogram with an area of about I 346 square miles. The river Severn flows through the county, and Shrewsbury, with a population of about 30,000 , is the county seat. In I 803 Plymley wrote ${ }^{1}$ :

Though no part of this county can be called flat, generally speaking, yet the northeastern parts are comparatively so, as contrasted with the hills on its southern and western borders, leading on to the Welsh mountains, and with the hills of Derbyshire and Stafforashire to the east unite with the still more level country of Chester, in forming a great plain or valley.

The Clee Hills to the southwest rise to an altitude of 1800 feet. The soil varies from light alluvial to heavy clay, and the small cereals, grasses, and root crops do well. The climate is moderate and well suited to sheep.

The origin of Shropshire sheep is from several native types on which Southdown, Leicester, and Cotswold blood was used. In 1803 Plymley wrote that considerable flocks were then kept in southwest Shropshire, but in the county, as a whole, flocks were few and small. He states that there is a breed of sheep on the Longmynd with horns and black faces that seems an indigenous sort; these sheep are nimble, hardy, and weigh near ten pounds a quarter when fatted, and have fleeces that may weigh two and onehalf pounds, of which a half will be breechin, or coarse wool. He also states that the farmers of the hill country seem to think the greatest advantage they derive from the access of foreign stock is from the cross of the Southdown with Longmynd sheep. In I 792 the Bristol Wool Society, reporting on the sheep of England, ${ }^{2}$ stated

1 Joseph Plymley, General View of the Agriculture of Shropshire, I803.

2 John A. Craig, Sheep Farming in North America. New York, I9I3. 


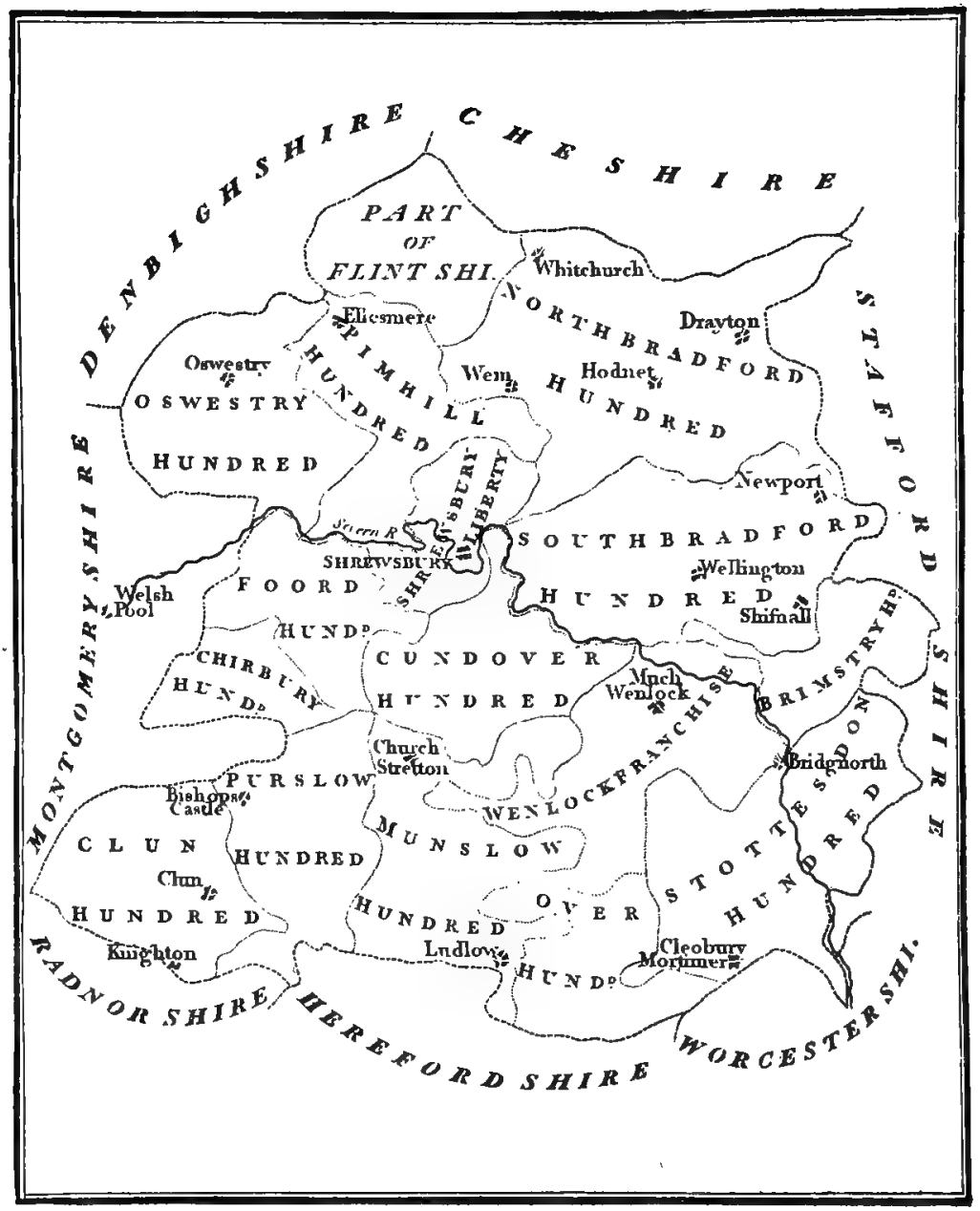

FIG, 252. An old map of Shropshire, England, reproduced from Plymley's "General View of the Agriculture of Shropshire," 1803 . The word "Hundred" seen on the map represents a division of the country in which originally one hundred families were supposed to reside 
that on Morfe Common, near Bridgnorth in southeast Shropshire, as many as IO,O00 sheep were pastured in summer which produced wool of superior quality. "They are considered a native breed - a black-faced or a brown or spotted face, horned sheep, little subject to either rot or scab, clipping nearly two pounds of fleece exclusive of the-breeching, which may be taken at one-seventh or one-eighth part of the whole." On Cannock Chase in Staffordshire was found a similar but somewhat larger, slow-maturing sheep, from which was descended some

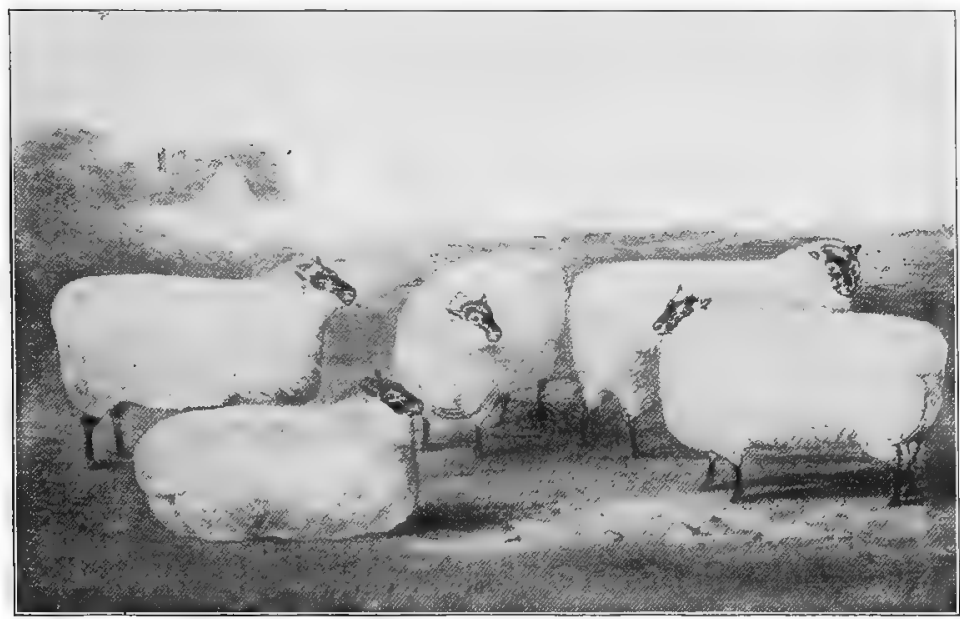

Frg. 253. Shropshire yearling ewes, prize winners at the 1859 show of the Royal Agricultural Society of England. Exhibited by J. Crane. From a photograph of an old English painting

of the best Shropshire flocks of to-day. On Whittington Heath in Shropshire a type similar to that of Cannock Chase also existed and became amalgamated in the general improvement. The Southdown was used on these to secure quality, while the Leicester and Cotswold blood were used to obtain size and fleece, and from this combination, after a considerable process of selection, came the modern Shropshire. The breed is comparatively recent in its present character, though Alfred Mansell says the best characteristics were present when the work of improvement was begun. As late as 1858 Professor Tanner wrote ${ }^{1}$ : "Only a few years

1 Henry Tanner, "The Agriculture of Shropshire," Joum. Royal Ag. Soc., 1858. 
since any mention of the Shropshire Down sheep raised an inquiry, even among intellectual agriculturists, as to their character, and few, comparatively speaking, knew anything of them." Tanner, however, refers to the rapid rise in popularity of the breed and states that at the time of writing Shropshires "stand high as general favorites, and are rapidly extending throughout this and foreign countries." In I 859, in an interesting essay on crossbreeding, ${ }^{1}$ W. C. Spooner discusses the origin of various British breeds, in which he quotes J. Meire, with the following statement to a farmers' club in Shropshire :

It is not attempted to be denied that the Shropshire is a cross-bred sheep; the original breed was horned, and the first attempt at improvernent was to get rid of these incumbrances, and there is little doubt that this was effected by a cross of the Southdown. This sheep was well adapted for the Downs, but for the enclosures of Shropshire something more docile was required, consequently recourse was had to the Leicester.

Spooner states that this crossing and recrossing was followed by careful selection, until at the time of his writing (1859) "no further cross is required."

Two early prominent improvers of the Shropshire are said to have been Samuel Meire of Berrington and later of Harley, near Shrewsbury, and George Adney of Harley. Meire sought to remove the Shropshire coarseness and horns and to improve the levelness of back and spring of rib, the obliqueness of shoulder, and the breadth and fullness of rump. He purchased or hired Southdown rams from John Ellman of Glynde and used them in his flock. $\mathrm{He}$ also used Leicester blood, with the purpose of getting better feeders and animals of shorter body. After securing his type he practiced the selection necessary to establish his improvement. Adney did not cross extensively, but a ram named Buckskin used in his flock, with Southdown blood in his veins, produced superior sheep, one of which, the ewe Old Patentee, was a famous dam and prize winner whose blood is prominent in the best early Shropshire pedigrees. Many of the best flocks of to-day trace to those of Meire and Adney. Other prominent breeders and improvers were G. M. Kettle of Dallicott, Henry Smith of Shiffnal, Green of

1 Journal of Royal Agricultural Society of England, Vol. XX (1859), p. 294. 
Marlow, Horton of Shrewsbury, Farmer of Bridgnorth, Thomas Mansell, Thomas Harley, J. \& E. Crane, and John Stubbs.

Shropshires were first exhibited at the Royal Show in England in 1853 in a special class for short-wooled sheep, and in 1859 were given a class as a separate breed. Within a few years it was the most prominent breed shown, 875 head being exhibited at the Shrewsbury Royal in 1884 compared with 420 representing all other breeds. At the Royal Show in I9I4, held at Shrewsbury, which was attended by the author, the total entries of sheep of

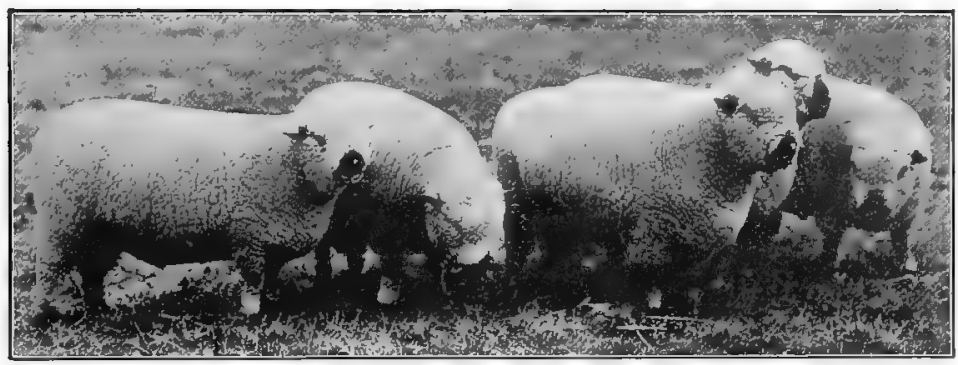

FIG. 254. Second-prize pen of Shropshire yearling rams at the Royal Agricultural Society of England Show, 1904. Bred and exhibited by Sir R. P. Cooper, Bart., Shenstone, England. From photograph, by courtesy of William Cooper \& Nephews, Berkhamsted, England

all breeds were 886 , of which the Shropshire numbered I45, the second in numbers being the Romney Marsh with 84 head, and the third the Southdown with 76 head.

The introduction of the Shropshire to America was necessarily comparatively recent. Shaw and Heller state that they were introduced to Virginia as early as $\mathrm{I} 855$, but the records do not state by whom. In I 860 Samuel Sutton of Relay House, Maryland, imported a ram and twenty ewes, which the American Farmer for August, I86I, reports were the first of the breed to be imported to America. According to Randall ${ }^{1}$ two Shropshires were imported by N. L. Chaffee of Jefferson, Ashtabula County, Ohio, in $\mathrm{r} 86 \mathrm{I}$ - a ram, Lion, and a ewe, Nancy, both bred by Lord Berwick of Shrewsbury. About I86I A. B. Conger of Haverstraw, New York, had a flock, and in I 864 he sold the first of the

1 Henry S. Randall, The Practical Shepherd (1863), p. 64. 
breed to go into New Hampshire, to P. W. Jones of Amherst. Shropshires were exhibited at the New York State Fair at Elmira, in $186 \mathrm{I}$, including the ram Gratitude, that had been shown the year previous at the Royal Agricultural Society Show at Canterbury, England. In I 862 P. Lorillard of Fordham, New York, also had a flock, and in I 868 L. C. Fish of Otego, New York, began breeding them. About 1875 the first Shropshires were brought from Canada to Michigan by Mrs. Ann Newton of Pontiac. In 1880 this breed was advertised by J. A. Brown \& Son of Decatur, Illinois. Along in the eighties numerous importations were made into Indiana, Illinois, and Michigan, and the breed became well

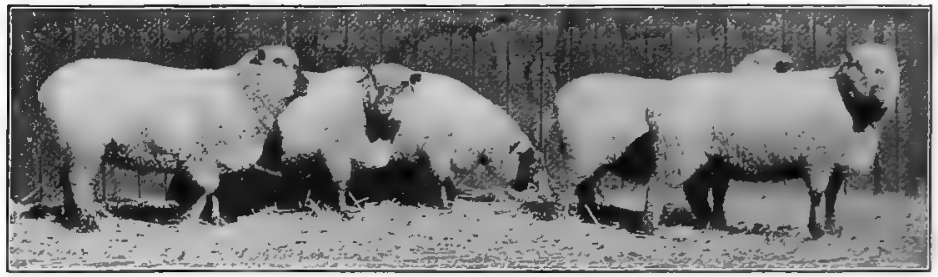

FIG. 255. The champion pen of Shropshire yearling ewes at the Royal Agricultural Society of England Show, 1897. Bred and exhibited by T. Bowen-Jones, Shrewsbury, England. From photograph by the author

distributed. The World's Columbian Exposition Show at Chicago in 1893 excited much interest in the Shropshire and greatly stimulated importation, and large numbers of these sheep were brought to America in the next few years.

Characteristics of the Shropshire. This breed is of the mediumwool class and is somewhat heavier and larger than the Southdown. The face, ears, and legs are usually a dark brown or blackish brown, although prior to Igoo they were often grayish brown of face. There may be some variations in color, and steel gray is often found in accredited flocks, though it is not popular. A light rusty brown of a faded reddish shade or spotted markings may disqualify. The head is hornless and is slightly larger than the Southdown, and in the best specimens is covered with a striking cap of wool even to the nostrils, covering all but a small part of the nose. The ears should be small, short, and moderately broad, and be well covered with short, fine wool. Shropshire ears are often bare of 
wool and too large and plain. The back and loin of the Shropshire is one of its strong features, combining level carriage, width, and covering to a commendable degree. Fullness of bosom, a wide, prominent.brisket, and a well-sprung, deep rib combine to give an impression of strong digestive capacity. The hind quarters on the average Shropshire lack in width and level carriage of rump and thickness of thigh and twist of the Southdown. The fleece covers the entire body admirably, being compact and fairly long and of superior quality. In temperament Shropshires are of first class, being easily handled. The skin of representatives of this breed is very often mottled or bluish pink and lacks the superior quality and color of either the Merino or Cheviot. Modern-day Shropshire breeders discriminate against dark skins and emphasize the importance of a clear, bright pink or cherryred color. Evidence of horns or stubs, heads bare of wool, and obscurity of breed character are disqualifications, on the basis of the official standard of

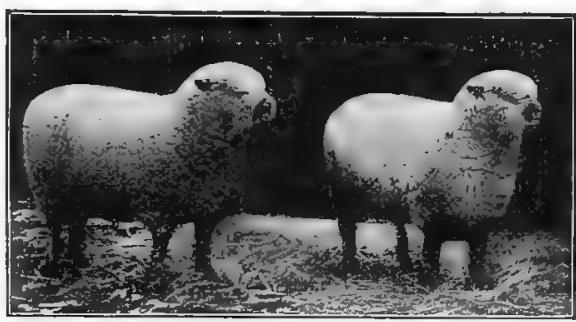

FIG. 256. A pair of prize-winning Shropshire ewes at the Pan-American Exposition, I9or. Owned and exhibited by G. H. Davison, Millbrook, New York. From photograph, by courtesy of the National Stockman and Farmer excellence. "In style and show-yard finish," says Coffey, " "the Shropshire is impressive and it leads the mutton breeds in drawing attention and admiration at live-stock exhibitions. With its head set proudly upon a gracefully turned neck, and its smoothly turned symmetrical body, and its picturesque extension of downy, white wool over the face and legs, it possesses an air of grandeur rather than of smartness and nattiness which is characteristic of the Southdown."

The size of the Shropshire is about medium among breeds of its class. A standard weight for rams in good breeding condition is 225 pounds, with I 50 to 180 for ewes. Coffey gives 200 to 250 pounds for rams and 150 to 180 pounds for ewes. The official standard of the American Shropshire Association is 175 
to 250 pounds for rams and 140 to I 80 pounds for ewes. Twohundred-and-fifty-pound rams and one-hundred-and-eighty-pound ewes are very exceptional, notwithstanding the present tendency to breed for more size than was the case a few years ago. In the show ring, providing there is sufficient quality, the larger Shropshires receive preference from the critics, although excessive size is as undesirable as undersize.

The Shropshire as a mutton sheep is of a superior order, ranking next to the Southdown, and when well fed often equaling it.

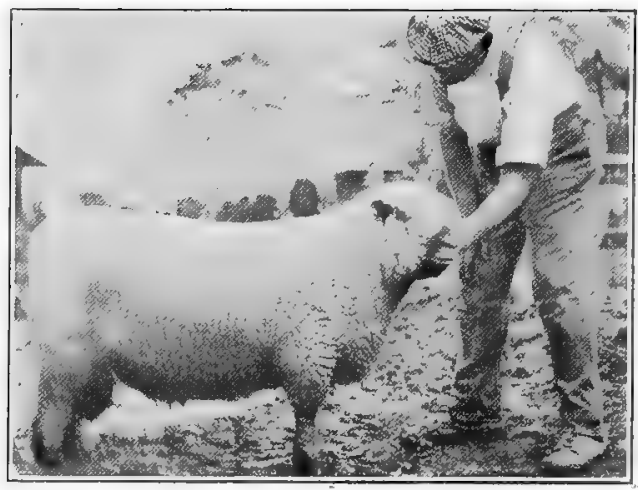

FIG. 257. Montford Emblem (imp.), the champion Shropshire ram in America in 1918 at the leading shows. Owned by Jess C. Andrew, West Point,

Indiana. From photograph by the author In the Iowa Station breed test Shropshire fattening wethers of an average age of three hundred and seventyone days; in the first trial, made an average daily gain of .48 pound, and in the second trial, covering two hundred and seventy-nine days, gained an average of .36 pound daily. In one trial it required 7 I 8 pounds dry matter for Ioo pounds gain, and in the other I026 for Ioo pounds gain. The valuation per Ioo pounds live weight ranked second to the Southdowns, namely, $\$ 4.63$ and $\$ 5.60$ for each trial. In feeding experiments on Shropshire lambs conducted by Professor Brown at the Ontario College, grades of this breed made the best record among five tested. The Shropshire has not figured prominently in the carcass contests at the International Live-Stock Exposition, perhaps because breeders were not interested to present this breed in an aggressive way for this purpose. In 1908 the University of Wisconsin won first in the yearling carcass class with a Shropshire that weighed ${ }^{6} 67$ pounds on foot and dressed 59.88 per cent carcass, but won the grand championship with the carcass of a Southdown lamb. In general 
practice, however, the Shropshire has proved to be a superior feeder and produces a choice grade of mutton, though not likely to take on fat with quite the smoothness and evenness of the Southdown.

Crossbred or grade Shropshires are to-day one of the most common types of mutton sheep found on the market. Shropshire rams used on native ewes furnish lambs of a much-desired class; they fatten easily, are not too large, and are profitable killers. In the Mississippi Valley states Shropshire grades are the common sheep outside of Merino communities. A Shropshire ram-Merino ewe cross is also a very beneficial one from a mutton point of view. Used on the long-wool grade ewes a smaller, better mutton sheep results, with a more profitable fleece. In I894 Alexander Bruce, chief live-stock inspector for New South Wales, wrote: "For the production of prime fat lambs there is no better ram (if there be as good) than the Shropshire,

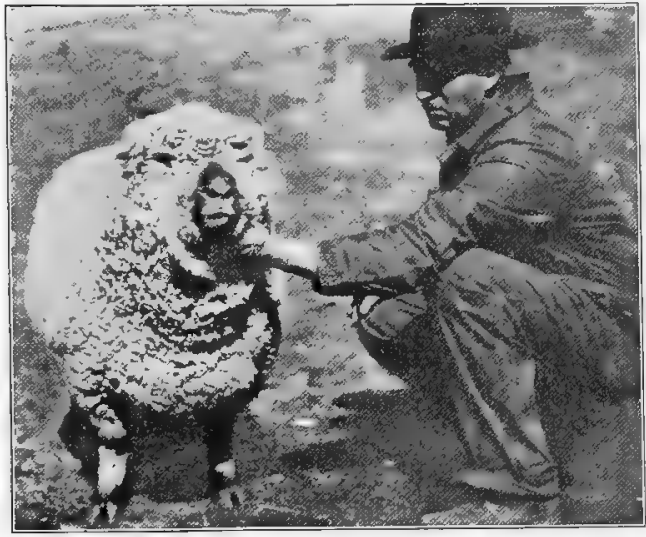

FIG. 258. Front view of the Shropshire ram Broughtons 2532 in field condition. Owned by the Ohio State University. From photograph by the author and the result is equally favorable where that ram is put to crossbred ewes." From a fleece point of view the Shropshire crossbred or grade produces a class of wool much in favor and for which, other things being equal, there is a great demand at the higher market price. Reporting on the use of Shropshire rams on Merino ewes, Craig states of the first cross that "the fleece is exceptional in the degree to which it meets the demand of the market for a medium combing wool. The fiber is coarser and longer than the pure Merino, but these qualities in connection with its firmness and strength make the fleece worth more in the market."

The Shropshire as a grazing sheep ranks but fair. It is especially adapted to regions where the pastures are superior, but it 
is not so well adapted to hilly land nor to sparse pasturage as the Merino, Southdown, or Cheviot. It is distinctly suited to the corn belt of America, where it is most abundant. It is also well suited to the better Canadian pastures, and in New England satisfactory results have been secured on the more fertile lowlands or in the upland valleys. It may, in fact, be regarded as adapted to average conditions.

The early maturing qualities of the Shropshire are pronounced, ranking in the first class. Lambs at four months will easily weigh 40 pounds and under special feeding will attain a weight of approximately 70 pounds. The grand-champion carload at the I9I 3 International - a very choice exhibit by Knollin and Finch of Idaho - was of pure-bred Shropshire lambs. They were lambed between April 10 and 20, and the 55 head in Chicago had an average weight of 98 pounds, which shows an approximate daily gain of .4I pound for two hundred and thirty days. Considering the long shipment from Idaho to Chicago, this is a fine showing. At twelve months, under fair conditions, the weight should be about IOO pounds without forced feeding. Wallace gives 20 to 22 pounds per quarter the dead weight at twelve months old. The early-maturing, easy-fattening character of the breed or its cross or gracle is what makes it so popular among feeders. Further, for years dark-faced mutton has been more popular in the market than the white-faced.

The constitutional vigor of the Shropshire has been criticized as not of the hardiest sort. Compared with the Merino, the Shropshire is more subject to colds in winter and shows less resistance to the twisted stomach worm (Strongylus) than is desirable. From the observation of the author, while the Shropshire is not lacking in vitality in comparison with other mutton breeds, it does not show the resistance to disease and parasites that the Delaine, Rambouillet, or Cheviot do.

The fecundity of Shropshire sheep is notable. The ewes of this breed have long been noted for the number of lambs they will produce. A ewe owned by a Mr. Pochin at Leicester, England, dropped 5 lambs in I882, 4 in I883, and 4 in 1884 . A writer in the English Agricultural Gazette in 1879 reports that in 1877 he had 125 cwes suckle 194 lambs, in 1878 he 
had I 20 suckle 176, and in 1879 he had 124 suckle I9I. Mr. Alfred Mansell, secretary of the English Shropshire Socicty, states that 150 to 175 lambs per 100 is the usual average and that I I,666 ewes in 1896 reared 168 lambs per Ioo ewes. In a study of 23,037 Shropshires recorded in the "American Shropshire Flock Book" the author found 13,659, or 59.2 per cent, of single birth; 9053, or 39.2 per cent, registered as twins; and 3 I5, or 1.3 per cent, as triplets - this record covering the years

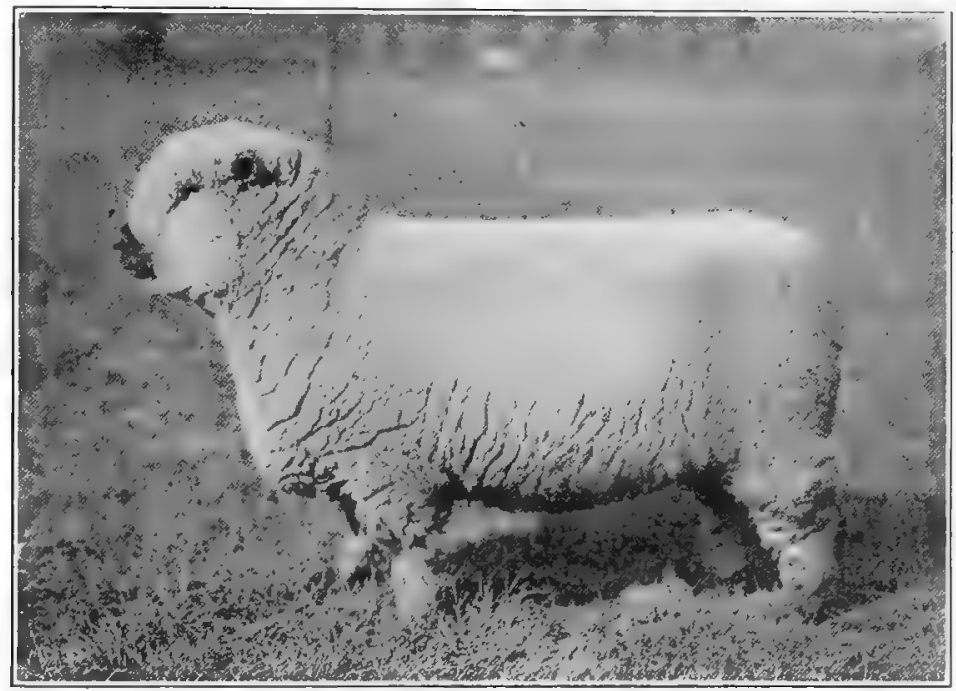

Fig. 259. A first-prize Shropshire ewe lamb at the I9I8 International Live-Stock Exposition. Bred and exhibited by Illinois University. This is a very beautiful example of the breed. From photograph, by courtesy of Professor W. C. Coffey

I 890 to I899. Undoubtedly one may safely count on I 25 to I 50 per cent lambs to ewes and, where carefully selected for prolificacy, even I75. But twins and triplets are as a rule less strong than single lambs, and the first thing of importance is a strong, lusty, growthy lamb. While breed advocates have reason to be proud of the fecundity of the Shropshire, in which regard it is not surpassed, triplets are undesirable, and Ioo per cent lambs raised to full strength for a year is a fine record.

The Shropshire as a wool producer ranks very well. The average fleece of unwashed wool will probably not much cxceed 
8 pounds. Wallace places 7 or 8 pounds a good average weight for the fleece of an ordinary ewe flock, while Professor Thomas Shaw gives 9 to 10 pounds for the ewes and 12 to I 5 pounds for the rams as the average of a "good flock." Coffey gives the average weight of fleece at 8 to Io pounds, and Shaw and Heller refer to a flock of 200 ewes where fleeces averaged I0.3I pounds. The staple of the Shropshire is rather compact, of better than medium quality usually, and grades as three-eighths combing in the wool trade. In good specimens it is of superior fineness and

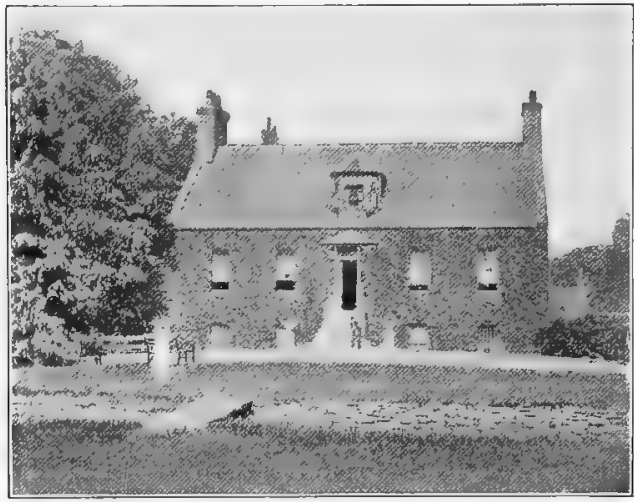

FIG. 260. Corston, the home of T. A. Buttar at Cupar-Angus, Scotland. Mr. Buttar is perhaps the greatest breeder of Shropshires living to-day (1920), and his sheep are famous for their excellence. From photograph by the author crimp and ranges from two and one-half to three inches long, distinctly longer than the Southdown but shorter than Oxford or Hampshire. When the fleece is opened it frequently shows a considerable yolk for medium wool and has a most attractive fiber. A good specimen of Shropshire should be well covered with wool over the belly and down the legs to below knee and hock. Dark wool should not

occur, unless in a slight degree below the hocks, but dark or black locks occasionally appear in a small way, more especially about the poll. In the pure-bred flock it is not only important to use a ram that has a fleece of good quality and weight but the color should be a pure white.

The prices paid for Shropshires, while not comparable with some of the other breeds, such as the Merino and Lincoln, have attained very high figures. In I88I Mr. A. B. Allen wrote: "I notice from late sales reported in the English papers the choicest are bringing high prices, Io to I oo guineas (\$50 to $\$ 500$ ) each, and one ram has been sold for the extraordinary sum of 
200 guineas (\$1000)." Mr. Alfred Mansell, long a prominent auctioneer of Shropshires abroad, has published quite a record of Shropshire sale prices. A list of 464 rams ranged in average selling price at auction from slightly above $\$$ I 00 per head to over $\$ 200$, while 1700 ewes sold at prices ranging from $\$ 20$ to over $\$ 50$ per head. A list of 53 rams is also given by name, which have either sold or been hired for from $\$ 305$ up to $\$ 250$ each, 9 of which came within the $\$ 1000$ list. In I893 W. BowenJones of England sold a ram at auction for \$1000 to Thomas and Son. In I $896 \mathrm{Mr}$. Mansell wrote: "Foreign and colonial flockmasters have been good customers, and at high prices, running up to 200 guineas for rams, 30 guineas for ram lambs, 40 pounds for ewes, and 15 guineas for ewe lambs." In I9ro Thomas Minton of Montford, Shrewsbury, a most noted constructive English breeder, sold the two-year-old ram Montford Trader at auction for $\$$ I I 25 , the record price up to that date. It is interesting to note that the Minton flock, owing to the death of Mr. Minton, was dispersed at auction, September 19, I917, when 391 head averaged $\$ 50$ each, 39 rams averaged $\$ 85$, and 90 stock ewes about $\$ 45$ each. In the United States values as a rule have been conservative. The champion ram of the breed at the 1909 International Live-Stock Exposition, exhibited by Elmendorf Farm of Kentucky, was sold for $\$ 500$ to D. V. Perrine of Idaho. In 1916 T. F. Jones of Iowa paid George McKerrow of Wisconsin $\$ 500$ for a half interest in the ram Senator Bibby. On January 14, I9 19, A. T. Jones and Sons of Iowa broke American Shropshire price records in the dispersal sale of their herd, 142 head (of which $\times 37$ were ewes) bringing $\$ 17,475$. One ram brought $\$ 550$ and one ewe $\$ 500$. Twenty daughters of the ram Senator Bibby brought an average of \$I I I per head.

The distribution of the Shropshire is world-wide; no other mutton breed has approached it in universal popularity. From England these sheep have been exported to many different countries. In 1907, according to Alfred Mansell, ${ }^{1}$ secretary of the English Shropshire Society, 1427 Shropshires were exported to the United States, Canada, and Newfoundland ; 569 to South America, including Argentina, Uruguay, Brazil, Chile, Peru;

1 Lize Stock Jounnal Almancic, London, rgi7. Digitized by Microsofte 
2 I 2 to Australia, Tasmania, and New Zealand; 45 to South Africa, Algiers, Algoa Bay; 6I to Russia, Germany, France, Spain, Denmark, Sweden, Hungary, Jamaica, Finland, Greece, Portugal, a total of 2314 head. Since I9I4 the number exported has greatly diminished, but 368 head were shipped to different countries in 1916. Shropshires are popular in England, especially in the county of its nativity, in Australasia, Canada, and the United States. In 1908 it was reported by J. B. Spencer ${ }^{1}$ that of 19,545 head of pure-bred sheep in Canada 6000 were Shropshires, leading all other breeds but the Leicester. In the United States, where this is the favorite mutton breed, they are found from the

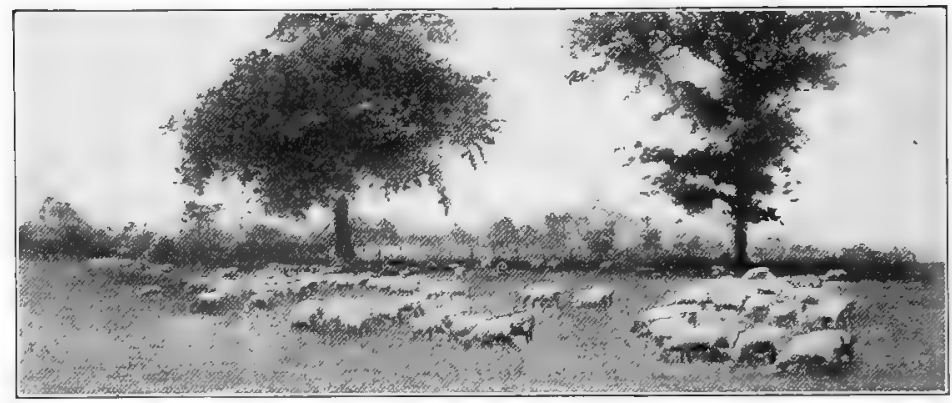

Fig. 26I. Shropshire ewes on pasture at Corston, Cupar-Angus, Scotland. From a photograph by the author in I9I 4

Atlantic to the Pacific and from the northern to the southern boundaries. However, the breed is most abundant in New York, Pennsylvania, Ohio, Indiana, Michigan, Wisconsin, Illinois, and Iowa. This wide distribution gives evidence of the adaptability of the breed. The ideal conditions are found in a country with rolling surface, well grassed, and not too hot and dry. The great Shropshire shows in the United States are at the International Live-Stock Exposition and the state fairs of Ohio, New York, Indiana, Michigan, Wisconsin, and Illinois.

The official promotion of Shropshire sheep has been in very efficient hands. In I882 the English Shropshire Society was established, and the first volume of its flock book published in

1 "Sheep Husbandry in Canada," Bulletin 12, Dominion of Canada Department of Agriculture, I 908 . 
I 884. This society up to I9 8 had published thirty-six flock books and registered a large number of sheep. The American Shropshire Sheep Association was organized at Lafayette, Indiana, in February, 1884, and has made a remarkable record. As early as I 893 it had a membership of one thousand, since which time it has become the largest sheep association in the world. Its first flock book was published in 1889 , and the association has published thirty volumes up to I919, registering 436,248 sheep. A national Shropshire sheep association was organized in 1900 and published one flock book in 1902, but none since. Flockbook societies are maintained in Australia and Tasmania. This breed is also promoted by a number of state Shropshire associations. The Ohio Shropshire Sheep Breeders' Association was organized in January, I892, at Columbus, and the New York State Shropshire Breeders' Association about I 89 I. 


\section{CHAPTER L}

\section{THE OXFORD DOWN}

The native home of the Oxford Down sheep is in the county of Oxford in south-central England, the southern boundary of which is some sixty miles from the sea. Oxford contains about 750 square miles, and the city of Oxford, the county seat, where the famous Oxford University is located, has a population of approximately 200,000 . It is a fine agricultural county, with much fertile soil, where cereals, roots, and grasses especially thrive, and sheep do well.

The origin of the Oxford Down sheep is comparatively recent. About I833 Mr. Samuel Druce of Eynsham, Messrs. William Gillett of Southleigh and Blake of Stanton Harcourt, all in Oxfordshire, and Mr. Twynham in Hampshire began to develop a new breed, though Mr. Druce was the leader in the movement. In $1859 \mathrm{Mr}$. Druce wrote to Mr. Pusey ${ }^{\mathbf{1}}$ :

The foundation of this class of sheep was begun about the year 1833 , by using a well-made and neat Cotswold ram with Hampshire Down ewes. At the same period several breeders of sheep in this neighborhood also tried the experiment; consequently there has always been an opportunity of getting fresh blood by selecting sheep which suited different flocks and thereby maintaining the uniform character which is now established.

Although Twynham may perhaps have a claim to priority in crossing the Hampshire Down ewe with the Cotswold ram, writes Spooner, ${ }^{2}$ yet from various causes, probably because the Hampshire hills were scarcely adapted for such large sheep, they failed to establish themselves in this locality. Druce and Gillett also used Southdowns to some extent in the early days of their crossbreeding. In establishing this cross $\mathrm{Mr}$. Druce wrote in 1853 that he found no difficulty in keeping the form and size of the animal as it should be, and the wool of a valuable quality and not deficient in quantity.

1 Journal of Royal Agricultural Society of England, Vol, XX, p. 309.

2 Ibid. p. 309. 
He also maintained that the good qualities could be better secured by using crossbred animals on both sides than by using the first cross. Crossing was undoubtedly continued for many years, with the view of securing a sheep better suited to light farm land and producing superior mutton and a heavier fleece than that yielded by the pure-bred. "Mr. C. S. Read," says Wrightson, "tells us

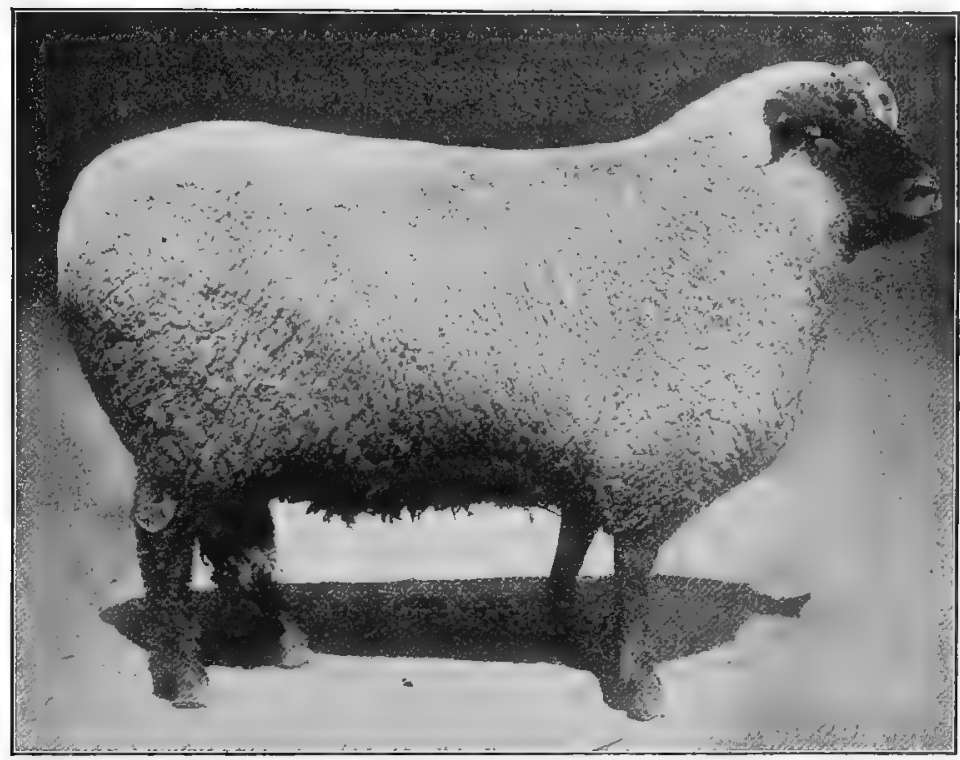

FIG. 262. An Oxford ram imported in 1900 by George McKerrow \& Sons of Wisconsin, a first-prize winner at six state fairs that year and five times sweepstakes ram. This ram is blacker and barer of face than with the present-day Oxford Down. From photograph, by courtesy of the National Stockman and Farmer

that the (flock) owner formerly divided his flock into three parts, putting a half-bred ram to the ewes that were about right - a Cotswold to the small ones and a Down to the coarser sheep."

It is said that the breed has "been kept distinct from either parent strain" since about I854. At this time the breed, then known as New Oxfordshire, was coming into high favor. In I8.57 the name "Oxford Down" was adopted. In 1859, in comments in the Royal Agricultural Society Report on the sheep at English shows, it is stated that some excellent sheep of this breed 
have been shown at the various meetings, but their career has been most noticed in the yard of the Smithfield Club Show, where Oxford Down fat wethers "again and again astonished the public." Oxford Downs were first given a class at the Royal Show in I 862 at Battersea, and from this time on, for some years, the lack of uniformity in breed character and type caused considerable unfavorable comment by the judges, which resulted in marked improvements into a more fixed type.

The introduction of Oxford Down sheep to America first occurred in 1846 , when "New Oxford or Cotswold crossbred sheep" were imported to the United States by Clayton Reybold of Delaware. In $1853 \mathrm{~W}$. C. Rives, then in England, sent to his home in Virginia I ram and 5 ewes. In September, I853, R. S. Fay of L,ynn, Massachusetts, imported a ram and Io ewes. The Ohio Cultivator of August I5, I 853, reports that Messrs. Baldwin and Boardman of Columbiana County, Ohio, sold Oxfordshire bucks and Southdown bucks - -20 head for $\$ 8$ oo. Late in 1853 J. T. Andrew of West Cornwall, Connecticut, established a flock which became famous, as did also that of Mr. Fay. Lawrence Smith of Middlefield, Massachusetts, must have established a flock about this time, or even before, for in I 860 Charles L. Flint states ${ }^{1}$ that Mr. Smith "has bred them for over eight years." Smith has also been credited with buying 27 head in I 857 from J. T. Andrew, who also sold a flock to C. L. Whiting of Granville, Ohio. This breed seems to have attracted considerable attention, and even as early as I 859 a flock was owned in Texas by Colonel C. G. Forshay, who had purchased from J. T. Andrew. The Civil War caused a break in Oxford Down interests, and not until years afterward did this breed again come into prominence. Along in the nineties importations again became active, and for many years considerable numbers of Oxfords were brought to America, W. A. Shafor of Ohio, R. J. Stone of Illinois, George McKerrow of Wisconsin, and Robert Miller of Ontario, Canada, being prominent in this work. In recent years Oxfords have not been brought to the United States in important numbers.

Characteristics of Oxford Down sheep. This breed, at a superficial glance, closely resembles the Shropshire. It is hornless, has

1 Eighth Annual Report Secretary Massachusetts State Board of Agriculture. 
a dark brown face and legs, is wooled over the forehead, and is a typical mutton sheep. However, under average conditions the Oxford Down is lighter brown than the Shropshire, is not so heavily wooled over the head, though with longer, looser forelock, has a larger frame and more scale, with a longer, more open fleece. In early days the Oxford face was speckled or mottled brown and white or gray, and the fleece was rather long and open, quite suggestive of the long-wool type, as might he expected, considering the Cotswold blood used. The modern Oxford, however, has been bred to be uniformly brown in face, though the American standard calls for an even dark gray or brown face with or without a gray spot on the lower part of the nose, and the fleece has been bred shorter and more compact. The head of the Oxford is rarely wooled much below the forehead, and the dark gray or brown ears tend to be somewhat long and

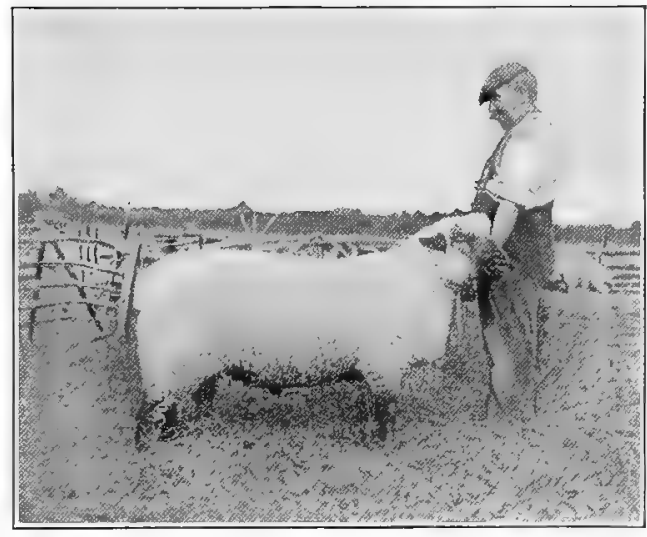

FIG. 263. A reserve Oxford Down stud ram in the flock of the late John Bryan, South Leigh, England.

From photograph by the author

thin and free of wool. As a rule Oxfords show the distinctive mucton form, with a strong breadth of back and excellent leg of mutton. The skin of the Oxford Down, like the Shropshire, is frequently bluish tinted, lacking the pink, bright cherry color most admired. The twentieth-century Oxford Down is a sheep of much merit, but lacks the refinement of Southdown or Shropshire, as expressed in the grosser size and quality of bone and fleece. An interesting comparison of the Oxford and Shropshire by John Wrightson ${ }^{1}$ of England, who was a keen observer of sheep and lived close to their native home, is well worth quoting here:

1 Sheep: Breeds and Management, p. 70. London, 1895. 
As the remark has been made by a practical man that the Oxfordshire and Shropshire sheep are so alike that when classed together at earlier meetings of the Royal, "many considered them one kind of sheep," I will point out the characteristic difference which close inspection will reveal. The Oxfordshire head is longer, and the profile is bolder and slightly more Roman and fine; the Oxfordshire ear is long and thin, whereas the Shropshire has a shorter and rounder ear. The Oxford carries himself a little more gaily and sprightly, and his wool is rather longer and looser than the Shropshire. The wool on the head of the Oxford is longer, and more of the flowing nature of a fore lock. That of the Shropshire sheep is closer, fitting like a continuous cap or helmet.

The size of the Oxford Down places it in the first rank. Rams have been shown that weighed above 400 pounds, and 275 pounds for the mature male is a weight easily attained. Mature ewes should weigh close to 200 pounds or more. In a statement in the Breeders' Gazette in 1889, on Oxford weights, Mr. George McKerrow, a prominent breeder, gave the following figures: 2 rams two years old averaged $303 \frac{1}{2}$ pounds each; 4 yearling rams averaged 203 pounds each; 4 aged ewes averaged 215 pounds each; 5 yearling ewes 177 pounds each; and 8 March and April lambs, about September I, averaged II 8 pounds each. These were not fat sheep. In the American Sheep Breeder an Ohio man writes that in September, I890, his ewes from one to five years old averaged I93 pounds and his rams 325 pounds. The standard of excellence places the weights of mature rams at 250 to 350 pounds and ewes at 180 to 275 pounds. Coffey places the weights at 275 to 300 pounds for rams in breeding condition and ewes at 200 pounds or more.

The 0xford Down as a feeder ranks deservedly high. Being quiet of temperament and of considerable size, the breed easily thrives under conditions of restraint and fattens rapidly to large size. In the Iowa fattening wether-lamb test the Oxfords in one trial gained a daily average of .52 pound and in a second trial .40 pound, requiring in the first trial 740 and in the second 103 I pounds of dry matter for each IOO pounds of gain. The Oxford carcasses did not dress out as well as most of the other breeds, those in the first trial rating 55.2 per cent and in the second 50.08 , and bringing $\$ 4.50$ per hundredweight live weight in the first trial and $\$ 5.40$ in the second. The Iowa records give the Oxford about an average rating in feeding results. In 
the Smithfield Club Shows from I895 to I9I 2 fifty-three Oxford wethers showed a daily gain of .44 pound, and fifty-six wether lambs .66 pound per day, surpassing both Southdown and Shropshire. The general evidence shows the Oxford to be a feeder that will do well for considerable periods and such as the market readily purchases. It is as feeders that these sheep have met with the greatest favor in the corn belt and in Canada.

The 0xford Down crossbred or grade has long met with favor, and in the United States more especially in the fertile upper Mississippi Valley. From the first this merit of the Oxford was extolled; it is a crossbred that feeds rapidly to advantage on a variety of lands. The large size and heavy-shearing quality of this breed have attracted our farmers, so that purebred rams are in demand to grade up flocks with Merino or common ewes. This produces offspring of

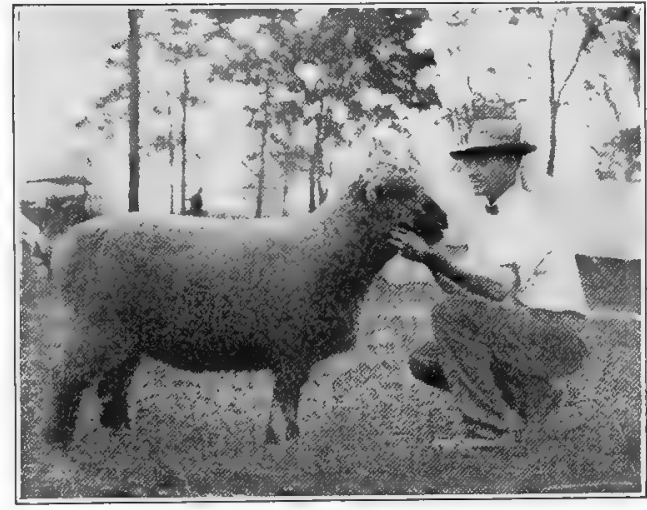

FIG. 264. The champion Oxford Down ewe at the Ohio State Fair, I9I8. Bred and exhibited by J. C. Williamson \& Son, Xenia, Ohio. From photograph by the author excellent mutton qualities, shearing large fleeces and meeting with popular favor. This demand is not restricted to America. The English writers state that Oxford rams have been in special favor in Germany for crossing on Merino ewes, and that this use of them has been quite extensive. In Scotland the use of Oxford rams on Cheviot ewes or crossbred ewes is regarded with favor. At the Scotch National Fat-Stock Show Oxford crossbreds have made most excellent records. In $1908 \mathrm{D}$. W. Black of Ohio won the grand championship on a carload of mutton lambs with grade Oxford Downs averaging I 3 pounds - a very choice, uniform lot, sired by Oxford Down rams and out of grade Western Merino ewes of the smooth, muttony sort that make the best of mothers. 
The prolific quality of the Oxford Down has long caused favorable comment among the breeders of this class. Twins are fairly frequent, and the ewes usually make good mothers and furnish ample milk to the lambs. The ewes, however, do not rank with the Shropshire in producing twins. Craig states ${ }^{1}$ :

One of the leading agricultural societies of the country has offered prizes to the shepherd who shall rear up to the first of May the greatest number of lambs from the ewes put to the ram. In 1886 the winner reared $198 \mathrm{lambs}$ from 130 ewes, slightly better than one and one-half lamb from each ewe in the flock previous to September. The next year in the same flock, 132 ewes gave a return of 213 lambs reared by the first of May.

Approximately a lamb and a half to a ewe may be estimated for carefully selected ewes.

The Oxford Down as a wool producer is in special favor to-day. Shearing a heavy fleece of quarter-blood combing wool, three to four inches long, which tends to coarseness and length of staple, it satisfies the demand of the farmer for weight. There is considerable variation, however, in the quality of the Oxford wool, those sheep with, open fleeces having much coarser and longer staple than those of a more compact sort. In I 860 Lawrence Smith of Massachusetts stated that his flock of store and breeding ewes usually sheared from 5 to 7 pounds, with his rams' fleeces sometimes weighing Io pounds. Thirty years later an Ohio breeder wrote that his Oxford Down flock sheared an average that year of I I pounds I 4 ounces per head. In the Iowa breed test the Oxford wether lambs in one trial sheared I I pounds and in another 8 pounds, the fleeces bringing $\$ I .44$ and $\$$ I.I6 respectively, materially excelling all other middle-wool breeds. This is in fact the heaviest shearing of any of the Down breeds, and instances are reported of fleeces weighing as much as 20 pounds. A weight of Io to I 2 pounds unwashed wool may be expected in the case of well-bred sheep given proper care.

The prices paid for Oxford Down sheep have not ranged very high. In I 860 R. S. Fay had a sale at Lynn, Massachusetts, when the prices ranged from $\$ 7.50$ to $\$ 5 \mathrm{I}$ a head. In I876 T. S. Cooper of Pennsylvania showed the ram Freeland at the

I John A. Craig, Sheep Farming in North America (1913), p. I24. 
Centennial Exposition at Philadelphia, a famous prize winner there and in England, which he hired of A. F. M. Druce of England for \$425. The annual Oxford Ram Fair in England shows something of prices current for this breed. In I900 at this sale the highest price paid was 42 guineas (\$2IO) for a yearling ram, and fifty yearlings from the flock of Worley \& Son averaged slightly over $\$ 50$ per head. In 1903 sixty rams sold by George Adams averaged $\$ 40$. The same year, at the sale of J. T. Hobbs, the average was in excess of $\$ 75$ per head, one ram bringing $\$ 290$. At the I916 ram sale at Oxford a lamb consigned by R. W. Hobbs and Son sold for $\$ 360$, and thirty lambs averaged

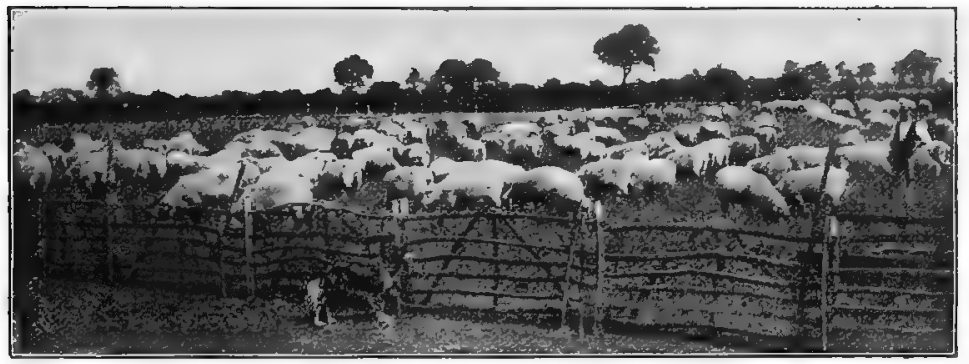

FIG. 265. Oxfords on pasture on the farm of George Adams, Faringdon, England. From photograph by the author

about $\$$ I I o a head. In the United States, Oxford Downs have not come under the high-priced classification, and the better-class sheep change hands at reasonable and modest values.

The distribution of the Oxford Down is very widespread. Originally confined to Oxfordshire, it is now found in about a score of counties in England, as well as in Scotland, Wales, and Ireland. So greatly has the breed grown in favor in recent years that it has become very widely distributed, flocks now existing in Germany, France, Sweden, Switzerland, Russia, Brazil, Argentina, Australia, New Zealand, Canada, the United States, and elsewhere. In this country there are Oxfords in many states, although Illinois, Ohio, Indiana, Wisconsin, and New York have noted flocks, as well as Ontario, Canada, where the breed has long met with favor. In 1908 it was estimated that there were four thousand head of pure-bred Oxfords in Canada, and to-day it may be fairly 
assumed that most of the choice flocks of the breed in America are located in Ontario. While essentially a type of sheep suited for a fertile, arable, or well-grassed country, level or slightly rolling, it has seemed to adapt itself to a considerable range of conditions. Within a comparatively few years Oxford rams have grown in favor on the range west of the Missouri. But as a breed the Oxford is not suited to a short-grass country.

The promotion of Oxford Down sheep was first attempted in an official way by the American Oxford Down Sheep Record Association, which was organized in 1882 at Cincinnati, Ohio. This association published its first flock book in 1883 and has since then, up to I9I9, issued fourteen volumes, including the registration of about 83,500 sheep. In 1888 the Oxford Down Sheep Breeders' Society was organized at Oxford, England, and the first volume of their flock book appeared in 1889 , in which fifty-four flocks were registered. Since its organization the English society, up to I9I8, has published thirty flock books and registered 9270 rams, $324 \mathrm{I}$ ewes; and 358 flocks. 


\section{CHAPTER LI}

\section{THE HAMPSHIRE DOWN ${ }^{1}$}

The native home of Hampshire Down sheep is in south-central England, ir the county of Hampshire, or, as it is commonly known in that country, Hants. The county, including the Isle of Wight, contains I626 square miles, and its south boundary is along the English Channel. Winchester is the county seat, while Portsmouth and Southampton are large and important maritime cities of Great Britain. Like all of south England, the climate is very temperate the year round; in fact, the Isle of Wight is regarded as possessing the mildest climate on the entire coast. The land is rolling, being crossed by the North and South Downs. The soil is of a chalky character, none too fertile, but producing fair crops of the small cereals and roots and fine grass for sheep pasture.

The origin of the Hampshire Down sheep traces back to at least two sources, crossed with improved stock. In the counties of Hampshire and Wiltshire and also to some extent in other near-by counties were large, slow-maturing, white-faced, narrowbacked, fine-fleeced sheep with horns, known as Wiltshires. The horns turned back behind the ears and about the cheeks, from which peculiarity they were known as "crooks." There were no other sheep like them in England, and by 1837 , as a result of crossing, they had practically disappeared. In the county of Berks there was also another old type with horns, strong and vigorous, with dark face and legs. Early in the last century these two types were crossed again and again with the Southdown. About 1835 the sheep of Hampshire and Wiltshire generally showed Southdown type and character, and they were exhibited at the Royal Agricultural Society Show at Oxford in I840 as

1 In view of the fact that a breed of swine is also named Hampshire, the author feels that the word "Down" may well be used as a part of the name as applied to the breed of sheep. Hampshire Down is also the official title used to-day in England. 
West Country Down sheep, which name they long retained. From this stock was evolved the present type, known as Hampshire Down.

The early improvement of the Hampshire Down is largely due to Mr. William Humphrey of Oak Ash, Newbury, Hampshire, and Mr. James Rawlence of Bulbridge, Wilton, the same county. Mr. Humphrey, however, is the most important of these, being

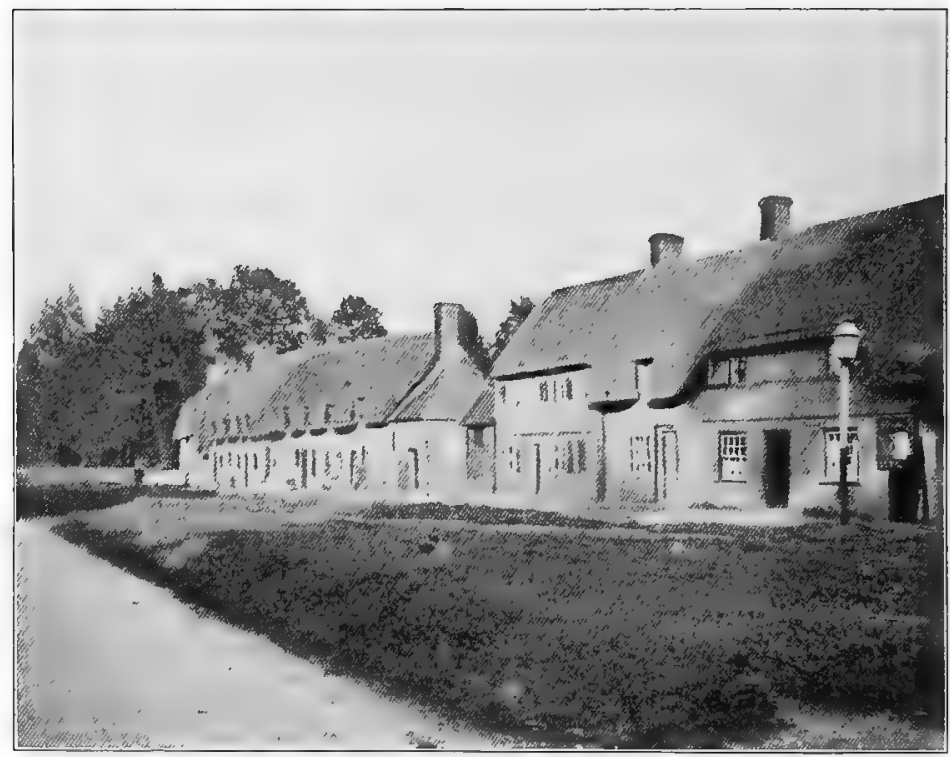

FIG. 266. Thatched cottages in the village of Downton, near Salisbury, England, in the Hampshire Down country. From photograph by the author

essentially the great Hampshire Down improver, with Mr. Rawlence a most important later factor. About I 834 Humphrey began gathering up as choice a flock as possible of West Country Down ewes, breeding to them rams of the same class. In $\mathrm{r} 842$ he became impressed with the improved breeds at the royal show at Oxford, notably the Cotswolds, and believed that his sheep might be improved by crossing. Consequently he obtained a choice Southdown ram from Jonas Webb and crossed on his ewes with much success. Later he obtained other rams, three in all, the only outside ones ever used in his flock. At first 
he suffered loss in size, but he culled out the finer-boned, smaller ewes and bred only the larger, more robust ones, using choice crossbred rams of his own breeding. Mr. Humphrey was very particular about his sires and the ewes to which they were bred, selling all undesirable animals to the butcher. According to his old shepherd, Abraham Hopkins, ${ }^{1}$ he never bought ewes but once, on which occasion he secured 25 from a lot of 100 ;

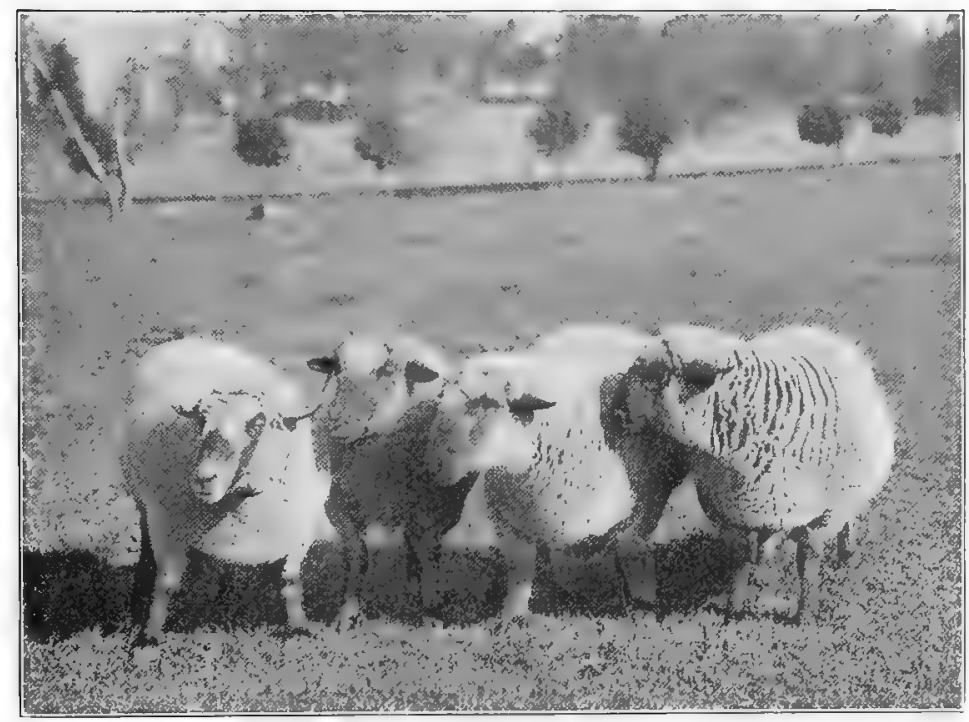

FiG. 267. Hampshire Down rams owned at Chilmark Farms, New York. From photograph, by courtesy of C. V. Phelps, superintendent

Rawlence secured 25 also, and a neighbor I00. In narrating to Professor Wrightson the method of building up the breeding flock, Hopkins said :

Every lamb was marked as it fell, and those which showed any breachiness or coarseness were notched at the top of the ear; and no matter how well these lambs turned out, they were castrated and went to the butcher. Every lamb, in fact, which was not let for breeding was fattened off, and no ewes were ever sold. Only good ewes were kept for breeding, and all the rest were sold to butchers. The ewes which were thought good enough for the flock were bred from until they were worn out. One favorite was kept till she was fourteen

1 John Wrightson, Sheep: Breeds and Management. London, I895. 
years old, and her last lamb was Oliver Twist. This ewe had no udder for the last four years of her life, and Oliver Twist was given to another ewe. This ram was first in his class at Leeds and Battersea.

Humphrey died in 1868 , when his flock, one of very superior merit, was dispersed. Mr. James Rawlence of Bulbridge bred rather differently, beginning with the Sussex breed, crossing the larger and more robust ewes with the West Country Down or Hampshire Down rams. He frequently used rams of Mr. Humphrey's breeding, and later bought Hampshire Down ewes to which he bred rams of his own stock. By using new blood gradually and practicing careful selection, Mr. Rawlence developed a flock "of the highest merit," a distinct improvement over the type bred by Humphrey. Wrightson, himself a Hampshire Down breeder, states that Mr. Rawlence "is regarded by many as the father of the breed" and further notes that "we may look on the Bulbridge flock as fairly representing the Hampshire Down as we see him at the present time" (I895).

The introduction of Hampshire Down sheep to America is said to have occurred in I855, when Thomas Messenger of Clarence Hall, Great Neck, Long Island, New York, imported a ram and five ewes bred by Francis Budd of Hampshire. These were exhibited in the United States and won prizes at various shows, and Henry S. Randall states ${ }^{1}$ that they found a rapid sale in the South prior to the Civil War. But little was done, however, prior to I880, to introduce more Hampshires. In I $88 \mathrm{I}$ Henry Metcalf of Canandaigua, New York, imported the ram Shepherd's Pride 2d. In May, r887, E. F. Bowditch of Framingham, Massachusetts, made an importation from Thomas Chick of Stratton, Dorsetshire, England, and by I $892 \mathrm{Mr}$. Bowditch had a flock of seven hundred head, the largest number of sheep owned by one man in the state. About 1883 the breed found its way into Michigan, and in 1885 became known in Ohio, Wisconsin, and elsewhere. In recent years the Hampshire Downs have grown much in popularity, and many sheep have been imported to America.

Characteristics of the Hampshire Down. The head is very dark brown or almost black in color, is rather large, and frequently has

1 The Practical Shepherd (1868), p. 6I. 
a pronounced Roman nose. The lips and nostrils are black. The ears are moderately long, large, and thin, of a dark mouse color behind, and are more pointed than with Shropshire or Southdown. In the best type the ears lean outward slightly. The neck tends to be a bit long, lacking the shortness of the Southdown; yet Wrightson, the best British authority on this breed, states that it is thick and muscular and is considered to be a point of special excellence and importance. He further states that the shoulder tops are wide and that the girth behind the shoulders and of the entire fore end must be well marked to secure any attention either in the prize or sale ring. This breed has been criticized by Wallace, who states that a conspicuous defect in ordinary specimens is a falling away behind the shoulder, but this defect is not common in the improved Hampshire Down of to-day. The type of body and general carcass is in common with accepted standards for other mutton breeds. The legs are dark brown in

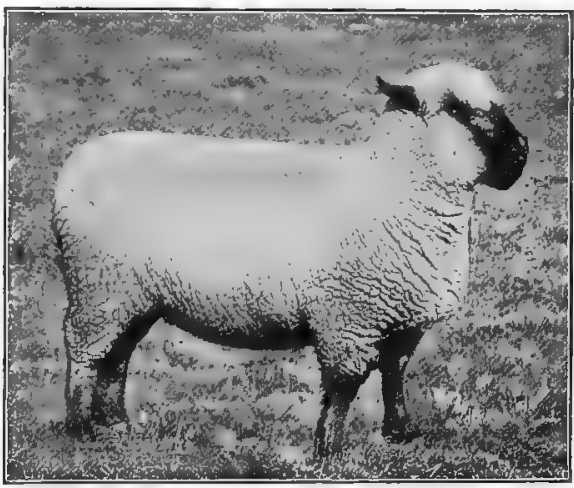

FIG. 268. A two-year-old Hampshire Down ewe, first and champion at seven American fairs in 1904. Owned and exhibited by Chilmark Farms, New York. From photograph, by courtesy of Charles V. Phelps, superintendent color, like the face; in fact, the color is so deep a brown that it may almost be regarded as black. The skin should be a bright pink, but Hampshire Downs frequently have a bluish or dark skin much resembling the Oxford Down. In further reference to these breed characteristics Wrightson makes the following interesting comments upon the sources of their inheritance:

The slightly Roman character of the face and the fine wool have no doubt partly been derived from the old Wiltshire horned sheep. ... The quality of the flesh and the color have come through the Southdown, but the color has been deepened by selection. The length of ear has probably been derived from an alliance with the Cotswold. 
The size of the Hampshire Down is large, being second only to the Oxford Down, although Wrightson classes the former as the largest of the middle-wool breeds. J. H. Taft of Michigan made an importation of ewes which in fair flesh averaged from 175 to 200 pounds, while lambs of his own raising at about ten months old weighed an average of I I $3 \frac{1}{2}$ pounds. James Wood of New York, once a leading American authority on the breed, gave 300 pounds for weight of the mature ram and something over 200 pounds for the ewes. Shaw and Heller place the weight of mature rams

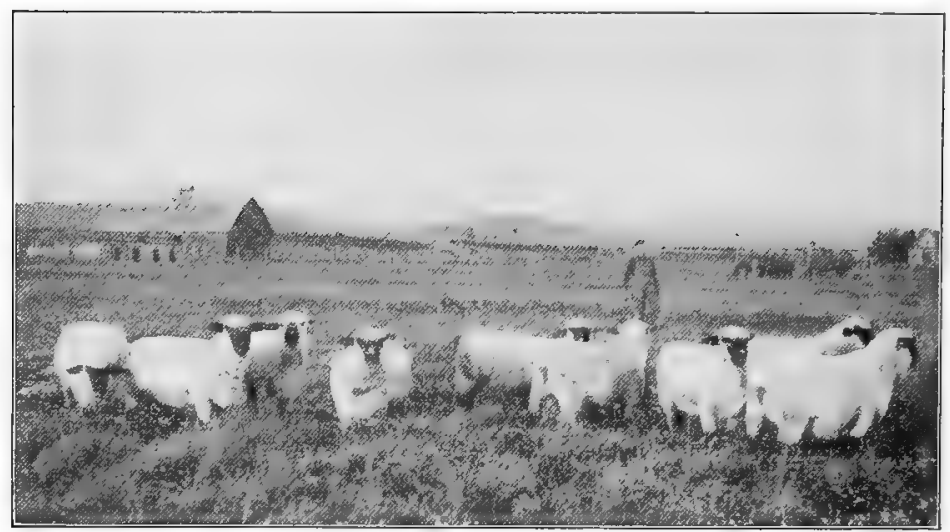

FIG. 269. Hampshire Downs on pasture, the Butterfield Ranch, Weiser, Idaho. From photograph, by courtesy of the American Sheep Breeder

at 225 to 275 pounds and ewes at from 175 to 200 pounds, and state that it is, with the possible exception of the Oxford Down, the largest of the Down breeds and excelled in size only by the Lincoln and Cotswold among the long wools. Coffey gives the weight of rams in breeding condition at 250 to 300 pounds and ewes at I 80 to 225 pounds. The standard of excellence of the breed makes no reference to size or weight.

The Hampshire Down as a mutton sheep ranks high. It has long been a popular breed in the English mutton market on account of its rapid growth under intensive feeding. In Hampshire these sheep are generally hurdled on rape, kale, vetches, or roots, and are pushed faster than any other breed — lambs making gains of about a pound a day in many instances. They seem to 
have a great capacity for assimilating food to advantage. At the Smithfield Fat-Stock Show in England, Hampshire Downs have held a leading place among the best killers and have demonstrated daily gains rarely surpassed. In giving weights and gains of fat wethers at this show, from I895 to I9I5 inclusive, Henry and Morrison ${ }^{1}$ show that 78 yearling Hampshire Down wethers had an average weight of 282 pounds at six hundred and sixty-one days of age, showing an average daily gain of .42 pound. Yearling wethers of the breed in carcass contests had a live weight of 185 pounds and dressed out 64 per cent carcass. These sheep, owing to their large size and heavy bone, will not dress out as well as some of the lighter breeds, neither does the mutton rank quite so high in quality.

The Hampshire Down for early lambs has held a premier place in the United States for many years. They were first promoted in the East for

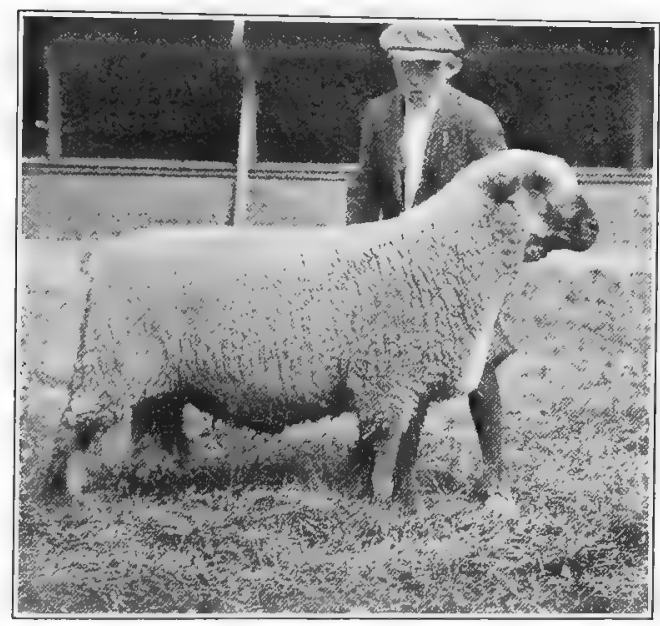

Fig. 27o. Hampshire Down ram, champion at the 19I 8 Ohio State Fair. Shown by the Munroe Stock Farm, Lucas, Ohio. From photograph by the author this special quality, as

a valuable feature for the Eastern early-lamb market; and James Wood and J. S. Woodward, both of New York, imported many years ago for this special purpose and became large early-lamb producers. One may find many testimonials in behalf of the rapid gains in weight by the lambs, and it is probable that this breed has no superior for gains made during the first two or three months after birth. Smithfield records compiled by Henry show that 94 Hampshire Down lambs, averaging three hundred and nine days of age, gained an average of .67 pound a day per

1 Feeds and Feeding (1915), p. 5 I8.

Digitized by Microsoft(a) 
head, being equaled by no other Down breed but the Suffolk, which is credited with .70 pound. The lambs do not finish off for killing much before reaching 75 to 80 pounds live weight.

The Hampshire Down for crossing or grading is valued by lamb producers in particular. In England it is customary to draft from the flock the old ewes and sell them at fairs, after which Cotswold or light-faced rams are bred to them. The result of the cross fatten rapidly and, if kept till yearlings, produce a large amount of mutton and wool. It is said that large numbers of Hampshire Down rams are sold into Lincolnshire, where they are bred to old Lincoln ewes for producing fat lambs or wethers. The Hampshire Down also crosses well on the Leicester. The Hampshire Down ram used on grade Merinos or pure-breds produces the dark face and superior mutton type of early lamb. This is one of the most popular crosses in America for using Hampshire Down blood. The demand for Hampshire Down rams on the Western range has been strong for some years on account of the value of the crossbred. A combination of pure-bred rams on grade Delaine Merino or Rambouillet ewes results in a class of lambs eagerly sought in the market, heavy weighers and profitable killers under fair conditions.

The Hampshire Down as a grazer has recognized merit in England, where flocks are generally grazed in summer within hurdles, a condition to which they are well suited. They graze together, often in semicircles, and pasture closely. In Hampshire and Wiltshire a large number of sheep are maintained upon the land. Wrightson notes that his summer flock on the College Farm of six hundred acres at Downton, with a favorable lambing season, consists of from I 250 to I 300 sheep and lambs, besides a dairy of 30 cows and young stock, a very superior showing. This method of feeding has greatly increased the fertility of the lands where they are kept. In America the pure-breds do best on the more fertile lands of the corn belt, where feed is abundant; or under conditions in the Far West, where alfalfa and grain, rather than the open range, is made use of. The Hampshire Down cannot be regarded as a class of sheep equally qualified with the Merino or Cheviot to rustle for its food. A large, heavy type of sheep of this sort is naturally better adapted to arable lands than to less fertile areas. 
The fecundity of the Hampshire Down, while not of the highest, is distinctly superior. In 1903 the English association kept a lambing record of 37 flocks comprising 15,482 ewes. These reared I 8,462 lambs, or II9.I 7 per cent, while only 2.2 I per cent of the lambs dropped were lost. In a similar record for I902 the percentage raised was II6.82. This speaks well for the fecundity and maternal character of Hampshire Down ewes. The lambs are usually strong and lusty at birth and often weigh Io pounds or more. Craig states there is one case on record of a

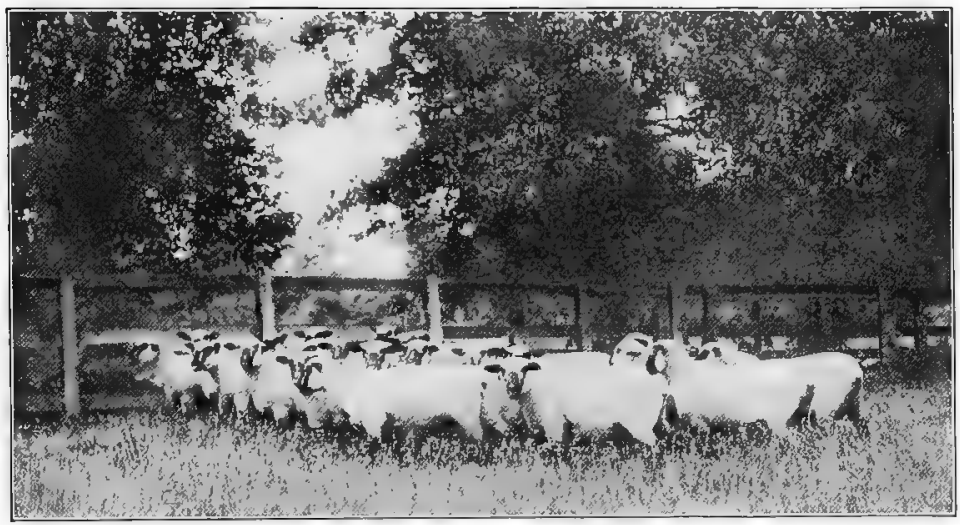

FIG. 27I. Hampshire Down ewes on pasture at Walnut Hall Farms, Donerail,

Kentucky. From photograph, by courtesy of Robert S. Blastock, manager

Hampshire Down lamb weighing i 8 pounds at birth. The ewes are rated as good mothers, have large udders, are excellent milkers, and bring their lambs on rapidly to heavy weight for early age.

The Hampshire Down as a producer of wool has only a very moderate place among the breeds. The wool is coarse in quality, grading three-quarters or three-eighths blood combing, has an average length of three inches, and covers the body with just fair density. The weight of a typical unwashed fleece of twelve months' growth will approximate eight pounds, which is light for so large a sheep, and furnishes just grounds for criticism.

The prices received for Hampshire Down sheep in recent years have been undergoing greatly increased value. In I903 Waters and Rawlence sold at public sale about 2500 head, which in Digitized by Microsofte 
general brought good prices. At the Earl of Carnarvon's sale one ram brought about $\$ 550$ and 100 yearling ewes averaged about $\$ 35$ each. At James Flower's Chilmark sale and ram letting, two rams were let at I 35 guineas $(\$ 675)$ each, the record for thirtytwo years up to that time, with several ram lambs selling for from 34 to 76 guineas (\$I 70 to $\$ 380$ ). This was then regarded as one of the memorable sales of the breed. In IgI2, at the Britford Sheep Fair held at Salisbury, England, a ram lamb bred by

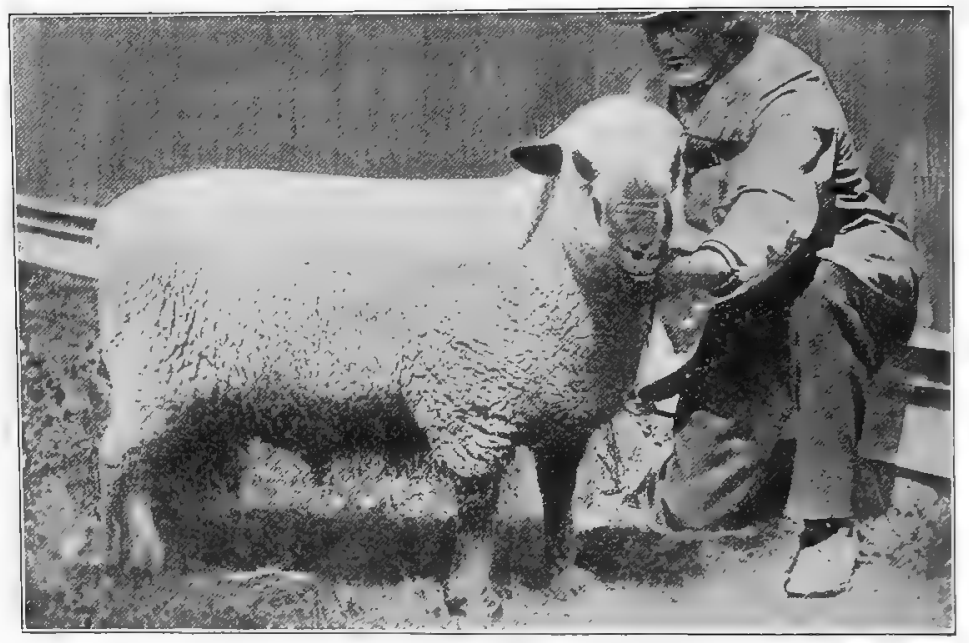

FIG. 272. Bishopstone Northington F82I-2564I (imp.), a Hampshire Down ram sold for $\$ 1700$ by Walnut Hall Farms, Donerail, Kentucky. From photograph, by courtesy of Robert S. Blastock, manager

Mr. Flower sold to J. H. Ismay for 230 guineas (\$I I 50), then the record price for the breed. Remarkable prices have been paid very recently in America for Hampshire Downs, especially at the ram sales held at Salt Lake City, Utah. In 1917, at this sale, Walnut Hall Farm of Kentucky sold an imported ram to D. F. Detweiler of Idaho for $\$ 1500$, a new record for the breed. John Nebeker also paid Walnut Hall Farm $\$ 750$ for a ram. Sixty-three of the top rams of the breed averaged \$196 and 425 ewes averaged $\$ 72.81$. At the 1918 ram sale at Salt Lake City, Walnut Hall Farm again broke the record in selling another ram to Mr. Detweiler for \$I $\$ 700$. Another was sold to the Wood Live 
Stock Company of Idaho for \$IO50, one ram went to the Butterfield Live Stock Company at $\$ 525$, and nine rams sold at prices ranging from $\$ 200$ to $\$ 325$. The Butterfield Live Stock Company of Idaho sold one ram for $\$ 700$ and another for $\$ 425$; and H. L. Finch of Idaho sold one ram at $\$ 750$, another at $\$ 700$, a third at $\$ 500$, and twelve rams at prices ranging from $\$ 200$ to $\$ 450$. Nineteen ewes consigned by Finch averaged \$105.25 per head. This 1918 Salt Lake sale of Hampshire Downs, all things considered, was the most remarkable sale of mutton sheep ever held in America.

The distribution of the Hampshire Down is widespread. In 1903, for example, exports were made from England to the United States, Canada, Mexico, Argentina, Uruguay, Chile, Australia, New Zealand, South Africa, Germany, Russia, Hungary, Portugal, Jamaica, and elsewhere. In I9I 3 , the year prior to the opening of the World War, 424 Hampshire Downs were exported from England, I66 going to North America, I 29 to South America, 65 to Germany, and the rest to South Africa, Russia, and elsewhere. In England the breed is found in a score of counties, though chiefly in Hampshire, Wiltshire, Dorset, Sussex, Surrey, and vicinity, and is bred on a large scale. In 1913 James Harris and Son of Winchester, England, disposed of 3I,000 head, and at each of the Salisbury, Britford, and Wilton fairs I5,000 ewes and lambs were sold at auction. Interest in the Hampshire Down in the United States until within a few years has been largely restricted to the eastern part of the country, especially New York, Pennsylvania, Ohio, and Indiana, but now the breed has a strong hold in the Far West, with large and superior flocks in Idaho, Utah, Oregon, Washington, and California. Hampshire Downs have a comparatively small hold in Canada.

Hampshire Down Sheep associations exist in England and America. The Hampshire Down Sheep Breeders' Society of England was organized in 1889 and up to 1918 has published thirty-nine volumes of the flock book. The Hampshire Down Sheep Breeders' Association of America was also organized in I889, the first flock book being published in 1890 . Up to I91 8 fifteen volumes had been issued and 24,633 rams and 57,982 ewes recorded. 


\section{CHAPTER LII}

\section{THE DORSET HORN}

The native home of Dorset Horn sheep is in the counties of Dorset, Somerset, and Wiltshire in southern England. Dorset, from which the breed is named, faces the English Channel on the south, with Somerset and Wiltshire in the interior as the northern boundaries. Dorset contains about one thousand square miles and is strictly an agricultural county, crossed by low-lying Downs, fertile, rolling hills, yielding rich harvests of the cereals, roots, and grasses. It is a soil rich in lime, and as one approaches the high cliffs from the sea he is much impressed with their chalky whiteness. The climate is mild and moist and well suited to outdoor life the year round. From Weymouth harbor passenger ships make regular trips across the Channel to Jersey and Guernsey.

The origin of the Dorset Horn sheep seems to be from the old native stock of Dorset and Somerset, which, so far as we have records, possessed horns in both sexes and was entirely white. As far back as I 749 Ellis in his "Shepherd's Guide" describes the sheep in this region as having "white faces, white and short legs, broad loins, and fine curled wool." In 1842 Professor Low wrote that from time immemorial there had existed in Dorset a breed of sheep with horns common to both sexes, having white face and legs, low shoulders, broad, deep loins, long but not coarse limbs, black lips and nostrils (though sometimes flesh-colored), and possessing fine wool. In the adjoining county of Somerset was a rather larger type of much the same breed, lanker in form, longer wooled, and with pink or flesh-colored nose (by which they were known as "Pink-Nosed Somersets"), which fattened to greater weight and had larger lambs than the sheep of Dorsetshire. Low further comments on the encroachment of the Southdown and Leicester on the Dorset territory, stating that pure-bred flocks were becoming scarce owing to the crossing of these breeds. In fact, he stated that the breed was gradually diminishing and was 
in danger of being extinguished. In 1856 Professor Wilson, another British authority, writes that "the practice of crossing with the Southdown is becoming very general." In this same connection Youatt, in I837, comments on the use of Devonshire Knots and Leicesters on Dorsets, but says the cross was not successful. However, some flocks were apparently kept free from crossing, notably on the isle of Portland, where about four thousand sheep of a small Dorset type existed in I 840 . The general improvement of the breed as a whole was secured by selection

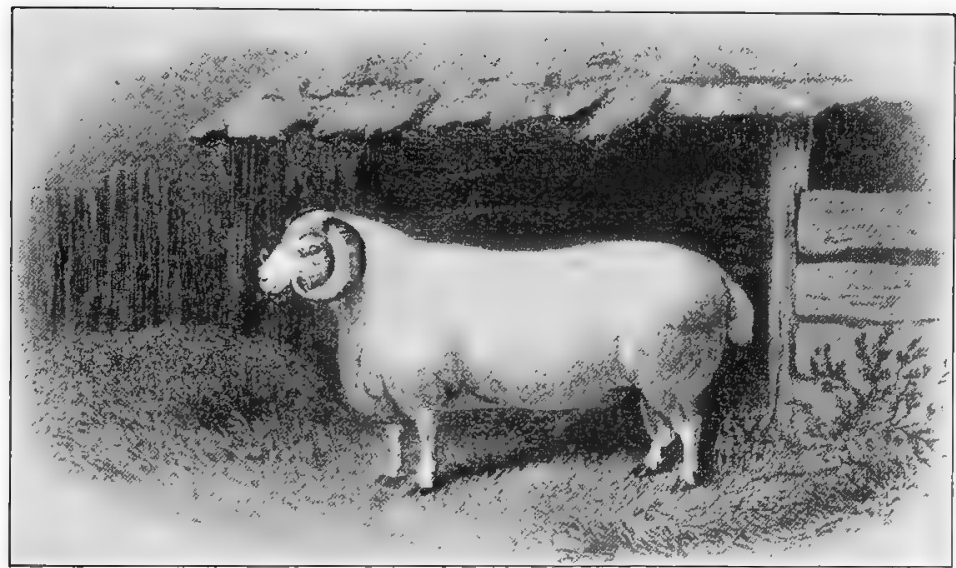

FIG. 273. A "royal winner" Dorset Horn ram, the property of $\mathbf{H}$. Mayo, Coker's

Frome, Dorchester, England. From an English engraving published in 1870

on the part of various breeders in the western part of Dorset, but especially by Richard Seymour of Bradpole, who, between 1830 and I840, perhaps, had the best flock extant. Between I 860 and 1885 the breed was much improved by Henry Mayo of Coker's Frome.

The introduction of the Dorset Horn to America is very recent, being the last of the well-known breeds brought from England to this country. The first Dorsets shown in the United States were some ewes and lambs exhibited in 1885 at the American FatStock Show at Chicago by E. and A. Stanford of Steyning, England. The first owned in this country were purchased in March, I 887, by William Daley of Lockport, New York, from Valancey 
E. Fuller of Canada. In May, I887, E. F. Bowditch of Framingham, Massachusetts, made an importation, he being a specialist in early-lamb raising. The following month Adin Thayer of Hoosic Falls, New York, imported 12 head. This same year (I887) Woodward \& Jaques of Lockport, New York, and R. J. Buck of Bridgeton, New Jersey, made importations, and the following year, in July, Rutherford Stuyvesant of New Jersey imported 2 rams and 28 ewes from the English flocks of John and William Kinder. In September, I 889, Mr. T. S. Cooper of Coopersburg,

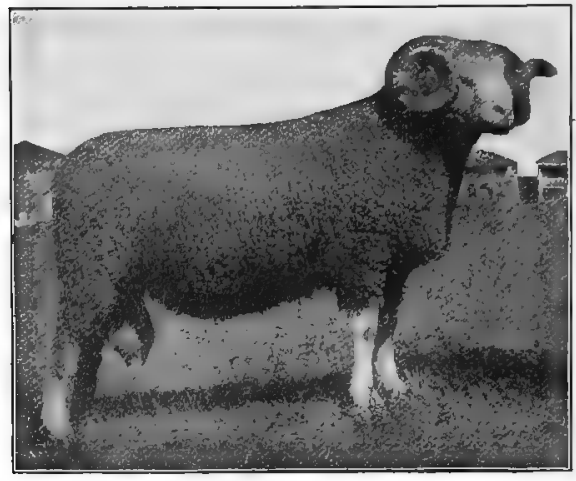

FIG. 274. A Dorset Horn ram, first prize in class at several state fairs in 1898 , shown by Tranquillity Farm of New Jersey. From photograph by the author

Pennsylvania, imported I 53 head, mostly from the flock of Thomas Mayo, and again in $\mathrm{I} 89 \mathrm{I}$ brought over 204 more head. The sheep imported by Mr. Cooper were very superior and were sold and distributed among numerous breeders, especially in the East. The first Dorsets in Ohio were shipped to that state by Mr. Cooper in I89I.

The characteristics of the Dorset Horn sheep are distinctive in part, as this is the only horned breed in Britain with white face and leg. In general conformation the Dorset tends to have a body a bit long and rangy and lacking in refinement. The head is conspicuous in having horns present with each sex. The well-matured ram has a strong horn which curves backward and around spirally, making, perhaps, nearly a turn and a half and coming somewhat close to the head. The horns on the ewes curve around forward, with the tips about level with the eye and turning in slightly. The head has a short foretop of wool which comes down to a line with the eyes, while the face and much of the jaws are covered with hard, white hair. The face is strong, with considerable breadth between the eyes, and the nostrils are white. Below the knees and hocks the legs are covered with white hair, though a short 
covering of wool may prevail on the hind legs. The skin color is generally pink and attractive, breeders seeking a good color and especially objecting to spots. The hoofs, like the horns, should be white. In comparison with a Southdown or Shropshire, the Dorset is a rougher, coarser sort of sheep, longer of neck, with a tendency to prominent shoulder, high withers, uneven back line, and a lack of thickness in the hind quarters from the rump to twist. One is impressed with the Dorset as a strong, hardy sheep with considerable room for improvement in conformation, fleshing, and quality.

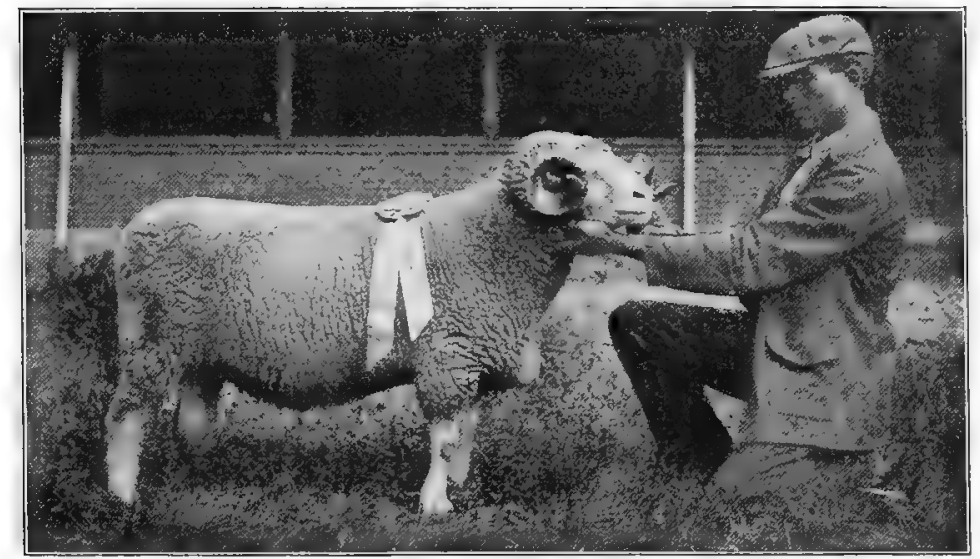

FIG. 275. A Dorset Horn ram, champion at the 1918 Ohio State Fair. Exhibited by L. R. Bradford, Rochester, Ohio. From photograph by the author

The size of the Dorset Horn is from medium to heavy among middle-wool breeds. Mature rams in fair flesh should weigh about 225 pounds and ewes 165 pounds. In some cases, however, much larger weights are secured. Mr. T. S. Cooper selected a large type in his importations. One two-year-old ram attained a weight of 3 I 7 pounds and a yearling 287 pounds, while ram lambs weighed I 84 and I 64 pounds at five months and one week old. These were mostly first-prize winners. Three first-prize yearling ewes at the 1889 royal show weighed at shearing time 262, 245, and 222 pounds respectively, and in August each dropped twin lambs. These, however, were excessive weights. Shaw and Heller credit the breed with considerable variation in 
size and give weights of 200 to 225 pounds to the ram in breeding condition, with 150 to 175 pounds to the ewe; while Coffey states that mature rams weigh approximately 275 pounds and ewes 180 to 200 pounds. According to Henry and Morrison the average weight of 23 yearling fat Dorset wethers at the Smithfield Show, six hundred and seventy-nine days old, was $26 \mathrm{I}$ pounds, while 49 lambs at three hundred and thirty-one days of age averaged 200 pounds. The present-day demand for Dorset

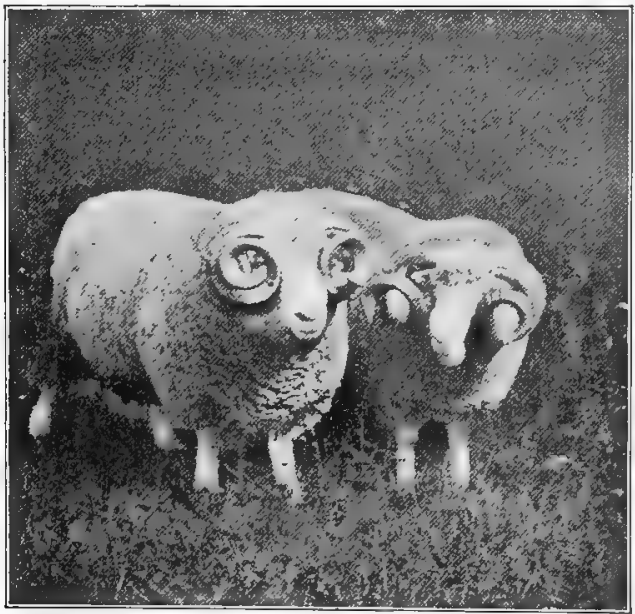

FIG. 276. A pair of Dorset Horn rams in Dorsetshire, England. From a photograph by the late J. E. Wing, by courtesy of Mrs. Wing Horns is for the larger type of ram and ewe, but even under most favorable conditions these are not likely to surpass 250 and 180 pounds respectively.

\section{The Dorset Horn as} a mutton producer cannot be placed in the first class, ranking about medium. The meat of the wether is of fair quality when not overfat, while fat lambs rank very well indeed. In the dressed carcass the Dorset does not reach the best standard. In the Iowa Station breed tests, in the first trial with fattening wether lambs, the Dorset made an average daily gain of .48 pound and dressed 52.6 per cent carcass, being valued at $\$ 3.75$ per hundred - the poorest record made by ten breeds; while in the second trial they made a daily gain of .43 pound and dressed 54. I I per cent (being surpassed only by the Southdown), the carcass selling at $\$ 5.50$ a hundred compared with $\$ 5.75$ for the Southdown and $\$ 5.60$ for the Shropshire. The average daily gain for the 23 yearling wethers shown at the Smithfield Show between I 895 and I912, as given by Henry and Morrison, was .38 pound, while 49 lambs made an average daily gain of .60 pound. In 
these gains the Dorset Horn surpassed the lighter Down breeds but did not do so well as Suffolk, Hampshire, or Oxford.

The Dorset Horn as an early-lamb producer has great distinction, having long been famus in this regard over other British breeds. The ewes will breed during much of the year, so that they have a special value for producing Christmas lambs. It has long been customary in England to breed the ewes in June and July to lamb in November and December, furnishing early lambs for the London market. In the United States, owing to the hot summers, the ewes are more readily bred from the middle of March into May. The lambs fatten rapidly and soon attain good weights. In England November or December lambs are generally sold fat in March and April, when they weigh 40 to 44 pounds in the dressed carcass, according to Thomas Chick, long a wellknown. Dorset breeder. Dorsets were first introduced to America for hothouse lambs, and in the late eighties J. S. Woodward of Lockport, New York, was shipping these lambs to New York. This industry has continued more or less in the eastern United States ever since. Mr. Fred Huyler writes ${ }^{1}$ that recently he received a letter from one of the largest sheep breeders in the country, in which he says :

We have slaughtered over 400 hothouse lambs since January first, and expect to slaughter about Ioo more before the warm weather sets in. These were all Dorsets, or a cross with Southdown ewes and a pure-bred Dorset ram. The average price received for them was $\$ 16$ apiece, with an average weight of 55 pounds. Most of the lambs were dropped since October I, I917.

Mr. Huyler states that in his own experience six lambs dropped in his flock October 15,1917 , at the end of five months weighed an average of about $\mathrm{r} 30$ pounds, showing a daily gain of almost I pound each.

The Dorset Horn for grading or crossing has a special value if mutton production is the thing sought. Shropshire or Southdown rams on old Dorset Horn ewes will produce very high-class lambs with dark faces, just what the market wants. A grade or cross from Merino stock meets with favor in America. In discussing this subject Messrs. Wing and Miller state that a

1 American Sheep Breeder, May, Igir8.

Digitized by Microsofte 
Merino grade from large, roomy Merino ewes and a blocky, vigorous Dorset ram will prove a surer breeder, if possible, than the pure-bred Dorset ewe. There are not many growers of hothouse lambs who do not prefer Dorset Horn grades from Merino foundation to any other, the pure-bred not excepted. These ewes are again bred to pure-bred Dorset Horn rams, and the result is a very blocky, easily fattened lamb. These grade ewes are also better milkers than the pure-breds. At Purdue University

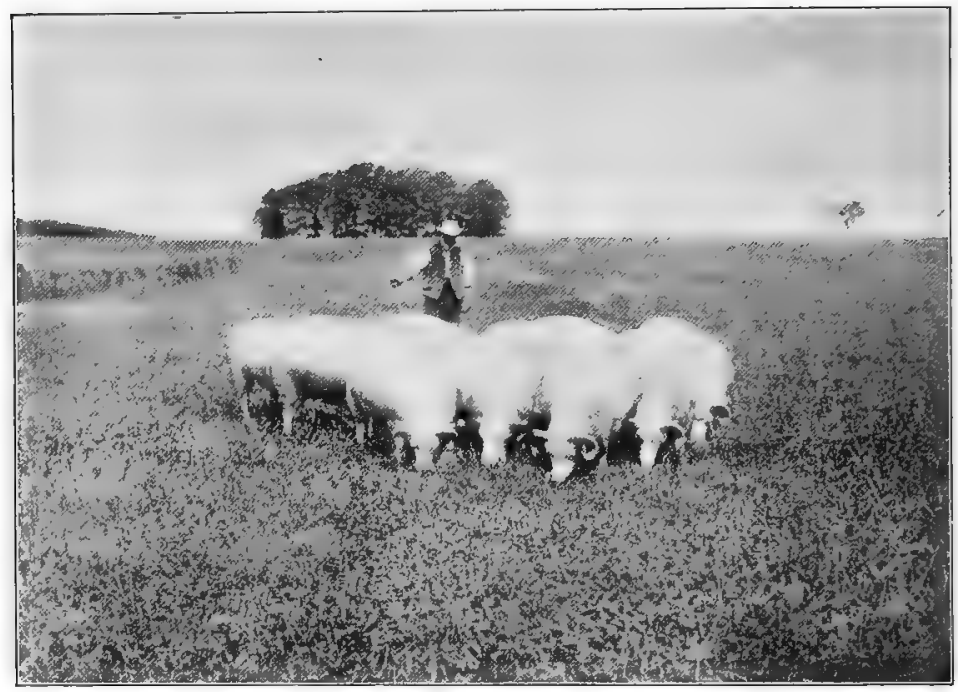

FIG. 277. A group of choice Dorset Horn ewes on pasture in Dorsetshire, England. From a photograph by the late J. E. Wing, by courtesy of Mrs. Wing

especially fine results were secured from crossing a Dorset ram on Rambouillet ewes, as compared with lambs from the same kind of ewes sired by Shropshire and Rambouillet rams. The Dorset crosses showed the heaviest weight and gave the best dressing percentage, and the carcasses were thicker and showed more finish than the others.

The prolificacy of the Dorset Horn sheep is one of its outstanding characteristics. This is manifested in two ways: one, that the ewes naturally breed so as to lamb twice a year; the other that the ewes are especially prolific, even if lambing but 
once a year. The custom of breeding the ewes twice a year has been in vogue since the earliest history of the breed. It is doubtful, however, on the basis of lambing once a year, if the Dorset is the equal of the Shropshire in prolificacy. A writer on the Dorset Horn in the American Breeder (October 5, I9 I6) states that the rate of increase may be put at 150 lambs per I oo ewes, and when bred twice a year they will average I80 to 200 lambs per roo ewes annually. Craig places the rate of increase as high as 180 per cent. Relative to this subject Professor Frank Kleinheinz states ${ }^{1}$ that at Wisconsin University Dorset ewes as a rule have dropped twins, and he cites one ewe of the flock that gave birth to 4 lambs, all of which she raised, and which weighed on an average $\sigma_{3}$ pounds at three months of age. He believes that 75 per cent of pure-bred ewes will lamb twice a year if bred for that purpose. The ewes make excellent mothers and produce a large amount of milk, often times drying off with difficulty.

The Dorset Horn as a grazer is not in the first class. It will not do well on inferior pastures and is better suited to the richer, lower-lying farms than to uplands, especially if rough. In their native home, according to the English flock book, about one to one and one-half ewes are kept to the acre, and "they require plenty of room and are generally allowed to roam the pasture in the daytime, being brought to the arable land at night." They are also hurdled to a considerable extent on forage plants and roots.

The Dorset Horn as a wool producer is open to material improvement. Mature rams will shear about 9 pounds and ewes about 6 pounds of unwashed wool. Twenty imported sheep of J. B. Henderson of Pennsylvania are credited with shearing an average of Io pounds each. The fleece of the Dorset has improved in weight and quality. Wrightson states that fifty years ago it was computed as averaging $3 \frac{3}{4}$ pounds, whereas now (I 895 ) a breeding flock of ewes will clip from 5 to 6 pounds of wool, and yearling ewes from 6 to 7 pounds, while rams will clip 8 to I 2 pounds each, all these weights following brook washings. Dorset sheep have too short a fleece and show too little wool on the underside of the body. The quality of the staple is of

1 American Sheep Breeder (May, I918), p. 309.

Digitized by Microsofte 
medium grade. Shaw and Heller state ${ }^{1}$ that twenty-five samples of Dorset fleece were graded upon the Philadelphia market for the United States Department of Agriculture, fifteen of which were three-eighths-blood combing and the other ten quarterblood combing wool. The wool is rated as lacking somewhat in weight, but of excellent quality and free from discoloration.

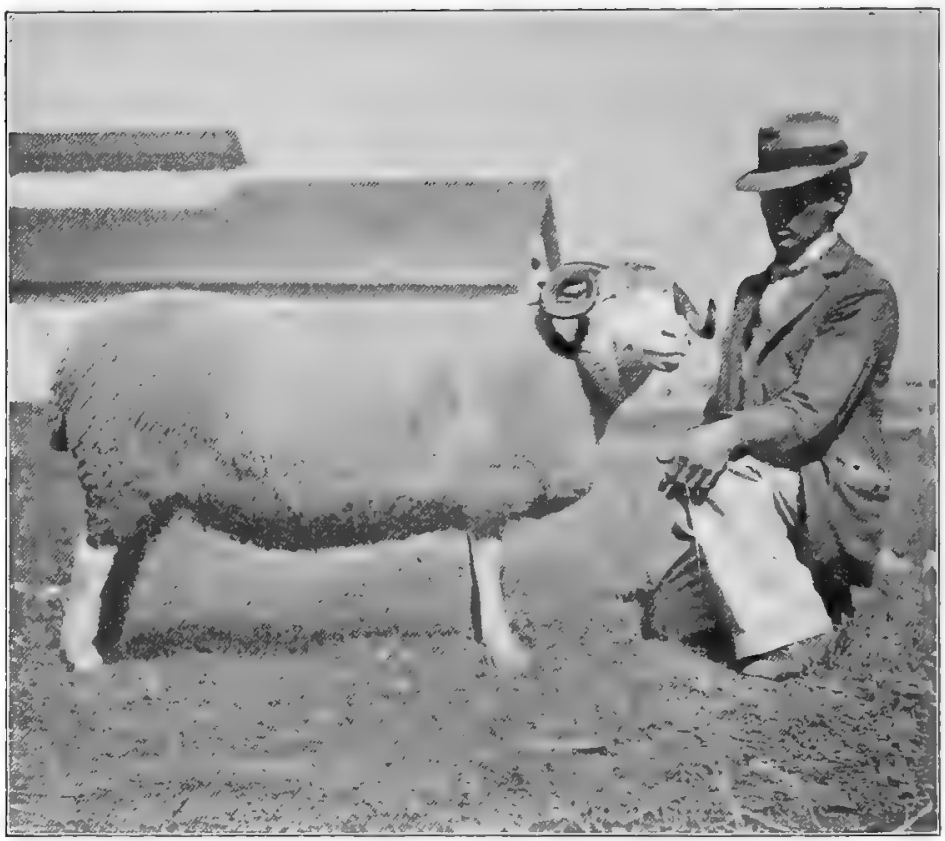

FIG. 278. A Dorset Horn ewe, champion at the Indiana State Fair, shown by Tranquillity Farm, Allamuchy, New Jersey. From photograph by the author

"A well-known wool authority," discussing Dorset wool," makes the point that it possesses two advantages over the wool of the Down breeds; namely, it is pure white when scoured and not a cream white, and it contains no trace of the black or brown fibers invariably found in Down wools, consequently its uses are not so limited, as traces of brown fibers found in any wool prevent it from

1 "Domestic Breeds of Sheep in America," Bulletin 94, United States Department of Agriculture, 19I4.

2 American Sheep Breeder, May, 1918. 
being used for all-white or pale-colored woolen goods. This expert regards it as a little finer than Shropshire and a little coarser than Southdown wool. It is especially adapted for high-class winter hosiery and "is exclusively used for this purpose in England."

Horns a protection to the Dorset Horn. Early advocates of the breed argued that by means of its horns the Dorset would protect itself better from dogs than would hornless sheep, but this claim has been very generally discarded in recent years as not being worthy of special distinction.

The distribution of the Dorset Horn is not so widespread as most other British breeds. In England it is found most abun. dantly in Dorset and Somerset counties, especially on the island

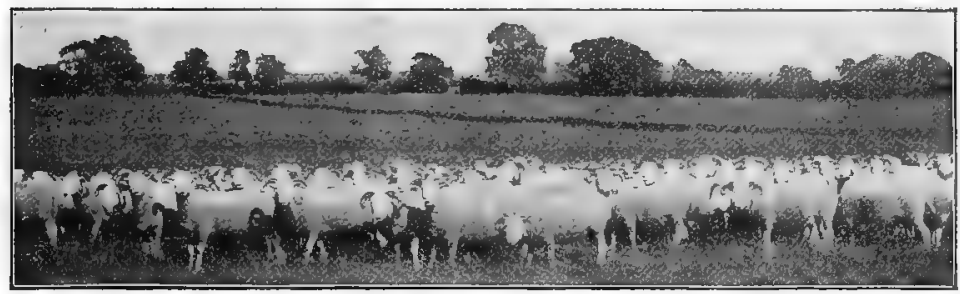

FIG. 279. A view in Dorsetshire, showing part of the Flower flock of Dorsets soon after shearing. From photograph by H. B. Arbuckle, by courtesy of the National Stockman and Farmer

of Wight, and about Purbeck and Portland, where superior flocks exist. In 1903, at the annual meeting of the Dorset Horn Association, 46,878 head were reported in Dorset, 9458 in Somerset, and 6728 on the Isle of Wight, these all being registered sheep. In I9I 3 the Dorset Down Association in England had ninetytwo members, possessing flocks which aggregated 43, I94 sheep. At the annual sale of Dorsets at Dorchester as many as I 5,000 head are sold. The breed has not been taken up with much activity abroad. In the United States high-class flocks are found in New York, New Jersey, Connecticut, Vermont, Pennsylvania, West Virginia, Ohio, Indiana, and Illinois, but the breed is found in many other states and also in Canada. Dorsets have also been exported to Australasia and other British provinces. Of nearly 20,000 pure-bred sheep in Canada in 1908 but 350 were Dorset Horns. The breed seems well adapted to the level 
or slightly rolling lands where food is abundant. It has also thrived in the Allegheny Mountain region under conditions of good grazing.

Organizations of the Dorset Horn sheep breeders were perfected in $189 \mathrm{I}$ in both England and the United States. In England the Dorset Horn Sheep Breeders' Association gives official supervision to the breed. Its first flock book was published in I 892, since which up to I9I 7 it has issued twenty-six volumes. There is also in England another association for promoting the breed - the Dorset Down Sheep Breeders' Association. Each of these organizations has its office at Dorchester. In 189I the Dorset Horn Sheep Breeders of America organized and established a flock book, publishing the first and second volumes in one in 1894. This association for many years has manifested no symptoms of activity. Owing to a disagreement among the members, in I 1897 the Continental Dorset Club was organized, with headquarters in Ohio. This club published its first flock book in 1900 and in 19I 8 issued its eighteenth volume. This is essentially the only organization promoting the breed in America. 


\section{CHAPTER LIII}

\section{THE CHEVIOT}

The native home of the Cheviot breed of sheep is in the border country between England and Scotland, especially in the counties of Roxburgh (Scotland) and Northumberland (England). On the east these two counties are bordered by the North Sea. The country is hilly or mountainous, rising to an elevation of nearly three thousand feet in the section known as the Cheviot Hills. The hillsides are free of timber, excepting in the case of small artificial plantings, but are covered with short, nutritious grass. The climate is moist and rough, snow falling frequently in winter, although not usually attaining much depth. The country is supplied with many mountain streams, and the river Tweed and its tributaries drain much of the Scotch Cheviots. A great woolen industry is conducted in this region, with Kelso on the Tweed and Hawick on the Teviot as important centers.

The origin of the Cheviot is obscure, like most other breeds. Cheviots have been bred in the border country from very early times. In I79 I David Irving published a letter in the "Annals of Agriculture" relating to experiments by him on Cheviots commencing in $\mathbf{1 7 7 7}$. The Cheviot has been crossed more or less with Black Faced Highland, Leicester, Southdown, and Merino, and the character of the breed has undergone great changes through careful selection, but the influence of the breeds mentioned has not been notable. In 1796 Naismyth wrote ${ }^{1}$ that the Cheviot was well polled, was smooth and white of face and leg or somewhat mixed with black or brown. There was a tendency to too much leg, the shoulders were thin in some individuals, and the fleece was generally close and even, the wool soft and fine, from two to three and one-half inches long. He further says: "The same kind of sheep have fed in this district (Cheviot Hills) from time immemorial; nor does anybody allege that they were 
ever natives of any other region." The British Wool Society over a century ago did much to popularize the breed, and at one time it became generally distributed over Scotland. The improvement of the Cheviot was gradually brought about by the breeders in general, although Mr. Robson of Belford, from 1757 on, by the use of Lincolnshire rams is credited with being the great constructive Cheviot breeder of the eighteenth century. Douglas,

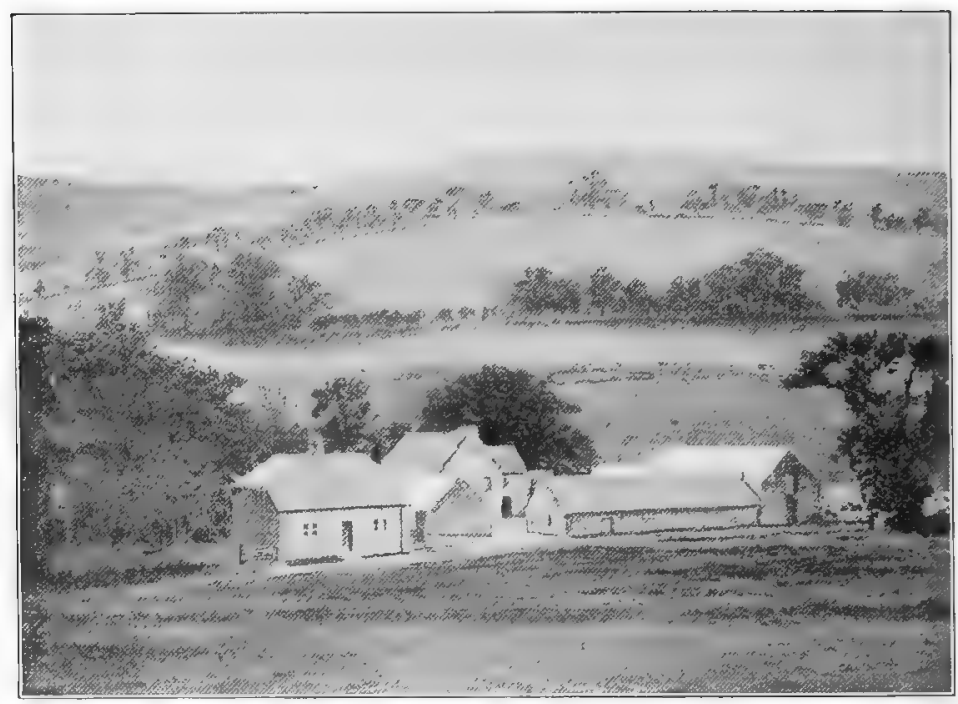

FIG. 280. The old home of James Robson, Philhope, Yetholm, Scotland, where important early constructive breeding of the Cheviot took place. From photograph by the author

in 1798 , states ${ }^{1}$ that to remedy low and thin shoulders three farmers - John Edmistoun of Mindrum, James Robson of Philhope, and Charles Ker of Riccaltoun - went to Lincolnshire "about forty years ago" and bought fourteen white-faced rams, and through these marked improvements were secured in their flocks. During the nineteenth century Thomas Elliott of Under Hindhope, Jedburgh, and his son John were very famous breeders and improvers.

1 Reverend Robert Douglas, General View of the Agriculture in the Counties of Roxburgh and Selkirk, I798. 
The introduction of the Cheviot to the United States first occurred in 1838 by Robert Youngs of Delhi, Delaware County, New York. They had some time previously been imported into Canada by a Mr. Pope of Cookshire, Quebec. In I 842 George Lough and a Mr. Davidson of Delaware County, New York, made importations. In $1845 \mathrm{~T}$. J. Carmichael imported three rams and six ewes to Jefferson County, Wisconsin. Cheviots were introduced into Pennsylvania in I889 by T. M. Patterson, into Illinois in 1888 by E. Pumphrey, and into Indiana in $189 \mathrm{I}$ by $\mathrm{H}$. H. Keim. In recent years quite a number of fine Cheviots have been imported into the United States.

\section{Characteristics of the} Cheviot. The head is usually hornless and is covered with hard, white, short hair to behind the ear and around the jaw. The lips and nostrils should be black, though frequently they are also mottled flesh-color and black. The nose should

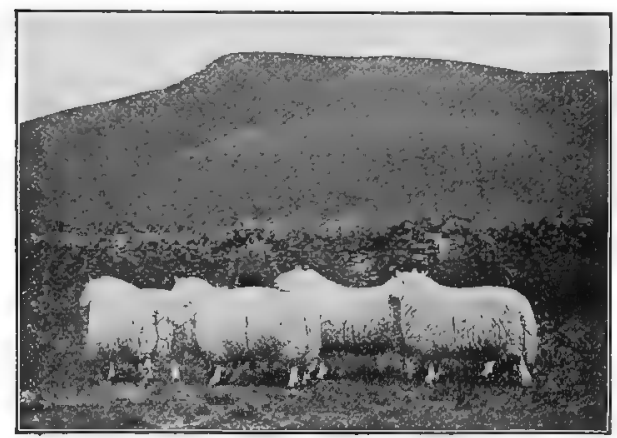

FrG. 28I. Cheviot rams, the first-prize pen at the Royal Agricultural Society of England Show, I900. Owned and exhibited by John Elliott, Under Hindhope, Jedburgh, Scotland. From photograph by the author

be broad, with a tendency to a Roman curve. The head is short and broad between the prominent, large eyes. The ears are white and free from wool and are thinner and longer than the Shropshire ear. The Cheviot shoulder is lighter than with lowland breeds, and the body lacks the breadth of the Shropshire and the Southdown. The withers incline to be high and sharp, the back is none too level, and the depth of body is only moderate. The bone is of fine quality and strong, as is quite manifest in the clean white legs. The skin is unusually pink and rich in color. The fleece covers the body and extends up the neck to behind the ears, forming a sort of collar and covering the legs to knees and hocks. The fleece is of the middle-wool class, neither fine nor coarse, of staple grading quarter-blood combing, and in the better flocks even 
three-eighths-blood, and averages about three inches long. Sometimes the wool on the lower, back part of the thigh is long and tends to be hairy, a very objectionable feature. The head and ears often have small black spots which are not disqualifications but are regarded as objectionable. Reddish or sandy hair also occasionally occurs on face and legs, which is strongly objected to. All rams possessing well-defined horns an inch or more long are ineligible for registration. Horns occur occasionally on the rams, but are becoming more and more rare. The hoofs should be black.

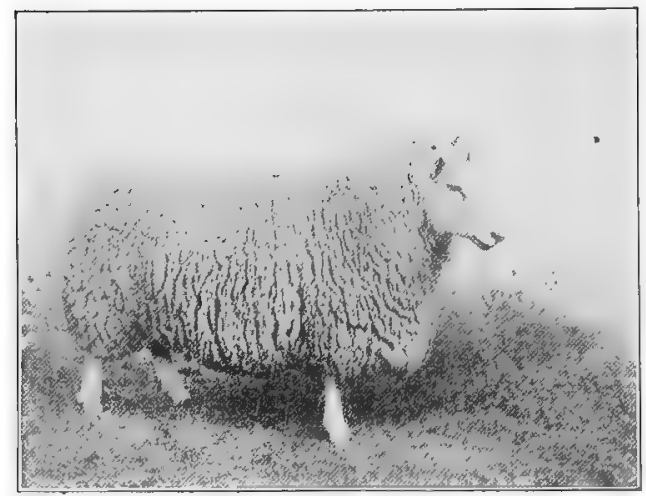

FIG. 282. A Cheviot ram, champion at the show of the Highland and Agricultural Society, Hawick, Scotland, I9I4. From photograph by the author

The temperament of the Cheviot is a striking characteristic. $\mathrm{He}$ carries himself with an uplift of head and alertness of ear and general style very distinctive of the breed and one of its greatest charms. In more recent years the tendency among the best breeders of Scotland and America has been to produce a broader-backed, wider sheep all through, full in his hind quarter, short of leg, and with a fleece of marked quality and density. Judges in the best shows recognize this improvement.

The size of the Cheviot is medium, comparable with the Shropshire for weight. Mature rams weigh about 200 pounds, with 225 a standard, and ewes from I 50 to 160 pounds. But few rams exceed 225 pounds, though ewes frequently surpass I60 pounds. The standard of the American Cheviot Sheep Society, adopted in I 908 , states that a ram at twenty-four months should weigh not less than 225 pounds and the ewe of the same age not less than I 50 . It has been stated that this is a "rather small " breed, with weights for rams at I75 to 200 pounds and ewes at I40 to I60 pounds, but the Cheviot certainly cannot be classed as small, even on the basis of these figures. 
The Cheviot as a mutton producer stands high. In England the mutton of this breed, which is rarely too fat and has very superior quality, ranks in the first class. External fat is not abundant, but there is a desirable proportion of lean to fat. Professor Wallace of Scotland states that ewes fed on turnips twelve to fourteen weeks, and wethers from the hills at three years, weigh, killed and dressed, 60 to 70 pounds. Wethers a year younger, fed turnips, weigh about the same. The Cheviot at the Smithfield FatStock Show has always made a good place for itself, and in I9I 4 Archibald MacNeilage, editor of the Scottish Farmer, stated thatas a mutton breed at this show it has been preeminent from the beginning. Henry and Morrison show ${ }^{1}$ from Smithfield Club records that 53 yearling wethers averaging five hundred and ninety-two days and 224 pounds live weight made an average daily gain of .37 pound, and 35 wether lambs weighing an average of I4I pounds at two hundred and thirty-eight days gained .59 pound daily,

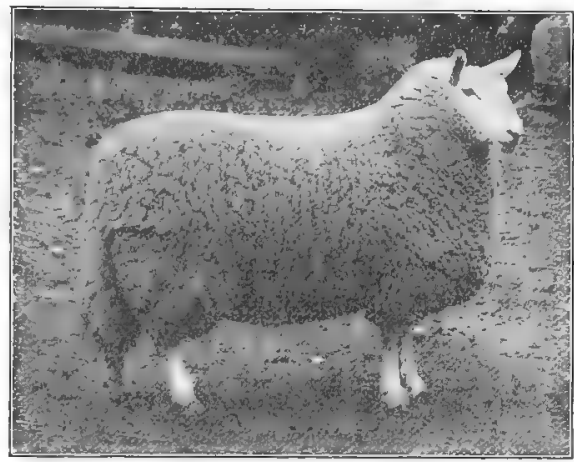

FIG. 283. A Cheviot yearling ewe, first prize in class at the Edinburgh. Show, Scotland, 1904. This is a fine example of Cheviot style and character. Bred and exhibited by J. R. C. Smith, Mowhaugh. From photograph, by courtesy of the owner

surpassing both Shropshire and Southdown in daily gain. In the carcass tests at the Smithfield Show 54 Cheviot lambs dressed 59 per cent carcass, which is better than average. At the I9I I International Live-Stock Exposition, in the carcass contest the second-prize yearling wether was a Cheviot shown by Wisconsin University that had a live weight of 160 pounds and dressed 60 per cent carcass.

The crossbred or grade Cheviot has much merit as a mutton producer. The use of Border Leicester or Lincoln rams on aged Cheviot ewes has been practiced for a great many years in the border country, such half-breds having a comparatively high 
value. MacNeilage brings out the Scotch system in an interesting manner, in which comparative merits are discussed as follows:

In the southeast of Scotland, and to a large extent in northeast Northumberland, the produce of the Border Leicester tup (ram) and the Cheviot ewe has been the savior of agriculture. There you have land, too good to be utilized as a rearing ground for a mountain breed like the Cheviot, and not good enough to do justice to the Border Leicester. Some farseeing men, recognizing that there was some sort of affinity between the two white-faced breeds, crossed them, and gave them the suggestive name of half-breds. It is not certain who actually was the first to suggest and practice the cross, but two names are usually mentioned as prominent. These are John Borthwick of West Newton, Northumberland, and Mr. Elliott of Lamberton, Berwickshire. From the Cheviot is derived a hardier constitution than the Border Leicester can boast, and from the Border Leicester more size and a greater tendency to ripen early. The half-bred is said to have wool more close planted, to be better clad than the Border Leicester, and the mutton is of finer quality than that produced by the latter breed. In addition to these qualities the half-bred is more prolific, and a better mother than her progenitor, four out of five producing twins.

Oxford Down rams are also used on Cheviot ewes with success. Both of these crosses produce very rapid-fattening lambs, giving a leaner and better quality of flesh, dressing out 16 to 18 pounds to the quarter at about twelve months old. Cheviot rams have not been used extensively in crossing, but when used on Merino grade ewes produce an easier-fattening lamb of more salable type.

The Cheviot as a grazing sheep is unsurpassed. On its native hills it subsists entirely on pasture, excepting for hay which may be fed during excessive snow when the grass is covered. Ordinarily the Cheviots paw aside the thin covering of snow on the hillsides and thus secure winter grazing. No breed is more essentially a grazing sheep.

The Cheviot as a range sheep is of peculiar character. This breed does not flock in the ordinary manner, each sheep moving about independently, thus scattering to a considerable extent. On the Scotch hillsides one sees no evidence of flockings such as the Merino exhibits. There are but few of these sheep on the Western range, but if the natural hardiness of the Cheviot could be combined with reasonable restriction of movement it would serve a valuable purpose to the ranchman. In recent years the 
breed has secured some foothold in the Canadian Northwest, where one very large flock is kept on the range. It is also growing in favor in eastern Canada, especially Quebec.

The hardiness of the Cheviot is one of its strong characteristics. For generations raised on the hills, rarely seeing the inside of a shed or barn, summer or winter, it has from very force of circumstances

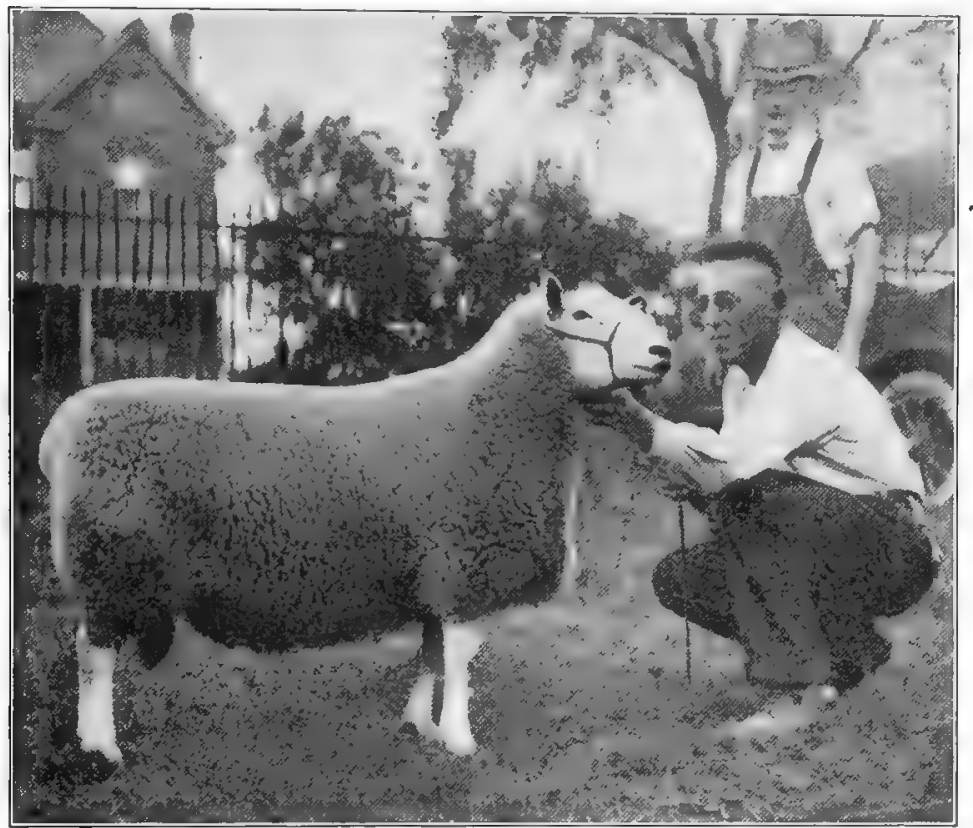

Fig. 284. Cock Robin, champion Cheviot ram at the 1918 Ohio State Fair. Owned by R. D. Grieve, Xenia, Ohio. From photograph by the author

developed into the hardiest of the middle-wool breeds. The lambs are vigorous from birth and seem well suited to severe conditions of environment. On their native hills Cheviots, as a rule, receive no grain unless they be rams or show sheep.

The prolificacy of the Cheviot is above the average, and one may be safe in assuming above 125 per cent. The lambs are usually dropped under rather vigorous conditions, yet they soon get up on their feet and begin nursing and are naturally very active. The ewes are excellent mothers and produce an abundant flow of milk. 
The Cheviot as a wool producer is only fair. The fleeces lack weight, although they have very satisfactory quality, the wool bringing a price equal to any of the medium class. Twenty-five Cheviot breeders give the average weights of fleeces in their flocks as ranging from $7 \frac{3}{4}$ to II pounds per fleece for rams and 6 to 9 pounds for ewes. Wallace states that a good average clip for ewes is $4 \frac{1}{2}$ to 5 pounds of washed wool. The author has received from Scotland records of individual weights of a considerable number of fleeces in prominent flocks, the heaviest being 8 pounds

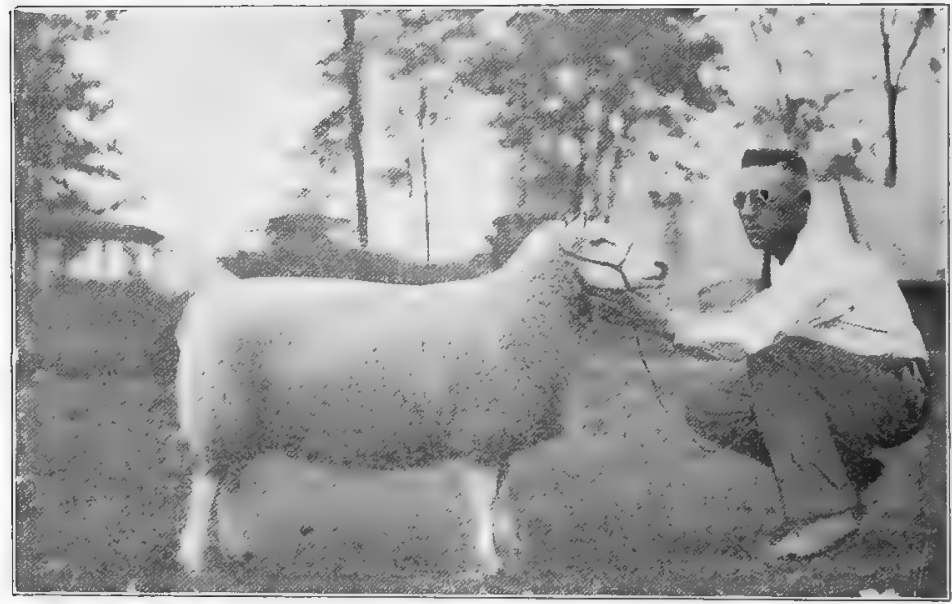

FIG. 285. A Cheviot ewe, champion at the rgr8 Ohio State Fair. Owned by R. D. Grieve, Xenia, Ohio. From photograph by the author

for a stud ram, with many ranging from 5 to 6 pounds. Formerly Cheviot fleeces appeared somewhat open and long, and the breed has ignorantly been referred to by some as a long wool, whereas it is a true middle wool of three-eighths combing grade. In American flocks the fleece is being bred to be more compact and heavier, with a length averaging as near four inches as possible. Cheviot wool is valued by buyers, and in scouring tests at the Michigan Experiment Station the wool of this breed shrunk less than that of any other.

High prices for Cheviot sheep have been paid in Scotland. Each year at Hawick annual ram sales are held on a large scale, 
thousands of sheep being sold and many high prices paid, with good averages. At this sale in 1903 five breeders sold rams at prices ranging from $\$ 50$ to $\$ 575$ each. At the I 9 I 2 sale the ram Cheviot Dinmont sold to J. S. Dickson and A. and J. K. Smith for $\$ 625$. At the 1914 sale the ram Millknowe Masterpiece sold for about $\$ 525$, and the ram No. I Hindhope, bred by John Elliott, sold for a like sum. At a sale in 1865 at Beattock 165 Cheviot rams owned by Mr. Oliver of Hawick brought over \$I 2,000, one three-year-old bringing $\$ 775$ and a two-year-old $\$ 605$. In 1902

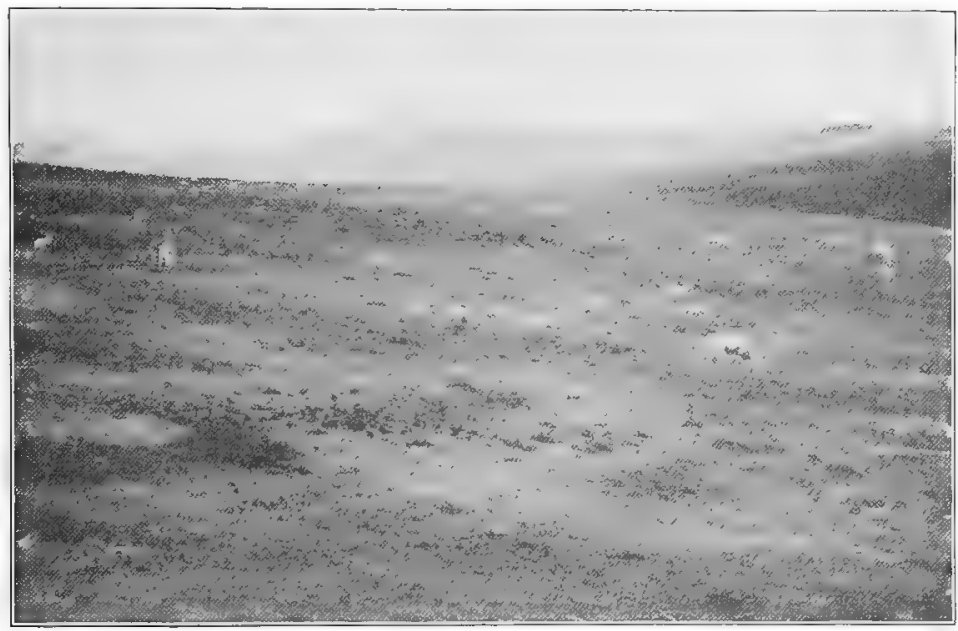

Fig. 286. A valley scene in the Cheviot Hills, Scotland. This picture shows the lack of the flocking habit with the Cheviot. From photograph by the author

Mr. J. R. C. Smith of Yetholm, Scotland, purchased the ram Ambush (I 545) for about \$600. In I9 I 5 John Elliott purchased at Hawick at auction a two-year-old ram for about $\$$ I I25. In I917 a ram sold at Hawick for \$1000. In I9I9 all Cheviot price records were broken when a yearling ram, the champion at the show of the Highland and Agricultural Society of Scotland, was sold by John Robson, Millknowe, to Messrs. Hogg, Newlands, and Robson for 6620 ( $\$ 3020)$.

The distribution of the Cheviot is mainly in England, Scotland, and North America. In a considerable territory in the border country in Britain there are many large flocks, men counting their 
holdings by thousands, this being the one breed in evidence on these hills. Cheviots are chiefly bred in Roxburgh, Dumfries, Peebles, and Sutherland counties (Scotland), and in Northumberland County (England). They are also bred to a small extent in Ireland and have been exported to New Zealand. In Canada the breed has grown in considerable favor in recent years, and in I9I8, in Saskatchewan, George W. Brown sold a flock of 600 high-grade ewes to the government for distribution among the farmers. In the United States the Cheviot has been pretty well distributed from Tennessee north and from the Atlantic to the Far West. There are many flocks in eastern New York, with flocks in Ohio, Indiana, Illinois, Wisconsin, Maine, Tennessee, and other states. In 1918 the largest flock in the United States, numbering about 500 head, was owned in Maine, and the breed is rapidly growing in favor in the northeastern United States.

Cheviot sheep breeders' organizations exist in Britain and the United States. The Cheviot Sheep Society of Great Britain was organized in I89I, Volume I of the flock book appearing in I 893, there having been published twenty-eight volumes up to I9I9, registering 3252 rams, ewes not being recorded. In I89I the American Cheviot Sheep Breeders' Association was organized in New York State. Owing to disaffection among the members, in 1894 the National Cheviot Sheep Society was organized in Indiana. In Igoo these organizations amalgamated, forming the American Cheviot Sheep Society, incorporated under the laws of New York. Each of the old associations published one flock book, while the new society in I90I published another as Volume III. Up to I9I8 this society had published its latest flock book in I905, as Volume IV, with registration brought up to 3500 . 


\title{
CHAPTER LIV
}

\author{
THE SUFFOLK
}

The native home of the Suffolk sheep is in southeastern England. There are four counties fronting the North Sea - Norfolk, Suffolk, Essex, and Kent, in the order named from north to south. Suffolk is a somewhat flat, low-lying county of 1489 square miles and contains considerable fertile area and is noted for breeds of horses and sheep, named after the county. Norfolk is a fairly level country of 2087 square miles and has long been noted for live stock and standard farm crops. Essex and Kent corner on the city of London, with the river Thames dividing them. Kent is the famous hop-growing section of England.

The original stock of the Suffolk sheep was the old Norfolk and Suffolk heath sheep. These had a long, slender carcass, says Youatt, long legs, horns, and a black face. The fore quarters were deficient, the shoulders low, and the withers sharp. The hind quarters were fairly well developed. The fleece was short and fine and weighed light. The breed was hardy and prolific. These sheep were crossed with Southdown and Hampshire rams, although English Suffolk breeders assume the breed to have been maintained fairly pure since 1810 . The Southdown blood bred off the horns, improved the form, and gave a better carcass and earlier-maturing, easier-fattened sheep than the Norfolk, while the Hampshire blood gave size and weight. Mr. George Dobito of Ludgate, Suffolk, was one of the most important improvers of the Suffolk in the last century. The breed was first exhibited under this name in 1859 at the show of the Suffolk Agricultural Association, but was not recognized by the Royal Agricultural Society until I 886.

The introduction of Suffolk sheep to America is as recent as I 888, when two importations were made - one by M. B. Streeter of Brooklyn, New York, said to have been prize-winning stock, and the other by B. D. Sewell of Frederickton, New Brunswick, who brought over 20 ewes. Suffolks were first imported to Canada 
also in I 888. In I 892 the Iowa Suffolk Sheep Society imported 2 rams and 20 yearling ewes and placed them on the farm of G. W. Franklin at Atlantic.

Characteristics of Suffolk sheep. The head, which is hornless, tends to be long and is characterized by a Roman nose. The ears are large and long and commonly incline forward; the neck is moderately long; the body, rangy but broad and full in the breast

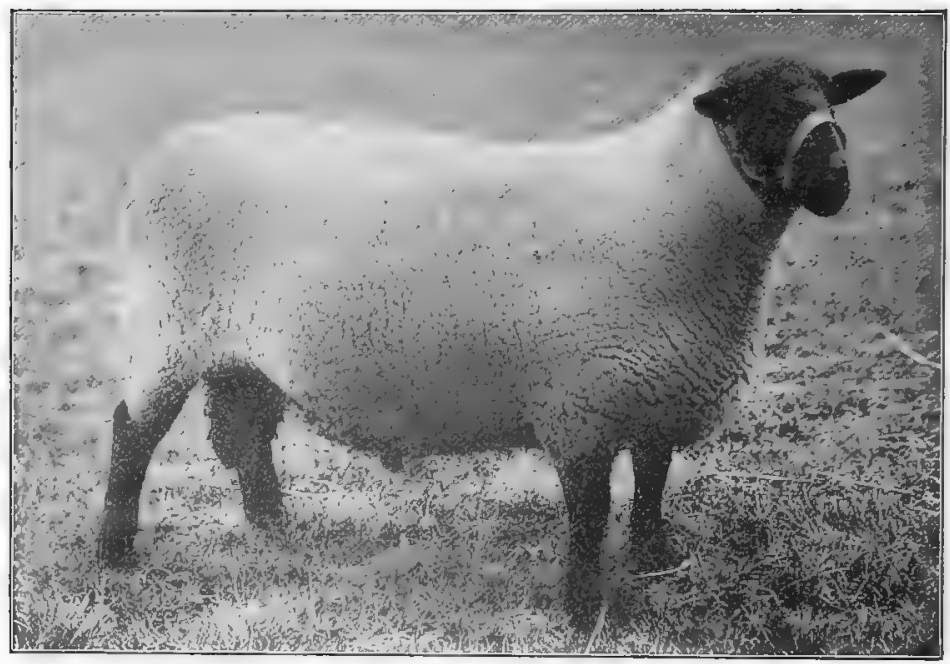

FIG. 287. Playford Model (773I), first-prize Suffolk ram at the Royal Agricultural Society of England Show, I904. Owned by S. R. Sherwood, Playford, England. From photograph, by courtesy of William Cooper \& Nephews, Berkhamsted, England

and wide through the chest, has a well-sprung, deep rib, is especially strong in the back and loin, full and thick in the hind quarters, and notably strong in the twist. The legs tend to be short, and one is impressed with this as a fairly low-set sheep. .The skin of the Suffolk should be "fine, soft, and pink." The head and ears are covered with distinctly black hair, and the legs also are black. Ordinarily the entire head is free from wool, but a small amount on the forehead is permissible. The Suffolk is quite similar to the Hampshire Down, and in this connection Wrightson says ${ }^{1}$ :

1 Sheep: Breeds and Management (1895), p. 76. 
In examining Suffolk sheep the observer is struck with the blackness of the face and the general absence of wool upon the head or between the ears, which is so characteristic of the Hampshire Down sheep. This is the principal characteristic difference in appearance between the two breeds.

The size of the Suffolk is nearly equal to the Hampshire and is greater than the Shropshire. It is stated that mature rams of Mr. Sewell weighed from 200 to 240 pounds, while one of the imported yearling ewes of Mr. Streeter weighed 200 pounds, and a ram lamb nine months old 195 pounds. From figures given by Henry and Morrison ${ }^{1}$ the average weight of forty-nine yearling wethers shown at the Smithfield Fat-Stock Show, between I 895 and I9 I 2, at six hundred and forty-eight days of age, was 29 I pounds, the heaviest of any breed but the Lincoln; while 76 wether lambs averaging two hundred and eighty-seven days weighed $20 \mathrm{I}$ pounds and showed an average daily gain of .70 pound, the best record of any middle-wool breed. Shaw and Heller credit the rams with 200 to 240 pounds' weight and the ewes I 50 to 200 pounds, while Coffey places the rams at 250 and the ewes at 165 pounds. The breed standard makes no reference to weight, but good examples weigh distinctly heavier than the Shropshire. The author has seen some Suffolks in American shows that were poor types of the breed and would find no favor in England.

The Suffolk as a mutton sheep holds high rank in its native country, evidently possessing superior qualities from Southdown inheritance, the fat and lean being in good proportion and the grain and flavor of the meat excellent. In the British muttoncarcass contests the Suffolk has won a place of the first rank; in fact, at Smithfield it has held first place on various occasions. Again quoting Henry, the Smithfield-show figures given by him bring out the fact that in twenty years the yearling Suffolk dressed 64 per cent carcass.

The Suffolk as a feeder also ranks well. It has been kept under conditions of moderate grain ration with considerable grazing, showing fair feeding returns. In experiments on fattening wether lambs at the Iowa Experiment Station the Suffolk gained rather faster per day than the Shropshire or Southdown in each trial, averaging .55 pound and .40 pound daily gain in two trials. They 
dressed out in carcass 53.6 and 52.54 per cent, and the carcasses were valued at $\$ 4.25$ and $\$ 5$ per hundred, a materially poorer showing, however, than most of the other breeds made. The average daily gain of Suffolk yearling wethers at the Smithfield show, of .45 pound per day, excelled any of the Down breeds, while the wether lambs made the remarkable daily average gain of .70 pound, being excelled only by the Lincoln with .72 pound.

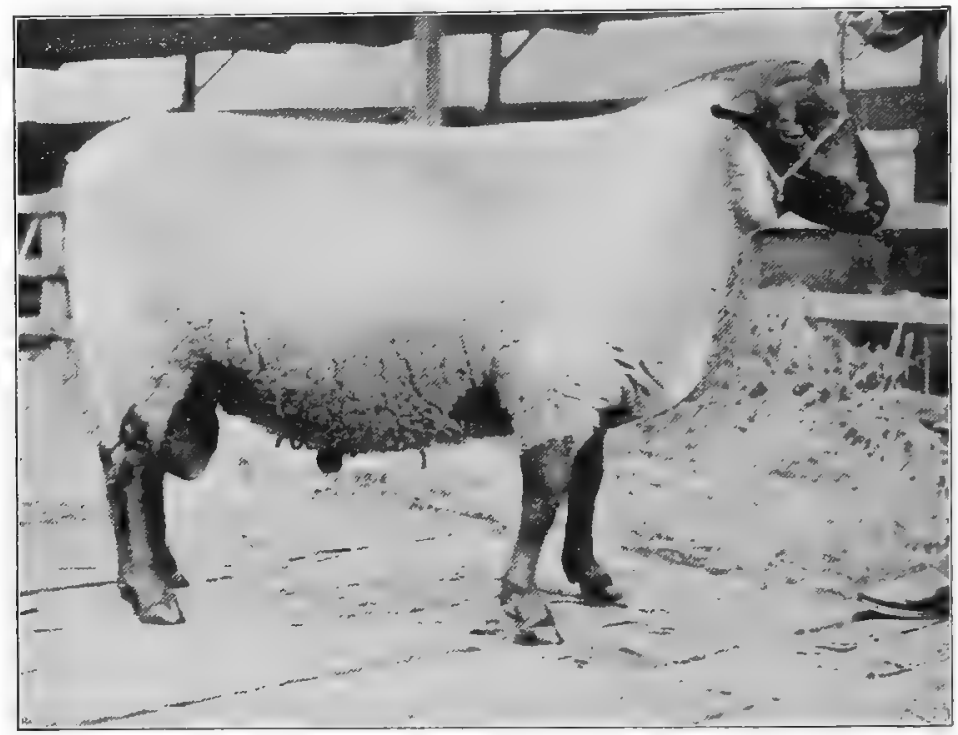

FIG. 288. A Suffolk ram, champion at the I914 Show of the Royal Agricultural Society of England. From photograph by the author

During twenty-one years, up to I915, in the Smithfield Club carcass competition Suffolks won eight championships and three reserves, in competition with all breeds and crosses.

The Suffolk crossbred or grade is comparatively unknown in North America, but in South America it has been used on Merino grades to produce good mutton sheep. Suffolk rams are gaining much in favor in some parts of England and Scotland for using on draft ${ }^{1}$ ewes. Commenting on the crossbred as it has appeared in Australasia, E. M. Prentice writes ${ }^{2}$ :

1 Aged ewes culled from the flock.

2 Live Stock Joumal Almanac (London, 1917), p. I34. 
The Victoria government recently included Suffolks in their well-conducted experiments to ascertain the comparative mutton value of various crosses. Lincoln, Border Leicester, Dorset Horn, Shropshire, Southdown, and Suffolk rams were mated with selected first cross Lincoln-Merino ewes, with the result that, in the first year, the Suffolk-cross lambs topped the market, were first in maximum weight of carcass, first in minimum weight, first in average weight, showed the least per cent of offal loss, and in value of the fleece were beaten only by the Lincoln cross. At fourteen to fifteen weeks the Suffolk-cross lambs were as heavy as the heaviest of the other crosses at seventeen weeks. At the last Canterbury show (the largest in New Zealand) an exhibit of Suffolk-cross wethers marked the first appearance of this cross on the show ground by winning the special prize offered by the Canterbury Frozen Meat Company for the best freezers.

The fecundity of Suffolk ewes is advocated as a valuable point in behalf of the breed. Twins are common and triplets not uncommon. In the spring of I89I, 32 ewes of Mr. Sewell raised 58 lambs, while the same year 5 imported ewes of Mr. Streeter produced I I lambs, and in I 892 the same ewes produced I 4 lambs. According to returns made to the Suffolk Flock Book Society of England, the number of lambs reared to June I, I903, was ${ }^{\circ} 40.66$ per cent per IOO ewes as compared with I 35.49 in I9I 5 and an average of 133.87 per cent for the previous twenty-eight years. The ewes have large udders, produce an abundance of milk, and are rated as excellent nurses.

The Suffolk as a producer of wool does not rank high. The fleeces are somewhat light, and the staple is of but moderate length, though fine and soft, and grades low three-eighths or quarter-blood combing. The Suffolk Society standard gives the fleece as of medium grade and specifies that it should be of even quality, present a smooth surface, and extend over the belly and well down on the legs. A fleece of nine pounds has been reported by some, but this no doubt would be a heavy average.

Prices for Suffolk sheep in England have not been excessive. In I9r6, at the Suffolk Sheep Society's Special Sale at Ipswich, I 439 yearling ewes averaged about $\$ 32$ each. One ram was sold to go to Scotland for $\$ 700$. The average price of 408 rams was $\$ 68$. At the three principal lamb sales 5629 ewes averaged $\$ 16$ per head. In the I9I8 sales 5326 ewe lambs from registered flocks averaged $\$ 7.50$ each and 2077 yearling ewes averaged $\$ 40$ each. The top price per head for a pen of io yearling ewes 
was $\$$ I 50. In September, 19I8, at the Suffolk Sheep Society's Sale at Ipswich, the top price was $\$ 525$ for a ram lamb.

The distribution of Suffolk sheep in recent years has grown greatly. They are most common in Suffolk and Norfolk counties in England, but the breed has steadily grown in favor in the colonies: These sheep have been exported to practically all the British colonies, as well as to Denmark, France, Germany, Spain, and Jamaica. At the I9I 5 sales at Ipswich it is reported that buyers were present from all parts of the United Kingdom Scotland, Wales, Ireland, Somerset, Shropshire - and many orders were executed for the Midland counties. The breed is securing a serious hold in Canada, although in 1908 , of nearly 20,000 pure-bred sheep in that country, but 75 were recorded as Suffolks.

In the United States breeders of Suffolks are almost unknown. In the great sheep shows of the country the breed is practically unrepresented. Suffolks of inferior character have been exhibited at some Eastern fairs where classes have been provided. From the show-ring point of view superior individuals are quite attractive and would add materially to the interest attached to our sheep exhibitions, notably at state fairs and the International Live-Stock Exposition.

Organizations for promoting Suffolk Down sheep were first established in I 886, when the Suffolk Down Sheep Society organized, publishing its first flock book in I887. Up to I9I9 this society had published flock books to Volume XXXII inclusive. In 1892 the American Suffolk Flock Registry Association was organized, with headquarters at Des Moines, Iowa, but never showed any activity while located there. In recent years the headquarters of the association have been in Ontario, Canada, and the few sheep of the breed are registered in the Canadian book. 


\section{CHAPTER LV}

\section{THE TUNIS}

The native home of the Tunis breed, often referred to as FatTailed Sheep, is in northern Africa, in Tunis, a French province of some 45,000 square miles fronting the Mediterranean Sea. Much of the land is hilly, some of it bordering the desert of Sahara, the climate is warm, and the main crops produced are wheat and barley. This breed is found mainly in the upland region.

The origin of Tunis sheep is unknown, but the type has no doubt existed for centuries in Tunis and the associated section of northern Africa sometimes termed Barbary.

The introduction of Tunis sheep to America is said to date back to I 799, when the Bey of Tunis allowed General William Eaton, then United States consul at Tunis, at his request, to ship from that country to the United States several "broadtailed Barbary or Mountain Tunis sheep," only one pair of which survived the voyage. These were placed in the hands of Judge Richard Peters, on his farm near Philadelphia, where they increased in number, the rams being used on native American ewes also. The original ram was later used in Lancaster County, Pennsylvania, on the farm of General Hand. It was soon discovered that they produced superior mutton, and sheep of Tunis stock came into demand. In 1807 or I 808 Commodore Barron of the United States Navy imported some Tunis sheep to Virginia and the District of Columbia. Later President Jefferson had a ram and ewe brought over on a government vessel, and in I825 some thirteen were landed at New York. A pair of these was sent to General Van Rensselaer of Albany. From the early stock, descendants of the Peters breeding, it is claimed, flocks were established in South Carolina by Colonel Richard Singleton and in Georgia by Richard Peters. These sheep increased in number, but the Civil War nearly exterminated them. Most of the importations were unsuccessful owing to the apparent physical disability 
of the ewes to breed on account of the tail interfering with service. A few Tunis sheep from Columbia, South Carolina, were shown in I893 at the World's Columbian Exposition at Chicago, some of which J. A. Guilliams of Indiana purchased. Charles Roundtree

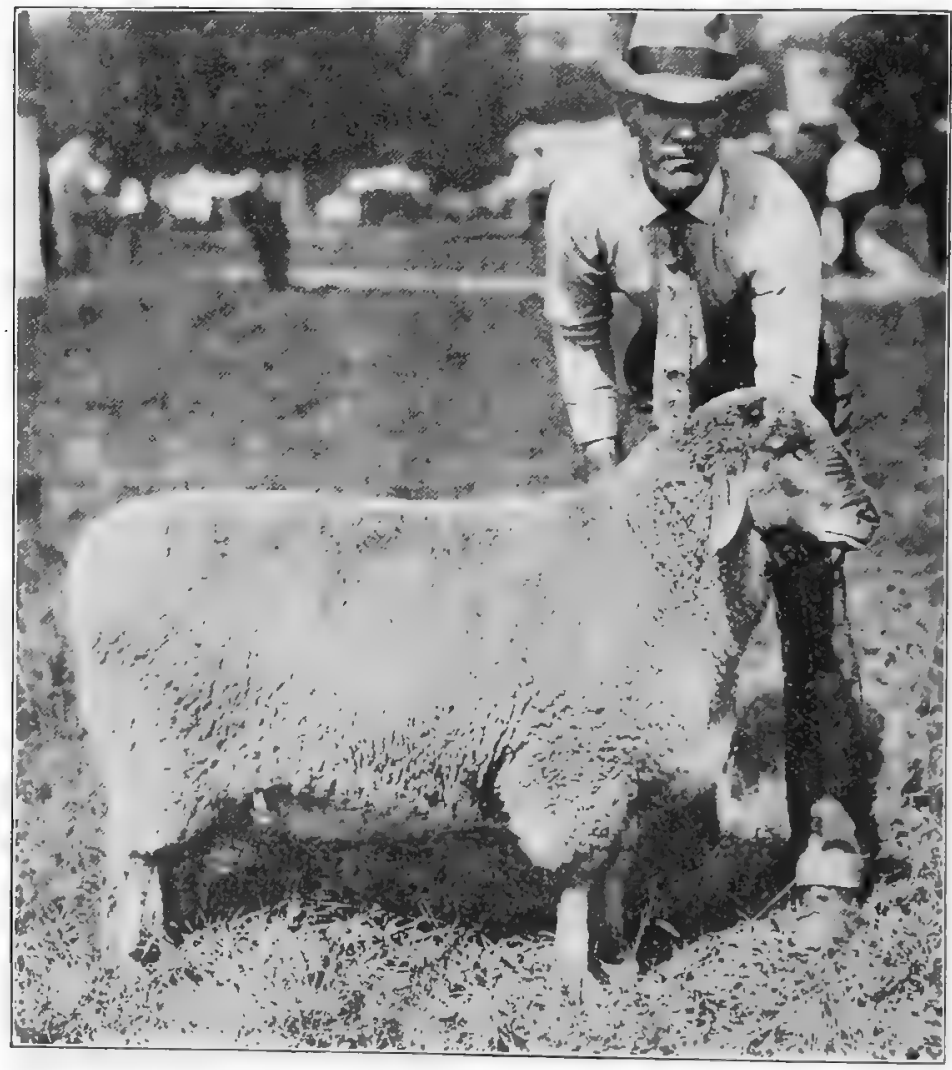

FIG. 289. General McPherson 619, a noted Tunis sire and prize winner. From photograph, by courtesy of the American Sheep Breeder

of the same state later on visited South Carolina, purchasing ten of the flock of twenty-five head there owned. For many years Mr. Roundtree was the main promoter of this breed.

The characteristics of Tunis sheep are not well fixed, even with the many years these sheep have been bred in America. The 
head is hornless with each sex, and the rams are characterized by a Roman nose. The ears are large, broad, pendulous, and covered with fine hair. The neck tends to be long, the breast is only moderately wide, the withers are frequently high, the back of medium width, and the $\mathrm{leg}$ of mutton only fair. The Tunis is naturally leggy, but the bone is fine and the quality superior. The tail is the most striking feature of the breed, being wide at its setting (perhaps measuring five inches at maturity), thick and moderately long, though the fleshy part is carried down only six or eight inches. The tail is usually cut off when the lamb is very young and so does not appear as an important feature in the sheep. Left on, it interferes with breeding the ewes. At the end of the rump, at the tail head, there is a more marked fullness and heaviness than with other docked sheep. The color of the head, ears, and legs varies, though a tawny or yellow brown is the favorite. Some faces are solid brown, others mottled brown and white. The ears are brown, white and brown, or yellow and white. In temperament the Tunis is mild and is easily handled.

The size of Tunis sheep varies considerably, but rams are expected to weigh I 50 pounds or more and ewes I 20 pounds and upward, according to the standard of the Tunis Association.

The Tunis as a mutton sheep has met with much favor. Early writers bear evidence of a high regard for the breed or its crosses for mutton in the markets of Philadelphia and vicinity. The claim has been made by the few promoters of the breed that on grass alone they will make excellent and fat mutton. In August, 1900, four grass-fed ewes, four years old, sold by Charles Roundtree, had a gross weight in the Union Stock Yards of 470 pounds. They averaged about 16 pounds for the hind quarter and $17 \frac{1}{3}$ pounds for the fore quarter and dressed out 56 per cent, an exceptionally good showing. The writer has examined Tunis lambs in October, said to have had no food but grass, which were in splendid flesh for killing. On various occasions Tunis grade lambs fed by Charles Roundtree have topped the Chicago market the day of sale and have received much favorable stockyards comment. On August I I, I900, two lambs one hundred and fifty days old weighed 200 pounds gross and dressed 57.6 per cent. 
Crossbred or grade Tunis sheep sired by Tunis rams are regarded on the market as of choice quality. At the Arizona Experiment Station the progeny of Tunis rams on native ewes proved superior as feeders and for range conditions to those sired by Shropshire, Hampshire, Oxford, or Dorset Horn rams. The lambs came early and soon attained large size, and the fleece was improved by the cross, being notably superior to that of the dams.

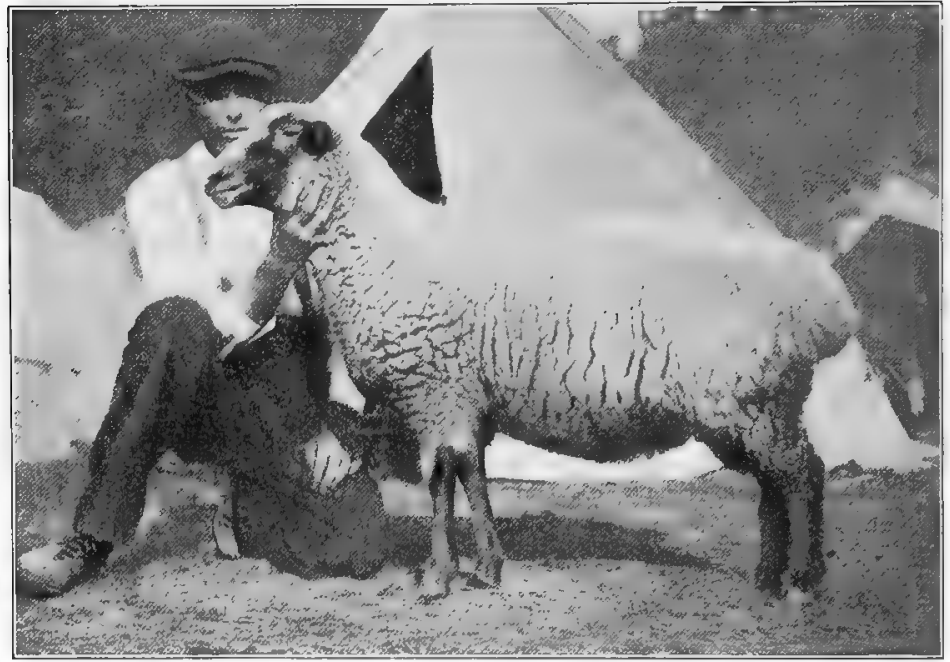

FIG. 290. Tunis ewe 2568, champion at the 1916 Ohio State Fair. Exhibited by R. E. Owen, Fulton, New York. From photograph by the author

The Tunis for early lambs has special qualifications. The purebred or crossbred ewe will breed at any season of the year and may be mated in spring to drop lambs in the fall for the Christmas market. The lambs fatten rapidly and if with dark faces are well suited to the Eastern market demand. Doubtless their use for early lambs will materially increase.

The fecundity of the Tunis sheep ranks high. Twins are frequent, and as the ewes will breed twice a year if desired, the flock may be rapidly increased if physical conditions do not interfere.

The fleece of the Tunis sheep is of special interest. It is of excellent quality, being soft, fine, and fairly compact, covering the body excepting the head from forehead down, averages about 
three inches long, and grades quarter-blood and three-eighths combing. One animal may have a clear white fleece, another a prevailing reddish tint, while in another reddish fibers may be generally interspersed among the white. The young lambs when dropped are of various colors, - white, red, tawny, and mottled, but this generally changes to a uniform color with maturity. As a producer of wool the Tunis has a fair degree of merit, although the variation in color is objectionable. Tunis breeders claim that they shear from 6 to 12 pounds, and Professor Shaw credits them with $7 \frac{1}{2}$ pounds wool. In an address before the Philadelphia Society for Promoting Agriculture, in 1810 , Judge Peters gave the average weight of the washed fleece at 5 to $5 \frac{1}{2}$ pounds, some flocks averaging 6 , with individuals of pure blood yielding as high as Io pounds, and it is questionable if the breed has changed much in wool production since.

The distribution of the Tunis sheep is widespread, yet but few flocks of importance exist, with Indiana the center for the breed. Several good flocks are maintained in Ohio and New York. The Arizona Experiment Station has found the breed well suited to that section, the sheep flocking well, being good grazers, and apparently quite resistant to heat and the sheep botfly. Some years ago Charles Roundtree sold two rams and six ewes for export to New Zealand. The Tunis has also been exported to South Africa and Australia. The breed is perhaps especially well suited to warm latitudes and for that reason should do much to improve the common sheep in the Southern states, especially Florida, Georgia, Alabama, Mississippi, Louisiana, and Texas.

The American Tunis Sheep Breeders' Association was organized in Indiana in 1896 for maintaining a flock book and promoting the breed, and up to 1919 has published three small flock books. The first rule of the standard adopted by the association allows twenty points for pedigrees extending back unbroken to Judge Richard Peters's stock or to direct recent importations from Tunis. 


\title{
CHAPTER LVI
}

\author{
THE LEICESTER ${ }^{1}$
}

The native home of the Leicester sheep is in the county of that name in central England. This is one of the small English shires, comprising $8 \mathrm{I} 3$ square miles. The land is gently rolling, the soil fertile to a more or less extent, and wheat, barley, oats, roots, and grass do unusually well. It is a noted farming section, where live stock is an important feature of agriculture. The climate is moist and fairly temperate much of the year.

The origin of the Leicester as a breed is obscure, further than that a long-wooled, large, coarse, narrow-backed, slow-feeding, leggy type had been bred in the county of Leicester from time immemorial. This was the old Leicester sort.

The first improvement of the Leicester began with Robert Bakewell, who lived at Dishley Hall, near Loughborough, in Leicestershire. Bakewell was born in I726 and began to experiment with and improve the sheep of his county just prior to 1760 . He purchased the best specimens of the breed to be obtained in the community, practiced rigorous selection, did much in-and-in breeding, and finally produced a remarkable improvement, so that sheep of his breeding became known as Dishley or Bakewell sheep. He converted the Leicester into a broad-backed, thickfleshed, easy-feeding, early-maturing breed, with small bones and much less offal than in the old sort. Bakewell had a collection of bones and meat in pickle, which represented selections from time to time from animals of his own breeding, by which he studied the improvement made. Marshall, who lived in Bakewell's time, stated that he kept four points in view: (I) breed, (2) utility of form, (3) quality of flesh, and (4) propensity to fatten - the three latter depending on the first. Bakewell attained such fame in improving these sheep, as well as Longhorn cattle and other

1 The English pronunciation of this word is as though spelled " Lester." 
stock, that he was often termed the father of improved live-stock husbandry. People visited him from various parts of England and Europe and paid him large sums for the hire of his rams, he being the first person to establish this custom. An item in the "Annals of Agriculture" in 1787 reports him letting three rams for 1200 guineas (\$6000) and that he had been offered IOOO guineas for twenty ewes and refused it. Bakewell died in I795. The Leicester as improved by him retains to-day many

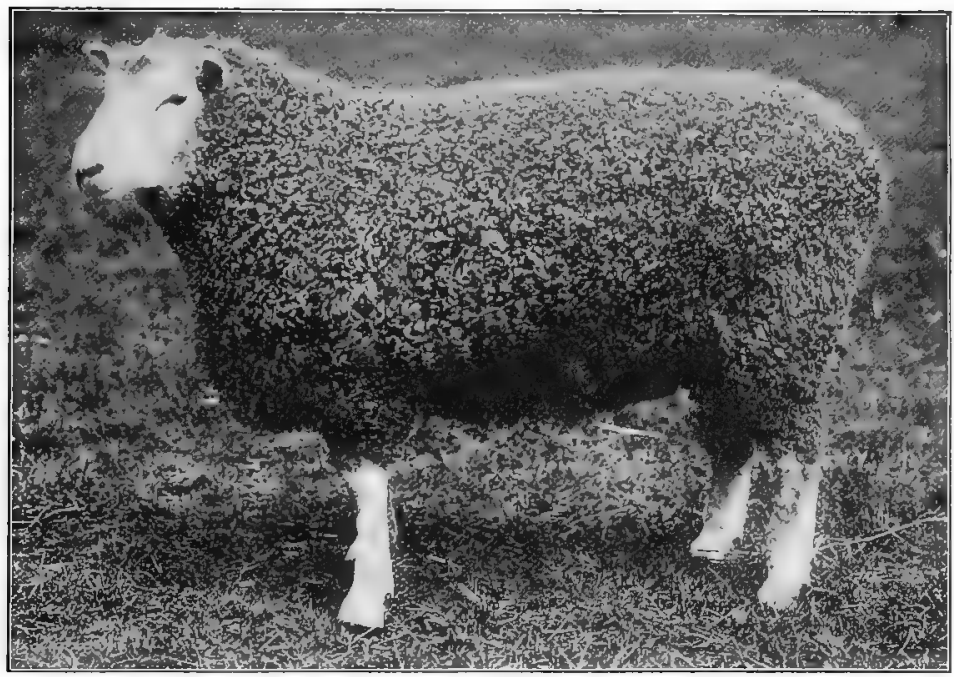

FIG. 29I. A Leicester yearling ram, first-prize in class at the Royal Agricultural Society of England Show, 1904. Exhibited by E. F. Jordan. From photograph, by courtesy of William Cooper $\&$ Nephews, Berkhamsted, England

of the original characteristics, though it may be somewhat smaller and more refined. His method of close breeding eventually reduced the fecundity, vigor, milking capacity of the ewes, and weight of wool. Breeders since his day have continued the practice of selection and early in the last century practiced much in-and-in breeding. Two types of Leicester sheep are now recognized - one the ordinary English sort, the history of which is notably associated with Bakewell and England; and the Border Leicester, an offshoot from Bakewell stock, especially developed among the hills where England and Scotland have their boundaries. 
In I9I 7 W. A. Brown, secretary of the English Leicester Sheep Society, gave expression to the following very pronounced opinion ${ }^{1}$ :

Confused ideas prevail about the Leicester in the minds of sheep men in several parts of the world, where the breed got a footing probably generations ago, and the name, but not the quality, has ever since been retained. In Canada, for instance, and in the United States also, there are so-called Leicesters which are entirely a discredit to the name, as we in this country know the pure descendants of our own home-bred stock; and confusion is made worse confounded in Canada and also in the United States by the inclusion under one head of Leicesters and Border Leicesters. The same anomalous condition applies to Australia.

The introduction of Leicester sheep to America occurred early in the history of the United States. Previous to the War of the Revolution some of the so-called Dishley or Bakewell sheep were brought (most of them smuggled) into the colonies, especially New Jersey and Virginia. As early as 1800 the New Leicester was known about Philadelphia, though it was not of pure breeding. About 1799 or 1800 the first pure-breds brought to America were imported to Quebec, Canada, by Reverend Mr. Toofy. In I806 John Hart of Cheshire, Massachusetts, secured a ram, and about I 805 or I 806 Captain Beanes of New Jersey brought some purebred rams and ewes from England and disposed of them to a retired ship captain, George Farmer, living near New Brunswick, New Jersey. These Beanes Leicesters were carefully and successfully bred and attained a wide reputation, Captain Farmer selling some rams for as much as \$1000 per head. From New Jersey and other states came a large demand for sheep from the Farmer flock. Miles Smith, a neighbor of Farmer, and Joseph Cooper of Flemington, New Jersey, also became prominent breeders. The craze for Merino sheep, however, was on in America and by 1818 , when Farmer died, there were no pure Leicesters on his or Smith's farm. During the War of I8 I 2 Christopher Dunn established the first pure-bred flock of this breed in New York, near Albany, they being stock destined for Canada, but captured by an American privateer. There were importations to New York in 1826 by J. S. Skinner, in I 83 I by D. Stockdale, and in I 835 by John Baker. The first Leicesters which found their way to Ohio were brought

1 Live Stock Joumal Almanac (London, I917), p. I45. 
here in I 834 by Isaac Maynard of Coshocton County, who also brought other breeds for trial. In 1840 Henry Parsons of Massillon had a large flock of breeding ewes. The first sheep of this breed were imported into Canada about 1842.

The characteristics of the English Leicester sheep. The head from the ears forward is covered with a soft white hair, the skin having a slight bluish tint and small black spots often occurring on head and ears. The face is of medium length; the nose is

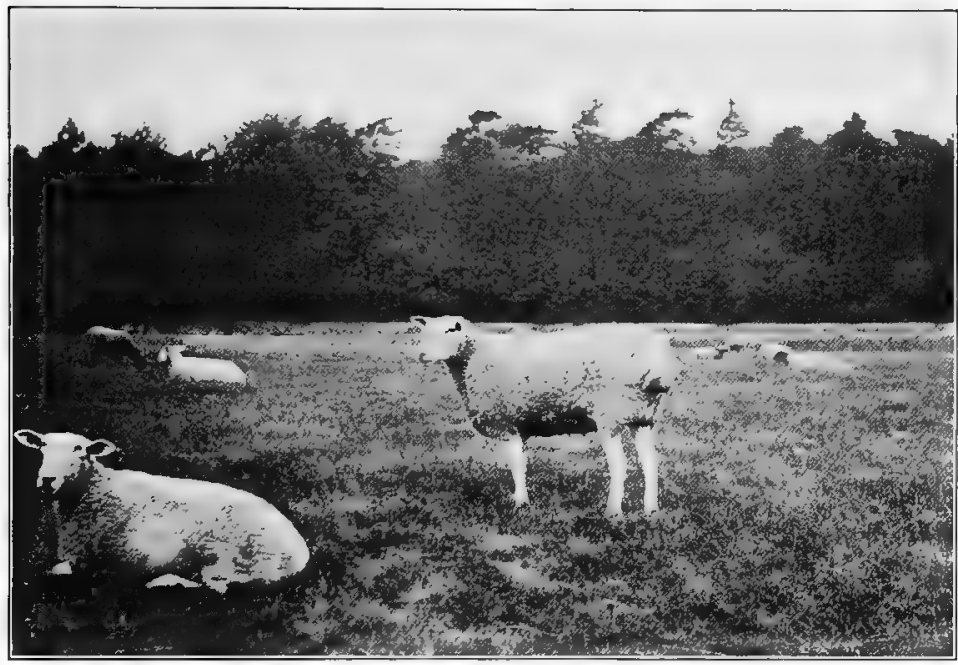

FIG. 292. Leicester ewes on pasture at the Royal Agricultural College, Cirencester, England. From photograph by the author

frequently Roman in form, with black skin at muzzle; and the ears are thin, somewhat large, and delicate, standing more or less erect. Neither rams nor ewes have horns. The neck tends to be short and is not much elevated in carriage. The body is very wide of rib but often lacks in depth, the proportion of breadth to depth being striking. The breast is usually quite prominent, both in extension and thickness, and the hind quarters frequently are not so large as they should be, being peaked. The legs tend to be long and fine of bone, and the hoofs should be black. The temperament is quiet and gentle, such as might be expected with the large breeds. The fleece is excellent for coarse wool, medium long, and 
lies over the body in fine spiral locks. Usually no wool extends beyond the ears, excepting a very small tuft, and the legs are not commonly wooled below knee and hock. One is impressed with the fact that the Leicester is somewhat upstanding or appears to lack depth of rib, as the case may be.

The size of the Leicester is large, though this is the smallest of the long-wooled breeds. Average-sized mature rams weigh from .225 to 250 pounds and the ewes from 175 to 200 pounds. Shaw and Heller state ${ }^{1}$ that the

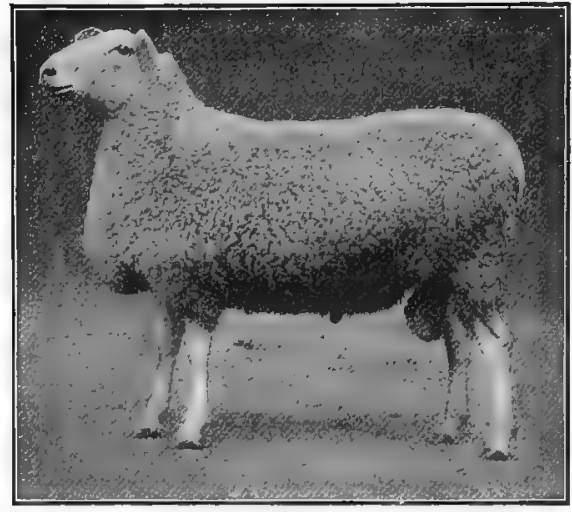

FIG. 293. A Border Leicester ram owned by Alexander Cross, Knockdon, Maybole, Scotland. From photograph by the author rams usually weigh from 225 to 275 pounds and the ewes from 175 to 225 pounds. Volume I of the "American Leicester Record" credits the rams with attaining a weight of 300 pounds and the ewes 200 to 250 pounds. These, however, are outside figures rather than fair averages.

The Leicesters as mutton producers do not rank high. They do not mature early, and when mature they are too large for common market demands and unless killed before twelve months of age produce too fat a mutton. Neither is the quality quite equal to the best standard. Wrightson states that the Leicester is best fattened when from twelve to fifteen months old, when the carcass weighs about 80 to IOO pounds. At three of the American Fat-Stock Shows held at Chicago the following figures were secured, showing the best records made by Leicester fat wethers :

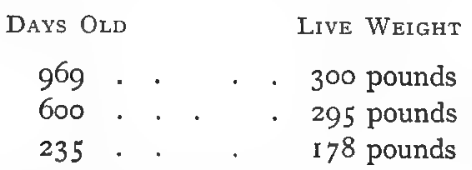

Average Daily GAIN FroM BIRTH

. .37 pound .49 pound . .75 pound

1 "Domestic Breeds of Sheep," Bulletin 94, U.S. Department of Agriculture, I9r4. 
At the Smithfield Show (according to Henry, in "Feeds and Feeding"), during seventeen years, ending in 1912,59 prizewinning Leicester wethers at an average age of six hundred and seven days showed an average weight of 273 pounds and a daily gain of .45 pound, while 54 wether lambs at two hundred and forty-seven days showed an average weight of 157 pounds and a gain of .64 pound. In the Iowa Station tests the Leicester did not make as good gains as Cotswold or Lincoln, either in daily gain or cost of production. The quality of the mutton has been subject to criticism, and Coffey designates it as tending "to be coarse, lacking in flavor, and too fat." Lambs in good condition, however, up to six or eight months produce very good cuts of meat.

Crossbred or grade Leicesters are regarded with favor by some superior sheep feeders. A compact, easy-feeding Leicester ram used on ewes of Merino character will sire sheep of more scale and easier-fattening qual-

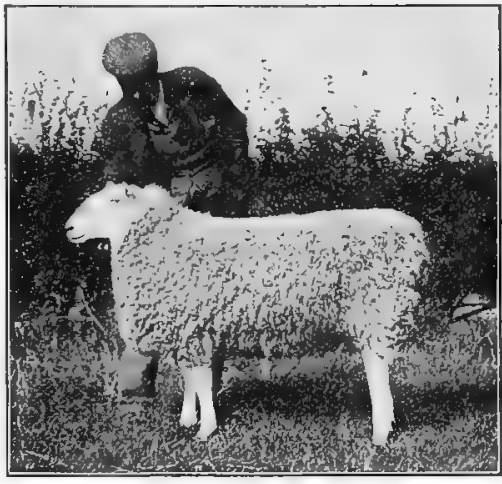

FIG. 294. A very choice Border Leicester ram, bred by J. R. C. Smith of Leaston, Scotland. It was sold in Igor for $£_{122}$ $(\$ 600)$. From photograph, by courtesy of Mr. Smith ity than where Merino rams are

used. In France a type of Leicesters termed "Dishley Merinos" has been developed by using Leicester rams on a Merino-ewe foundation, these sheep now showing little of Merino character. In New Zealand the Leicester ram on Merino ewes played an important part in developing the Corriedale. Robert Taylor of Nebraska has used Leicester rams on middle-wool ewes on the Western range with signal success. In both 1903 and $1904 \mathrm{Mr}$. Taylor won the grand championship at the International Live-Stock Exposition on carload show of lambs, these being a cross of Leicester rams on grade Hampshire ewes. In fact, it is conceded that crossbred Leicester mutton is produced more economically, matures earlier, and is of better quality than the pure-bred, although the size is somewhat lessened. In this connection it is interesting to note 
that the Leicester as improved by Bakewell has served a most important part in improving some of the British breeds in the days of early development, its blood being freely used on the Southdown, Cotswold, Lincoln, Shropshire, and Hampshire foundations.

The Leicester as a grazing or range sheep ranks as only fair. Leicesters will not flock equal to the Merinos. They require better range and more abundant pasture than the lighter breeds, are not suited to rough ground, and in winter lack the constitution to withstand roughing it without shelter. The open fleece is objectionable where much snow or cold rain prevails. In the so-called corn belt, where properly protected, with abundance of roughage, grain, and roots, this breed may do very well.

The breeding qualities of the Leicester are only moderate. None of the largest breeds are strongly prolific, and no doubt the early policy of very close in-and-in breeding followed by Leicester breeders injured the fecundity of the breed. Careful management will no doubt secure fair results and raising Ioo per cent lambs might be a reasonable estimate under average conditions. George Benedict reports I 36 per cent increase in his Leicester flock.

The Leicester as a wool producer yields a fine grade of braid or quarter-blood combing wool. Randall states that after the first shearing it will average about 6 inches long and will weigh 6 pounds. Professor Shaw thinks that the fleece should average from 9 to I I pounds weight, while the I 894 edition of the "Complete Grazier," by Youatt, places it at an average of 7 pounds. George Benedict of Nebraska, a breeder of pure Leicesters, in I 893 wrote, "The average weight of fleeces for ten years is I I pounds." The fleece of the Leicester being naturally fine and open weighs comparatively light, but a clip of about to pounds should be expected in an average flock. If grade Leicester ewes are bred to middle- or fine-wool rams, the fleece of the offspring is commonly finer, more compact, and shears heavier than that of the pure-bred.

The Border Leicester sheep belong to the Leicester family, but differ from it in type. The origin of the Border Leicester has been credited to the Culley brothers, who first used Leicester rams (obtained from Bakewell) on Teeswater ewes. Some authors have regarded the Border Leicester as originating from a cross of Leicester rams on Cheviot ewes, the result of the cross finally 
assuming a pure form of a variety of the Leicester. In 1767 the Culleys moved into northern Northumberland to Fenton, near Wooler, among the Cheviot Hills on the English side of the border between England and Scotland. In this region they developed the Border Leicester, which became very popular. In I 806 they retired and their flock was dispersed, being purchased by various breeders. There are to-day in the border region flocks

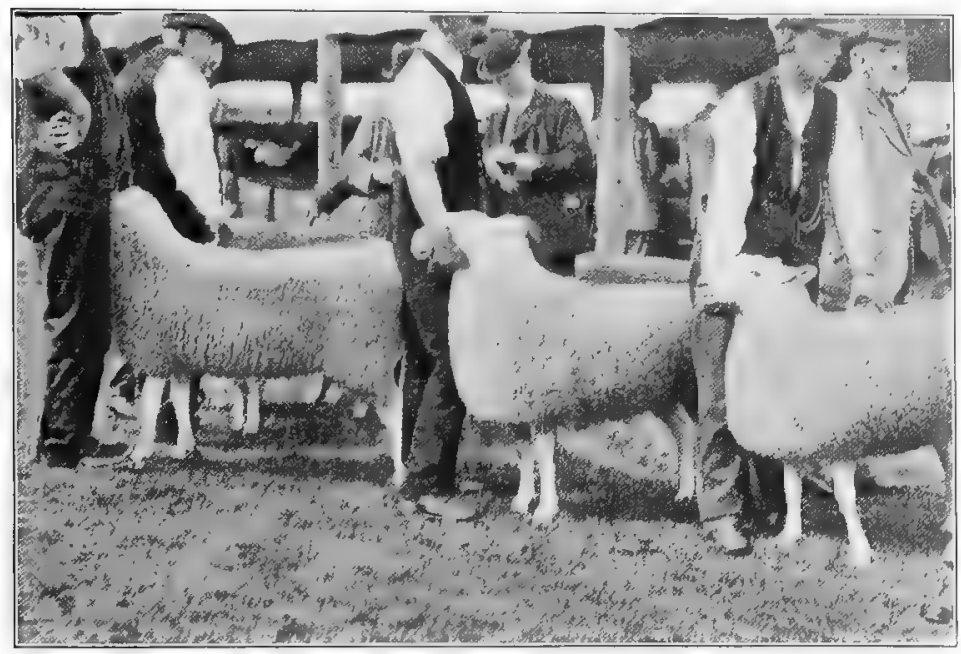

FIG. 295. Judging Border Leicesters in I9I4 at the Highland and Agricultural Society Show at Hawick, Scotland. From photograph by the author

directly descended from Culley rams. The Mertoun flock of Lord Polwarth, said to have been established in I 802, had a continuous existence for over a century, and a world-wide reputation.

The characteristics of the Border Leicester sheep in comparison with the Bakewell Leicester are interestingly shown by Professor Wrightson as follows:

The differences between the Leicester and Border Leicester are to be chiefly seen in the head, which in the Border Leicester is white and boldly carried, the nose slightly aquiline, the muzzle full, the nostrils wide, and the ears erect. The head is clean and free from wool, as is pretty well shown by the fact that they suffer from flies settling on their polls in summer. The English Leicester, unless trimmed and shaved for show, usually carries a tuft of wool on his head, which protects it from flies, and he is also wooled in the shanks. The English 
Leicester has a bluish-white face, whereas the Border Leicester's face is clear white. In carcass the Border Leicester is the larger and longer, and the belly is not quite so full in outline, being carried rather more lightly.

It may also be added that the flesh at the nose is black, that spots frequently occur in the white hair on head and ear, and that this is a heavier, more leggy type than the Bakewell Leicester.

Border Leicester rams crossed on Cheviot ewes make a cross which has long met with much favor in the British market. In the hill country the half-breds and three-quarter-breds feed extremely well on rather scant fare and produce a strictly choice

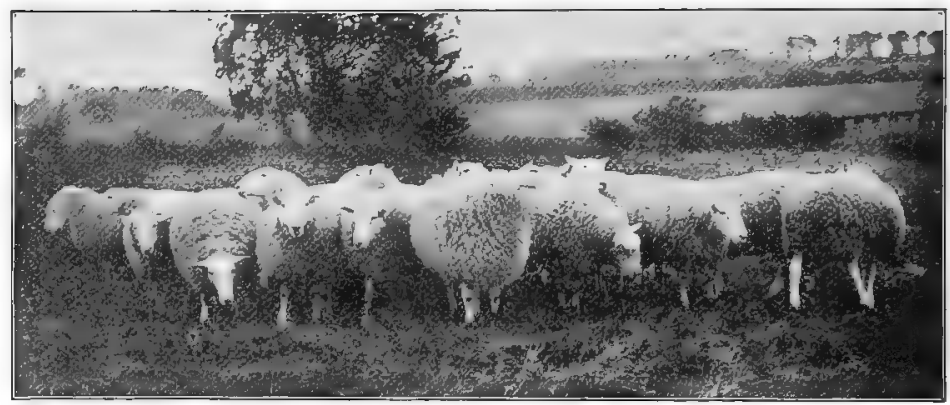

Fig. 296. A group of Border Leicester yearling rams owned by J. R. C. Smith, Scotland. From photograph, by courtesy of the owner

mutton. Each year in the hill country between Scotland and England large numbers of crossbred sheep of this stock find their way into the best British trade.

The prices paid for Leicester sheep have reached very respectable heights. In I9I4 a Border Leicester ram sold in Scotland for about $\$$ I 50O. At the Kelso (Scotland) ram sales in September, I9 I6, a yearling Border Leicester ram brought \$I I 50, and I 2 head brought an average of $\$ 360$. In I9I6, at the Little Dreffield Fair in England, I44 yearling Leicester rams brought prices ranging from $\$ 52$ to $\$ 36$ per head. In $1917 \mathrm{~J}$. D. Hay sold at Ayr, Scotland, I 66 Border Leicesters for an average of $\$$ I I o per head, and the three-year-old ram King David brought $\$ 850$. Finally, in I919, a Border Leicester ram sold at the Kelso auction for about $\$ 3000$ ( $£ 600$ ), and a yearling bred by D. P. Elliott sold to John Stewart for about $\$ 1400(£ 280)$. 
The distribution of the Leicester is world-wide. Since the days of Bakewell it has been more or less distributed over Europe, Australia, New Zealand, Tasmania, and North America. It is not a common breed to-day, however, in any part of the world, even in England, its native home. Referring to present-day flocks in England W. A. Brown states ${ }^{1}$ that the flocks of the members of the English society "are scattered over six counties as widely separated as Leicester and Cumberland, but the major portion of Leicesters are located in Yorkshire." The lambing season in 1916 in England was not a good one, but it was estimated there would be about Io,00o living lambs of the breed. There are numerous flocks in Canada, and in 1908, of the nearly 20,000 pure-bred sheep in that country, 6000 were listed as Leicesters. In the United States there are but few of these sheep, the breed being mainly represented in Michigan, Illinois, Iowa, Nebraska, and Oregon.

Organizations in behalf of Leicester sheep date back considerably over a century. In the time of Bakewell the Dishley Society was organized to support this great breeder in establishing a new breed. This society had various meetings and adopted different resolutions. No. 4, passed in I790, provided that "secrecy be kept by all members respecting the business of these meetings, except to absent members." Resolution No. I 3 provided that "no member shall let a ram, share or part of a ram, to any ram breeder residing within thirty miles of Leicester, not being a member, who hired a ram of Mr. Bakewell last season, I789." This society existed many years and was very influential. At the present time there is a Leicester Sheep Breeders' Society in England, which up to 19I8 had published twenty-six volumes of flock books. In this country we have the American Leicester Breeders' Association, established in I888, which has issued ten volumes of flock books up to I9r8.

The Society of Border Leicester Sheep Breeders has an organization in Britain, with headquarters in Edinburgh, Scotland. This society up to I9I 8 had published twenty volumes of flock books. In America the Border type is registered in the American Leicester flock book, no distinction being drawn in the registration of the two types. 


\section{CHAPTER LVII}

\section{THE COTSWOLD}

The name "Cotswold" is derived from a combination of circumstances. In early times sheep were folded in shelters locally known as "cots" or "cotes" and were pastured on the wild, treeless hills of the region, which were termed "wolds," from which the name "Cotswold" was evolved.

The native home of the Cotswold sheep is in central southwestern England in the county of Gloucester, ${ }^{1}$ which has an area of 1237 square miles. The river Severn flows southwesterly across the county and into Bristol Channel. The large city of Gloucester is the county seat. The Cotswold hills, which comprise about 280,000 acres, extend southwesterly nearly through and to the southern borders of the county. These low hills are of variable soils often poor in quality, gravelly or clayey in character, with much lime, grow a short pasturage, and yield moderate crops of wheat and roots. The climate is moist and temperate, well suited to large sheep. This is also noted as a dairy section, and many cattle are kept here.

The history of the Cotswold shows it to be a very ancient breed. In 1464 King Edward IV of England, says Stow in his "Chronicles," granted permission "for certain Coteswold sheep to be transported into the country of Spaine, which have there since mightily increased and multiplied to the Spanish profit." Marshall, a noted early writer on the agriculture of Gloucester, in I796 wrote 2 : "The Cotswolds have long been celebrated for their sheep, which still remain the grand object of the Cotswold husbandry." "The present breed," he writes, "is a polled, longwooled, middle-sized sheep, a breed which has been prevalent on the hills, time immemorial; it has been improved, but has not been changed. Hence, it is probable, the popular idea of the

1 Pronounced as though spelled "Gloster."

2 W. Marshall, The Rural Economy of Gloucestershire. London, I796. 2 vols. 628 
Spaniards having originally procured their breed of fine-wooled sheep from the Cotswold hills has no foundation." Marshall also states that the breed is light in front, but fuller behind, and that as Leicester rams are getting "a firm footing," they will fill up the fore quarter.

In I842 Low wrote that Cotswold sheep inhabited the district beyond the memory of the living generation. However, he believed that this breed was developed from a large type common in Warwick and Oxford counties adjoining, which it in some respects resembled. It is improbable that the Cotswold has a long ancestry on the hills of Gloucester, for a big breed of this type would not naturally thrive on hills comparatively poor in production. Yet the region in which this sheep developed became a noted wool-producing section, dating back to days of Roman conquest in the second century. Gervase Markham, writing in the sixteenth century, referred to Cotswold sheep as having long wool and large bones. It is generally conceded that the breed of to-day is much improved over the old type, this improvement having been largely secured by using Leicester rams on Cotswold ewes. So indiscriminately were they used between 1780 and 1820 that we are told not a Cotswold flock was spared. The Leicester blood reduced the size and constitution but improved the symmetry, producing better bodies, finer wool, more quality, and earliermaturing sheep. During the last century the families of Smith of Bibury, Hewer of North Leach, Lane, and Garne by judicious selection and some in-and-in breeding materially improved the breed. On the dispersion of the Hewer flock various breeders purchased and established flocks which are numbered among the important ones of to-day in England.

The introduction of Cotswold sheep to the United States probably first occurred in I832, when Christopher Dunn, who lived near Albany, New York, imported a ram. In I 834 Isaac Maynard of Coshocton County, Ohio, brought the first Cotswolds to that state, but within three years most of these had died.

In 1836 J. C. Haviland of Dutchess County, New York, began breeding Cotswolds, and continued his flock many years. In 1837 they were first brought to Kentucky, where they were very popular and seemed well suited to the conditions. In I $840 \mathrm{~W}$. H. Sotham 
imported a flock of 19 to New York, near Albany, for which he paid \$I I o each. This same year Erastus Corning and Mr. Sotham made two large importations of a crossbred Cotswold-New Leicester sheep from the Hewer flock at North Leach, Gloucestershire. Along in the early forties there were a number of Cotswold flocks in the Atlantic coast states, where they met with favor if on the

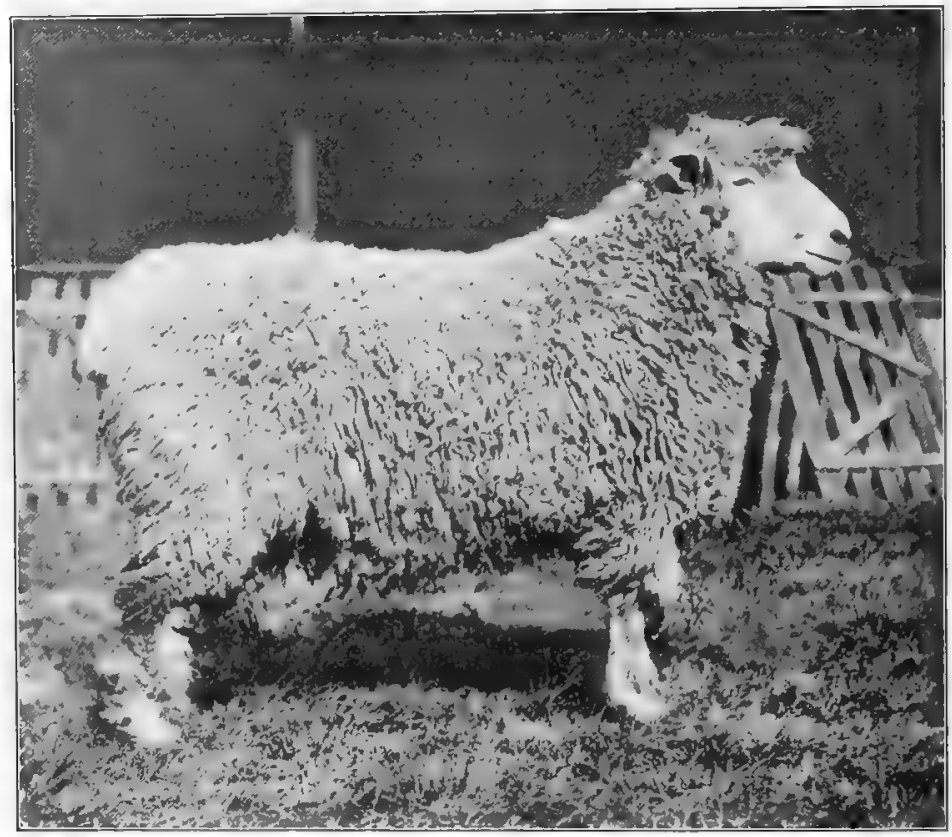

Fig. 297. A Cotswold ram, champion at the rgi6 Ohio State Fair. Unless protected by a covering, the curly foretop of the Cotswold is worn off, as in this case. From photograph by the author

more fertile lands. With the depreciation of Merino values about I 870-1875, Cotswold and other mutton sheep grew in favor, and considerable flocks were imported and developed in the Mississippi Valley.

Characteristics of the Cotswold. The head of the Cotswold is a distinguishing feature, being hornless, somewhat long, usually white but frequently slightly mixed or spotted with gray or brown, is dark at the nostrils, broad between muzzle and eyes, having a 
tendency to a Roman nose, and with curls or locks over the forehead, often falling to the nostrils. This forelock is a distinctive feature of this breed and is not usually cut off at shearing time. The ears are thick, soft, and of medium size for a large sheep. The back carries the same great breadth as the Leicester and Lincoln, though the body frequently lacks depth and appears leggy, especially behind. The heart girth is often striking, showing much thickness. Fream states that at a show some years ago in England two of the winning two-year-old rams girthed five feet and five feet four inches respectively. The breed ranks well in quality; the bone being strong but not coarse, though heavier than the Leicester, and the skin is naturally a bright cherry pink. In general appearance Cotswolds are regarded as especially toplofty and impressive. Professor Wrightson states ${ }^{1}$ :

The Cotswold was often described by the late Professor Coleman, when teaching at the Royal Agricultural. College (which is in the Cotswold district of England), as a sheep which could "look over a hurdle," that is, carried his head high and well poisęd on a somewhat erect neck. This is said to be accompanied with a tendency to be "ewe necked" and low in the rumps, or "down at both ends," as I have heard Professor Coleman repeatedly say. He knew the Cotswold sheep well, and was himself a Cotswold man, so his opinion carries weight. These faults have been corrected in the best flocks there can be no doubt, but they exist in second-rate animals, as is most evident in rough weather, when the animals are viewed at a disadvantage.

The size of the Cotswold is large, ranking very close to the Lincoln and often equaling it. A mature ram in breeding condition should weigh from 250 to 275 pounds and the ewe from 200 to 225. Shaw and Heller give 350 pounds for the ram and 200 to 250 for the ewe, while Coffey places the weight of the ram at 275 to 300 and the ewe at I 80 to 225 . The fact is a 300 -pound sheep is comparatively large, and this and heavier weights are with rare exceptions associated with high condition.

The Cotswold as a mutton sheep is rather ordinary. Lambs up to eight or ten months of age produce a very good grade of meat, but in the yearling wether or mature sheep the fiber lacks in quality, being long and coarse, and the per cent of external fat on the well-fed animals is too great. The present-day demand is for a

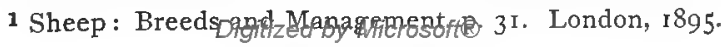


small class of mutton, consequently a sheep of the Cotswold type does not furnish a popular carcass where small cuts are wanted.

The Cotswold as a feeder makes an excellent showing. In various reports on feeding experiments where Cotswolds were used heavy gains have been recorded. In I 852 Sir John B. Lawes reported on important sheep-feeding experiments at Rothamsted, in which he showed that between December I and April I 7, 46 Cotswold lambs made a weekly increase per head of 3 pounds $22_{2}^{1}$ ounces. Twenty of these lambs, fasted weight, dressed out 6I.48 per cent

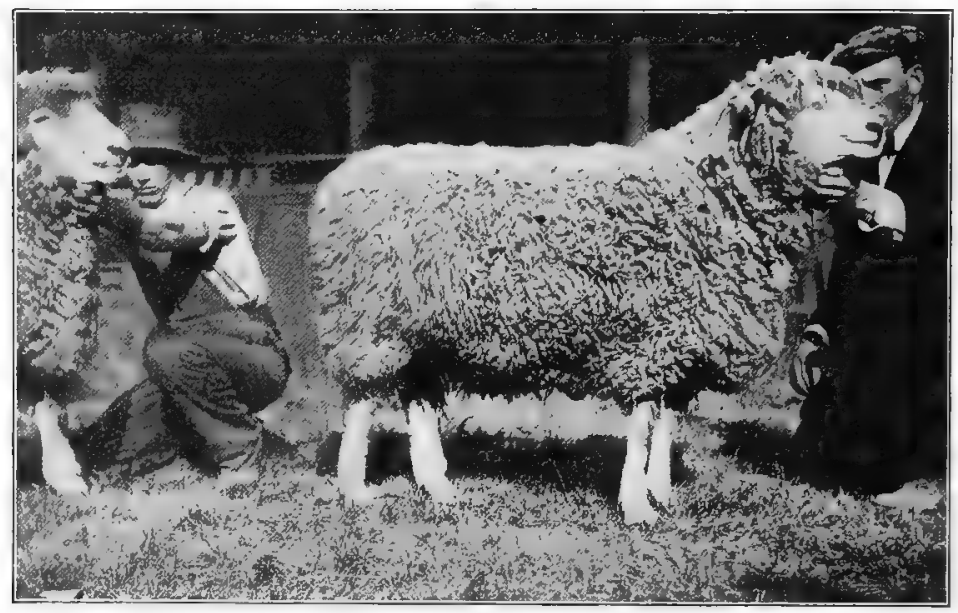

Fig. 298. A Cotswold ewe, champion at the 1916 Ohio State Fair. From photograph by the author

carcass. In extended experiments by Dr. Lawes the best results were secured with the Cotswold, which showed a more economical production than the Leicester, Hampshire, Sussex, or crossbreds. At the Iowa Experiment Station, in two breed trials with fattening lambs, the Cotswold made the heaviest gain, averaging .62 and .50 pound daily respectively, consuming less dry matter for a pound of gain than any other breed in each trial. In per cent of dressed carcass the Cotswold lambs showed an average of 54.9 and 53.57 respectively - just an average record. From figures compiled by Henry and Morrison ${ }^{1}$ of records of prize-winning wethers shown between 1895 and I 912 at the Smithfield Club Show at London,

1 Feeds and Feeding (1915), p. 518.

Digitized by Microsofte? 
I 5 Cotswold yearling wethers, averaging six hundred and twentyfour days old, weighing 292 pounds, made an average daily gain of .46 pound; while 25 wether lambs two hundred and seventy-six days old, weighing I 88 pounds, made an average daily gain of .68 pound. Henry and Morrison also give records showing average daily gain, from birth, of fat wethers at the American Fat-Stock Show at Chicago from I 879 to I 882 inclusive, in which yearlings averaged .4I pound daily and lambs .89 pound.

The Cotswold crossbred or grade is often a very excellent mutton sheep, and on the Western range, notably in Montana and Idaho, many Cotswold rams have been used on grade Merino ewes to distinct advantage from both mutton and wool point of view. Professor Hawkesworth states ${ }^{1}$ that for crossing with the Merino the Cotswold has advantages and disadvantages. The advantages are that the progeny are exceptionally well suited for the frozenmutton trade, as the two types appear to nick or blend well together, producing a well-balanced carcass covered with a most valuable crossbred wool of exceptional quality. He further says that for early maturity few crossbreds equal this one. The serious disadvantage in this case is that Merino ewes frequently die after dropping the lambs. The tendency is for the lamb to inherit the large head of the Cotswold, which results in the ewe's giving birth to the lamb with difficulty. At one time Cotswolds were used extensively in crossbreeding in the Midland counties in England, but not so much in recent years. An anonymous English writer makes the following comment, ${ }^{2}$ which is interesting from a British viewpoint:

These sheep are great feeders and become very fat, and are in consequence not a butcher's sheep; but when crossed with other sheep that suitably nick with them, the produce is remarkably good mutton. This year rams have averaged I 2 guineas and upwards. They are much sought after by Norfolk farmers, who cross them with a Suffolk ewe, the result being a capital butcher's sheep. The breed is also noted as having produced a magnificent sheep when mated with a Hampshire Down.

The Cotswold as a grazing sheep ranks high where pastures are abundant, but on hilly or rough land it is not a satisfactory breed. It does best on the fertile plains of America, where plenty of 
grass, roots, and grain may be grown. From its quiet temperament and heavy weight, like other long-wool breeds, it may be fed to great advantage on rape or turnips for a limited time, on restricted areas within hurdles.

The breeding qualities of the Cotswold are fairly good. Some authorities rank the breed as superior in this respect. None of the large breeds, however, are strongly fecund, though they are excellent nurses and produce large lambs. British writers credit

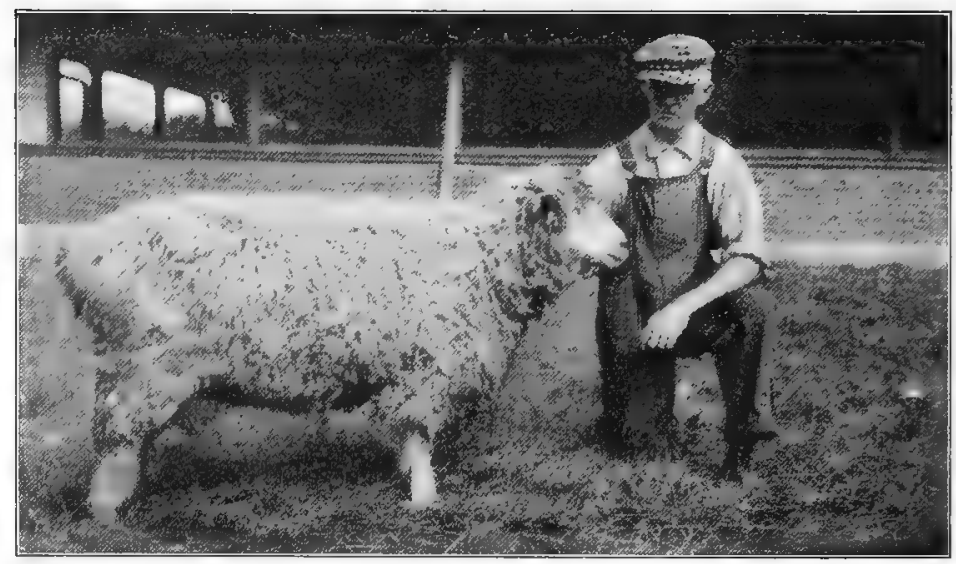

FIG. 299. A Cotswold ewe, champion at the I918 Ohio State Fair. Owned by P. W. Hintz, Clyde, Ohio. From photograph by the author

the Cotswold with about Ioo per cent living lambs, twins being the exception rather than the rule.

The Cotswold as a wool producer holds high rank. The fleece is of a lustrous character with a tendency toward coarseness, and with twelve months' growth may attain a length of I 2 to I 4 inches, though 8 is more commonly the case. The fleece is in somewhat large, open ringlets, rather than the finer curl of the Leicester, and is graded on the market as braid or low-quarter blood-combing wool. Hawkesworth states that "among manufacturers no other strong wool is held in such high estimation. It is one of the very brightest of the demi-lusters, but is not considered a pure luster like the Lincoln or Leicester. It is about the curliest of the British wools." Its great value lies in its exceptional silkiness, softness, 
and pliability, which qualify it to be spun to its extreme length. Many flocks yield an average weight of fleece of over Io pounds unwashed. George S. Baber of Kentucky for years kept about forty breeding ewes which averaged Io pounds of wool, and C. L. Day of Wisconsin had a large flock where the fleeces averaged about I I pounds. Wrightson says that in "crack" flocks the fleeces may average $9 \frac{1}{3}$ pounds, and many fleeces have been shorn weighing close to I 4 pounds, but the latter weight is exceptional.

The distribution of the Cotswold has been rather widespread in the past. It has seemed especially adapted to Gloucestershire and adjoining English counties, and while flocks are found elsewhere the breed is not common. It has been exported to France, Germany, Russia, Australia, New Zealand, Canada, and the United States. In 1908 about 2000 pure-bred Cotswolds were recorded in Canada. In the United States the breed has had a wide distribution. Late in the nineteenth century the Cotswold was a prominent breed in Ohio, Indiana, and Kentucky, but to-day these states have but comparatively few. The leading demand has been from the Far West, and superior flocks are owned in Oregon, Washington, and Utah. The climatic conditions of the Willamette valley in Oregon seem especially suited to the Cotswold, where it is most surcessfully bred.

Prices paid for Cotswolds hold very good, and some high values have been reached in recent years. At the ram sale at Salt Lake City in I9I $7 \mathrm{Mr}$. Frank Harding of Wisconsin sold to J. R. Allen of Utah I ram for $\$ 1000$, another for $\$ 750$, and 2 I rams consigned by Mr. Harding averaged \$2 I 5 each, while I 49 stud and range rams averaged $\$ 81.60$ each. Five rams consigned by J. H. Patrick of Canada averaged $\$ 182$ each. At the I9I 8 Salt Lake sale 2 rams brought $\$ 400$ each, and 62 head brought from $\$ 100$ to $\$ 300$ each. One lot of I 73 rams consigned by A. J. Knollin of Idaho averaged $\$ 25$ per head.

The promotion of Cotswold sheep is conducted in England by the Cotswold Sheep Society, organized in 1892, and in America by the American Cotswold Sheep Association, organized in I 878 . The English society up to I 916 had published sixteen flock books and registered a large number of sheep. The American association has published nineteen volumes up to I9I9. 


\section{CHAPTER LVIII}

\section{THE LINCOLN}

The native home of Lincoln sheep is in the county of Lincoln on the east coast of England by the North Sea. Lincolnshire is next to the largest county in England, embracing an area of 2638 square miles. The city of Lincoln, with a population of about 50,000 , is the county seat. The land is slightly hilly in places, but much of eastern Lincolnshire lies flat and low, even below sea level, the water being kept back by embankments as in Holland. The soil is naturally fertile, and the lowlands provide rich pastures. The small cereals, roots, and grasses are staple crops. This county is noted for its Lincolnshire Red Shorthorns and Lincoln sheep. The climate is moist and fairly temperate, though in winter the winds from the North Sea make the weather conditions somewhat rough.

The origin of the Lincoln dates back very many years. There had long existed in Lincolnshire a large, coarse type of sheep, much like the old Leicester, with white face and legs, heavy head, large neck, and prominent dewlap, long and hollow of back, with flat ribs but good loin and deep belly. The skin was especially thick, the fleece long and coarse, the size very large, and the flesh coarse and inferior. This old-fashioned type was improved by the use of Leicester rams of the new sort, such as Bakewell had produced. According to Youatt ${ }^{1}$ the Lincolnshire ewe was bred to the Leicester ram, and the progeny showed much of the excellence of the sire. What became known as the improved Lincoln matured fully a year earlier, weighed more for its age than the old Lincoln, and established a superior reputation, being much in demand. This work of improvement occurred late in the eighteenth century. Much jealousy existed between Leicester and Lincoln breeders in those early days. The story is told that Bakewell, the great improver of the Leicester, in 1788 challenged

1 Sheep: their Breeds, Management, and Diseases. London, 1837 . 
Mr. Charles Chaplin, a Lincoln breeder, who referred in uncomplimentary terms to his Leicesters, to a public contest:

If you are still desirous of a public exhibition, please to say if you would choose to send on the fifth of July next, to Lincoln or Leicester (as there is a fair at both places on that day), two rams of the "true Lincolnshire long staple," to each place, to be shown against the same number of the Dishley sort (Leicester), weighed alive, killed, and an exact amount given of the carcasses and offals, for the information of the public.

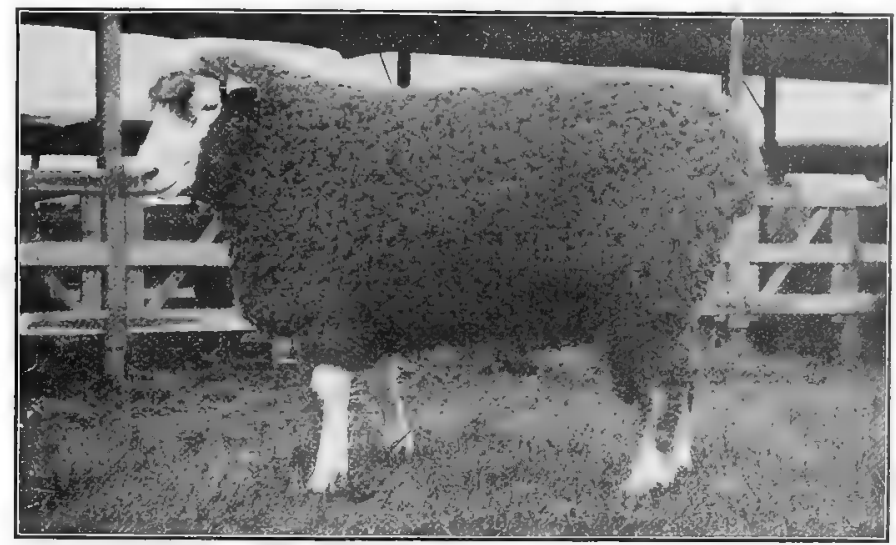

FIG. 300. Dowsby $35^{\circ}$ Guineas, champion Lincoln ram at the 1897 show of the Royal Agricultural Society of England. Bred by Henry Dudding; owned and exhibited by S. E. Dean \& Sons, Dowsby Hall, Folkingham, England. From photograph by the author

Mr. Chaplin refused to make the exhibition. During the past century the Lincoln has undergone a steady improvement among the breeders of Lincolnshire. In I 858 Robert Smith wrote ${ }^{1}$ that the leading ram breeders of the day were the Messrs. Clarkes, Kirkham, Casswell, Richardson, Chaplin, Gilliott, Torr, Abraham, Lynn, and others. The Dudding family of Riby Grove, Great Grimsby, Lincolnshire, was especially famous and bred these sheep for about one hundred and seventy-five years, the last member of the family - Henry Dudding, the greatest of modern Lincoln breeders - dispersing his flock in I9I 3.

The introduction of Lincoln sheep to America dates back over a century. Prior to I 796 it is stated that some of the old Lincolns

1 Joumal of the Royal Agricultural Society of England, Vol. XIX, p. $3^{8} 3$. 
were taken to Massachusetts, but, not thriving on the hills, were generally abandoned. In I 825 , however, A. A. Lawrence of the same state "imported 6 Southdowns and Io Lincolnshires." In I829 Mr. Pickering, also of Massachusetts, imported 2 rams and 2 ewes. It is reported that during the ocean voyage a fleece of 19 pounds was removed from one of the rams. In 1834 Isaac Maynard brought the first Lincolns to Ohio from the East. At Buffalo it is said he was offered $\$ 500$ for his Lincoln ram. In I 836 Leonard D. Clift of Carmel, New York, imported some Lincolns. One pair was sold to go to Virginia and another to Ohio for $\$ 250$ each. Later importations were made by Mr. Clift. The Lincoln has since then been brought occasionally to the United States, though in but a small way.

Characteristics of Lincoln sheep. The color of the Lincoln is white, although the face frequently has a grayish or mottled color along the bridge of the nose. The head is large and hornless, often broad between muzzle and eyes, tending to Roman character; the ears are large and broad and are dotted or mottled in color. The Lincoln has a very broad, level back, is covered with a firmer flesh than the Leicester, and shows a greater comparative depth of rib than that breed, not appearing so leggy. The nump is broad and level, and the hind quarter of a thick, meaty character, as a rule, and when heavily fed this is often patchy. The legs are in suitable proportion to the rest of the body, but appear rather large and coarse. The sheep in general appearance impresses one as massive. The roool covering is in rather coarse spirals or curly locks which naturally part along the back and hang down to considerable length on the sides. A short foretop, or group of locks, occurs in good specimens of the breed, more than with Leicesters and less than with Cotswolds.

The size of the Lincoln represents the largest of the British breeds of sheep, though Wallace states that it does not excced the Cotswold. The author has seen a Wensleydale ram that was comparable with the larger Lincoln. The average Lincoln, however, probably weighs heavier than does the average of any other breed. Rams of this breed sometimes attain a weight of nearly 400 pounds, and when in good flesh will easily weigh 300 , while the ewes average close to 275 pounds when mature. The standard 
of excellence of the National Lincoln Sheep Association specifies that matured rams should weigh not less than 250 pounds when in good condition, and ewes in similar age and condition not less than 200 pounds. Shaw and Heller give 250 to 375 pounds for the ram and 225 to 275 pounds for the ewe, while Coffey gives 300 and 250 pounds respectively for ram and ewe in breeding condition. Professor Wrightson, in comparing with the Leicester,

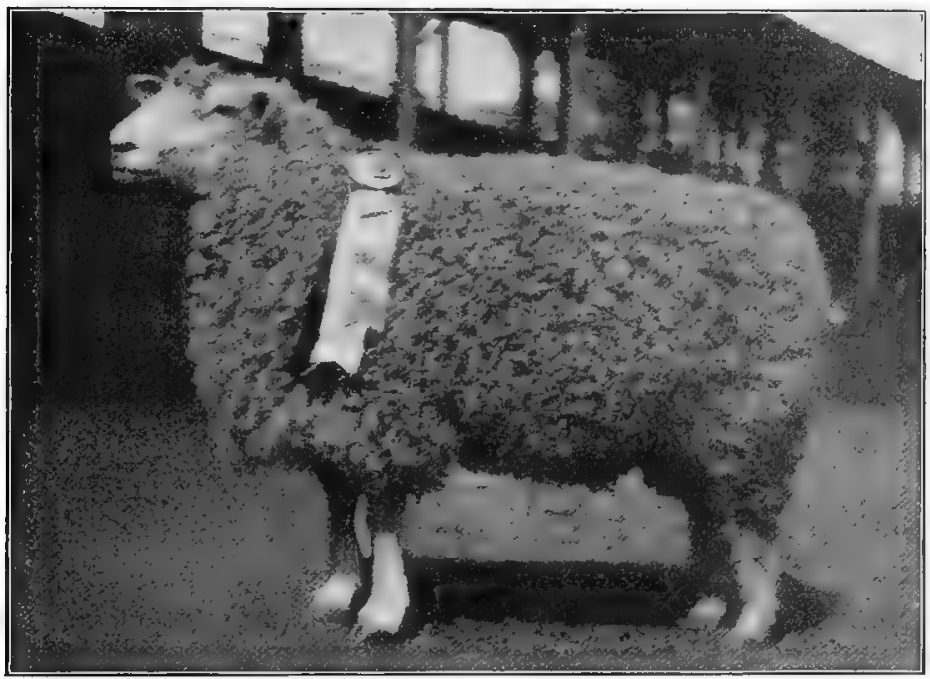

Fig. 30r. Gibson's 155-10858, grand-champion Lincoln ram at the Louisiana Purchase Exposition, 1904. Owned and exhibited by J. T. Gibson, Denfield, Ontario. From photograph by the author

says that "in size the Lincoln is greatly superior, and he may be credited with being the heaviest sheep of the British Isles, having been known to attain a weight of 90 pounds per quarter."

The quality of Lincoln mutton does not rank high. The size is too large, too much fat is produced, and the flesh tends to coarseness of fiber. All things considered, the Lincoln cannot be regarded as the equal of any of the Down breeds in the quality of its mutton. When killed during the lamb season, especially from eight to ten months of age, a more acceptable class of meat is produced. Wrightson, however, regards the Lincoln as producing a firmer flesh than the Leicester. The carcass dresses out 
very well, but the per cent of fat and bone is too great to suit the modern trade. There is too much waste for the average housewife.

The Lincoln as a feeder makes a creditable showing. In feeding experiments at the Iowa Experiment Station, Lincoln wether lambs in one trial made an average daily gain of .55 pound and in another trial of .46 pound. The price paid for the carcass was $\$ 4.50$ and $\$ 5.25$ per hundred compared with $\$ 4.75$ and $\$ 5.75$ respectively, the highest price paid. The Lincolns dressed out 55.7 and 51.08 per cent in the carcass, which was about an average of the breeds tested. Comparatively few feeding experiments with Lincolns are recorded. In the report on the prize-winning wethers at the Smithfield Club Show, compiled by Henry and Morrison, covering the years 1895 to I 912 inclusive, 48 Lincoln wether lambs, averaging two hundred and ninety days old, weighing 209 pounds each, made an average daily gain of .72 pound; while 55 yearling wethers, averaging six hundred and thirtynine days old, weighing 334 pounds, made an average daily gain of .52 pound. This record of daily gain for both ages surpassed each of the other thirteen breeds reported on. These figures clearly indicate the capacity of the Lincoln as a feeder and also show to what size the wether may be fed. To do as well as these reports indicate he must be fed in a generous manner the best of food, with concentrates and succulents suitably represented. Hawkesworth comments on this point and says if feed is scarce the Lincoln loses weight rapidly, and when in low condition is an expensive animal to put in good condition.

The crossbred or grade Lincoln is to-day an important factor in the British mutton market. A large number of Lincoln rams are used on the common ewes of Argentina or on the grade Merino ewes of Australia. A visit to the yards at Birkenhead, England, about I900, where shiploads of live sheep were received from Argentina, showed the prevalence of Lincoln blood. These crosses or grades made a big, growthy lamb which fattened easily and furnished a large chop or leg of mutton more acceptable in the English than in the American market. Hawkesworth says that the Lincoln and Merino make a really good serviceable cross and a suitable mutton for export, and many who have kept to that style of breeding have found good results in both carcass and wool. 
Much of the Lincoln coarseness is lost in the cross, the offspring producing fairly fine-grained and succulent meat. The fat is more evenly distributed than in the pure-bred and not so massed in a few places; the flesh is of a nice flavor; while the wool is one of the most serviceable crossbreds going into the market. Mr. Herbert Gibson gives an interesting statement ${ }^{1}$ regarding extensive crossbreeding in Argentina in which both mutton and

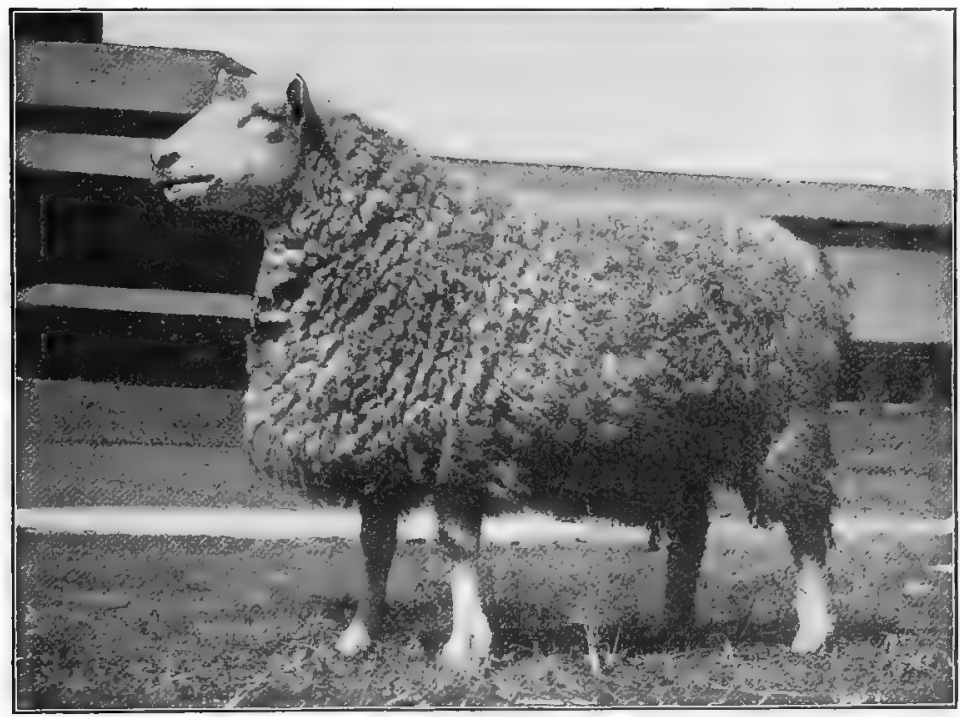

'FIG. 302. A Lincoln ewe, first prize in class at the Ohio State Fair, 1905. Owned and exhibited by J. R. Bickett, Xenia, Ohio. From photograph by the author

wool were considered. In I 863 five thousand Pampas ewes were selected and bred to Lincoln rams. These ewes were descended from long-wooled Spanish sheep taken to South America during the sixteenth and seventeenth centuries. They had white faces, thin long legs, and long, lusterless coarse wool. "The experiment was in every respect a successful one. The cross-Pampas soon grew to the large body and luster wool of the Lincoln. The ewes were prolific and excellent mothers, and the race hardy to a degree; they were kindly fatteners and easily shepherded."

1 The History and Present State of the Sheep-Breeding Industry in the Argentine Republic, 1893. 
This cross and their grades were continued with substantial satisfaction, many thousand ewes being bred. Lincoln rams have been used to some extent on Merino grade ewes on our Western ranges, yet not in a large way.

The Lincoln as a grazing sheep is best adapted to moderately dry upland meadows, where food is abundant. In the hill country the breed has never made a success and has not secured a foothold. Some English writers have called attention to the

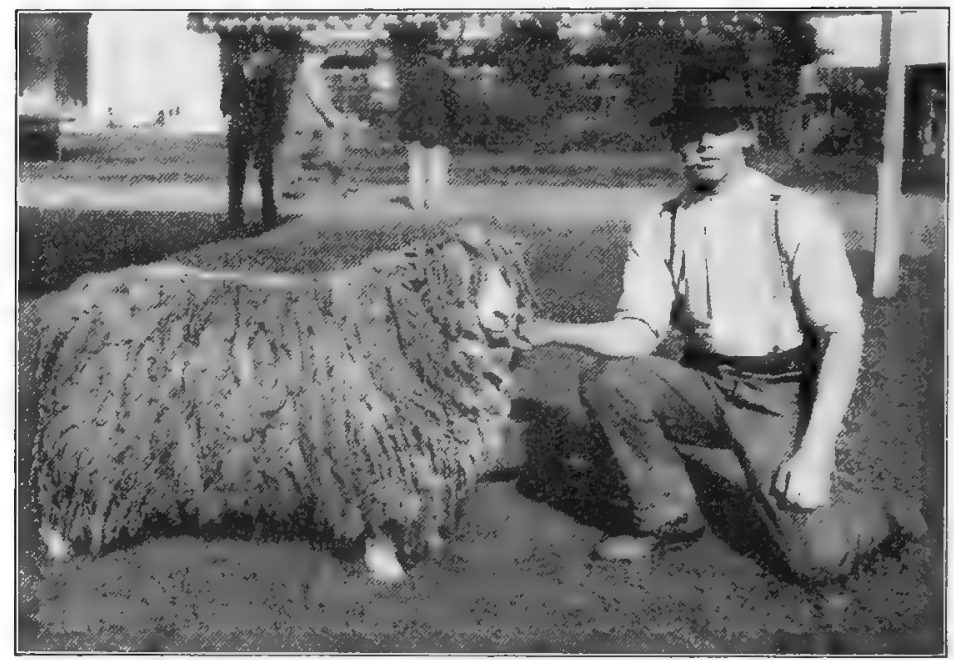

Fig. 303. A Lincoln ram from New Zealand exhibited in 1915 at the PanamaPacific Exposition. Such a curly foretop is unusual with this breed. From photograph, by courtesy of the American Sheep Breeder

eminent fitness of the Lincoln to the meadows of Lincolnshire, but further note the fact that they soon deteriorate in most other parts of England. In Argentina, where great pastures of superior quality exist, Lincolns have long met with much favor.

The breeding quality of the Lincoln is not of the first rank. The ewes are good mothers but produce only a fair amount of milk and are not of more than average fecundity.

The Lincoln as a wool producer is of special interest. No breed probably furnishes so long a fleece. Wrightson reports samples of Lincoln wool in his possession $2 \mathrm{I}$ inches long. The standard 
of the National Lincoln Sheep Breeders' Association requires a growth of at least 8 inches of fleece during one year. The weight of the fleece, which is naturally coarse and grades as a braid or low quarter-blood, may in the case of a ram reach 30 pounds. The average weight of fleeces on Lincoln wether lambs in the Iowa feeding experiments was 12.9 and 10.4 pounds respectively, the heaviest of the ten breeds under trial. A mature ewe should produce close to I 5 pounds and a ram 18 to 20 pounds. In fineness of quality this ranks slightly better than the Leicester. Compared with the Leicester fleece it is longer, is in larger spirals or curls, and covers the belly better. Wrightson states that the wool is very bright and lustrous when shorn, giving the name "luster wool." This feature, however, disappears when the sheep are bred away from their native county. The massing of the wool in flakes or strands upon the animal is characteristic of the breed, but the fiber is hairlike and "lashy" if separated and compared with the fiber of Merino wool.

Professor Hawkesworth ${ }^{1}$ writes:

Lincoln wool is made into fabrics of various descriptions and designs, all of a heavy, smooth nature, many of which are dyed into most delicate shades, for which only the best of lusters are suitable on account of their great reflective power, a quality possessed by the Lincoln beyond any other breed except the Leicester, the wool of which is very similar in this respect. Such goods as damasks, reps, russell-cords, braids, lastings, linings, camlets, furniture cloths, serges, boot laces, buntings, and even dolls' hair, are made of Lincoln wool.

The prices paid for Lincolns have run into sensational figures. Since the South Americans and Australians began to purchase rams for home trade high prices have ruled. The ram sales of Lincolnshire have attracted world-wide attention, especially those of Henry Dudding of Riby Grove, Great Grimsby. During fourteen years Mr. Dudding had sold, writes G. T. Burrows, ${ }^{2} 654$ rams for $\$ 202,508$, giving an average of about $\$ 306$. The individual prices have ranged from $\$ 74 \mathrm{I} 4$ to $\$ 17$. Four hundred and fortytwo ewes in the fourteen years have averaged $\$ 40$ per head. The 1906 sale at Riby Grove was a notable one. One ram sold for $£$ I522 IOs. (\$74I4). In all 56 yearling rams realized over

1 Australian Sheep and Wool. Sydney, 1906.

2 Breeders' Gazette, September I8, I9I 2.

Digitized by Microsofte? 
$\$ 42,000$, or brought an average of over $\$ 750$. In Igog one ram brought about $\$ 3000$. Owing to the death of Mr. Dudding the Riby Grove flock was dispersed in I9I3, on which occasion the ram Riby Bristol Champion brought $\$ 3000$ and I 39 yearling rams averaged about $\$ 233$ each. In I9I8, at the Lincoln ram sales, A. W. Dean of Dowsby Hall, Bourne, purchased I I stud rams at an average price of $\$ 800$ each for service in his own flock. However, he later sold these to go to Buenos Aires for the record price of $\$ 1650$ each, one of these rams bringing $\$ 6250$. The

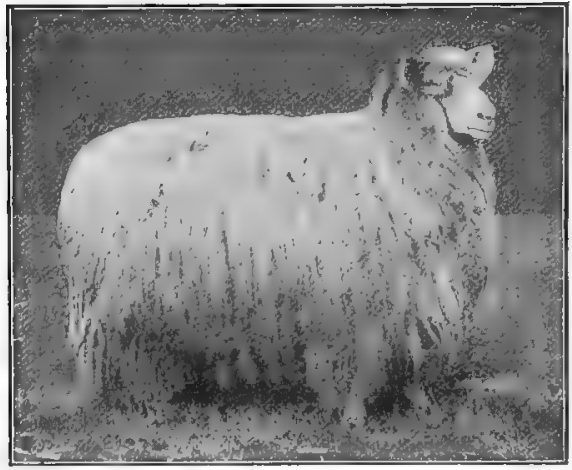

FIG. 304. A Lincoln ewe lamb of very superior character at the 1904 show of the Royal Agricultural Society of England. Her fleece swept the ground. From photograph by H. B. Arbuckle, by courtesy of the National Stockman and Farmer highest prices paid in the United States for Lincolns, up to 1918 , occurred in I 9 I 7 at the Salt Lake City sale, when an imported ram sold for $\$ 650$ to A. D. Blodgett of Colorado. One ram was also sold for $\$ 550$ to the Butterfield Live Stock Company of Idaho, and another for $\$ 550$ to Austin Brothers of Utah. Twentyone rams consigned by Anoka Farms of Wisconsin averaged \$I95.7 I.

The distribution of the Lincoln sheep is very widespread. In Britain it is largely limited to Lincolnshire and adjoining east counties in England, but it has been extensively imported to the British colonies and to South America and Canada. Herbert Gibson states that in 1862 one Lincoln ram was shipped to his father, Thomas Gibson, on the Yngleses estancia in Argentina; in $\mathbf{1} 863$ a large number were imported, followed by two lots in I864 and successive importations each year after. A very large per cent of the 67,000,000 sheep in Argentina about I9I0 are said to have been pure Lincolns or crosses of this breed. From October I, I912, to September 30, I9I3, there were exported from England 2400 rams and ewes as follows: 1728 rams and 468 ewes to 
South America, I I I to Australia, 60 to Russia, I6 to Spain, Io to Holland, 4 each to Italy and New Zealand, 3 to Canada, and I to South Africa. During the first nine months of 1916 there were exported I 709 rams to Argentina. This gives one an idea of the wide distribution of the breed. In 1908 it was reported that 4000 pure-bred Lincolns were registered in Canada, and mainly in Ontario. In the United States the Lincoln has had a rather modest development. There are good flocks in Ohio and Michigan, but the breed seems to meet with most favor in Oregon, Idaho, and Montana, doing especially well in the Willamette valley in Oregon, where the climatic conditions seem especially favorable.

The promotion of Lincoln sheep in an official way first began in I891 with the organization in the United States of the National Lincoln Sheep Breeders' Association. This organization has published but few flock books. The Lincoln Long Wool Sheep Breeders' Association, with headquarters in Lincolnshire, England, was organized in 1892 . 


\section{CHAPTER LIX}

\section{THE ROMNEY MARSH}

The native home of the Romney Marsh sheep is in the county of Kent in southeastern England, where it is also known as the Kent breed. Kent has an area of 1520 square miles, and on the north is bordered by the river Thames and the North Sea and on the east by the latter body of water. This is a fertile agricultural county, famous for its hop fields, with an undulating surface in part, but with much low land. The district known as Romney Marsh is located in southeast Kent and in the eastern part of Sussex. The land is about level with the sea, from which it is protected by sea walls built centuries ago. "The soil is usually a deep alluvial clay interspersed with portions of infertile sand or gravel," says Wrightson, "and the area is traversed by wide ditches full of water." This region is sparsely settled and is largely devoted to the Romney Marsh sheep; here they are kept in large numbers, grazing in the summer on the rich pastures. The climate is moist and comparatively mild.

The early type of Romney Marsh was rather comparable with other breeds in being deficient in rib, heavy of bone, long of leg, and coarse of wool. Very little is known of the early history of the breed, but it seems evident that in the first part of the nineteenth century Leicester blood was extensively used, though not with special success. Leicesters reduced the size and constitution, although improving the form and maturing qualities.

In 1855 , referring to these sheep, Professor Wilson thus describes the breed:

The head and legs are white; the head long and broad, with a tuft of wool on forehead; no horns; neck long and thin; breast narrow with moderate fore quarters; the body long with flattish sides and sharp chine; loins wide and strong; the belly large; thighs broad and thick; and legs and feet large, with coarse bone and muscle. They are very hardy and are well adapted for the bleak and exposed district of the Romney Marshes. They also bear stocking closer than other breeds, as it is not unusual to see six or eight fattening 
sheep placed to the acre. The improved breed produces sheep ready for market at from two to three years old, weighing from I 20 to 140 pounds. The fleece is valuable, weighing on the average 8 pounds.

The modern type of Romney Marsh sheep is a decided improvement over the breed as described by Wilson. The head is white and hornless, with a broad, aquiline nose, and a thick foretop of wool is common, although often lacking. The flesh at the nose is black. The ears are large and thick. Careful selection and breeding

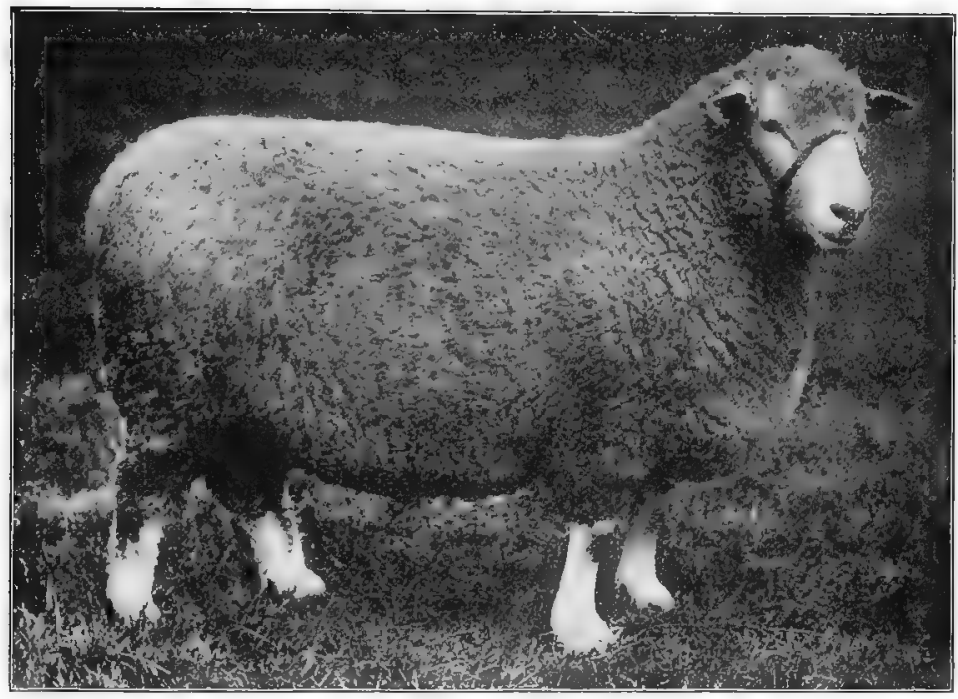

FIG. 305. A Romney Marsh ram, first prize in class at the 1904 show of the Royal Agricultural Society of England. Owned and exhibited by Charles File. From photograph, by courtesy of William Cooper \& Nephews, Berkhamsted, England

has reduced the size somewhat, but has produced a sheep more compact of frame and more easily fattened than the old sort. The back is broader, the ribs are longer, the coupling shorter, and the leg of mutton heavier and of excellent quality. In the improvement of the breed the fleece has been refined to a marked degree. The adaptability of the Romney Marsh sheep to low-lying lands has caused it to be regarded with favor in eastern England and in some other sections, for it seems freer from foot rot and liver fluke than most breeds; in fact, it is claimed that this breed on Romney Marshes is not affected with foot rot at all. 
The size of the Romney Marsh sheep gives it a second-class rating among the large breeds, the mature rams weighing about 225 to 250 pounds and the ewes from I75 to 200 pounds. A New Zealand standard adopted in 1916 assigned 240 pounds as a very acceptable weight for the ram.

The quality of Romney Marsh mutton is superior to that of the other long wools, being less coarse and more comparable with the

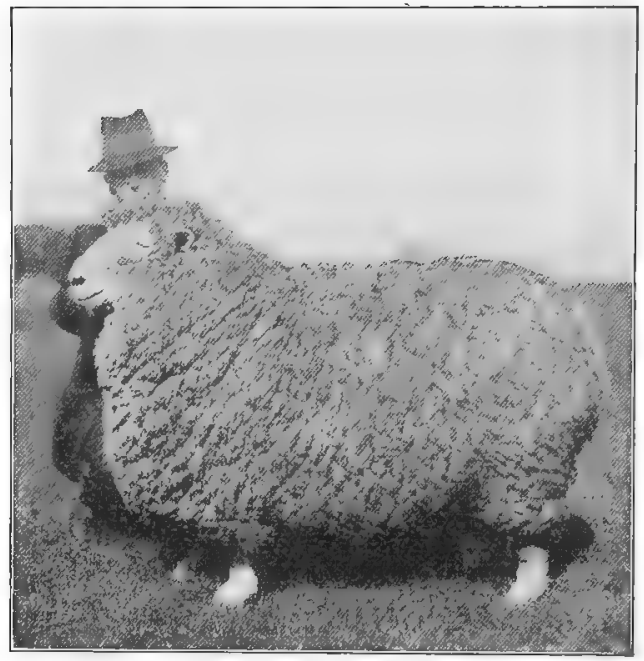

FiG. 306. A Romney Marsh ram, champion in I9I 5 at the Panama-Pacific Exposition, San Francisco. Exhibited by R. Matthews, Featherston, New Zealand. From photograph, by courtesy of the American Sheep Breeder heavier Down breeds, such as the Hampshire and Oxford. The fat is more evenly distributed and the bone is finer than in the case of Lincoln or Cotswold.

The Romney Marsh as a feeder ranks very high on its native marshes, where it has held popular favor for a long period of time. Here the use of grain is the exception and not the rule. In Argentina it has proved a very excellent feeder on the low-lying meadows of that country, and in New Zealand it has been received with special favor where low lands are common. At the Smithfield Club Show between I 895 and I9 I 2, quoting Henry and Morrison, 65 yearling wethers, averaging six hundred and six days old, showed an average weight of 267 pounds, with a daily gain of .44 pound, while 73 lambs weighing I 60 pounds at two hundred and fifty days old made an average gain of .64 pound a day.

The crossbred Romney Marsh sheep, with Merino blood on the dam's side, have proved very satisfactory in Australia. Hawkesworth states ${ }^{1}$ that few crosses give equal results and none better,

1 Australian Sheep and Wool, Igo6. 
both as a mutton and a wool-bearing sheep, while for exporting frozen carcasses, "they are almost an ideal sheep - useful weights, about 60 pounds as hoggets [wether lambs]; joints well balanced and plump; fat not excessive, is well distributed, and the flesh has an agreeable flavor.'

The fleece of the Romney Marsh sheep is long and compact and more refined than the Leicester, grading as low quarter-blood combing. It is hardly a braid or long wool, yet it seems closely related to it. Hawkesworth states that Romney Marsh wool is not understood in Australia, the mistake being that it resembles Lincoln or Leicester. He classes it as a demi-luster wool with a commanding length and an undulating crimp, much finer than the Leicester, and "of a fine, soft nature." It is suggested that the thigh wool should be improved in quality. The unwashed fleeces of twelve months' growth should weigh about I 2 to I4 pounds.

The prices paid for Romney Marsh sheep have attained high levels. In I9I I A. J. Hickman, a prominent dealer and breeder, stated that up to 1905 the record price for a Romney Marsh ram was $\$ 280$, whereas in 19 Io his whole consignment averaged $\$ 242$, the highest average that year for any breed sold in Great Britain. Between 1906 and I9I I "many Romney rams have topped the $\$ 500$ mark. One ram made $\$ 1300$ to a South American breeder this year, and another made \$I500 to go to New Zealand." 1 J. E. Quested sold 24 rams at the 1917 Ashford sale for an average of $\$ 315$, one bringing $\$ 1050$. All told, at this sale, 284 rams of the breed averaged $\$ 160$. In I9I9, at the Ashford ram sale in Kent, one ram brought $\$ 5000$ and was later sold to go to Buenos Aires for $\$ 8000$.

The distribution of the Romney Marsh sheep in England is essentially restricted to the southeastern section, more especially Kent and Sussex. In I 856 Robert Gibson visited Romney Marsh district and, noting its similarity to the Tuyu lands of Argentina, made a small importation. Since this time many sheep of the breed have been sent to South America from England. Romney Marsh sheep are popular in parts of Australia and New Zealand, and many have been exported to these countries, as well as to South Africa. These sheep are almost unknown in North

1 American Sheep Breeder, December, I9r. 
America. In 1904 William Riddell and Sons of Oregon importedI ram and 4 ewes from England. These were exhibited at the Louisiana Purchase Exposition at St. Louis the same year, but were not looked upon with favor, not being regarded as good specimens of the breed. In 1906 the Wyoming Experiment Station imported I ram and 3 ewes. Again in I909 Riddell and Sons made an importation, this time of I ram and I I ewes from New Zealand, since which this firm has made two other importations, all three coming

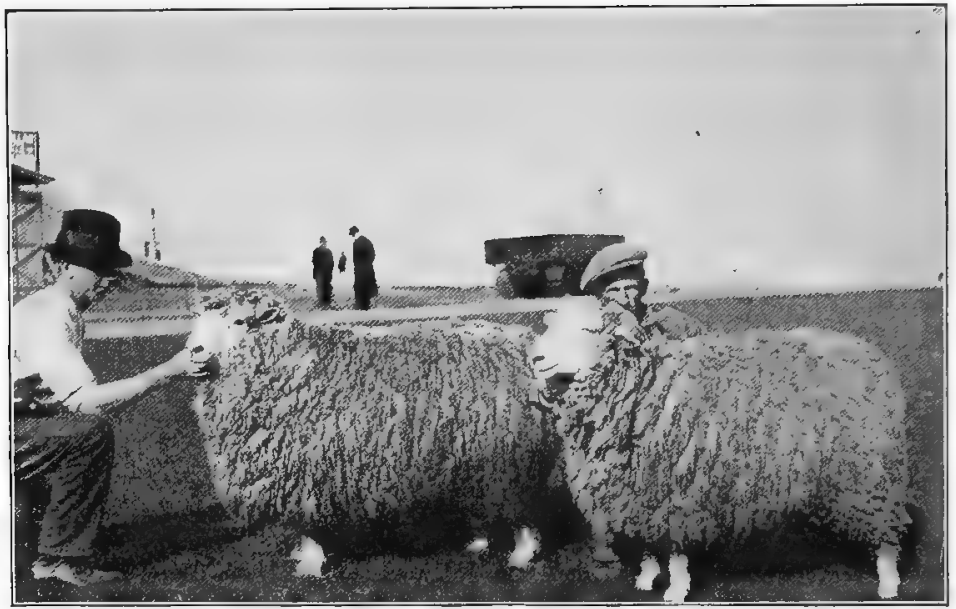

FIG. 307. A pair of Romney Marsh ewes exhibited in 1915 at the PanamaPacific International Exposition. From photograph, by courtesy of the American Sheep Breeder

from the flock of E. Short. In Ig09 A. J. Hickman of Kent, England, sent 32 rams to America, which were not well received. At present there are but few of these sheep in the United States.

The promotion of Romney Marsh sheep in England is under the supervision of the Kent or Romney Marsh Sheep Breeders' Association, with headquarters in London. This association has published twenty-four volumes of flock books up to I9I9.

On December 5, I9I I, the American Romney Sheep Breeders' Association was organized at Chicago, the late J. E. Wing being its main promoter and its first secretary. This organization up to I9I9 had registered but few sheep and published no flock book. 


\section{CHAPTER LX}

\section{THE BLACK-FACED HIGHLAND}

The native home of Black-faced Highland sheep is the more elevated sections of Scotland, especially in the counties of Perth and Dumbarton in what is known as the Highlands, not far removed from the city of Glasgow. The higher altitudes here reach nearly four thousand feet, and on these rough, bleak, heathertopped summits the Black-faced Highland is found in his element. This is a region that is sparsely settled, the winters are severe and cold, snow is abundant, and these sheep exist at times under very rigorous conditions, such as require the hardiest of constitutions.

The origin of the Black-faced Highland sheep is veiled in obscurity. Theories have been advanced, but whence the breed originated, says Scott, ${ }^{1}$ has not been revealed in any of the historical records. It has been claimed that the breed is native to the country, that it was introduced into Ettrick Forest in 1503 by James IV of Scotland, that "dun-faced" sheep were imported into Scotland from Denmark or Norway at a very early period, and that they came from the ships of the Spanish Armada wrecked on the coast of Scotland in 1588 . Scott believes there is no doubt but that this is the oldest breed known in Great Britain. The introduction of these sheep into the Highlands is definitely known to have taken place close to 1750 , and they were taken to the West Highlands about 1762 by a Mr. Campbell, who at one time lived in Ayrshire. Early in the nineteenth century the Cheviot grew greatly in popularity in the Highlands, but about I 860 the snows were unusually severe, and these sheep suffered severely on the higher elevations, while the Black-faced sheep proved more hardy and thereafter supplanted the Cheviots on the more exposed uplands. This is the case at the present time - the Cheviots occupying the grass-covered hills of the Border country rather than the rougher, heather-coated Highlands farther north.

1 John Scott, Black-faced Sheep. Edinburgh, I888. 
The introduction of Black-faced Highland sheep to America first occurred in June, I86I, Hugh Brodie importing I ram and 2 ewes for Brodie and Campbell, New York Mills, New York. In I 867 this flock and its increase was purchased by T. L. Harison of Morley, St. Lawrence County, New York. Isaac Stickney of New York also imported a small flock about 1867 for his farm in Illinois. Since then an occasional importation has been made, especially by wealthy men for country estates in the East. In I9I 3 Alexander Mowat of

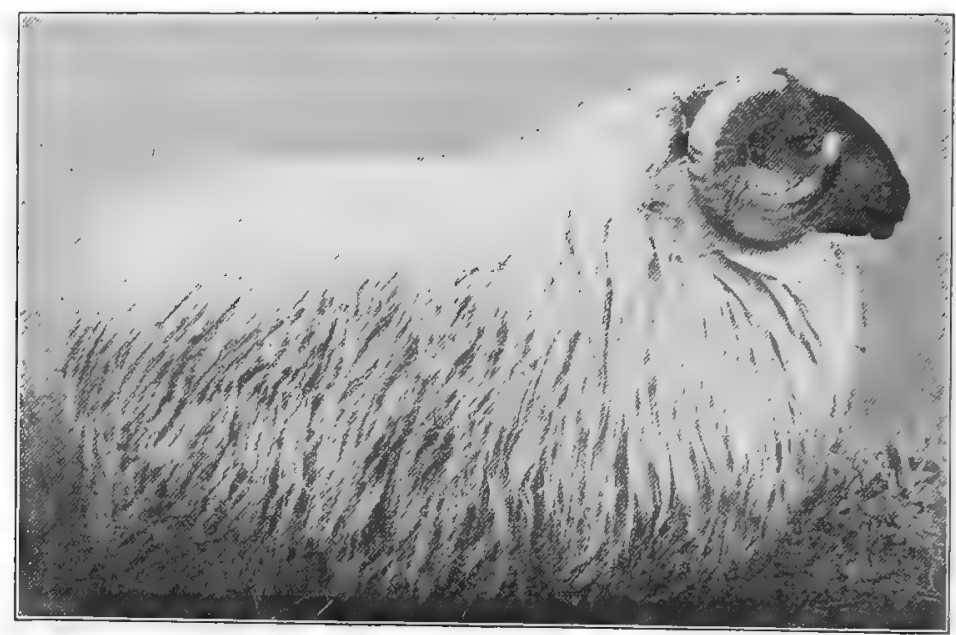

FIG. 308. A Black-Faced Highland ram. Frequently the wool sweeps the ground, completely covering the legs. From photograph secured by the author in Scotland

Scotland wrote the Breeders' Gazette that two lots of Black-faced Highland sheep were being exported to America for foundation flocks, one for New York and one for Massachusetts, the latter containing a ram and 20 ewes of the best breeding.

Characteristics of the Black-faced Highland sheep. Both sexes have horns, those of the males being rather large, taking one or two spiral curves. The ewes' horns are small, thin, and curved, but not spiral. The face is covered with hair - not wool — of either a solid black or a mottled white-and-black color. The nose is strong and prominent, the nostrils wide and black, and the ears short and small. The body is that of the typical mutton sheep, but is short and muscular, rather blocky, and smoothly turned. The 
fleece, which is of the long-wool class, is very long and coarse, attaining an extreme length of 20 to 22 inches, and with a year of growth often sweeps the ground. It is commonly kempy and very loosely covers the body. In temperament the breed is very wild and independent, quite unlike the heavier, lowland sheep.

The size of Black-faced Highland sheep ranges from small to medium. The rams in breeding condition weigh from I 40 to I60 pounds and the ewes from I 20 to I40. Weights of these sheep are rarely taken in Scotland, excepting after slaughter, at which time the weight is based on the quarters. In I 837 Youatt stated that when fattened these sheep weighed from 16 to 20 pounds per quarter, while fifty years later good average weights on the farm were given as 15 to 16 pounds per quarter. Scott states that when taken from the hills in autumn and put on ordinary fattening fare in the Lowlands, they easily attain a weight of 20 pounds per quarter.

The quality of Black-faced mutton is very superior; in fact, nothing equals it on the British market for grain, disposition of fat, small per cent of waste, and prime flavor, On this point Scott says that "their meat has a peculiarly delicate flavor, which is much prized at the tables of the rich. Around the mansions of the nobility it is common to see a number of wedders [wethers] of this breed, kept for the double purpose of ornament to the parks and supplying meat for the household."

Crossbred or grade Black-faced Highland sheep meet with favor in Scotland, giving a heavier-fleshed type with the good quality of mutton of the pure-bred. Robert Wallace states that the produce of a Black-faced ewe by a Leicester ram is called a "cross" or "mule" and by a Cheviot ram a "half long." The latter name is given because a Black-faced is sometimes termed the "short" sheep and a Cheviot the "long" sheep. As ewes these sheep of mixed breed are good milkers.

The Black-faced Highland sheep as a producer of wool does not rank very high. The staple is very coarse, grading as a low quarter-blood, and varies greatly in quality, according to whether from shoulder or thigh, that on the hind quarter as a rule being very coarse and hairy in character. The weight of fleece is light, that on ewes ranging from $3 \frac{1}{2}$ to $4 \frac{1}{2}$ pounds. In one of the noted 
flocks in Scotland - that of McKersie of Glenbuck - the average weight of fleece in I 886 was $5 \frac{1}{4}$ pounds. Scott gives the average weight of fleeces as 5 to 6 pounds. Wool of this class is extensively used in Scotland for blankets, carpets, and rugs.

The prices paid for Black-faced Highland sheep are nominal for American trade, but of some importance in Scotland. In 1887 there were sold 4952 head for the average price of $\$ 22.18$, with a top price of nearly $\$ 375$ for a ram, the highest price on record for a Black-faced Highland sheep to that time. In I9I4 a ram sold in Scotland for £IIO (\$535), and in September, I9I6, Mrs. Watters of Perthshire paid \$I 500 for a yearling ram at the Lanark sale. At this same sale James Clark sold his first-prize pen of 5 yearling rams at an average price of $\$ 566$, a new high record for a pen. At the Perth ram sale in 1916 the top price was nearly $\$ 900$, a second ram brought $\$ 750$, and 20 rams of one consignor averaged \$I50. In September, I9I9, Buchanan Brothers of Muirkirk, Scotland, sold a yearling ram for $\$ 2000$.

The distribution of Black-faced Highland sheep is mainly over the Highlands of Scotland and to a small extent on the higher of the mountain regions of north England. Large numbers are bred in the Highlands and this, with the Cheviot, occupies most of the space at the Scotch shows. These sheep have been exported to various countries where the conditions are rough and grazing relatively poor, but have secured no foothold of note. R. H. Williams of New Jersey, in I9I8, acquired a flock of I60 head that had been developed in that state from imported stock. There are some of these sheep in Massachusetts and also in West Virginia.

The promotion of Black-faced Highland sheep is essentially in the hands of the Scotch. A Black-faced Sheep Breeders' Association has its headquarters at Moniaive, Scotland, and publishes a flock book. On January 3I, 1907, the American Black-faced Highland Sheep Association was organized in New York City, but has had a nominal membership and shows little or no activity.

The special field for Black-faced Highland sheep in America should be the mountain regions east and west, but more especially the higher sections of the lower Alleghenies, where grass grows in abundance. The Cheviot, however, is almost equally hardy and is far better suited to the American market. 


\section{CHAPTER LXI}

\section{THE CORRIEDALE}

The native home of the Corriedale is the group of islands in the South Pacific Ocean known as New Zealand, lying about I 000 miles southeast from Australia. There are two main islands here, the North and South, separated by Cook Strait, I 6 to 90 miles wide. North Island is in the main gently undulating, though having volcanic peaks rising to gooo feet, while South Island along its western side has a lofty and majestic mountain range towering to I 2,000 feet. "The character of the country upon which the Corriedale is bred in New Zealand," says Professor Marsha11, " "varies from level and fairly rich artificial grass pasture to rough hills with altitudes around 3000 feet, on which snow lies for several months at a time." The climate of New Zealand is very equable, and the rainfall ranges from 20 to IOO inches a year. This is essentially an agricultural and pastoral country, with a greater number of sheep per acre than elsewhere in the world. In I9I 5 New Zealand was reported as having nearly 25,000,0oo sheep.

The origin of the Corriedale is quite recent. It is the result of crossing long-wool rams on Merino ewes, more especially the Lincoln and Leicester. The policy adopted was one of extensive breeding and persistent culling to secure a type of sheep best suited to New Zealand that would produce both mutton and wool to a satisfactory extent. The claim is made, however, that the line of Corriedale breeding was first suggested by James Little, who, in $\mathbf{I} 865$, brought to the Corriedale estate on the South Island some Romney sheep and proposed that they be bred to Merinos in order to improve the sheep of the island. This flock, however, was soon dispersed; and soon after Mr. Little moved to the North Island, where, in I878, he began systematic crossing on the Allendale estate at Waikiri. The Nere Zealand Farmer says ${ }^{2}$ :

1 Bulletin 313, United States Department of Agriculture, November I3, 1915.

2 The Wyoming Corriedale Sheep Company. A pamphlet on Corriedales ( 1916 ). 
He set to work to build up a flock and started out by buying the biggest framed and sturdiest looking Merino ewes he could get, four thousand being thus selected. These were bred to Lincoln rams, and from the best ram lambs, the progeny of these Merino ewes and Lincoln rams, Ioo of the best ram lambs were saved, then further severe cull was made, and 20 of the best picked out. These were mated with the pick of the half-bred ewes, the progeny of the Merino ewes and Lincoln rams. The flock did very well, indeed, under heavy culling and careful management, and the chief points which worried Mr. Little were a tendency to droop in the tail, a rough hip and weak shoulder. These defects had to be rectified, and the ideal that Mr. Little kept before him all

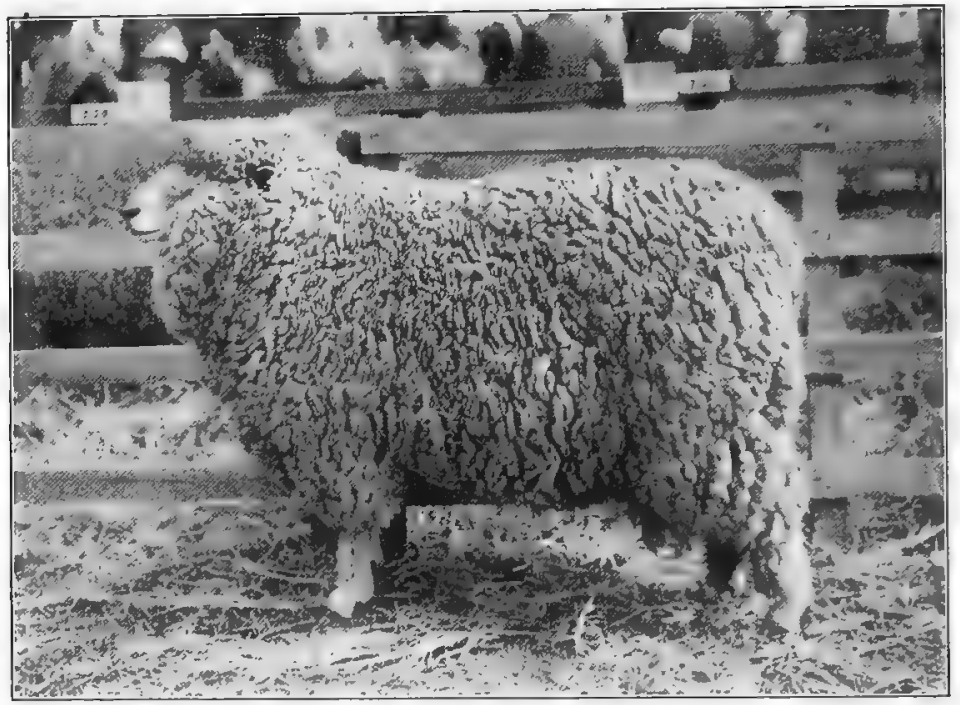

Fig. 309. Ensor's Double Brand, an aged Corriedale ram owned by C. H. Ensor,

New Zealand. From photograph, by courtesy of Professor F. R. Marshall

the time was to get the solid, well-shaped carcass of a Shropshire or Southdown, well covered with a good staple of the best quality half-bred wool. $\mathrm{He}$ also recognized that to make the breed worth while it must be a sheep that should be able to fight for itself and need no coddling, and there was the point of early maturity to be considered, as the development of the frozen meat trade would make this of considerable importance. Mr. Little's fleeces soon began to be known overseas, and there was very flattering competition for the clip on the market which he began to top.

Others engaged in crossing and culling on much the same line as Mr. Little, notably C. H. Ensor, who used Leicester rams, and W. S. Davidson, who, like Mr. Little, depended on Lincolns for sires. 
From the above it can be seen that the Corriedale is a very recent breed. In fact it has not been recognized as a breed where might have been expected. Professor Hawkesworth, noted as an Australian authority, in his standard work on sheep and wool, published in 1906, makes no reference to the Corriedale. The first important American presentation of the breed was by Professor F. R. Marshall in I9I 5 in Bulletin 313 of the United States Department of Agriculture, on "Features of the Sheep Industries of the United States, New Zealand, and Australia compared."

The importation of the Corriedale sheep into North America first took place in 1914, when Professor F. R. Marshall was sent to New Zealand by the United States Department of Agriculture to study the sheep industry of that country and Australia and "for the importation of Corriedale and other prom-

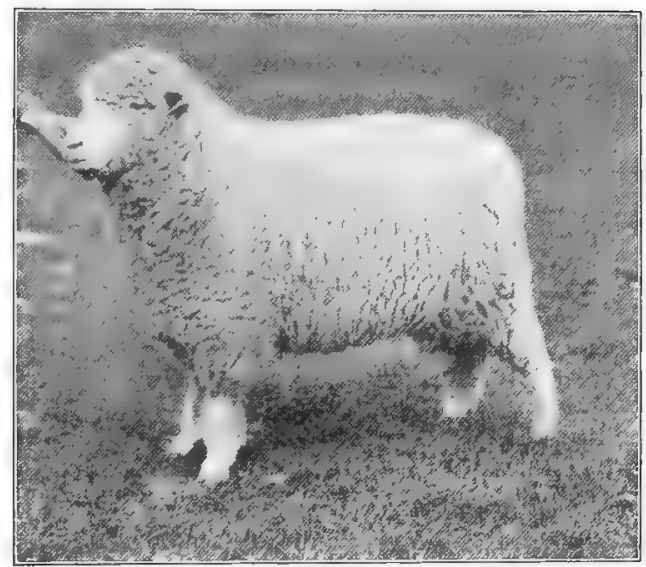

Fig. 310. A Corriedale ewe bred and owned by the Wyoming Corriedale Sheep Company, Cheyenne. From photograph, by courtesy of the owners ising breeds of sheep for breeding purposes." As a result of this trip there were landed at San Francisco on December 3I, I9I4, fifty-three ewes and ten rams, imported as a foundation flock. F. S. King of Wyoming accompanied Professor Marshall on his trip to New Zealand, and in I9I 5 he imported from the flock of C. H. Ensor, since which time he has brought many Corriedales to America.

The characteristics of the Corriedale sheep. This is an entirely white breed with a cap of wool over the head to the eyes or beyond, but showing plenty of white hair on the face. The back and loin are said to be especially good, while the hind quarters are thick and of excellent mutton form. In conformation it is a wide mutton sheep and with a depth of rib indicating a good feeder. 
The weight of the Corriedale sheep, according to $\mathrm{King}^{1}$ is 300 pounds for mature stud rams, 250 to 290 pounds for two-yearold rams, with yearlings up to 220 pounds. Six months' lambs are said to attain a weight of 100 pounds. Many ewes weigh from 200 to 250 pounds.

The fleece of the Corriedale sheep represents a very long staple suggesting the fine-wool ancestry, but with more coarseness and length. In discussing the fleece F. S. King offers the following ${ }^{2}$ :

The fleece is about 5 inches in staple, runs about 60 's in the count ${ }^{3}$ has a decided crimp, is a strong, robust wool of the half-blood type running into fine medium grade, carries a good luster, and the belly wool is thickly put on and free of grease. The fleece is fairly even throughout and is free from jars or dog hair.... The wool brings a top price, and being set well on the sheep in a quite dense, compact fleece that is free from any surplus grease, held well together with binders, makes a great protection to the body from cold wet winds or spring snows. It keeps out the dirt well and is quite an attractive article both to the buyer and seller.

The Corriedale fleece, being somewhat light in yolk, is a fairly heavy weigher. Marshall gives figures regarding eighteen sheep shown at the I9I4 Christchurch Show, New Zealand, on which occasion the fleeces ranged from I 5 to 20 pounds 14 ounces. According to F. S. King top-selected ewes will shear fleeces weighing from $\mathrm{I} 4$ to $\mathrm{I} 8$ pounds.

The rank of the Corriedale as a mutton producer is very good in its native country. It matures early and lays on weight rapidly, producing a smooth, well-covered carcass that dresses out very satisfactorily and seems especially suited for export in the frozenmeat trade. On the London market carcasses of Corriedale blood command a high price. In the Canterbury district of New Zealand crossbred ewes - the result of breeding Lincoln or Leicester rams to Merino ewes - are bred to Southdown rams, the combination producing a much-desired carcass in the London market known as "Canterbury lamb," which commands a premium for its excellence. King reports that in packing-plants lambs

1 American Sheep Breeder, May, I9I 5.

2 Ibid. February, 19r5.

${ }^{3}$ A technical term indicating that I pound of top wool in the mill can be spun into yarn 60 times 560 , or 33,600 yards in all. 
are usually killed at four to five months old and that they kill out 36 to 40 pounds dressed carcass.

The Corriedale as a grazer or forager is regarded as superior, showing the distinctive characteristics of the Merino in this respect, with its valuable flocking habit. The claim is made that the Corriedale is hardier than the Merino and will withstand severe changes of weather conditions in the mountains better than the Merino.

The prices paid for Corriedales are not remarkable. At the Sydney, New South Wales, ram sales in I9I 4 the top price for rams was $\$ 375$, while flock rams brought $\$ 35$. Reserve breeding ewes sold for $\$ 40$ and common ewes for $\$ 15$. Two hundred ewes of C. H. Ensor's breeding, in the 1918 Sydney sale, averaged $\$$ I 3 I, with the top at $\$$ I 76 . At the ram sales at Salt Lake City in I9I 8 fifteen rams were offered from the United States Department of Agriculture flock and three by the Wyoming Corriedale Company. The top price was $\$ 525$ for a government ram, with two from the Wyoming Company selling for $\$ 500$ each. The lowest price at which a ram of the breed sold on this occasion was $\$ 150$, twelve head selling from this price up to $\$ 250$.

The distribution of the Corriedale at present is in New Zealand nearly altogether, but they have also been introduced into Australia and Tasmania. Considerable numbers are now being brought to America, which thus far have been distributed in the Northwestern and Pacific coast states, with Wyoming interests especially promoting the breed. Some of these sheep have been shipped into western Canada, and they have also gained a foothold in Argentina and British East Africa. In view of the interests promoting these sheep in the United States, they are very likely to have a wide distribution in this country.

The official promotion of Corriedale sheep began with its recognition by the New Zealand Sheep Breeders' Association, which has already published a number of volumes of Corriedale flock books. In December, I9I 5, the American Corriedale Sheep Breeders' Association was organized, with headquarters at Cheyenne, Wyoming. 


\section{CHAPTER LXII}

\section{THE KARAKUL}

The native home of Karakul sheep is Bokhara and the neighboring districts in Turkestan, Russia, in the region between the Caspian Sea and northern Afghanistan. Bokhara is in about latitude $40^{\circ} \mathrm{N}$, between $60^{\circ}$ and $70^{\circ}$ east longitude, and about I 700 miles east of Constantinople. Western Bokhara comprises much desert land, while the eastern part is very mountainous. The summers are hot and dry, the winters cold and with much snow. Agriculture is the chief occupation of the country. Horses, cattle, sheep, goats, and camels are raised in considerable numbers. From three to four million sheep are found in this region. It has been stated ${ }^{1}$ that the name is derived from Kava-Kul (black lake), a village in eastern Bokhara.

The origin of Karakul sheep is one of obscurity. Dr. C. C. Young of Texas, who, in I909, visited Bokhara, believes that long-tailed black sheep of Danadar were the original fur-bearing stock of Central Asia, and when crossed on the white fine-wooled sheep of Afghanistan produced the gray Danadar. These gray sheep eventually were crossed with a fat-rumped breed, resulting in what is known as the Arabi, from which the Karakul is descended. Another type of fur-bearing sheep, the Duzbai, is also said to be derived from a cross of the black Danadar and fat-rumped sheep. Undoubtedly the sheep of this region are more or less mixed in blood lines if one can judge from specimens imported to America.

The introduction of Karakul sheep into America first took place in December, 1909, when Dr. C. C. Young of Belen, Texas, imported I 5 head - 3 rams and I 2 ewes. Other importations were made by Young in 1913 and I9I4 - a total of 3 I rams and 23 ewes in the three importations. What have been-known as Persian sheep were imported in June, 1892, by Truxton Beale, United

1 F. R. Marshall, L. L. Heller, and V. O. McWhorter, Karakul Sheep. Yearbook of the United States Department of Agriculture (19I 5), p. 249. 
States minister to Persia, who presented 6 head to Secretary of Agriculture Rusk. Another importation was made in I9IO. These Persian sheep apparently came from Bokhara and may be more or less grouped with the Karakul as producing Persian fur.

The characteristics of the Karakul sheep of special interest are as follows: The head, usually horned with the rams and hornless with the ewes, is narrow, with the nose of marked Roman type in the rams but fairly straight with the ewes. The ears are small, more or less drooping, and set somewhat low, even below the level of the eyes. The neck is long and scrawny, the shoulders prominent, the back narrow, the ribs flat rather than well arched, the loin high, the rump very drooping and terminating in a heavy, thick, broad fat tail, which tapers rapidly from the body but extends quite to the hocks. This tail may

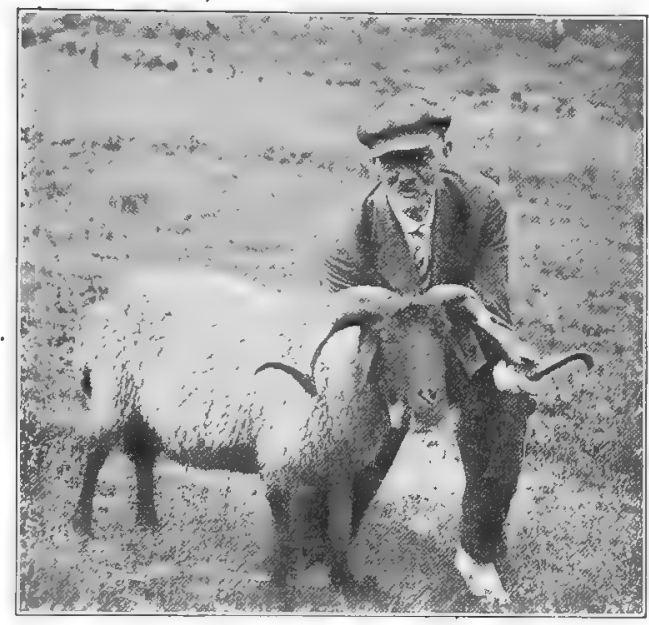

FIG. 3II. Doctor, an imported Karakul ram owned by the New England Karakul Company, Alton, New Hampshire. From photograph, by courtesy of F. E. Dawley weigh 5 or 6 pounds.

The legs are slender and somewhat long, just such as might be expected with mountain sheep. According to Holm the head, ears, legs, and feet should be black, though "occasionally a small white spot and, frequently, gray hairs are found on the head." Karakuls are of medium size.

The fleece of the Karakul sheep is the feature for which the breed is especially valued. On mature sheep the wool is long and very coarse, grading as an inferior braid or carpet wool and measuring up to 8 inches long, and lies in loose locks on the body. This coat (which some writers term hair and others wool) with age turns from black to a grayish or brownish black, while 
below this long outer fleece, with some sheep, is a covering of short, lustrous black hair which is regarded as undesirable. The fleece on the lambs at time of birth is very thick, curly, and extremely lustrous, and is usually a deep black in color, although shades of gray or brown occasionally occur. In the course of three to nine days after birth the fleece loses its curly character and gradually assumes a straight appearance. An important feature of the coat on the newborn lamb is that the curls should be very close together, with a minimum of open spaces between them. The curls should also cover the body completely. Alexander Albright, a Texas breeder, states that lambs four months old in July will shear 4 to 5 pounds of fleece.

The fur of the young Karakul lamb is used for making ladies' muffs, collars, coats, etc., and in the trade it is classed as Persian, Astrakhan, Broadtail, and Krimmer. According to Marshall and others, ${ }^{1}$ the color is black in each class except the Krimmer, but the character of curl varies. Persian has the most pronounced, the most uniform, and the tightest curls and is most valuáble. Astrakhan is longer, more open, and less lustrous than Persian. "Moiré" Astrakhan has a skin that is light and soft, with straight hair, but with marked luster. Broadtail skins are from lambs prematurely born, the skins being light and the fiber wavy rather than curled. Krimmer is a gray fur produced in the Crimea. The skins in the above classes are graded, and all but the Krimmer are derived from Karakuls reared in Bokhara.

The grade or crossbred Karakul has its chief interest as a producer of commercial fur. Pure-bred Karakul rams used on ewes of the long-wool type, such as Lincoln, Leicester, or Cotswold, sire lambs that tend to produce very good furs. The Animal Husbandry Division of the United States Department of Agriculture has conducted some interesting experiments in this field and secured good skins from some crosses with long-wool type ewes and poor results with medium and fine-wool ewes. A cross of Karakul ram on Barbadoes ewes resulted in low-grade furs, but the ewes of this cross, bred to another Karakul ram, produced some excellent furs. A Texas breeder of Karakuls secured good results from a mating of Karakul rams on half-bred

1 Yearbook of the United States Department of Agriculture, r9I 5. 
Karakul-Lincoln ewes. In I9I I Dr. Young wrote ${ }^{1}$ that an excellent fur is obtained by crossing a half- or three-quarter-bred Karakul ram with the long-wooled sheep known as "Romanovskaja," resembling the Black-faced Highland. He also states that the Russians are beginning to realize that the English breeds - as, the Lincoln, Leicester, Cotswold, and, especially, the Shropshire - yield fur far superior to anything that Asia can produce. Dr. Young produced some "salable skins" through a Karakul-Merino cross, and a "much prettier skin" in a Karakul-Shropshire cross, but he says:

If we wish to excel in luster the best of so-called Persian lamb skins we must confine ourselves entirely to the long-wooled sheep. In my opinion the Lincolns produce the best fur, although the difference in luster between the young Lincoln and Cotswold lamb is hardly sufficiently perceptible to entitle one to a positive statement.

It is important to note that some Karakul rams are much more prepotent than others in transmitting the more valued qualities of the fur, and that half-bred or grade Karakul rams as a rule yield inferior results.

The market value of Karakul furs varies in a great degree. About 1,500,000 skins are said to be exported annually from Bokhara and adjoining regions. Under pre-war conditions firstclass dyed skins sold in small lots at from $\$$ I 5 to $\$ 20$ each, while inferior ones were quoted as low as $\$ 3$. It is stated that the average value of all the skins sold at the Russian fair at Nijni Novgorod in I9I 3 was $\$ 6.25$. Skins from lambs from half-bred Karakul-Barbadoes ewes, produced by the United States Department of Agriculture, were valued at 50 cents to $\$ 10$, with an average of $\$ 4.70$. Dr. Young thinks that skins from a KarakulMerino cross on a three-day-old lamb should be worth $\$ 2$ or $\$ 3$ each, while that from a Karakul-Lincoln should bring $\$ 5$. The price on undyed skins in Europe has greatly increased in recent years, and Holm states that in Leipzig, where the dyeing is chiefly done, about 385,000 skins are handled annually, showing an average value of $\$ 4$.

The mutton value of the Karakul is regarded as very satisfactory. The mutton of the mature sheep is considered of good

${ }^{1}$ C. C. Young, The Karakul Breed of Sheep. American Breeders' Magazine, Vol. II, No. r. 
quality, while the tails in their native country are rated as a delicacy, the fat replacing butter. In October, I9I6, R. A. Tawney of Colorado marketed 400 black grade lambs on the Kansas City market that were five months old and averaged 70 pounds live weight, with price much the same as native lambs of the same weight.

The hardiness of the Karakul is very marked. In their native home they undergo conditions of great winter severity. As tried

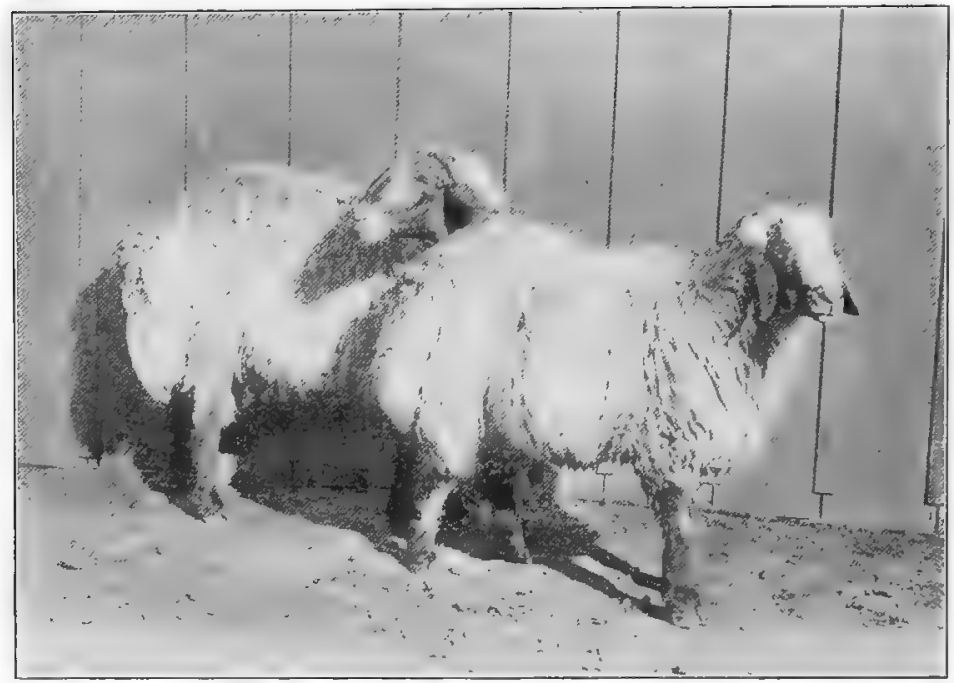

FIG. 312. Karakul ewes owned by C. P. Bailey \& Sons, San Jose, California. From photograph, by courtesy of the American Sheep Breeder

in South Africa and the United States they have proved most vigorous. The breed, however, is not suited to a damp climate and should not be reared under conditions of unusual moisture. "There is no evidence," writes Holm, ${ }^{1}$ "that although extremely hardy, they possess immunity to any of the South African sheep diseases, and the same care should be exercised with Karakuls as with other sheep."

The fecundity of the Karakul is not marked. As a rule the ewes drop one lamb a year. Pure-bred ewes require special attention during breeding season on account of the heavy tail ; in fact,

1 Alexander Holm, Liarakul Sheep. Pretoria, South Africa, 1916. 
this should be removed from the young ewe lambs reserved for breeding, thereby facilitating breeding operation.

The distribution of Karakul sheep is very widespread. Outside of their native home they are found in parts of Africa, in Europe, and in North America. In the Union and Southwest Africa the Karakul is receiving considerable attention. The native Afrikander sheep is of the fat-tail type and crosses well with the Karakul. In Canada, G. Erle O'Brien ${ }^{1}$ reports that these sheep are also being carefully tried, flocks having been established in Nova Scotia and Prince Edward Island in 1913. The following year other importations were made and flocks established in Nova Scotia, New Brunswick, and Alberta. In 1918 there were between 500 and 600 grade Karakuls in Canada, produced by crossing Karakul rams on native long-wool ewes. There were also about Ioo rams and ewes of imported stock or descended from the same. Flocks of pure-breds and grades or crossbreds have been established in Texas, New Mexico, Kansas, Colorado, Maryland, New York, and elsewhere. The claim was made in 19r 7 that nearly all the purebred Karakuls were combined in one ownership, with headquarters in New York.

1 Karakul Sheep and Persian Lamb Fur Production. Pamphlet 15. 15, April, Igr8, Sheep and Goat Division, Department of Agriculture, Ottawa, Canada. 


\section{CHAPTER LXIII}

\section{THE ANGORA GOAT}

The native home of the Angora goat is in the district of Angora in Asia Minor. This is a mountainous region 2000 to 4000 feet high, lying south of the Black Sea; Angora, the principal city, is in $40^{\circ}$ north latitude, 200 miles from the sea, and about 220 miles south by southeast from Constantinople. The climate has wide extremes of heat and cold. In January and February the temperature may reach zero, while in June and July it will touch 85 degrees. The rainfall is rather variable but light. The soil is frequently poor and free of vegetation. Forests occur to a considerable extent. It is probable that the Angora goat has inhabited this region for many centuries, dating back prior to the Christian Era. The atmospheric conditions about Angora are said to be especially favorable for producing a fine quality of hair.

The origin of the Angora goat is quite obscure. There are some ten species of wild goats in Europe and Asia, and these are divided into two groups: one, the ibexes; the other, the goats proper. The former are distinguished by horns "flat in front, with horizontal triangular sections, furnished with large transversal knots," while the latter have horns that are compressed and carinated in front, with a well-developed keel and with a rounded formation behind. Among the goats are two subspecies: Capra falconeri and Capra agagrus. "The latter," says Thompson, ${ }^{1}$ "is also known as the Paseng, the Bezoar goat, or wild goat of Persia, and is generally accepted as the goat from which the Angora is descended through Capra hircus, which is claimed to be the origin of all the common breeds of goats."

Several varieties of goat in Angora are reported, each located in a special district. These, according to Gatheral, are the following: (I) Yavan-Ova, having a heavy, lustrous fleece; (2) Chorba,

1 George F. Thompson, Information concerning the Angora Goat. Bulletin 27, Bureau of Animal Industry, United States Department of Agriculture. Revised I906. 
producing a very soft, fine mohair; (3) Chubouk-Ov'a, remarkable for length and fineness of fiber; (4) Ayash, white of fleece, but lacking luster; (5) Joevas, having a bright, showy, but kempy fleece. Other varieties are also referred to.

The introduction of the Angora goat to America dates back to I 849, when the Sultan of Turkey presented Dr. James B. Davis

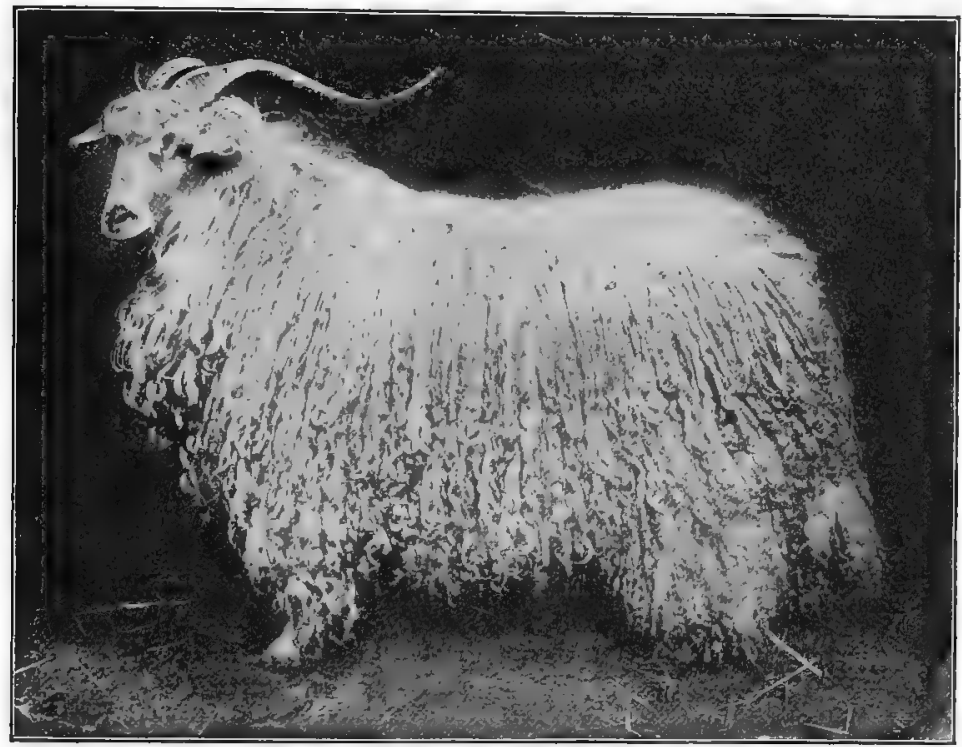

FIG, 313. Hobson's African, first in aged Angora buck class in 1905 at the Lewis and Clark Exposition, Portland, Oregon. Weight of fleece i $8 \frac{1}{2}$ pounds at thirteen months old, selling for $\$ 1.50$ per pound. At head of the flock of William Riddell \& Sons, Monmouth, Oregon. From photograph, by courtesy of L. A. Webster

of Columbia, South Carolina, with 9 choice animals -2 bucks and 7 does. These were long known as Cashmere goats, but evidence seems to show that they were true Angoras. These goats and their progeny were sold later to various people, especially to Colonel Richard Peters, who bought in I 854 . They were shown quite extensively and attracted much attention. From the Davis importation, flocks became established over considerable territory in many states. A number of other importations followed that of I849. In I 86I W. W. Chenery of Belmont, Massachusetts, made 
two importations and others in 1866 and 1867. About 1867 Messrs. I. S. Diehl and C. S. Brown imported 160 head and placed them on the farm of Mr. Brown at Newark, New Jersey. A number of other importations followed the above - notably that of John S. Harris of California, in 1876 ; Dr. W. C. Bailey of the same state, in I9OI (both of whom made personal selections in Asia Minor); and that of G. A. Hoerle of Kansas, who, in I904, landed 147 head at New York from Cape Colony.

The characteristics of the Angora goat are as follows: The head (which should be broad at the forehead and wide at the muzzle) from the eyes down is covered with white hair, the lower jaw having a beard of fine hair. Horns surmount the head of each sex - those of the male may be eighteen to twenty inches long, turning upward and outward, with a backward spiral twist, the tips widely separated; while the horns of the female, which attain a length of eight to ten inches, grow upward and point backward, with but little twist. The ears usually are large, six to eight inches long, and pendent. In some cases, however, the ears are foxlike - short, pointed, and pricked. The eye should be bright and of good size. The breast should be full, the shoulders well laid, the back straight and level, the ribs well sprung and deep, and the legs short. There is a tendency to steepness of mup, which is regarded as a serious objection. A pink skin is quite the thing, and no spots are tolerated by qualified judges. In quality the Angora ranks as superior. In temperament the breed is very quiet and easily managed. The musky odor of the common goat is not prevalent, unless with the males and then only during the breeding season.

The fleece of the Angora is its most striking and important feature. It is commercially known as mohair. It differs from wool in having no exterior scales and not possessing the felting property common with wool. It also has a lustrous or silky quality which is most highly valued, for the greater the luster the higher the market value. The fleece should be pure white and completely cover the body, "as dense on the belly and neck as on the back and sides." In some cases the head is crowned with a topknot, which falls in ringlets over the face or projects over the forehead only. The mohair attains a length of eight or ten inches during a year of growth and hangs in ringlets, which, Thompson 
says, "should be well formed from point to skin, and the tighter these ringlets are twisted the better ; loose, slightly wavy hair is objectionable and indicates coarseness and brittleness, and often lacks luster." Mohair is somewhat coarser than fine wool, but it is longer and much stronger. An average fleece weighs about four pounds. Very superior individuals will shear eight pounds or more. Riddell \& Sons of Monmouth, Oregon, report that their buck Sultan, sweepstakes at the Lewis and Clark Exposition in I905, sheared a fleece that weighed $18 \frac{1}{2}$ pounds, which they claimed made it the heaviest fleece on record at that time. Some owners of Angoras shear twice a year, in April and September, although this is not a general practice. This mohair lies over a short coat of hair known as kemp, which is hard and white, sometimes attaining a length of four inches. Kemp is a very objectionable fiber, as it is coarse and will not take the dyes used with mohair.

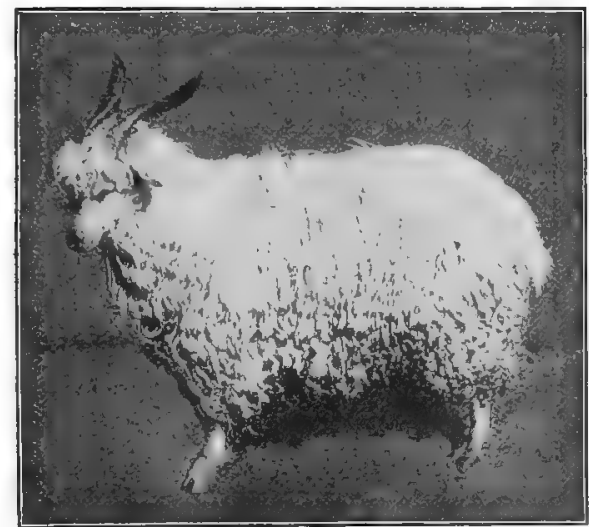

FIG. 3I4. Aztec 10664, a champion Angora goat in important shows. Bred by D. C. Taylor \& Son and sold for \$I 400 to Kemble Brothers of Iowa. Photograph from the National Stockman and Farmer Its presence in American flocks is materially due to the influence of common-goat blood, on which the Angora has been much crossed in the past. Very careful selection of breeding sires greatly reduces this difficulty. If not shorn, the Angora goat will shed its fleece each spring.

The prices of mohair differ according to the demand and quality. In Bradford, England, the mohair manufacturing center of the world, the price has undergone wide fluctuations. In March, I9I8, mohair tops made the high record of $\$ \mathrm{I} .80$ a pound at Bradford. Along at this same time choice mohair was quoted in America at 60 cents a pound in the bale. Kid fleeces as a rule bring the highest prices, and bucks, wethers, and old does the 
least. In I9I9 the better grades sold on the ranch at from 50 to 60 cents a pound with the more common fleece from 40 to 45 cents.

The weight of the Angora goat is considerably less than that of an average-sized sheep. From sixty to one hundred pounds is regarded as a satisfactory range of weight.

The Angora as a producer of mutton has grown in importance in recent years, though not regarded from the same point of view as that produced by sheep. The flesh of the fat young Angora makes excellent mutton, and in recent years large numbers have found

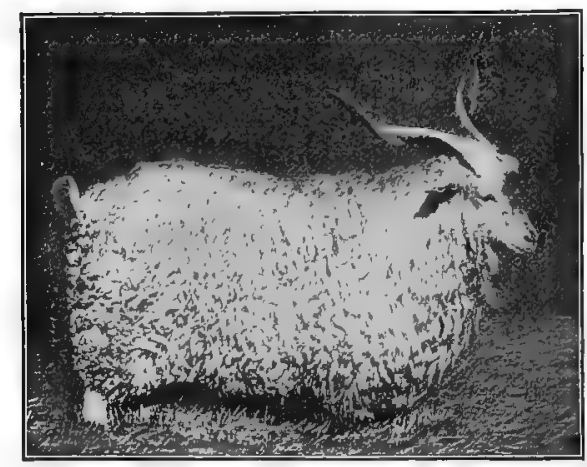

Fig. 315. Pasha Columbia, a great Angora sire and show buck, purchased by Mrs. M. Armer, Kingston, New Mexico, for $\$ 1050$. From photograph, by courtesy of the National Stockman and Farmer their way into the markets, where the carcasses have been sold as lamb. Some Angora breeders are enthusiastic over the superior quality of the mutton. Wethers may be shorn for some years and then fattened and sold for mutton. In the stockyards these goats usually bring a lower price than sheep.

The Angora as a renovator of brush land has a distinct value. The goat is naturally a browser and not a grazing animal. In brush lands he is in his element. He eats the slender tips and twigs and destroys young trees and brush very effectually. In Michigan, Wisconsin, and some other states large tracts of brush land have been pastured to flocks of goats, which have materially reduced the cost of clearing the land for farm purposes. From four to six goats are used per acre, and in two or three seasons they will destroy the brush, and grass will take its place.

The prolificacy of the Angora goat is not marked. Rarely more than one kid is dropped a year, though twins and even triplets may occur. Thompson states that on the southwestern ranches the average percentage of kids is about seventy, with instances of flocks attaining 120 per cent. Coaklin Brothers of California, in a 
communication to the American Angora Goat Association, ${ }^{1}$ report that but few of the ewes have twins, and that in I9I4 they had only about five pairs of twins to one hundred does, with fewer twins coming each year in a flock of five hundred does. These brothers state that they raise about 90 per cent of their kids one year with another.

Shelter for the Angora, in regions where considerable rainfall occurs, is emphasized by experienced breeders. The Angora will do well in cold or warm dry regions and at relatively high altitudes, but not when subjected to moisture. Goats from choice seek dry locations, and their barn or shed should be situated with good drainage, be well roofed, and given ample ventilation, with freedom from drafts.

The price for Angora goats varies greatly. Many have changed hands on Western ranches at two or three dollars a head, but very high prices have been paid. Pure-bred, fair specimens have sold at prices comparable with sheep of average breeding character. In I90 I, at the Kansas City Goat Show, the buck Pasha Columbia changed hands for $\$ 1050$, while the next year Mr. A. Kemble of Iowa paid \$I 400 at the same show for the buck Aztec. Still later, in I903, at the Kansas City Show, the buck Dick Junior, sweepstake of the show, sold for $\$ 300$. Lazarus, that sold in I900 for $\$ 700$, was a famous show buck and proved to be a sire of much merit. The highest price ever paid for a doe in America was \$9oo for Oregon Beauty, champion yearling at Kansas City in I905. In recent years no notable prices have been paid for Angoras.

The distribution of Angora goats is very widespread. They are found in various parts of the world, but especially in Asia Minor, South Africa, and the United States. South Africa has a large Angora industry and prior to the World War was credited with producing I 5,000,000 pounds of Mohair, as compared with I0,000,000 pounds produced by Turkey. In I9I 2 the British market imported over $35,000,000$ pounds of mohair, but the amount imported steadily declined during the war to 3,500,000 pounds in 1917 . In 1863 large flocks were reported in Massachusetts, New York, Maryland, Georgia, Tennessee, Kentucky,

1 The Angora Goat. A descriptive booklet, I9I8. 
Ohio, Indiana, Illinois, Michigan, Minnesota, Missouri, Iowa, Kansas, and Texas. With reasonable care they seem adapted to a wide range of climatic conditions, and do well in the drier southwestern states and in Wisconsin and the colder, moister North. A dry climate, however, seems to offer the best condition of health. At the present day Angora goats are found in nearly every state in the country, with very large flocks in New Mexico, Texas, Arizona, California, and Oregon. In 1917 a total production of $10,000,000$ pounds of mohair was estimated for Texas, New Mexico, Arizona, and California, where this industry is mainly centered.

The official promotion of the Angora goat is in the hands of the American Angora Goat Breeders' Association, with headquarters in Missouri. The association keeps the records of registration, but up to I9I9 had published no flock books. The Angora Journal and Milk Goat Bulletin, published in Oregon, also champions the breed. There is also a National Mohair Growers' Association, with headquarters in Texas and a warehouse in Boston, Massachusetts. This is organized as a marketing association. There is also a Canadian Goat Society, with headquarters at Ottawa, and also another at Vancouver, British Columbia. 


\section{CHAPTER LXIV}

\section{THE MILCH GOAT}

The goat as a source of milk supply has long held an important place as a producer, especially among the poorer people of the various countries of Europe. Travelers in Switzerland, Italy, France, and Spain are impressed with the large numbers of goats kept for milk production. Among common goats a yield of a quart a day is not uncommon. Some breeds are quite heavy producers.

The characteristics of the milk of the goat are somewhat variable. Nubian goats and their half-breds tend to produce a milk richer in fat and with more total solids than have the Swiss breeds. It seems to be the case, also, that goat milk varies considerably in its composition among individuals of the same breed. Pegler gives the analysis of a crossbred prize-winning goat as follows ${ }^{1}$ : casein, 4.06 per cent; fat, 5.14 ; sugar, 5.28 ; salts, .58; total solids, I 5.06 ; water, 84.94 per cent. A Toggenburg goat one hundred and eighty-three days in milk showed 3.21 per cent fat, while an Anglo-Nubian six hundred and thirty-five days in milk tested 7.48 per cent. In this connection it is to be noted that the Toggenburg was producing 9 pounds a day and the Nubian about $3 \frac{1}{3}$. The smaller the yield and the longer the goat has been in milk, the greater the per cent of fat. There are two special qualities in goat's milk that should make it popular, one, the ease with which it is digested, and the other its immunity from tuberculosis germs. Its superior digestibility is attributed to the fact that the fat globules are much smaller than in cow's milk and are in a more perfect state of emulsion. Dr. Barbellion, a French medical authority, gives a somewhat different explanation. He states that the curd of cow's milk forms a dense, adhering mass, which by agitation separates into clots that are but slightly soluble, while the curd of goat's milk is soft, pliable, and very soluble, like the milk of the ass and

H. S. H. Pegler, The Book of the Goat. London, Igio. 
the human. When the udder is clean and the does are properly milked, the milk has no obnoxious flavor.

Breeds or varieties of milk-producing goats are found in various countries, some of which have been especially bred for their value as milkers. The common goat of America and the Angora produce milk, but in small quantities, and there are no milking

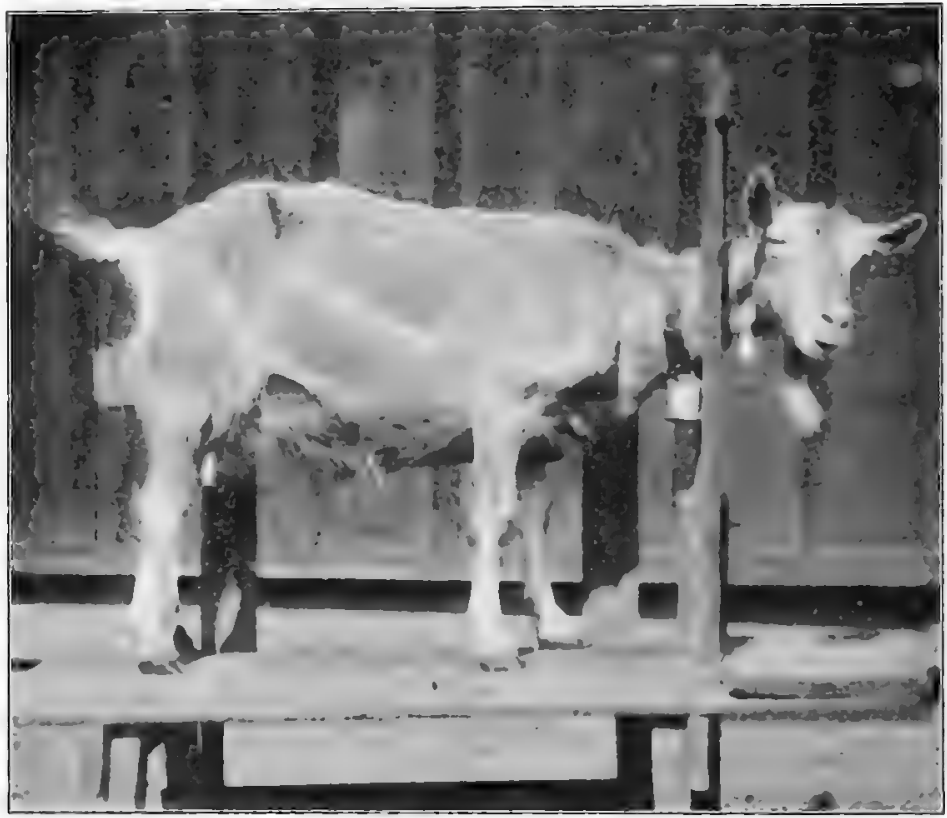

Ftr. 316. Fl ('hivars (ieneva 65 , a Toggenburg doe in milking stand, owned by Winchrop Ilowland, Redlands, California. This doe produced 2124 pounds of milk in ten months in official testing at the University of California Agticultural Experiment Station. From photograph, by courtesy of Mr. Howland

families of these. The following are prominent breeds in milk production and are considered somewhat in their order of importance from an American or British viewpoint.

The Toggenburg goat. This breed is raised more particularly in the Toggenburg valley in northeastern Switzerland, where it has been bred for centuries. This goat is a medium brown in color, with a white band passing along down each side of the face from eyes to mouth. The breed is rather slender and lean of body and 
neck. Horns may or may not occur, though it is regarded as a hornless breed. The ears are of moderate size and are usually carried somewhat erect. The males have a coarse beard and are rather more free of offensive odor than male goats of other breeds. The Toggenburg differs in character of coat of hair, some animals having a rough, long coat, others a short one, and still others one

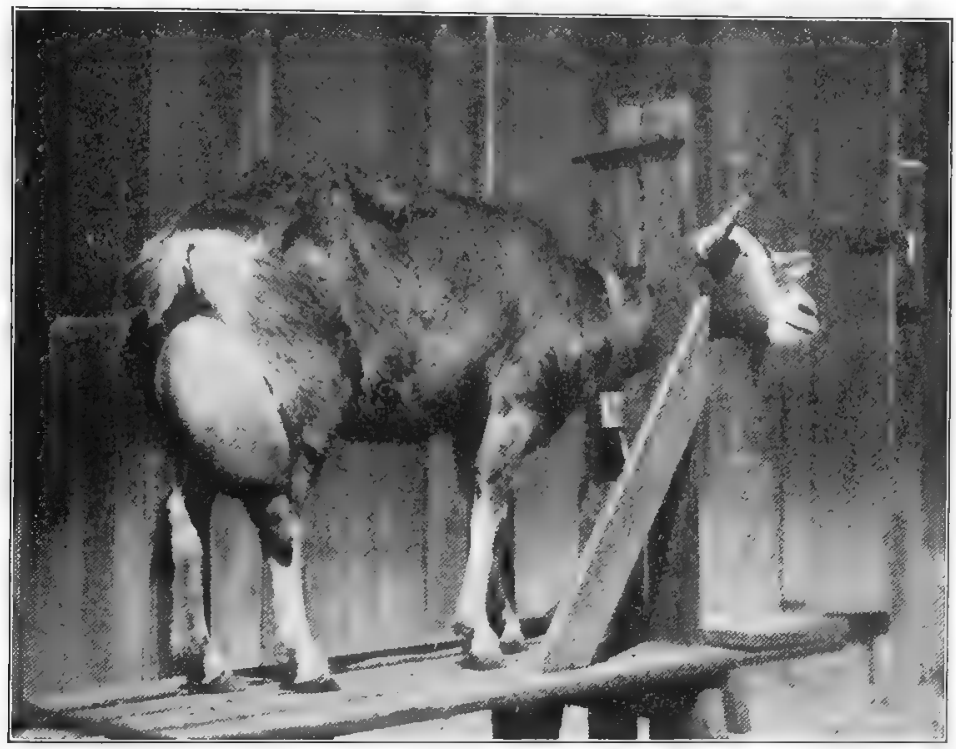

FIG. 317. Fanette I5I, an imported Toggenburg doe in milking stand, owned by Winthrop Howland, Redlands, California. This doe in one season produced 2680 pounds of milk, in one day yielding I 2 pounds 10 ounces. From photograph, by courtesy of Mr. Howland

of a medium character. The udder seems capable of great capacity. When full it is carried high between the legs and has two large, long teats. Many of these goats produce from four to five quarts of milk a day, while the best produce from five to six and even seven quarts. Winthrop Howland of California, one of the most noted American breeders, states in a pamphlet that "our pure Toggenburg does yield from three to six quarts of milk per day, and our three-quarters Toggenburg does yield from two to five quarts per day." At the California Station the doe El Chivars Geneva, owned by Mr. Howland, in three hundred and twelve 
days produced 2 I 58 pounds of milk testing 3.37 per cent fat, with a total content of 72.8 pounds fat. ${ }^{1}$ This remarkable yield was from a goat weighing about 108 pounds. Fanette I 5 I, owned by Mr. Howland, in one lactation period produced in twelve months 2680 pounds of milk and $\mathrm{I} 2$ pounds $\mathrm{I} O \mathrm{ounces}$ in her best daily yield. This is a hardy breed and will do well under a wide range of conditions of latitude and elevation.

The Saanen goat derives its name from the Saanen valley in Switzerland. It is the largest breed of that country, is lean and lank, is pure white or creamy white of color, and in general has short hair over the body excepting along the spine and at flanks and lower thighs. It also has a beard. Thompson says:

The does are especially beautiful, with slim, long, graceful necks and clean, breedy-looking heads. The head of the buck is decidedly masculine, but does not have the serious look of the Toggenburger. The breast is well developed; as a rule the udder is very pretty and is carried high. This is considered a hornless breed, but, as with the Toggenburger, occasionally one is found with horns.

There are mar:; fine milkers in this breed, though the average wi:. not show to q.1 te so good an advantage as the Toggenburg. Pecr states that "the best of them are probably the best in the world, giving from five to six quarts per day of the very best quality. Thompson gives a statement of ten goats which made annual records ranging from 423 to 95 I quarts. In I9I I, at the New York State Experiment Station at Geneva, the Saanen doe No. I I produced I 845 pounds of milk. ${ }^{2}$ The two-year-old doe Swiss Echo 390, owned by J. S. Comins of Michigan, in a little less than eight months produced 2374 pounds of milk.

The Maltese goat is especially bred on the island of Malta in the Mediterrancan Sea. This island of 95 square miles supports a population of about 200,000 people, and nearly 30,000 goats and 900 cows are used in milk production. Describing this goat, Pegler says ${ }^{3}$ :

1 E. C. Voorhies, The Milch Goat in California. Bulletin 285, University of California Agricultural Experiment Station, September, I9I7.

2 Goat's Milk for Infant Feeding. Bulletin 429, New York Agricultural Experiment Station, February, I9I7.

8 The Book of the Goat, I9Io. 
As with most breeds, the color varies cronsiderably from white or grey to black, whilst some are spotted. Those I have kept or seen have been generally either greyish-white or reddish-brown. Their breed is regarded as practically hornless, but it is not absolutely so, as a few of those in Malta are horned. The ears vary somewhat in regard to their position. Some are carried horizontally, whilst others are what we should call semi-pendulous, and a few completely so, these being extra long and with a slight outward curl at the extremities, showing more or less of the Syrian, from which this breed is supposed by some to have originated, in part at least. The facial outline is straight, the head long and narrow and free from beard, this last being a noticeable and special feature of the Maltese, imparting to the female a more feminine appearance than with some breeds. When horns are present, which is undoubtedly a defect, they are small and curl back over the head. The udder of the Maltese is a long, narrow bag, with large, unshapely teats like little udders themselves, its color, like that of the skin generally, being of a peculiar orange red.

This is highly regarded as a milkproducing breed, the

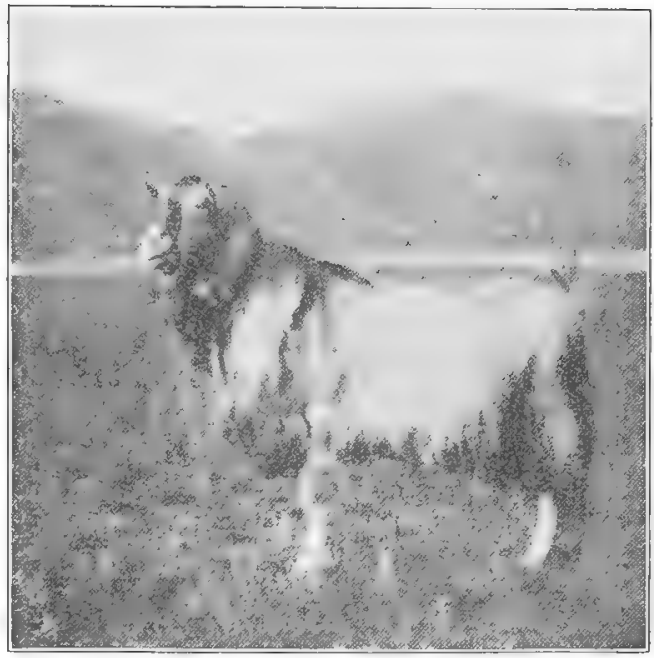

FIG. 318. Prince Bismark I 59, a noted Toggenburg buck owned by Winthrop Howland, Redlands, California. This buck weighs 203 pounds. From photograph, by courtesy of Mr. Howland

better individuals producing from three to four quarts a day.

In the summer of 1905 the late Professor G. F. Thompson went to Malta for the United States Department of Agriculture and imported sixty-eight of these goats, but they developed Maltese fever, and the importation was quarantined and proved a failure. Thus far the breed is essentially unknown in America.

The Nubian goat is found in Nubia, Upper Egypt, Abyssinia, and also in South Africa. It is very large and has long legs. The head is of striking appearance, being almost always hornless, and has a remarkable Roman face with depressed nostrils. The lower 
jaw extends beyond the upper, showing the teeth. The ears are frequently very large, long, and droopy, or they may be short and pointed. The color is very bright brown or black. The hair is short on some specimens and long on others. The udder is large and the lobes are deeply divided, with very good-sized teats. This is one of the highest types of milch goats, is credited with as much as ten to twelve quarts of milk a day, and is said to rarely

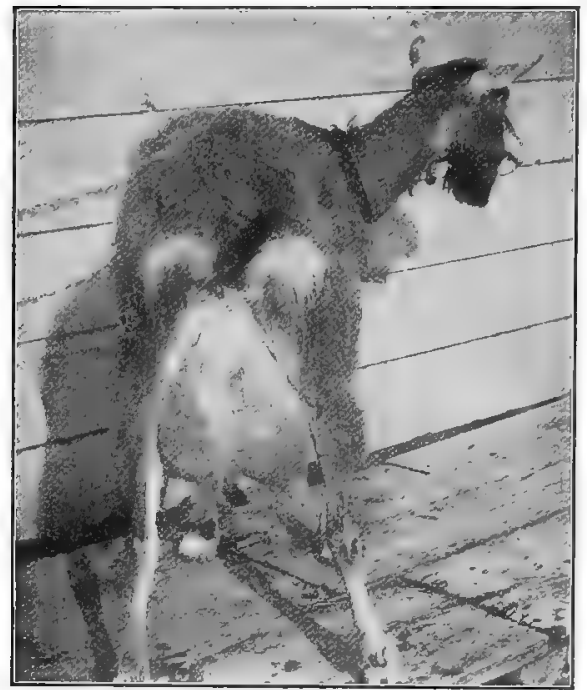

FIG. 319. Phyllis, an imported Toggenburg doe showing a very great development of the udder. From photograph, by courtesy of Professor F. K. Cooke, Winnetka, Illinois give less than four quarts per day. This breed has been crossed on other goats to special advantage. $\mathrm{Nu}$ bian goats are very docile. They lack hardiness, being quite unable to withstand cold.

The Anglo-Nubian goat orginated from crossing the prick-eared common English goat with the lopeared Nubian. Crossbred goats of this ancestry were shown in England as far back as I875, at the first goat show held at the Crystal Palace, and since then it has been continuously before the British public. Pegler regards it as a distinct breed. Thompson, however, gives it a very incidental reference. Pegler specifies the following as points of an Anglo-Nubian:

Coat short throughout, with no fringe of long hair on the back or long tufts on the flanks; color preferably black and tan, or reddish-brown, with or without black or black-and-white markings, but free from white streaks on the sides of the face, which would indicate Swiss blood. The horns, if any, should be small and curve downwards and outwards, rather than directly upwards. The ears must be long, wide, and pendulous, or semi-pendulous, but not broken or twisted. The facial line should be somewhat arched, the head neat, with a slight taper toward the muzzle, which is small, and in the female without beard. The eye should be large and full, and the forehead wide. 
Anglo-Nubians produce a milk richer in fat than the Swiss breeds, although the yield is not so great. This is one of the largest and strongest breeds and is well suited for draft purposes for children. Anglo-Nubians are bred in the United States.

The Schwarzhal goat is especially found in the Canton Valais, Switzerland, and in the Rhone valley. It is also known as the Glacier and the Saddle goat. This is a rather large breed of

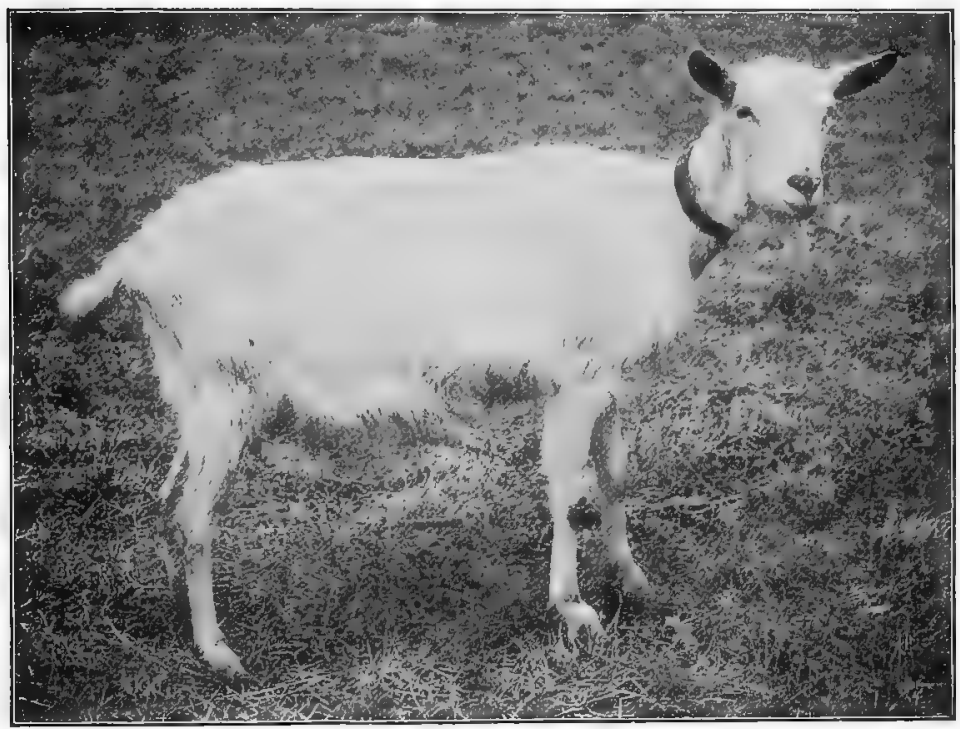

Frg. 320. Marina, an imported Saanen doe owned by Professor F. K. Cooke, Winnetka, Illinois. From photograph, by courtesy of the owner

striking appearance, with widespreading horns, a large and very thick beard, and a tuft of long hair on the forehead. The front part of the body to back of the shoulders is black, while the balance of the body is white. The legs are slender; the front hoofs are black and the hind ones yellow. This is an extremely hardy breed, perhaps the toughest of any. It does not yield as heavily of milk as some other breeds. Another Swiss goat, the Schwarzwald, has a very similar name, but the breed is quite different from the Schwarzhal and has only a local reputation, being one of the sixteen breeds, according to Professor Anderegg, that are found in Switzerland. 
The weight of milch goats varies considerably. Voorhies states ${ }^{1}$ that mature Toggenburg bucks weigh from I IO to I 40 pounds and the does from 100 to 140 pounds, while Saanen bucks weigh from 175 to 200 pounds and the does from I 10 to I 40 pounds. In England, according to "Home Counties," 2 the heaviest weights of goats published have been I 70 pounds for a six-year-old AngloNubian nanny and 195 pounds for a billy of the same breed. The size is not regarded as of prime importance. T. F. Jager, in submitting standards of both Toggenburgs and Saanens for criticism in a report on the first American milch-goat show, held in Rochester, New York, in I9I3, suggests I 30 to I 80 pounds for

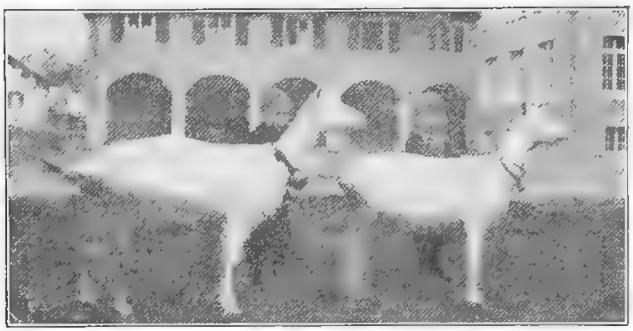

FIG. 321. A pair of fine young Saanen goats. From photograph by the author, taken at Interlaken, Switzerland Toggenburg bucks and 80 to I Io pounds for the does, and 140 to I 8 o pounds for Saanen bucks and Ioo to I 50 pounds for the does.

The age attained by milch goats naturally varies. They have been known to live to be sixteen years old, but will probably attain to ten or twelve years of age with reasonable care. The doe is in her prime at from five to seven years of age.

The cost of producing goat's milk is a subject of interest to many people who desire to keep this animal if the expense is not too great. In extensive experimental feeding at the New York Agricultural Experiment Station at Geneva, the average cost of the food per month varied from 48 to 99 cents, while the average cost of the food for a year was $\$$ I I.05, a daily expense of 3 cents. The food cost of the milk for a period of three years was 3.4 cents per quart, while the lowest cost was for the Saanen goat No. I I, of 1.27 cents per quart. During the same period of time the average cost of a quart of milk that was produced

1 Bulletin 285, University of California Agricultural Experiment Station, September, 1917.

2 The Case for the Goat. London, Igos. 
by the 25 Jerseys in the Station herd was .92 cent. At the California Experiment Station at Davis the cost of feed per year averaged $\$$ II.25, the cost of a gallon of milk 6.4 cents, and a pound of butter fat 22.9 cents, while the cost for milk from the cows in the herd was 8.3 cents per gallon, and a pound of butter fat 24.4 cents. It is to be noted in the above records that a charge at its market value was made for all food eaten, but there are various conditions where people may keep goats at nominal expense for feeds, making use of by-products about the place.

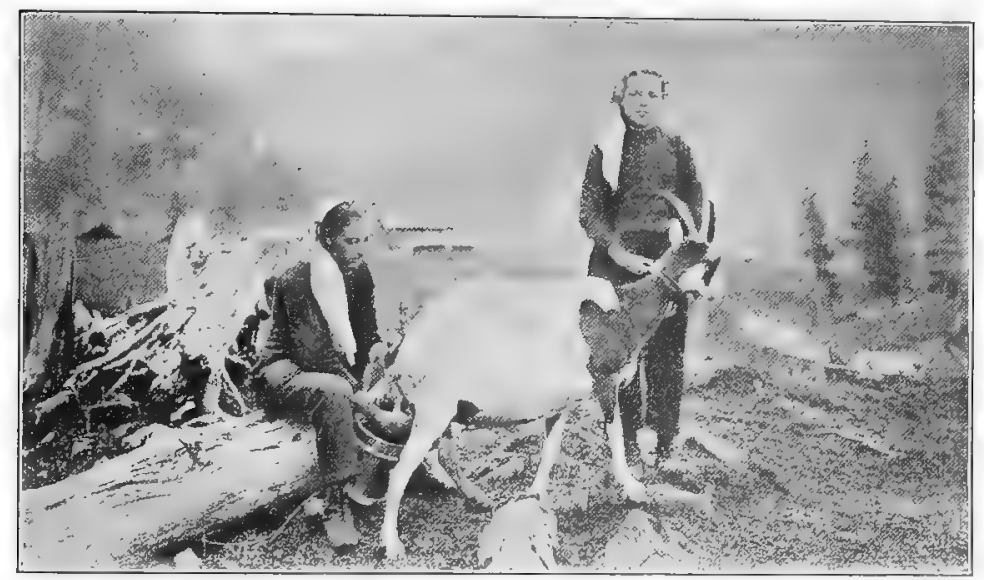

FIG. 322. Milking the goat in Switzerland. This doe shows the characteristic features of the Schwarzhal, though probably not pure bred. Reproduced from a Swiss postal card

Importations of milch goats to America began in 1893, when Mr. W. A. Shafor of Ohio brought to this country 4 Toggenburg goats which he purchased in England. In May, 1904, Mr. F. S. Peer of New York imported I6 Toggenburg and Io Saanen goats to this country for Messrs. W. J. Cohill of Maryland, R. N. Riddle of New Jersey, W. M. Decker of New York, and S. K. Bayley of Massachusetts. Mr. Cohill also secured 2 goats from Carl Hagenback at the World's Fair, St. Louis, in I904, that Hagenback had brought from the Black Forest of Germany. These are supposed to be Schwarzwald goats. In 1905 Professor Thompson imported 68 Maltese goats, as noted on page 677 . 
The prices for milch goats are quite variable. Common American goats of no milking strains sell at nominal figures. Since the World War, prices have naturally become stimulated in Europe because the goat herds of Europe suffered terrible destruction. Prior to the war the best milkers in Switzerland sold for about $\$ 25$. In England prices for milch goats have long ruled quite high. In I9 7 Mr. Howland priced his pure Toggenburg bucks, in a circular, at $\$ 75$ to $\$ 100$, and the does at the same price, while threequarter blood does were listed at $\$ 30$ to $\$ 35$. Many goats have been advertised in recent years at prices ranging from $\$ 25$ to $\$ 50$.

The fecundity of the milch goat. Does usually drop two kids at one time, and occasionally three. It is stated by Thompson that there is a record of a Nubian goat which dropped eleven kids within twelve months. The pregnancy period is five months.

The period of lactation of the goat varies according to the breeding and care. The common goat of this country produces milk from three to five months. In Europe, with the distinctly milking breeds, the period is more extended. There the plan is to have one doe come fresh in the spring and milk for about six months (where two are used in the family), having the other kid in the fall. This provides a supply of milk for the entire year.

The official promotion of the milch goat was first attempted in America by the organization on November I2, I903, of the American Milch Goat Record Association. This association has published, up to I9I9, two flock books, including the registration of I 800 goats. A goat of any breed, native or foreign, which gives two or more quarts of milk per day when fresh, according to the rules of the association, may be registered in the grade record. A goat from pure-bred registered sire and dam is eligible to registry in the pure-bred record. An imported goat of any recognized pure-milk breed is eligible to registry in the pure-bred record. In May, I9I3, the Western New York Milch Goat Breeders' Association was organized at Rochester, but in September the association took on a wider scope and changed its name to that of The Standard Milch Goat Breeders' Club of North America. There is also an International Nubian Breeders' Association, with headquarters in New Jersey. Several journals are devoted to promoting milch goats. 


\section{PART IV-SWINE}

\section{CHAPTER LXV}

\section{THE AMERICAN, OR LARD, TYPE OF PIG}

The type of swine most valued in the United States possesses great compactness of form, breadth of back, fullness of ham, shortness of limb, and is capable of fattening rapidly and maturing early. It is a type that in its highest-fed and most popular form contains a large amount of fat, especially in leaf lard and external covering. It represents the extreme development of meat production and, as ordinarily corn fed in the states, is not looked upon with favor by people of other countries. It is commonly referred to as the lard type of pig, from its natural heavyfat production. In this connection it may be said that while this type is quite generally popular, the character and degree of fleshing is materially influenced by the sort of food fed. Even those breeds recognized as of the bacon type, kept and fed under the conditions of the corn belt, undergo a gradual evolution toward the type most popular in this country, losing to some extent the bacon-producing attributes. In connection with a consideration of this type it is to be borne in mind that the fattest specimens do not represent the best pigs. A pig may easily be made overfat. It would be in the interests of swine in general if judges at shows deprecated and turned down excessively fat animals and placed suitable emphasis on breeding stock or fat stock according to its purpose and merit.

The general appearance of the pig should be markedly compact and thick, involving shortness of head, broad back, strong hams, deep body, short legs, and plenty of quality, as shown in abundance and fineness of hair and strong bone and joints. The temperament should be mild yet active, for the disposition has much to do with determining whether the animal is a desirable 
breeder or feeder. Size or weight has a bearing on the market price, and pigs of this type, well fattened, weigh heavy for their age. As a rule the tendency of the breeders is to produce stock of large size, and "big type" is a common expression used among those promoting the leading breeds. A popular weight for nonbreeding stock on the market is about 225 pounds, which is not far from the average weight of the pig sold on the more important markets in the Mississippi Valley states.

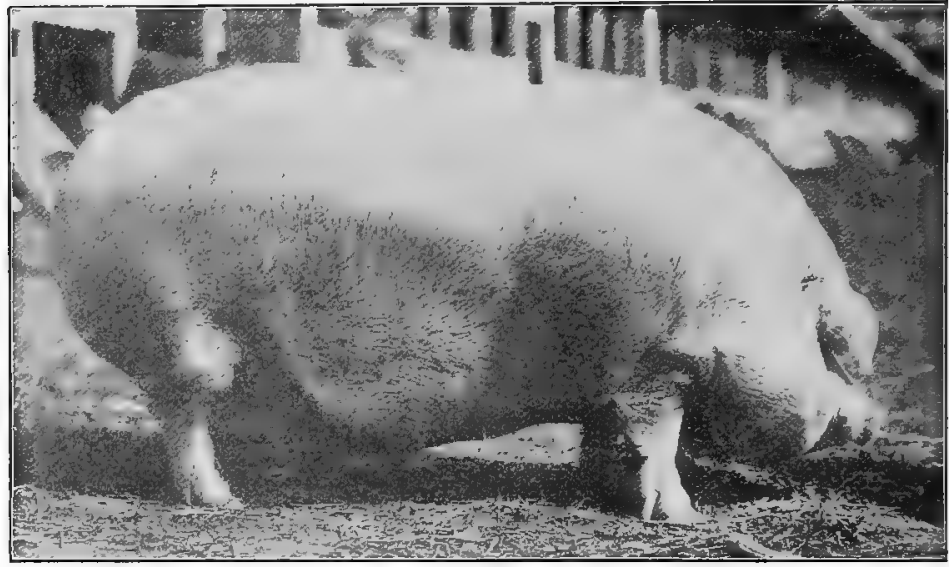

FIG. 323. A typical example of a lard type of hog, showing the short head, wide back, thick hams, deep body, and short legs. From photograph, by courtesy of the National Stockman and Farmer

The head should be comparatively short and wide in the forehead, without great length of snout. A very short snout is associated with the smaller sort of pigs, so that a medium length may not be regarded as undesirable. The end of the snout also should not be too pointed, but should be wide and strong. The space between the eyes should be wide and in fair proportion with the rest of the head. A prominent, clean eye is important, and excessive fat about the eyes is quite undesirable.

The ears should be placed well on the head, be neatly attached, and show refinement in quality of hair and texture. A large ear is undesirable, one of medium size and neatly pointed being preferred. A smooth, round jowl, full and firm, yet not heavily fat 
and flabby, is desirable. Wrinkles or seams on any part of the head are distinctly objectionable, as set forth on page 687.

The neck should not be long, but rather broad and short, with a smooth blending at head and shoulder. The tendency is toward a narrow neck on top; too much width or depth does not often occur.

The breast and chest indicate constitution. When the breast is wide and deep, the breast bone carried well forward, and the curve about the chest good and strong both above and below, plenty of room for the heart and lungs is shown. A narrow chest is inconsistent with vigorous development and good feeding qualities.

The shoulders should fit smoothly back into the body, showing no roughness or openness at the top. A smooth, broad, evenly fleshed shoulder on the fat pig is most desirable from the market point of view. The mature boar will show some thickness and heaviness of skin here at the "shields," - those parts inherited from the wild boar as a protection in fighting. It is objectionable, however, even with the boar, to have notable thickness of shoulder, as this is quite liable to be transmitted.

The front legs should show good position, superior bone, and shortness. Standing in natural position, viewed from in front, the legs should stand just under the shoulders, the knees straight, the toes directing forward, the entire position indicating easy posture. Pigs of narrow heart girth usually stand with the knees close together and are what is sometimes termed "knock-kneed." Viewed from one side the leg should come down true and plumb from the center of the shoulder, standing strong on the toes, with pasterns fairly erect and dew claws (the rudimentary toes on back of leg) well above the foot surface. A strong, wellsustained pastern is important. If the foot is weak and the pasterns badly depressed, the animal supports its weight poorly. A clean, smooth, hard bone, with strong yet not coarse joints, represents the better leg development. Too fine and small a bone is often seen with pigs when they really should have a heavier bone to support the weight properly.

The back and loin of the American type of pig in most favor is of medium length, has a strong arch from front to rear, the 
ribs are well sprung, and the loin is broad and thick. In the case of breeding stock the back may not appear wide, although feeding would soon give it considerable breadth. The width should be carried the entire length from shoulders to hips, offering excellent room for covering. As one views the back from front or rear, the width should be carried uniformly. A heaviness of front and lightness behind is not in good form, indicating heaviness of shoulder and lightness of loin. A view of the back from the side should show it somewhat arched and strongly carried. A droop of the back or a falling away behind the shoulders is quite common - evidences of a weak back and lack of constitution.

The hips, rump, and ham involve the highest-priced meat on the modern porker. The hips should be neatly placed and not prominent, and should be smoothly covered with flesh. The rump has a tendency to be droopy, with the tail set low, although good form calls for a long, broad, somewhat level rump, thickfleshed, with the tail neatly attached fairly well up. Below the rump the hams carry down fairly straight behind or with some outward curve, then rounding into the lower thigh and twist above the hocks. A high-class ham viewed from behind is notably thick, with considerable depth from the tail to the point where the hams join low down at the twist. From the side the relative length is long from the hip point to the lower corner of the ham, while considerable side breadth shows, with a strong, well-turned lower thigh and hock joint.

The hind legs in natural position should have strong hocks, wide and muscular, yet not fat, standing well apart when viewed from the rear, so that the legs appear quite plumb from that point. Viewed from the side, the hocks should seem deep and the legs below carried down straight, with the pig standing strong on the toes. All the features of quality, bone, and strength of position desirable in the front legs are equally desirable in the hind ones.

The sides from shoulder to hind flank and ham require a long, well-arched rib. This gives a body of ample digestive or breeding capacity. Not only should the sides be deep, but the lower part of the body in good formation will be wide, thus preserving a straight line from front to hind flank. Such a 
body as this, full and thick at the flanks, is associated with the animal of easy fattening tendency.

The fleshing and fattening quality of the pig is most important. If an animal is well fleshed the back and loin, sides, shoulders, rump, and hams will be uniformly covered with meat which will feel mellow yet firm and not harsh and hard to the touch of the hand. When fattened, the condition should be one of smoothness, with uniformity and depth of covering, and firmness of touch. The skin will be free of roughness or scurviness, and wrinkles will be quite lacking. This smoothness of covering is equally essential with the breeding or fat pig. Creases or seams are most common about the head, jowl, shoulders, and sides, and interfere with high-grade work in dressing the carcass at slaughter. In the modern packing-house the pig's carcass, after scalding, is scraped by mechanical device, and seams on the body necessitate more handwork to follow the automatic scraping, which naturally adds to the cost of preparing the carcass. In recent years much emphasis has been laid on the importance of smoothness and quality with pigs of all breeds.

The hair of the pig indicates quality. A reasonable degree of fineness is desirable, this being associated with animals that dress out well in killing. Large, coarse bristles go with heavy joints and much bone and offal. Curly hair is often seen on the pig, but straight coats are popular, while curly ones are not. The hair should not only be of good quality but also of a fair degree of abundance. Boars generally have heavier, stronger hair than sows, and it is much coarser and longer over the upper part of the spine than elsewhere. This is very marked in the wild boar.

The temperament of the lard type of pig is usually quiet and docile. Among individuals of the same breed those which flesh up most readily and respond best to feeding are those of the most quiet temperament. Even though a quiet temperament and good disposition are highly desirable, it is important that the pig be lively and active, ready to forage if necessary, and by its habits promoting vigor and health. It is doubtless true also that the American breeds of swine differ to some extent in disposition and easy-feeding quality. The Poland-China, for example, is notable for its quiet and phlegmatic habits. As feeding progresses 
and the animal enters the fat stage, there is a natural tendency to become sluggish and sleep a great deal. This results in lack of vigor and strength afoot. To avoid this, persons who fit hogs for the show ring compel the animals to exercise to a certain extent each day for some time prior to and during the show season. Some breeds, however, notably those of the bacon type, being of a more active temperament do not require special exercise.

The color of the pig is usually regarded as of secondary importance, excepting as an evidence of purity of breeding or trueness tc type. The color with some breeds, as the Chester White, jersey Red, Large Black, and Large White, is made apparent to the uninitiated by the name. In recent years color has become more and more a fad, so that breeders are not satisfied with irregularities in this respect. Color also has its relationship to climatic conditions. In warm, moist climates, white is an unpopular color for swine, associated as it often is with scurviness or sun scald. For that reason black or red pigs receive the preference under such climatic conditions. In the tropics the dark skin absorbs heat from the air more rapidly than does the white. The heat also radiates more quickly from the dark skin than the white, during which process a black animal cools off sooner than a white one. 


\section{CHAPTER LXVI}

\section{THE BERKSHIRE}

The native home of the Berkshire pig is in south-central England, and more especially the counties of Berks and Wilts. The neighboring counties of Leicester and Stafford also have been prominently associated with Berkshire history. The climate of this section of England is mildly temperate. The soil tends to be a clay loam and is cold and retentive. The standard crops of this section are the small grains, roots, and the grasses. Beautiful pastures are found in Berkshire, where there are lands that have not been plowed within the memory of man.

The foundation of the Berkshire breed is veiled in obscurity. In I 767 "A Country Gentleman " wrote ${ }^{1}$ as follows of English swine:

There are three sorts of swine commonly bred in England; the first I shall mention is the large Herefordshire, or as some would have it, Lincolnshire breed, which is the quickest grower, and ripens to the greatest size of any we know with us. ... Another sort, which is famous here, is called by some the Bantam breed, or the Guinea breed, or the African hog, or the black French hog. ... But the sort of swine most frequent in England, requiring the least care, and bringing the most profit, are the cross kind, bred between the two foregoing sorts.

No information of a descriptive nature in this work offers any evidence of the existence at that time of what might be termed a Berkshire breed. In I 789 George Culley, a noted English stockman, wrote in an often-quoted book ${ }^{2}$ :

The most numerous breed of hogs in this island is that excellent kind generally known by the name of the Berkshire pigs, now spread through almost every part of England and some places of Scotland. They are in general reddish brown, with black spots upon them, large ears hanging over their eyes, short-legged, small-boned, and exceedingly inclined to make readily fat.

1 The Complete Grazier (second edition), London.

2 Observation on Live Stock (second edition), Dublin. 
He also testifies to the large weight of the breed and mentions one referred to by Young weighing over I I 30 pounds, and to another still larger. Laurence, in I 790 , agrees with Culley excepting in bone, which he states was large, while he also adds that the muzzle turned up.

The first improvement of the native Berkshire pig was due to the use of Siamese or Chinese and Neapolitan blood. The habitat and some of the more characteristic features of these so-called breeds are described as follows by Low $^{1}$ and Youatt. ${ }^{2}$

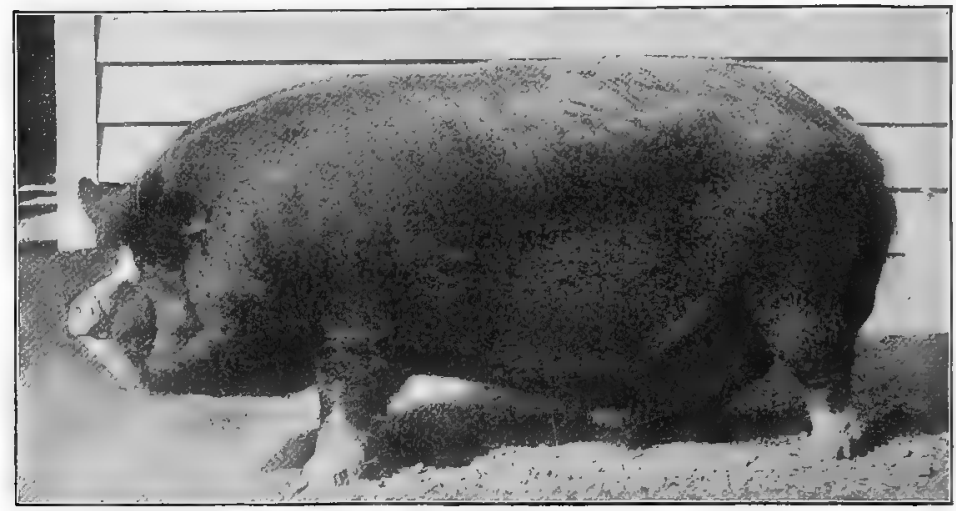

FIG. 324. Masterpiece 77000, second-prize Berkshire boar at the Louisiana Purchase Exposition, I9o. Sold by A. J. Lovejoy \& Son, Roscoe, Illinois, to W. S. Corsa of Illinois for $\$ 2500$. One of the greatest Berkshire sires. From photograph, by courtesy of Professor William Dietrich

The Siamese. Native to southeastern Asia, especially Siam, Cochin China, Cambodia, Malacca, and Burma, where hogs have long been domesticated. The name "Siamese breed," therefore, applies to extensive territory, including much more than Siam. Low states that the individuals are of small size, with cylindrical body, back somewhat hollow, and belly trailing near the ground in consequence of the shortness of limbs. The bristles are soft, approaching hair in character. The color is usually black, and the skin a rich copper tint. The ears are short, small, and somewhat erect. The Siamese pigs are less hardy and prolific than

1 Javid Low, Breeds of the Domestic Animals of the British Islands. London, 1842. 2 William Xouat, The Pig. Ihiladelphia, $1 S_{47}$. 
the native races of Europe. They mature early and fatten on a small amount of feed, and their flesh is white and delicate. Late in the eighteenth and early in the nineteenth century English and American writers frequently referred to Chinese swine, and these varied - some being white, others black; and some were known as Big China and others as just China or Chinese. In Great Britain the prevailing color was black, while in America China hogs were frequently white. It is presumable that there was more or less confusion in the use of the name and that Siamese and Chinese may mean one and the same thing. The important point, however, is that these pigs were fine of quality and fattened easily, making most desirable stock to cross with the coarse British hogs.

\section{The Neapolitan. Writing in 1842 , Low states :}

At the present time a breed from the country near Naples has been introduced and has been employed very extensively to cross other breeds. This breed is of small size and of a black color. It is nearly destitute of hair or bristles, but on being bred several times in their country, the bristles come. The flesh is exceedingly good, but the animals themselves are destitute of hardiness, and unsuited for general use. But they have been made to cross the other swine of the country, and the progeny exhibit much fineness of form and aptitude to fatten. Their flesh, too, is delicate, on which account the Neapolitan crosses are at the present time in considerable favor in several parts of England.

Thus, in the days when British shipping was bringing in hogs from Siam or China and from Italy, they were crossed upon the hogs of Berkshire, thus lessening them in size, reducing coarseness, and producing a finer quality of pork.

The older Berkshire type is of special interest to present-day students when we consider the typical Berkshire of to-day. The two leading early authorities describing this early type are Low and Youatt. Writing in 1840 , in his great edition de luxe, of the "Breeds of the Domestic Animals of the British Islands," Low says :

The true Berkshires are of the larger races of swine, though they fall short in size of some of the older breeds, as the Hampshire, the Rudgwick, and others. They are usually of a reddish brown color, with brown or black spots, a character which makes it appear that one of the means employed to improve them was a cross with the wild boar. The Berkshire has long been regarded 
as one of the superior breeds of England, combining size with sufficient aptitude to fatten, and being fitted for pork and bacon. It has been regarded also as the hardiest of the more improved breeds. The Berkshire breed has, like every other, been crossed and recrossed with the Chinese or Chinese crosses, so as to lessen the size of the animal, and render them more suited to the demand which has arisen for small and delicate pork. Many of the modern breed are nearly black, indicating their approach to the Siamese character, and sometimes they are black broken with white, showing the effects of the cross with the White Chinese. From this intermixture, it becomes in many cases difficult to recognize in the present race the characters of the true Berkshire.

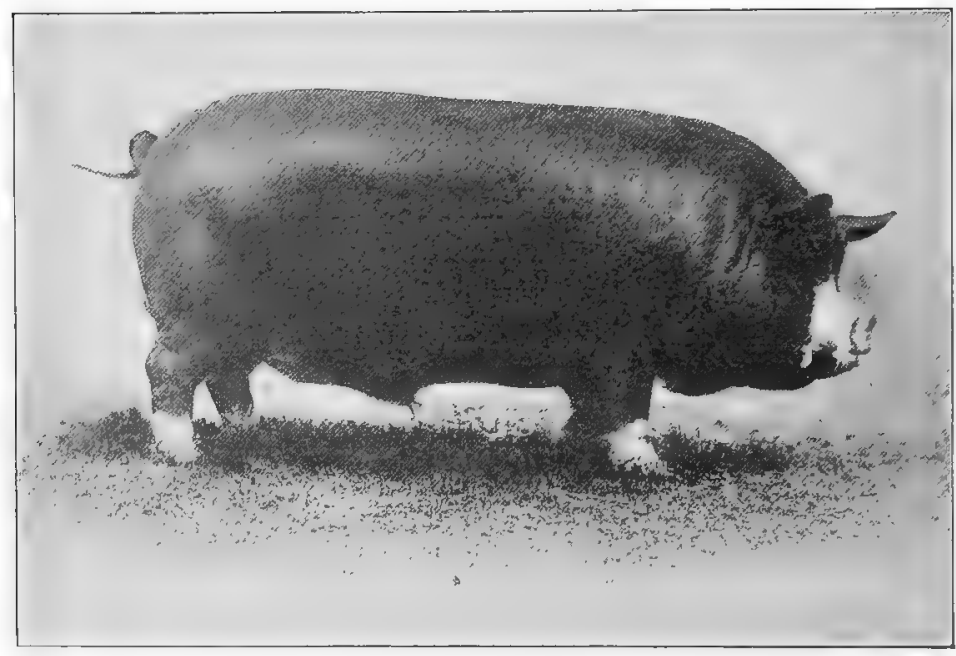

FIG. 325. Epochal 232232 (imp.), a Berkshire boar owned by the Gossard Breeding Estates, Martinsville, Indiana. Epochal has been widely advertised as a great sire, and his progeny have commanded large prices. From photograph, by courtesy of the Gossard Estates

Youatt, writing about this same time, ${ }^{1}$ says that they were sandy or whitish brown, spotted regularly with dark brown or black. The body was free of bristles and was covered with long, thin, and somewhat curly hair. The ears were erect and fringed with long hair, the head and snout were short, the body thick and compact, the legs short, the skin thin, the flesh of good flavor, and the bacon superior. At this time the breed was regarded as one of the best in England, due to early maturity, easy fattening,

1 The Pig. 1847 . 
small bone, hardiness, and the prolificacy of the females. Yet, according to various authorities, there must have been wide extremes in color, size, and type of the Berkshire in these formative days. In 1897 Sanders Spencer, in commenting on changes in swine, due to the breeder's art, wrote: ${ }^{1}$ "Take, for example, the style, character, formation, and color of a Berkshire pig, which was considered to be of correct type some forty years ago ; it bears but the very slightest resemblance in color, form, and character to the Berkshire pig of the present day." No one was better qualified to express this opinion than $\mathrm{Mr}$. Spencer.

Important early British improvers of the Berkshire were Richard Astley of Oldstonehall, whom Low notes as the great improver of the breed, and Lord Barrington, who died in 1829. In I 860, Sidney, a noted authority on swine, wrote that Lord Barrington did a great deal toward improving the Berkshire breed, the improved stock of that time nearly all tracing back to his herd. The methods of these two breeders, however, have not been given publicity, and very little is known concerning them. About the middle of the nineteenth century William Hewer of Sevenhampton, Wiltshire, was a noted breeder and improver. Closely following him came Russell Swanwick of the Royal Agricultural College at Cirencester and Heber Humfrey of Abingdon, both of whom did much for the breed in England.

The introduction of the Berkshire pig to America took place in I823, according to A. B. Allen, who credits John Brentnall, an English farmer, who settled in the English neighborhood in New Jersey, with this importation. In 1832 Sidney Hawes, another English farmer, brought some Berkshires to America and settled near Albany, New York. Allen states that he owned pigs descended from each of these importations. In I835 Munson Beach of Butler County, Ohio, purchased from New York the Berkshire boar Dick Johnson and the old sow Superior. These two individuals did much to establish the Berkshire in Ohio, Kentucky, Illinois, and Missouri. In I 839 Messrs. Bagg and Wait, English farmers who had settled in Orange County, New York, made a large importation, which they followed by still others. In I84I A. B. Allen of New York, after visiting England and

1 The Pig: Breeds and Management. 
carefully examining the herds of that country, imported over forty head. Later Allen imported more Berkshires and became a prominent promoter of the breed.

Characteristics of the Berkshire pig. The face of the Berkshire should be of medium length and gracefully dished; excessive dish is undesirable, as is a very short head, these two features as a rule being associated with the smaller, less growthy type of pig. The ears in the immature animal should be set wide. apart and carried strongly erect or point slightly forward; with age the ear

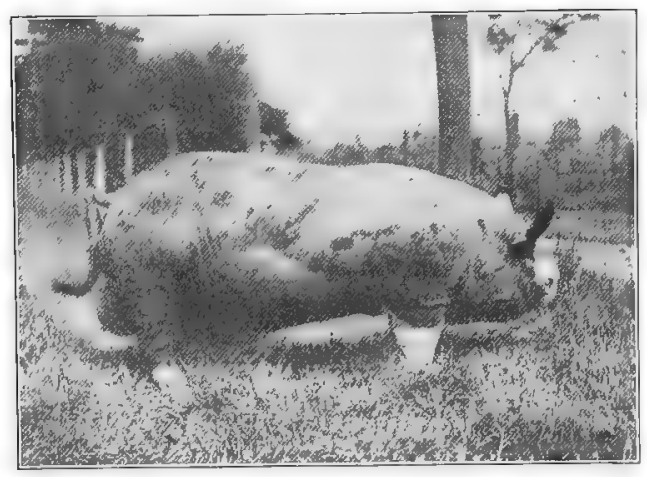

FIG. 326. Sensational Masterpiece 135260 , one of the great sons of Masterpiece 77000. Owned by H. V. Shulters, Mentor, Ohio. This shows a great boar in thin flesh on pasture. From photograph by the author frequently leans forward, but should never lop over the eyes. The typical Berkshire back is not so wide as Poland China or Chester White, but is of good breadth and carried with a slight arch. The body shows considerable length and depth of side and is deep and full at the front and hind flanks. The mump should be rather long, level, and wide, with the tail set high. In the approved type the entire back outline shows less arch than is characteristic of some of the other breeds. The jozel tends to be only moderately full, the shoulders of medium thickness and breadth, and the hams rather deep and full to the hocks, yet not notably thick and round, like a Poland China. The legs should be fairly short; individuals are frequently too leggy. The bone is of fair quality, and Berkshires stand moderately well on their feet.

The color of the Berkshire has already been given, as relates to the formative period of the breed. At the present time and in fact for many years the characteristic color of the body has been black. This has been illuminated by "six white points," the hair of the face, tail, and lower legs being more or less white. White 
frequently occurs also on the jowl or on the front arm or at the armpit, by the shoulder. This color need not occur in any exact degree, and if a white spot occur on the body elsewhere, there is no clause to disqualify in the "American Berkshire Herdbook." The color markings of English show Berkshires were studied by

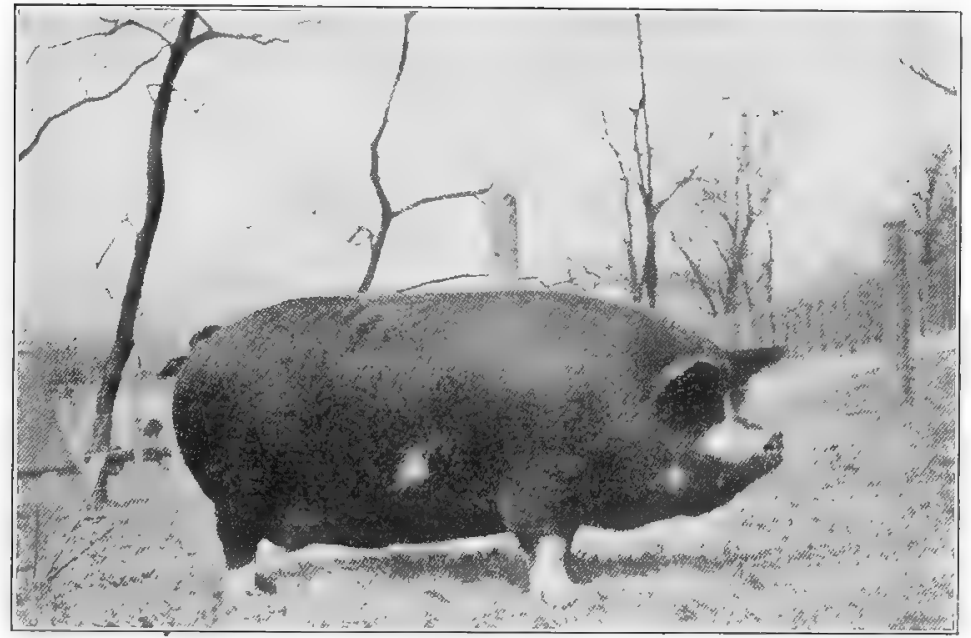

FIG. 327. Princess Bernice 8th II 2969, at one time owned by Sheffield Farm, Glendale, Ohio. This was a very fine sow, yet with irregular white markings, as may be seen. From photograph by the author

Heber Humfrey some years ago at the Royal Show at Windsor. Quoting from Mr. Humfrey's report:

We examined every Berkshire in the show. Taking them at all ages, there were I 39 animals. We took the generally accepted standard of "four white feet, white tip of tail, more or less white in face, and a little or not, as the case may be, under the jowl, on the point of the elbow, or inside the ear," and we found on looking through our notes that we had marked I I 9 down as within the limits of this standard. Only half a dozen were described as having serious defects in the marking; the remaining I 4 had only a single small spot, generally on the shoulder or between the ears; one or two were on the sides, but several of them not large enough to attract notice if we had not been looking for them. Out of the half dozen which we thought might be ruled out of competition, only one had a second objection: this was a spot on the front and another on the back of the ham; the second had a large sandy and white spot on the bottom of the shoulder; a third had a black foot; Nos. 4 and 5 had black tails, and the 6th a white ear. 
Occasionally pure-bred Berkshires are found in the herd that are irregular in color or markings. The author has seen a number of animals in service marked with white on the body where it is not expected to occur, and he has also seen on several occasions Berkshires with hair of a noticeable tint of red or copper color. This red tint in the hair is not an uncommon characteristic and is no doubt an inheritance from the early Berkshire parentage. In fact a breed of red Berkshires is credited to Kentucky, the red hair being a distinctive feature. If color is important in breed identification, then it should be reasonably uniform in character, and distinct irregularities should justify disqualification. In fact, in I 893 the British Berkshire Society suggested that judges disqualify pigs notably irregular in markings or with black face or foot.

The size of the Berkshire pig may by classed as medium to large. In 1842 Low wrote that "the true Berkshires are of the larger races of swine." In 1893 Professor Long wrote:

Thirty years ago... some of Mr. Sadler's prize pigs under seven months old weighed 240 pounds each, although they were turned out into an orchard daily while fattening. The same gentleman exhibited, and won the first prize at Baker Street with a fat pig which weighed 856 pounds, the length of her body being 6 feet 4 inches and her girth 7 feet 6 inches. At that time, however, the ordinary weight of a well-bred Berkshire bacon hog was, when ready for the butcher, about 50 stone of 8 pounds (400 pounds), but for the curing of the best hams these were generally considered a little too large.

The Berkshire is sometimes advertised under the name "Large English Berkshire," but in England only one Berkshire breed exists, and the title "Large English" is rather uncalled for and misleading. Young pigs at six months old should easily weigh I75 pounds and at one year about 300 pounds. The ordinary mature boar in breeding condition should weigh 500 pounds and sows 400 pounds. The British Berkshire Society gives the following as standard weights:1 "Berkshire sows at six months of age in ordinary growing condition, given proper exercise, weigh from i 50 to I6o pounds and boars from 160 to 170 pounds. Sows in breeding condition weigh from 400 to 500 pounds at one year of age and 550 to 650 pounds when full grown. Boars one year old have been known to weigh 600 pounds in show condition." The latter 
weights will impress many as quite extreme and rarely reached with one year's development. The following noted Bcrkshire boars have been credited with the weights given against their names: Longfellow 16835 at seventeen months, 726 pounds; Lord Premier 5000 I at seven years, 890 pounds ; Lord Premier's Successor I6I 500 weighed I 000 pounds in show form ; Sensational Masterpiece I35260 in show form, I000 pounds; Baron's Successor I97499, grand champion I9I6 International, 860 pounds ; King Lee 27500 at ten months, 420 pounds; Longfellow's Double 209000 three hundred and sixty-five days old, 507 pounds. One of the special needs of the present day is that Berkshires at maturity should show plenty of size and quality.

The Eerkshire as a grazing pig ranks high wherever fairly tried. On the clover fields of the Middle West they thrive to perfection, while rape pasture in the more northerly sections seems well suited

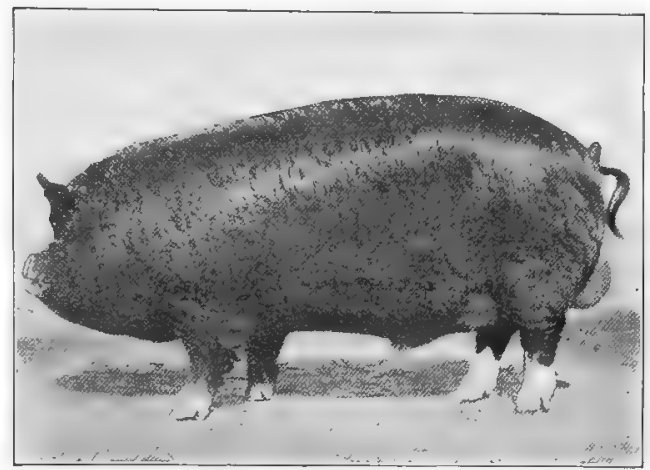

Fig. 328. Grand Leader 2d I90377, by Superbus I36000, grand-champion Berkshire boar at the Panama-Pacific Exposition, San Francisco, 19I 5. A notable recent-day sire, bred by W. A. Corsa, Whitehall, Illinois. Owned and exhibited by A. B. Humphrey, Mayhews, California. From photograph, by courtesy of the Berkshire World to them. In general pasturage in America, Berkshires hold theirown. Writing of the Berkshires as foragers, Walker states that they are hardly surpassed when grown in a temperate climate. He says:

You may see herds of a score or two each, any year towards October, running over the wide stubble fields on the borders of Wiltshire, nearly average pork, and yet they have made their growth and their flesh pretty much on waste material, that is, shed corn, weeds, roots, pasturage, and so on.

The Berkshire as a feeder has a very creditable record. A number of American agricultural experiment stations have conducted feeding trials in which breed comparison was a feature. In twenty-three trials, involving I23 Berkshires fed at eight 
institutions in the United States and Canada, it required 369 pounds of feed for each 100 pounds of gain in live weight, the Tamworth, Chester White, and Poland China surpassing the Berkshire in this respect. In breed tests at the Iowa Experiment Station the Berkshire made an average daily gain of .98 pound, the Poland China .90, and the Chester White .89 pound, the cost per 100 pounds' gain being $\$ 2.33, \$ 2.23$, and $\$ 2.46$ respectively. At the Ontario Agricultural College the average of trials for four years show almost identically the same daily gains, requiring a less amount of meal than any other breed; that is, $378 \frac{3}{4}$ pounds for 100 pounds of gain. At the Massachusetts Experiment Station 7 Berkshires, fed one hundred and forty days, made an average daily gain of $\mathrm{I} . \mathrm{I} 6$ pounds each, requiring 289 pounds of feed for 100 pounds of gain. From the records quoted above or published elsewhere it may be seen that the Berkshire as a feeder ranks well, though the average of breed trials do not give it first place. Among British authorities on swine Professor Long takes high rank, and in his "Book of the Pig" he writes of "its comparative slowness as a feeder" and says that it is generally found that a fast-feeding Berkshire has not only alien blood in its veins but that, when killed, it exhibits far too large a proportion of fat. At the International Live-Stock Exposition in past years most of the grand-champion carload lots of feeders have been pure-bred or high-grade Berkshires.

The maturing qualities of the Berkshire are not of the first rank. Individual animals of the breed may attain ample size and mature early, but as a breed the Berkshire is secondary in the capacity to mature early and yet reach a satisfactory weight. Without question many persons have discontinued breeding Berkshires on account of slow maturity and lack of size. The most successful Berkshire breeders of to-day are those who have produced a large type of pig which matured with fair rapidity, making satisfactory comparison with other breeds.

The adaptability of the Berkshire to a wide range of conditions is of the first class. The breed is found in special favor over much of the United States and Canada, irrespective of elevation or temperature. There are famous herds on the Atlantic and Pacific coasts, as well as in Canada and the gulf states of the 
South. Walker, however, in discussing the adaptability of the Berkshire to climate says: "As far as our own actual, experience goes, Berkshires do not prove nearly so profitable in the north of England and in Scotland as in the south, and this harmonizes with our remark that they love warmth and a genial clime." In spite of this opinion it is doubtless true that no breed of swine is bred and fed under more varied climatic and other conditions with the success that is attained with the Berkshire.

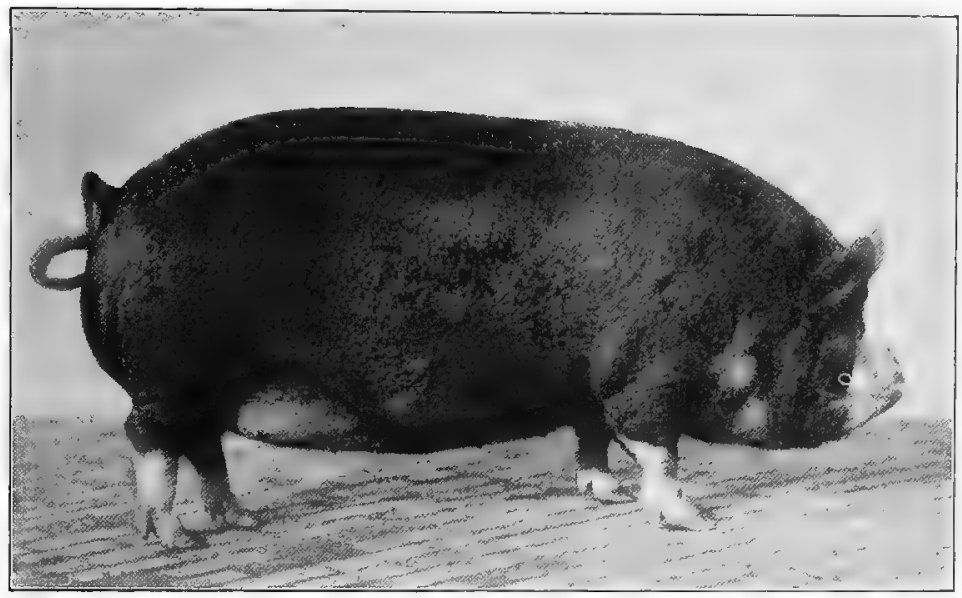

FI'G. 329. Double's Duchess 5 th 252585 , first-prize junior yearling and champion Berkshire female at the rgl 8 International Live-Stock Exposition. Bred and shown by Hood Farm, Lowell, Massachusetts. From photograph, by courtesy of the Berkshire World

The quality of Berkshire pork, viewed from the standpoint of the American market, is of the very best class. Fed in the same manner as the Poland-China, Chester White, and Duroc-Jersey, the Berkshire will show a class of meat with a larger percentage of lean than any of them. In feeding experiments conducted by the author at the Indiana Station, in a comparison of Berkshires, and Poland-Chinas bearing on the influence of food on carcass, the larger percentage of lean to fat in the Berkshire was strikingly shown. The meat of this breed has a fine grain and, when not all corn fed, a desirable blending of fat and lean. In certain localities where select sausages are made Berkshire pork has been 
relied upon for securing superior quality. Where properly fed this breed makes a bacon pig of high class, and is so regarded in Great Britain, though it may not be the equal of the Large Yorkshire or Tamworth in this respect.

In carcass contests at the International Live-Stock Exposition the Berkshire has won a high place. In I9I 7 the Berkshire not only was awarded grand-champion carcass but won more carcass prizes than any other breed. In 1916 the grand-champion carcass was a Berkshire. At the Smithfield Club shows in London, from I904 to I9I6 inclusive, Berkshire carcasses won all the championships, a remarkable showing. Not only this, but the first prizes in every class have been won every time by Berkshires, excepting on six occasions, and on two of these the winners were Berkshire crossbreds.

The crossbred or grade Berkshire, where fair samples of pigs are used in breeding, merit high praise. A cross of Berkshire boar on Poland-China sows produces offspring that feed rapidly and sell well, the two breeds blending admirably. This cross gives more vigor and a better feeder. Also a cross of the Berkshire on the Chester White female is productive of a better feeder than the sire, with a class of pork superior to that of the dam. The great value of the Berkshire in crossing is amply demonstrated from the fact that the blood of the breed has been used to improve that of other breeds for over a century, and no doubt has done much to help the most prominent breeds of to-day in their early stages. Sidney states that Fisher Hobbs, who did much in improving British pigs, used the Berkshire as a cross on his Essex pigs, and thereby size and condition were materially affected. In fact, so strong was the Berkshire influence that some twenty-eight years after the cross was made some of the young Essex reverted to their alien ancestor and were, in reality, exact types of the true Berkshire pig. Mr. W. H. Wykes, an experienced breeder, according to Long, finds that the best crosses are made by the Berkshire on the Black Suffolk and the Tamworth. The value of the Berkshire boar in grading up a herd is unquestioned. Feeders of such blood always command the top price in America and are purchased by discriminating buyers who recognize the place the well-finished feeder has in the market. 
The style and finish of the Berkshire, when well bred, are of the very best. The symmetrical outline, the shapely head and pricked-up ear, and the easy movement, so characteristic of the breed, add to its popularity. Persons not familiar with the breeds of swine are usually favorably impressed with the appearance of the Berkshire if well cared for and typical of the breed.

The prolificacy of the Berkshire is of a fair degree of merit. An extensive study of the relative prolificacy of three breeds

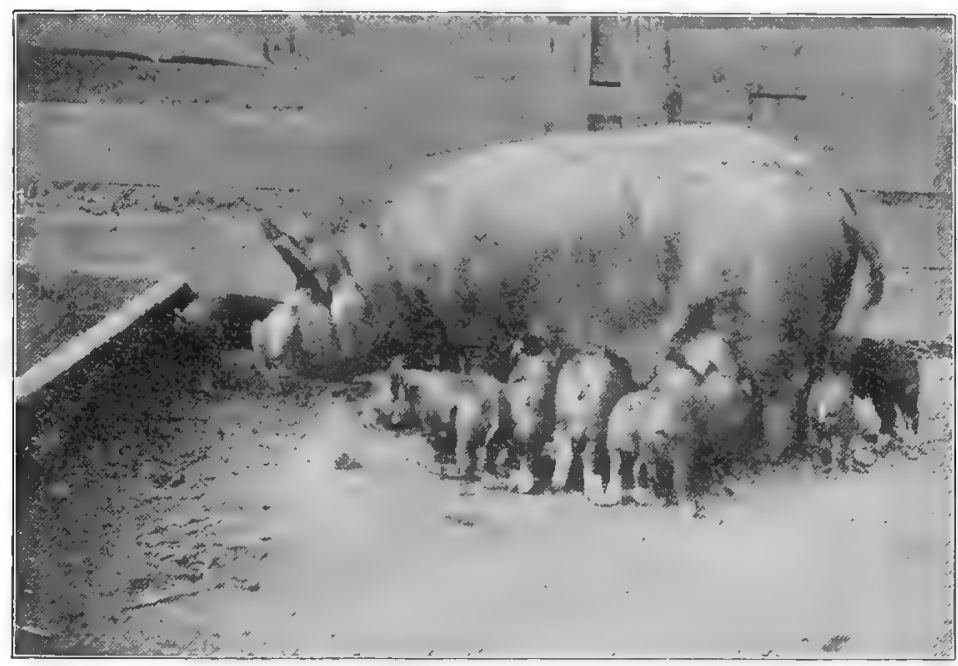

Fig. 330. A Berkshire sow and litter. Owned by Brookline Farm, Aurora, Illinois. From photograph, by courtesy of L. E. Troeger

of swine (the Berkshire, Poland-China, and Chester White) by Dr. A. W. Bitting shows that the average size of 400 Berkshire litters was 8.22 pigs, while 600 Chester W' hite litters averaged 8.96 pigs and I086 Poland-China litters averaged 7.45. These records were based on herdbook figures of sizes of litters. There are many large litters of Berkshire pigs, and litters of 10 are not uncommon. Walker states that about 7 or 8 at a farrow are reckoned an average family for even the older sows. William Ashcroft, a successful English breeder, is quoted by Professor Long as saying that the tendency to produce medium litters, of say 6 to 8 , may be corrected by breeding less closely. "If 
unrelated stock pigs are used," says Ashcroft, "the litters will come pretty regularly twice a year and average about 8 to I I." There are numerous instances of large litters of Berkshires. Among these the following by a firm claiming to be the largest breeders of Berkshires in America is of interest: ${ }^{1}$

We have a strain of sows we term Highwood Columbias. Sows of this strain in our herd have farrowed during March, I9I2, as follows: one sow farrowed 10 , the next one farrowed 14 , the next 13 . These latter two were yearlings. The next one farrowed $I 4$, which makes just $I 30$ pigs this sow has farrowed in ten consecutive litters; another farrowed 9 and another 18 . This last sow, farrowing 18 , farrowed I 5 her first litter, and she is a full sister of the sow that has farrowed 130 in ten litters. These sows have been selected and bred with this end in view, apparently with some success.

The Berkshire ranks very well as a producer of good-sized litters, and this more especially applies in regions where corn is not the important feature of the diet.

The prepotency of the Berkshire is of the first class. Being one of the oldest breeds, long bred with care, its prepotency has become well established. Compared with breeds of swine of American origin, this undoubtedly is more prepotent. When Berkshire males are used in crossing or grading, the dominant characteristics of the breed are reproduced with much uniformity.

Important Berkshire families. Among those especially worthy of note are the following: Duchess, of which Royal Duchess 900 , by Othello 259, is the founder; Sallie, descended from Sallie I, by Duke of Gloucester I; Charmer, descended from Royal Charmer 9082, by Exor 389I ; Lee, descended from Minnie Lee I 4606, by Exor 389 ; Nora, descended from Nora B. I 4052, by Liverpool Bob IO4I7; Artful Belle, descended from Artful Belle 24th 50023, by Baron Lee 4th 33446. Most of these foundation sows date back many years, and so we have subfamilies, offshoots from the above, that are more or less prominent.

Famous Berkshire boars in the history of the breed in America make up an extended list. Among those prominent mainly for their influence on the breed are Othello 259, Lord Liverpool 221 , Charmer's Duke I 3360, Longfellow I6835, Baron Lee IV 33446 , Lord Premier 50001, Governor Lee 47971, Combination 56028,

${ }^{1}$ H. C. and H. B. Harpending in National Stockman and Farner, May 2, 1912. 
Royal Windsor 22889, Model Duke 17397, Columbia's Duke 33855, Masterpiece 77000, Lord Premier's Successor I6 I 500, Superbus I 36000, Grand Leader 2d I 90377 , and Epochal 232232. Of the above Longfellow had far more influence on the breed than any other sire. Masterpiece also was one of the most famous of Berkshire sires. In recent years the breeding of Epochal has received much attention and special advertising.

\section{High prices for}

Berkshire pigs. In I 889 N. H. Gentry sold the yearling boar Model Duke I 7397 at private sale to Andrew Smith of California for $\$ 750$. Mr. Gentry paid $\$ 700$ for Lord Liverpool $22 \mathrm{I}$ in England. In the seventies Robin Hood 8oI was sold by T.S. Cooper of Pennsylvania for \$ I 400 . In I903 Mr. Gentry sold Lord Premier 5000 I to G. C. Council for \$I 500 . This boar died in I905, after which

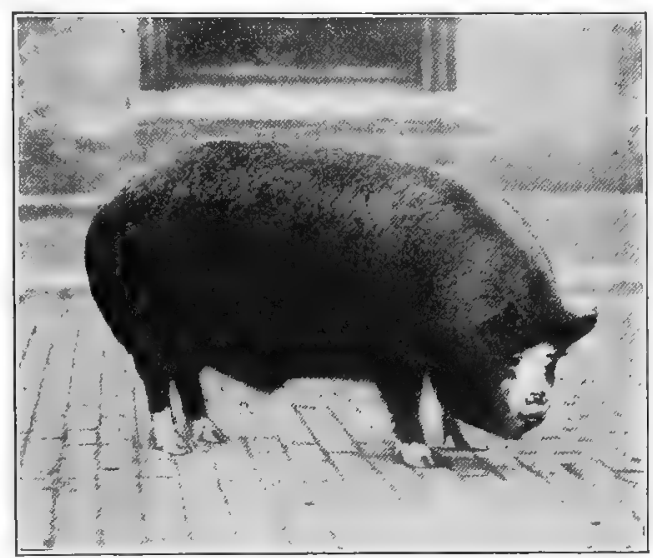

FIG. 33I. Baron Duke 5th, champion Berkshire barrow at the 19r6 International Live-Stock Exposition, and grand champion over all breeds, grades and crossbreds. Bred and exhibited by Sheffield Farm, Glendale, Ohio. From photograph by Hildebrand, by courtesy of Sheffield Farm

Mr. Council bought

Premier Longfellow 68600 of Mr. Gentry for $\$ 2000$. The grandchampion sow of the breed at the Louisiana Purchase Exposition, Duchess 279th 75009, was sold for $\$ 2000$ to Still \& Laughlin of Missouri. In 1905 A. J. Lovejoy of Illinois sold Masterpiece 77000 to W. S. Corsa of the same state for $\$ 2500$. In 1906 James Qurollo of Missouri sold to F. W. Morgan of Wisconsin the boar Lord Bacon 874I 5 for $\$ 3000$. In 1906, at a public sale of G. C. Council of Illinois, Lord Premier's Rival 92805 sold for $\$ 3200$ to I. L. Weirick of the same state. Star Value I I7336 sold by E. J. Barker of Indiana at private sale to Townshend Farms of Ohio for $\$ 4000$. Star Masterpiece 102000 sold at 
auction by W. S. Corsa for $\$ 5500$ to Kinloch Farm of Missouri. Rival's Lord Premier I I 3100 when six years old sold for $\$ 4050$. Epochal's Emancipator 250000 is reported by the Gossard Estate to have been sold by them in I9I 8 to Tom Stanton for $\$ 10,000$. Many Berkshires have changed hands at from $\$ 500$ to $\$$ IOOO per head. Seventeen daughters of Lord Premier are credited with having brought a total of $\$ 10,560$, or an average of $\$ 62$ I each.

The distribution of the Berkshire pig is very widespread. It is found in various parts of England, although more generally in the south section. It is also found to some extent in Scotland, Wales, and Ireland. On the continent of Europe the breed is not so common, although it has been more or less exported to various European countries. In the British provinces of Canada and Australasia the Berkshire is common. Between I905 and I9I6 there were issued 2272 export certificates by the British Berkshire Society, I ooo being for Argentina, I 48 for the United States, I 29 for Russia, 200 for South Africa, I63 for Brazil, and 94 for Germany. In the United States no breed is more widely distributed than this, and it is generally found all over the Union, although it is perhaps most common in New York, Peninsylvania, Ohio, Indiana, Illinois, Iowa, Missouri, Michigan, and:Wisconsin. In recent years Berkshires have attracted considerable attention on the Pacific coast, especially in California. In the South they have a great lead over other breeds as a popular favorite.

Organizations for the promotion of the Berkshire pig exist in England and the United States. The American Berkshire Swine Breeders' Association was organized in I875 at Springfield, Illinois, since which time to January, I9 8 , fifty-three herdbooks have been published, including the registration of 235,000 pigs. The National Berkshire Record Association was organized March I, I893, at Indianapolis, Indiana. This society up to I905 had published seven herdbooks, including the registration of about 9000 animals. This organization is now defunct. The "British Berkshire Herdbook," published by the British Berkshire Society, first appeared in I885, since which time, up to I9I9, thirty-five volumes have thus far appeared, registering about 21,000 animals. 


\section{CHAPTER LXVII}

\section{THE DUROC-JERSEY}

Red, or sandy-colored, pigs have been bred in America for very many years. When pigs of this color were first imported is not recorded. A number of so-called breeds of red pigs were kept early in the last century, and from these it has been assumed the present-day red American pig, the Duroc-Jersey, is descended. One well-known breeder of red hogs in New Jersey, in a circular published about I9I 3, states that "a century ago the Jersey Red was known as the hog native to New Jersey."

The Guinea breed of pigs is frequently referred to in agricultural writings of a half century or more ago. In that section of western Africa known as Guinea, slave-trading ships secured cargoes for American ports. Here existed a red, or sandy, breed of swine, which no doubt found its way to our shores. Youatt states that these pigs were "large in size, square in form, of a reddish color, the body covered with short, bristly hair, and smoother and more shiny than almost any other variety of the porcine race." W. H. Montgomery in 1852 wrote that the Red Guinea hog was imported into his county in Iowa in I 849 from Steuben County, New York. A correspondent of the American Famer states that the African, or Guinea, breed was brought to America as early as 1804 or possibly earlier.

The Portuguese breed of pigs was imported from Portugal by Daniel Webster, about I 852, for his farm in Massachusetts. They arrived at New York about the time of Webster's death, and his heirs disposed of them to S. IV. Jewett of Middlebury, Vermont, and A. E. Beach of New L'ork. They were dark red in color, and in form resembled the Chinese pig. Red pigs from the Webster importation and ancestry were distributed over several states east and south.

Spanish red pigs were imported by Henry Clay in 1837 , four in number, and taken to his farm, Ashland, at Lexington, Kentucky, 
where they bred and successfully increased. This stock met with favor and was considerably distributed south, notably in Kentucky and Virginia. These had erect ears and were of a red color.

The Berkshire as a source of red swine early occupied a place of prominence. Writings relating to swine prior to I 875 commonly refer to the more or less red color of this breed. Undoubtedly numerous red, or sandy-colored, Berkshires were imported to America many years ago. In view of the generally accepted

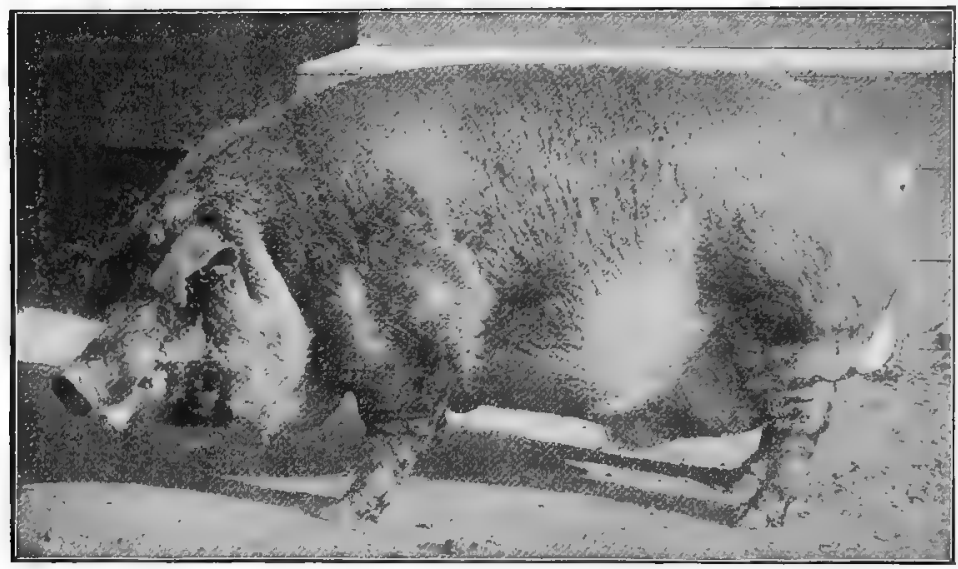

FIG. 332. Ohio Chief 8727 a, first-prize aged Duroc-Jersey boar at the Louisiana Purchase Exposition, I904. One of the great sires of the breed. Bred and exhibited by S. E. Morton \& Co., Camden, Ohio. From photograph, by courtesy of Professor William Dietrich

prevalence of sandy-haired Berkshires early in the last century, and their considerable use in crossing on other breeds, it would not seem unreasonable to believe that the Duroc-Jersey inherited its color to some degree from the Berkshire.

The Jersey Red breed of pigs was for many years a favorite one in New Jersey and the East. They were very large and coarse, weights of 500 to 600 pounds being common, with specimens exceeding Iooo pounds. In reporting on this breed to the National Swine Breeders' Convention in I872, Colonel F. D. Curtis stated that D. M. Brown of Windsor, New Jersey, had known of them back to nearly I832. In neighborhoods they were bred very 
uniformly, the color usually being a dark red, although in some sections they were light sandy, and often "patched with white."

The characteristics of the Jersey Red as agreed upon by the National Swine Breeders' Convention in 1872 were as follows:

A good specimen of a Jersey Red should be red in color, with a snout of moderate length, large lop ears, small head in proportion to size and length of body. They should be long in the body, standing high and rangy on their legs ; bone coarse, hairy tail and brush, and hair coarse, inclining to bristles on the back. They are valuable on account of their size and strong constitution and capacity for growth. They are not subject to mange.

It is said ${ }^{1}$ that the breed was first named Jersey Reds in 1857 by Joseph B. Lyman, then agricultural editor of the Nezu York Tribune. Previous to this period they had been commonly called Red hogs and Durocs.

In August, I 880, a writer in the National Live Stock Journal refers to "Jersey Reds or Durocs" as sandy or yellowish-red hogs with black spots, large of size, but not very uniform of appearance, and probably mainly derived from some of the earlier importations of Berkshire swine of this color. "In fact they bear a close resemblance, so far as they have a uniformity of type at all, to the large Berkshire of fifty years ago." A letter received in I9I 3 from a man prominent in live-stock affairs in New Jersey contains the following statement:

There exists among certain swine growers a relative of the old Jersey Red breed of swine. They are quite characteristic of the old type of hog that is described as the predominating type of this breed, but unfortunately we do not have very many breeders that have attempted to modernize and continually improve the type. They are much smaller than the prevailing type in the corn belt of the Duroc-Jerseys, evidence less quality and finish, are somewhat darker in color, and require a longer feeding period than prevails generally in the corn belt.

The Duroc breed of red pigs is said to have been established by Isaac Frink of Milton, Saratoga Courity, New York. In 1823 he obtained a red boar pig from a litter of ten, the product of a pair of red pigs purchased in 1822 by Harry Kelsey of Florida, New York, from persons either at Oyster Bay, Queens County, New

1 Robert J. Evans, History of the Duroc. Chicago, 1918. 
York, or imported from England, concerning which point there is doubt. Mr. Kelsey owned the famous stallion Duroc, and the pigs in question were known simply as red pigs. Mr. Frink called his boar and descendants Durocs, in honor of the horse. This boar was crossed on common sows, and many of the offspring resembled him, being long and deep of body, lop-eared, heavy of shoulder and ham, quiet of disposition, and making rapid growth. The Durocs were finer in bone and carcass than the Jersey Reds. In I830 William Ensign of Stillwater, Saratoga County, secured a

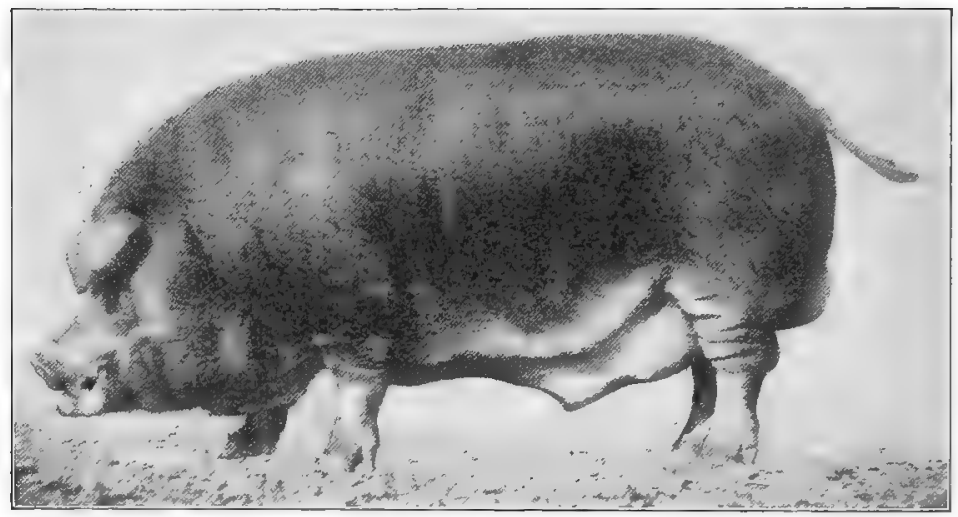

FIG. 333. Orion Chief I3333, a champion Duroc-Jersey boar at the Louisiana Purchase Exposition. A great sire of brood sows. Bred by Ira Jackson of Ohio, and sold to Thomas Johnson, Columbus, Ohio, for $\$ 3500$. From photograph, by courtesy of the National Stockman and Farmer

pair of red pigs from Connecticut, where they were known as Red Berkshires. The following year he purchased still more, and from then on for some years was an active breeder and distributor of Durocs: The Frink and Ensign families of Durocs became very popular.

The origin of the Duroc-Jersey pig is the result of the amalgamation of the blood of these early red breeds or families. Colonel F. D. Curtis of Saratoga County, New York, long a breeder and familiar with existing conditions, did much to promote improvement of this breed during the stage of amalgamation. Mr. IVilliam H. Holmes also was a leading breeder and improver in Colonel Curtis's time. The Durocs of New York, the 
Red Berkshires of Connecticut, and the Red Rocks of Vermont, as they were called, were of the same general type. Some system in breeding was attempted, and in 1877 the breeders of Washington and Saratoga Counties in New York met and decided what the characteristics of the best type of this red pig should be. This standard, which was published in the agricultural press, was the first thing of the kind printed regarding red pigs and was essentially the one adopted by the National Swine Breeders' Convention at Indianapolis in 1872. In 1885 Colonel Curtis wrote that the breeders of the so-called Red Berkshire and Red Rocks cordially united with the New York men, and the Duroc-Jersey standard was universally accepted by the best breeders of all the red hogs of America.

The improvement of the Duroc-Jersey began with the union of the breeders' interests. It resulted in a pig of some less scale than the Jersey Red, lacking its coarseness, having a better quality of flesh, feeding easier, and maturing more readily at a younger age. Instead of developing a big hog, one of medium scale was regarded as preferable. The standard of the old type of Berkshire closely resembled the Duroc-Jersey as late as I880. Since then the Berkshire has perhaps become more refined than before, and for some time the Duroc-Jersey showed evidences of a similar improvement. However, realizing that much criticism was being directed by swine raisers at excessive refinement, especially in the case of the Poland-China, Duroc-Jersey breeders began to emphasize size and bone, not losing sight of quality. This improvement perhaps dates from the year I900, since which time the breed has made marked progress. In fact, no other breed as a whole has made so pronounced improvement in recent years as has the Duroc-Jersey.

Characteristics of the Duroc-Jersey. The head is of medium size, though with young boars it sometimes appears somewhat long. The face is either straight or slightly dished, the nose of medium size and length, and the forehead of fair width. Duroc breeders emphasize large, well-placed eyes and clearness of vision. The ears are of medium size, moderately thin, and, according to the official scale of points, "pointing forward and downward and slightly outward, carrying a slight curve." The fact is the ear 
should break over at its top third, with a tendency to carry the lower two thirds somewhat erect. The back of the approved type has considerable length and exhibits a somewhat strong arch. With maturity the body shows much depth, but immature animals often appear shallow bodied and long of leg; however, from this conformation comes the big type of Duroc-Jersey that in I9I9 was in such great favor - the short, deep-bodied, short-legged pig

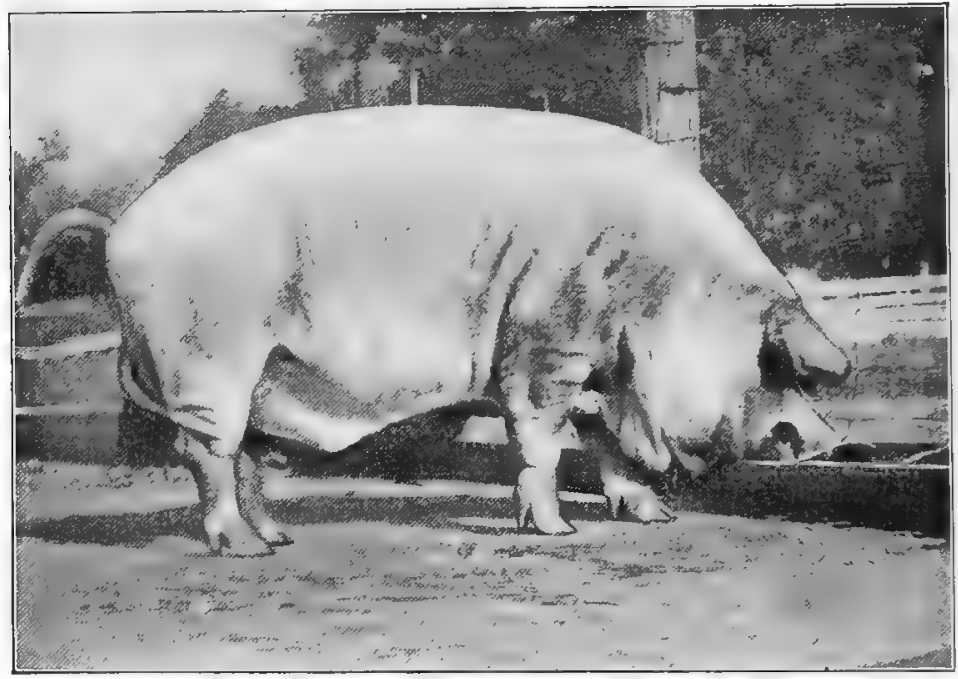

Fig. 334. Orion Cherry King 42475, perhaps the most noted Duroc-Jersey sire of recent years. Bred and owned by Ira Jackson, Tippecanoe City, Ohio. From photograph by the author. The light color shown is largely due to the picture's being taken when this boar had a very thin coat of hair

never attains the large size valued by the best breeders. The ham of the Duroc-Jersey tends to be long from the top of the rump to the hocks, but frequently lacks the fullness or thickness of lower thigh and twist so characteristic of the Poland-China. The bone and pastern in times past have been rather deficient, but in recent years this trouble has been largely overcome, so that now no breed is superior to the Duroc-Jersey in this respect. Students of the breed should recognize the existence of two types - the medium and the big, with the latter meeting with far more favor from the worth-while critics and breeders. Another feature much emphasized 
among Duroc breeders is that of smoothness and quality. At the opening of the present century the Duroc-Jersey pig tended to be markedly rough, heavy at the shoulders, and too frequently marked with seams or creases on the head, shoulders, and sides. These defects have been largely removed through selection of breeding stock showing smoothness and quality.

The color of the Duroc-Jersey pig is red, although the shades vary from light to dark. A medium cherry red is the most popular color, but there is no discrimination against a lighter or darker shade. One unpopular color sometimes seen, though not subject to disqualification, is a more or less dark shade of chestnut. Young pigs may have a bright color, but with age the shade may turn; especially is this so with a chestnut tint. Among the official objections on color are "very dark red or shady brown; very light or pale red; black spots over the body; and black flecks on the belly and legs." One of the most noted boars of the breed, costing a large sum of money, had a tendency to sire pigs that possessed small black spots in the skin to such an extent as seriously to injure his standing among breeders familiar with the facts. His value was so depreciated as to lead his purchaser to discontinue his use.

The size of the Duroc-Jersey is somewhat variable and, as has already been stated, at maturity we have essentially two types the medium and the big type, the latter being the result of more recent development within the breed. The following are given as official weights of Duroc-Jersey pigs at different ages, as adopted by both American and National Associations: Boars two years old or over should weigh 600 pounds and sows of the same age and condition 500 pounds; boars eighteen months old should weigh 475 pounds and sows 400 pounds; boars twelve months old 350 pounds and sows 300 pounds; while for boars and pigs six months of age I 50 pounds is standard weight. Many large animals of the breed are found to-day, and much emphasis is placed on half-ton boars in the breed advertising, a weight rarely attained. Ohio Chief 8727 a, a very noted show boar and sire in his day, according to S. E. Morton, who owned him, could easily have been fitted to weigh over Iooo pounds. In the January I, I9 I8, Duroc Bulletin advertising, the following weights are credited: John's 
Combination $65055 \mathrm{a}^{1}$ (a boar), IOIO pounds; John's Orion 42853 a (a boar), IO40 pounds; Sensation Queen 196494 (a sow, grand champion at Iowa and Nebraska State fairs in 1917), Soo pounds; Chief Invincible I $77825 \mathrm{n}$ (a boar), Io Grand Model 8th I63999 n (a boar), Iooo pounds; Advance Defender 79097 a (a boar), rooo pounds; and Critic D I68503n (a boar), at twelve months 510 pounds while in active service. Referring to Duroc-Jersey size, Fred Devore makes the following

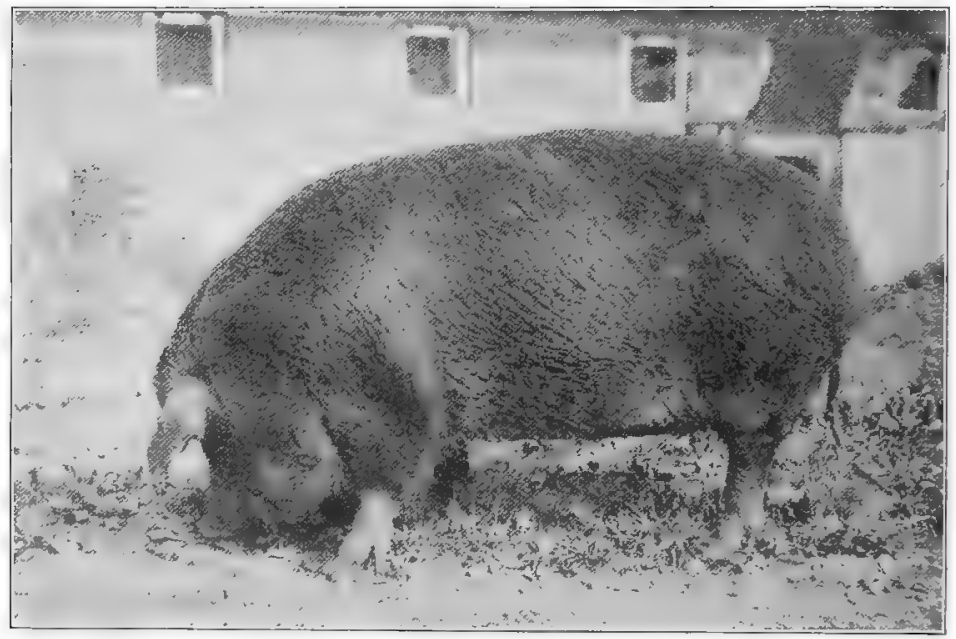

Fig. 335. Brookwater Lass D 218148, bred by Professor H. W. Mumford, Ann Arbor, Michigan; sold for $\$ 2200$ to Thomas Johnson of Ohio in the International

Duroc-Jersey sow sale, December 3, 1918. From photograph by E. K. Emslie

comment:" "I have always maintained that we must have big type Durocs, and that means 9oo-pound mature boars, 700-pound mature sows, and a yearling that can be made to weigh 500 pounds if you want him to do it. But never lose sight of feeding quality or the feet and legs to carry him."

The Duroc-Jersey as a grazer seems suited to such pasture as other breeds will do well on, and for this reason is a favorite to-day with many farmers. On blue grass, clover, and alfalfa it thrives

1 The letter "a" after the number signifies registry in the American DurocJersey Association, while " $n$ " stands for the National Association.

2 Duroc Bulletin, March I5, Igr7. 
well. The breed is getting a good foothold in the South, where it seems quite adapted to cowpeas and velvet beans as pasture crops.

The Duroc-Jersey as a feeder holds its own with other breeds. It has grown greatly in popularity for the feed lot, and this is clearly shown by the remarkable increase in red hogs in the big stockyards of the Middle West. Most of the feeding experiments in which breeds are compared have been rather to the disadvantage of the Duroc-Jersey, but in spite of this it seems to be the

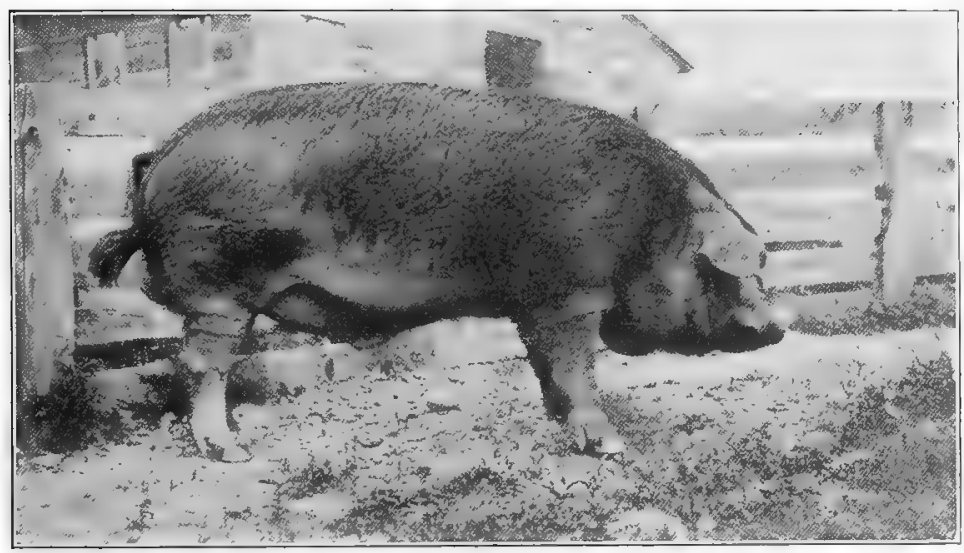

FIG. 336. Sky Pilot 121715 a,-a yearling Duroc-Jersey boar of the big type, farrowed in 1917 and purchased by Thomas Johnson for service in the Oakland herd. From photograph by the author

opinion among investigators that there is essentially no material difference in the lard-type breeds in feeding value. At the Iowa Experiment Station, on low-priced feed, the cost of producing Ioo pounds live weight with the Duroc-Jersey is given at the very low figure of $\$ 2.27$. In the experience of the writer with this breed during the past ten years the Duroc makes a strictly first-class showing.

The maturing qualities of the Duroc-Jersey are distinctly high class. Pigs easily mature at six months of age to dress out I 75 pounds. At the Iowa Agricultural Experiment Station 19 pigs at an average of two hundred and fourteen days weighed an average of 197 pounds. These are not unusual records and are such as may be secured by any competent feeder with fair representatives 
of the breed. In the experience of the writer in which the DurocJersey has been under observation along with other breeds during the past twenty-five years, it has attained a greater size of the same age than any other breed excepting the Large Yorkshire. It may not mature or finish off so quickly as the Poland-China or Chester White, but it will attain a most satisfactory weight for the age, which is not always the case with other breeds.

The quality of Duroc-Jersey pork in time past has been subject to unfavorable comment. Twenty-five years ago this was an unpopular breed with the packers, their reasons being that there was too much waste in killing and the fat was too soft and oily. However, the breed has been so improved that this criticism no longer prevails. In slaughter tests, however, the Duroc-Jersey has not attained so high a place as the Berkshire, Poland-China, or Chester White. In carcass studies in breed tests at the Iowa Station, the Duroc-Jersey yielded less lard than any other breed except the Chester White. There was a total of 20.35 pounds of lard and more total guts than any other breed excepting the Berkshire, though the difference was not great. In killing, the Yorkshire led with 79.18 per cent dressed meat, while the Duroc-Jersey was fifth, with 77.05 per cent. In the carcass contest at the International Live-Stock Exposition there have been but few entries of the Duroc-Jersey, and while the breed has won no championship, it has made some creditable records. In I 908 the first-prize heavy carcass was of a Duroc-Jersey, weighing 466 pounds cold, that dressed out 89.6 per cent, the highest dressing of the prize-winning carcasses. This same year the first-prize light-weight carcass was of a DurocJersey dressing out 88.6 per cent. In I9IO second place was awarded in both medium and light-weight carcasses, the former dressing out 83.2 per cent and the latter $8 \mathrm{I} .8$ per cent.

The crossbred or grade Duroc-Jersey pig is to-day a common sight in the markets of the great corn-producing section of the Mississippi Valley. Duroc-Jersey boars are now widely used in herds where grade sows are the rule, and pigs of such breeding feed well, tend to good size while growing, and mature early. Crossed on any of the lard breeds, satisfactory results may be expected, although the Poland-China and Berkshire nick especially well with the Duroc-Jersey. The use of the Berkshire male on 
the Duroc-Jersey sows is commended rather than otherwise, for it will result in superior meat, and the litters may also be somewhat larger from this union. In I9 I6 the Ohio State University showed some barrows of this cross at the International Live-Stock Exposition, which not only won first and second in class on foot but also first and second in the carcass contest, having carcasses of unusual excellence in smoothness, quality, condition of flesh, fat, and color.

The adaptability of the Duroc-Jersey to a range of conditions is above the average. It has established itself strongly in the favor of the feeder of the corn belt, where the climatic and food conditions are especially favorable to swine husbandry. In the warm climate of the southern United States the breed has rapidly grown in favor, not seeming to be affected by the dry, warm summers, especially as regards skin troubles. In Canada the Duroc-Jersey has but a small foothold, due to the popularity of the bacon hog.

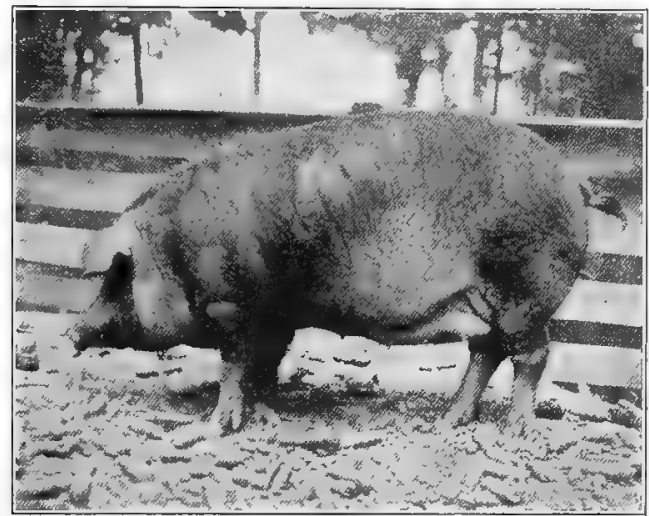

FIG. 337. A Duroc-Jersey yearling sow of much excellence bred by Thomas Johnson, Columbus, Ohio. From photograph by the author

The prolificacy of the Duroc-Jersey pig is of the first class. Twenty years ago Colonel Curtis wrote that young sows had from 7 to Io pigs and old sows from Io to I 8 , while I 2 and I 4 strong pigs at one litter were not at all uncommon. Rommel, in a report on Duroc-Jersey fecundity, published in I906, based on herdbook figures, shows that 21,652 litters, comprising 200,574 pigs, averaged 9.26 pigs per litter. This is a most excellent record and reflects great credit on the prolificacy of this breed. There are many individual cases of sows producing large litters, of which the two following are examples: Sunny Side Fancy 46726 in I910 farrowed I9 pigs, I 7 of which she cared for. A writer in the Ohio Famer, in I9I0, reported on a pure-bred Duroc-Jersey sow of his 
farrowing I 2 pigs in her first litter, I 4 in her second, and 2 I in her third, the last being a remarkable number for a sow of any breed.

The prepotency of the Duroc-Jersey may be regarded as about average. Males show a fair amount of prepotency when mated to grade sows, but the breed cannot be regarded the equal of either the Large Yorkshire or Berkshire in this respect. In the crossing of the Duroc-Jersey with the Poland-China or Chester White, one breed will not have any special advantage over the other, although some individuals will naturally be more prepotent than others.

Families of Duroc-Jersey pigs that have attained special distinction are comparatively modern. These trace from both boars and sows of fame. A few of the best-known and most popular families are the Colonel, descending from Colonel M $3285 \mathrm{a}$, farrowed in I $89 \mathrm{I}$; the Ohio Chief, descended from Ohio Chief 8727 a, farrowed in I900; the Orion, descended from Orion $490 \mathrm{I}$ a, farrowed in I 895 ; the Golden Model, descendedfrom Golden Model 53675 n, farrowed in 1906 ; the Golden Rule, descended from Golden Rule I 4 IOI a, farrowed in 1904 ; the Crimson Wonder, descended from Crimson Wonder $26355 \mathrm{n}$, farrowed in 1903 ; the Duchess, descended from Duchess II 5932 a, farrowed in I887; and the Lucy Wonder, descended from Lucy Wonder 6334 a, farrowed in I889. These family names, with the exception of the last two, are credited to males of which those of most prepotency are given first recognition in this list. In fact the Colonel and Orion families have attained a great degree of popularity among Duroc-Jersey breeders. Breeders thus far, however, have not lost their balance in following lines of breeding, so that prominent families of the breed really stand for the greatest vigor and productive value.

Duroc-Jersey pigs of distinction first became prominent with the appearance of the breed at the important exhibitions, notably in the early eighties. Among the prominent show and breeding boars between I880 and I 885 were Major I7, Climax 2I, Phil D I67, Richard III I8I, John Jordan 297, and King Stoner I65 I. Of the sows of that period the following may be mentioned: Holmes Ruby 70, Lulu 76, Bess III 82, Mona II 90, Mojeska 96, Bessie I0O, Valleria 200, Lou Edna 226, and Red Stumpy 926. Following these sires and dams may be mentioned Hoosier King 3205 a, Colonel M 3285 a, Protection 4697 a, Orion 4901 a, 
Walts Colonel 5795 a, Ohio Chief 8727 a, Top-Notcher 8803 a, and King of Kings rogr9. Among the many more recent DurocJerseys celebrated as sires are Orion Chief 13333 a, Golden Rule I4 IOI a, Cherry Chief 2I 333 a, Tippy Colonel 22567 a, Good-LNuff 22437 a, Proud Advance 23549 n, Defender 25893 a, Fancy Colonel 27427 a, Pals Colonel 29167 a, The Professor 35475 a, Joe Orion II 35527 a, Crimson Wonder Again 40785 n, and Orion Cherry King 42475 a. A few of the famous dams are Cherry Vale Queen I 8468 a, Duchess 40th I 8958 a, Lucy D 2 d I 8 I 06 n, Love 35060a, Cherry Queen T 100466, and H. A's Queen 143382 n.

\section{Prices paid for} Duroc-Jersey pigs have risen to high figures in recent years. Some of the notable sales of individual boars are as follows: in Igo5 S. E. Morton \& Company of Ohio sold to R. I. Harding and $\mathrm{O}$. E. Osborn of Iowa the famous boar Ohio Chief 8727 a for $\$ 2000$. Later they sold a third

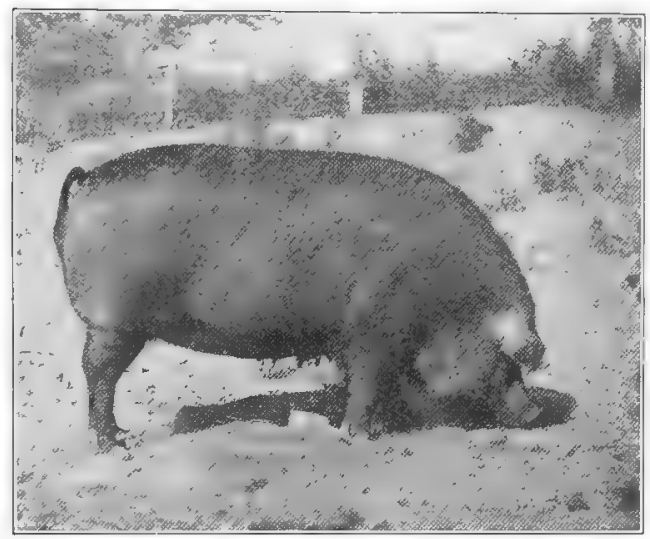

FIG. 338. A Duroc-Jersey gilt of superior conformation and quality, bred by Sears \& Nichols of Ohio. From photograph by the author interest in him to J. M. Morrison of Nebraska for the same sum. At a sale held during the winter of 1907-1908 the sow Savannah Belle, with a litter sired by Ohio Chief, sold for $\$ 3300$. On February 6, I907, E. A. Baxter sold to McNeil Brothers, at public auction, the hog Buddy K IV 2086 I a for $\$ 5025$, the highest price at public sale up to I9I9 for a Duroc-Jersey boar; in 1908 Ira Jackson sold Orion Chief I 3333 a to Thomas Johnson for $\$ 3500$; in I9I I Superba 3 I 403 a was sold by H. E. Browning to East Brothers and Ewing for $\$ 500$; in 1915 Royal King 56047 a was sold by Ira Jackson to Johnson Brothers for \$2650; in I9I $5 \mathrm{Hugh}$ Stewart sold Colonel S Jr. 43869 a to Thomas Johnson for \$2500; and in Igr 8 Charles F. Sprague sold Joe Orion II 35527 a, 
at eight years of age, to Enoch Farms for $\$ 5000$. The climax on high prices with the Duroc-Jersey took place in August, I919, when Ira Jackson of Ohio sold at private sale to $\mathrm{H}$. L. White, Columbia, Mississippi, the boar Jackson's Orion King I 34009 for $\$ 3 \mathrm{I}, 000$, the top price for a Duroc-Jersey. There have been many public sales in which the average price paid was very high. In November, I9I r, at the sale of H. E. Browning of Illinois, 35 head sold for an average price of $\$ 303.65$. At a sale held at the International Iive-Stock Exposition in December, 1918, Professor H. W. Mumford, owner of Brookwater Farm herd of Michigan, sold 55 head for an average of $\$ 428$, the top price for a sow being $\$ 2225$. In February, I919, at the sale of Ira Jackson of Ohio, 54 sows averaged \$IOI8, and I boar, Jack’s Top King I 2372 I a, by Orion Cherry King, sold to J. B. Goodbar, Forest Hill, Tennessee, for \$IO,500. The highest-priced sow sold for $\$ 3500$ and the lowest for $\$ 500$.

The distribution of the Duroc-Jersey is now very widespread. It has attained its greatest popularity in Ohio, Indiana, Illinois, Iowa, Nebraska, and Minnesota, although it is generally getting a foothold in the corn belt. The breed is also rapidly growing in favor in the South, especially in Kentucky, Mississippi, South Carolina, Georgia, and Virginia. Duroc-Jerseys are not so well known on the Pacific coast as the Berkshire, although there are excellent herds in this region. The breed has a slight representation in Canada, but does not gain much in favor, for, as has been said, Canadians prefer a bacon-type hog.

Organizations to promote Duroc-Jersey pigs date back to 1883 , when the American Duroc-Jersey Swine Breeders' Association was established, the first annual meeting being held at Chicago, November I5-I6, I883, at which time Colonel F. D. Curtis of New York was elected president and C. H. Holmes of Iowa, secretary. In 1885 this association published its first herd record, since which time, to I920, fifty volumes have been issued, including the registration of about 68 , o0o boars and 150 ,000 sows. On November 20, I891, the National Duroc-Jersey Record Association was organized at Geneseo, Illinois, with J. M. Stonebraker of Illinois as president and G. W. Philippo of Illinois as secretarytreasurer. This association published Volume I of its herd record 
in 1893 , since which time a total of sixty-two volumes have been issued to 1919, including the registration of over 500,000 boars and sows. The letter "a " after the registration number of a Duroc-Jersey pig indicates its registration in the American Association and an "n," in the National Association. Each of these organizations has been very prosperous. In addition to these associations for promoting the purity of the breed and the registration of animals, there have been organized a number of state and local associations for the same purpose. In general, it may be stated that the organized interests in behalf of the Duroc-Jersey are strong and have accomplished much important publicity and breed-welfare work. The Duroc Bulletin, a semimonthly in behalf of the breed, published in Chicago, and the Duroc Digest, published in Minneapolis, are valuable mediums for circulation among the breeders, as they contain a large amount of Duroc-Jersey literature and advertising matter of importance. 


\section{CHAPTER LXVIII}

\section{THE POLAND-CHINA}

The native home of the Poland-China pig is in Butler and Warren Counties in southwestern Ohio. This is an undulating region with a prevailing clay-loam soil, excepting in the river bottoms. The Great Miami flows through Butler County, the valley of which is twelve miles wide and very fertile. The Little Miami River drains the greater part of Warren County. Corn, wheat, oats, grass, and clover are grown extensively in these two counties, which cover about eight hundred and fifty square miles. Hamilton County, Ohio, and Union and Vayne Counties in Indiana were also associated with carly Poland-China development. All these five counties are grouped together. The climate is fairly temperate both in summer and winter, typical of the Central West east of the Mississippi.

The origin of the Poland-China pig is not clearly understood. In the past considerable discussion has taken place concerning the accuracy of statement of various persons regarding the blood used in the early days of the formation of the breed. Radical difference of opinion has existed on this point. In important essentials the history of the establishment of the breed is very well understood.

The foundation stock of the Poland-China begins with the breeds or types of swine found in the Miami valley early in the nineteenth century. The settlers of this region had come in from Virginia, Pennsylvania, Kentucky, Indiana, and various parts of Ohio, and had brought with them hogs of considerable variety. Undoubtedly the stock of the settlers became crossed;, but from this mingling of blood was developed a large, coarse, very hardy, prolific, slow-maturing pig. The claim has been made that previous to I 8 I 6 two breeds - the Russian (or Russia) and the Byfield were known in the Miami valley. Dawson states $^{1}$ that in 1830

1 The Hog Book, p. 34. Chicago, 19 Ir. 
the predominating breeds in the Miami valley were, in the order named: Bedfordshire, China, Berkshire, Byfield, Big Spotted China, Irish Grazier, and Russian. However, it is well established that the Berkshire was not introduced into that section until 1835 .

The Bedford, or Bedfordshire, pig was also known under other names, especially Parkinson and Woburn. One man is credited with the statement ${ }^{1}$ that he "has seen and owned no less than five distinct varieties called Bedfords." These pigs were of various

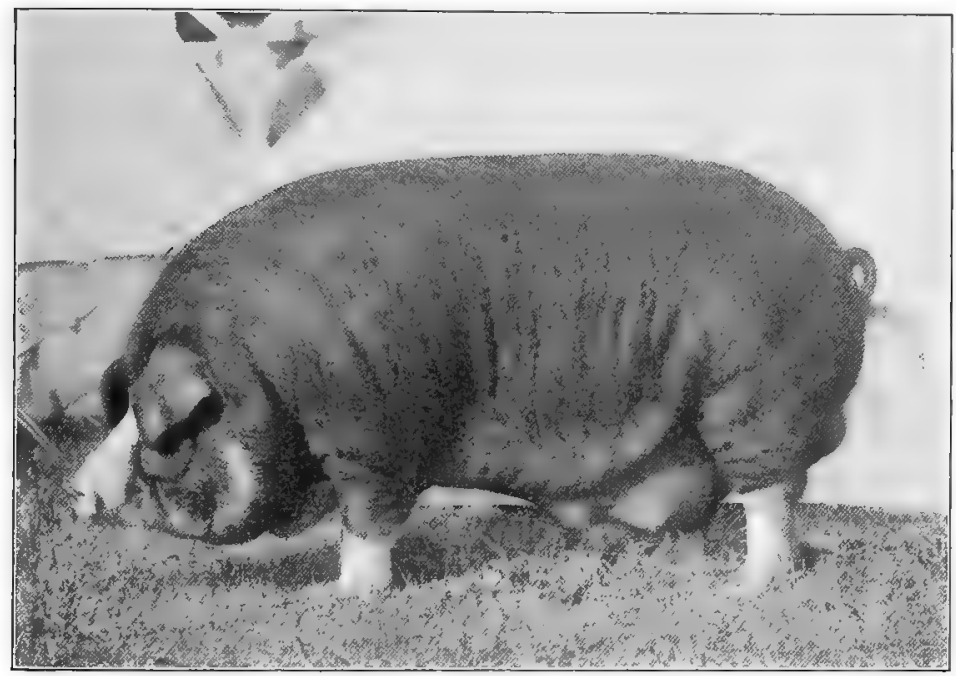

FIG. 339. Long Chief 90243, a big-type Poland-China boar said to have weighed Iooo pounds at three years of age. Owned by the Rockfield Breeding Association, Rockfield, Indiana. From photograph by J. C. Allen

colors, perhaps more especially sandy or spotted, had large drooping ears, narrow backs, were of large size, and matured at three to four years of age. The evidence is strong that this so-called breed was extensively used in the settled portion of the United States prior to 1830 . Bedfords were noted as good travelers.

The Russian pig is described as generally white, with long, coarse hair, a long and coarse head, with a narrower ear than possessed by the common pigs of the region. The breed was of superior length and height, the bone strong and fine, the pigs

1 S. M. Shepard, The Hog in America (1896), p. 224. 
stood well on their feet, were quiet of temperament, and were regarded with favor. These pigs sometimes reached large size.

The Byfield pig was of two types, both being white in color. One was very large, with long, flat sides and heavy, lopped ears; the other was more refined, with small ears pointing noseward, with broad back, deep chest, large jowl, short nose, dish face, and thin hair.

Previous to 1816 the Russian and Byfield breeds were very generally bred, and their blood mingled with the common pigs of the community.

The Big China breed of pigs was introduced into the Miami valley in I816, one boar and three sows having been brought from Philadelphia by John Wallace, a trustee of the Shakers' Society of Union Village, Warren County, whose members had much to do with the development of the Poland-China breed. The boar and two sows were white, while one sow had some sandy spots in which were small black spots. This was a mediumsized breed of unknown ancestry, of fine form, small head and ears, short legs and fine bone, and superior feeding qualities. Shepard thinks this may have been the Grass breed known in Maryland, Virginia, and Pennsylvania as the Bedford or Parkinson hog. The spotted China referred to by Dawson is said to have been introduced into Union County, Indiana, in 1836 and was probably a variety of the China breed. Used on the Russian and Byfield crosses the Big China produced very superior feeders and much improved the character of Miami valley pigs, resulting in what became widely and favorably known in the middle of the last century as the Warren County hog. Between I 816 and I 835 the swine industry of southwestern Ohio had a great impetus, due to the beneficial effects of this cross.

The Berkshire as an element in Poland-China evolution first attracted attention in I835, when Munson Beach of Lebanon, Warren County, introduced some pigs of this breed from New York State. These Berkshires had erect ears, were stylish in appearance, and at once met with much favor. Others soon introduced Berkshires, and up to $\mathrm{I} 842$ they were extensively used on the Miami valley pigs. The Berkshire gave more symmetry, greater activity, more quality, and the black color to the Warren County hog. 
The Irish Grazier as a factor in Poland-China history was introduced into Warren County by William Neff of Cincinnati, who imported from Ireland in the fall of 1839. This was a white, thinly-haired hog, varying somewhat in size and type. The Neff stock had an erect ear, a long body with superior back, excellent legs, and very fine hams. For several years Irish Grazier blood was mingled with the Miami valley mixture, but the purebred stock soon became extinct; not, however, until it had assisted in the improvement of the Warren County hog. Mr. Cephas Holloway, who from 1813 for very many years lived in the Shaker community at Union Village, stated that "the two breeds - the Berkshires and Irish Graziers - were extensively used in making crosses by our best breeders of swine in Warren, Butler, Hamilton, Clinton, and Montgomery counties." In I 87 I Mr. Tytus, an extensive pork packer from I 836 to I 860 , said that the Warren County breed was greatly improved by crossing with the Berkshire and Irish Grazier. From I845, at least, up to the present time it is claimed that no foreign blood has been used in the development of the Warren County pig, or what later became known as the Poland-China.

The adoption of the name "Poland-China" has an important history. The name "Poland " or "Poland and China" had been given to herds of Miami valley pigs by certain breeders as early as along in the sixties. Mr. Ayers McCreary and Mr. D. M. Magie claimed that their pigs were a combination of Poland and Big China blood. Mr. A. C. Moore of Illinois, who formerly lived in Ohio, also termed his pigs Poland and Chinas. These men in particular, and some others, claimed that a Poland breed of pigs had been used, presumably introduced to America by Polish settlers. Much controversy developed over the accuracy of the claim that such a breed as Poland had ever been used in Warren County. More or less investigation followed, and no satisfactory evidence seemed to support the claim. Evidence was secured, however, to show that in one neighborhood an individual used the word "Poland " "to designate the progeny of a particular animal that had been obtained from Asher Asher, who was a Polander by birth and who many years ago resided for a time in Butler County, some five or six miles south of Monroe." After 
an investigation of the subject of the origin of the breed, a committee reported to the National Swine Breeders' Convention at Indianapolis, Indiana, in November, I872, and the report was accepted. In this no recognition was given to the influence of Poland blood, but the committee recommended that "in view of the difficulties in making a change in the name of any breed, that the said name of 'Poland-China' be recognized as the accepted name of said breed, and the report of the committee was approved."

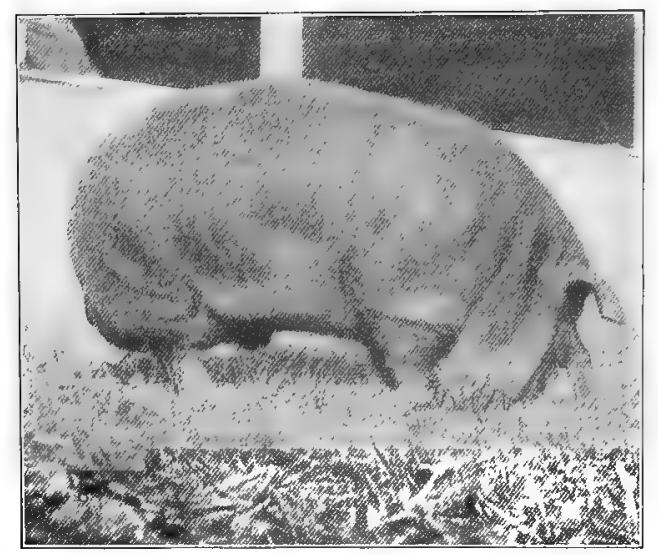

FIG. 340. A prize-winning Poland-China boar of the Medium type, owned by L. C. McLaughlin, Pleasantville, Ohio. From photograph by the author

The early improvers of the Poland-China pig in the days of its formation as a breed were represented by numerous intelligent farmers and stockmen, more particularly in the Miami valley. The Shakers of Union Village in Warren County were most prominent in this work, and the herds of various breeders who later obtained distinction traced back to Shaker breeding. Mr. John Harkrader of Springboro, Warren County, who has been classed as one of the originators of the breed, developed a herd generally recognized as being of great merit, from which descended much prepotent blood. Most prominent among the promoters of the breed about I865-I870 were D. M. Magie of Oxford, Butler County, Ohio, who claims to have originated the Poland-China; Alexander Young and James Duffield of Somerville and John Irvin of Darrtown, all of Butler County, Ohio; and A. C. Moore of Canton, Illinois. Magie and Moore extensively advertised the breed and did much to bring it before the public: Other important constructive breeders in Ohio established herds as follows: W. C. Hankinson, Blue Ball, I 857 or I 858 ; J. Douthett, Xenia, 
Greene County, I863; Noah Coler \& Son, Liberty, r 868 ; James Hankinson, Carlisle Station, I870; L. N. Bonham, Oxford, I87 I and Edward and J. M. Klever, Bloomingburg, 1873.

Characteristics of the Poland-China pig. The head is of medium length and breadth in good specimens, with a rather full jowl. The face is classed as straight, the nose and space from below the eyes to nostrils being free of dishing. The checks tend to be rounding and full and frequently are somewhat seamed. The ears should be fine and break over at the top third into a neat droop; thick, heavily attached ears are objectionable. The neck of the Poland-China tends to be short and thick, the shoulders a bit prominent but well covered, the back strongly supported with a gradual yet strong arch the entire length, the loins and ribs being thickly covered, wide, and strikingly arched in well-fattened specimens. The sides have but a moderate length, with an excellent depth. The nump is of medium length but is frequently somewhat low, so that the entire upper line of the pig from ear to tail has a more curved outline than most breeds. The hind quarter is characterized by great thickness of flesh, the hams being thick for the entire length from top to bottom, with a full, deep twist between. The leg's of the Poland-China are usually short and show refinement, and the pasterns tend to slope too much. In recent years the subject of type has caused much discussion among the breeders. Many have recognized the fact that there was too much refinement, with a lack of bone and substance. As a result of this agitation, there has developed a larger, heavierboned, coarser, more upstanding type, as compared with the smaller, lower-set, more refined sort - the former being known as the "big type" and the latter as the "medium type." Between these two types one finds a wide range of size and breed character, greater perhaps than in any other breed. The most characteristic features of the Poland-China are the color, straight nose and face, droopy ear, very broad and arched back, superior hams, and short legs.

The color of the Poland-China pig has undergone something of an evolution. Originally the use of white pigs formed a leading feature in the development of the breed, but the advent of Berkshire blood caused a change to a darker type. Thirty years 
ago large white or sandy markings were common on the body. Twenty-five years ago many "spotted" pigs were registered in the "Ohio Poland-China Record," although at this time black pigs with white points were receiving special attention. The older breeders were attached to the lighter colors, but the solid-black color with white feet, tail, and face met with show-ring favor and attained a popularity which has held up to date, although white elsewhere argues no impurity of blood. This uniform color marking is said to be largely due to the influence of the boar Tom Corwin 2d 2037.

The size of the Poland-China classes it among the large or middle-weight breeds, according to type. In 1875 , in the early days of the breed, very large weights were attained, but the modern demand for a more refined and smaller market type turned the tide toward a pig of less scale and earlier maturity. As already noted, however, a reaction has become well established, so that there is a large constituency of breeders of the big-type PolandChina. Pigs of the medium type, fed for market, will readily attain 200 pounds at six months, while 250 pounds is not uncommon with good feeders. Boars at one year old should weigh about 300 pounds and sows 250 to 275 pounds. At full maturity boars should weigh about 500 pounds and sows 400 pounds in breeding form. The big-type pig shows greater scale in every way, is coarser in bone and hair, and at maturity is of large size and heavy weight. Boars at one year old may weigh fully 400 pounds and at maturity about 800 pounds or more when in good condition. A leaflet of the Standard Poland-China Association states that from the point of scale the Poland-China excels all other breeds. "It is a common occurrence to see boars at maturity weigh 900 to I I 20 pounds and sows 550 to 850 pounds, and several still larger." It is hardly a conservative statement, however, to state that such weights are "common." They are rather remarkably exceptional. Among well-known boars of the medium type, Chief I Know I I 992 and Model Boy I 3959 each weighed 650 pounds and Lookout $3245 \mathrm{I}$ some 700 pounds in breeding condition. The big type calls for much heavier figures, and the following weights are reported as applied to this kind: Grand Master 67666 weighed I I 20 pounds on the Iowa State Fair grounds 
in I9I4, Long Jumbo 627 I9 weighed I 106 pounds, Columbus 64898 and The Big Orphan 63348 (full brother) each weighed I050 pounds. Queen of Wonders I6900I, a senior yearling sow, weighed 780 pounds in I9I4, and Big Nellie I6I5I I weighed 850 pounds, the girth of her shin bone being Io inches. Shelton \& Son, in their August I3, I9I9, catalogue, give the weight of Long Big Bone 2d 256457 as 1200 pounds, height 44 inches, length (from a point between the eyes to tail head) 83 inches, heart girth 76 inches, hind-flank girth 86 inches, and circumference of shank bone, I I $\frac{1}{2}$ inches. Long Big Bone, sire of Long Big Bone $2 \mathrm{~d}$, is said to have weighed I I 50 pounds at thirty-one months of age. Finally, in reference to size, I_yman Peck writes : ${ }^{1}$

Quite a number of boars are in service to-day that weigh over I000 pounds, and sows have attained record weight up to 960 pounds. At the last Nebraska State Fair the grand championship was won by a boar that in his three-year form carried his 900 pounds with ease on almost perfect feet and pasterns. He showed a clean $10 \frac{1}{2}$-inch bone and the phenomenal heart girth of 80 inches. Now it did not take three years to make this hog. He was possessed of early maturity enough to win first as a six-months pig at the same fair, weighing 255 pounds at that time.

The Poland-China as a grazer is well suited to blue-grass and clover pastures, where it has long been a common figure in the Middle West. The general custom of the Western farmer is to pasture his pigs in the summer season, and this breed long ago showed its suitability for this purpose, keeping easily with little grain.

The Poland-China as a feeder is one of the most popular of American breeds, although its popularity in recent years has not been so great as formerly. Any loss of popularity in this respect has been largely due to the inability of the more refined pig of the breed to finish off within ordinary limits, such as eight months, with sufficient size to satisfy the feeder. In the opinion of the author the big-type Poland-China, with sufficient quality, will remedy this breed criticism. Early maturity is a most valuable factor, but it must be associated with profitable weight, else it is a detriment rather than an advantage. In extensive feeding experiments the Poland-China makes a satisfactory showing. The following records of Poland-Chinas in feeding trials indicate the

1 Breeders' Gazette, January II, I9II. 
capacity of individuals of the breed to produce gains in weight. In five feeding trials at the Ontario Agricultural College the Poland-China consumed in the several tests the following amounts of "meal" to make I oo pounds of gain in live weight; namely, $417,333,383,350$, and 474 . In three trials at the Iowa Station, to produce roo pounds of gain, the Poland-China consumed the following amounts of dry matter; namely, 424, 392, and 441. In twenty-two tests involving 96 pigs at eight experiment stations and agricultural colleges, as reported by Rommel, it required 357 pounds of feed for Ioo pounds of gain in live weight. In breed comparisons, results show considerable variation, in which the Poland-China ranged from the poorest to the best.

The early-maturing qualities of the Poland-China are of the first class, and the breed has been noted in this respect for many years. No other breed, unless the Chester White, will finish off fat so early as this, and this quality is more especially applied to the medium type of the breed, to which reference has already been made. In the change in the market from a large, slow-maturing, older type of fat hog to a smaller, less mature, younger sort, the Poland-China has been an important factor. Until comparatively recently, on the great Chicago hog market the blood of this breed has played a most prominent part, due largely to the ability of feeders to finish off early.

The adaptability of the Poland-China to environment is at least medium. It is primarily a breed for the corn belt, where it is found in its greatest perfection and where it thrives best. It has never had much of a hold in the more rough or hilly regions East or West nor in the cooler sections of the North. However, with an abundance of food, it adjusts itself to a range of conditions comparable with other breeds. Like other lard breeds PolandChinas tend to be phlegmatic in winter, consequently a region relatively free from snow is better suited to them.

The quality of Poland-China meat has been subject to criticism from certain sources. The export trade has especially called for a lean type of bacon, such as is only produced by a lean type of pig or one that is fed a nitrogenous ration. The Poland-China produces rather more external fat than do most other breeds. This is readily seen in comparing the carcasses of pigs of this 
with those of other breeds. There is more lard, more mechanically separable fat, and a greater thickness of surface fat. In a carcass study of the Poland-China and Berkshire made by the writer this was clearly shown. This has also been demonstrated at the Wisconsin Station, where the loin fat of the Poland-China was 1.75 inches thick, the back 2.5 inches, and the shoulder 2.75 inches, exceeding in thickness both Berkshire and Yorkshire. The American trade, however, does not object to this fat, nor is the price paid by the packer any less. So far as the grain and quality of Poland-China meat is concerned, when not too fat it compares very favorably with the Chester White and Duroc-Jersey. Fed on a nitrogenous ration the Poland-China produces an acceptable carcass for the American market.

The crossbred or grade Poland-China is regarded with favor, both by feeders and the man on the market. Pure-bred boars bred to common sows result in a class of pigs that fatten rapidly and mature early. In fact many think that the females of this cross show more vigor and greater breeding power than do the purebreds. Poland-China boars crossed with Duroc-Jersey, Berkshire, or Chester White sows produce offspring which often feed better and more rapidly than the pure-breds. The author has secured superior feeding pigs by mating large Yorkshire boars to PolandChina sows. This cross fed rapidly and carried ample flesh, yet did not become too fat, dressing out a choice carcass.

The prolificacy of the Poland-China has subjected this breed to much unfavorable criticism in recent years, especially in the period between 1900 and I910. This criticism has been especially directed toward the smaller, more compact type, for sows of this sort will not breed so easily nor have such large litters as the larger, more rangy kind of females. Many breeders of recent years have seriously criticized the fecundity and reproductive power of this breed, and no doubt the great increase in the herds of Chester Whites and Duroc-Jerseys is due to dissatisfaction with the Poland-China as a producer. There is no doubt but that the average sow of the breed produces smaller litters than any other breed well known in our feed lots. Dr. Bitting has shown this to be true in his herdbook-record study, in which he shows that the average size of 1086 Poland-China litters was 7.45 pigs 
each, 400 Berkshires 8.22 pigs, and 600 Chester Whites 8.96 pigs. In a study made by the writer of the litters of I 300 PolandChina brood sows, farrowing 9335 pigs, the average size of litter was 7.4 pigs, essentially the same result as secured by Dr. Bitting. In 1906 George M. Rommel published a study of Poland-China fecundity, based on herdbook records covering the years 1882I886 and I898-1902. Over 50,000 litters were considered, including 103,458 pigs for $1882-1886$ which averaged 7.04 pigs

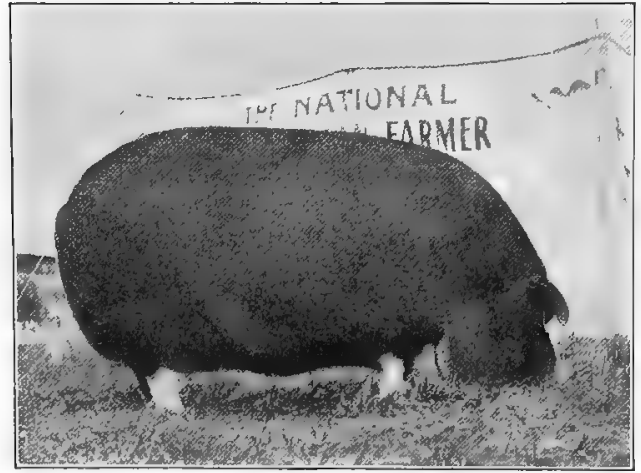

FIG. 34I. Miss Rooseveldt 138448 , reserve champion Poland-China sow at the Louisiana Purchase Exposition at St. Louis, Missouri, 1904. This sow was of the medium type and showed much refinement. Owned by Charles E. Keller, Newark, Ohio. From photograph by the author per litter, and 299,324 pigs for 1898-1902 which averaged 7.52 pigs per litter. These figures seem to show a slight gain rather than loss in the prolificacy of this breed. In the leaflet of the Standard Poland-China Record Association previously quoted, the statement is made that this breed has "stood considerable abuse from other breeds, on the grounds of not being prolific." Letters were sent to nearly one hundred breeders inquiring as to the average number of pigs farrowed per sow during three years, and from these replies the following interesting statement is made up. There was an average of 9.75 pigs per litter, and one herd had this average for a term of five years from 40 sows. Another breeder averaged Io pigs from 25 sows for five years. Others for periods of three to four years gave averages of 8.5 to IO, with some litters of I 5 to I 8 pigs. "There were many litters of I 2, I 3, I4, and I 5 pigs each." Many of the sows making these records were gilts with their first litters. In a study of the prolificacy of the PolandChina, Professor H. W. Vaughan states ${ }^{1}$ that of 2895 litters of

1 Breeders' Gazette, August 16, 1917. 
big type, including 24, I 46 pigs, and 3029 litters of medium type, comprising 22,678 pigs, the big type averaged 8.34 pigs to the litter and the medium 7.49 .

The prepotency of the Poland-China is very pronounced, though hardly the equal of some of the older breeds, as, for example, the Large Yorkshire. But the color markings and characteristic features of the head, back, and hams are transmitted with much consistency. The large number of grade Poland-Chinas in the stockyards show the distinctive features in the breed and bear striking evidence of its prepotency.

Poland-China families and foundation sows date back to the establishment of the breed. Of the older brood sows of distinction the following are notable: Bessy Pugh 88, Lady Pugh 516, Lady Rue 518, Old Warner sow 7I4, Queen Duffield 804: Queen of Black Bess Tribe 808, White Bess 1000, and White Face 1002. In addition to these and following their time are F's Black Bess 304 , foundress of the Black Bess family; The Old Harkrader sow 950; Graceful I 554, foundress of the Graceful family; Beauty 2558, dam of Tecumseh 4339 and foundress of the Tecumseh family; Cora Shellenberger 2880, dam of Success I999, a famous sire; Lady Duffield 3776, dam of Tom Corwin $2 \mathrm{~d} 2037$ and foundress of the Corwin family; Bess.Stibbens I I 68, foundress of the U.S. family; Bessie Wilkes 8082, dam of Chief Perfection 32 199, head of the Perfection family. The above animals and families represent breeding of the corn-belt states east of the Mississippi. In more recent years examples of the big type, as developed farther West, have descended from these noted foundation animals: Wonder Maid 277520, Mollie Fair 246474, Mammoth Giantess 97276, Big Lill I86I74, Kramer's Kind 592374, and Lady Lunker 192572.

Poland-China sires of distinction comprise a long list. Prominent among the early sires that played a most important part in the improvement of the breed were Alex No. I, Butler 93, John 3d 3I I, World Beater I 2 I 3, Perfection 447, Young Perfection 631, Old Sweepstakes 253, Success I999, Tom Corwin 2d 2037, Tecumseh 4339, and Black U. S. I 347 I. Early in the twentieth century Ideal Sunshine 37885, Chief Perfection 3993 I and his son Chief Perfection 2d 42559 (perhaps the most noted sire of the breed), Meddler 99999 (grand champion at the Louisiana Purchase 
Exposition in 1904), Keep On 61015, Corrector 2d 87699, Thickset 71221, Perfection E. L. 71635, Perfect Perfection 80971, and High Roller 84255 were in great favor. In more recent years, especially since I9IO, big-type hogs have commanded the attention of Poland-China breeders. The three big-type boars Expansion 26292, Pawnee Lad 30853, and Big Hadley 40832 have been termed "the fathers" of the Poland-Chinas of this type.

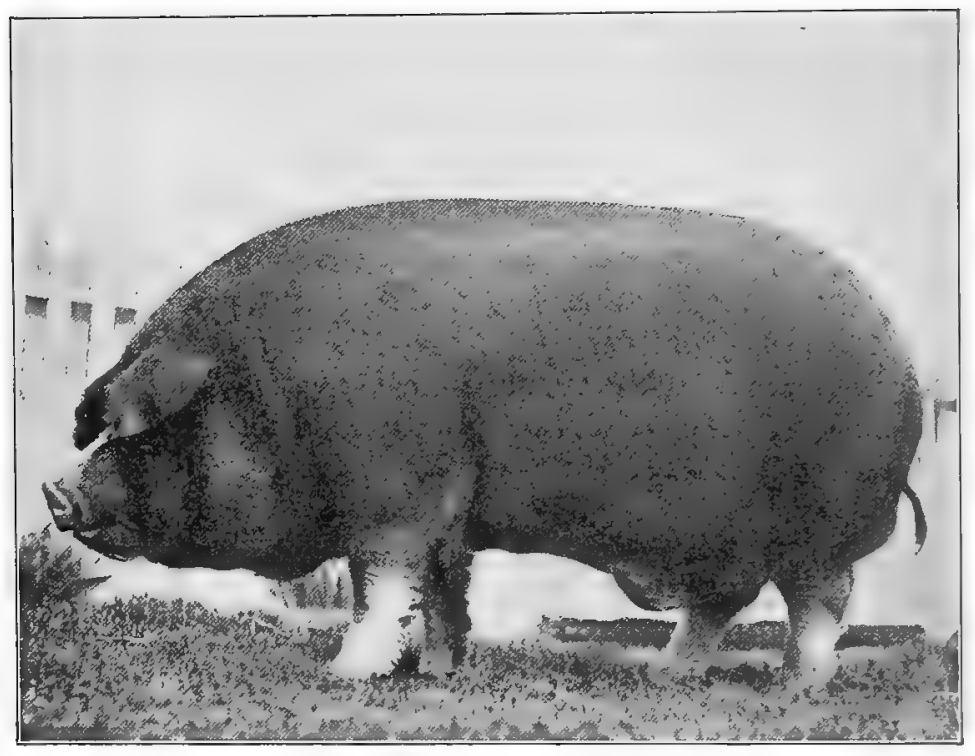

FIG. 342. Mountain Bill II1963, a Poland-China boar of the big type, sold by Silver Brook Farm, Muncie, Indiana, to E. E. Furver of Iowa for $\$ 5000$. From photograph, by courtesy of Silver Brook Farm

Other very noted big-type boars are A Wonder 47460, Big Timm 67 II I, Wonder 2d 75767, Long Wonder 66688, Disher's Giant 240655, Giant Buster 240657, Giant Wonder 94537, Longfellow I I9997, Grand Master 67666, Gerstdale Jones 244I87, The Clansman 103093, and Evolution 33I333.

Prices for Poland-China pigs surpass those paid for any other breed of swine. Some of the highest reputed prices occurred in the summer of 1903, when at auction sales held in Indiana a number of pigs were sold to companies of buyers on a shares 
basis. For example, two men owned a half interest in a boar, which they sold by shares, ten shares being issued. Each owner reserved one share and then offered the other eight at auction. Thus ten men came into ownership of a boar, eight giving security in notes or cash, usually the former. By such a plan eight shares of interest in the boar Chief Perfection 2d were sold in July, I903, for $\$ \mathbf{I} 3,850$, eight men bidding off the shares at sums ranging from $\$ 500$ to $\$ 2000$ each. On the basis of purchase the boar was valued at $\$ 34,625$, an absurd proposition on the face of it. Such sales for a season made a great furor, but soon became discredited and were discontinued. Among noteworthy sales of regular form is that of King Medium on December 23, I896, which sold for $\$ 1025$, the highest auction-sale price to that date. Happy Union $345 \mathrm{I}$ I at the Howard and McAllister sale in Iowa, in I897, sold for $\$ 4000$ to the Happy Union Stock Company. The same year Look-Me-Over I94 I 7, another boar, sold for \$3600 at the Hart \& Minnis sale at Edinburg, Illinois. In 1905 the boar Meddler 99999 sold for $\$ 3000$ to Edward Ware. In August, I907, at Eldon, Missouri, at Goodrich Farm, the litter of pigs of the sow Cute-Keep-On $237084 A$ sold for a total of $\$ 13,060$. Of these the boar Ten Strike was sold to T. M. Chambers of Kansas for \$5 I25; another pig, Storm Center, went to William Wingate of Missouri for $\$ 4250$; while a third, Sure Shot, sold to Alters and Belshaw of Illinois for $\$ 2$ r 50 . Forty-three head in this sale brought $\$ 25,160$. In 19r 8 the boar Colonel Jack 28899 I was sold by Fred Sievers of Iowa for \$IO,200 to George Klosterman \& Sons of Ohio. This same year Peter Mouw of Iowa sold the noted boar Gerstdale Jones 244187 to Carter and Van Deventer of Missouri for $\$ 6600$. Wonder Buster 997 I 5 was also sold by W. B. Wallace to Carter and Van Deventer for $\$ 5300$. In I9I9 the Silver Brook Farm of Indiana sold the big-type boar Mountain Bill I I I 963 to E. E. Furver of Iowa for $\$ 5000$. Also the big-type boar Mountain Giant IO7 IO I was sold by E. J. Emrick \& Sons of Ohio to Myer Brothers of Nebraska for $\$ 5000$. This same year two other notable sales were made, William Wrigley, Jr., paying \$ I 5,000 for The Clansman I03093, and Uittenbogaard, Henry, \& Wegter, on August I4, paying $\$ 25,200$ for the boar Evolution 331333. Up to I9I 7 but few sows of the breed had reached four figures, 
but recently very high figures have been attained. The top price was paid in February, 1919, when the sow Kramer's Kind 592374, dam of The Clansman I03093, was sold by J. L. Davis to T. E. Thompson \& Sons of Indiana for $\$ 5600$. It is interesting to note that on October 2I, I919, Thompson \& Sons sold a litter of 9 sow pigs and I boar from Kramer's Kind, sired by Giant Buster, for $\$ 17,325$, a world's record. Robert Halford in 1918 sold a yearling sow for $\$ 3400$. On February 23 , I9 I 8, J. A. Pfander sold the sow Mammoth Giantess I $3^{\text {th }}$ I91790, said to have been the largest Poland-China sow ever bred, for $\$ 3300$. The sow Buster's Big Model 2 I 248 was bought in I9I9 by Glover \& Moore for $\$ 2525$. Fred Sievers of Iowa made a great sale on January 15, 1919, when he sold 38 sows and gilts for $\$ 28,850$, an average of $\$ 760$ per head. Ten Colonel Jack gilts sold for \$10,878. At another remarkable sale held August I4, I9I9, by W. E. Green, Algona, Iowa, 3 I head sold for $\$ 49,955$, an average of $\$ 1610$. This is the highest-priced sale of the breed up to 1920. The Poland-China has reached higher levels on prices paid at public auction than has any other breed of swine. Some of these high prices are regarded as a detriment to the welfare of the breed, and more than one editorial has been published in the agricultural press severely criticizing this kind of price booming.

The distribution of Poland-China swine is mainly through the Mississippi Valley states - notably Ohio, Indiana, Illinois, Iowa, Missouri, Oklahoma, Kansas, and Nebraska. The breed is common also in other states. Among pigs of this class in Canada heavy-fat producers are not popular and have but slight hold. The breed has been introduced abroad in a small way. In I877 D. M. Magie sent three head to Joseph Munson, at Liverpool, England. This is said to have been the first exportation of purebred swine from the United States. In I 898 twelve head were sent to Russia, six from the Iowa State College and six from H. G. McMillan of Iowa. In I9I9 many pigs of the breed were exported to Brazil and Argentina. The Poland-China, however, has never met with favor outside of the United States. This is due to the fact that a leaner type of pork is usually. desired.

Organizations for the promotion of Poland-China pigs are strong and influential. The Ohio Poland-China Record Association was 
organized at Dayton in 1878 , although the first volume of the "Ohio Poland-China Record" was publiṣhed in 1877 by Carl Friegau and M. J. Lawrence. Twenty-six volumes of this record have been published as a full set. The American Poland-China Record Company was organized in January, I878, at Cedar Rapids, Iowa, publishing the first volume of its herdbook in I879, since which it has published seventy volumes. The Central Poland-China Association was organized in February, I880, at Indianapolis, publishing its first volumethesame year. The Northwestern PolandChina Swine Association was organized at Washington, Kansas, I88I. The Standard Poland-China Record Association was organized in 1887 at Maryville, Missouri, publishing the first volume of its swine record that year, and has published forty volumes up to the year I9I9. In I896 the Southwestern Poland-China

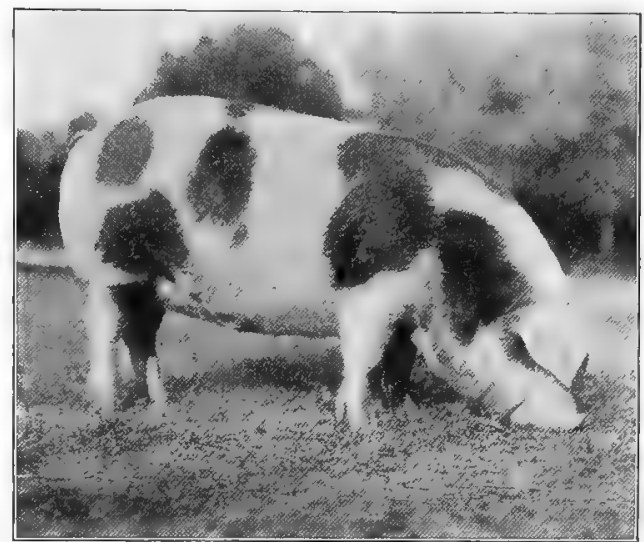

FIG. 343. Perfect Lass 7 th, junior-champion Spotted Poland-China sow at the Indiana State Fair in 1916. Owned by A. S. Booco, Jeffersonville, Indiana. From photograph, by courtesy of the National Spotted Poland-China Record Association

\section{Record Association}

was organized at Ripley, Tennessee. Two very small herdbooks have been published, including approximately two thousand registrations. In I9IO this association merged with the American. Several hundred thousand Poland-China hogs have been registered, the American, Standard, Central, and Ohio associations each doing a large business. Some years ago an effort was made to amalgamate all the different Poland-China associations into one. This resulted in the consolidation in 1905 of the Ohio and Central Poland-China associations under the name of the "National Poland-China Record," which, up to I9I9, had published forty-one volumes. 


\section{The Spotted Poland-China}

The Spotted Poland-China is a type of Poland-China that has been receiving more or less public attention since about 19I2. Its promoters assume it to be essentially the same thing as the oldfashioned spotted hogs of this breed of long years ago that had been bred more or less pure in Indiana for many years. On January I, I9I4, there was incorporated in Indiana the National Spotted Poland-China Record Association for preserving the purity and promoting the welfare of this family by registration and otherwise. An official publication of this association states:

There are a number of well-known breeders in central Indiana who have been breeding these hogs to the exclusion of all others for many years, and they have become so popular and widely known that in the opinion of most men in this section they are not only superior as the most profitable pork producer and all-around farmers' hog, to any other breed, but also to any other type of Poland-China.

The characteristics of the Spotted Poland-China are as follows: the color is a well-defined black background, over which is scattered irregular white spots of varying size. The general form is that of the Poland-China, excepting that it is characterized by good length of body, heavy bone, and some coarseness of ear, tail, and hair, as compared with the medium type. The Spotted type weigh up to 800 pounds or more at maturity, farrow from 9 to I 2 pigs, and the sows are excellent nurses. "Evenness of litters, or the absence of runts, is a matter of common knowledge and frequent comment."

In I9I 5 the association championing the spotted type had something over two hundred members, of whom a large percentage were located in Indiana. A few herds are owned in Ohio, Illinois, Iowa, Missouri, Kansas, Nebraska, and perhaps in other states. Large exhibits of the Spotted Poland-China are made at the Indiana. State Fair, but thus far to no great degree elsewhere. It is very likely that the spotted hog will meet with growing favor on account of its large size and prolificacy, the two chief arguments in its behalf. This association up to I9I8 had published four herdbooks, with registrations numbering up to $2 \mathrm{I}, 2 \mathrm{rO}$. 


\section{CHAPTER LXIX}

\section{THE CHESTER WHITE}

The native home of the Chester White breed of swine is in extreme southeastern Pennsylvania, in Chester and Delaware Counties. Geographically these two counties lie between $75^{\circ}$ and $76^{\circ}$ west longitude, and $40^{\circ}$ north latitude passes through each county. Little Delaware County borders the river of that name, the city of Philadelphia is close by, while bordering Delaware on the west lies the much larger county of Chester. The region is crossed by numerous streams of fine water, the land is rolling and, as a rule, fertile. Heavy crops of the small cereals, Indian corn, and grass are grown here. Joining Chester County on the west is Lancaster County, one of the richest and most productive agricultural counties in all the United States.

The original type of Chester White pig first became prominent in Chester County. Long ago there existed in both Chester and Delaware counties a large, coarse, white pig. It has even been assumed that the original stock of this sort came over with the early colonists, possibly at the time of William Penn. Captain James Jeffries of Westchester, Pennsylvania, in a voyage to Eng land early in the last century (I820), secured a pair of white pigs, male and female, from Bedford County, England. These pigs have been referred to both as Bedfordshire and Cumberland breeds, though the former is the usually accepted title. The boar, which was retained by Captain Jeffries, had been a prize winner in England and, used on the old white type in Pennsylvania, had a distinctly refining influence. This Jeffries boar was white, though he had bluish or blackish skin spots, a broad back, excellent hams, short legs, and a refined head with droopy ears. Following the Jeffries importation, Harvey Atwood of Delaware County, Pennsylvania, imported some white Chinese stock from England. This was a sway-backed sort, with short legs, short face, droopy ears, and having black, blue, and sandy spots in the hair, and possessing 
excellent feeding and maturing qualities. The stock from Jeffries and Atwood were blended together along with the common white pigs of the region, and from this has come the first strain, if it may be so termed, of the Chester White blood.

The adoption of the name "Chester White" for this breed of swine is said to have come about in the following manner. ${ }^{1}$ Uncle Bennie Hickman, in 1848 , made the comment that at the various

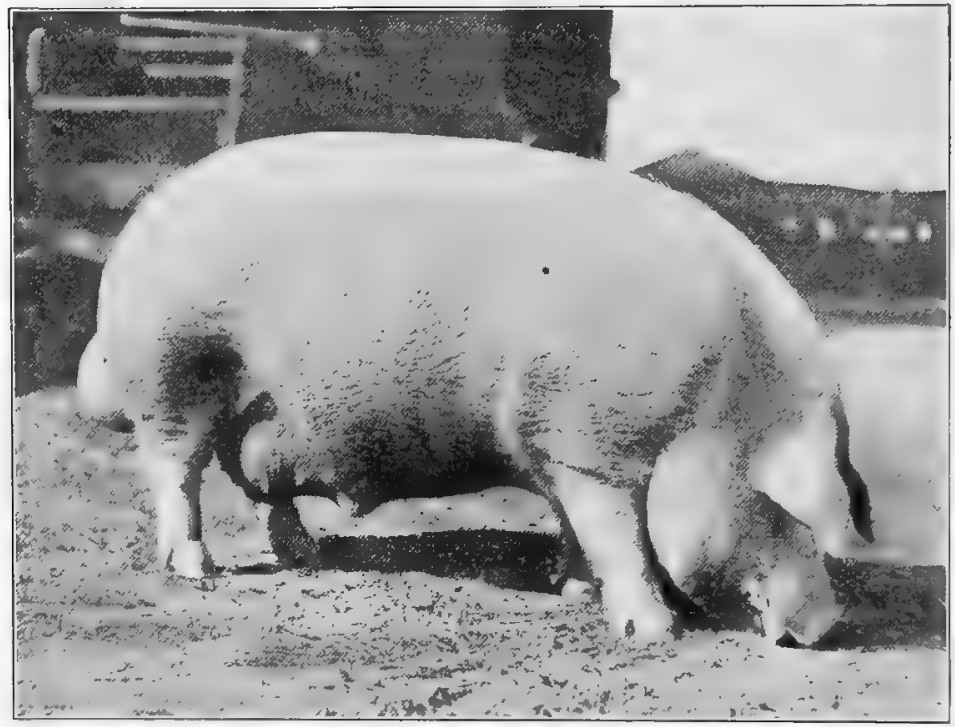

FIG. 344. Combination's Defender 29509, a noted Chester White show boar and sire owned by A. G. Satre, Stanhope, Iowa. From photograph, by courtesy of Mr. Satre

fairs he had attended he noticed that all of the hogs but those he regarded as the best had names given them, so he proposed that the best ones be called Chester County Whites. Mr. Atwood took exception to this, claiming that the best hogs were from Delaware County. As these gentlemen could not agree upon the name, the advice of Aaron Clements was sought, who suggested that the winner of the most prizes at the Baltimore and Richmond fairs should give the name. This was agreed to, but upon their

${ }^{1}$ Booklet No. 4, Chester White Swine Record Association, July I, I9I 5. 
return from the fairs it was found that each had won the same number of prizes. Accordingly a committee of Messrs. Thomas Chenney and Aaron Clements was requested to settle the selection of the name, and they chose Chester County White.

The origin of the so-called Improved Chester White goes back to England also. This has a special application to what is known as Todd's Improved Chester White and is based on a statement by S. H. Todd, and adopted January I6, I90 I, by the American Chester White Record Association. This is the most detailed information published concerning the ancestry of the improved breed. In I827 W. K. Townsend of East Haven, Connecticut, imported from England some Norfolk Thin Rind pigs. These were black dotted with white, or white belted with black, and were blocky of type, short-legged, fine of hair, and vigorous. Kneeland Todd and his brother Isaac bought a boar of this breed and a white sow of medium size of a breed known locally in Connecticut as the Grass breed. No doubt this sow was an Irish Grazier. In 1830 the Todd brothers removed from Connecticut to Ohio and brought these two pigs with them. These were bred together in Ohio with considerable success, producing pigs that would dress 365 pounds at nine months of age. In 1833 Joseph Haskins removed from Massachusetts to Wakeman, northern Ohio, and took with him a pair of pigs, a boar of the Byfield breed, and a sow pig similar to the one brought from Connecticut by the Todds. The Todd and Haskins pigs were bred back and forth until I848. That year Isaac Todd bought from Joel Meade of Norwalk, Ohio, a large white boar which the seller called the Large Grass breed. This was used in his herd on account of its good-feeding and early-maturing quality. In I862 Isaac Todd secured a so-called Normandy boar of unknown breeding, white in color, said to be of French ancestry. This nicked well with his stock, and he produced superior feeders and handsome pigs, with which he attained show-ring success. At the second state fair held in Ohio, Isaac Todd with this stock vanquished all competitors in the show ring. In 1865 Todd first introduced Chester White blood in his herd with satisfactory results. At this period his son, Seth H. Todd, took up the work. More Chester White blood was used, and in I 867 the son bought a pair of pure-bred 
Chester White pigs of George B. Hickman. These were used in the herd, and the boar proved a most successful sire. From this period on, for about forty years, S. H. Todd bred and improved the Chester White and played a leading part in its development. The claim has been made that Poland-China blood has been used in the improvement of this breed, but this Mr. Todd says "is entirely false" in its application to his own breeding. He rather attributed it to a reversion to the black color found in

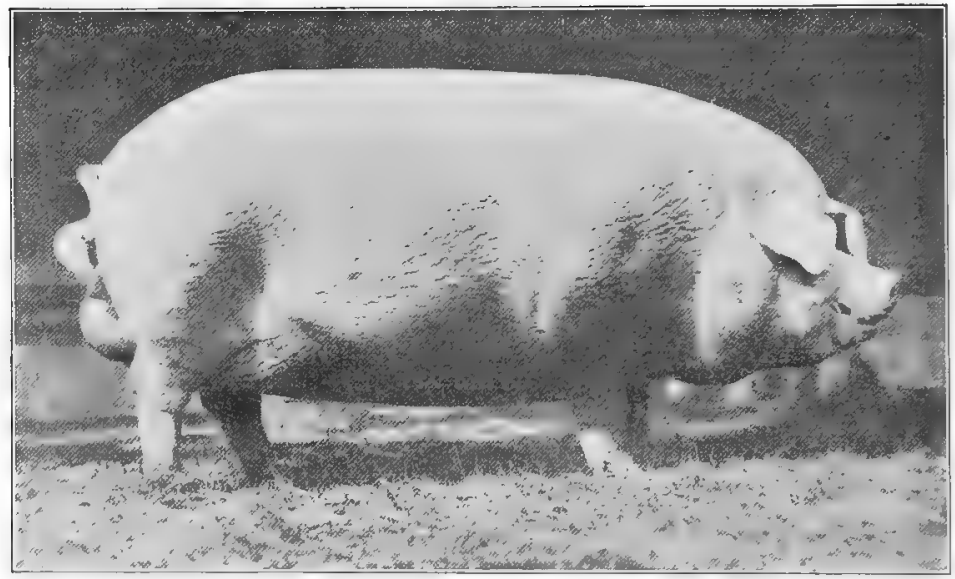

FIG. 345. Big Buster 46015 , grand-champion Chester White boar at the r918 National Swine Show. This boar at seventeen months of age weighed $S z 0$ pounds. From photograph, by courtesy of the Chester IITite Joumal

the Thin Rind or Bedford hog. Besides S. H. Todd, Thomas Wood of Chester County, Pennsylvania, has been an important improver of the breed.

The Ohio Improved Chester White, commonly referred to as the O. I. C., is a line of breeding especially promoted by L. B. Silver, who began breeding at Salem, Ohio. In 1865 he made a trip through the Eastern states to study the pure breeds of swine. In an article written in I9I I he states ${ }^{1}$ that the parent stock was selected with much care in Chester County, Pennsylvania, "from time to time, from the best herds, and as many as possible, in order to have a large number not akin." Mr. Silver desired to

1 Breders' Gazette, November I, I9II. 
produce a hog that would meet the wants of the farmer or stock breeder. He writes: "I saw they sadly needed improvement, and did not present evidence of careful breeding. There was not that uniformity of size, shape, or style that should characterize a herd of whatever name." The O.I. C. strain, as promoted by Mr. Silver, in the opinion of many, was larger and more prolific than the common run of Chester Whites. Mr. Silver has made the claim that this is "now known as a distinct breed," but such is not the case, and it has never been regarded by the well informed as a separate breed.

Characteristics of the Chester White. As is indicated by the name, this is a pure-white breed, although small black or bluishblack spots occur on the skin to some extent. Such spots do not disqualify, but are undesirable. The official Chester White scale of points states that "red or black spots in the hair disqualify, but blue spots in the hide (commonly known as freckles), while objectionable and should be discouraged, do not argue impurity of blood." The head has a straight face, the nose often tends to be long and narrow, and the ears droop forward, breaking over one third to one half of the length. Thick, heavy ears are not uncommon. The more desirable ear is thin and covered with fine hair and of medium size. In the best examples the back is very wide, with a tendency to considerable arch. The depth of body' is usually excellent, showing large digestive and reproductive capacity with the females. In recent years the breed has gone through some improvement, and both shoulders and hams are superior in smoothness and thickness to what they were at one time. The legs may be short, the pastern weak, the toes too much spread and bent, and the dewclaws too low set. This weakness is due no doubt to the early-maturing, rapid-fattening quality of the breed, the weight being too great for the feet to sustain properly. This calls for stronger bone in the make-up of the Chester White, a feature to which the better breeders are giving attention. The quality of hair is about medium, with a tendency to coarseness, while curly hair is not uncommon. The modern specimen of the breed shows a finer hair than did the older type. A tendency on the part of this as well as other white breeds is to sun scald and scurfiness of skin, especially in the West, when 
exposed to a hot sun and dry weather. In temperament the Chester White is excellent, being quiet and well suited to feeding.

The size of the Chester White is about medium. Formerly it was our largest breed, and specimens were exhibited weighing over Iooo pounds. The tendency about the beginning of the twentieth century was toward too much refinement, but in recent years breeders have sought more size and bone. The official scale of points of the Chester White Swine Record Association

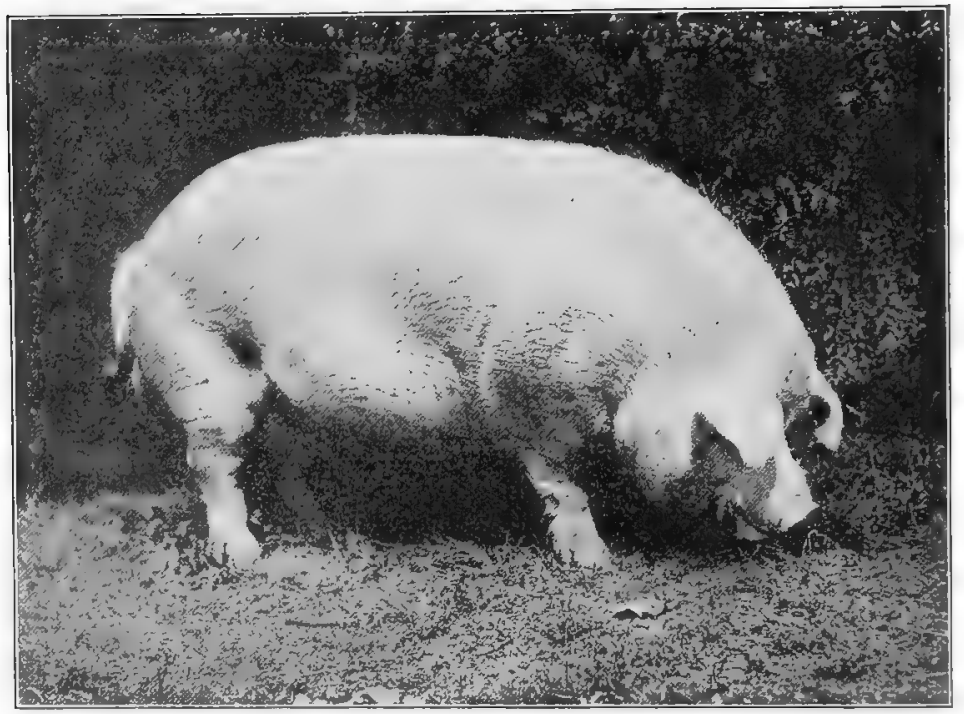

FIG. 346. Combination Again 39181, a noted Chester White boar owned by W. A. McMahon, West Liberty, Iowa. From photograph, by courtesy of Mr. McMahon

gives the following standard weights: boars two years old and over, in good flesh, not less than 500 pounds, and sows of the same age and condition, not less than 450 pounds; boars eighteen months old, in good flesh, should weigh not less than 400 pounds and sows 350 pounds; boars twelve months old not less than 350 pounds and sows 300 pounds; boars and sows six months old not less than I 50 pounds each, and other ages in proportion. In the opinion of the writer the weights given for the older hogs are too light. In common with the Poland-China and Duroc-Jersey, the Chester White leaders of to-day are promoting 
the big type, and the advertisements are full of references to the giant or mammoth Chester White. For example, Mammoth King, Jumbo Wonder, Big Bone Industry, Big Chief, Big Büster, and Ohio's Giant are samples of names in common use to-day, indicative of the emphasis on size. Mammoth King 409I7 when eighteen months old is said to have weighed 750 pounds in breeding condition, and at maturity he stood 3 feet high, measured $\mathrm{IO}_{2}^{1}$ inches shank bone, "and could easily have been made to weigh 1050 pounds." The following weights are given as representing the big-type Chester White, the figures being quoted from standard advertising: White Rex 45079, 750 pounds ; Prince Big Bone 43569, about 720 pounds ; Ohio's Giant 33573 and Chief Kossuth 3I839, each about 800 pounds; Creditor IOI6 pounds. Big Buster 46015, according to his owner, H. A. Derenthal, is 84 inches from butt of ear to tail head, 70 inches heart girth, 72 inches hind-flank girth, and II inches in circumference of shank bone.

The Chester White as a grazer will do very well in the North and will make satisfactory showing on alfalfa, the clovers, or rape, comparing favorably with other breeds. In the Central States these white hogs are commonly seen on the pastures during the growing season.

The Chester White as a feeder is regarded with esteem. Barrows of this breed will compare favorably with any breed in returning results for grain fed. Experimental feeding at various stations has given excellent returns. At the Indiana Experiment Station gains have been made of I pound live weight from less than 3 pounds of grain. In a test of one hundred and seventy-two days at the Vermont Station, Chester Whites made an average daily gain of $I .36$ pounds, dressing out 84.5 per cent carcass. At the Maine Station a daily average gain of I.I 5 pounds was secured for one hundred and forty days and of I.O5 pounds for one hundred and seventeen days at the Ontario Agricultural College. In the carcass contests at the International Live-Stock Exposition the Chester White has made a very creditable showing, winning many prizes, including firsts and grand championships. Records are given of carcasses that dressed out as high as 88 per cent. The grandchampion barrow of I9II, shown by J. W. Brendel of Indiana, 
weighed alive 352 pounds and dressed out 86.3 per cent. In I9I 2, in an exhibit of 59 carcasses represented by six breeds, grades and crossbreds, the Chester White won a large percentage of the prizes, including the grand-champion carcass. Again, at the I9 I9 International the breed was preeminent in the carcass contest, winning 90 per cent of the prizes, including the grand championship.

The maturing qualities of the Chester White are above the average. The pigs have much the same tendency as the Poland-China

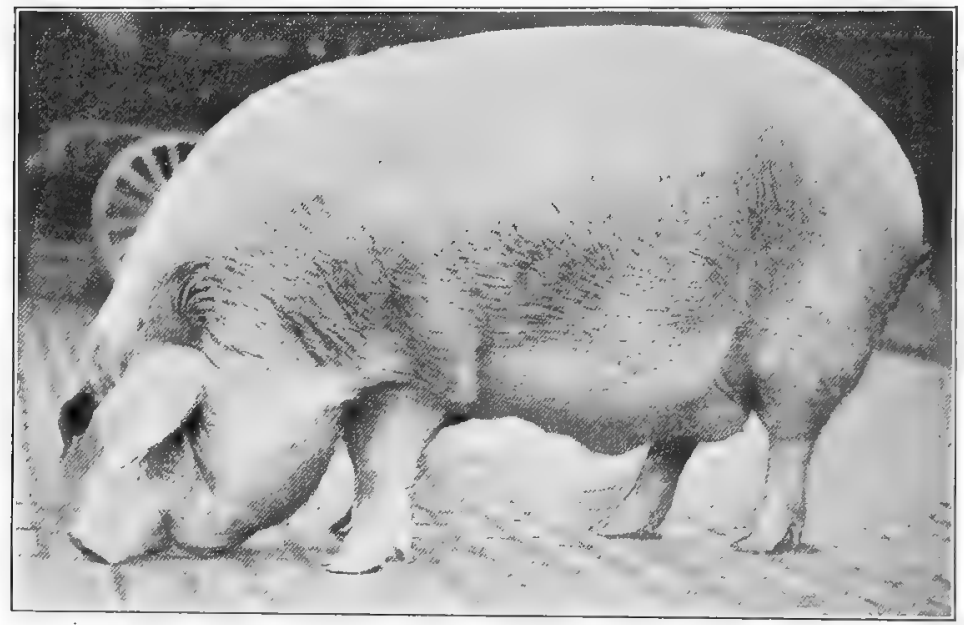

FiG. 347. The grand-champion Chester White barrow at the 1918 International Live-Stock Exposition. Bred and exhibited by the University of Illinois. From photograph, by courtesy of the Chester White Joumal

to mature and finish off early in the fattening pen, especially when of the medium type. Sometimes this feature is carried to an undesirable extreme.

The adaptability of the Chester White is not as great as some of the dark-skinned breeds. It has found its greatest foothold on the lower-lying and more fertile lands of the Middle West. It is not so well suited to extreme heat, such as may prevail in some sections of the South, as it tends to suffer from sun scald.

The quality of Chester White pork may be regarded as good. The breed, however, carries much fat and will not produce a high-class bacon, as bastd on the English market; neither under 
ordinary conditions as fed in the corn belt will the meat be quite the equal in percentage of fat to lean to that of the Berkshire.

The crossbred or grade Chester White makes a superior feeder. The Chester White and Poland-China cross well and in the opinion of many make better feeders than the pure-breds of either breed. Both crossbreds and grade fat stock at the International Live-Stock Exposition have made very high-class records. In I9 I I F. E. Bone won the first prize in each 'class of heavy, medium, and light-weight barrow with grade Chester Whites. Again, in I9I 2, Mr. Bone won first place on heavy and medium-weight grade barrows in strong competition, and the first-prize light-weight barrow was a cross of pure-bred Poland-China boar on Chester White sow, shown by John Francis and Sons of Illinois, noted Poland-China breeders. This same cross shown by Francis and Sons won the grand championship on carcass. The IOI 7 International grand-champion carcass was also a light-weight grade Chester White exhibited by F. E. Bone, which sold at twentyeight cents a pound, three and one-half cents higher than the next highest-priced carcass. In addition to advantages as feeders that may be possessed by the crossbred or grade, prolificacy is quite marked.

The prolificacy of the Chester White is very pronounced; in fact, this may be regarded as one of the most prolific of the lard type of pigs. In I 897 Dr. A. W. Bitting of Purdue University made a special study of the prolificacy of swine, in which he showed that the Chester White sows averaged 8.96 pigs per litter, surpassing both Berkshire and Poland-China in the order given. Chester White breeders have long maintained that prolificacy was one of the strong features of the breed, and there is no doubt as to the truth of the claim. This quality of reproduction is interestingly set forth by O. H. Smith of Trumbull County, Ohio, ${ }^{1}$ who reports on a sow of the breed owned by him that farrowed I6 pigs January 22, 1910; I4 pigs June 26, 1910; and 20 pigs December 5, 1910-a total of 50 in three hundred and seventeen days, which might be regarded as maximum production. Queen Viola, one of the most noted sows of the breed, farrowed a litter of 19 pigs in 1917. A writer in the National Stockman and

1 Ohio Farnier, February 25, I91.

R 
Farmer, in 1898, reports on a three-quarter blood Chester White sow, five years of age, that during the full period of her life farrowed 78 pigs, an average of almost 20 pigs a year. As a rule the sows have excellent udders and make good mothers, at least as good as other breeds.

The prepotency of the Chester White is very marked. The white color is transmitted with great uniformity, and a boar of this breed may be expected to impress himself on his crossbred or grade offspring to a noteworthy degree.

Families of Chester White swine. Until very recent years not much attention was given by Chester White breeders to the development of special families. Blood lines were very generally mingled, and the breed was developed in a quiet way. Present-day breeders seldom refer to families as descended from females of note, but rather emphasize important sires. Among the families looked upon with special favor are the St. Elmo, Schoolmaster, Kossuth, Pathfinder, Combination, and Pocket Piece.

Chester White sires of distinction, as might be presumed, do not date back many years in the history of the breed. The last ten years have given us most of our knowledge of the Chester White sires of importance. Among them the following are regarded with special favor: Wonder I 8069, Pocket Piece 2000 I 5 , Schoolmaster 24325, Wildwood Prince 28531, Chickasaw Kossuth 20279.

The prices paid for Chester White pigs until recently were very modest compared with those paid for other prominent breeds. In the past breeders have largely relied upon private sales. In I 893 S. H. Todd sold the boar pig Banker 2293, that was first in class at the World's Columbian Exposition at Chicago, for \$ I 50. This Mr. Todd claimed to be the highest price paid for a Chester White up to that time. Early in I9I 3 the boar Pocket Piece 200015 was sold by J. W. Brendel of Indiana to Maple Farm of Illinois for $\$ 500$. In 1915 the boar Schoolmaster 24325 was bought by Crandall Brothers of Michigan for $\$ 800$. On February 22, I9I 7 , J. L. Barber sold the sow Queen Viola, grand champion of the breed at the National Swine Show of 1916 , for $\$ 1000$ to Albert C. Brecher of Iowa. The greatest auction sale of Chester Whites up to 191 8 occurred at Ames, Iowa, on January 24, 1918, when W. T. Barr sold 47 head for $\$ 9582.50$, an average of 
$\$ 203.88$. The sow Our Maid 3d 86502, National Swine Show grand champion for 19I7, sold for \$1005 to A. G. Satre of Iowa. In 1919 Miss Leonora 4th 100772 , champion at the National Swine Show, sold on February I9 at the W. T. Barr auction in Iowa for $\$ 4200$ to B. M. Boyer \& Sons of Iowa. At this sale of Mr. Barr 40 head averaged $\$ 557$ each. The top price on a boar was $\$ 6000$, paid by M. F. Black of Nebraska for V'ildwood Prince, Jr., 34827, champion at the National Swine Show in 1918. In 191 8 the average price paid for 5456 sows sold at public auction was $\$ 36.75$. Seven of these sows brought $\$ 1000$ or more and 85 brought $\$ 500$ or more. In I9I9 the boar King Anak 69539, junior champion at the National Swine Show, was bought by $\mathrm{C}$. F. Brown of Webster City, Iowa, for \$2000. Prince 32743 was purchased for $\$ 3000$ in 1919 by Henry Wiemers, Diller, Nebraska.

The distribution of the Chester White is

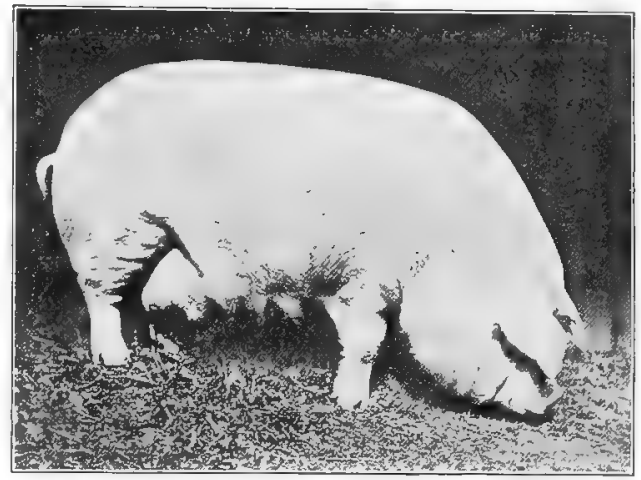

FiG. 348. Miss Leonora 4th I00772, grand-champion Chester White female at the I9I 8 National Swine Show. Exhibited by W.T. Barr, Ames, Iowa. Sold by Mr. Barr in I9I9 to B. M. Boyer \& Sons for $\$ 4200$. From photograph, by courtesy of Mr. Barr

widespread in the United States, but more especially in the cornbelt section. The Chester White Record Association has a large membership, distributed over forty-eight states, with Illinois, Indiana, Iowa, Minnesota, Missouri, Nebraska, Ohio, and Wisconsin furnishing a large share of the total. In recent years the breed has steadily grown in favor in the above-named states, but has not increased much elsewhere. Some sections of the eastern United States, especially Pennsylvania, have long looked with favor on this breed, but work in its behalf is not active, as in the West. For reasons already given, the distribution in the South is quite nominal, though it has found a few advocates in Kentucky, West Virginia, South Carolina, and Mississippi. 
Organizations promoting the Chester White. In I 884 there was organized at Eminence, Kentucky, the National Chester White Swine Record Association, but after a few years the headquarters were moved to West Chester, Pennsylvania, where it is still located. The first volume of the herdbook contained five hundred and fifty-one registrations. Up to 1918 this association had published eighteen volumes. In 1885 the Chester White Record Association was organized in Ohio, and later this became known as the "American Chester White Record," "for the purpose of making and maintaining a registry of the Todd Improved Chester White Swine," with headquarters at Columbus. Four volumes of "Todd's Improved Chester White Swine Record" were published, the first appearing in I 885. In I 894 the articles of incorporation were changed to read American Chester White Record Association, and Volume $\mathrm{V}$ was designated "American Chester White Record." Up to I9I9 twenty-three records had been published. In 1895 the International Ohio Improved Chester Record was incorporated in New York State, although in I89 I this association had published a herd record. The Ohio Improved Chester White Swine Breeders' Association was organized in I 897 at Cleveland, Ohio. Twenty records have thus far been published. The Standard Chester White Record Association was organized in I 894 at Indianapolis, Indiana. Volume I appeared in I895, and eighteen volumes were published up to I9I 3 , when it and the American association consolidated to form the Chester White Swine Record Association, with headquarters at Rochester, Indiana. This is now the main promoting organization of the breed. In 1909 the Western O. I. C. Recording Company organized in Nebraska, later changing its name to the National O. I. C. Chester White Record Association, with headquarters at Kansas City, Kansas, but in I9I 5 this consolidated with the Chester White Record Association at Rochester, Indiana. A monthly publication known as the Chester White Journal, published at Rochester, Indiana, is devoted to the promotion of the breed. This was formerly known as the White Breeders' Companion, but in I9I8 the title was changed. 


\section{CHAPTER LXX}

\section{THE HAMPSHIRE}

The early history of the Hampshire breed of swine is veiled in obscurity. This breed was known for many years in the United States as the Thin Rind, and this name was made use of by the author in the first edition of this book. In 1904 the American Thin Rind Record Association changed its name and the name of the breed to that of "Hampshire." With absolutely no prejudice in the matter, the author expressed the opinion that the use of this name was ill-advised, for the reason that "quite a different breed of pigs exists at present under that name in England." In fact, all of the historical and other information available to the writer seems to support the opinion that there never did cxist in Hampshire, England, a recognized breed of belted swine. George Culley, an authority on the breeds in his time, in I 789 refers ${ }^{1}$ neither to the Hampshire nor to a belted breed. In 1807 a "Lincolnshire grazier" describes ${ }^{2}$ the Hampshire as "chiefly white; neck and carcass long ; body not so well formed as the Berkshire pigs ; size large." In 1842 Professor Low wrote ${ }^{3}$ that " the Hampshire hogs were a very noted breed, from their being of large size, and well suited for bacon," but he made no reference to the color. In 1846 William Youatt, the greatest of the early authors on the subject of breeds, wrote: 4 "Here there are two varieties, the one larger than the other; in color they are either white or black and white with long necks and bodies, flat sides, and large bones." Further, he writes that there is also a third variety found in Hampshire, "in many points strongly resembling the wild boar," which he states "is of a dark or blackish color" and is no favorite in Hampshire. In I87 I Samuel Sidney refers ${ }^{5}$ to the Hampshire

1 Observations on Live Stock. Dublin, I 789.

2 The Complete Grazier (second edition). London, 1807.

${ }^{3}$ David Low, Domesticated Animals of the British Islands. London, I842.

4 William Youatt, The Pig. Philadelphia, 1847.

6 The Pig. London, 1871 . 
as black or spotted with red and about the size of a Berkshire. $\mathrm{He}$ also states that there are "a considerable number of white pigs in Hampshire." Sanders Spencer, an acknowledged British authority on the pig, in correspondence assures the author that a belted breed of swine has not been known in Hampshire. In his most recent work Mr. Spencer says ${ }^{1}$ that the Hampshire pig reminds one somewhat of the large black pigs found in the west of England, whence perhaps stock pigs have been brought. Walker, in 1905,2 gives a picture of three Hampshire pigs, black in color,

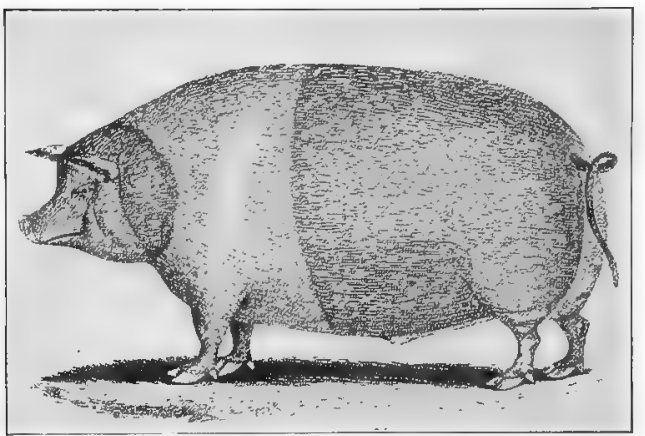

FIG. 349. "A portrait of a Norfolk Thin Rined Hog." From an engraving printed about 1840 , sent the author by the late W. R. Goodwin of the Breeders' Gazette with erect ears, suggesting an Essex, excepting for a somewhat straight face. The author has dwelt somewhat at length on this subject to set forth the character of swine natural to Hampshire, England, and to show that there is no logical reason to give that name to a belted breed. In fact, with a recognized black Hampshire in England, it would seem unfortunate to attach the same name to quite a different breed in another country.

The recognition of a belted, or sheeted, breed of swine dates back to early in the nineteenth century. In 1842 there was published in London a special edition de luxe of Low's "Breeds of the Domesticated Animals of the British Islands," containing large and beautiful illustrations in colors. One page is of a roughlooking, lop-eared sow with white belt, white head, and white legs. This illustration is given the title of an "Old English Sow from the Midland Counties," and in the chapter on the "Old English Breed," of which this picture is a part, no reference whatever is made to Hampshire as the home of this belted hog. In fact

1 Pigs: Breeds and Management. London, 1898.

2 Pigs for Profit, p. 132. London, 1905. 
Hampshire is in extreme south England and is not one of the Midland counties. No evidence whatever can be deduced from Low's writings even to suggest the existence of a belted breed in Hampshire, notwithstanding published statements to the contrary. Sidney, in $187 \mathrm{I}$, stated ${ }^{1}$ that the original Essex pig was a particolored animal, black with white shoulders, nose, and legs - in fact, a sort of sheeted pig, large, upright, and coarse in bone. Later, in I 898 , Spencer also writes ${ }^{2}$ :

There existed in Essex and a part of Cambridgeshire a variety of pigs curiously marked, being, as it was commonly called, sheeted or saddle-backed, the actual color being a black with a streak of white which extended from behind the shoulders to about the hips. ... One may occasionally see a few specimens of the sheeted pig in Essex, but these are simply the outcroppings of the old breed, as they have ceased to be bred to those points which were at one time considered to be distinctive of the sort.

The introduction of the Hampshire pig to America seems of questionable date. The claim has been made that Captain John Mackay, who commanded a packet ship plying between Boston and Liverpool, brought some belted swine to America between I 820 and 1825 to a farm which he owned near Boston. While there are numerous references in early American agricultural periodicals to the Mackay hog, the writer is unable to secure any description that refers to the Mackay as a belted hog; in fact, the references give it as a white breed which sometimes is marked with a few black or sandy spots. In I842, in an almanac published by the Western Farmer and Gardener at Cincinnati, is an illustrated chapter on hogs, in which the different prominent breeds are discussed. In this we find a picture of the Thin Rind, or Rhinoceros, breed, with an account of its characteristics and probable ancestry, as set forth by the editor of the Kentucky Fanncr, who was a breeder of these hogs. Herein he states that their color is not fixed, and that he has seen them jet black and pure white, but that they are commonly listed (sheeted or belted) and never spotted. In this article the writer says: "They were imported some years ago, as I understand, from Tonquin in China, by a merchant of New Orleans, and then brought to Kentucky by Captain John A. Holton of

1 Samuel Sidney, The Pig, p. 29. London, 187 I.

2 Sanders Spencer, Pigs : Breeds and Management. 
Franklin County. They are generally supposed to be nearly identical with the Siamese, but may be akin to the Swingtailed breed of the early English writers." According to H. F. Work of Indiana, Henry James, a Boone County (Kentucky) farmer, in a visit to some of the Eastern states in the early thirties, saw some belted hogs. These he described to Major Joel Garnett, who investigated and later purchased from people in Atlantic seaboard states I4 or 15 of these pigs, which were delivered to his agent

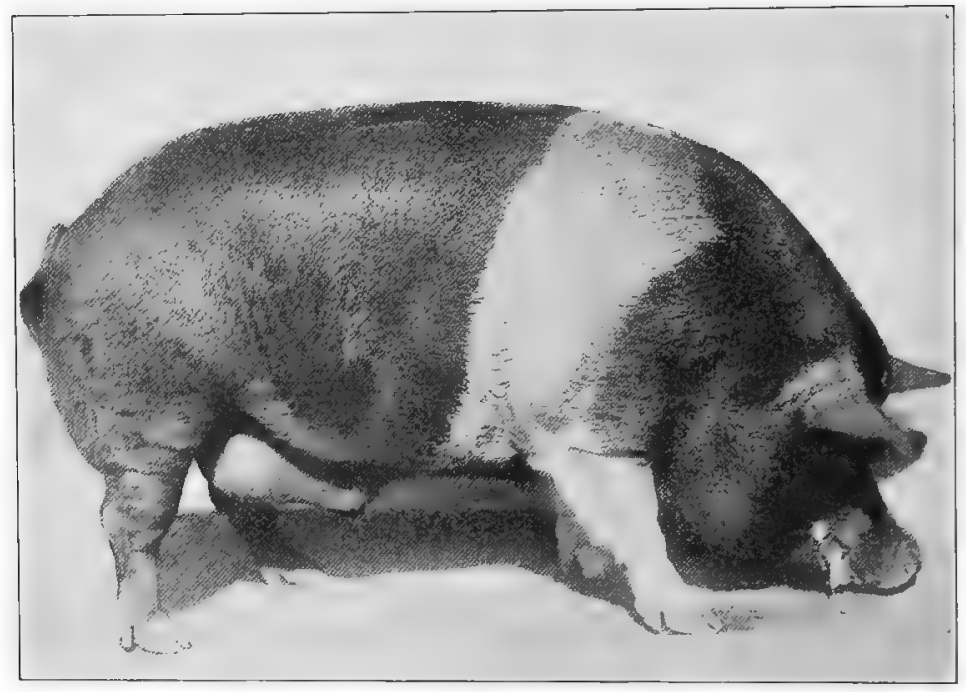

FIG. 350. Colonel Lakeside 2 I865, winner of the Hampshire Advocate trophy as the best boar under one year old at the Illinois State Fair in I9r4. A successful sire owned by C. L. Moore \& Sons, Tremont, Illinois. From photograph, by courtesy of the owners

in Philadelphia and later driven on foot or hauled in wagons to Pittsburgh, from which point they were taken by boat to Kentucky, reaching there in 1835 . Shepard, in his writings, ${ }^{1}$ refers to the Norfolk Thin Rind-first imported from England in 1830 by Henry Degroot of New York — as similar to the Thin Rind, although his references to color do not specify a belted pig. However, the author has in his possession ${ }^{2}$ a wood engraving of special

$1 \mathrm{~S}$. M. Shepard, The Hog in America. Indianapolis, 1886.

2 Received through the courtesy of the Breeders' Gazette. 
print, entitled "Portrait of a Norfolk Thin Rined Hog." This shows a true belted hog, resembling the present-day Hampshire, bred and fattened by William K. Townsend of Prospect Hill, near New Haven, Connecticut, that was butchered in January, I840, and that at sixteen months old had a dead weight of 480 pounds. The probability is that this Norfolk Thin Rind pig did not represent a distinct breed of this sort in Norfolk, England, for British authorities do not refer to any belted swine in that county;

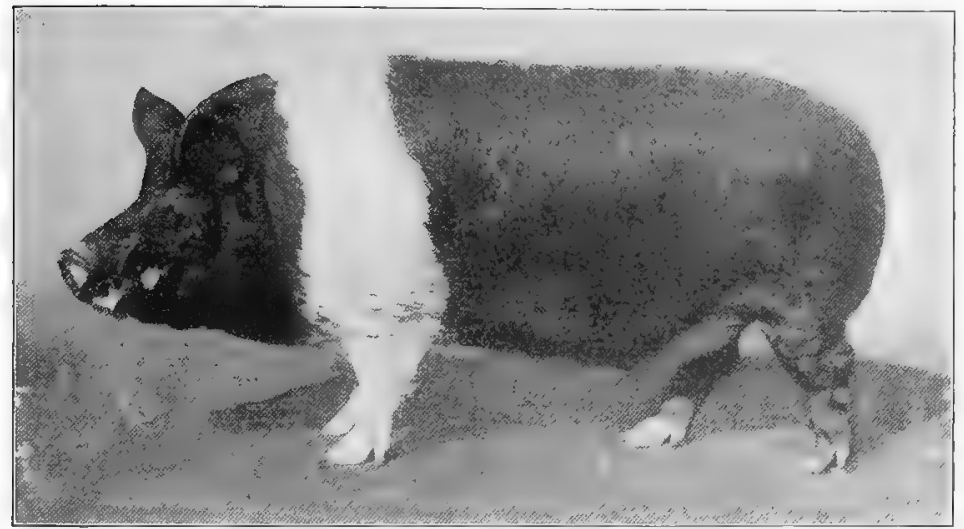

Fig. 351. General Allen ro6r, a noted Hampshire show boar and sire. Grand champion at eleven state fairs and expositions. Owned by J. Crouch \& Son, Lafayette, Indiana. From photograph, by courtesy of the owners

furthermore, they are hardly complimentary in their comments on the pigs there. It is possible that the first belted pigs came to America from Holland. Mr. F. R. Sanders in I 907 visited Holland to study the belted cattle of that country, and on his return reported ${ }^{1}$ that in North Holland for more than one hundred years noblemen there had bred belted cattle, pigs, and poultry.

Characteristics of the Hampshire. The hcad is straight of face, of medium size, with a tendency to lightness of jowl. The ears on young pigs stand rather erect, but with age they incline more or less forward and outward. The back is usually of medium width, though in recent years the breed has been developed to increased width in this respect. Hampshires do not carry a

1 Dutch Belted Cattle IIerd́book, Vol. VIII.

Digitized by Microsofte 
noteworthy arch of back, as a rule, but they are not deficient in this regard. The shoulders generally are light and well set in, but boars occasionally are prominent in the shoulders and somewhat narrow at the withers. The body as a whole has only moderate depth and length, producing a fair side for bacon, especially with the lighter-weight pigs. The hams lack somewhat the fullness of the highly developed American breeds, more especially in the lower thigh. The legs tend to be of moderate length, with excellent bone, and the pasterns and feet are strongly carried, as might be expected in so active a breed. In general appearance the Hampshire is a smooth, trim kind of pig, such as kills out well.

The color of the Hampshire, which is its most striking feature, is usually black, with a white belt about the body, this being known as a "listed" color. This white band, or belt, is from four to twelve inches wide and encircles the body just back of and about the forelegs, the latter also usually being white. It is not at all uncommon for sows to farrow solid-black pigs in a litter with belted ones. The revised standard of perfection of the Hampshire association objects to white color running high on the hind legs or extending more than one fourth the length of the body. Solidblack color is objectionable, while spotted pigs or those with more than two thirds white are disqualified. In discussing the color H. F. Work of Indiana, in a little history of this breed published many years ago, wrote:

While the list will long be retained by many of the breeders as the most fashionable color, there are also those who try to run their herds pure black. An ideal color is made up much as one may fancy, and the "color craze" should not exclude worthy animals that are a little "off color," save where spots occur. The breeding of blacks is an absolute necessity when the listed hogs begin to show too much white, so as to narrow the belt.

A writer in the Indiana Famer (May 28, I910), discussing the color question, states that he has been breeding Hampshires for fifteen years, raising from two to three hundred a year, and that 80 per cent of his pigs have good belts. Commenting on the solid-black color, he says these cannot be sold for breeders, and nine out of ten will not buy if they knew the pig - no matter how well belted - was from black ancestry. One can hardly question the good judgment of the breeder on such a decision on color. 
The size of the Hampshire pig is about medium among the breeds. The standard size as approved by the Hampshire association is as follows: boar two years old and over, 450 pounds, sow of same age 400 pounds; boar eighteen months old 350 pounds, sow of same age 325 pounds; twelve-months-old pig of either sex 300 pounds ; six-months-old pig of either sex I 40 pounds. Among the heavier weights reported for boars of the breed are 700 to 750 pounds. The noted boar Lookout Lad $2037 \mathrm{I}$ is said to have weighed 800 pounds as a senior yearling.

The Hampshire pig as a grazer ranks high. In early days in Kentucky and Indiana the pigs of this breed ranged the forest for roots and were obliged in many instances to "rustle" for a living. With the improvement of the Hampshire as developed in the corn belt in recent years, it has proved itself a good grazer on the pastures of clover or alfalfa now so common in this region.

The Hampshire as a feeder holds a very good rank. As a rule the pigs of the breed make a good accounting for the feed consumed, and no doubt will make a favorable comparison with other breeds. There is very little information concerning experimental feeding of the Hampshire.

The Hampshire pig for early maturity is of about average rank. It probably will not mature so rapidly as the Poland-China or Chester White, but is not regarded as deficient in this respect.

The adaptability of the Hampshire pig to a wide range of conditions is well established. While the breed is to-day recognized as especially suited to the Middle West, it has also a foothold in a modest way over much of the United States and to some extent in Canada. With his rustling qualities so well established, it is reasonable that he should adjust himself to a considerable range of elevation, temperature, and variety of food and care.

The quality of Hampshire pork is rated by packers as superior. The fact that pigs of Hampshire breeding are popular with the packers indicates their value as killers. The carcass may be compared with that of the Berkshire for relationship of lean to fat and quality of flesh. Excess of fat is not the rule, and the carcass dresses out very well. In fact this breed, in its leaner type, holds a good position in bacon production. R. S. Sinclair of T. M. Sinclair \& Company, packers in Iowa, is credited by the 
Hampshire association with stating that the Hampshires " are good bacon hogs and cut the heaviest and best loin of any hog that passes through our packing-house. The Hampshire has a distinct advantage over all other first-class breeds of hogs in the thinness of the jowls. This part of the hog always sells at a low price, and therefore the less of it there is on the carcass, the more it is to the advantage of the killer." Pure-bred or grade Hampshires have made a very fine showing in the carcass contests at the International Live-Stock Exposition on various occasions. In 19I I

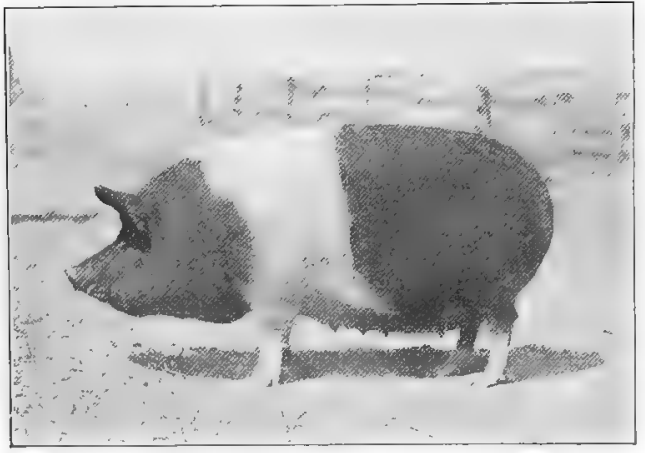

FIg. 352. Rosie's Ilazel 40400, a grand-champion Hampshire sow. Owned by J. Crouch \& Son, I a Fayette, Indiana. From photograph, by courtesy of the owners the grand-champion carcass was a pure-bred Hampshire shown by J. Crouch and Son of Indiana, and the grand-champion carloads of 1918 and I9I9 were Hampshires.

The crossbred or grade Hampshire pig is commonly seen in Illinois, Indiana, Iowa, and Ohio and other parts of the corn belt. The pure-bred boars on grade sows transmit their white and black markings with considerable persistency. Even on pure-bred sows of other breeds this is a dominant character. The special advantage of the Hampshire cross on the heavier lard type is a more active, smootherfinished sort of pig, somewhat lighter in weight than with other breeds, but killing out to the advantage of the buyer. The black and white colors are not always transmitted, however, and instances are found where Hampshire boars mated to Duroc-Jersey sows result in a red body and white belt. Perhaps the most desirable cross has been with the Poland-China and Chester White.

The prolificacy of the Hampshire pig is one of its important features. It has always been noted for farrowing litters of good size, this feature being emphasized in the writings of seventy-five 
years ago. The sows frequently farrow litters of ten or twelve pigs after the first farrowing and make excellent mothers and nurses. In this respect they rank with the most prolific breeds of American ancestry.

Prominent Hampshire sires do not date back for a very extended period of years. Among the noted boars of the breed are the following: David Harum 909, Lookout 7499, Lookout I ad, 2037 I, General Allen I06I, Hoosier Lad 34607, Messenger Boy 6i79, General Wickware 26879, Cherokee Lad 9029, and General Jones 24453.

Prices paid for Hampshire swine have kept within rather reasonable figures, with comparatively little speculation. The boar Longfellow 35I33, at one time champion at the International LiveStock Exposition, sold for \$I000. In I9I 5 John J. Shaffer, Jr., bought the boar Paulsen's Model 24423 for \$80o. On February 22, I919, Seth T. Hadley of Indiana held a sale, when one sow brought $\$$ IO3O and another $\$ 1000$, while the first thirty sold averaged $\$ 330$. Late in I9I9 the sow Merry Look of Glenview 89096 was sold by Zene Hadley of Wilmington, Ohio, for \$2 I 50 .

The distribution of the Hampshire pig has become widespread in recent years. According to the recognized organ of the breed, the Hampshire Advocate (December, I9I7), in 1904 there were but 16 owners of Hampshires in the world, while at the close of I 917 there were over 30,000 owners of registered Hampshire sows in the United States alone. The breed is in the main found in the central corn-belt states, but there has been a wide distribution also in the Southern States. The state of Iowa is credited with I 442 persons that at some time have purchased Hampshires. During 19 I 7 the American Hampshire Swine Record Association registered 32,646 hogs. The following figures give the number of registration in the states most actively breeding Hampshires: Iowa, 6004; Illinois, 4860; Indiana, 45 I 5 ; Nebraska, 34 IO : Georgia, 2 I98 ; South Dakota, I996; Alabama, I 581 ; Missouri, I 228 ; Ohio, 873; and Kansas, 591. To show the rapid increase of the breed it is but necessary to note that in I9I 5 the secretary of the association reported I 36 persons in Pennsylvania taking up the breeding of Hampshires, although in I9I I but 4 pigs of the breed were registered in that state. 
An organization to promote the Hampshire pig was incorporated by six Boone County (Kentucky) farmers in 1893 , when they formed the American Thin Rind Record Association. At this time about twelve herds of swine of this breed were eligible for registration, mainly located in Kentucky and Indiana. In 1904 this association changed its name to the American Hampshire Swine Record Association. This association has had a remarkable growth, and on January I, I920, numbered over one thousand members. There are numerous state and local Hampshire swine breeders' associations, the more aggressive ones being in the central corn-belt section. The American Hampshire Breeders' Association publishes a monthly journal, the Hampshive Adrocate, which renders most excellent service in behalf of the breed. Up to January I, I920, there havie been published thirteen volumes of the herdbook, including the registration of nearly one hundred thousand boars and sows. 


\section{CHAPTER LXXI}

\section{THE MULE-FOOT}

The name "Mule-Foot" is given this breed for the reason that it has a solid hoof, suggestive of the narrow foot of the mule, instead of the cloven one common with swine.

The native home of Mule-Foot swine is not satisfactorily established. Various claims have been made on this point, but it is generally admitted that the evidence is very superficial. They have been bred in Sweden and Norway for a century or more, it is said, and Kreglow states ${ }^{1}$ that Linnæus, the noted Swedish scientist, classified this type in 1735 . He also states that mulefoot swine were extensively bred in England by Lord Reagh as far back as about 1810 .

The introduction of Mule-Foot swine to America is of uncertain date. It is not a native breed, and no doubt was brought here long ago, possibly from northern Europe. J. H. Dunlap, a noted breeder, has stated that these hogs have been known in America for a hundred years ${ }^{2}$ and refers to the fact that for many years they have been bred by members of the Dunkard Church, although he does not mention the locality. The claim has also been made that these pigs were brought from the South Sea Islands about I 850.

The characteristics of Mule-Foot swine, as seen in the improved form of to-day, suggest the Poland-China, excepting for the ear and single hoof. The head is short, very nearly straight of face or quite so, and the ears are of medium size and incline forward, rather than stand erect or break over. The general conformation is typical of the lard type, with a fairly wide back and wide, deep, full ham. A slight arch of back is sought. As already noted, the hoofs are of one piece instead of cloven. The color of the Mule-Foot, including the feet, is a pronounced black, but white spots sometimes occur and are admissible.

1 C. G. Kreglow, The Mule-Foot Hog. A pamphlet.

2 American Agriculturist, March 10, I9IO. 
The size of the Mule-Foot places it in the medium class, although on the basis of some claims it might be regarded as a large breed. Dunlap states that the Mule-Foot equals the PolandChina and Duroc-Jersey in size, easily attaining weights from 600 to 800 pounds, while Kreglow places the weight for the sows at 400 to 500 pounds at maturity, with IOO pounds more for the boar. "Some of our brood sows," he writes, "could be fattened to weigh 700 and one of our herd boars will weigh 1000 pounds." By the standard a boar two years old should weigh 500 pounds, a sow of the same age 450 , and a twelve-months boar or sow 300 pounds.

The feeding qualities of Mule-Foot swine are said to rank very well. In recent years they show much sign of improvement and without doubt will fatten satisfactorily.

The quality of meat of the Mule-Foot ordinarily shows superior mingling of lean and fat and is more comparable with the Berkshire than the Poland-China. Dunlap regards the bacon of this breed as an intermediate between the lard and bacon type. In the more improved form it suggests the lard type.

The prolificacy of the Mule-Foot swine is of moderate degree. The average size of two hundred litters reported by Kreglow was eight plus, and these included ninety-one gilts with their first litters.

The prepotency of the Mule-Foot is a pronounced characteristic. Not only is the general conformation and color transmitted but in crossbreeding it is said that the solid hoof is reproduced to "a remarkable degree."

The immunity of Mule-Foot swine to cholera has been claimed on various occasions, and early in the present century, prior to I9IO, much publicity was given to this statement. As a fair sample of the claims made in behalf of the breed, the following by R. G. Long is quoted : " "Mule-Foot breeders do claim that their hogs will not take the cholera from being confined with cholera infected hogs, and I believe that their animals have made good on that claim." In I9 I0 J. H. Dunlap published this statement: ${ }^{2}$

1 Ohio Farmer, July 8, rgi 1.

2 National Stockman and Farmer; March 3, 19 ro. 
I have a list of two hundred and forty-five Mule-Foot breeders in twentyfive states, furnished me by C. E. Quinn of the United States Department of Agriculture, and have written to a great many of them regarding the immunity of the Mule-Foot hog. They have all replied that they have never known a full-blood Mule-Foot to die with cholera. Mr. Quinn also wrote me that he was unable to learn of Mule-Foot hogs dying with cholera in the thirteen states in which he investigated the claim of immunity.

These statements, however, are not supported by veterinarians, and the author is informed by an official of the Ohio State Veterinarians' office that in 1914 hog cholera was brought to the Ohio State Fair by a herd of Mule-Foot hogs exhibited the previous week at the Forest City Fair at North Randall. It is not regarded as impossible for herds of these hogs, under certain conditions, to contract cholera.

The distribution of Mule-Foot swine is quite widespread at the present time. There are many breeders in the corn belt, especially in Ohio and Indiana. Messrs. J. H. Dunlap of Pickaway County, Ohio, and C. G. Kreglow of Hardin County have long been prominent improvers and active exhibitors and promoters of the breed and have interested many persons in establishing herds.

The promotion of Mule-Foot swine has been taken up by two registry associations - the National Mule-Foot Association, organized in $\mathbf{I} 908$ at Indianapolis, and the American Mule-Foot Record Association, with headquarters at Columbus, Ohio. 


\section{CHAPTER LXXII}

\section{THE LARGE BLACK}

The native home of the Large Black swine is in Somerset, Devonshire, and Cornwall, in southwest England, a region with an attractive, mild climate and a comparatively short winter well suited to swine husbandry.

The origin of the Large Black swine is in keeping with the local development of other British breeds that have been evolved from the operations of numerous small breeders. Until recently little was known of it outside of its own county, and not much is known of its early history, but in recent years Large Blacks have grown rapidly in favor in England. Sidney states that the original Devon pigs were valued according to the length of their bodies, ears, noses, tail, and hair, the longer the better, without reference to quality or substance. ${ }^{1}$ Improvements began to be made in them early in the last century, and about I 850 George Turner, according to Sidney, had hogs that "are black with short faces, thick bodies, small bone, and but little hair, and exhibit as much good breed, shape, and constitution as any tribe of pigs in the kingdom." Mr. Ernest Prentice states that Large Blacks have been continuously and carefully bred in Cornwall for upwards of fifty years by R. S. Olver of Trescowe and George Lucas of Leigh Barton.

The introduction of the Large Black pig to America is of very recent date, a number having been brought to Kentucky about I9IO.

The characteristics of the Large Black pig are as follows: the head is of medium length, with straight face, and ears that are rather large and thin and which incline well over the face. Walker says ${ }^{2}$ they have great overhanging ears that often considerably interfere with their vision. The body is of good size, deep of rib, rather of the lard than bacon type and yet not lardy as we regard the fat hog in America. The back is very strong, the hams fairly

1 Samuel Sidney, The Pig. London, 1860.

2 John Walker, Pigs for Profit. London, about I905. 
thick, the legs a bit long and inclined to heavy bone. Originally these hogs were coarse and large of frame, but in recent years the quality has greatly improved. The color is solid black.

The size of the Large Black pig places it in the class indicated by its name among British breeds. The standard of the Large Black Pig Society gives no weights. Large Blacks seen by the author in England, in very good condition, at maturity approximated 500 pounds for females, with somewhat heavier weights for boars. In the Nerv Zealand Farmer an article on the breed refers to a farmer having pigs at three and one-half months weighing I I o pounds.

The Large Black pig as a feeder has very good rank and makes excellent use of its food. It is said that these pigs "pork at any age," which means they are good feeders.

The Large Black pig as a grazer is

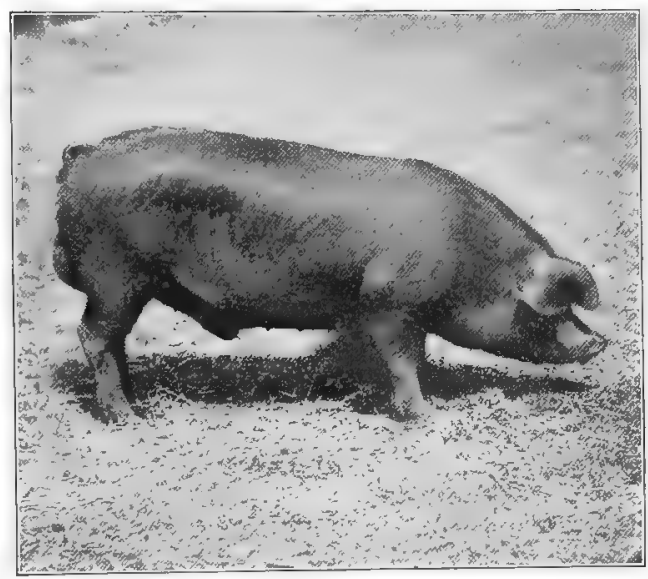

FIg. 353. A Large Black boar, a winner at the I 904 show of the Royal Agricultural Society of England. From photograph, by courtesy of William Cooper \& Nephews, Berkhamsted, England regarded with special favor in England, although the British farmer knows little of grazing swine, as understood by his American cousin. However, Walker states that they are great grazers, and that he has seen them roaming about the fields and orchards of Devon and Cornwall, where "they appear to have things their own way."

The quality of meat of the Large Black pig is very good, but comparisons seem to favor the Berkshire and large Yorkshire. Years ago, it is agreed by English breeders, the carcass was large and coarse and not of the best class, but "the great weight has given way to greater quality," writes Ernest Prentice, " "and the

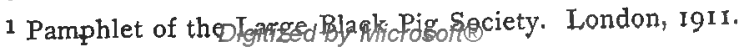


Large Black now yields at a very early age the chief desideratum, namely, a long, deep-sided carcass, of 160 to I90 pounds dead weight, light in shoulder, jowl, and offal, and showing a larger proportion of lean meat than any other breed." Spencer states that while making a good grade of meat, the Large Black cannot be regarded as the equal of the leading British breeds.

The prolificacy of the Large Black pig is said to be above average in comparison with English breeds. They tend to produce large litters, somewhat comparable with the Tamworth and Large Yorkshire. They are reported as having litters of from 17 to 18

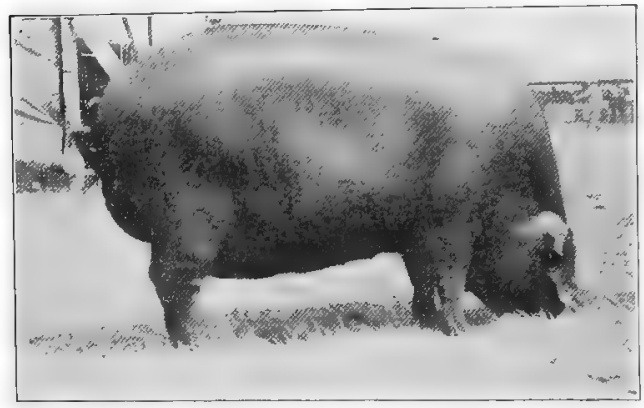

FIG. 354. A Large Black sow, a first-prize winner in I9I 4 at the Royal Counties Show, Portsmouth,

England. From photograph by the author pigs, and one sow in New Zealand, "typical of the breed," is reported as farrowing in her first four litters 9, I 2, I 5, and I 8 pigs respectively.

The popularity of the Large Black pig seems to be having a rather remarkable development. Comparatively little known a few years ago and scarcely referred to in the best British works on swine, it is to-day one of the breeds that is attracting wide attention at the important shows in England, and is being bought for export to a considerable extent. As substantial evidence of this public favor it is but necessary to record the sale of K. M. Clark, in I9I8, where a Large Black sow sold for $\$ 2275$, and on which occasion four other animals were struck off at \$I575, \$I 500, \$1250, and $\$$ I 000 respectively. This was the outstanding swine sale in Great Britain in a period of high prices generally. Present indications are that the Large Black is to have a great growth in popularity in the next few years.

The distribution of Large Black swine in England is more especially in the south counties of Cornwall, Devon, Somerset, Essex, and Suffolk, where numerous herds of merit are to be found. 
Large Blacks, however, have been widely distributed in other counties and in many foreign countries, including Tasmania, Australia, New Zealand, South Africa, Russia, Denmark, Argentina, Brazil, Austria, Germany, Chili, Spain, Italy, Switzerland, and the United States.

The promotion of the Large Black pig in England is under the official direction of the Large Black Pig Society, organized in I 898 at the Smithfield Show in London. This society has a large membership and has published up to I9I9 about twenty herdbooks, registering a great number of pigs. In I9I I a National Large Black Pig Association was organized at Lexington, Kentucky, but thus far it has not been active in claiming public attention. 


\section{CHAPTER LXXIII}

\section{THE CHESHIRE}

The native home of the Cheshire pig is Jefferson County, New York, in the north-central part of the state, on the eastern shore of Lake Ontario. The climate is quite cold and rough in winter, and the conditions as a whole are not ideal for swine raising.

The origin of the Cheshire dates back to about I855. The cause for the use of the name of the breed is unknown. About I 855 Messrs. Hungerford and Brodie of Jefferson County imported from England a Yorkshire boar of the large or middle class. This was used upon sows in the county, and soon after White Suffolk blood was mingled with the descendants of this boar. Early in the sixties A. C. Clark of Belleville and S. P. Huffslater of Watertown began to show pigs of this class at the fairs. Later, in 1870 , Mr. Clark won the Packer's Prize of $\$ 500$ for the best pen of pigs exhibited at a fair at St. Louis, Missouri. The name "Cheshire," or "Jefferson County," was officially adopted in 1872 by the Swine Breeders' Convention at Indianapolis, Indiana. The evidence indicates that the breed is the result of constant crossing and breeding of Large Yorkshires and White Suffolks to the white pigs in Jefferson County. In r 876 Colonel F. D. Curtis, a prominent New York live-stock authority, wrote Mr. F. D. Coburn that he knew "of but one breeder of these pigs in Jefferson County." Mr. J. H. Sanders bred these pigs pure for about seven years in Iowa, and wrote $\mathrm{Mr}$. Coburn as follows:

I produced all the different types of the Yorkshire from the Large York down to the Lancashire Short-face. ... The type which I finally succeeded in fixing upon the Cheshires, as bred by me, was almost identical in size, form, and quality with the most approved Berkshires. Indeed, so marked was this resemblance in everything but color that they were often facetiously called "White Berkshires."

About $1873 \mathrm{E}$. W. Davis began to improve this pig and added much to the permanence of type. 
Characteristics of the Cheshire. This breed closely resembles in form the Yorkshire of the middle class. The face while dished is not extremely so, and the ears, which are small and fine, stand erect or point slightly forward. The back is wide and very slightly arched, the Cheshire scale of points requiring it to be "long, broad, and straight nearly to root of tail." The body' as a whole has considerable length but often lacks depth. The shoulders and hams are regarded as of the thick-fleshed, well-developed sort. The legs

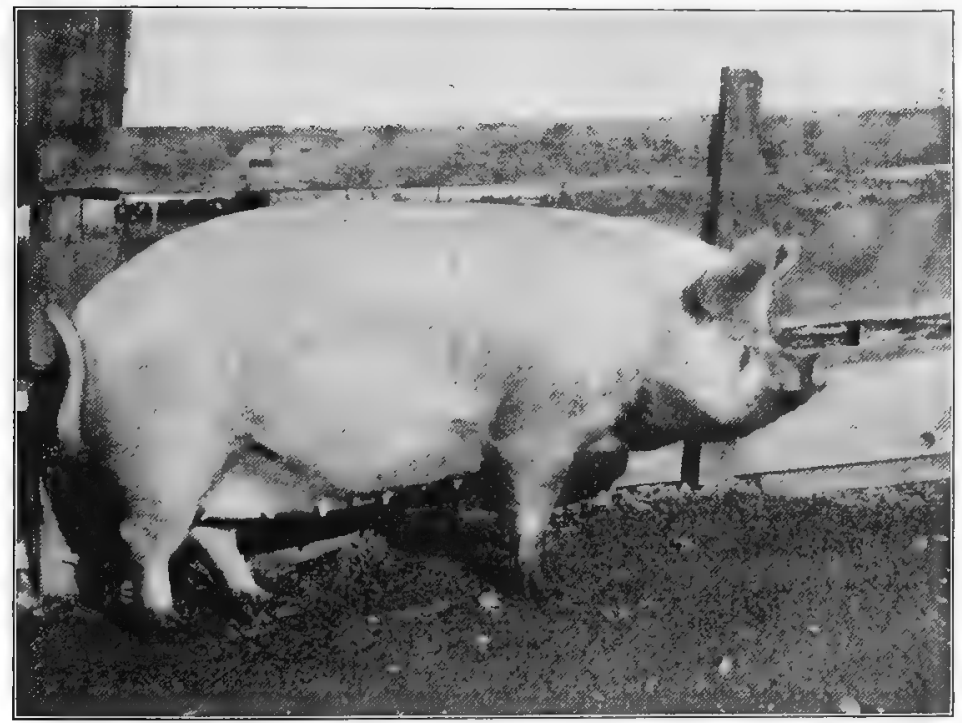

FIG. 355. Eildene 6179, a fine specimen of a Cheshire sow owned by E. S. Hill, Freeville, New York. From photograph, by courtesy of Mr. Hill

show considerable refinement of bone, frequently to an undesirable extent. The feet and pasterns are only moderately strong. The color of the hair and skin is white. Black spots may occur on the skin of pure-breds, and while objectionable do not disqualify. Both skin and hair are regarded as of superior quality by those who are familiar with the breed.

The size of the Cheshire pig is about medium, though it has been classed by Professor Shaw as the smallest of the middle-sized breeds. This is hardly in accordance with the standards of the Cheshire Swine Assocjation. The standard of excellence in 
Volume I of the herdbook states that when grown and well fattened the hogs should show a dressed weight of from 400 to 600 pounds. That represents a heavy-weight hog. There are said to be numerous instances on record of pigs dressing over 400 pounds when nine months old. The Cheshire barrows shown at the International Live-Stock Exposition in I905 were a heavy-weight lot and gave no impression of being of a small breed. One of these at eight and one-half months weighed 353 pounds. The Cheshire is said to weigh heavy for its size. Mr. A. H. Bates, once a prominent breeder of swine, has the following to say in a letter which is quoted from the "Cheshire Herdbook":

I find that buyers are not able to guess the weights of Cheshires. One lot of thirteen culls I offered at 325 pounds each. The buyers thought they would not weigh over 300 pounds. They averaged $39^{\circ}$ each. Another lot of twenty culls I offered at 150 pounds average. They weighed I $85 \frac{1}{2}$ pounds on the average. I have found it will not do to sell Cheshires by guess.

The quality of Cheshire meat ranks high. Sanders, writing of those he bred, stated that "their meat was most excellent, tender, and juicy." Others have rendered similar testimony. The flesh is fine grained and, with hogs not fed too much corn, is of a desirable bacon type.

Crossbred or grade Cheshires are not common, but are looked upon with favor in some localities. Where superior and prepotent boars are kept they may be used on common sows to material advantage, securing a high class of pork.

The Cheshire as a feeder is not well known. But few have been tried in the great swine-producing sections of the country. Only experiment stations in the Eastern states have fed Cheshires experimentally. The Maine Station reports in 1890 a comparison of breeds of swine, Cheshires gaining daily I.23 pounds, Yorkshires I.I4, Chester Whites I.08, Poland-Chinas I.oI, and Berkshires I. Two pigs of each breed were used, one of each sex, and they were fed from five to eight weeks. The Berkshires ate the least food to make a pound of gain, and the Cheshires the most. Experiments in I89I at the Maine Station, also, showed more food required for the growth of the Cheshire than for that of other breeds. 
The fecundity of the Cheshire is above medium, the sows breeding readily and producing fairly large litters, especially as commonly fed in the Eastern states.

The Cheshire as a grazer is not well known, for it has been in the main a sty-fed hog. It should, however, do well on good pastures. Shaw credits the breed with fair grazing qualities. The fact that the Cheshire has never secured much of a hold in the great swine-producing sections of our country, although introduced there, would argue that it had not satisfactorily adapted itself to Western conditions.

The popularity of the Cheshire is distinctly local, it being one of the least-known breeds in America, being rarely seen on the market or at agricultural fairs west of New York. The late S. M. Shepard, a well-known Western judge and authority on swine, states that following the exhibit of Clark at St. Louis in I 870 the breed did not gain much in favor beyond the state of its origin.

The distribution of the Cheshire pig is mainly in the eastern United States, with New York the leading state interested in the breed. Herds are also owned in the New England states, Pennsylvania, Ohio, and elsewhere, though to but a slight extent.

The Cheshire Swine Breeders' Association, organized in 1884 in New York State, promotes the purity and welfare of this breed. The association published its first volume of a herd record in I889, since which time five others have been issued up to and including 1919. 


\section{CHAPTER LXXIV}

\section{THE SMALL YORKSHIRE}

The origin of the Small Yorkshire pig, known as the Small White in England, is obscure. It has been assumed that it came from Chinese stock, though different to-day from the early Chinese type. Charles Mason of Chilton and Robert Colling of Darlington, Yorkshire, both Shorthorn cattle breeders, are the earliestknown persons to have bred Small Yorkshires, then termed "Chinese." They owned herds as early as I8I8, but nothing is known of the parent stock. Following this period the breed met with some extensive distribution in England by Shorthorn breeders.

Some strains or families of Small Whites early developed in England. A local breed, known as the Solway in Cumberland, assisted in the improvement of the Small Yorkshire, although this was descended from the Mason-Colling breeding of Small Whites. The Solway also played a part in improving the Large Yorkshire as bred by Mr. Wainman of Carhead. There existed some twenty-five or so years ago a small white pig known as the Suffolk, which was essentially absorbed by the Small Yorkshire. In Cumberland was another type, some larger than the Small Yorkshire but of the same general character, the blood of the two being freely mixed. Still another branch, descended from Mason-Colling stock, was known as the Windsor breed. A more modern and very popular strain was developed by Lord Ducie, which really resulted from a judicious blending of Cumberland and Small Yorkshire blood.

The introduction of the Small Yorkshire pig to America under that name occurred many years ago. In I 888 Curtis wrote that it was first brought to this country about I860, but did not attract much attention. Colonel Richard M. Hoe of New York and William H. Cole of New Jersey made importations in I872, I874, I 875 , I 876 , I 877 , and I 878 , and to these importations trace the 
best-known herds of America. Small Yorkshires were first exhibited at New York and New Jersey fairs in 1875, while in I876 they were extensively shown in Ohio, Indiana, and at St. Louis and also at the Centennial Exposition at Philadelphia.

The characteristics of the Small Yorkshire are most striking. This breed among swine is the most highly developed of any from the standpoint of "fancy" points. The head in its most fashionable form presents a remarkable development. The face is very

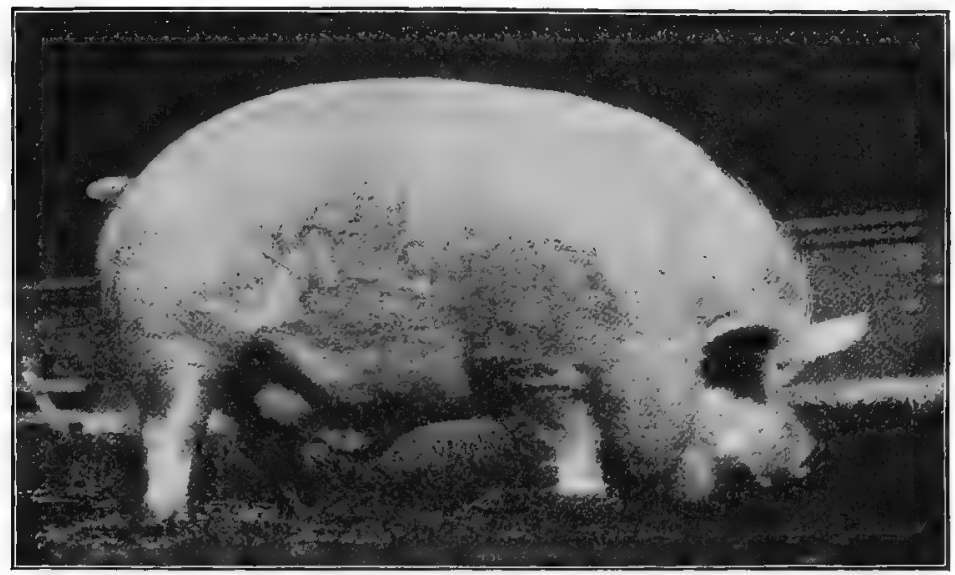

FIG. 356. A Small Yorkshire boar, first in class at the 1905 Ohio State Fair. Owned and exhibited by George Ineichen of Indiana. From photograph by the author

short and broad and is dished or curved to such a degree in specimens as to point the end of the nose upward. The lower jaw also is curved upward in a marked degree. In this highly dished face the eyes are often obscured by rolls of fat about the side of the head. The ears are short, fine, and erect, pointing forward. The jozel is naturally very round and highly developed. This breed is famous for great fat production - the neck short and thick, the back very broad, short, and deeply laid with fat or flesh, the tail set up well on a line with the back, the hams and shoulders heavy and full for the size, and the bone, hair, and quality quite refined. The color is entirely white except for black spots occasionally occurring on the skin. In referring to the characteristics of the breed Professor James Long writes: "In 
breeding the Small White pig the breeder should make it his aim to maintain the characteristic points of the variety, the chief of which are form (much in little), fineness of bone, quantity and quality of hair, shortness of snout, and aptitude to fatten." As a whole pigs of this breed have great breadth and depth for their size.

The size of the Small Yorkshire ranks it as the smallest of the breeds kept in this country. The matured pig will usually weigh from I 80 to 200 pounds, although Mr. Sanders Spencer has had them weigh nearly 300 pounds at fifteen months of age. Owing to the very compact form individuals weigh more than might be anticipated.

The early-maturing qualities of the Small Yorkshire are of a high order, so that the pigs may be fattened at almost any stage of development.

The Small Yorkshire as a feeder is easily fattened, but does not make large gains. This has been regarded as a superior sort for making small roasting pigs, as the young things finish off early for this purpose. Some British authorities on swine claim that pigs of this breed can be brought to excessive fatness on less food by half than any other breed. It will not, however, increase as rapidly in actual gains as the larger breeds. At the Vermont Experiment Station Small Yorkshires made an average daily gain of I.O4 pound live weight, having an average weight of $20 \mathrm{I}$ pounds after one hundred and eighty-four days of feeding, starting at 23 pounds. It required 353 pounds of feed for 100 pounds gain, and the carcasses dressed 84 . I per cent. This record somewhat excelled that of the Berkshire.

The quality of Small Yorkshire meat, while of fine grain and sweet, is not in favor to-day in Great Britain, containing as it does a high percentage of fat. Mr. John Walker, writing in 1905 in "Pigs for Profit," says: "As far as quality goes these pigs are despised by the butcher because they give such a very small proportion of lean to fat that the public leaves the joints of pork on the butcher's slab, it being so leanless, while the bacon curer will have naught to do with the fat little animals."

The crossbred or grade Small Yorkshire pig is in general an improvement over the pure-bred, if mated to a larger breed, for thereby a better grade of pork is produced and a more hardy and prolific stock results. 
The small Yorkshire as a grazing pig will do extremely well; at least, that is the experience in England. Professor Long states that when a Small White pig is fit for exhibition it gets very little but grass, and that he has repeatedly seen fat pigs of this breed which in summer were entirely grass-fed.

The fecundity of the Small Yorkshire is about medium, with a tendency to small litters, such as might be expected from a breed tending to excess of fat development. The nursing females produce but a moderate amount of milk.

The popularity of the Small Yorkshire has decreased to such an extent that it is but slightly bred to-day in England or America. As a breed it was largely developed by fanciers, often for show. Its excessive fat, however, caused it to become unpopular in the British market, where a lean type of bacon is most in favor. About 19I3 the Royal Agricultural Society of England discontinued recognition of this breed, and it was dropped from its prize list. This is equivalent to the death sentence of a breed in Great Britain. In the United States there are a few herds, but they are almost unknown, unless brought out for live-stock shows.

The distribution of the Small Yorkshire is mainly in England and the United States, in small herds and in a limited degree, as has been indicated. They are mainly located in the eastern United States, notably in New York, Massachusetts, and Pennsylvania, with a few small herds in the Middle West and on the Pacific slope.

The promotion of Small Yorkshire Swine in America was first brought about by the organization in New York City, in I878, of The American Small Yorkshire Club. This club, which has long been defunct, registered about fifteen hundred pigs in the first two and only volumes of the herdbook issued. The American Yorkshire Club, organized in I893, with headquarters in Minnesota, registers this breed in the "American Yorkshire Record," of which five volumes have been published. In the herdbooks of this club the Small Yorkshires are registered in a group by themselves, as Class A, the Large Yorkshires being in Class B. Only a few hundred of the Small Yorkshires have been registered in this club, these being mainly in the Western states. There is also what is known as the United States Small Yorkshire Association, with headquarters in Michigan. 


\section{CHAPTER LXXV}

\section{THE ESSEX}

The native home of the Essex pig is in the county of Essex in eastern England, lying just northeast of London. The land is level or rolling and the climate temperate and moist.

The early native type of Essex pig is said to have been of mixed color, black and white, with white shoulders, nose, and legs. It was roach-backed, flat-ribbed, had long legs, a sharp head, was coarse in bone, was a large feeder, and had a nervous disposition.

The improvement of the Essex pig was first secured by Lord Western, formerly an Essex squire, who, when in Italy in I 830 , purchased a pair of black Neapolitans, male and female, and brought them to England. The Neapolitan was then crossed upon some well-selected pigs such as were common in Essex, with most satisfactory results. It is also thought that Black Suffolk and Berkshire blood was used. The white coloring was entirely removed and a black Essex-Neapolitan pig of improved form resulted, with shorter heads and legs, more quality, and fattening much more readily. These improved pigs were vęry popular for a time. They were inbred, however, at least in Lord Western's hands, and became of enfeebled constitution, lacking in fecundity and in size.

The establishment of the Improved Essex breed was accomplished by Mr. Fisher Hobbes of Boxted Lodge, a tenant of Lord Western. Even prior to I 840 he began to use EssexNeapolitan boars on hardy, high-class Essex sows. By careful selection and mating he developed what became famous as the Improved Essex breed. Lord Western died in I844, and on his death Hobbes purchased his best breeding sows. This improved form had more size and constitution than the original EssexNeapolitan, and for more than twenty years this was maintained by selection from three distinct families. In I $840 \mathrm{Mr}$. Hobbes 
received first prizes on a boar and sow at the Royal Agricultural Society Show at Cambridge, which gave the breed much fame. Since the time of Mr. Hobbes this breed has become distributed in England, especially in Suffolk County, adjoining Essex, where the leading breeders reside. In England to-day the Essex is generally known as the Small Black breed or Black Suffolk.

The introduction of the Essex pig to America dates back to early in the last century. The old-fashioned type of Essex, it is thought, was owned about 1820 in Massachusetts, John Prince having a crossbred sow, part Essex, part Chinese. In 1839 Henry Parsons of Canada imported and kept Essex pigs near Massillon, Ohio. In I 886 S. M. Shepard wrote that of recent years a number of importations had been made and a few herds kept in New York, Michigan, Wisconsin,

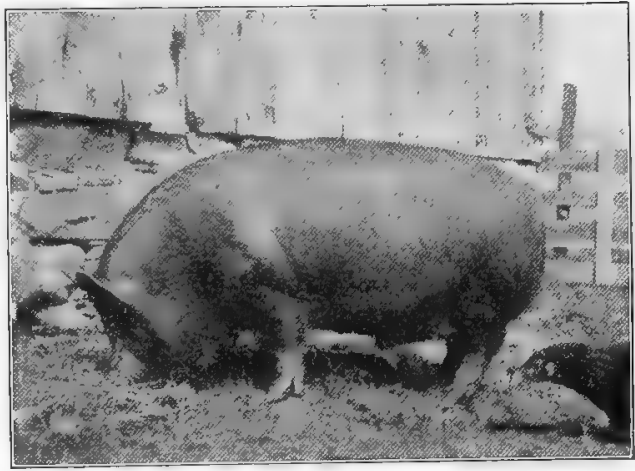

FIG. 357. An Essex boar owned by Charles Lafferty, Little Valley, New York. From photograph, by courtesy of Mr. Lafferty

Kentucky, Tennessee,

and a few other states. One of the extensive breeders and importers of twenty-five years ago was William Smith of Michigan.

Characteristics of the Essex pig. This breed has certain very distinguishing features. The color is entirely black. The head is rather short, the face is slightly dished, the forehead is broad, and the ears are small, fine, and carried erect. The jozel is rather broad and full. The neck is short, the back very broad and somewhat short and strongly carried, while the sides are deep and short. The shoulders are well laid and thickly fleshed, and the hams are thick and deep and of superior merit. The legs, which tend to be rather short, show bone of fine quality. In form the Essex is distinctly of the thick-fleshed, fat, chunky sort, and perhaps no breed in England has been fattened to so high a degree. There is also criticism of enfeebled constitution. 
The size of the Essex pig is small compared with the PolandChina or Berkshire, ranking among the smaller breeds. In I 860 Samuel Sidney wrote that "with age they attain considerable weight and often make 500 pounds at twenty-four months old." Sidney states that the Emperor, a boar bred by Fisher Hobbes, is 2 feet $8 \frac{1}{4}$ inches high at the shoulder and 6 feet I inch long. Mr. F. D. Coburn quotes William Smith, an extensive breeder of the Essex in Michigan, that these pigs often reach a weight of 400 to 500 pounds. Dr. Chase of Kansas places their weight, under ordinary treatment, when full grown at 250 to 275 pounds.

The Essex as feeders rank high in combining early maturity with great flesh production. The capacity of the breed to lay on flesh has not been placed on record by American investigators, but it has long been famous as a profitable feeding kind, although producing a fatter pork than is at present in favor abroad. The temperament of the Essex is very docile, which naturally promotes easy as well as profitable feeding.

The quality of Essex meat is fine and of excellent flavor, but a large per cent of fat to lean meat prevails unless care is exercised in the kind of foods fed. Mr. J. A. Smith of Ipswich, England, who breeds and shows the Essex, is quoted by Professor Long as saying that "one objection which is urged against the breed is their tendency to produce an undue proportion of fat, consumers complaining that the bacon is not sufficiently streaky."

The crossbred or grade Essex pig may be of considerable comparative value. A half century ago it is said that the Berkshire breed was much improved by Essex blood. In fact Essex blood, as improved by Lord Western and Fisher Hobbes, is said to have been responsible for much of the improvement through crossing or grading in the herds of England. It is a wellestablished fact that the Essex used on the coarser, rougher type imparts quality and early maturity.

The fecundity of the Essex pig became impaired by its excessive development in fat production, a criticism made against the breed years ago. Mr. Smith, already quoted, says that his pigs, when properly managed, are very prolific, fifteen or sixteen being frequently in a litter, although ten to eleven is a fair number. The breed, however, does not stand high in this respect, being 
ranked below the Berkshire. As nurses the Essex sows are regarded as simply medium, not as a rule yielding an abundance of milk. The fecundity of individuals and their capacity to nurse their young will depend in a measure on the character of food fed and condition of body.

The maturing qualities of the Essex are noteworthy, the breed having been famous for early maturity since the improvement first effected by Lord Western. Feeders easily mature at six months, though of course they represent a small type of pig.

The popularity of the Essex breed of swine is at a low ebb, and at the present time, in America, it is kept in a small way by very few breeders, largely for showing at fairs. Sanders Spencer states: 1

Suffolks, Essex, or Small Blacks, as they are usually called, have well nigh become a breed of the past; these . . had become reduced in size, as was the proportion of lean meat in the carcass, so that the prize-winning specimens were merely animated black bladders of lard, very comely to look upon, but of comparatively little value for farm purposes.

W. J. Malden, another English authority, states ${ }^{2}$ that the Essex is losing favor year by year, for the reason that it has too large a per cent of fat, a delicate constitution, and an inaptitude to "grow into money."

The distribution of Essex pigs is quite widespread. They are found in England in a small way in various counties, notably in Essex and Suffolk. They have also been exported to France and other European countries and to. Canada and Australia. In the United States a few herds have been kept in Michigan, Indiana, Texas, Nebraska, Alabama, Ohio, and elsewhere. The breed has met with favor in the South, and an Ohio breeder informs the author that he has a strong demand for his pigs from that section.

The promotion of Essex swine in America has been supervised by the American Essex Swine Association, which was organized in I887. This has always been a small association, and in recent years has been little in evidence. So far as the author can learn, but two volumes of the herdbook have been published, the last one appearing in I893, with registrations numbering up to 537 for boars and 982 for sows. In England the National Pig Breeders' Association has officially represented the breed under the title "Small Black."

1 Pigs for Breeders and Feeders, 1907. 2 Pigs for Profit, I905. 


\section{CHAPTER LXXVI}

\section{THE BACON TYPE OF PIG}

The general characteristics of the bacon pig as compared with the so-called lard hog are as follows: back not broad, head somewhat long, side long and deep, a smoother shoulder, lighter ham, and somewhat longer leg. When in good condition there is much less depth of fat than with the lard type. The muscles are evident in a greater degree than with the other type. In motion the bacon pig is animated and free of action, showing lively temperament.

The head varies rather according to breed. Excessive length is undesirable, but the Tamworth often has a very long head. A medium length of nose and face is preferred, while a broad forehead, with ample width between the eyes, which should be of good size and easily seen, denotes a mild disposition. A deep head with strong lower jaw is preferred.

Ears of a fine quality, not large, thick, and coarse, but of moderate thickness, covered with silky hair, attached neatly well up on the head, and actively carried are desirable.

The reck tends to be a bit long, but a medium length is sought, with not too much width, blending nicely with head and shoulders. The jooul lacks the extreme fullness found in the lard hog and is free from wrinkles such as often occur with the heavy jowl. This part bacon-pig buyers regard as of little importance.

The shoulders lie well into the body and do not bulge out prominently. They should have considerable width and depth, with a neat, smooth, not too deep covering of flesh. A good specimen of this type never has prominent shoulders. Some extra thickness of skin and heaviness is expected with boars, but no notable heaviness.

The forelegs should be well placed, coming down true, either viewed from front or side, the knees not "knocking in " and the toes turning out but with the pasterns being strongly carried, and the pig standing up in shapely form on the toes. A fine, hard 
bone is very important, as evidenced by clean-cut limbs and smooth joints, lacking coarseness and meatiness. A smooth, clean, hard bone is evidence of quality and is associated with the better sort of dressing out in killing.

The chest may be compared to that of the race horse. It should be deep and full, yet not too broad. As one looks at the front of the pig the breast and brisket appear full and not peaked. Viewed

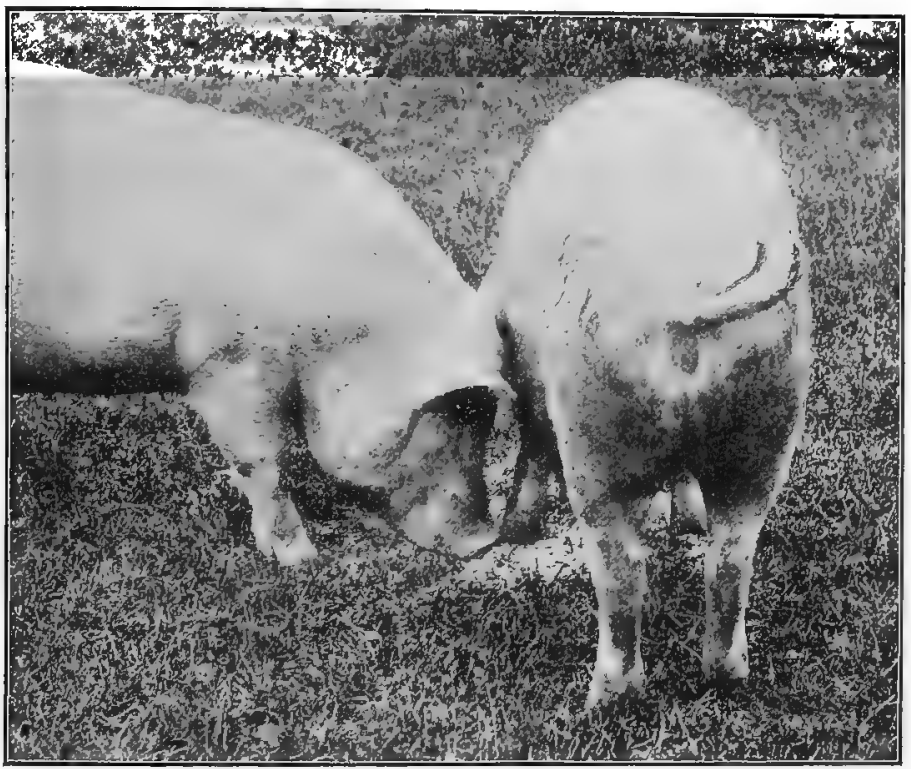

FIG. 358. A shoulder and ham view of the bacon type of pig, showing the smooth shoulder and neatly tapering ham. From photograph, by courtesy of Professor G. E. Day

from one side the brisket projects slightly beyond the legs. A hidden, retreating brisket indicates a poor constitution.

The back should be carried level and show no sag, and the width should be uniformly maintained from shoulder to ham. A strong, nicely arched loin, as wide as any point of the back and smoothly fleshed, is important. A thickness of one and one-quarter to one and one-half inch of fat along the back is regarded as best on the finished pig. The back of this type has a moderately arched rib, not flat, giving a body capacity in harmony with the best feeder. 
The sides are a most important part, because from here comes the bacon so highly valued in this class. The sides must be long, evenly carried from shoulder to ham, be thick and full at flank, and of moderate depth. A very deep side of a paunchy character provides too much belly or cheap meat. Breeders of bacon hogs, however, place a premium on brood sows of great length and depth, for these features are associated with high-class breeding and feeding capacity. The side must be quite smooth and free of wrinkles and be covered evenly with flesh. In touching on this subject the Ingersoll Packing Company of Canada says: "The packer calls for the long, lean pigs, as they are the ones that suit best and are most difficult to procure; this is the only kind that will furnish the desired 'Wiltshire side,' and it will also make any of the other cuts the market calls for."

The rump and hams lack the heavy development of the lard type, but a level, long, moderately broad rump is important. The hams in their lower parts should be long, gradually tapering, not necessarily split up high between, with shallow, neatly turned twist. They should also be broad from front to rear, with a medium thick covering of flesh, tapering to the hocks.

The hind legs should have all the merits of the forelegs in bone, quality, and smoothness, and in position of pasterns and toes. Besides this the hocks should be well placed, being smooth of joint and neither close nor wide behind.

The quality of the bacon pig is most important. This is seen in the clean, smooth bone and joints and the abundant hair, lacking in coarseness, lying close to the mellow skin. Wrinkles should be lacking, and the entire body be smooth and evenly covered with flesh in breeding as well as in feeding stock.

The weight of bacon pigs most acceptable in the market is from I 70 to I 80 pounds, although 200 is not excessive. Danish bacon pigs range from 180 to 220 pounds. The larger type is not approved in Canada, the smaller being preferred.

Breeding bacon pigs should show the characteristics associated with sex, but in general the above description applies to the bacon type. The boar should have a strong, masculine head, neck, and shoulder, the sow a smaller, more refined sort, with more depth of belly than possessed by boar or barrow. 
The demand for the bacon pig in America has not been very active. Only in recent years, perhaps since the beginning of the twentieth century, has the American swine producer had his attention directed to this type of pig. The British market demands superior bacon, and a call for such meat is growing in America. Denmark, Ireland, and Canada furnish most of the bacon consumed in England and Scotland. This bacon shows a liberal mixture of lean with fat and suits the foreign trade much better than the fatter, thicker-fleshed type produced in the Mississippi Valley. In spite of the British demand for high-class bacon, neither the American pork producer nor the packer has seriously considered bacon production of this kind. Without question, however, our people are consuming greatly increased amounts of bacon, and the demand is steadily growing for a high-class article. The future will no doubt show more serious interest in this type of pig in America, with a resulting improvement in production of breeding stock. 


\section{CHAPTER LXXVII}

\section{THE LARGE YORKSHIRE}

The ancestry of the Large Yorkshire clearly goes back ovel a century. Swine from time immemorial have been known in England, and a large, coarse, leggy, narrow-backed, white hog was common in early days in that country. In 1789 George Culley referred to what is no doubt parent stock of the breed, as follows:

There was a breed of large white pigs with very large ears hanging over their eyes, which a few years ago were very common in many parts of Yorkshire and Lancashire. They were very plain, thin, awkward hogs, with very long legs, but what distinguished them more were two wattles or dugs, not unlike the teats of a cow's udder, which hung down from their throats on each side.

Early in the nineteenth century Dickson wrote that the old Yorkshire breed was the worst of the large sort, being long legged and weak loined, with a constitution not of the soundest kind. These were, however, he writes, being improved by Berkshire stock. In I 842 Low wrote as follows: "In Yorkshire, Lincolnshire, Norfolk, and generally in the eastern counties there are breeds of large size, of a white color, and with pendent ears. These breeds have been cultivated with more or less care, and have all been affected in their form and characters by crossing." The white pigs of Cumberland County were also closely related to those of Yorkshire and were much intermixed.

This old type of Yorkshire had a strong coat of white hair, some blackish or bluish skin spots covered with white hair, a large, long head, big ears, and strong bone. It was slow of maturity and was fed up to over eight hundred pounds.

The modernizing of the Large Yorkshire began about the middle of the nineteenth century. Sidney credits the first correct movement to improve by using white Leicesters on old Yorkshires. These Leicesters were large, with smaller heads than the Yorkshire, had erect ears, were fine of hair and light of bone compared with the others. This cross was improved by breeding the 
largest and best young sows to Small Yorkshire boars of great fattening capacity. The improvement thus effected mainly took place sixty or so years ago about the cities of Leeds, Keighley, and Skipton in the county of York, and to a considerable extent by factory hands and laborers. In I85 I Joseph Tuley, a weaver of Keighley, exhibited a pig at the Royal. Agricultural Show at Windsor that attracted great attention, and later his strain of Large Yorkshires was very popular, and his pigs sold at high

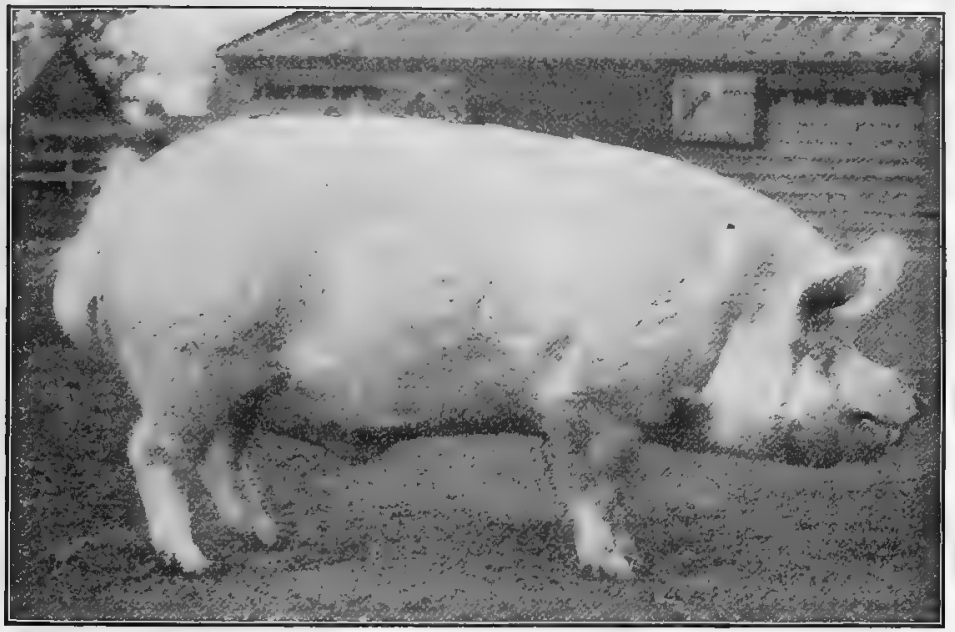

FIG. 359. Holywell Royalty II, a fine example of a Large Yorkshire boar. Bred and owned by Sanders Spencer, St. Ives, England. From photograph, by courtesy of Mr. Spencer

prices. At this time the pig breeders of Yorkshire and Cumberland kept pedigrees of their pigs, which they printed. The agricultural societies of the region offered prizes to promote the breed, and there was keen competition in the show ring. The various towns had agricultural societies and shows. Regarding these Sidney wrote as follows :

At these shows there is often a row of twenty or thirty fat pigs, worth from $£^{6}$ to $£_{1} 2$ each, all as white as soap and water can make them, stretched on beds of clean straw, with wrappers of some kind to protect them from the sun or rain, contending for the first prize, $£ 4$; second prize, $£ 3$; third prize, $£ 2$; fourth prize, $£$ I. 
At this time Yorkshire was credited with being in the first rank as a pig-breeding county, having the largest white breed in England and the largest hogs in the world.

The early improvers of the Large Yorkshire may perhaps date from Mr. Tuley, as has been indicated. From a sow Matchless and a boar Sampson of his breeding came some of his best stock. Mr. W. B. Wainman of Carhead, Yorkshire, used hogs of Tuley blood and added to the merits of the breed, for he produced stock

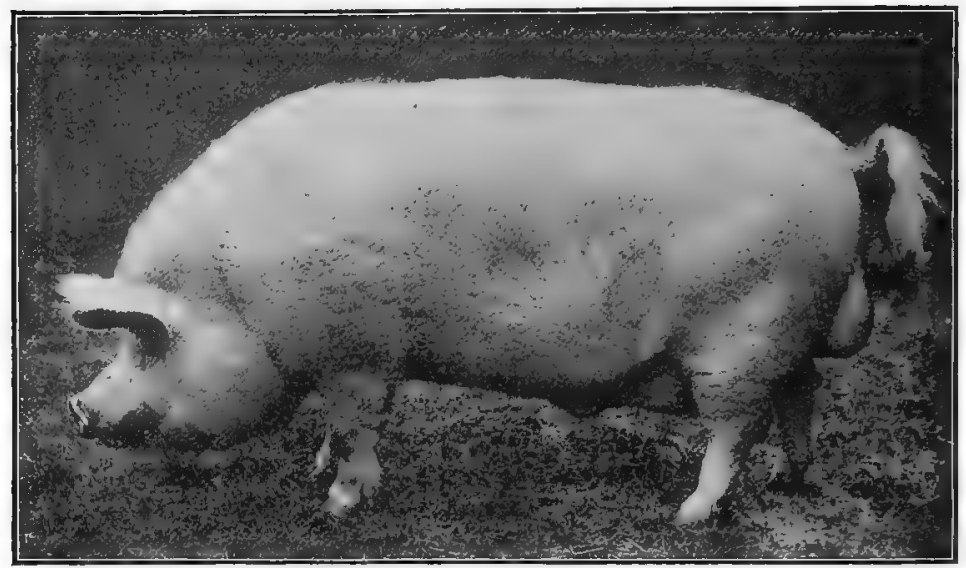

FIG. 360. Roger (7203), first-prize and champion Large Yorkshire boar and winner of the Berkshire Society gold medal at the Royal Agricultural Society of England Show, 1904. Owned by the Earl of Ellesmere. From photograph, by courtesy of William Cooper \& Nephews, Berkhampstead, England

of much quality and sent them to various parts of the world. In his herd selected pigs by careful feeding would attain a weight of about five hundred pounds in twelve months. Besides Tuley and Wainman numerous others have long bred and improved this breed, notably Sanders Spencer of St. Ives, Huntingdon County, who for a half century was a most distinguished breeder.

The introduction of the Large Yorkshire to the United States occurred prior to 1840 , and in I $84 \mathrm{I}$ a pair was imported by A. B. Allen and brought to Ohio. Undoubtedly specimens of this breed have been brought to America from time to time for over a century. In I 893 Wilcox and Liggett of Minnesota imported some of the more modern type, and from this and Canadian 
stock have come most of the present Large Yorkshire stock in this country. The people of Canada have been breeding Yorkshires for many years, and the most important herds in America are in that country.

The important characteristics of the Large Yorkshire are as follows: the head is medium long and should have but little upward curve. Some prefer a lengthy head, but modern ideas object to too much extension. A broad, strong underjaw is desired.

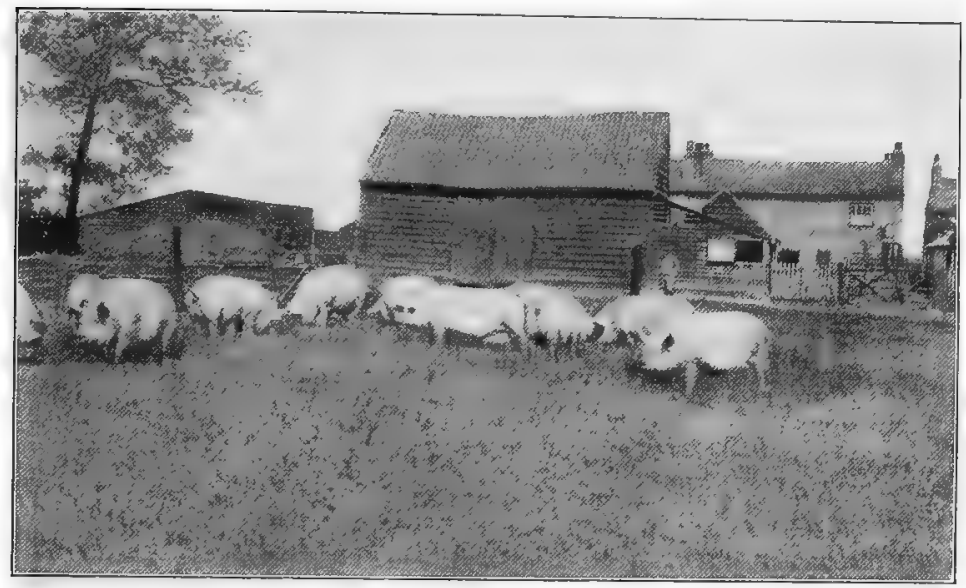

Fig. 36r. Large Yorkshire brood sows owned by Chivers \& Sons, Histon, England. These are very large sows of much excellence. From photograph by the author

The ears tend to be heavy and droop forward. They should be fine, of medium size, and be carried well upward but pointing forward slightly. Loppy ears are objectionable.

The body should have considerable length. The back is not broad like that of the Poland-China, but should be of fair and uniform width with considerable depth, the sides being long and deep at the flanks and full between shoulder and hip. From the American point of view this breed tends to have a weak loin and too narrow a back.

The hams are not expected to be extremely fat and heavy, but should be of good size and thickness, with the thighs well carried down. Thin thighs and cow hocks are very common with this type of hog but are not admired by critics. 
The legs should be of medium length with good bone. The tendency is towards an undesirably long leg, whereas its length at maturity should not exceed the depth of body. It is also important that the legs come down straight and be free of kneeing or hocking-in.

The color of the hair should be white on every part of the body. Bluish or blackish spots occur occasionally on the skin under this white hair, and, while objected to by fanciers, do not affect purity of breeding, neither do they disqualify registration. The skin should be pink and healthy. White pigs in America, especially in the sunny West and South, tend to scurfiness of skin and sun scald, which causes them to be more or less unpopular.

The type of the Large Yorkshire pig fashionable in the show yard, says Sanders Spencer, ${ }^{1}$ varies.

The chief points to be caught are length and depth of body, thickness of flank, length of hind quarters and squareness of hams, lightness of fore quarters, the head being generally of fair length, lightness in the jowl, and width between the eyes. The bone and skin should be firm and the hair straight and silky.

Although there have been the usual variations in the type and form of the Large White pig of the day, the general character of the pig of the breed which was most in demand by practical men is still preferred by the baconcurer and the purveyor of pork. Among the changes noticed during the last thirty years was the reversion for a brief period to the thick, compact type, after some dissatisfaction had been created by the cultivation of length of head and leg and strength of bone. A number of Large Yorkshires of this latter type were exported to the United States some twenty-five years ago, with results most unfortunate to the breed.

The size of the Large Yorkshire places this breed in the first rank. Long writes of a Wainman sow that weighed $\mathrm{I} 203$ pounds. In I90 I several sows of the breed were exhibited at the International Live-Stock Exposition which weighed over Iooo pounds each. Mr. Spencer, in reply to a letter from Professor Long, says:

The Large Whites reach, in the heaviest animals, I 2 stone (I 68 pounds) at six months old; at nine months, 20 stone to 25 stone ( $280-350$ pounds); at twelve months, 30 stone ( 420 pounds); and at eighteen months, 45 stone ( 630 pounds). . Sampson VI, a boar bred and exhibited by myself, and winner at the Royal two years in succession, weighed, alive, 9 $\frac{3}{4}$ hundredweight (I092 pounds) at twenty-three months, and was light in bone and carried but little offal.

${ }^{1}$ Country, Gentleman, November 23, 1912. 
While the market demand for breeding stock is for good-sized animals at maturity, excessive weight is undesirable. A boar in moderate flesh that weighs 700 pounds would be very acceptable, while 600 pounds for a sow in breeding condition would meet with most requirements. There are now comparatively few of this very large, coarse type of pig.

Early maturity with the Large Yorkshire is not a characteristic feature. The pigs grow well, but do not fatten and mature after the manner of the lard type of pigs. The Yorkshire keeps growing when other breeds fatten and finish. So far as weight is concerned,

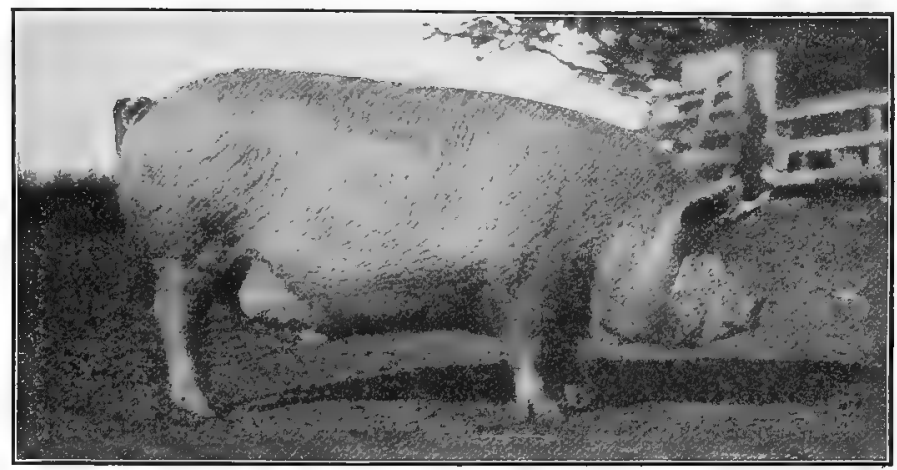

FIG. 362. A pure-bred Large Yorkshire barrow about six months old, one of the champion pen of the breed in 1905 at the International Live-Stock Exposition, Chicago. Bred and exhibited by Ohio State University. From photograph by the author

of pigs of several breeds farrowed at the same date and carried along under similar conditions for six months, the Yorkshire will very likely weigh decidedly the most. Feeders in the corn belt, used to pigs that will finish off in eight months, find the Large Yorkshire slow to mature. In fact, having a leaner inheritance, it cannot be expected to fatten and mature in the manner of the lard hog.

Large Yorkshire crossbreds are a very superior type. The Yorkshire boar bred to either Poland-China or Berkshire sows produces most excellent feeders. In experiments conducted by the author with this combination the pigs grew rapidly, fed extremely well, finished off smoothly, and produced the best sort of meat. At the International Live-Stock Exposition there have 
been shown model porkers, the progeny of Yorkshire boars, out of lard-type sows. In numerous crossbreds examined the interesting fact has been brought out that the white color of the Yorkshire is almost invariably dominant. This demonstrates the prepotency and fixity of character of the breed. The use of Large Yorkshire boars on our typical American sows should not only give larger and better frames but produce most desirable feeders and also increase the size of litters and thus improve the defective fecundity of many sows.

The reputation of the Large Yorkshire as a bacon producer is of the first class. For many years it has been the standard British breed used in bacon production. Further, Large Yorkshire boars on common sows have sired a large percentage of the British bacon stock. In placing the Irish bacon industry on a substantial basis, Large Yorkshires were relied upon to furnish the type of carcass most desired. Considerable numbers of boars and sows of this breed have been exported from England to Denmark and Sweden. Bacon production is one of the great industries of Denmark, and here the Large Yorkshire boar is extensively crossed on ordinary Danish sows. Canadian packing establishments also not only advocate the Yorkshire as a highclass bacon breed but they have furthermore taken an active part in placing pure-bred boars among farmers engaged in supplying them with hogs. Some years ago W. H. Fisher, prominent as a breeder of Large Yorkshires, addressed letters to a number of American packers for their opinions on the merits of Yorkshire bacon. Armour \& Company replied:

Within the last four or five years we have not been able to produce sufficient prime bacon to satisfy the demands of our customers. This coupled with the high standard of prices of the past few years would justify the breeders and feeders of Yorkshire hogs to increase their output. Another encouragement is the constant demand for hogs of the bacon type throughout the year; other types are wanted at periods, but well-fed bacon hogs can be sold at a premium any time they are placed in the market.

John Morrell \& Company of Liverpool, England, but having a packing-house in Iowa, wrote as follows :

We have for years distributed Yorkshire boars within the limits of our territory, and we pay a premium of twenty-five cents per hundred pounds 
for pure Yorkshires or good grades. Our reason for doing this is that it is the recognized type of hog for making English meat and the best grade of American breakfast bacon.

The Large Yorkshires as killers dress out only just fair. Sanders Spencer credits the breed with dressing 76 to 82 per cent. At the Ontario Provincial Winter Fair in Igor the average percentage of dressed weight of the Yorkshire carcass was 78.4. It is well established that the older and fatter hog dresses out the heaviest per cent of carcass to offal. Within the breed the percentage of dressing will depend on the degree of fatness, and inasmuch as bacon hogs never carry so great an amount of fat as do those of the lard type, one should not expect them to dress equally high. There are comparatively few records of carcass contests in which Large Yorkshires have participated.

The Large Yorkshires as feeders have not given equal satisfaction in America. They tend to grow, rather than fatten, as the cornbelt farmer desires; and while they will attain plenty of weight, they will not feed off to an early finish along with a PolandChina or Chester White. It is for this reason that so many farmers have discontinued feeding Large Yorkshires. They want what they regard as an easier feeder, quite losing sight of the purpose for which this breed is best adapted. Professor G. E. Day is a recognized Canadian authority on bacon production, and he states : ${ }^{1}$

From a bacon curer's standpoint, Large Yorkshires will reach desirable market weight and condition at as early an age as any existing breed, and there are few breeds that will equal them in this respect. . From the fact that it grows rapidly and develops bone and muscle more rapidly than it forms fat, feeders are inclined to regard the Large Yorkshire as an expensive hog to feed; but experiments go to show that such is not the case, and that, under most circumstances, it is capable of giving as large gains for feed consumed as any other breed.

Corn exclusively is not recommended for this breed, but when fed good grain mixtures, such as corn, oats, and middlings, satisfactory results follow.

The Yorkshire as a grazer is of secondary importance. In those countries where this breed is common, grazing of swine is rarely practiced. These pigs, however, will do very well on pasture as provided by the American feeder.

1 Productive Swine.Husbandry (1913), p. 94. 
The Large Yorkshire as a prolific breed stands in the front rank. The females from very early days have been noted for producing large litters. Long refers to a sow of Wainman breeding that reared 153 pigs in 13 litters, while one of her daughters raised 33 pigs in 3 litters. Richard Gibson, formerly a prominent Canadian breeder, owned an imported sow that produced 96 pigs in three years without the least apparent injury to her constitution. James Howard, long an English Yorkshire breeder of prominence, prefers sows of this breed to have twelve teats and emphasizes the

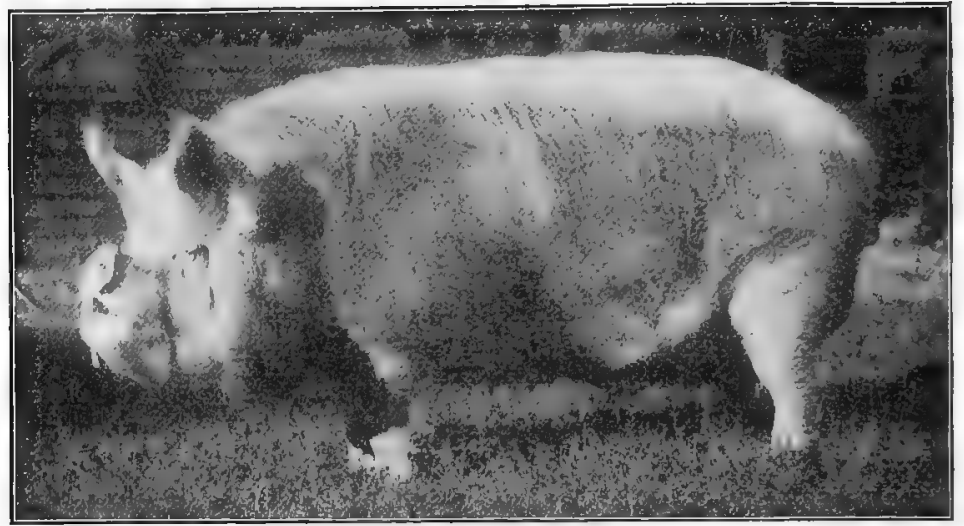

Fig. 363. Holywell Rosador, a Middle White boar, first prize in 1899 at the Royal Counties Show and at the Highland and Agricultural Society of Scotland Show. Bred and exhibited by Saunders Spencer, St. Ives, England. From photograph by the author

importance of her being a good milker. In the herd of the Ohio State University 17 sows in 38 litters farrowed 436 pigs, an average of I I.47 to the litter. There were but 6 litters of less than Io each, while the largest litter in the 38 was 18 .

The popularity of the Large Yorkshire in the United States is quite restricted, and the breed during the years has not grown much in favor. Among those breeding Large Yorkshires are very few who have given much publicity to their operations. Without question this is a breed of distinct merit in bacon production and in farrowing large litters. Its slow fattening character, its usual lean, long, narrow, leggy type, and its white color furnish more or less of the objection of the Western pork producer. However, in 
view of the great increase in the use of bacon, it is surprising that more people have not taken up the Large Yorkshire for its production. If good-sized hogs of the right type were selected, no doubt the breed would steadily grow in popular favor, as, indeed, it should. It may be classed as one of the world's great breeds of swine.

The distribution of the Large Yorkshire is very widespread. It is the leading breed of England, Scotland, Ireland, Canada, and Denmark, and has had a wide distribution in continental Europe. Sanders Spencer has exported them from England to forty-six different countries, embracing Europe, Asia, Africa, Australia, and North and South America. In the United States, Yorkshires are bred to a limited extent in Ohio, Minnesota, Iowa, Indiana, Illinois, New York, and elsewhere. In recent years important herds have been established in Ohio.

The American Yorkshire Club was organized in 1893 for the promotion of the breed. The official headquarters have long been in Minnesota. Up to January I, 1920, five herdbooks had been published, in which were also registered a small number of Middle and Small Yorkshires, these being grouped as Class A and the Large Yorkshires as Class B. In Canada these pigs are recorded in the Canadian Swine Breeders' Record, published by the government. In Volume XXIX, for I9I8, the registration of Large Yorkshires concludes with the grand-total number 62747 . In England, Scotland, Ireland, and Wales, Yorkshires are recorded by the National Pig Breeders' Association.

Middle Whites, as they are known in Great Britain, represent a special type of Yorkshire. They have a shorter, wider, and more dished face, a broader back, heavier shoulders and hams, and commonly carry more fat or condition than does the true type of Large Yorkshire. Middle Whites may come from Large Yorkshire litters, being selections of the correct form, or they may result from crossing the small type of Yorkshire boars on large sows. The Middle White is recognized as a breed in Britain though not in America. A distinct tendency exists among Yorkshire breeders in the United States to breed along the Middle White type, and without doubt many such pigs are registered in the American herdbook. With no other breed of swine exhibited at American shows is it so essential for the judge to draw a sharp line of discrimination on type. 


\section{CHAPTER LXXVIII}

\section{THE TAMWORTH}

The native home of the Tamworth is the counties of Stafford, Leicester, Northampton, and Warwick in central England, but notably in Stafford. This is generally a rolling but not very hilly region, with a temperate, moist climate. The name of the breed is taken from the town of Tamworth, located partly in Staffordshire and partly in Warwickshire. Sidney, in I87I, says, "the Staffordshire breed is the 'Tamworth.'

The ancestry of the Tamworth pig is obscure. Tradition and history refer to a pig of Tamworth type existing early in the last century. Most writers on the pig say but little of this breed, and we know almost nothing of its early development. Spencer states that this is one of the oldest English varieties, which fed in large droves on oak and beech mast in the forests of the midland counties even before the battle of Waterloo. In an address before a breeders' association at Detroit in I899, Mr. E. N. Ball stated that the breed was introduced into England from Ireland by Sir Robert Peel about I8I2, but the author has found no evidence elsewhere to support this statement.

The early type of Tamworth was long of leg and snout, narrow of back, and shallow of body, slow to mature, very active and hardy, and usually of a sandy or reddish color.

The improvement of the Tamworth came with the conversion of England into a cultivated region, when farmers wanted a less active type of pig. The opinion seems to prevail that this breed was mainly improved by selection, the breeders seeking to secure a quieter type, fattening more rapidly than of old and yet retaining the characteristic color. In I $886 \mathrm{Mr}$. F. C. Fidgeon of Tamworth, England, who had a considerable knowledge of the breed, informed Professor Long that in the nearly sixty years he had known the Tamworth he had never noticed so great a change as from about $\mathrm{I} 880$ to $\mathrm{I} 886$. 
A generation ago [he says] they were a lean pig, of a very dark red color, which never varied in shade and were provided with a very long snout. Of late the color has altered in shade, having become a sandy or lighter red, a point which is apparently growing in favor, although I question very much whether this color is as pure as the original dark red, for I believe it has been obtained by a not very distant cross with a white pig.

Spencer has also suggested the white cross and Neapolitan cross. For years the breed was almost unnoticed. In comparatively recent years it has received renewed attention for its bacon value.

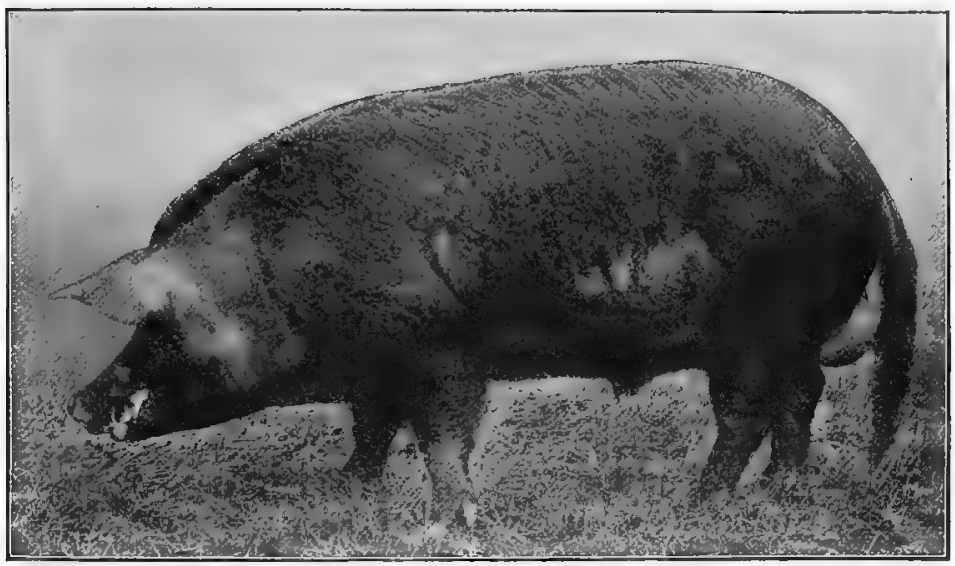

FIG. 364. A Tamworth boar, winner of first prize in class at the I904 show of the Royal Agricultural Society of England. Exhibited by Robert Ibbotson. From photograph, by courtesy of William Cooper \& Nephews, Berkhampstead, England

In 1847 a Tamworth sow won first honors at the show of the Royal Agricultural Society of England, but the breed was not given a special class recognition until I885. At the I9I4 Royal Show there were entered 42 exhibits of Tamworths, as compared with I 32 of Large Yorkshires.

The introduction of the Tamworth to America is generally credited to Mr. Thomas Bennett of Rossville, Illinois, who imported some pure-bred pigs in I882. Professor Shaw states that since I 888 large numbers have been introduced into Canada. Most of the importations to the United States have been from Canada. Characteristics of the Tamworth. The color is red, varying in shade from light to dark, "a golden red hair on a flesh-colored 
skin free from black" being preferred. In form the Tamworth is large, lean in type, and long in head, body, and leg. The head is a very striking feature, being notably long, inclined to be narrow, and with a large snout, which is usually straight. The National Pig Breeders' Association standard of excellence specifies that the snout should be "moderately long and quite straight," with the "face slightly dished" and "wide between ears." The ears should be rather large, but not coarse, and should stand erect or lean but slightly forward, not breaking over. It is not uncommon to see Tamworths with coarse, long heads and large, heavy, poorly carried ears, and these make an unpleasant impression on the beholder. The modern type of Tamworth is free of all coarseness of head. The back and loin tend to be narrow, but show considerable length. It is important that the sides be long and deep, though too frequently they lack in the latter respect, as based on American standards. It is highly important that the shoulders be fine and deeply laid in, and the hams "broad and full, well let down to the hocks," yet without the roundness or plumpness of the lard type. The legs should be strong, neat, not too long, and be "set well outside of the body." In judging Tamworths emphasis should be placed on smoothness, trimness, firm flesh, and quality. In temperament individuals of this breed are usually very active, almost to the point of restlessness, although the disposition is mild. The National Pig Breeders' Association of Great Britain lists the following as objectionable points in the Tamworth: "Black hair, very light or ginger hair, curly coat, coarse mane, black spots on skin, slouch or drooping ears, short or turned up snout, heavy shoulders, wrinkled skin, inbent knees, and hollowness back of shoulders."

The size of the Tamworth classes it among the large breeds of swine. The average mature boar will probably weigh about 600 pounds, with sows approximating 450 pounds. Boars have been exhibited in recent years at American fairs that are said to have weighed up toward 1000 pounds. The Buffalo Rerieres (August 17, I899) refers to a Tamworth boar in England, under three years of age, which alive weighed 1607 pounds and dressed I 330 pounds. Such a weight as this last is open to question and is given here simply as evidence of the reputed 
large size of the Tamworth. At six months of age, pigs should weigh about 175 pounds, and 300 pounds at twelve months.

The Tamworth as a bacon pig ranks very high. The claim is made that owing to dissatisfaction with the fat quality of bacon produced in the average pig in England along in the early eighties, the Tamworth came to the front to supply the necessary lean meat. The sides are long and (in good specimens) deep and have a superior admixture of lean and fat of highly acceptable quality. Professor Day states ${ }^{1}$ that "the Tamworth produces bacon of exceptionally fine quality, well mixed with lean, and fine in the grain."

The maturing quality of the Tamworth is inferior, probably being less forward in development than any other breed in America. While growth is constantly made, an early-finished, matured product does not usually obtain. However, some British feeders have argued that the Tamworth will mature early. Mr. G. M. Allender, long a famous British breeder, says: "I find that the Tamworths feed early, and I have hams now hanging. which exceed 20 pounds each in weight, smoked and dried, although they were cut from pigs which were only twenty-seven weeks old." This hardly seems credible. Mitchell Brothers of Birmingham, who won first prize at the Birmingham Fat-Stock Show in I884, informed Professor Long that the Tamworths they exhibited were only five and one-half months old and weighed I 2 score per pig, or 240 pounds. These pigs were from a sow twelve months old at farrowing. Professor G. E. Day specifies that for a bacon carcass fit for export the Tamworth will mature at as early an age as any other breed. This will not apply, however, where fat production is involved.

The feeding quality of the Tamworth is fairly good, the pig making considerable growth for the food fed. Mr. E. N. Ball of Michigan reports on 3 pigs about sixteen weeks old, which during ninety-seven days gained a total of 340 pounds from 1224 pounds of grain, or 100 pounds of gain for 360 pounds of feed. Rommel, of the United States Department of Agriculture, averaging the results of feeding six breeds as brought out in representative tests by experiment stations, shows that in sixteen tests involving 
92 Tamworths it required 344 pounds of feed for IoO pounds gain live weight, less than was required for any other breed. In the Iowa feeding trials on breeds three experiments were conducted, showing daily gains for Tamworths of 1.77 and 1.05 pounds respectively, the average cost per pound of gain being 2.42 cents, ranking fifth in cost of production among the breeds. The lowa experiments also showed that the Tamworths dressed out in carcass very well, the average being 78.46 per cent for 14 pigs, comparing creditably with five other breeds and surpassing three of them.

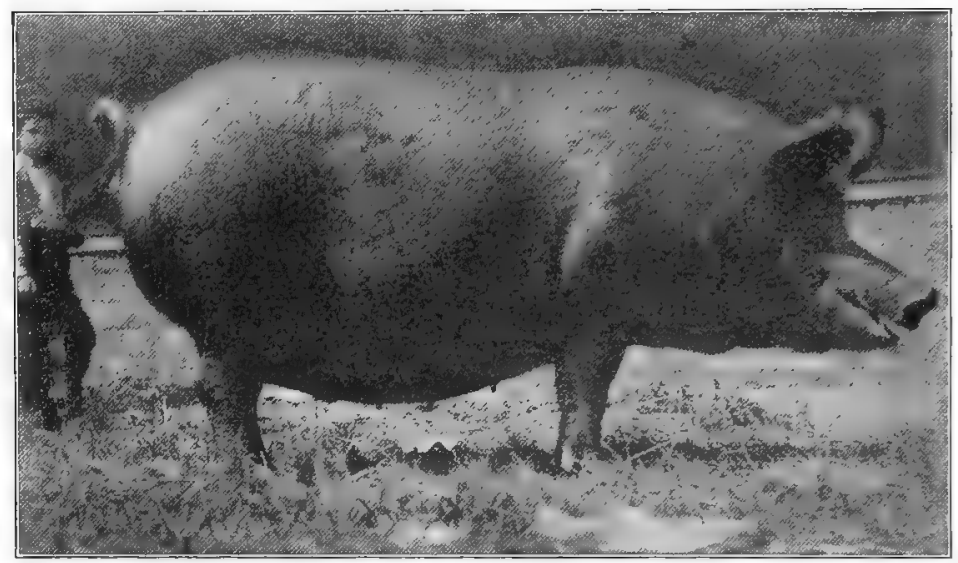

Fig. 365. Springbrook Nell, a successful prize-winning Tamworth sow at many state fairs. Owned by W. W. Morton, Russellville, Kentucky. From photograph by the author

At the Ontario Agricultural College, in comparisons of six breeds, covering five years of feeding, 390.I 7 pounds meal were required for IoO pounds gain, this being the best showing made by any breed but the Berkshire.

The crossbred or grade Tamworth has considerable merit. Tamworth boars on Berkshire sows are a favorite cross with some feeders in England. When bacon curers complained of Berkshires fattening too heavily, the Tamworth cross was resorted to with desirable results. Long reports that the Messrs. Mitchell during two years bred and fed 300 pigs, all by Tamworth boars from Berkshire and Yorkshire sows that averaged 200 to 240 pounds weight under nine months old. Tamworth boars bred on the fat type of 
American sows will produce a very attractive, easy-feeding, highly marketable porker. A Champaign County (Ohio) farmer, K. S. Hawk, produced feeding shoats with much success, using a Tamworth boar on grade Duroc-Jersey sows. In January he shipped forty-six April, May, and June pigs that averaged 318 pounds and brought $\$ 6.80$ straight at Cleveland, I 3 cents over the general market. The Tamworth, being very prepotent, sires offspring uniformly red in color and, when mated with the lard-type female, produces a very neat and attractive killer that dresses out well.

The fecundity of the Tamworth is a striking feature of the breed. Mr. Fidgeon reports his sows as usually bringing from ten to fifteen pigs at a litter. It is generally conceded in Britain that the Tamworth is unsurpassed for fecundity and size of litter. One of the quoted objections to the breed in England was that it was too prolific, the sows bringing 50 per cent too many young ones. Professor H. M. Cottrell writes : 1

The two strongest characteristics of the Tamworth are lean meat and large litters. For two years on the agricultural college (Colorado) farm, the average for all sows was ro live pigs to a litter. A two-year-old sow, weighing 750 pounds, had 18 live pigs at one farrowing. Fully matured sows, well cared for, can produce two litters a year. A Tamworth sow at the Iowa Agricultural College raised 33 pigs in one year.

It is this highly important quality of fecundity which has furnished important arguments for Tamworth breeders in behalf of the breed. The sows make excellent mothers and, as might be expected in this type, produce an abundance of milk.

The Tamworth as a grazer ranks very high. While not used as a grazing pig in its native home, in the United States it has proved very satisfactory in this respect. The pigs are hardy and naturally adapt themselves to clover or rape or any other pasture suited to swine. Day states ${ }^{2}$ that the Tamworth, like the Large Yorkshire, "is probably rather better adapted to pen feeding than to pasturing" ; however, these hogs have grazed well at several experimental farms in the United States. The late Professor John A. Craig states ${ }^{3}$ that the Tamworth holds first rank in this respect.

\footnotetext{
1 Indiana Famer, July 4, I 908.

2 Productive Swine Husbandry (I913), p. Ioo.

B National Szuine Magazine, July, 1909.
} 
Too frequently it is this excellent quality of the breed that induces growers to choose them in preference to others on the supposition that during the busy summer season, when the work of cultivating and harvesting the crops is crowding all hands on the farm, they will take care of themselves and grow just as good as ever.

Criticisms of the Tamworth. Several characteristics of the Tamworth have caused unfavorable comment in America. The long head, narrow back, short ribs, and long legs are not looked upon with favor by American breeders. They will not accept the Tamworth, regarding it as an unprofitable feeder and an undesirable type. However, if one will select the more approved type, with good depth of body, long smooth sides, and superior quality, such as has been produced to a fair degree in recent years, this criticism will not hold good. There has been a tendency to be unfair in criticism of the Tamworth, which the author feels convinced is based on old rather than on new standards. It is the heavyheaded, long-legged, rough sort that has caused this criticism. If buyers will be discriminating they will have no difficulty to-day in securing a class of Tamworths that in good hands should do well. The present-day bacon demand justifies the use of the breed.

The distribution of the Tamworth is very limited. The breed is kept in a small way in England, and the same applies to Canada - and the United States. Specimens are not shown in great numbers at the important stock shows of England or in this country. The principal herds in America are found in Ontario, Canada, and in the United States, more especially in Kentucky, Iowa, Illinois, Kansas, Texas, Wisconsin, and Ohio.

Organizations to promote Tamworths exist in England in the authority of the National Pig Breeders' Association of Great Britain and, in America, in the American Tamworth Swine Record Association, the latter being organized in Michigan in 1897. The American association up to 1919 has published four small herd records. The Dominion Swine Breeders' Association of Canada also registers this breed under government supervision. 


\section{INDEX}

Aaggie family, 373

Aberdeen-Angus bullock, crossbred or grade, 292

Aberdeen-Angus cattle, 279; characteristics, 284 ; color, 285 ; distribution, 299 ; earliest improvers, 280; families, 293; introduction "to America, 283 ; maturing qualities, 287 ; as milk producers, 288; native home, 279 ; organizations promoting, 299 ; origin, 279 ; prices, 297; as producers of beef, 289; prolificacy, 288; weight, 286

Aberdeen-Angus steers, prices, 298

Action, of Clydesdale, 137; of draft horse, 94; of heavy harness horse, 67; of light harness horse, 43 ; of Shire, I 53

Adaptability, of American Merino, 505 ; of Berkshire, 698; of Brown Swiss, 468; of Chester White, 744; of Delaine Merino, 5I8; of Duroc-Jersey, 7I5; of Hampshire pig, 755; of Holstein-Friesian, 365; of Jersey, 330; of Poland-China, 728; of Shorthorn, 239; of Southdown, 547 Adney, George, 554

Advanced Registry of American Guernsey Cattle Club, 396; of Ayrshire Breeders' Association, $4 \mathbf{1} 7$; official testing of Holstein-Friesians for, 367 ; requirements for HolsteinFriesians in, 367

African Wild Ass, I82

Age attained by milch goats, 680

Aguirre Merinos, 49I

Amalgamation of Suffolk and Norfolk Red Polled cattle, 452

America, Clydesdales of merit in, I44; demand for bacon pig in, 78I ; distribution of jacks and jennets in, I9I; early foundation improvers of Merino in, 497; early use of trotter in, 44; first Clydesdales brought to, I38; first Shorthorns imported to, 224; history of Suffolk horse in, I6I; importation of milch goats to, 68I; importation of Shires to, $\mathrm{I}_{52}$; noted jacks in, I89; popularity of Devon in, 479; present-day recognition of Arab horse in, I4; use of Shetland pony in, I78

America, introduction to, of Angora goat, 667 ; of Arab horse, 10; of Ayrshire, 4r4; of Belgian horse, I24; of Berkshire, 693; of Blackfaced Highland, 652 ; of Brown Swiss, 464 ; of Cleveland Bay, 85; of Devon, 475 ; of Dexter, 442 ; of Dorset Horn, 587; of Dutch Belted, 428; of Essex, 775; of Galloway, 302 ; of German coach horse, 82 ; of Guernsey, 389 ; of Hackney, 72 ; of Hampshire Down sheep, 578 ; of Hampshire pig, 75I ; of Hereford, 256; of Holstein-Friesian, 358; of jack ; I 88; of Jersey, 327 ; of Karakul, 660 ; of Kerry, 438; of Large Black, 762; of Leicester, 620; of Lincoln, 637; of Mule-Foot, 759; of Oxford Down, 568; of Red Polled, 452; of Small Yorkshire, 770 ; of Southdown, 540; of Suffolk sheep, 607; of Tamworth, 793; of Tunis, 613 ; of West Highland, 3II American French Coach studbook, 8I American jack, I85

American Jersey families, 34

American Merino, 488; size, 500; as a wool producer, 501

American, or lard, type of pig, 683

American Percheron horse associations, II6

American saddle horse, 3I; ancestry, 3I; characteristics, 33; color, 34; native home, $3 \mathrm{I}$; noteworthy mares, 38 ; prices, 38 ; prominent sires, 38 ; size, 33 ; two notable families, 36 ; value of Thoroughbred in developing, 32

American Saddle Horse Breeders: Association, 39

American trotter and pacer, 44

American Yorkshire club, $79 \mathrm{I}$

Ancestry of Tamworth pig, 792

Andalusian jack, 183 
Anglo-Nubian goat, 678

Angora, varieties of goats in, 666

Angora goat, 666; characteristics, 668; distribution, $67 \mathrm{I}$; fleece, 668; introdurtion to America, 667 ; native home, 666; official promotion, 672; origin, 666; as producer of mutton, 670; prices, 67I; as renovator of brush land, 670; shelter for, 67I; varieties, 666 ; weight, 670

Angus. See Aberdeen-Angus

Anna tribe, 215

Anxiety family, 265

Appearance of American pig, 683

Arab horse, 7; characteristics, 9 ; five great original families, 8 ; influence of, II ; introduction of, to America, Io; notable individuals, I3; origin of pure, 7 ; present-day recognition, I4; societies, I6; value of, in crossbreeding, 13

Arab pony, I73

Ardennais, I I 9

Arms and forearms of light harness horse, 4I

Asiatic Wild ass or Kiang, I 82

Ass, I82; African Wild, I82; ancestry, I82; Asiatic Wild, or Kiang, I82; characteristics of domestic, I83; Persian Wild, 182

Association, American Saddle Horse Breeders', 39; American Tunis Sheep Breeders', 6I7; Cheshire Swine Breeders', 760

Associations, American Percheron horse, I16; Hampshire Down, 585; for promoting jacks and jennets, I9I; to promote Shire horse, I59

A-type Merino, 482

Augusta tribe, 223

Australia, modern type of Merino in, 499; popular type of Merino in, 500 Australian Merino, 494

Ayrshire cattle, 412; characteristics, 4I4; color, 4I 5 ; crossbred or grade, 4I 7 ; distribution, 425 ; early improvers, 4I3; early maturity, 4I7; introduction to America, 4I4; milk for cheese-making, 422 ; as milk producers, 4I9; native home, $4 \mathrm{I} 2$; organizations promoting, 426; origin, 4I2; prepotency, 4I7; prices, 424; as producers of beef, 423; public tests, 422 ; size, 4I6; temperament and disposition, $4 \mathrm{I} 7$; ten leading butter-fat records, $42 \mathrm{I}$; ten leading milk records, 420; ten leading sires, 424

Ayrshire Breeders' Associations, Advanced Registry, 4I7

Babraham, 538

Bacon, reputation of Large Yorkshire for, 788

Bacon pig in America, breeding, 780; demand for, 78I; Tamworth as, 795; weight, 780

Bacon-type pig, 778

Bakewell, Robert, 618; Shire improved by, I 49

Bar None, I 56

Baron of Buchlyvie, I43

Baron's Pride, I 43

Bates, Thomas, 2 I 2

Bayard, 130

Beau Donald family, 266

Beautiful Bells, 56

Bedford, or Bedfordshire, pig, $72 \mathbf{I}$

Beef, Aberdeen-Angus as producer of, 289; Ayrshire as producer of, 423 ; Brown Swiss as producer of, $47 \mathrm{I}$; Dutch Belted as producer of, 43I; Jersey as producer of, 332; Red Polled as producer of, 455 ; Shorthorn as producer of, $23 \mathrm{I}$; West Highland as producer of, $3 \mathrm{I} 3$

Beef animal, fleshing, 206; general appearance, 20I ; quality, 205

Beef production, Guernsey in, 395

Beef-type cattle, 20I; compared with dual-purpose, 447

Belgian government, methods employed by, to encourage horse breeding, 122

Belgian horses, I2I; characteristics, I 25 ; color, I 26 ; crossbred, I 28 ; distribution, I3I; exhibitors of, in United States, I33; foundation sires, I29; height and weight, I27; introduction to America, I 24 ; maturing quality, I28; native home, I2I; notable recent-day, 130 ; organizations for promoting, I3I ; prices, I3I; temperament, I 27

Belgium, draft-horse shows in, $\mathbf{I}_{32}$; horse production in, I2I; influence of World War on horse in, I33; stud fees in, I24; two breeds of horses of ancient origin in, I2I

Bellfounder, 45

Belted, or sheeted, pig, recognition of, 750 
Berkshire pig, 689; adaptability, 698; characteristics, 694; color, 694; crossbred or grade, 700; distribution, 704; element in Poland-China evolution, 722 ; families, 702 ; 'famous boars, 702; as feeder, 697; first improvement of native, 690; foundation of breed, 689; as grazer, 697; important early British improvers, 693; introduction to America, 693; maturing qualities, 698; native home, 689; older type, 601 ; organizations promoting, 704; prepotency, 702 ; prices, 703; prolificacy, 701; quality of pork, 699 ; size, 696 ; as source of red swine, 706

Big China pig, 722

Birdsall Menestrel, I 58

Blackbird family, 294

Blackcap family, 296

Black-faced Highland sheep, 65I ; characteristics, 652 ; crossbred or grade, 653 ; distribution, 654 ; introduction to America, 652; native home, $65 \mathrm{I}$; origin, $65 \mathrm{I}$; prices, 654 ; as producer of wool, 653; promotion, 654 ; quality of mutton, 653 ; size, 653 ; special field, 654

Black pig. See Large Black

Black-Top Spanish Delaine, characteristics, 514

Black-Top Spanish Merino, 513

Blake strain, $x 60$

Boars, famous Berkshire, 702

Bonnie Lassie family, 40I

Booth family, 2I4

Booth, John, 214

Booth, Richard, 2 I4

Booth, Thomas, 2I4

$[626$

Border Leicester rams on Cheviot ewes,

Border Leicester sheep, 624 ; characteristics, 625

Boulonnais, II 8

Bracelet tribe, 2 I 6

Brawith Bud tribe, 219

Breeders, early constructive Hereford, 253

Breeding bacon pig, 780

Breeding in Germany, early records of horse, 82

Breeding qualities, of American Merino, 505; of Cotswold, 634; of Delaine Merino, 5I7; of Leicester, 624; of Lincoln, 642; of Rambouillet, 529; of Southdown, 547; of West Highland, 3I 5
Breeding of Southdown by English nobility, 539

Breeding three types of Merinoes, 483

Breeds, of cattle in Holland at present day, 357; of French Draft horses, distinct, II8; of horses of ancient origin in Belgium, two, 121 ; or varieties of milk-producing goats, 674

Breton, II9

Brilliant, I 30

British improvers of Berkshire, important early, 693

British thoroughbreds, list of famous, 23

Broadhooks tribe, 2 I 9

Bronchos, Indian ponies, mustangs, I 73

Broomfield Champion, I4I

Brown Swiss cattle, 463; adaptability, 468 ; as beef producers, $47 \mathrm{I}$; characteristics, 464; color, 466; crossing or grading, 467 ; distribution, $47 \mathrm{I}$; introduction to America, 464; milk production, 468; native home, 463 ; origin, 463 ; prepotency, 467 ; promotion, 472 ; register of production, 470; size, 466

Brush land, Angora as renovator of, 670

B-type Merino, 482

Buena Vista, I89

Bullock, crossbred or grade AberdeenAngus, 292

Bulls of distinction, Galloway, 309; Jersey, 346; leading imported Jersey, 349 ; leading native Jersey, 348

Bury Chief Victor, 157

Butcher's beast, Devon as, 477

Butter-fat producers, Guernseys, 398 ; Holstein-Friesians, 370; Jerseys, 334; Red Polled, 457

Butter-fat production, Ayrshire, 42I

Butter-fat records, of ten leading Ayrshire cows, 42I; leading Guernsey, 400; leading semiofficial HolsteinFriesian, 370; of Shorthorn cows, important, 238

Butter-fat tests, of Jersey cows, authenticated, 336 ; for ten leading Jersey cows for one year, 337

Butter tests of Jerseys, private, 335

Byerly Turk, I 9

Byfield pig, 722

Cambridge Rose Tribe, 213

Canadian cattle. See French Canadian 
Cannons of light harness horse, 41

Carriage or saddle animal, mule as, I99

Catalonian jack, 183

Cattle, Ayrshire, 4I 2 ; beef type, $20 \mathrm{I}$; Brown Swiss, 463 ; color of Ayrshire, 4I5; color of Guernsey, 392 ; dairy type, 317; Devon, 473; Dexter, 442; distribution of Ayrshire, 425; distribution of Brown Swiss, 47I; distribution of Devon, 478 ; distribution of Dexter, 446; distribution of Dutch Belted, 432 ; distribution of French Canadian, 436 ; distribution of Holstein-Friesian, 382 ; distribution of Jersey, 35I ; distribution of Kerry, 440; distribution of Red Polled, 46I; dual-purpose type, 447; Dutch Belted, 428 ; earliest improvers of Aberdeen-Angus, 280; French Canadian, 434; Guernsey, 385; HolsteinFriesian, 354; Kerry, 438; milk production of Ayrshire, 4I9; native home of Ayrshire, 412; native home of Galloway, 300; native home of Holstein-Friesian, 354; Norfolk Red Polled, 45I ; Polled Jersey, 353; present-day breeds in Holland, 357; prices on Aberdeen-Angus, 297; prices on Ayrshire, 424; prices on Guernsey, 408; prices on HolsteinFriesian, 379; prices on Jersey, 349; Red Polled, 450; size of Ayrshire, 4I6; size of Brown Swiss, 466; size of Devon, 476 ; size of Guernsey, 393; size of Holstein-Friesian, 363 ; size of Red Polled, 454; Suffolk Red Polled, 450; two classes of dual-purpose, 448; West Highland, 3II

Cattle on Jersey, legislation protecting purity of, 325

Cattle organizations, to promote Ayrshire, 426; to promote Devon, 478 ; to promote Guernsey, 4II ; to promote Jersey, 35I

Channel Islands, 323

Characteristics, of Aberdeen-Angus, 284; of American Merino, 498; of American saddle horse, 33; of Angora goat, 668; of Ayrshire, 4I4; of Belgian horse, I25; of Berkshire, 694; of Black-faced Highland, 652 ; of Black-Top Spanish Delaine, 5I4; of Border Leicester, 625; of Brown Swiss, $464 ;$ of Cheshire, 767 ; of
Chester White, 74I ; of Cheviot, 599; of Cleveland Bay, 86; of Clydesdale, 136; of Corriedale, 657; of Cotswold, 630 ; of Devon, 475 ; of Dexter, 443; of Dickinson Delaine, 5I2; of domestic ass, I83; of Dorset Horn, 588; of Duroc-Jersey, 709 ; of Dutch Belted, 428; of early Southdown, 540; of English Leicester, $62 \mathrm{I}$; of Essex, 775; of French Canadian, 434; of French Coach, 79; of Galloway, 302; of German Coach, 82 ; of Guernsey, 391; of Hackney, 73; of Hampshire Down, 578; of Hampshire pig, 753; of Hereford, 258; of Holstein-Friesian, 36I ; of Jersey, 327; of Jersey Red, 707; of Karakul, 66I; of Kerry, 438; of Large Black, 762 ; of Large Yorkshire, 785 ; of Lincoln, 638 ; of Merino, 484; of milk of goat, 673; of mule, 194; of Mule-Foot, 759 ; of National, Standard, or Victor-Beall Delaines, 5I5; of Oxford Down, 568; of Percheron, 104; of Poland-China, 725; of Rambouillet, 524; of Red Polled, 453; of Shetland pony, I77; of Shire, I52; of Shorthorn, 225; of Shropshire, 556 ; of Small Yorkshire, 77I; of Southdown in more recent years, 45I; of Spotted Poland-China, 736; of Suffolk horse, I62; of Suffolk sheep, 608; of Tamworth, 793; of Tunis, 6I4; of West Highland cattle, 3 I2

Cheese, from Holstein-Friesian milk, 372 ; from Ayrshire milk, 422; from Jersey milk, 338 ; value of Guernsey milk for, 4 or

Cherry tribe, 2 II

Cheshire Breeders' Association, 769

Cheshire pig, 766; characteristics, 767 ; crossbred or grade, 768 ; distribution, 769; fecundity, 769; as feeder, 768 ; as grazer, 769 ; quality of meat, 768 ; native home, 766 ; origin, 766 ; popularity, 760 ; size, 767

Chester White pig, 737; adaptability, 744 ; adoption of name, 738 ; characteristics, 741 ; crossbred or grade, 745 ; distribution, 747 ; families, 746 ; as feeder, 743 ; as grazer, 743 ; maturing qualities, 744 ; native home, 737 ; Ohio Improved, 740; organizations promoting, 748 ; origin of Im- 
proved, 739 ; original type, 737 ; prepotency, 746 ; prices, 746 ; prolificacy, 745 ; quality of pork, 744 ; sires of distinction, 746 ; size, 742

Cheviot ewes, Border Leicester rams on, 626

Cheviot sheep, 597; characteristics, 599 ; crossbred or grade, 60x; distribution, 605; as grazer, 602 ; hardiness, 603; introduction to United States, 599; as mutton producer, 601 ; origin, 597 ; prices, 604 ; prolificacy, 603 ; on range, 6I 2 ; size, 600 ; as wool producer, 604

Cheviot sheep breeders' organizations, 606

Chief family, 36

China pig, Big, 722

Cholera, immunity of Mule-Foot pig from, 760

Classes, of dual-purpose cattle (two), 448; of Merino sheep (three), 48I ; of mules in market, 195

Clay family, 53

Cleveland Bay, 85 ; characteristics, 86 ; distribution, 87 ; introduction to America, 85 ; native home, 85 ; organizations to promote, 87 ; origin, 85 ; as roadster, 87

Clipper tribe, 219

Clothilde family, 373

Clyde, I42

Clydesdale horse, I34; action, I37; adaptability, I39; characteristics, I36; color, I38; criticisms of, I40; distribution, I 46 ; early history, I 34 ; first brought to America, I38; halfbred, or grade, r40; height and weight, 138 ; an honor roll of sires, I44; important sires, I4O; of merit in America, I44; native home, I 34; organizations promoting, 147 ; origin of modern, I34; prices, I 45 ; prolificacy, I39; temperament, I39; use of English blood on, I35

Coach horse, Yorkshire, 87

Cob, 69

Colling brothers, 209

Color, of Aberdeen-Angus, 285; of American saddle horse, 34; of Ayrshire, 415 ; of Belgian horse, 126 ; of Berkshire, 694; of Brown Swiss, 466; of Clydesdale, 138 ; of Dexter, 444 ; of Duroc-Jersey, 7II ; of Guernsey, 392 ; of Hackney, 74; of Hampshire pig, 754; of Hereford,
260; of Holstein-Friesian, 362; of jack, 187; of Jersey, 328; of Large Yorkshire, 786; of mule, 197; of Percheron, ro6; of pig, 688; of Poland-China, 725; of Red Polled, 454 ; of Shetland pony, I77; of Shire, I54; of Shorthorn, 229; of Suffolk horse, I64; of Thoroughbred, 23

Combination family, 344

Conformation, of draft horses, general, 89; general mutton, 533; of Merino, general, 48I ; of Thoroughbred, 2 I

Connemara pony, I 72

Coomassie family, 342

Coquette family, 296

Corrector family, 266

Corriedale sheep, 655 ; characteristics, 657; distribution, 659; fleece, 658; as grazer or forager, 659; importation into North America, 657; as mutton producer, 658 ; native home, 655 ; official promotion, 659 ; origin, 655 ; prices, 659 ; weight, 658

Cotswold sheep, 628; breeding qualities, 634 ; characteristics, 630 ; crossbred or grade, 633; derivation of name, 628; distribution, 635; as feeder, 632 ; as grazer, 633; history, 628 ; introduction to United States, 629 ; for mutton, 63I; native home, 628 ; prices, 635 ; promotion, 635 ; size, 63I; as wool producer, 634

Cows, French Canadian as milk producers, 435; Holstein-Friesian as milk producers, 368 ; official publicdairy tests of Shorthorn, 235

Cowslip family, 340

Crimp and elasticity of Merino wool, 503

Criticisms, of Clydesdale, I40; of Galloway, 310; of Tamworth, 798

Crossbred Belgian, I 28

Crossbred Dexter, 445

Crossbred Galloway, 305

Crossbred or grade Aberdeen-Angus bullock, 292

Crossbred or grade Ayrshire, 4I 7

Crossbred or grade Berkshire, 700

Crossbred or grade Black-faced Highland, 653

Crossbred or grade Cheshire, 768

Crossbred or grade Chester White, 745

Crossbred or grade Cheviot, 6or

Crossbred or grade Cotswold, 633 
Crossbred or grade Delaine Merino, 5I7

Crossbred or grade Duroc-Jersey, 7I4

Crossbred or grade Dutch Belted, 43I

Crossbred or grade Essex, 776

Crossbred or grade Guernsey, 393

Crossbred or grade Hampshire pig, 756

Crossbred or grade Hereford, 263

Crossbred or grade Holstein-Friesian, 366

Crossbred or grade Karakul, 662

Crossbred or grade Leicester, 623

Crossbred or grade Lincoln, 640

Crossbred or grade Merino, 503

Crossbred or grade Oxford Down, $57 \mathrm{I}$

Crossbred or grade, Percheron, I08

Crossbred or grade Poland-China, 729

Crossbred or grade Rambouillet, 528

Crossbred or grade Shire, I55

Crossbred or grade Shropshire, 559

Crossbred or grade Small Yorkshire, 772

Crossbred or grade Southdown, 546

Crossbred or grade Suffolk horse, I65

Crossbred or grade Suffolk sheep, 6ro

Crossbred or grade Tamworth, 796

Crossbred or grade Tunis sheep, 616

Crossbred or grade West Highland, 314

Crossbred Romney Marsh, 648

Crossbreds, Large Yorkshire, 787

Crossbreeding, of Brown Swiss, 467; of Devon, 478; of Dorset Horn, 591; of Hampshire Down, 582; of Jersey, 332; of Kerry, 439; of Red Polled, 458; of Shorthorn, 234; value of Arab in, 13

Cruickshank, Amos, 218

C-type Merino, maintenance of Delaine or, $510^{\circ}$

Dairy cattle, general appearance, 3 I 7 ; udder, 320

Dairy point of view, Shorthorn from, 235

Dairy tests of Shorthorn cows, official public, 235

Dairy type of cattle, 3I7; compared with dual-purpose type, 447 ; quality of, 322

Daisy tribe, 2 II

Darley Arabian, I9

Darnley, I42

Dartmoor pony, I7o

Davy, John Tanner, 474

DeKol family, 373

Delaine Merino sheep, 5 II ; adaptability, 5I8; breeding quality, 5I7; characteristics of Black-Top Spanish, 514; characteristics of Dickinson, $5 \mathrm{I} 2$; crossbred or grade, $5 \mathrm{I} 7$; derivation of word, 5 II ; distribution, 5 I9; as feeder, 518; national, 514; origin, 5II; promotion, 5 I9

Delaine or C-type Merino, maintenance, 5 I6; mutton value, 517

Demi-Sang, 79

Denmark family, 36

Derby, thoroughbred records of English, 27

Development of Hackney, 7 I

Devon cattle, 473; for beef, 477; characteristics, 475; crossing and grading, 478 ; distribution, 478 ; early improvers of, 473 ; as grazer, 478 ; introduction to America, 475 ; as milk producer, 477; native home, 473 ; organizations to promote, 478 ; origin, 473 ; oxen, 478 ; popularity in America, 479 ; size, 476 ; two types of, 476

Dexter cattle, 442 ; characteristics, 443 ; color, 444; crossbred, 445 ; distribution, 446 ; hardy character, 444 ; introduction to America, 442 ; as milk producer, 445; native home, 442; official promotion, 446 ; origin, 442 ; prices, 445 ; size, 444

Dickinson Delaine, 5 II ; characteristics, 512

Diomed, 45

Disease, resistance of mules to, I98

Disposition and temperament, of Ayrshire, 4I 7 ; of Holstein-Friesian, 365 ; of Jersey, 33 I

Distribution, of Aberdeen-Angus, 299; of Angora goat, 671; of Ayrshire, 425; of Belgian, I3I; of Berkshire, 704; of Black-faced Highland, 654; of Brown Swiss, 47I; of Cheshire, 769 ; of Chester White, 747; of Cheviot, 605; of Cleveland Bay, 87; of Clydesdale, I46; of Corriedale, 659; of Cotswold, 635; of Delaine Merino, 519; of Devon, 478; of Dexter, 446; of Dorset Horn, 595; of Duroc-Jersey, 7I8; of Dutch Belted, 432; of Essex, 777; of French Canadian, 436; of French Coach, 80; of Galloway, 309; of German Coach, 84 ; of Guernsey, 4IO; of Hackney, 76; of Hampshire Down sheep, 585 ; of Hampshire pig, 757 ; of Hereford, 273; of Holstein- 
Friesian, 382; of jacks and jennets" in America, I9I ; of Jersey, 35I; of Karakul, 665; of Kerry, 440; of Large Black, 764 ; of Large Yorkshire, 79I ; of Leicester, 627 ; of Lincoln, 644; of Merino, 509; of mule, geographical, I93; of Mule-Foot, 76I; of Oxford Down, 573; of Percheron, II4; of Poland-China swine, 734; of Polled Hereford, 277 ; of Polled Shorthorn, 250; of Rambouillet, 532; of Red Polled, 46I; of Rommey Marsh, 649; of Shetland pony, I8I; of Shire, I58; of Shorthorn, geographical, 244; of Shropshire, 563; of Small Yorkshire, 773 ; of Southdown, 550; of Standard-bred horse, 63 ; of Suffolk horse, 166; of Suffolk sheep, 612; of Tamworth, 498; of Thoroughbred, 29; of Tunis, 6I 7 ; of West Highland, 3 55 Disturber family, 266

Dolly Bloom family, 402

Dorset Horn sheep, 586; characteristics, 588; crossing or grading, 59I ; distribution, 595; as early-lamb producer, 59r; as grazer, 593; horns a protection, 595; introduction to America, 587 ; as mutton producer, 590 ; native home, 586 ; origin, 586 ; prolificacy, 592; size, 589 ; as wool producer, 593

Dorset Horn sheep breeders, organizations of, 596

"Double standard" Polled Shorthorn, 247

Draft horse, action, 94; distribution of Belgian, I3I; height, 89; the Suffolk as, I66; type, 80

Draft horse shows in Belgium, I32

Draft-horse type, 89

Draft mules, I95

Draft, value of Shetland pony for, I 99

Drivers of race horses, 62

Drives in Spain, annual Merino, 489

Dual-purpose type of cattle 447 ; two classes, 448

Duchess of Gloster tribe, 223

Duchess tribe, 2II ; of Bates, 2I2

Dunure Footprint, I44

Durham, "single standard" Polled, 247

Duroc-Jersey pig, 705, 707; adaptability, 7 I 5 ; characteristics, 709 ; color, 7II; crossbred or grade, 7I4; of distinction, 7I6; distribution, $7 \mathrm{r} 8$; families, $7 \mathrm{I} 6$; as feeder, $7 \mathrm{I} 3$; as grazer, 712 ; improvement, 709 ; maturing qualities, $7 \mathrm{I} 3$; organizations promoting, 718 ; origin, 708 ; prepotency, 7I6; prices, 7I7; prolificacy, 715 ; quality of pork, 7I4; size, 7II

Dutch cattle, origin, 355

Dutch Belted cattle, 428 ; as beef producer, 43I; characteristics, 428; crossbred or grade, 43I; distribution and adaptability, 432 ; introduction to America, 428 ; as milk producer 430 ; native home, 428 ; origin, 428 ; popularity, 433 ; promotion 3432

Early lambs, Dorset Horn for, 591; Hampshire Down for, 58I; Tunis for, $6 \mathrm{I} 6$

Eclipse, 20

Elasticity and crimp of Merino wool, 503

Ellman, John, 537

Endurance of mule, I97

England, improvement of Jersey in, 326; horse in, prior to reign of Queen Elizabeth, I7

English blood on Clydesdale, use of, I35

English Merinos, 494

English Shorthorn breeders, less prominent early, 2I 7

English Thoroughbred sires, three early, Ig

English trotting horse, history, 44

Eohippus, 3

Epihippus, 4

Equus, 4

Erica family, 293

Escurial Merinos, 49I

Escutcheon, 322

Essex pig, 774; characteristics, 775; crossbred or grade, 776 ; distribution, 777; early native type, 774; establishment of Improved, 774 ; fecundity, 776 ; as feeder, 776 ; improvement, 774 ; introduction to America, 775; maturing quality, 777; native home, 774; popularity, 777; promotion in America, 777; quality of meat, 776 ; size, 776

Estantes, 489

Eurotas family, 342

Evolution of Hackney, important, 7I

Evolution of the horse, 2; tracing the, 4 Ewes, fecundity of Suffolk, 6II

Exmoor pony, I 70 
Fairholm, or Blossom, Tribe, 2I 7

Families, Aberdeen-Angus, 293 ; American saddle horse, two notable, 36 ; Berkshire, important, 702; Chester White, 746; Duroc-Jersey, 7I6; Guernsey, 40I ; Hereford, of note, 264; Holstein-Friesian, 372; Jersey, of distinction, 339; Merino, important subtypes, 505; Poland-China, and foundation sows, 73I; Small Whites, strains or, 770 ; trotting, of note, 50

Family, Clay, 53; Hal, 56; Hambletonian, 50; Mambrino, 52; Morgan, 53; Pilot, 55

Fancy, or Orange Blossom, tribe, 22I

Farm mules, I96

Fattening and fleshing quality of pig, 687

Fecundity and Iongevity, of Cheshire, 769; of Essex, 776; of Hampshire Down, 583 ; of Karakul, 664; of milch goat, 682 ; of Shropshire, 560 ; of Small Yorkshire, 773; of Suffolk ewes, 6II; of Suffolk horse, I65; of Tamworth, 797; of Tunis, 6II

Feeder, Berkshire as, 697; Cheshire as, 768; Chester White as, 743; Cotswold as, 632; Delaine as, 5I8; Duroc-Jersey as, 713; Essex as, 776; Hampshire as, 755; Large Black as, 763 ; Large Yorkshire as, 789 ; Lincoln as, 640; Mule-Foot as, 760; Oxford Down as, 570; Poland-China as, 727; Romney Marsh as, 648; Small Yorkshire as, 772 ; Southdown as, 544; Suffolk sheep as, 609; Tamworth as, 795

Fibre, fineness of Merino, 502

Financial Interest family, 340

Fine-wool type of sheep, Merino or, $48 I$

Fleece, of Angora goat, 668; of Corriedale, 658; of Karakul, 66I; of Romney Marsh, 649; of Tunis, 6I6

Fleece, relationship of Merino to body weight, 502

Fleshing and fattening quality, of pig, 687 ; of beef animal, 206

Foggathorpe tribe, 2I4

Fontaine family, 340

Foot, of light harness horse, 4I; single, 34

Forearms and arms of light harness horse, 4I

Forton of Wynhuize, I29
Foundation, of Berkshire, 689; of Poland-China, 720

Foundation $J \in$ tsey sires, important, 346

France family, 403

France, horse racing in, 78; improvement of Percheron in, 102

French Canadian cattle, 434; characteristics, 434; distribution, 436; grazing qualities, 436 ; hardy character, $43^{6}$; maturing qualities, 436 ; as milk producer, 435 ; native home, 434 ; origin, 434 ; promotion of pure, 437

French Coach horse, 78 ; characteristics, 79 ; distribution, 80 ; origin, 79; speed records, 80

French Draft horse, II8; distinct breeds, Ir8

French Draft Horse Association of America, National, I20

French Jockey Club, 79

French Merino, or Rambouillet, 494

French race track, 80

Friesian, origin of name, 358

Fullerton, William, 282

Fur of Karakul lamb, 662

Furs, market value of Karakul, 663

Futurity records of Thoroughbred, 28

Futurity shows, Percheron, II 2

Gait, of Hackney, 73; of saddle horse, 34 ; of trotter and pacer, 47

Galliers, William, 254

Gallipoly, 98

Galloway cattle, 300 ; bulls of distinction, 309; characteristics, 302; criticisms, 310 ; crossbred, 305 ; distribution, 309; hardiness, 307 ; hide, 307 ; improvement, 300 ; introduction to America, 302 ; as meat producers, 304 ; in milk production, 306 ; native home, 300 ; organizations for promoting, 309; origin, 300; prepotency, 308 ; prices, 309 ; size, 304

Geldings, Percheron, II 3

General-purpose and dual-purpose types of cattle, 447

German Coach horse, 82 ; characteristics, 82 ; distribution, 84 ; introduction to America, 82 ; native home, 82; organization of, in America, 84; type, 83

German, or Silesian, Merinos, 493

Germany, early records of horse breeding in, 82 
Glancer, I40

Glenwood girl family, 403

Glista family, 378

Goat, Anglo-Nubian, 678; Angora, see

Angora goat; breeds or varieties of milk-producing, 674; characteristics of milk, 673 ; cost of producing milk of, 680; Maltese, 676; milch, see Milch goat; Nubian, 677; period of lactation, 682; Saanen, 676; Schwarzhal, 679; as source of milk, 673; Toggenburg, 674

Godolphin, 98

Godolphin Barb, I9

Golden Lad family, 339

Governor Wood, I9O

Grade or cross, of Aberdeen-Angus, 292; of Ayrshire, 4I7; of Berkshire, 700 ; of Black-faced Highland, 653; of Cheshire, 768; of Chester White, 745; of Cheviot, 60I ; of Clydesdale, I40; of Cotswold, 633; of Delaine Merino, 5I7; of Duroc-Jersey, 7I4; of Dutch Belted, 43I ; of Essex, 776; of Guernsey, 393; of Hackney, 75; of Hampshire pig, 756; of Hereford, 263 ; of Leicester, 623; of Lincoln, 640; of Merino, 503; of HolsteinFriesian, 366; of Oxford Down, 571; of Percheron, I08; of Poland-China, 729; of Rambouillet, 258; of Shire, I55; of Shropshire, 559; of Small Yorkshire, 772 ; of Southdown, 546; of Suffolk horse, I65; of Suffolk sheep, 610; of Tamworth, 796; of Tunis, 6I6; of West Highland, 3I4

Grading and crossing, Brown Swiss in, 467; Devon in, 478; Dorset Horn" in, 59I ; Hampshire Down in, 582; importance of Shorthorn in, 234 ; Jersey in, 332; Red Polled in, 458

Grant, George Macpherson, 283

Grazer, Berkshire as, 697; Cheshire as, 769; Chester White as, 743; Cheviot as, 602 ; Corriedale as, 659 ; Cotswold as, 633; Devon as, 478; Dorset Horn as, 593; Duroc-Jersey as, 7I 2 ; French Canadian as, 436; Hampshire Down as, 582; Hampshire pig as, 755; Hereford as, 263 ; Kerry as, 440 ; Large Black as, 763 ; Large Yorkshire as, 789; Leicester as, 624; Lincoln as, 642; PolandChina as, 727 ; Shropshire as, 559; Small Yorkshire as, 773; Tamworth as, 797
Great Britain, horse racing and the race track in, 18

- Green Mountain Maid, 56

Groups and tribes, of Red Polled cattle, 460; of Spanish sheep, two great, 489

Guadaloupe Merinos, 49x

Guernsey, protection and improvement of cattle on, 387

Guernsey cattle, 385 ; in beef production, 395 ; character, 393; characteristics, $39 \mathrm{r}$; cheese value of milk, 401 ; color, 392 ; crossbred or grade, 393 ; distribution, 4IO; families, 401 ; introduction to America, 389; leading butter-fat records, 400 ; native home, 385 ; organizations promoting, $4 \mathrm{II}$; origin, 358 ; prices, 408 ; as producer of butter fat, 398 ; as producer of milk, 398; prolificacy, 395; scale points (early), 387; size, 393; skin secretions, 392; temperament, 393; ten leading sires, 408

Guernsey Cattle Club, Advanced Registry of America, 396

Guinea breed of pigs, 705

Hackney, characteristics, 73 ; color, 74 ; derivation of word, 70; distribution, 76; early development, 7I; effect of the motor on breeding, 77; gait, 73; half-bred or grade, 75 ; height, 74 ; imitation, 76 ; important evolution, $7 \mathrm{I}$; introduction to America, 72 ; native home, 70 ; original stock, 70 ; promotion, 77 ; soundness, 75

Hackney pony, 173

Hair, and skin of Hereford, 259; of pig, 687 ; of Shetland pony, I 77

Hairy legs of Shire, I 53

Hal family, 56

Half-bred. See Grade or cross

Halnaby, or Strawberry, tribe, 2 I6

Hambletonian family, 5o

Hambletonian Io, pedigree of, 52

Hampshire Down sheep, 575 ; characteristics, 578; distribution, 585; early improvement, 576 ; for early lambs, 58I; fecundity, 583; for grading or crossing, 582; as grazer, 582 ; introduction to America, 578 ; as mutton animal, 580 ; native home, 575 ; origin, 575 ; prices, 583 ; as producer of wool, 583 ; size, 580

Hampshire Down sheep associations, 585 
Hampshire pig, 749; adaptability, 755; characteristics, 753; color, 754; crossbred or grade, 756 ; distribution, 757 ; early history, 749 ; early maturity, 755; as feeder, 755; as grazer, 755 ; introduction to America, 75I; organization to promote, 758 ; prices, 757; prolificacy, 756; prominent sires, 757; quality of pork, 755 ; size, 755

Hardiness, of Cheviot sheep, 603; of Dexter, 444; of French Canadian, 436; of Galloway, 307; of Karakul, 664; of Kerry, 439; of Rambouillet, 529 ; of West Highland, 315

Harness horse, heavy, 64; light, 40

Harold, I 56

Head of light harness horse, 40

Heather Bloom or Heather Blossom family, 296

Heavy harness horse, action, 67 ; general appearance, 64; subclasses, 68 ; type, 64

Height and weight, of Belgian, I27; of Clydesdale, 138 ; of draft horse, 89 ; of Hackney, 74; of jack, I87; of Percheron, IO6; of Shetland pony, I78; of Thoroughbred, 23

Hereford cattle, 252; characteristics, 258; color, 260; crossbred or grade, 263 ; distribution, 273 ; early constructive breeders, 253 ; early maturity, 262; families of note, 264 ; foundation ancestors, 256 ; as grazers, 263 ; as meat producers, $26 \mathrm{I}$; native home, 252 ; noted sires, 270 ; origin, 252; prepotency, 263; prices, $27 \mathrm{I}$; prolificacy, 264; promotion of interests, 274; skin and hair, 259; size, 260

Herefords, Polled, 275. See Polled Hereford

Herod (King Herod), I9

Hesiod family, 267

Hewer, John, 255

Hide of Galloway, 307

Highland cattle. See West Highland

Highland pony, I 72

Highland sheep. See Black-faced HighIand

Hindquarters of light harness horse, 42

History, of English trotting horse, 44; of early Hampshire pig, 749

Hitchin Conqueror, 157

Holland, present-day breeds of cattle in, 357
Holstein-Friesian cattle, 354 ; adaptability, 365; Advanced Registry official testing, 367; Advanced Registry requirements, 367 ; as butter-fat producers, 370 ; characteristics, 361; color, 362 ; disposition, 365 ; distribution, 382 ; families, 372 ; introduction to America, 256; maturing qualities, 365 ; measurements, 364 ; milk for cheese, 372 ; as milk producers, 368 ; native home, 354 ; organizations for promoting, 382 ; origin of name, 358; prepotency, 366 ; prices, 379 ; prolificacy, 365 ; semiofficial yearly butter-fat records, $37 \mathrm{I}$; semiofficial yearly milk records, 369 ; size, 363 ; ten leading sires, 379; types, 36I

Holstein-Friesian oxen, 367

Honest Tom, I 56

Horns a protection to Dorset Horn sheep, 595

Horse, action of draft, 94 ; action of heavy harness, 67 ; action of light harness, 43; Ámerican Saddle, 3I; Arab, 7 ; arms and forearms of light harness, 4I; in Belgium, influence of World War on, I33; body of light harness, 4I; cannons of light harness, 4I ; characteristics of American saddle, 33; characteristics of Belgian draft, I 25 ; characteristics of French Coach, 79; characteristics of German Coach, 83; characteristics of Percheron, IO4; characteristics of Suffolk, I62; color of American saddle, 34; color of Belgian, I 26; color of prehistoric, 5 ; color of Suffolk, I64; discovery of American prehistoric, I ; distinct breeds of French draft, II 8; distribution of French Coach, 80; distribution of German Coach, 84; distribution of Percheron, II4; distribution of standard-bred, 63 ; distribution of Suffolk, I66; early history of Suffolk, 60 ; in England prior to reign of Queen Elizabeth, I7; evolution of, 2 ; foot of light harness, 4I; general appearance of heavy harness, 64 ; general conformation of draft, 89 ; head of light harness, 40 ; height of draft, 89; hindquarters of light harness, 42 ; history of English trotting, 44; history of modern Suffolk, I6I; influence of Arab, II; 
introduction of Belgian, to America, 124; light harness, 40; link between prehistoric and modern, 6; man and the prehistoric, 6 ; modern Shire, $15 \mathrm{I}$; money paid for standard-bred, $6 \mathrm{I}$; native home of Belgian, I2I; native home of Clydesdale, I34; native home of German Coach, 82; native home of Percheron, 95; native home of Suffolk, I60; neck of light harness, 40; notable Arabs, I3; notable recent-day Belgians, I 30 ; organizations for promoting the Belgian, I3I ; organizations for promoting the Percheron, II 5 ; organizations for promoting the Shire, 159 ; origin of French Coach, 79; Park, 68; pasterns of light harness, 4I; prices for Belgian, I3I; prices for Suffolk, I67; production of, in Belgium, I2I ; promotion of Suffolk, I67; shoulders of light harness, 40; size of American saddle, 33 ; soundness of Shire, I56; subclasses of heavy harness, 68 ; tracing the evolution of, 4; two ancient breeds in Belgium, I2I ; type of heavy harness, 64; type of German Coach, 83; value of Thoroughbred, in developing American saddle, 32 ; very early history of Shire, 148; weight of draft, 89; world-wide distribution of, in prehistoric times, I

Horse associations, American Percheron, II6; German Coach, 84; National French Draft, I 20

Horse breeding, in England, special region of Shire, I48; in Germany, early records of, 82 ; methods employed by Belgian government to encourage, I 22

Horse racing, in Great Britain, I8; in France, 78

Humphrey, William, 576

Hybrid, mule a, I92

Immunity of Mule-Foot to cholera, 760

Importation to America, of Corriedale, 657 ; of milch goat, 68I; Improved Black-Top Spanish Merino, 5133 of Thoroughbred, 24

Improved Chester White, the Ohio, 740 Improved Essex, establishment of, 774 Improvement, of Duroc-Jersey, 709; early, of Hampshire Down, 576; early, of Percheron, 97; of Essex, 774; first, of Leicester, 618; first, of native Berkshire, 690; and protection of cattle on Guernscy, 387 ; of Rambouillet, 520; of Tamworth, 792

Improvers, earliest, of Aberdeen-Angus, 280 ; distinguished early, of Shorthorn, 208; early, of Ayrshire, 4I3; early, of Devon, 473 ; early, of Large Yorkshire, 784; early, of PolandChina, 724; early foundation, of Merino in America, 497; important early, of Southdown, 537; two early prominent, of Shropshire, 554

Indian ponies, mustangs, or bronchos, I 73

Infantado Merinos, 492

Interest family, the Financial-, 340

Interest family, the Owl-, 346

Introduction to America, of AberdeenAngus, 283; of Angora goat, 667 ; of Ayrshire, 4I4; of Berkshire, 693; of Black-faced Highland, 652 ; of Brown Swiss, 464; of Cheviot, 599; of Cleveland Bay, 85; of Cotswold, 629; of Devon, 475; of Dexter, 442 ; of Dorset Horn, 587; of Dutch Belted, 428; of Essex, 775; of Galloway, 302 ; of German Coach, 82; of Guernsey, 389; of Hackney, 72; of Hampshire Down sheep, 578; of Hampshire pig, 75I; of Hereford, 256 ; of Holstein-Friesian, 358 ; of jack, I88; of Jersey, 327 ; of Karakul, 660; of Large Black, 762; of Large Yorkshire, 784; of Leicester, 620; of Lincoln, 637; of Merino, 495; of Mule-Foot, 759; of Oxford Down, 568; of Percheron, I02; of Rambouillet, 52I; of Red Polled, 452; of Shropshire, 555; of Small Yorkshire, 770; of Southdown, 540; of Suffolk sheep, 607; of Tamworth, 793; of Tunis, $61_{3}$; of West Highland, 3II

Irish grazier as a factor in PolandChina history, 723

Isabella tribe, 2 I 5

Island-bred families, 339

Island-bred Jersey sires, comparison of native with, 348 ;

Island of Jersey, 323

Jacks, American, 185; Andalusian, 183; associations promoting jennets 
and, I9I; Catalonian, I83; color, 187; distribution in America, I9I; height, I87; introduction to America, I88; Majorca, I84; Maltese, I84; noted, in America, I89; Poitou, I 85 ; prices, I 90

Jeffries, Thomas, 256

Jennets, associations promoting jacks and, I9I ; distribution of, in America, I9I

Jersey, 323 ; legislation protecting purity of cattle on, 325

Jersey cattle, adaptability, 330; American families, 34I; authenticated butter-fat tests, 336 ; as beef producer, 332 ; bulls of distinction, 346 ; characteristics, 327 ; color, 328 ; comparison of native sires with Islandbred, 348; crossing or grading, 332 ; distribution, 35I; early maturity, 330; families of distinction, 339; important foundation sires, 346; improvement of, in England, 326 ; improvement of old type, 325 ; introduction to America, 327 ; leading imported bulls, 349; leading sires, 347 ; milk in cheese production, 338; milk records, 334; organizations promoting, $35 \mathrm{I}$; origin, 324; Polled, 353; prepotency, 332; prices, 349 ; private butter tests, 335 ; as producer of milk-fat, 334 ; as producer of milk, 332; prolificacy and vitality, 33I; sires of privatetest offspring, 347 ; sires of registerof-merit offspring, 347 ; size, 329 ; temperament and disposition, 33I; ten leading, in butter-fat tests for one year, 337

Jersey Red pig, 706; characteristics, 707 Jilt family, 296

Jockey Club, French, 79

Johanna family, 375

Jupiter, I30

Karakul sheep, 660; characteristics, $66 \mathrm{I}$; crossbred or grade, 662 ; distribution, 665; fecundity, 664; fleece, $66 \mathrm{I}$; fur of lamb, 662; hardiness, 664; introduction to America, 66o; market value of furs, 663 ; mutton, 663 ; native home, 660 ; origin, 660

Keillor, Hugh Watson of, 280

Kerry cattle, 438 ; characteristics, 438 ; crossbreeding, 439; distribution, 440 ; grazing value, 440; hardy character,
439; introduction to America, 438; maturing characteristics, 439 ; milk producer, 440; native home, 438; organizations for promoting, 44I; origin, 438 ; prepotency, 439

Kiang, Asiatic Wild ass or, I82

Killer, Large Yorkshire pig as, 789

Korndyke family, 375

Kyloe, 3I I

Lactation of goat, period of, 682

Lady Maynard tribe, 662

Lady tribe, 2 II

Lamb, fur of Karakul, 662

Lard, or American, type of pig, 683; temperament, 687

Large Black pig, 762 ; characteristics, 762 ; distribution, 764; as feeder, 763 ; as grazer, 763 ; introduction to America, 762; native home, 762 ; origin, 762 ; popularity, 764 ; prolificacy, 764; promotion, 765 ; quality of meat, 763 ; size, 763

Large Yorkshire pig, 782; ancestry, 782 ; characteristics, 785 ; color, 786 ; crossbreds, 787 ; distribution, 791 ; early improvers, 784 ; as feeder, 789 ; as grazer, 789 ; introduction to United States, 784; as killer, 789; maturity, 787 ; popularity, 790 ; prolificacy, 79o; reputation of, as bacon producer, 788 ; size, 786 ; type, 786

Lavender tribe, 220

Legislation protecting purity of cattle on Jersey, 325

Leicester rams on Cheviot ewes, Border, 626

Leicester sheep, 618; Border, 624; breeding qualities, 624 ; characteristics of Border, 625 ; characteristics of English, 62I ; crossbred or grade, 623 ; distribution, 627 ; first improvement of, 618 ; as grazer, 624 ; introduction to America, 620; as mutton producer, 622; native home, 618 ; organizations in behalf of, 627 ; origin, 618 ; prices, 626 ; size, 622 ; as wool producer, 624

Leicester Sheep Breeders, Society of Border, 627

Leonese, 489

Light harness horse, action, 43; arms and forearms, 4I ; body, 4I ; cannons, $4 \mathrm{I}$; foot, $4 \mathrm{I}$; head, 40 ; hind quarters, 42; neck, 40; pasterns, 4I; shoulders, 40 ; type, 40 
Limestone Mammoth, Igo

Lincoln sheep, 636; breeding quality, 642; characteristics, 638; crossbred or grade, 640 ; distribution, 644 ; as feeder, 640; as grazer, 642 ; introduction to America, 637; native home, 636 ; origin, 636 ; prices, 643 ; promotion, 645 ; quality of mutton, 639 ; size, 638; as wool producer, 642

Lincolnshire Lad II, I56

Lockinge Forest King, 158

Longevity and fecundity of Suffolks, 165

Louis Napoleon, IO3

Lovely tribe, 22 I

McCombie, William, 282

Majorca jack, 184

Maltese goat, 676

Maitese jack, I84

Mambrino family, 52

Mammoth, I 89

March On family, 267

Mares, list of famous trotting or pacing brood, 56; noteworthy American saddle-horse, 38

Martin's Boxer strain, I6I

Masher family, 404

Matchem, 20

Materna family, 405

Maturity, of Aberdeen-Angus, 287; of Berkshire, 698; of Chester White, 744; of Duroc-Jersey, 713; early, of American Merino, 505; early, of Ayrshire, 4I7; early, of Hampshire pig, 755; early, of Hereford, 262 ; early, of Jersey, 330 ; early of Poland-China, 728; early, of Rambouillet, 529; early, of Shorthorn, 239; early, of Small Yorkshire, 772; early, of Shropshire, 560; of Essex, 777 ; of French Canadian, 436; of Guernsey, 393; of Holstein-Friesian, 365; of Kerry, 439; of Tamworth, 795

May Rose family, 405

Meat, quality of Cheshire, 768 ; quality of Essex, 776 ; quality of Large Black, 763; quality of Mule-Foot, 760 ; quality of Poland-China, 728 ; quality of Small Yorkshire, 772

Meat producer, Galloway as, 304; Hereford as, 26I

Meire, Samuel, 554

Mercury, I39
Merino, or fine-wool type of sheep, 48I; A-type, 482; adaptability of American, 505 ; Aguirre, 491; American, 488; American, as wool producer, 50I; annual drives in Spain, 489; Australian, 494; Australia's popular type of, $500 ; \mathrm{B}$-Type, 482 ; Black-Top Spanish, 5I3; breeding qualities of American, 505; breeding, three types, 483 ; characteristirs of American, 498; crossbred or grade, 503 ; Delaine, 5 I I ; distribution, 509; distribution of Delaine, $5 \mathrm{Ig}$; early foundation improvers in America, 497 ; early-maturing qualities of American, 505 ; English, 494; Escurial, 49I ; exportation from Spain, 492; fineness of fiber, 502; general conformation, 48I ; German or Silesian, 493; Guadaloupe, 49I; important subtypes of families, 505; Infantado, 492; introduction to United States, 495; line of demarcation in, 483; mania for, 497; maintenance of Delaine or C-type, 516; modern type of, in Australia, 499 ; the more general characteristics of, 484 ; mutton qualities of American, 503 ; mutton value of Delaine or C-type, 5I7; national Delaine, 5I 4 ; native home, 488 ; Negretti, 49 I ; origin, 488 ; origin of Delaine, 5 II ; Paular, 490; promotion, 510; promotion of Delaine, 5 5 ; ; reduction of flocks in Spain, 492; ratio of fleece to weight of body, 502 ; remarkable prices, 508; Saxon, 493; size of American, 500; some famous rams, 506; Swedish, 493; three classes or types, 48I ; wool, 487, 503 Merino show-ring victory, a notable American, 507

Merit, Register of, 336

Mesohippus, 4

Messenger, 45

Methods employed by Belgian government to encourage horse breeding, I 22 Middle White pigs, 79I

Milch goat, 673 ; age attained by, 680 ; fecundity, 682 ; importation to America, 68I; official promotion, 682 ; prices, 682 ; weight, 680

Milk, Aberdeen-Angus as producer of, 288; of Ayrshire for cheese-making, 422 ; of Ayrshire as producer of, 4I9; Brown Swiss as producer of, 468; 
characteristics of goat's, 673; cheese value of Guernsey, $40 \mathrm{O}$; cost of producing goat's, 680; Devon as producer of, 477; Dexter as producer of, 495; Dutch Belted as producer of, 430; French Canadian as producer of, 435; Galloway as producer of, 306 ; goat as source of, 673 ; Guernsey as producer of, 398 ; of Holstein-Friesian for cheese, 372 ; Holstein-Friesian as producer of, 368 ; of Jersey in cheese production, 338 ; Jersey as producer of, 332 ; Kerry as producer of, 440; Red Polled as producer of, 455

Milk-producing goats, breeds or varieties of, 674

Milk records, of Guernsey, 398; of Jersey, 334; semi-official yearly Holstein-Friesian, 369 ; of Shorthorn, 237 ; ten leading Ayrshire, 420

Milk veins, 32 I

Milking qualities of West Highland cattle, 3I4

Mimulus tribe, $22 \mathrm{I}$

Mine mules, I96

Miss Russell, 57

Mohair, 668; prices, 669

Money winnings on the race track, $6 \mathrm{I}$

Morgan family, 53

Moss Rose tribe of Booth, 2 I 7

Motor on Hackney breeding, effect of the, 77

Mule, I92; best type, I97; as carriage or saddle animal, I 99 ; characteristics, 194; color, 197; draft, 195; endurance, I97; farm, I96; geographical distribution, I93; history, I93; a hybrid, I92 ; market classes, I95; mine, I96; plantation, I95; Poitou, I96; prices, I99; raising in United States, I94; resistance to disease, I98; sex, I92; sterility, I92; temperament, I97; weight, 194

Mule-Foot pig, 759; characteristics, 759 ; distribution, 76I; feeding qualities, 760 ; immunity from cholera, 760; introduction to America, 759 ; name, 759; native home, 759; prepotency, 760; prolificacy, 760; promotion, $76 \mathrm{I}$; quality of meat, 760 ; size, 760

Mustangs, bronchos, or Indian ponies, I 73

Mutton, American Merino as producer of, 503; Angora as producer of,
670; Cheviot as producer of, 60I ; Corriedale as producer of, 658; Cotswold as producer of, 63I ; Dorset Horn as producer of, 590 ; general conformation for, 533; Hampshire Down as producer of, 580; Leicester as producer of, 622; quality of Black-faced Highland, 653; quality of Lincoln, 639; quality of Romney Marsh, 648; quality of Southdown, 545; Rambouillet as producer of, 537 ; Shropshire as producer of, 558; Suffolk as producer of, 609 ; Tunis as producer of, 615; value of Delaine or C-type Merino for, 517; value of Karakul for, 663

Mutton-type sheep, 533; skin, 535; wool, 535

Name, of Chester White, 738; of Holstein-Friesian, 358; of Mule-Foot, 759 ; of Poland-China, 723

National Delaine Merino, 5 I4

National French Draft horse association, 120

Neapolitan pig, 69I

Neck of light harness horse, 40

Negretti Merinos, 49I

Netherland family, 376

New Forest pony, I 7 I

Nivernais, II 9

Nonpareil tribe, 22 I

Norfolk Red Polled cattle, 45I ; amalgamation of Suffolk and, $45^{2}$

North America, importation of Corriedale sheep into, 657

Nosegay family, 296

Nubian goat, 677

Ohio Importing Company, 224

Ohio Improved Chester White pig, 740

Old Grannie, $28 \mathrm{I}$

Old Jack, 28 I

Orange Ist, I30; Orange Blossom, or Fancy, tribe, $22 \mathrm{I}$

Organization, Cheviot sheep breeders', 606; Aberdeen-Angus, 299; Ayrshire, 426; Belgian horse, I3I; Berkshire, 704; Chester White, 748; Cleveland Bay; 87; Clydesdale, I47; Devon, 478; Dorset Horn Sheep breeders', 596; Duroc-Jersey, 718; Galloway, 309; Guernsey, 4II; Hampshire, 758; Holstein-Friesian, 382 ; Jersey, 35I ; Kerry, 44I ; Leicester, 627; Lincoln, 645 ; Percheron, 
II5; Poland-China, 734; Red Polled, $46 \mathrm{I}$; Shetland pony, I8I; Shorthorn, 245 ; Suffolk sheep, 612 ; Tamworth, 798; West Highland cattle breeders', 3I 6

Oriental horses, three early, $\mathrm{x} 9$

Origin, of Aberdeen-Angus, 279; of Angora goat, 666; of Black-faced Highland, 65I; of Brown Swiss, 463; of Cheshire, 766; of Cheviot, 597 ; of Cleveland Bay, 85 ; of Corriedale, 655 ; of Delaine Merino, 5II; of Devon, 473; of Dexter, 442 ; of Dorset Horn, 586 ; of Duroc-Jersey, 708; of Dutch Belted, 428 ; of Dutch cattle, 355 ; of French Canadian, 434; of French Coach, 79; of Galloway, 300; of Guernsey, 385 ; of Hampshire Down sheep, 575 ; of Hereford, 252 ; of Improved Chester White, 739; of Jersey, 324; of Karakul, 660 ; of Kerry, 438; of Large Black, 762 ; of Leicester, 618 ; of Lincoln, 636; of Merino, 488; of Oxford Down, 566; of Percheron, 95; of Poland-China, 720 ; of Polled Hereford, 275; real, of Shire, I49; of Red Polled, 450; of Shorthorn, 207; of Shropshire, 55I; of Small Yorkshire, 770; of Suffolk, 607; of Thoroughbred, 2I; of Tunis, $6 \mathrm{I} 3$; of West Highland, 3 I I

Orohippus, 3

Oxen, Devon, 478; Holstein-Friesian, 367

Oxford Down sheep, 566; characteristics, 568 ; crossbred or grade, 57I; distribution, 573; as feeder, 570; introduction to America, 568; native home, 566 ; origin, 566 ; prices, 572 ; prolific -quality, 572 ; promotion, 574 ; size, 570 ; as wool producer, 572

Oxford family, 340

Oxford tribe, 213

Owl-Interest family, 346

Pace, 35, 47; interchangeable with trot, 48

Pacer, American, 44, 46; number with records, 6 I

Pacing brood mares, list of famous, 56

Pacing horses, leading sires, 58

Pacing standard, 50

Packington Blind Horse, 156

Park horse, 68
Pasterns of light harness horse, 4I

Paular Merinos, 490

Pauline Paul family, 377

Percheron horse, 95; American associations for, II6; characteristics, I04; color, I06; crossbred or grade, I08; deterioration, Ioo; distribution, II4; early type, 99; famous sires, IIo; futurity shows, II2; geldings, I13; improvement of early, 97; improvement of, in France, ro2; introduction to United States, IO2; leading shows, III ; maturing quality, ro7; native home, 95; organizations for promoting, II 5 ; origin, 95; prices, II2; prolificacy, IO9; temperament, Io7; type of, about I877, I00; weight and height, I06

Perfection family, 268

Persian Wild ass, 182

Picardy, 20

Pietertje family, 376

Pig, adaptability of Hampshire, 755; American, or lard, type of, 683 ; ancestry of Large Yorkshire, 782 ; bacon, 778; bacon, demand in America for, 781; bacon, weight of, 780 ; Bedford or Bedfordshire, 721 ; Belted or sheeted, 750; Berkshire, 689 ; Berkshire as grazer, 697 ; Berkshire as source of red, 706; Big China, 722; Byfield, 722; characteristics of Berkshire, 694; characteristics of Cheshire, 767 ; characteristics of Chester White, 74I ; characteristics of Duroc-Jersey, 709; characteristics of Essex, 775 ; characteristics of Hampshire, 753; characteristics of Large Black, 762; characteristics of Large Yorkshire, 785; characteristics of Mule-Foot, 759; characteristics of Poland-China, 725; characteristics of Small Yorkshire, 77I; characteristics of Spotted PolandChina, 736 ; characteristics of Tamworth, 793; Cheshire, 766; Cheshire as feeder, 768; Cheshire as grazer, 769 ; Chester White, 737 ; color, 688; color of Hampshire, 754; color of Large Yorkshire, 786; criticisms of Tamworth, 798; distribution of Berkshire, 704; distribution of Cheshire, 769; distribution of Chester White, 747; distribution of Duroc-Jersey, 718 ; distribution of Essex, 777; distribution of 
Hampshire, 757; distribution of Large Black, 764; distribution of Large Yorkshire, 79I; distribution of Mule-Foot, 76I; distribution of Small Yorkshire, 773 ; distribution of Tamworth, 798; Duroc, 707 ; DurocJersey, 705; early history of Hampshire, 749 ; early improvers of Large Yorkshire, 784; Essex, 774; fecundity of Tamworth, 797; feeding qualities of Mule-Foot, 760 ; fleshing and fattening quality, 687; general appearance, 683; Guinea, 705; hair of, 687; Hampshire, 749; Hampshire as feeder, 755 ; Hampshire as grazer, 755 ; improvement of Duroc-Jersey, 709 ; Large Black, 762 ; Large Yorkshire, 782 ; maturity of Hampshire, 755; maturity of Large Yorkshire, 787; Middle White, 791; most valued type of, in United States, 683; Mule-Foot, 759; native home of Cheshire, 766 ; native home of Large Black, 762; Neapolitan, 691; organizations promoting Berkshire, 704; organizations promoting Chester White, 748 ; organizations promoting Hampshire, 758; organizations promoting Poland-China, 734; origin of Duroc-Jersey, 708; origin of Small Yorkshire, 770; Poland-China, 720; popularity of Cheshire, 760 ; popularity of Essex, 777; popularity of Large Black, 764; Portuguese, 705; prices of Berkshire, 703; prices of Chester White, 746 ; prices of DurocJersey, 717; prices of Hampshire, 757 ; prices of Poland-China, 732; prolificacy of Duroc-Jersey, 7I5; prolificacy of Large Black, 764 ; promotion of Essex, 777; promotion of Large Black, 765; promotion of Small Yorkshire, 773; quality of meat of Large Black, 763; red or sandy-colored, 705; Russian, 721; Siamese, 690 ; size of Berkshire, 696; size of Cheshire, 767 ; size of Chester White, 742 ; size of Duroc-Jersey, $7 \pi I$; size of Essex, 776; size of Hampshire, 755; size of Large Black, 763; size of Large Yorkshire, 786; size of Mule-Foot, 760; size of Poland-China, 726; size of Small Yorkshire, 772; size of Tamworth, 794; Small Yorkshire as feeder, 772 ; Spanish Red, 705; Tamworth, 792;
Tamworth as bacon, 795; temperament of lard type, 687

Pilot family, 55

Plantation mules, I95

Pliohippus, 4

Poitou jack, I85

Poitou mule, I 96

Poland-China pig, 720; adaptability, 728 ; adoption of name, 723 ; the Berkshire as an element in evolution of, 722; characteristics, 725 ; color, 725 ; crossbred or grade, 729 ; distribution, 734; early improvers, 724 ; early-maturing qualities, 728 ; families and foundation sows, 731 ; as feeder, 727 ; foundation stock, 720 ; as grazer, 727 ; Irish Grazier a factor in history of, 723 ; native home, 720 ; organizations promoting, 734 ; origin, 720 ; prepotency, 73I; quality of meat, 728 ; prices, 732 ; prolificacy, 729 ; sires of distinction, 73I; size, 726 ; Spotted, 736

Polled Durham, "single standard," 247

Polled Hereford cattle, 275; distribution, 277 ; origin, 275 ; prices, 277 ; promotion, 277; two strains of, 276 ; type, 276

Polled Jersey cattle, 353

Polled Shorthorn cattle, 247 ; distribution, 250; "double standard," 247; important requirements for registering, 249; origin, 247; popularity. 249 ; prepotency, 249; prices, 250; promotion of interests, $25 \mathrm{I}$; tribes, 248

Polo pony, I 74

Pony, I68; Arab, I73; Connemara, I72; Dartmoor, I70; Exmoor, I70; Hackney, I73; Highland, I72 ; Indian (mustangs and bronchos), 173 ; New Forest, I7I; Polo, I74; Shetland, I75 (see Shetland pony); Welsh, I68; definition, I68

Popularity, of Devon in America, 479; of Dutch Belted, 433; of Essex, 777; of Large Black, 764; of Large Yorkshire, 790; of Small Yorkshire, 773

Pork, of Berkshire, 699; of Chester White, 744; of Duroc-Jersey, 714; of Hampshire, 755

Portuguese pigs, 705

Prehistoric horse, I; color, 5 ; man and the. 6 ; and modern horse, link between, 6

Premier, 156 
Prepotency, of Ayrshire, 4I7; of Berkshire, 702; of Brown Swiss, 467; of Chester White, 746; of DurocJersey, 7I6; of Galloway, 308; of Hereford, 263; of Holstein-Friesian, 366 ; of Jersey, 332; of Kerry, 439; of Mule-Foot pig, 760; of PolandChina, 73I ; of Polled Shorthorn, 249; of Red Polled, 459; of Shorthorn, 240

Price of Ryall, John, 254

Prices, for Aberdeen-Angus, 297, 298; for American saddle horse, 38 ; for Angora goat, 67I; for Ayrshire, 424; for Belgian horse, I3I ; for Berkshire, 703; for Black-faced Highland, 654; for Chester White, 746; for Cheviot, 604; for Clydesdale, I 45 ; for Corriedale, 659 ; for Cotswold, 635; for Dexter, 445 ; for Duroc-Jersey, 7I7; for Galloway, 309; for Guernsey, 408; for Hampshire Down sheep, 583 ; for Hereford, 27I; for Holstein-Friesian, 379; for jack, I90; for Jersey, 349; for Leicester, 626; for Lincoln, 643; for Merino, 508; for milch goat, 682 ; for mohair 669; for mule, I 99 ; for Oxford Down, 572 ; for Percheron, II 2 ; for Poland-China, 732; for Polled Hereford, 277; for Polled Shorthorn, 250 ; for Rambouillet, 530 ; for Romney Marsh, 649; for Shetland pony, 181; for Shire, I58; for Shorthorn, $24 \mathrm{I}$; for Shropshire, 562 ; for Southdown, 548; for standard-bred, 6r; for Suffolk horse, I67; for Suffolk sheep, 6II; for Thoroughbred, 29

Pride family, 294

Pride of Aberdeen family, 294

Prime Lad family, 269

Prime Scots, 305

Prince of Wales, I42

Prince William, 157

Princess Tribe, 210

Private-test offspring, Jersey sires of, 347

Prolificacy, of Aberdeen-Angus, 288; of Berkshire, 70I; of Chester White, 745; of Cheviot, 603; of Clydesdale, I39; of Dorset Horn, 592; of Duroc-Jersey, 7r5; of Guernsey, 395; of Hampshire pig, 756; of Hereford, 264 ; of Holstein-Friesian, 365 ; of Jersey, 33I ; of Large Black, 764; of Large Yorkshire, 790; of
Mule-Foot, 760; of Oxford Down, 572; of Percheron, I09; of PolandChina, 729; of Red Polled, 459; of Shorthorn, 240

Promotion, of Aberdeen-Angus, 299; of Black-faced Highland, 654; of Brown Swiss, 472 ; of Corriedale, 659; of Delaine Merino sheep, 519; of Duroc-Jersey, 7I8; of Dutch Belted, 432; of Essex, 777; of Hackney, 77; of Hereford, 274; of Holstein-Friesian, 382; of Kerry, 44I; of Large Black, 765 ; of Merino, 5IO; of milch goat, 682 ; of MuleFoot, 76I; official, of Dexter, 446; of Oxford Down, 574; of Polled Hereford, 277; of pure French Canadian, 437; of Rambouillet, 532; of Romney Marsh, 650; of Shropshire, 564; of Small Yorkshire, 773; of Southdown, 550; of standardbred horse, 63; of Tamworth, 798

Protohippus, 4

Protorohippus, 3

Provincial flocks of Spain, 490

Quality, of beef animal, 205; of dairy type, 322

Quartly, Francis, 473

Queen Elizabeth, horse in England prior to reign of, I 7

Queen Mother family, 293

Racing, in America, 44, 61, 62; in France, 78,80 ; in Great Britain, 18

Rack, the, 35

Rambouillet sheep, 520; breeding qualities, 529; characteristics, 524; crossbred or grade, 528 ; distribution, 532; early maturity, 529; French Merinos, or, 494; hardiness, 529; improvement, 520; introduction to the United States, 52I; as mutton producer, 527 ; native home, 520; prices, 530; promotion, 532; size, 526 ; as wool producer, 527

Rams, famous Merino, 506

Range sheep, Cheviot as, 602 ; Leicester as grazing or, 624

Rawlence, James, 578

Records, of Thoroughbreds on American turf, 27; butter-fat, of Ayrshires, $42 \mathrm{I}$; butter-fat, of Guernseys, 400 ; butter-fat, of Shorthorns, 238 ; early, of horse breeding in Germany, 
82; milk, of Ayrshires, 420; milk, of Guernseys, 398; milk, of HolsteinFriesians, 369; milk, of Jerseys, 334; milk, of Shorthorns, 237; speed, of French Coachers, 80; trotters and pacers with, $6 \mathrm{I}$; trotting and pacing, 60

Red, or sandy-colored, pigs, 705

Red pigs, Jersey, 706; Spanish, 705

Red Polled cattle, 450 ; as beef producers, 455 ; as butter producers, 457 ; as milk producers, 455 ; characteristics, 453 ; color, 454 ; in crossing and grading, 458; distribution, $46 \mathrm{I}$; groups and tribes, 460 ; introduction to America, 452 ; native home, 450; organizations to promote, $46 \mathrm{I}$; origin, 450; prepotency, 459; prolificacy, 459; sires, 460; size, 454 ; temperament, 459

Red Rose tribe, 2 II

Red swine, Berkshire as source of, 706

Register of Merit, 336; Jersey sires represented in, 347

Register of production of Brown Swiss cattle, $47^{\circ}$

Registry, Advanced, of American Guernsey Cattle Club, 396; of Ayrshire Breeders' Association, 4I 7

Registering Polled Shorthorn cattle, requirements, 249

Renovator of brush land, Angora as, 670

Roadster, 40; Cleveland Bay as, 87

Romney Marsh sheep, 646; crossbred, 648; distribution, 649; early type, 646 ; as feeder, 648; fleece, 649; modern type, 647 ; native home, 646 ; prices, 649 ; promotion, 650 ; quality of mutton, 648 ; size, 648

Rose of Sharon, 2 I 3

Rosette family, 34 I

Runabout, the, 69

Running walk, 34

Russian pig, 72 I

Saanen goat, 676

Saddle animal, mule as carriage or, 199

Saddle horse gaits, 34. See American saddle horse

St. Lambert family, 343

Samson, I 29

Sandy-colored, or red, pigs, 705

Saxon Merinos, 493

Sayda family, 345

Scale of points, early Guernsey, 387
Schwarzhal goat, 679

Scotland, development of Shorthorn in, 217

Scots, prime, 305

Secret tribe of Cruickshank, 22 I

Segis family, 378

Semiofficial yearly Holstein-Friesian records, of butter fat, $37 \mathrm{I}$; of milk, 369

Sex of mule, I92

Shadingfield strain, I6I

Sheep, Black-faced Highland, 65I; Border Leicester, 024 ; organizations of Dorset Horn breeders, 596; characteristics of Black-faced Highland, 652; characteristics of Cheviot, 599; characteristics of Corriedale, 657; characteristics of Cotswold, 630; characteristics of Dorset. Horn, 588; characteristics of early Southdown, 540; characteristics of English Leicester, 62I; characteristics of Hampshire Down, 578; characteristics of Karakul, 661; characteristics of Lincoln, 638 ; characteristics of Oxford Down, 568; characteristics of Rambouillet, 524 ; characteristics of Shropshire, $55^{6}$; characteristics of Southdown, 54I; characteristics of Suffolk, 608; characteristics of Tunis, 6r4; Cheviot, 597; Corriedale, 655; Cotswold, 628; crossbred or grade Karakul, 662; distribution of Black-faced Highland, 654; distribution of Cheviot, 605; distribution of Corriedale, 659; distribution of Cotswold, 635; distribution of Dorset Horn, 595; distribution of Hampshire Down, 585 ; distribution of Karakul, 665 ; distribution of Leicester, 627 ; distribution of Lincoln, 644; distribution of Merino, 509; distribution of Oxford Down, 573; distribution of Rambouillet, 532; distribution of Romney Marsh, 649; distribution of Shropshire, 563; distribution of Southdown, 550; distribution of Suffolk, $6 \mathrm{I} 2$; distribution of Tunis, 6r7; Dorset Horn, 586; early type of Romney Marsh, 646; fleece of Corriedale, 658; Hampshire Down, 575; husbandry in Spain, 488; Karakul, 660; Leicester, 6I8; Lincoln, 636; Lincoln as grazer, 642; mania for Merino, 497 ; Merino, or 
fine-wool type, $48 \mathrm{r}$; modern type of Romney Marsh, 647; mutton type, 533; native home of Lincoln, 636; native home of Shropshire, 55I; native home of Southdown, 537; official promotion of Corriedale, 659; official promotion of Shropshire, 564; organizations promoting Lincoln, 645 ; origin of Corriedale, 655 ; original stock of Southdown, 537; Oxford Down, 566; prices for Cheviot, 604; prices for Corriedale, 659 ; prices for Cotswold, 635 ; prices for Hampshire Down, 583; prices for Oxford Down, 572 ; prices for Rambouillet, 530; prices for Shropshire, 562; prices for Southdown, 548 ; prices for Suffolk, 6II; prolificacy of Dorset Horn, 592 ; promotion of Cotswold, 635; promotion of Delaine Merino, 519; promotion of Merino, 510; promotion of Oxford Down, 574; promotion of Rambouillet, 532 ; promotion of Romney Marsh, 650; Rambouillet, 520; Romney Marsh, 646; Shropshire, $55 \mathrm{I}$; size of Black-faced Highland, 653 ; size of Cheviot, 600; size of Cotswold, 63I ; size of Dorset Horn, 589; size of Hampshire Down, 580 ; size of Leicester, 622; size of Lincoln, 638; size of Oxford Down, 570 ; size of Rambouillet, 526; size of Romney Marsh, 648; size of Shropshire, 557; size of Southdown, 543 ; size of Suffolk, 609; size of Tunis, 615; Southdown, 537; Suffolk, 607; Tunis, 613; two great groups of Spanish, 489; weight of Corriedale, 658

Sheeted pig, 750

Shelter for Angora goat, $67 \mathbf{I}$

Shetland pony, I75; ancestry, I75; characteristics, I77; coat of hair, I77; color, I77; distribution, I8I; hardy nature, I 79 ; height, $\mathbf{x} 78$; improvement, I78; native home, 175 ; notable sires, I79; organizations for promoting, I8I; prices, I8I; type, I75, I76; use of, in America, I78; value for draft purposes, I79

Shire horse, I48; action, I53; associations to promote, 159 ; characteristics, 152; color, I54; crossbred or grade, I 55 ; different varieties, I5I ; distribution, I58; hairy legs, I53; important stallions, I56; importation to America, I52; improved by Robert Bakewell, I49; modern, I5I; old-fashioned type, 150 ; prices, 158 ; real origin, I49; size, I54; soundness, 156 ; special field, 155 ; special region in England for breeding, 148; temperament, I55; very early history, 148

Shorthorn cattle, 207; adaptability, 239 ; as beef producers, 23I ; breeders, less prominent early English, 2 I 7 ; characteristics, 225 ; color, 220 ; dairy point of view, 235; development of, in Scotland, 217; distinguished early improvers, 208; distribution of Polled, 250; doublestandard Polled, 247; early maturity, 239; famous recent, 24I ; first importation to America, 224; geographical distribution, 244; important butter-fat records, 238; important milk records, 237; important requirements for registering Polled, 249; importance of, in grading and crossing, 234; native home, 207; notable recent sires, 240; official public-dairy tests, 235 ; organizations promoting, 245; origin, 207 ; origin of Polled, 247; Polled, 247; popularity of Polled, 249; prepotency of Polled, 249; prolificacy, 240 ; promotion of interests of Polled, $25 \mathrm{r}$; size, 230 ; in show ring, 232 ; temperament, 239 ; prices, $24 \mathrm{I}$; prices for Polled, $25^{\circ}$

Shoulders of light harness horse, 40

Shows, of draft horse in Belgium, $\mathrm{I}_{32}$; leading Percheron, III; Percheron futurity, II 2

Shropshire sheep, 551 ; characteristics, 556 ; constitutional vigor, 560 ; crossbred or grade, 559; distribution, 563 ; early-maturing qualities, 560 ; fecundity, 560; as grazer, 559 ; introduction to America, 555; native home, 55I; official promotion, 564; origin, $55 \mathrm{I}$; prices, 562 ; rank as mutton, 558; size, 557; two early prominent improvers, 554 ; as wool producer, $56 \mathrm{I}$

Southdown sheep, 537; adaptability, 547; breeding, by English nobility, 539 ; breeding qualities, 547 ; characteristics of early, 540; crossbred or grade, 546 ; distribution, 550 ; as 
feeder, 544; important early improvers of, 537 ; introduction to America, 540; native home, 537; original stock, 537 ; prices, 548 ; promotion, 550; quality of mutton, 545 ; recent characteristics, $54 \mathrm{I}$; size, 543 ; as wool producer, 548

Siamese pig, 690

Signal family, 34I

Silesian, or German, Merinos, 492

Single foot, 34

Single-standard Polled Durham, 247

Sires, American saddle-horse, 38; Ayrshire, 424; Chester White; 746; Clydesdale, r4o; Clydesdale, honor roll of, I44; foundation Belgian, I29; Hampshire, 757; Hereford, 270; Holstein-Friesian, 379; Jersey, 347; Jersey foundation, 346; Jersey, Island-bred compared with native, 348; of pacing horses, 58 ; Percheron, I10; Poland-China, 73I; recent Shorthorn, 240; Red Polled, 460; Shetland, I79; Thoroughbred, of winners, 25; of trotting horses, 58

Size, of American Merino, 500; of American saddle horse, 33 ; of Ayrshire, 4r6; of Berkshire, 696; of Black-faced Highland, 653 ; of Brown Swiss, 466; of Cheshire, 767; of Chester White, 742; of Cheviot, 600; of Cotswold, 63I; of Devon, 476; of Dexter, 444; of Dorset Horn, 589; of Duroc-Jersey, 7II; of Essex, 776; of Galloway, 304; of Guernsey, 393; of Hampshire Down, 580; of Hampshire pig, 755; of Hereford, 260; of HolsteinFriesian, 363; of Jersey, 329; of Large Black, 763 ; of Large Yorkshire, 786 ; of Leicester, 622 ; of Lincoln, 638; of Mule-Foot, 760; of Oxford Down, 570; of PolandChina, 726; of Rambouillet, 526; of Red Polled, 454; of Romney Marsh, 648; of Shire, I54; of Shorthorn, 230; of Shropshire, 557; of Small Yorkshire, 772; of Southdown, 543; of Suffolk sheep, 609; of Tamworth, 794; of Tunis, 615; of West Highland, 3 I 3

Skin secretions of Guernsey, 392; of mutton-type sheep, 535

Small White, strains or families, 770

Small Yorkshire pig, 770 ; characteristics, 771 ; crossbred or grade, 772 ; distribution, 773; early maturity, 772 ; fecundity, 773 ; as feeder, 772 ; as grazer, 773 ; introduction to America, 770; origin, 770 ; popularity, 773 ; promotion, 773 ; quality of meat, 772 ; size, 772

Sophie Igth of Hood Farm, 333, 338

Soundness of Hackney, 75; of Shire, I 56

Sows, Poland-China, families and foundation, $73 \mathbf{I}$

Spain, annual Merino drives in, 489; exportation of Merinos from, 492; important provincial flocks in, 490; reduction of Merino flocks in, 492 ; sheep husbandry in, 488

Spanish Merino, Black-Top, 5I3

Spanish red pigs, 705

Spanish sheep, two great groups, 489

Speed records, of French Coacher, 80; of Thoroughbred, 26

Speed of trotter, 59

Spicy tribe, 222

Spotted Poland-China, 736; characteristics, 736

Stallions, important Shire, I 56

Standard, for trotters, 49 ; for pacers, 50

Standard-bred horse, definition of, 48 ; distribution, 63 ; prices, 61 ; official promotion, 63

Standard, National, or Victor-Beall Delaines, 515

Steers, Shorthorn, in show ring, 232; grand-champion, 290; prices for Aberdeen-Angus, 298

Sterility of mule, I 92

Strawberry, or Halnaby, tribe, $2 \pi 6$

Studbook, American French Coach, 8I; Thoroughbred, 30

Stud fees in Belgium, I 24

Subclasses of heavy harness horses, 68

Suburban hándicap records, 28

Suffolk and Norfolk Red Polled cattle, amalgamation of, $45^{2}$

Suffolk horse, I60; characteristics, I62; color, I64; distribution, I66; as draft animal, I66; early history, I60; fecundity and longevity, I65; foreign blood used to improve, 160 ; foundation of pure-bred, I6o; grade or crossbred, I65; history of, in America, I6I; history of modern, I6I; promotion, I67; native home, I60; prices, I67 
Suffolk Red Polled cattle, $45^{\circ}$

Suffolk sheep, 607 ; characteristics, 608; crossbred or grade, 610; distribution, 6I 2 ; fecundity, 6II ; as feeder, 609; introduction to America, 607; for mutton, 609; native home, 607; organizations for promoting, 61 2 ; original stock, 607; prices, 6II; as producer of wool, OII; size, 609

Swedish Merinos, 493

Swine. See Pig

Tamworth pig, 792 ; ancestry, 792 ; for bacon, 795; characteristics, 793; criticisms, 798; crossbred or grade, 796; distribution, 798; early type, 792 ; fecundity, 797; feeding quality, 795; as grazer, 797; improvement, 792 ; introduction to America, 793; maturing qualities, 795; native home, 702 ; organizations promoting, 798; size, 794

Temperament and disposition, of Ayrshire, $4 \mathrm{I} 7$; of Belgian, I27; of Clydesdale, I39; of Guernsey, 393; of Jersey, 33I; of lard-type, 687; of mule, I97; of Percheron, I07; of Red Polled, 459; of Shire, I55; of Shorthorn, 239; of Thoroughbred, 23

Testing of Holstein-Friesians, Advanced Registry Official, 367

Tests, public, Ayrshires in, 422

Thoroughbreds, I7; of American breeding, 25; color, 23; conformation, $2 \mathrm{I}$; distribution, 29 ; early improvement, I8; height, 23; importation to America, 24; list of famous British, 23 ; origin, 21 ; prices, 29 ; records of, at English Derby, 27; records of, on American turf, 27; sires of winners, 25; speed record, 26; studbook, 3o; temperament, 23; three early English sires, 19; value of, in developing American saddle horse, 32 ; weight, 23 ; winnings, 28

Toggenburg goat, 674

Tomkins family, 254

Tomkins, Benjamin, father and son, 254

Tormentor family, 344

Transhumantes, 489

Tribes and groups of Red Polled cattle, 460

Tricksey family, 406

Trot, 35,47 ; fox, 35 ; interchangeable with pace, 48
Trotter, American, 44, 46; definition of standard-bred, 48; early use of, in America, 44; families of note, 50 ; famous brood mares, 56 ; foundation blood of, in America, 44; history of English, 44; leading sires, 58; number with records, 6I ; some records, 60; speed, 59; standard of eligibility, 49; type of American, 46

Tunis sheep, 6I3; characteristics, 6I4; crossbred or grade, 6I6; distribution, 6I7; for early lambs, 6I6; fecundity, 616; fleece, 616; introduction to America, 613; as mutton animal, 615; native home, 613 ; origin, 6 I 3 ; size, 6 I 5

Tunis Sheep Breeders' Association, American, 6I 7

Turf, Thoroughbred records on American, 27

Type, bacon pig, 778; Chester White, original, 737; Essex, early native, 774; improvement of old Jersey, 325; Large Yorkshire, 786; line of demarcation in Merino, 483; modern, of Merino in Australia, 499; older Berkshire, 69r ; Romney Marsh, early, 646; Romney Marsh, modern, 647 ; of swine most valued in United States, 683; Tamworth, early, 792

Types, of Devon, two, 476 ; of Holstein-Friesian, 36I; of Merino, three, $48 \mathrm{I}$; of Merino, breeding of three, 483

Udder of dairy cow, 320

United States, distribution of Percheron in, II4; exhibition of Belgians in, I 33 ; introduction of Cheviot to, 599 ; introduction of Cotswold to, 629 ; introduction of Large Yorkshire to, 784 ; introduction of Merino to, 495; introduction of Percheron to, I02; introduction of Rambouillet to, 521; mule-raising in, I94; type of swine most valued in, 683

Veins, milk, 32I

Venus tribe, 222

Victor-Beall Delaine Merino, 5I5

Victoria tribe, 222

Vigor of Shropshire, 560

Violet tribe, 223

Warrior, I89 
Waterloo tribe, 213

Watson of Keillor, Hugh, 280

Webb, Jonas, 538

Weight, of Aberdeen-Angus, 286; of Angora goat, 670; of bacon pig, 780; of Corriedale, 658 ; of draft horse, 89; and height of Belgian, I27; and height of Clydesdale, I38; and height of Percheron, I06; of Merino fleece compared with body, 502; of milch goat, 680 ; of mule, I94; of Thoroughbred, 23

Welsh pony, I68

West Highland cattle, 3 II ; as beef producer, $3 \mathrm{I}_{3}$; breeding qualities, 3I5; characteristics, 3 I2 ; crossbred or grade, 3I4; distribution, 3I5; hardiness, 315 ; introduction of, to America, 3II; milking qualities, 3I4; native home, 3 II; organization of breeders, 3I6; origin, 3II; size, 313

Wild Eyes tribe, 214

William the Conqueror, 156

Winnings, of Thoroughbred, 28; on the race track, $6 \mathrm{I}$
Wool, American Merino as producer of, 50I; Black-faced Highland as producer of, 653; Cheviot as producer of, 604; Cotswold as producer of, 634; crimp and elasticity of Merino, 503 ; Dorset Horn as producer of, 593; Hampshire Down as producer of, 583 ; Leicester as producer of, 624; Lincoln as producer of, 642 ; of Merino, 487; of mutton-type sheep, 535; Oxford Down as producer of, 572 ; Rambouillet as producer of, 527 ; Shropshire as producer of, 56I; Southdown as producer of, 548; Suffolk as producer of, 6II

World War, influence of, on horse in Belgium, I33

Wright strain, 16r

Yeksa family, 407

Yolk, 48I

Yorkshire Club, American, 79I

Yorkshire Coach horse, 87

Yorkshire pig. See Large Yorkshire and Small Yorkshire 


\section{ANNOUNCEMENTS}


Digitized by Microsofte 


\section{COUNTRY LIFE EDUCATION SERIES}

A SERIEs of practical texts for the student and the professional farmer, written by experts in their respective lines. These books aim to give a thorough exposition of both the theory and the practice of the various branches of farming and breeding.

\section{TYPES AND BREEDS OF FARM ANIMALS (Revised)}

By Charles S. Plumb, Professor of Animal Husbandry in the College of Agriculture, Ohio State University. 820 pages, illustrated

\section{PRINCIPLES OF BREEDING}

By Eugene Davenfort, Dean of the College of Agriculture, Director of the Agricultural Experiment Station, and Professor of Thremmatology in the University of Illinois, 727 pages, illustrated

\section{FUNGOUS DISEASES OF PLANTS}

By Bexjamin Minge Duggar, Professor of Plant Physiology, Washington University, St. Louis. 508 pages, illustrated

SOIL FERTILITY AND PERMANENT AGRICULTURE By CYRIL George HOPKixs, late Professor of Agronomy in the University of Illnois. xxiii +653 pages

\section{PRINCIPLES AND PRACTICE OF POULTRY CULTURE}

By John H. Robinsor. xvi +6 I r pages, illustrated

\section{GARDEN FARMING}

By Lee Clevelaxid Corbetr, Horticulturist in the Bureau of Plant Industry, United States Department of Agriculture. 462 pages, illustrated

THE APPLE

By Albert E. Wilkinson, formerly of the Department of Forticulture in Cornell University. $49^{2}$ pages, illustrated

EQUIPMENT FOR THE FARM AND THE FARMSTEAD

By Harry C. Ramsower, Director of Agricultural Extension Service, Ohio State University. 523 pages, illustrated

$$
\text { Other zolumes in preparation }
$$

\section{GINN AND COMPANY PUBlishers}




\section{BOOKS ON AGRICULTURE}

\section{SHEEP FEEDING AND FARM MANAGEMENT}

By D. HOWARD DOANE, formerly Professor of Farm Management in the University of Missouri. I2mo, cloth, I28 pages, illustrated.

A PRACTICAL manual on the feeding of sheep for market, embodying the experience of successful sheepmen and farmers throughout the country. As a textbook for classes in farm management, animal husbandry, and agronomy the book contains much useful material.

\section{EXAMINING AND GRADING GRAINS}

By Thomas L. Lyon, Professor of Soil Technology in the Federal Experiment Station, Cornell University, and EDWARD G. Montgomerx, Comell University. I2mo, cloth, ror pages, illustrated.

TEXI and exercises providing a thorough drill in the study of the structure and quality of all the cereals, in the identification of seeds of the common grasses, millets, and legumes, and in judging the quality of hay of these crops.

\section{EXPERIMENTAL DAIRY BACTERIOLOGY}

By H. L. Russeld, Dean of the College of Agriculture, and E. G. Hastings, Professor of Agricultural Bacteriology in the University of Wisconsin. I2mo, cloth, I47 pages, illustrated.

A STUDY of the bacteriological processes which must be understood before the relation of microörganisms to dairy processes can be appreciated. This guide will be found equally valuable for the student and the practical worker.

\section{PRINCIPLES OF RURAL ECONOMICS}

By Thomas Nixon Carver, David A. Wells Professor of Political Economy in Harvard University. 8vo, cloth, $\mathrm{xx}+386$ pages.

CHAPTERS on the history of agriculture, the factors of agricultural production, farm management, agricultural coöperation, the distribution of the agricultural income, and the problems of rural social life are among those included in this book.

\section{GINN AND COMPANY Publishers}


Digitized by Microsofte 
Digitized by Microsofte 
Digitized by Microsoft(a) 
Digitized by Microsoft(a) 
Digitized by Microsoft(a) 
